\title{
STATE OF THE CLIMATE IN 2018
}
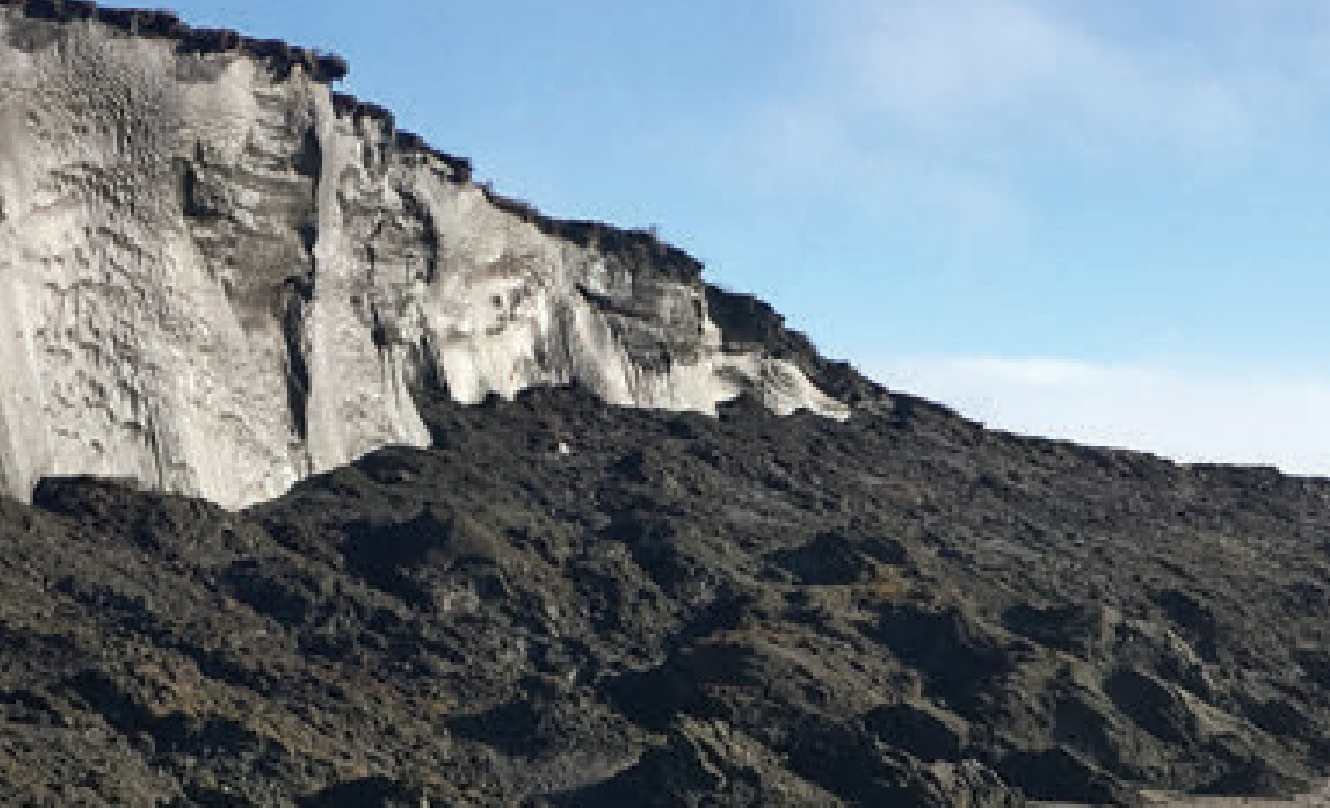

a.
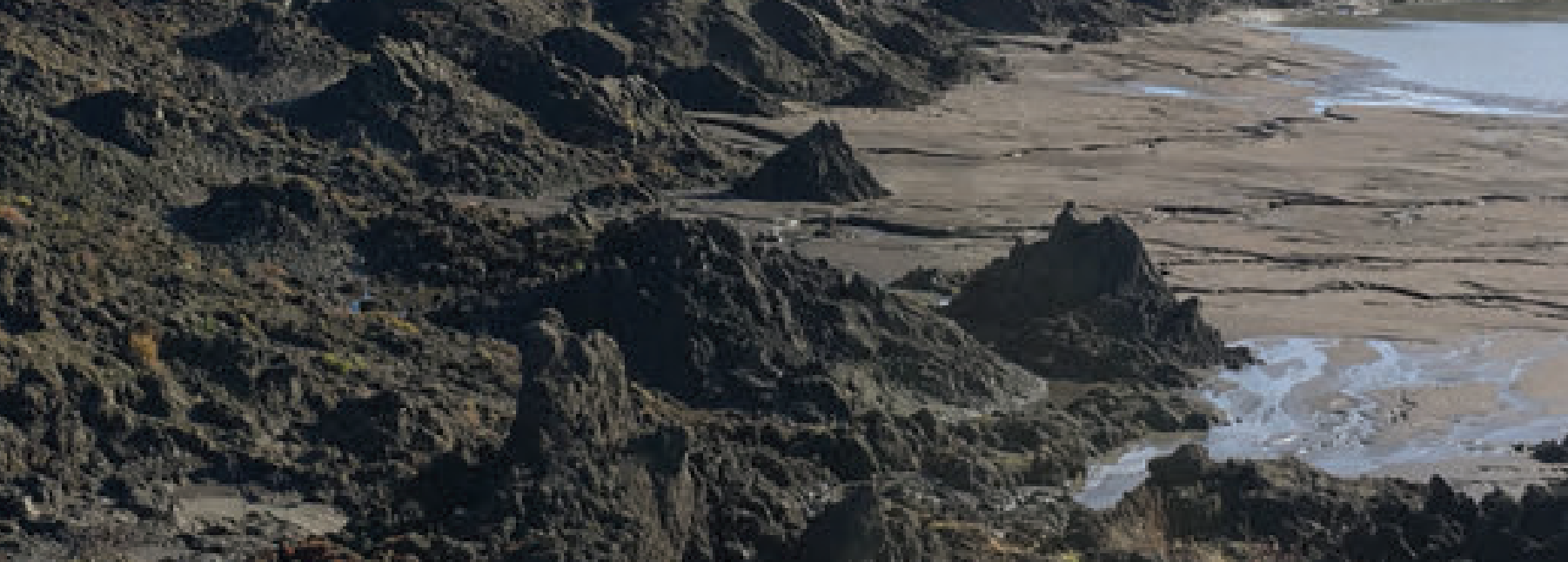

\section{Special Supplement to the}

Bulletin of the American Meteorological Society

Vol. 100, No. 9, September 2019 


\section{STATE OF THE CLIMATE IN 2018}

Editors

Jessica Blunden

Derek S. Arndt

\section{Chapter Editors}

Peter Bissolli Howard J. Diamond Matthew L. Druckenmiller Robert J. H. Dunn Catherine Ganter Nadine Gobron
Martin O. Jeffries

Tim Li

Rick Lumpkin

Ademe Mekonnen

Emily Osborne

Jacqueline A. Richter-Menge

Technical Editor

Andrea Andersen
Ahira Sánchez-Lugo

Ted A. Scambos

Carl J. Schreck III

Sharon Stammerjohn

Diane M. Stanitski

Kate M. Willett

BAMS Special Editor for Climate

Richard Rosen 
COVER CREDITS:

Front/BACK: @ Bов Busey, International Arctic Research Center, University of Alaska Fairbanks

Ice-rich permafrost exposed on the face of Itkillik Bluff on the North Slope of Alaska. The bluffs and surrounding ice-rich permafrost have lost large volumes of ice over recent years due to lateral erosion and surface disturbances such as wildfire and climate warming. Members of NASA's Arctic-Boreal Vulnerability Experiment visit this site annually to collect frozen soil and ground ice for carbon analysis. The team also uses regional airborne and space-borne remote sensing to identify potential volume of major ground ice loss in previously unidentified ice-rich parts of the landscape.

How to cite this document:

Citing the complete report:

Blunden, J. and D. S. Arndt, Eds., 2019: State of the Climate in 2018. Bull. Amer. Meteor. Soc., 100 (9), Si-S305, doi:I0.II75/20I9BAMSStateoftheClimate.I.

\section{Citing a chapter (example):}

Scambos, T. and S. Stammerjohn Eds., 2019: Antarctica and the Southern Ocean [in "State of the Climate in 2018”]. Bull. Amer. Meteor. Soc., 100 (9), SI69-SI88, doi:I0.II75/2019BAMSStateoftheClimate.I.

\section{Citing a section (example):}

Meijers, A. J., B. Sallée, A. Grey, K. Johnson, K. Arrigo, S. Swart, B. King, and M. Mazloff, 2019: Southern Ocean [in "State of the Climate in 2018”]. Bull. Amer. Meteor. Soc., 100 (9), SI8I-SI85, doi:I0.II75/2019BAMSStateoftheClimate.I. 
Ades, M., European Centre for Medium-Range Weather Forecasts, Reading, United Kingdom

Adler, R., University of Maryland, College Park, Maryland

Aldeco, Laura S., Servicio Meteorológico Nacional, Buenos Aires, Argentina

Alejandra, G., Instituto Geofísico del Perú, Lima, Perú

Alfaro, Eric J., Center for Geophysical Research and School of Physics, University of Costa Rica, San José, Costa Rica

Aliaga-Nestares, Vannia, Servisâo Nacional de Meteorología e Hidrología del Perú, Lima, Perú

Allan, Richard P., University of Reading, Reading, United Kingdom

Allan, Rob, Met Office Hadley Centre, Exeter, United Kingdom

Alves, Lincoln M., Centro de Ciencias do Sistema Terrestre, Instituto Nacional de Pesquisas Espaciais, Cachoeira Paulista, Sao Paulo, Brazil

Amador, Jorge A., Center for Geophysical Research and School of Physics, University of Costa Rica, San José, Costa Rica

Andersen, J. K., Geological Survey of Denmark and Greenland, Copenhagen, Denmark

Anderson, John, Department of Atmospheric and Planetary Science, Hampton University, Hampton, Virginia

Arndt, Derek S., NOAA/NESDIS National Centers for Environmental Information, Asheville, North Carolina

Arosio, C., University of Bremen, Bremen, Germany

Arrigo, Kevin, Department of Earth System Science, Stanford University, Stanford, California

Azorin-Molina, César, Regional Climate Group, Department of Earth Sciences, University of Gothenburg, Gothenburg, Sweden; Centro de Investigaciones sobre Desertificación Spanish National Research Council, Moncada (Valencia), Spain

Bardin, M. Yu, Yu. A. Izrael Institute of Global Climate and Ecology, and Institute of Geography, Russian Academy of Sciences, Russia

Barichivich, Jonathan, Instituto de Geografía, Pontificia Universidad Católica de Valparaíso, Valparaíso, Chile

Barreira, Sandra, Argentine Naval Hydrographic Service, Buenos Aires, Argentina

Baxter, Stephen, NOAA/NWS Climate Prediction Center, College Park, Maryland

Beck, H. E., Department of Civil and Environmental Engineering, Princeton University, Princeton, New Jersey

Becker, Andreas, Global Precipitation Climatology Centre, Deutscher Wetterdienst, Offenbach am Main., Germany

Bell, Gerald D., NOAA/NWS Climate Prediction Center, College Park, Maryland

Bellouin, Nicolas, University of Reading, Reading, United Kingdom

Belmont, M., Seychelles National Meteorological Services, Pointe Larue, Mahé, Seychelles

Benedetti, Angela, European Centre for Medium-Range Weather Forecasts, Reading, United Kingdom

Benedict, Imme, Meteorology and Air Quality Group, Wageningen University and Research, Wageningen, Netherlands
Bernhard, G. H., Biospherical Instruments Inc., San Diego, California

Berrisford, Paul, NCAS-Climate, European Centre for Medium-Range Weather Forecasts, Reading, United Kingdom

Berry, David I., National Oceanography Centre, Southampton, United Kingdom

Bettio, Lynette, Bureau of Meteorology, Melbourne, Victoria, Australia

Bhatt, U. S., Geophysical Institute, University of Alaska Fairbanks, Fairbanks, Alaska

Biskaborn, B. K., Alfred Wegener Institute Helmholtz Centre for Polar and Marine Research, Potsdam, Germany

Bissolli, Peter, Deutscher Westterdienst, WMO RA VI Regional Climate Centre Network, Offenbach, Germany

Bjella, Kevin L., Cold Regions Research and Engineering Laboratory (CRREL), Fairbanks, Alaska

Bjerke, J. K., Norwegian Institute for Nature Research, Tromsø, Norway

Blake, Eric S., NOAA/NWS National Hurricane Center, Miami, Florida

Blenkinsop, Stephen, School of Engineering, Newcastle University, Newcastle-upon-Tyne, United Kingdom

Blunden, Jessica, NOAA/NESDIS National Centers for Environmental Information, Asheville, North Carolina

Bock, Olivier, Paris Institute of Globe Physics, Université Paris Diderot, Sorbonne Paris Cité, Paris, France

Bosilovich, Michael G., Global Modeling and Assimilation Office, NASA Goddard Space Flight Center, Greenbelt, Maryland

Boucher, Olivier, Sorbonne Université, Paris, France

Box, J. E., Geological Survey of Denmark and Greenland, Copenhagen, Denmark

Boyer, Tim, NOAA/NESDIS National Centers for Environmental Information, Silver Spring, Maryland

Braathen, Geir, WMO Atmospheric Environment Research Division, Geneva, Switzerland

Bringas, Francis. G., NOAA/OAR Atlantic Oceanographic and Meteorological Laboratory (AOML), Miami, Florida

Bromwich, David. H., Byrd Polar and Climate Research Center, The Ohio State University, Columbus, Ohio

Brown, Alrick, Department of Physics, The University of the West Indies, Jamaica

Brown, R., Climate Research Division, Environment and Climate Change Canada, Montréal, Quebec, Canada

Brown, Timothy J., Western Regional Climate Center, Desert Research Institute, Reno, NV

Buehler, S. A., Universität Hamburg, Hamburg, Germany

Cáceres, Luis, Instituto Nacional de Meteorología e Hidrología de Ecuador, Ecuador

Calderón, Blanca, Center for Geophysical Research, University of Costa Rica, San José, Costa Rica

Camargo, Suzana J., Lamont-Doherty Earth Observatory, Columbia University, Palisades, New York

Campbell, Jayaka D., Department of Physics, The University of the West Indies, Jamaica 
Campos Diaz, Diego A., Dirección Meteorológica de Chile, Santiago de Chile, Chile

Cappelen, J., Danish Meteorological Institute, Copenhagen, Denmark

Carrea, Laura, Department of Meteorology, University of Reading, Reading, United Kingdom

Carrier, Seth B., National Institute of Water and Atmospheric Research, Ltd., Auckland, New Zealand

Carter, Brendan R., Joint Institute for the Study of the Atmosphere and Ocean, University of Washington, and NOAA/OAR Pacific Marine Environmental Laboratory, Seattle, Washington

Castro, Anabel Y., Servicio Nacional de Meteorología e Hidrología del Perú, Lima, Perú

Cetinić, Ivona, NASA Goddard Space Flight Center, Greenbelt, Maryland, and Universities Space Research Association, Columbia, Maryland

Chambers, Don P., College of Marine Science, University of South Florida, St. Petersburg, Florida

Chen, Lin., Institute for Climate and Application Research (ICAR)/KLME/ILCEC/CIC-FEMD, Nanjing University of Information Science and Technology, Nanjing, China

Cheng, Lijing, International Center for Climate and Environment Sciences, Institute of Atmospheric Physics, Chinese Academy of Sciences, Beijing, China

Cheng, Vincent. Y. S., Environment and Climate Change Canada, Toronto, Ontario, Canada

Christiansen, Hanne H., Geology Department, University Centre in Svalbard, Longyearbyen, Norway

Christy, John R., The University of Alabama in Huntsville, Huntsville, Alabama

Chung, E.-S., IBS Center for Climate Physics, Busan, South Korea

Claus, Federico, Argentine Naval Hydrographic Service, Buenos Aires, Argentina,

Clem, Kyle R., Institute of Earth, Ocean, and Atmospheric Sciences, Rutgers, the State University of New Jersey, New Brunswick New Jersey

Coelho, Caio A. S., CPTEC/INPE Center for Weather Forecasts and Climate Studies, Cachoeira Paulista, Brazil

Coldewey-Egbers, Melanie, German Aerospace Center (DLR) Oberpfaffenhofen, Wessling, Germany

Colwell, Steve, British Antarctic Survey, Cambridge, United Kingdom

Cooper, Owen R., Cooperative Institute for Research in Environmental Sciences, University of Colorado Boulder, Boulder, Colorado, and NOAA/OAR Earth System Research Laboratory, Boulder, Colorado

Cosca, Cathy, NOAA/OAR Pacific Marine Environmental Laboratory, Seattle, Washington

Covey, Curt, Lawrence Livermore National Laboratory, Livermore, California

Coy, Lawrence, Science Systems and Applications, Inc., NASA Goddard Space Flight Center, Greenbelt, Maryland

Dávila, Cristina P., Servicio Nacional de Meteorología e Hidrología del Perú, Lima, Perú
Davis, Sean M., Cooperative Institute for Research in Environmental Sciences, University of Colorado Boulder, and NOAA/OAR Earth System Research Laboratory, Boulder, Colorado

de Eyto, Elvira, Marine Institute, Furnace, Newport, Ireland de Jeu, Richard A. M., VanderSat B.V., Haarlem, Netherlands

De Laat, Jos, Royal Netherlands Meteorological Institute (KNMI), DeBilt, Netherlands

Decharme, B., Centre National de Recherches Météorologiques, France

DeGasperi, Curtis L., King County Water and Land Resources Division, Seattle, Washington

Degenstein, Doug, University of Saskatchewan, Saskatoon, Saskatchewan Canada

Demircan, Mesut, Turkish State Meteorological Service, Ankara, Turkey

Derksen, C., Climate Research Division, Environment and Climate Change Canada,Downsview, Ontario, Canada

Dhurmea, K. R., Mauritius Meteorological Service, Vacoas, Mauritius

Di Girolamo, Larry, University of Illinois at UrbanaChampaign, Champaign, Illinois

Diamond, Howard J., NOAA/OAR Air Resources Laboratory, College Park, Maryland

Diaz, Eliecer, Instituto de Hidrología de Meteorología y Estudios Ambientales de Colombia (IDEAM), Bogotá, Colombia

Diniz, Fransisco A., Instituto Nacional de Meteorologia, Brasilia, Brazil

Dlugokencky, Ed J., NOAA/OAR Earth System Research Laboratory, Boulder, Colorado

Dohan, Kathleen, Earth and Space Research, Seattle, Washington

Dokulil, Martin T., Research Department for Limnology Mondsee, University of Innsbruck, Austria

Dolman, A. Johannes, Department of Earth Sciences, VU University Amsterdam, Amsterdam, Netherlands

Domingues, Catia M., Institute for Marine and Antarctic Studies, University of Tasmania, Antarctic Climate and Ecosystems Cooperative Research Centre, and Australian Research Council's Centre of Excellence for Climate System Science, Hobart, Tasmania, Australia

Domingues, Ricardo, Cooperative Institute for Marine and Atmospheric Studies, University of Miami and NOAA OAR Atlantic Oceanographic and Meteorological Laboratory (ADML), Miami, Florida,

Donat, Markus G., Barcelona Supercomputing Centre, Barcelona, Spain

Dorigo, Wouter A., Department of Geodesy and Geoinformation, TU Wien - Vienna University of Technology, Vienna, Austria

Drozdov, D. S., Earth Cryosphere Institute, and Tyumen State University, Tyumen, Russia

Druckenmiller, Matthew L., National Snow and Ice Data Center, Boulder, Colorado 
Dunn, Robert J. H., Met Office Hadley Centre, Exeter, United Kingdom

Durre, Imke, NOAA/NESDIS National Centers for Environmental Information, Asheville, North Carolina

Dutton, Geoff S., Cooperative Institute for Research in Environmental Sciences, University of Colorado Boulder, and NOAA/OAR Earth System Research Laboratory, Boulder, Colorado

EIKharrim, M., Direction de la Météorologie Nationale Maroc, Rabat, Morocco

Elkins, James W., NOAA/OAR Earth System Research Laboratory, Boulder, Colorado

Epstein, H. E., Department of Environmental Sciences, University of Virginia, Charlottesville, Virginia

Espinoza, Jhan C., Instituto Geofisico del Perú, Lima, Perú, and Université Grenoble Alpes, Grenoble, France

Famiglietti, James S., Global Institute for Water Security, School of Environment and Sustainability, and Department of Geography and Planning, University of Saskatchewan, Saskatoon, Canada

Farrell, Sinead L., NOAA Earth System Science Interdisciplinary Center, University of Maryland, College Park, Maryland

Fausto, R. S., Geological Survey of Denmark and Greenland, Copenhagen, Denmark

Feely, Richard A., NOAA/OAR Pacific Marine Environmental Laboratory, Seattle, Washington

Feng, Z., Atmospheric Sciences and Global Change Division, Pacific Northwest National Laboratory, Richland, Washington

Fenimore, Chris, NOAA/NESDIS National Centers for Environmental Information, Asheville, North Carolina

Fettweis, X., University of Liège, Liège, Belgium

Fioletov, Vitali E., Environment and Climate Change Canada, Toronto, Canada

Flemming, Johannes, European Centre for Medum-Range Weather Forecasts, Reading, United Kingdom

Fogt, Ryan L., Department of Geography, Ohio University, Athens, Ohio

Forbes, B. C., Arctic Centre, University of Lapland, Rovaniemi, Finland

Foster, Michael J., Cooperative Institute for Meteorological Satellite Studies, Space Science and Engineering Center, University of Wisconsin-Madison, Madison, Wisconsin

Francis, S. D., National Weather Forecasting and Climate Research Centre, Nigerian Meteorological Agency, Abuja, Nigeria

Franz, Bryan A., NASA Goddard Space Flight Center, Greenbelt, Maryland

Frey, Richard A., Cooperative Institute for Meteorological Satellite Studies, Space Science and Engineering Center, University of Wisconsin-Madison, Madison, Wisconsin

Frith, Stacey M., Science Systems and Applications, Inc, Lanham, Maryland, NASA Goddard Space Flight Center, Greenbelt, Maryland

Froidevaux, Lucien, Jet Propulsion Laboratory, California Institute of Technology, Pasadena, California
Ganter, Catherine, Bureau of Meteorology, Melbourne, Victoria, Australia

Garforth, J., Woodland Trust, Grantham, United Kingdom

Gerland, Sebastian, Norwegian Polar Institute, Fram Centre, Tromsø, Norway

Gilson, John, Scripps Institution of Oceanography, University of California San Diego, La Jolla, California

Gleason, Karin, NOAA/NESDIS National Centers for Environmental Information, Asheville, North Carolina

Gobron, Nadine, Knowledge Management for Sustainable Development and Food Security Unit, European Commission, Joint Research Centre, Ispra, Italy

Goetz, S., School of Informatics, Computing, and Cyber Systems, Northern Arizona University, Flagstaff, Arizona

Goldenberg, Stanley B., NOAA/OAR/AOML Hurricane Research Division, Miami, Florida

Goni, Gustavo, NOAA/OAR Atlantic Oceanographic and Meteorological Laboratory (AOML), Miami, Florida

Gray, Alison, School of Oceanography, University of Washington, Seattle, Washington

Grooß, Jens-Uwe, Forschungszentrum Jülich, Jülich, Germany

Gruber, Alexander, Department of Geodesy and Geoinformation, TU Wien - Vienna University of Technology, Vienna, Austria; Department of Earth and Environmental Sciences, KU Leuven, Heverlee, Belgium

Gu, Guojun, University of Maryland, College Park, Maryland

Guard, Charles “Chip” P., NOAA/NWS Weather Forecast Office, Guam

Gupta, S. K., Science Systems and Applications, Inc., Hampton, Virginia

Gutiérrez, Dimitri, Instituto del Mar del Perú, Callao, Perú

Haas, Christian, Alfred Wegener Institute, Helmholtz Centre for Polar and Marine Research, Bremerhaven, Germany

Hagos, S., Atmospheric Sciences and Global Change Division, Pacific Northwest National Laboratory, Richland, Washington

Hahn, Sebastian, Department of Geodesy and Geoinformation, TU Wien - Vienna University of Technology, Vienna, Austria

Haimberger, Leo, Department of Meteorology and Geophysics, University of Vienna, Vienna, Austria

Hall, Brad D., NOAA/OAR Earth System Research Laboratory, Boulder, Colorado

Halpert, Michael S., NOAA/NWS Climate Prediction Center, College Park, Maryland

Hamlington, Benjamin D., NASA Jet Propulsion Laboratory, Pasadena, California

Hanna, E., School of Geography and Lincoln Centre for Water and Planetary Health, University of Lincoln, Lincoln, United Kingdom

Hanssen-Bauer, I., Norwegian Meteorological Institute, Blindern, Oslo, Norway

Harris, Ian, National Centre for Atmospheric Science (NCAS), University of East Anglia, Norwich, United Kingdom and Climatic Research Unit, School of Environmental Sciences, University of East Anglia, Norwich, United Kingdom 
Hazeleger, Wilco, Meteorology and Air Quality Group, Wageningen University and Research, Wageningen, Netherlands; Netherlands eScience Center, Amsterdam, Netherlands; and Faculty of Geosciences, Utrecht University, Utrecht, Netherlands.

He, Q., Earth System Modeling Center, Nanjing University of Information Science and Technology, Nanjing, China

Heidinger, Andrew K., NOAA/NESDIS/STAR University of Wisconsin-Madison, Madison, Wisconsin

Heim, Jr., Richard R., NOAA/NESDIS National Centers for Environmental Information, Asheville, North Carolina

Hemming, D. L., Met Office Hadley Centre, Exeter, United Kingdom; Birmingham Institute of Forest Research, Birmingham University, Birmingham, United Kingdom

Hendricks, Stefan, Alfred Wegener Institute, Helmholtz Centre for Polar and Marine Research, Bremerhaven, Germany

Hernández, Rafael, Instituto Nacional de Meteorología e Hidrología de Venezuela (INAMEH), Caracas, Venezuela

Hersbach, H. E., European Centre for Medium-Range Weather Forecasts, Reading, United Kingdom,

Hidalgo, Hugo G., Center for Geophysical Research and School of Physics, University of Costa Rica, San José, Costa Rica

Ho, Shu-peng (Ben), NOAA/NESDIS Center for Satellite Applications and Research, College Park, Maryland

Holmes, R. M., Woods Hole Research Center, Falmouth, Massachusetts

Hu, Chuanmin, College of Marine Science, University of South Florida, St. Petersburg, Florida

Huang, Boyin, NOAA/NESDIS National Centers for Environmental Information, Asheville, North Carolina

Hubbard, Katherine, Florida Fish and Wildlife Conservation Commission, St. Petersburg, Florida

Hubert, Daan, Royal Belgian Institute for Space Aeronomy (BIRA), Brussels, Belgium

Hurst, Dale F., Cooperative Institute for Research in Environmental Sciences, University of Colorado Boulder, and NOAA/OAR Earth System Research Laboratory, Boulder, Colorado

Ialongo, Iolanda, Finnish Meteorological Institute, Helsinki, Finland

Ijampy, J. A., Nigerian Meteorological Agency, Abuja, Nigeria Inness, Antje, European Centre for Medium Range Weather Forecasts, Reading, United Kingdom

Isaac, Victor, Environment and Climate Change Canada, Toronto, Ontario, Canada

Isaksen, K., Norwegian Meteorological Institute, Blindern, Oslo, Norway

Ishii, Masayoshi, Climate Research Department, Meteorological Research Institute, Japan Meteorological Agency, Tsukuba, Japan

Jeffries, Martin O., Cold Regions Research and Engineering Laboratory, ERDC-USACE, Hanover, New Hampshire

Jevrejeva, Svetlana, National Oceanography Centre, Liverpool, United Kingdom
Jia, G., Institute of Atmospheric Physics, Chinese Academy of Sciences, Beijing, China

Jiménez, C., Estellus, Paris, France

Jin, Xiangze, Woods Hole Oceanographic Institution, Woods Hole, Massachusetts

John, Viju, EUMETSAT, Darmstadt, Germany

Johnsen, Bjørn, Norwegian Radiation and Nuclear Safety, Østerås, Norway

Johnson, Gregory C., NOAA/OAR Pacific Marine Environmental Laboratory, Seattle, Washington

Johnson, Kenneth S., Monterey Bay Aquarium Research Institute, Moss Landing, California

Johnson, Bryan, NOAA/OAR Earth System Research Laboratory, Global Monitoring Division, and University of Colorado, Boulder, Colorado

Jones, Philip D., Climatic Research Unit, School of Environmental Sciences, University of East Anglia, Norwich, United Kingdom

Jumaux, Guillaume, Météo France, Direction Interrégionale pour l'Océan Indien, Réunion

Kabidi, Khadija, Direction de la Météorologie Nationale Maroc, Rabat, Morocco

Kaiser, J. W., Max Planck Institute for Chemistry, Mainz, Germany; Deutscher Wetterdienst, Offenbach, Germany

Karaköylü, Erdem M., NASA Goddard Space Flight Center, Greenbelt, Maryland, and Science Application International Corporation, Beltsville, Maryland

Karlsen, S.-R., Norut Northern Research Institute, Tromsø, Norway

Karnauskas, Mandy, NOAA/NMFS Southeast Fisheries Science Center, Miami, Florida

Kato, Seiji, NASA Langley Research Center, Hampton, Virginia

Kazemi, A. FazI, Islamic Republic of Iranian Meteorological Organization, Iran

Kelble, Christopher, NOAA/OAR Atlantic Oceanographic and Meteorological Laboratory (AOML), Miami, Florida

Keller, Linda M., Department of Atmospheric and Oceanic Sciences, University of Wisconsin-Madison, Madison, Wisconsin

Kennedy, John, Met Office Hadley Centre, Exeter, United Kingdom

Kholodov, A. L., Geophysical Institute, University of Alaska Fairbanks, Fairbanks, Alaska

Khoshkam, Mahbobeh, Islamic Republic of Iranian Meteorological Organization, Iran

Kidd, R., Earth Observation Data Centre for Water Resources Monitoring $\mathrm{GmbH}$, Vienna, Austria

Killick, Rachel, Met Office Hadley Centre, Exeter, United Kingdom,

Kim, Hyungjun, Institute of Industrial Science, The University of Tokyo, Tokyo, Japan

Kim, S.-J., Korea Polar Research Institute, Incheon, Republic of Korea

King, A. D., University of Melbourne, Melbourne, Australia

King, Brian A., National Oceanography Centre, Southampton, United Kingdom 
Kipling, Z., European Centre for Medium-Range Weather Forecasts, Reading, United Kingdom

Klotzbach, Philip J., Department of Atmospheric Science, Colorado State University, Fort Collins, Colorado

Knaff, John A., NOAA/NESDIS Center for Satellite Applications and Research, Fort Collins, Colorado

Korhonen, Johanna, Freshwater Centre, Finnish Environment Institute (SYKE, Helsinki, Finland

Korshunova, Natalia N., All-Russian Research Institute of Hydrometeorological Information - World Data Center, Obninsk, Russia

Kramarova, Natalya A., NASA Goddard Space Flight Center, Greenbelt, Maryland

Kratz, D. P., NASA Langley Research Center, Hampton, Virginia

Kruger, Andries, South African Weather Service and Department of Geography, Geoinformatics, and Meteorology, University of Pretoria, Pretoria, South Africa,

Kruk, Michael C., KBR, NOAA/NESDIS National Centers for Environmental Information, Asheville, North Carolina

Krumpen, Thomas, Alfred Wegener Institute, Helmholtz Centre for Polar and Marine Research, Bremerhaven, Germany

Labbé, L., Météo France, Direction Interrégionale pour l'Océan Indien, Réunion

Ladd, C., NOAA/OAR Pacific Marine Environmental Laboratory, Seattle, Washington

Lakatos, Mónika, Climatology Division, Hungaran Meteorological Service, Budapest, Hungary

Lakkala, Kaisa, Finnish Meteorological Institute, Arctic Research Centre, Sodankylä, Finland

Lander, Mark A., University of Guam, Mangilao, Guam

Landschützer, Peter, Max Planck Institute for Meteorology, Hamburg, Germany

Landsea, Chris W., NOAA/NWS National Hurricane Center, Miami, Florida,

Lareau, Neil P., Department of Physics, University of Nevada, Reno, NV

Lavado-Casimiro, Waldo, Servicio Nacional de Meteorología e Hidrología del Perú, Lima, Perú

Lazzara, Matthew A., Department of Physical Sciences, School of Arts and Sciences, Madison Area Technical College, and Space Science and Engineering Center, University of Wisconsin-Madison, Madison, Wisconsin

Lee, T. C., Hong Kong Observatory, Hong Kong, China

Leuliette, Eric, NOAA/NWS NCWCP Laboratory for Satellite Altimetry, College Park, Maryland

L'Heureux, Michelle, NOAA/NWS Climate Prediction Center, College Park, Maryland

Li, Bailing, Hydrological Sciences Laboratory, NASA Goddard Space Flight Center, Greenbelt, Maryland, USA; Earth System Science Interdisciplinary Center, University of Maryland, College Park, Maryland

Li, Tim, Department of Atmospheric Sciences, University of Hawaii, Honolulu, Hawaii
Lieser, Jan L., Antarctic Climate and Ecosystems Cooperative Research Centre and Institute for Marine and Antarctic Studies, University of Tasmania, Hobart, Tasmania, Australia

Lim, J.-Y., Climate Prediction Division, Korea Meteorological Administration, South Korea

Lin, I.-I., National Taiwan University, Taipei, Taiwan

Liu, Hongxing, Department of Geography, University of Cincinnati, Cincinnati, Ohio

Locarnini, Ricardo, NOAA/NESDIS National Centers for Environmental Information, Silver Spring, Maryland

Loeb, Norman G., NASA Langley Research Center, Hampton, Virginia

Long, Craig S., NOAA/NWS National Centers for Environmental Prediction, College Park, Maryland

López, Luis A., Instituto de Hidrología, Meteorología y Estudios Ambientales de Colombia, Bogotá, Colombia

Lorrey, Andrew M., National Institute of Water and Atmospheric Research, Ltd., Auckland, New Zealand

Loyola, Diego, German Aerospace Center (DLR) Oberpfaffenhofen, Wessling, Germany

Lumpkin, Rick, NOAA/OAR Atlantic Oceanographic and Meteorological Laboratory (AOML), Miami, Florida

Luo, Jing-Jia, Institute for Climate and Application Research (ICAR)/KLME/ILCEC/CIC-FEMD, Nanjing University of Information Science and Technology, Nanjing, China

Luojus, K., Finnish Meteorological Institute, Helsinki, Finland

Lyman, John M., NOAA/OAR Pacific Marine Environmental Laboratory, Seattle, Washington, and Joint Institute for Marine and Atmospheric Research, University of Hawaii, Honolulu, Hawaii

Malkova, G. V., Earth Cryosphere Institute, Tyumen Science Center, Tyumen, Russia

Manney, Gloria L., NorthWest Research Associates, and New Mexico Institute of Mining and Technology, Socorro, New Mexico

Marchenko, S. S., Geophysical Institute, University of Alaska Fairbanks, Fairbanks, Alaska

Marengo, José A., Centro Nacional de Monitoramento e Alertas aos Desastres Naturais, Cachoeira Paulista, São Paulo, Brazil

Marin, Dora, Servicio Nacional de Meteorología e Hidrología de Perú, Lima, Perú

Marquardt Collow, Allison B., Universities Space Research Association, Columbia, Maryland; NASA GSFC Global Modeling and Assimilation Office, Greenbelt, Maryland

Marra, John J., NOAA/NESDIS National Centers for Environmental Information, Honolulu, Hawaii

Marszelewski, Wlodzimierz, Department of Hydrology and Water Management, Nicolaus Copernicus University, Toruń, Poland

Martens, B., Laboratory of Hydrology and Water Management, Ghent University, Ghent, Belgium

Martínez-Güingla, Rodney, Centro Internacional para la Investigación del Fenómeno de El Niño, Guayaquil, Ecuador 
Massom, Robert A., Australian Antarctic-Division, and Antarctic Climate and Ecosystems Cooperative Research Centre, University of Tasmania, Hobart, Tasmania, Australia

May, Linda, Centre for Ecology and Hydrology, Edinburgh, United Kingdom

Mayer, Michael, Department of Meteorology and Geophysics, University of Vienna, Vienna, Austria; European Centre for Medium-Range Weather Forecasts, Reading, United Kingdom

Mazloff, Matthew, Scripps Institution of Oceanography, University of California San Diego, La Jolla, California

McBride, Charlotte, South African Weather Service, Pretoria, South Africa

McCabe, M., Division of Biological and Environmental Sciences and Engineering, King Abdullah University of Science and Technology, Thuwal, Saudi Arabia

McClelland, J. W., Marine Science Institute, University of Texas at Austin, Port Aransas, Texas

McEvoy, Daniel J., Western Regional Climate Center, Desert Research Institute, Reno, Nevada

McGree, Simon, Bureau of Meteorology, Melbourne, Victoria, Australia

McVicar, Tim R., CSIRO Land and Water, Canberra, Australian Capital Territory; and Australian Research Council Centre of Excellence for Climate Extremes, Sydney, New South Wales, Australia

Mears, Carl A., Remote Sensing Systems, Santa Rosa, California

Meier, Walt, National Snow and Ice Data Center, University of Colorado, Boulder, Boulder, Colorado

Meijers, Andrew, British Antarctic Survey, Cambridge, United Kingdom

Mekonnen, Ademe, Department of Physics, North Carolina A \& T State University, Greensboro, North Carolina

Mengistu Tsidu, G., Department of Earth and Environmental Sciences, Botswana International University of Science and Technology, Palapye, Botswana, and Department of Physics, Addis Ababa University, Addis Ababa, Ethiopia

Menzel, W. Paul, Space Science and Engineering Center, University of Wisconsin-Madison, Madison, Wisconsin

Merchant, Christopher J., Department of Meteorology, University of Reading, Reading, United Kingdom; National Centre for Earth Observation, University of Reading, Reading, United Kingdom

Meredith, Michael P., British Antarctic Survey, Cambridge, United Kingdom

Merrifield, Mark A., Scripps Institution of Oceanography, University of California San Diego, La Jolla, California

Miller, Ben, Cooperative Institute for Research in Environmental Sciences, University of Colorado Boulder, and NOAA/OAR Earth System Research Laboratory, Boulder, Colorado

Miralles, Diego G., Laboratory of Hydrology and Water Management, Ghent University, Ghent, Belgium

Misevicius, Noelia, Instituto Uruguayo de Meteorología, Montevideo, Uruguay
Mitchum, Gary T., College of Marine Science, University of South Florida, St. Petersburg, Florida

Mochizuki, Y., Tokyo Climate Center, Japan Meteorological Agency, Japan

Monselesan, Didier, CSIRO Oceans and Atmosphere, Hobart, Tasmania, Australia

Montzka, Stephen A., NOAA/OAR Earth System Research Laboratory, Boulder, Colorado

Mora, Natali, Center for Geophysical Research and School of Physics, University of Costa Rica, San José, Costa Rica

Morice, Colin, Met Office Hadley Centre, Exeter, United Kingdom

Mosquera-Vásquez, Kobi, Instituto Geofísico del Perú, Lima, Perú

Mostafa, Awatif E., Department of Seasonal Forecast and Climate Research, Cairo Numerical Weather Prediction, Egyptian Meteorological Authority, Cairo, Egypt

Mote, T., Department of Geography, University of Georgia, Athens, Georgia

Mudryk, L., Climate Research Division, Environment and Climate Change Canada, Downsview, Ontario, Canada

Mühle, Jens, Scripps Institution of Oceanography, University of California San Diego, La Jolla, California

Mullan, A. Brett, National Institute of Water and Atmospheric Research, Ltd., Wellington, New Zealand

Müller, Rolf, Forschungszentrum Jülich, Jülich, Germany

Myneni, R., Department of Earth and Environment, Boston University, Boston, Massachusetts

Nash, Eric R., Science Systems and Applications, Inc., NASA Goddard Space Flight Center, Greenbelt, Maryland

Nauslar, Nicholas J., NOAA/NWS/NCEP Storm Prediction Center, Norman, Oklahoma

Nerem, R. Steven, Colorado Center for Astrodynamics Research, Cooperative Institute for Research in Environmental Sciences, University of Colorado Boulder, Boulder, Colorado

Newman, Paul A., NASA Goddard Space Flight Center, Greenbelt, Maryland

Nicolas, Julien P., European Centre for Medium-Range Weather Forecasts, Reading, United Kingdom

Nieto, Juan José, Centro Internacional para la Investigación del Fenómeno de El Niño, Guayaquil, Ecuador

Noetzli, Jeannette, WSL Institute for Snow and Avalanche Research SLF, Davos-Dorf, Switzerland

Osborn, Tim J., Climatic Research Unit, School of Environmental Sciences, University of East Anglia, Norwich, United Kingdom

Osborne, Emily, NOAA/OAR Arctic Research Program, Silver Spring, Maryland

Overland, J., NOAA/OAR Pacific Marine Environmental Laboratory, Seattle, Washington

Oyunjargal, Lamjav, Hydrology and Environmental Monitoring, Institute of Meteorology and Hydrology, National Agency for Meteorology, Ulaanbaatar, Mongolia

Park, T., Department of Earth and Environment, Boston University, Boston, Massachusetts 
Pasch, Richard J., NOAA/NWS National Hurricane Center, Miami, Florida

Pascual Ramírez, Reynaldo, National Meteorological Service of Mexico, Mexico

Pastor Saavedra, Maria Asuncion, Agencia Estatal de Meteorología, Madrid, Spain

Paterson, Andrew M., Dorset Environmental Science Centre, Ontario Ministry of the Environment and Climate Change, Dorset, Ontario, Canada

Pearce, Petra R., National Institute of Water and Atmospheric Research, Ltd., Auckland, New Zealand

Pelto, Mauri S., Nichols College, Dudley, Massachusetts

Perovich, Don, Thayer School of Engineering, Dartmouth College, Hanover, New Hampshire

Petropavlovskikh, Irina, Cooperative Institute for Research in Environmental Sciences, University of Colorado Boulder, and NOAA/OAR Earth System Research Laboratory, Boulder, Colorado

Pezza, Alexandre B., Greater Wellington Regional Council, Wellington, New Zealand

Phillips, C., Department of Atmospheric and Oceanic Sciences, University of Wisconsin-Madison, Madison, Wisconsin

Phillips, David, Environment and Climate Change Canada, Toronto, Ontario, Canada

Phoenix, G., Department of Animal and Plant Sciences, University of Sheffield, Sheffield, United Kingdom

Pinty, Bernard, European Commission, Joint Research Centre, Ispra, Italy

Pitts, Michael, NASA Langley Research Center, Hampton, Virginia

Po-Chedley, S., Lawrence Livermore National Laboratory, Livermore, California

Polashenski, Chris, USACE, ERDC, Cold Regions Research and Engineering Laboratory, and Thayer School of Engineering, Dartmouth College, Hanover, New Hampshire

Preimesberger, W., Department of Geodesy and Geoinformation, TU Wien - Vienna University of Technology, Vienna, Austria

Purkey, Sarah G., Scripps Institution of Oceanography, University of California San Diego, La Jolla, California

Quispe, Nelson, Servicio Nacional de Meteorología e Hidrología del Perú, Lima, Perú

Rajeevan, Madhavan, Earth System Science Organization, Ministry of Earth Sciences, New Delhi, India

Rakotoarimalala, C. L., Madagascar Meteorological Service, Antananarivo, Madagascar

Ramos, Andrea M., Instituto Nacional de Meteorologia, Brasilia, Brazil

Ramos, Isabel, Servicio Nacional de Meteorología e Hidrología del Perú, Lima, Perú

Randel, W., National Center for Atmospheric Research, Boulder, Colorado

Raynolds, M. K., Institute of Arctic Biology, University of Alaska Fairbanks, Fairbanks, Alaska
Reagan, James, Earth System Science Interdisciplinary Center/ Cooperative Institute for Climate and Satellites-Maryland, University of Maryland, College Park, Maryland and NOAA/ NESDIS National Centers for Environmental Information, Silver Spring, Maryland

Reid, Phillip, Australian Bureau of Meteorology, and Antarctic Climate and Ecosystems Cooperative Research Centre, Hobart, Tasmania, Australia

Reimer, Christoph, Earth Observation Data Centre for Water Resources Monitoring GmbH, Vienna, Austria

Rémy, Samuel, Institut Pierre-Simon Laplace, CNRS / UPMC, Paris, France

Revadekar, Jayashree V., Indian Institute of Tropical Meteorology, Pune, India

Richardson, A. D., School of Informatics, Computing, and Cyber Systems and Center for Ecosystem Science and Society, Northern Arizona University, Flagstaff, Arizona

Richter-Menge, Jacqueline, University of Alaska Fairbanks, Fairbanks, Alaska

Ricker, Robert, Alfred Wegener Institute, Helmholtz Centre for Polar and Marine Research, Bremerhaven, Germany

Ripaldi, A., Climate Variability Division, Center for Climate Change Information, BMKG, Indonesia

Robinson, David A., Department of Geography, Rutgers University, Piscataway, New Jersey

Rodell, Matthew, Hydrological Sciences Laboratory, NASA Goddard Space Flight Center, Greenbelt, Maryland

Rodriguez Camino, Ernesto, Agencia Estatal de Meteorología, Madrid, Spain

Romanovsky, Vladimir E., Geophysical Institute, University of Alaska Fairbanks, Fairbanks, Alaska; Earth Cryosphere Institute, Tyumen Science Center, Tyumen, Russia

Ronchail, Josyane, Université Paris Diderot/Laboratoire LOCEAN-IPSL, Paris, France

Rosenlof, Karen H., NOAA/OAR Earth System Research Laboratory, Boulder, Colorado

Rösner, Benajamin, Laboratory for Climatology and Remote Sensing, Faculty of Geography, University of Marburg, Marburg, Germany

Roth, Chris, University of Saskatchewan, Saskatoon, Saskatchewan, Canada

Rozanov, A., University of Bremen, Bremen, Germany

Rusak, James A., Dorset Environmental Science Centre, Ontario Ministry of the Environment and Climate Change, Dorset, Ontario, Canada

Rustemeier, Elke, Global Precipitation Climatology Centre, Deutscher Wetterdienst, Offenbach am Main, Germany

Rutishäuser, T., Institute of Geography and Oeschger Center, University of Berne, Berne, Switzerland

Sallée, Jean-Baptiste, Sorbonne Universités, UPMC University of Paris, L'OCEAN-IPSL, Paris, France

Sánchez-Lugo, Ahira, NOAA/NESDIS National Centers for Environmental Information, Asheville, North Carolina

Santee, Michelle L., NASA Jet Propulsion Laboratory, California Institute of Technology, Pasadena, California 
Sawaengphokhai, P., Science Systems and Applications, Inc., Hampton, Virginia

Sayouri, Amal, Direction de la Météorologie Nationale Maroc, Rabat, Morocco

Scambos, Ted A., Earth Science and Observation Center, CIRES, University of Colorado, Boulder Colorado

Scanlon, T., Department of Geodesy and Geoinformation, TU Wien - Vienna University of Technology, Vienna, Austria

Scardilli, Alvaro S., Argentine Naval Hydrographic Service, Buenos Aires, Argentina

Schenzinger, Verena, Department of Meteorology and Geophysics, University of Vienna, Vienna, Austria

Schladow, S. Geoffey, Tahoe Environmental Research Center University of California at Davis, Davis, California

Schmid, Claudia, NOAA/OAR Atlantic Oceanographic and Meteorological Laboratory (AOML), Miami, Florida

Schmid, Martin, Eawag, Swiss Federal Institute of Aquatic Science and Technology, Kastanienbaum, Switzerland,

Schoeneich, P., Institut de Géographie Alpine, Grenoble, France

Schreck III, Carl J., North Carolina State University, Cooperative Institute for Climate and Satellites - North Carolina (CICS-NC), Asheville, North Carolina

Selkirk, H. B., Universities Space Research Association, NASA Goddard Space Flight Center, Greenbelt, Maryland

Sensoy, Serhat, Turkish State Meteorological Service, Ankara, Turkey

Shi, Lei, NOAA/NESDIS National Centers for Environmental Information, Asheville, North Carolina

Shiklomanov, A. I., University of New Hampshire, Durham, New Hampshire; Arctic and Antarctic Research Institute, St. Petersburg, Russia

Shiklomanov, Nikolai I., Department of Geography, George Washington University, Washington, DC

Shimpo, A., Tokyo Climate Center, Japan Meteorological Agency, Tokyo, Japan

Shuman, Christopher A., UMBC JET at NASA Goddard Space Flight Center, Code 615, Greenbelt, Maryland

Siegel, David A., Earth Research Institute and Department of Geography, University of California - Santa Barbara, Santa Barbara, California

Sima, Fatou, Division of Meteorology, Department of Water Resources, Banjul, The Gambia

Simmons, Adrian J., European Centre for Medium-Range Weather Forecasts, Reading, United Kingdom

Smeets, C. J. P. P., Institute for Marine and Atmospheric Research Utrecht, Utrecht University, Utrecht, Netherlands

Smith, Adam, NOAA/NESDIS National Centers for Environmental Information, Asheville, North Carolina

Smith, Sharon L., Geological Survey of Canada, Natural Resources Canada, Ottawa, Ontario, Canada

Soden, B., Rosenstiel School of Marine and Atmospheric Science, University of Miami, Key Biscayne, Florida

Sofieva, Viktoria, Finnish Meteorological Institute (FMI), Helsinki, Finland
Sparks, T. H., Poznań University of Life Sciences, Poznań, Poland

Spence, Jacqueline, Meteorological Service, Jamaica, Kingston, Jamaica

Spencer, R. G. M., Florida State University, Tallahassee, Florida

Spillane, Sandra, Met Éireann, Irish Meteorological Service, Dublin, Ireland

Srivastava, A.K., India Meteorological Department, Pune, India

Stabeno, P. J., NOAA Pacific Marine Environmental Laboratory, Seattle, Washington

Stackhouse Jr., Paul W., NASA Langley Research Center, Hampton, Virginia

Stammerjohn, Sharon, Institute of Arctic and Alpine Research, University of Colorado, Boulder, Colorado

Stanitski, Diane M., NOAA/OAR Earth System Research Laboratory, Boulder, Colorado

Steinbrecht, Wolfgang, Deutscher Wetterdienst (DWD), Hohenpeissenberg, Germany

Stella, José L., Servicio Meteorológico Nacional, Buenos Aires, Argentina

Stengel, M., Deutscher Wetterdienst, Offenbach, Germany

Stephenson, Tannecia S., Department of Physics, The University of the West Indies, Jamaica

Strahan, Susan E., Universities Space Research Association, NASA Goddard Space Flight Center, Greenbelt, Maryland

Streeter, Casey, Florida Commercial Watermen's Conservation, Matlacha, Florida

Streletskiy, Dimitri A., Department of Geography, George Washington University, Washington, DC

Sun-Mack, Sunny, Science Systems and Applications, Inc., Hampton, Virginia

Suslova, A., Woods Hole Research Center, Falmouth, Massachusetts

Sutton, Adrienne J., NOAA/OAR Pacific Marine Environmental Laboratory, Seattle, Washington

Swart, Sebastiann, Department of Marine Sciences, University of Gothenburg, Gothenburg, Sweden and Department of Oceanography, University of Cape Town, Rondebosch, South Africa

Sweet, William, NOAA/NOS Center for Operational Oceanographic Products and Services, Silver Spring, Maryland

Takahashi, Kenneth S., Servicio Nacional de Meteorología e Hidrología del Perú, Lima, Perú

Tank, S.E., University of Alberta, Edmonton, Alberta, Canada

Taylor, Michael A., Department of Physics, The University of the West Indies, Jamaica

Tedesco, M., Lamont Doherty Earth Observatory, Columbia University, Palisades, New York, and NASA Goddard Institute of Space Studies, New York, New York

Thackeray, S. J., Centre for Ecology and Hydrology, Lancaster, United Kingdom

Thompson, Philip R., Joint Institute for Marine and Atmospheric Research, University of Hawaii, Honolulu, Hawaii 
Timbal, Bertrand, Centre for Climate Research, Singapore Meteorological Service, Singapore

Timmermans, M.-L., Yale University, New Haven, Connecticut

Tobin, Skie, Bureau of Meteorology, Melbourne, Victoria, Australia

Tømmervik, H., Norwegian Institute for Nature Research, Tromsø, Norway

Tourpali, Kleareti, Aristotle University, Thessaloniki, Greece

Trachte, Katja, Laboratory for Climatology and Remote Sensing, Faculty of Geography, University of Marburg, Marburg, Germany

Tretiakov, M., Arctic and Antarctic Research Institute, St. Petersburg, Russia

Trewin, Blair C., Australian Bureau of Meteorology, Melbourne, Victoria, Australia

Triñanes, Joaquin A., Laboratory of Systems, Technological Research Institute, Universidad de Santiago de Compostela, Campus Universitario Sur, Santiago de Compostela, Spain; NOAA/OAR Atlantic Oceanographic and Meteorological Laboratory (AOML), Miami, Florida, and Cooperative Institute for Marine and Atmospheric Studies, Rosenstiel School of Marine and Atmospheric Science, University of Miami, Miami, Florida

Trotman, Adrian R., Caribbean Institute for Meteorology and Hydrology, Bridgetown, Barbados

Tschudi, Mark, Aerospace Engineering Sciences, University of Colorado, Boulder, Colorado

Tye, Mari R., Capacity Center for Climate and Weather Extremes (C3WE), National Center for Atmospheric Research, Boulder, Colorado

van As, D., Geological Survey of Denmark and Greenland, Copenhagen, Denmark

van de Wal, R. S. W., Institute for Marine and Atmospheric Research Utrecht, Utrecht University, Utrecht, Netherlands; Geosciences, Physical Geography, Utrecht University, Utrecht, Netherlands

van der A, Ronald J., Royal Netherlands Meteorological Institute (KNMI), De Bilt, Netherlands

van der Schalie, Robin, VanderSat B.V., Haarlem, Netherlands

van der Schrier, Gerard, Royal Netherlands Meteorological Institute (KNMI), De Bilt, Netherlands

van der Werf, Guido R., Faculty of Earth and Life Sciences, VU University Amsterdam, Netherlands

van Heerwaarden, Chiel, Meteorology and Air Quality Group, Wageningen University and Research, Wageningen, Netherlands

Van Meerbeeck, Cedric J., Caribbean Institute for Meteorology and Hydrology, Bridgetown, Barbados

Verburg, Piet, National Institute of Water and Atmospheric Research, Hamilton, New Zealand

Vieira, G., CEG/IGOT, Universidade de Lisboa, Lisbon, Portugal

Vincent, Lucie A., Environment and Climate Change Canada, Toronto, Ontario, Canada
Vömel, Holger, Earth Observing Laboratory, National Center for Atmospheric Research, Boulder, Colorado

Vose, Russell S., NOAA/NESDIS National Centers for Environmental Information, Asheville, North Carolina

Walker, D. A., Institute of Arctic Biology, University of Alaska Fairbanks, Fairbanks, Alaska

Walsh, J. E., International Arctic Research Center, University of Alaska Fairbanks, Fairbanks, Alaska

Wang, Bin, Department of Atmospheric Science and IPRC, University of Hawaii, Honolulu, Hawaii

Wang, Hui., NOAA/NWS Climate Prediction Center, College Park, Maryland

Wang, Lei, Department of Geography and Anthropology, Louisiana State University, Baton Rouge, Louisiana

Wang, M., Joint Institute for the Study of the Atmosphere and Ocean, University of Washington, Seattle, Washington

Wang, Mengqiu, College of Marine Science, University of South Florida, St. Petersburg, Florida

Wang, Ray, Georgia Institute of Technology, Atlanta, Georgia

Wang, Sheng-Hung, Byrd Polar and Climate Research Center, The Ohio State University, Columbus, Ohio

Wanninkhof, Rik, NOAA/OAR Atlantic Oceanographic and Meteorological Laboratory (AOML), Miami, Florida

Watanabe, Shohei, Tahoe Environmental Research Center, University of California at Davis, Davis, California

Weber, Mark, University of Bremen, Bremen, Germany

Webster, Melinda, NASA Goddard Space Flight Center, Greenbelt, Maryland

Weerts, Albrecht, Deltares, Delft, Netherlands, and Hydrology and Quantitative Water Management Group, Wageningen University and Research, Wageningen, Netherlands

Weller, Robert A., Woods Hole Oceanographic Institution, Woods Hole, Massachusetts

Westberry, Toby K., Department of Botany and Plant Pathology, Oregon State University, Corvallis, Oregon

Weyhenmeyer, Gesa A., Department of Ecology and Genetics/Limnology, Uppsala University, Uppsala, Sweden

Widlansky, Matthew J., Joint Institute for Marine and Atmospheric Research, University of Hawaii, Honolulu, Hawaii

Wijffels, Susan E., Woods Hole Oceanographic Institution, Woods Hole, Massachusetts

Wilber, Anne C., Science Systems and Applications, Inc., Hampton, Virginia

Wild, Jeanette D., NOAA Climate Prediction Center, College Park, MD, USA; ESSIC/University of Maryland, College Park, Maryland

Willett, Kate M., Met Office Hadley Centre, Exeter, United Kingdom

Wong, Takmeng, NASA Langley Research Center, Hampton, Virginia

Wood, E. F., Department of Civil and Environmental Engineering, Princeton University, Princeton, New Jersey 
Woolway, R. lestyn, Dundalk Institute of Technology, Dundalk, Ireland

Xue, Yan, NOAA/NWS National Centers for Environmental Prediction, Climate Prediction Center, College Park, Maryland

Yin, Xungang, ERT Inc., NOAA/NESDIS National Centers for Environmental Information, Asheville, North Carolina

Yu, Lisan, Woods Hole Oceanographic Institution, Woods Hole, Massachusetts

Zambrano, Eduardo, Centro Internacional para la Investigación del Fenómeno de El Niño, Guayaquil, Ecuador

Zeyaeyan, Sadegh, Islamic Republic of Iran Meteorological Organization, Tehran, Iran

Zhang, Huai-Min, NOAA/NESDIS National Centers for Environmental Information, Asheville, North Carolina
Zhang, Peiqun, Beijing Climate Center, Beijing, China

Zhao, Guanguo, University of Illinois at Urbana-Champaign, Champaign, Illinois

Zhao, Lin, Cold and Arid Regions Environmental and Engineering Research Institute, Lanzhou, China

Zhou, Xinjia, Center for Satellite Applications and Research, NOAA, College Park, Maryland

Zhu, Zhiwei, Nanjing University of Information Science and Technology, China

Ziemke, Jerry R., Goddard Earth Sciences Technology and Research, Morgan State University, Baltimore, Maryland, and NASA Goddard Space Flight Center, Greenbelt, Maryland

Ziese, Markus, Global Precipitation Climatology Center, Deutscher Wetterdienst, Offenbach am Main, Germany

\section{EDITORIAL AND PRODUCTION TEAM}

Andersen, Andrea, Technical Editor, TeleSolv Consulting LLC, NOAA/NESDIS National Centers for Environmental Information, Asheville, North Carolina

Griffin, Jessicca, Graphics Support, Cooperative Institute for Satellite Earth System Studies, North Carolina State University, Asheville, North Carolina

Hammer, Gregory, Content Team Lead, Communications and Outreach, NOAA/NESDIS National Centers for Environmental Information, Asheville, North Carolina

Love-Brotak, S. Elizabeth, Lead Graphics Production, NOAA/NESDIS National Centers for Environmental Information, Asheville, North Carolina
Misch, Deborah J., Graphics Support, TeleSolv Consulting LLC, NOAA/NESDIS National Centers for Environmental Information, Asheville, North Carolina

Riddle, Deborah B., Graphics Support, NOAA/NESDIS

National Centers for Environmental Information, Asheville, North Carolina

Veasey, Sara W., Visualization Team Lead, Communications and Outreach, NOAA/NESDIS National Centers for Environmental Information, Asheville, North Carolina 


\section{TABLE OF CONTENTS}

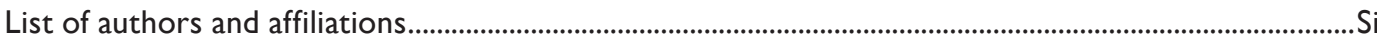

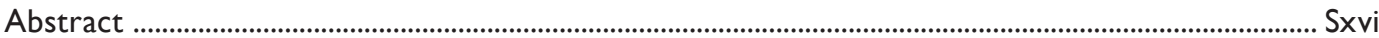

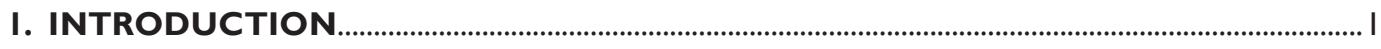

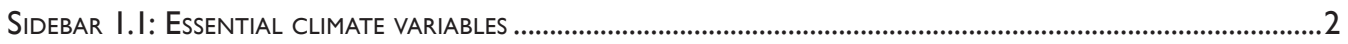

2. GLOBAL CLIMATE

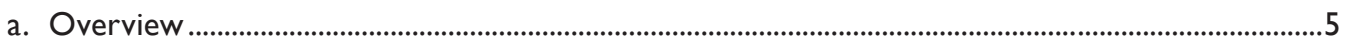

b. Temperature

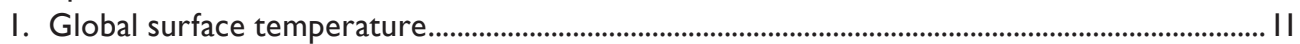

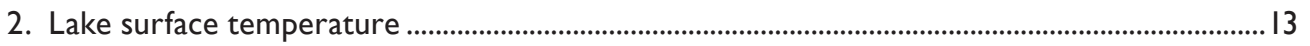

3. Land surface temperature extremes ........................................................................................... 14

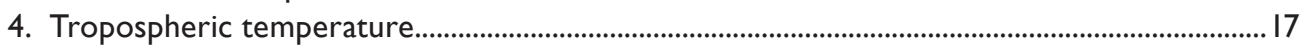

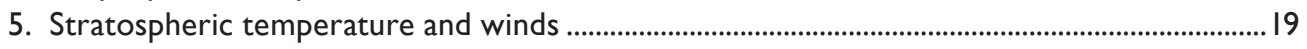

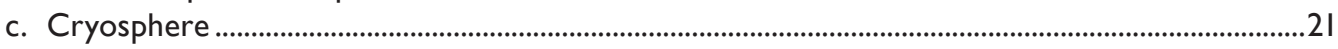

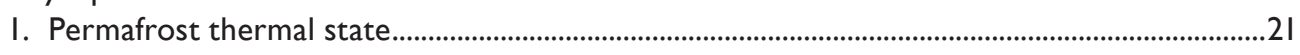

2. Northern Hemisphere continental snow cover extent ................................................................ 23

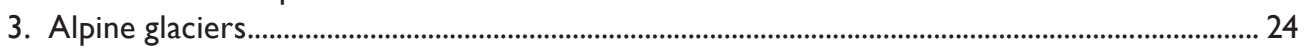

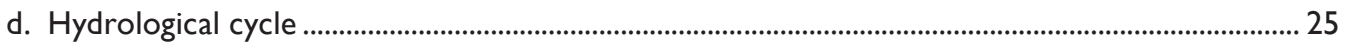

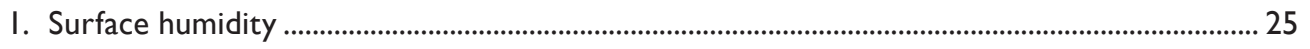

2. Total column water vapor ........................................................................................................ 27

3. Upper tropospheric humidity..................................................................................................... 28

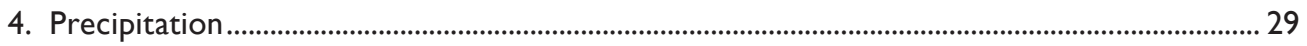

5. Land surface precipitation extremes........................................................................................... 30

SidebAR 2.I: JULY RECORD-BREAKING RAINFALL AND FLOODING IN THE MID-ATLANTIC REGION OF THE

UNITED STATES FROM THE PERSPECTIVE OF REANALYSES ............................................................................. 32

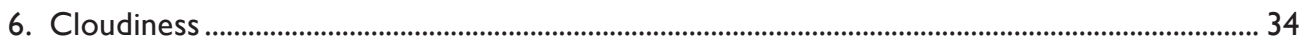

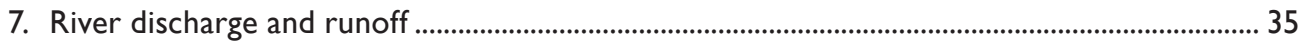

8. Groundwater and terrestrial water storage .............................................................................. 37

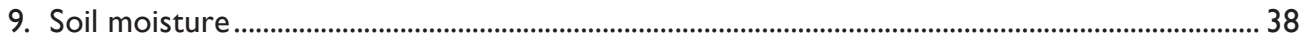

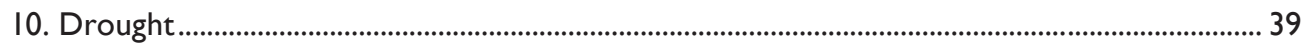

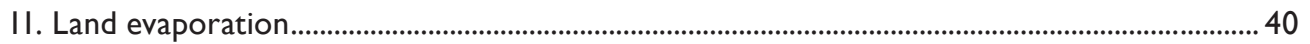

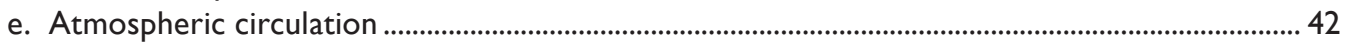

I. Mean sea level pressure and related modes of variability............................................................ 42

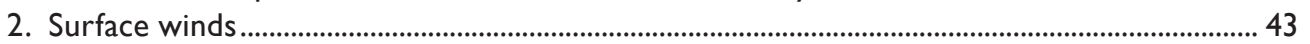

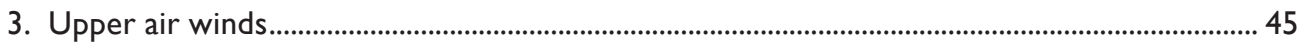

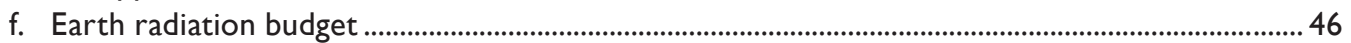

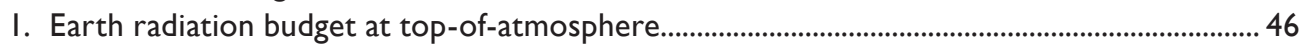

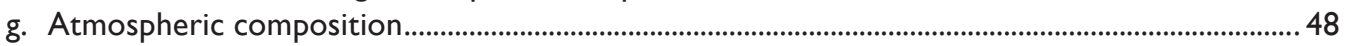

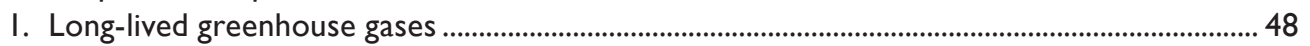

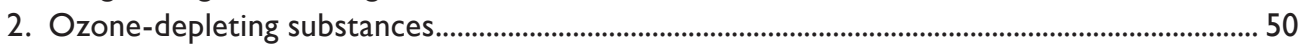

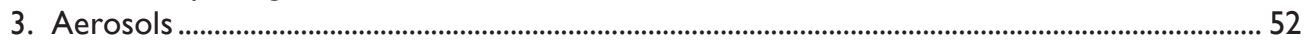

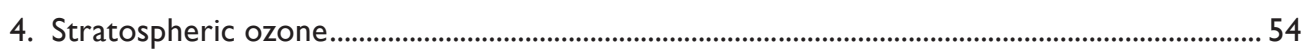

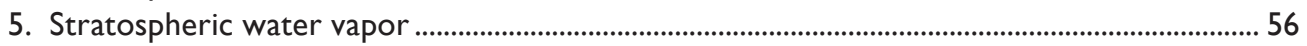

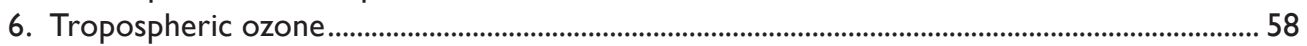

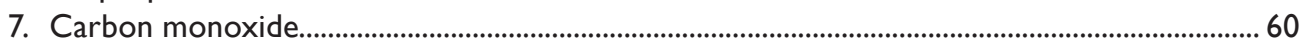

h. Land surface properties.................................................................................................................

I. Land surface albedo dynamics .......................................................................................................61

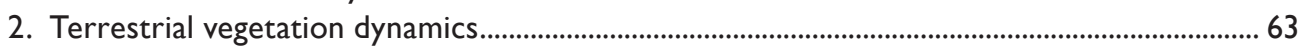

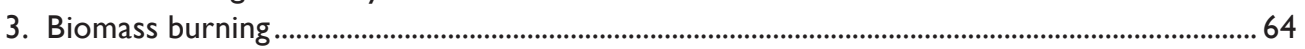

4. Phenology of primary producers.................................................................................................. 65 


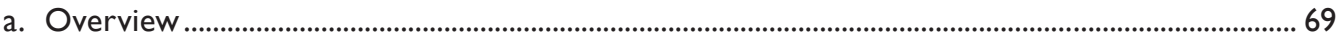

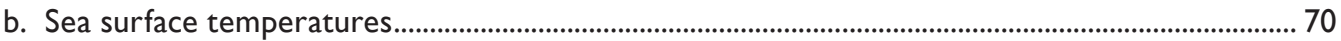

SIDEBAR 3.I: UNPRECEDENTED SARGASSUM BLOOMS IN THE TROPICAL ATLANTIC................................................... 73

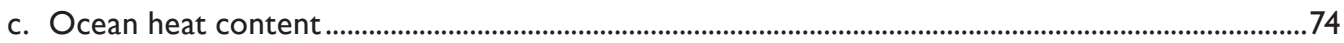

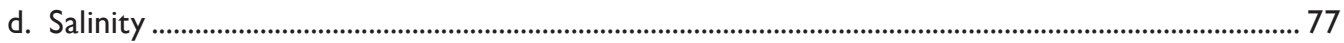

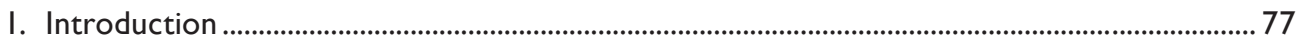

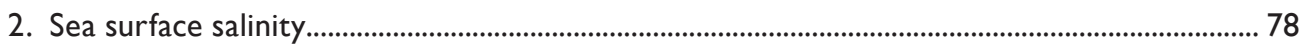

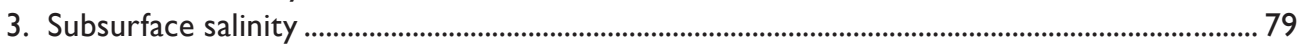

e. Global ocean heat, freshwater, and momentum fluxes .................................................................

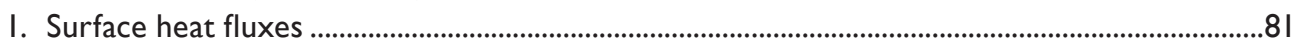

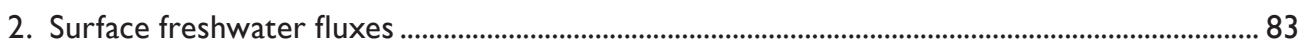

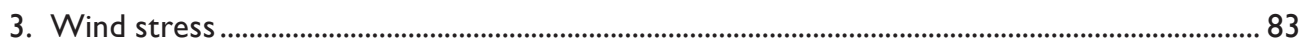

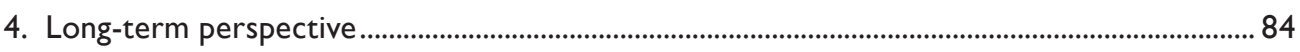

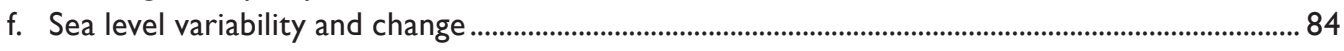

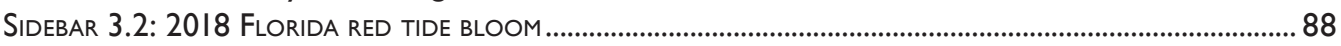

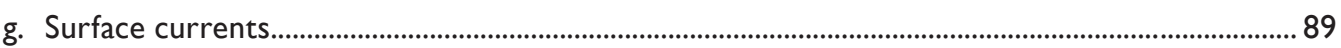

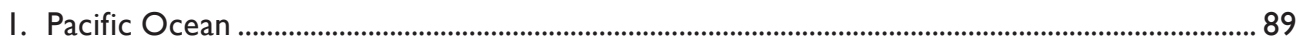

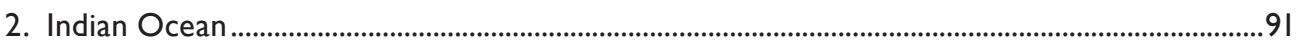

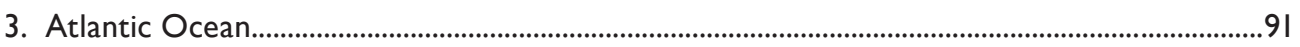

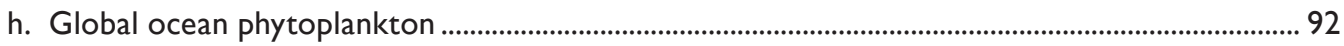

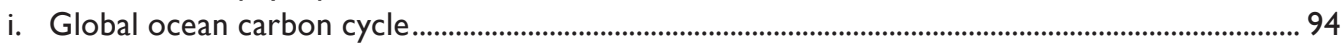

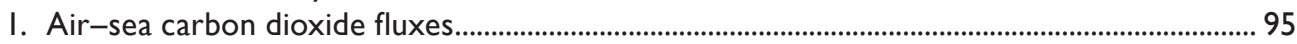

2. Interannual variability of $\mathrm{pCO}_{2}$ in the tropical Pacific................................................................. 97

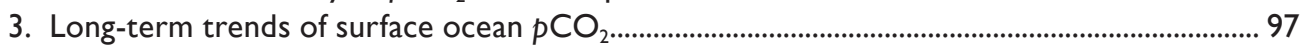

4. Global ocean carbon inventories...................................................................................................... 98

4. THE TROPICS

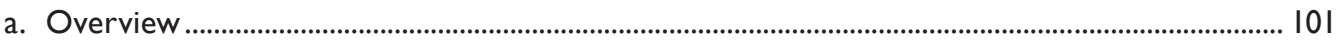

b. ENSO and the tropical Pacific............................................................................................... 101

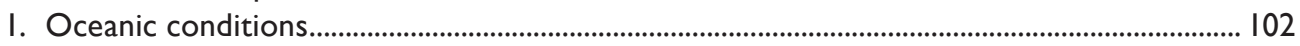

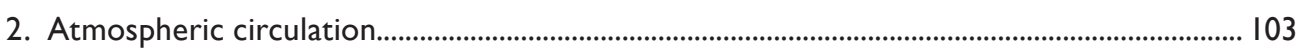

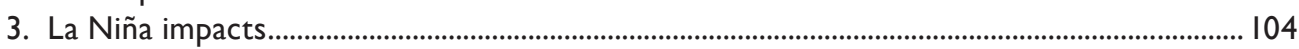

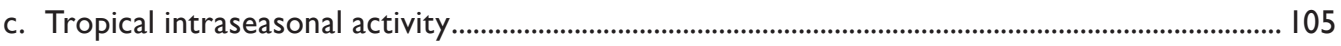

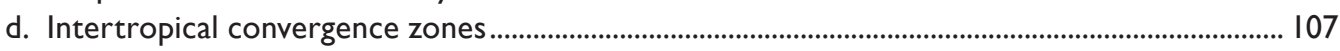

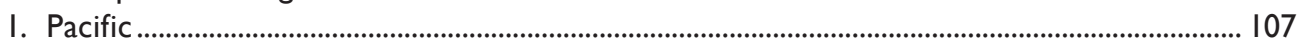

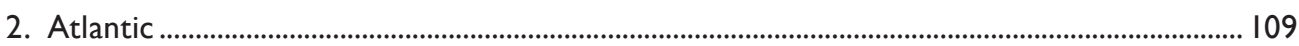

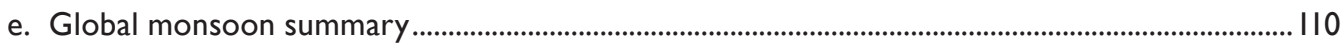

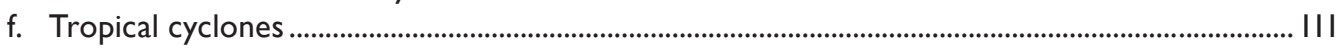

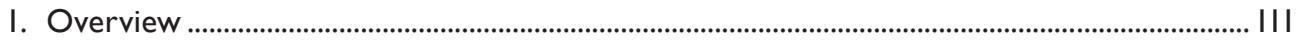

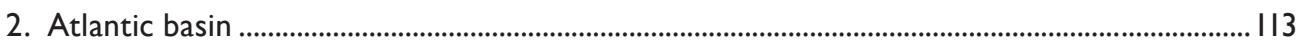

Sidebar 4.I: Hurricane Michael: A Florida Panhandle record-breaking landfall ............................. I19

3. Eastern North Pacific and Central North Pacific basins........................................................... 12I

4. Western North Pacific basin ................................................................................................... 124

5. North Indian Ocean basin ............................................................................................................. 127

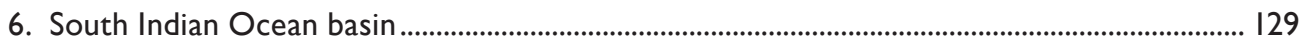

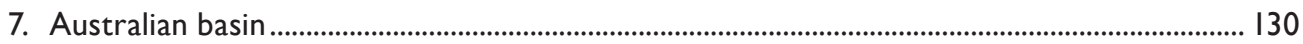

8. Southwest Pacific basin ..................................................................................................................... 132

g. Tropical cyclone heat potential................................................................................................. 133

Sidebar 4.2: Upper-ocean conditions in the Gulf of MeXico during HurRicane Michael ................ 135

h. Indian Ocean dipole...................................................................................................................... 138 


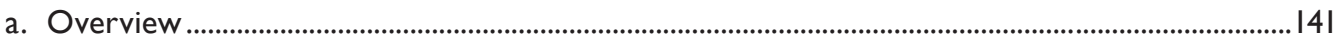

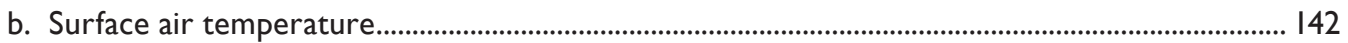

I. Mean annual land surface air temperature.............................................................................. 142

2. Seasonal air temperature variation .............................................................................................. 142

3. Geopotential heights and resulting regional temperature patterns........................................ 143

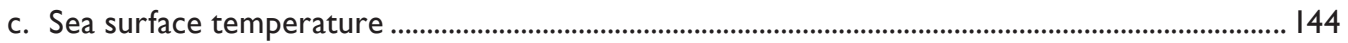

d. Sea ice cover

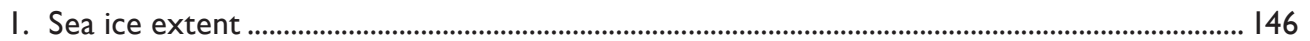

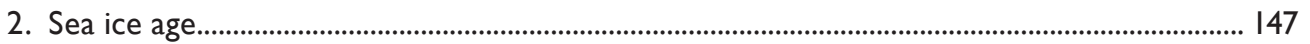

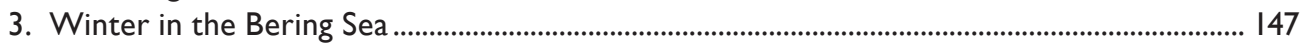

Sidebar 5.I: The eastern Bering Sea: DeClining ICE, Warming SEAS, and a

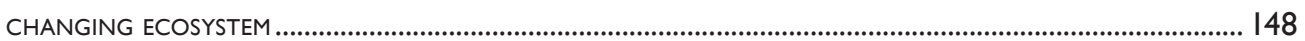

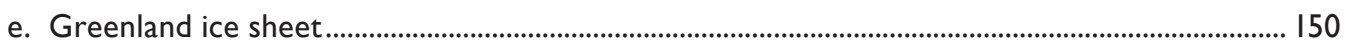

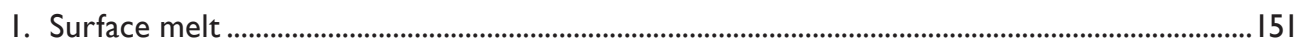

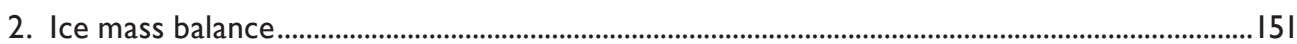

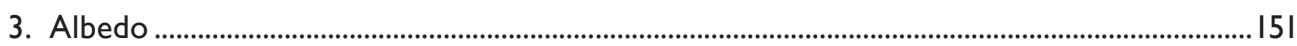

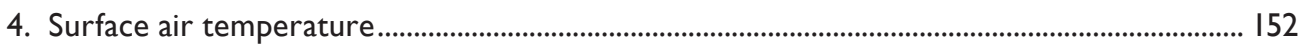

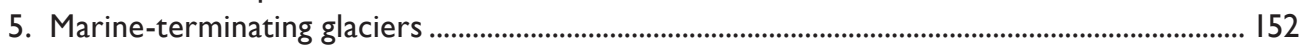

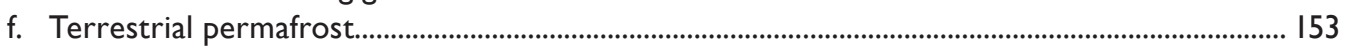

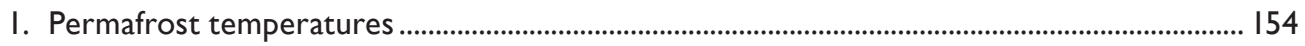

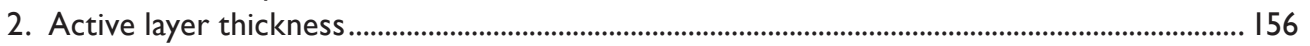

SIDEBAR 5.2: WARMING AND THAWING PERMAFROST AND IMPACTS ON INFRASTRUCTURE ................................ 157

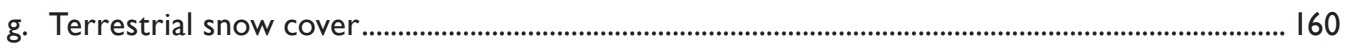

h. River discharge

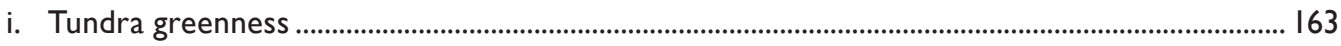

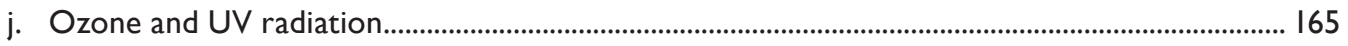

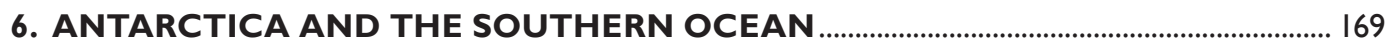

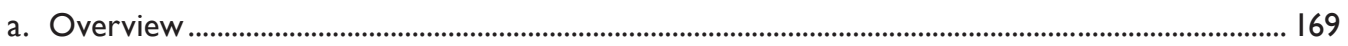

b. Atmospheric circulation and surface observations ....................................................................... 170

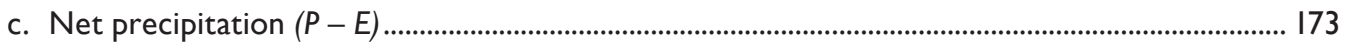

Sidebar 6.I: Record-Warm conditions at the South Pole and the unusual atmospheric

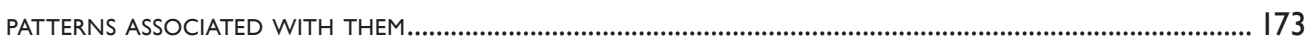

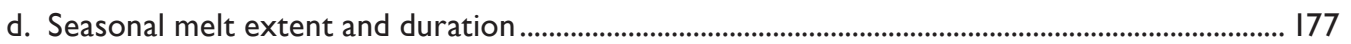

e. Sea ice extent, concentration, and seasonality ……………………………………...................... 178

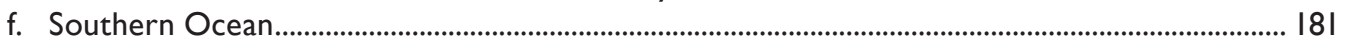

I. Surface mixed layer properties ..................................................................................................... 18 I

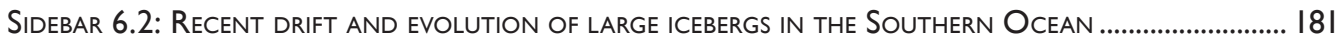

2. Ocean color: phytoplankton abundance ................................................................................... 183

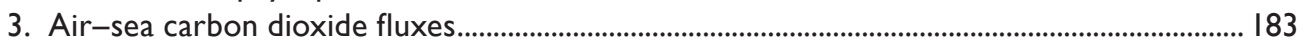

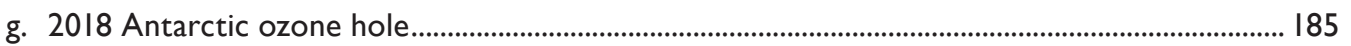




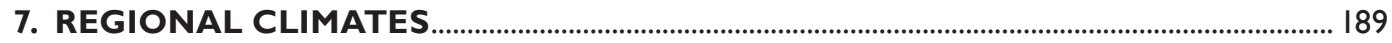

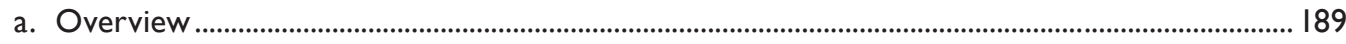

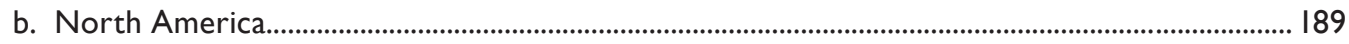

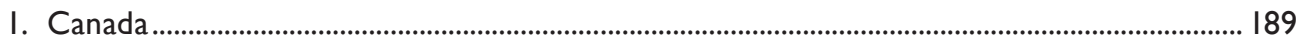

2. United States

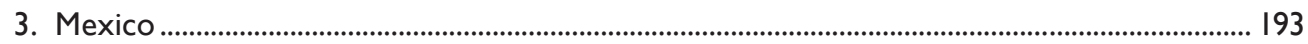

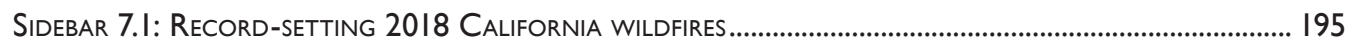

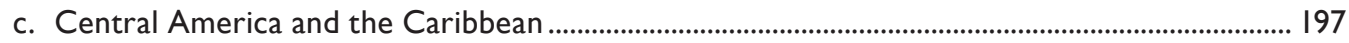

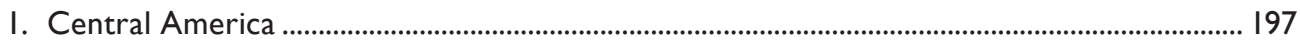

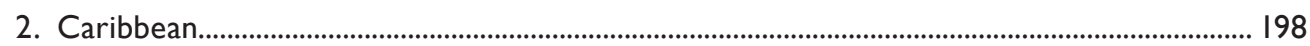

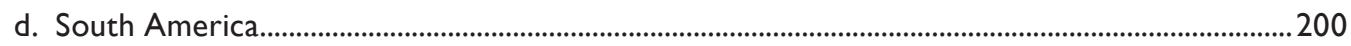

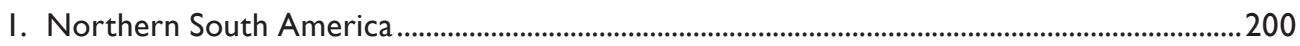

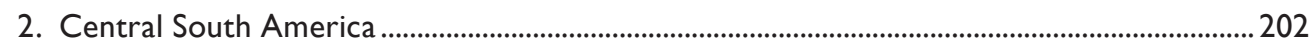

Sidebar 7.2: Heavy snowfalls in the Peruvian Andes: The Wettest Winter of the

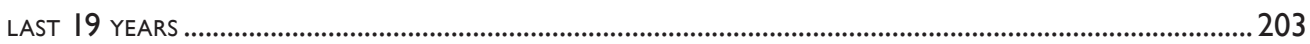

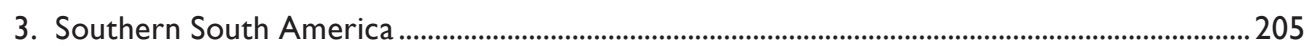

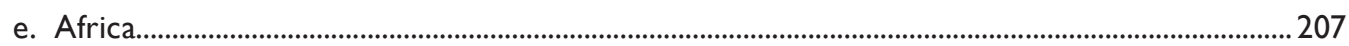

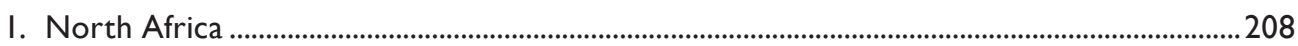

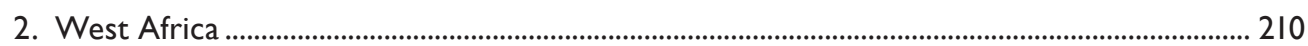

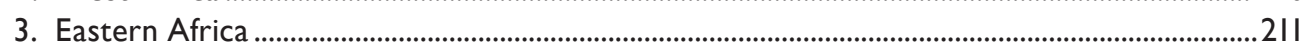

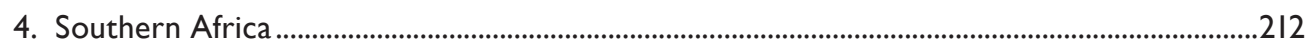

5. Western Indian Ocean island countries .............................................................................214

f. Europe and the Middle East............................................................................................................2

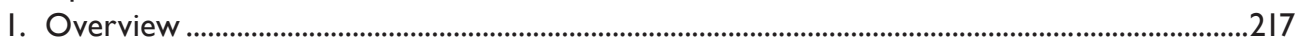

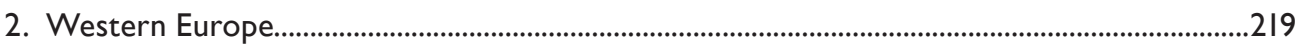

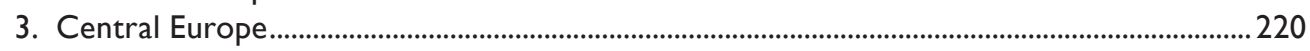

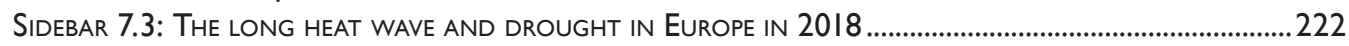

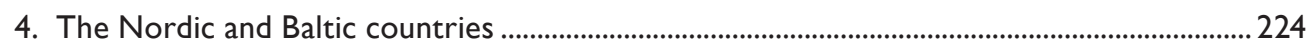

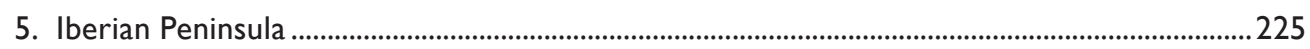

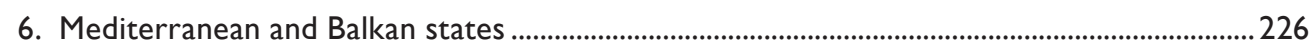

7. Eastern Europe ............................................................................................................................. 227

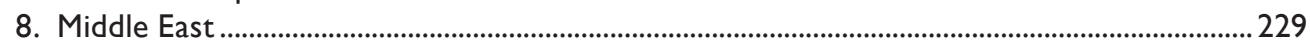

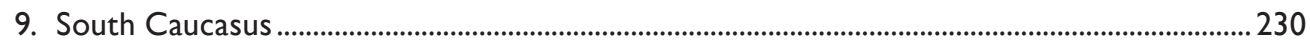

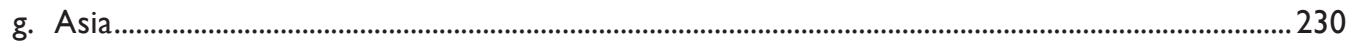

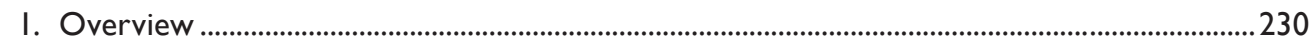

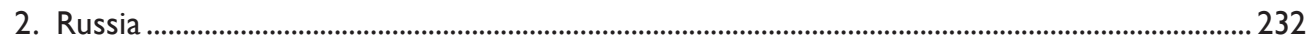

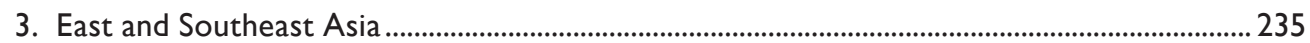

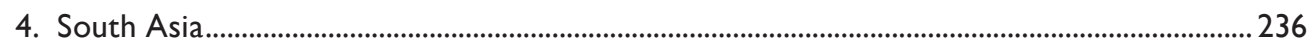

SIDEBAR 7.4: THE WEAKEST EAST AsIAN SUMMER MONSOON DURING THE PAST 40 YEARS.................................22

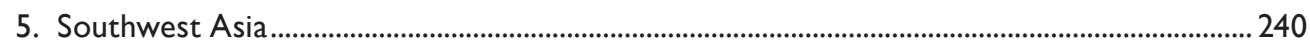

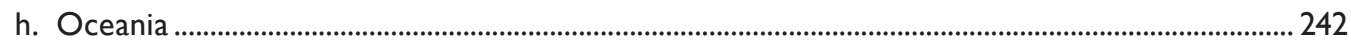

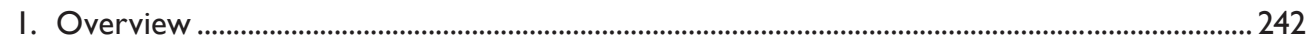

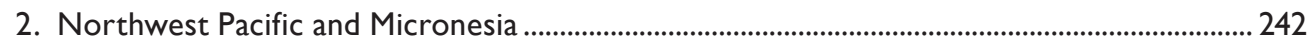

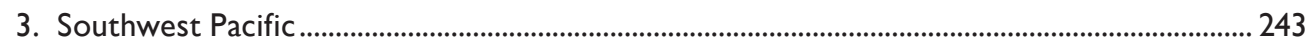

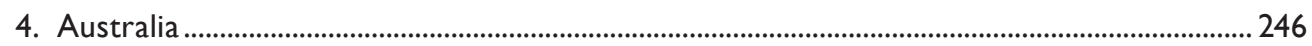

Sidebar 7.5: EXTENDED DROUGHT IN AUSTRALIA IN 2018......................................................................... 248

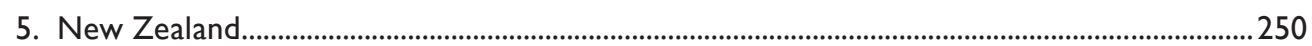

APPENDIX I: Relevant Datasets and Sources .............................................................................. 253

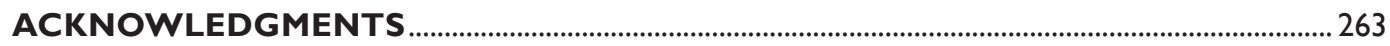

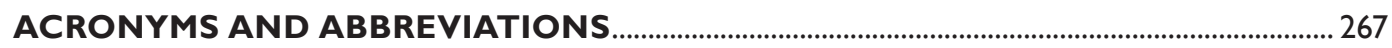

REFERENCES 


\section{ABSTRACT—J. BLUNDEN AND D. S. ARNDT}

In 2018, the dominant greenhouse gases released into Earth's atmosphere-carbon dioxide, methane, and nitrous oxide-continued their increase. The annual global average carbon dioxide concentration at Earth's surface was $407.4 \pm$ $0.1 \mathrm{ppm}$, the highest in the modern instrumental record and in ice core records dating back 800000 years. Combined, greenhouse gases and several halogenated gases contribute just over $3 \mathrm{~W} \mathrm{~m}^{-2}$ to radiative forcing and represent a nearly $43 \%$ increase since 1990. Carbon dioxide is responsible for about $65 \%$ of this radiative forcing.

With a weak La Niña in early 2018 transitioning to a weak El Niño by the year's end, the global surface (land and ocean) temperature was the fourth highest on record, with only 2015 through 2017 being warmer. Several European countries reported record high annual temperatures. There were also more high, and fewer low, temperature extremes than in nearly all of the 68-year extremes record. Madagascar recorded a record daily temperature of $40.5^{\circ} \mathrm{C}$ in Morondava in March, while South Korea set its record high of $41.0^{\circ} \mathrm{C}$ in August in Hongcheon. Nawabshah, Pakistan, recorded its highest temperature of $50.2^{\circ} \mathrm{C}$, which may be a new daily world record for April. Globally, the annual lower troposphere temperature was third to seventh highest, depending on the dataset analyzed. The lower stratospheric temperature was approximately fifth lowest.

The 2018 Arctic land surface temperature was $1.2^{\circ} \mathrm{C}$ above the 198I-2010 average, tying for third highest in the II8-year record, following 2016 and 2017. June's Arctic snow cover extent was almost half of what it was 35 years ago. Across Greenland, however, regional summer temperatures were generally below or near average. Additionally, a satellite survey of 47 glaciers in Greenland indicated a net increase in area for the first time since records began in 1999. Increasing permafrost temperatures were reported at most observation sites in the Arctic, with the overall increase of $0.1^{\circ}-0.2^{\circ} \mathrm{C}$ between 2017 and 2018 being comparable to the highest rate of warming ever observed in the region.

On 17 March, Arctic sea ice extent marked the second smallest annual maximum in the 38-year record, larger than only 2017. The minimum extent in 2018 was reached on 19 September and again on 23 September, tying 2008 and 2010 for the sixth lowest extent on record. The 23 September date tied 1997 as the latest sea ice minimum date on record. First-year ice now dominates the ice cover, comprising $77 \%$ of the March 2018 ice pack compared to $55 \%$ during the 1980 s. Because thinner, younger ice is more vulnerable to melting out in summer, this shift in sea ice age has contributed to the decreasing trend in minimum ice extent. Regionally, Bering Sea ice extent was at record lows for almost the entire 2017/18 ice season.

For the Antarctic continent as a whole, 2018 was warmer than average. On the highest points of the Antarctic Plateau, the automatic weather station Relay $\left(74^{\circ} \mathrm{S}\right)$ broke or tied six monthly temperature records throughout the year, with August breaking its record by nearly $8^{\circ} \mathrm{C}$. However, cool conditions in the western Bellingshausen Sea and Amundsen Sea sector contributed to a low melt season overall for 2017/18. High SSTs contributed to low summer sea ice extent in the Ross and Weddell Seas in 2018, underpinning the second lowest Antarctic summer minimum sea ice extent on record. Despite conducive conditions for its formation, the ozone hole at its maximum extent in September was near the 2000-18 mean, likely due to an ongoing slow decline in stratospheric chlorine monoxide concentration.

Across the oceans, globally averaged SST decreased slightly since the record El Niño year of 2016 but was still far above the climatological mean. On average, SST is increasing at a rate of $0.10^{\circ} \pm 0.01^{\circ} \mathrm{C} \mathrm{decade}^{-1}$ since 1950 . The warming appeared largest in the tropical Indian Ocean and smallest in the North Pacific. The deeper ocean continues to warm year after year. For the seventh consecutive year, global annual mean sea level became the highest in the 26-year record, rising to $81 \mathrm{~mm}$ above the 1993 average. As anticipated in a warming climate, the hydrological cycle over the ocean is accelerating: dry regions are becoming drier and wet regions rainier.

Closer to the equator, 95 named tropical storms were observed during 2018 , well above the $1981-2010$ average of 82. Eleven tropical cyclones reached Saffir-Simpson scale Category 5 intensity. North Atlantic Major Hurricane Michael's landfall intensity of $140 \mathrm{kt}$ was the fourth strongest for any continental U.S. hurricane landfall in the 168 -year record. Michael caused more than 30 fatalities and $\$ 25$ billion (U.S. dollars) in damages. In the western North Pacific, Super Typhoon Mangkhut led to 160 fatalities and $\$ 6$ billion (U.S. dollars) in damages across the Philippines, Hong Kong, Macau, mainland China, Guam, and the Northern Mariana Islands. Tropical Storm Son-Tinh was responsible for 170 fatalities in Vietnam and Laos. Nearly all the islands of Micronesia experienced at least moderate impacts from various tropical cyclones.

Across land, many areas around the globe received copious precipitation, notable at different time scales. Rodrigues and Réunion Island near southern Africa each reported their third wettest year on record. In Hawaii, $1262 \mathrm{~mm}$ precipitation at Waipā Gardens (Kauai) on 14-15 April set a new U.S. record for 24-h precipitation. In Brazil, the city of Belo Horizonte received nearly $75 \mathrm{~mm}$ of rain in just 20 minutes, nearly half its monthly average.

Globally, fire activity during 2018 was the lowest since the start of the record in 1997, with a combined burned area of about 500 million hectares. This reinforced the long-term downward trend in fire emissions driven by changes in land use in frequently burning savannas. However, wildfires burned 3.5 million hectares across the United States, well above the 2000-10 average of 2.7 million hectares. Combined, U.S. wildfire damages for the 2017 and 2018 wildfire seasons exceeded $\$ 40$ billion (U.S. dollars). 
I. INTRODUCTION-D. S. Arndt, J. Blunden, and

R. J. H. Dunn

We are pleased to offer the State of the Climate's 29th edition, and 24th in the Bulletin. Often referred to as the "annual physical of the climate system," the report endeavors to bring a comprehensive set of measurements to detail the status of the climate system and our capacity and willingness to observe it.

A broad overview of global and near-global indicators is placed in this chapter (Plate 1.1). The year 2018 was another warm year globally. Among these indicators, global radiative forcing by greenhouse gases and upper ocean heat content, arguably the most integrative of human forcing of the climate system and the resultant heating, respectively, reached new highs for their observational histories.

As valuable as the takeaway indicators can be, they more fully come to life in subsequent chapters, where they are put into richer context. The most impactful and regionally meaningful phenomena can be difficult to capture in a standard indicator plate format. We encourage the reader to explore each chapter, in which the authors examine significant, internal dynamics that influence annual outcomes; the challenges and successes in measuring a phenomenon or variable; the connection to other physical processes; and, of course, the impacts of change and variability most relevant to the chapter's topic.

The presence of ENSO throughout the climate system is pervasive in this report, spilling even into the polar chapters. The year 2018 began in La Niña status, continuing the weak-to-moderate La Niña that closed out 2017. The calendar's middle months saw a transition to neutral conditions, and by late 2018, a developing El Niño was evident in sea surface characteristics, although a true coupling of the ocean and atmosphere would not occur until early 2019. As is the case in any State of the Climate edition, due to the large variation in the characterization of ENSO, considerable discretion rests with the authors to define those metrics by which their disciplines measure the phenomenon.

This series strives to cover as many essential variables and climate phenomena as possible. To that end, the composition of the report and its chapters evolves each year. The Global Climate chapter incorporates two new sections-measures of extreme precipitation and some phenological indicators-after previewing their methodologies in sidebars last year. The Arctic chapter reintroduces its river discharge section and dedicates a new section and a sidebar to the dramatic changes in the Bering Sea in recent years. The European regional section further subdivides the continent into more focused subregions and includes the first explicit treatment of the South Caucasus region in many years of this series. Although new sections and approaches bring dynamism to this report, inevitably some passages, particularly those that describe observational or analytical methods, borrow heavily from previous reports.

Many sidebars in the early, near-global-scale chapters focus on extremes in and around the Atlantic. One analyzes the extensive precipitation and flooding in the United States' mid-Atlantic region. Two more detail the impacts of the "Red Tide" and, separately, Sargassum blooms around the U.S. Atlantic coast, and both tropical chapter sidebars examine Atlantic Hurricane Michael, plus the role that upper ocean heat content may have played in its development.

This year's cover image was taken by an Arctic researcher during 2018 field work. It reminds us of one of this series' consistent recent findings: that Arctic change is accelerating beyond the global average rate. Further, it depicts the difficult-to-visualize connections between subterranean and surface change.

We routinely express our respect and gratitude for the dedication of the authors and editors to thoroughly and rigorously document the state of the climate system. This year, many U.S. government scientists, and those dependent on U.S. government data, re-prioritized their post-furlough activities to reduce disruption to the report's contents and schedule. Thanks to their dedication, and the generous expanded support from those who were able to contribute during the episode, we were able to produce the report roughly on schedule and with the apparent loss of only one section.

Put simply, we will remember this edition, as ever, for the value of the many scientific contributions. But perhaps more so for the depth of professional generosity built into this series. We are pleased to recognize the efforts and generosity of contributors in the Acknowledgments section following the Appendix.

An overview of findings is presented in the Abstract, Fig. 1.1, and Plate 1.1. Chapter 2 features global-scale climate variables; Chapter 3 highlights the global oceans; and Chapter 4 discusses tropical climate phenomena including tropical cyclones. The Arctic and Antarctica respond differently through time and are reported in separate chapters (5 and 6, respectively). Chapter 7 provides a regional perspective authored largely by local government climate specialists. A list of relevant datasets and their sources for all chapters is provided as an Appendix. 


\section{ESSENTIAL CLIMATE VARIABLES—D. S. ARNDT, J. BLUNDEN, AND R. J. H. DUNN}

Time series of major climate indicators are again presented in this introductory chapter. Many of these indicators are essential climate variables (ECVs), originally defined in GCOS (2003) and updated again by GCOS (2010). The following ECVs, included in this edition, are considered "fully monitored," in that they are observed and analyzed across much of the world, with a sufficiently long-term dataset that has peer-reviewed documentation:

- Atmospheric Surface: air temperature, precipitation, air pressure, water vapor, wind speed and direction

- Atmospheric Upper Air: Earth radiation budget, temperature, water vapor, wind speed and direction

- Atmospheric Composition: carbon dioxide, methane, other long-lived gases, ozone

- Ocean Surface: temperature, salinity, sea level, sea ice, current, ocean color, phytoplankton

- Ocean Subsurface: temperature, salinity
Terrestrial: snow cover, albedo ECVs in this edition that are considered "partially monitored," meeting some but not all of the above requirements, include:

- Atmospheric Upper Air: cloud properties

- Atmospheric Composition: aerosols and their precursors

- Ocean Surface: carbon dioxide, ocean acidity

- Ocean Subsurface: current, carbon

- Terrestrial: soil moisture, permafrost, glaciers and ice caps, river discharge, groundwater, ice sheets, fraction of absorbed photosynthetically active radiation, lakes, biomass, fire disturbance

Remaining ECVs that are desired for the future include:

- Atmospheric Surface: surface radiation budget

- Ocean Surface: sea state

- Ocean Subsurface: nutrients, ocean tracers, ocean acidity, oxygen

- Terrestrial: water use, land cover, leaf area index, soil carbon

Plate I.I. Global (or representative) average time series for essential climate variables through 2018. Anomalies are shown relative to the base period in parentheses although base periods used in other sections of the report may differ. The numbers in the square brackets that follow in this caption indicate how many reanalysis (blue), satellite (red), and in situ (black) datasets are used to create each time series in that order. (a) NH polar stratospheric ozone (Mar) [0,0,I]; (b) SH polar stratospheric ozone (Oct) [0,0,l]; (c) Arctic air temperature $\left(60^{\circ}-90^{\circ} \mathrm{N}\right)[0,0,1]$; (d) Surface temperature [0,0,4]; (e) Lower tropospheric temperature [3,2,4]; (f) Lower stratospheric temperature [3,3,4]; (g) Extremes [warm days (solid) and cool days (dotted)] [0,0,I]; (h) Arctic sea ice extent [ $\max$ (solid) and $\min ($ dashed)] [0,0,I]; (i) Antarctic sea ice extent [max (solid) and min (dashed)] $[0,0,1]$; (j) Glacier cumulative mean specific balance $[0,0,1]$; (k) NH snow cover extent $[0,1,0]$; (I) Lower stratospheric water vapor $[0,0,1] ;(m)$ Cloudiness $[0,8,0] ;(n)$ Total column water vapor-land $[3,1,1] ;(0)$ Total column water vapor-ocean [3,2,0]; (p) Upper tropospheric humidity [0,2,0]; (q) Specific humidity-land [3,0,4]; (r) Specific humidity-ocean [3, I,3]; (s) Relative humidity-land [3,0,4]; (t) Relative humidity-ocean [3,0,2]; (u) Precipitation-land $[0,0,4]$; (v) Southern Oscillation index [0,0,1]; (w) Ocean heat content $(0-700 \mathrm{~m})[0,0,5]$; (x) Sea level rise $[0,0,1]$; (y) Tropospheric ozone $[0,1,0]$; (z) Tropospheric wind speed at $850 \mathrm{hPa}$ for $20^{\circ}-40^{\circ} \mathrm{N}$ $[4,0,1]$; (aa) Land wind speed $[0,0,1]$; (ab) Ocean wind speed $[3,1,0]$; (ac) Biomass burning [0,3,0]; (ad) Soil moisture $[0,1,0]$; (ae) Terrestrial groundwater storage [0, I,0]; (af) Fraction of absorbed photosynthetically active radiation (FAPAR) [0,I,0]; (ag) Land surface albedo-visible (solid) and infrared (dashed) [0, I,0]. 

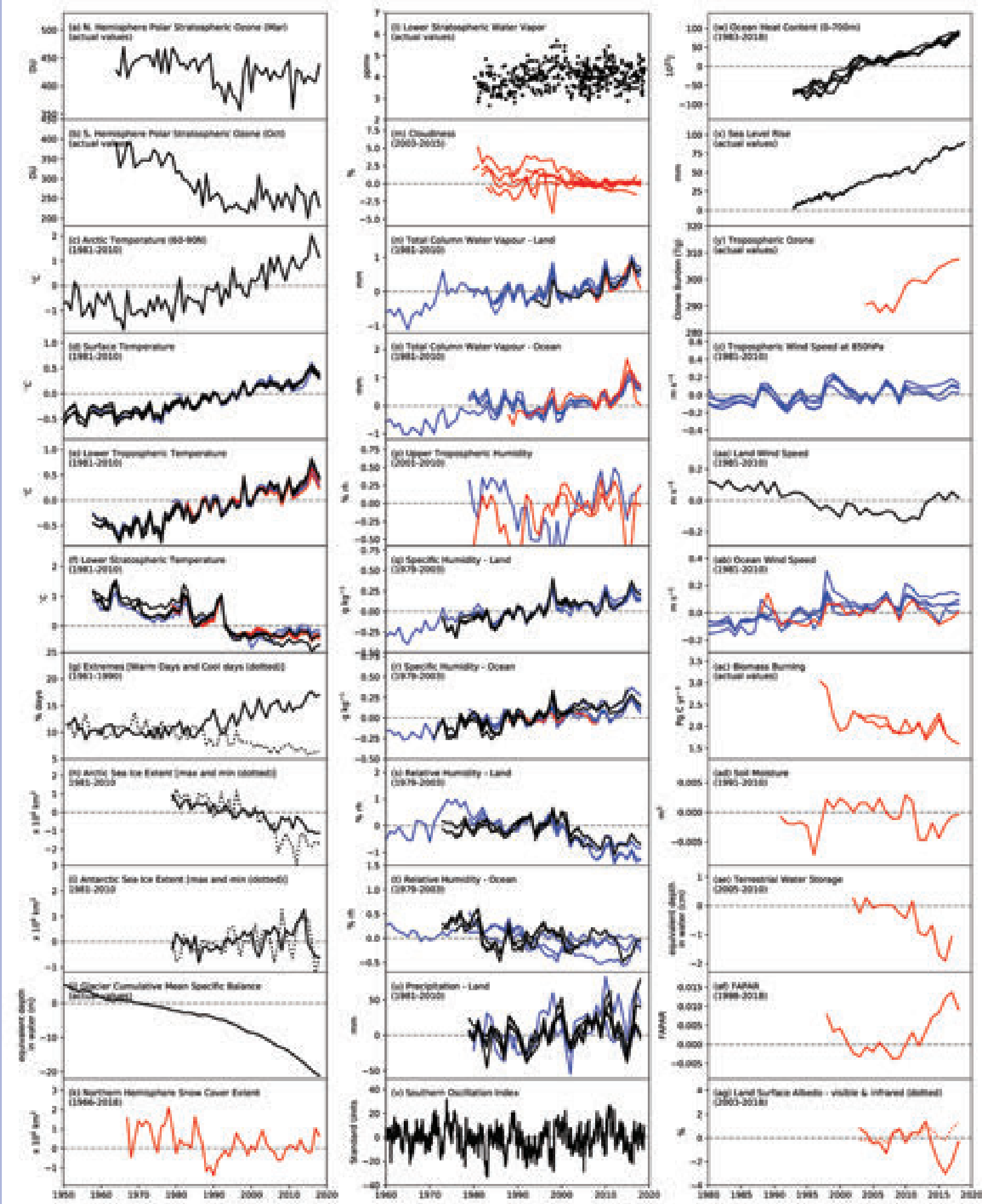


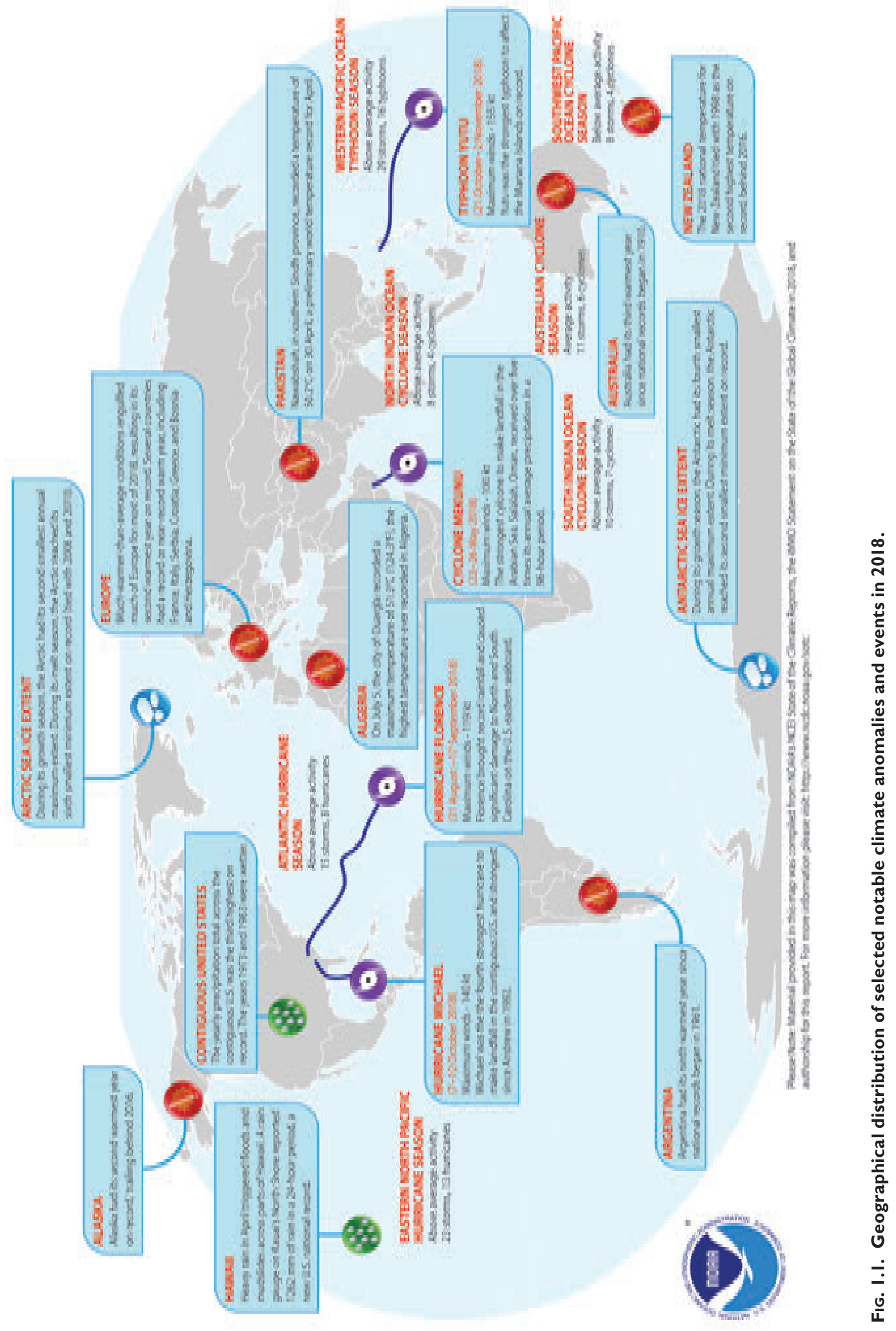


2. GLOBAL CLIMATE-R. J. H. Dunn, D. M. Stanitski, N. Gobron, and K. M. Willett, Eds.

a. Overview-R. J. H. Dunn, D. M. Stanitski, N. Gobron, and K. M. Willett

Another year passes, another warm year. In fact, 2018 was the fourth warmest year after 2016, 2015, and 2017, based on four independently constructed datasets measuring global land and ocean surface temperatures since global records began in the midto-late 1800 s. Every year since the start of the twentyfirst century has been warmer than the 1981-2010 global average. The warmth was also observed in the atmosphere, with annual tropospheric temperatures in 2018 third to seventh highest on record, depending on the dataset, and the stratospheric temperatures (12-25 km) approximately fifth lowest.

Along with warmer average conditions across the globe, there were more positive, and fewer negative, temperature extremes during 2018 than in nearly all the 68 previous years in the observational record. A number of prolonged heat waves in North America, Europe, Australia, and East Asia were widely reported, along with some unusually cold periods, for example, in Europe. It is clear that lakes are also affected by the warm conditions, as the majority of the lakes assessed show continual increases in annual temperatures, especially in the northern midlatitudes.

These continued above-average temperatures are apparent across the many observations assessed within this chapter. The initial results of a consistent assessment of permafrost temperature changes show increases of $0.29^{\circ} \pm 0.12^{\circ} \mathrm{C}$ over the decade 2007-16, and these were reflected regionally in the Alps, Central Asia, and Antarctica. Global glacier mass continues its decline, now the 30th consecutive year of significant negative mass balance; around a further meter of ice has melted off the top of the average glacier in 2018, bringing the total to $24 \mathrm{~m}$ since 1980. The overwhelming majority of monitored glaciers continue to show terminus retreat. In contrast, snow cover over North America and Eurasia in 2018 was above average in both spring and autumn, but shows a decadal tendency toward below-average extent during May-June.

The continued warmth was reflected in high humidity at the surface and in the above-average total column water vapor over both land and ocean. These were lower than during the El Niño-related 2016 peak, in part due to on-average neutral El NiñoSouthern Oscillation conditions during most of 2018. Evaporation of water from the Northern Hemisphere land surface was also high because of the higher temperatures.
For the first time, reanalyses estimates for global precipitation are included in this chapter. A sidebar demonstrates the capability of reanalyses for this variable using an example extreme synoptic event over the United States. The fraction of global land area experiencing drought was below average by the end of 2018; however, around 20\% was under moderate or worse drought, with Afghanistan, other regions in the Middle East, and Australia experiencing extreme drought. Globally, groundwater amounts have continued to recover from a minimum in 2016, although regions of dry soils have increased since last year.

In the atmosphere, concentrations of many longlived greenhouse gases continued to increase at rates comparable to, or greater than, their respective averages of the past decade. Globally averaged $\mathrm{CO}_{2}$ at Earth's surface was $407.4 \pm 0.1 \mathrm{ppm}$ for 2018, an increase of $2.4 \pm 0.1 \mathrm{ppm}$ from 2017, comparable to the average rate of increase over the past decade. Emissions of CFC-11, an ozone-depleting gas, have declined more slowly than expected under the Montreal Protocol and its amendments phasing out ozone-depleting substances, which could delay the recovery of stratospheric ozone.

Aerosol emissions in 2018 from biomass burning over the northwest United States and southern Canada were higher than normal, along with dust aerosols over most of the Near and Middle East. The decreasing trend of anthropogenic aerosols over Europe, China, and the eastern United States continued, as did the increasing trend over the Indian subcontinent.

Global levels of vertical ozone columns (or total ozone) in 2018 were mostly above average compared to recent years but well within the variability seen during the last decade. Long-term total ozone trends were small $\left(<1 \%\right.$ decade $\left.^{-1}\right)$ and, although insignificant, agreed with model simulations accounting for changes in ozone-depleting substances (in accordance with the Montreal Protocol) and the climate. In the upper stratosphere, zonal mean ozone levels in 2018 were within the range of variability in recent years and follow the positive trend observed during the last decade. Upper stratospheric ozone trends in the extratropics in both hemispheres were largest in the Pacific region by up to $+6 \%$ decade $^{-1}$. These showed the clearest sign of ozone recovery related to the Montreal Protocol. Stratospheric water vapor was mostly near average during 2018, until a large drop occurred in November that was driven by an anomalously cold tropical tropopause. 
(a) Surface Temperature

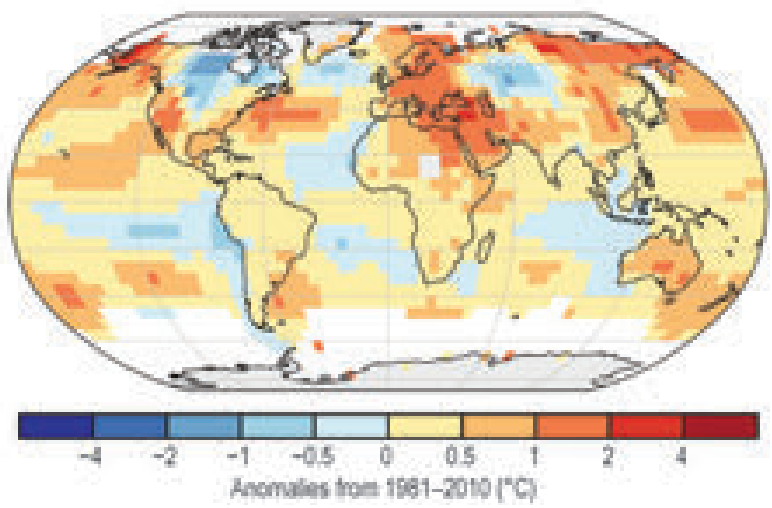

(c) Warm Days

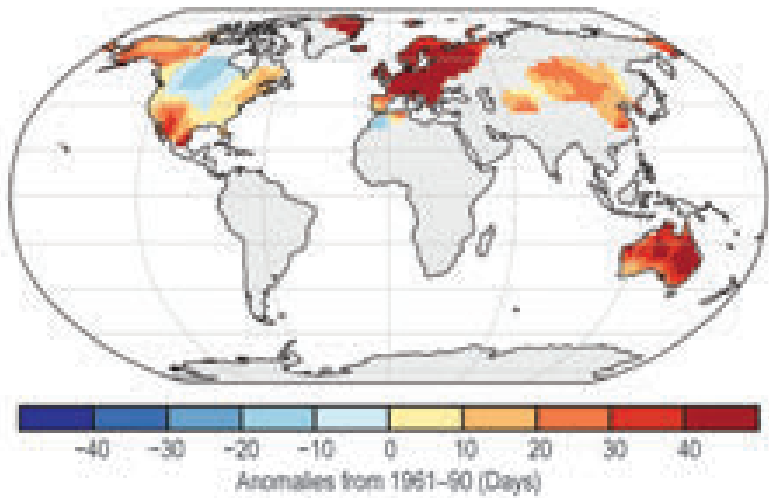

(e) Lower Troposphenio Temperature

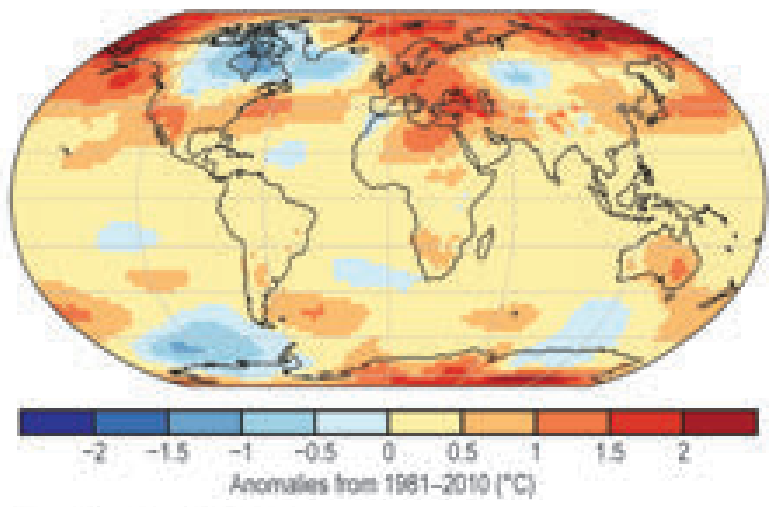

(g) Surface Specific Humidity

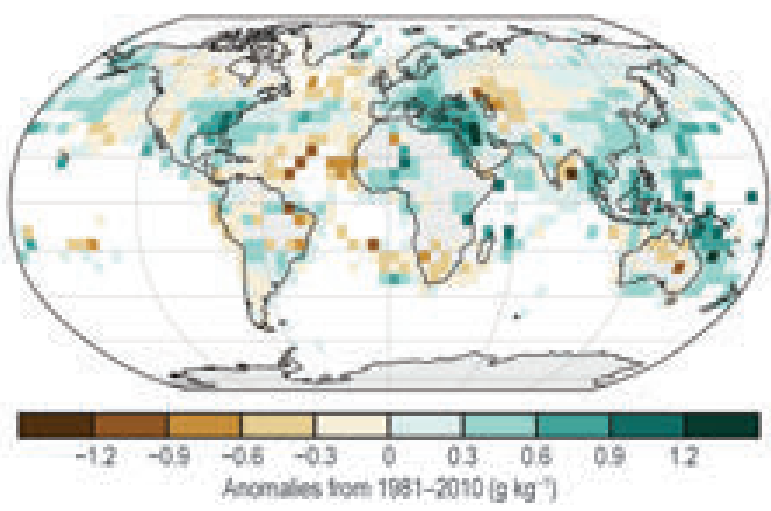

(b) Lake Temperatures

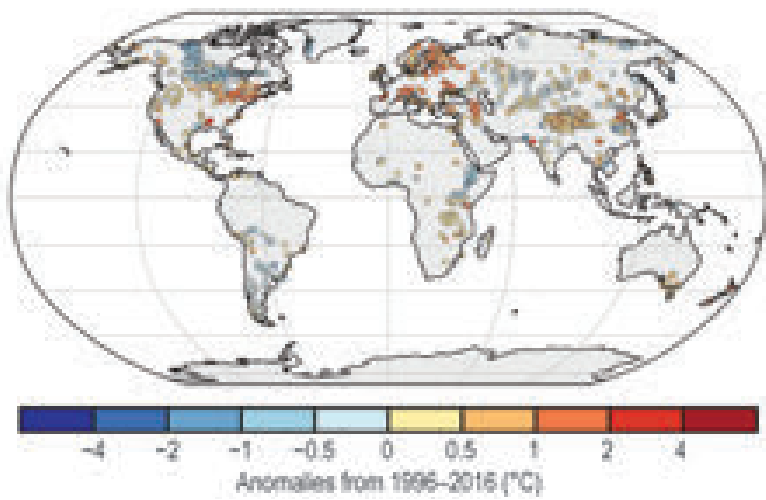

(d) Cool Nights

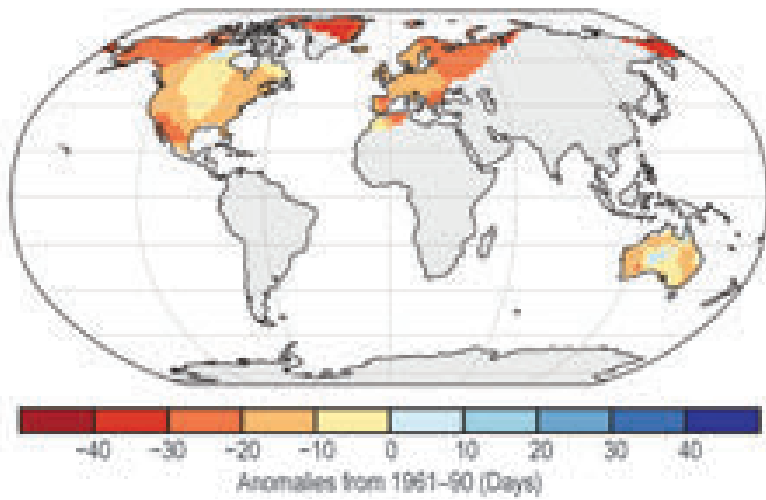

(f) Lower Stratosphenc Temperature

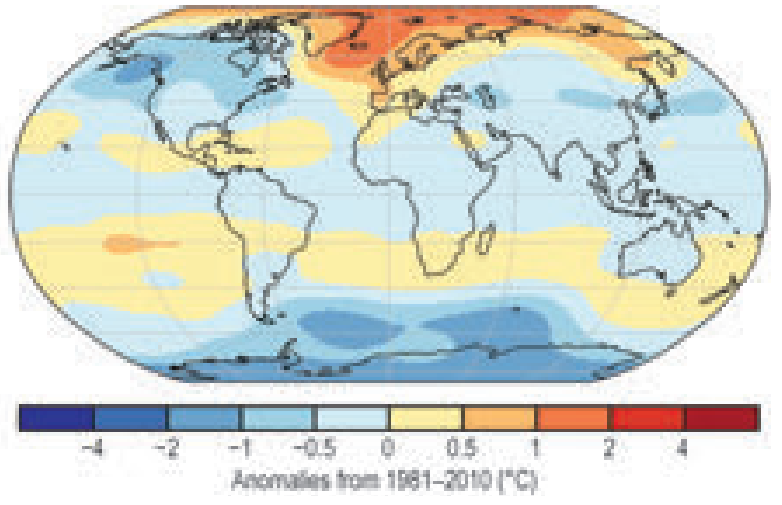

Plate 2.I. (a) NOAA GlobalTemp surface temperature anomalies; (b) Satellite-derived lake surface water temperature anomalies; (c) GHCNDX warm day threshold exceedance (TX90P); (d) GHCNDX cool night threshold exceedance (TNIOP); (e) ERA5 lower tropospheric temperature grid anomalies; (f) ERA-Interim gridpoint lower stratosphere temperature anomalies; (g) HadISDH annual average anomaly surface specific humidity over land; 
(h) Surface Relative Humidity

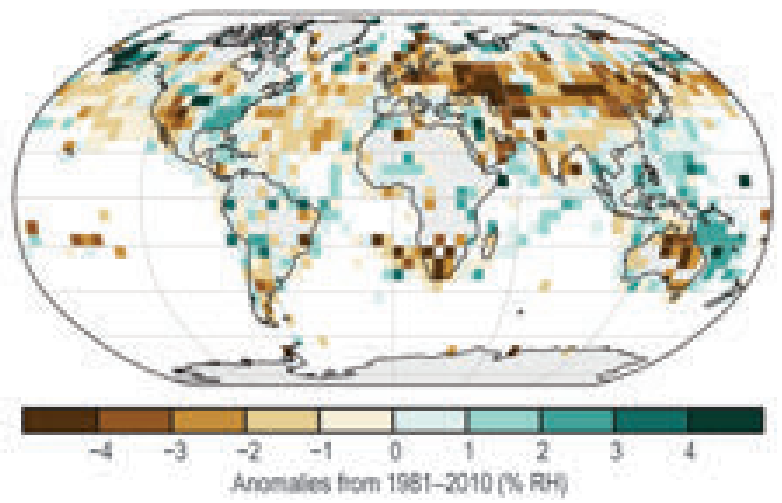

(1) Upper Tropospheric Humidity

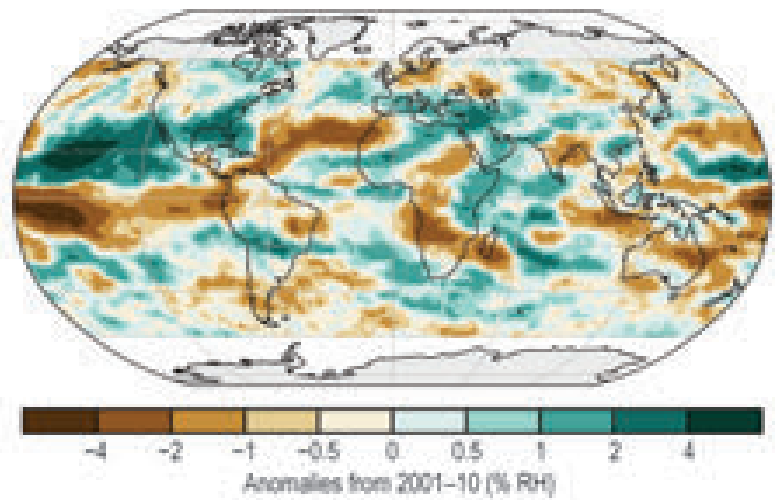

(1) Percentle of the Annual Precipitation Total

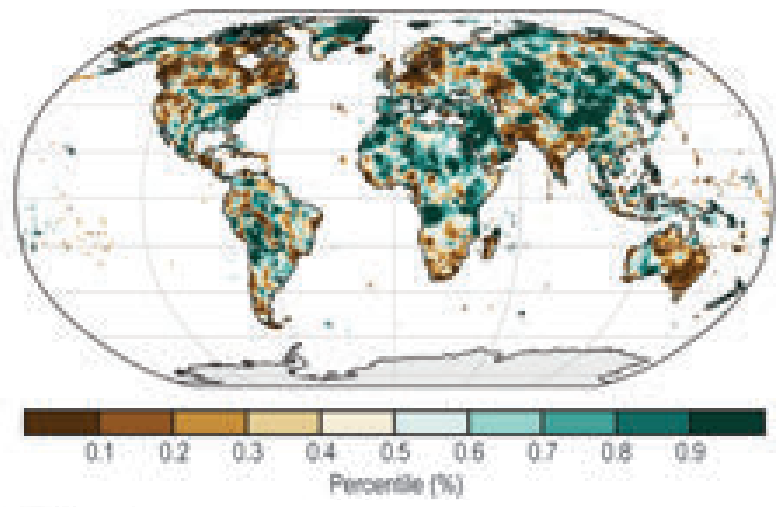

(n) Cloudiness

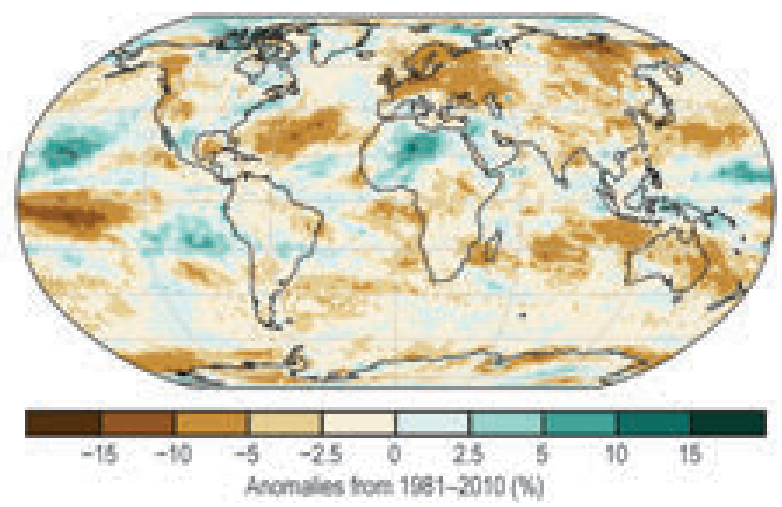

(1) Total Column Waser Vapor

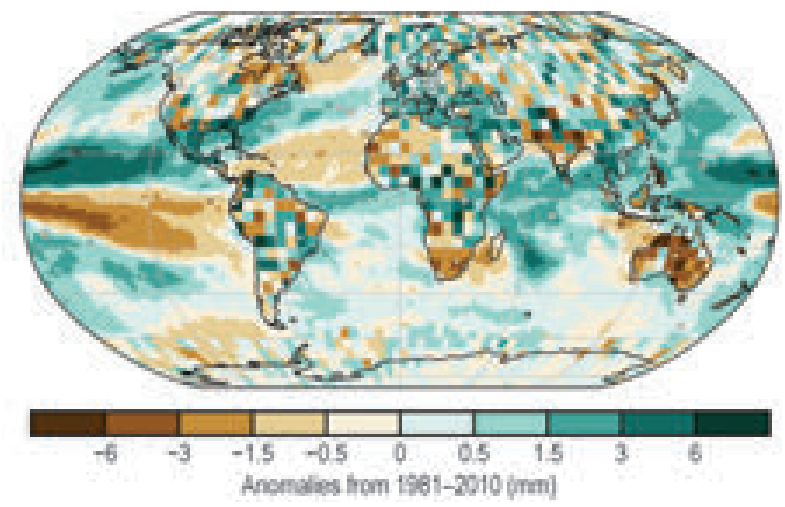

(k) Precipitation

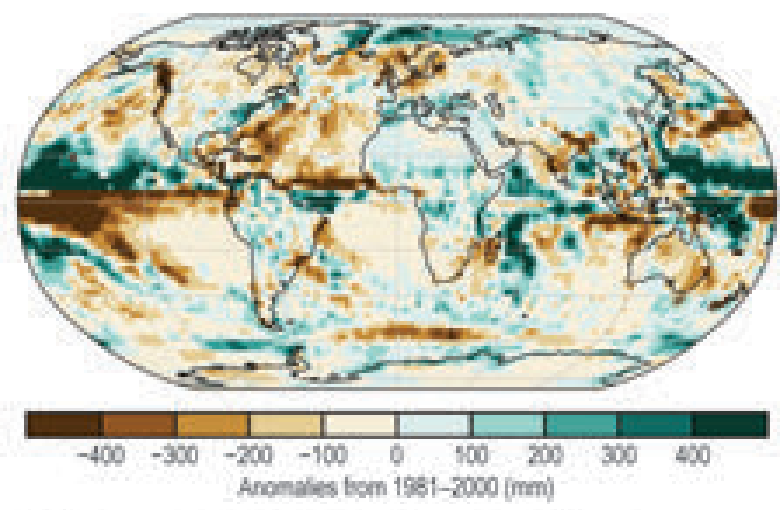

(m) Maximum 1-day Precipitation Anomales (Rxtday)

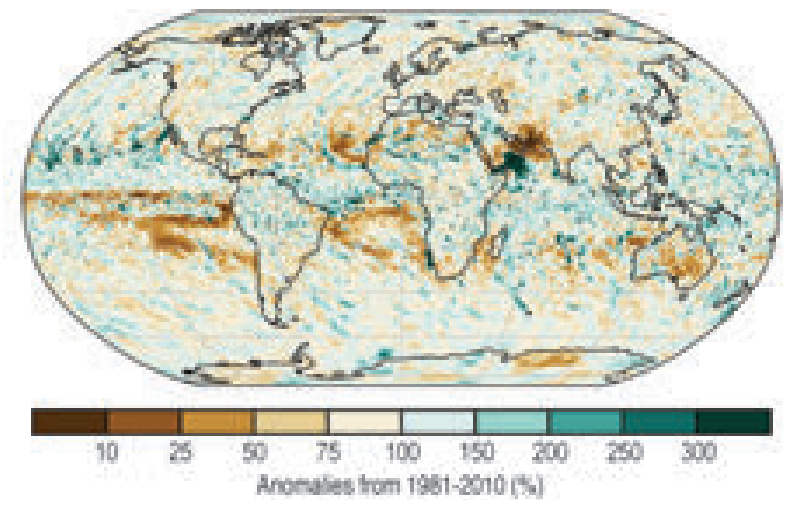

Plate 2.I. (cont.) (h) Hadisdh annual average surface relative humidity; (i) ERA5 total column water vapor anomalies (circles: GNSS station data); (j) “All sky" microwave annual UTH anomalies; (k) GPCP v2.3 annual mean precipitation anomalies; (I) GPCC percentile of annual precipitation total; (m) ERA5 maximum I-day (RxIday) precipitation total anomalies; (n) PATMOS-x/AVHRR global cloudiness anomalies; 
(o) River Discharge

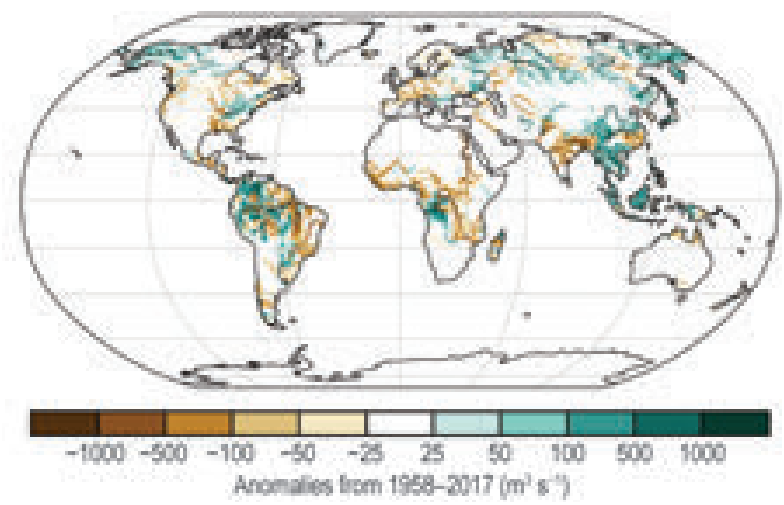

(4) Terrestrial Water Storage

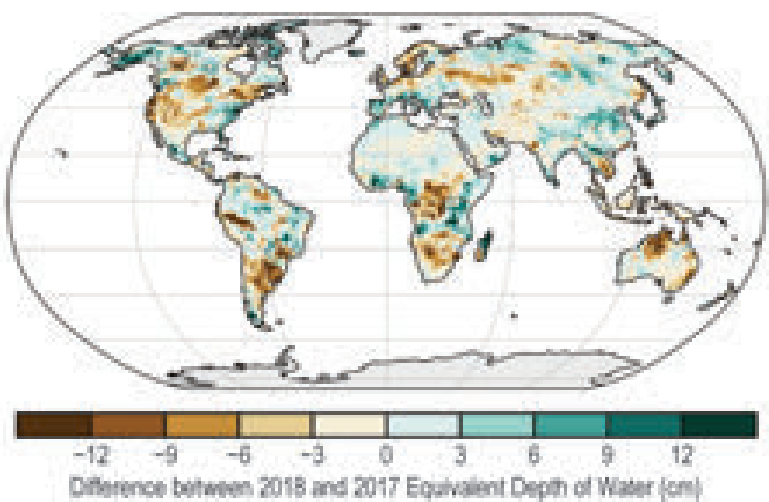

(s) Drought

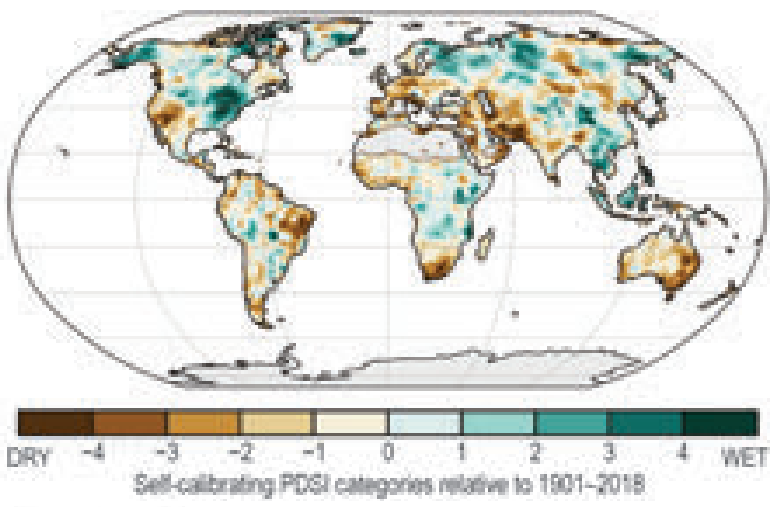

(u) Sea Level Pressure

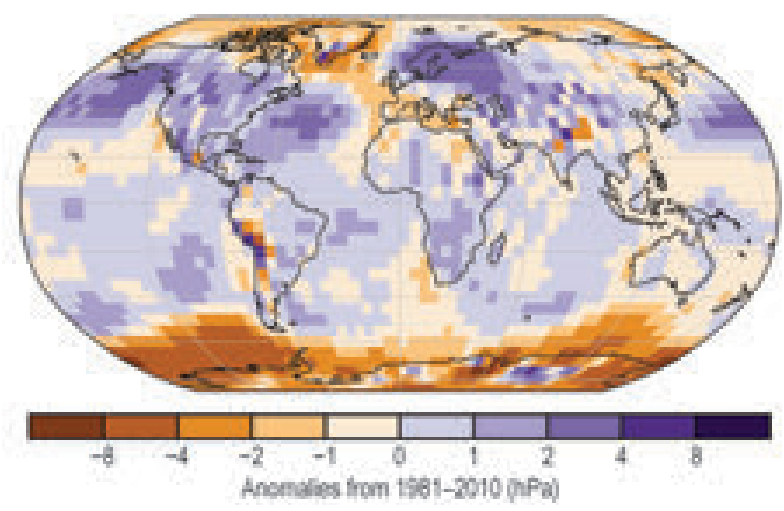

(p) Runott

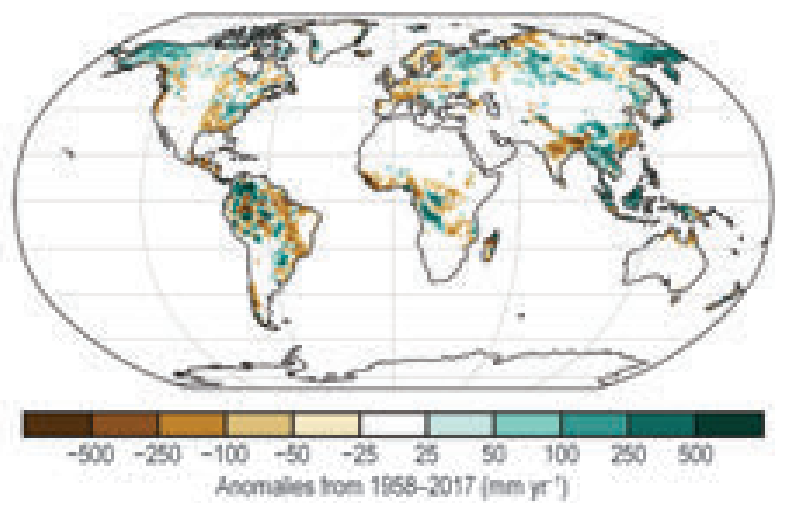

(n) Soil Moisture

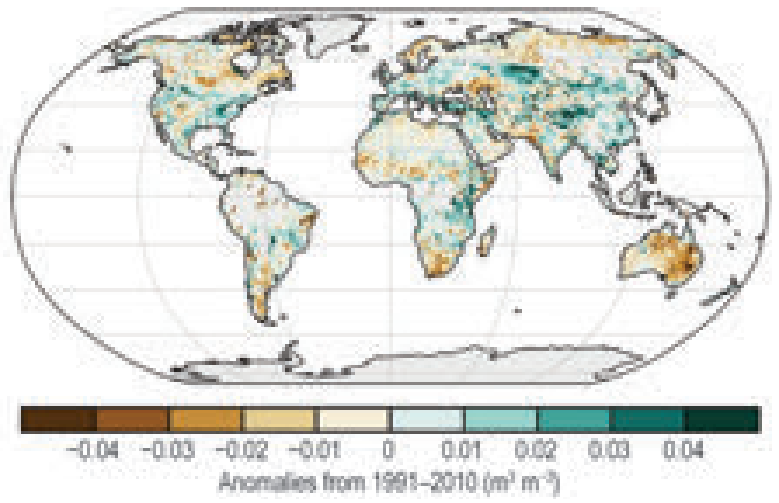

(1) Land Evaporation

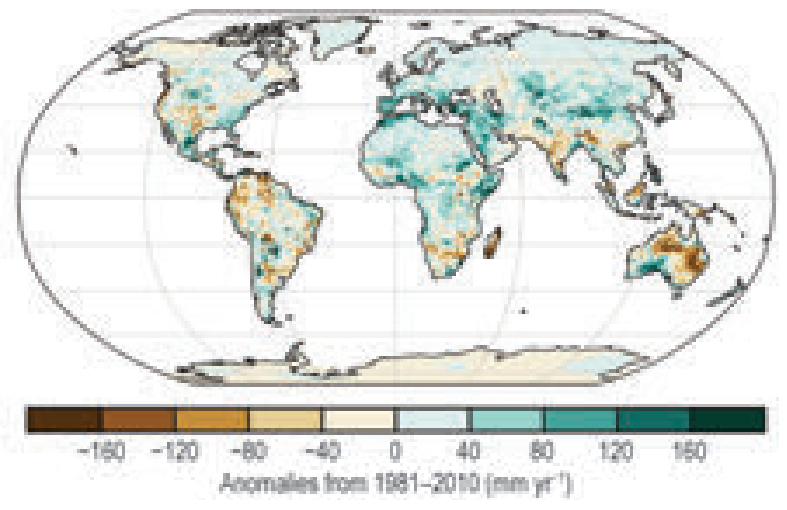

Plate 2.I. (cont.) (o) ElSE (Ensemble Land State Estimator; Kim et al. 2009) global distribution of river discharge anomalies; (p) ELSE (Ensemble Land State Estimator; Kim et al. 2009) global distribution of runoff anomalies; (q) GRACE difference in annual mean terrestrial water storage between 2017 and 2018; (r) ESA CCI average surface soil moisture anomalies; (s) Mean scPDSI for 2018 . Droughts (brown), wet episodes (green); (t) GLEAM land evaporation anomalies; (u) HadSLP2r surface pressure anomalies; 
(v) Surface Winds

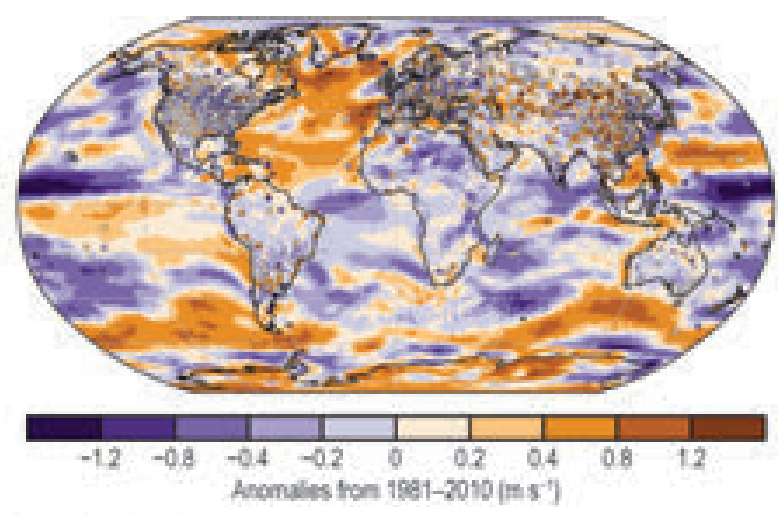

(x) Total Aerosol
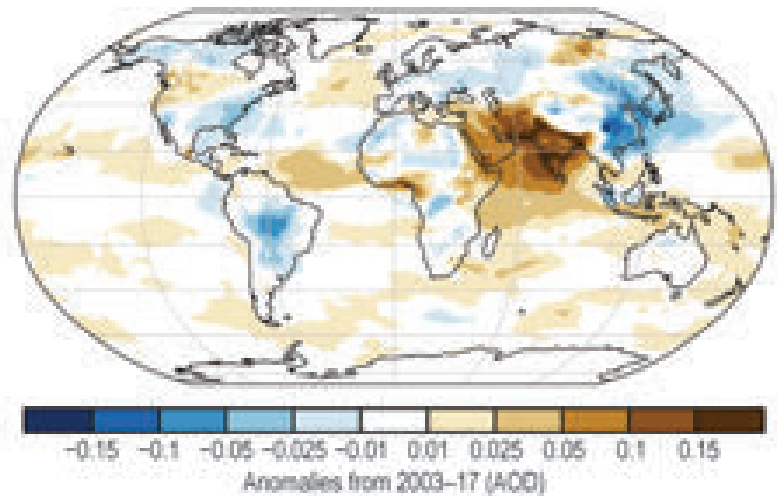

(z) Dust Aerosol

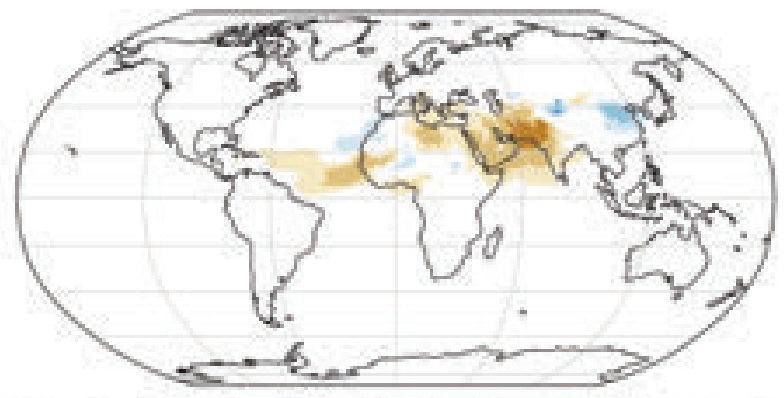

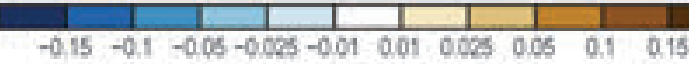
Anomales from $2003-17(200)$

(ab) OMUMLS Tropospheric Column Ozone

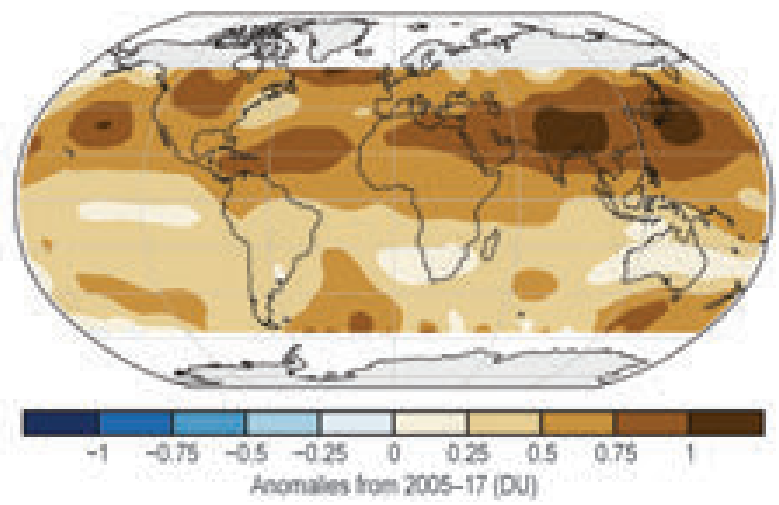

(w) Upper Air (850-hPa) Winds

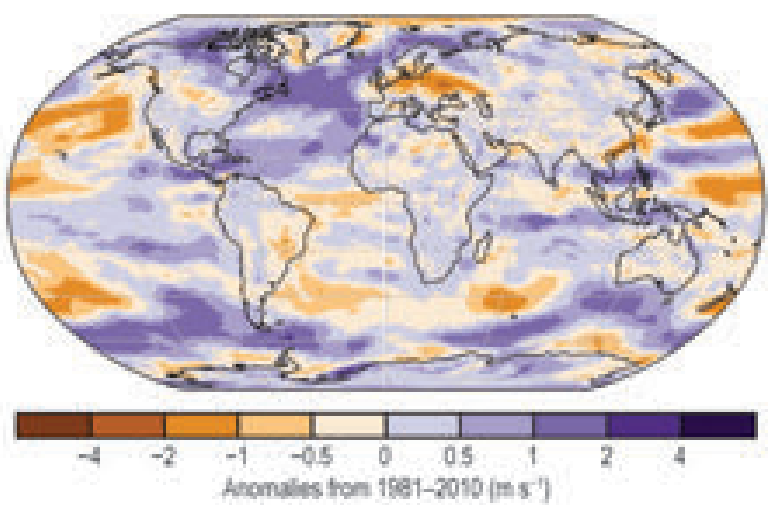

(y) Black Carbon and Organic Matter Aerosol

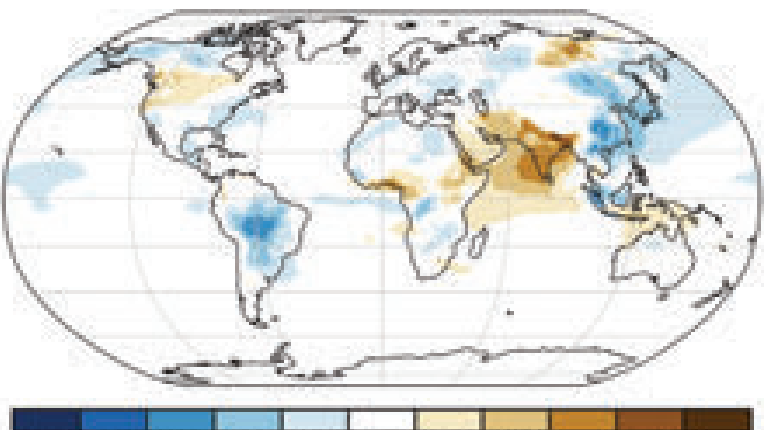

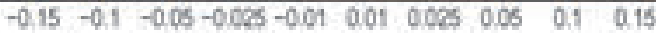
Anomales from $2003-17(A C O)$

(aa) Stratosphenc (Total Column) Ozone

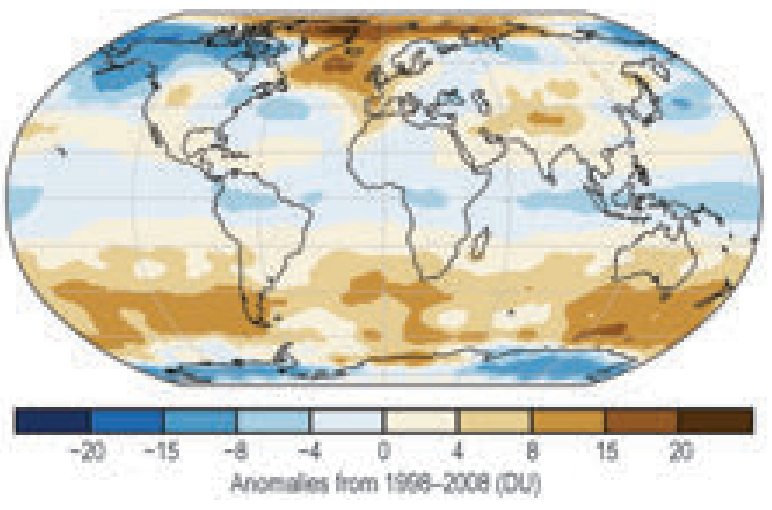

Plate 2.I. (cont.) (v) Land surface wind speed anomalies (circles: observational HadISD3 and Australian datasets), and worldwide shaded grids: MERRA-2; (w) ERA5 upper air winds; (x) Total AOD anomalies at $550 \mathrm{~nm}$; (y) Organic and black carbon AOD anomalies at $550 \mathrm{~nm}$ (includes aerosols from both biomass burning and anthropogenic sources); (z) Dust AOD anomalies at 550 nm; (aa) GOME-2 total column ozone 2018 anomalies [using GOME, SCIAMACHY, and GOME-2 (GSG)]; (ab) OMI/MLS tropospheric column ozone 2018 annual mean anomalies for $60^{\circ} \mathrm{N}-60^{\circ} \mathrm{S}$; 
(ac) Carbon Monowide

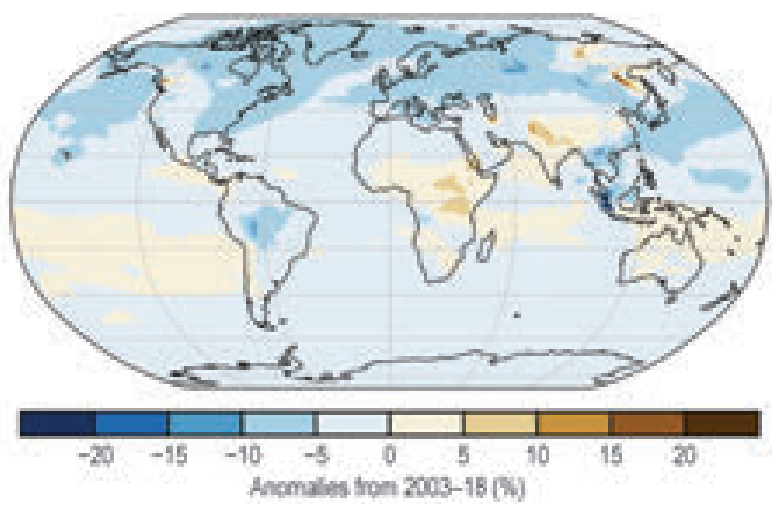

(ae) Land Surface Abedo in the Near-Infrared

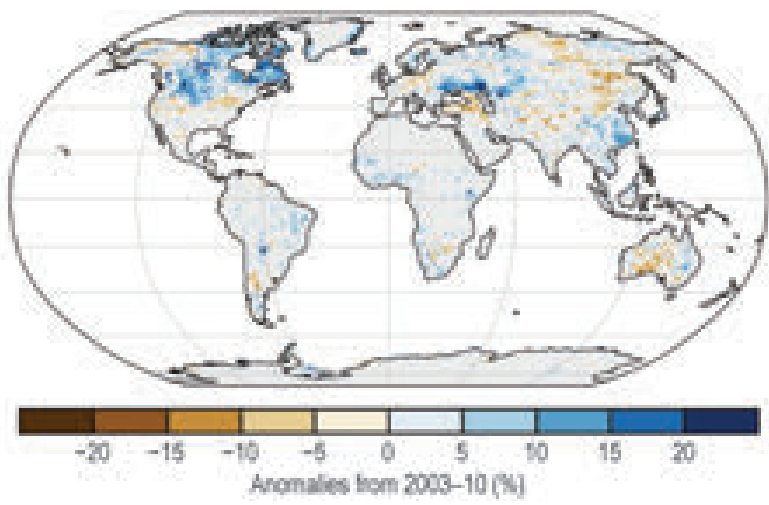

(ag) Carbon Emissions from Biomass Burning

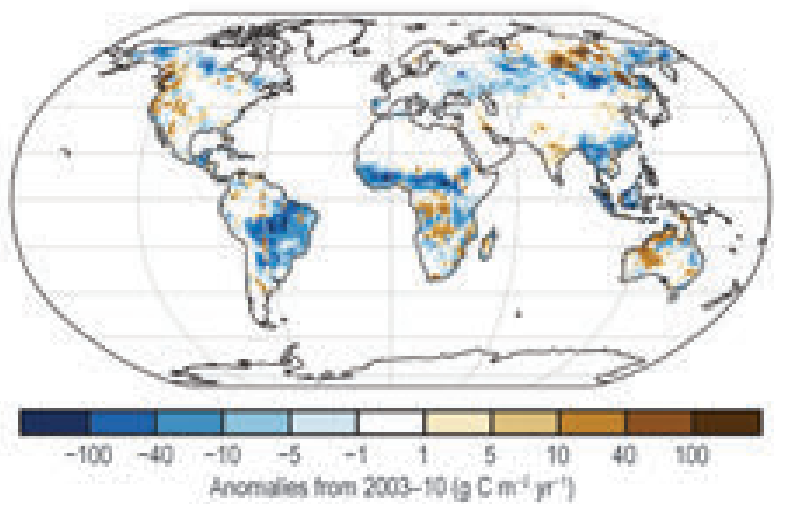

(ad) Land Surface Albedo in the Visible

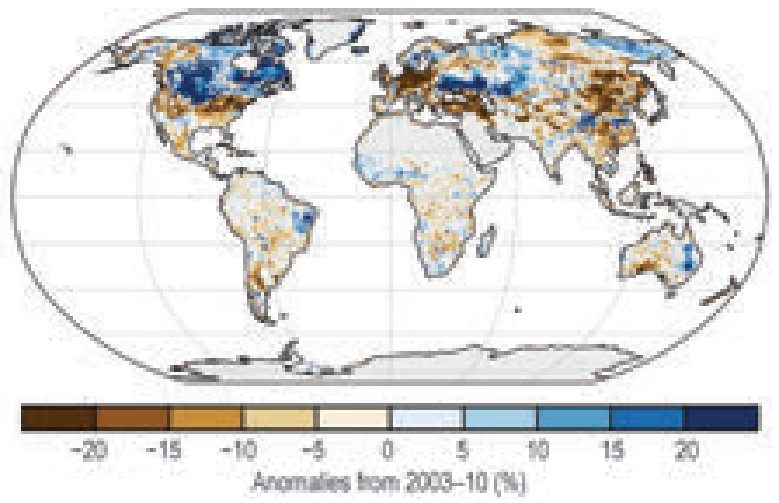

(af) Fraction of Absorbed Photosynehetically Afctive Radiation

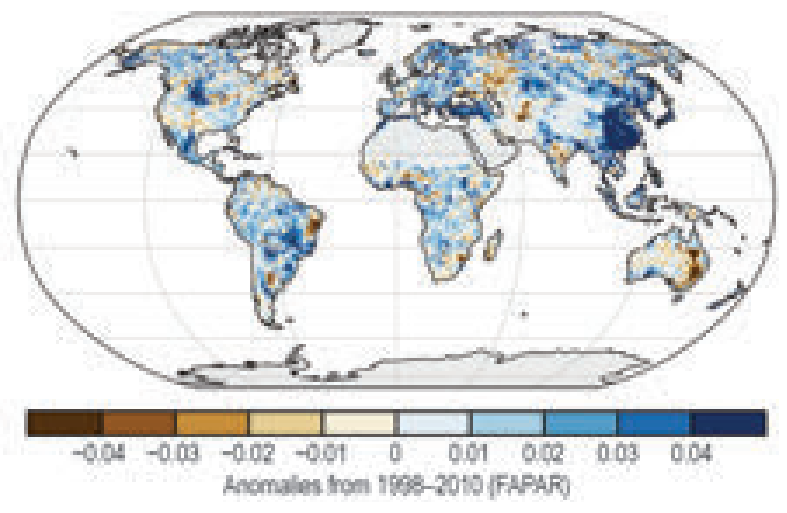

Plate 2.l. (cont.) (ac) CAMS total column CO anomalies; (ad) Visible broadband land surface albedo anomalies; (ae) Near-infrared broadband land surface albedo anomalies; (af) FAPAR anomalies; (ag) GFASvI.4 carbonaceous emission anomalies for biomass burning. 
Tropospheric ozone over India and East and Southeast Asia continued to increase, likely driven by increases in pollution including ozone precursors in the region. Ongoing surface ozone measured from remote atmospheric baseline observatories at Mauna Loa (MLO), the South Pole (SPO), and Utqiagivik (Barrow - BRW), Alaska, provide a long record of measurements. BRW and SPO indicate little or no trend in surface ozone through 2018, while MLO indicates a $\sim 23 \%$ increase from 1973 through 2018 for air arriving from the west, which is consistent with increases in tropospheric ozone observed in the North Pacific over 2004-18 and consistent with previous work that has linked the MLO ozone trend to increasing emissions in Asia.

There has been a smaller reduction in global carbon monoxide (CO) levels over the period 2003-18 inferred from the new Copernicus Atmosphere Monitoring Service (CAMS) reanalysis in comparison to the previously used CAMS interim reanalysis. In 2018, there were no major annual CO anomalies, but a seasonal maximum in boreal summer due to large wildfires in Canada and Siberia was observed. Some widely reported fires, which had locally large impacts on life, property, and the environment, contributed only a relatively minor amount to the total area burned in 2018. The downward trend in global fire emissions continues, driven in part by changes in land use over savannahs.

Time series and anomaly maps for many of the variables described in this chapter are shown in Plates 1.1 and 2.1 respectively. A number of sections refer to online figures that can be found here (http://doi.org/ 10.1175/2019BAMSStateoftheClimate.2).

\section{b. Temperature}

I) Global surface temperature-A. Sánchez-Lugo, P. Berrisford, C. Morice, and J. P. Nicolas

Every year since the start of the twenty-first century has had a global land and ocean temperature departure from average above the 1981-2010 averageand 2018 was no exception. The 2018 global land and ocean surface temperature was $0.30^{\circ}-0.40^{\circ} \mathrm{C}$ above the 1981-2010 average and was the fourth warmest year since global records began in the mid-to-late 1800 s, according to four independently constructed in situ analyses (NASA-GISS, Hansen et al. 2010; HadCRUT4, Morice et al. 2012; NOAAGlobalTemp, Smith et al. 2008, Huang et al. 2015; JMA, Ishihara 2006; Fig. 2.1). Only the immediately preceding years of 2016, 2015, and 2017 were warmer.

The year began with a La Niña episode present across the equatorial Pacific Ocean, transitioning

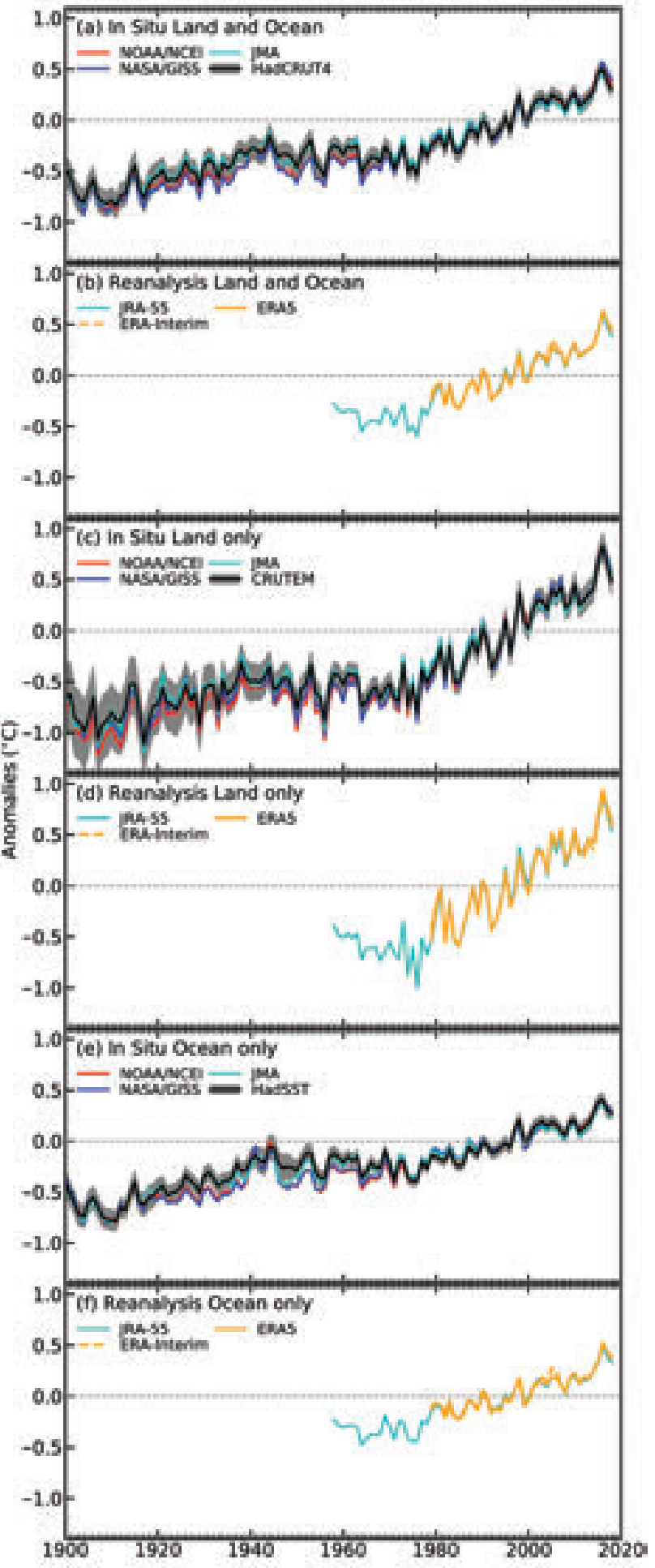

Fig. 2.I. Global average surface air temperature anomalies ( ${ }^{\circ} \mathrm{C}$; $198 \mathrm{I}-2010$ base period). In situ estimates are shown from NOAA/NCEI (Smith et al. 2008), NASA-GISS (Hansen et al. 2010), HadCRUT4 (Morice et al. 20I2), CRUTEM4 (Jones et al. 20I2), HadSST3 (Kennedy et al. 20I la,b), and JMA (Ishihara 2006). Reanalyses estimates are shown from ERA5 (Hersbach et al. 2019), ERA-Interim (Dee et al. 20II), and JRA-55 (Ebita et al. 20II; Kobayashi et al. 2015). 
to ENSO-neutral conditions by April. The presence of a La Niña (El Niño) tends to have a slight cooling (warming) influence on global temperatures. Although the 2018 global average temperature was lower than the last three years, it was $0.05^{\circ}-0.20^{\circ} \mathrm{C}$ higher than 1998. That year was marked by a strong El Niño (similar in strength to the 2015/16 El Niño) at the beginning of the year and, at the time, was the warmest year on record.

The in situ datasets indicate that the 2018 annual surface temperatures were higher than average across much of the world's land and ocean surfaces (Plate 2.1a; Online Figs. S2.1 and S2.2). The most notable positive anomalies found across the southwestern contiguous United States, Alaska, Europe, the Middle East, north-central and far east Russia, as well as Australia and parts of the northern Atlantic Ocean and the northern Pacific Ocean, where temperatures were at least $1.0^{\circ} \mathrm{C}$ above their respective $1981-2010$ averages. Below-average temperatures were present across northern North America, western Russia, Kazakhstan, and across parts of the tropical Pacific Ocean, Atlantic Ocean, and eastern Indian Ocean.

Averaged separately, the global temperature over land surfaces was the fourth highest on record at $0.48^{\circ}-0.58^{\circ} \mathrm{C}$ above average, trailing 2016 (highest), 2015 (second), and 2017 (third). The global ocean temperature was $0.24^{\circ}-0.30^{\circ} \mathrm{C}$ above average and also the fourth highest on record. Similarly, the temperatures for 2016, 2015, and 2017 were higher for the global oceans.

The in situ global surface temperature analyses assessed here are derived from air temperatures observed at weather stations over land and SST observed from ships and buoys. Differences between analyses are mainly due to how each methodology treats areas with little to no data and how each analysis accounts for changes in measurement methods (for more details see Kennedy et al. 2010; Hansen et al. 2010; Huang et al. 2015; and Sánchez-Lugo et al. 2017).

Globally averaged surface air temperatures are also estimated using reanalyses. Reanalysis produces datasets with quasi-uniform temporal and spatial coverage of the whole globe but can suffer from regional model biases and the effects of changes in the observation network during the analysis period. However, surface temperatures from reanalyses should be consistent with observations in regions of good observational coverage. Here, three reanalyses are considered: ERA5 (Hersbach et al. 2019), ERAInterim (Dee et al. 2011), and JRA-55 (Ebita et al. 2011; Kobayashi et al. 2015). The ERA-Interim 2-m temperature was adjusted by merging analyses over land with short forecasts over ocean and subtracting $0.1^{\circ} \mathrm{C}$ from the latter before 2002, following Simmons et al. (2017) and Simmons and Poli (2015). Currently, ERA5 and ERA-Interim provide data from 1979, and JRA-55 from 1958.

The annual global 2-m air temperature for 2018 was the third highest annual average for ERA5 and the fourth highest for ERA-Interim and JRA-55 since their records began. The temperature was between $0.29^{\circ} \mathrm{C}$ and $0.46^{\circ} \mathrm{C}$ above average, depending on the reanalysis (Table 2.1). Comparatively, the temperatures for the warmest year, 2016, ranged between $0.47^{\circ} \mathrm{C}$ and $0.63^{\circ} \mathrm{C}$ above average.

The reanalyses also show warmer-than-average conditions over many regions of the world, particularly at high northern latitudes (see Online Figs. S2.3-S2.5). The 2018 2-m air temperature over the global ocean was the third highest on record in all the reanalyses considered here, whereas over global land it was fourth highest in ERA5, ERA-Interim, and JRA-55.

\begin{tabular}{|c|c|c|c|c|c|c|c|}
\hline Global & $\begin{array}{l}\text { NASA- } \\
\text { GISS }\end{array}$ & HadCRUT4 & $\begin{array}{c}\text { NOAA- } \\
\text { Global Temp }\end{array}$ & JMA & ERA5 & ERA-Int & JRA-55 \\
\hline Land & +0.58 & $+0.48 \pm 0.13$ & $+0.50 \pm 0.14$ & +0.56 & +0.64 & +0.58 & +0.54 \\
\hline Ocean & +0.29 & $+0.27 \pm 0.07$ & $+0.30 \pm 0.16$ & +0.24 & +0.39 & +0.37 & +0.33 \\
\hline $\begin{array}{l}\text { Land } \\
\text { and } \\
\text { Ocean }\end{array}$ & $+0.40 \pm 0.05$ & $+0.30 \pm 0.08$ & $+0.36 \pm 0.15$ & +0.31 & +0.46 & +0.43 & +0.39 \\
\hline
\end{tabular}


2) Lake surface temperature-L. Carrea, R. I. Woolway, C. J. Merchant, M. T. Dokulil, E. de Eyto, C. L. DeGasperi, J. Korhonen, W. Marszelewski, L. May, A. M. Paterson, J. A. Rusak, S. G. Schladow, M. Schmid, P. Verburg, S. Watanabe, and G. A. Weyhenmeyer

The satellite-derived lake surface water temperature (LSWT) used for this analysis is spatially averaged per lake for a total of 923 of the 1000 GloboLakes sites (Politi et al. 2016) for which high-quality temperatures were available in 2018. Lake-wide average surface temperatures have been shown to provide a representative picture of LSWT responses to climate change (Woolway and Merchant 2018). This analysis follows previous studies (Schneider and Hook 2010; O'Reilly et al. 2015; Woolway and Merchant 2017) in determining warm-season averages for midlatitude lakes [July-September in the Northern Hemisphere (NH); January-March in the Southern Hemisphere)] and whole-year averages for tropical lakes.

In 2018, the satellite-derived LSWT anomaly averaged over the target lakes $(n=923)$ was $+0.17^{\circ} \mathrm{C}$ compared to the 1996-2016 average. Thus, 2018 temperatures continue the warming trend identified in previous analyses (Woolway et al. 2017, 2018) of about 0.27 $\pm 0.01^{\circ} \mathrm{C}$ decade $^{-1}$, although anomalies were $0.14^{\circ} \mathrm{C}$ and $0.43^{\circ} \mathrm{C}$ cooler than those observed in 2017 and 2016, respectively. The anomalies for each lake are shown in Plate $2.1 \mathrm{~b}$ where latitudes have been maintained and longitude shifted to avoid overlapping of lakes in the plot. The LSWT anomaly was positive for $60 \%$ of lakes and negative for $40 \%$. About $62 \%$ of the lakes in the $\mathrm{NH}$ above $23.5^{\circ}$ latitude have positive anomalies.

The regions where lakes have the largest positive anomalies were Europe and East Asia, while cooler lakes were observed in North America around Canada and warmer lakes around the continental United States. Figure 2.2 shows spatial maps for: (a) Europe $(n=127)$; (b) Africa $(n=68)$; (c) Canada $(n=245)$; and (d) the Tibetan Plateau $(n=106)$. Regionally averaged LSWT calculated from the satellite data shows a warming tendency of $+0.50 \pm 0.03^{\circ} \mathrm{C}$ decade $^{-1}$ in Europe, $+0.30 \pm 0.04^{\circ} \mathrm{C}$ decade $^{-1}$ in Canada, and $+0.22 \pm 0.02^{\circ} \mathrm{C}$ decade $^{-1}$ in the Tibetan Plateau (Fig. 2.3). In Africa, the tendency is more neutral. The behavior of LSWT for the Tibetan area in these data appears to be in agreement with Wan et al. (2017) when daytime LSWT for July-September are considered. The period July-September 2018 was the warmest for European lakes since 1995, consistent with strong positive July-September averaged surface air temperature (SAT) anomalies (Fig. 2.2), calculated from the GHCN v3 (250-km smoothing radius) data of the NASA GISS surface temperature analysis (Hansen et al. 2010; GISTEMP Team 2016). Lake temperature anomalies broadly track surface temperature (Section 2b1), although factors such as wind speed, humidity, insolation, and the thermal time constants of lakes contribute to variation within this broad pattern.

Overall, 94\% $(n=29)$ of lakes with in situ LSWT measurements had positive anomalies in 2018. Similar to the satellite data, in situ positive anomalies were observed in Europe. For example, the second largest (a) Europe

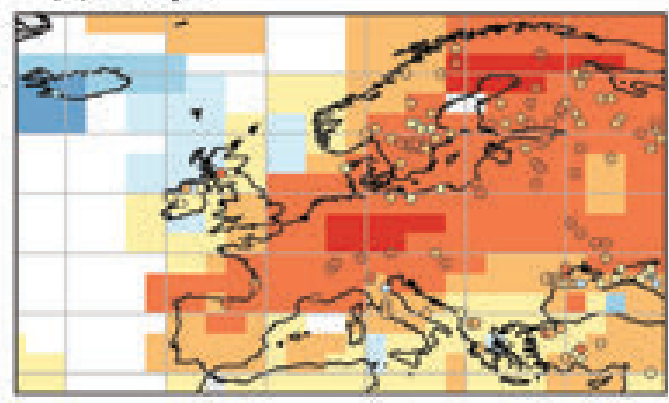

(c) Canada
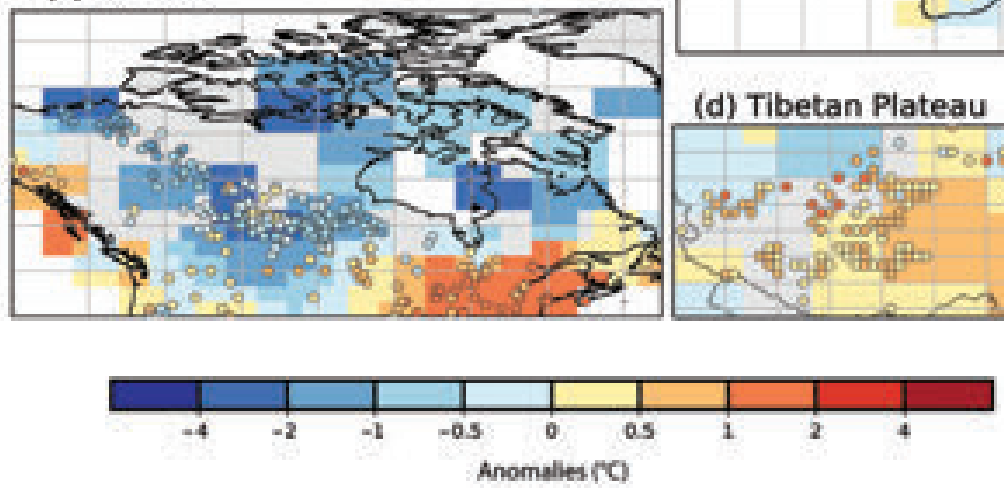

Fıg. 2.2. Satellite-derived lake surface water temperature anomalies in 2018. Shown are the patterns in lake temperature anomalies (colored points) together with surface air temperature (calculated from GHCN v3 data of the NASA GISS surface temperature analysis) (a) in Europe, (b) Africa, (c) Canada, and the (d) Tibetan Plateau. Air and lake surface water temperature anomalies $\left({ }^{\circ} \mathrm{C}\right.$; relative to $\left.1996-2016\right)$ are calculated for the warm season (Jul-Sep in NH; Jan-Mar in SH; and over the whole year in the tropics). 


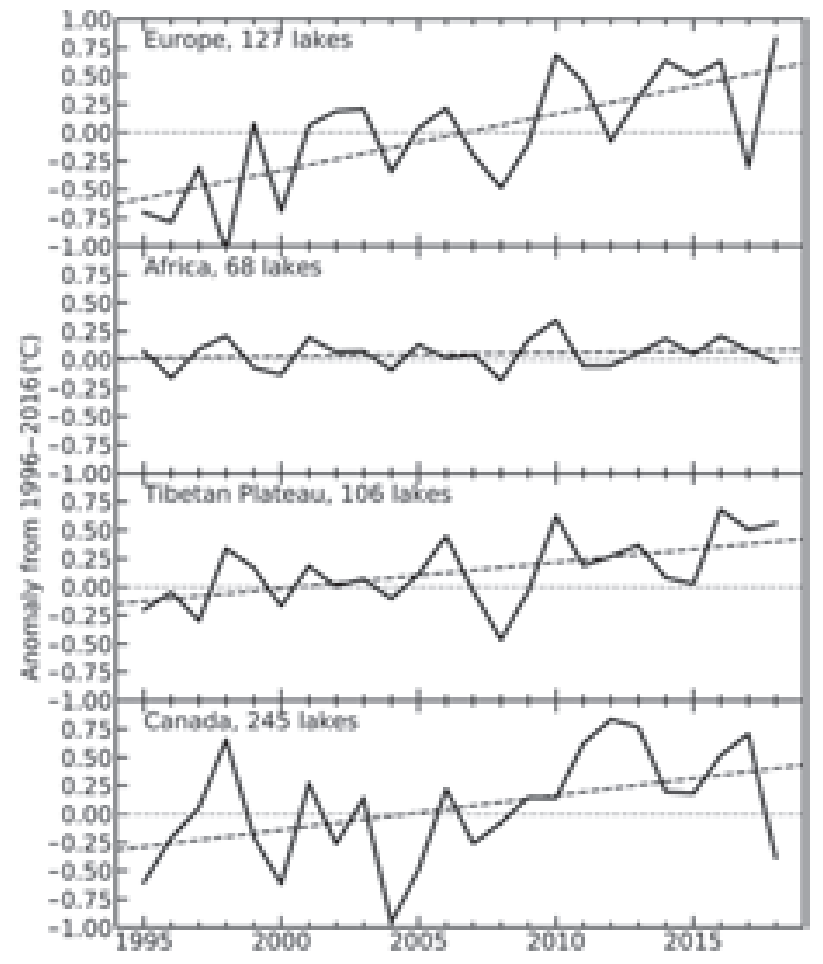

FIG. 2.3. Satellite-derived annual lake surface water temperature anomalies from 1995 to 2018 for Europe, Africa, the Tibetan Plateau, and Canada. Shown are the regional average satellite-derived lake surface temperature anomalies. Annual lake surface water temperatures anomalies ( ${ }^{\circ} \mathrm{C}$; relative to 1996-2016) are calculated for the warm season (Jul-Sep in $\mathbf{N H}$; Jan-Mar in SH; and over the whole year in the tropics).

lake in Sweden by surface area, Vättern, had a LSWT anomaly of $+2.1^{\circ} \mathrm{C}$ in 2018 . A similar anomaly was observed in Lower Lake Zurich. The average 2018 LSWT anomaly for European lakes in the in situ collection was $+1.2^{\circ} \mathrm{C}$. Strong positive anomalies from in situ data were also observed in New Zealand lakes $\left(+0.9^{\circ} \mathrm{C}\right)$.

Satellite and in situ observations consistently show strong positive anomalies across Europe, which is also confirmed by the global surface temperature analysis (Section 2b1) and the land surface temperature extreme (Section 2b3).

LSWT time series were derived from satellite observations from the series of Along Track Scanning Radiometers and the Advanced Very High Resolution Radiometers on MetOp A and B platforms, using the retrieval methods of MacCallum and Merchant (2012) on image pixels filled with water according to both the inland water dataset of Carrea et al. (2015) and a reflectance-based water detection scheme. LWST from 1996 to 2016 have been derived with the GloboLakes project and the 2017-18 extension within the Copernicus Climate Change Service (C3S) Programme. In addition, in situ lake surface temperature observations from some of the world's best-studied lakes have been analyzed $(n=31)$.

3) Land surface temperature eXtremes-A. D. King, M. G. Donat, and R. J. H. Dunn

As average temperatures have risen in most locations, there have been associated increases in warm extremes and reductions in the frequency and intensity of cold extremes. In 2018, the broad-scale pattern continued, with more widespread, frequent, and intense warm extremes coupled with fewer and less intense cold extremes.

The GHCNDEX dataset (Donat et al. 2013) is used for contextualizing temperature extremes in 2018. GHCNDEX uses the large archive of station data in the Global Historical Climatology Network - Daily (GHCND; Menne et al. 2012) known as Global Historical Climatology Network (GHCN to calculate extreme indices proposed by the World Meteorological Organization Expert Team on Climate Change Detection and Indices (ETCCDI; Zhang et al. 2011). The format here follows that of previous State of the Climate reports. It should be noted that the available data are unfortunately sparse. The lack of spatial coverage is in part due to a lack of historical data in many areas of sub-Saharan Africa and northern South America (Donat et al. 2013) and in part because the 2018 data from some areas are incomplete at the time of writing due to delays from some data sources. As a result, many of the indices considered are restricted to North America, Europe, eastern Asia, and Australia (see Online Figs. S2.5-S2.7), but these observation-based anomalies are complemented with results from the ERA-Interim (Dee et al. 2011) and new ERA5 (Hersbach et al. 2019) reanalyses (see Online Figs. S2.8-S2.12). The indices considered here are shown in Table 2.2 and have been calculated both annually and seasonally with respect to a 1961-90 climatological base period.

In 2018, the annual anomalies of TX90p and TN10p indicate more frequent warm extremes and less frequent cool extremes compared to the climatological average for the majority of locations where data are available (Plates 2.1c,d). Across much of Europe, Australia, and the southwestern United States, there were around double the number of days where the daily maximum temperature was above the climatological 90th percentile than would be expected (36.5 by definition, Fig. 2.4). Continental Canada and a small area of northwest Africa are the only locations with available data that exhibited 


\begin{tabular}{|c|c|}
\hline Index & Definition \\
\hline $\mathbf{T X x}$ & Hottest daily maximum temperature of the season or year \\
\hline $\mathbf{T X n}$ & Coldest daily maximum temperature of the season or year \\
\hline TNx & Hottest daily minimum temperature of the season or year \\
\hline TNn & Coldest daily minimum temperature of the season or year \\
\hline TX90p & Frequency of maximum temperatures above the 90 th percentile (warm days) \\
\hline TXIOp & Frequency of maximum temperatures below the 10th percentile (cool days) \\
\hline TN90p & Frequency of minimum temperatures above the 90 th percentile (warm nights) \\
\hline TNIOp & Frequency of minimum temperatures below the 10 th percentile (cool nights) \\
\hline
\end{tabular}

fewer-than-normal warm days (TX90p) for 2018. The higher annual frequency of warm extremes in 2018 in both Europe and Australia was not due to unusual heat in a single season but rather observed in all seasons during the year.

The annual anomalies of TN10p show a broadly similar pattern as seen in TX90p with fewer cold extremes in almost all areas of available data. The anomalies are smaller in TN10p but this is to be expected due to the TN10p statistical distribution being bounded at zero, so that negative anomalies are bounded at -36.5 . Europe and some high-latitude regions, including Greenland and Alaska, exhibit the largest anomalies for fewer cool extremes in 2018 (see Section $7 f$ ). The global average values of these indices

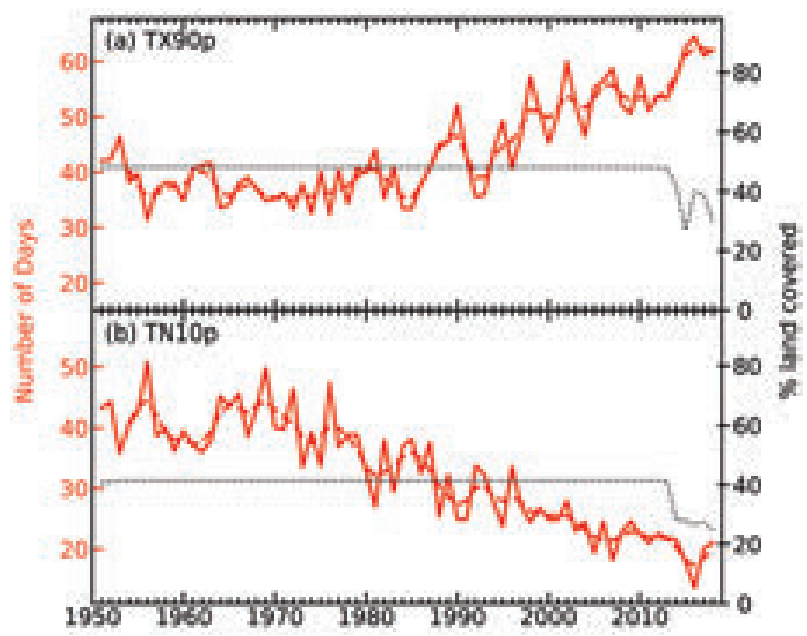

FIG. 2.4. Timeseries of (a) TX90p (warm days) and (b) TNIOp (cool nights) from GHCNDEX. The red dashed line shows a binomial smoothed variation. The dotted line shows the percentage of land grid-boxes with valid data in each year.
(Fig. 2.4) show an overall slight increase in both warm days and cool nights from 2017 to 2018. When these indices are placed in the longer-term context, they fit the overall warming trend shown from 1950 onward.

The anomalies for the hottest and coldest daily maximum temperatures in each season (TXx and TXn, respectively; Fig. 2.5), show a pattern of more intense hot days and warmer-than-normal cold days across many land regions of the world. This index is based on a more extreme measure of the climate, thus there is greater spatial heterogeneity. While most of the maps show warmer hot days and warmer cold days than normal, there are some exceptions. For example, in Europe in boreal spring, the coldest days were considerably colder than normal (Fig. 2.5). These cold extremes were particularly prominent in March and associated with the aftermath of a sudden stratospheric warming event, which promoted atmospheric blocking and anomalous easterly winds that brought colder temperatures and late-season heavy snowfall. A new record low March daily maximum temperature (TXn) on 1 March was set in the UK (see Section 7f2). Other extremes in 2018 included much colder-thannormal values of TXn in the eastern United States in boreal autumn and a lack of warm daytime temperatures in southern Africa in austral winter.

Boreal summer was typified by heat waves and extreme, often record-breaking, temperatures in many areas of the $\mathrm{NH}$ at different times. The high seasonal TXx in northeastern North America, Europe, and East Asia (Fig. 2.5) are associated with these heat extremes as new record daily maximum temperature records were set in locations including Tokyo (Japan), Montreal (Canada), and Ouargla (Algeria; WMO 2018b). For each of the events in 


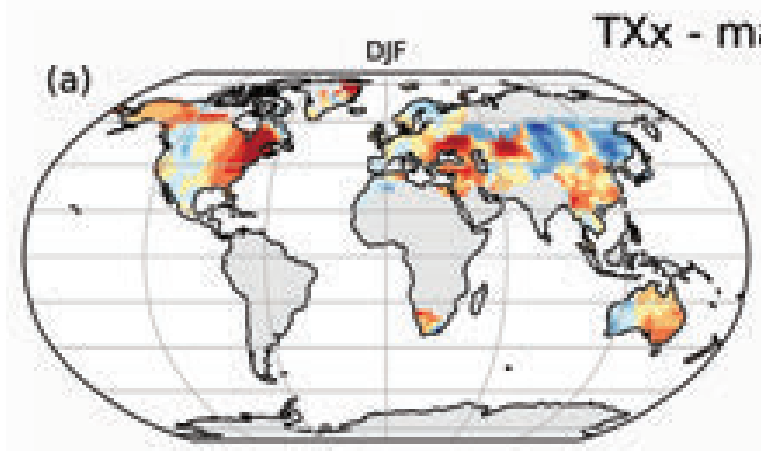

\section{ax Tmax}
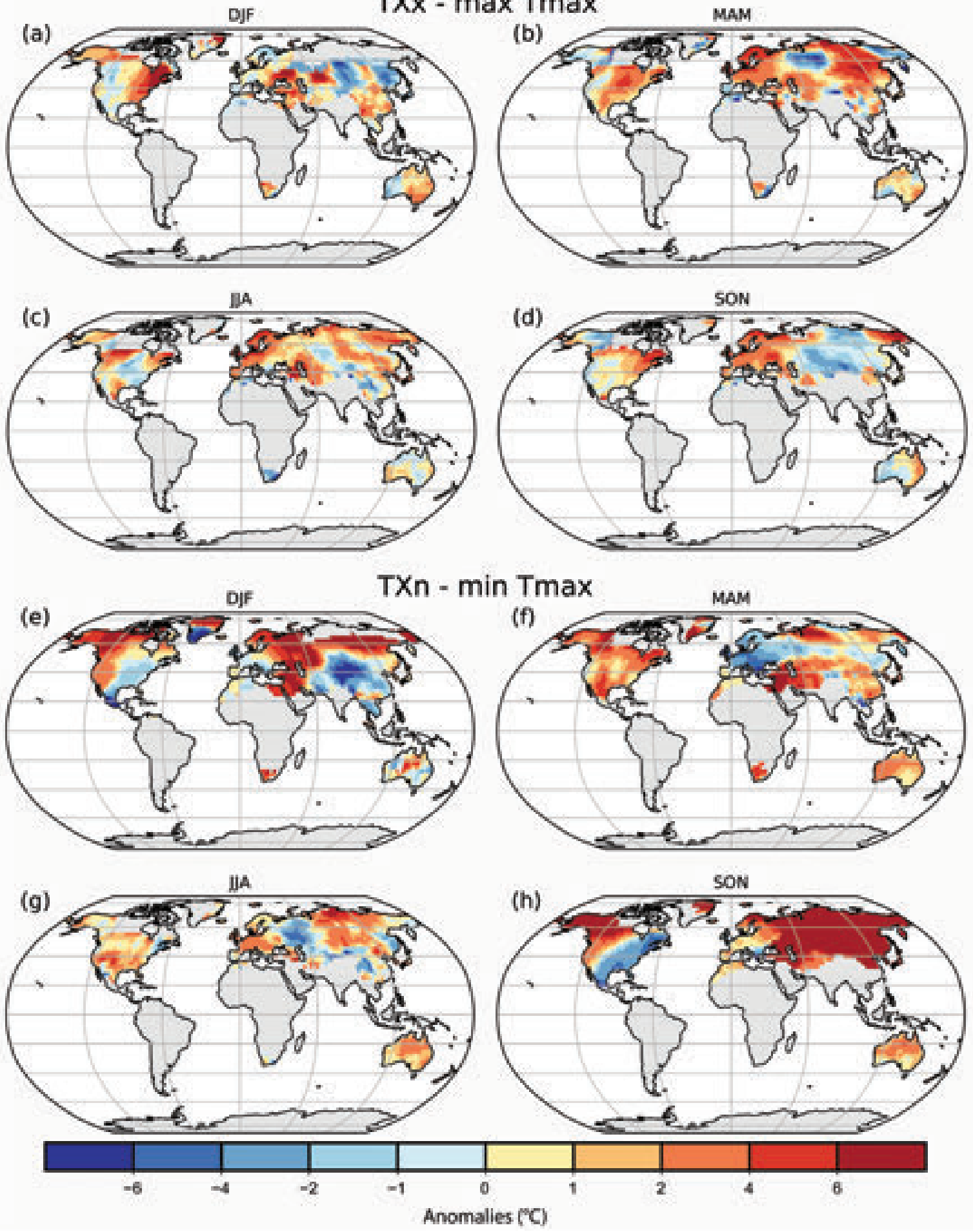

Fig. 2.5. Anomalies, relative to $1961-90$ of (a-d) the hottest daily maximum temperature and (e-h) coldest daily maximum temperature in each season of 2018 from GHCNDEX. Note that the DJF anomalies are for Dec 2017-Feb 2018.

eastern North America, western Europe, and East Asia, unusually persistent blocking high-pressure systems associated with a weakened and displaced jet stream allowed extreme heat to build. The European heatwave was linked with a spike in fatalities in the
United Kingdom (see Section 7f2). The heat also triggered wildfires, even in northern Europe, e.g., in May through July in Scandinavia, but also during 23-26 July in Greece which, combined with strong winds, resulted in around 100 fatalities (see Sections 7f3, 7f5). 
4) Tropospheric temperature-J. R. Christy, S. Po-Chedley, C. R. Mears, and L. Haimberger

The 2018 annual global lower troposphere temperature (LTT; surface to $\sim 10 \mathrm{~km}$ ) ranked third to seventh highest as monitored by radiosondes since 1958 and satellites since 1979 according to nine datasets examined for this analysis. (As noted in Section $2 \mathrm{~b} 1$, the 2018 global average surface temperature was fourth highest.) A weak La Niña event extending into early 2018 suppressed the global LTT in the 2018 boreal winter and spring. In contrast, the tropical Pacific exhibited higher-than-average temperatures in boreal autumn, indicating the eventual initiation of a weak El Niño at the end of 2018 that contributed to higher-than-average temperatures in the following seasons in 2019. Among the nine datasets, the 2018 anomaly ranged from $+0.23^{\circ} \mathrm{C}$ to $+0.47^{\circ} \mathrm{C}$ relative to the 1981-2010 average and was $\sim 0.3^{\circ} \mathrm{C}$ lower than the record warm year of 2016 .

The ranking of the warmest or coldest years on record is sensitive to minor differences in the annual LTT anomaly. For example, had the ERA5 temperature been only $0.02^{\circ} \mathrm{C}$ lower, the 2018 value would have ranked as the fifth warmest year rather than third. Since 1958, the LTT from radiosondes has increased at a rate of $+0.19^{\circ} \pm 0.03^{\circ} \mathrm{C}$ decade $^{-1}$ and since 1979 by $+0.17^{\circ} \pm 0.03^{\circ} \mathrm{C} \mathrm{decade}^{-1}$ (Fig. 2.6, Table 2.3). The error ranges here and below are determined since 1958 by all available datasets and since 1979 by

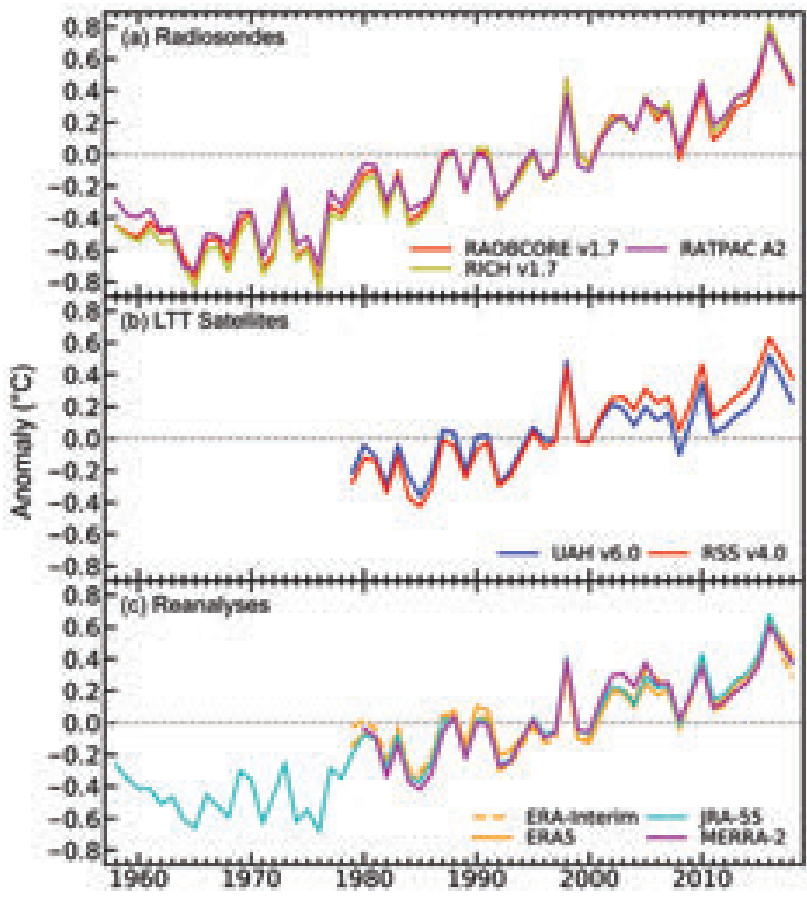

Fig. 2.6. Annual anomalies of global LTT from (a) radiosondes; (b) satellites; and (c) reanalyses. the datasets remaining after the highest and lowest values are eliminated.

The geographic distribution of 2018 LTT anomalies (Plate 2.1e) indicates large areas of much aboveaverage temperatures over Europe as well as north central Africa to its south and the Barents Sea to its north, the Arctic in general (some anomalies of $+2^{\circ} \mathrm{C}$ ) with adjacent areas in Russia, Alaska with the adjacent North Pacific Ocean, and eastern Antarctica. Cooler-than-average conditions appeared across northeastern Canada to the North Atlantic Ocean, Kazakhstan, and over the far southeastern Pacific Ocean. With respect to monthly global anomalies, the highest value was observed in July, and the lowest in May and September. However, the difference between the highest and lowest monthly anomalies was relatively small-about $0.2^{\circ} \mathrm{C}$, half of the typical range.

Extremes in tropospheric temperature occur somewhere around the globe during each month in nearly every year due to the dynamical nature of the climate system. For periods with positive trends, whether due to natural variability or increasing greenhouse gas forcing, one way to depict change is to measure the areal extent of those locations experiencing the extreme. Figure 2.7 displays the percentage of area that recorded the highest (red) and lowest (blue) temperatures by month. For example, there are 40 Januaries, so for each January gridbox, the year of the hottest and coldest temperature is determined, then for January of each year, the total area of gridpoints experiencing an extreme event in that January is computed. As a result of the background global warming trend, relatively large areas experience the highest temperature at the end of the record and lowest near the beginning. El Niños and La Niñas contribute to the major excursions of areal coverage as seen in

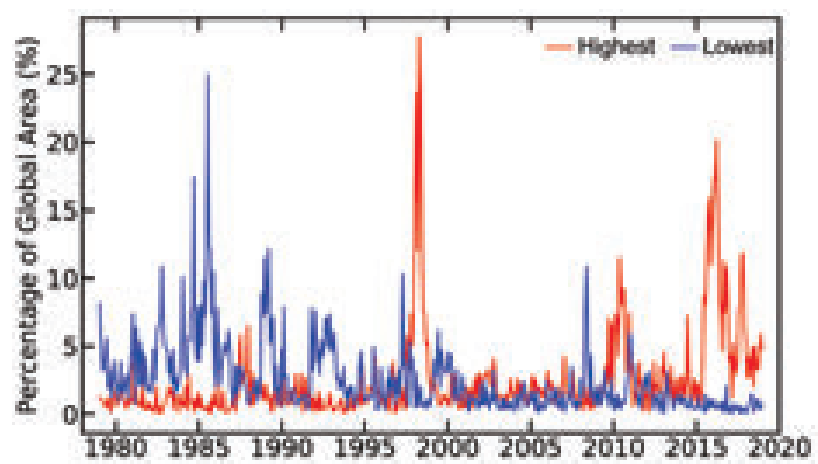

FIG. 2.7. Time series of the global area experiencing the highest monthly temperature (red) and lowest monthly temperature (blue) relative to 1979-2018. Values are the average of RSSv4.0, UAHv6.0, and ERA5. For a trendless, random process, the expected value in any month would be $2.5 \%$ (i.e., I in 40 ). 
TABLE 2.3. Estimates of lower tropospheric temperature decadal trends $\left({ }^{\circ} \mathrm{C}\right.$ decade $\left.{ }^{-1}\right)$ beginning in 1958 and 1979 from the available datasets.

\begin{tabular}{|c|c|c|c|c|c|}
\hline Area & & Global & Global & Tropical & Tropical \\
\hline Layer & & LTT & LTT & TTT & TTT \\
\hline Start Year & & 1958 & 1979 & 1958 & 1979 \\
\hline Radiosonde & NOAA/RATPACvA2 & +0.18 & +0.20 & +0.15 & +0.15 \\
\hline & RAOBCOREvI.7 & +0.19 & +0.20 & +0.14 & +0.13 \\
\hline & RICHvI.7 & +0.20 & +0.22 & +0.18 & +0.18 \\
\hline Satellite & RSSv4.0 & & +0.20 & & +0.17 \\
\hline & UAHv6.0 & & +0.13 & & +0.12 \\
\hline & NOAA/STARv4.I & & & & +0.22 \\
\hline Reanalyses & UWv1.0 & & & & +0.16 \\
\hline & ERA-I & & +0.14 & & +0.14 \\
\hline & JRA5 & & +0.16 & & +0.14 \\
\hline & NASA/MERRA-2 & & +0.16 & & +0.14 \\
\hline Median & & +0.16 & +0.17 & +0.16 & +0.15 \\
\hline & & +0.19 & +0.17 & +0.16 & +0.15 \\
\hline Surface & GISSv3 & +0.16 & +0.18 & & \\
\hline & HadCRUTv4 & +0.14 & +0.17 & & \\
\hline & JMA & +0.12 & +0.14 & & \\
\hline & NCDCv4 & +0.15 & +0.17 & & \\
\hline & & Global & $\mathbf{G l o b a l}$ & & \\
\hline
\end{tabular}

${ }^{1}$ The UAH LTT weighting function is slightly different in order to eliminate most of the surface emissions resulting in a global trend value typically cooler by $0.01{ }^{\circ} \mathrm{C}$ decade $^{-1}$ relative to the standard LTT weighting function.

${ }^{2}$ NASA/MERRA-2 begins in 1980.

1998 (record warm area) and 1985 (record cold area). For a random process with zero trend it would be anticipated that on average, $2.5 \%$ of the globe would record the highest and lowest temperatures in any year of a 40 -year time series. For 2018, 3.90\% (0.73\%) of Earth exhibited their hottest (coldest) events on record. We note the period of record here is only 40 years and thus represents a very limited time frame for analysis of extremes.

The tropical tropospheric temperature (TTT) is highly, positively correlated with the ENSO phase and is also likely to be sensitive to rising greenhouse gas forcing. As in Christy et al. (2018), TTT (surface to $\sim 15 \mathrm{~km}$ ), is calculated as the linear combination of the mid-tropospheric layer (MTT) and lower stratospheric layer (LST) to eliminate nearly all of the stratospheric influence in MTT $\left(\mathrm{TTT}=1.1^{\star} \mathrm{MTT}-\right.$ $\left.0.1^{*} \mathrm{LST}\right)$. The trend values for the various products are shown in Table 2.3. In this tropical band $\left(20^{\circ} \mathrm{N}-\right.$ $\left.20^{\circ} \mathrm{S}\right)$, TTT has increased at a rate of $+0.16(+0.15) \pm$ $0.03^{\circ} \mathrm{C}$ decade $^{-1}$ since 1958 (1979).
Since late 1978, microwave radiometers on polarorbiting satellites have monitored the temperaturesensitive radiation emitted from relatively deep layers of the atmosphere, providing near-global coverage. Radiosondes measure the temperature at discrete levels of the troposphere and stratosphere in the narrow, upward path through which the balloon ascends. The balloons are released from almost 1000 stations daily, essentially restricted to continent and island locations but with reasonable coverage starting in 1958. The values from these discrete levels are utilized to generate a deep-layer temperature to match that observed by satellites. Reanalyses create global depictions of atmospheric conditions by incorporating all available observations, including radiosondes and satellites, through a continuously running numerical weather-prediction forecasting model, representing a synthesis of observations with dynamical consistency. Versions of the datasets are the same as in last year's report (Christy et al. 2018) except (a) NOAA satellite is now v4.1 (Zou et al. 2018); (b) the European Centre 
for Medium-Range Weather Forecasts (ECMWF) has released ERA5 (Hersbach et al. 2019) to replace ERA-Interim (shown here for the final time); and (c) University of Vienna (RAOBCORE and RICH) is now version 1.7 (Haimberger et al. 2012). New this year is a version of the mid- and upper stratospheric temperatures from NCAR (Randel et al. 2016).

\section{5) Stratospheric temperature and Winds-} J. R. Christy, C. Covey, and W. Randel

The middle (MST $\sim 28-48 \mathrm{~km}$ ) and upper (UST $\sim 35-55 \mathrm{~km}$ ) stratospheric temperatures continued to decline to their lowest levels recorded since 1979, i.e., the satellite era. However, the 2018 global lower stratospheric temperature (LST; 12-25 km) ranked approximately fifth coldest in both the satellite and radiosonde eras (beginning in 1958). It should be noted that global LST has been relatively constant since 1996 and interannual differences in anomalies are only a few hundredths of a degree in many cases. This leads to a wide range of rank placement for 2018 among the datasets, from third to fourteenth coolest. The global LST was influenced by the easterly shear (cool) phase of the QBO for most of the year. In the northern polar region, the sixth warmest sudden stratospheric warming (SSW) event in 40 years oc-

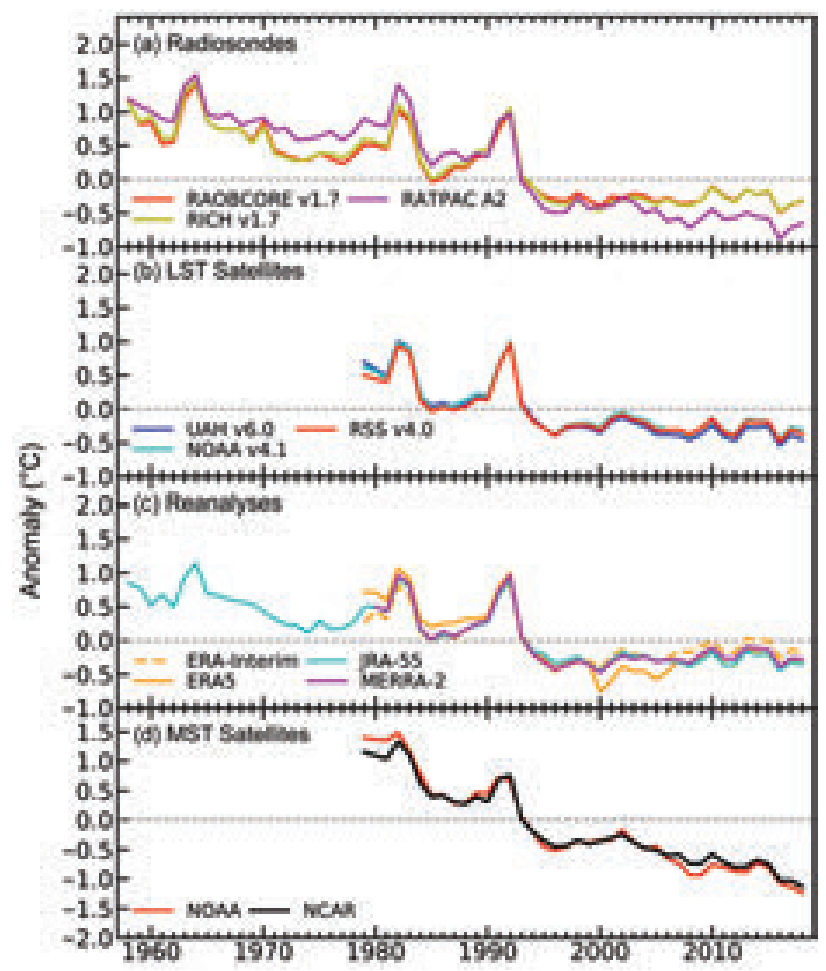

FIG. 2.8. Annual anomalies of global LST from (a) radiosondes; (b) satellites; and (c) reanalyses. (d) Annual anomalies of global MST from Stratospheric Sounding Unit channel 2 curred in February; as the year ended, another SSW began and produced the second warmest event in early January 2019.

The time series of the annual anomalies of LST, observed from microwave sensors, radiosondes, and reanalyses, and MST observed with infrared and microwave sensors are displayed in Fig. 2.8, with trend values presented in Table 2.4, including trends of layers above and below MST. The LST values have been generally trendless since 1996, following the transient warming associated with the Mount Pinatubo volcanic eruption in 1991. The MST trend since 1996 indicates continued decline (about $-0.4^{\circ} \mathrm{C}$ decade $^{-1}$ ).

The geographical distribution of the 2018 LST anomalies is shown in Plate 2.1f, where the easterly shear phase (cold) of the QBO is evident in the tropical band. Anomalies are somewhat antisymmetric between the polar regions. Regional tropospheric and stratospheric temperature anomalies are often anti-correlated, which can be seen in comparison with Fig. 2.6.

The global LST trend since 1996 is near zero (Table 2.4) but has an unusual spatial distribution with significant warming over the North Atlantic (related to recent SSWs) as well as broad warming over the South Pacific Ocean (not shown). The lack of LST cooling, despite tropospheric warming, since 1996 is related to the quasi-stabilization of ozone concentrations in this layer as well as the small warming influence of the upper troposphere in the tropics that is included in the LST layer (Maycock et al. 2018). At higher levels, the temperature decline continues, indicating enhanced radiative cooling associated with continued increases in concentrations of thermally active gases, most notably $\mathrm{CO}_{2}$, and the possible impact of a weak solar cycle (Manabe and Wetherald 1967; Maycock et al. 2018).

Christy and Covey (2018) noted in 2017 that the behavior of the QBO, an east-west oscillation of stratospheric wind lasting 25-30 months and accompanied by associated temperature swings, was unusual with the recent period being rather shortabout 18 months. This disruption was described in Coy et al. (2017) and Watanabe et al. (2017) as a response to an unusual distribution of the prevailing upper air winds near the tropics. The current cycle returned to its normal periodicity as indicated by the evolution of the time-phase relationship between the two leading patterns of variation in the vertical wind profile at Singapore (Wallace et al. 1993 with updates from NASA 2018; see also Section 2e3). 
TABLE 2.4. Linear trends ( ${ }^{\circ} \mathrm{C}$ decade ${ }^{-1}$ ) of global and polar LST. The global trends of temperatures from the three channels of the stratospheric sounding unit are included. NP and SP are defined as the areas poleward of $65^{\circ} \mathrm{N}$ and $65^{\circ} \mathrm{S}$, respectively.

\begin{tabular}{|c|c|c|c|c|c|c|}
\hline Area & & GL & $\mathbf{G L}$ & GL & $\mathbf{N P}$ & SP \\
\hline Layer & Lower Stratosphere & LST & LST & LST & LST & LST \\
\hline Start Year & & 1958 & 1979 & 1996 & 1979 & 1979 \\
\hline \multirow[t]{3}{*}{ Radiosonde } & NOAA/RATPACvA2 & -0.36 & -0.46 & -0.15 & & \\
\hline & RAOBCOREvI.7 & -0.24 & -0.26 & 0.00 & & \\
\hline & RICHvI.7 & -0.25 & -0.28 & +0.04 & & \\
\hline \multirow[t]{3}{*}{ Satellite } & RSSv4.0 & & -0.23 & -0.03 & -0.12 & -0.24 \\
\hline & UAHv6.0 & & -0.29 & -0.06 & -0.17 & -0.29 \\
\hline & NOAA/STARv4.I & & -0.25 & -0.04 & -0.02 & -0.32 \\
\hline \multirow[t]{4}{*}{ Reanalyses } & ERA-I & & -0.16 & +0.14 & -0.06 & -0.18 \\
\hline & ERA5 & & -0.31 & +0.10 & -0.19 & -0.35 \\
\hline & JRA-55 & -0.21 & -0.26 & -0.02 & -0.07 & -0.29 \\
\hline & NASA/MERRA-2' & & -0.22 & +0.07 & & \\
\hline \multirow[t]{2}{*}{ Median } & & -0.25 & -0.26 & -0.01 & -0.10 & -0.29 \\
\hline & $\begin{array}{l}\text { Middle and Upper } \\
\text { Stratosphere }\end{array}$ & & GL & GL & $\mathbf{N P}$ & $\mathbf{N P}$ \\
\hline Satellite Peak & & & 1979 & 1996 & 1979 & 1979 \\
\hline \multirow[t]{2}{*}{30 km } & NOAA/STAR CH I & & -0.57 & -0.34 & -0.69 & -0.25 \\
\hline & NCAR & & -0.55 & -0.32 & & \\
\hline \multirow[t]{2}{*}{38 km MST } & NOAA/STAR CH 2 & & -0.65 & -0.44 & -0.87 & -0.32 \\
\hline & NCAR & & -0.58 & -0.32 & & \\
\hline \multirow[t]{2}{*}{$50 \mathrm{~km}$} & NOAA/STAR CH 3 & & -0.75 & -0.58 & -1.04 & -0.43 \\
\hline & NCAR & & -0.69 & -0.45 & & \\
\hline
\end{tabular}

${ }^{1}$ MERRA-2 begins in 1980.

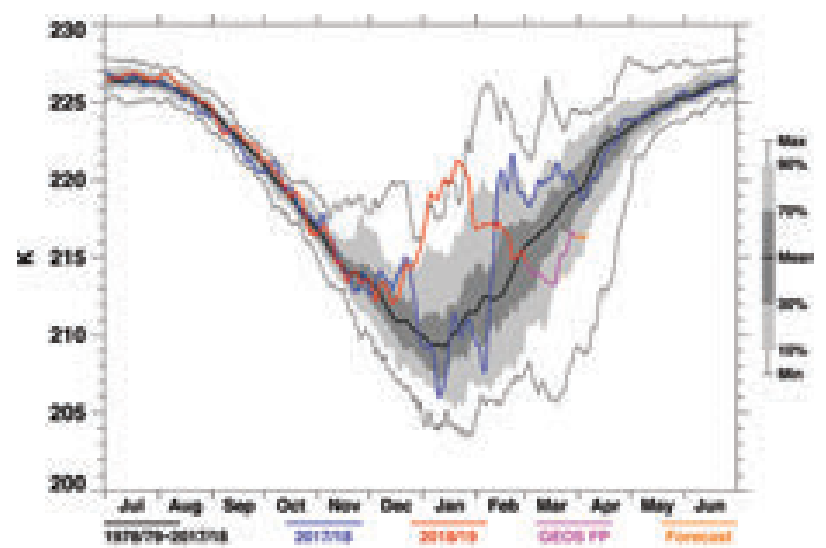

FIG. 2.9. Daily time series of $100-\mathrm{hPa}$ temperatures (K) for $60^{\circ}-90^{\circ} \mathrm{N}$ for 2017-18 (blue) and 2018-19 (red, pink) against the background of percentile variability since 1980.
One of the more transient but common features of LST variability is the SSW process that often occurs in winter-more often over the North Pole (NP) than the South Pole (SP). At least one SSW occurred in 33 of the past $61 \mathrm{NH}$ winters. In certain dynamical situations, some of the energy that is usually constrained to reside in the troposphere is released to the polar cap stratosphere which, owing to its minimal mass, will warm rapidly. Figure 2.9 places the last two years of NP 100-hPa polar winter temperatures in the context of the historical average and range. Using 5 -day polar-cap averages of UAH LST $\left(65^{\circ}-90^{\circ} \mathrm{N}\right.$; not shown but see Christy and Covey 2018 for reference), the anomaly in February 2018 exceeded $+11^{\circ} \mathrm{C}$, the sixth highest of the 40-year period, while the SSW beginning in 2018 and peaking in early January 2019 was the second highest at $+13^{\circ} \mathrm{C}$. 
c. Cryosphere

I) Permafrost thermal state-J. Noetzli, B. K. Biskaborn, H. H. Christiansen, K. Isaksen, P. Schoeneich, S. Smith, G. Vieira, L. Zhao, and D. A. Streletskiy

The first globally consistent assessment of permafrost temperature changes revealed a mean increase in all permafrost regions worldwide by $0.29^{\circ} \pm 0.12^{\circ} \mathrm{C}$ over the decade $2007-16$ based on field data recorded close to the depth of the zero annual amplitude (ZAA) in 154 boreholes (Biskaborn et al. 2019). The ZAA is the depth where seasonal variations become negligible (less than $0.1^{\circ} \mathrm{C}$ ), which is typically between ca. $10 \mathrm{~m}$ to $20 \mathrm{~m}$ depending on the thermo-physical properties at the site. The most substantial increase was observed where permafrost temperatures are lowest. At ice-rich locations with permafrost temperatures little below $0^{\circ} \mathrm{C}$, the increase is typically smaller because of the energy needed for ice-water phase change (latent heat; e.g., Romanovsky et al. 2010; PERMOS 2019; Biskaborn et al. 2019): permafrost temperatures in the continuous permafrost zone in the high Arctic increased by $0.39^{\circ} \pm 0.15^{\circ} \mathrm{C}$ during this period (Biskaborn et al. 2019), which is nearly twice as much as in the discontinuous permafrost zone $\left(0.20^{\circ} \pm\right.$ $0.10^{\circ} \mathrm{C}$ ). The overall trend and pattern described in the decadal assessment continued in 2018. Across the entire Arctic, permafrost continued to warm in 2018, with permafrost temperatures among the highest ever recorded (see Section $5 f$ for more details).

Mountain permafrost data are primarily available from boreholes in the European Alps, the Nordic countries, and central Asia, which show a permafrost temperature increase of $0.19^{\circ} \pm 0.05^{\circ} \mathrm{C}$ during 2007-16. Absolute values are, however, highly heterogeneous, particularly related to topography, snow regime, and ground ice. The pronounced warming trend observed in the European Alps during the reference period (PERMOS 2019; Pogliotti et al. 2015, Fig. 1) was interrupted in debris slopes and rock glaciers due to a late and thin snow cover in winter 2015/16 and 2016/17 (Noetzli et al. 2018; PERMOS 2019), especially at colder sites in the eastern Swiss Alps (e.g., Corvatsch, Schafberg). Due to the large thermal inertia of the subsurface thermal regime, permafrost temperatures remained stable or even decreased in 2018 at depths between about $10 \mathrm{~m}$ and $20 \mathrm{~m}$ (Fig. 2.10). In contrast, as a result of the warmest year on record in many central European countries (see Section $7 \mathrm{f3}$ ), ground temperatures in the uppermost meters were above average or at record level at the majority of the observed sites (PERMOS 2019; Noetzli et. al. 2018). Time series from steep bedrock locations above $3000 \mathrm{~m}$ a.s.l. are sparse and only cover the past decade

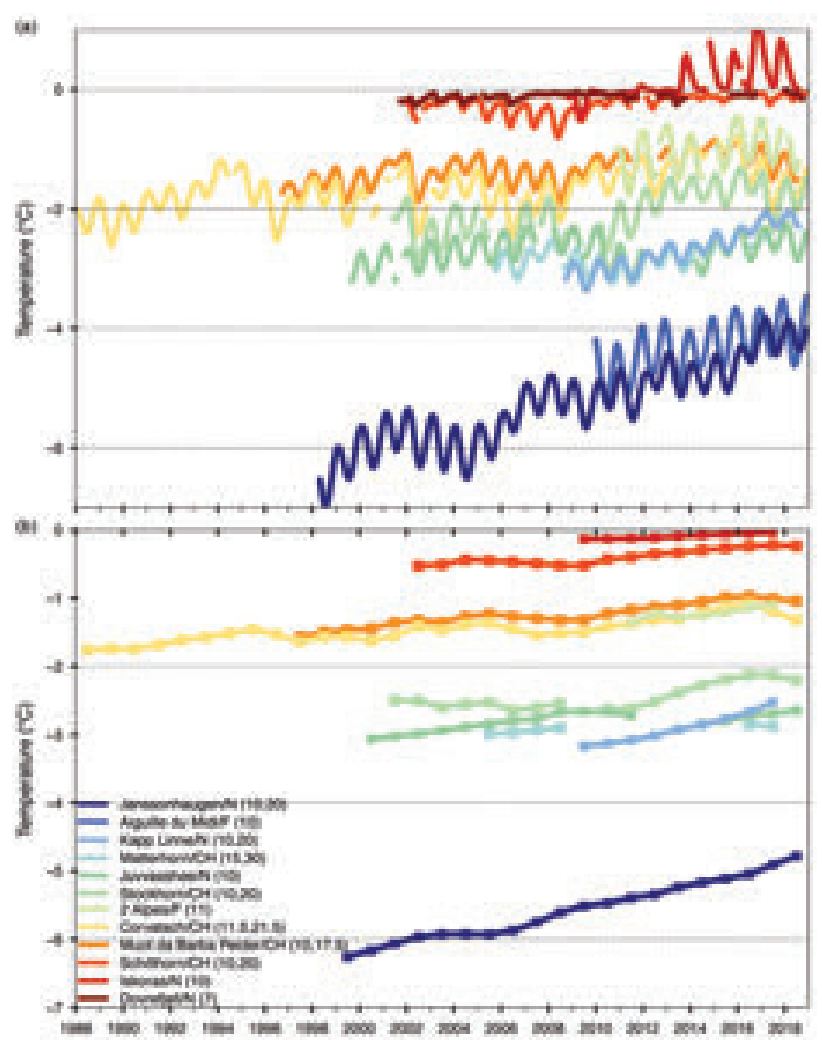

Fig. 2.10. Permafrost temperature $\left({ }^{\circ} \mathrm{C}\right)$ measured in boreholes in the European Alps and the Nordic countries at a depth of approximately (a) $10 \mathrm{~m}$ (monthly means) and (b) $20 \mathrm{~m}$ (annual means). [Sources: Swiss Permafrost Monitoring Network (PERMOS); Norwegian Meteorological Institute and the Norwegian Permafrost Database (NORPERM); and French Permafrost Monitoring Network (PermaFRANCE).]

(Magnin et al. 2015; PERMOS 2019). Here, permafrost temperature increased without interruption and at high rates due to low ice content and the negligible influence of winter snow cover (e.g., Aiguille du Midi). In Nordic countries, mountain permafrost temperatures continued to increase in both cold and warm permafrost (updated from Isaksen et al. 2007; Christiansen et al. 2010). In southern Norway, permafrost temperatures were the highest on record (e.g., Juvvasshøe since 1999 and Dovrefjell since 2001), and in northern Norway (Iškoras since 2008), permafrost has been thawing. Here, ground temperatures have been well above $0^{\circ} \mathrm{C}$ at $10-\mathrm{m}$ depth since 2013/14 and have now risen to $0^{\circ} \mathrm{C}$ at a depth of $20 \mathrm{~m}$ (Fig. 2.10). During the period 2005-17, permafrost temperature rose significantly on the Qinghai-Tibetan Plateau in central Asia (Fig. 2.11). All observation sites there showed remarkable warming tendencies, but the increments and rates are highly variable. The rate of annual temperature increase at $10-\mathrm{m}$ depth varies 

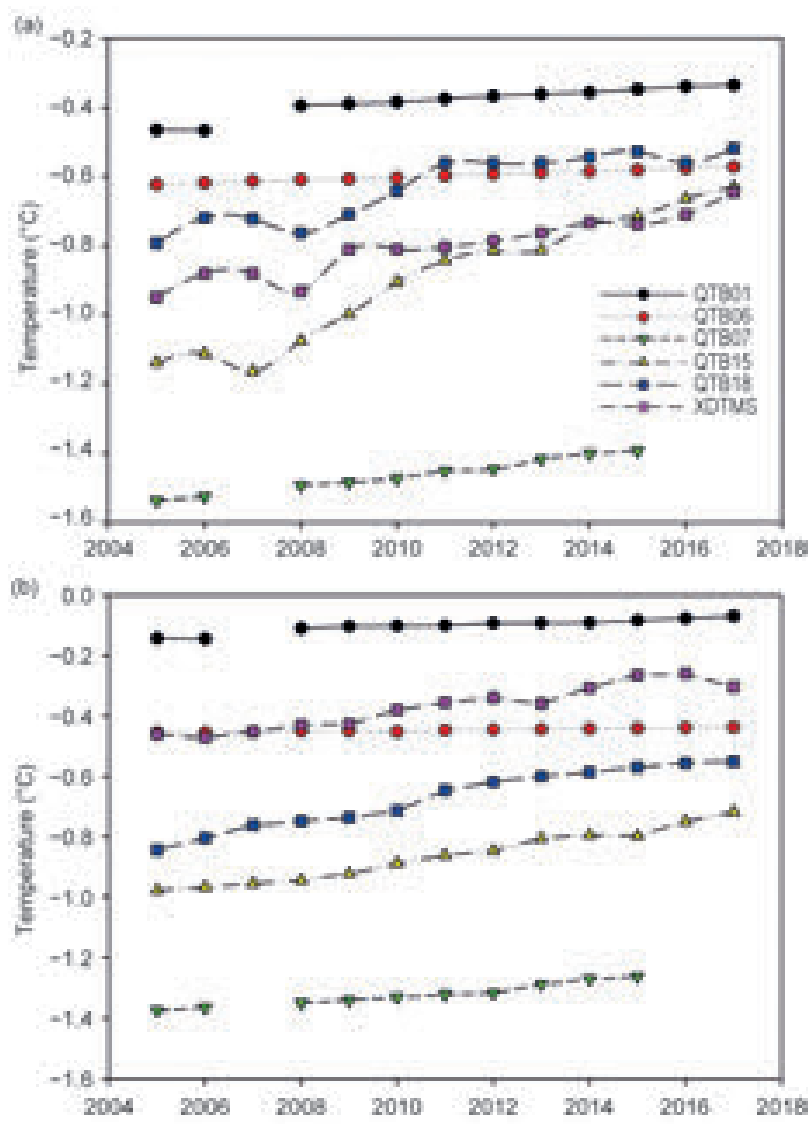

FIG. 2.II. Temperature $\left({ }^{\circ} \mathrm{C}\right)$ measured in permafrost boreholes along the Qinghai-Xizang Highway on the Tibetan Plateau at 10- and 20-m depth. (Source: Cryosphere Research Station on Qinghai-Xizang Plateau, CAS.)

from $0.04^{\circ}-0.47^{\circ} \mathrm{C}$ per decade (max: QTB15; min: QTB06). At 20-m depth, the decadal rates of increase are in the range of $0.02^{\circ}-0.26^{\circ} \mathrm{C}$.

Permafrost temperature in Antarctica increased by $0.37^{\circ} \pm 0.1^{\circ} \mathrm{C}$ during the decade 2007-16 (Biskaborn et al. 2019). However, deep boreholes and complete time series data in Antarctica are scarce, the warming trends are not evident everywhere, and lack statistical significance. For example, Cierva Cove on the western Antarctic Peninsula showed stable permafrost temperatures at 10- and 15-m depth during 2012-18, with the summers of 2016-18 showing lower temperatures than during 2012-15.

The maximum thaw depth in summer, the active layer thickness (ALT), generally follows summer temperature anomalies. The warm summer of 2018 in the North American sub-Arctic, Eurasian Arctic, and mountain regions of Eurasia resulted in continued ALT increase in the majority of the observation sites since the mid-1990s (Fig. 2.12). Of 85 sites report-

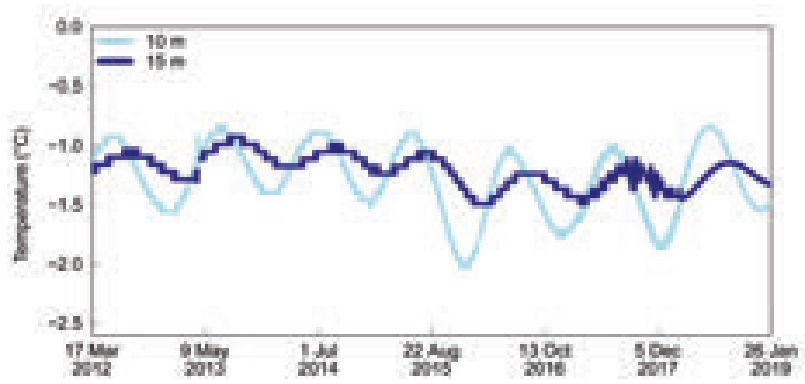

FIG. 2.I2. Temperature $\left({ }^{\circ} \mathrm{C}\right)$ measured in a permafrost borehole on the Antarctic Peninsula in Cierva Cove at 10-m and $15-\mathrm{m}$ depth.

ing data to Circumpolar Active Layer Monitoring (CALM) in 2018, 64 had an above-average ALT. In the Nordic countries and European Alps, new record values were observed at several sites (e.g., PERMOS 2019). Active layer thickness also continued to increase in 2018 at sites located in permafrost regions along the Qinghai-Tibet highway, reaching $28 \mathrm{~cm}$ above the 1981-2018 mean. The Eurasian Arctic, with the exception of a few sites located in southeastern Siberia and Chukotka, had above-average ALT in 2018. Sites located in northern Canada have been characterized by an overall increase of ALT since 2003. Sites in northern Alaska had generally lower ALT in 2018 relative to 2017, while interior Alaska had record high ALT in 2018. Greenland was the only region with significantly lower ALT, close to its minimum values since 1996, reflecting cold summer conditions in 2018 (see Section 5g for more details on Arctic sites). The ALT in Antarctica showed no clear trend for 2006-15 and significant spatial variability (Hrbáček et al. 2018). Some sites in the South Shetlands have shown a decreasing ALT because of increased snow cover (Ramos et al. 2017).

Long-term observation of permafrost change relies on ground temperatures measured in boreholes, which are collected in the framework of the Global Terrestrial Network for Permafrost as part of the Global Climate Observing System of the World Meteorological Organization. Borehole temperatures are recorded manually or continuously using multisensor cables down to at least the depth of the zero annual amplitude. An assessment of the measurement accuracy of borehole temperatures in permafrost worldwide varied from $0.01^{\circ} \mathrm{C}$ to $0.25^{\circ} \mathrm{C}$ (Biskaborn et al. 2019) and a mean overall accuracy of about $0.1^{\circ} \mathrm{C}$ can be assumed (Biskaborn et al. 2019; Romanovsky et al. 2010). 


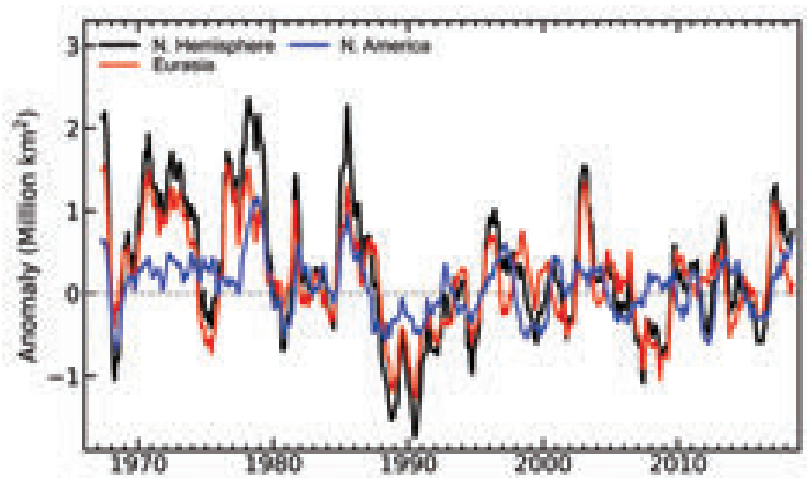

FIG. 2.I3. Twelve-month running anomalies of monthly snow cover extent (million $\mathrm{km}^{2}$ ) over $\mathbf{N H}$ lands as a whole and Eurasia and North America separately, plotted on the seventh month using values from Nov 1966 to Dec 2018. Anomalies are calculated from NOAA snow maps. Mean hemispheric snow extent is 25. I million $\mathbf{~ k m}^{2}$ for the full period of record. Monthly means for the period of record are used for nine missing months between 1968 and 1971 in order to create a continuous series of running means. Missing months fall between Jun and Oct; no winter months are missing.
2) Northern Hemisphere Continental snow COVER EXTENT-D. A. Robinson

Annual snow cover extent (SCE) over NH lands averaged 25.6 million $\mathrm{km}^{2}$ in 2018. This is 0.5 million $\mathrm{km}^{2}$ larger than the 49-year average (Fig. 2.13; mapping extends back to late 1967; however, several early years in the record are incomplete), the 12th largest cover on record (Table 2.5). This is also 0.2 million $\mathrm{km}^{2}$ less than the 2017 mean extent. Snow cover extent over both $\mathrm{NH}$ continents, including the Greenland ice sheet, is considered in this analysis. Monthly SCE in 2018 ranged from 47.2 million $\mathrm{km}^{2}$ in January to 3.0 million $\mathrm{km}^{2}$ in August.

January 2018 NH SCE was close to average, with the 27th most extensive cover over the past 52 years. Both Eurasia and North America ranked similarly. February NH SCE was just 0.6 million $\mathrm{km}^{2}$ smaller than January (it is normally about 1.2 million $\mathrm{km}^{2}$ lower). Snow was slow to melt in March and April, especially over North America, where snow cover was fifth and fourth most extensive, respectively. Nearaverage Eurasian extent brought the $\mathrm{NH}$ rankings to 13 th and 10th most extensive cover for March and

\begin{tabular}{|c|c|c|c|c|c|c|c|}
\hline & Years & $\begin{array}{l}\text { Mean } \\
\text { SCE }\end{array}$ & $\begin{array}{l}\text { Std. } \\
\text { Dev. }\end{array}$ & 2018 & $\begin{array}{c}2018 \\
\text { NH } \\
\text { Rank }\end{array}$ & $\begin{array}{c}\text { Eurasia } \\
\text { Rank }\end{array}$ & $\begin{array}{c}\text { N. } \\
\text { Am. } \\
\text { Rank }\end{array}$ \\
\hline Jan & 52 & 47.2 & 1.6 & 46.9 & 27 & 29 & 30 \\
\hline Feb & 52 & 46.0 & 1.8 & 46.3 & 19 & 24 & 19 \\
\hline Mar & 52 & 40.5 & 1.8 & 41.8 & 13 & 22 & 5 \\
\hline Apr & 52 & 30.5 & 1.7 & 32.1 & 10 & 26 & 4 \\
\hline May & 52 & 19.2 & 1.9 & 18.3 & 37 & 34 & 33 \\
\hline Jun & 51 & 9.6 & 2.4 & 7.8 & 41 & 41 & 36 \\
\hline Jul & 49 & 4.0 & 1.2 & 3.0 & 39 & 41 & 29 \\
\hline Aug & 50 & 3.0 & 0.7 & 2.7 & 27 & 44 & 17 \\
\hline Sep & 50 & 5.4 & 0.9 & 6.4 & 9 & 33 & I \\
\hline Oct & 51 & 18.4 & 2.7 & 20.1 & 14 & 22 & 2 \\
\hline Nov & 53 & 34.2 & 2.1 & 37.8 & 3 & 13 & I \\
\hline Dec & 53 & 43.7 & 1.9 & 44.5 & 15 & 16 & 21 \\
\hline Ann & 49 & 25.1 & 0.8 & 25.6 & 12 & 23 & 3 \\
\hline
\end{tabular}


April. The pace of melt accelerated significantly in May, which contributed to the 16th least extensive $\mathrm{NH}$ cover of the past 52 years. June NH SCE was 12th smallest.

In autumn, snow began to blanket the higher latitudes and altitudes of the NH rather quickly, giving September its ninth largest SCE. With the second largest extent over North America, the October NH SCE was 14th most extensive overall. The coverage continued to build quickly in November, the third largest extent on record over NH, with North American SCE the most extensive on record for the month and Eurasian SCE 13th most extensive. The pace of increasing cover slowed in December, although SCE was still 15th largest on record across the $\mathrm{NH}$ for the month. On average, there is approximately 10 million $\mathrm{km}^{2}$ greater coverage in December than in November; in 2018 the NH increase was only about 7 million $\mathrm{km}^{2}$.

The 2018 SCE over the contiguous United States was similar to that over the entirety of North America and over all $\mathrm{NH}$ lands. This included increasingly positive SCE anomalies from January through April, prior to a rapid decline in May. The largest difference between the United States and North American SCE rankings occurred in October, when the most extensive SCE on record over Canada contributed most to the second most extensive North American extent, while, not surprisingly, snows took longer to arrive farther south over the United States. By November and December, with Canada essentially fully snow covered, the North American SCE was dictated by variations in U.S. cover, which ranked 3rd and 25th most extensive, respectively.

Snow cover extent is calculated at the Rutgers Global Snow Lab from daily SCE maps produced by meteorologists at the National Ice Center (a U.S. joint NOAA, Navy, and Coast Guard facility), who rely primarily on visible satellite imagery to construct the maps (see https://snowcover.org to access maps and gridded products at various timescales).

\section{3) Alpine glaciers-M. Pelto and World Glacier Monitoring} Service (WGMS)

The WGMS record of mass balance and terminus behavior (WGMS 2017) provides a global index for alpine glacier behavior. Glacier mass balance is the difference between accumulation and ablation, reported here in millimeters of water equivalence. Mean annual glacier mass balance was $-921 \mathrm{~mm}$ for the 42 long-term reference glaciers (which have a minimum 30 years of record) and $-951 \mathrm{~mm}$ for all 142 monitored glaciers in 2017. Preliminary 2018 data reported from reference glaciers in Argentina, Austria,

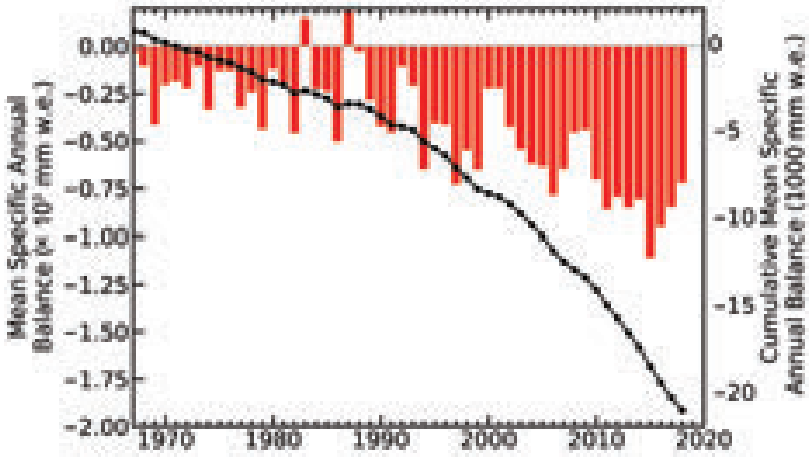

FIG. 2.14. Global alpine glacier annual mass balance record ( $\times 10^{3} \mathrm{~mm}$ w.e.) of reference glaciers submitted to the WGMS 1968-20I8, with a minimum of 30 reporting glaciers.

China, France, Italy, Kazakhstan, Kyrgyzstan, Nepal, Norway, Russia, Sweden, Switzerland, and the United States indicate that 2018 will be the 30 th consecutive year of significant $(-200 \mathrm{~mm})$ negative global annual balance, with a mean balance of $-1247 \mathrm{~mm}$ for the 25 reporting reference glaciers, with one glacier reporting a positive mass balance (WGMS 2018). This rate of mass loss may result in 2018 surpassing 2003 $(-1246 \mathrm{~mm})$ as the year of maximum mean observed loss. Global annual balance is calculated using a simple, single averaged value for each of 19 mountain regions to avoid bias from well-observed regions.

The cumulative mass balance from 1980 to 2018 is $-21.7 \mathrm{~m}$ (Fig. 2.14), the equivalent of cutting a $24-\mathrm{m}$ thick slice off the top of the average glacier. The trend is remarkably consistent across regions (WGMS 2017). The WGMS mass balance from 42 reference glaciers has close to the same value as from all glaciers $(-21.5 \mathrm{~m})$. The decadal mean annual mass balance was $-228 \mathrm{~mm} \mathrm{yr}^{-1}$ in the $1980 \mathrm{~s},-443 \mathrm{~mm} \mathrm{yr}^{-1}$ in the $1990 \mathrm{~s},-676 \mathrm{~mm} \mathrm{yr}^{-1}$ for the 2000s, and $-921 \mathrm{~mm} \mathrm{yr}^{-1}$ for 2010-18. Glacier retreat reflects sustained negative mass balances over the last 30 years (Zemp et al. 2015). The increasing rate of glacier mass loss during a period of retreat indicates that alpine glaciers are not approaching equilibrium and retreat will continue to be the dominant terminus response (Pelto 2018).

Exceptional glacier melt occurred across the European Alps, leading to high snowlines and contributing to large negative mass balance. In the European Alps, annual mass balance was reported from 17 glaciers in Austria, France, Italy, and Switzerland. All had negative annual balances, with 15 exceeding -1000 $\mathrm{mm}$ and a mean of $-1640 \mathrm{~mm}$. This continues the pattern of substantial negative balances in the Alps, which may equate to further terminus retreat. Of 81 observed glaciers in 2017 in Switzerland, 80 retreated and one was stable (Huss et al. 2018). In 2017, 83 gla- 


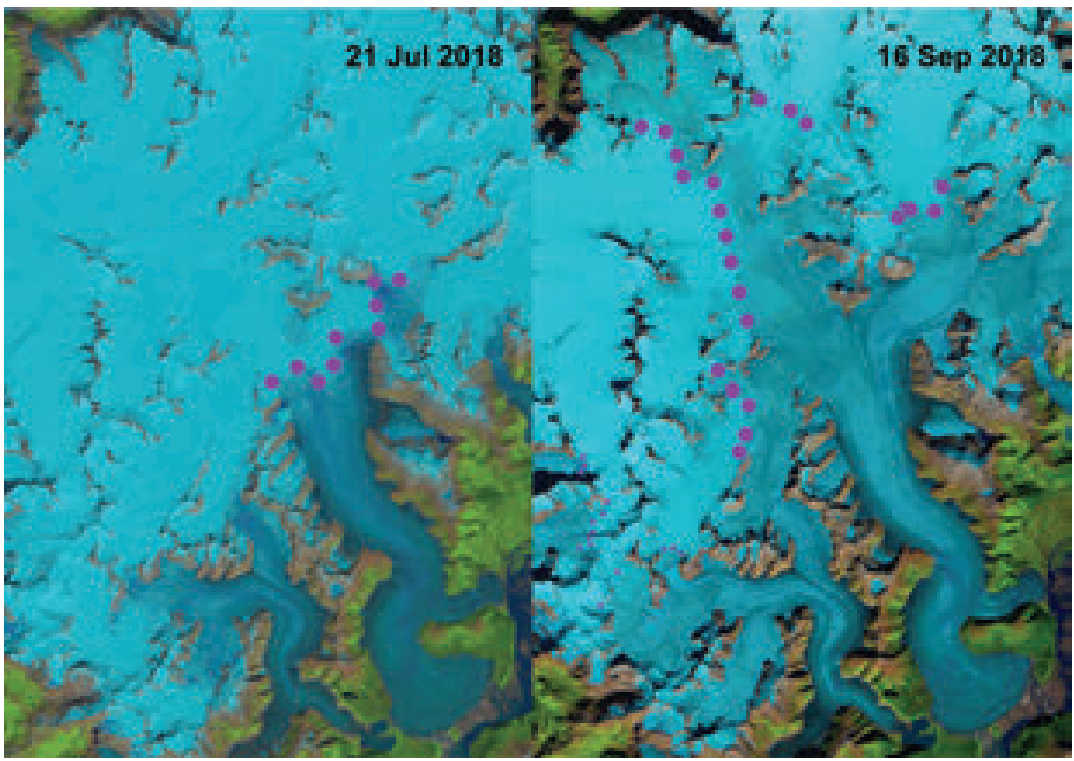

FIG. 2.I5. Landsat 8 images from 21 Jul 2018 (left) and 16 Sep 2018 (right) illustrating the Taku Glacier transient snowline. The 21 Jul snowline is at $975 \mathrm{~m}$ and the 16 Sep snowline is at $1400 \mathrm{~m}$. Average end-of-summer snowline is $975 \mathrm{~m}$; the 2018 end-of-summer snowline was the highest observed in the 73-year record.

ciers were observed in Austria: 82 retreated and one was stable. Mean terminus retreat was $25 \mathrm{~m}$, the highest observed since 1960, when mean length change reporting began (Lieb and Kellerer-Pirklbauer 2018).

In Norway and Sweden, mass balance surveys with completed results are available for eight glaciers; all had negative mass balances with an average loss of $-1420 \mathrm{~mm}$ water equivalent. All 25 glaciers with terminus observations during the 2007-17 period have retreated (Kjøllmoen et al. 2018).

Data from all 11 glaciers in Alaska and Washington in the United States indicate negative mass balances, with a mean loss of $-870 \mathrm{~mm}$. The longest mass balance record in North America is from Taku Glacier (Alaska, Fig. 2.15). In 2018, this glacier had its most negative mass balance since the beginning of its record in 1946, along with its highest end-of-summer snowline elevation at $1400 \mathrm{~m}$. The North Cascade Range (Washington) from 2014-18 had its most negative five-year value in the 39 -year WGMS record.

In the high mountains of Asia, data were reported from ten glaciers in China, Kazakhstan, Kyrgyzstan, and Nepal. Nine of the ten had negative balances with a mean of $-710 \mathrm{~mm}$. This is a continuation of regional mass loss that has driven thinning and a slowdown in glacier movement in 9 of 11 regions there from 2000 to 2017 (Dehecq et al. 2019).

Marzeion et al. (2017) compared WGMS direct observations of mass balance to remote sensing mass balance calculations and climate-driven mass balance model results. They found that each method yields reconcilable estimates relative to each other and fall within their respective uncertainty margins. Ongoing global glacier retreat is affecting human society by increasing the rate of sea level rise, changing seasonal stream runoff, and increasing geo-hazard potential, e.g., landslides and glacier lake floods (Huss et al. 2017).

\section{d. Hydrological cycle}

I) SURFACE HUMIDITY -K. M. Willett, D. I. Berry, M. G. Bosilovich, and A. J. Simmons

Surface specific humidity decreased slightly from its 2016 peak but remained well above average over both land and ocean in 2018 (all datasets adjusted to a 1979-2003 common averaging period). Meanwhile, $\mathrm{RH}$ remained well below average over land and close to average over oceans. The new ERA5 (C3S 2017; Hersbach et al. 2019) reanalysis and in situ-based HadISDH.marine surface humidity (Willett et al. 2018, manuscript submitted to Earth Syst. Sci. Data) monitoring products are now available and presented here for the first time. Both deliver results consistent with established products used to monitor specific humidity. For RH, there is more diversity between the reanalyses themselves and hence between the reanalyses and in situ products.

Following the strong El Niño that ended in 2016, and with mostly La Niña or neutral conditions throughout 2018, the drier air compared to 2016 and 2017 was largely expected (Fig. 2.16). This is reflected in the specific humidity over both land and ocean while RH over land is lower than 2016 but close to 2017. Over land, the more limited spatial coverage (mostly NH) of HadISDH compared to the reanalyses clearly makes a difference (Plates 2.1g,h; Online Figs. S2.13, S2.14). The HadISDH-masked series of ERA5 (Fig. 2.16e) shows lower $2018 \mathrm{RH}$ than in 2017, whereas the full coverage ERA5, ERA-Interim, and JRA-55 2018 values (Fig. 2.16f) are similar to or slightly above 2017 values. RH over oceans has increased slightly since $2014-15$, but 2018 values remained close to those recorded in 2017. This result was seen in the in situ products, including the HadISDH, as well as the reanalysis datasets (except ERA-Interim). 


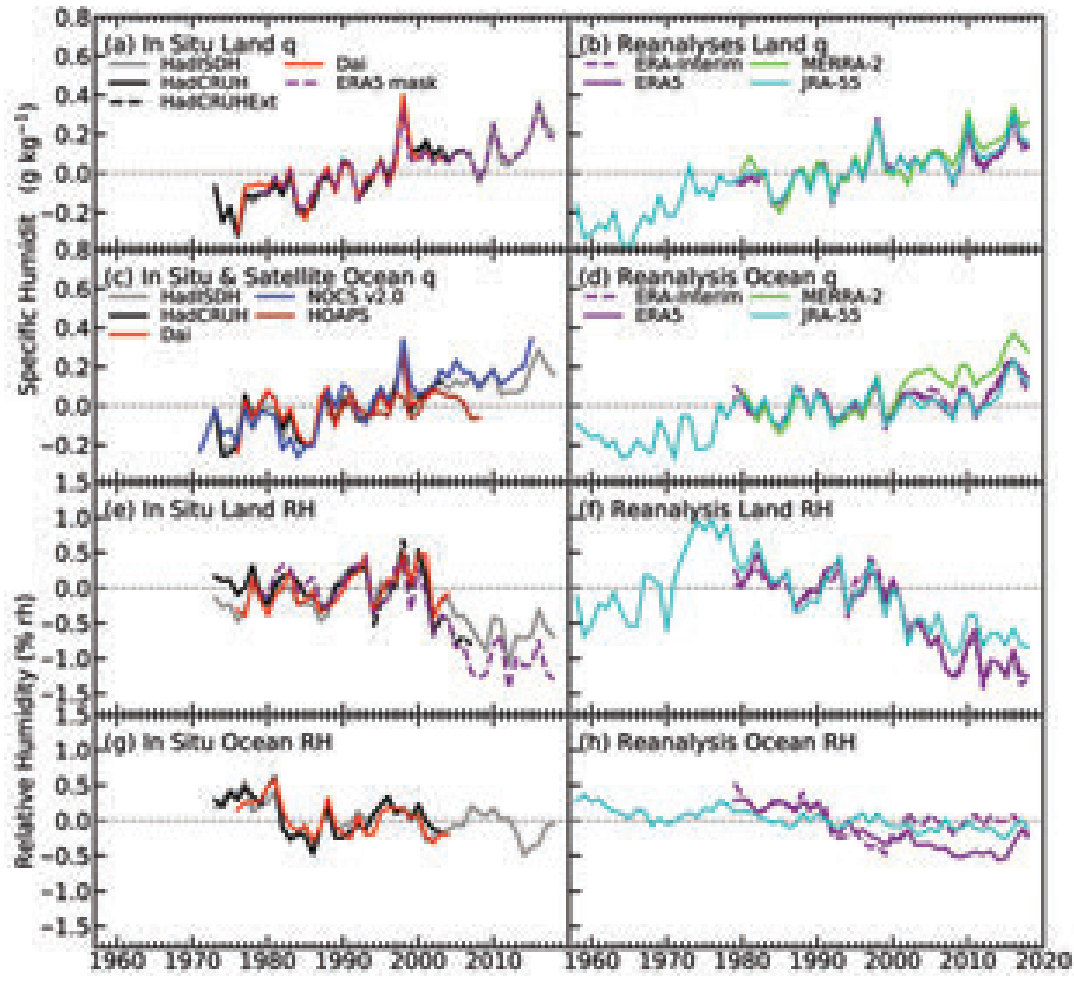

FIG. 2.16. Global average surface humidity annual anomalies (1979-2003 base period). For the in situ datasets, 2-m surface humidity is used over land and $\sim 10-\mathrm{m}$ over the oceans. For the reanalysis, 2-m humidity is used over the whole globe. For the ERA-Interim and ERA5 ocean series, only points over open sea are selected. For ERA-Interim, background forecast values are used as opposed to analysis values because of unreliable use of ship data in producing the analysis. Analysis values over sea are by design equal to background values in ERA5. All data have been adjusted to have a mean of zero over the common period 1979-2003 to allow direct comparison, with HOAPS given a zero mean over the 1988-2003 period. [Sources: HadISDH (Willett et al. 2013; 2014; 2018, manuscript submitted to Earth Syst. Sci. Data); HadCRUH (Willett et al. 2008); Dai (Dai 2006); HadCRUHext (Simmons et al. 20I0); NOCSv2.0 (Berry and Kent 2009, 20II); HOAPS (Fennig et al. 20I2), ERA-Interim (Dee et al. 20II), ERA5 (C3S 20I7, Hersbach et al. 2019), JRA-55 (Ebita et al. 20II) and MERRA-2 (Gelaro et al. 20I7).]

space and time (Willett et al. 2013; 2014; 2018, manuscript submitted to Earth Syst. Sci. Data)

Over land regions with in situ data, spatial patterns are generally consistent in HadISDH (Plate 2.1g), ERA5 (Online Fig. S2.13), and MERRA-2 (Online Fig. S2.15) for specific humidity. Western Europe, the Arabian Gulf region, and northern Africa had widespread and strong positive anomalies in 2018. Drier, negative anomalies were strong and widespread over northern North America (excluding Alaska), southern Africa, and central-eastern Australia. Regions of disagreement include India, where ERA5 and HadISDH show positive anomalies but MERRA-2 shows a patch of negative anomalies; western Asia, where negative anomalies are weaker and less widespread in MERRA-2; and eastern Brazil where ERA5 shows positive anomalies but MERRA-2 and HadISDH show negative anomalies. Over oceans, the limited spatial coverage provided by ship data is clear in $\mathrm{HadISDH}$ (Plate 2.1g) and there are larger differences between HadISDH and the reanalyses. Dry anomalies over the North and central Atlantic are common features.

Similarly, RH over the land regions with in situ data are mostly

Over land, the HadISDH-masked values of ERA5 are almost identical to those of HadISDH for specific humidity but show a greater decline in $\mathrm{RH}$ (Figs. 2.16a,e). The differences between the masked and unmasked versions highlight that spatial coverage is a large source of uncertainty. Note that where there are no values for HadISDH, there are likely few or no in situ observations assimilated into the reanalyses, so model uncertainty may play a larger role here than it does elsewhere. Other sources of uncertainty include instrument measurement ability; representativeness of the climatological values used to create anomalies, given missing data over time; adjustments used to account for biases in the data and detectability of those biases; and gridbox sampling uncertainty due to uneven and sparse observations in spatially consistent between HadISDH (Plate 2.1h) and ERA5 (Online Fig. S2.14). Generally, dry anomalies were more widespread than in 2017, with northern Europe moving from positive to negative anomalies. However, Brazil, along with northern Africa, the Arabian Gulf region, and southern Europe, was more positive/less negative than in 2017, consistent with the widespread positive specific humidity anomalies there. Over oceans, HadISDH and ERA5 show different patterns.

Of note, ERA5 will replace ERA-Interim as of next year's State of the Climate report. ERA5 offers significant improvements in temporal consistency and the quantity of observations assimilated. There is close agreement with ERA-Interim, but ocean RH diverges from around 2000. HadISDH.marine significantly 
improves monitoring capability of surface humidity over ocean and is the only regularly updated, in situ-only monitoring product. It uses weather observations from ships that have been quality controlled and bias adjusted for changes in ship height over time and different instrument types. However, spatial coverage is limited, so there is large uncertainty in global average values. Nevertheless, good, broad agreement has been shown between this new product and the reanalyses for specific humidity. $\mathrm{RH}$ is more sensitive to the choice of product.

2) Total column water vapor-C. Mears, S. P. Ho, 0. Bock, X. Zhou, and J. Nicolas

In 2018, total column water vapor (TCWV) remained below the record levels observed in 2016, but above the 1981-2010 climatological average in most monitoring products and most locations (Fig. 2.17, Plate 2.1i). Estimates of TCWV are available from satellite-borne microwave radiometers (MW) over ocean (Mears et al. 2018), reanalyses and COSMIC

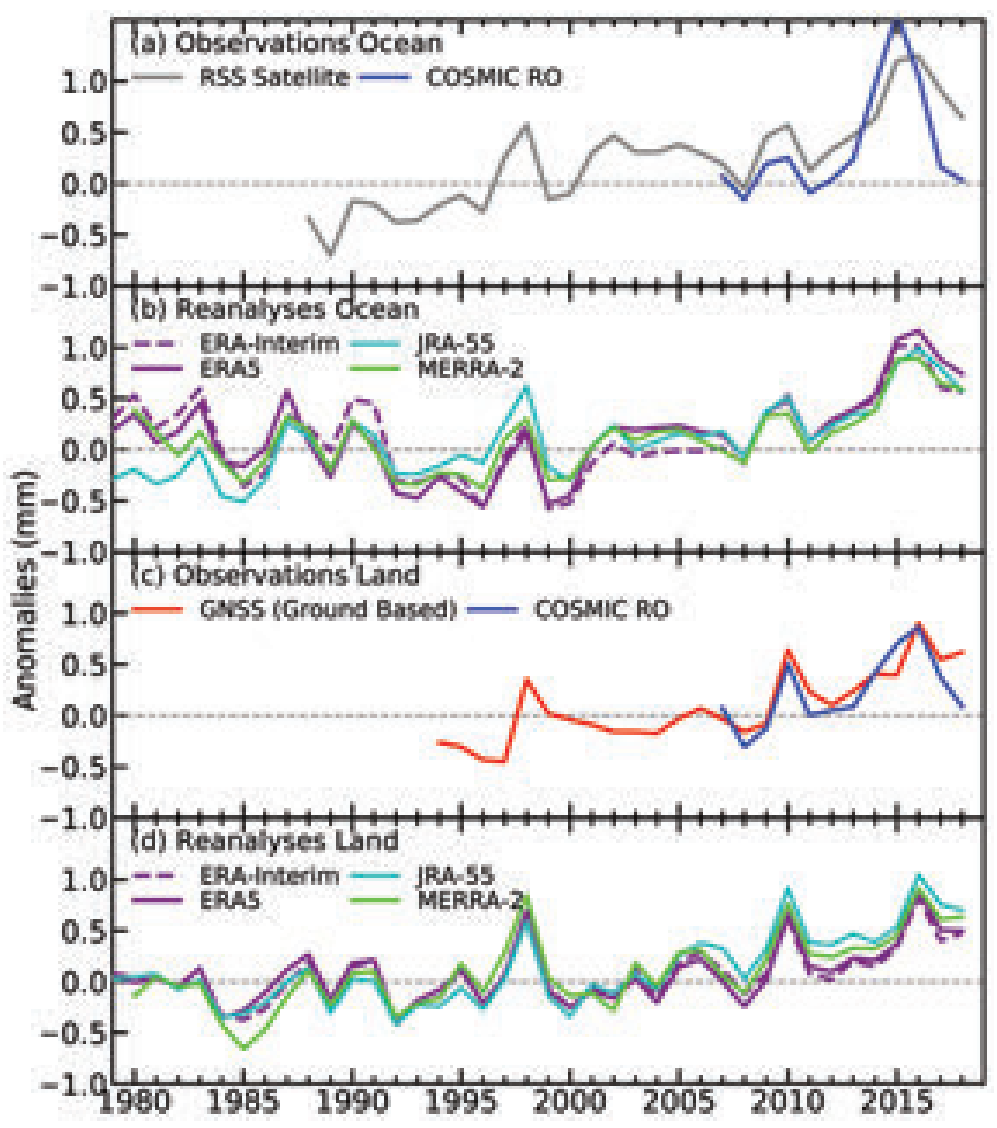

Fig. 2.17. Global mean total column water vapor annual anomalies $(\mathrm{mm})$ for (a), (b) ocean only and (c), (d) land only for observations and reanalysis (see Fig. 2.16 for reanalysis references) averaged over $60^{\circ} \mathrm{N}-60^{\circ} \mathrm{S}$. The shorter time observational series have been adjusted so that there is zero mean difference relative to the ERA5 results during their respective periods of record.
Global Positioning System-Radio Occultation (COSMIC GPS-RO) over land and ocean (Ho et al. 2010a,b; Teng et al. 2013; Huang et al. 2013), and ground-based Global Navigation Satellite System (GNSS) stations over land (Bock and Parracho 2019).

A large, wet anomaly was present in the tropical Pacific north of the equator, and a dry anomaly of roughly equal strength was present south of the equator. There were also wet anomalies over the southeastern United States, northern Africa, and most of Europe. Other regions showed a mix of smaller wet and dry anomalies, with more regions wetter than drier relative to the 1981-2010 normal. The patterns in TCWV over the ocean are similar between ERA5 and MW data (Plate 2.1i; Online Fig S2.16), confirmed by COSMIC ocean measurements (Fig. 2.17) and by output from MERRA-2, ERA-Interim, and JRA-55 reanalyses (not shown). Over land, the patterns from COSMIC show some of the same general patterns as the reanalysis output but are limited by sampling uncertainty, because only one of the original six COSMIC satellites was still producing data near the end of 2018. A COSMIC follow-on mission, COSMIC-2, is scheduled to be launched in 2019, which will collect more samples ( 6000 per day) than COSMIC. Samples will be collected over the tropics and subtropics. The ground-based GNSS results are in good agreement with reanalysis.

Over the ocean, the TCWV anomaly time series (Fig. 2.17) from reanalysis and microwave radiometers show maxima in 1982/83, 1987/88, 1997/98, 2009/10, and 2015/16 associated with El Niño events. The 2015/16 anomaly is the largest recorded in all datasets. The radiometer data show a discernible increasing trend over their period of record, while the different reanalysis products show a wide range of long-term trends over the entire period but agree well with the radiometer data after the mid-1990s. The COSMIC data are in relative agreement with both the radiometer and reanalysis data after COSMIC began in 2006. The TCWV is strongly driven by ENSO conditions and to a lesser extent by stratospheric aerosols from volcanic eruptions. After the 2015/16 El Niño peak, all datasets show a recovery to drier conditions due to a weak La Niña at the end of 2017 into early 2018. Monthly time series (not 


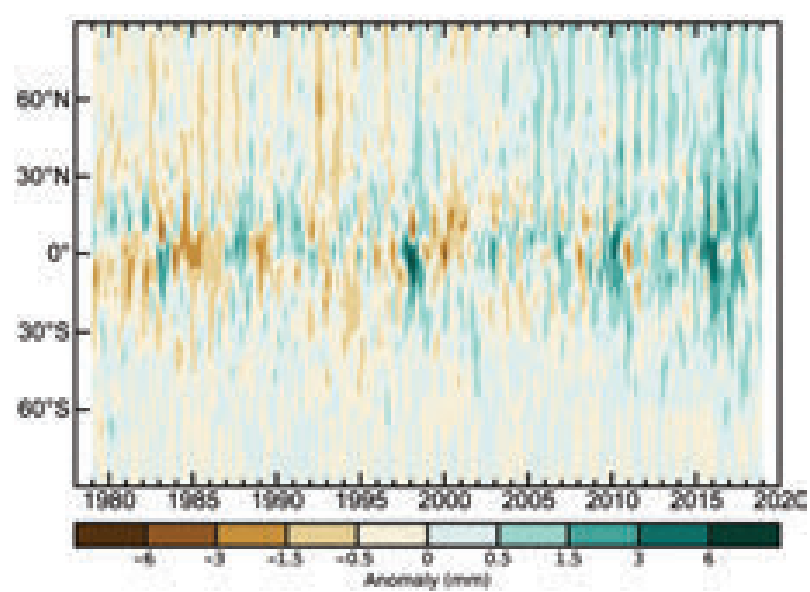

FIG. 2.18. Hovmöller plot of TCWV anomalies $(\mathrm{mm}$; base period 198I-2010) including both land and ocean derived from the JRA-55 reanalysis.

shown) indicate an increase over the oceans in late 2018, possibly due to the onset of a weak El Niño in winter-spring 2018/19.

Over land, the various reanalysis products, COSMIC, and GNSS are in good agreement (Fig. 2.17). The small differences in GNSS anomalies are due to an asymmetry in the spatial sampling (more stations are located in the $\mathrm{NH}$ ), but the general trend and interannual variability are well observed. Landand-ocean Hovmöller plots derived from JRA-55 and ERA5 (Fig. 2.18, Online Fig. S2.17) indicate that the long-term increase in TCWV is occurring at all latitudes, with less variability outside the tropics. Previous strong El Niños (1982/83, 1997/98) showed pronounced drying events in the years following, which is not seen to the same degree after the 2015/16 event in the reanalyses (Fig. 2.17). The level of drying varies across monitoring products, with the strongest drying shown by COSMIC (land and ocean).

3) UPPER TROPOSPHERIC HUMIDITY - V. 0. John, L. Shi, E.-S. Chung, R. P. Allan, S. A. Buehler, and B. J. Soden

Global-average upper tropospheric (relative) humidity (UTH) in 2018 was close to the 2001-10 average, with global anomalies changing from negative to positive in the second half of 2018 (Fig. 2.19). This reflects the shift to weak El Niño-like conditions in the latter part of the year. A near-zero decadal trend in the UTH, as has generally been the case, requires an increase in absolute (specific) humidity commensurate with the warming upper troposphere (Section 2b3) and hence is consistent with a positive water vapor feedback (Chung et al. 2016). There is broad agreement among the datasets in the interannual variability, despite their structural differences: ERA5 samples all regions and hours but only at $400 \mathrm{hPa}$,

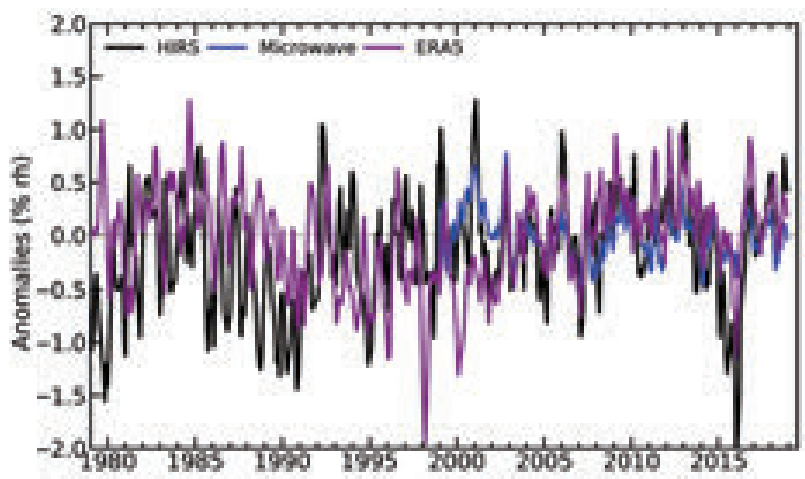

FIG. 2.19. Global $\left(60^{\circ} \mathrm{N}-60^{\circ} \mathrm{S}\right)$ average time series of UTH anomalies (\%) using HIRS (black), microwave (blue), and ERA5 (purple) datasets. Anomalies are computed with respect to the 200I-10 average, and the time series are smoothed to remove variability on time scales shorter than three months.

satellite data sample a broader upper tropospheric region a few times per day, and infrared observations only sample clear-sky scenes (John et al. 2011). Agreement among the diverse datasets provides confidence in the observed long-term behavior of UTH. The long-term mean and standard deviation of the anomaly time-series are $-0.15 \% \pm 0.70 \%,-0.03 \% \pm$ $0.59 \%$, and $0.00 \% \pm 0.34 \% \mathrm{RH}$ for the HIRS, ERA 5 , and microwave datasets, respectively. Compared to its previous version (ERA-Interim), the ERA5 time series shows improved consistency with the satellite datasets, although it appears to underestimate mean UTH by around 1\% RH during early 1998 and early 2000 with respect to the HIRS dataset.

Annual anomalies of UTH for 2018 are shown in Plate 2.1j and Online Fig S2.18 for the microwave and HIRS datasets, respectively. Positive anomalies in the (subtropical) central and eastern Pacific and negative anomalies over the Maritime Continent are indicative of the weak El Niño conditions. Positive anomalies over East Africa coincide with severe floods that occurred in that region (see Section 7e3), while negative anomalies over Australia reflect the drought conditions experienced there during 2018 (see Section $7 \mathrm{~h} 4$ ). These features demonstrate the close connection between convection and UTH on seasonal or longer time scales (as can also be seen from Plate $2.1 \mathrm{k}$ showing precipitation anomalies in 2018) and the usefulness of UTH for monitoring large-scale dynamics of the atmosphere. Note that the absolute amount of water vapor in the upper troposphere is significantly less than the amount of water vapor in the boundary layer. Despite this, UTH contributes a major part to the feedbacks present in the climate system (Held and Soden 2000). This is due to its radiative effect that is proportional to relative changes in water vapor, and relative changes in 
UTH in the upper troposphere are larger than relative changes in water vapor in the lower troposphere and at the surface (John and Soden 2007).

UTH has been monitored by two satellite-based datasets: an infrared radiances product HIRS from 1979 onward (Shi and Bates 2011), and a shorter microwave radiances-based product beginning in 1999 (Chung et al. 2013). Here, UTH represents a layer roughly between $500 \mathrm{hPa}$ and $200 \mathrm{hPa}$, using the Jacobian weighted average of $\mathrm{RH}$ with respect to water. The layer varies slightly depending on the atmospheric humidity profile. Bias corrections and intersatellite calibration have been applied to create the datasets. This year, a model-based reanalysis dataset ERA5 (Hersbach et al. 2019) is included. Although the full vertical $\mathrm{RH}$ profile is available from ERA5, only $400-\mathrm{hPa} \mathrm{RH}$ is used here to represent UTH. RH in ERA5 is defined as a mixed water/ice $\mathrm{RH}$ : with respect to water for temperatures higher than $0^{\circ} \mathrm{C}$, with respect to ice for temperatures colder than $-23^{\circ} \mathrm{C}$, and a quadratic interpolation of the two in the $0^{\circ} \mathrm{C}$ to $-23^{\circ} \mathrm{C}$ temperature range.

4) Precipitation - R. S. Vose, R. Adler, G. Gu, A. Becker,
Precipitation over global land areas in 2018 , as estimated from six different monitoring products, ranged from near $(-5 \mathrm{~mm})$ to well above $(+78 \mathrm{~mm})$ the 1981-2010 longterm average (Fig. 2.20a). Compared with most years in the historical record, there was a particularly wide range of estimates across the available analyses in 2018. The observational datasets with the most complete global coverage, that is, the gauge-based product from the Global Precipitation Climatology Centre (GPCC; Becker et al. 2013) and the blended gauge-satellite product from the GPCP (Adler et al. 2018), both depict 2018 as near-normal (about $1 \mathrm{~mm}$ above and $5 \mathrm{~mm}$ below, respectively). The ERA-Interim reanalysis (Dee et al. 2011) is generally in agreement with GPCC and GPCP, with an annual anomaly about $1 \mathrm{~mm}$ below average. In contrast, the operational version of the gauge-based Global Historical Climatology Network (GHCNv2; Peterson and Vose 1996) dataset is much wetter, with an anomaly of about $40 \mathrm{~mm}$, while a new experimental version (exp) of GHCN (with five times as many stations) has an even larger anomaly of about $78 \mathrm{~mm}$, implying 2018 was the wettest year in the satellite era. MERRA-2 (Reichle et al. 2017a) reanalysis is quasi-consistent with the GHCN datasets, with an annual anomaly of about $45 \mathrm{~mm}$. All except GHCN (exp) place 2018 as drier than 2017, which was generally a local peak. Precipitation over global oceans (Fig. 2.20b) from the satellite component of the GPCP dataset estimates 2018 as slightly below the 1979-2017 average, continuing the drop from the El Niño-boosted peak of 2015/16.

To put 2018 in context, Fig. 2.20c shows the annual GPCP anomaly of the global total (plus land and ocean separately) from 1979 to 2018 , including annual mean values for Niño-3.4 as a measure of ENSO for comparison. The ocean and land values "flip-flop" between El Niño and La Niña years, with the global total value having smaller year-to-year variations, although larger during El Niño years (e.g., 1998, 2010, 2015/16). The evolution during 2018 of a weak La Niña, via neutral conditions to a weak El Niño produces a neutral annual mean Niño-3.4 index.

According to GPCP, much of Africa and Eurasia were wetter than normal in 2018, as were significant portions of South America and eastern North America (Plate 2.1k). Australia had the largest spatial extent of below-normal precipitation, with smaller

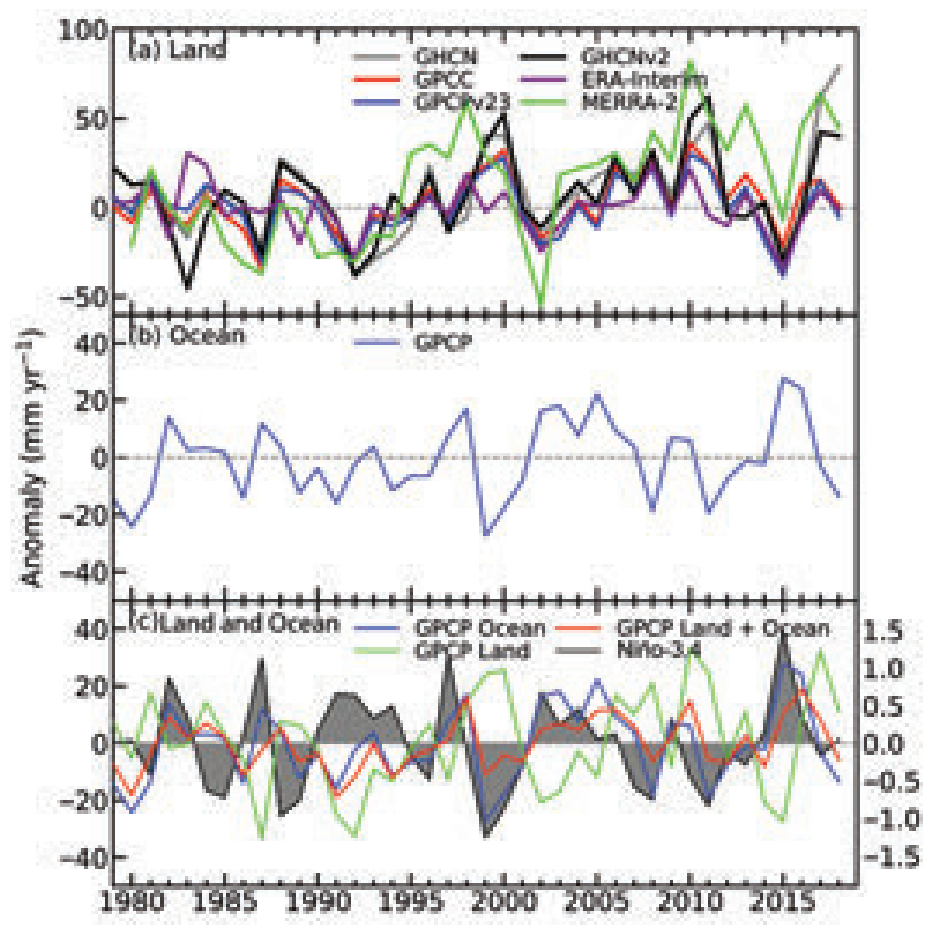

FIG. 2.20. Globally averaged precipitation anomalies $\left(\mathrm{mm} \mathrm{yr}^{-1}\right)$ relative to the 198I-2010 base period over (a) land areas; (b) ocean areas; and (c) GPCP land, ocean, and combined time series overlaid with the Niño-3.4 index (right axis). Land time series for panel (a) were created using a proportional land/sea mask at the $1^{\circ} \times 1^{\circ}$ scale whereas ocean and land time series for panels (b) and (c) were created using a proportional land $/ \mathrm{sea}$ mask at the $2.5^{\circ} \times 2.5^{\circ} \mathrm{scale}$. 
areas such as Central America, northern Europe, and the Indian subcontinent also exhibiting drierthan-normal conditions. Much of the North Pacific Ocean and almost the entire North Atlantic Ocean were also drier than normal. The annual pattern over tropical oceans featured an apparent northward displacement of the ITCZ, that is, there was a strong positive anomaly stretching across the entire equatorial Pacific slightly north of the equator, while directly to the south of this positive anomaly was an equally deep negative anomaly that spanned almost the entire equatorial Pacific. A relatively weak negative anomaly was evident over the Maritime Continent, with a positive anomaly to the east. Many of these features were related to the ENSO variations, as indicated by the Niño-3.4 index moving from weak negative (La Niña) to weak positive (El Niño) during 2018. The biggest differences relative to 2017 were relatively wetter conditions in the equatorial North Pacific Ocean and drier in the Maritime Continent.

The variability among land precipitation products, especially in 2018, demonstrates how difficult it is to observe global average precipitation. Datasets are highly sensitive to spatial coverage of observations, the various methods used for quality control and to account for biases, averaging methods, and also the choice of land mask in the case of global products (e.g., GPCP, reanalyses). There is general agreement in the interannual and multidecadal variability, but the actual global average amount estimated on any particular year can have a wide spread.

5) LAND surface PRECiPitation extremesM. R. Tye, S. Blenkinsop, M. G. Bosilovich, M. G. Donat, I. Durre, A. J. Simmons, and M. Ziese

Precipitation extremes can have some of the greatest impacts on society. Rapid oscillations or "whiplashes" (Swain et al. 2018) from extreme low (i.e., drought, Section 2d10) to intense precipitation can exacerbate those effects. Events are often localized, short-lived, and difficult to observe with a relatively sparse network or limited high-frequency data. Hence, global analysis is less meaningful, so a more regional approach is taken here. Results are presented for a selection of precipitation extreme indices (Zhang et al. 2011; Tye et al. 2018): Rxlday, maximum 1-day precipitation total; Rx5day, maximum 5-day precipitation total; R95P, very wet days; $\mathrm{R} 10 \mathrm{~mm}$, number of heavy precipitation days; R20 mm, number of very heavy precipitation days; and PRCPTOT, total annual precipitation (see Online Table S2.1 for full definitions of ETCCDI indices referred to in this section) using data from GHCND (Menne et al. 2012),
GHCND-based GHCNDEX (Donat et al. 2013), and GPCC-First Guess Daily (Schamm et al. 2013). To expand the spatial coverage, reanalysis datasets are also employed from ERA5 (Hersbach et al. 2019) and MERRA-2 (Gelaro et al. 2017). Note that reanalyses may not fully resolve the most extreme precipitation events (Sidebar 2.1) and that their trends and anomalies may suffer from lack of homogeneity due to changes in the contributing observations.

In 2018, PRCPTOT (see also Section 2d4) exceeded the 90th percentile with respect to the 1951-2010 climatology (Plate 2.11) in many parts of North, Central, and South America, the Arabian Peninsula, Asia, and Australasia, resulting from intense individual events such as tropical cyclones or deep convective systems. Similarly, anomalous annual totals in parts of Africa arose from intense monsoonal systems over a longer period. Atmospheric river-driven floods in California and floods in Bolivia during January were unusual given the weak La Niña/neutral conditions in the first part of the year.

The 2018 cyclone season, a key driver of extreme rainfall, was unusually active in all basins (see Section $4 \mathrm{f}$ ), contributing to $35 \%$ of global damage losses (Munich Re 2019). The Atlantic season started early with Hurricane Alberto affecting the U.S. state of North Carolina in May, a region later affected by Hurricane Florence in September.

As also mentioned in Section 2d4 and Plate 2.1k, anomalies from climatology suggest a northward shift of the ITCZ with more precipitation in the second half of 2018, with Pacific Islands (e.g., Hawaii, the Philippines, and Indonesia) experiencing above-average $\mathrm{R} 10 \mathrm{~mm}$ and R20mm frequencies. Regions with high values of R95p also had high-intensity Rxlday or Rx5day events. These include the aforementioned events, as well as orographic events (e.g., Afghanistan in May), some unusual cyclone activity in the Indian Ocean (Yemen in May; Oman in October), and intense convective systems (the northwest region of the Persian Gulf in November).

Mesoscale convective systems (MCS) were particularly active in the U.S. Midwest and Atlantic Coast during 2018. Typically, MCS contribute 30\%-70\% of the seasonal precipitation in these regions, and the longer storms are responsible for most inland flooding (Feng et al. 2018). Model simulations suggest future increases in MCS frequency and intensity (Prein et al. 2017). Observations and 2018 events in spring and early summer in Maryland (United States) and surrounding states are consistent with this. Ellicott City and Catonsville, Maryland, experienced their second extreme events in 22 months, 
with a 15-h precipitation total of up to $362.67 \mathrm{~mm}$ on 27-28 May (Floodlist 2019). Several stations in these states exceeded their previous Rxlday record totals, and most were in the top five. These records were further exceeded during Hurricane Florence in August, when 17 stations reported $>250 \mathrm{~mm} \mathrm{Rx} 5$ day values, breaking their respective previous records.

Hawaii broke two records in one year from different events. A verified $1262 \mathrm{~mm}$ precipitation total was recorded at Waipā Gardens (Kauai) on 14-15 April, setting a new U.S. record for precipitation received in a 24-h period and exceeding the previous record set in 1979 at Alvin, Texas (Arndt et al. 2018). The top two Rx5day (Figs. 2.21a-d) were then observed between 22-26 August on the Big Island following Hurricane Lane. Kahuna Falls reported an Rx5day of $1475.5 \mathrm{~mm}$, while Hilo International Airport reported $953.5 \mathrm{~mm}$, its highest value in 70 vears.
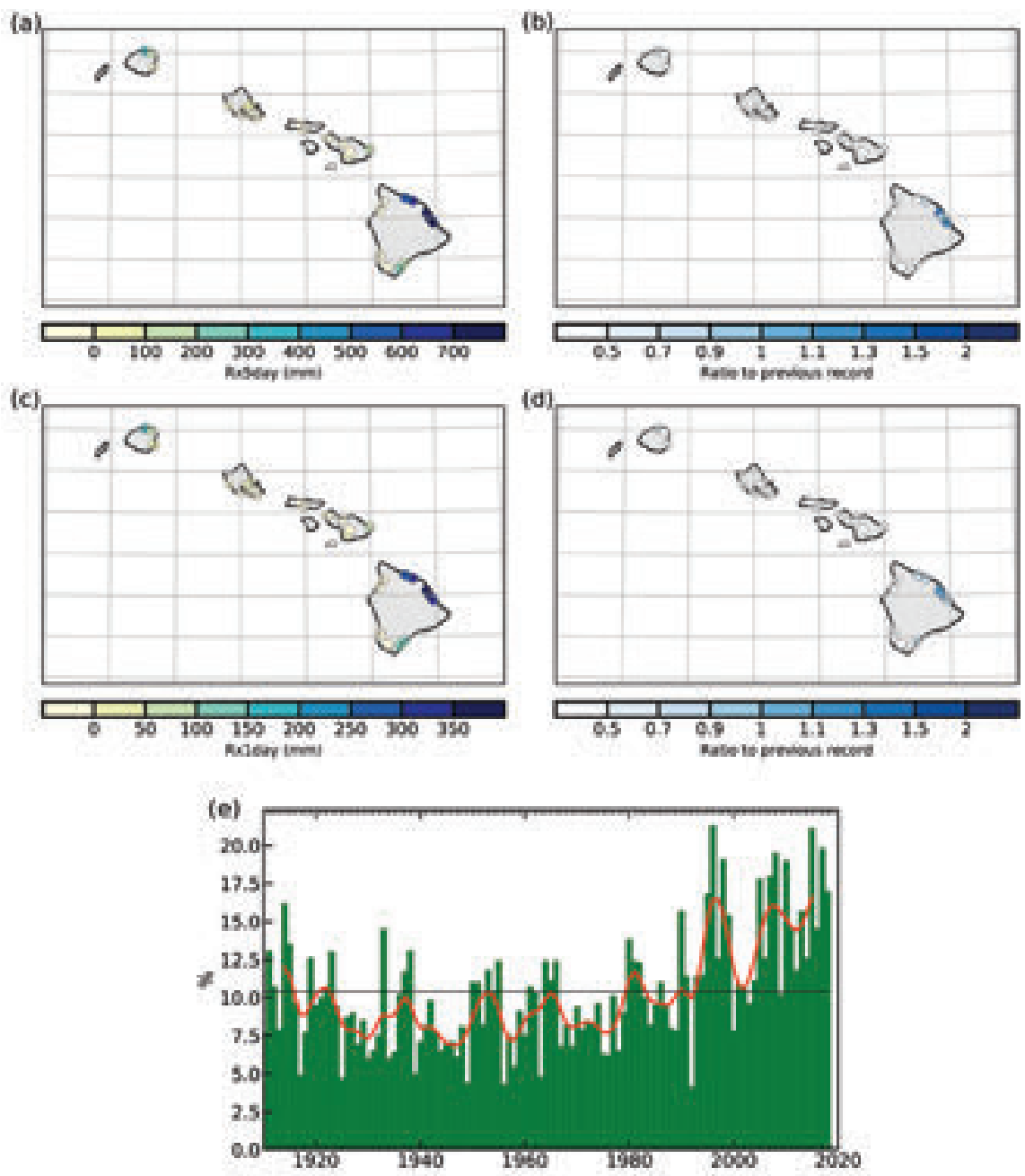

FIG. 2.2I. (a) Rx5day and (c) RxIday from GHCNDEX for Hurricane Lane over Hawaii; and (b), (d) ratios of the 2018 values to the previous maxima in the record. (e) Percentage of the contiguous United States with a much-greaterthan-normal proportion of precipitation derived from extreme (equivalent to the highest I0th percentile) I-day precipitation events (Gleason et al. 2006).

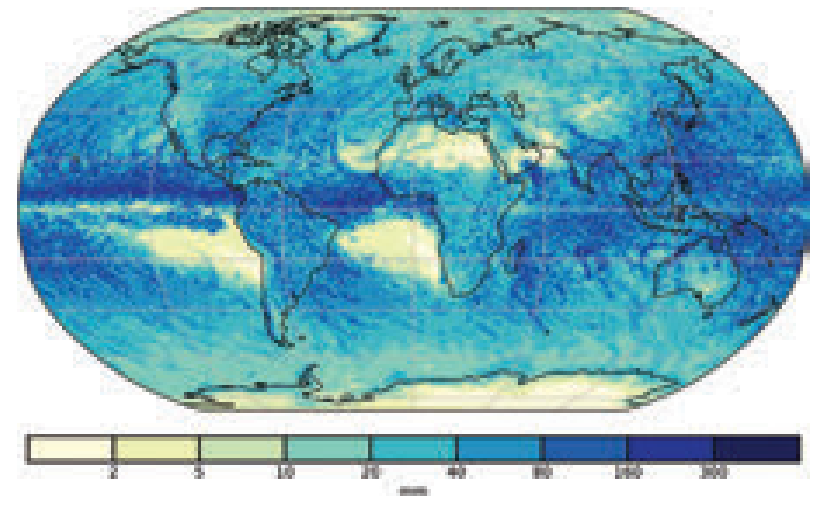

FIG. 2.22. Maximum I-day precipitation amount (RxIday, $\mathrm{mm}$ ) for 2018 from ERA5.

According to the NOAA NCEI Climate Extremes Index Component 4 (a measure of the area of the United States that experienced 1-day precipitation totals $>90$ th percentile; Gleason et al. 2008), 2018 is in the top 10 ranked years along with three other years $(2010,2015,2017)$ from the most recent decade (Online Fig S2.21e). However, droughts and wildfires were also observed elsewhere across the globe throughout the year (Munich Re 2019), which is alluded to in global plots of Rxlday (Fig. 2.22) and the anomalies with respect to 1981-2010 (Plate $2.1 \mathrm{~m})$. See Online Tables S2.2 and S2.3 for more details on notable extreme precipitation events.

There remains a need for improved monitoring of sub-daily extremes using similar indices; however the Online Supplement provides details of some notable events that were reported in 2018 that may be used as indicative intensities on these timescales. 


\section{SIDEBAR 2.I: JULY RECORD-BREAKING RAINFALL AND FLOODING IN THE MID-ATLANTIC REGION OF THE UNITED STATES FROM THE PERSPECTIVE OF REANALYSES-A. B. MARQUARDT COLLOW,}

M. G. BOSILOVICH, AND E. RUSTEMEIER

Reanalyses, such as NASA's MERRA-2 (Gelaro et al. 2017) and ECMWF's ERA5 (Hersbach et al. 2019), are valuable tools that can provide detailed information regarding both the precipitation and the synoptic setup behind extreme precipitation events. As this is the first time reanalyses have been used to evaluate precipitation in this chapter, the strengths and weaknesses of extreme precipitation in reanalyses are discussed here using the example of a multiday, extreme precipitation event that occurred in the mid-Atlantic region of the United States during the second half of July 2018. This month began relatively dry, but a mid-month shift in the large-scale circulation resulted in the wettest July on record for the state of Pennsylvania and the second wettest in Maryland. A persistent trough over the eastern half of the United States and the northwestward extension of the subtropical high over the Atlantic Ocean led to a week of rainy conditions that culminated in major flooding.

While precipitation fell in the entire mid-Atlantic region, exceptionally heavy rainfall occurred along a north-south strip through eastern-central Pennsylvania and Maryland. Figure SB2.Ia shows the spatial map of accumulated precipitation during 2I-26 July 2018 from the NOAA Climate Prediction Center's Unified Gauge-Based Analysis of Daily Precipitation (Xie et al., 2007; Chen and Xie, 2008), MERRA-2, and ERA5. For comparison, all three datasets are shown at the coarser $0.5^{\circ}$ by $0.625^{\circ}$ resolution of MERRA-2. The CPC observations indicate over $150 \mathrm{~mm}$ of precipitation fell within the region with a regional maximum of almost $280 \mathrm{~mm}$ near Harrisburg, Pennsylvania, at $40.5^{\circ} \mathrm{N}, 76.875^{\circ} \mathrm{W}$. While both MERRA-2 and ERA5 were able to capture a swath of precipitation, neither MERRA-2 nor ERA5 were able to capture that the largest accumulations fell in Pennsylvania and instead had the regional maximum near $39^{\circ} \mathrm{N}$ for ERA5 and $39.5^{\circ} \mathrm{N}$ for MERRA-2. Furthermore, MERRA-2 exaggerated the accumulation and shifted the entire swath to the southwest, while ERA5 underestimated the total precipitation, particularly in Pennsylvania. A likely explanation for this is the coarse resolution of the reanalyses and the fact that despite the assimilation of observations, precipitation within MERRA-2 and ERA5 is generated by the underlying numerical weather prediction model.

Figure SB2. Ib shows a time series of daily precipitation from observations and the reanalyses during the event for a $1^{\circ}$ grid box containing the Baltimore/ Washington International Airport (BWI). The most prolonged episode of precipitation in the region occurred in the evening and overnight hours of 21 into 22 July and resulted in the largest daily accumulation at BWI for the event as well as a new record for $2 \mathrm{I}$ July. This is also the date with the largest spread in accumulation among MERRA-2 and the individual ensemble members of ERA5. MERRA-2 and the gauge observations indicate roughly $120 \mathrm{~mm}$ of precipitation, yet the ERA5 ensemble members range from $40 \mathrm{~mm}$ to $76 \mathrm{~mm}$. Precipitation through the rest of the event tended to be more sporadic in nature, and for the most part, there was a better agreement between MERRA-2 and ERA5. However, observations show larger accumulations, particularly on 24 July. This is not surprising given that a $1^{\circ}$ box is being compared to a point observation.

Vertically integrated fluxes of atmospheric water vapor and total precipitable water vapor (TPW) in MERRA-2 and ERA5, respectively (GMAO 2015a, b; C3S 2017) indicate the presence of an atmospheric river throughout the 21-24 July period, during which GPCC's gauge-only precipitation totals indicate a wide-

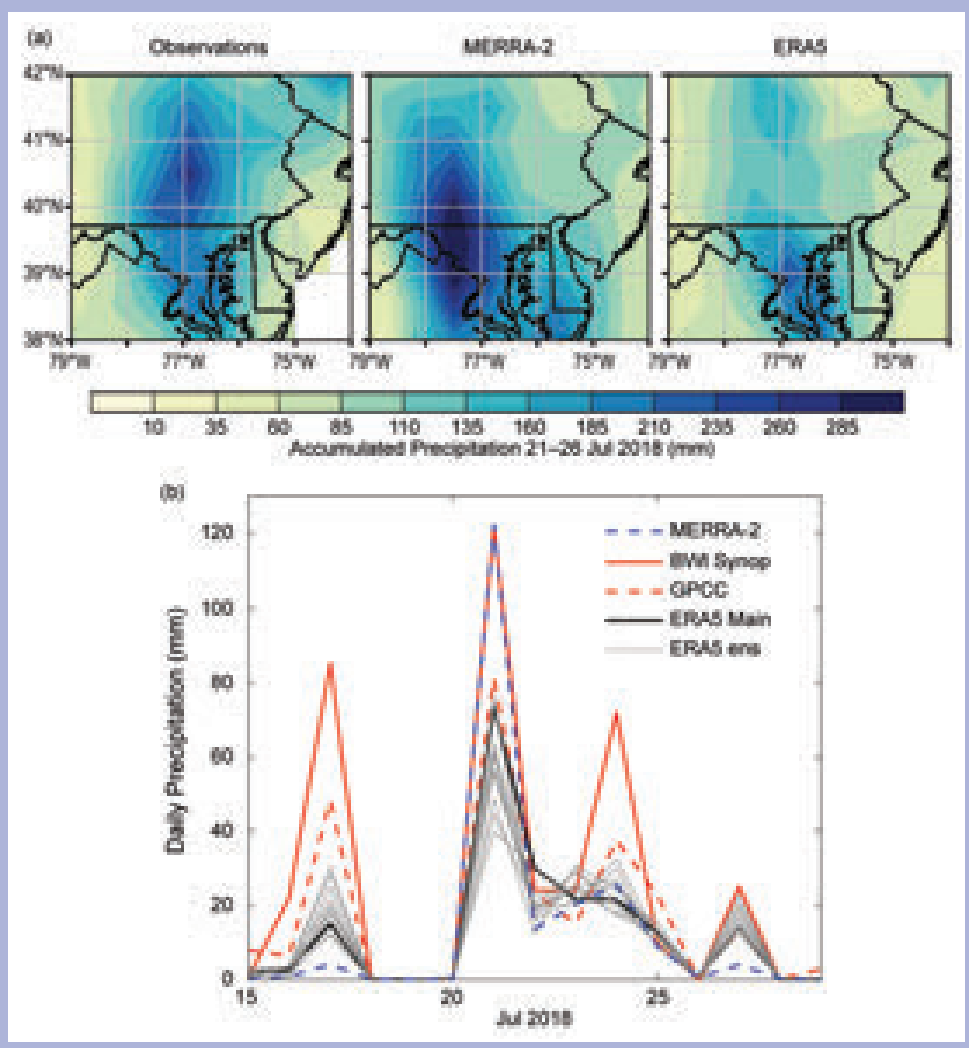

FIG. SB2.I. (a) Accumulated precipitation ( $\mathrm{mm}$ ) in the mid-Atlantic region during 21-26 Jul 2018 from the CPC Unified Gauge-Based Analysis of Daily Precipitation and ERA5 smoothed to the resolution of MERRA-2 (also shown). (b) Time series of daily precipitation $(\mathrm{mm})$ for the $I^{\circ}$ box containing BWI from MERRA-2, ERA5, GPCC (Schamm et al. 2013), and BWI synoptic gauge observations. 
spread two-fold exceedance of the monthly normal in the area. From a large-scale perspective, MERRA-2 and ERA5 agree quite well, although the magnitude of the vertically-integrated water vapor flux heading directly into the mid-Atlantic region is slightly stronger in MERRA-2. The majority of the moisture originated from the Gulf of Mexico and Gulf Stream, but moisture from the ITCZ had converged with the large-scale flow from the Gulf of Mexico two days prior (Figs. SB2.2a,b). Maximum values of the integrated water vapor flux exceeded $1000 \mathrm{~kg} \mathrm{~m}^{-3} \mathrm{~s}^{-1}$ and flowed into Maryland and southeastern Pennsylvania. Meanwhile, a low-pressure system developed over the southeast of the United States and began moving north along the East Coast, providing the synoptic forcing for the precipitation, in addition to the advection of additional moisture into the region. With an atmospheric river in place and persistent southerly flow, tropical levels of TPW remained in the region after the initial precipitation from the low-pressure system (Fig. SB2.2). On 26 July, the atmospheric river finally began to move out of the region as the subtropical high weakened and returned to a more normal state (Figs. SB2.2c, d).

Thus, in this case study, despite how well the assimilated observations constrain atmospheric moisture, uncertainty still remains regarding detailed aspects of the precipitation. Throughout the event, reasonable agreement in precipitation can be seen among the reanalyses and observations, but a lack of consistency in the individual ensemble members of ERA5 alone shows that the underlying atmospheric models struggle to faithfully reproduce the timing and location of precipitation. Further uncertainties arise when observations are incorporated into the analysis. Gauge observations (Fig. SB2.Ib for BWI) are only representative of the local area and not the coarser resolution of gridded satellite products and reanalyses. Conversely, the $I^{\circ}$ resolution of GPCC and the $0.25^{\circ}$ - and $0.5^{\circ}$-degree resolutions of
ERA5 and MERRA-2, respectively, are too coarse to highlight localized maxima within an extreme precipitation event. Regardless of the uncertainty and the source of precipitation data, reanalyses agree on the synoptic conditions that produced record-breaking precipitation across the mid-Atlantic region.

Remarkable agreement between MERRA-2 and ERA5 for TPW and the vertically integrated water vapor flux shows the usefulness of weather depictions in reanalyses. Reanalyses have strength in fields that are assimilated, such as temperature and surface pressure, and especially in regions with many observations. Surface pressure, for example, tends to have dense station networks, and the field also represents the column and the synoptic scales. Independent station comparisons to reanalysis surface pressure are highly correlated. However, physical quantities, such as precipitation, cloud fraction, and radiation, depend on the model parameterizations. These are then sensitive to the model's realization of the observational initial conditions and can change quickly in the forecast cycle. In using these quantities, the investigator should intercompare a number of reanalyses as well as available observations to ascertain the uncertainties for their time and space scale, as demonstrated in sections of this chapter.

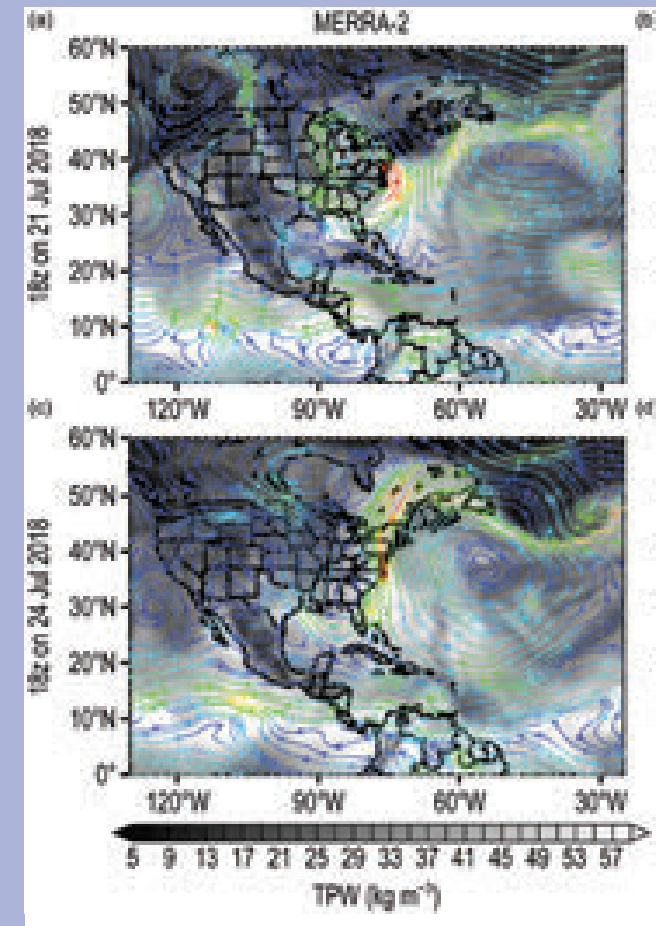

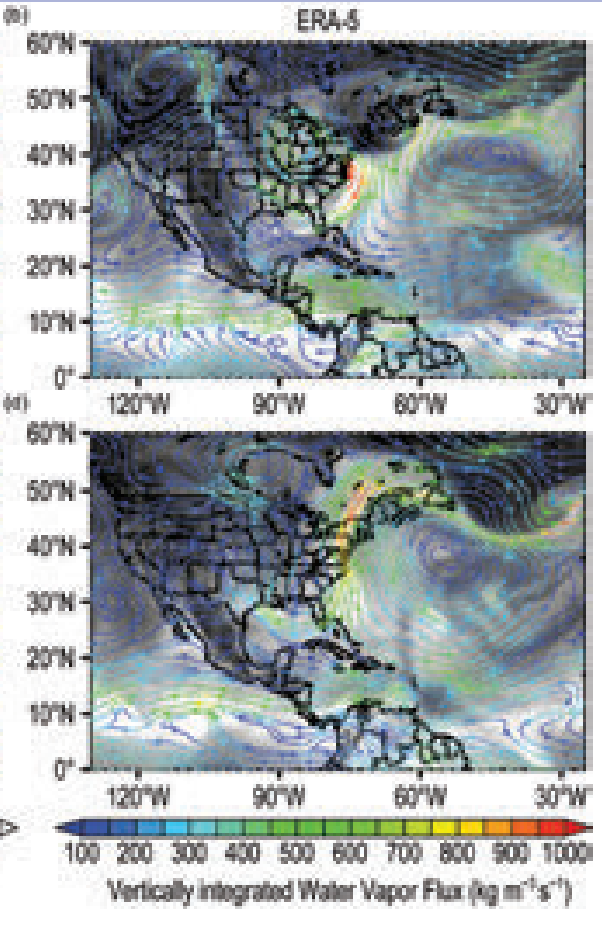

FIG. SB2.2. Total precipitable water vapor $\left(\mathrm{kg} \mathrm{m}^{-3}\right.$, gray scale shading) and the vertically integrated water vapor flux $\left(\mathrm{kg} \mathrm{m}^{-3} \mathrm{~s}^{-1}\right.$, colored streamlines) from (a), (c) MERRA-2 and (b), (d) ERA5 at $18 \mathrm{z}$ on 21 Jul 2018 and $18 \mathrm{z}$ on $24 \mathrm{Jul} 2018$, respectively. 
6) Cloudiness-M. J. Foster, L. Di Girolamo, R. A. Frey, A. K. Heidinger, S. Sun-Mack, C. Phillips, W. P. Menzel, M. Stengel, and G. Zhao

In 2018, global cloudiness increased incrementally from that of $2017(0.2 \pm 0.2 \%)$. This finding is based on several satellite cloud records including PATMOS- $\mathrm{x} /$ AVHRR (Pathfinder Atmospheres Extended/Advanced Very High Resolution Radiometer; Heidinger et al. 2013); Aqua MODIS C6 (Moderate Resolution Imaging Spectroradiometer Collection 6; Ackerman et al. 2008); CALIPSO (Cloud-Aerosol Lidar and Infrared Pathfinder Satellite Observation; Winker et al. 2007); CERES (Clouds and the Earth's Radiant Energy System; Minnis et al. 2008; Trepte et al. 2010); Aqua MODIS, CLOUD_CCI (Cloud Climate Change Initiative AVHRR-PM v3.0; Stengel et al. 2017); and PATMOS-x/ Aqua MODIS. Figure 2.23 shows global cloudiness from 1981 to present with additional records: HIRS High Cloud (High Resolution Infrared Sounder; Wylie et al. 2005; Menzel et al. 2016); CLARA-A2 (cloud, albedo and radiation dataset; Karlsson et al. 2017); and SatCORPS (satellite cloud and radiative property retrieval system; Minnis et al. 2016) that do not currently extend through 2018. Terra MISR (Multi-angle Imaging SpectroRadiometer; Di Girolamo et al. 2010) includes a mean cloudiness value for 2018 based on the first half of the year. The HIRS record is focused on detection of high cloud, thus the actual cloudiness is lower than that of the other records though its anomalies are comparable.

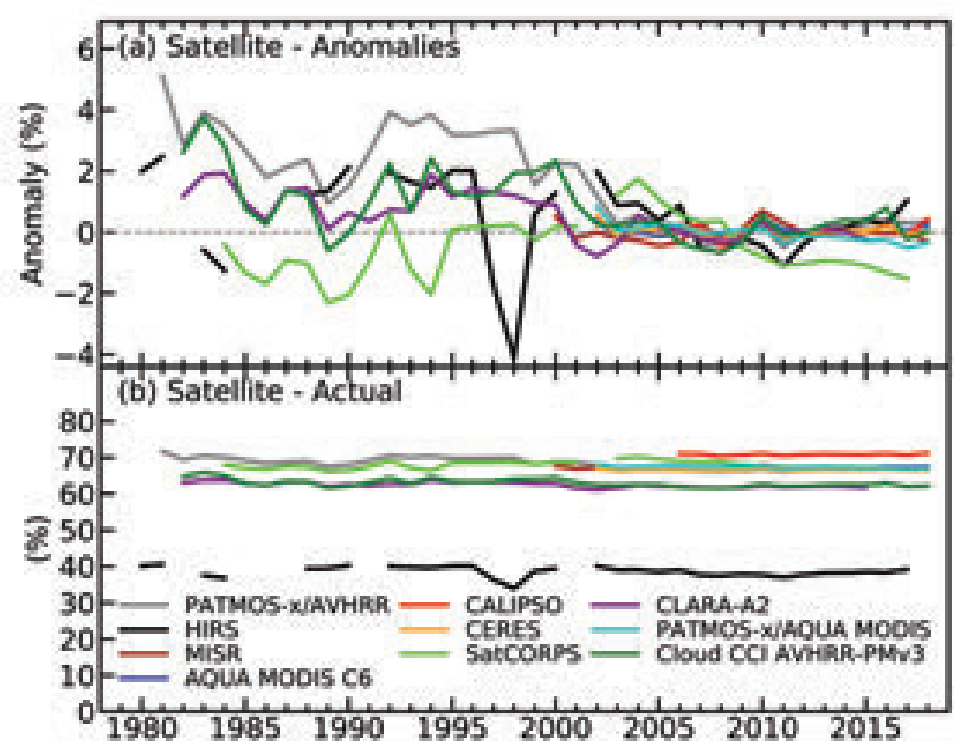

Fig. 2.23. (a) Annual global cloudiness anomalies (\%) for 1980 2018, defined as the annual value minus the mean, derived between 2003 and 2015, a period common to the satellite records excluding CALIPSO, where the entire record was used instead. (b) Annual actual global cloudiness (\%).
The small change in mean annual cloudiness from 2017 to 2018 is not surprising. While the global distribution of cloudiness can change significantly from year to year, the average annual cloudiness tends to remain relatively stable. The mean cloudiness for 1981-2018 for the PATMOS-x/AVHRR record is $68.2 \%$, while the standard deviation of the annual mean cloudiness is $1.5 \%$. For records that began more recently, this number is lower. For example, the standard deviations for the Aqua MODIS C6 and CERES Aqua MODIS records (2002-18) are both $0.2 \%$, and $0.27 \%$ for Terra MISR (2000-18). Much of the recent convergence of the records seen in Fig. 2.23 can be explained by the use of a common period (2003-16) when creating the cloudiness anomalies. However, there does seem to be greater variability in the records that extend back to the 1980s. There are instrumental reasons as to why this may be the case, because the longer records are derived from many different satellites, requiring complex inter-calibrations using independent data to reduce inconsistency (Stubenrauch et al. 2012). There were also fewer satellites to take measurements early in the record, and they tended to drift from their original orbits faster. That said, there are also physical reasons why there is more variability in the early record, such as the eruptions of El Chichón and Pinatubo and strong El Niños in the 1980s and 1990s.

Even with a relatively stable year-to-year globalaverage cloudiness, changes in geographical and inter-seasonal cloud distribution have an important effect on climate. Clouds have a dual nature in that they can both cool the planet by reflecting incoming radiation and warm it by trapping terrestrial radiation. Clouds also store and transport atmospheric water and subsequent precipitation. Therefore, clouds play an important role in modulating global energy and water budgets. In fact, cloud simulation in general circulation models is still a leading cause of divergence among climate prediction scenarios (Bony and Dufresne 2005; Boucher et al. 2014; Klein et al. 2017; Zelinka et al. 2016).

In 2018 , there were several statistically significant cloud anomalies, defined as when measured cloudiness, averaged over the year, falls more than two standard deviations outside the mean as determined from the PATMOS- $x$ /AVHRR climatology (1981-2010). These anomalies covered a little over $9 \%$ of the globe. Positive anomalies (more cloudy) covered parts of central 
and northern Africa (Plate 2.1n). To be statistically significant, the cloudiness anomaly typically must persist for several months. In this case, anomalies were weak in the boreal spring but otherwise present throughout most of the year (Fig. 2.24). Northern Europe experienced negative anomalies (less cloudy) that were strongest in the boreal autumn but persisted throughout much of the year. A negative anomaly also occurred in eastern Europe, although unlike northern Europe, it was strongest in boreal spring. Continental cloudiness anomalies are important because negative anomalies frequently coincide with warm and dry conditions, while positive anomalies coincide with cool and wet conditions. In this case, many of the European anomalies coincided with much-warmerthan-average conditions.

Frequently, anomalies seen over the Pacific Ocean correspond with large-scale circulation patterns characteristic of ENSO. Gradients in SST and lowlevel wind between the central equatorial Pacific and Indonesia can enhance or suppress convection, which in turn affects global cloudiness. This can be seen in Online Fig. S2.19, where equatorial positive and negative cloudiness anomalies correspond to $\mathrm{El}$ Niño and La Niña in the PATMOS-x/AVHRR record. In 2018, the ENSO index began weakly negative (La Niña) and rose through the year (Wolter and Timlin 1998). In the early part of the year, negative cloud anomalies existed over the equatorial Pacific while positive anomalies existed over the north-central Pacific near the Hawaiian Islands (which experienced
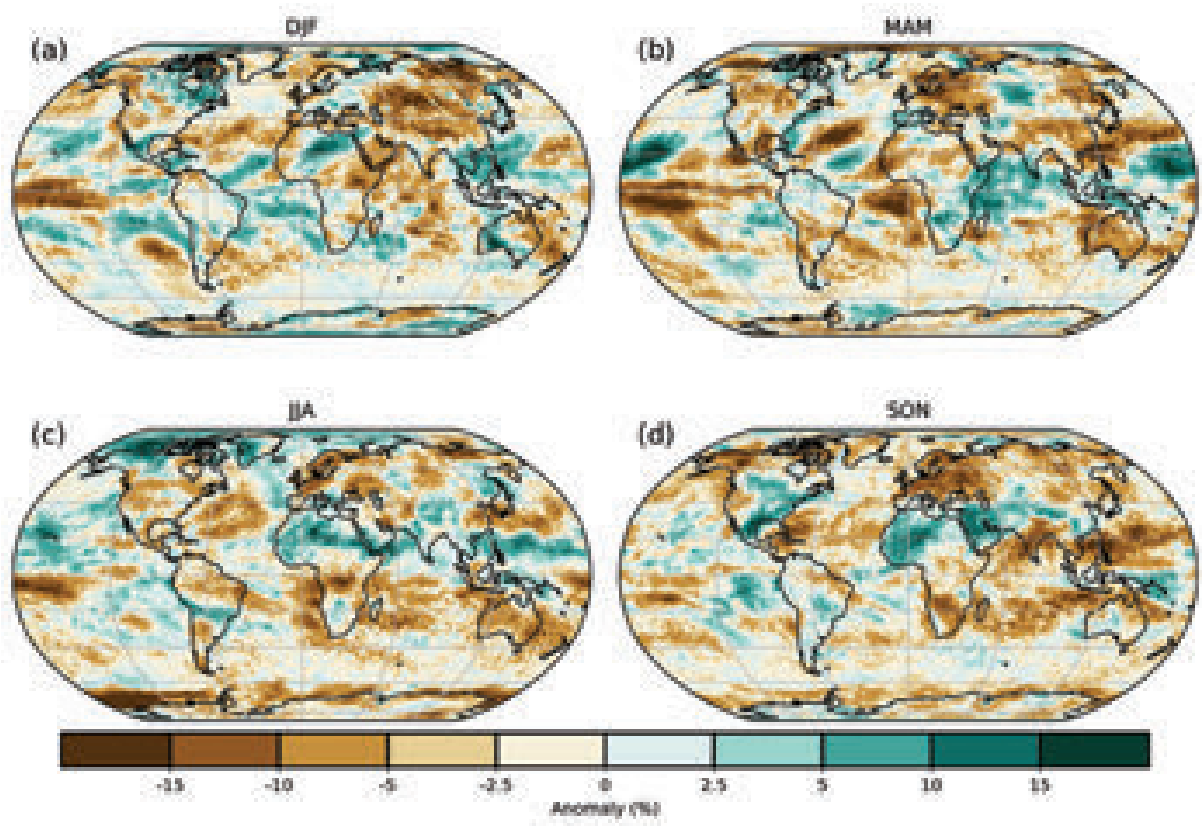

FIG. 2.24. Global seasonal cloudiness anomalies (\% relative to I98I-20I0) for 2018 from the PATMOS-x/AVHRR cloud climatology. above-average precipitation at this time), forming a north-south dipole. These conditions peaked in the boreal spring and persisted through summer to reach statistical significance for the year (Fig. 2.24). Other significant maritime negative anomalies occurred over the North Atlantic, the western Pacific, and the South Indian Oceans (see ITCZ discussion in Sections $2 \mathrm{~d} 4$ and $2 \mathrm{~d} 5$ ).

\section{7) RIVER DISCHARGE AND RUNOFF-H. Kim}

Runoff is water flux draining from the soil column and is one of various interacting physical processes related to the energy and water cycles at Earth's surface. For example, runoff occurs when precipitated water exceeds the soil's capacity for infiltration and the gravitational drainage is greater than capillary flux. Runoff water forms networks of fluvial flows concentrated within narrow channels as surface or subsurface streams and rivers and is eventually discharged to the oceans, transporting integrated heat and chemical exchanges from upstream to downstream. River discharge has long been a concern of human civilization, and the issue is becoming more serious with increasing water demand and the hydroclimatic intensification (e.g., Madakumbura et al. 2019) under Earth's warming climate.

In 2018, global discharge (Plate 2.10) and runoff (Plate 2.1p) anomalies against the long-term mean showed patterns generally similar to those in 2017. Large areas of Africa, India, the southern United States, and western Europe, including the Mediterranean, were under drier conditions. On the other hand, South America, Southeast Asia, eastern Europe, and western and eastern Siberia were under significantly wetter conditions than normal. Additionally, notable changes between wet and dry conditions were found in a few regions. Central Siberia and Alaska, which showed significant dry conditions in 2017, became less dry in 2018, and southern China was largely drier in 2018. In terms of rivers, the major African rivers (e.g., Congo, Niger, Nile, and Zambezi) 


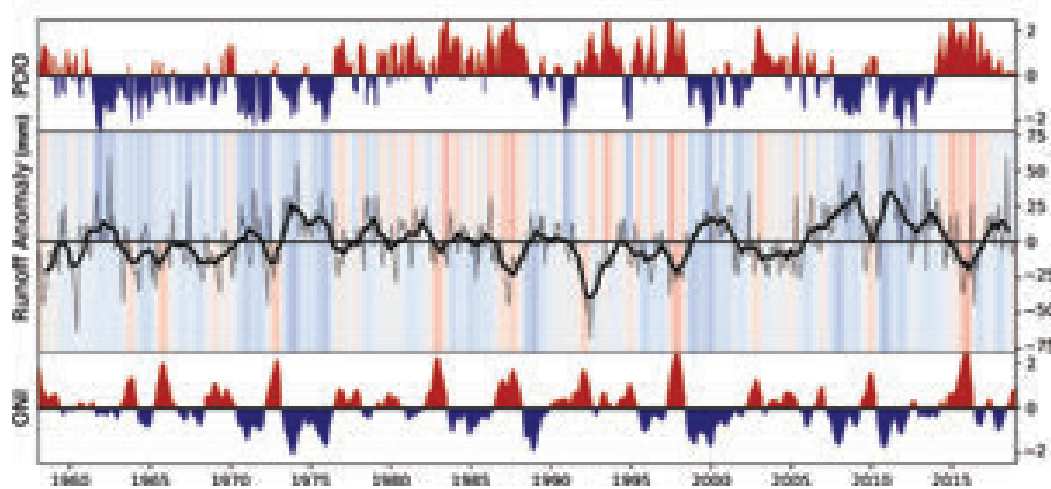

FIG. 2.25. Interannual variability of ONI (lower), PDO (upper), and global runoff (middle; $\mathrm{mm}$; thick line is 12 -month moving average). ONI and PDO are shaded red (positive phase) or blue (negative phase). Shading above and below the zero-line of global runoff is proportional to PDO and ONI, respectively.

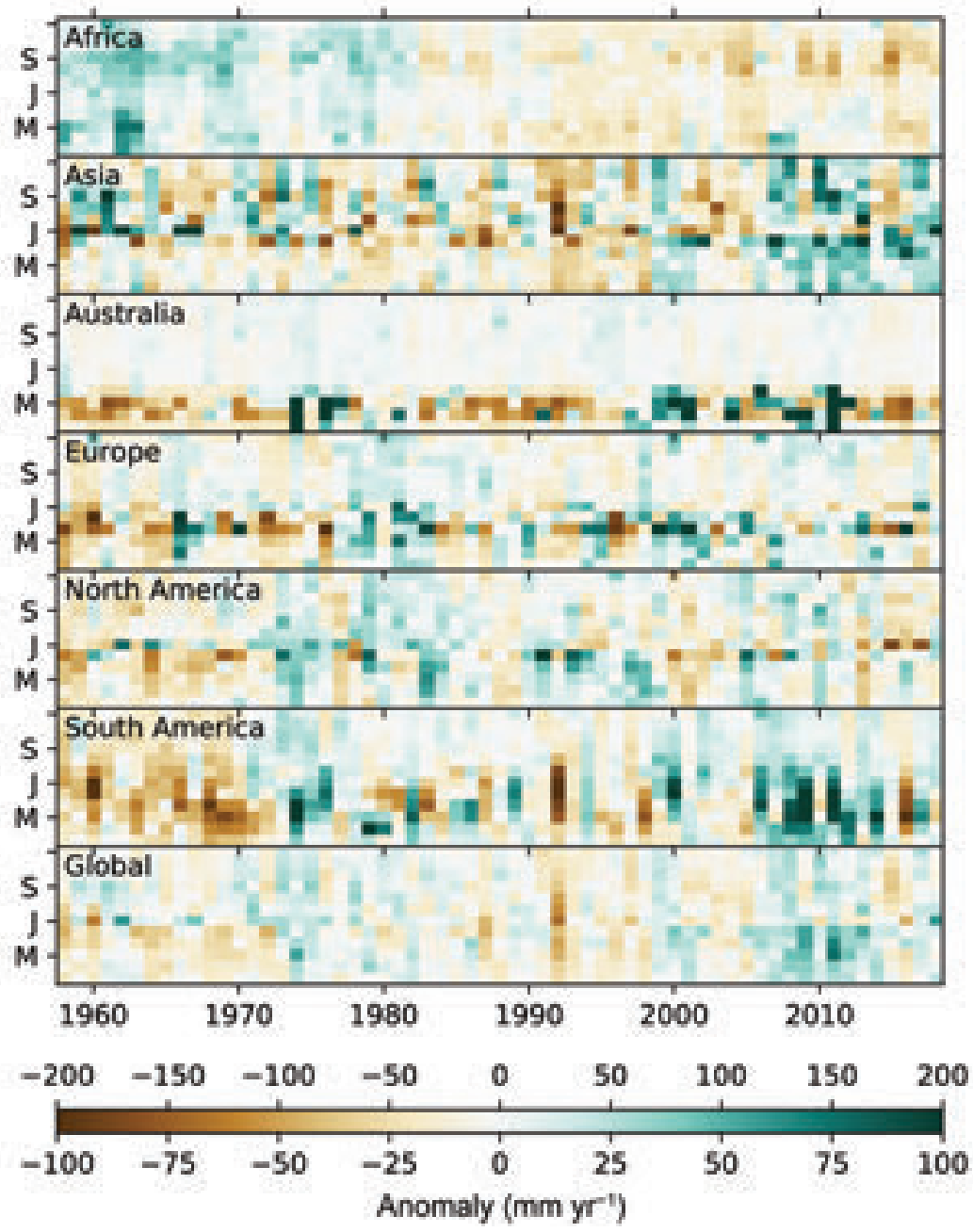

FIG. 2.26. Interannual variability of global and continental runoff anomalies $\left(\mathrm{mm} \mathrm{yr}^{-1}\right)$ for the entire estimation span (1958-2018). The $\mathrm{x}$ - and $y$-axes correspond to annual and seasonal variations, respectively. Europe and South America refer to the upper scale of the color bar, and the others refer to the lower scale. The continental mask used in the analysis is referred to http://hydro.iis.u-tokyo.ac.jp/ hjkim/soc /continents.png. maintained discharge levels below their long-term means. On the Eurasian continent, the Ob, Kolyma, and Mekong Rivers have maintained wetter conditions, and the Ganges showed drier conditions compared to normal, similar to 2017. In contrast, the Amur, Danube, Lena, and Yenisei Rivers shifted from dry to wet, and the Volga from wet to dry. Some rivers in North America, such as the Yukon and Mackenzie, have trended toward wet conditions. Most major rivers in South America showed similar conditions to the previous year except for the Rio Madeira of the Amazon basin and the Uruguay of the La Plata basin, which shifted dry to wet and wet to dry in 2018 , respectively.

Global total freshwater discharge strongly correlates with various climate modes (e.g., Kim 2017, 2018). In particular, it is strongly modulated by ENSO and the PDO. Their longterm variabilities, depicted in Fig. 2.25, show that combined ENSO and $\mathrm{PDO}$ in a positive (negative) phase causes dry (wet) conditions in the global average. According to multivariate regression analysis, the Oceanic Niño Index (ONI), which indicates SST variability of the Niño-3.4 region, and PDO indices explained $49 \%$ of the total variance. By the end of 2018, the Pacific Ocean (i.e., Niño3.4 region, specifically) had passed the threshold for El Niño, but global freshwater discharge remained near the long-term mean after the dry perturbation due to a strong positive phase of 2015/16 ENSO.

Monthly anomalies in continental- and global-scale runoff are shown in Fig. 2.26. Africa has experienced persistent dry conditions since the 1980s but was slightly wet during the latter half of 2018. On average, Asia has been anomalously wet for about 10 years and has frequently faced extremely wet summers. This period includes July 2018, when many countries, including Cambo- 
dia, China, Japan, India, Myanmar, and Pakistan, experienced exceptional flooding. Australia, Europe, North America, (including Central America) and South America were in a near-neutral state in 2018; however, western and northern Europe had significantly drier conditions. The extremely or relatively wet summers in Asia, Europe, North America, and South America are reflected in the global-scale estimation, which shows a wetter-than-normal year with a significant excess of water in July 2018.

The 1958-2018 record of global river discharge and runoff has been estimated by off-line land surface simulations using the Ensemble Land State Estimator (ELSE; Kim et al. 2009). Atmospheric boundary conditions were extended by combining the JRA-55 (Kobayashi et al. 2015) and the GPCC Monitoring Product version 6 (Schneider et al. 2018a). Air temperature, specific humidity, and surface pressure were corrected to be consistent with each other on the adjusted elevation while they were interpolated to global $1^{\circ}$ grids. The configurations of the modeling system remain the same as previously described (e.g., Kim 2018).

8) Groundwater and terrestrial Water storageM. Rodell, B. Li, and J. S. Famiglietti

Terrestrial water storage (TWS) comprises groundwater, soil moisture, surface water, snow, and ice. While groundwater varies more slowly than the surficial components, it often dominates TWS variability on multi-annual timescales (Li et al. 2015). In situ measurement records of groundwater and soil moisture are difficult to obtain outside of the United States and parts of Europe and Australia, but from 2002 to 2017, the Gravity Recovery and Climate Experiment (GRACE; Tapley et al. 2004) satellite mission used precise observations of changes in Earth's gravity field to enable estimation of TWS variations. The successor to GRACE, GRACE Follow-On, was launched on 22 May 2018; however, its data are not yet publicly available. Thus, herein we rely on output from a land surface model forced by observationbased meteorological fields, which assimilated GRACE data from March 2003 to June 2017 and ran without data assimilation thereafter (B. Li et al. 2019, manuscript submitted to Water Resour. Res.).

Plate 2.1q presents a map of the changes in annual mean TWS between 2017 and 2018, as equivalent heights of water in centimeters. TWS changes reflect the integrated effects of other hydroclimatic variables (see Plates 2.1g-t), including model inputs precipitation, solar radiation, air temperature, wind speed, and humidity. A TWS drought that began in southern
Brazil and Paraguay in 2017 spread southward across Argentina, which had its ninth warmest year since records began in 1961. Aside from extreme drying in parts of Peru and western Brazil, TWS changes in northern South America were unremarkable despite their capacity for huge swings (Thomas et. al. 2014). Record rainfall across the eastern United States filled aquifers and produced flooding during storms, including two land-falling hurricanes. Central Mexico was also wet, while drying was common across the central and western United States and Canada. In Africa, the Congo endured more drying following a severe drought in 2017, and southern African TWS decreased after a wet 2017. In-between and to the east, TWS increased. As Europe recorded its warmest year on record, central Europe dried, while TWS increased across most of the region adjacent to the Mediterranean Sea. Wetting was widespread in Asia, with various pockets of drying. Northwestern Australia, which saw substantial TWS gains in 2017, dried again in 2018.

In recent decades, changes in TWS in Antarctica, Greenland, the gulf coast of Alaska, and polar islands have been dominated by ice sheet and glacier ablation, which is not simulated by the model. Hence no data are plotted over these regions in Plate 2.1q. Figures 2.27 and 2.28 display time series of zonal mean and global mean, deseasonalized monthly TWS anomalies, excluding the ice-covered regions identified above. The dryness in Argentina, central and southern Africa, and northwestern Australia in 2018 is manifest in Fig. 2.27 from $10^{\circ} \mathrm{N}$ to $35^{\circ} \mathrm{S}$. At the global scale (Fig. 2.28), TWS increased only slightly during 2018. By December, global mean TWS was about $2 \mathrm{~cm}$ above the twenty-first century minimum achieved at

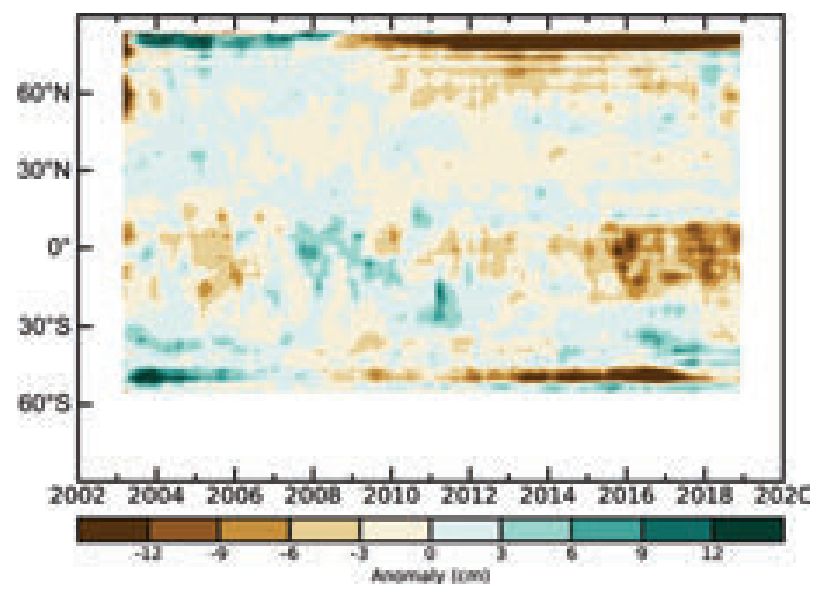

Fig. 2.27. Zonal mean terrestrial water storage anomalies in cm equivalent height of water, based on output from a GRACE data assimilating land surface model. Anomalies are relative to a base period of 2005-10. 


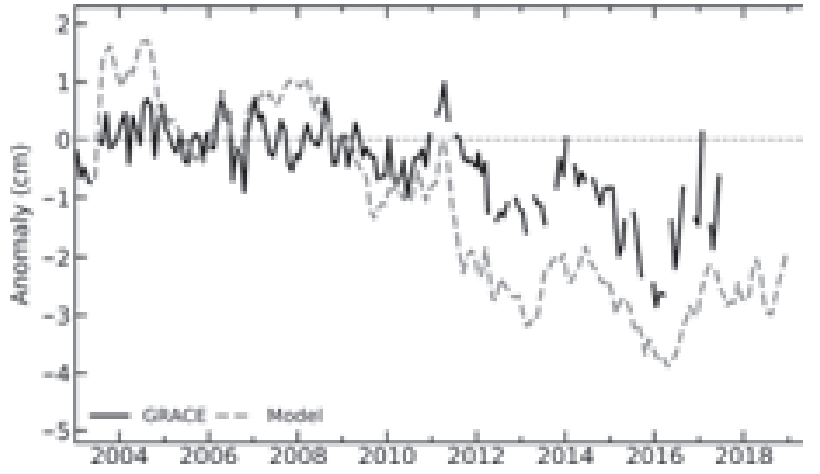

FIG. 2.28. Global average terrestrial water storage anomalies from GRACE (black) and from a GRACE data assimilating land surface model (gray), in cm equivalent height of water relative to a 2005- 10 mean baseline.

the start of 2016 and $2 \mathrm{~cm}$ below the 2005-10 mean used as a baseline in Fig. 2.28.

9)' Soll Molsture-T. Scanlon, R. van der Schalie, W. Preimesberger, C. Reimer, S. Hahn, A. Gruber, R. Kidd, R. A. M. de Jeu, and W. A. Dorigo

The ESA Climate Change Initiative for Soil Moisture (ESA CCI SM) v04.5 COMBINED product combines observations from seven passive and four active microwave instruments (Dorigo et al. 2017a; Gruber et al. 2017; Liu et al. 2012) into a single, harmonized, long-term (November 1978-December 2018) dataset. This dataset has reduced uncertainties and data gaps compared to the single sensor products (Dorigo et al. 2017a; Gruber et al. 2017; Liu et al. 2012). The dataset has been validated against both land surface models and in situ measurements and has been widely used for a range of applications (Dorigo et al. 2017a). The monthly and annual anomalies were computed here with respect to a 1991-2010 climatology. Anomalies and trends in average global soil moisture should be treated with caution owing to dataset properties, for example, temporal coverage, changing over time and to the inability to observe beneath dense vegetation, in mountain areas, or frozen or snow-covered soils.

In 2018, spatial soil moisture patterns (Plate 2.1r) were notably drier or wetter than normal in several regions across the globe. The areas affected by dry conditions expanded compared to 2017; this is evident in the dry anomalies around $30^{\circ} \mathrm{S}$ (South Africa and Australia; Fig. 2.29 and Plate 2.1r).

Dry soil moisture conditions observed in 2016 (Dorigo et al. 2017b) and 2017 (Dorigo et al. 2018) in parts of South Africa persisted into 2018, leading to Cape Town being put on alert for "Day Zero" (predicted for mid-April 2018) when water reserves were expected to become depleted (Sousa et al. 2018). The implementation of water-saving measures resulted in the city's reserves being recharged to $74 \%$ capacity by November 2018; however, with respect to agriculture, persistent dry conditions throughout the year led to reduced harvests (WMO 2018). In contrast, strong wet anomalies were observed in eastern Africa during March-May (Online Fig. S2.20).

Australia has been notably affected by low soil moisture conditions. As 2018 progressed, dry conditions spread throughout the country and continued to the end of the year (Online Fig. S2.20). Australia's annual national rainfall was just $89 \%$ of the $1961-90$ average but was low in the southeast, with much of the region experiencing totals in the lowest $10 \%$ of historical observations (see Section $7 \mathrm{~h} 4$ and Sidebar 7.5 for more details).

Exceptional drought conditions also occurred in northern Europe during June-August, with southern Europe experiencing wetter-than-normal conditions during the same period. This is a reversal of the 2017 situation when severe drought affected Italy (Dorigo et al. 2018). The extreme drying of soils in Scandinavia in June 2018 contributed to wildfires in Sweden with 25000 hectares being burned (WMO 2018); Germany also suffered wildfires.

The strong anomalously negative soil moisture conditions seen in northeastern Brazil for the past six years (see Dorigo et al. 2018) persisted into 2018, with the driest anomalies observed during June-September 2018 (Online Fig. S2.20).

Wetter-than-normal conditions persisted over much of southeast Asia (Plate 2.1r), continuing the trend of the past two years (Dorigo et al. 2018). In addition, wet conditions continued into 2018 along the west coast of Peru and Chile, strongly contrasting with simultaneous dry conditions in neighboring Argentina (Plate 2.1r).

Over North America, the Canadian Prairies continued to show anomalously dry behavior, especially during the summer months (Online Fig. S2.20), whereas much of the continental United States was wetter than normal throughout the year. Hurricane Michael brought extremely heavy precipitation in early October, which affected much of the eastern United States.

Toward the end of 2018, flooding in Saudi Arabia resulted in strong positive anomalies, in stark contrast to the previous winter. In Pakistan, a drought warning was issued in September, with dry conditions continuing to the end of the year (Online Fig. S2.20).

The middle of 2018 was dominated by a neutral state of the ENSO following the end of a weak La Niña in April. ENSO anomalies are known to potentially 
cause continent-wide deviations in terrestrial water storages (Bauer-Marschallinger et al. 2013; Boening et al. 2012; Dorigo et al. 2017b; Miralles et al. 2014a). Despite the myriad of localized extreme events seen across the globe in 2018, the average global soil moisture was near-normal (Figs. 2.29, 2.30). However, there was a switch in the hemispheric anomalies compared to 2017, with wetter conditions in the $\mathrm{NH}$ and drier conditions in the SH (Fig. 2.30).

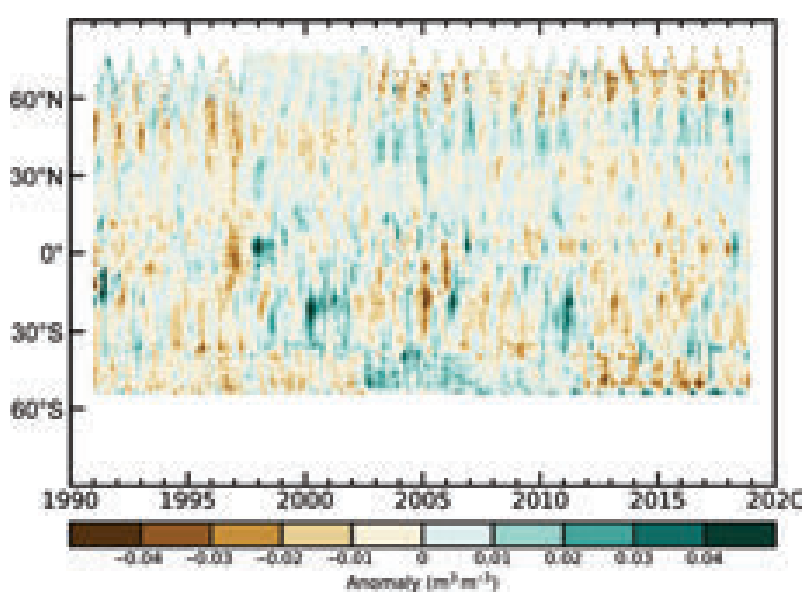

FIG. 2.29. Time-latitude diagram of surface soil moisture anomalies $\left(\mathrm{m}^{3} \mathrm{~m}^{-3}\right.$; 199I-2010 base period). Data were masked as missing where retrievals are either not possible or of low quality due to dense forests, frozen soil, snow, ice, etc. (Source: ESA CCI Soil Moisture.)

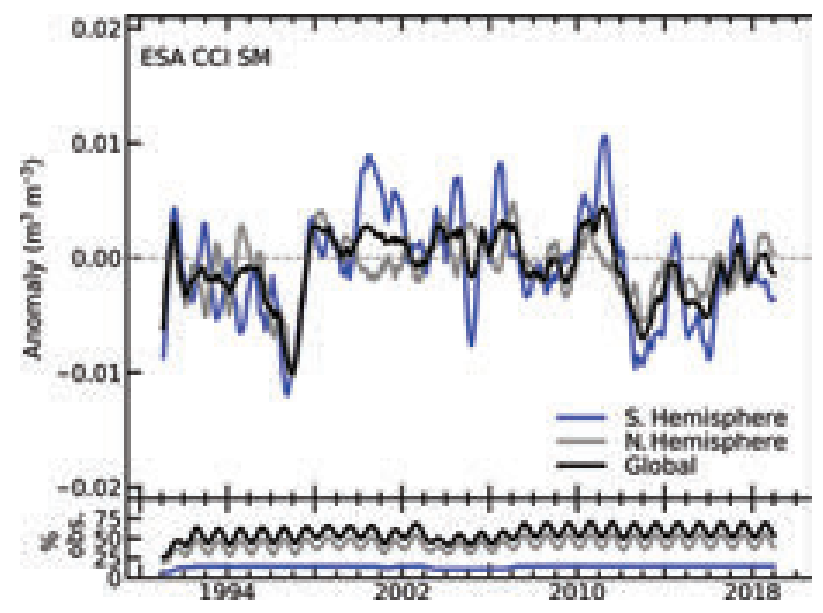

FIG. 2.30. Time series of average global, NH, and SH surface soil moisture anomalies for 1991-2018 ( $\mathrm{m}^{3} \mathrm{~m}^{-3}$; 1991-2010 base period). Data were masked as missing where retrievals were either not possible or of very low quality due to dense forests, frozen soil, snow, ice, etc. (Source: ESA CCI Soil Moisture.)
10) Drought-J. Barichivich, T. J. Osborn, I. Harris, G. van der Schrier, and P. D. Jones

Hydrological drought results from a period of abnormally low precipitation, sometimes exacerbated by additional evapotranspiration (ET), and its occurrence can be apparent in reduced river discharge, groundwater storage, and/or soil moisture (Sections $2 \mathrm{~d} 7,2 \mathrm{~d} 8$, and $2 \mathrm{~d} 9$, respectfully), depending on the season and duration of the event. Here, an estimate of drought called the self-calibrating Palmer Drought Severity Index (scPDSI; Wells et al. 2004; van der Schrier et al. 2013) is presented, using precipitation and Penman-Monteith Potential ET from an early update of the CRU TS v4.03 dataset (Harris et al. 2014). Moisture categories are calibrated over the complete 1901-2018 period to ensure that extreme droughts and pluvials (wet episodes) relate to events that do not occur more frequently than in approximately $2 \%$ of the months. This affects direct comparison with other hydrological cycle variables in Plate 2.1 that use a different baseline period.

This analysis differs from Osborn et al. (2018) by using the new CRU TS v4.03 climate dataset. This dataset is based on angular-distance weighting of station observations, with a modified sine curve imposing a distance-based relaxation to climatology that helps ensure a continuous interpolated surface. This approach allows full control over station selection for each interpolated value and delivers further benefits for secondary variables and traceability. This change in climate dataset has introduced a mean offset in the estimated areas affected by drought, but the relative variability between years is little affected.

After a notable peak in the overall area of drought across the globe in 2016, drought area had declined by early 2017 (Osborn et al. 2018). After a slight increase in the second half of 2017, drought area then declined slowly during 2018 to reach below-average levels (Fig. 2.31). Over the course of 2018, the global land area under extreme drought conditions (according to scPDSI) declined by $0.8 \%$, from $3.5 \%$ in January to $2.7 \%$ in December. The area experiencing severe or extreme drought conditions decreased during 2018 from $10.3 \%$ to $8.1 \%$ of the global land area, while moderate or worse drought conditions declined from $21.8 \%$ to $20.3 \%$ of the global land area. These values should be interpreted with caution as they may change when additional observations become available.

Moderate to severe drought conditions particularly affected most of South America, the western United States, Europe, the Middle East, southern and western Africa, and Australia (Plate 2.1s). The eastwest contrast across the United States strengthened 


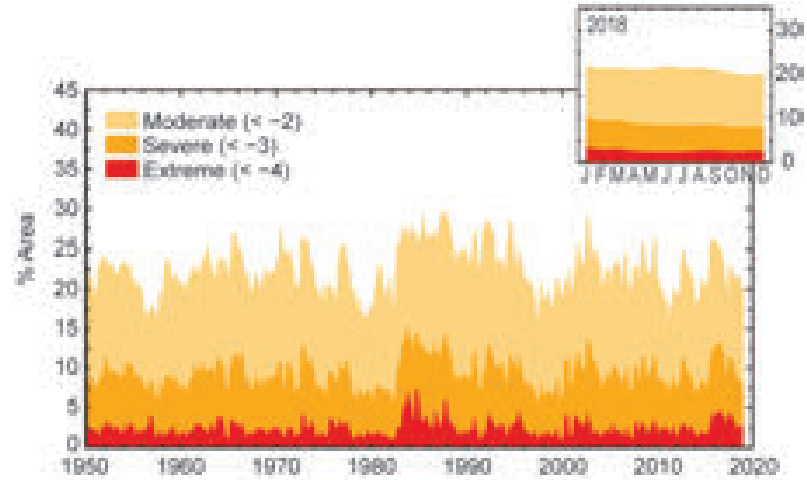

FIG. 2.3I. Percentage of global land area (excluding ice sheets and deserts) with scPDSI indicating moderate $(<-2)$, severe $(<-3)$ and extreme $(<-4)$ drought for each month of 1950-2018. Inset: Each month of 2018.

from 2017 to 2018, with wetter conditions in the east and drier in the west. California experienced a return to dry conditions in 2018 after very wet conditions in 2017 that ended the severe five-year drought event (Lund et al. 2018). Protracted droughts in semiarid northeastern Brazil (Jimenez-Muñoz et al. 2016) and central Chile (Garreaud et al. 2017) continued in 2018 but eased with respect to 2017 (Fig. 2.32).

Moderate to severe drought persisted and expanded along the west coast of Africa between Ghana and Senegal, causing concerns about food insecurity. Wetter conditions occurred in most of central and eastern Africa, with the 2017 drought in Madagascar easing in 2018 (Fig. 2.32). The Cape region in South Africa also continued under severe to extreme drought (Otto et al. 2018; Section 2d9).

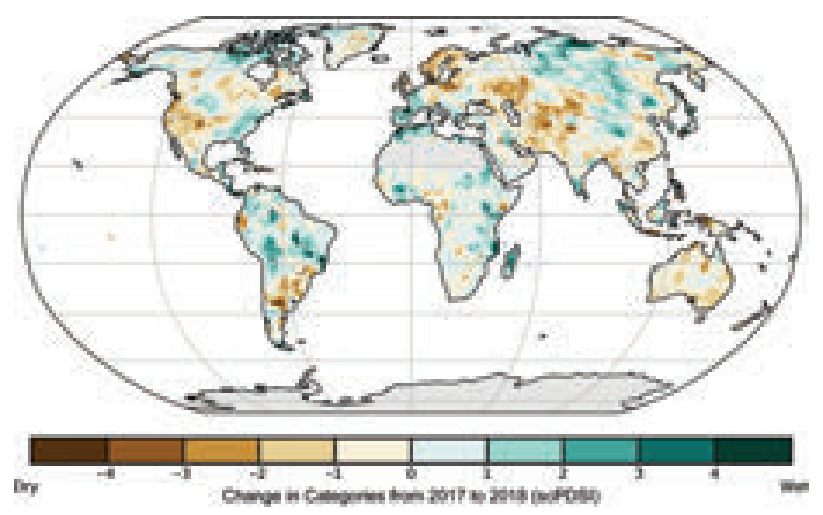

Fig. 2.32. Change in drought from 2017 to 2018 (mean scPDSI for 2018 minus mean scPDSI for 2017). Increases in drought severity are indicated by negative values (brown), decreases by positive values (green). No calculation is made where a drought index is meaningless (gray areas: ice sheets or deserts with approximately zero mean precipitation).
In the Middle East, extreme drought conditions affected Afghanistan. United Nations estimates suggest that about 2 million people were affected, leading to a humanitarian crisis in the northern and western parts of the country. Severe or extreme drought conditions also occurred in some surrounding Middle East countries, either due to a continuation of dry conditions since 2017 or a deterioration toward dry conditions (Fig. 2.32). Most of Australia saw an increase in drought conditions due to belowaverage rainfall and high temperatures (see Section 7h4). Extreme drought impacted New South Wales and most of Queensland. The North Island of New Zealand was also affected by severe drought during 2018 (Plate 2.1s; see Section 7h5).

The hot and dry summer in northern Europe (see Section 7f4) lowered the 2018 scPDSI values compared with 2017 (Fig. 2.32), although the annual mean remained out of drought conditions except in Germany (Plate 2.1s). Northern Sweden experienced extensive forest fires, especially in July. Wetter conditions in southern Europe shifted the drought index closer to normal, although some Mediterranean countries remained in drought (Plate 2.1s; see Section 7f5).

II) Land evaporation-D. G. Miralles, B. Martens, H. E. Beck, A. J. Dolman, C. Jiménez, M. F. McCabe, and E. F. Wood

Evaporation estimates are crucial to determine water availability for human use, analyze ecosystem productivity and species richness, and monitor agricultural needs for irrigation (Fisher et al. 2017). Moreover, quantifying the return flow of water from terrestrial surfaces to the atmosphere enables the detection of land use and climate impacts on the hydrological cycle (Dolman et al. 2014). Despite being seldom measured in situ and not directly observed from space, a range of datasets exists today to monitor evaporation at continental scales (McCabe et al. 2016; Miralles et al. 2016; Yo. Zhang et al. 2019). These datasets are hybrids between observations and modeling and have been used to study trends in hydrology and climate (Jung et al. 2010; Zhang et al. 2016; Cheng et al. 2017); impacts of climate oscillations (Miralles et al. 2014b; Martens et al. 2018); irrigation requirements (Anderson et al. 2015); and hydrometeorological extremes (Miralles et al. 2014a; Mu et al. 2013). Only a few of the existing datasets are produced in near-real time and, typically, only for specific continents (Ghilain et al. 2011; Anderson et al. 2011). Data for this analysis were obtained from the Global Land Evaporation Amsterdam Model (GLEAM; Miralles et al. 2011) version v3.2a (Martens 
et al. 2017), a simple land surface scheme run with satellite data. While not deliberately designed with an operational intent, GLEAM is updated with a few months' latency and has been widely validated in multiple initiatives over the past few years (McCabe et al. 2016; Miralles et al. 2016).

Global average land evaporation was higher in 2018 than the 1981-2010 mean (Fig. 2.33), mainly due to a positive anomaly over the $\mathrm{NH}$ from spring to autumn (Fig. 2.34). This anomalous behavior is attributed to the high temperatures experienced during this period, particularly in Europe (see Section 7f). This also agrees with expectations based on the positive phase of the NAO in 2018, which is commonly associated with higher evaporation rates in most of Europe (Martens et al. 2018). At monthly and annual scales, variability in the $\mathrm{SH}$ terrestrial evaporation is closely linked to ENSO (Miralles et al. 2014b; Martens et al. 2017). With the average ENSO index being

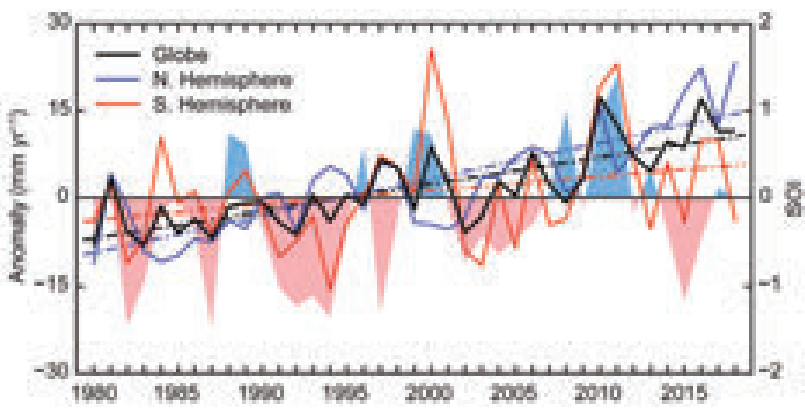

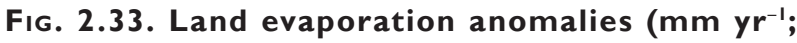
198I-2010 base period) for the NH, SH, and the entire globe (blue, red, and black solid lines, respectively). Linear trends in evaporation (dashed lines) and the SOI from CRU (right axis, shaded area) are also shown. (Source: GLEAM.)

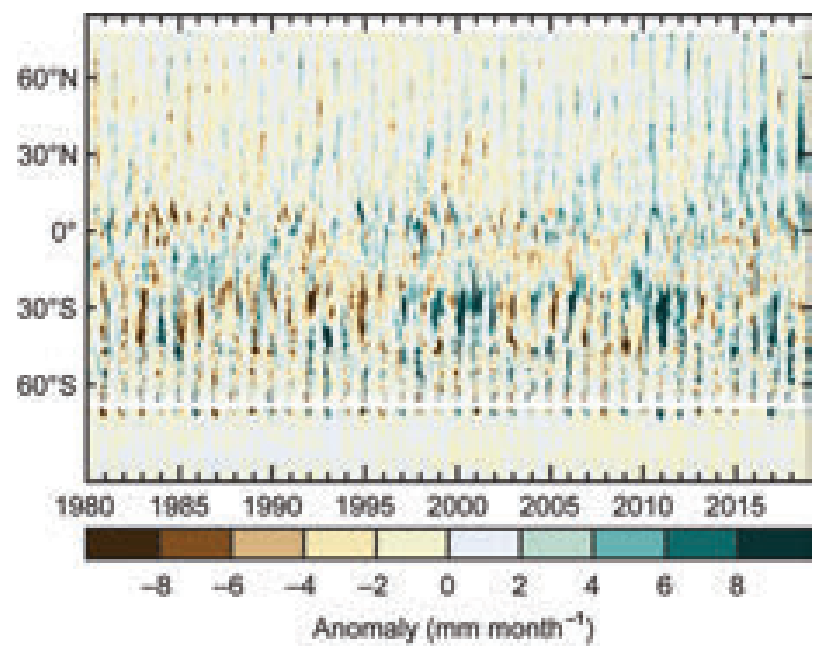

FIG. 2.34. Zonal mean terrestrial evaporation anomalies (mm month ${ }^{-1}$; relative to I98I-2010). (Source: GLEAM.) neutral during 2018, the $\mathrm{SH}$ average evaporation was not particularly anomalous (Fig. 2.33). At decadal scales, the vast majority of studies have reported a mildly positive linear trend in global land evaporation (Miralles et al. 2014b; Yo. Zhang et al. 2016; Brutsaert 2017; Jung et al. 2010). From Fig. 2.33, an average increase in evaporation of approximately $0.4 \mathrm{~mm} \mathrm{yr}^{-2}$ $(p<0.01)$ can be inferred, which agrees in sign and magnitude with Clausius-Clapeyron expectations associated with recent rates of global warming (Miralles et al. 2014b; Brutsaert 2017). The globally averaged mean land evaporation for 2018 was just above this linear trend (Fig. 2.33).

At regional scales, anomalously low evaporation was observed across most of southeast Asia, northern and eastern Australia, Amazonia, southern Africa, and the western and central United States (Plate 2.1t). In some of these areas, such as southern Africa and the U.S. west coast, the reduced evaporation was associated with anomalously low precipitation (Section 2d4). In northern and eastern Australia, the negative anomalies reflect severe drought conditions that occurred in the latter half of 2018 (Section 2d10). Regions of higher-than-average evaporation include southern Australia, continental Asia, the Arabian Peninsula, the Horn of Africa, the Sahel, the Mediterranean region, and most of North America. In the Mediterranean, the positive anomaly was associated with abnormally high temperatures and surface incoming solar radiation since early spring, which escalated to yield a summer heatwave affecting central and northern Europe in particular (see Section $7 f$ ). Because precipitation had been near-average during spring and early summer, soil moisture was still sufficient to fuel high rates of evaporation in the Mediterranean region from spring to autumn. This terrestrial evaporation anomaly largely reflected a peak in ecosystem transpiration (not shown).

Monitoring the dynamics in continental evaporation facilitates the scrutiny of anticipated impacts of climate change on hydrology, such as the acceleration of the global water cycle or the hypothesis that dry (wet) areas are becoming drier (wetter). Despite progress made in recent years to retrieve evaporation from satellite data and the novel insights in remote sensing science (McCabe et al. 2017; Fisher et al. 2017), anomalies and trends depicted here should be interpreted with care. While uncertainties in satellite and meteorological forcing remain high, large errors still originate from the retrieval algorithms despite the progress of evaporation monitoring in recent years (McCabe et al. 2019). 


\section{e. Atmospheric circulation}

I) Mean sea level pressure and related modes of VARIABILITY-R. Allan

Mean sea level pressure (MSLP) data can be used to derive indices of many regional modes of variability that drive significant weather and climate events (Kaplan 2011) such as ENSO, the Arctic Oscillation (AO), NAO, and the Antarctic Oscillation (AAO; Fig. 2.35). ENSO, which is measured in the atmosphere by the sea level pressure-derived SOI (Allan et al. 1996; Kaplan 2011), arguably has the most global impact.

ENSO describes a variety of events and episodes that, individually, can exhibit wide-ranging characteristics across the Indo-Pacific region and have teleconnections to higher latitudes in both hemispheres (Capotondi et al. 2015; L'Heureux et al. 2017; Wang et al. 2017; Timmermann et al. 2018, Santoso et al. 2019). These different "flavors" of ENSO include protracted El Niño and La Niña episodes (Allan and D’Arrigo 1999; Allan et al. 2018, manuscript submitted to Holocene).

Since the strong 2014-16 protracted El Niño episode, the SLP-derived SOI has fluctuated between positive and negative values, especially throughout 2018 (Fig. 2.35b). Oceanic measures of ENSO, such as SSTs measured in the Niño $1+2,3,3.4$, and 4 regions across the tropical Pacific, exceeded El Niño thresholds by early June 2018 .

In the $\mathrm{NH}$, the last seven boreal winters have

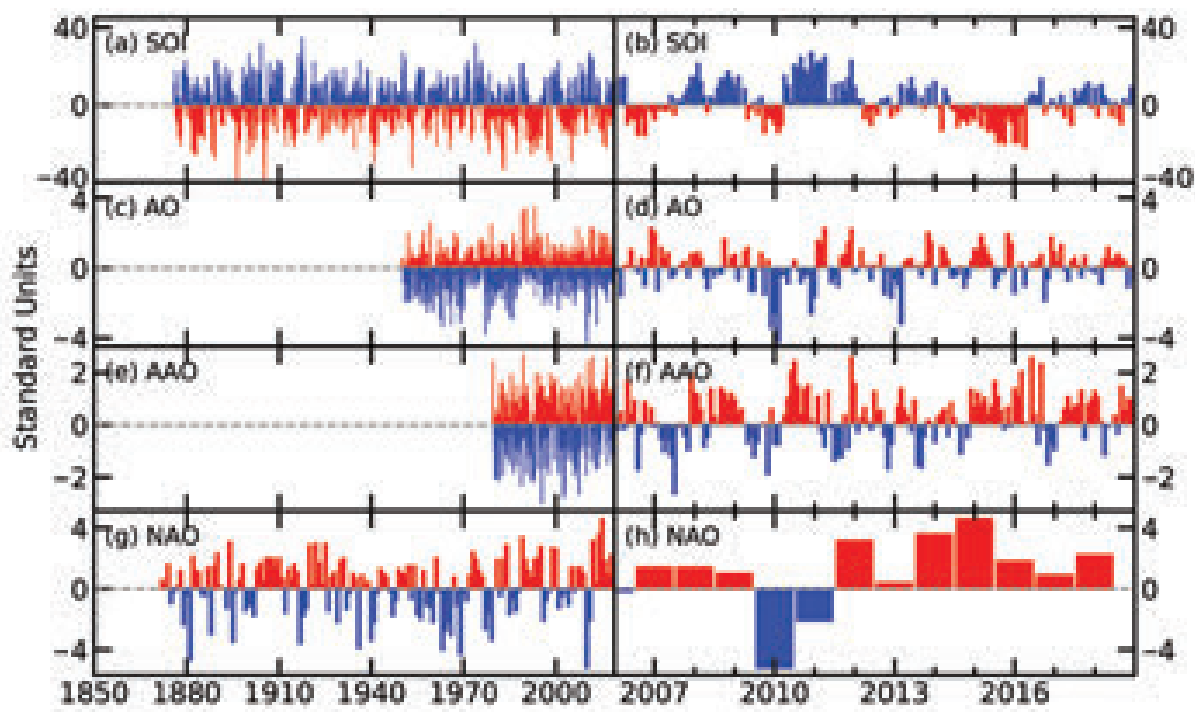

FIG. 2.35. Time series for modes of variability described using sea level pressure for the (left) complete period of record and (right) 2006-18. (a),(b) SOI (provided by the Australian Bureau of Meteorology); (c),(d) AO (NCEP Climate Prediction Center); (e),(f) AAO (NCEP Climate Prediction Center); (g),(h) winter (DecFeb) NAO average (NCAR; presented for winter at the beginning of each year so winter $2018 / 19$ is not shown). displayed mixed $\mathrm{AO}$ and $\mathrm{NAO}$ conditions (Figs. 2.35 c,d,g,h). The 2016/17 boreal winter (Fig. 2.36a) was marked by an increasingly positive NAO through mid-December 2016, temporarily negative NAO values around the start of 2017, and then a fluctuation between phases for the rest of January of that year (Fig. 2.36d; Allan and Folland 2017). During the 2017/18 boreal winter (Fig. 2.36b), the NAO was mainly positive (Fig. 2.36e), with temperatures in Europe mild to warm, (see Section 7f). In particular, France, Germany, Switzerland, the Netherlands, and Denmark experienced record or near-record warm conditions in 2018.

During the 2018/19 boreal winter (Fig. 2.36c), the NAO swung from moderate positive values in early-to-mid-December to moderate negative values from late December to mid-January 2019, fluctuating between positive and negative values thereafter (Fig. 2.36f). These were weaker than the substantial regular fluctuations in the winter of 2016/17 (Figs. $2.36 \mathrm{a}, \mathrm{d})$ and the irregular variations in the winter of 2017/18 that included extreme negative values in late February 2018 (Figs. 2.36b,e). In winter 2018/19, the anticyclonic circulation with southerly flow over Europe led to exceptionally high temperatures in February 2019.

In the $\mathrm{SH}$, the $\mathrm{AAO}$ has been predominantly in its positive phase since 2015/16 (Figs. 2.35e,f) and, during late October to late December 2018, resulted in eastern Australian circulation patterns associated with more rainfallbearing systems. This phase also favors reduced sea ice extent in the West Antarctic Peninsula (WAP) region, owing to enhanced westerly wind conditions (Stammerjohn et al. 2008). In the last months of 2018, the weak El Niño continued the reinforcement of low WAP sea ice extents, which were the fourth smallest in annual maximum extent on record (see Section 6e for further detail). 
(a) 201617

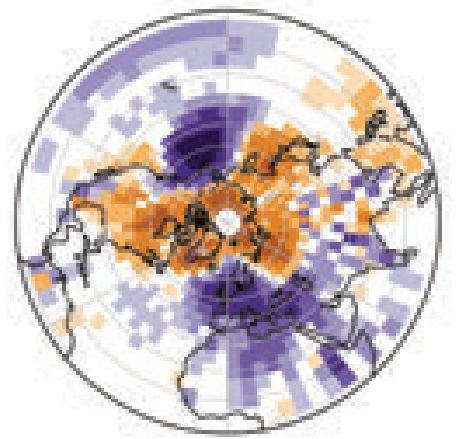

(b) $2017 / 18$

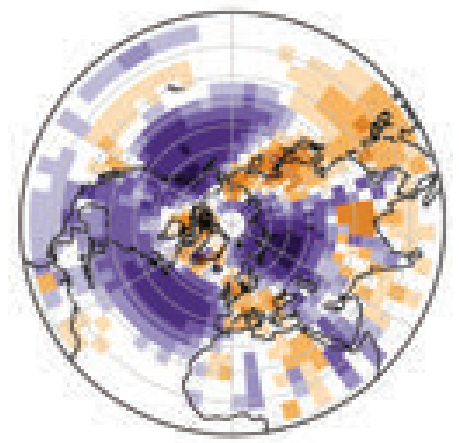

(e) $2018 / 19$
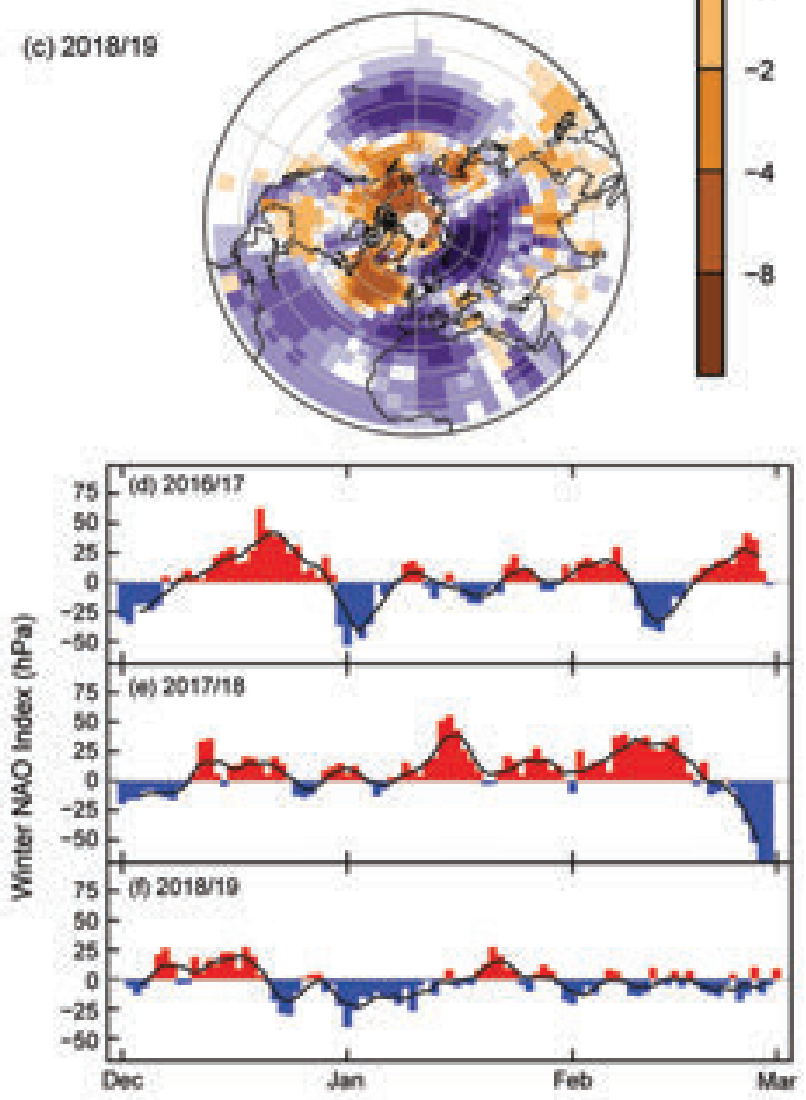

FIG. 2.36. Boreal winter sea level pressure anomalies (hPa; 198I-2010 base period) around the NH (hPa; 1981-2010 base period) averaged over Dec-Feb for (a) $2016 / 17$, (b) $2017 / 18$, and (c) $2018 / 19$. NAO daily time series $(\mathrm{hPa})$ for winter (d) $2016 / 17$, (e) $2017 / 18$, and (f) $2018 / 19$. The 5 -day running mean is shown by the solid black line. [Source: HadSLP2r (Allan and Ansell 2006).]
2) Surface Winds-C. Azorin-Molina, R. J. H. Dunn, C. A. Mears, P. Berrisford, T. R. McVicar, and J. P. Nicolas Surface winds (i.e., typically within $10 \mathrm{~m}$ of the surface) over land continued the recovery that started in 2013 (Tobin et al 2014), after 30-50 years of slowing (termed "stilling" by Roderick et al. 2007). In 2018 (Fig. 2.37a), terrestrial wind speed showed a near-global (excluding Australia) average anomaly of $+0.017 \mathrm{~m} \mathrm{~s}^{-1}$ with respect to its 1981-2010 climatology (Table 2.6). Following 18 years (1996-2012) of consistent negative anomalies, 2018 was the fifth consecutive year with a positive anomaly over land. Regionally, the strongest positive anomalies were found over central Asia $\left(+0.238 \mathrm{~m} \mathrm{~s}^{-1}\right)$ and East Asia $\left(+0.159 \mathrm{~m} \mathrm{~s}^{-1}\right.$; its highest positive anomaly since

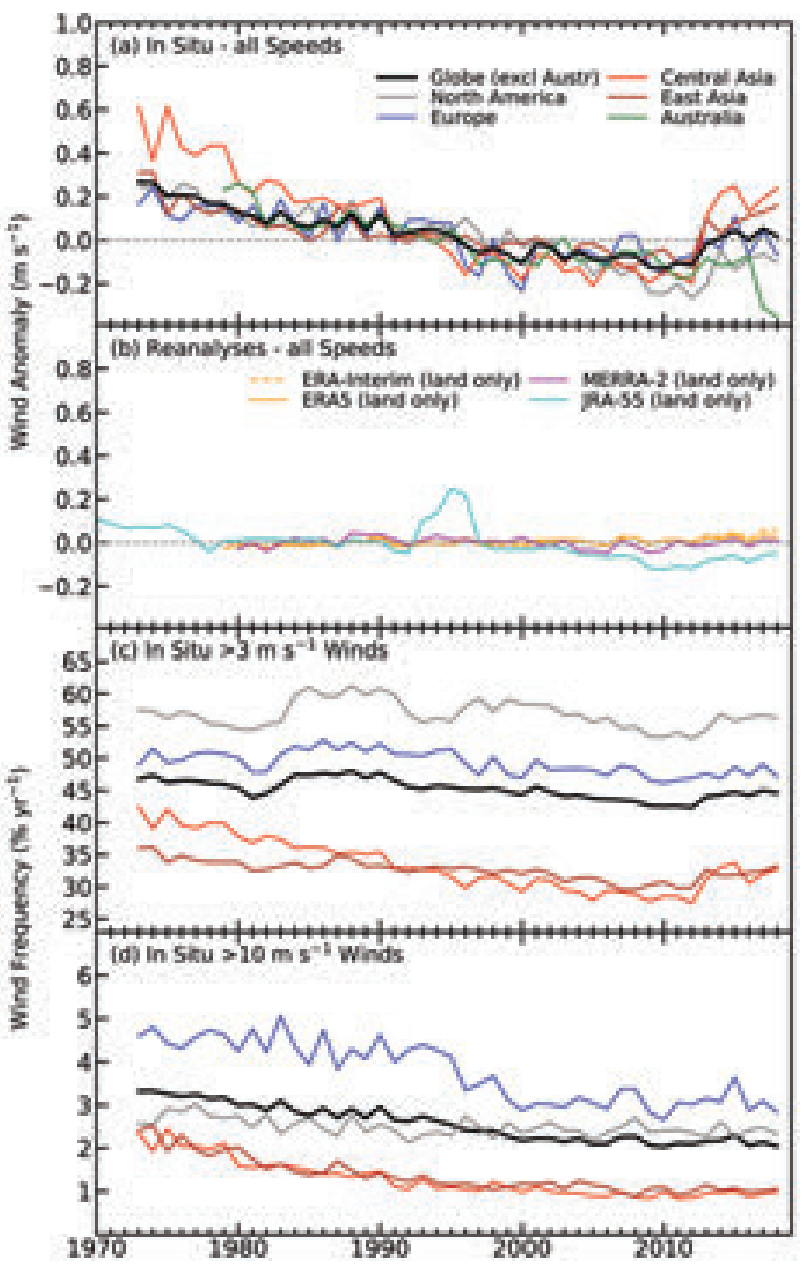

Fıg. 2.37. Global (excluding Australia) and regional annual time series of land surface wind speed anomaly (m s$~^{-1}$; relative to $\left.198 \mathrm{I}-2010\right)$ using (a) HadISD3 (1973-2018) and an Australian dataset (1974-2018) and (b) ERA-Interim (1979-2018), ERA5 (1979-2018), MERRA-2 (1980-20I8) and JRA-55 (1970-20I8). HadISD3 occurrence frequencies (in \%) for wind speeds (c) $>3 \mathrm{~m} \mathrm{~s}^{-1}$ and (d) $>10 \mathrm{~m} \mathrm{~s}^{-1}$ do not include Australia. 


\begin{tabular}{|c|c|c|c|c|}
\hline Region & $\begin{array}{c}\text { Mean } \\
198 \mathrm{I}-2010 \\
\left(\mathrm{~m} \mathrm{~s}^{-1}\right)\end{array}$ & $\begin{array}{c}\text { Anomaly } \\
2018 \\
\left(\mathrm{~m} \mathrm{~s}^{-1}\right)\end{array}$ & $\begin{array}{c}\text { Trend } 1979-2018 \\
\left(\mathrm{~m} \mathrm{~s}^{-1} \text { decade }^{-1}\right) \text { and } \\
\text { 5th to } 95 \text { th percentile } \\
\text { confidence range }\end{array}$ & $\begin{array}{l}\text { Number of } \\
\text { Stations }\end{array}$ \\
\hline $\begin{array}{c}\text { Globe } \\
\text { (excluding } \\
\text { Australia) }\end{array}$ & 3.327 & +0.017 & $\begin{array}{c}-0.063 \\
(-0.07 \mid \rightarrow-0.053)\end{array}$ & 2585 \\
\hline $\begin{array}{l}\text { North } \\
\text { America }\end{array}$ & 3.714 & -0.102 & $\begin{array}{c}-0.084 \\
(-0.095 \rightarrow-0.074)\end{array}$ & 589 \\
\hline Europe & 3.666 & -0.067 & $\begin{array}{c}-0.050 \\
(-0.062 \rightarrow-0.040)\end{array}$ & 774 \\
\hline $\begin{array}{l}\text { Central } \\
\text { Asia }\end{array}$ & 2.875 & +0.238 & $\begin{array}{c}-0.106 \\
(-0.133 \rightarrow-0.085)\end{array}$ & 258 \\
\hline East Asia & 2.732 & +0.159 & $\begin{array}{c}-0.034 \\
(-0.044 \rightarrow-0.024)\end{array}$ & 463 \\
\hline Australia & 2.091 & -0.354 & -0.098 & 28 \\
\hline
\end{tabular}

Fig. 2.37b indicates that reanalyses underestimate multi-decadal wind speed variability given by observations (Torralba et al. 2017; Coburn 2019), in particular for the twentieth century (Wohland et al. 2019).

Over the last 40 years (since 1979), landsurface wind speed declined globally at a rate of $-0.063 \mathrm{~m} \mathrm{~s}^{-1}$ decade $^{-1}$ (Table 2.6). Nevertheless, the above-mentioned stabilization and recovery of winds is weakening the magnitude of the observed stilling in the most recent five years. For instance, less negative trends, compared

1976). Across North America $\left(-0.102 \mathrm{~m} \mathrm{~s}^{-1}\right)$ and Europe $\left(-0.067 \mathrm{~m} \mathrm{~s}^{-1}\right)$, negative anomalies persisted but were smaller compared to previous years, that is, supporting the stabilization or recovery of terrestrial winds shown in previous reports (Dunn et al. 2016a; Azorin-Molina et al. 2017, 2018a). Recent wind studies have also documented a rebound of land surface wind speeds across countries such as South Korea (Kim and Paik 2015), Saudi Arabia (Azorin-Molina et al. 2018b), and China (Zhang et al. 2019), among a few other regions. In contrast, Australia $\left(-0.354 \mathrm{~m} \mathrm{~s}^{-1}\right)$ showed its most negative anomaly of the last 40 years. The occurrence of moderate $\left(>3 \mathrm{~m} \mathrm{~s}^{-1}\right)$ and strong $\left(>10 \mathrm{~m} \mathrm{~s}^{-1}\right)$ winds indicates that the recovery of terrestrial surface winds is caused by the increase of moderate winds (Fig. 2.37b), as strong winds still show a weak downward or stabilization trend (Fig. 2.37c).

This assessment of terrestrial surface winds is based on two quality-controlled datasets from anemometer observations: (1) the HadISD3 (1973-2018, Dunn et al. 2012, 2016b) and (2) an Australian dataset (1974-2018, McVicar et al. 2008), with 2585 and 28 stations, respectively, for the period 1979-2018. Reanalyzed products were used to assess global terrestrial and oceanic (see below) wind speed trends, incorporating (3) the new ERA5 (1979-2018, Hersbach et al. 2019) along with ERA-Interim (1979-2018, Dee et al. 2011), MERRA-2 (1980-2018, Gelaro et al. 2017), and JRA-55 (1970-2018, Kobayashi et al. 2015). However, the relatively stable trend shown in to the 1979-2017 period, were observed (see Table 2.4 in Azorin-Molina et al. 2018a) particularly in Central Asia $\left(-0.106 \mathrm{~m} \mathrm{~s}^{-1}\right.$ decade $\left.^{-1}\right)$ but also across East Asia $\left(-0.034 \mathrm{~m} \mathrm{~s}^{-1}\right.$ decade $\left.^{-1}\right)$, North America $\left(-0.084 \mathrm{~m} \mathrm{~s}^{-1}\right.$ decade $\left.^{-1}\right)$, and Europe $\left(-0.050 \mathrm{~m} \mathrm{~s}^{-1}\right.$ decade $\left.^{-1}\right)$; except for Australia which showed a more negative trend $\left(-0.098 \mathrm{~m} \mathrm{~s}^{-1}\right.$ decade $\left.^{-1}\right)$. Station-based trends shown in Fig. 2.38 display a dominance of negative terrestrial wind speed trends $(64.2 \% ; 92.9 \%$ for Australia), particularly for northern and southern midlatitude regions as previously reviewed by McVicar et al. (2012). Based on the tendency of wind speed toward positive anomalies shown in the last five

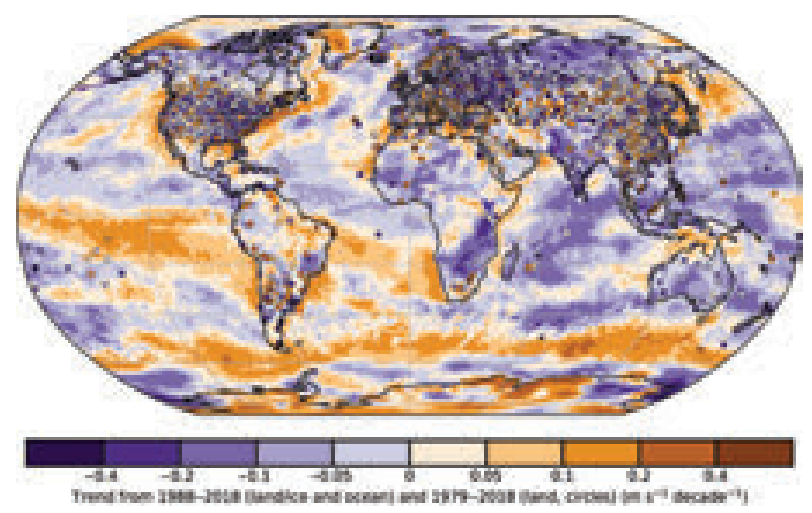

FIG. 2.38. Wind speed trends ( $\mathrm{m} \mathrm{s}^{-1}$ decade $\left.^{-1}\right)$ for the observational HadISD3 and Australian datasets (circles) over land for 1979-2018, and MERRA-2 over land/ice and RSS over ocean for 1988-20I8 (shaded areas). 
years, the dominance of negative trends over land may disappear in the future.

Winds over the oceans for 1979-2018 were evaluated using merged data from microwave imaging radiometers [Wentz 1997, Wentz et al. 2007, 2015; including the Special Sensor Microwave/Imager (SSM/I), the Special Sensor Microwave Imager/ Sounder (SSMIS), the Advanced Microwave Scanning Radiometer (AMSR and AMSR2), and WindSat], along with the above-mentioned reanalyses. For 2018 , the global mean wind speed anomalies for both satellite estimates and reanalyses (Fig. 2.39) show slight positive values, which agrees with the global positive anomalies and the recovery observed over land. The most characteristic feature of the spatial anomalies shown in Plate 2.1v (from MERRA-2 as it best captures long-term wind variability from satellite estimates) corresponds to (1) the strong negative anomaly or "wind hole" in the Pacific Ocean north of the equator, and (2) the widespread positive anomalies over much of the North Atlantic and a belt across the Southern Ocean. The location of the "wind hole" closely corresponds to a region of large positive anomalies in total column water vapor (see Plate 2.1i). Since 1988, wind speed trends estimated by remote sensing (Fig. 2.38) have shown a dominance of negative anomalies, except for a strengthening of trade winds over the Pacific and Atlantic Oceans south of the equator, the Southern Ocean, the Arctic Ocean, and large ocean bodies near the coastline (e.g., North America).

The stilling phenomenon has been attributed to three major causes: (1) increased surface roughness (e.g., forest growth, land use changes, and urbanization; Vautard et al. 2010; Bichet et al. 2012; Wever 2012; Wu et al. 2016), with a recent study suggesting that greening (i.e., enhanced vegetation leaf

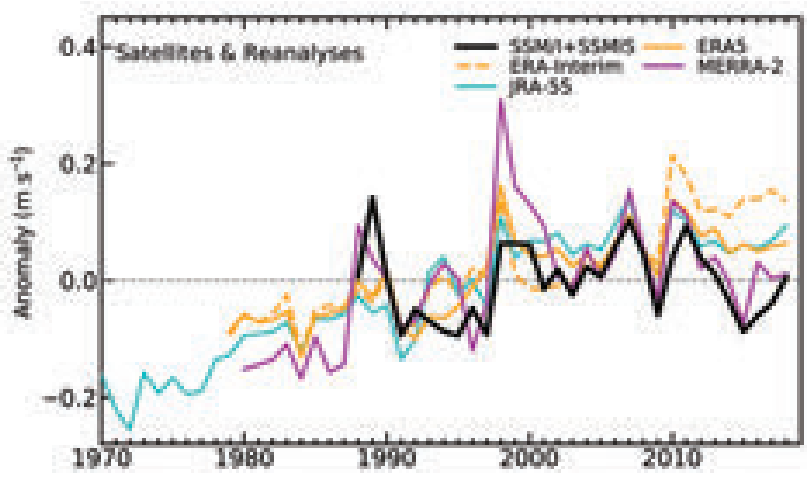

Fig. 2.39. Global average surface wind anomaly $\left(\mathrm{m} \mathrm{s}^{-1}\right.$; base period 198I-2010) over ocean from satellite radiometers (SSM/I + SSMIS) and reanalyses (ERA5, ERA-Interim, MERRA-2, and JRA-55). area index) is not a dominant driver for terrestrial stilling (Zeng et al. 2018); (2) changes in large-scale atmospheric circulation and weather patterns (e.g. pressure gradient force; Zhang et al. 2019); and (3) instrumental issues (e.g., anemometer aging; AzorinMolina et al. 2018c). However, the recent rebound of surface winds over both land and ocean areas introduces uncertainty to the stilling debate and the precise cause(s) remains largely uncertain. Scientists are currently divided as to whether global warming has had, or will have, an impact on surface wind speed changes.

3) UPPER AIR WINDS—L. Haimberger, M. Mayer, V. Schenzinger, and H. Hersbach

For comparison with surface wind speed anomalies in Section 2e2, Fig. 2.40 shows the global (land and ocean) mean $850-\mathrm{hPa}$ wind speed anomalies from five reanalyses. There is a general tendency toward higher wind speeds at this level, but only trends from ERA-Interim and MERRA2 for 1980-2018 are significant. Wind speeds from the new ERA 5 reanalysis (Hersbach et al. 2019) are slightly lower in recent years than those from ERA-Interim.

The annual mean 850-hPa wind speeds for 2018, calculated from ERA5, are above the 1981-2010 base period mean of $0.14 \mathrm{~m} \mathrm{~s}^{-1}$, consistent with the overall increasing trend. The wind speeds appear anomalously high over almost the entire North Atlantic and over the Southern midlatitudes, as can be seen from Plate 2.1v. Over the Pacific Ocean, conversely, winds appear to be slightly weaker than average overall. Over land (not shown), the 850-hPa trends from reanalyses are only weakly positive $\left(0.02 \mathrm{~m} \mathrm{~s}^{-1}\right.$ decade $^{-1}$ in ERA-5 for the 1979-2018 period; the 2018 anomaly is

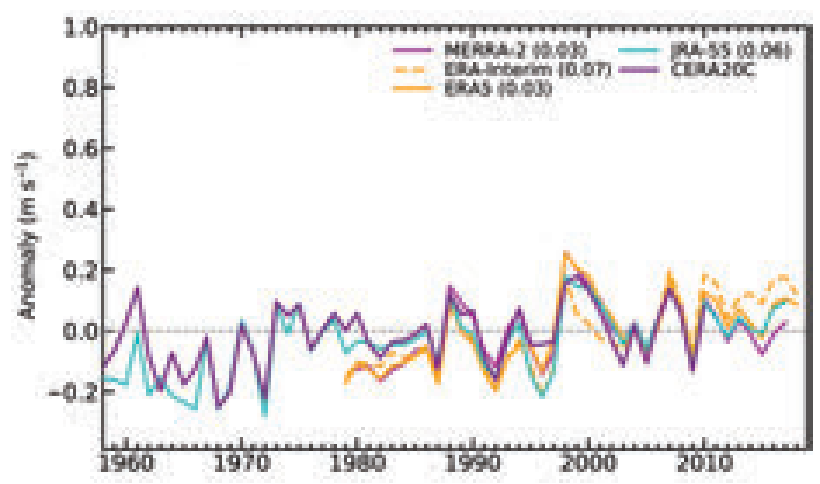

FIG. 2.40. Annual anomalies of global mean wind speed ( $\mathrm{m} \mathrm{s}^{-1}$; base period I98I-20I0) at $850 \mathrm{hPa}$ from five reanalyses [ERA5, ERA-Interim, MERRA-2, JRA-55, and ECMWF's Coupled Reanalysis of the Twentieth Century (CERA20C)]. The numbers in brackets are linear trends in $\mathrm{m} \mathrm{s}^{-1}$ decade $^{-1}$ for the period 1980-2018. 


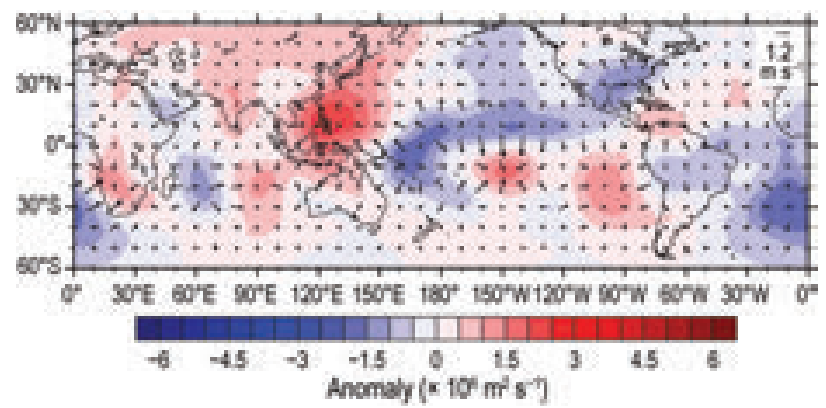

FIG. 2.4I. Oct-Dec 2018 velocity potential anomalies at $200 \mathrm{hPa}$ (shaded contours) and Oct-Dec 2018 divergent wind anomalies at the same level, scale as indicated. The fields are mean anomalies from four reanalyses (ERA5 high res, ERA-Interim, MERRA2, and JRA55).

$\left.0.05 \mathrm{~m} \mathrm{~s}^{-1}\right)$. These trends are slightly greater than the surface wind trends over land (Section 2e2).

Weak El Niño conditions developed in late 2018, the signal of which can be clearly seen in the $200-\mathrm{hPa}$ velocity potential and divergent wind field averaged over October-December 2018 (Fig. 2.41). There is anomalous divergence northwest of Australia, with a maximum near the equator, and convergence over the Philippines. Compared to the strong El Niño condition described in the upper air wind section in an earlier State of the Climate report (Haimberger et al. 2016), the signal is not spectacular. Still, its peaks on the order of $\pm 2 \times 10^{6} \mathrm{~m}^{2} \mathrm{~s}^{-1}$ are well above the uncertainties for this field, as derived from the velocity potential spread of the five reanalyses noted above, which is on the order of $0.2 \times 10^{6} \mathrm{~m}^{2} \mathrm{~s}^{-1}$ (Fig. 2.42a). The velocity potential spread, which is particularly strong near the equator, is strongly related to the

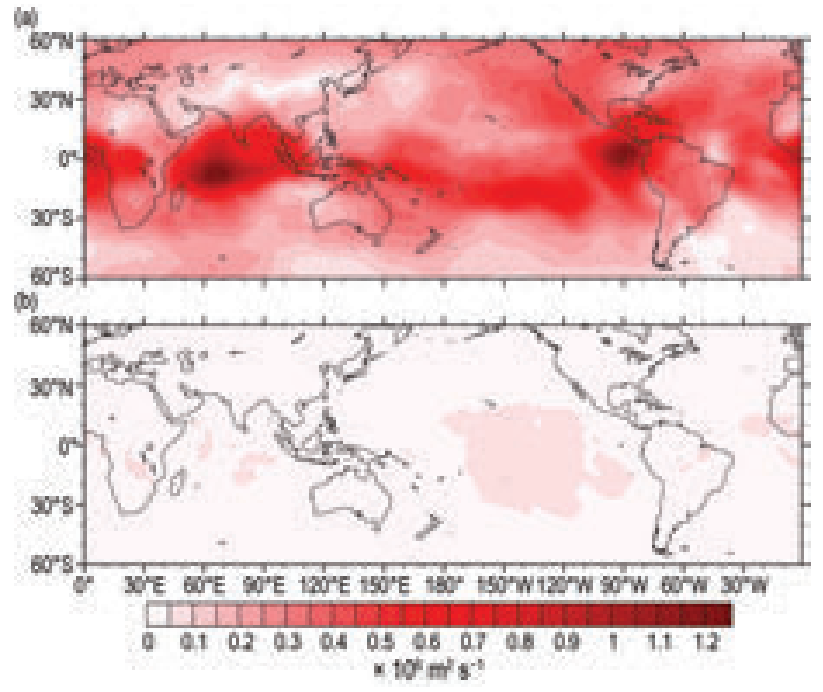

FIG. 2.42. (a) Velocity potential spread (std. dev.) in Oct-Dec 2018 between (ERA5 high res, ERA-Interim, MERRA2, and JRA55). (b) Velocity potential spread from the ERA5 10-member ensemble. spread in cross-equatorial flow, even in the zonal mean, which differs by $10 \%$ in the different analyses (not shown). ERA5 provides its own 10-member ensemble, but its spread (Fig. 2.42b) appears much weaker than the spread between reanalyses. It appears likely that the perturbations used to create the ERA5 ensemble are not sufficient to describe the true uncertainty of the velocity potential field.

The 2018 QBO (see Online Fig. S2.21 for Hovmöller diagram of zonal mean zonal wind) can mainly be characterized by its standard behavior. It started with an easterly shear zone between $10 \mathrm{hPa}$ and $50 \mathrm{hPa}$, which descended at $0.76 \mathrm{~km} \mathrm{yr}^{-1}$, close to the mean of $0.67 \pm 1.23 \mathrm{~km} \mathrm{yr}^{-1}$. The westerly phase, which began in May, also showed a steady descent to date at $0.84 \mathrm{~km} \mathrm{yr}^{-1}$, which is well within the normal range of $0.80 \pm 0.64 \mathrm{~km} \mathrm{yr}^{-1}$. Given that the QBO was in a westerly phase in late 2018 , it remains to be seen whether it evolves regularly or whether sudden easterlies (Osprey et al. 2016) appear to disrupt the normal cycle as happened in 2015/16. One noteworthy characteristic is the large amplitude of the easterly shear zone on the reference height of $20 \mathrm{hPa}$ of $-37.5 \mathrm{~m} \mathrm{~s}^{-1}$, a value that has only been recorded once at this level (in 1963), never been exceeded, and well above the average of $-33.1 \pm 3.2 \mathrm{~m} \mathrm{~s}^{-1}$.

All values for the QBO were calculated as in Schenzinger et al. (2017); means and standard deviations are for the period 1953-2018.

\section{f. Earth radiation budget}

I) EARTH RADIATION BUDGET AT TOP-OFATMOSPHERE-P. W. Stackhouse, Jr., T. Wong, D. P. Kratz, P. Sawaengphokhai, A. C. Wilber, S. K. Gupta, and N. G. Loeb

The energetic state of the Earth-atmosphere system is defined by the balance of the incoming total solar irradiance (TSI) with the reflected shortwave (RSW) and the outgoing longwave radiation (OLR) from Earth. This balance characterizes Earth's radiation budget (ERB) at the top of the atmosphere (TOA) and drives weather processes and climate forcings as well as climate feedbacks.

An analysis of all CERES ERB measurements (Table 2.7) shows that 2018 global annual mean OLR decreased by $\sim 0.40 \mathrm{~W} \mathrm{~m}^{-2}$ while the RSW increased by $\sim 0.05 \mathrm{~W} \mathrm{~m}^{-2}$ relative to their corresponding values in 2017 (rounded to nearest $0.05 \mathrm{~W} \mathrm{~m}^{-2}$ ). Over the same timeframe, the global annual mean TSI was nearly unchanged. The sum of these components amounts to an increase of $\sim 0.40 \mathrm{~W} \mathrm{~m}^{-2}$ in the global annual mean total net radiation into Earth's climate system for 2018 compared with 2017. Figure 2.43 shows the annual mean regional difference maps in 
TABLE 2.7. Global annual mean TOA radiative flux changes between 2017 and 2018 , the global annual mean radiative flux anomalies relative to their corresponding $200 \mathrm{I}-17$ mean climatological values, and the 2-sigma interannual variabilities of the 200I-17 global annual mean fluxes (all units in $\mathrm{W} \mathrm{m}^{-2}$ ) for the outgoing longwave radiation (OLR), total solar irradiance (TSI), reflected shortwave (RSW) and total net fluxes. All flux values have been rounded to the nearest $0.05 \mathrm{~W} \mathrm{~m}^{-2}$ and only balance to that level of significance.

\begin{tabular}{|c|c|c|c|}
\hline & $\begin{array}{c}\text { One Year Change } \\
(2018 \text { minus 2017) }\end{array}$ & 2018 Anomaly $\left(\mathbf{W ~ m}^{-2}\right)$ & $\begin{array}{c}\text { Interannual Variability } \\
(2001-17)\end{array}$ \\
\hline OLR & -0.40 & 0.00 & \pm 0.60 \\
\hline TSI & 0.00 & -0.10 & \pm 0.15 \\
\hline RSW & +0.05 & -0.70 & \pm 0.85 \\
\hline Net & +0.40 & +0.60 & \pm 0.80 \\
\hline
\end{tabular}

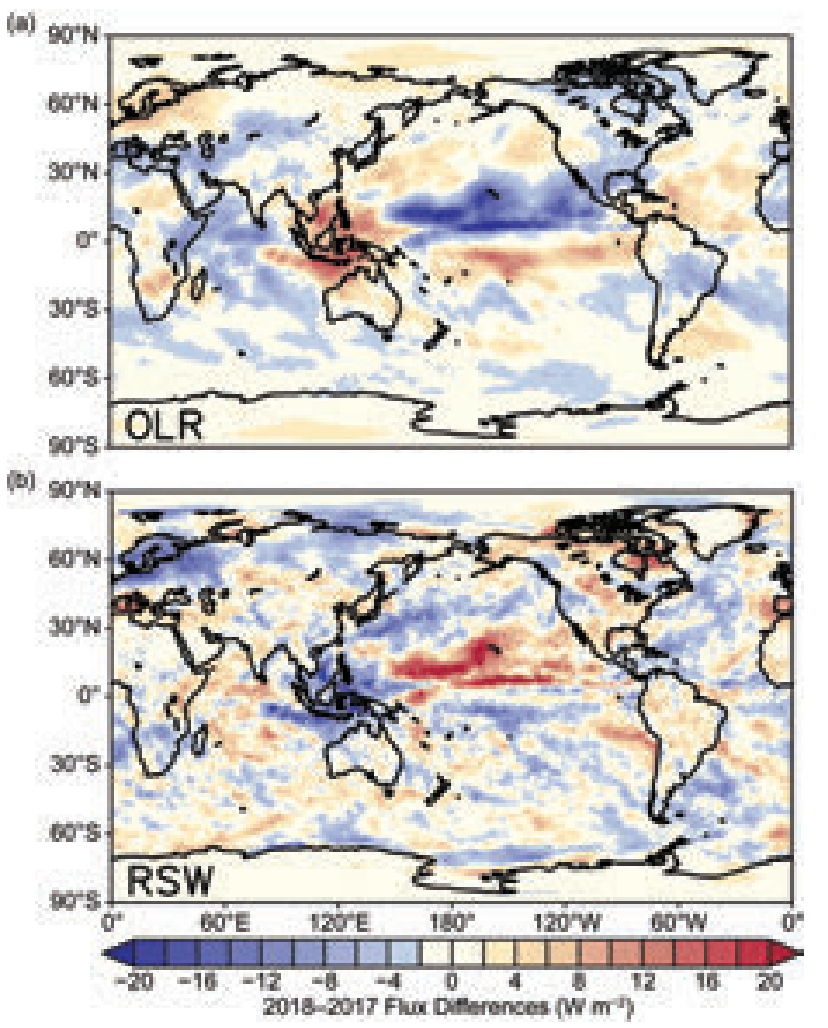

Fig. 2.43. Annual average TOA flux differences between 2018 and $2017\left(\mathrm{~W} \mathrm{~m}^{-2}\right)$ for the (a) OLR (top panel) and (b) TOA RSW (bottom panel). The differences are dominated by large changes in the equatorial Pacific Ocean that are consistent with annual average cloud fraction changes (not shown) in these regions. The pattern of differences shows several significant features including changes over the tropical Pacific, Indian, North Atlantic, and Arctic Oceans dominated by an atmospheric shift from La Niña to near-EI Niño conditions. the OLR and RSW between 2018 and 2017. Peak OLR flux changes are largely compensated by RSW changes, but OLR reductions are spread over broader areas including the Indian Ocean, continental Asia, and North America. Large increases in OLR and decreases in RSW are observed over the western Pacific Indonesian region and in the southern tropical central Pacific. These regional changes are associated with the tropical climate oscillation between weak La Niña conditions near the end of 2017 to weak El Niño conditions at the end of 2018 (see discussion in Section 2d6). Relative to the multiyear data average from 2001 to 2017, the 2018 global annual mean flux anomalies (Table 2.7) are $0.0,-0.1,-0.7$, and $+0.6 \mathrm{~W} \mathrm{~m}^{-2}$ for OLR, TSI, RSW, and total net flux, respectively. Although the global annual OLR anomaly is near zero, the 2018 annual mean regional anomaly maps relative to climatology (not shown) showed similar patterns as the 2017 to 2018 differences shown in Fig. 2.43 but were uniformly larger over the Arctic Ocean. The global annual averaged changes are within the corresponding 2-sigma interannual variability (Table 2.7) for this period.

The global monthly mean anomaly time series of TOA fluxes (Fig. 2.44) reveal that the global monthly mean OLR anomaly fluctuated between positive and negative throughout 2018. The OLR anomalies in 2018 dropped to a value of $-0.85 \mathrm{~W} \mathrm{~m}^{-2}$ in February, reached their maximum value of $+0.5 \mathrm{~W} \mathrm{~m}^{-2}$ in June, dropped to $-0.45 \mathrm{~W} \mathrm{~m}^{-2}$ in August, then mostly increased each month for the rest of the year. The global monthly mean absorbed shortwave (TSI - RSW) anomaly remained mostly positive during 2018, and the magnitudes of this anomaly were larger than the corresponding OLR anomaly. The absorbed shortwave anomaly reached a maximum 


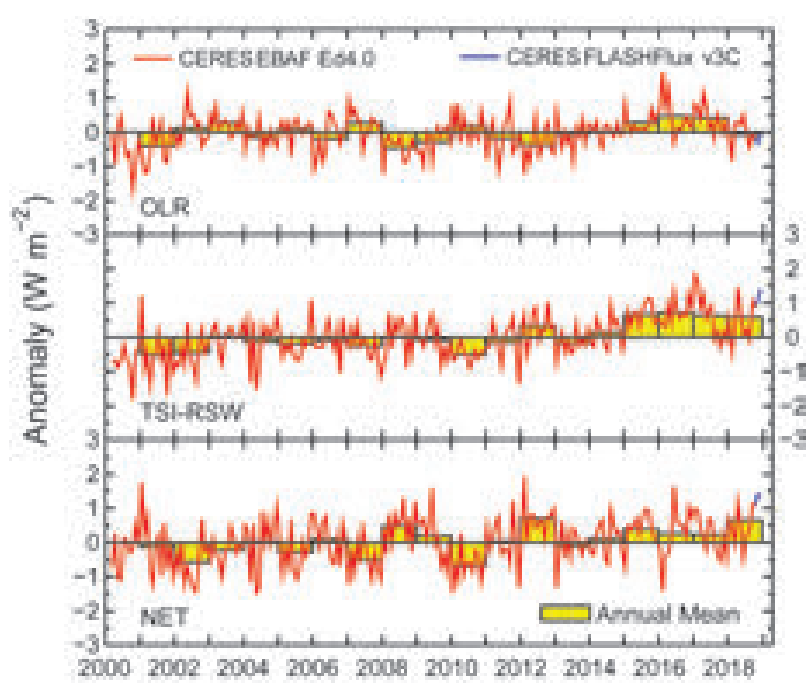

FIG. 2.44. Time series of global monthly mean deseasonalized anomalies $\left(\mathrm{W} \mathrm{m} \mathrm{m}^{-2}\right)$ of TOA Earth radiation budget for OLR (upper), absorbed shortwave (TSIRSW; middle), and total net (TSI-RSW-OLR; lower) from Mar 2000 to Dec 2018. Anomalies are relative to their calendar month climatology (200I-17). Annual averaged anomalies are also shown (yellow bars). Time series shows the CERES EBAF Ed4.0 I $^{\circ}$ data (Mar 2000-Oct 2018) in red and the CERES FLASHFlux version 3C data (Nov-Dec 20I8) in blue; see text for merging procedure (Sources: https://ceres-tool.larc .nasa.gov/ord-tool/jsp/EBAF4Selection.jsp and https: //ceres-tool.Iarc.nasa.gov/ord-tool/jsp/FLASH _TISASelection.jsp.)

value of $+1.5 \mathrm{~W} \mathrm{~m}^{-2}$ in April, decreased to a minimum value of about $-0.1 \mathrm{~W} \mathrm{~m}^{-2}$ in August, then climbed back to a positive value at year's end, ending with a value of $+1.4 \mathrm{~W} \mathrm{~m}^{-2}$. For the year as a whole, the 2018 global annual mean absorbed shortwave anomaly was $+0.6 \mathrm{~W} \mathrm{~m}^{-2}$. The global monthly mean total net anomaly, which is calculated from the absorbed shortwave anomaly minus the OLR anomaly, began 2018 with a value of $+0.7 \mathrm{~W} \mathrm{~m}^{-2}$, fluctuated between positive and negative values, remained positive for the last six months of the year, and ended with a value of about $+1.4 \mathrm{~W} \mathrm{~m}^{-2}$. The positive absorbed shortwave anomalies in 2018 dominated the negative effect of the OLR anomaly and resulted in the positive 2018 global annual mean total net anomaly of $+0.65 \mathrm{~W} \mathrm{~m}^{-2}$. This was the fifth consecutive year that the TOA global net anomaly was positive relative to climatology (see yellow bars in Fig. 2.44). Long-term trend analyses that include the last two months of the merged dataset are discouraged because of the natural fluctuation in ERB components, uncertainty from the data merging process, and potential for drift in the FLASHFlux product.

The TSI data used in this study are provided by the Total Irradiance Monitor aboard the Solar Radiation and Climate Experiment (SORCE) mission (Kopp and Lean 2011), and the Royal Meteorological Institute of Belgium composite dataset (Dewitte et al. 2004), both renormalized to the SORCE Version 15. The RSW and OLR data were obtained from the CERES mission (Wielicki et al. 1996, 1998) aboard Terra and Aqua spacecraft.

The time series (Fig. 2.44) were constructed from the CERES EBAF (Energy Balanced And Filled) Ed4.0 product (Loeb et al. 2009, 2012, 2018) for March 2000-October 2018 and from the CERES Fast Longwave and Shortwave Radiative Fluxes (FLASHFlux) version 3C product (Kratz et al. 2014) for November-December 2018. The normalization of the FLASHFlux data (Stackhouse et al. 2016) results in 2-sigma monthly uncertainties of \pm 0.42 , $\pm 0.08, \pm 0.22$, and $\pm 0.53 \mathrm{~W} \mathrm{~m}^{-2}$ for the OLR, TSI, RSW, and total net radiation, respectively. Global annual averaged maps were normalized on a regionby-region basis.

\section{g. Atmosperic composition}

I) LONG-LIVED GREenHOuSE GASES-E. J. Dlugokencky, B. D. Hall, S. A. Montzka, G. Dutton, J. Mühle, and J. W. Elkins

The main anthropogenic driver of climate change is the increased atmospheric burden of carbon dioxide $\left(\mathrm{CO}_{2}\right)$ from fossil fuel combustion. Methane $\left(\mathrm{CH}_{4}\right)$ and nitrous oxide $\left(\mathrm{N}_{2} \mathrm{O}\right)$ add significantly and increasingly to radiative forcing. Combined, these three long-lived greenhouse gases (LLGHGs) are responsible for $89 \%$ of the increase in radiative forcing since the pre-industrial era.

Systematic measurements of atmospheric $\mathrm{CO}_{2}$ began at Mauna Loa, Hawaii (MLO), in 1958, when $\mathrm{CO}_{2}$ was $\sim 315 \mathrm{ppm}$ [parts per million (by moles) in dry air]. In 2018, the annually averaged $\mathrm{CO}_{2}$ at MLO reached $408.5 \pm 0.1 \mathrm{ppm}$ (all uncertainties are $68 \%$ confidence intervals, unless noted otherwise) while globally averaged $\mathrm{CO}_{2}$ at Earth's surface was $407.4 \pm 0.1$ ppm (Fig. 2.45a).

Based on calibrated measurements of air extracted from ice in Greenland and Antarctica, it is known that the global abundance of atmospheric $\mathrm{CO}_{2}$ was $\sim 278 \pm 1.2 \mathrm{ppm}$ in $\sim 1750$ (Etheridge et al. 1996); the increase to $407.4 \pm 0.1 \mathrm{ppm}$ in 2018 increased the radiative forcing caused by $\mathrm{CO}_{2}$ by $>2 \mathrm{~W} \mathrm{~m}^{-2}$. During this time, $\sim 430 \mathrm{Pg} \mathrm{C}\left(1 \mathrm{Pg} \mathrm{C}=10^{15} \mathrm{~g} \mathrm{C}\right)$ were emitted as $\mathrm{CO}_{2}$ to the atmosphere from fossil fuel burning and cement production (Boden et al. 2017). Global $\mathrm{CO}_{2}$ emissions remained nearly constant from 2013-16, but increased by $1.7 \%$ in 2018 (IEA 2018). Constant, or slowly increasing $\mathrm{CO}_{2}$ emissions, are not sufficient to halt the increase in radiative forc- 


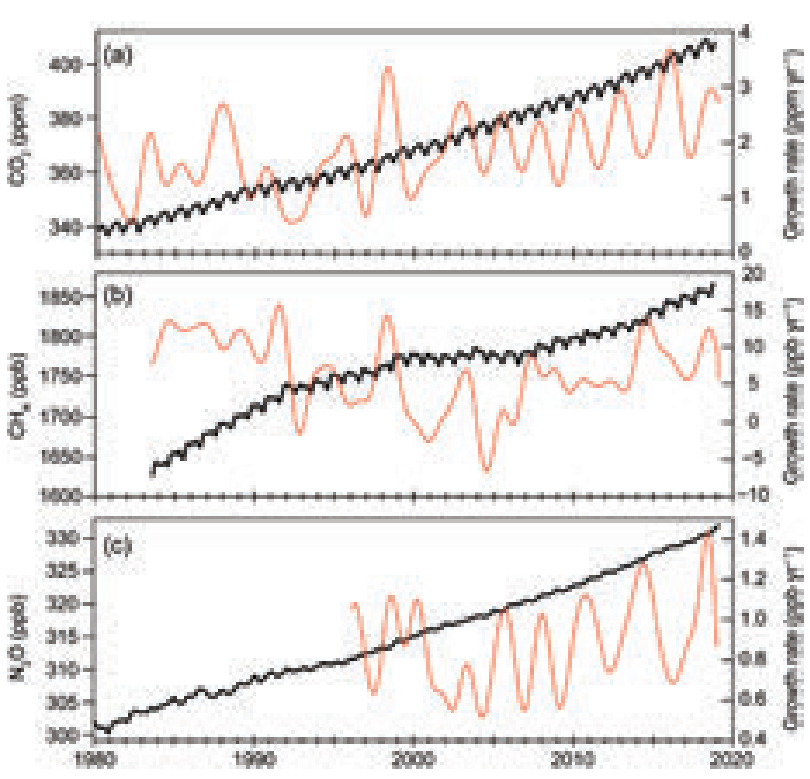

Fig. 2.45. Global monthly mean dry-air surface mole fractions (black) of (a) $\mathrm{CO}_{2}$, (b) $\mathrm{CH}_{4}$, and (c) $\mathrm{N}_{2} \mathrm{O}$ derived from the NOAA air sampling network. Instantaneous growth rates (red), calculated as the time-derivative of a deseasonalized trend curve (see Dlugokencky et al. 1994b for methods) are shown on the right axis $\left(\mathrm{N}_{2} \mathrm{O}\right.$ growth rate not shown prior to 1995 because the measurements were too noisy to adequately represent the instantaneous growth rate prior to this time). Note that 2018 data are preliminary.

ing (Montzka et al. 2011). It is difficult to determine exactly the total cumulative $\mathrm{CO}_{2}$ emissions that cannot be exceeded to avoid a dangerous threshold of warming, but various reports (Hansen et al. 2017; IPCC 2018) suggest the threshold is close or has already been reached.

About half of the $\mathrm{CO}_{2}$ emitted from fossil fuel combustion has dissolved in the world's oceans (Tans 2009 ) where it has made seawater $\sim 30 \%$ more acidic [as indicated by $\left(\mathrm{H}^{+}\right)$], with potential impacts on marine life. While the terrestrial biosphere is currently also a sink for fossil fuel $\mathrm{CO}_{2}$, emissions of $\mathrm{CO}_{2}$ to the atmosphere from land use change prior to $\sim 1940$ cancel recent uptake (Tans 2009).

Decadally averaged global growth of $\mathrm{CO}_{2}$ has risen monotonically from the 1960s to an average of 2.3 ppm $\mathrm{yr}^{-1}$, varying by $\pm 0.4 \mathrm{ppm} \mathrm{yr}^{-1}$ (1-sigma), during the past ten years; the increase in global annual mean $\mathrm{CO}_{2}$ from 2017 to 2018 was $2.5 \pm 0.1 \mathrm{ppm}$, comparable to the average rate of increase over the past decade. While emissions of $\mathrm{CO}_{2}$ from fossil fuel combustion drive its increasing atmospheric burden, variability in net terrestrial exchange resulting from meteorological impacts cause the interannual variability in $\mathrm{CO}_{2}$ growth rate.
Globally averaged methane $\left(\mathrm{CH}_{4}\right)$ at Earth's surface in 2018 was $1857.7 \pm 0.8 \mathrm{ppb}$ (Dlugokencky 2018). The increase in annual mean $\mathrm{CH}_{4}$ from 2017 to 2018 was $8.1 \pm 0.9 \mathrm{ppb}$, higher than the average growth rate over the past ten years of $6.9 \pm 2.6 \mathrm{ppb} \mathrm{yr}^{-1}$ (where the uncertainty is the standard deviation of annual increases). Since $1750, \mathrm{CH}_{4}$ has increased by $\sim 1137 \mathrm{ppb}$ from $722 \pm 15 \mathrm{ppb}$, contributing $0.51 \mathrm{~W} \mathrm{~m}^{-2}$ direct radiative forcing. $\mathrm{CH}_{4}$-related production of tropospheric $\mathrm{O}_{3}$ and stratospheric $\mathrm{H}_{2} \mathrm{O}$ also contributes $\sim 0.3 \mathrm{~W} \mathrm{~m}^{-2}$ indirect radiative forcing (Myhre et al. 2013).

Atmospheric $\mathrm{CH}_{4}$ has a complex budget with emissions from both anthropogenic $(\sim 60 \%)$ and natural ( 40\%) sources (Fung et al. 1991); its main loss process, atmospheric oxidation, is initiated by reaction with the short-lived ( 1 second lifetime) hydroxyl radical $(\mathrm{OH}$, which is poorly constrained by observations); and methane's rate of increase has varied interannually and decadally. Total global emissions of $\mathrm{CH}_{4}$ are reasonably well-constrained by the current network of atmospheric measurements and an estimate of its lifetime (Dlugokencky et al. 2011), but the magnitude and trend in emissions from individual sources and trends in $\mathrm{CH}_{4}$ atmospheric lifetime are still greatly uncertain. In the past three decades, methane's growth rate has undergone large changes (red line in Fig. 2.45b); from 1999 to 2006, its growth rate decreased to near zero, which is consistent with constant emissions, if there was no trend in its lifetime. On shorter time scales, there is significant interannual variability in growth rate, which results predominantly from changes in emissions from wetlands and biomass burning driven by meteorology but has also been affected by volcanic eruptions (Dlugokencky et al. 1994a; Bândă et al. 2013). Since 2007, atmospheric $\mathrm{CH}_{4}$ has been increasing again; measurements of $\mathrm{CH}_{4}$ abundance and its isotopic composition strongly suggest increased emissions from biogenic sources, both natural and anthropogenic (Nisbet et al. 2019; Schaefer et al. 2016; Schwietzke et al. 2016), rather than changes in fossil fuel-related emissions. Changes in $\mathrm{CH}_{4}$ loss rate have also been implicated, but such changes are highly uncertain (Naus et al. 2018).

Nitrous oxide $\left(\mathrm{N}_{2} \mathrm{O}\right)$ is a greenhouse gas and an ozone-depleting substance (Ravishankara et al. 2009). It is emitted to the atmosphere from natural and agricultural soils, and from the oceans. The imbalance between emissions and sinks, $40 \%$, is mostly caused by nitrogen-containing fertilizers and manure used for agriculture (Ciais et al. 2013). Except for a brief period in the 1940s, atmospheric $\mathrm{N}_{2} \mathrm{O}$ has been increasing 
steadily throughout the industrial era (MacFarling Meure et al. 2006). The mean global atmospheric $\mathrm{N}_{2} \mathrm{O}$ mole fraction in 2018 was $330.9 \pm 0.1 \mathrm{ppb}$, an increase of $1.1 \pm 0.2 \mathrm{ppb}$ from 2017 (Fig. 2.45c). This $1.1 \mathrm{ppb}$ increase in the annual mean is similar to the average annual increase over the past decade $(1.0 \pm 0.2 \mathrm{ppb})$.

Combined, the LLGHGs $\mathrm{CO}_{2}, \mathrm{CH}_{4}, \mathrm{~N}_{2} \mathrm{O}$, and several halogenated gases contribute just over $3 \mathrm{~W} \mathrm{~m}^{-2}$ to radiative forcing. The NOAA Annual Greenhouse Gas Index (AGGI; Fig. 2.46a) summarizes trends in the combined direct radiative forcing by $\mathrm{CO}_{2}, \mathrm{CH}_{4}$, $\mathrm{N}_{2} \mathrm{O}$, CFC-11, CFC-12, and 15 minor gases (Table 2.8; Fig. 2.46b; Hofmann et al. 2006). The AGGI represents the annual cumulative radiative forcing of these gases relative to the Kyoto Protocol baseline year of 1990. It does not include indirect radiative forcing (e.g., influences of methane increases on ozone and water vapor). The combined forcing in 2018 was $3.10 \mathrm{~W} \mathrm{~m}^{-2}$ and represents a nearly $43 \%$ increase since $1990\left(2.16 \mathrm{~W} \mathrm{~m}^{-2} ; 2018\right.$ AGGI $\left.=1.434\right)$. While the atmospheric abundances of some greenhouse gases such as chlorofluorocarbons have declined in recent decades (Fig. 2.47), the combined radiative forcing of LLGHGs has increased each year (Fig. 2.46b). The average increase in radiative forcing since 1980 is $0.036 \mathrm{~W} \mathrm{~m}^{-2} \mathrm{yr}^{-1}$. Year-to-year variations in this increment correspond roughly with variability in $\mathrm{CO}_{2}$, because $\mathrm{CO}_{2}$ is responsible for about $65 \%$ of radiative forcing by LLGHGs.

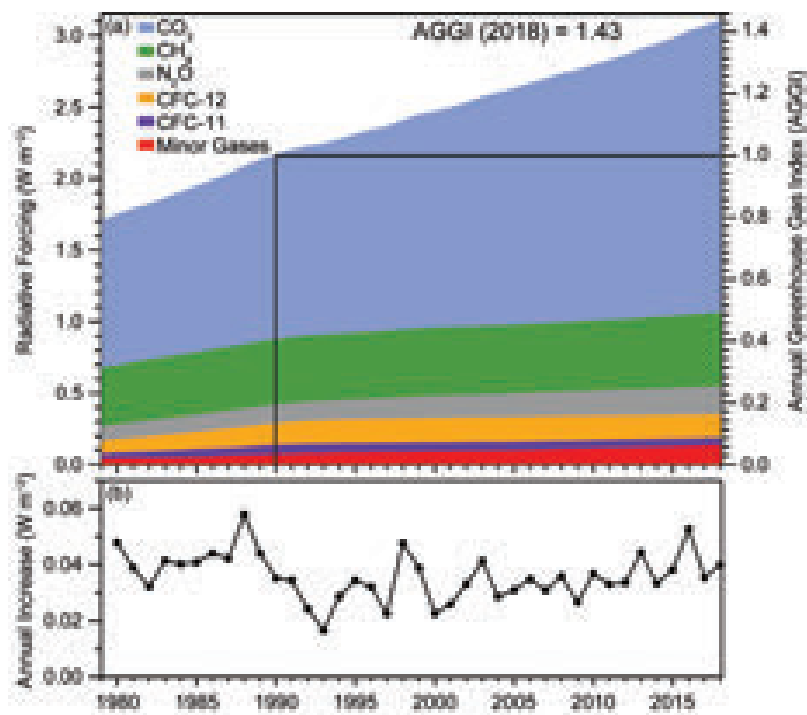

FIG. 2.46. (a) Direct radiative forcing $\left(\mathrm{W} \mathrm{m}^{-2}\right)$ due to 5 major LLGHG and 15 minor gases (left axis) and the associated values of the NOAA AGGI (right axis), and (b) annual increase in direct radiative forcing $\left(\mathrm{W} \mathrm{m}^{-2}\right)$. Solid black lines indicate that the AGGI had a value of 1.0 in 1990.

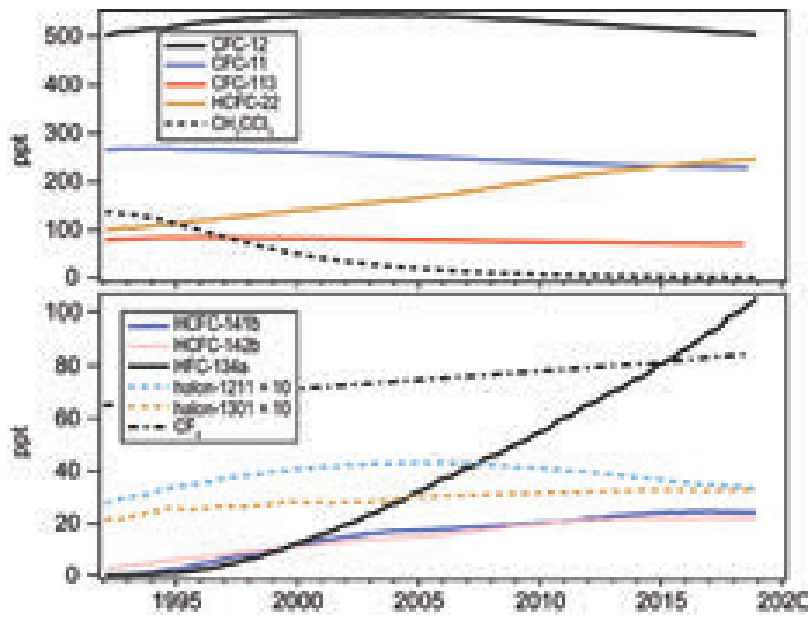

FIG. 2.47. Global mean mole fractions at Earth's surface (ppt, dry air) for several LLGHG, many of which also deplete stratospheric ozone. See Table 2.8 for the 2018 global mean mole fractions of these gases.

2) Ozone-depleting substances-B. D. Hall, S. A. Montzka, G. Dutton, B. R. Miller, and J. W. Elkins

Halogenated gases, such as CFCs and HCFCs, not only contribute to direct radiative forcing, but also impact stratospheric ozone, which influences climate (Karpechko et al. 2018). The emissions and atmospheric abundances (Fig. 2.47) of most ozonedepleting substances (ODS) are declining as expected due to controls implemented in the Montreal Protocol (Engel et al. 2018). A notable exception is CFC-11, for which emissions have unexpectedly increased in recent years (Montzka et al. 2018) even though atmospheric concentrations are still declining slowly (Fig. 2.47 and Table 2.8). Newly discovered sources of $\mathrm{CCl}_{4}$ emissions and a revision of the global atmospheric lifetime have improved our understanding of the $\mathrm{CCl}_{4}$ global budget (Engel et al. 2018; Lunt et al. 2018; Park et al. 2018). Continued emissions of ozonedepleting substances over what is expected under the Protocol could delay the recovery of stratospheric ozone (Montzka et al. 2018; Carpenter et al. 2018). While atmospheric abundances of HCFCs, which are replacements for CFCs, continue to increase, the rates of increase of HCFC-22, HCFC-141b, and HCFC142b, which are the most abundant HCFCs, have slowed in recent years. While non-ozone-depleting substitutes for HCFCs, known as HFCs, currently contribute little to radiative forcing, they are powerful greenhouse gases and concern about future emissions led to new controls on HFC production under the Kigali Amendment to the Montreal Protocol, which took effect in early 2019. 
TABLE 2.8. Summary table of long-lived greenhouse gases for $2018\left(\mathrm{CO}_{2}\right.$ mixing ratios are in ppm, $\mathrm{N}_{2} \mathrm{O}$ and $\mathrm{CH}_{4}$ in ppb, and all others in ppt).

\begin{tabular}{|c|c|c|c|c|c|c|}
\hline $\begin{array}{l}\text { Industrial } \\
\text { Designation or } \\
\text { Common Name }\end{array}$ & $\begin{array}{l}\text { Chemical } \\
\text { Formula }\end{array}$ & AGGI & ODGI & 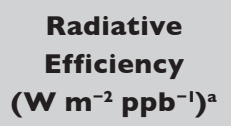 & $\begin{array}{c}\text { Mean Surface Mole } \\
2018 \text { Fraction } \\
\text { (change from prior year) }\end{array}$ & $\begin{array}{c}\text { Life- } \\
\text { time } \\
\text { (years) }\end{array}$ \\
\hline Carbon Dioxide & $\mathrm{CO}_{2}$ & Y & $\mathrm{N}$ & $1.37 \times 10^{-5}$ & $407.4(2.4)$ & \\
\hline Methane & $\mathrm{CH}_{4}$ & $Y$ & $\mathrm{~N}$ & $3.63 \times 10^{-4}$ & $1857.8(8.2)$ & 9.1 \\
\hline Nitrous Oxide & $\mathrm{N}_{2} \mathrm{O}$ & Y & $\mathrm{N}$ & $3.00 \times 10^{-3}$ & $330.9(1.1)^{c}$ & 123 \\
\hline \multicolumn{7}{|c|}{ Chlorofluorocarbons } \\
\hline CFC-II & $\mathrm{CCl}_{3} \mathrm{~F}$ & Y & Y & 0.26 & $228.2(-0.7)^{c}$ & 52 \\
\hline CFC-12 & $\mathrm{CCl}_{2} \mathrm{~F}_{2}$ & $\mathrm{Y}$ & $\mathrm{Y}$ & 0.32 & $505.6(-2.8)^{c}$ & 102 \\
\hline CFC-II3 & $\mathrm{CCl}_{2} \mathrm{FCClF}_{2}$ & $Y$ & $\mathrm{Y}$ & 0.30 & $70.3(-0.5)^{c}$ & 93 \\
\hline \multicolumn{7}{|c|}{ Hydrochlorofluorocarbons } \\
\hline HCFC-22 & $\mathrm{CHClF}_{2}$ & Y & Y & 0.21 & $244.1(3.8)$ & 11.9 \\
\hline HCFC-I4Ib & $\mathrm{CH}_{3} \mathrm{CCl}_{2} \mathrm{~F}$ & Y & Y & 0.16 & $24.4(-0.1)$ & 9.4 \\
\hline HCFC-142b & $\mathrm{CH}_{3} \mathrm{CClF}_{2}$ & $Y$ & $Y$ & 0.19 & $22.0(-0.1)$ & 18 \\
\hline \multicolumn{7}{|c|}{ Hydrofluorocarbons } \\
\hline HFC-134a & $\mathrm{CH}_{2} \mathrm{FCF}_{3}$ & $Y$ & $\mathrm{~N}$ & 0.16 & $102.0(6.3)$ & 14 \\
\hline HFC-I52a & $\mathrm{CH}_{3} \mathrm{CHF}_{2}$ & $\mathrm{Y}$ & $\mathrm{N}$ & 0.10 & $7.0(0.2)$ & 1.6 \\
\hline HFC-143a & $\mathrm{CH}_{3} \mathrm{CF}_{3}$ & $Y$ & $\mathrm{~N}$ & 0.16 & $22.2(1.6)$ & 51 \\
\hline HFC-I25 & $\mathrm{CHF}_{2} \mathrm{CF}_{3}$ & $Y$ & $\mathrm{~N}$ & 0.23 & $25.9(3.1)$ & 30 \\
\hline HFC-32 & $\mathrm{CH}_{2} \mathrm{~F}_{2}$ & $\mathrm{~N}$ & $\mathrm{~N}$ & 0.11 & I5.I (2.I) & 5.4 \\
\hline HFC-23 & $\mathrm{CHF}_{3}$ & $Y$ & $\mathrm{~N}$ & 0.18 & $31.2(1.3)$ & 228 \\
\hline HFC-365mfc & $\mathrm{CH}_{3} \mathrm{CF}_{2} \mathrm{CH}_{2} \mathrm{CF}_{3}$ & $\mathrm{~N}$ & $\mathrm{~N}$ & 0.22 & $0.97(0.04)$ & 8.9 \\
\hline HFC-227ea & $\mathrm{CF}_{3} \mathrm{CHFCF}_{3}$ & $\mathrm{~N}$ & $\mathrm{~N}$ & 0.26 & $1.42(0.13)$ & 36 \\
\hline \multicolumn{7}{|l|}{ Chlorocarbons } \\
\hline Methyl Chloroform & $\mathrm{CH}_{3} \mathrm{CCl}_{3}$ & Y & Y & 0.07 & $1.9(-0.3)$ & 5.0 \\
\hline Carbon Tetrachloride & $\mathrm{CCl}_{4}$ & $Y$ & Y & 0.17 & $79.3(-1.0)^{c}$ & 33 \\
\hline Methyl Chloride & $\mathrm{CH}_{3} \mathrm{Cl}$ & $\mathrm{N}$ & Y & 0.01 & $545.0(-2.6)$ & 0.9 \\
\hline \multicolumn{7}{|l|}{ Bromocarbons } \\
\hline Methyl Bromide & $\mathrm{CH}_{3} \mathrm{Br}$ & $\mathrm{N}$ & Y & 0.004 & $6.6(0)$ & 0.8 \\
\hline Halon $121 \mathrm{I}$ & $\mathrm{CBrClF}_{2}$ & $Y$ & $Y$ & 0.29 & $3.35(-0.08)$ & 16 \\
\hline Halon 1301 & $\mathrm{CBrF}_{3}$ & Y & Y & 0.30 & $3.26(0.00)$ & 72 \\
\hline Halon 2402 & $\mathrm{CBrF}_{2} \mathrm{CBrF}_{2}$ & Y & $\mathrm{Y}$ & 0.31 & $0.4 I(0)$ & 28 \\
\hline \multicolumn{7}{|c|}{ Fully fluorinated species } \\
\hline Sulfur Hexafluoride & $\mathrm{SF}_{6}$ & Y & $\mathrm{N}$ & 0.57 & $9.60(0.33)^{c}$ & $>600$ \\
\hline PFC-14 & $\mathrm{CF}_{4}$ & $\mathrm{~N}$ & $\mathrm{~N}$ & 0.09 & $84.6(1.0)$ & $\sim 50000$ \\
\hline PFC-116 & $\mathrm{C} 2 \mathrm{~F}_{6}$ & $\mathrm{~N}$ & $\mathrm{~N}$ & 0.25 & $4.76(0.10)$ & $\sim 10000$ \\
\hline PFC-218 & $\mathrm{C}_{3} \mathrm{~F}_{8}$ & $\mathrm{~N}$ & $\mathrm{~N}$ & 0.28 & $0.66(0.03)$ & $\sim 2600$ \\
\hline
\end{tabular}

${ }^{a}$ Radiative efficiencies were taken from IPCC AR5 (Myhre et al. 2013). Steady-state lifetimes were taken from Appendix A in WMO (2018), except for $\mathrm{SF}_{6}$, which is taken from Ray et al. (2017). For $\mathrm{CO}_{2}$, numerous removal processes complicate the derivation of a global lifetime. ${ }^{\mathrm{b}}$ Mole fractions are global, annual surface means for the indicated calendar year determined from the NOAA cooperative global air sampling network (Hofmann et al. 2006), except for PFC-14, PFC-116, PFC-218, and HFC-23, which were measured by AGAGE (Mühle et al. 2010; Miller et al. 2010). Changes indicated in brackets are the differences between the 2018 and 2017 means. All values are preliminary and subject to minor updates.

"Global mean estimates derived from multiple NOAA measurement programs ("Combined Dataset"). 


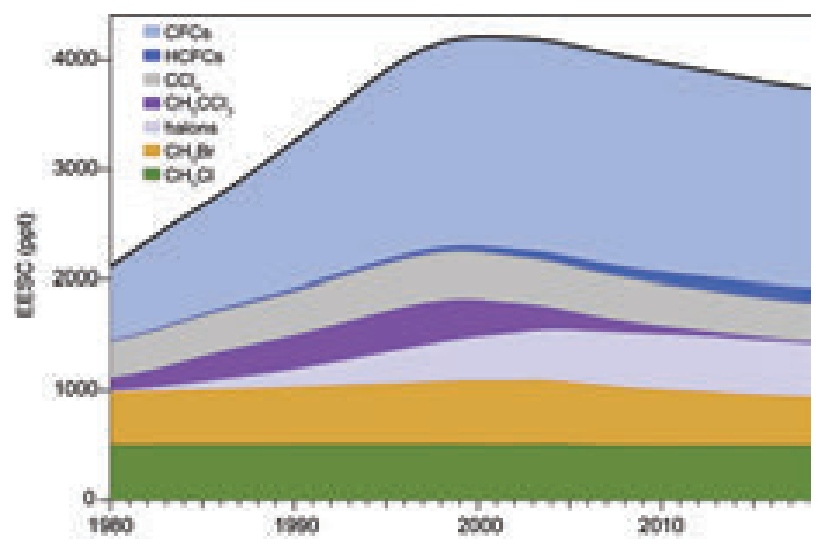

FIG. 2.48. EESC for the Antarctic stratosphere derived from NOAA surface measurements of long-lived ozone-depleting substances, supplemented with data from the WMO AI scenario (Harris et al. 20I4). EESC values correspond to Jan of each year.

Equivalent effective stratospheric chlorine (EESC) is a measure of the ozone-depleting potential of the stratospheric halogen loading at a given time and place. EESC is calculated from global average surface mole fractions of long-lived ozone-depleting gases and weighting factors that include surfaceto-stratosphere transport times, mixing during transit, photolytic reactivity, and ozone-destruction efficiency (Montzka et al. 1996; Newman et al. 2007). EESC is typically calculated for two regions that differ in total available reactive halogen: the Antarctic and midlatitude stratosphere. EESC and its components are shown for the Antarctic stratosphere in Fig. 2.48. The impact of declining $\mathrm{CH}_{3} \mathrm{CCl}_{3}$ (Fig. 2.47) on EESC is illustrated in Fig. 2.48. Stratospheric ozone is showing signs of recovery as EESC declines (Kuttippurath and Nair 2017; Strahan and Douglass 2018; see also Section 6g).

By the start of 2018, EESC decreased to $3733 \mathrm{ppt}$ and $1586 \mathrm{ppt}$ in Antarctic and midlatitude regions, respectively. These represent $21 \%$ and $45 \%$ reductions from the peak values in EESC over Antarctica and the midlatitudes, respectively, toward the 1980 benchmark values. EESC is expected to return to 1980 benchmark levels around 2050 in the midlatitudes and around 2075 in the Antarctic (Carpenter et al. 2018).

3) Aerosols-S. Rémy, N. Bellouin, Z. Kipling, M. Ades, A. Benedetti, and 0. Boucher

Atmospheric aerosols play an important role in the climate system by scattering and absorbing short- and long-wave radiation, and by indirectly affecting the life cycle, optical properties, and precipitation activity of clouds. Aerosols are also considered in many countries as a serious public health issue and, hence, are subject to monitoring and forecasting as part of air quality policies. They can be directly emitted (e.g., sea salt, dust, and carbonaceous aerosols) or the product of chemical reactions of precursor gases, such as sulfate, nitrate, and secondary organic aerosols.

The Copernicus Atmosphere Monitoring Service (CAMS) runs a near-real time global analysis of aerosols and trace gases. The CAMS project also produced a reanalysis of global aerosols and trace gases that covers the years 2003-18 (Inness et al. 2019), named the CAMS reanalysis (CAMSRA). Verification of total aerosol optical depth (AOD), a measure of the extinction of the solar beam by aerosols, against independent observations from the Aerosol Robotic NETwork (AERONET), shows that the CAMS reanalysis has a smaller bias and error than its predecessors, the CAMS interim reanalysis (Flemming et al. 2017) and the Monitoring Atmospheric Composition and Climate (MACC) reanalysis (Inness et al. 2013). This section uses data exclusively from the CAMSRA.

Retrievals of AOD at $550 \mathrm{~nm}$ (Levy et al. 2013) from the MODIS instrument onboard NASA Aqua and Terra satellites as well as from the Advanced Along-Track Scanning Radiometer (AATSR) instrument onboard ENVISAT (Popp et al. 2016) were assimilated. The anthropogenic emissions were taken from the MACCity inventory (Granier et al. 2011), while biomass burning emissions were provided by the Global Fire Assimilation System (GFAS) inventory (Kaiser et al. 2012). Dust and sea salt aerosol emissions were computed dynamically as a function of wind speed, temperature, and soil type.

The time series of monthly and annual globally averaged total AOD during 2003-18 (Fig. 2.49) shows strong seasonality, driven mainly by dust episodes between March and July in the Sahara and Taklimakan/Gobi Deserts and the Middle East, and

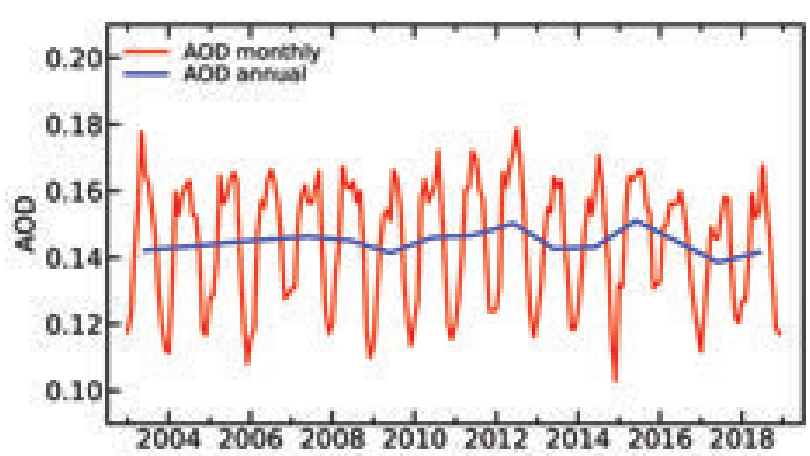

FIG. 2.49. Global average of total AOD at $550 \mathrm{~nm}$ averaged over monthly (red) and annual (blue) periods for 2003-I8. 
seasonal biomass burning in Africa, South America, and Indonesia. There is no significant trend over the period, but extreme events such as the 2015 El Niño fires over Indonesia are prominent.

As compared to the 2003-17 average from the CAMSRA, 2018 had negative anomalies of total AOD over most of Brazil, the eastern United States, boreal North America, China, Japan, and the Korean Peninsula as well as southeastern Siberia and most of Europe (Plate 2.1x). The negative anomalies over Brazil, the United States, Europe, and China are part of a longer trend over these regions, as shown in Fig. 2.50b. Over Europe and the United States, this negative trend is present throughout the period and is more pronounced after 2009; it is associated with a general decrease of anthropogenic emissions over these regions. Over China, the negative trend appears after 2012 and is consistent with the observed decrease in industrial sulfur dioxide $\left(\mathrm{SO}_{2}\right)$ emissions, the main precursor of sulfate aerosols, driven by tighter emission standards (Karplus et al. 2018). Aerosol emissions of biomass burning origin were reduced over Brazil due to less intense deforestation (Aragao et al. 2018). The 2018 negative anomalies in parts of boreal North America and parts of eastern Siberia were caused by a lower occurrence of fires in these regions as shown in Plate 2.1y. Positive anomalies of total AOD cover most of the Near and Middle East and India, as well as large swaths of the western United States, Canada, and Africa. The positive anomaly over the Indian subcontinent corresponds to a long-term trend of increasing anthropogenic emissions (Satheesh et al. 2017), as shown in Fig. 2.50b. The western United States and southwest Canada had extreme fires during July, August, and November [e.g., the Camp Fire in California, which caused many casualties (see Sidebar 7.1 for more details)]. British Columbia had its worst fire season on record, breaking the record set just the previous year in 2017. The positive anomalies over the Near and Middle East and North Africa were caused by an active dust season there (Plate 2.z), particularly over Iran and Pakistan. The northern Arabian Sea and the Persian Gulf were $1.5^{\circ}-2.0^{\circ} \mathrm{C}$ above normal during most of the year except June-September, which possibly contributed to the development of strong winds over the adjacent dust-producing regions. The positive anomaly of dust AOD over most of the Sahara during 2018 was associated with stronger transatlantic transport than usual and high dust concentrations over the Caribbean Islands and parts of Central America.

Global maps of the 2003-18 average total AOD and statistically significant ( $95 \%$ confidence) linear trends over the period are shown in Figs. 2.50a,b. High AOD values include the highly polluted areas of southern and eastern Asia, the dust-producing regions of the Sahara, Saudi Arabia, the Middle East, and the Taklimakan and Gobi Deserts, and the regions mostly concerned with seasonal biomass burning such as equatorial Africa, Brazil, and Indonesia. The high values
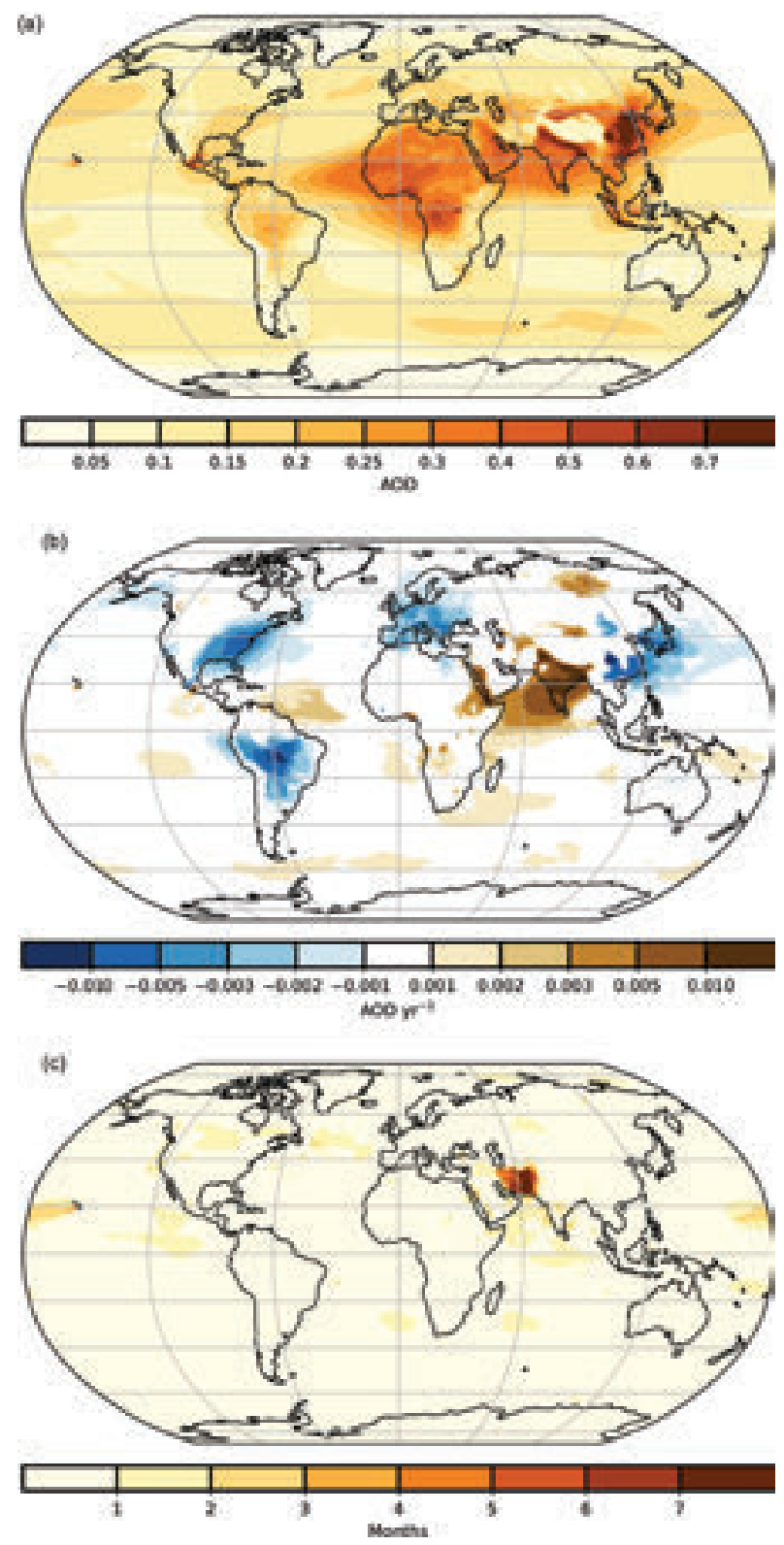

FIG. 2.50. (a) Total AOD at $550 \mathrm{~nm}$ averaged over the period 2003-18. Note the regional differences, with much greater total AOD values over parts of northern Africa, the Arabian Peninsula, southern Asia, and eastern China. (b) Linear trends of total AOD (AOD $\mathrm{yr}^{-1}$ ) for 2003-I8. Only trends that are statistically significant ( $95 \%$ confidence) are shown. (c) Number of months in 2018 with extreme AOD (above the 2003-17 average plus four std. dev.). 
over Hawaii and near Mexico City are a known artifact of the CAMSRA related to volcanic outgassing. Figure 2.50c shows a simple indicator of the occurrence of extreme monthly AOD values. The region most impacted was around Iran and Pakistan and, to a lesser extent, the rest of the Middle East and the Arabian Sea, due to a series of dust storms from April to June. The high values over southern Canada, the western United States, and parts of the North Atlantic are associated with extreme fires in August and November.

Radiative forcing resulting from aerosol-radiation (RFari) and aerosol-cloud interactions (RFaci) for the period 2003-18 is shown in Fig. 2.51, as estimated using the methods described in Bellouin et al. (2013) but with CAMSRA data. The year 2018 was average in terms of RFari, while RFaci was relatively weak due to fewer anthropogenic aerosols over the ocean, where clouds are more sensitive to aerosol perturbations. Trends remain statistically fragile because of large uncertainties in the estimates.

4) Stratospheric ozone-M. Weber, W. Steinbrecht, C. Arosio, R. van der A, S. M. Frith, J. Anderson, M. Coldewey-Egbers, S. Davis, D. Degenstein, V. E. Fioletov, L. Froidevaux, D. Hubert, C. S. Long, D. Loyola, A. Rozanov, C. Roth, V. Sofieva, K. Tourpali, R. Wang, and J. D. Wild

Global stratospheric ozone levels vary from year to year depending on the dynamical state of the atmosphere. Generally, ozone variability becomes larger with increasing latitude. Plate 2.1aa shows the global distribution of annual mean total ozone anomalies for 2018. Total ozone variability in the tropics is mainly governed by the Quasi-bienniel Oscillation (QBO). During NH winter 2017/18, the QBO at 50 $\mathrm{hPa}(\sim 22 \mathrm{~km}$, lower stratosphere) was in its easterly phase. This is associated with negative total ozone anomalies in the inner tropics (e.g., Diallo et al. 2018) and positive anomalies in the subtropics and midlatitudes. Throughout the entire $\mathrm{SH}$ extratropics, total ozone levels in 2018 were, therefore, well above the mean [up to 15 Dobson units (DU)] compared to the reference period 1998-2008. Over much of the Ant- arctic region, values were lower than the long-term mean. This is related to an above-average size spring ozone hole in 2018 (see low October means in Fig. $2.52 \mathrm{e}$ and Section 6j). Extratropical ozone variability maximizes in winter/spring when meridional ozone transport related to the Brewer-Dobson circulation and QBO is most active. These transport variations are the main contributors to variations in annual mean total ozone. In the $\mathrm{NH}$, therefore, total ozone was slightly above average in 2018 but with extended regions of negative anomalies. Above the Aleutian region in Alaska, total ozone was up to 15 DU below the long-term average, while above Greenland and the North Atlantic region, total ozone was higher by more than 15 DU (Plate 2.1aa). In spring 2018, NH polar ozone losses were largely absent due to warm conditions (and enhanced ozone transport) and a weak polar vortex (North Atlantic region). The March $\mathrm{NH}$ polar cap total ozone mean in 2018 (Fig. 2.52e) was in the upper range of values observed during the last two decades.

Figure 2.52 shows the annual mean total ozone time series from various merged datasets for the near-global average $\left(60^{\circ} \mathrm{N}-60^{\circ} \mathrm{S}\right)$ average, tropics, extratropics, and selected months in the polar regions. Midlatitude total ozone means were high in 2018, while the tropical values were low compared to the annual means observed in the recent decade (see also 


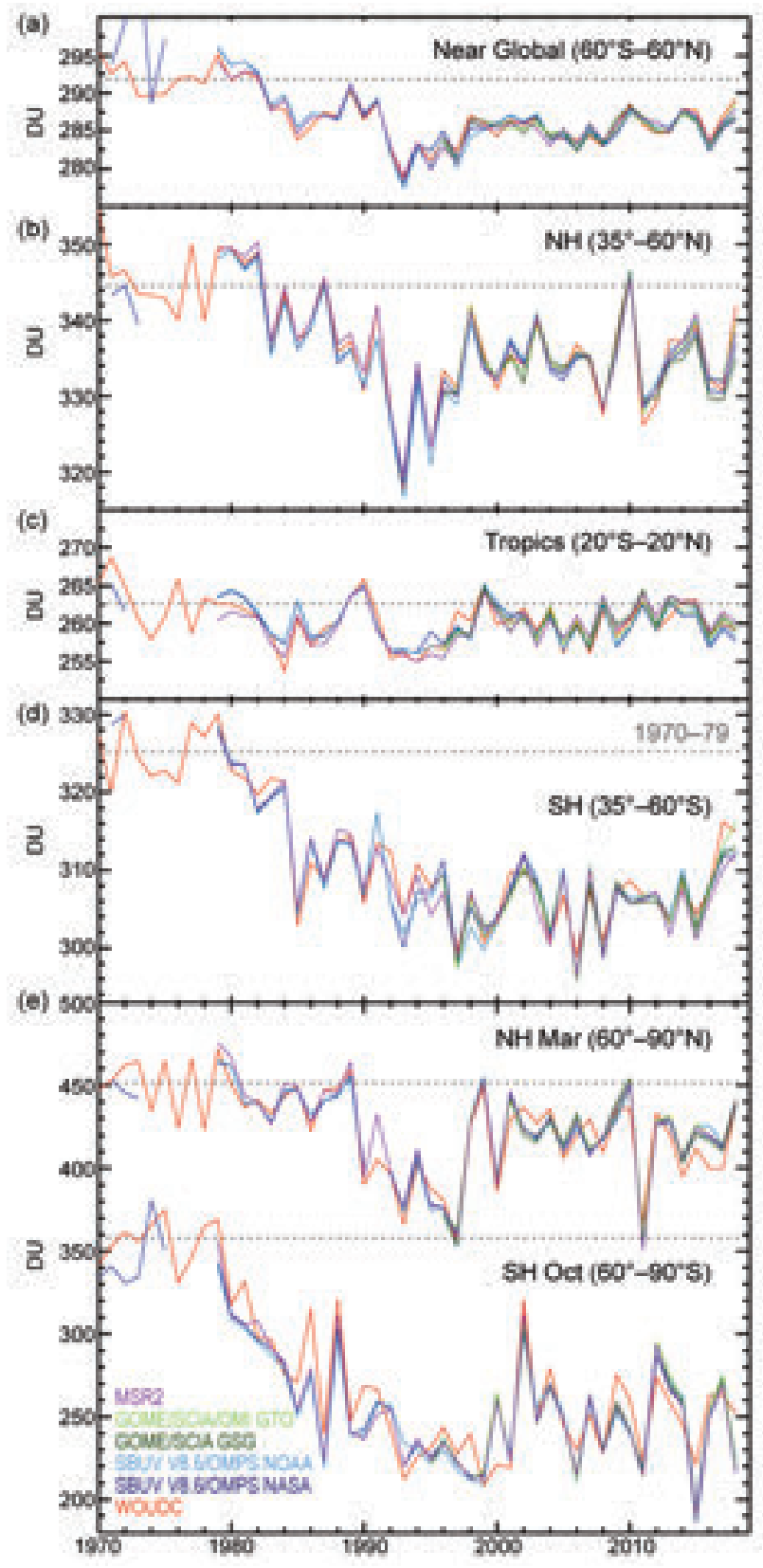

FIG. 2.52. Time series of annual mean total ozone (DU) in (a)-(d) four zonal bands, and (e) polar $\left(60^{\circ}-90^{\circ}\right)$ total ozone in Mar (NH; see also Section $\left.5 \mathrm{j}\right)$ and Oct (SH), the months when polar ozone losses usually are largest. Data are from WOUDC (World Ozone and Ultraviolet Radiation Data Centre) groundbased measurements combining Brewer, Dobson, SAOZ (Système D'Analyse par Observations Zénithales), and filter spectrometer data (red: Fioletov et al. 2002, 2008); the BUV/SBUV/SBUV2 V8.6/OMPS merged products from NASA (MOD V8.6, dark blue, Frith et al. 2014, 2017) and NOAA (light blue: Wild and Long, personal communication, 2019; the GOME/SCIAMACHY/GOME-2 products GSG from University of Bremen (dark green, Weber et al. 2018) and GTO from ESA/DLR (light green, Coldewey-Egbers et al. 2015; Garane et al. 2018). MSR-2 (purple) assimilates nearly all ozone datasets after corrections with respect to the ground data (van der $A$ et al. 2015). All six datasets have been bias corrected by subtracting averages for the reference period 1998-2008 and adding back the mean of these averages. The dotted gray lines in each panel show the average ozone level for 1970-79 calculated from the WOUDC data. All data for 2018 are preliminary.
Plate 2.1aa). For all latitude bands, except the tropics, cance. Still, the small increase in global total ozone following the significant decline before the $1990 \mathrm{~s}$ Amendments, responsible for phasing out ODSs, has been successful. The observed changes in total ozone and in lower stratospheric ozone are reproduced well by state-of-the-art chemistry-transport model calfor changes in Protocol (Chipperfield et al. 2018).

Apart from the polar regions, the largest effect of ccurs in the upper stratosphere (around $40 \mathrm{~km}$ 2017; WMO 2018a; SPARC/IO3C/GAW 2019). The ozone decline from the late 1970s to the late 1990s, due to increasing atmospheric concentrations of ODSs, stopped. Since around 2000, ozone has been sing slowly in both hemispheres, indicating et al. 2018; WMO 2018a; SPARC/IO3C/GAW 2019). At northern midlatitudes, ozone in 2018 was within the range observed in recent years.

Figure 2.54 shows that ozone profile trends vary with longitude. The largest (and most significant) ozone increases from 2003-18 have occurred between $40 \mathrm{~km}$ and $45 \mathrm{~km}$ altitude in the Western Hemisphere, and at higher latitudes in both hemispheres. Longitudinal variations arise from zonally non-symmetric changes in circulation patterns, which influence trace gas transports and chemical reactions relevant for ozone. More studies are needed to consolidate these results and their interpretation.

In the lower stratosphere, ozone variations are largely driven by meteorological 
variations in transport, and less so by changes in ODSs (e.g., Chipperfield et al. 2018). Ozone near $50-\mathrm{hPa} / 22-\mathrm{km}$ altitude at midlatitudes in both hemispheres declined before the mid-1990s and remained more or less stable during the last 20 years (Fig. 2.53c). In the tropics (e.g., $20^{\circ} \mathrm{N}-20^{\circ} \mathrm{S}$ ), observations and CCMI model simulations at $50 \mathrm{hPa}$ do show a continuing long-term decline, which is linked to a climate

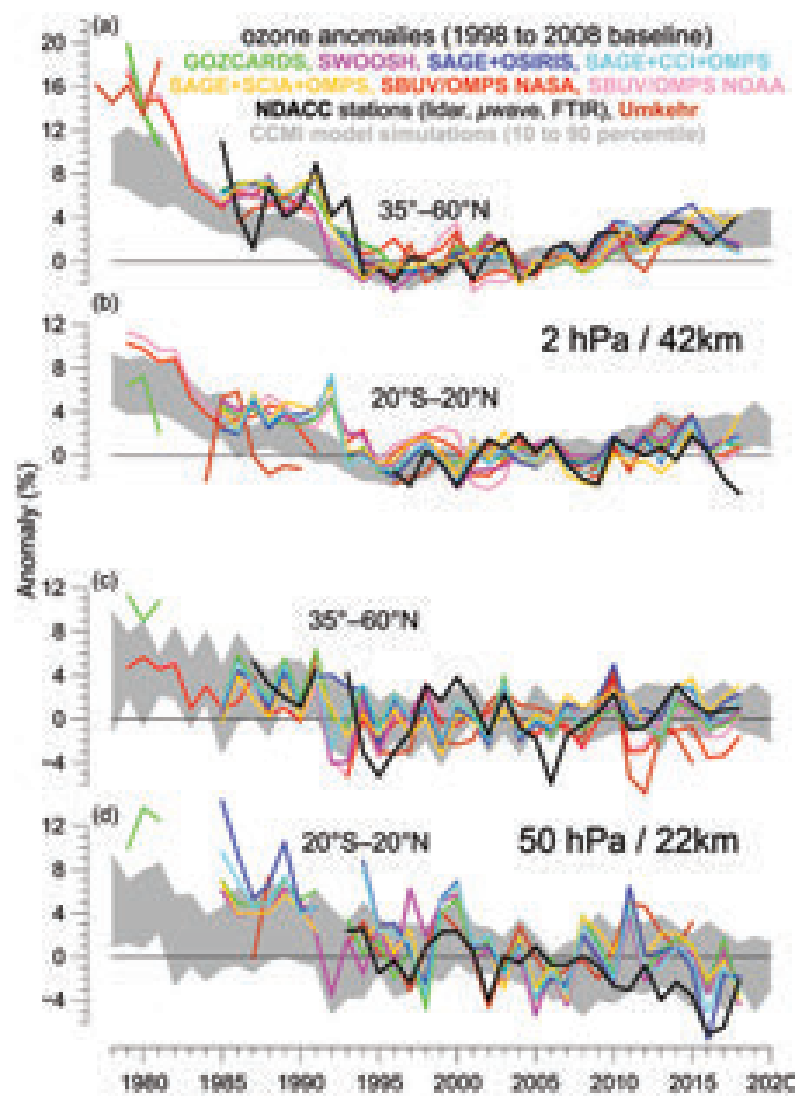

Fig. 2.53. Annual mean anomalies of ozone in the upper stratosphere near (a) and (b) $42 \mathrm{~km}$ altitude (2 $\mathrm{hPa}$ ) and (c) and (d) near $22 \mathrm{~km} \mathrm{(50} \mathrm{hPa)} \mathrm{for} \mathrm{two} \mathrm{zonal}$ bands: $35^{\circ}-60^{\circ} \mathrm{N}$ and $20^{\circ} \mathrm{N}-20^{\circ} \mathrm{S}$ (tropics), respectively. Anomalies are referenced to the 1998-2008 baseline. Colored lines are for long-term records obtained by merging different limb (GOZCARDS, SWOOSH, SAGE+OSIRIS, SAGE+CCI+OMPS-LP, SAGE+SCIAMACHY+OMPS-LP) or nadir viewing (SBUV, OMPS-NP) satellite instruments. Black line is from merging ground-based ozone records at NDACC stations employing differential absorption lidars, microwave radiometers, or Fourier Transform InfraRed spectrometers (FTIRs). Brown line is for ground-based Umkehr measurements. See Steinbrecht et al. (2017), WMO 2018a, and Arosio et al. (2018) for details on the various datasets. Gray shaded area shows the range of chemistry-climate model from CCMI (WMO 2018a; SPARC/IO3CIGAW 2019; Dhomse et al. 2018). Ozone data for 2018 are not yet complete for all instruments and are still preliminary.
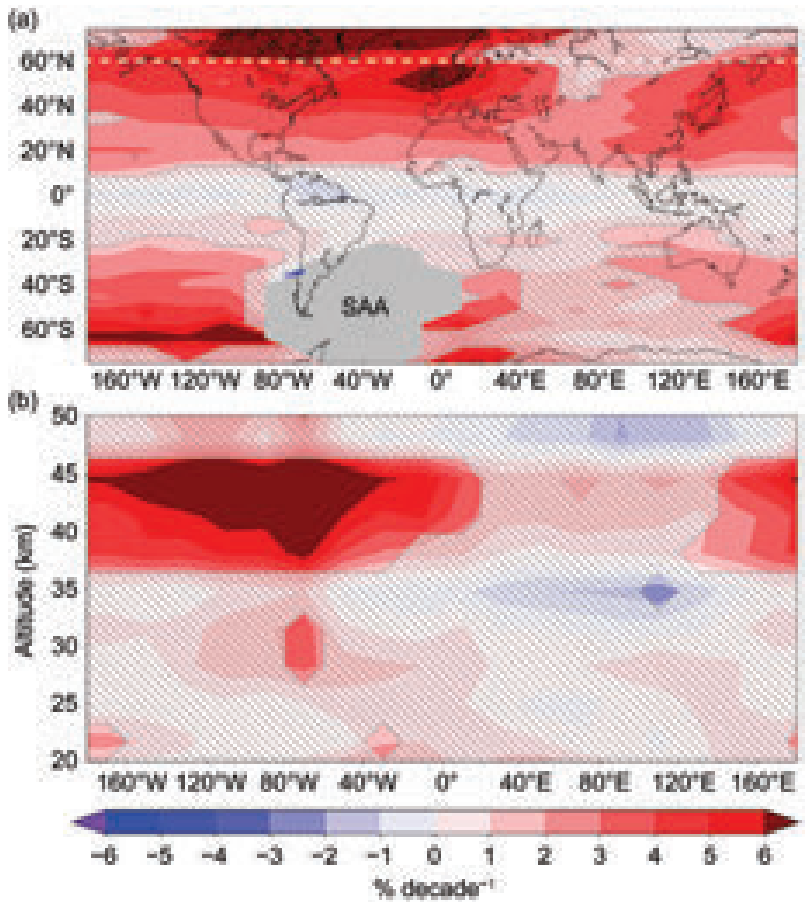

FIG. 2.54. Ozone trends (\% decade ${ }^{-1}$ ) at (a) $43.1 \mathrm{~km}$ for (latitude vs. longitude) and (b) $60^{\circ} \mathrm{N}$ (altitude vs. longitude) from the longitudinally resolved SCIAMACHYOMPS-LP merged ozone profile dataset for the 2003-18 period as derived from a multiple variate linear regression. Dashed areas indicate non-significant trends and the gray polygon indicates the location of the South Atlantic Anomaly (SAA) where data quality is poor. Update from Arosio et al. 2018.

change-related acceleration of the meridional BrewerDobson circulation (Ball et al. 2018; Chipperfield et al. 2018; WMO 2018a). The large interannual variations and the uncertainties in the observational data records result in considerable spread for the time series to date, thus making reliable detection of small underlying trends rather difficult.

5) Stratospheric water vapor-S. M. Davis, K. H. Rosenlof, D. F. Hurst, H. B. Selkirk, and H. Vömel

Following several years of dramatic changes in lower stratospheric water vapor (SWV), 2018 started as a relatively quiescent year. In January, the tropical mean $\left(15^{\circ} \mathrm{N}-15^{\circ} \mathrm{S}\right)$ water vapor anomaly in the lowermost stratosphere (at $82 \mathrm{hPa}$ ), as measured by the Aura Microwave Limb Sounder (MLS) satellite instrument, was $+0.14 \mathrm{ppm}$ (parts per million mole fraction, equivalent to $\mu \mathrm{mol} \mathrm{mol}^{-1}$ ), which corresponds to a deviation of only $5 \%$ from its long-term 2004-18 average value for this month (2.9 ppm). From January through October this Aura MLS tropical mean lower stratospheric water vapor anomaly remained within $11 \%$ of its long-term average 
(Fig. 2.55). A significant drop of $0.5 \mathrm{ppm}$ occurred in November.

The tropical lower stratospheric water vapor anomaly is an important quantity because the primary pathway for air to enter the global stratosphere is via crossing the tropical tropopause, and the mixing ratio of water vapor in this region is quasi-conserved as it is transported vertically and horizontally (Fig. 2.55). In general, the qualitative behavior of tropical lowermost stratospheric water vapor observed by Aura MLS is consistent with balloon-borne frost point hygrometer soundings at tropical sites Hilo, Hawaii $\left(20^{\circ} \mathrm{N}\right)$, and San José, Costa Rica $\left(10^{\circ} \mathrm{N}\right.$; Figs. $2.56 \mathrm{c}$,d), although there is some evidence of drifts of the MLS measurements relative to the balloon measurements (Hurst et al. 2016).

Variations in the cold-point temperature (CPT) in the tropical tropopause layer (TTL) provide the

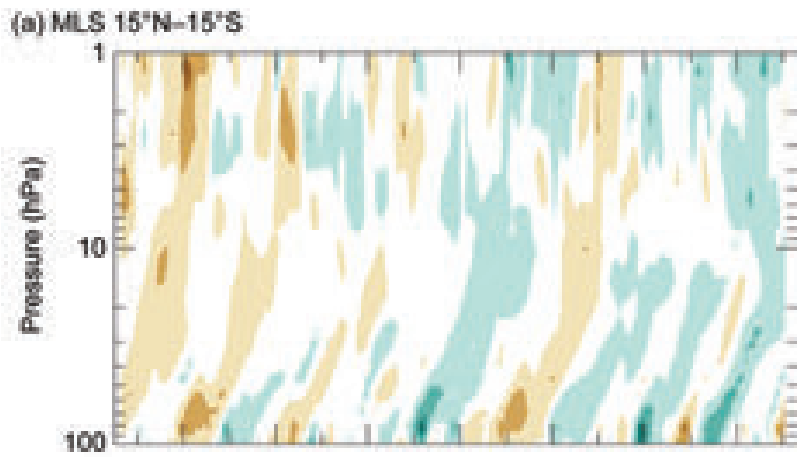

(b) MLS $82 \mathrm{hPa}$

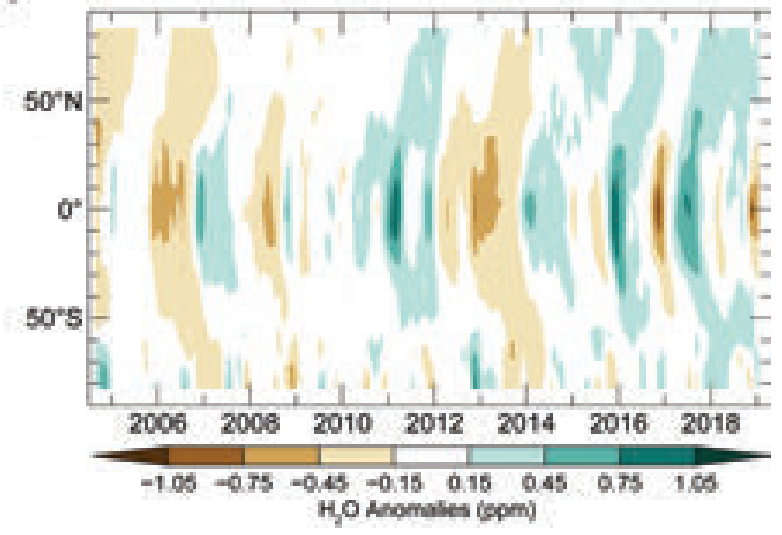

FIG. 2.55. (a) Time series of vertical profiles of tropical $\left(15^{\circ} \mathrm{N}-15^{\circ} \mathrm{S}\right) \mathrm{SWV}$ anomalies and (b) latitudinal distributions of SWV anomalies at $82 \mathrm{hPa}$. Both are based on Aura MLS data. Anomalies are differences from the mean 2004-18 water vapor mixing ratios (ppm) for each month. Panel (b) shows the propagation of tropical lower SWV anomalies to higher latitudes in both hemispheres as well as the influences of dehydrated air masses from the Antarctic polar vortex as they are transported toward the $\mathrm{SH}$ midlatitudes at the end of each year. dominant control of water vapor entering into the lowermost stratosphere. Air is freeze-dried as it slowly ascends through the TTL $(14-19 \mathrm{~km}, \sim 150-70 \mathrm{hPa})$, and because of this, seasonal to interannual variability in tropical SWV around $82 \mathrm{hPa}$ is highly correlated with CPT temperature variations. The dramatic $0.5 \mathrm{ppm}$ drop in SWV in November 2018 that persisted through the end of the year (Figs. 2.56d, 2.57) coincided with a drop in the tropical average CPT during this same time period (Fig. 2.56d). During November, the dry anomalies were confined to the $\pm 10^{\circ}$ latitude band centered on the equator (Fig. 2.55b) and were fairly uniform in longitude (Fig. 2.57b). By December, the pattern was less zonally uniform
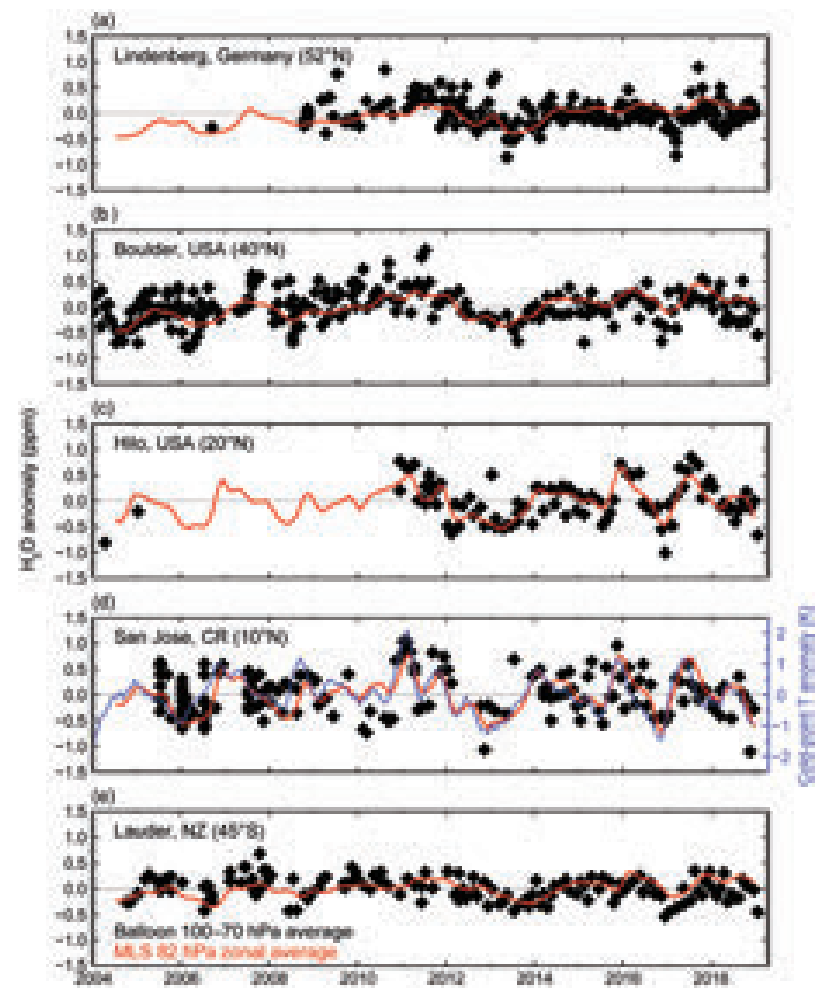

FIG. 2.56. Lower stratospheric water vapor anomalies over five balloon-borne frostpoint (FP) hygrometer stations. Each panel shows the lower stratospheric anomalies of individual FP soundings (black) and of monthly zonal averages of MLS retrievals at $82 \mathrm{hPa}$ in the $5^{\circ}$ latitude band containing the FP station (red). High-resolution FP vertical profile data were averaged between 70 and $100 \mathrm{hPa}$ to emulate the MLS averaging kernel for $82 \mathrm{hPa}$. Each MLS monthly zonal mean was determined from 2000-3000 profiles. Anomalies for MLS and FP data are calculated relative to the 2004- 18 period for sites except for Lindenberg (2009-18) and Hilo (20II-18). Tropical CPT anomalies based on the MERRA-2 reanalysis (d, blue curve), which are generally well correlated with the tropical lower SWV anomalies, are the driving force behind the variations in tropical SWV during 2018. 


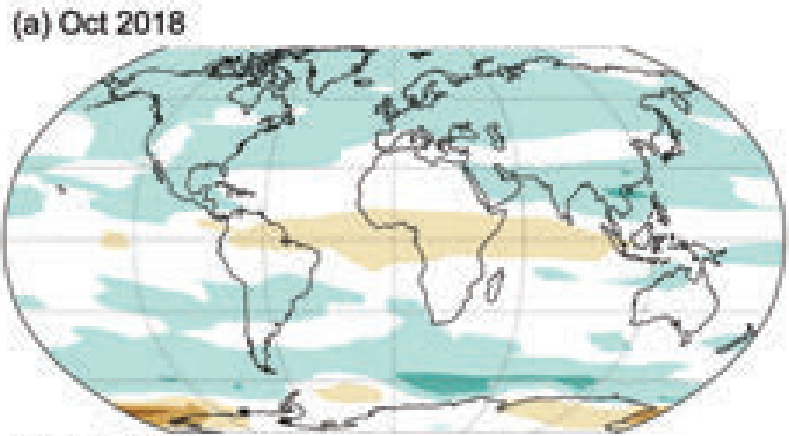

(b) Nov 2018

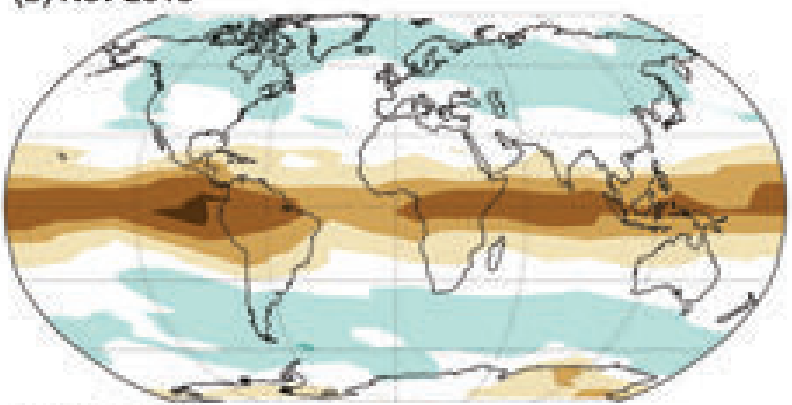

(c) Dec 2018

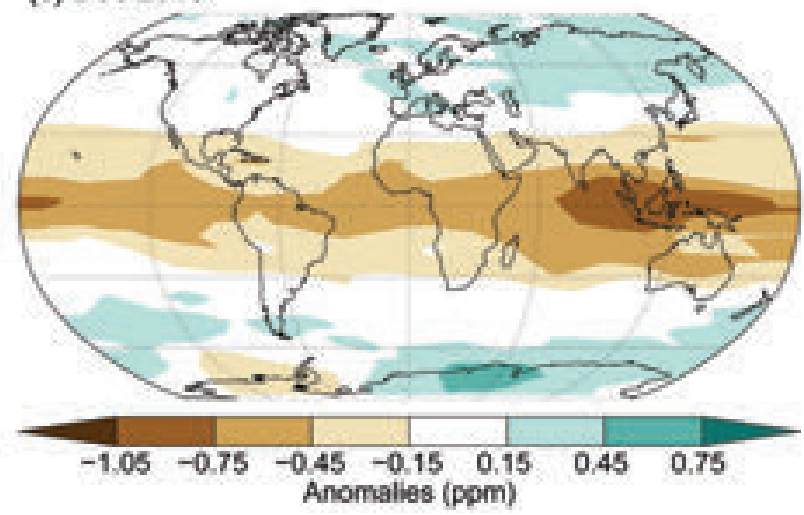

FIG. 2.57. Global stratospheric water vapor anomalies (ppm) centered on $82 \mathrm{hPa}$ in (a) Oct 2018, (b) Nov 2018, and (c) Dec 2018 from the Aura MLS.

with the strongest dry anomalies over the maritime continent and the tropical western Pacific (Fig. 2.57c).

What caused the decrease in tropical CPTs at the end of 2018 that produced the dry conditions in the lowermost stratosphere? In general, interannual variations in CPTs can be impacted by interannual variability in the phases of ENSO and the QBO in tropical stratospheric winds (Dessler et al. 2014). During 2018, the QBO was in a westerly (warm) phase at $70 \mathrm{hPa}$ from January until June, and then switched to an easterly (cold) phase from July through the end of the year (Section 2e3). ENSO was in a weak La Niña through March, followed by a neutral phase that developed into a weak El Niño by the end of the year. It is possible that enhanced tropical upwelling due to the $\mathrm{QBO}$ easterly phase contributed to the nega- tive (cold) CPT anomalies and negative (dry) SWV anomalies in the tropical lower stratosphere at the end of 2018. However, it is worth noting that several other climate phenomena were in play at the end of 2018 and may have also contributed to the CPT and SWV anomalies, for example, wave forcing in the $\mathrm{NH}$ midlatitudes, as well as enhanced convection west of the antimeridian associated with the MJO (see Section 4c). Enhanced wave forcing would drive enhanced upwelling, and ultimately colder temperatures in the tropics. Enhanced convection can be associated with enhanced upwelling or changes in the radiative balance at the tropopause, also producing colder temperatures.

Finally, relatively small changes in SWV anomalies were observed over the midlatitude balloon sounding stations (Figs. 2.56a,b,e) during 2018. These sites can be impacted by quasi-isentropic transport from the tropics. Indeed, the wet tropical anomalies from 2017 reached all three extratropical sites during 2018 (Fig. 2.55b). However, the dry tropical anomalies that appeared in late 2018 had not yet arrived at these sites by the end of the year. This is not unexpected, as an examination of Fig. 2.55b shows that it takes 4-6 months for the wet and dry QBO-related anomalies to reach high latitudes.

6) Tropospheric ozone-J. R. Ziemke and 0. R. Cooper

Tropospheric ozone is both a surface pollutant and a greenhouse gas, contributing to global warming and atmospheric radiative forcing, and it is also the main source of the global hydroxyl radical $(\mathrm{OH})$, which is the cleanser of tropospheric pollutants. As a greenhouse gas, tropospheric ozone has an estimated globally averaged radiative forcing of $0.40 \pm 0.20 \mathrm{~W} \mathrm{~m}^{-2}$ (IPCC 2013). Tropospheric ozone originates from photochemical reactions involving precursor gases including biogenic hydrocarbons, methane, lightning $\mathrm{NO}_{\mathrm{x}}$, emissions from combustion of fossil fuels and biomass burning, and also ozone transported from the stratosphere (e.g., Monks et al. 2015; Yu. Zhang et al. 2016; Lin et al. 2017).

This report, as in those dating to 2012 (Cooper and Ziemke 2013), is based on ground-based measurements and Aura Ozone Monitoring Instrument/Microwave Limb Sounder (OMI/MLS) satellite measurements (e.g., Ziemke and Cooper 2018, and references therein). Plate 2.1ab shows broad regions of positive 2018 tropospheric column ozone anomalies (relative to the 2005-17 average) of up to $1.2 \mathrm{DU}(4 \%)$ in the $\mathrm{NH}$ midlatitudes, especially over northern India and the Tibetan Plateau as well as Japan, and smaller anomalies of $\sim 1$ DU or less elsewhere. Hemispheric 
and global average tropospheric ozone burdens and their 95\% confidence levels for 2018 were 160 $\pm 7 \mathrm{Tg}$ for $0^{\circ}-60^{\circ} \mathrm{N} ; 147 \pm 7 \mathrm{Tg}$ for $0^{\circ}-60^{\circ} \mathrm{S}$; and 308 $\pm 7 \mathrm{Tg}$ for $60^{\circ} \mathrm{N}-60^{\circ} \mathrm{S}$ (Fig. 2.58). Linear trends of the tropospheric ozone burden in both hemispheres and for $60^{\circ} \mathrm{N}-60^{\circ} \mathrm{S}$ from October 2004 through December 2018 indicate statistically significant increases of 0.83 $\operatorname{Tg~yr}^{-1}\left(\sim 0.6 \% \mathrm{yr}^{-1}\right)$ in the SH to $0.94 \mathrm{Tg} \mathrm{yr}^{-1}\left(0.7 \% \mathrm{yr}^{-1}\right)$ in the $\mathrm{NH}$ (Fig. 2.58).

The spatial distribution of trends in tropospheric ozone on a $5^{\circ} \times 5^{\circ}$ grid for October 2004-December 2018 are shown in Fig. 2.59. Statistically significant trends up to $\sim+3.2 \mathrm{DU}$ decade ${ }^{-1}\left(+1.1 \% \mathrm{yr}^{-1}\right)$ extend from India to East/Southeast Asia and farther eastward across the North Pacific Ocean. These large increases are consistent with model simulations based on strengthening emissions of ozone precursors in this region (Yu. Zhang et al. 2016; Lin et al. 2017; Ziemke et al. 2019). Positive trends are also located over the North Atlantic Ocean, tropical Atlantic/ Africa region, and in the $\mathrm{SH}$ extratropics. $\mathrm{Lu}$ et al. (2018a) suggest that tropospheric ozone throughout the SH extratropics has increased since 1990 due to a broadening of the Hadley circulation and associated increases in ozone precursors and influx from the stratosphere.

Updating global surface ozone measurements on an annual basis is difficult since most ground stations do not provide quality-assured final data soon

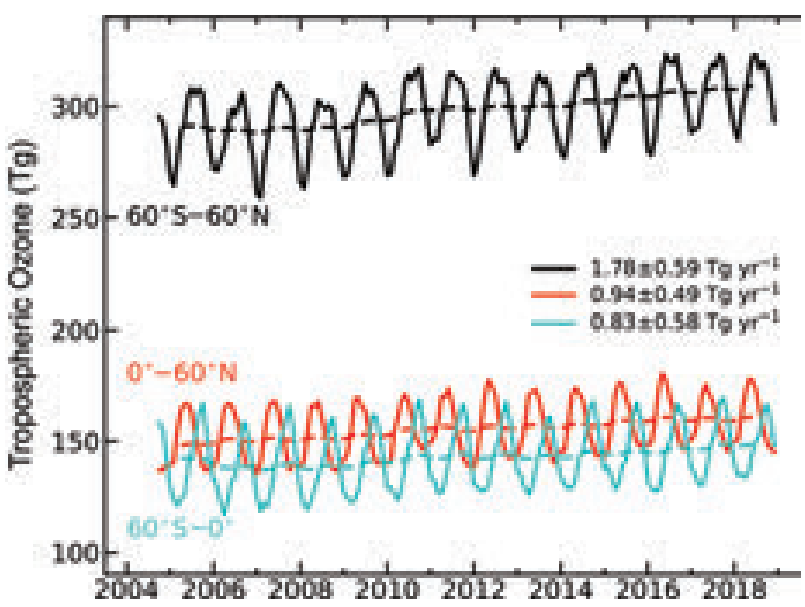

FIG. 2.58. Monthly averages of OMI/MLS tropospheric ozone burdens (Tg) from Oct 2004 through Dec 2018. The top curve (black) shows $60^{\circ} \mathrm{N}-60^{\circ} \mathrm{S}$ monthly averages with 12-month running mean. The bottom two curves show monthly averages and running means for the NH (red) and SH (blue). Slopes of linear fits to the data are presented with their $95 \%$ confidence level uncertainties. All three trends are statistically significant at the $95 \%$ confidence level. enough for the timing of this report; however, there are three NOAA atmospheric baseline observatories with rapidly updated data at remote locations: 1) the high-elevation Mauna Loa Observatory (MLO) in Hawaii $\left(19.5^{\circ} \mathrm{N}, 155.6^{\circ} \mathrm{W}, 3397 \mathrm{~m}\right.$ a.s.l.); 2) South Pole Observatory (SPO), Antarctica $\left(90^{\circ} \mathrm{S}, 59^{\circ} \mathrm{E}, 2840 \mathrm{~m}\right.$ a.s.l.); and 3) Barrow Observatory, Utqiagivik, Alaska $\left(71.3^{\circ} \mathrm{N}, 156.6^{\circ} \mathrm{W}, 11 \mathrm{~m}\right.$ a.s.l.). Continuous ozone measurements began at MLO in September 1973, at SPO in January 1975, and at Barrow in March 1973. Reliable ozone observations based on the Regener Automatic wet-chemical method are also available at SPO for the years 1961-63 (Oltmans and Komhyr 1976) and at MLO for 1957-59 (Price and Pales 1963). These time series, the world's longest at remote locations, are reported in Fig. 2.60 as monthly medians, based on all 24 hours of the day at SPO and Barrow, but with MLO restricted to nighttime values to focus on the time of day when local winds are downslope, ensuring that the observations are representative of the lower free troposphere.

The limited data at MLO and SPO from the 1950s and 1960s indicate that ozone levels at these remote high-elevation sites were similar in the midtwentieth century despite being located in different hemispheres. Ozone at SPO has changed little since the 1960s with no significant trend since continuous measurements began in $1975\left(0.03 \pm 0.04 \mathrm{ppbv} \mathrm{yr}^{-1}\right)$. In contrast, ozone at MLO has increased significantly since the 1970s at the rate of $0.14 \pm 0.05 \mathrm{ppbv} \mathrm{yr}^{-1}$, resulting in an overall increase of $6.3 \mathrm{ppbv}$ since 1973 , or $17 \%$. MLO experiences high interannual

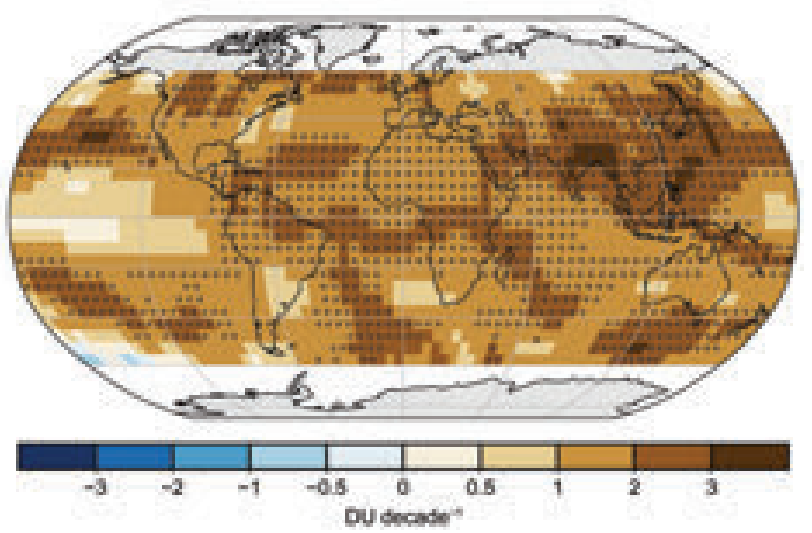

FIG. 2.59. Linear trends in OMI/MLS tropospheric column ozone (DU decade ${ }^{-1}$ ) on a $5^{\circ} \times 5^{\circ}$ grid from Oct 2004 through Dec 2018. Circles denote statistically significant trends at the $95 \%$ confidence level. Trends were calculated using a multivariate linear regression model (Ziemke et al. 1997, and references therein) that included a seasonal cycle fit and the Niño-3.4 index as an ENSO proxy; trend uncertainties included autoregressive adjustment via Weatherhead et al. (1998). 


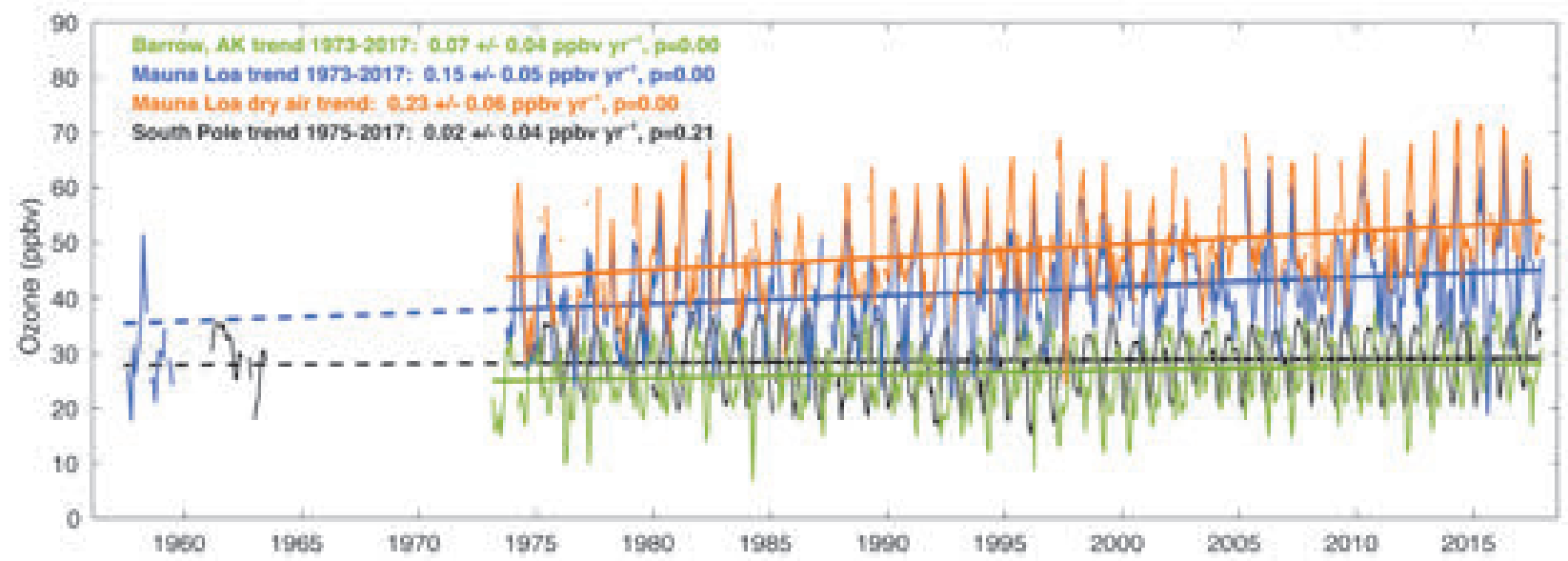

FIg. 2.60. Monthly median ozone at Utqiagivik (Barrow), Alaska (Mar 1973-Dec 20I8, green), and South Pole (Jan 1975-Dec 2018, black) using data from all hours of the day. Additional data from South Pole are shown for the early 1960s. Also shown are nighttime monthly median ozone values at Mauna Loa Observatory (MLO) calculated with all available data for months with at least 50\% data availability, Oct 1973-Dec 2018 (blue), with early observations from the late 1950s. In addition, the monthly median values associated with dry air masses (orange) at MLO are included (dewpoint < climatological monthly 40 th percentile, and a monthy sample size $\geq 24$ individual hourly nighttime observations). Trends (solid straight lines) are based on least-squares linear regression fit through the monthly values (1970s-2018), and reported with $95 \%$ confidence intervals and p-values. The MLO and South Pole trend lines are extrapolated back in time to the late 1950s (dashed lines).

ozone variability due to its location in the transition region between tropical and extratropical air masses. The ozone trend in the extratropical air masses can be isolated by focusing on the dry air masses, which tend to originate at higher altitudes and latitudes to the west and northwest of MLO, while moist air masses tend to come from the east at lower latitudes and altitudes (Harris and Kahl 1990; Oltmans et al. 2006; Gaudel et al. 2018). The trend in the dry air masses is $50 \%$ greater compared to the trend using all air masses (9.9 ppbv total increase since 1974, or $23 \%$ ), which implies that the site is influenced by ozone increases in upwind regions to the west and northwest, most likely Asia (Lin et al. 2014), where in situ observations have shown general ozone increases over the past two decades at the surface (Gaudel et al. 2018; Lu et al. 2018b) and in the free troposphere (Cohen et al. 2018; Gaudel et al. 2018).

\section{7) Carbon monoxide-J. Flemming and A. Inness}

Carbon monoxide (CO) is emitted into the atmosphere from combustion processes of fossil fuels and biomass, and it is chemically produced in situ from formaldehyde as part of the oxidation chains of methane $\left(\mathrm{CH}_{4}\right)$, isoprene, and other volatile organic trace gases. The chemical source is about one-third larger than the direct emissions of $\mathrm{CO}$ at the global scale according to model simulations (Duncan et al. 2007). Oxidation of $\mathrm{CO}$ with the hydroxyl radical $(\mathrm{OH})$, which is the main loss process for $\mathrm{CO}$, impacts the atmospheric abundance of $\mathrm{OH}$ and the atmosphere's oxidation capacity. $\mathrm{CO}$ is therefore regarded as an indirect climate forcing agent, because it controls the lifetimes of greenhouses gases such as $\mathrm{CH}_{4}$ and tropospheric ozone by its impact on $\mathrm{OH}$ (Hartmann et al. 2013).

The global distribution of the anthropogenic and biomass burning emission sources dominate the spatial variability of $\mathrm{CO}$. The spatial and temporal anomalies of the CO burden are often linked to extreme global wildfire emissions (Flemming and Inness 2016). Global CO trends are caused by regionally varying changes in fossil fuel and biomass burning emissions as well as the variability of the emissions of the organic precursors.

The global CO burden since the early 2000s has been recorded by reanalyses of atmospheric composition, which assimilate $\mathrm{CO}$ satellite retrievals in chemistry transport modeling systems (Miyazaki et al. 2015; Flemming at al. 2017; Gaubert et al. 2017; Inness et al. 2019). Surface CO concentrations are measured at sites of the Global Atmosphere Watch (GAW) network using in situ sensors and flask observations, as well as by air quality networks. The small number of in situ CO observations available in nearreal time, as well as pronounced spatial variability of surface CO, limits a timely analysis of the 2018 $\mathrm{CO}$ anomalies based on surface observations. As an 
example of one station, see Online Fig. S2.22, which shows monthly mean CO flask observations at Izaña Station (Tenerife, $28.3^{\circ} \mathrm{N}, 16.5^{\circ} \mathrm{W}, 2373 \mathrm{~m}$ a.s.l.) and the corresponding values from the CAMS reanalysis. The graph suggests that the CAMS reanalysis reproduces the seasonal variability and trends at this station, which is representative of the eastern Atlantic, relatively well. CAMS produced a new retrospective analysis of CO, aerosols, and ozone (CAMSRA) from 2003 to the present by assimilating satellite retrievals of atmospheric composition with the ECMWF model (Inness et al. 2019). This dataset is an update of the CAMS interim reanalysis (CAMSIRA; Flemming et al. 2017), which has been used previously to infer trends and anomalies of CO for the BAMS State of the Climate reports since 2013. The main differences between the two datasets are documented in Table S2.4 of the online supplement.

Figure 2.61 shows a time series of the global burden of CO from the CAMS reanalysis (CAMSRA) for the period 2003-18. From 2003 to 2018 the total CO burden decreased by $1.8 \mathrm{Tg} \mathrm{yr}^{-1}$, based on an approximation with a linear trend. Piecewise trends for 2003-07, 2008, and 2009-18 were -3.1, -17.0, and +0.1

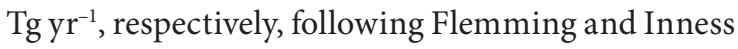
(2018). These trend estimates differ from those of the CAMSIRA over the same period. The CAMS interim RA shows a stronger reduction of the $\mathrm{CO}$ burden over the whole period of $-3 \mathrm{Tg} \mathrm{yr}^{-1}$ and piecewise trends of $-2.6,-20.0$, and $-1.3 \mathrm{Tg} \mathrm{yr}^{-1}$, respectively. The different trends of CAMSRA and CAMSIRA are mainly caused by the assimilation of an improved MOPITT CO retrieval product (TIR version 6 vs. version 5; Deeter et al. 2013, 2014) in CAMSRA in the first half of the period. The differences highlight the uncertainties in trend estimates from satellite retrieval assimilating reanalysis products. It should be noted that the small positive trend in the global CO burden for the

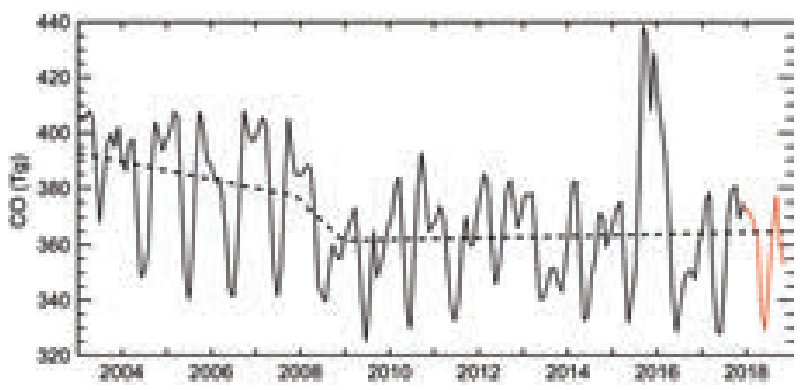

FIG. 2.6I. Time series (black solid line for 2003-17, red for 20I7-I8) of monthly global CO burdens (Tg) from the CAMS interim reanalysis and a piecewise linear trend (dotted line) for the periods 2003-07, 2008, and 2009-18.

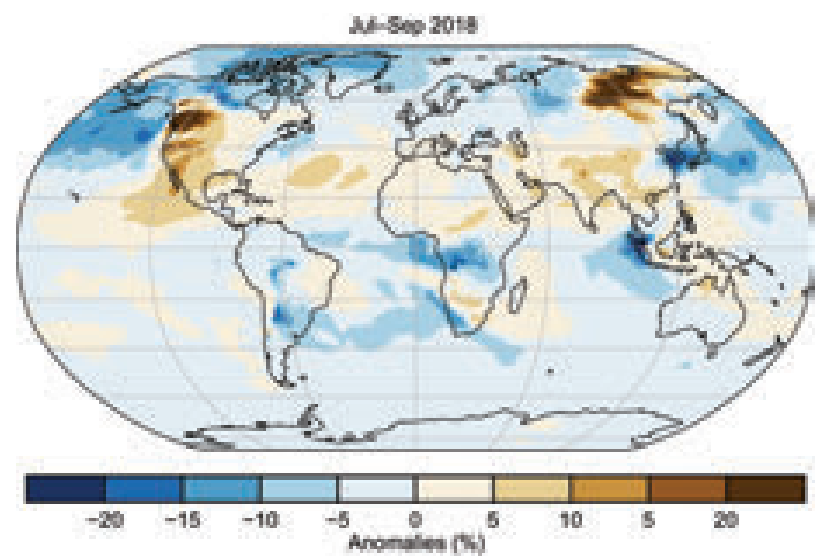

Fig. 2.62. Jul-Sep total column CO anomaly (\%) for 2018 with respect to the Jul-Sep 2003-I8 median from the CAMS interim reanalysis.

period 2009-18 of CAMSRA is caused by the globally increased CO values in the second half of 2015 and the first half of 2016. The high CO emissions of the intense peat fires in Indonesia in October 2015 were the reason for this global $\mathrm{CO}$ anomaly (Flemming and Inness 2016). Without this increase in fire activity, the CAMSRA data would also indicate a continuous decreasing global CO burden after 2009.

No strong spatial anomalies of the annual CO burden occurred in 2018 (Plate 2.1ac). Widespread negative anomalies up to $-10 \%$ were present in the $\mathrm{NH}$ as a manifestation of the general negative trend in the $\mathrm{CO}$ burden in this region. Localized positive anomalies were caused by strong fires in April, May, and July in Yakutia (southern Siberia) and in August in British Columbia (western Canada). The impact of the wildfires was strongest in summer (Fig. 2.62) when positive anomalies reached $20 \%$ or higher. The positive annual anomalies over tropical and southern Africa were caused by an earlier onset of the fire activity in this region in January and February against the background of an increasing trend in that region. Positive $\mathrm{CO}$ anomalies over India occurred throughout the year and are a sign of the increasing anthropogenic emissions in that region.

\section{h. Land surface properties}

I) Land surface albedo dynamics-B. Pinty and N. Gobron

Mid- and high-latitude regions of the $\mathrm{NH}$ are characterized by both positive (blue) and negative (orange) albedo anomalies (Plates $2.1 \mathrm{ad}$, ae), mainly as a consequence of interannual variations in snow cover (Section 2c2), amount, and duration in winter, spring, and autumn. The positive anomalies, especially in the visible range (Plate 2.1ad), over the northern United States and the High Plains Canadian southwest, 
central, and eastern regions; and across southern areas of eastern Europe north of the Black Sea are probably associated with above-average snow cover and extent in spring and autumn with the occurrence of significant snow events in these regions (Section $2 \mathrm{c} 2$ ). The most pronounced negative anomalies reaching (or locally exceeding) $-30 \%$, in the visible and about $-10 \%$ in the near-infrared domain (see Plate 2.1ae) occurred over northeastern Europe, Turkey, and northeastern Iran, across the eastern and western United States, northwestern Canada, Mexico, eastern Mongolia, and northern China.

A few snow-free regions show positive anomalies, especially in the visible domain, in northeastern Brazil, eastern Australia, and some West African countries including Nigeria, along with other localized spots on the African continent and Madagascar. These are generally associated with less favorable vegetation-growing conditions (Section $2 \mathrm{~h} 2$ ) due to adverse temperature conditions and below-normal precipitation, for example, over eastern Australia (see Section 7h4).
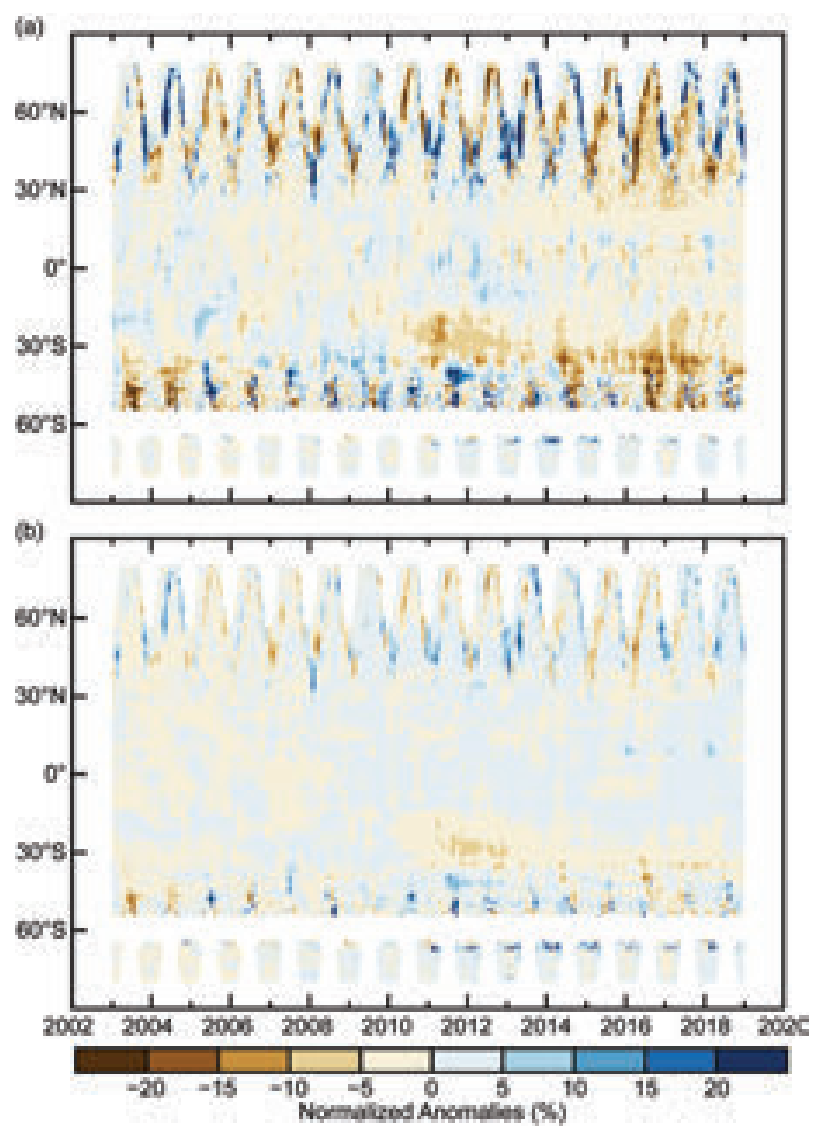

FIG. 2.63. Zonally averaged surface albedo anomalies (\%; 2003-10 base period) in (a) visible and (b) nearinfrared broadband.
Negative anomalies are particularly noticeable in the visible range over southern China, central Argentina (e.g., around the Rio Negro province), and southwestern Australia. The occurrence of negative anomalies in the visible domain correlated with positive anomalies in the near-infrared domain-as is the case over south China-are probably attributable to vegetation dynamics over such regions.

The amplitude of these positive and negative anomalies is variable and often changes with seasons. This spatio-temporal variability at a regional scale is related to above-average temperatures and extreme precipitation and drought events occurring across the world.

The zonally-averaged albedo anomalies in the visible and near-infrared broadband spectral domains, displayed in Figs. 2.63a,b respectively, indicate large interannual variations related to the occurrence of snow events in winter and spring at mid- and high northern latitudes as well as to vegetation conditions during spring and summer. Negative anomalies are noticeable around $30^{\circ}-40^{\circ} \mathrm{S}$, featuring a deviation from average conditions mainly over Argentina and Australia. Consistent negative anomalies in the visible domain are discernible across midlatitude regions in the $\mathrm{NH}$.

The amplitude of the globally averaged normalized anomalies resulting from a 12-month running mean (Figs. 2.64a,b) is within $\pm 5 \%$ (3\%) in the visible (near-infrared) domain. The year 2018 is characterized by a trend of negative anomalies toward average conditions in the visible domain and a trend to positive anomalies in the near-infrared domain that are driven by the dominant contributions from the $\mathrm{NH}$

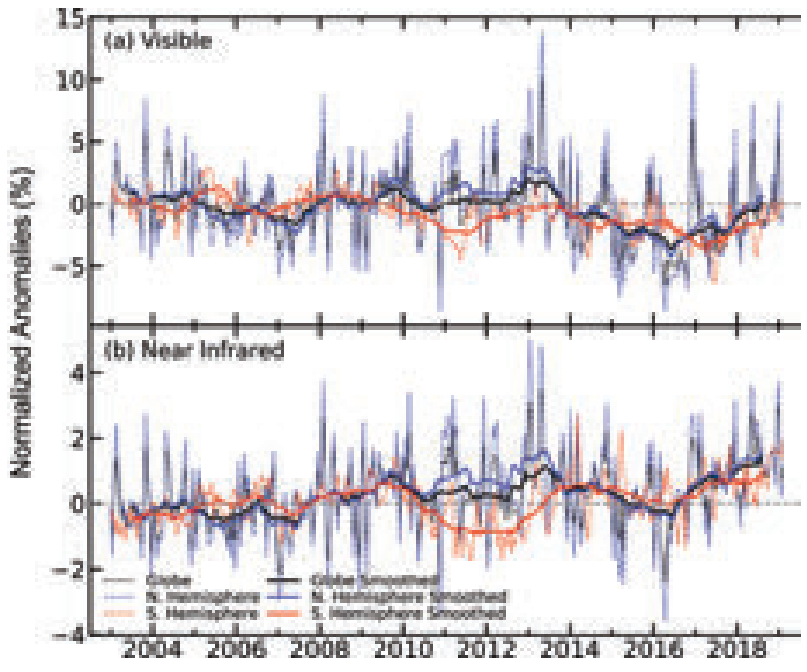

Fig. 2.64. Global and bi-hemispherical averaged surface albedo (\%; 2003-10 base period) in (a) visible and (b) near-infrared broadband. 
regions. These figures also indicate the presence of spectrally correlated multi-annual variations during the 2003-18 period.

The land surface albedo represents the fraction of solar radiation scattered backward by land surfaces. In the presence of vegetation, surface albedo results from complex nonlinear radiation transfer processes determining the amount of radiation that is scattered by the vegetation and its background, transmitted through the vegetation layer, or absorbed by the vegetation layer and its background (Pinty 2012; Pinty et al. 2011). The normalized anomalies in visible and near-infrared surface albedo for 2018 are calculated for a 2003-10 base period [for which two MODIS sensors are available (Schaaf et al. 2002; Schaaf and Wang 2015)]. Note that MODIS Collection 6 albedo products are used. Positive (blue) and negative (brown) anomalies are mainly a consequence of interannual variations in snow cover and amount, and duration in winter and spring seasons (https://climate .copernicus.eu/). The MODIS broadband shortwave White Sky Albedo (WSA) Collection 6 compares well with representative ground-based albedos over a variety of land types with on average RMSEs of $<0.0318$ and biases within \pm 0.0076 (Z. Wang et. al. 2018).

\section{2) Terrestrial Vegetation dynamics-N. Gobron}

Fraction of absorbed photosynthetically active radiation (FAPAR) anomalies exhibited significant regional differences in vegetation conditions worldwide in 2018 (Plate 2.1af). The greatest negative anomalies (brown: not favorable for vegetation) were observed in eastern regions of both Australia and Brazil. A number of comparatively weaker local negative anomalies were present across the globe, including southern Madagascar, central Argentina, central France, south central Asia, and India. The greatest positive anomaly (blue) was observed in eastern China, similar to 2017, and in Turkey. To a lesser extent, Mexico, the U.S. Upper Midwest, and southern Paraguay also had positive deviations.

The strong negative anomalies observed in eastern Brazil stem mainly from repetitive and persistent droughts observed at the beginning of the year and during the austral winter months (see Section 7d2). In Australia, the negative anomalies are due to various weather events, including heat waves in January and an annual rainfall deficit in New South Wales (see Section 7h3).

Seasonal rainfall deficits associated with high temperatures can have a significant negative local impact on terrestrial activities during the growing season that affect the annual anomaly, such as in central France during summer (see Section 7f2). Some regions in India faced a mild to severe drought due to the weakened monsoon season (see Section 7g4).

Terrestrial photosynthesis was enhanced over eastern China as above-average temperatures in spring combined with heavy precipitation favored vegetation growth in 2018, similar to 2017 (Gobron 2018). Vegetation conditions improved in Turkey, possibly due to high temperatures during the first half of the year and above-normal precipitation. Plant activity in the U.S. Upper Midwest was above normal, particularly in summer, as surface moisture was above normal as well (Section 2d8).

Figure 2.65 displays the longitudinal average anomalies from 1998 to 2018 compared to the 19982010 base period. Strong seasonal deviations include mainly positive anomalies north of $20^{\circ} \mathrm{N}$ after 2014 . Negative anomalies from 2002-14, except in 2010-12, affected the $\mathrm{SH}$. Contrasting with positive anomalies around $30^{\circ} \mathrm{S}$ from $2014-17$, anomalies were once again negative in 2018.

Figure 2.66, which shows the global and bihemispherical anomalies, reveals more oscillations between seasons in the $\mathrm{SH}$ with its smaller land area compared to the NH. The NH has had fewer negative events than the $\mathrm{SH}$, and its vegetation activity has increased since 2010 until last year. The SH data analysis reveals two positive extreme peaks in 2000 and 2017, while the extreme minima events occurred during 2008-09. Overall, there has been an increase in positive values since 2011 following the decline from positive anomalies to negative values between 2002 and 2009. Global 2018 anomalies were smaller compared to 2017 but still positive.

Satellite measurements are essential for monitoring terrestrial plant activity at the global scale. These

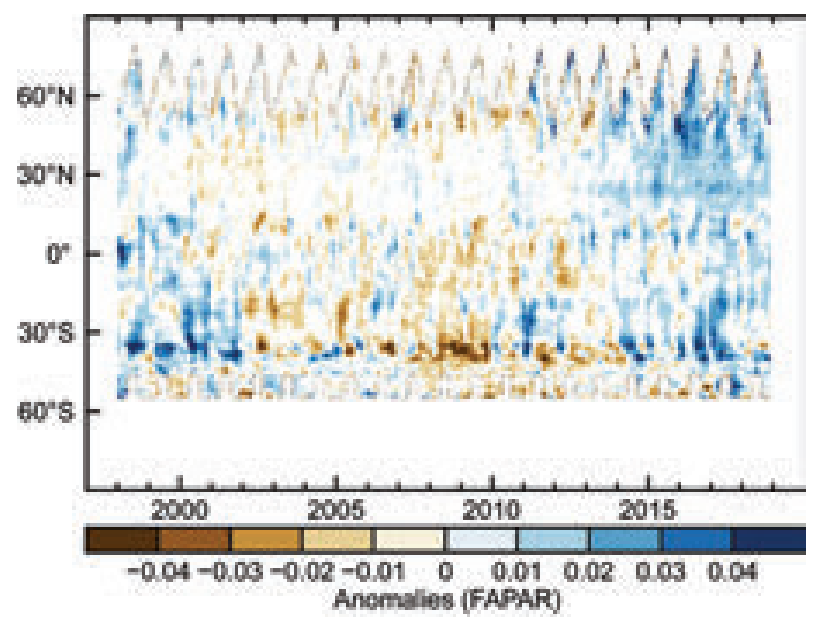

FIG. 2.65. Zonally averaged FAPAR anomalies from 1998-2010. 


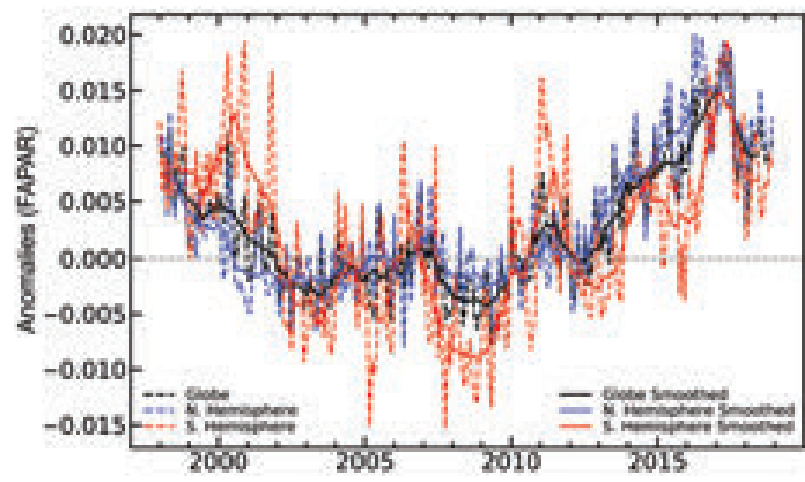

FIG. 2.66. Global, NH, and SH FAPAR anomalies from 1998-2018, plotted in black, blue, and red, respectively. Dotted lines denote each monthly period; solid lines indicate the 6-month running averaged mean.

measurements are used to retrieve the FAPAR, an essential climate variable [as defined by GCOS (2016)]. The 2018 analysis merged 21 years of global FAPAR products based on three passive optical satellite sensors from 1998 to 2018 (Gobron et al. 2010; Pinty et al. 2011; Gobron and Robustelli 2013; the base period is 1998-2010). Comparisons between each dataset and with several proxy values using ground-based measurements provide an estimate of uncertainties and bias. Taking into account biases between the different sensors products, this long-term global dataset has an estimated average uncertainty close to $5 \%-10 \%$.

3) BıOMASS BURNING-J. W. Kaiser and G. R. van der Werf

Biomass burning is one of the largest sources of atmospheric aerosols and trace gases globally, especially in the tropics where most fires occur (Fig. 2.67). Biomass burning is, like most disturbances, highly variable in time and space and has varied greatly over geologic time scales (Bowman et al. 2009). Today, fire incidence is, in large part, controlled by humans, both amplifying and lowering natural fire rates due to fighting fires, controlling fuel loadings, and using fire as a land management tool.

The combined use of the Global Fire Assimilation System (GFAS; Kaiser et al. 2012, 2017) and the Global Fire Emissions Database (GFED4s; van der Werf et al. 2017) indicates that 2018 had the lowest global emissions since the time series began in 1997. Total emissions are estimated to be $1.6 \mathrm{Pg} \mathrm{C}, 18 \%$ below the 2003-17 GFAS average (Table 2.9). Given that GFED includes a number of high fire years such as 1997-98, the difference from the 1997-2016 average was even larger (about 26\%), although the two datasets are not fully compatible. The second lowest emissions occurred in 2017.

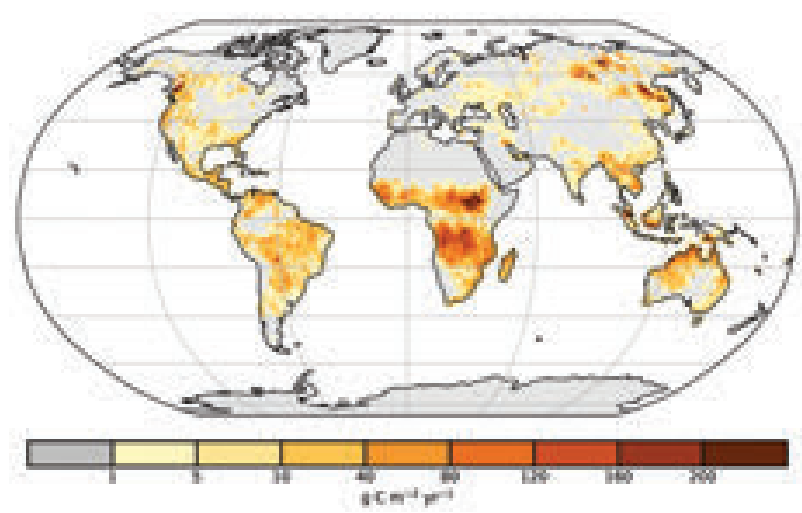

FIG. 2.67. Global map of fire activity in 2018 in terms of carbon consumption $\left(\mathrm{g} \mathrm{C} \mathrm{m}^{-2} \mathrm{yr}^{-1}\right)$. (Source: GFASvI.4.)

Fires were in the news regularly in 2018, including in California, Portugal, Greece, and Sweden. While those fires were devastating for people and property, they are a relatively minor contribution to the global amount of burned area of about 500 million ha. However, large-scale fires in California contributed to North America being one of two regions (the other, Australia) where fire emissions were higher than normal (Fig. 2.68).

Overall, the low 2018 fire year confirms the long-term downward trend in fire emissions driven primarily by the conversion of frequently burning savannas to agricultural areas in sub-Saharan Africa (Andela et al. 2017); northern hemispheric Africa and South America each experienced their lowest annual fire activities, according to GFAS data. In past years, drought conditions in boreal regions or in tropical forests (e.g., the $2015 \mathrm{El} \mathrm{Niño-induced} \mathrm{drought} \mathrm{in}$ Indonesia) temporarily elevated emissions to or over background levels. However, this was not the case in 2018 when, except for North America and Australia, all major biomass burning regions had anomalously low emissions.

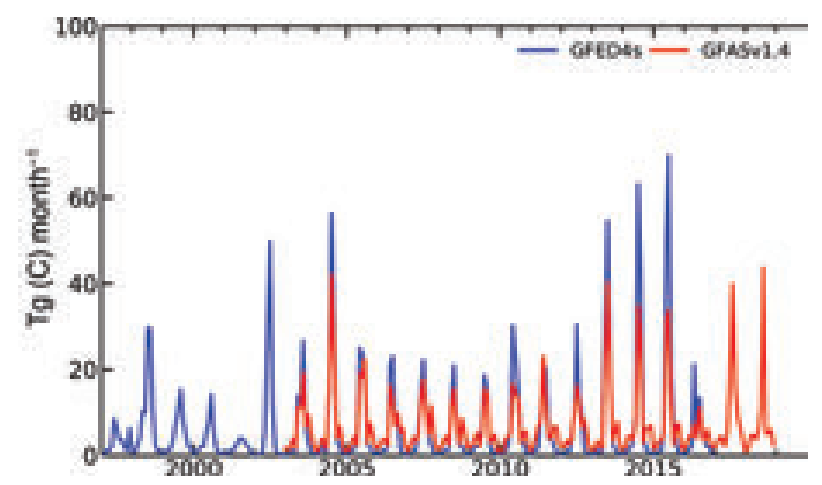

FIG. 2.68. Time series of fire activity during 1997-20I8 in terms of carbon consumption [ $\mathrm{Tg}(\mathrm{C})$ month $^{-1}$ ] for North America. 


\begin{tabular}{|c|c|c|c|c|}
\hline Time Period & & $2003-17$ & & 018 \\
\hline Quantity in $\mathrm{Tg}^{\mathrm{C}} \mathrm{yr}^{-1}$ & & $\begin{array}{c}\text { Mean Value } \\
\text { (Range) }\end{array}$ & Value & $\begin{array}{c}\text { Anomaly } \\
\text { (\%) }\end{array}$ \\
\hline Global & & $\begin{array}{c}1954 \\
(1683-2272)\end{array}$ & 1603 & $\begin{array}{l}-350 \\
(-18 \%)\end{array}$ \\
\hline North America & $\begin{array}{c}30^{\circ}-75^{\circ} \mathrm{N} \\
170^{\circ}-30^{\circ} \mathrm{W}\end{array}$ & $\begin{array}{c}86 \\
(56-113)\end{array}$ & 93 & $+8(+9 \%)$ \\
\hline Central America & $\begin{array}{c}0^{\circ}-30^{\circ} \mathrm{N} \\
170^{\circ}-30^{\circ} \mathrm{W}\end{array}$ & $\begin{array}{c}84 \\
(65-122)\end{array}$ & 76 & $-7(-9 \%)$ \\
\hline South America & $\begin{array}{c}0^{\circ}-60^{\circ} \mathrm{S} \\
170^{\circ}-30^{\circ} \mathrm{W}\end{array}$ & $\begin{array}{c}318 \\
(190-473)\end{array}$ & 176 & $\begin{array}{c}-142 \\
(-45 \%)\end{array}$ \\
\hline Europe and Mediterranean & $\begin{array}{c}30^{\circ}-75^{\circ} \mathrm{N} \\
30^{\circ} \mathrm{W}-60^{\circ} \mathrm{E}\end{array}$ & $\begin{array}{c}34 \\
(19-62)\end{array}$ & 26 & $-7(-22 \%)$ \\
\hline NH Africa & $\begin{array}{c}0^{\circ}-30^{\circ} \mathrm{N} \\
30^{\circ} \mathrm{W}-60^{\circ} \mathrm{E}\end{array}$ & $\begin{array}{c}401 \\
(353-453)\end{array}$ & 331 & $-70(-17 \%)$ \\
\hline SH Africa & $\begin{array}{c}0^{\circ}-35^{\circ} \mathrm{S} \\
30^{\circ} \mathrm{W}-60^{\circ} \mathrm{E}\end{array}$ & $\begin{array}{c}485 \\
(444-528)\end{array}$ & 445 & $-38(-8 \%)$ \\
\hline Northern Asia & $\begin{array}{c}30^{\circ}-75^{\circ} \mathrm{N} \\
60^{\circ} \mathrm{E}-170^{\circ} \mathrm{W}\end{array}$ & $\begin{array}{c}183 \\
(99-418)\end{array}$ & 176 & $-7(-4 \%)$ \\
\hline Southeast Asia & $\begin{array}{c}10^{\circ}-30^{\circ} \mathrm{N} \\
60^{\circ} \mathrm{E}-190^{\circ} \mathrm{E}\end{array}$ & $\begin{array}{c}119 \\
(8 I-150)\end{array}$ & 79 & $-40(-34 \%)$ \\
\hline Tropical Asia & $\begin{array}{l}10^{\circ} \mathrm{N}-10^{\circ} \mathrm{S} \\
60^{\circ}-170^{\circ} \mathrm{E}\end{array}$ & $\begin{array}{c}135 \\
(23-425)\end{array}$ & 67 & $-67(-50 \%)$ \\
\hline Australia & $\begin{array}{c}10^{\circ}-50^{\circ} \mathrm{S} \\
60^{\circ} \mathrm{E}-170^{\circ} \mathrm{W}\end{array}$ & $\begin{array}{c}112 \\
(47-219)\end{array}$ & 133 & $+21(+19 \%)$ \\
\hline
\end{tabular}

Fires are readily observed from space, either as burned area comparing surface reflectances mostly in the near-infrared before and after a fire, or directly when a fire burns during satellite overpass, the socalled "active fire observations." Both approaches were used for this analysis; GFED4s ingests burned area in a biogeochemical model and estimates emissions for the 1997-2016 period while GFAS employs satellite observations of the thermal radiation released by active fires to provide emissions from 2003 to near real time. GFAS has been calibrated against GFED but provides independent spatial and temporal variability.
4) Phenology of Primary PROducersD. L. Hemming, J. Garforth, T. Park, A. D. Richardson, T. Rutishauser, T. H. Sparks, S. J. Thackeray, and R. Myneni

Following the sidebar on phenology in the State of the Climate in 2017 report (Hemming et al. 2018), this is a new section dedicated to phenology, the study of relationships between climate and recurring events in nature (Demarée and Rutishauser 2011). In this section, NH spring growth of primary producers (terrestrial vegetation and lake plankton) is compared using records from satellite remote sensing and sitelevel monitoring.

During 2018, the MODIS-derived normalized difference vegetation index (NDVI; Park et al. 2016) revealed both earlier and later onset (up to 30 days) of start of season (SOS, the day when the NDVI value is greater than 0.1 and has increased by $25 \%$ of the growing season amplitude) across the $\mathrm{NH}\left(>30^{\circ} \mathrm{N}\right)$, 
relative to the 2000-10 baseline. The continental mean SOS during the baseline was 140 (20 May) for North America and 135 (15 May) for Eurasia, whereas, in 2018, mean SOS was 1.9 days later and 2.0 days earlier across North America and Eurasia, respectively. These SOS differences correlate with the mean spring (March-May) temperature (NASA MERRA-2; Gelaro et al. 2017) anomaly (NA: $r=$ 0.81 , EA: $r=0.60$ ), which was $0.8^{\circ} \mathrm{C}$ cooler in North America and $0.1^{\circ} \mathrm{C}$ warmer in Eurasia, compared to the baseline.

Regionally, earlier SOS occurred across northwest North America, Scandinavia, and northeastern Eurasia, and later SOS occurred across Alaska; central

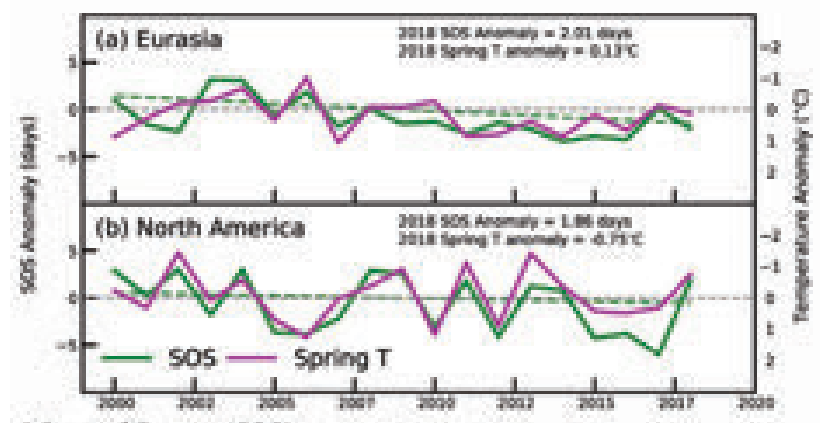

c) Start of Season (SOS)

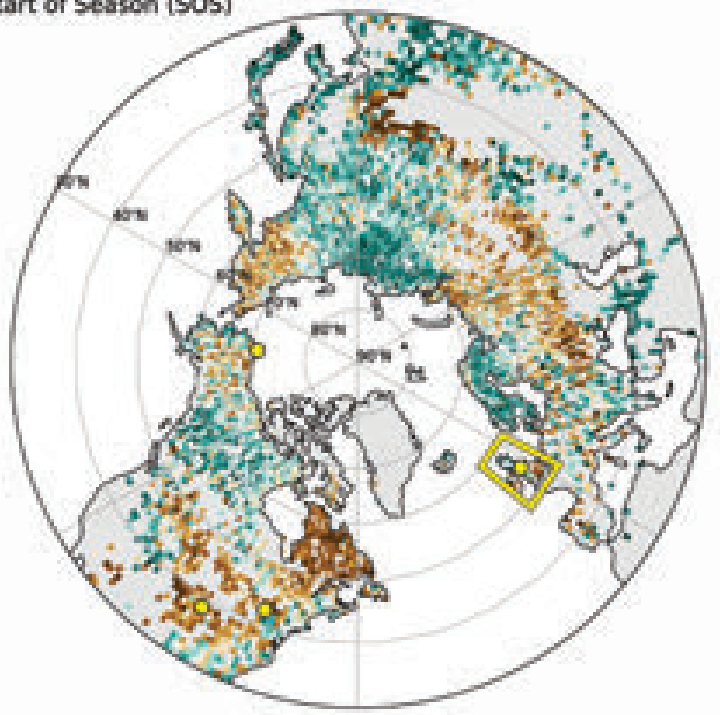

FIG. 2.69. Time series (and linear trend line) of area-mean anomalies (relative to 2000-10 baseline) in MODIS NDVI-based vegetation growing season onset (SOS, days, green) and spring (Mar-May) temperature $\left({ }^{\circ} \mathrm{C}\right.$, magenta) for (a) Eurasia and (b) North America. Note temperature scale reversal. (c) Spatial pattern of SOS anomalies (days) in 2018 with respect to the baseline. Highlighted points and box identify the location of sites shown in Fig. 2.70 and discussed in the text [in United States from west to east: Barrow (Utqiagivik); (Alaska), Ozarks (Missouri), Turkey Point (Maryland), and in the United Kingdom, Windermere Lake and UK mean]. and northeastern North America; and western, central, southern and northeastern Eurasia (Fig. 2.69). A significant advancement in SOS over the last 19 years was noted in Eurasia (Eurasia: $-1.5 \pm 0.59$ days per decade, $p=0.019$; North America: $-0.64 \pm 0.41$ days per decade, $p=0.134$ ). These phenology changes are broadly consistent with surface air temperature variations noted in Sections $2 \mathrm{~b} 1$ and $2 \mathrm{~b} 3$.

A "vegetation greenness index" (Sonnentag et al. 2012), calculated from PhenoCam images, generally aligns well with the spatial and temporal patterns of phenology derived from satellite products (Richardson 2018; Richardson et al. 2018; Zhang et al. 2018).During 2008-18, camera-derived start-ofspring transition dates for Harvard Forest, a deciduous forest in Massachusetts, United States, correlate well with the MODIS SOS estimates described above ( $r=0.82, n=11$ years). Because few PhenoCams were deployed before 2010, it is not possible to reference the 2018 SOS against a 2000-10 baseline. However, relative to 2017, MODIS data indicate that the 2018 SOS was delayed for $75 \%$ of the land area in North America above $30^{\circ} \mathrm{N}$; this finding is supported by PhenoCam observations for three sites spanning a wide geographic range, which also provide visual context for the phenological anomalies (Figs. 2.70c-e).

Among other events, Nature's Calendar registers "budburst," when leaf buds of Pedunculate Oak (Quercus robur) first burst and reveal their leaf color. During 2018, the United Kingdom (UK) mean budburst (based on 270 observations) for this species was on day 110 (20 April), 3 days later than mean budburst during the $2000-10$ baseline (Fig. 2.70b). This is consistent with a slightly later MODIS-derived SOS for the UK in 2018 and with a $1^{\circ} \mathrm{C}$ colder January-March Central England Temperature (CET) in 2018.

Biweekly data on lake water concentrations of the photosynthetic pigment chlorophyll- $a$ were used to derive the timing of the spring phytoplankton peak, in both the North and South Basins of Windermere (Fig. 2.70a). During the 2000-10 baseline, the mean day of year of spring bloom was 122 (2 May) in the North Basin and 112 (22 April) in the South Basin, compared with day 128 (8 May) in both basins in 2018; a delay in spring bloom of approximately 6 and 16 days, respectively, relative to the baseline. This later SOS in 2018 concurs with the Nature's Calendar observations of both the budburst of $Q$. robur and mean large-scale MODIS SOS indicator for the UK.

Satellite remote sensing provides large-scale and reasonably long-term records of land-surface phenology by tracking the seasonal trajectory of vegetation greenness. Radiance measures from MODIS on the 

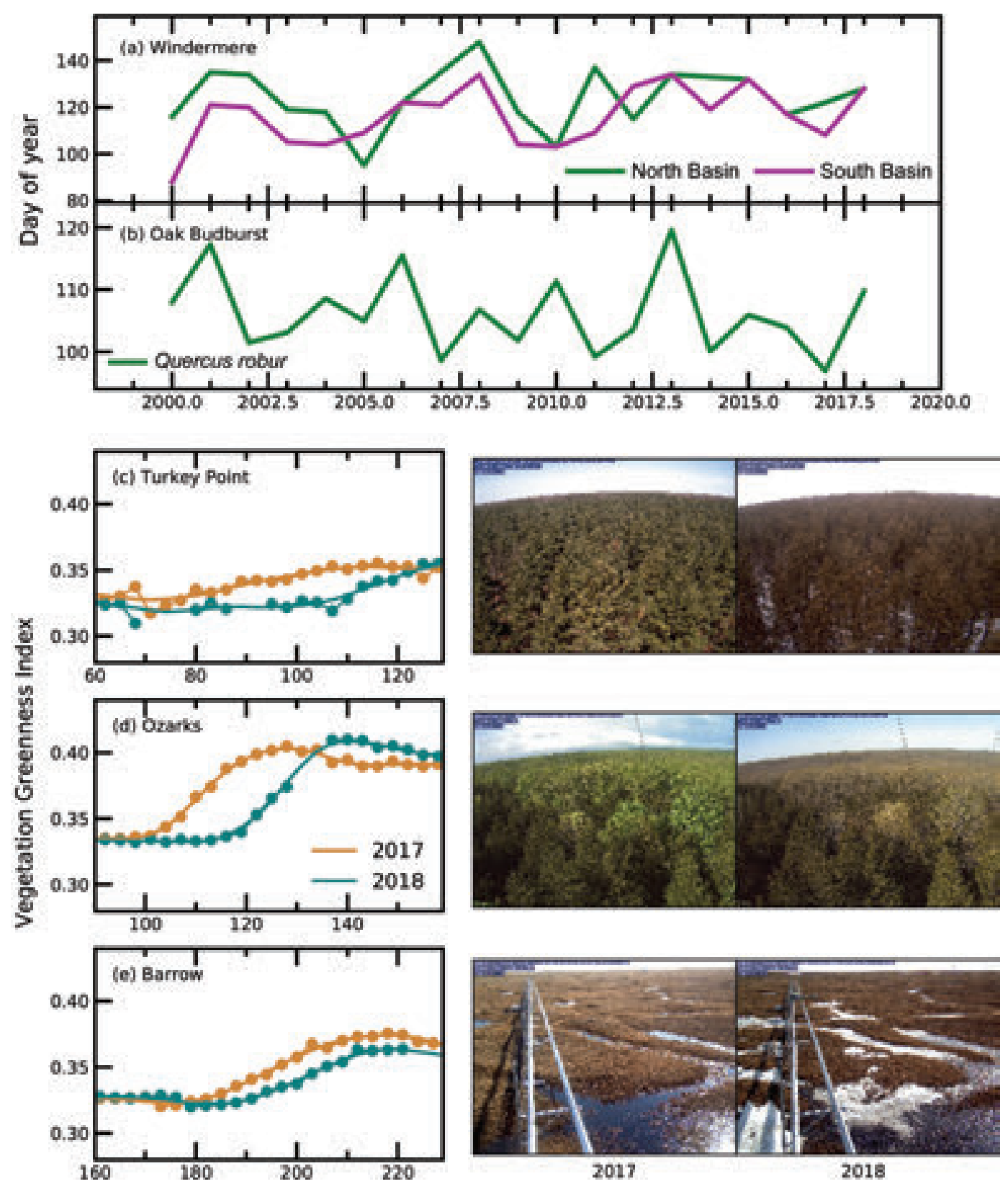

FIG. 2.70. Time series of day of year of (a) spring phytoplankton peak in the North and South Basins of Lake Windermere, UK, and (b) UK mean budburst of Pedunculate Oak (Quercus robur) monitored by Nature's Calendar. Spring trajectory for 2017 (earlier) and 2018 (later) vegetation greenness index derived from PhenoCam imagery at three sites across North America: (c) Turkey Point (upper), (d) Ozarks (middle), (e) Barrow (lower). PhenoCam photographs show visually obvious differences in the state of each ecosystem on the same day of year (Barrow = 27 Jun, Ozarks = 30 Apr, Turkey Point $=18$ Apr) in 2017 (middle column) and 2018 (right column).

NASA Terra and Aqua platform were used to retrieve the hemispheric spring green-up. This retrieval can capture $73 \%$ of 140 flux tower measured spring onset variations ( $\mathrm{MD} \pm 1$ std. dev., $4.1 \pm 9.3$ days; Park et al. 2016). These are complemented by individual site records, which provide a unique, ground-level perspective on phenology at the organism-to-ecosystem level. Spring phenology indicators from a range of surface sites in the North American PhenoCam network, the UK Nature's Calendar network, and the North and South Basins of Windermere, UK were also studied.

In North America, sites are selected from the PhenoCam network, which uses digital camera imagery to track vegetation phenology at fine spatial and temporal resolution (Richardson 2018). In the UK, the observations shown are from Nature's 
Calendar, a UK-wide Citizen Science scheme to record phenology, coordinated by the Woodland Trust since 2000, and in situ monitoring of England's largest lake, Windermere, which has been conducted since the 1940s by the Centre for Ecology and Hydrology, its predecessor organizations, and the Freshwater Biological Association. 


\section{GLOBAL OCEANS}

a. Overview-R. Lumpkin

The global oceans impact weather events and are the memory of the climate system at time scales from subseasonal to millennial. They absorb vast amounts of heat, carbon dioxide, and other properties from the atmosphere, store them throughout the water column, transport them via a network of interconnected surface and subsurface currents, and ultimately return them to the atmosphere or sequester them in sediments.

Focusing on 2018, this chapter describes the evolution of sea surface temperature (SST), ocean heat content, salinity, air-sea fluxes, sea level, surface currents, phytoplankton, and ocean inorganic carbon. As we are reminded in Section 3i, the ocean is responding to an atmosphere with higher carbon dioxide levels than at any time in the last 800000 years. Globally averaged sea level reached a record high in 2018-for the seventh consecutive year (Section 3f). Globally averaged SST cooled slightly since the record El Niño year of 2016 but is still far above the climatological mean (Section 3b). Meanwhile, the deeper ocean continues to warm year after year (Section 3c). In the Atlantic Ocean, SST and heat content anomaly patterns show the characteristic coldwarm-cold tripole fingerprint expected of a slowing meridional overturning circulation (MOC; Caesar et al. 2018). Cooling in the subpolar North Atlantic was driven by turbulent heat fluxes from increased winds (Section 3e). Climatologically, this cooling is balanced by northward advection of warm water in the MOC, but this advection has decreased (Smeed et al. 2018) as the MOC responds to a warmer high-latitude atmosphere and an increase in surface buoyancy due to ice melt (Sevellac et al. 2017). As anticipated in a warming climate, the hydrological cycle over the ocean is accelerating (Rhein et al. 2013): dry regions are becoming drier and wet regions rainier (Section $3 e)$. These changes are reflected in sea surface salinity anomaly patterns (Section 3d). Meanwhile, the upper $600 \mathrm{~m}$ of the western Atlantic have steadily become saltier from 2005 to 2018; 2018 is the first year with all monthly salinity anomalies in the upper $1500 \mathrm{~m}$ of the Atlantic saltier than the long-term mean (Section 3d). In contrast, the eastern North Atlantic is becoming fresher. Year-to-year changes in rainfall and salinity are also seen, including the 2018 drought and high salinity anomalies over the Maritime Continent (Sections 3d,e). Due to anomalously shallow mixed layers exposing phytoplankton to prolonged sunlight, and possibly lower nutrient input due to increased stratification, concentrations of chlorophyll- $a$ were suppressed by $10 \%-30 \%$ in warm SST regions of the tropical Pacific, western North Pacific, and subtropical North Atlantic (Section 3h).

Our understanding of the climate system has advanced, and there is more to learn about what was observed in 2018. New estimates of ocean uptake of anthropogenic $\mathrm{CO}_{2}$ are increased by $\sim 20 \%$ by better accounting for riverine input (Section 3i). A dramatic new global map of changes in the concentration of anthropogenic $\mathrm{CO}_{2}$ from the 1980s to the 1990s depicts the global MOC pathways sequestering this $\mathrm{CO}_{2}$ into the abyssal and deep oceans (Section 3i; Gruber et al. 2019). The GRACE Follow-On satellite mission began data collection in May 2018 and will help determine how much of the sea level rise in 2017-18 was due to ice melt (versus thermal expansion; Section 3f).

Unfortunately, this State of the Climate report was not able to include a section on changes in the Atlantic Meridional Overturning Circulation (AMOC). However, significant recent progress in understanding variations of the AMOC has been made. During 2004-17, the AMOC at $26^{\circ} \mathrm{N}$ shifted to a reduced state in approximately 2008 (Smeed et al. 2018). The first results from the Overturning in the Subpolar North Atlantic Program (OSNAP) demonstrate that Labrador Sea Water formation changes may not significantly impact overall year-to-year AMOC variability (Lozier et al. 2019). In fact, at interannual time scales, AMOC variability in the South Atlantic at $34.5^{\circ} \mathrm{S}$ has significant variations in both the eastern and western boundaries, in contrast to the primarily western boundary-associated variability at $26^{\circ} \mathrm{N}$ (Meinen et al. 2018), highlighting the role of the South Atlantic in modifying water masses carried by the AMOC. Furthermore, new AMOC observing arrays are now in place at both $11^{\circ} \mathrm{S}$ and $47^{\circ} \mathrm{N}$ and are expected to produce results soon (Hummels et al. 2015; Roessler et al. 2015; Frajka-Williams et al. 2019). As such, an invigorated AMOC section should be available in the 2019 report.

Finally, chapter sidebars highlight the Sargassum inundations that have plagued Caribbean beaches since 2011 (Sidebar 3.1) and the destructive red tide blooms off the Florida coasts in 2017-19 (Sidebar 3.2), both of which have caused enormous economic damage. The year 2018 set a new record for areal coverage of tropical Atlantic Sargassum, raising the question, "Does this reflect a climate-change driven regime shift in the ecology of these macroalgae?" The red tide caused significant decreases in fishery yields and tourism revenues in 2018, demonstrating the urgent need to better understand the relevant mechanisms, predict future blooms, and provide mitigation strategies. 
b. Sea surface temperatures-B. Huang, J. Kennedy, Y. Xue, and H.M. Zhang

Global SST in 2018 is assessed using the Extended Reconstruction Sea-Surface Temperature version 5 (ERSSTv5; Huang et al. 2017); Daily Optimum Interpolation SST (DOISST; Reynolds et al. 2007); and U.K. Met Office Hadley Centre SST version 3 (HadSST.3.1.1.0; Kennedy et al. 2011a, 2011b). ERSSTv5 is a monthly $2^{\circ} \times 2^{\circ}$ SST product from 1854 to present based on in situ observations only. The DOISST is a daily $0.25^{\circ} \times 0.25^{\circ}$ SST product for the modern satellite era from September 1981 to present using both in situ and satellite observations. The HadSST.3.1.1.0 is a monthly $5^{\circ} \times 5^{\circ}$ SST product from 1850 to present using in situ observations only. SST anomalies (SSTAs) are calculated relative to their own climatologies over 1981-2000.

Averaged over the global oceans, ERSSTv5 analysis shows that SSTAs continued to decrease from the record El Niño year maximum of $0.44^{\circ} \pm 0.05^{\circ} \mathrm{C}$ in 2016 to $0.38^{\circ} \pm 0.05^{\circ} \mathrm{C}$ in 2017 and $0.33^{\circ} \pm 0.05^{\circ} \mathrm{C}$ in 2018 . Uncertainty ranges indicate the $95 \%$ confidence level estimated from a 1000-member ensemble based on ERSSTv4 (Huang et al. 2016). Later in this section, ERSSTv5 results are compared to those from DOISST and HadSST3.1.1.0.

Figure 3.1a shows annually averaged SSTA in 2018. In the Pacific Ocean, SSTA was $+0.5^{\circ} \mathrm{C}$ to $+1.0^{\circ} \mathrm{C}$ in the northwestern North Pacific and near the Bering Strait, about $+0.5^{\circ} \mathrm{C}$ in the eastern North Pacific extending from the U.S.-Mexico coasts toward the western tropical Pacific, and about $+0.5^{\circ} \mathrm{C}$ in the midlatitude South Pacific between $30^{\circ} \mathrm{S}$ and $60^{\circ} \mathrm{S}$. SSTA was about $-0.2^{\circ} \mathrm{C}$ in the southeastern tropical Pacific between $150^{\circ} \mathrm{W}$ and $70^{\circ} \mathrm{W}$ and $-0.5^{\circ} \mathrm{C}$ in the South Pacific near $60^{\circ} \mathrm{S}$. In the Atlantic, SSTA was $+0.5^{\circ}$ to $+1.5^{\circ} \mathrm{C}$ in the western North Atlantic between $25^{\circ} \mathrm{N}$ and $45^{\circ} \mathrm{N},+1.0^{\circ}$ to $+1.5^{\circ} \mathrm{C}$ in the northern North Atlantic stretching toward the Arctic, and about $+0.5^{\circ} \mathrm{C}$ in the midlatitude South Atlantic near $45^{\circ} \mathrm{S}$. SSTA was about $-0.5^{\circ} \mathrm{C}$ south of Greenland near $50^{\circ} \mathrm{N}$ and west of Africa near $15^{\circ} \mathrm{N}$. In the Indian Ocean, SSTA was small.

In comparison with SST in 2017, SST in 2018 was $-0.2^{\circ} \mathrm{C}$ to $-0.5^{\circ} \mathrm{C}$ cooler over most of the global oceans (Fig. 3.1b). However, SST increased by $0.5^{\circ}-1.0^{\circ} \mathrm{C}$ in the northern North Pacific, by about $0.2^{\circ} \mathrm{C}$ in the central equatorial Pacific and the South Pacific between $20^{\circ} \mathrm{S}$ and $60^{\circ} \mathrm{S}$, and by about $0.5^{\circ} \mathrm{C}$ in the western North Atlantic near $40^{\circ} \mathrm{N}$ and the South Atlantic between $30^{\circ} \mathrm{S}$ and $60^{\circ} \mathrm{S}$.

The cooling of $-0.2^{\circ} \mathrm{C}$ to $-0.5^{\circ} \mathrm{C}$ in the southeastern tropical Pacific in 2018 (Fig. 3.1b) was associated

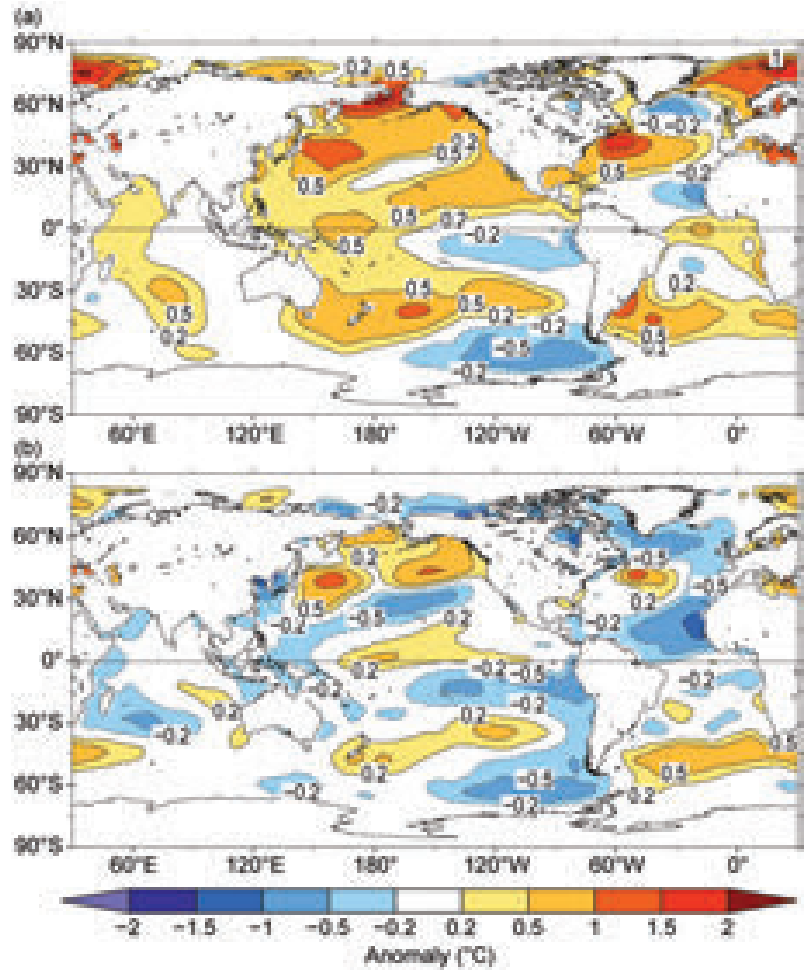

Fig. 3.I. (a) Annually averaged SSTA of ERSSTv5 in 2018, and (b) difference of annually averaged SSTAs between 2018 and 2017 . SSTAs $\left({ }^{\circ} \mathrm{C}\right)$ are relative to 198I-2010 climatology.

with the weak La Niña of 2017-18. Tropical Pacific SSTAs in December-January-February (DJF) and March-April-May (MAM) of 2018 (Figs. 3.2a,b) were $-0.5^{\circ} \mathrm{C}$ to $-1.0^{\circ} \mathrm{C}$, about 1 standard deviation ( $\sigma$ ) colder than the average of 1981-2010. The warming of $0.2^{\circ} \mathrm{C}$ in the western-central tropical Pacific in 2018 (Fig. 3.1b) resulted from the emerging El Niño of 2018-19 (see Section 4b). Western-central tropical Pacific SSTAs in June-July-August (JJA) and September-October-November (SON) of 2018 (Figs. 3.2c,d) were $+0.5^{\circ} \mathrm{C}$ to $+1.0^{\circ} \mathrm{C}$, which were $1 \sigma$ to $2 \sigma$ warmer than average.

Warming in the northern North Pacific (Fig. 3.1b) was associated with a higher SSTA that developed throughout 2018 and intensified with time, and was $1 \sigma$ to $2 \sigma$ warmer than average (Fig. 3.2). The higher SSTA resulted in a weak negative Pacific Decadal Oscillation (PDO; Mantua and Hare 2002) index throughout 2018. In the South Pacific (Fig. 3.2), an SSTA of $+0.5^{\circ} \mathrm{C}$ to $+1.0^{\circ} \mathrm{C}(1 \sigma-2 \sigma$ warmer than average) was sustained southeast of Australia along $45^{\circ} \mathrm{S}$ throughout 2018 , while an SSTA of $-1.0^{\circ} \mathrm{C}(1 \sigma$ colder than average) was sustained near $60^{\circ} \mathrm{S}$ between $60^{\circ} \mathrm{W}$ and $170^{\circ} \mathrm{W}$. 


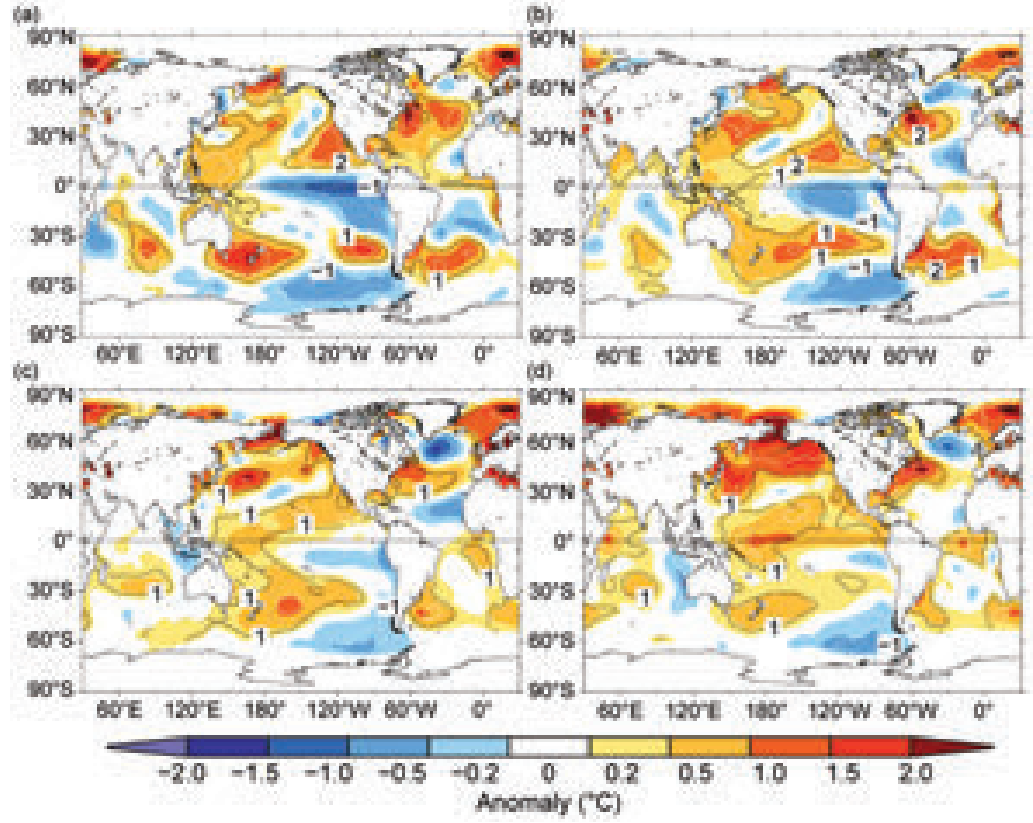

Fig. 3.2. Seasonal averaged SSTAs of ERSSTv5 ( ${ }^{\circ} \mathrm{C}$; shading) for (a) Dec 2017 to Feb 2018, (b) Mar to May 2018, (c) Jun to Aug 2018, and (d) Sep to Nov 2018. The normalized seasonal mean SSTA based on the seasonal mean std. dev. over 198I-2010 are indicated by contours of -I (dashed white), I (solid black), and 2 (solid white).

In the North Atlantic, SSTAs in 2018 were $+1^{\circ} \mathrm{C}$ to $+1.5^{\circ} \mathrm{C}(2 \sigma$ warmer than average) in the western basin between $25^{\circ}$ and $45^{\circ} \mathrm{N}$ and in the Nordic Seas (Fig. 3.2). In contrast, SSTAs in 2018 were $-0.5^{\circ} \mathrm{C}$ to $-1.0^{\circ} \mathrm{C}$ ( $1 \sigma$ colder than average) south of Greenland in MAM, JJA, and SON (Figs. 3.2b,c,d). This SSTA pattern of warm-cold-warm has been sustained since 2014, which may be associated with variations of the Atlantic Meridional Overturning Circulation (AMOC; Sevellec et al. 2017; Caesar et al. 2018). In the midlatitude South Atlantic along about $45^{\circ}$ S, SSTAs in 2018 were $+1.0^{\circ} \mathrm{C}$ in DJF (Fig. 3.2a), and MAM (Fig. 3.2b) and $+0.5^{\circ} \mathrm{C}$ in JJA (Fig. 3.2c) and SON (Fig. 3.2d). These SSTAs were about $1 \sigma$ to $2 \sigma$ above average. In the tropical Atlantic, SSTAs in 2018 were about $+0.5^{\circ} \mathrm{C}$ $(1 \sigma-2 \sigma)$ in DJF (Fig. 3.2a), disappeared in MAM (Fig. 3.2b), and reemerged in JJA and SON (Figs. 3.2c,d).

In the tropical Indian Ocean, SSTAs in 2018 were weak in DJF, MAM, and JJA (Figs. 3.2a,b,c). A pattern similar to the Indian Ocean Dipole (IOD; Saji et al. 1999) can be identified in SON (Fig. 3.2d). In the southern Indian Ocean between $20^{\circ}$ and $60^{\circ}$ S, SSTAs in 2018 were about $-0.5^{\circ} \mathrm{C}$ ( $1 \sigma$ colder than average) near $30^{\circ} \mathrm{E}$ and $+1.0^{\circ} \mathrm{C}$ near $75^{\circ} \mathrm{E}$ in DJF (Fig. 3.2a), and about $+0.5^{\circ} \mathrm{C}(1 \sigma$ warmer than average) between $60^{\circ} \mathrm{E}$ and $90^{\circ} \mathrm{E}$ in MAM, JJA, and SON (Figs. 3.2b,c,d).
Overall, warming trends of SSTs since the 1950 s or 1880 s over the global oceans can be identified (Figs. 3.3a,b), although the global average SST has cooled since 2016. The linear trends of globally annually averaged SSTs were $0.10^{\circ} \pm 0.01^{\circ} \mathrm{C}$ decade $^{-1}$ over 1950-2018 (Table 3.1). The warming appears largest in the tropical Indian Ocean (Fig. 3.3g) and smallest in the North Pacific (Fig. 3.3d). The uncertainty of the trends represents the $95 \%$ confidence level of the linear fitting.

In addition to the long-term SST trend, interannual variations of SSTAs can be seen in all ocean basins, although the amplitude of variations was smaller in the Southern Ocean. The variations associated with the Atlantic Multidecadal Oscillation (AMO; Wanner et al. 2001) can be identified with a warm period over the 1990s-2010s and a cold period over the 1950s-80s (Fig. 3.3f). Similarly, SSTA in the North Pacific (Fig. 3.3d) decreased from the 1950s to the later 1980s and increased from the later 1980s to the 2010s.

SSTAs in ERSSTv5 were compared with those in DOISST and HadSST3.1.1.0. All datasets were averaged to monthly $2^{\circ} \times 2^{\circ}$ grid for a comparison purpose. Comparisons (Fig. 3.3) indicate that the SSTA departures of DOISST and HadSST.3.1.1.0 from ERSSTv 5 are largely within $2 \sigma$ (gray shading in Fig. 3.3). The $2 \sigma$ envelope was derived from a 1000 -member ensemble analysis based on ERSSTv4 (Huang et al. 2016), and $\pm 2 \sigma$ and $-2 \sigma$ uncertainties are shaded above and below the SSTAs of ERSSTv5. However, SSTAs were slightly higher in the 1950s-70s and the 1920s-30s in HadSST.3.1.1.0 than in ERSSTv5. Similarly, SSTAs were slightly higher in the 2000s-2010s in HadSST.3.1.1.0 and DOISST than in ERSSTv5, particularly in the Southern Ocean. Previous studies (Huang et al. 2015; Kent et al. 2017) showed that these SSTA differences were mostly attributed to the differences in bias corrections to ship observations in those products. These SST differences resulted in a slightly weaker SSTA trend in HadSST.3.1.1.0 over both 1950-2018 and 2000-18 (Table 3.1). In contrast, SST trends were similar to in DOISST over 2000-18. 
TABLE 3.I. Linear trends $\left({ }^{\circ} \mathrm{C}\right.$ decade-I) of annually and regionally averaged SSTAs from ERSSTv5, HadSST3, and DOISST. The uncertainties at $95 \%$ confidence level are estimated by accounting for AR(I) effect on the degrees of freedom of annually averaged SST series.

\begin{tabular}{|c|c|c|c|}
\hline Product & Region & $\mathbf{2 0 0 0 - 1 8}$ & 1950-2018 \\
\hline HadSST.3.I.I.0 & Global & $0.131 \pm 0.069$ & $0.084 \pm 0.016$ \\
\hline DOISST & Global & $0.162 \pm 0.062$ & N/A \\
\hline ERSSTv5 & Global & $0.164 \pm 0.085$ & $0.100 \pm 0.013$ \\
\hline ERSSTv5 & Tropical Pacific $\left(30^{\circ} \mathrm{S}-30^{\circ} \mathrm{N}\right)$ & $0.182 \pm 0.201$ & $0.100 \pm 0.028$ \\
\hline ERSSTv5 & North Pacific $\left(30^{\circ}-60^{\circ} \mathrm{N}\right)$ & $0.297 \pm 0.141$ & $0.068 \pm 0.038$ \\
\hline ERSSTv5 & Tropical Indian Ocean $\left(30^{\circ} \mathrm{S}-30^{\circ} \mathrm{N}\right)$ & $0.197 \pm 0.110$ & $0.140 \pm 0.019$ \\
\hline ERSSTv5 & North Atlantic $\left(30^{\circ}-60^{\circ} \mathrm{N}\right)$ & $0.118 \pm 0.107$ & $0.105 \pm 0.049$ \\
\hline ERSSTv5 & Tropical Atlantic $\left(30^{\circ} \mathrm{S}-30^{\circ} \mathrm{N}\right)$ & $0.127 \pm 0.110$ & $0.108 \pm 0.021$ \\
\hline ERSSTv5 & Southern Ocean $\left(30^{\circ}-60^{\circ} \mathrm{S}\right)$ & $0.127 \pm 0.068$ & $0.099 \pm 0.016$ \\
\hline
\end{tabular}

(a) Giobal Ocean

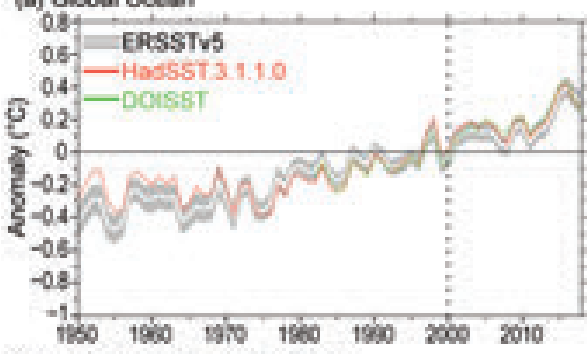

(c) Tropical Pacific $\left(30^{\prime} \mathrm{S}-30 / \mathrm{N}\right)$

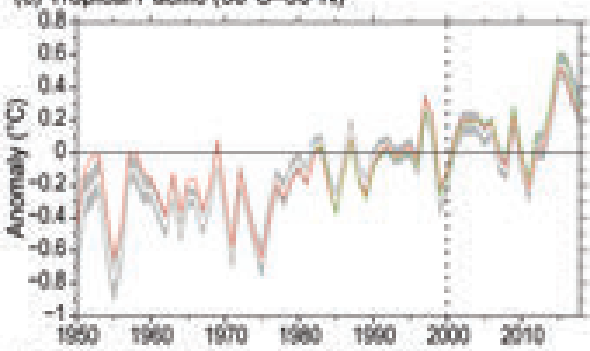

(e) Trepical indian Ocean $\left(30^{\prime} 8-30^{\prime} \mathrm{N}\right)$

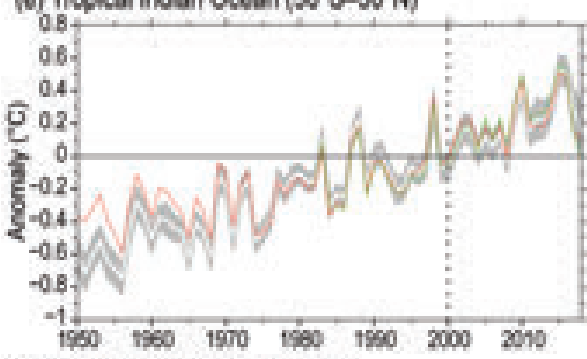

(a) Tropical Allartic $\left(30^{\circ} \mathrm{S}-30^{\circ} \mathrm{N}\right)$

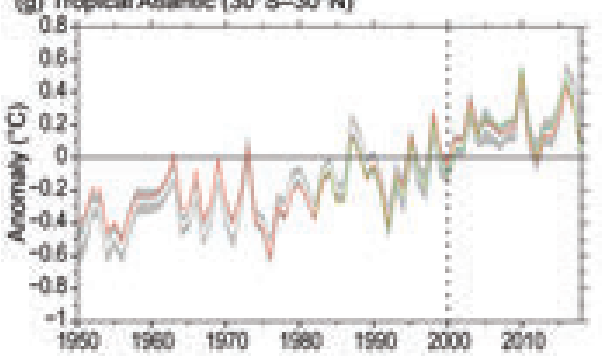

(b) Global Ocean

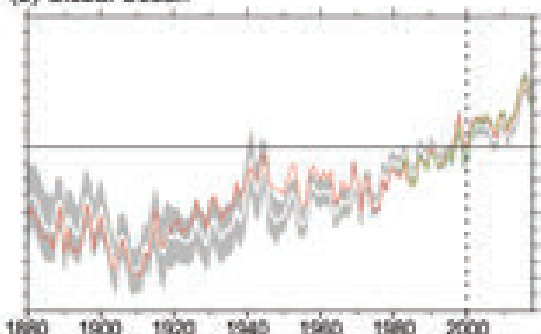

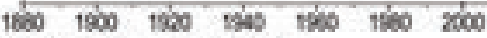
(d) North Packe $\left.130^{\prime}-60^{\prime} \mathrm{N}\right)$

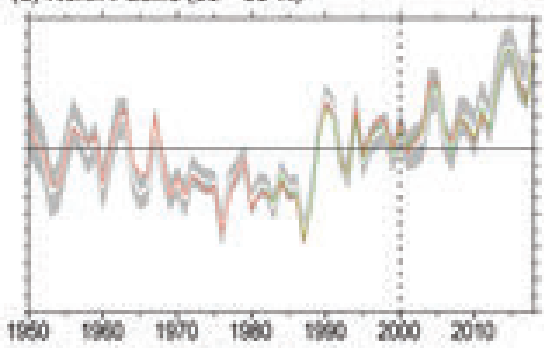

(f) North Alarbie $\left(30^{\circ}-60^{\prime} \mathrm{W}\right)$

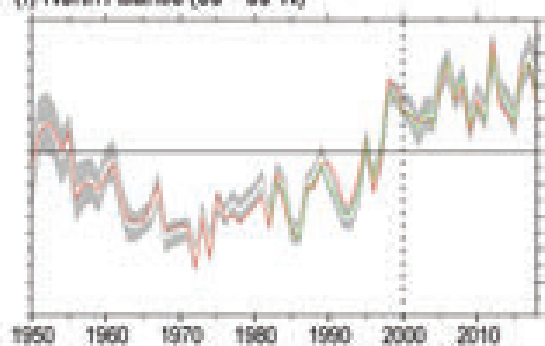

(h) Southem Coean $\left(30^{\circ}-60^{\prime} 8\right)$

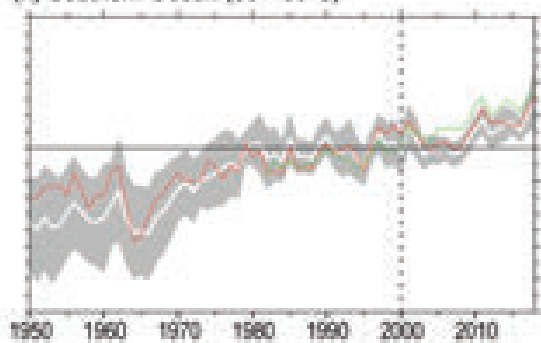

Fig. 3.3. Annually averaged SSTAs of ERSSTV5 (solid white) and $2 \sigma$ (gray shading) of ERSSTV4, SSTAs of DOISST (solid green), and SSTAs of HadSST.3.1.1.0 (solid red) in 1950-2018 except for (b). (a) Global, (b) Global in 1880-2018, (c) Tropical Pacific, (d) Tropical Indian Ocean, (e) Tropical Atlantic, (f) North Pacific, (g) North Atlantic, and (h) Southern Ocean. The year 2000 is indicated by a vertical black dotted line. 


\section{SIDEBAR 3.I: UNPRECEDENTED SARGASSUM BLOOMS IN THE TROPICAL ATLANTIC_C. HU AND M. WANG}

Starting in 20II, large amounts of pelagic Sargassum washed onto the beaches of many Caribbean islands almost every summer (Gower et al. 2013; Wang and Hu 2017). While these brown macroalgae, comprised primarily of $S$. natans and $S$. fluitans, provide important habitat to many marine animals such as fish, shrimp, crabs, and turtles (Rooker et al. 2006; Witherington et al. 2012; Lapointe et al. 2014; Doyle and Franks 2015) and thus can influence various trophic levels and the ocean's biogeochemistry (Parr 1939; Culliney 1970; Carpenter and Cox 1974; Phlips and Zeman 1990; Lapointe 1995; Turner and Rooker 2006; Zepp et al. 2008), excessive Sargassum on beaches represents a nuisance and a health hazard as well as a burden to local management, tourism, and economy. Numerous local and international news media have reported how local governmental agencies and environmental groups in the Caribbean reacted to the increased

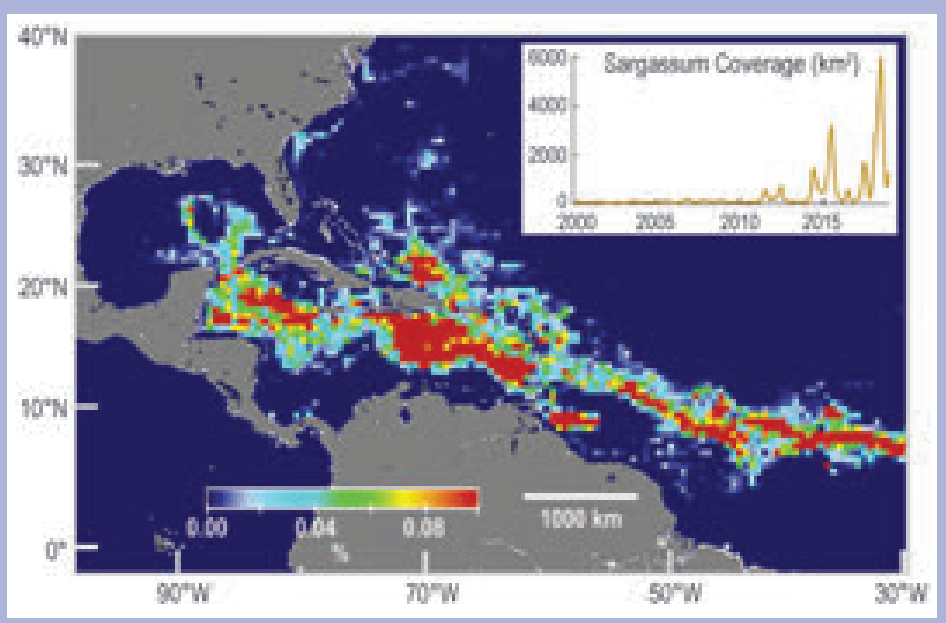

FIG. SB3.I. Sargassum areal density in Aug 2018 derived from MODIS observations (Wang and Hu 2016; Wang 2018). The inset shows the total Sargassum areal coverage (if they are aggregated together) between 2000 and 2018. The coverage extended further east to at least $10^{\circ} \mathrm{W}$ (not shown here).

Sargassum beaching events (Franks et al. 201I; Higgins 201I; Kirkpatrick 2015; Schell et al. 2015; Stasi 2015). In 2015, Mexico called its Navy to take action (Partlow and Martinez 2015). In 2018, Barbados declared a national emergency due to excessive Sargassum inundation (Rawlins-Bentham 2018).

Given these unprecedented Sargassum amounts found in the Caribbean after 20II, many questions remain unanswered. For example, what caused the recent blooms? Where do they originate? Are we entering a regime shift where recurring blooms become a new norm as a result of climate change?

Satellite images show that the Caribbean Sargassum originated from the central Atlantic (Gower et al. 2013; Wang and Hu 2016, 2017). A region off the Amazon River mouth was speculated to be the source region (Gower et al. 2013), while more recent studies indicate the entire central Atlantic, extending from west Africa to the Lesser Antilles islands, could provide initial seeds (Franks et al. 2016; Wang 2018). Figure SB3.I shows the Sargassum density distributions in the Tropical Atlantic including the central Atlantic, Caribbean Sea, and Gulf of Mexico. Unpublished data even show the eastward extension of the coverage to at least $10^{\circ} \mathrm{W}$. In this example, the Sargassum is estimated to cover an area of $>4000 \mathrm{~km}^{2}$ if aggregated together. Using a conversion factor determined from field measurements (Wang et al. 2018), the total Sargassum wet biomass is estimated to be at least 12 million metric tons. Assuming a 50:I biomass:Chla ratio for the water-column phytoplankton, in Sargassum-occupied waters, Sargassum biomass is comparable to water-column phytoplankton, while the carbon content of Sargassum may also represent a signifi- cant portion of total particulate organic carbon (Wang et al., 2018). Clearly, the unprecedented Sargassum amount in the Tropical Atlantic may significantly affect the ocean's ecology and biogeochemistry.

Satellite images show the seasonality and long-term trend in the amount of Sargassum found in the Caribbean Sea (Fig. SB3.I, inset). The amount usually peaks in summer and reaches minimum in winter, a possible consequence of favorable growth conditions (water temperature, nutrient and light availability) during spring. While Gower et al. (2013) only showed the initial bloom year of 2011, the new time-series shows an unambiguous increasing trend, with annual fluctuations, in subsequent years, with 2018 being the historical record year (Langin 2018).

Several hypotheses have been proposed on why a sudden increase occurred in 2011 and what caused the annual fluctuations after 20II. Rising SST, enhanced nutrient inputs from major rivers, dust depositions, and equatorial upwelling, as well as recent climate changes and ocean current variations may have created favorable conditions for the unprecedented Sargassum blooms in the Tropical Atlantic (Franks et al. 201I; Franks et al. 2014; Johnson et al. 2013; Djakouré et al. 2017). Indeed, under a changing climate where coastal eutrophication and other environmental conditions may lead to increased macroalgae blooms (Smetacek and Zingone 2013), the recurrent Sargassum blooms in the Tropical Atlantic may represent a regime shift. Currently, the scientific community is facing challenges on understanding exactly the reasons behind bloom initiation, maintenance, dissipation, and their ecological and biogeochemical implications. On the other hand, the unprec- 


\section{CONT. SIDEBAR 3.I: UNPRECEDENTED SARGASSUM BLOOMS IN THE TROPICAL ATLANTIC_C. HU AND M. WANG}

edented amount of Sargassum experienced across much of the Caribbean may provide opportunities to develop innovative methods to fully utilize the macroalgae for fertilizers, biofuel, and other uses. In the meantime, the one-way transport from the central Atlantic to the Caribbean makes it relatively easy to provide early warning of bloom likelihood in the Caribbean (Wang and Hu 2017), and near real-time satellite imagery together with surface ocean currents can be used continuously to guide field experiment and resource management (Hu et al. 2016).

Finally, Sargassum blooms have also been reported in other regions in recent years. For example, in the East
China Sea, an unprecedented bloom of Sargassum horneri occurred in spring 2017, which was speculated to be a result of a warm winter and accumulated eutrophication due to local aquaculture (Qi et al. 2017). Although S. horneri is a different species that usually grows on rocks, the initial bloom year of 2012 in this western Pacific region poses the question of whether it is simply a coincidence with the initial bloom year of 2011 in the Caribbean, or the global ocean has experienced subtle shifts to favor Sargassum growth in recent years. Clearly, more fundamental research is required to understand their response to environmental conditions under a changing climate. c. Ocean heat content-G. C. Johnson, J. M. Lyman, T. Boyer, L. Cheng, C. M. Domingues, J. Gilson, M. Ishii, R. E. Killick, D. Monselesan, S. G. Purkey, and S. E. Wijffels

The ocean has an enormous heat capacity. One degree of warming in the global ocean stores about 1000 times the heat energy of one degree of warming in the atmosphere. Ocean warming accounts for about 93\% of the total increase in Earth's energy storage from 1971 to 2010, compared to the atmosphere's 1\% (Rhein et al. 2013). Ocean currents transport substantial amounts of heat (Talley 2003). Ocean heat storage and transport play large roles in ENSO (Johnson and Birnbaum 2017), tropical cyclone development (Goni et al. 2009), rates and variations in sea level rise (Section 3f), and melting of ice sheet outlet glaciers around Greenland (Castro de la Guardia et al. 2015) and Antarctica (Schmidtko et al. 2014).

Maps of annual (Fig. 3.4) upper (0-700 m; or to the ocean floor where it is shallower) ocean heat content anomaly (OHCA) relative to a 1993-2018 baseline mean are generated from a combination of in situ ocean temperature data and satellite altimetry data following Willis et al. (2004) and using Argo (Riser et al. 2016) data downloaded in January 2019. Near-global average seasonal temperature anomalies (Fig. 3.5) versus pressure from Argo data (Roemmich and Gilson 2009, updated) since 2004 and in situ global estimates of OHCA (Fig. 3.6) for three pressure layers from seven different research groups (including that responsible for the 2000-6000 m estimate) are also discussed.

The 2017/18 tendency of 0-700-m OHCA (Fig. 3.4b) shows an increase in a band across much of the equatorial Pacific north of about $15^{\circ} \mathrm{S}$ and a decrease in a band to the north. The node between is located around $5^{\circ} \mathrm{N}$ in the west and $10^{\circ} \mathrm{N}$ in the central and east $\mathrm{Pa}-$ cific, near the North Equatorial Countercurrent, which, consistently, was anomalously strong in 2018 (see Fig. 3.18a). This pattern is strongly reminiscent of the mode involved in the recharge of warm water in the equatorial Pacific prior to El Niño (Meinen and McPhaden, 2000). The tendency is toward increases in the North Pacific north of about $10^{\circ} \mathrm{N}$ in the west and $30^{\circ} \mathrm{N}$ in the east. Tendencies south of $15^{\circ} \mathrm{S}$ in the Pacific are patchier: east of Australia cooling is apparent, then warming southeast of New Zealand, then cooling again west of the Drake Passage. Throughout much of the Pacific, the 2018 upper OHCA is generally above the long-term average (Fig. 3.4a), with the most notable departures being a narrow band of below average values along $\sim 10^{\circ} \mathrm{N}$, a patchy region of low values in the central South Pacific, and low values west of Drake Passage.

In the Indian Ocean, the 2017/18 tendency of 0-700-m OHCA (Fig. 3.4b) is patchy, with warming in many locations, some cooling in the western Arabian Sea and in the center of the basin south of the equator, but no striking large-scale patterns. Upper OHCA values for 2018 were above the 1993-2017 mean in much of the Indian Ocean (Fig. 3.4a), with the notable exception of a persistent patch of low values in the western equatorial region that formed in 2017 and was discussed in last year's report (Johnson et al. 2018) and a prominent cool patch west of Australia.

The 2017/18 tendencies of 0-700-m OHCA (Fig. $3.4 \mathrm{~b})$ in the Atlantic Ocean show warming most noticeable in the western boundary current extensions of both hemispheres, although as usual those energetic, eddy-rich regions exhibited both warming and cooling tendencies. The $2017 / 18$ cooling tendency was most prominent in a band just north of the equator, in a patch located between Madeira and the Strait of Gibraltar, and in the North Sea and Norwegian Sea. With these relatively small changes from 2017 to 2018, the 2018 anomalies (Fig. 3.4a) look much like those in 

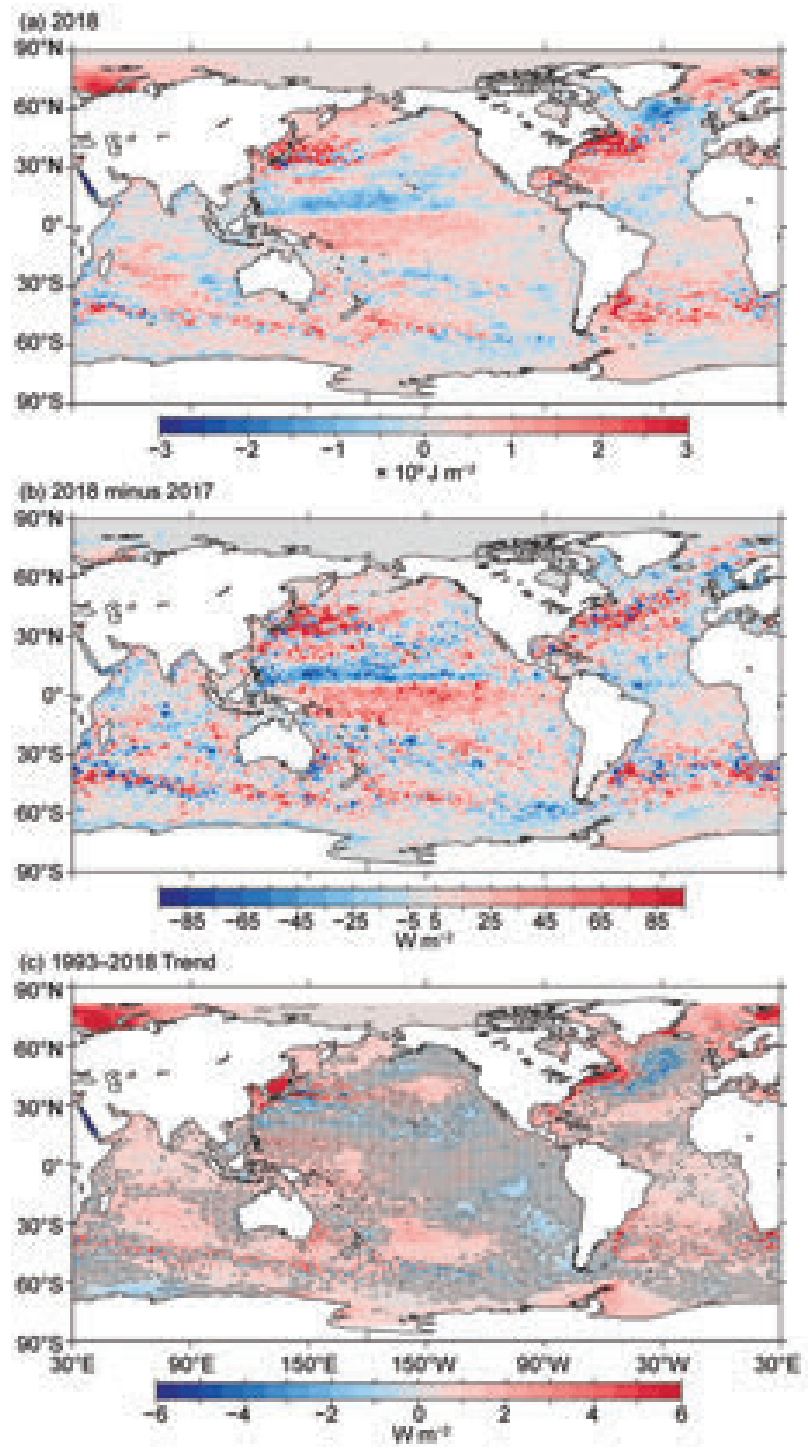

FIG. 3.4. (a) Combined satellite altimeter and in situ ocean temperature data estimate of upper $(0-700 \mathrm{~m})$ OHCA $\left(\times 10^{9} \mathrm{~J} \mathrm{~m}^{-2}\right)$ for 2018 analyzed following Willis et al. (2004), but using an Argo monthly climatology and displayed relative to the 1993-2018 baseline. (b) 2018-2017 combined estimates of OHCA expressed as a local surface heat flux equivalent $\left(\mathrm{W} \mathrm{m}^{-2}\right)$. For (a) and (b) comparisons, note that $95 \mathrm{~W} \mathrm{~m}^{-2}$ applied over one year results in a $3 \times 10^{9} \mathrm{~J} \mathrm{~m}^{-2}$ change of OHCA. (c) Linear trend from 1993-2018 of the combined estimates of upper $(0-700 \mathrm{~m})$ annual OHCA $\left(\mathrm{W} \mathrm{m}^{-2}\right)$. Areas with statistically insignificant trends are stippled.

2017. The large cold area south of Greenland, in the vicinity of the Irminger Sea, has persisted since at least 2014 and the warm conditions off the east coast of North America since around 2009 (see previous State of the Climate reports). The only other prominent areas in the Atlantic colder than the 1993-2018 average were in the Labrador Sea and just north of the equator in the western Atlantic. The latter may be

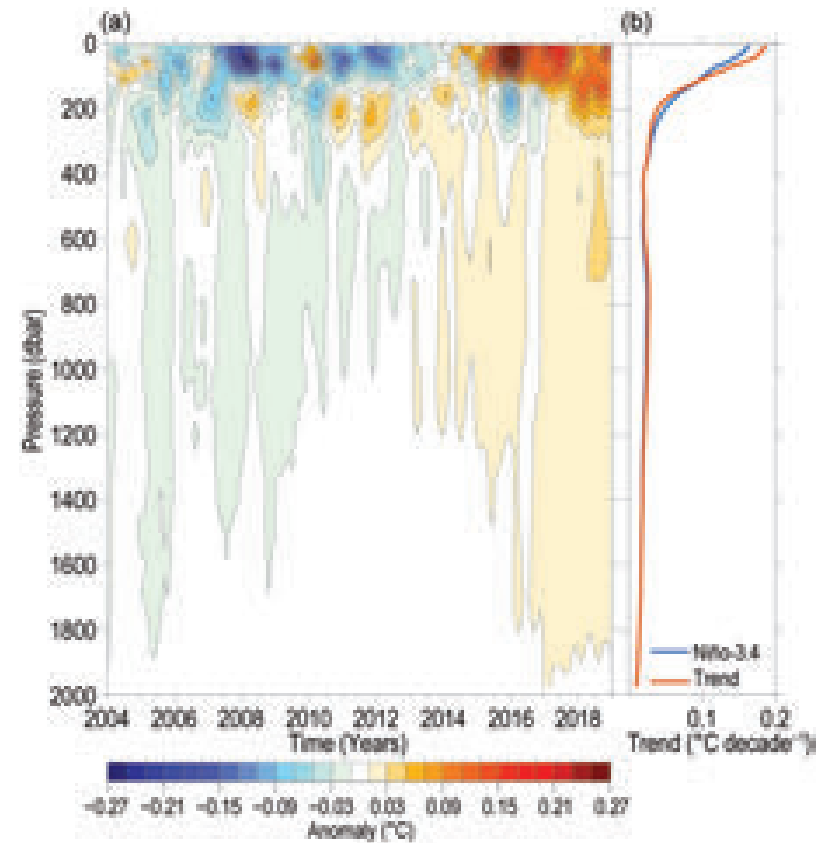

Fig. 3.5. (a) Near-global $\left(65^{\circ} \mathrm{S}-80^{\circ} \mathrm{N}\right.$, excluding continental shelves, the Indonesian seas, the Sea of Okhostk, the Caribbean Sea, and the Gulf of Mexico) integrals of monthly ocean temperature anomalies $\left[{ }^{\circ} \mathrm{C}\right.$; updated from Roemmich and Gilson (2009)] relative to record-length average monthly values, smoothed with a 5-month Hanning filter and contoured at odd $0.02^{\circ} \mathrm{C}$ intervals (see colorbar) vs. pressure and time. (b) Linear trend of temperature anomalies over time for the length of the record in (a) plotted vs. pressure in ${ }^{\circ} \mathrm{C}$ decade $^{-1}$ (orange line), and trend with a Niño-3.4 regression removed (blue line) following Johnson and Birnbaum (2017).

associated with a change in the strength of the North Brazil Current and its retroflection (www.aoml.noaa .gov/phod/altimetry/cvar/nbc/transport.php).

The large-scale statistically significant (Fig. 3.4c) regional patterns in the 1993-2018 local linear trends of upper OHCA are quite similar to those from 19932017 (Johnson et al. 2018). The areas with statistically significant negative trends are found mostly south of Greenland in the North Atlantic, south of the Kuroshio Extension in the North Pacific, and in a small portion of the eastern South Pacific. Those areas are quite small compared with those with statistically significant positive trends, which include much of the rest of the Atlantic Ocean, the region around the Maritime Continent and the western tropical Pacific, nearly the entire Indian Ocean, most of the marginal seas except the Red Sea, and much of the South Pacific and south Indian Oceans. As noted in previous reports, the apparent warming and cooling trends adjacent to Antarctica are located in both in situ and altimeter data-sparse regions and are not as 
robust as suggested by the statistics that do not reflect undersampling.

Near-global average seasonal temperature anomalies (Fig. 3.5a) reflect both a long-term warming trend (Fig. 3.5b, orange line) and ENSO redistributing heat (e.g., Roemmich and Gilson 2011) from the upper 100 dbar to a roughly 300-dbar thick layer just below, as described in last year's report (Johnson et al. 2018). In 2018, as in 2017, the entire water column measured by Argo was visibly warmer than the 2004-18 average (Fig. 3.5a). However, in 2018, the waters from 0 dbar to 100 dbar were less warm than in 2017, with a maximum difference of about $-0.06^{\circ} \mathrm{C}$ near the surface, consistent with the SST analysis (Section 3.3a). In contrast, the waters below (around 100-1000 m) were warmer, with a maximum difference of about $+0.06^{\circ} \mathrm{C}$ near $160 \mathrm{dbar}$, and another local maximum difference of $0.01^{\circ} \mathrm{C}$ near $600 \mathrm{dbar}$. This vertical redistribution may be partly due to the very strong 2016/17 El Niño (e.g., Johnson and Birnbaum 2017). However, as noted below, the net effect was that the water column from 0-2000 m gained a substantial amount of heat from 2017 to 2018 . The overall warming trend (Fig. 3.5b, orange line) from 2004 to 2018 exceeds $0.18^{\circ} \mathrm{C}$ decade $^{-1}$ near the surface, declining to less than $0.03^{\circ} \mathrm{C}$ decade ${ }^{-1}$ below 300 dbar and about $0.01^{\circ} \mathrm{C}$ decade $e^{-1}$ by 2000 dbar. As noted in previous reports, removing a linear regression against the Niño-3.4 index (e.g., Johnson and Birnbaum 2017) results in a decadal warming trend (Fig. 3.5b, blue line) that is slightly smaller, at about $0.16^{\circ} \mathrm{C}$ decade $^{-1}$, near the surface and slightly larger than the simple linear trend from about $100 \mathrm{dbar}$ to $1600 \mathrm{dbar}$. This difference is because of the influence of the 2016/17 El Niño near the end of the relatively short record.

The analysis is extended back in time from the Argo period to 1993, and deeper, using sparser, more heterogeneous historical data collected mostly from ships (e.g., Abraham et al. 2013). The six different estimates of annual globally integrated in situ 0-700m OHCA (Fig. 3.6a) all reveal a large increase since 1993, with five of the analyses reporting 2018 as a record high. The globally integrated 700-2000-m OHCA annual values (Fig. 3.6b) vary more among analyses, and only two report 2018 as a record high, but the long-term warming trend in this layer is also clear. Globally integrated OHCA values in both layers vary more both from year-to-year for individual years and from estimate-to-estimate in any given year prior to the achievement of a near-global Argo array around 2005. Causes of differences among estimates are discussed in Johnson et al. (2015).
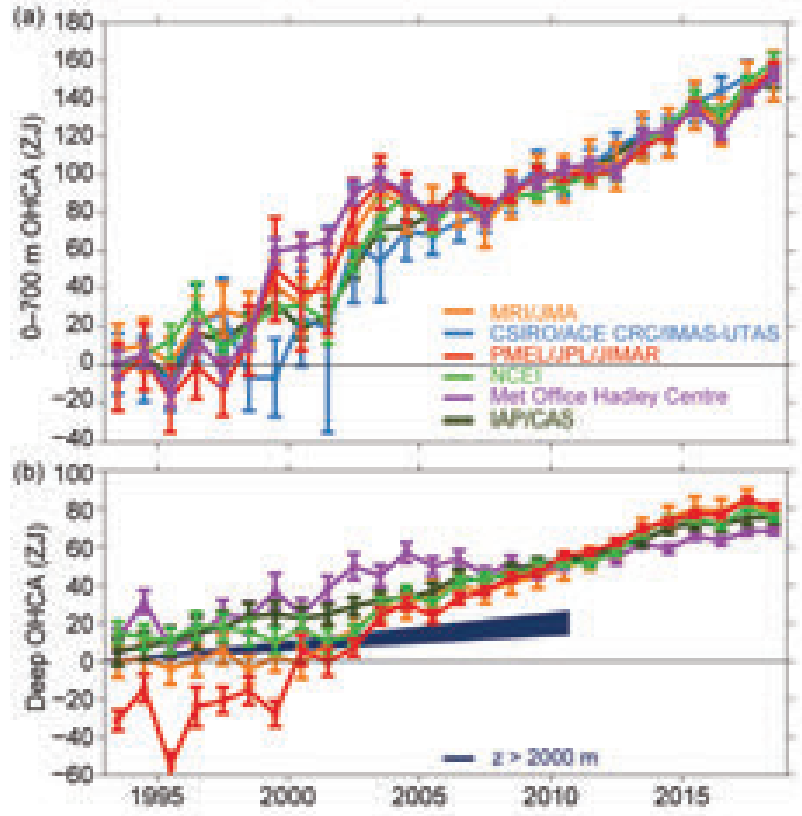

FIG. 3.6. (a) Annual average global integrals of in situ estimates of upper $(0-700 \mathrm{~m})$ OHCA $\left(\mathrm{ZJ}\right.$; I ZJ = I $\left.0^{21} \mathrm{~J}\right)$ for 1993-2018 with standard errors of the mean. The MRI/JMA estimate is an update of Ishii et al. (20I7). The CSIROIACE CRCIIMAS-UTAS estimate is an update of Domingues et al. (2008). The PMEL/JPL/JIMAR estimate is an update and refinement of Lyman and Johnson (20I4). The NCEI estimate follows Levitus et al. (20I2). The Met Office Hadley Centre estimate is computed from gridded monthly temperature anomalies (relative to 1950-2018) following Palmer et al. (2007). The IAPICAS estimate is an update of that reported in Cheng and Zhu (2018). See Johnson et al. (2014) for details on uncertainties, methods, and datasets. For comparison, all estimates have been individually offset (vertically on the plot), first to their individual 2005- 8 means (the best sampled time period), and then to their collective 1993 mean. (b) Annual average global integrals of in situ estimates of intermediate (700-2000 m) OHCA for 1993-2018 with standard errors of the mean, and a long-term trend with one standard error uncertainty shown from 1992-2010 for deep and abyssal (z> $2000 \mathrm{~m}$ ) OHCA following Purkey and Johnson (2010) but updated using all repeat hydrographic section data available from https://cchdo.ucsd.edu/ as of December 2018.

The rate of heat gain from linear fits to each of the six global integral estimates of 0-700 m OHCA from 1993 through 2018 (Fig. 3.6a) ranges from $0.36( \pm 0.06)$ to $0.42( \pm 0.06) \mathrm{W} \mathrm{m}^{-2}$ applied over the surface area of Earth (Table 3.2). Linear trends from $700 \mathrm{~m}$ to $2000 \mathrm{~m}$ over the same time period range from $0.14( \pm 0.05)$ to $0.32( \pm 0.03) \mathrm{W} \mathrm{m}^{-2}$. Trends in the $0-700-\mathrm{m}$ layer all agree within uncertainties, but one of the trends in the 700-2000-m layer, which is quite sparsely sampled prior to the start of the Argo 
era (circa 2005), does not. It is likely the different methods for dealing with under-sampled regions in analyses cause the disagreement in the long-term trends for the 700-2000-m layer OHCA estimates. For 2000-6000 $\mathrm{m}$, the linear trend is $0.07( \pm 0.04) \mathrm{W} \mathrm{m}^{-2}$ from September 1992 to May 2011, using repeat hydrographic section data collected from 1981 to 2018 to update the estimate of Purkey and Johnson (2010). Summing the three layers (with their slightly different time periods), the full-depth ocean heat gain rate ranges from 0.57 to $0.81 \mathrm{~W} \mathrm{~m}^{-2}$ roughly applicable to 1993-2018. Estimates starting circa 2005 have much smaller uncertainties, e.g., $0.61 \pm 0.09 \mathrm{~W} \mathrm{~m}^{-2}$ for ocean warming at depths of 0-1800 dbar during 2005-15 (Johnson et al. 2016).

\section{d. Salinity-G. C. Johnson, J. Reagan, J. M. Lyman, T. Boyer,} C. Schmid, and R. Locarnini

I) INTRODUCTION-G. C. Johnson and J. Reagan

Salinity is the fraction of dissolved salts in water, nominally in $\mathrm{g} \mathrm{kg}^{-1}$, but measured and reported here as a dimensionless quantity on the 1978 Practical Salinity Scale, or PSS-78 (Fofonoff and Lewis 1979). Salinity and temperature together determine the density of seawater at a given pressure. Their variability can alter the density patterns that are integral to the global thermohaline circulation (e.g., Gordon 1986; Broecker 1991). One prominent limb of the global thermohaline circulation, the AMOC, is particularly susceptible to changes in salinity (e.g., Liu et al. 2017). Salinity is also a conservative water property, traceable back to where a water mass was originally formed at the surface and subducted into the ocean's interior (e.g., Skliris et al. 2014). Where precipitation dominates evaporation, fresher surface seawater is found (i.e., along the ITCZ and at high latitudes), and where evaporation dominates precipitation, saltier surface seawater is found (i.e., in the subtropics). Salinity acts as a natural rain gauge (e.g., Terray et al. 2012), useful since $\sim 80 \%$ of the global hydrological cycle takes place over the ocean (e.g., Durack 2015). Salinity changes are used to estimate changes in the hydrological cycle (e.g., Durack et al. 2012). They also play a role in local sea level changes through seawater contraction with salinification and expansion with freshening (e.g., Durack et al. 2014). Finally, besides atmospheric freshwater fluxes, other factors can modify salinity such as advection, mixing, entrainment, sea ice melt/ freeze, and river runoff (e.g., Ren et al. 2011).

Different data sources are used for different salinity analyses in this section owing to data availability and accuracy. To investigate interannual changes of subsurface salinity, all available salinity profile data are quality controlled following Boyer et al. (2013) and then used to derive $1^{\circ}$ monthly mean gridded salinity anomalies relative to a long-term monthly mean for years 1955-2012 [World Ocean Atlas 2013 version 2 (WOA13v2); Zweng et al. 2013] at standard depths from the surface to $2000 \mathrm{~m}$ (Boyer et al. 2013). In recent years, the largest source of salinity profiles is the Argo program (Riser et al. 2016). These data are a mix of real-time (preliminary) and delayed-mode (scientific quality controlled) observations. Hence, the estimates presented here could change after all data are subjected to scientific quality control. The sea surface salinity (SSS) analysis relies on Argo data downloaded in January 2019, with annual maps generated following Johnson and Lyman (2012) as well as monthly maps of bulk (as opposed to skin) SSS data from the Blended Analysis of Surface Salinity (BASS) (Xie et al. 2014). BASS blends in situ SSS data with data from the Aquarius (Le Vine et al. 2014; mission ended in June 2015), Soil Moisture and Ocean Salinity (SMOS; Font et al. 2013), and recently Soil Moisture Active Passive (SMAP; Fore et al. 2016) satellite 
missions. BASS maps can be biased fresh around land (including islands), and features at high latitudes should be validated with in situ maps. Despite the larger uncertainties of satellite data relative to Argo data, their higher spatial and temporal sampling allows higher spatial and temporal resolution maps than are possible using in situ data alone at present.

\section{2) Sea surface salinity-G. C. Johnson and J. M. Lyman}

Extratropical 2018 SSS anomalies (Fig. 3.7a, colors) exhibit large-scale similarities with those from 2004 to 2017 (see previous State of the Climate reports). With the partial exception of the North Pacific in 2018 and 2017, subtropical salinity maxima are mostly salty with respect to the WOA13v2 climatology. The fresher higher latitude regions such as the subpolar North Pacific, the Irminger and portions of the Nordic seas of the North Atlantic, and some portions of the Southern Ocean are anomalously fresh with respect to climatology. A warmer atmosphere can hold more water, withdrawing more in evaporative regions and depositing more in precipitation-prone regions, which would lead to the salinity patterns observed (Rhein et al. 2013), as well as those seen in the extratropical 2005-18 trends discussed below. Within the tropics, which have large SSS excursions with ENSO and other interannual variations, both the ITCZ and SPCZ in the Pacific are quite fresh in 2018 with respect to climatology (Fig. 3.7a), as is the region near the Amazon and Orinoco river mouths in the Atlantic.

A tight relationship between anomalies of air-sea freshwater fluxes (precipitation minus evaporation; $P-E$ ) and SSS anomalies is especially apparent in the year-to-year changes of both quantities. Where SSS changes from 2017 to 2018 (Fig. 3.7b, colors) are positive, $P-E$ tendencies over that same period are often negative (see Fig. 3.12b). With a reduction in rainfall from 2017 to 2018 around the Maritime Continent, that region between the Indian and Pacific Oceans sees an increase in SSS from 2017 to 2018. With increased freshwater flux into the ocean around the Pacific ITCZ, the SSS in the region decreases from 2017 to 2018, whereas south of the equator the opposite pattern holds. This relationship can also be seen in the freshening tropical Indian Ocean, the salinifying subtropical North Pacific, and the freshening Gulf of Alaska, among other regions. The freshening SSS tendency from 2017 to 2018 just south of the equator in the Indian Ocean may be partly owing to an increase in anomalous westward currents between 2017 and 2018 there (see Fig. 3.18b) in the presence of mean SSS that increases from east to west.
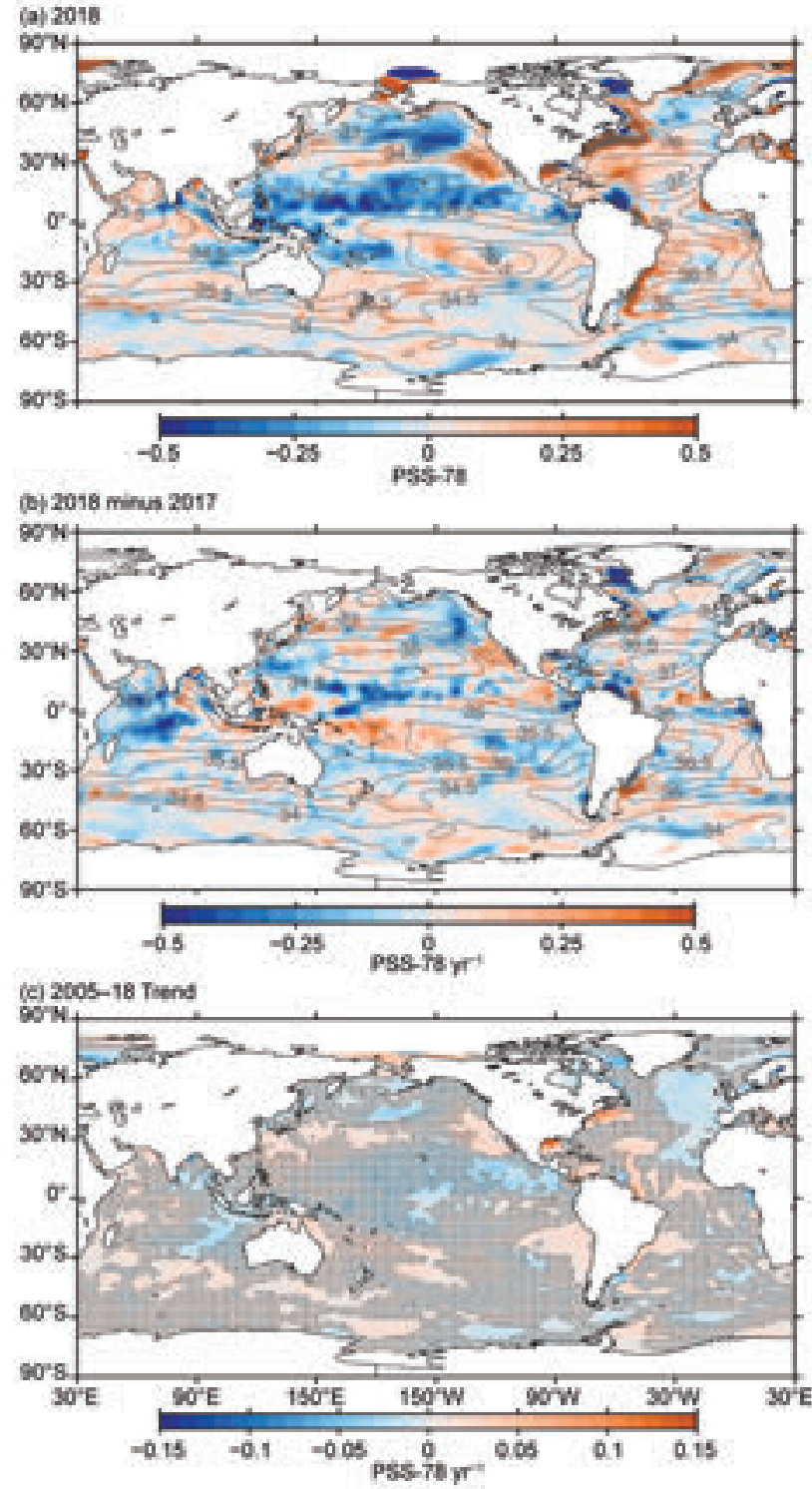

FIG. 3.7. (a) Map of the 2018 annual surface salinity anomaly (colors, PSS-78) with respect to monthly climatological 1955-20I2 salinity fields from WOAI3v2 (long-term average-gray contours at $\mathbf{0 . 5}$ intervals, PSS-78). (b) Difference of 2018 and 2017 surface salinity maps (colors, PSS-78 yr $^{-1}$ ). White ocean areas are too data-poor (retaining $<80 \%$ of a large-scale signal) to map. (c) Map of local linear trends estimated from annual surface salinity anomalies for 2005- 18 (colors, PSS-78 $\mathrm{yr}^{-1}$ ). Areas with statistically insignificant trends at 5\%-95\% confidence are stippled. All maps are made using Argo data downloaded in Jan 2019.

As in 2017, strong seasonal variations of BASS (Xie et al. 2014) SSS anomalies (Fig. 3.8) are evident near the Amazon and Orinoco River plumes in 2018. For the first three quarters of the year, there is a fresh anomaly localized near the coast, but it extends eastward across much of the northern equatorial Atlantic in September-November. In the tropical Pacific, a 


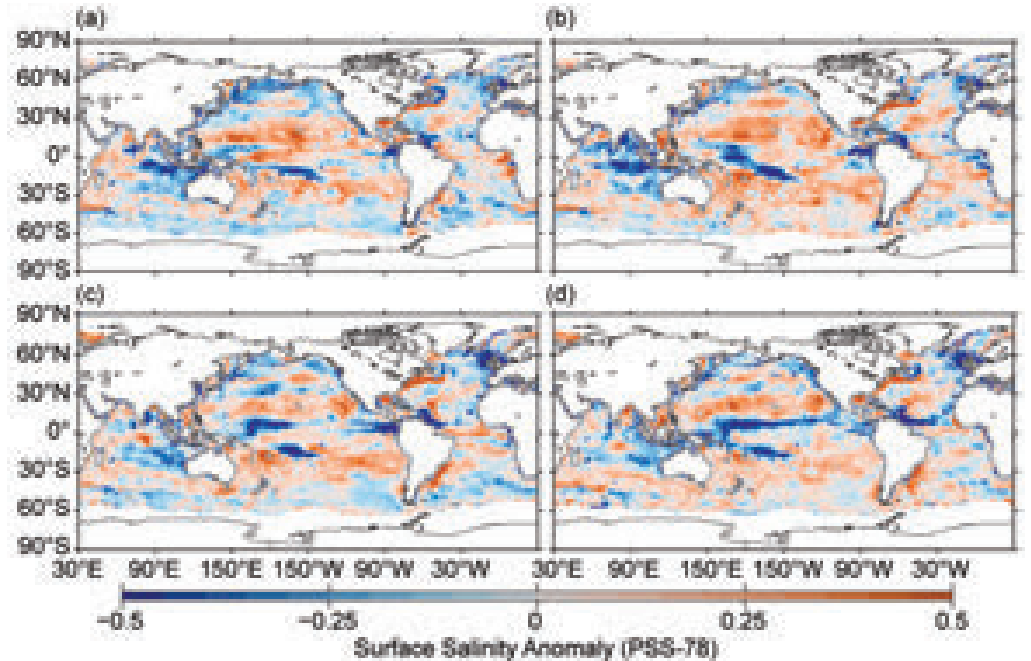

FIG. 3.8. Seasonal maps of SSS anomalies (colors) from monthly blended maps of satellite and in situ salinity data (BASS; Xie et al. 20I4) relative to monthly climatological $1955-2012$ salinity fields from WOAI3v2 for (a) Dec 20I7-Feb 2018, (b) Mar-May 2018, (c) Jun-Aug 2018, and (d) Sep-Nov 2018. Areas with maximum monthly errors exceeding 10 PSS-78 are left white.

fresh anomaly builds under the ITCZ in June-August and strengthens in September-November.

Sea surface salinity trends for 2005-18, the era of near-global Argo coverage, are estimated by local linear fits to annual average SSS maps from Argo data (Fig. 3.7c). Large-scale patterns of local trends have not changed much from last year's report. Regions with already high salinity values, such as the subtropical salinity maxima in all the ocean basins and the Arabian Sea, show increasing trends, with statistical significance in some portions of those regions, especially in the South Indian Ocean and in the Pacific off the west coasts of the Americas. Statistically significant freshening trends are apparent in the subpolar North Pacific, the eastern subpolar North Atlantic, the eastern warm fresh pool in the tropical North Pacific, and the Bay of Bengal. These are all regions that are climatologically fresh relative to their surroundings. In the Gulf of Mexico and along the east coast of North America from roughly Cape Hatteras northward, strong, statistically significant trends toward saltier and warmer (Section 3c) conditions are evident.

3) Subsurface SALINITY-J. Reagan, T. Boyer, C. Schmid, and R. Locarnini

The 2009-18 basin-average monthly salinity anomalies (Fig. 3.9a) for the Atlantic Ocean continued the same pattern that has been evident for the past decade, with weak anomalies $(<|0.005|)$ below $\sim 600 \mathrm{~m}$ and salty anomalies $(>0.005)$ extending and increasing from $\sim 600 \mathrm{~m}$ to the surface where they reach values exceeding 0.05 . There is freshening $(\sim-0.015)$ between 2017 and 2018 in the upper 50 $\mathrm{m}$ with salinification extending from $100 \mathrm{~m}$ to $1200 \mathrm{~m}$ and a maximum ( 0.01) around $150 \mathrm{~m}$ (Fig. 3.9b). The deeper (250-700 m) salinification tendency in 2018 may be related to the deepening of the salinity anomalies from 2017 (Fig. 3.9a). 2018 is also the first year in the past decade when all $0-1500$ - $\mathrm{m}$ basin-average monthly salinity anomalies were saltier than the long-term mean (Fig. 3.9a).

The 2018 Pacific Ocean basin-average monthly salinity anomalies for 0-1500 m continued the same pattern that has been evident since mid-2014 (Fig. 3.9c). There are fresh anomalies in the upper $100 \mathrm{~m}$, salty anomalies from 100-250 $\mathrm{m}$, fresh anomalies from 275-600 m, and weak $(<|0.005|)$ anomalies at depths below $600 \mathrm{~m}$ (Fig. 3.9c). Changes from 2017 to 2018 (Fig. 3.9d) include freshening in the upper $\sim 100 \mathrm{~m}$ ( $\max$ of $\sim-0.015$ at $50 \mathrm{~m}$ ) and salinification from $125-375 \mathrm{~m}$ (max of $\sim 0.015$ at $200 \mathrm{~m}$ ). These tendencies are very similar to what was seen between 2016 and 2017 (see Fig. 3.9d in Reagan et al. 2018). 2018 also marks the fourth straight year with fresh anomalies in the upper $100 \mathrm{~m}$, following a 5-year period (2009-14) of persistent salty anomalies in the upper $100 \mathrm{~m}$ (Fig. 3.9c). A possible cause for these persistent anomalies may be related to in-phase transitions of ENSO and PDO (see discussion in Reagan et al. 2018).

The Indian Ocean basin-average monthly salinity anomalies experienced persistent fresh anomalies in the upper 0-100/200 $\mathrm{m}$ from mid-2011 through mid2016 , with salty anomalies in a $100-200$-m thick layer below (Fig. 3.9e). The $0-100-\mathrm{m}$ salinity exceeded the long-term average in mid-2016 through early 2018, followed by some near-surface $(<50 \mathrm{~m})$ freshening evident in mid-2018. There are also salty anomalies extending from the surface to depths of $\sim 700 \mathrm{~m}$ during the latter half of 2018 (Fig. 3.9e). The major change between 2017 and 2018 was very strong freshening $(<\sim-0.025)$ in the upper $30 \mathrm{~m}$ (Fig. 3.9f), discussed further below.

The zonally-averaged salinity tendency from 2017 to 2018 in the upper $500 \mathrm{~m}$ of the Atlantic Ocean shows strong freshening in the upper $50 \mathrm{~m}$ along the equator $(\max <-0.15$ at $0 \mathrm{~m}$, Fig. $3.10 \mathrm{a})$ which is associated with a narrow strip of near-surface fresh- 


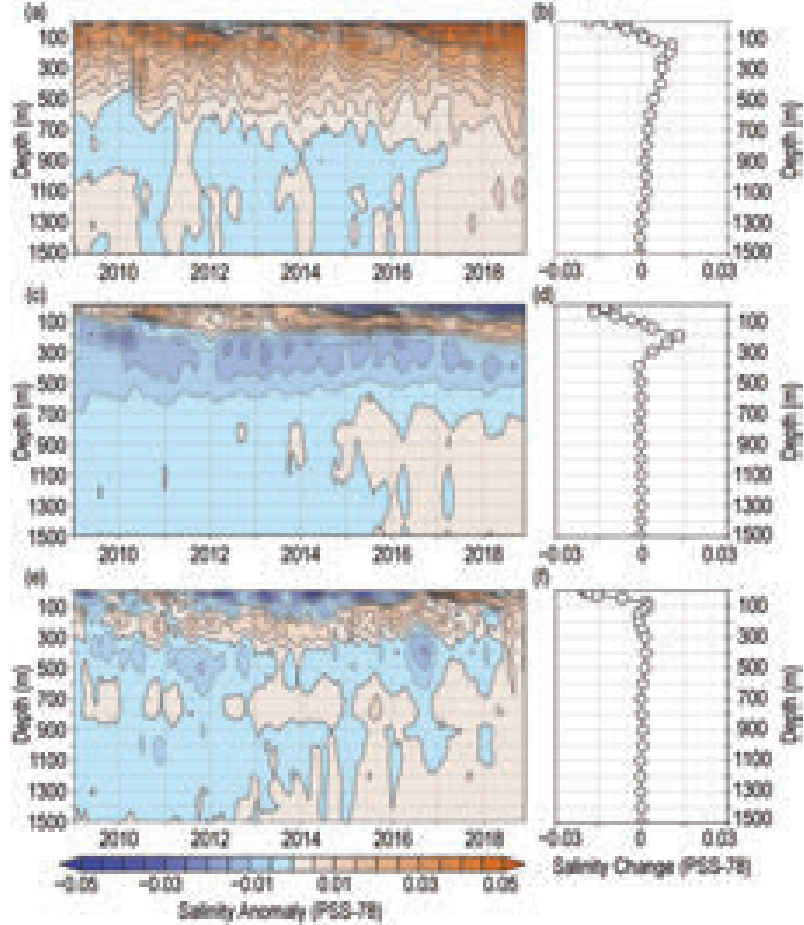

FIG. 3.9. Average monthly salinity anomalies from 0-1500 $\mathrm{m}$ for the (a) Atlantic from 2009-18 and (b) the change from 2017 to 2018; (c) Pacific from 2009-18 and (d) the change from 2017 to 2018; (e) Indian from 200918 and (f) the change from 2017 to 2018. Data were smoothed using a 3-month running mean. Anomalies are relative to the long-term WOA $13 \mathrm{v} 2$ monthly salinity climatology for years 1955-2012 (Zweng et al. 2013).

ening between the Gulf of Guinea and Northeast Brazil (Fig. 3.7b). Additionally, there is freshening $(<$ -0.03 ) from $10^{\circ}$ to $20^{\circ} \mathrm{N}$ extending from $0 \mathrm{~m}$ to 200 $\mathrm{m}$. There is also freshening from $45^{\circ}$ to $52^{\circ} \mathrm{N}$ in the upper $150 \mathrm{~m}$, which is opposite to the salinification observed between 2016 and 2017 (see Fig. 3.10a in Reagan et al. 2018). Finally, there is salinification (>0.03) from $0 \mathrm{~m}$ to $500 \mathrm{~m}$ near $40^{\circ} \mathrm{N}$ and $40^{\circ} \mathrm{S}$, from $0 \mathrm{~m}$ to $175 \mathrm{~m}$ between $48^{\circ}-55^{\circ} \mathrm{S}$, and a subsurface area from $20^{\circ}-30^{\circ} \mathrm{N}$ at $75-250 \mathrm{~m}$ (Fig. 3.10a).

The changes in the Pacific Ocean zonally-averaged salinity from 2017 to 2018 are mainly confined to the upper $300 \mathrm{~m}$ (Fig. 3.10b). There is freshening $(<-0.03)$ from $18^{\circ}-32^{\circ} \mathrm{S}$ and $0-75 \mathrm{~m}$ that deepens northward to $10^{\circ} \mathrm{S}$ and $100 \mathrm{~m}$, freshening from $8^{\circ}$ to $16^{\circ} \mathrm{N}$ and $0-40 \mathrm{~m}$, and salinification from $4^{\circ}-12^{\circ} \mathrm{S}$ and $0-50 \mathrm{~m}$. The latter freshening and salinification tendencies are likely associated with changes in oceanic freshwater gains and losses from evaporation and precipitation (see Fig. 3.12b). All of the aforementioned freshening and salinification tendencies shifted southward from where they were located the previous year (see Fig. 3.10b in Reagan et al. 2018). Finally, there was
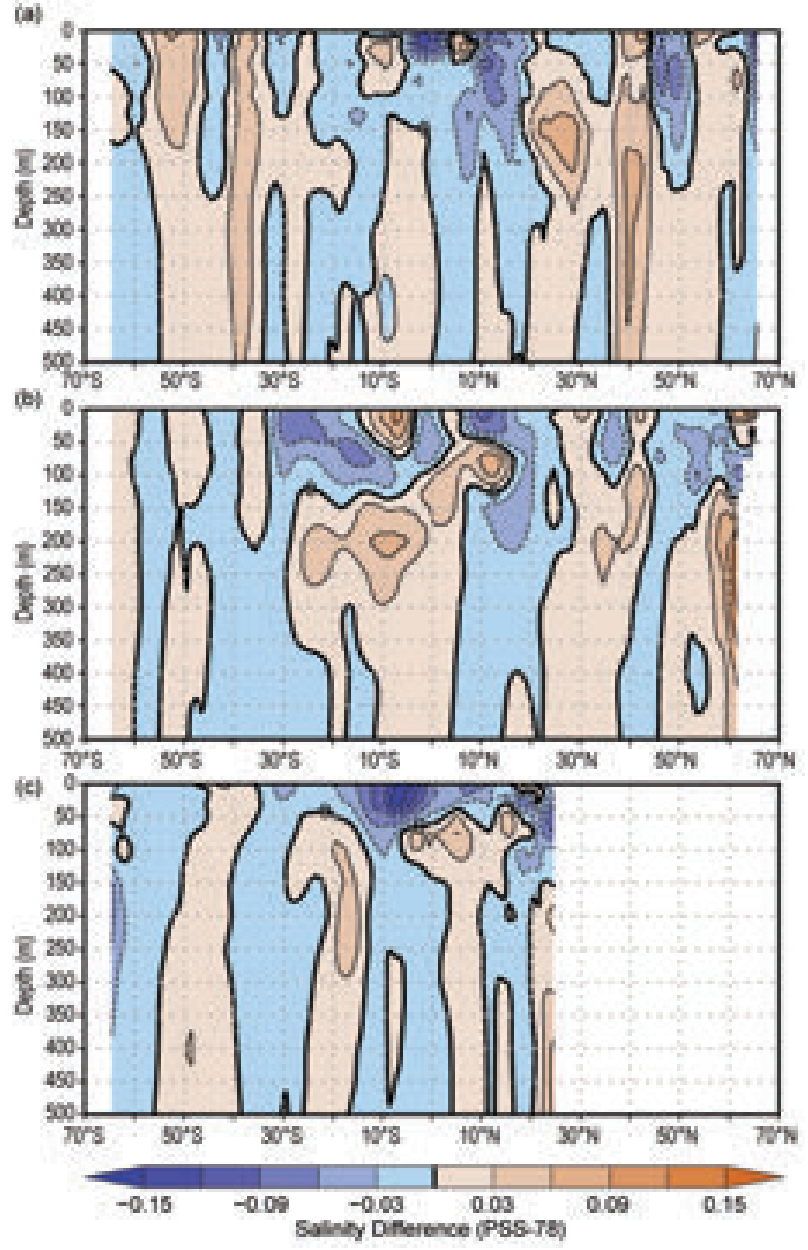

FIG. 3.10. Difference between the 2018 and 2017 zonal average monthly salinity anomalies from $0-500 \mathrm{~m}$ for the (a) Atlantic, (b) Pacific, and (c) Indian Ocean basins. Anomalies are relative to the long-term WOA13v2 monthly salinity climatology for years 1955-20I2 (Zweng et al. 2013). Contours represent multiples of \pm 0.03 with a bold 0 contour.

also salinification (>0.03) in two subsurface Pacific regions, one centered at $10^{\circ} \mathrm{S}$ and $200 \mathrm{~m}$ and the other at greater depths between 125-500 m northward of $55^{\circ} \mathrm{N}$.

Much of the larger changes $(>|0.03|)$ of the zonally averaged salinity anomalies from 2017 to 2018 in the Indian Ocean occurred in the upper $100 \mathrm{~m}$ (Fig. 3.10c). There was freshening from $20^{\circ} \mathrm{S}$ to $10^{\circ} \mathrm{N}$ in the 0-50 m layer, which is a complete reversal of the prominent salinification observed there between 2016 and 2017 (see Fig. 3.10c in Reagan et al. 2018). This freshening may be due to anomalous westward surface currents (see Fig. 3.18b) in the equatorial Indian Ocean transporting fresher water westward, a reversal from what was observed last year (Johnson and Lyman 2018). Much of this freshening is located in the Arabian Sea and the central and western 
portions of the tropical Indian Ocean, northward of $15^{\circ} \mathrm{S}$ (Fig. 3.8b). There is also freshening in the upper $150 \mathrm{~m}$ northward of $20^{\circ} \mathrm{N}$ from 2017 to 2018 .

e. Global ocean heat, freshwater, and momentum fluxes - L. Yu, X. Jin, P. W. Stackhouse, A. C. Wilber, S. Kato, N. G. Loeb, and R. A. Weller

The ocean and the atmosphere communicate via interfacial exchanges of heat, freshwater, and momentum. These air-sea fluxes are the primary mechanisms for keeping the global climate system in near balance with the incoming insolation at Earth's surface. Most of the shortwave radiation (SW) absorbed by the ocean's surface is vented into the atmosphere by three processes: longwave radiation (LW), turbulent heat loss by evaporation (latent heat flux, or LH), and by conduction (sensible heat flux, or $\mathrm{SH}$ ). The residual heat is stored in the ocean and transported away by the ocean's surface circulation, forced primarily by the momentum transferred to the ocean by wind stress. Evaporation connects heat and moisture transfers, and the latter, together with precipitation, determines the local surface freshwater flux. Identifying changes in the air-sea fluxes is essential in deciphering observed changes in ocean circulation and its transport of heat and salt from the tropics to the poles.

Air-sea heat flux, freshwater flux, and wind stress in 2018 and their relationships with ocean surface variables are examined here. The net surface heat flux, $\mathrm{Q}_{\text {net }}$, is the sum of four terms: $\mathrm{SW}+\mathrm{LW}+\mathrm{LH}+\mathrm{SH}$. The net surface freshwater flux into the ocean (neglecting riverine and glacial fluxes from land) is simply Precipitation $(P)$ minus Evaporation $(E)$, or the $P-E$ flux. Wind stress is computed from satellite wind retrievals using the bulk parameterization of Edson et al. (2013). The production of the global maps of $\mathrm{Q}_{\text {net }}, P-E$, and wind stress (Figs. 3.11-3.13) and the longterm perspective of the change of the forcing functions (Fig. 3.14) is made possible through integrating multi-group efforts. Ocean-surface $\mathrm{LH}, \mathrm{SH}$, $E$, and wind stress are from the OAFlux project's newly developed satellite-derived, (c) high-resolution (hereafter OAFlux-HR) products (Yu and Jin 2014; Yu 2019). Surface SW and LW radiative fluxes are from the CERES Fast Longwave And Shortwave Radiative Fluxes (FLASHFlux) Ed3A product (Stackhouse et al. 2006). Global $P$ is from the GPCP version 2.3 products (Adler et al. 2003). The CERES Energy Balanced and Filled (EBAF) surface SW and LW version 4.0 products (Loeb et al. 2018; Kato et al. 2018) are used in the time series analysis.

\section{I) SURFACE HEAT FLUXES}

The dominant features in the $2018 \mathrm{Q}_{\text {net }}$ anomaly field (Fig. 3.11a) are the broad-scale oceanic heat gain (positive $\mathrm{Q}_{\text {net }}$ anomalies) in the equatorial and southern Pacific and Indian Oceans $\left(40^{\circ} \mathrm{S}-10^{\circ} \mathrm{N}\right)$, and the oceanic heat loss (negative $\mathrm{Q}_{\text {net }}$ anomalies) in the subtropical North Pacific $\left(10^{\circ}-30^{\circ} \mathrm{N}\right)$, the North Atlantic $\left(10^{\circ}-60^{\circ} \mathrm{N}\right)$, and the southern higher latitudes $\left(40^{\circ} \mathrm{S}\right.$ poleward). Positive and negative anomalies both exceeded $25 \mathrm{~W} \mathrm{~m}^{-2}$. The 2018-minus-2017 $\mathrm{Q}_{\text {net }}$ tendency field (Fig. 3.11b) was predominantly determined by the $\mathrm{LH}+\mathrm{SH}$ change pattern. The spatial pattern of $\mathrm{Q}_{\text {net }}$ tendencies is similar to that of the 2018-minus-2017 anomaly pattern (Fig. 3.11b) over most of the global ocean, showing that the 2018 anomalies were a strong departure from the climatological mean state. However, the two patterns differ considerably in a few regions, most notably the tropical Pacific where the 2018 tendencies have signs opposite to the
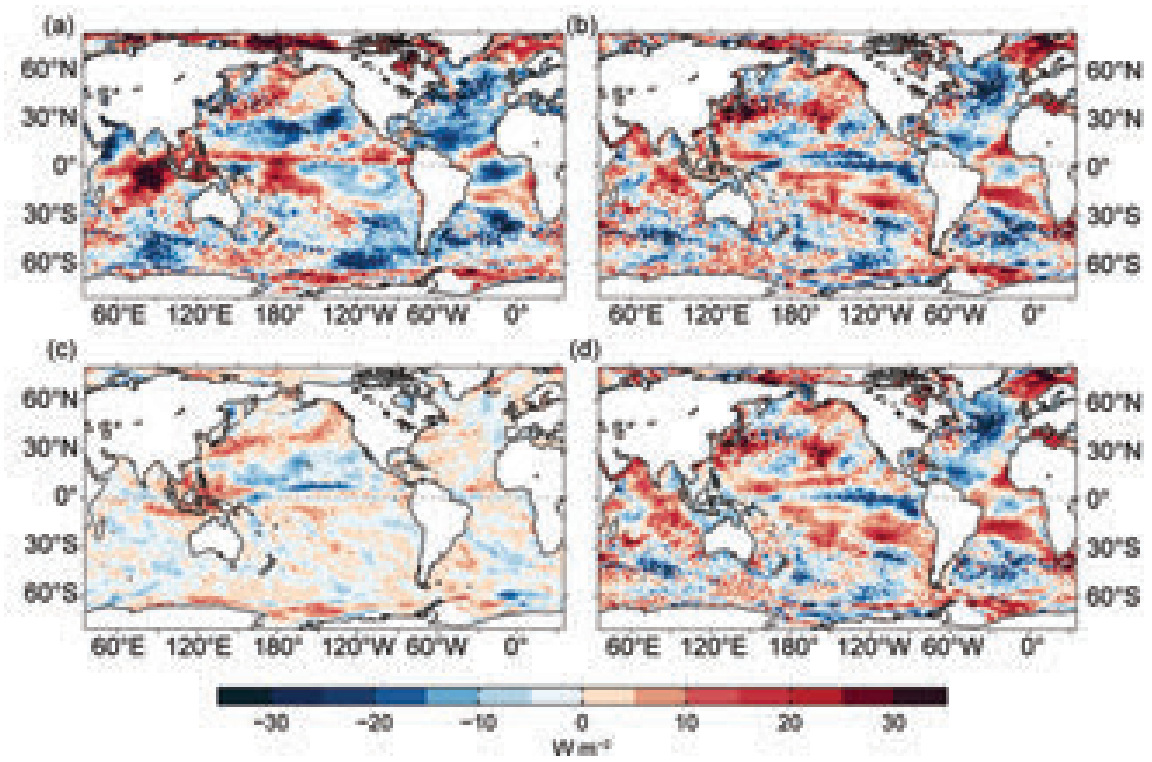

FIG. 3.II. (a) Surface heat flux $\left(Q_{\text {net }}\right)$ anomalies $\left(\mathrm{W} \mathrm{m}^{-2}\right)$ for 2018 relative to a 5-yr (2010-14) mean. Positive values denote ocean heat gain. (b) 2018 minus 2017 tendency for $Q_{\text {net }}$, (c) surface radiation (SW+LW), and (d) turbulent heat fluxes (LH+SH), respectively. Positive tendencies denote more ocean heat gain in 2018 than in 2017 , consistent with the reversal of the color scheme in (d). LH+SH are produced by the OAFlux high-resolution (HR) satellite-based analysis, and SW+LW by the NASA FLASHFlux project. 
2018 anomalies. Note that the net heat loss tendencies south of $60^{\circ} \mathrm{S}$ may be influenced by sea-ice edge effect on flux estimates.

The tropical Pacific returned to ENSO-neutral conditions after a weak La Niña ended in March 2018 (see Section 4 b). There was a widespread sea-surface cooling tendency over most of the equatorial ocean with the exception of a weak warming tendency in the central equatorial Pacific (Fig. 3.1). The 2018 $\mathrm{LH}+\mathrm{SH}$ tendencies (Fig. 3.11d) show a large increase in the central and eastern equatorial region (positive $\mathrm{LH}+\mathrm{SH}$ anomalies, blue colors) and a substantial reduction south of the equator (negative $\mathrm{LH}+\mathrm{SH}$ anomalies, red colors). Note that the color scheme is reversed to indicate that increased $\mathrm{LH}+\mathrm{SH}$ (positive anomalies, blue colors) have a cooling effect on the ocean surface and, conversely, reduced $\mathrm{LH}+\mathrm{SH}$ (negative anomalies, red colors) have a warming effect. The 2018 SW+LW tendencies (Fig. 3.11c) show less radiative heat input to the ocean in 2018 than in 2017 to the north of the equatorial Pacific and more radiative heat input to the south, with a maximum reduction occurring in the central basin under the ITCZ and a maximum enhancement occurring in the far western equatorial Pacific and the Maritime Continent. Outside of the equatorial ocean, a zonal band of larger SW+LW tendencies $\left(>10 \mathrm{~W} \mathrm{~m}^{-2}\right)$ in the mid-latitude North Pacific extended from the Kuro- shio Extension northeastward to the Gulf of Alaska. $\mathrm{SW}+\mathrm{LW}$ tendencies were small $\left(<5 \mathrm{~W} \mathrm{~m}^{-2}\right)$ elsewhere.

In the Northeast Pacific, the "Warm Blob" (Bond et al. 2015) reemerged in June 2018 (Fig. 3.2), featuring a large mass of warmer water underneath a higherthan-normal pressure zone off North America's west coast and particularly noted in the Gulf of Alaska. Under the higher-pressure system, surface radiative heat input increased (positive SW+LW tendencies, Fig. 3.11c) due to the reduction of clouds and reduced surface turbulent heat loss $(\mathrm{LH}+\mathrm{SH}$ negative anomalies, Fig. 3.11d) due to wind weakening (Fig. 3.13b). Both $\mathrm{SW}+\mathrm{LW}$ and $\mathrm{SH}+\mathrm{LH}$ tendencies had a warming effect on the ocean surface. The radiative and turbulent heat flux tendencies also created a warming effect in the vicinity of the Kuroshio Extension.

In the North Atlantic, the cooling effect of $\mathrm{LH}+\mathrm{SH}$ tendencies dominated over the warming effect of $\mathrm{SW}+\mathrm{LW}$ tendencies. A strong positive NAO index persisted from December 2017 through October 2018, then showed a transition to neutral phase. Surface winds were intensified significantly in 2018 (Fig. $3.13 \mathrm{~b}$ ), leading to pronounced turbulent heat loss (positive $\mathrm{LH}+\mathrm{SH}$ tendencies, blue color) over the basin from the equator to $60^{\circ} \mathrm{N}$ latitude. In the equatorial and south subtropical Atlantic, $\mathrm{LH}+\mathrm{SH}$ tendencies produced a warming effect; this appears to be associated with wind weakening in these regions.

In the Indian Ocean, a (a)

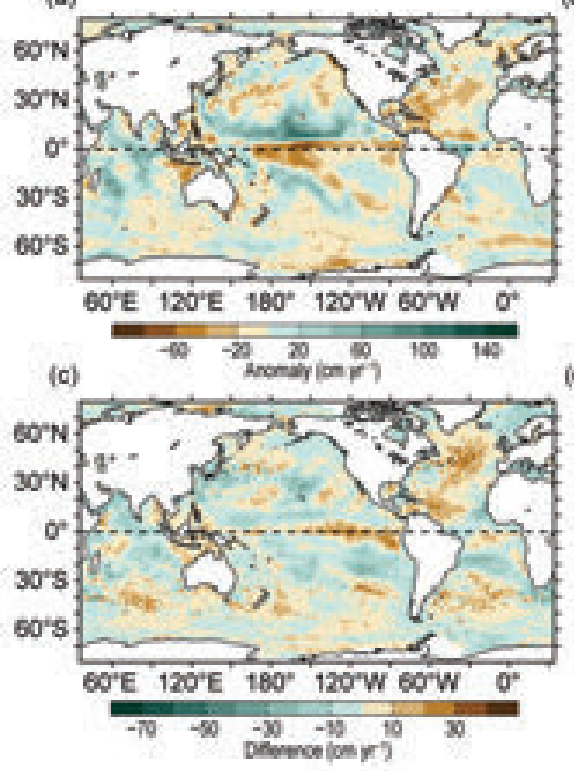

(b)

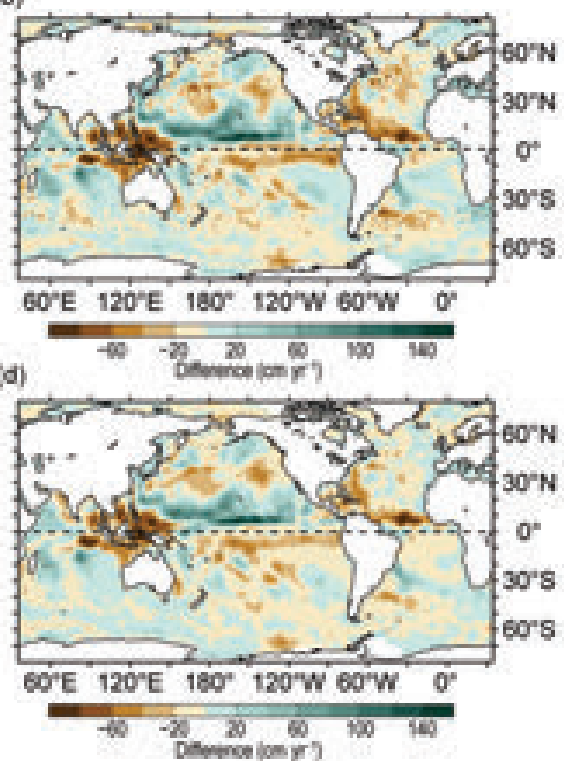

FIG. 3.I2. (a) Surface freshwater $(P-E)$ flux anomalies $\left(\mathrm{cm} \mathrm{yr}^{-1}\right)$ for 2018 relative to the 1988-2014 climatology. 2018 minus 2017 tendencies for (b) $P-E$, (c) evaporation $(E)$, and (d) precipitation $(P)$. Green colors denote anomalous ocean moisture gain, and browns denote loss, consistent with the reversal of the color scheme in (c). $P$ is computed from the GPCP version 2.3 product, and $E$ from OAFlux-HR. positive dipole event occurred during SeptemberNovember. Albeit short lived, both $\mathrm{SW}+\mathrm{LW}$ and $\mathrm{LH}+\mathrm{SH}$ tendencies displayed a dipolelike pattern in the equatorial creased and $\mathrm{LH}+\mathrm{SH}$ reduced, which combined to produce a marked increase of heat gain at the ocean surface (positive $\mathrm{Q}_{\text {net }}$ tendencies). In the central equatorial basin, there was a slight reduction in SW+LW and a slight increase in $\mathrm{LH}+\mathrm{SH}$, giving rise to a slight increase of heat loss at the ocean surface (negative $\mathrm{Q}_{\text {net }}$ tendencies). zone. In the east, SW+LW in- 


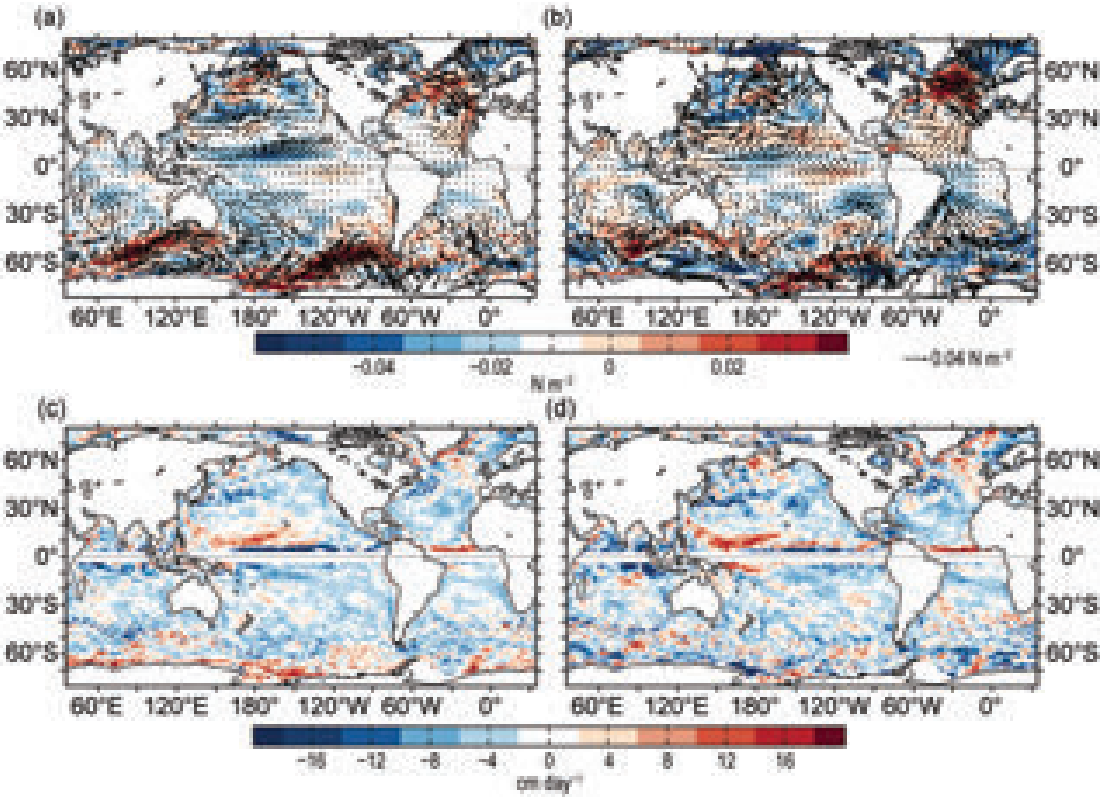

Fig. 3.13. (a) Wind stress magnitude (colors) and vector anomalies $\left(\mathrm{N} \mathrm{m}^{-2}\right)$ for 2018 relative to the $1988-2014$ climatology, (b) 2018 minus 2017 tendencies in wind stress, (c) Ekman vertical velocity $\left(W_{E K} ; \mathrm{cm}\right.$ day $\left.{ }^{-1}\right)$ anomalies for 2018 relative to the 1988-2014 climatology, and (d) 2018 minus 2017 tendencies in $W_{E K^{\circ}}$. In (c) and (d), positive values denote upwelling tendency, and negative downwelling tendency. Winds are computed from the OAFlux-HR. equatorial Indian Ocean, with maximum magnitude exceeding $45 \mathrm{~cm}$ from 2017 to 2018 . The $P$ tendencies also display a dipole-like pattern in the tropical Indian Ocean, with reduced freshwater input (drying) in the east and enhanced freshwater input (wetting) in the west. In the Gulf of Alaska where $\mathrm{Q}_{\text {net }}$ increased coinciding with the return of the "Warm Blob," P $E$ increased, and it decreased to the south.

\section{3) WIND STRESS}

The 2018 wind stress anomaly pattern (Fig. 3.13a) indicates that the trade winds weakened north of the equator and strengthened south of the equator in the tropical Pacific with respect to climatology. Marked increase of westerly winds is evident in the mid-

\section{2) Surface freshWATER fluXES}

The $2018 P-E$ anomaly pattern shows that net freshwater input at the ocean surface increased in the north tropical Pacific and the tropical Indian Ocean (positive anomalies, green colors) but decreased in the south tropical Pacific and mid-latitudes in both Northern and Southern Hemispheres (negative anomalies, brown colors) (Fig. 3.12a). A similar global pattern is also shown in the $2018 P-E$ tendencies (Fig. $3.12 b)$ with the exception of the equatorial Pacific, where $P-E$ negative anomalies were more oriented to the south of the equator in the central and eastern basin. The tropical $P-E$ tendencies are attributable to the $P$ tendencies (Fig. 3.12d) and are consistent with the SW+LW tendencies. The tropical SW+LW tended to decrease in areas of increased ITCZ rainfall and to increase in area of reduced ITCZ rainfall.

The $E$ tendencies (Fig. 3.12c) show that ocean evaporation increased in the equatorial Pacific and Atlantic Oceans and also at mid latitudes $\left(30^{\circ}-60^{\circ}\right.$ north and south). The increase of $E$ was most pronounced in the North Atlantic, spanning latitudes from the equator to $60^{\circ} \mathrm{N}$. Coherent drying tendencies were also evident in the $P$ flux, indicating that the North Atlantic had a deficit in surface freshwater input in 2018.

The largest drying tendencies in the $P$ flux occurred in the far western equatorial Pacific and the eastern latitude North Pacific and Atlantic $\left(50^{\circ}-60^{\circ} \mathrm{N}\right)$ and along the Antarctic Circumpolar Current (ACC) in the Southern Ocean $\left(40^{\circ}-60^{\circ} \mathrm{S}\right)$. Strengthening of surface winds in the North Atlantic associated with the positive NAO event is clear in the 2018 tendency map (Fig. 3.13b), as is the weakening of surface winds in the northeast Pacific associated with the "Warm Blob." The strong wind tendencies were the primary cause of the large turbulent heat loss tendencies in the eastern equatorial Pacific and North Atlantic.

Winds vary considerably in space. This causes divergence and convergence of the Ekman transport, leading to a vertical velocity, denoted by Ekman pumping (downward) or suction (upward) velocity $W_{E K}$, at the base of the Ekman layer. Computation of $W_{E K}$ follows the equation: $W_{E K}=1 / \rho \nabla \times(\tau / f)$, where $\rho$ is the density, $\tau$ is the wind stress, and $f$ the Coriolis force. The 2018 $W_{E K}$ tendencies (Fig. 3.13d) show upwelling (positive) anomalies in the vicinity of the ITCZ $\left(3^{\circ}-7^{\circ} \mathrm{N}\right)$ in the equatorial Pacific and Atlantic and downwelling (negative) anomalies in the equatorial Indian Ocean. Outside of the tropical region, the strengthened westerly band in the mid-latitude North Pacific induced a band of downwelling anomalies (negative) to the south. In the North Atlantic, $W_{E K}$ anomalies were characterized by negative downwelling anomalies in the low-mid latitudes $\left(0-50^{\circ} \mathrm{N}\right)$ and positive upwelling anomalies at higher latitudes $\left(50^{\circ}-60^{\circ} \mathrm{N}\right)$. Negative downwelling 
anomalies predominated the ocean basins in the Southern Hemisphere.

\section{4) LONG-TERM PERSPECTIVE}

A long-term perspective on the change of oceansurface forcing functions in 2018 is assessed in the context of multi-decade annual-mean time series of $\mathrm{Q}_{\text {net, }}$, $P-E$, and wind stress averaged over the global ice-free oceans (Figs. 3.14a-c). The $\mathrm{Q}_{\text {net }}$ time series commenced in 2001, when CERES EBAF4.0 surface radiation products became available. The $P-E$ and wind stress time series are each 30 years long, starting from 1988 when higher quality global flux fields can be constructed from SSM/I satellite retrievals. $Q_{\text {net }}$ anomalies are relative to the 2001-15 climatology, and $P-E$ and wind stress anomalies are relative to the $1988-2015$ period.

$\mathrm{Q}_{\text {net }}$ remained relatively level between 2001 and 2007, but after a sharp dip in 2008, it underwent a steady increase and peaked in 2016. In general, the ocean surface has received more heat from the atmosphere in recent years. The $2018 \mathrm{Q}_{\text {net }}$ was a slight increase from the sharp reduction in 2017. The 30year records of $P-E$ and wind stress show a regime shift around 1999. The downward trend in $P-E$ and upward trend in wind stress that dominated the 1990s

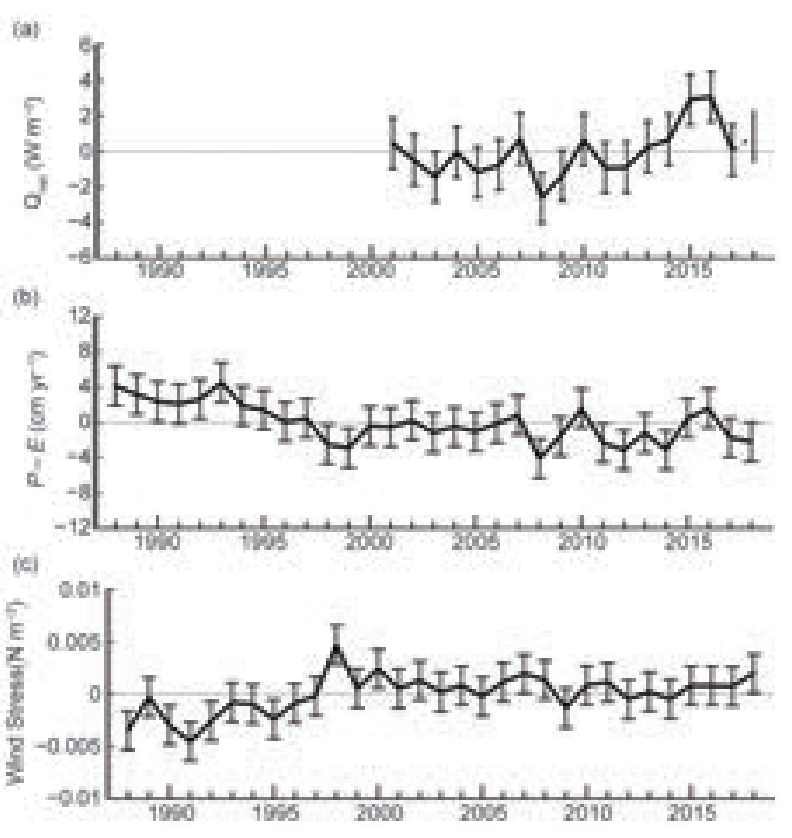

Fig. 3.14. Annual-mean time series of global averages of (a) net surface heat flux $\left(Q_{\text {net }} ; W^{-2}\right)$ from the combination of CERES EBAF4.0 SW+LW and OAFlux-HR $\mathrm{LH}+\mathrm{SH}$. The $2018 \mathrm{Q}_{\text {net }}$ estimate is based on FLASHFlux and OAFlux-HR. (b) net freshwater flux $\left(P-E ; \mathrm{cm} \mathrm{yr}^{-1}\right)$ from the combination of GPCP $P$ and OAFlux-HR E, and (c) wind stress magnitude $\left(\mathrm{N} \mathrm{m}^{-2}\right)$ from OAFluxHR. The error bars denote one standard deviation of annual-mean variability. have flattened since 1999, and the 2018 conditions continued weak interannual fluctuations.

f. Sea level variability and change-P. R. Thompson, M. J. Widlansky, E. Leuliette, W. Sweet, D. P. Chambers, B. D. Hamlington, S. Jevrejeva, J. J. Marra, M. A. Merrifield, G. T. Mitchum, and R. S. Nerem

Global mean sea level (GMSL) during 2018 was the highest annual average in the satellite altimetry record (1993-present), rising to $81 \mathrm{~mm}$ (3.2 in) above the 1993 average (Fig. 3.15a). This marks the seventh consecutive year (and 23rd of the last 25) that GMSL increased relative to the previous year. The new high reflects an ongoing multi-decadal trend in GMSL during the satellite altimetry era, $3.1 \pm 0.4 \mathrm{~mm} \mathrm{yr}^{-1}$ (Fig. 3.15a). Accelera-

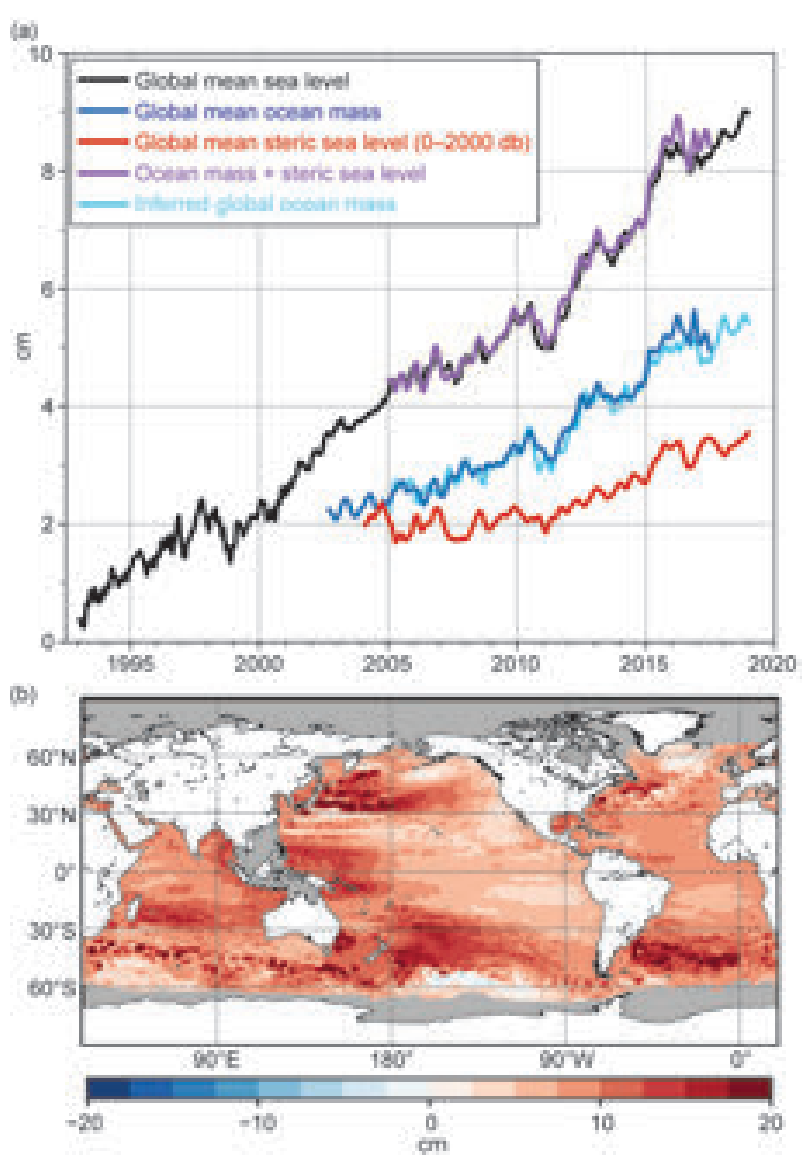

Fig. 3.15. (a) (black) Monthly averaged global mean sea level observed by satellite altimeters (1993-2018 from the NOAA Laboratory for Satellite Altimetry). (blue) Monthly averaged global ocean mass (2003-Aug 2017 from the Gravity Recovery and Climate Experiment). (red) Monthly averaged global mean steric sea level (2004-18) from the Argo profiling float array. (purple) Mass plus steric. (cyan) Inferred global ocean mass calculated by subtracting global mean steric sea level from global mean sea level. All time series have been smoothed with a 3-month filter. (b) Total local sea level change from altimetry during 1993-2018. 
tion in GMSL (i.e., two times the quadratic coefficient in a second-order polynomial fit) during the altimetry era is $0.097 \pm 0.04 \mathrm{~mm} \mathrm{yr}^{-2}$. When effects of the Pinatubo volcanic eruption and ENSO are subtracted from GMSL variability, the estimated climate-change-driven acceleration in GMSL over the altimeter record is 0.084 $\pm 0.025 \mathrm{~mm} \mathrm{yr}^{-2}$ (Nerem et al. 2018).

Variations in GMSL (Fig. 3.15a) result from changes in both the mass and density of the global ocean (Leuliette and Willis 2011; Cazenave et al. 2018). During 2005-16, increasing global ocean mass observed by the NASA Gravity Recovery and Climate Experiment (GRACE), $2.5 \pm 0.4 \mathrm{~mm} \mathrm{yr}^{-1}$, contributed about twothirds of the GMSL trend. The positive trend in ocean mass primarily resulted from melting of glaciers and ice sheets (Sections 2c, 5, 6), but these contributions from land ice were partially offset by increased hydrological storage of fresh water on land, $-0.7 \pm 0.2 \mathrm{~mm} \mathrm{yr}^{-1}$ (Reager et al. 2016). Unfortunately, failure of an accelerometer on board one of the GRACE satellites and degrading batteries resulted in only five months of valid GRACE observations during 2017 (January and March-June). The mission was finally terminated in October 2017 with no additional scientific observations. Although the GRACE-FO mission was launched in May 2018 and scientific data were collected, the processing centers are still evaluating and calibrating the data. Thus, ocean mass observations for 2018 are not available as of this writing. Steric (i.e., density-related) sea level rise (0-2000 m) observed by the Argo profiling float array during 2005-16, $1.1 \pm 0.2 \mathrm{~mm} \mathrm{yr}^{-1}$, which is mostly due to ocean warming, accounts for most of the balance of GMSL change during the GRACE period. Steric sea level rise updated for 2005-18 increases to 1.3 $\pm 0.2 \mathrm{~mm} \mathrm{yr}^{-1}$.

Annual GMSL from altimetry observations increased by $0.4 \mathrm{~cm}$ from 2017 to 2018 (Fig. 3.15a). Annual global mean steric sea level observed by Argo did not appreciably change from 2017 to 2018 (Fig. 3.15a). The lack of steric change suggests that the increase in GMSL was almost entirely due to an increase in ocean mass, but as discussed above, observations of ocean mass were not possible during 2018. We can, however, infer the change in ocean mass by subtracting global mean steric sea level from GMSL (Fig. 3.15a) with the assumption that steric changes below 2000 $\mathrm{m}$ do not contribute significantly at interannual timescales. The inferred ocean mass curve is highly correlated with the observed mass curve during 2005-16, suggesting that the inferred ocean mass curve during 2017-18 represents a reasonable surrogate in the absence of mass observations.

Regional sea level change can differ substantially from the global mean. The total amount of GMSL change from 1993-2018 is less than $10 \mathrm{~cm}$ (Fig. 3.15a), but multiple regions around the global ocean have experienced $15-20 \mathrm{~cm}$ during the same period. During the altimetry era, east-west differences in sea level change across the Pacific-and specifically enhanced rise in the western tropical Pacific-resulted from fluctuations in trade winds, which strengthened during a multi-decadal trend toward the LaNiñalike phase of the PDO during the first 15-20 years of the satellite record (e.g., Merrifield 2011). Enhanced sea level rise has also occurred over $30^{\circ}-60^{\circ} \mathrm{S}$ in the South Pacific and South Atlantic basins, which has been attributed in the Pacific to deep-ocean warming (Volkov et al. 2017). Finally, the Kuroshio Extension region stands out as an area of enhanced sea level rise due to both wind-forced and eddy-forced warming (Qiu et al. 2015).

Positive annual sea level anomalies spanned much of the global ocean during 2018 (Fig. 3.16a), which is consistent with the global pattern of sea level rise since 1993 (Fig. 3.15b). A notable exception to the above-normal sea levels is in the tropical northwestern Pacific where a zonal band of below-normal sea

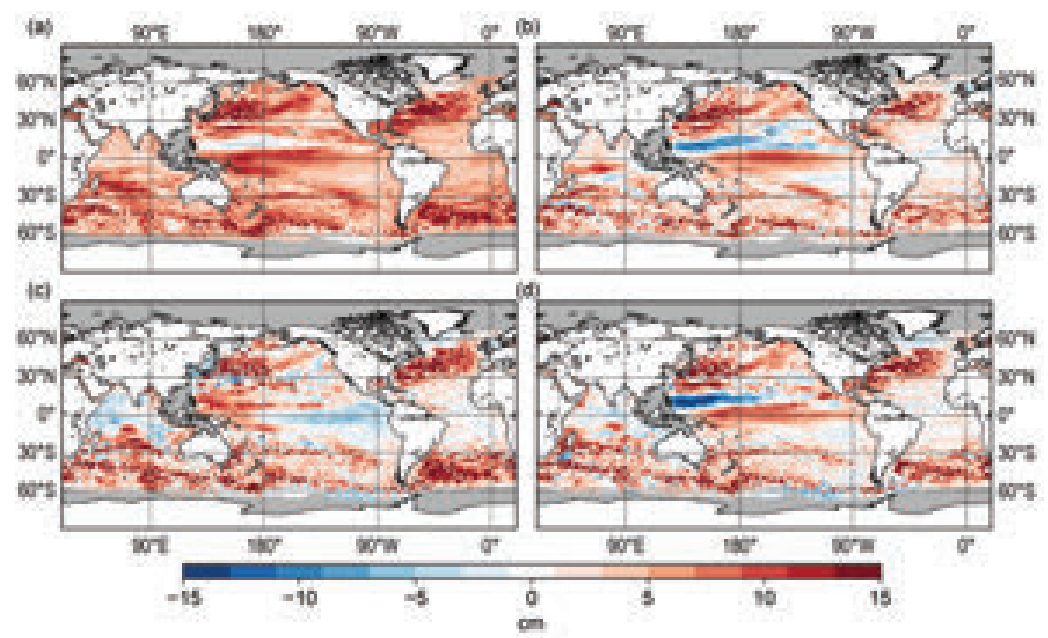

Fig. 3.16. (a) Annual average sea level anomaly during 2018 relative to the average sea level at each location during 1993-2018. (b) Average 2018 sea level anomaly minus 2017. (c) Average sea level anomaly during DJF of 2018 relative to the DJF average during 1993-2018. (d) Same as (c), but for SON. GMSL was subtracted from panels c-d to emphasize regional, non-secular change. Altimetry data was obtained from the gridded, multi-mission product maintained by the Copernicus Marine and Environment Monitoring Service (CMEMS). 
levels occurred during most of 2018. In the tropical North Pacific, the annual mean sea level decreased from 2017 to 2018 (Fig. 3.16b) and reached the lowest levels near the end of the year (Figs. 3.16c,d). The area of sea level decrease extends from near the Philippines, eastward through most of Micronesia, and includes the area around Hawaii where the record high sea levels of 2017 (Yoon et al. 2018) returned to normal during 2018. Elsewhere in the Pacific, sea levels increased relative to 2017 nearly everywhere, except for small-scale decreases associated with upwelling mesoscale eddy activity such as around the Kuroshio Current region (Fig. 3.16b; e.g., Qiu et al. 2015). Increased sea levels in the equatorial Pacific are consistent with the warming ocean there resulting from the El Niño of 2018/19 (Section 4b). During 2018, the decrease in sea level in the tropical northwestern Pacific (the change from December-February to September-November exceeded $-25 \mathrm{~cm}$ ) and the increase of similar magnitude in the equatorial central Pacific (Fig. 3.16c,d) are consistent with the OHCAs (Fig. 3.4b), although the prolonged high sea levels in the tropical southwestern Pacific (e.g., around the Samoan Islands) are unusual compared to previous El Niño development.

In the Atlantic Ocean, sea level tendencies from 2017 to 2018 were positive in the tropical northwestern basin (generally $+5 \mathrm{~cm}$ to $+10 \mathrm{~cm}$ ), whereas smaller changes (typically $\pm 5 \mathrm{~cm}$ ) occurred near the eastern boundary, along the equator, and in the tropical South Atlantic (Fig. 3.16b). Notable changes during 2018 (Fig. 3.16c,d) were the rising sea levels around Florida, the Bahamas, and the Greater Antilles ( $\sim 10 \mathrm{~cm}$ increase), consistent with locally higher surface heat flux (Fig. 3.11b) and ocean heat content (Fig. 3.4b). Wind-stress anomalies in the tropical North Atlantic were also conducive for generation of downwelling Rossby waves (i.e., negative Ekman vertical velocity; Fig. 3.13d), which have been associated with past high sea level anomalies near Florida (Calafat et al. 2018). Poleward of $30^{\circ} \mathrm{N} / \mathrm{S}$, sea level mostly increased compared to 2017 (Fig. 3.16b), although there were small-scale decreases associated with upwelling eddies (Qiu et al. 2015). The change pattern in the higher latitudes $\left(30^{\circ}-60^{\circ} \mathrm{N} / \mathrm{S}\right)$ is similar in the North and South Pacific as well as the South Indian Oceans, where some of the largest sea level increases during the satellite altimetry era have occurred (1993-2018, Fig. 3.15b).

In the North Indian Ocean, the greatest changes relative to 2017 were primarily related to eddy activity near the Arabian Peninsula and the east coast of India, although there was a basin-scale rise in sea level (Fig. 3.16b), which is consistent with the regional increase in surface heat flux (Fig. 3.11b) as well as downwelling Ekman vertical velocity (Fig. 3.13d). In the southern tropical latitudes, larger positive sea level anomalies during 2018 ( $+10 \mathrm{~cm}$; Fig. 3.16a) are consistent with the above-normal surface heat flux in the region (up to $+30 \mathrm{~W} \mathrm{~m}^{-2}$; Fig. 3.11a). Even higher sea level anomalies poleward of $20^{\circ} \mathrm{S}$ (exceeding $+15 \mathrm{~cm}$ east of Madagascar) are collocated with downwelling Ekman vertical velocities associated with regional wind-stress anomalies (Fig. 3.13).

Ongoing trends and year-to-year changes in sea level impact coastal communities by increasing the magnitude and frequency of positive sea level extremes that cause flooding and erosion. In many areas, coastal infrastructure is currently exposed to nuisance-level (i.e., minor-impact) flooding when water levels exceed a threshold defined by the top $1 \%$ of observed daily maxima from a global network of tide gauges (Sweet et al. 2014). These thresholds vary geographically (Fig. 3.17a) but are typically around $0.5 \mathrm{~m}$ above mean higher high water (MHHW) - the average of observed daily maxima - and are expected to be exceeded 3-4 times per year. Most locations along the U.S. East Coast experienced greater-thanexpected numbers of exceedances during 2018 (Fig. 3.17b), which is a continuation of enhanced numbers of exceedances during 2017 (Fig. 3.17c) and is related to positive sea level trends (Fig. 3.15b) and 2018 anomalies (Fig. 3.16a) in the region. Year-overyear increases in threshold exceedances occurred on a majority of islands across the tropical South Pacific, while year-over-year decreases occurred on a majority of islands across the tropical North Pacific (Fig. 3.17c). These changes in the tropical Pacific directly relate to changes in mean sea level of the same signs in these regions from 2017 to 2018 (Fig. 3.16b). The increase in exceedances in the eastern Atlantic from 2017 to 2018 (Fig. 3.17c) represents a return to expected numbers of exceedances (Fig. 3.17b) after few exceedances occurred in the region during 2017. 
(a)

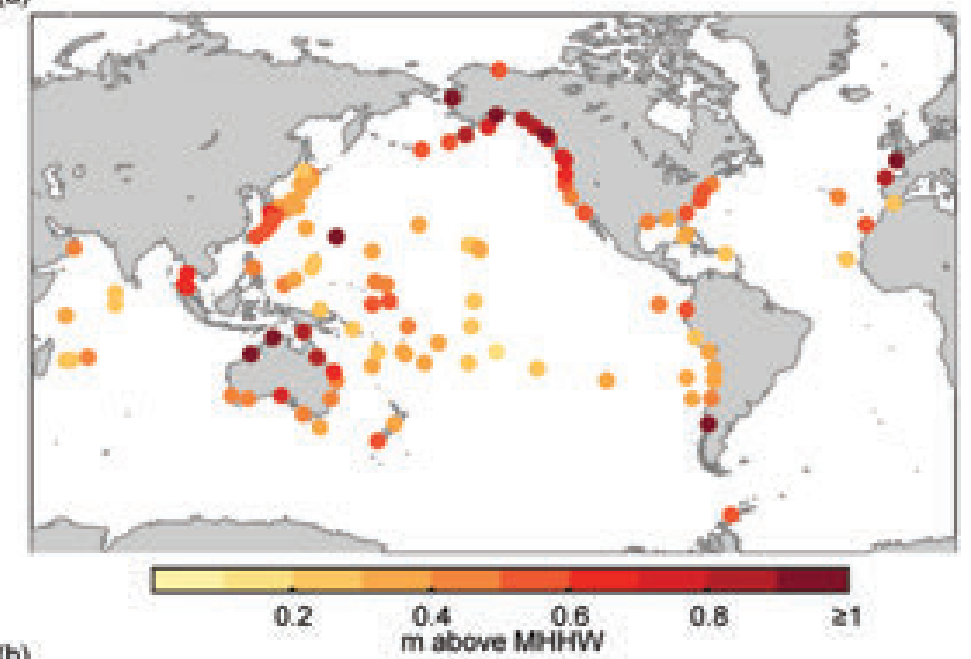

(b)

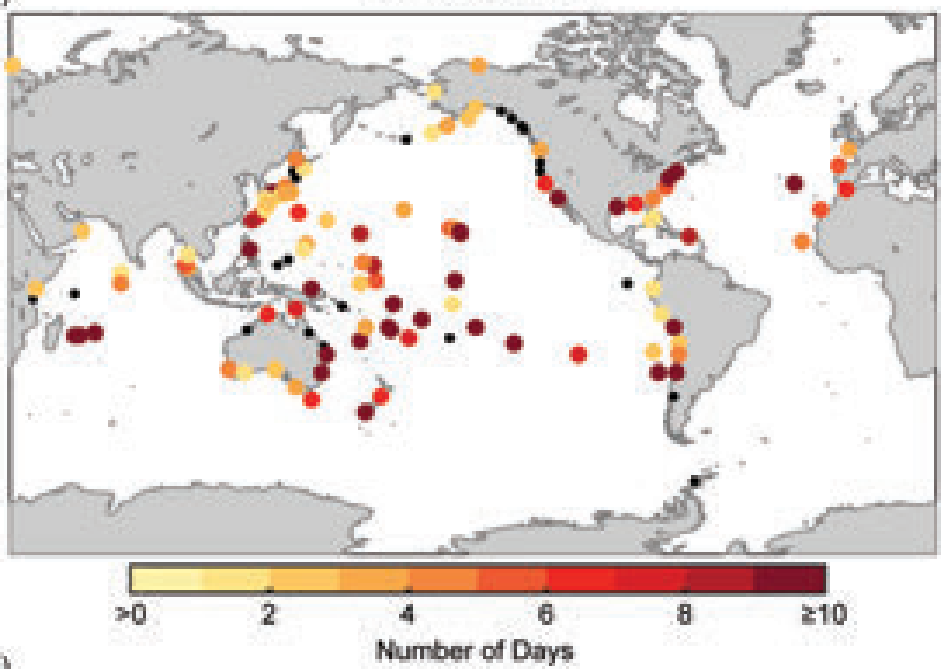

(c)

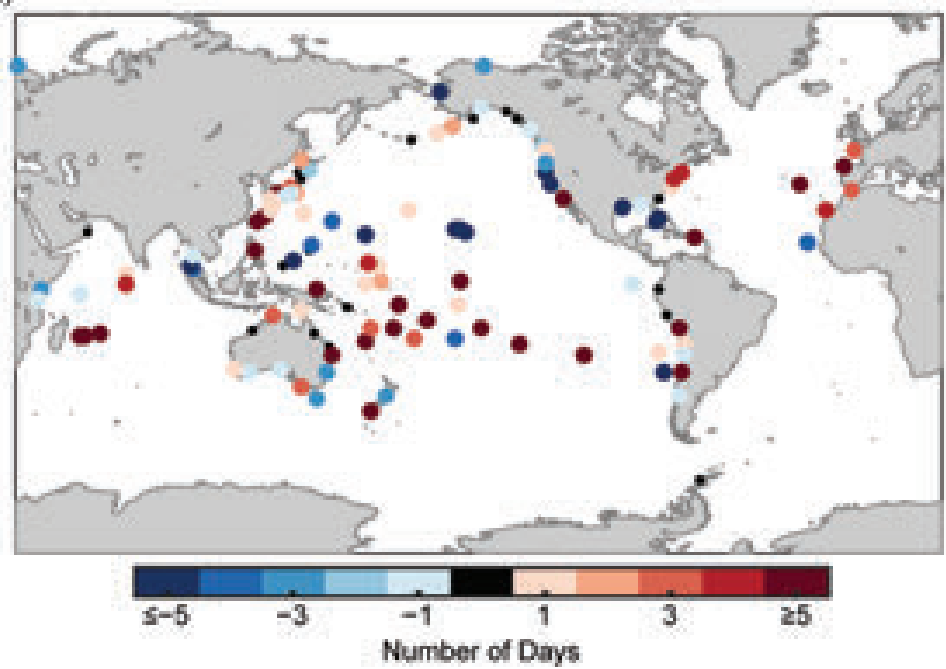

Fig. 3.17. (a) Nuisance-level flooding thresholds defined by the level of the top $1 \%$ of observed daily maxima during 1999-2017 from tide gauge records. Units are in meters above MHHW calculated over 1999-2017. (b) Number of daily maximum water levels during 2018 above the thresholds in (a). (c) Same as in (b), but for 2018 minus 2017. Small, black circles in (b) and (c) indicate a value of zero. Daily maximum water levels were calculated from hourly tide gauge observations obtained from the University of Hawaii Sea Level Center Fast Delivery database. Only records with at least $80 \%$ completeness during $1999-2017$ and $80 \%$ completeness during 2018 were analyzed. 
Red tides caused by the dinoflagellate, Karenia brevis, are a naturally occurring phenomenon in the Gulf of Mexico, including the west Florida shelf (Steidinger 2009). This alga blooms nearly annually in the coastal waters of southwest Florida and occurs less frequently along Florida's Panhandle and Atlantic coasts (Steidinger 2009). There are reports suggestive of red tides from early European explorers dating back to the early 1500 s, but perhaps the earliest well-documented $K$. brevis bloom on the west Florida shelf was in 1844 (Magaña et al. 2003). Mortalities in marine animals and human respiratory irritation caused by toxins produced by $K$. brevis during red tide events can be widespread (Steidinger 2009). The duration, spatial extent, and movement of the red tide are factors that influence considerable variations in severity of impacts on the ecosystem and human communities. The 2017-19 bloom was the fifth longest-lasting bloom since 1953, when more intensive state monitoring was instituted. This 16 -month event resulted in impacts on Florida's Panhandle, southwest, and east coasts including extensive wildlife mortalities and strandings, numerous reports of human respiratory irritation, persistent shellfish harvest area closures, and/or other undesired consequences including economic ones (Fig. SB3.2).

The 2017-19 red tide bloom impacted southwest Florida most severely, including known hotspots (i.e., the greater Charlotte Harbor and Tampa Bay areas). From late 2017 to early 2019, K. brevis cells persisted in these general areas
(Fig. SB3.2). Not only was this an intense, long-lasting red tide in southwest Florida, it was also geographically widespread. After the passage of Tropical Storm Gordon in early September 2018, the bloom in southwest Florida intensified, and bloom concentrations ( $>100000$ cells per liter) were first detected in Florida's Panhandle and endured through November. At the end of September and through October 2018, bloom concentrations were also detected on Florida's east coast. The northwest and east coast blooms were thus comparatively short-lived relative to the southwest bloom. It is worth noting that these occurrences took place in late summer into autumn, when new bloom initiation most typically occurs in southwest Florida, and that northwest and southwest blooms are hypothesized to share a single offshore initiation zone; cells are transported from initiation zones toward shore by subsurface currents. Transport of cells from southwest Florida to the east coast of Florida has been previously documented (Weisberg et al. 2009) and can occur when cells are transported southward and then entrained in the Florida Current; sampling in October 2018 also revealed the presence of red tide in the Florida Keys and the currents during this time period support transport of the southwest bloom to the east coast (Fig. SB3.3).

Red tides have significant negative impacts on the ecosystem, including fisheries. The effects of red tide on marine organisms are both direct via brevetoxins or low dissolved oxygen and indirect via changes in the food web (DiLeone and
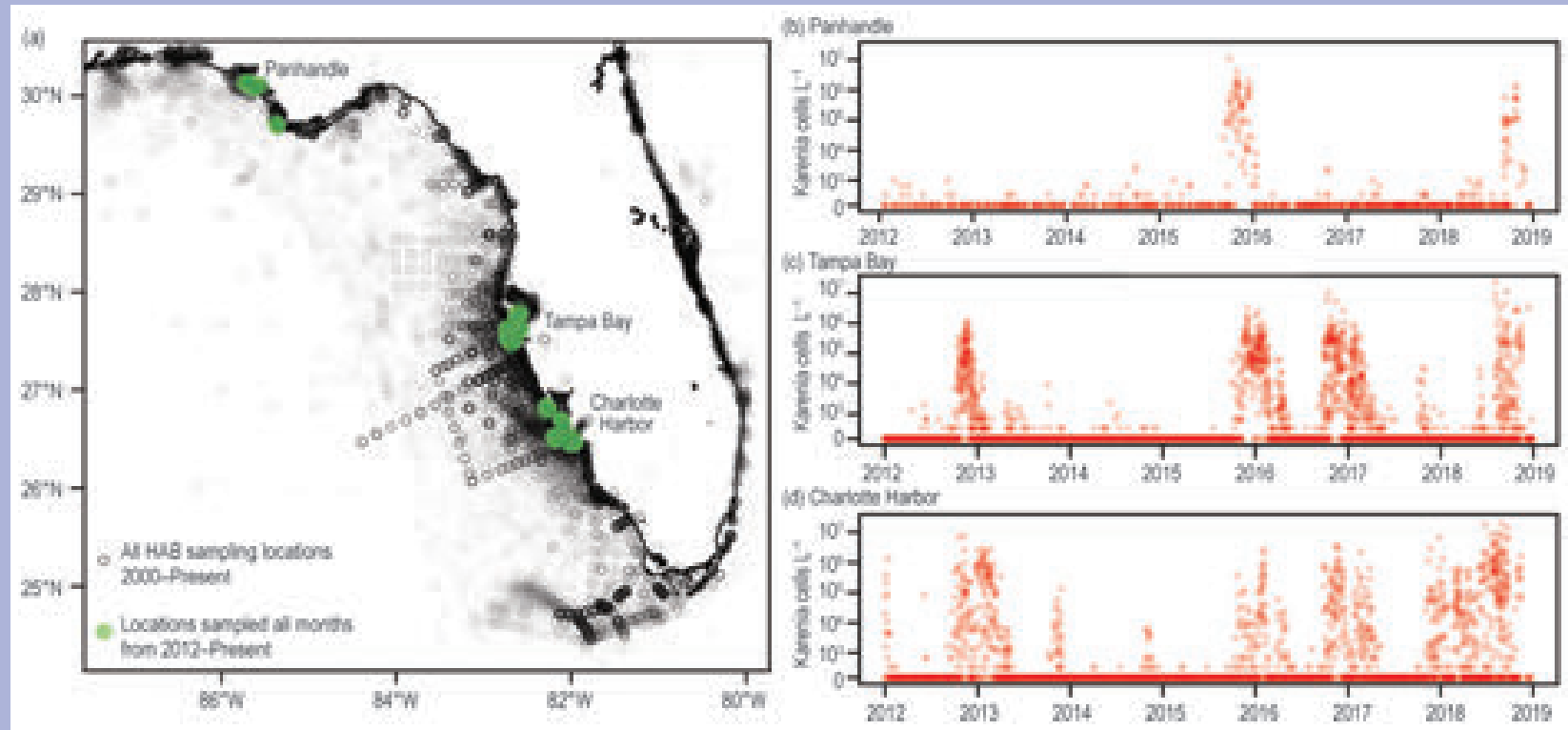

FIG. SB3.2. Left: All sampling locations for Karenia brevis cell counts throughout Florida from 2000 through the end of 2018. Right: Karenia brevis cell counts (cells/I) for locations, binned as $1 / 10^{\circ}$ longitude and latitude cells, which have been sampled at least monthly since 2012 . 
Ainsworth 2019). The 2017-19 red tide on Florida's west coast coincided with substantial decreases in fisheries landings as evidenced by the landings for five common commercial categories in Lee and Charlotte counties, near Charlotte Harbor (Table SB3.I). All of the landings decreased substantially in 2017 and 2018 , and reports from fishermen indicated that fishing was challenging with little success during the latter part of 2018 . Based, at least in part, on these concerns, an emergency rule was requested by the Gulf of Mexico Fisheries Management Council to decrease the red grouper quota. In addition to fisheries impacts, an unusual mortality event affected 149 dolphins along with manatees and turtles beginning in July 2018. These observations collectively underscore the significance of events like this on local fisheries and help direct efforts to assess further ecological impacts related to this severe bloom in years to come.

Red tides cause significant economic losses to coastal communities in Florida not only through declines in fisheries landings, but also through negative impacts on tourism. These are two of the biggest industries in the state, and thus their losses propagate from locally impacted communities. The Fort Myers Florida Weekly surveyed 156 businesses in Fort Myers Beach. The businesses reported $\$ 48.8$ million (U.S. dollars) in lost revenue during the 13-week period from July 27, 2018 through October 26, 2018 (https://fortmyers.floridaweekly.com/articles/in-the

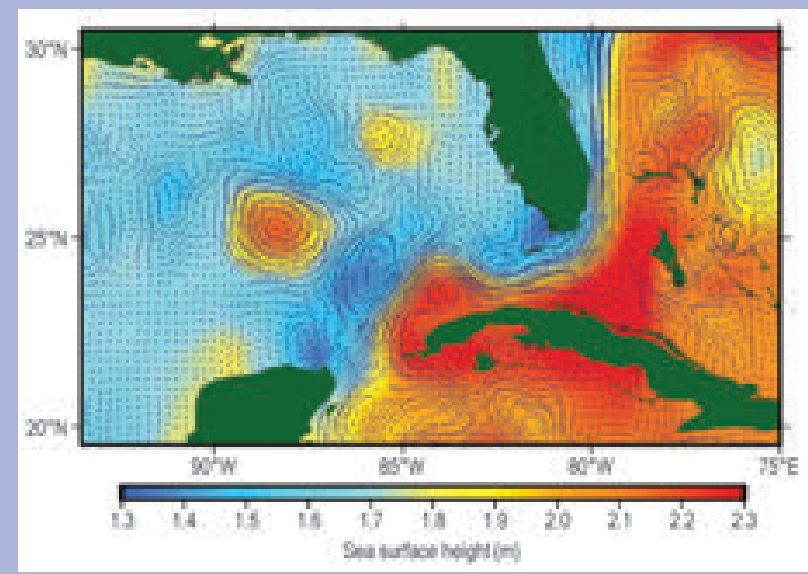

FIG. SB3.3. Satellite altimetry-derived sea surface height (background color) and surface currents (arrows) for 10 Oct 2018 . The currents suggests southerly flow on the west Florida shelf that would allow for advection of red tide to the east coast of Florida.

-wake-of-red-tide/). Although events such as the substantial 20I719 red tide clearly have widespread detrimental effects, these events also provide opportunities to study related mechanisms, further the ability to predict future blooms, and consider potential mitigation strategies.

\section{TABLE SB3.I. Fisheries landings in thousands of pounds from Charlotte and Lee counties in Florida (trip ticket data from the Florida Fish and Wildlife Commission).}

\begin{tabular}{|c|c|c|c|c|c|c|c|}
\hline Species & $\mathbf{2 0 1 2}$ & $\mathbf{2 0 1 3}$ & $\mathbf{2 0 1 4}$ & $\mathbf{2 0 1 5}$ & $\mathbf{2 0 1 6}$ & $\mathbf{2 0 1 7}$ & $\mathbf{2 0 1 8}$ \\
\hline Red Grouper & 254 & 220 & 386 & 342 & 429 & 352 & 197 \\
\hline Mullet & 3111 & 3455 & 3401 & 2963 & 3082 & 1790 & 1401 \\
\hline $\begin{array}{c}\text { Stone Crabs, } \\
\text { Jumbo }\end{array}$ & 29 & 21 & 11 & 29 & 27 & 9 & 5 \\
\hline $\begin{array}{c}\text { Stone Crabs, } \\
\text { Large }\end{array}$ & 59 & 54 & 54 & 83 & 80 & 42 & 22 \\
\hline $\begin{array}{c}\text { Stone Crabs, } \\
\text { Medium }\end{array}$ & 71 & 76 & 80 & 91 & 95 & 76 & 39 \\
\hline
\end{tabular}

\section{g. Surface currents - R. Lumpkin, G. Goni, and K. Dohan}

This section describes ocean surface current changes, transports derived from ocean surface currents, and features such as rings inferred from surface currents. Surface currents are obtained from in situ (global array of drogued drifters and moorings) and satellite (altimetry and wind stress) observations. Transports are derived from a combination of sea surface height anomaly (from altimetry) and climatological hydrography. See State of the Climate in 2011 for details of these calculations. Zonal surface current anomalies are calculated with respect to 1993-2007 climatology and are discussed below for individual ocean basins.

\section{I) Pacific Ocean}

In 2018, the Pacific basin exhibited an annual mean zonal eastward current anomaly of 10-15 cm $\mathrm{s}^{-1}$ from $130^{\circ} \mathrm{E}-135^{\circ} \mathrm{W}$, with peak anomalies shifting from $6^{\circ} \mathrm{N}$ at the western edge to $8^{\circ} \mathrm{N}$ at the eastern edge (Fig. 3.18a). This anomaly band indicates that there was a strengthened North Equatorial 
Countercurrent (NECC) extending farther north than in climatology. Because 2017 was characterized by westward anomalies in this latitude band with peak values in the central basin $\left(125^{\circ}-145^{\circ} \mathrm{W}\right)$, the 2018-minus-2017 map (Fig. 3.18b) has larger eastward anomalies here. This shift in the NECC was likely associated with the co-located wind stress anomalies seen in 2018 (Fig. 3.13a), which veered from westerly in the western Pacific to south-southwesterly in the central Pacific.

Figure 3.19 shows the development of zonal geostrophic current anomalies with respect to monthly climatology, averaged season by season. In December 2017-February 2018 (Fig. 3.19a), the largest anomalies were $25-30 \mathrm{~cm} \mathrm{~s}^{-1}$ eastward between the equator and $2^{\circ} \mathrm{S}, 115^{\circ}-170^{\circ} \mathrm{W}$, where the seasonal mean current is near zero. This countercurrent, associated with a seasonally shoaling equatorial undercurrent, does not develop until April-May in climatology derived from drifters drogued at 15-m depth (www .aoml.noaa.gov/phod/gdp/mean_velocity.php). Along these same longitudes, a band of positive (eastward) anomalies at $8^{\circ}-10^{\circ} \mathrm{N}$ and negative (westward) anomalies at $3^{\circ}-5^{\circ} \mathrm{N}$ indicated that the NECC was strengthened and shifted anomalously north of its climatological position, while the northern core of the South Equatorial Current (nSEC) was strengthened at $3^{\circ}-4^{\circ} \mathrm{N}$. The eastward anomalies intensified March-May (Fig. 3.19b), indicating that the NECC was $30 \mathrm{~cm} \mathrm{~s}^{-1}$ faster than its climatological strength of $\sim 35 \mathrm{~cm} \mathrm{~s}^{-1}$, and the countercurrent at $0^{\circ}-2^{\circ} \mathrm{S}$, where climatological currents are near zero, was $25 \mathrm{~cm} \mathrm{~s}^{-1}$. Westward anomalies centered on the nSEC diminished, however. During June-August (Fig. 3.19c), anomalies not associated with the NECC weakened significantly and, apart from that current system, the basin-scale zonal currents were close to climatology. Large eastward anomalies of $30-35 \mathrm{~cm} \mathrm{~s}^{-1}$ persisted in the western NECC at $160^{\circ} \mathrm{E}-130^{\circ} \mathrm{W}$, centered near the climatological core latitude of the NECC at $7^{\circ}-8^{\circ} \mathrm{N}$. The anomalies in the NECC weakened significantly (to $15-20 \mathrm{~cm} \mathrm{~s}^{-1}$ ) during September-November (Fig. 3.19d), while eastward anomalies of $25-30 \mathrm{~cm} \mathrm{~s}^{-1}$ developed along the equator in the eastern basin at $100^{\circ}-150^{\circ} \mathrm{W}$.

Shifts in the location of the Kuroshio Jet are associated with a decadal stable/unstable oscillation (Qiu and Chen 2005). The Kuroshio shifts to the north when it intensifies and becomes stable thus lowering eddy kinetic energy (EKE). Averaged in the downstream Kuroshio Jet region $141^{\circ}-153^{\circ} \mathrm{E}$, $32^{\circ}-38^{\circ} \mathrm{N}$ (Qiu and Chen 2005), EKE was low in 1994/95, elevated in 1999-2001, low in 2002/04, high in 2005-08, and then decreased from 2009 to 2018. Since 2015, EKE has remained relatively steady (at annual to interannual time scales) and lower than the 1993-2018 average in the downstream Kuroshio Jet region, indicating that the system is in its stable mode, while exhibiting intra-annual variations such as a short-lived increase in EKE in mid-2016. During 2018, EKE in the region averaged $0.102 \mathrm{~m}^{2} \mathrm{~s}^{-2} \mathrm{com}-$ pared to the 1993-2017 average of $0.117 \mathrm{~m}^{2} \mathrm{~s}^{-2}$, while maximum speeds were at $35.6^{\circ} \mathrm{N}$, slightly north of the climatological average latitude of $35.3^{\circ} \mathrm{N}$.

The equatorial Pacific current system advects waters across the basin, contributing to anomalies in the SST fields. Historically, surface current (SC) anomalies in this region are a strong indicator of upcoming SST anomalies with SC anomalies leading SST by several months and a reversal of the SC anomaly usually coinciding with peak SST anomaly. This behavior can be seen in the first principal EOFs of SC anomaly and SST anomaly across the tropical Pacific basin (Fig. 3.20). The maximum lagged correlation between SC and SST is R $=0.65$ for 1993-2018, with SC leading SST by 76 days. The year 2018 began with negative SST anomalies, with a maximum negative SST EOF amplitude of $-1.2 \sigma$ in early January,

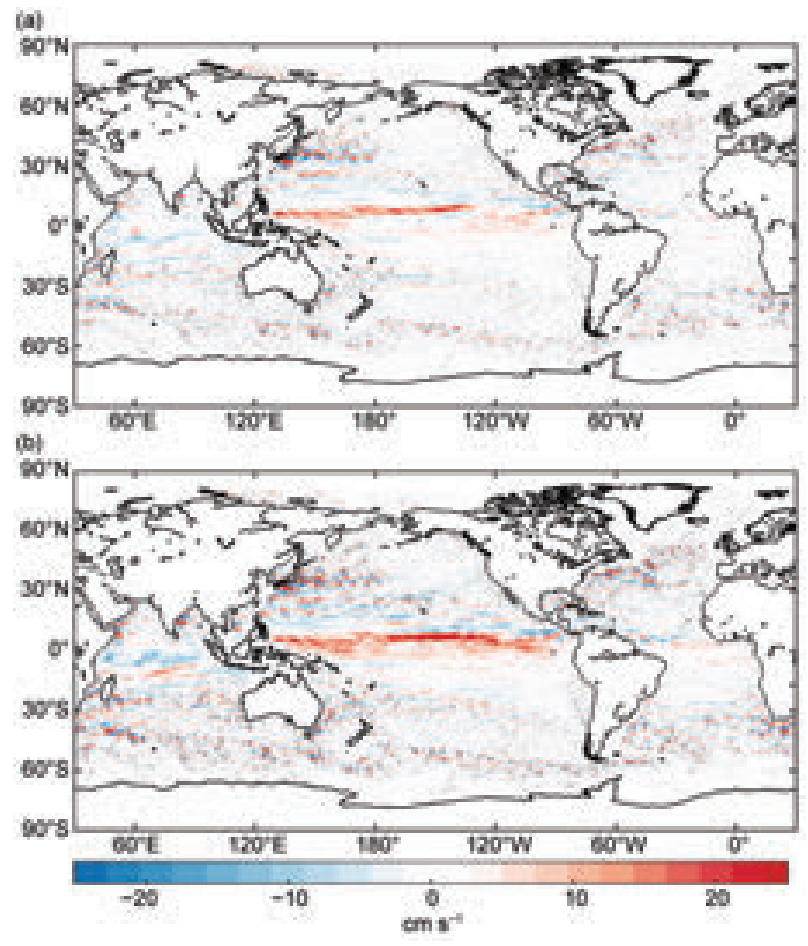

FIG. 3.18. Annually-averaged geostrophic zonal current anomalies (cm s${ }^{-1}$ ) for (a) 2018 and (b) 2018-minus-2017 derived from a synthesis of drifters, altimetry, and winds. Positive (red) is eastward; negative (blue) is westward. 
(a)

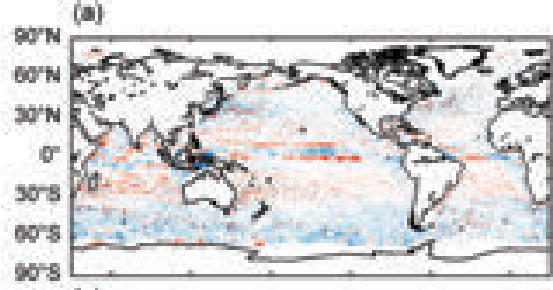

(c)

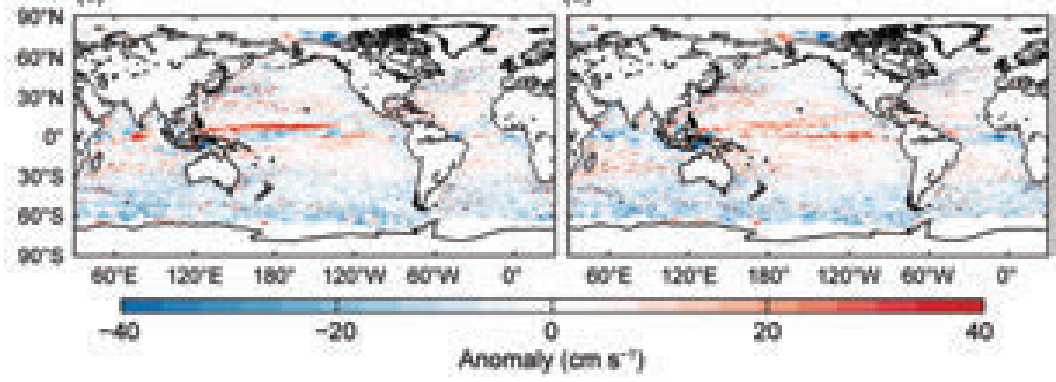

Fig. 3.19. Seasonally-averaged zonal geostrophic anomalies with respect to seasonal climatology, for (a) Dec 2017-Feb 2018, (b) Mar-May 2018, (c) Jun-Aug 2018, and (d) Sep-Nov 2018.

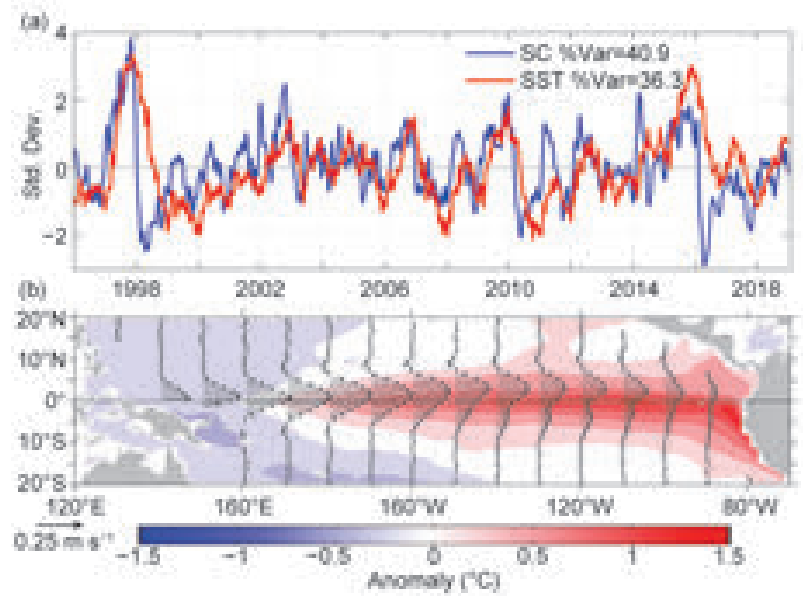

FIG. 3.20. Principal EOFs of surface current (SC) and of SST anomaly variations in the Tropical Pacific from the OSCAR model (Bonjean and Lagerloef, 2002). (a) amplitude time series of the EOFs normalized by their respective std. dev. (b) spatial structures of the EOFs.

rising for most of 2018, and peaking in November at 0.9 . The SC anomalies rose from their minimum of -1.8 in October 2017, consistent with the lagged rising SST anomalies, then experienced negative anomalies from May to September, down to -0.9 in mid-July, before rising to positive values for the rest of 2018, with a maximum of 0.7 in October. The year was unusual in that while SST anomalies did experience some slowing in their rising in July-September, it was not nearly as significant as the reversal in SC. The year ended with a reversal of SC anomalies and a decrease in positive SST anomalies.

\section{2) INDIAN OCEAN}

At basin scales, 2018 annuallyaveraged zonal currents in the Indian Ocean basin were very close to climatology, with large-scale anomalies weaker than $\pm 5 \mathrm{~cm} \mathrm{~s}^{-1}$ (Fig. 3.18a). In contrast, 2017 was characterized by equatorial eastward anomalies of $\sim 8 \mathrm{~cm} \mathrm{~s}^{-1}$ and westward anomalies of $\sim 15 \mathrm{~cm} \mathrm{~s}^{-1}$ at $10^{\circ} \mathrm{S}$ in the eastern half of the basin; thus, the 2018-2017 map (Fig. 3.18b) reflects these 2017 anomalies with reversed sign.

The season-by-season maps of zonal current anomalies (Fig. 3.19) show that strong anomalies were only present in June-August 2018 , when $>20 \mathrm{~cm} \mathrm{~s}^{-1}$ eastward anomalies were present at $3^{\circ} \mathrm{S}-$ $2^{\circ} \mathrm{N}, 70^{\circ}-85^{\circ} \mathrm{E}$. These anomalies are consistent with a strengthened southwest monsoon current extending farther north than in the seasonal climatology. In these months in this longitude band, the climatological southwest monsoon current has maximum speeds of $20-25 \mathrm{~cm} \mathrm{~s}^{-1}$ at $1^{\circ}-2^{\circ} \mathrm{S}$, while in 2018 the maximum speeds were $40-50 \mathrm{~cm} \mathrm{~s}^{-1}$ at $1^{\circ} \mathrm{N}-3^{\circ} \mathrm{S}$.

\section{3) Atlantic Ocean}

Annual mean zonal currents in the tropical Atlantic Ocean were close to their climatological values in 2018 (Fig. 3.18a). During December 2017-February 2018 (Fig. 3.19a), a countercurrent of $20-25 \mathrm{~cm} \mathrm{~s}^{-1}$ was centered on $1^{\circ} \mathrm{S}$ in the longitude band $15^{\circ}-40^{\circ} \mathrm{W}$, where the climatological current is not significantly different from zero. This countercurrent was no longer present in March-May (Fig. 3.19b), while westward anomalies of $-20 \mathrm{~cm} \mathrm{~s}^{-1}$ at $0.5^{\circ}-1.5^{\circ} \mathrm{N}$ were associated with a strengthened nSEC. Tropical Atlantic currents were very close to climatology in June-August (Fig. 3.19c). In September-November, westward near-equatorial anomalies of $-10 \mathrm{~cm} \mathrm{~s}^{-1}$ were present in the northern Gulf of Guinea.

The changes in transport and location of several key surface currents and associated mesoscale rings in the Atlantic Ocean basin are continuously monitored using satellite altimetry observations ( $w w w . a o m l$ .noaa.gov/phod/altimetry/cvar/index.php). We present here the state of four key dynamic features in the Atlantic Ocean: (1) During 2018, satellite altimetry observations show that the number of rings shed by the Agulhas Current remained similar to the mean 1993-2018. The transport by these rings is indica- 
tive of water mass properties exchanges between the Indian and Atlantic Oceans. (2) In the southwest Atlantic Ocean, the separation of the Brazil Current from the continental shelf break (located at $37.6^{\circ} \mathrm{S}$ in the mean) reveals the intrusion of subtropical waters into the subpolar region. Since 1993, this current has separated farther to the south from the continental shelf break by $3^{\circ}$ latitude (c.f., Lumpkin and Garzoli, 2010; Goni et al., 2011). During 2017 the location of separation moved to the south by about $2^{\circ}$ latitude (see www.aoml.noaa.gov/phod/altimetry/cvar/mal /BM_ts.php), the largest southward shift in the altimeter time period 1993-present. During 2018, this location remained unchanged. (3) To the north, the North Brazil Current, which transports waters from the South Atlantic into the North Atlantic basin, showed a slight increase in the number and size of the rings shed and in the number of rings that eventually made their way into the Caribbean Sea. This increased transport is important because the rings carry fresh Amazon River water into the Caribbean Sea, creating barrier layers that often contribute to Atlantic hurricane intensification. (4) Altimetry and cable measurements of the Florida Current during 2018 do not show any deviation from their expected annual mean values at $27^{\circ} \mathrm{N}$.

h. Global ocean phytoplankton-B. A. Franz, I. Cetinić, E. M. Karaköylü, D. A. Siegel, and T. K. Westberry

Marine phytoplankton contribute roughly half the net primary production (NPP) on Earth, fixing atmospheric $\mathrm{CO}_{2}$ into food that fuels global ocean ecosystems and drives biogeochemical cycles (e.g., Falkowski et al. 1998; Field et al. 1998). Phytoplankton growth is dependent on availability of light and nutrients (e.g., iron, nitrogen, phosphorous) in the upper ocean euphotic zone, which in turn is influenced by physical factors such as ocean temperature (e.g., Behrenfeld et al. 2006). SeaWiFS (McClain 2009) and MODIS (Esaias et al. 1998) are satellite ocean color sensors that provide observations of sufficient frequency and geographic coverage to globally monitor changes in the near-surface concentration of the phytoplankton pigment chlorophyll- $a\left(\mathrm{Chl} a ; \mathrm{mg} \mathrm{m}^{-3}\right)$, and phytoplankton carbon biomass $\left(\mathrm{C}_{\mathrm{phy}} ; \mathrm{mg} \mathrm{m}^{-3}\right)$. While both quantities vary with phytoplankton abundance and thus serve as proxies for phytoplankton biomass, cellular Chla can also vary significantly due to physiological response to light and nutrient conditions or changes in species composition (Dierssen 2010; Geider et al. 1997). In combination, these two satellite products provide insight into multiple dimensions of environmental and climate-driven variability in phytoplankton biomass, composition, and physiology (Behrenfeld et al. 2008; Siegel et al. 2013; Westberry et al. 2016).

Here, global Chl $a$ and $\mathrm{C}_{\text {phy }}$ distributions for 2018 are evaluated within the context of the continuous 21-year record provided through the combined observations of SeaWiFS (1997-2010) and MODIS on Aqua (MODISA, 2002-present). The NASA standard MODISA daytime SST product, version R2014.0, is used to provide context on the physical state of the oceans. All ocean color data used in this analysis correspond to NASA processing version R2018.0, which utilizes common algorithms and calibration methods to maximize consistency in the multi-mission satellite record. The R2018.0 Chla product was derived using the algorithm of $\mathrm{Hu}$ et al. (2012), while $\mathrm{C}_{\text {phy }}$ was derived from the R2018.0 particle backscattering coefficient, $b_{b p}$, at $443 \mathrm{~nm}$ (Werdell et al. 2013) and a linear relationship between $\mathrm{b}_{\mathrm{bp}}$ and $\mathrm{C}_{\mathrm{phy}}$ as described in Graff et al. (2015). In combining the ocean color records, the overlapping period from 2003 through 2008 was used to assess and correct for residual bias between the two mission datasets.

To evaluate changes in the distribution of phytoplankton during 2018, mean values for MODISA Chla and $\mathrm{C}_{\text {phy }}$ in each month of the year were subtracted from monthly climatological means for MODISA (2003-11). These monthly fields were then averaged to produce the global Chla and $\mathrm{C}_{\text {phy }}$ anomaly maps for 2018 (Figs. 3.21a,b). Similar calculations were performed on MODISA SST $\left({ }^{\circ} \mathrm{C}\right)$ data to produce an equivalent SST annual mean anomaly (Fig. 3.21c). The permanently stratified ocean (PSO) is defined as the region covering the tropical and subtropical oceans where annual average SST is greater than $15^{\circ} \mathrm{C}$ and is characterized by surface mixed layers that are typically low in nutrients and shallower than the nutricline (black lines near $40^{\circ} \mathrm{N}$ and $40^{\circ} \mathrm{S}$ in Fig. 3.21; Behrenfeld et al. 2006).

For 2018, Chla concentrations (Fig. 3.21a) were suppressed $10 \%-30 \%$ relative to the climatological mean in the western warm pool and northern and southern regions of the tropical Pacific, as well as the western North Pacific and the western subtropical North Atlantic. These locations correspond to regions of strongly elevated SSTs (Fig. 3.21c). $\mathrm{C}_{\text {phy }}$ concentrations within the tropical Pacific show similar but weaker patterns of negative anomalies in the east $(-5 \%)$ but neutral to positive anomalies ( $+5 \%)$ in the west, with $\mathrm{C}_{\text {phy }}$ anomalies generally more homogeneous across the Atlantic and Pacific Oceans (Fig. 3.21b). Positive SST anomalies in these permanently stratified ocean regions generally coincide with shallower surface 
mixed layer depths (MLD), exposing phytoplankton to prolonged daily sunlight exposures. Phytoplankton respond to this increased light by decreasing their cellular chlorophyll levels (Behrenfeld et al. 2015). Shallower MLDs might also indicate a decrease in vertical nutrient transport, adding to the physiological response of the cell and potentially driving additional decoupling of Chl $a$ and $\mathrm{C}_{\text {phy }}$ anomalies due to decreased cellular chlorophyll to carbon ratios (Westberry et al. 2016). Coherent patches of elevated phytoplankton biomass, as evident from both Chla and $\mathrm{C}_{\text {phy }}$ anomalies, were visible in the Arabian Sea and Bay of Bengal, the southern Pacific subtropical gyre, and the eastern equatorial and subtropical Atlantic. Outside of the PSO, a much weaker correlation was observed between phytoplankton biomass anomalies and SST anomalies, consistent with past reports (e.g., Franz et al. 2018). Notably, strong negative anomalies in SST were visible across the subpolar North Atlantic and the Labrador Sea $\left(\sim 1^{\circ} \mathrm{C}\right)$, but the biological response differed for these regions, as Chl $a$ and $\mathrm{C}_{\text {phy }}$ demonstrated positive anomalies $(+35 \%$ and $+15 \%$ respectively) in the Labrador Sea, while both measurements were depressed (-15\%) in the North Atlantic.

Seasonal changes in phytoplankton biomass in the permanently stratified ocean typically display two pronounced peaks, reflecting vernal increases in biomass in the Northern and Southern Hemispheres (Figs. 3.22a,b). Peaks in monthly climatological $\mathrm{C}_{\mathrm{phy}}$ tend to trail behind peaks in Chla with a 2-month delay, likely due to a reduction in phytoplankton chlorophyll to carbon ratios as the seasonal bloom progresses (e.g., Westberry et al. 2016). During 2018, however, primary and secondary peaks in Chla (red circles in Fig. 3.22) occurred slightly earlier than the climatological norm, leading to some significant deviations that include anomalously high values in January and May-June and low values in September and October. During 2018, $\mathrm{C}_{\text {phy }}$ values generally remained within the interquartile range of monthly climatological distributions, except during October-November, when mean phytoplankton biomass peaked earlier than the climatology.

Over the 21-year time series of spatially integrated monthly mean Chla within the PSO (Fig. 3.23a), concentrations varied by $\sim 15 \%\left( \pm 0.02 \mathrm{mg} \mathrm{m}^{-3}\right)$ around a long-term average of $0.142 \mathrm{mg} \mathrm{m}^{-3}$ (Fig. 3.23a). This variability includes significant seasonal cycles in Chla distributions and responses to climatic events, as has been observed previously (e.g., Behrenfeld et al. 2006; Franz et al. 2018). $\mathrm{C}_{\text {phy }}$ over the same 21 -yr period varied by $\sim 5 \%\left( \pm 1.25 \mathrm{mg} \mathrm{m}^{-3}\right)$ around an average of $23.7 \mathrm{mg} \mathrm{m}^{-3}$ (Fig. 3.23c). Seasonal cycles in $\mathrm{C}_{\text {phy }}$ are more clearly de-

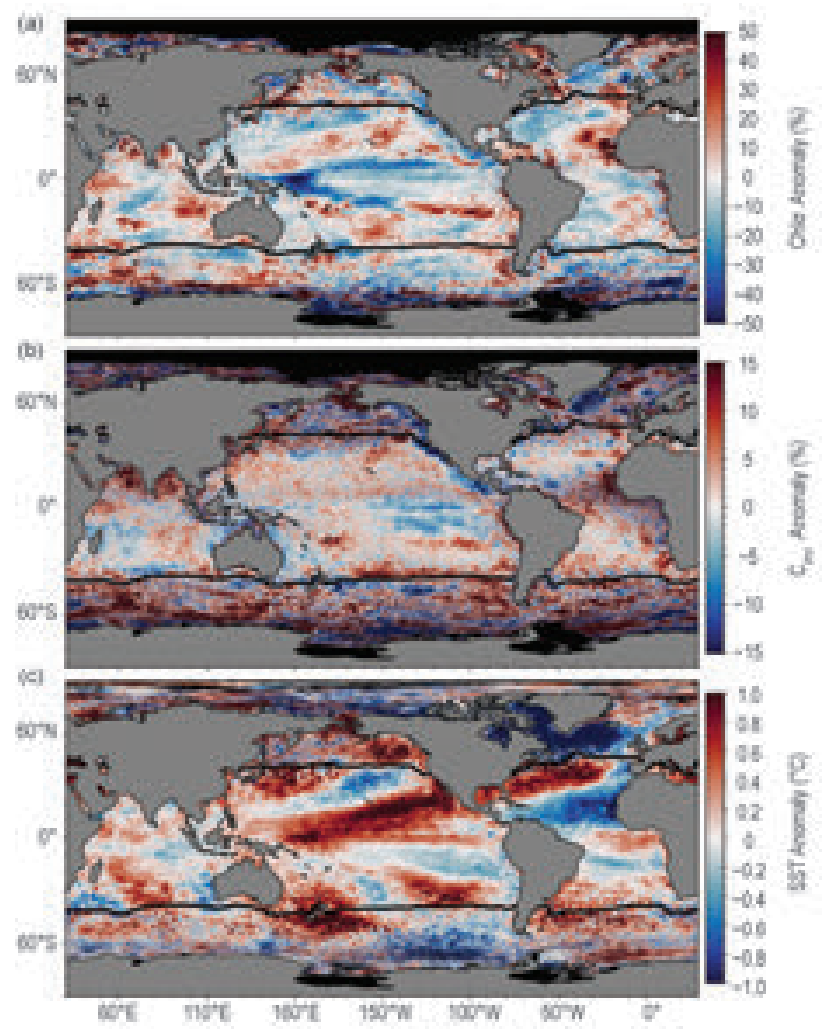

Fig. 3.2I. Annual mean for 2018 of monthly (a) MODISA Chla, (b) MODISA $C_{\text {phy, }}$ and (c) MODISA SST anomalies, where monthly differences were derived relative to a MODISA 9-year climatological record (2003-II). Chla and $\mathrm{C}_{\text {phy }}$ are stated as \% difference from climatology, while SST is shown as an absolute difference. In each panel, black lines indicate the location of the mean $15^{\circ} \mathrm{C} \mathrm{SST}$ isotherm delineating the PSO region.

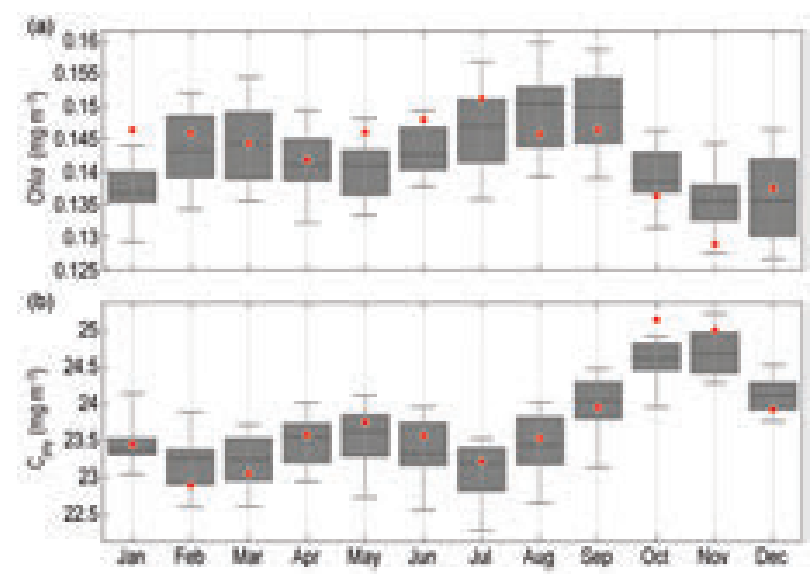

FIG. 3.22. Distribution of 2018 monthly means (red circles) for (a) MODISA Chla and (b) MODISA $\mathrm{C}_{\mathrm{phy}}$ for the PSO region, superimposed on the climatological values as derived from the combined time-series of SeaWIFS and MODISA over the 20-year period 19982017. The gray boxes show the interquartile range of the climatology, with black line for the median value and whiskers extending to the 5 th and 95 th percentiles. 
lineated than those of Chla, consistent with the assertion that $\mathrm{C}_{\text {phy }}$ represents true variability in phytoplankton biomass.

Chla monthly anomalies within the PSO (Fig. 3.23b) show variations of $\pm 10 \%\left( \pm 0.015 \mathrm{mg} \mathrm{m}^{-3}\right)$ over the multi-mission time series, with largest deviations generally associated with El Niño/La Niña events. This link between ENSO variability and mean Chla response in the PSO is demonstrated by the correspondence of anomaly trends with the Multivariate ENSO Index [(MEI; Wolter and Timlin (1998); presented in the inverse to illustrate the correlation, with $\mathrm{R}=-0.44)$ ]. For 2018, Chla anomalies were relatively small $( \pm 3 \%)$, consistent with weak ENSO conditions. Similar comments can be made about the $\mathrm{C}_{\text {phy }}$ anomaly trends, which show nominal to slightly elevated values in 2018 and also track well with the MEI over the 21-year timeseries $(\mathrm{R}=-0.39)$.

Variability and trends in Chla reflect both adjustments in phytoplankton biomass and physiology (or health), while $\mathrm{C}_{\text {phy }}$ reflects changes in biomass alone. Both of these properties are mechanistically linked to physical conditions of the upper ocean, as well as to ecological interactions between phytoplankton and their zooplankton predators. Unraveling the diversity and covariation of factors that influence Chla concentrations is essential for correctly interpreting the implications of Chla anomalies on ocean biogeochemistry and food webs. For example, inverse relationships between Chla and SST can emerge from changes in either mixed-layer light levels or vertical nutrient flux, but these two mechanisms have opposite implications on phytoplankton NPP (Behrenfeld et al. 2015). An additional complication is that measured changes in ocean color often contain a contribution from colored dissolved organic matter (Siegel et al. 2005) or from the changing phytoplankton population, with its type-specific optical characteristics (Dierssen 2010) that can be mistakenly attributed to changes in Chla (Siegel et al. 2013). $\mathrm{C}_{\text {phy }}$ provides a more direct measurement of phytoplankton biomass that is insensitive to changes in physiological status of the cell, and thus offers complementary information on the state of the oceans. Future satellite missions, such as the planned hyperspectral Plankton, Aerosol, Cloud, ocean Ecosystem mission (PACE), will enable the rigorous separation of phytoplankton absorption features from non-algal features, as well as the assessment of changes in phytoplankton species or functional group distributions (Werdell et al. 2019). Such data will provide a major step forward in our ability to disentangle the impacts of climate forcing on global phytoplankton communities.
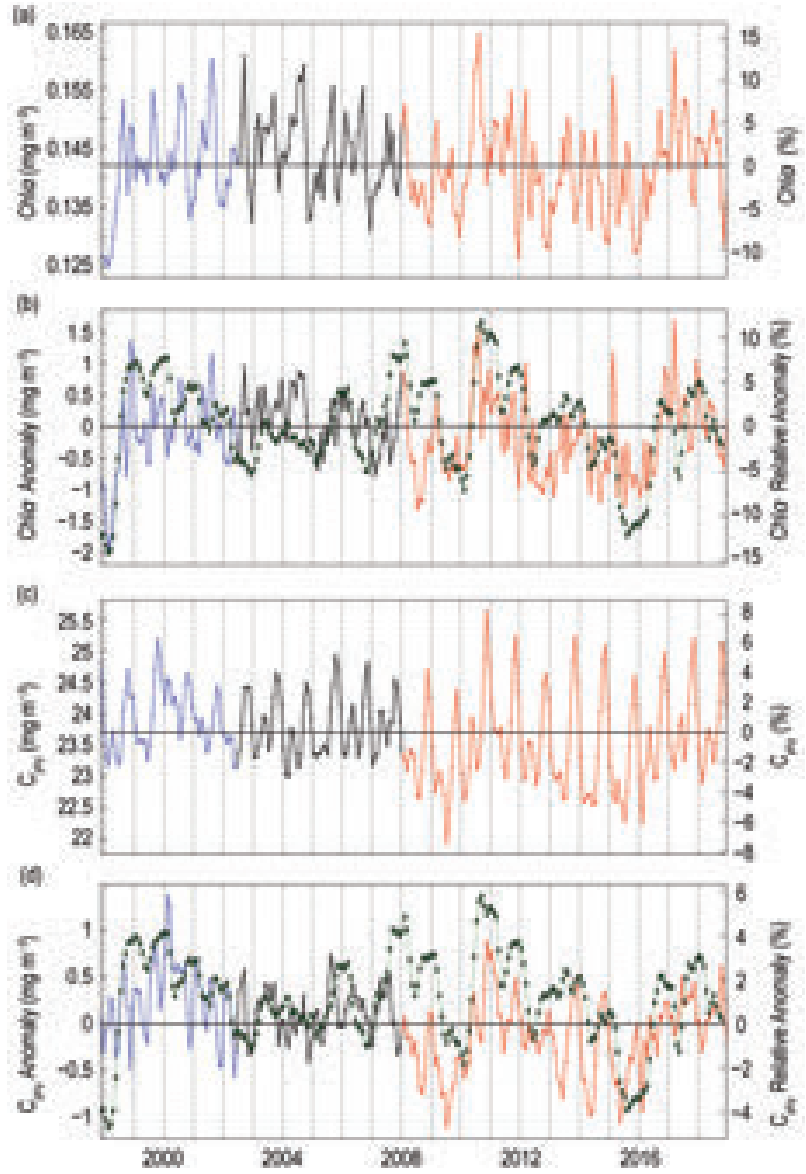

FIG. 3.23. 2I-year, multi-mission record of $\mathrm{Chla}$ and $\mathrm{C}_{\text {phy }}$ averaged over the PSO for SeaWiFS (blue), MODISA (red), and combined (black). Panel (a) shows Chla from each mission, with horizontal line indicating the multi-mission mean Chla concentration for the region. Panel (b) shows the monthly Chla anomaly from SeaWiFS and MODISA after subtraction of the 20-year multi-mission climatological mean (Fig. 3.22). Panel (c) and (d) show the same as (a) and (b) respectively, but for $\mathbf{C}_{\text {phy }}$. Green diamonds show the MEI, inverted and scaled to match the range of the Chla and $C_{\text {phy }}$ anomalies.

i. Global ocean carbon cycle-R. A. Feely, R. Wanninkhof, B. R. Carter, P. Landschützer, A. J. Sutton, C. Cosca, and J. A. Triñanes

The global oceans play a major role in the global carbon cycle by taking up a significant fraction of the excess $\mathrm{CO}_{2}$ humans release into the atmosphere every year. As a consequence of humankind's collective release of $\mathrm{CO}_{2}$ emissions into the atmosphere from fossil fuel burning, cement production, and land use changes over the last two-and-a-half centuries, commonly referred to as "Anthropogenic $\mathrm{CO}_{2}\left(\mathrm{C}_{\text {anth }}\right)$," the atmospheric $\mathrm{CO}_{2}$ concentration has risen from pre-industrial levels of about $278 \mathrm{ppm}$ (parts per million) to about $408 \mathrm{ppm}$ in 2018. The 
atmospheric concentration of $\mathrm{CO}_{2}$ is now higher than has been observed on Earth for at least the last 800000 years (IPCC 2013). As discussed in previous State of the Climate reports, the global ocean is a major long-term sink for $\mathrm{C}_{\text {anth }}$, which is the major cause of ocean acidification. Here the discussion is updated to include recent estimates of that sink. Over the last decade, the global ocean has continued to take up a substantial fraction of the $\mathrm{C}_{\text {anth }}$ emissions and therefore is a major mediator of global climate change. Of the $10.8( \pm 0.9) \mathrm{Pg} \mathrm{C} \mathrm{yr}^{-1} \mathrm{C}_{\text {anth }}$ released during the period 2008-17, about $2.4( \pm 0.5) \mathrm{Pg} \mathrm{C} \mathrm{yr}^{-1}$ (22\%) accumulated in the ocean, $3.2( \pm 0.8) \mathrm{Pg} \mathrm{C} \mathrm{yr}^{-1}$ (29\%) accumulated on land, and $4.7( \pm 0.1) \mathrm{Pg} \mathrm{C} \mathrm{yr}^{-1}$ (44\%) remained in the atmosphere with an imbalance of $0.5 \mathrm{Pg} \mathrm{C} \mathrm{yr}^{-1}$ (Le Quéré et al. 2018). This decadal ocean carbon uptake estimate is a consensus view based on a combination of measured decadal inventory changes, models, and global air-sea $\mathrm{CO}_{2}$ flux estimates based on surface ocean partial pressure of $\mathrm{CO}_{2}\left(\mathrm{pCO}_{2}\right)$ measurements from ships and moorings. Using ocean general circulation models that include biogeochemical parameterizations (OBGCMs) and inverse models that are validated with observationsbased air-sea exchange fluxes and basin-scale ocean inventories, Le Quéré et al. (2018) have demonstrated that the oceanic $\mathrm{C}_{\text {anth }}$ sink has grown from $1.0( \pm 0.5)$ $\mathrm{Pg} \mathrm{C} \mathrm{yr}^{-1}$ in the 1960s to $2.5( \pm 0.5) \mathrm{Pg} \mathrm{C} \mathrm{yr}^{-1}$ in 2017 . Air-sea $\mathrm{CO}_{2}$ flux studies reported here and shown in Fig. 3.24 indicate a greater ocean uptake than provided in Le Quéré et al. (2018), due to an increased estimate of $0.78 \mathrm{PgC} \mathrm{yr}^{-1}$ riverine contribution. This higher estimate in carbon from rivers is applied to the whole time series shown in Fig. 3.24.

\section{I) Air-Sea CARbON DiOXIDE fluXes}

Ocean uptake of $\mathrm{C}_{\text {anth }}$ can be estimated from the net air-sea $\mathrm{CO}_{2}$ flux derived from the bulk flux formula with air-sea differences in $\mathrm{CO}_{2}$ partial pressure $\left(\triangle p \mathrm{CO}_{2}\right)$ and gas transfer coefficients as input. A steady contribution of carbon from riverine runoff, originating from organic and inorganic detritus from land, revised upward from 0.45 to $0.78 \mathrm{Pg} \mathrm{C} \mathrm{yr}^{-1}$ (Resplandy et al. 2018) is included to obtain the $\mathrm{C}_{\text {anth }}$ uptake by the ocean. The data sources for $p \mathrm{CO}_{2}$ are annual updates of surface water $p \mathrm{CO}_{2}$ observations from the Surface Ocean $\mathrm{CO}_{2}$ Atlas (SOCAT) composed of mooring and ship-based observations (Bakker et al. 2016) and the Lamont-Doherty Earth Observatory (LDEO) database with ship-based observations (Takahashi et al. 2017). The increased observations and improved mapping techniques, including neural network methods and self-organizing

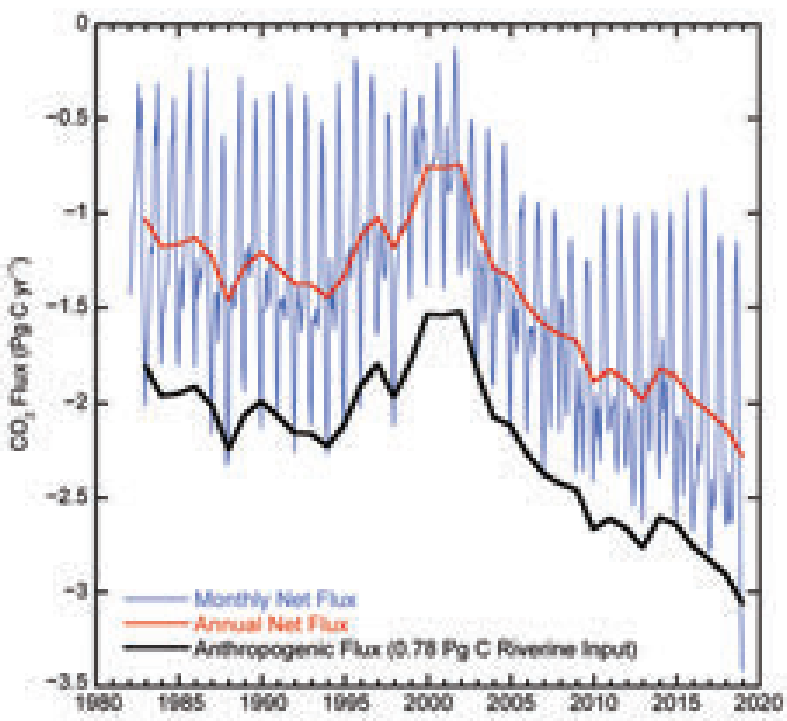

FIG. 3.24. Global annual (red line) and monthly (blue line) net $\mathrm{CO}_{2}$ fluxes ( $\left.\mathrm{PgC} \mathrm{yr}^{-1}\right)$ for 1982-20 I8. The black line is the anthropogenic $\mathrm{CO}_{2}$ flux, which is the net flux minus the riverine component of $0.78 \mathrm{Pg} \mathrm{C} \mathrm{yr}^{-1}$. Negative values indicate $\mathrm{CO}_{2}$ uptake by the ocean.

maps (Landschützer et al. 2013, 2014; Rödenbeck et al. 2015), provide global $p \mathrm{CO}_{2}$ fields on a $1^{\circ} \times 1^{\circ}$ grid at monthly time scales annually. This allows investigation of variability on sub-annual to decadal time scales. The $\triangle p \mathrm{CO}_{2}$ and a parameterization of the gas transfer with wind described in Wanninkhof (2014) are used to calculate the air-sea $\mathrm{CO}_{2}$ fluxes.

The monthly $2018 \Delta p \mathrm{CO}_{2}$ maps are based on an observation-based neural network approach of Landschützer et al. $(2013,2014)$. The 2018 values are projections based on surface temperature, sea surface salinity, climatological mixed-layer depth, satellite chlorophyll- $a$, atmospheric $\mathrm{CO}_{2}$, and the neural network for seawater $p \mathrm{CO}_{2}$ developed from the data from the previous three decades. Changes in winds over time have a small effect on annual global air-sea $\mathrm{CO}_{2}$ fluxes (Wanninkhof and Triñanes 2017). The $C_{\text {anth }}$ fluxes from 1982 to 2018 suggest a decreasing ocean sink in the first part of the record and a strong increase from 2001 onward that continued into 2018 (Fig. 3.24). The amplitude of seasonal variability is large $(\approx 1 \mathrm{Pg}$ C) compared to the long-term trend with minimum uptake in the June-September timeframe. The $\mathrm{C}_{\text {anth }}$ air-sea flux of $3.1 \mathrm{Pg} \mathrm{C} \mathrm{yr}^{-1}$ in 2018 is 36\% above the revised 1996-2016 average of $2.24( \pm 0.4) \mathrm{Pg} \mathrm{C} \mathrm{yr}^{-1}$.

The average fluxes in 2018 (Fig. 3.25a) show the characteristic pattern of effluxes in the tropical regions and in the high-latitude Southern Ocean around $60^{\circ} \mathrm{S}$, and uptake at mid-latitudes. The region with largest efflux is the equatorial Pacific. Coastal upwelling regions including the Arabian Sea, off the 
coast of Mauritania, and the Peruvian upwelling system are significant $\mathrm{CO}_{2}$ sources to the atmosphere as well. Large sinks are observed poleward of the subtropical fronts, and the frontal position determines the location of a maximum that is farther south and weaker in the Pacific sector of the Southern Ocean compared to the other basins.

In the Northern Hemisphere, there is a significant asymmetry in the sub-Arctic gyre with the North Atlantic being a large sink while the North Pacific is a significant source of $\mathrm{CO}_{2}$. This is due in part to the position of the western boundary currents that are known $\mathrm{CO}_{2}$ sinks at high latitudes. The Gulf Stream/ North Atlantic drift extends farther north than the Kuroshio.

Ocean carbon uptake anomalies (Fig. 3.25b) in 2018 relative to the 1996-2016 average are attributed to the increasing ocean $\mathrm{CO}_{2}$ uptake with time (Fig. 3.24 ) and to variations in large-scale climate modes. The long-term air-sea flux trend since 2000 is $-0.7 \mathrm{Pg}$ $\mathrm{C}$ decade $^{-1}$ (or $-0.16 \mathrm{~mol} \mathrm{~m}^{2} \mathrm{yr}^{-1}$ decade $^{-1}$ ), which leads to predominantly negative flux anomalies (greater ocean uptake). Despite this trend there are several large regions showing positive anomalies for 2018, notably the eastern equatorial Pacific, the subtropical North and South Pacific, and the high-latitude Southern Ocean. The increased effluxes in the eastern equatorial Pacific are related to a predominant negative sign of the Oceanic Niño Index (ONI) that followed an extensive period of predominantly positive ONI (El Niño) conditions in the preceding 20 years. This is borne out by the colder SST values (Fig. 3.26a) that indicate increased upwelling of waters with high $\mathrm{CO}_{2}$ content. Positive anomalies in the Pacific subtropical regions (Fig. 3.25b) are related to the warm SST anomalies over the past year compared to the long-term average (Fig. 3.1a).

The differences between the air-sea $\mathrm{CO}_{2}$ fluxes in 2018 compared to 2017 (Fig. 3.25c) are appreciable with anomalies roughly in the same regions as the difference of 2018 compared to the 20-year average. This indicates that conditions in 2018 are unique as compared to annual and decadal means. The increase in $\mathrm{CO}_{2}$ effluxes in the eastern equatorial Pacific from 2017 to 2018 are associated with a return to more upwelling favorable conditions after the stalled El Niño in 2017. The Southern Ocean (south of $40^{\circ} \mathrm{S}$ ) shows an increasing sink in the polar front region $\left(\approx 50^{\circ} \mathrm{S}\right)$ and increasing source to the south for all three basins. The increasing sink near the polar front is partially compensated by a decreasing sink to the north. The correlations with SST anomaly (SSTA) are more nuanced. The large negative SSTA in the

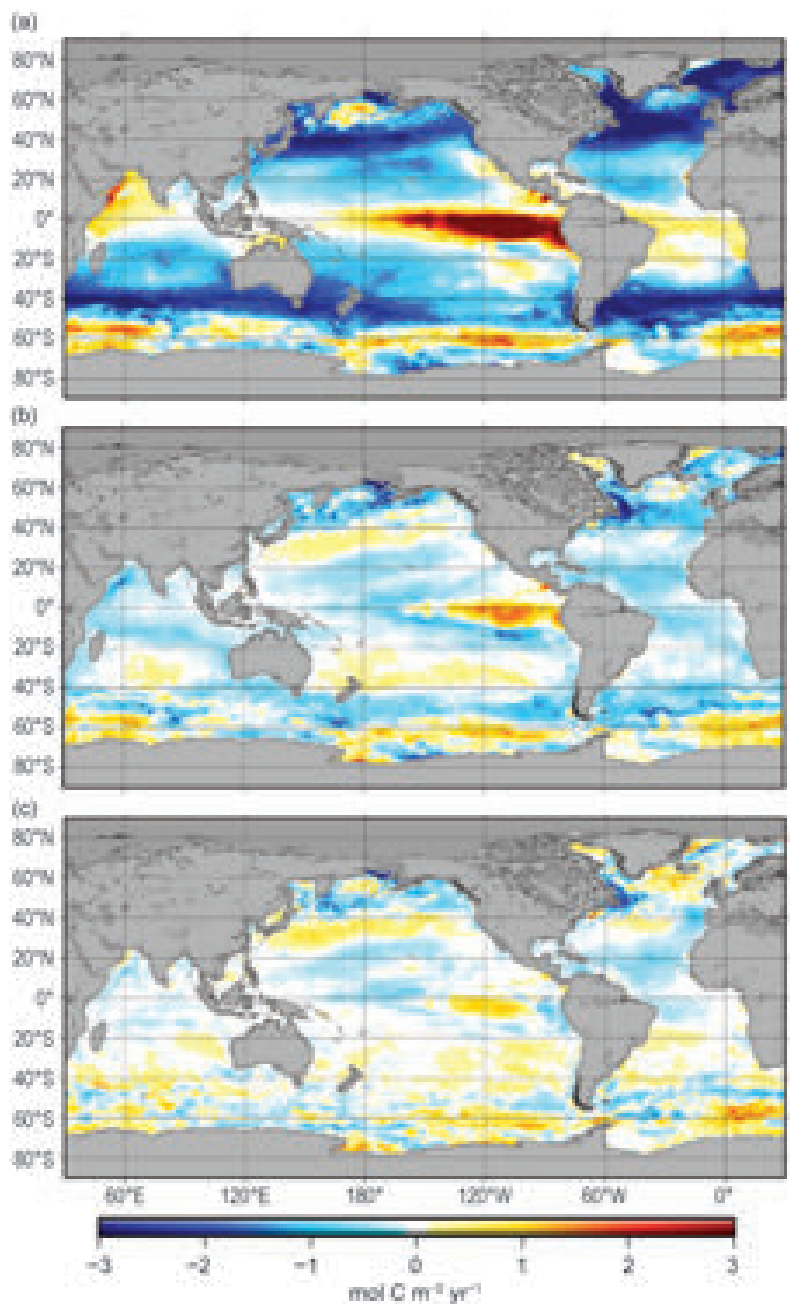

FIG. 3.25. Global map of (a) net air-sea $\mathrm{CO}_{2}$ fluxes for 2018, (b) net air-sea $\mathrm{CO}_{2}$ flux anomalies for 2018 relative to a 1996-2016 average, and (c) net air-sea $\mathrm{CO}_{2}$ flux anomalies for 2018 minus 2017 values following the method of Landschützer et al. (2013), all in $\mathrm{mol} \mathrm{C} \mathrm{m}^{-2} \mathrm{yr}^{-1}$.

eastern South Pacific centered at $60^{\circ} \mathrm{S}$ is attributed to deeper convection and upwelling contributing to the positive $\mathrm{CO}_{2}$ flux anomaly (Fig. 3.25b). However, the large positive $\mathrm{CO}_{2}$ flux anomaly in the eastern South Atlantic sector does not have a strong SSTA associated with it. The band of negative flux $\mathrm{CO}_{2}$ anomalies compared to 2017 centered near $50^{\circ} \mathrm{S}$ is in a region with predominantly positive SSTA that suggests that in this band, SSTA and flux anomalies are decoupled. The North Pacific shows a large decrease in sink strength roughly following the path of the Kuroshio Current with a positive SSTA.

As detailed above, many of the $p \mathrm{CO}_{2}$ and flux anomalies can be attributed to variations in largescale climate modes and associated physical anomalies, notably temperature, but the causality is often 


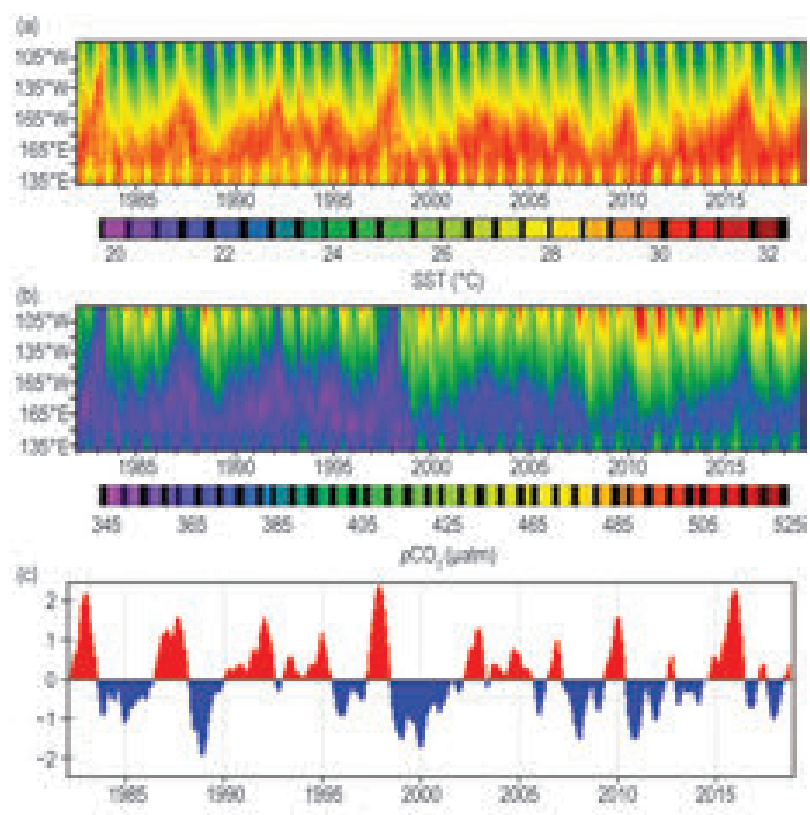

FIG. 3.26. Time-longitude plots of: (a) SST, (b) $\mathrm{pCO}_{2}$, and the (c) ONI from 1982-2018 in the equatorial Pacific. Significant reductions in surface water $\mathrm{pCO}_{2}$ values (low $\mathrm{CO}_{2}$ outgassing) correspond with the EI Niño events of 1982-83, 1986-87, 1991-94, 1997-98, 2002-05, 2006-07, 2009-10, and 2015-16. Significant enhancement of the $\mathrm{PCO}_{2}$ values (high $\mathrm{CO}_{2}$ outgassing) occurred with the strong La Niña events in 1984-85, 1998-99, 1995-96, 1998-2000, 2007-08, and 20II-I2. 2018 was a normal non-EI Niño year.

complex. For example, the behavior of $p \mathrm{CO}_{2}$ with respect to temperature includes competing processes: thermodynamics dictate decreasing $p \mathrm{CO}_{2}$ with decreasing SST, but waters originating from the deep with a cold temperature signal will have a high $p \mathrm{CO}_{2}$. Moreover, the drawdown of $p \mathrm{CO}_{2}$ due to biology is often associated with increasing temperature, but this depends on region and season.

The strong trend of increasing $\mathrm{CO}_{2}$ uptake since 2002 has continued through 2018 with an increase of $0.15 \mathrm{Pg} \mathrm{C}$ above the 2017 estimate. This increase is well within the uncertainty of the estimate, but it is within the overall expectation that the ocean will remain an increasing sink as long as atmospheric $\mathrm{CO}_{2}$ levels continue to rise. The sequestration of $\mathrm{CO}_{2}$ by the ocean partially mitigates the atmospheric $\mathrm{CO}_{2}$ rise, but it comes at a cost of increased acidification of surface and subsurface waters (Carter et al. 2017).

2) INTERANNUAL VARIABILITY OF PCO $\mathrm{CO}_{2}$ IN THE TROPICAL PACIFIC

From previous studies in the tropical Pacific, it is well-established that the oceanic variability of the air-sea exchange fluxes in this region are largely controlled by the surface ocean $p \mathrm{CO}_{2}$ variability and wind forcing influenced by the nature and phasing of ENSO events (e.g., Feely et al. 1999, 2002, 2006; Ishii et al. 2009, 2014; Takahashi et al. 2009; Wanninkhof et al. 2013; Landschützer et al. 2014, 2016). The central and eastern equatorial Pacific is a major source of $\mathrm{CO}_{2}$ to the atmosphere during non-El Niño and La Niña periods; it is near neutral during strong El Niño periods, and a weak source during weak El Niño periods. The warm El Niño phase of the ENSO cycle is characterized by a large-scale weakening of the trade winds, decrease in upwelling of $\mathrm{CO}_{2}$ and nutrient-rich subsurface waters, and a corresponding warming of SST in the eastern and central equatorial Pacific. The opposite phase of the ENSO cycle, called La Niña, is characterized by strong trade winds, cold tropical SSTs, and enhanced upwelling along the equator. Figure 3.26 shows time-longitude plots of SST and $p \mathrm{CO}_{2}$ for the region from $5^{\circ} \mathrm{N}$ to $10^{\circ} \mathrm{S}$ and $130^{\circ} \mathrm{E}$ to $95^{\circ} \mathrm{W}$, and the Oceanic Niño Index (ONI) for the 36-yr period from 1982 through 2018. During the strong eastern Pacific El Niño events of 1982-83, 1997-98, and 2015-16, the cold waters of the eastern equatorial Pacific disappear and $p \mathrm{CO}_{2}$ values are close to equilibrium with the atmosphere. However, during the weaker central Pacific El Niños of 1991-94, 2002-05, and $2006-07$, the equatorial cold tongue is present but less pronounced, and $\mathrm{pCO}_{2}$ values are higher than atmospheric values but lower than corresponding values for non-El Niño periods. The strongest El Niño event of 1997-98 had SST anomalies exceeding $4^{\circ} \mathrm{C}$ and the lowest $p \mathrm{CO}_{2}$ values throughout most of the equatorial Pacific. In contrast, the 2015-16 El Niño event had SST anomalies that are similar to the 1997-98 event, yet the $p \mathrm{CO}_{2}$ values were significantly higher because the upwelling-favorable winds were stronger in the easternmost and westernmost parts of the region. By 2018, the region returned to nonEl Niño conditions and near-normal $p \mathrm{CO}_{2}$ levels.

\section{3) LONG-TERM TRENDS OF SURFACE OCEAN $\mathrm{PCO}_{2}$}

Another feature of the time series of $p \mathrm{CO}_{2}$ measurements in the Pacific is the secular increase of oceanic $p \mathrm{CO}_{2}$ in response to the rise in atmospheric $\mathrm{CO}_{2}$. Studies from surface ships and moorings have demonstrated de-seasoned secular increases of surface ocean $p \mathrm{CO}_{2}$ ranging from 2.3-3.3 $\mu$ atm $\mathrm{yr}^{-1}$; however, rates of change are lower during El Niño periods and higher during La Niña periods (Feely et al. 2006; Sutton et al. 2014). The highest rates of increase are observed in the eastern Pacific near $125^{\circ} \mathrm{W}$. In the tropical Pacific, the strong influence of interannual and decadal variability on surface ocean $p \mathrm{CO}_{2}$ makes it challenging to detect the anthropogenic change. 
In the subtropical Pacific, time-series observations are long enough to detect the anthropogenic signal above the natural variability of the ocean carbon system (Sutton et al. 2017, 2019). De-seasoned monthly means of surface ocean $p \mathrm{CO}_{2}$ observations at the Woods Hole Oceanographic Institution Hawaii Ocean Timeseries Station (WHOTS) in the subtropical North Pacific and Stratus in the South Pacific gyre show anthropogenic trends of $1.8 \pm 0.3 \mu$ atm yr ${ }^{-1}$ and $2.0 \pm 0.3 \mu$ atm $\mathrm{yr}^{-1}$, respectively (Fig. 3.27). These trends are not significantly different from each other or from the atmospheric $\left(x \mathrm{CO}_{2}\right)$ rate of increase at Mauna Loa Observatory of $2.2 \mathrm{ppm}$ over this same time period.

\section{4) Global ocean carbon inventories}

Synoptic ship-based hydrographic measurements are the primary data with which the ocean carbon inventory, its anthropogenic component, and their changes are calculated. Ocean carbon inventories were first quantified in detail as part of the mid-1990s World Ocean Circulation Experiment (WOCE). The Climate Variability (CLIVAR) Repeat Hydrography Program in the mid-2000s and the Global Ocean Ship-based Hydrographic Investigations Program (GO-SHIP) since 2010 have re-measured a subset of the oceanbasin-spanning hydrographic cruise-tracks needed to update the inventories. Critically, these three programs each provided synoptic measurements of a range of seawater parameters with sufficient accuracy and spatial density (vertically and horizontally) in consistent locations to constrain anthropogenic carbon inventory changes with high confidence.

During the last year, a major analysis was completed quantifying the oceanic sink for $\mathrm{CO}_{2}$ between 1994 and 2007 (Gruber et al. 2019). It was enabled by recent refinements to methods for processing interior ocean carbon data (e.g., Clement and Gruber 2018) and a data product released as the culmination of a decade of ship-based data synthesis and quality control work (Olsen et al. 2016). The analysis finds that ocean inventory increased by $34( \pm 4) \mathrm{PgC}$ (i.e., $10^{15} \mathrm{~g}$ carbon) over this span at an average rate of $2.6( \pm 0.3) \mathrm{PgC}_{\mathrm{gear}}{ }^{-1}$. The scientists project this rate forward to estimate a global inventory for the year 2010 of $160( \pm 20)$ PgC. These findings are consistent with recent findings based on combinations of models and data (Khatiwala et al. 2013) and inversions of a variety of data types (DeVries et al. 2017). The rate of storage is increased relative to periods prior to 1994, but consistent with expectations from steadily increasing atmospheric $\mathrm{CO}_{2}$ concentrations. However, broad regional variations were observed in the rate of $\mathrm{CO}_{2}$ accumulation, suggesting that variability in ocean circulation and other modes of climate variability have important effects on ocean carbon concentrations on decadal timescales.

The patterns of accumulation vary by ocean basin (Fig. 3.28) in a manner consistent with broad-scale ocean circulation features, with significantly higher accumulation in shallower waters and in the warmer subtropical gyres, and less accumulation in the regions where dense waters upwell near the equator and in the subpolar oceans and the Southern Ocean. Higher accumulation occurs in shallower waters due to the close contact with the atmosphere, and slower accumulation occurs in upwelling waters that have been out of contact with the changing atmosphere for longer. As a secondary impact, higher accumulation occurs in warmer waters because elevating seawater chemistry drives reactions and gas exchange that result in the waters being more well-buffered against changing $p \mathrm{CO}_{2}$, meaning atmospheric $p \mathrm{CO}_{2}$ increases elevate the total carbon content of seawater by a larger amount before the seawater approaches air-sea equilibrium. 


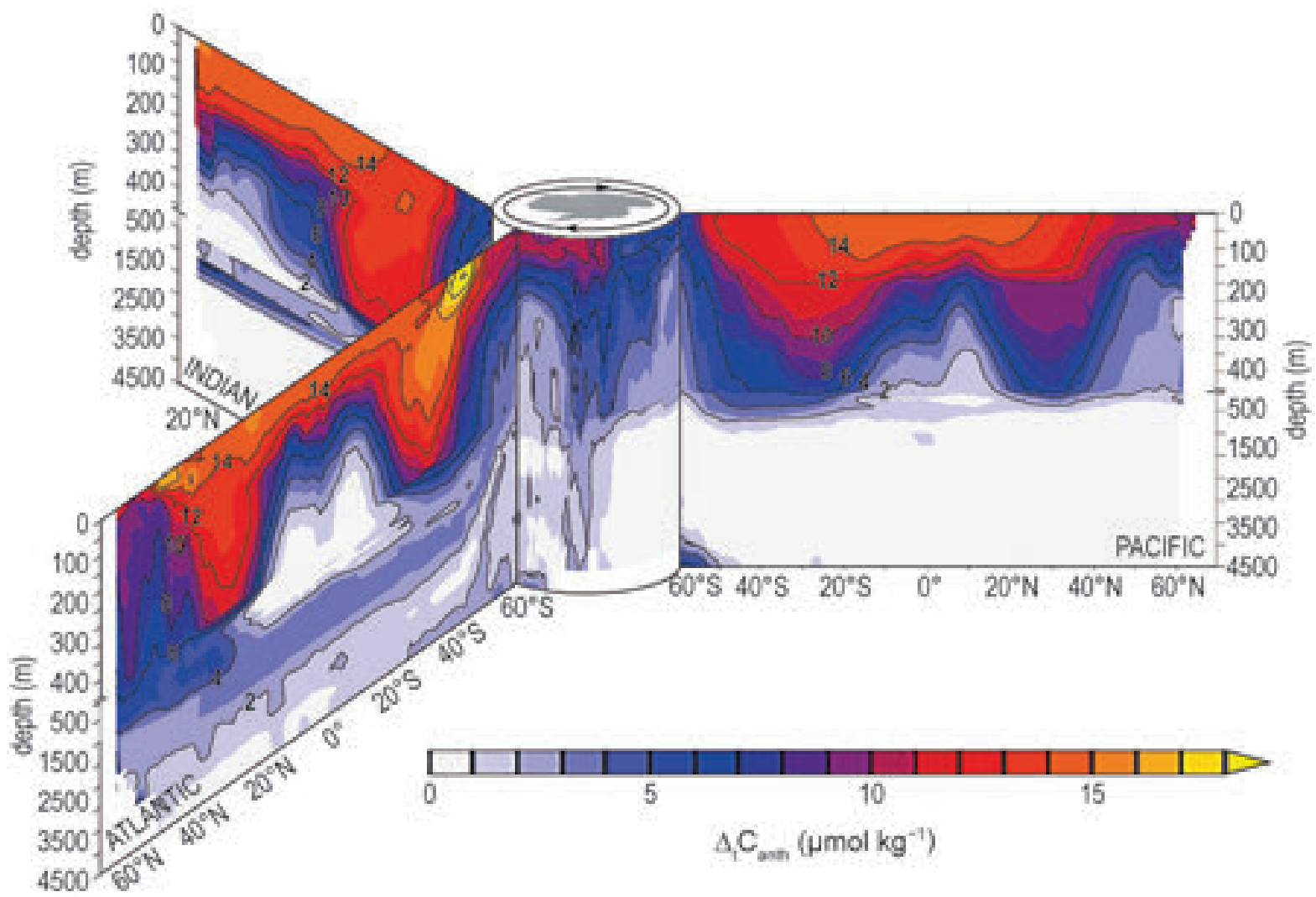

FIG. 3.28. Vertical sections of the accumulation of anthropogenic carbon in $\mu \mathrm{mol} \mathbf{~ k g}^{-1}$ between the WOCE and CLIVAR periods of the repeat hydrographic records, as inferred by Gruber et al. (2019). Shown are the zonal mean sections in each ocean basin organized around the Southern Ocean (center). The upper $\mathbf{5 0 0} \mathbf{m}$ are expanded and contour intervals are spaced at $2 \mu \mathrm{mol} \mathbf{k g}^{-1}$ of $C_{\text {anth. }}$. 
4. THE TROPICS - H. J. Diamond and C. J. Schreck, Eds. a. Overview-H. J. Diamond and C. J. Schreck

The tropics in 2018 began with La Niña conditions that started during boreal autumn 2017 and extended through April 2018. These La Niña sea surface temperature (SST) conditions then transitioned into neutral ENSO SST conditions from April through August. While overall ENSO SST conditions exceeded the minimum threshold for El Niño (e.g., Niño-3.4 $>+0.5^{\circ} \mathrm{C}$ ) from September through December, the ocean-atmosphere coupling that is an intrinsic aspect of El Niño was not present until January 2019.

For the global tropics, land and ocean surfaces (measured $20^{\circ} \mathrm{N}-20^{\circ} \mathrm{S}$ ) combined to register $0.19^{\circ} \mathrm{C}$ above the 1981-2010 average. This ranks 2018 as the 11th warmest year for the tropics since records began in 1880, and coolest since 2013. Precipitation over land for the same latitudes was above the 1981-2010 average for three major datasets (GHCN, GPCC, GPCP), although anomalies among them ranged from 5 to $85 \mathrm{~mm}$ above average.

Globally, 95 named tropical cyclones (TCs; $>33 \mathrm{kt}$ ) were observed during the $2018 \mathrm{NH}$ season and the 2017/18 SH season (see Table 4.2), as documented in IBTrACSv4 (Knapp et al. 2010). Overall, this number was well above the 1981-2010 global average of 82 TCs as well as the 85 TCs reported during 2017 (Diamond and Schreck 2018).

In terms of Accumulated Cyclone Energy (ACE; Bell et al. 2000), each NH basin was above its 1981-2010 average. The eastern North Pacific set a new basin record of $316 \times 10^{4} \mathrm{kt}^{2}$, which is nearly triple its 1981-2010 average. In the western North Pacific, seven storms (six of Category 5 intensity) accounted for $71 \%$ of the above-average seasonal ACE of $341 \times 10^{4} \mathrm{kt}^{2}$. The North Atlantic basin had an ACE nearly $145 \%$ of its 1981-2010 median value, but well below the $241 \%$ of median recorded in 2017 (Bell et al. 2018). The North and South Indian basins were each above their median ACE levels, while the Australian and southwest Pacific basins were fairly quiet, each having below-normal ACE seasons. The global total was in the top quartile for 1981-2010 with $1002 \times 10^{4} \mathrm{kt}^{2}$.

Eleven TCs across the globe reached the Saffir-Simpson scale Category 5 intensity level-six in the western North Pacific, three in the eastern North Pacific, and one each in the Australian and North Atlantic basins. This was five more than recorded in 2016 (Diamond and Schreck 2017), six more than recorded in 2017 (Diamond and Schreck 2018), and only one less than the record of 12 Category 5 TCs set in 1997 (Schreck et al. 2014).

b. ENSO and the tropical Pacific-G. D. Bell, M. S. Halpert, and M. L'Heureux

ENSO is a coupled ocean-atmosphere climate phenomenon over the tropical Pacific Ocean. For historical purposes, NOAA's Climate Prediction Center (CPC) classifies and also assesses the strength and duration of El Niño and La Niña using the Oceanic Niño Index (ONI, shown for 2017 and 2018 in Fig. 4.1). The ONI is the 3-month (seasonal) running average of SST anomalies in the Niño-3.4 region $\left(5^{\circ} \mathrm{N}-5^{\circ} \mathrm{S}\right.$, $170^{\circ}-120^{\circ} \mathrm{W}$ ), currently calculated as the departure from the $1986-2015$ base period. El Niño is classified when the $\mathrm{ONI}$ is $\geq+0.5^{\circ} \mathrm{C}$ for at least five consecutive and overlapping seasons. La Niña is classified when the $\mathrm{ONI}$ is $\leq-0.5^{\circ} \mathrm{C}$ for at least five consecutive and overlapping seasons.

The ONI shows that La Niña developed during September-November (SON) 2017 (L'Heureux et al. 2018) and continued through February-April (FMA) 2018. The CPC officially declared that La Niña ended in April. This event peaked during October-December (OND) 2017 through December-February (DJF) $2017 / 18$ seasons, with ONI values approaching $-1.0^{\circ} \mathrm{C}$ during November-January (NDJ). According to informal CPC criteria, this peak value is borderline between a weak $\left(-0.5^{\circ} \mathrm{C}\right.$ to $\left.-1.0^{\circ} \mathrm{C}\right)$ and moderate strength $\left(-1.0^{\circ} \mathrm{C}\right.$ to $\left.-1.5^{\circ} \mathrm{C}\right)$ event.

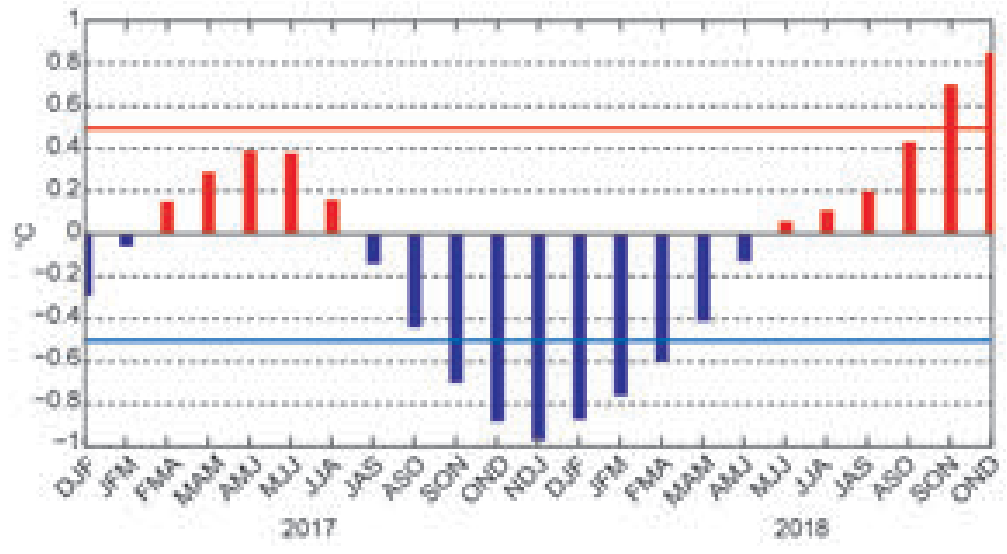

FIG. 4.I. Time series of the $\mathrm{ONI}\left({ }^{\circ} \mathrm{C}\right)$ during $2017 / 18$. Overlapping 3-month seasons are labeled on the $x$-axis; initials indicate the first letter of each month for each season. Red (blue) bars indicate positive (negative) values. The thresholds used to define EI Niño and La Niña events $\left( \pm 0.5^{\circ} \mathrm{C}\right)$ are shown by red and blue horizontal lines, respectively. ONI values are derived from the ERSSTv5 dataset and based on departures from the 1986-2015 monthly means (Huang et al. 2017). 
The ONI values then returned to near-zero for the April-June (AMJ) through July-September (JAS) seasons and became increasingly positive thereafter. The ONI exceeded the minimum threshold for El Niño during the SON season and reached $+0.85^{\circ} \mathrm{C}$ by the end of the year (OND). While these values exceeded the minimum threshold for El Niño, the ocean-atmosphere coupling that is an intrinsic aspect of $\mathrm{El}$ Niño was not yet present. According to CPC's official updates, El Niño conditions developed in January 2019, when this coupling finally became evident.

\section{I) Oceanic conditions}

The evolution of equatorial SSTs and anomalies during 2018 is further illustrated in Fig. 4.2. The La Niña seen early in the year featured a well-defined and amplified cold tongue across the eastern half of the equatorial Pacific Ocean (Figs. 4.2a-d). During DJF 2017/18, SSTs below $25^{\circ} \mathrm{C}$ extended westward to approximately $145^{\circ} \mathrm{W}$, and values less than $28^{\circ} \mathrm{C}$ extended westward to the date line (Fig. 4.2a). SSTs

(a) D.F $2017 / 16$

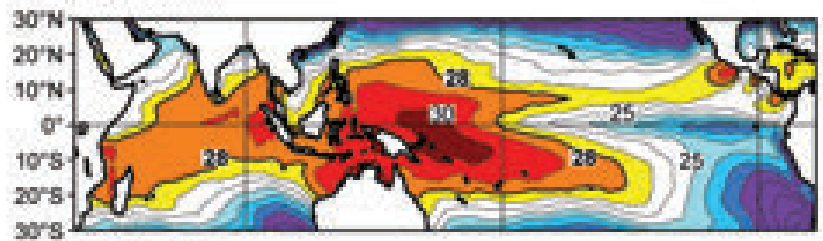

(c) MAM 2018

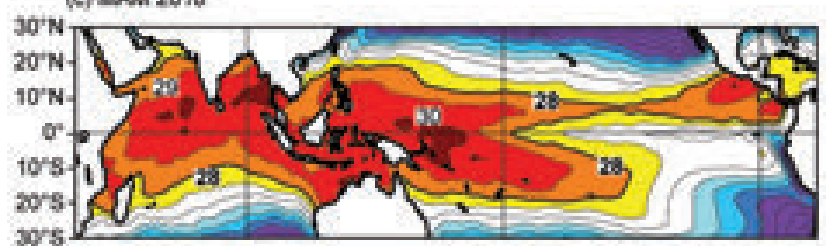

(e) JAA 2018
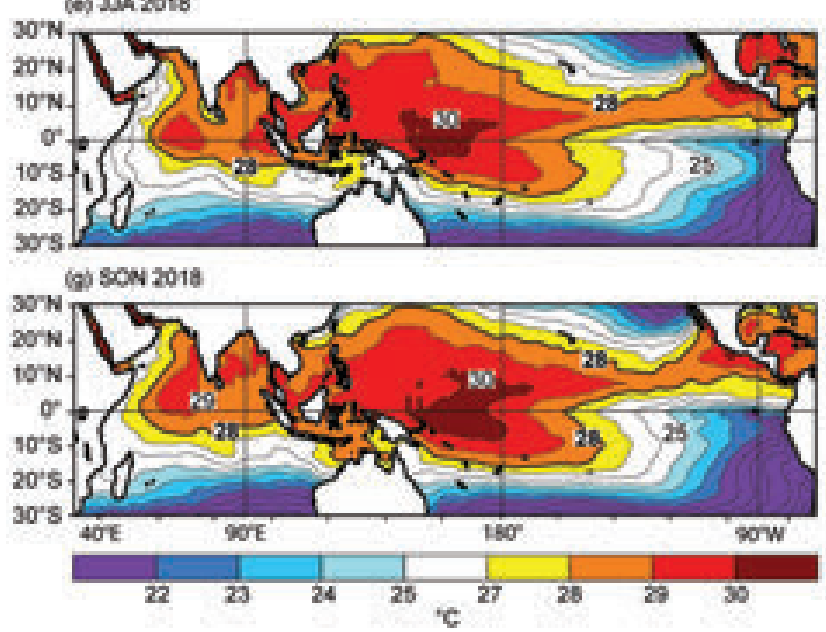

were more than $0.5^{\circ} \mathrm{C}$ below average from the date line to the west coast of South America, with regional departures more than $-1.0^{\circ} \mathrm{C}$ across the east-central and eastern equatorial Pacific (Fig. 4.2b).

Similar SST and anomaly patterns were observed during March-May (MAM), but with overall smaller negative anomalies (Figs. $4.2 \mathrm{c}, \mathrm{d}$ ). Along the equator, MAM anomalies were generally $-0.5^{\circ} \mathrm{C}$ to $-1.0^{\circ} \mathrm{C}$ across the east-central equatorial Pacific, and near zero at the date line. However, SSTs remained more than $2^{\circ} \mathrm{C}$ below average along the west coast of South America.

Equatorial Pacific SST anomalies increased following La Niña's demise in April (Figs. 4.2e-h). During SON, SSTs were more than $+0.5^{\circ} \mathrm{C}$ above average across the central and eastern equatorial Pacific, with departures exceeding $+1^{\circ} \mathrm{C}$ in portions of the eastcentral Pacific and near the date line (Figs. $4.2 \mathrm{~g}, \mathrm{~h}$ ). These conditions reflected a weaker and less extensive equatorial cold tongue, with the $25^{\circ} \mathrm{C}$ isotherm extending westward to only $120^{\circ} \mathrm{W}$ and the $28^{\circ} \mathrm{C}$

(b) DF 2017nts

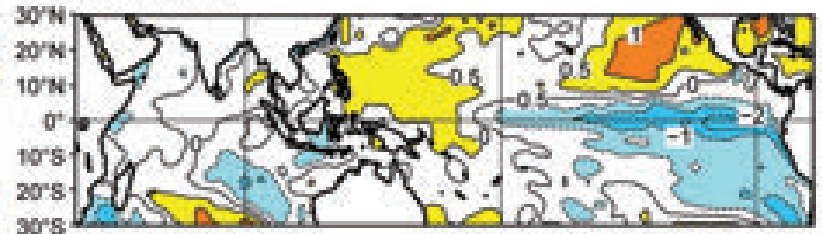

(d) MAM 2018

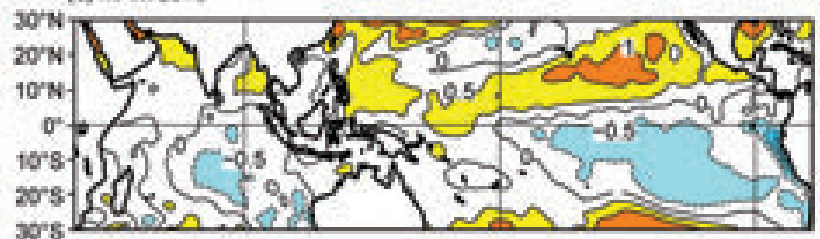

(f) $J$ A 2018

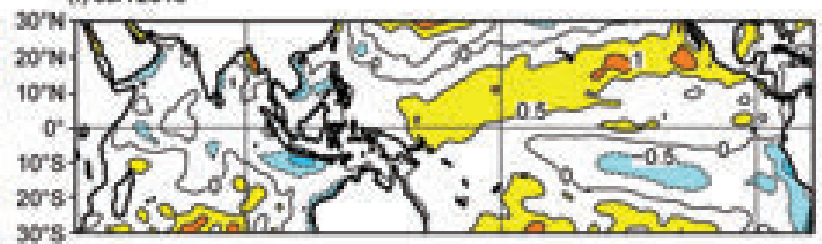

(0) SON 2018

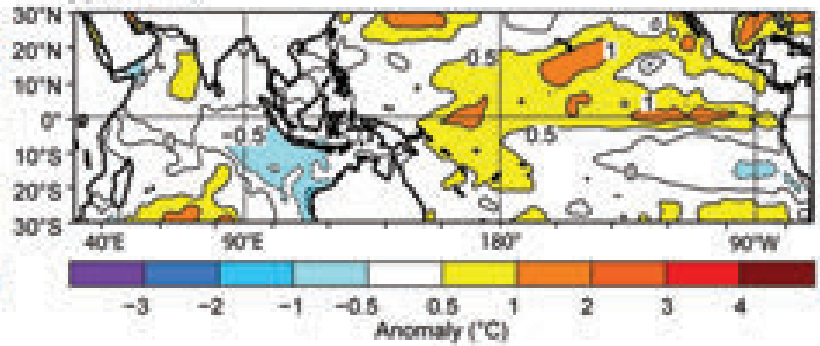

FIG. 4.2. Seasonal SST (left) and anomaly (right) for (a),(b) DJF 20I7/I8; (c),(d) MAM 20I8; (e),(f) JJA 20I8; and (g),(h) SON 2018. Contour interval for total SST is $1^{\circ} \mathrm{C}$. For anomalous SST, the contour interval is $0.5^{\circ} \mathrm{C}$ for anomalies between $\pm I^{\circ} \mathrm{C}$, and $I^{\circ} \mathrm{C}$ for anomalies $> \pm I^{\circ} \mathrm{C}$. Anomalies are departures from the I98I-20I0 seasonal adjusted Ol climatology (Reynolds et al. 2002). 

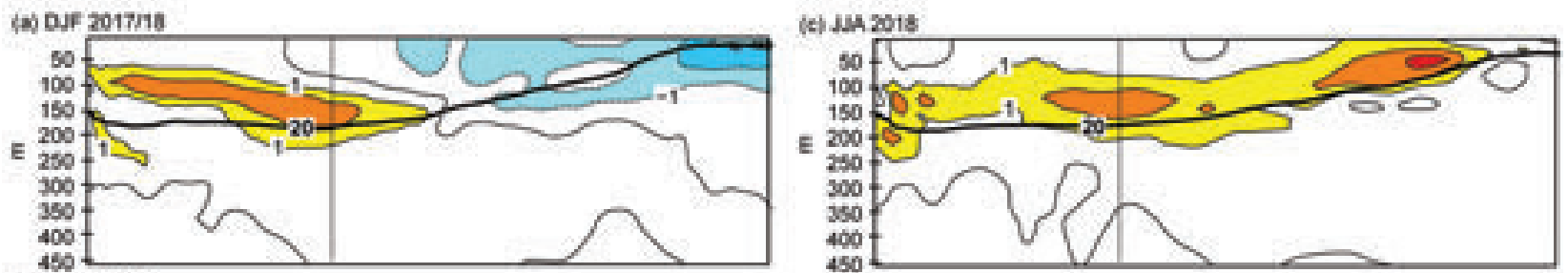

(b) MaM 2018

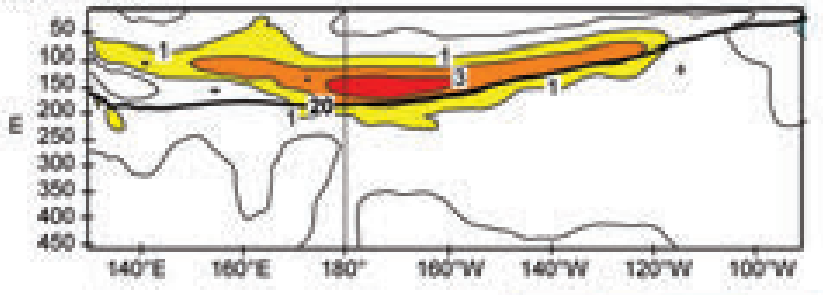

(d) SCN 2018
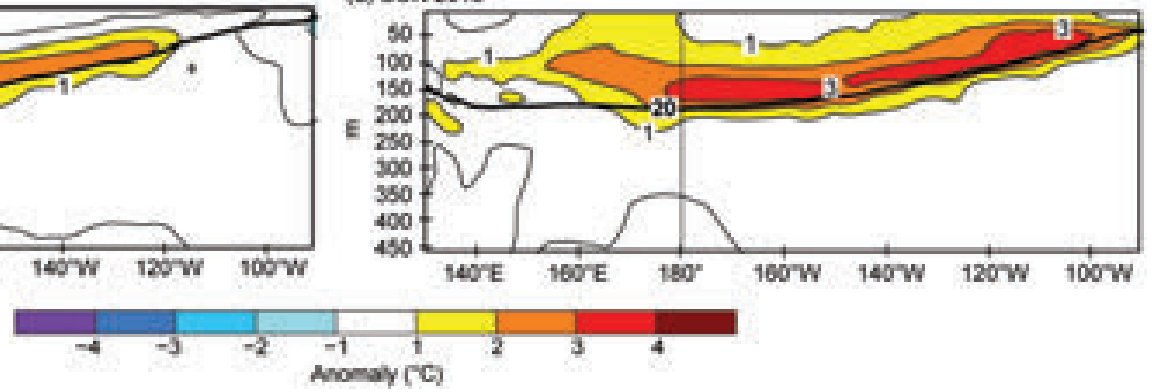

Fig. 4.3. Equatorial depth-longitude section of Pacific Ocean temperature anomalies $\left({ }^{\circ} \mathrm{C}\right)$ averaged between $5^{\circ} \mathrm{N}$ and $5^{\circ} \mathrm{S}$ during (a) DJF 2017/18, (b) MAM 2018, (c) JJA 2018, and (d) SON 2018. The $20^{\circ} \mathrm{C}$ isotherm (thick solid line) approximates the center of the oceanic thermocline. The data are derived from an analysis system that assimilates ocean observations into an ocean general circulation model (Behringer et al. 1998). Anomalies are departures from the 198I-2010 monthly means.

isotherm limited to well east of the date line (Fig. 4.2g). Accompanying these conditions, the western Pacific warm pool expanded eastward, and the area of SSTs greater than $30^{\circ} \mathrm{C}$ shifted eastward and extended to east of the date line in both hemispheres. These are all typical precursors for El Niño, which officially developed in January 2019.

Consistent with the SST evolution, subsurface temperatures during DJF 2017/18 were below average across the eastern half of the equatorial Pacific Ocean (Fig. 4.3a). This cooling reflected the typical shoaling of the oceanic thermocline and enhanced upwelling that accompany La Niña.

During MAM 2018, subsurface temperatures rose to above average across the central and east-central Pacific as La Niña dissipated (Fig. 4.3b). The warm anomalies near the $20^{\circ} \mathrm{C}$ isotherm suggest a deepening of the thermocline. This subsurface warming pattern became more extensive later in the year as the thermocline deepened farther across the eastern half of the Pacific (Figs. 4.3c,d). The SON 2018 anomaly pattern is a typical precursor for El Niño.

\section{2) AtMospheric CIRCULATION}

Seasonal atmospheric anomalies during DJF 2017/18 and MAM 2018 reflected La Niña conditions (Figs. 4.4a,b and 4.5a,b). Tropical convection (as measured by OLR) was suppressed across the central and east-central equatorial Pacific during these two seasons (Figs. 4.4a,b, brown shading). The corresponding low-level $(850-\mathrm{hPa})$ tropical wind anomalies were easterly in both seasons, indicating

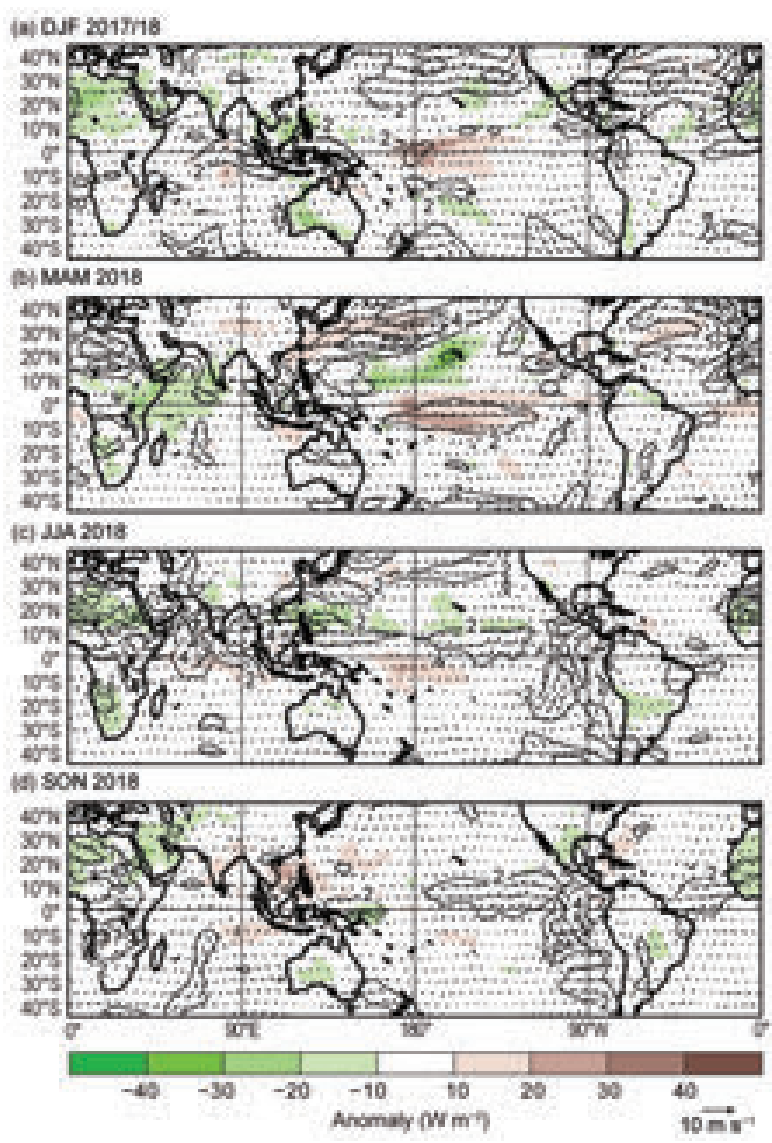

Fig. 4.4. Anomalous $850-\mathrm{hPa}$ wind vectors and speed (contour interval is $2 \mathrm{~m} \mathrm{~s}^{-1}$ ), and anomalous OLR (shaded, $\mathrm{W} \mathrm{m}^{-2}$ ), during (a) DJF 2017/18, (b) MAM 2018, (c) JJA 2018, and (d) SON 2018. Anomalies are departures from the 198I-2010 monthly means. Wind data are from the NCEP-NCAR reanalysis (Kalnay et al. 1996) and OLR are from AVHRR (Liebmann and Smith 1996). 


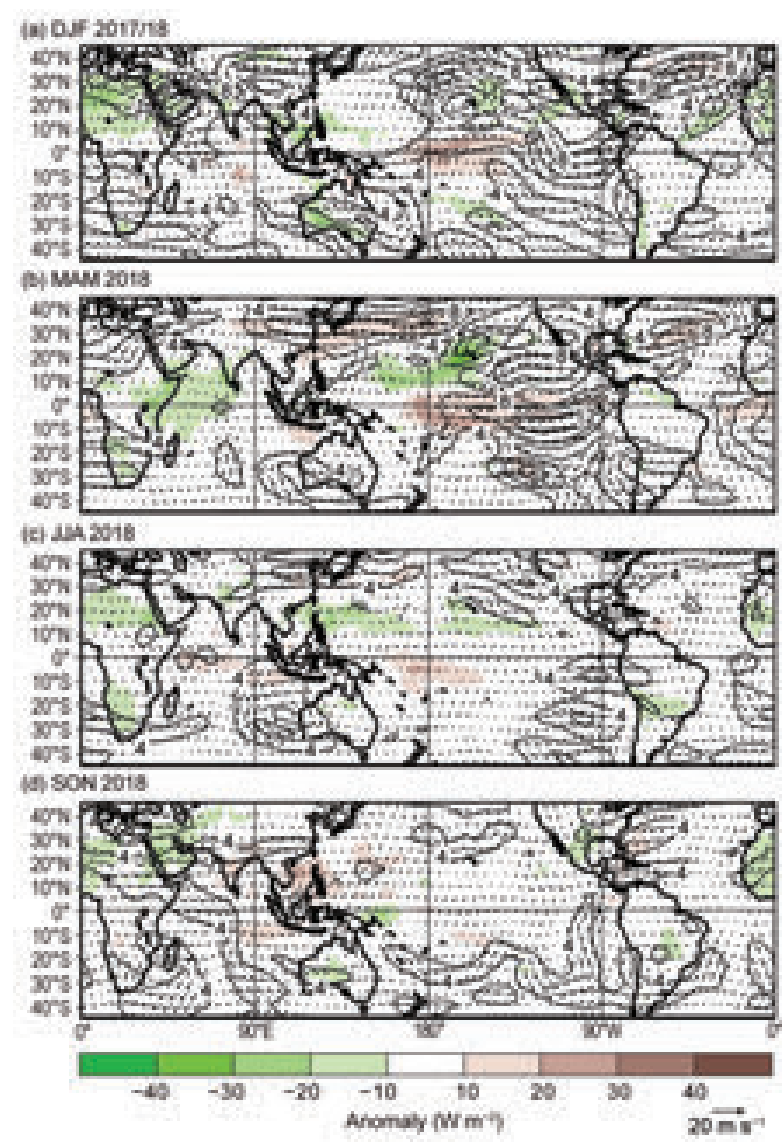

Fig. 4.5. Anomalous 200-hPa wind vectors and speed (contour interval: $4 \mathrm{~m} \mathrm{~s}^{-1}$ ), and anomalous OLR (shaded, $\mathrm{W} \mathrm{m}^{-2}$ ), during (a) DJF 20I7/I8, (b) MAM 20I8, (c) JJA 2018, and (d) SON 2018. Anomalies are departures from 1981-2010 means. Wind data are from the NCEP-NCAR reanalysis (Kalnay et al. 1996) and OLR are from AVHRR (Liebmann and Smith 1996)

strengthened trade winds (Figs. 4.4a,b), while at 200 $\mathrm{hPa}$, anomalous upper-level westerly winds extended across the eastern half of the equatorial Pacific (Figs. $4.5 \mathrm{a}, \mathrm{b})$. These conditions reflected an enhanced $\mathrm{Pa}$ cific Walker circulation (Bjerknes 1969) and a reduced strength of the tropical Hadley circulation over the central Pacific.

Also typical of La Niña, the upper-level wind anomalies indicated a strong cyclonic rotation over the central subtropical North Pacific during DJF (Fig. 4.5a) and across the east-central subtropical Pacific in both hemispheres during MAM (Fig. 4.5b). These anomalies indicate enhanced mid-Pacific troughs in response to the suppressed equatorial convection and reduced Hadley circulation.

In the NH during DJF, another aspect of the enhanced Pacific trough was strong easterly anomalies (indicating a weaker jet stream) over the extratropical central North Pacific between $20^{\circ}-40^{\circ} \mathrm{N}$. This wind pattern reflected a retraction toward the western $\mathrm{Pa}$ - cific of the wintertime East Asian jet stream and its associated jet exit region. This anomalous jet stream represents a fundamental component of the tropical-extratropical teleconnection pattern seen during La Niña. The 500-hPa height anomalies (Online Figs. S4.1-S4.4) highlight that teleconnection pattern, which also includes anomalous ridges over the high latitudes of the central North Pacific and the southern United States, and an anomalous trough over western Canada.

Later in the year, low-level wind anomalies (Figs. 4.4c,d) were opposite to those during DJF 2017/18 and MAM. During both June-August (JJA) and SON, low-level westerly anomalies were present across the central and east-central tropical Pacific north of the equator, in association with overall weaker trade winds (Figs. 4.4c,d). This wind pattern contributed to anomalous oceanic downwelling and to a progressive deepening of the oceanic thermocline (Figs. $4.3 \mathrm{c}, \mathrm{d}$ ), both of which contributed to the increase in the ONI. Despite these conditions, tropical convection was near average east of the date line, and the upper-level wind anomalies were generally near average (Figs. $4.5 c, d)$.

\section{3) LA NIÑA IMPACTS}

Typical La Niña-related surface temperature (Halpert and Ropelewski 1992) and precipitation (Ropelewski and Halpert 1989) anomalies were evident during DJF 2017/18 and MAM 2018 in many areas of the globe. Over the eastern half of the equatorial Pacific rainfall was well below average, with many areas recording totals in the lowest 10 th percentile during DJF 2017/18 and in the lowest 30th percentile during MAM (see Online Figs. S4.5-S4.8).

In contrast, rainfall during DJF was well above average across northern Indonesia, with totals above the 90th percentile. In southern Africa, the monsoon rains were also above average across most of the region during both DJF and MAM, with DJF totals in the east exceeding the 90th percentile.

In North America, typical wintertime La Niña impacts included below-average surface temperatures in southwestern Canada and the northwestern United States, and above-average temperatures across the southern and southeastern United States. Also consistent with typical La Niña impacts, precipitation was above average in the northwestern United States, with many areas recording totals in the upper 90th percentile. In contrast, precipitation was below average across the southeastern United States and Gulf of Mexico, with totals in the Gulf of Mexico and southern Florida being in the lowest 10th percentile. 
C. Tropical intraseasonal activity-S. Baxter, C. Schreck, and G. D. Bell

Tropical intraseasonal variability was especially prominent during 2018. Two leading aspects of this variability were the Madden-Julian Oscillation (MJO) (Madden and Julian 1971, 1972, 1994; Zhang 2005) and convectively coupled equatorial waves (Wheeler and Kiladis 1999; Kiladis et al. 2009), which include equatorial Rossby waves and atmospheric Kelvin waves. There were two prolonged periods of MJO activity in 2018 spanning a total of nearly 10 months (Fig. 4.6) that were interspersed with the convectively coupled waves (Fig. 4.7). Between the two MJO periods, the tropical convective anomalies were dominated by lower-frequency variability and convectively coupled waves.

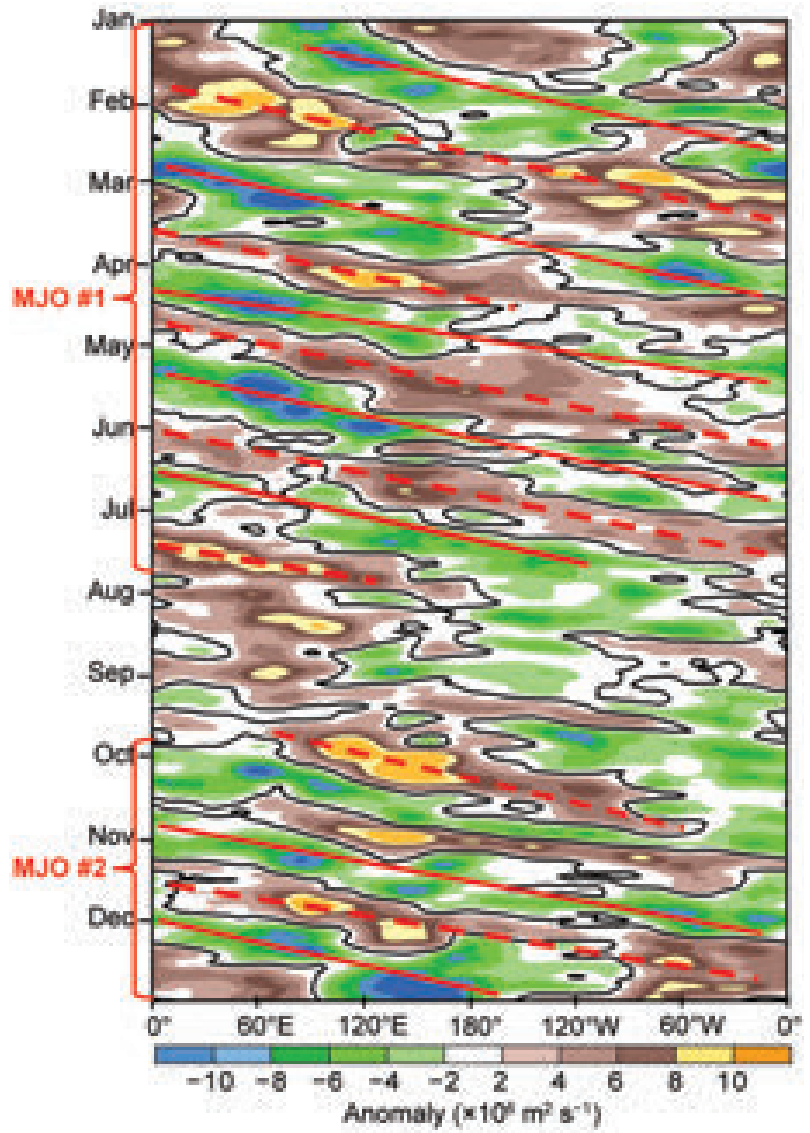

FIG. 4.6. Time-longitude section for 2018 of 5-day running anomalous $200-\mathrm{hPa}$ velocity potential $\left(\times 10^{6} \mathrm{~m}^{2} \mathrm{~s}^{-1}\right)$ averaged between $5^{\circ} \mathrm{N}-5^{\circ} \mathrm{S}$, from NCEPNCAR reanalysis (Kalnay et al. 1996). For each day, the period mean is removed prior to plotting. Green (brown) shading highlights likely areas of anomalous divergence and rising motion (convergence and sinking motion). Red lines and labels highlight the periods when the MJO was most active; solid (dashed) lines indicate the MJO enhanced (suppressed) phase. Anomalies are departures from 198I-2010 means.
The MJO is a leading intraseasonal climate mode of tropical convective variability. Its convective anomalies often have a similar spatial scale to ENSO, but differ in that they exhibit a distinct eastward propagation and generally traverse the globe in 30-60 days. The MJO affects weather patterns around the globe, including monsoons, Tropical Cyclones, and extratropical circulations (Zhang 2013). The MJO is often episodic, with periods of moderate-to-strong activity sometimes followed by little or no activity. The MJO tends to be most active during ENSOneutral and weak ENSO periods and is often absent during strong El Niño events (Hendon et al. 1999; Zhang and Gottschalck 2002; Zhang 2005), though the strong El Niño winter of 2015/16 exhibited unusually strong MJO activity (Baxter et al. 2017).

No single measure exists for identifying the MJO, but common metrics include time-longitude plots of anomalous 200 -hPa velocity potential (Fig. 4.6) and

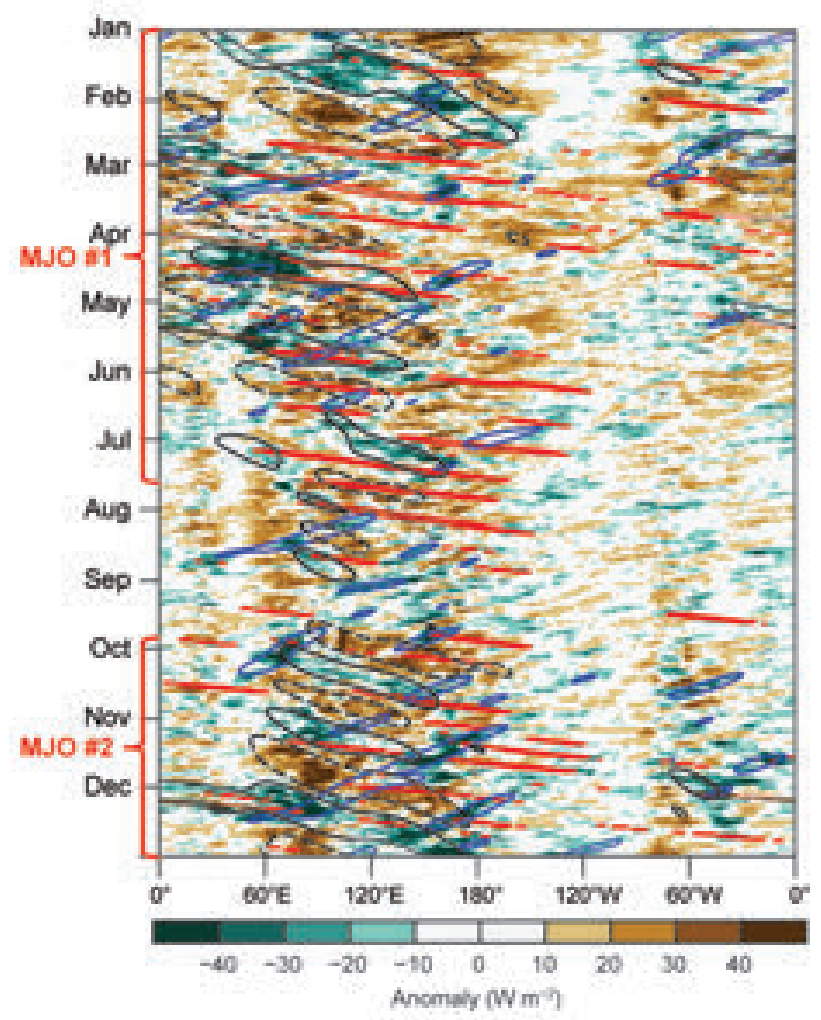

FIG. 4.7. Time-longitude section for 2018 of anomalous OLR (W m ${ }^{-2}$; Schreck et al. 2018) averaged for $10^{\circ} \mathrm{N}-10^{\circ} \mathrm{S}$. Negative anomalies indicate enhanced convection and positive anomalies indicate suppressed convection. Contours identify anomalies filtered for the MJO (black), atmospheric Kelvin waves (red), and equatorial Rossby waves (blue). Red labels highlight the main MJO episodes. Contours are drawn at $\pm 10 \mathrm{~W} \mathrm{~m}^{-2}$, with the enhanced (suppressed) convective phase of these phenomena indicated by solid (dashed) contours. Anomalies are departures from 1981-2010 means. 
(a) Jan-Mar 2018

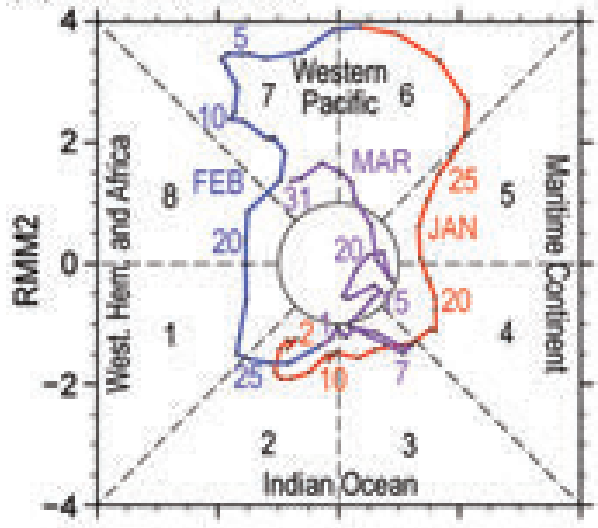

(c) Jul-Sep 2018

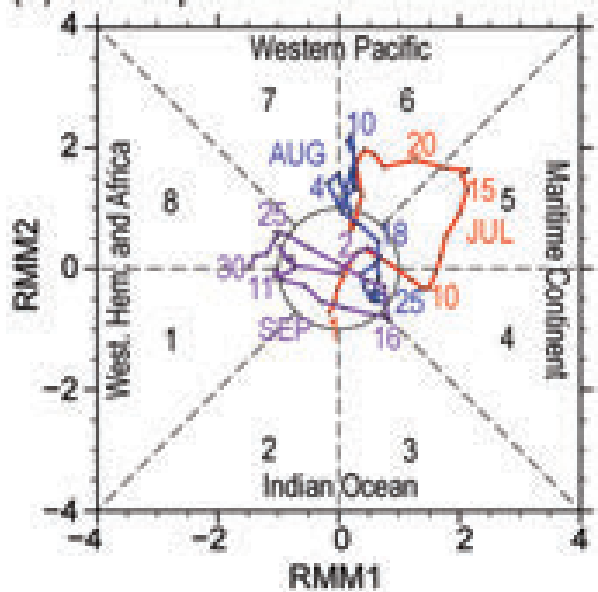

(b) Apr-Jun 2018

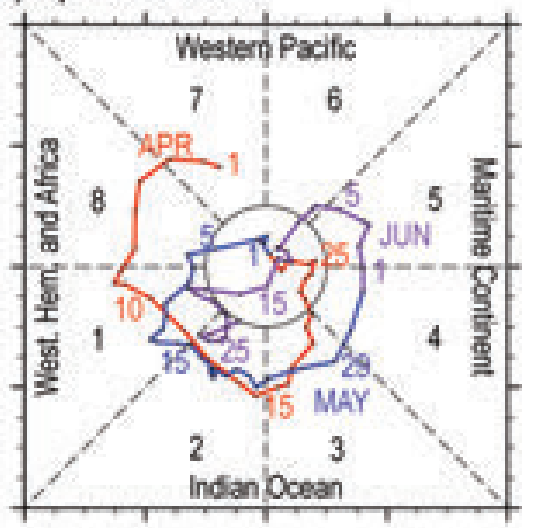

(d) Oct-Dec 2018

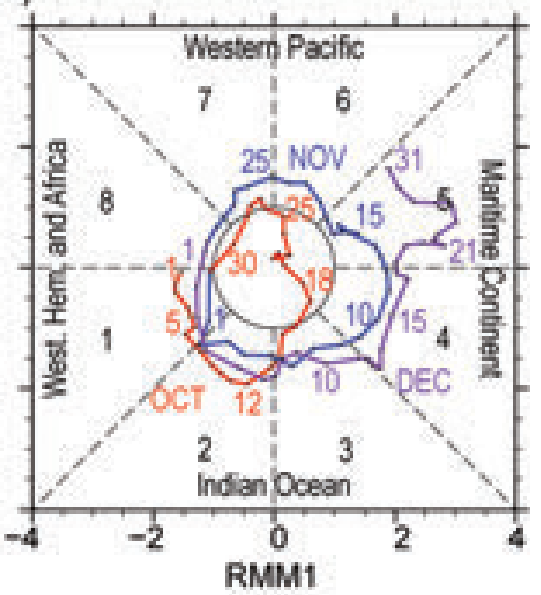

FIG. 4.8. Wheeler-Hendon (2004) RMM MJO index during 2018 for (a) Jan-Mar, (b) Apr-Jun, (c) Jul-Sep, and (d) Oct-Dec. Each point represents the MJO amplitude and location on a given day, and the connecting lines illustrate its propagation. Amplitude is indicated by distance from the origin, with points inside the circle representing weak or no MJO. The eight phases around the origin identify the region experiencing enhanced convection, and counterclockwise movement reflects eastward propagation.

OLR (Fig. 4.7), as well as the Wheeler-Hendon (2004) Real-time Multivariate MJO (RMM) index (Fig. 4.8). In the time-longitude plots, the MJO exhibits eastward propagation from upper-left to lower-right. In the RMM, the MJO propagation and intensity are seen as large, counterclockwise circles around the origin. When considered together, these diagnostics point to two prolonged MJO episodes during 2018. MJO \#1 was a strong, long-lasting episode that continued from October 2017 (Baxter et al. 2018) into July 2018. MJO \#2 began in late September and persisted through the end of the year. Both MJO periods were associated with either westerly wind bursts or trade wind surges over the central Pacific (Fig. 4.9a).

MJO \#1 featured a zonal wave-1 pattern of strong convective anomalies. Its periodicity was approximately 50 days during January-March, with a faster period of about 35 days associated with a more rapid eastward propagation during April-May (Figs. 4.6, 4.8a). The plot of anomalous velocity potential (Fig. 4.6) shows that $\mathrm{MJO} \# 1$ circumnavigated the globe about four times during January-July. The RMM index indicates the event was strongest in January and February (Fig. 4.8a). By the end of July, eastward propagation gave way to a more stationary pattern with upper-level divergence centered over the Pacific Ocean and convergence over the Indian Ocean.

Impacts from MJO \#1 included alternating periods of westerly and easterly zonal wind anomalies over the western Pacific (Fig. 4.9a). A significant easterly wind event occurred in January, called a trade wind surge (labeled TWS; dotted line, Fig. 4.9b). This TWS triggered an upwelling equatorial oceanic Kelvin wave in early February, which is indicated by an eastward propagating local minimum in anomalous heat content during FebruaryMarch across the central and eastern equatorial Pacific.

This wave reached the west coast of South America in mid-March. Another TWS associated with MJO \#1 occurred in May, and it also triggered an upwelling wave during June-August as seen as a local minimum in heat content (dotted line, Fig. 4.9b).

MJO \#1 also produced two significant westerly wind bursts (WWBs) over the western and central Pacific, one during early February and one in late March. These WWBs triggered downwelling equatorial oceanic Kelvin waves during February and late April, respectively (dashed lines, Fig. 4.9b). These waves are indicated by eastward propagating local maxima in anomalous heat content during February-March and May-June, respectively. The second wave reached the west coast of South America in June 2018. While most of the intraseasonal upwelling and downwelling Kelvin waves were largely associated with the MJO, a downwelling oceanic Kelvin wave 

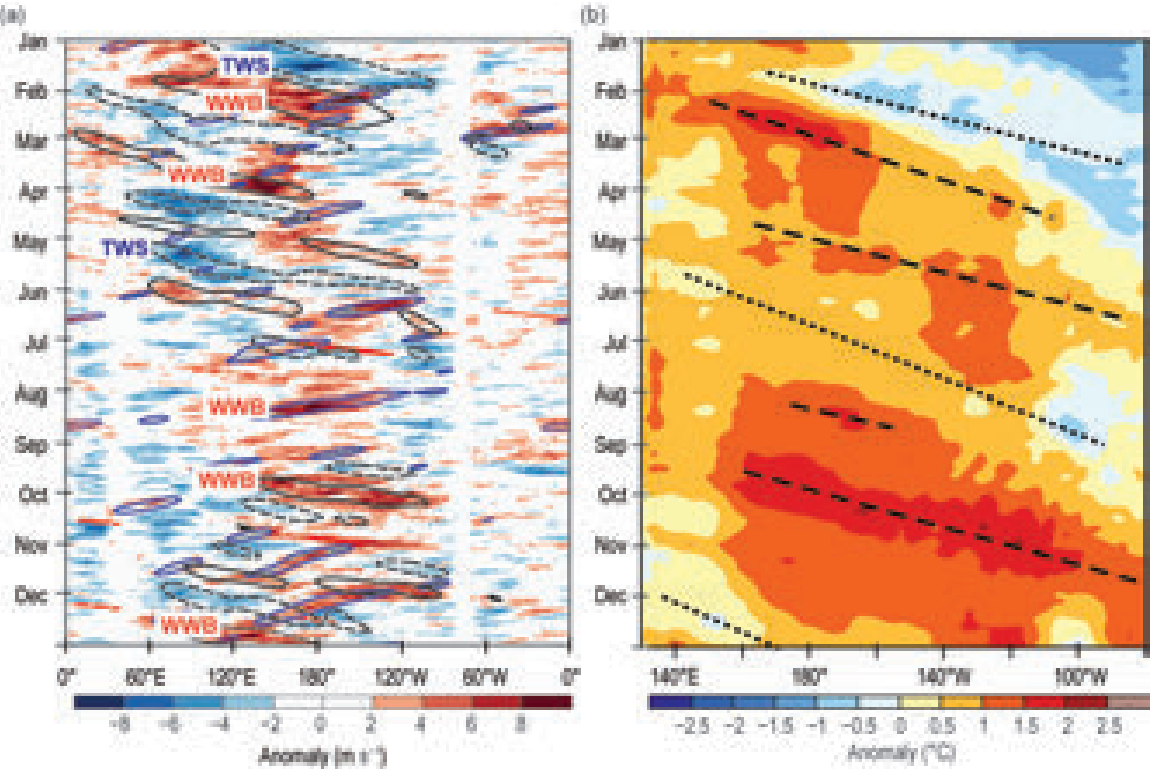

FIG. 4.9. (a) Time-longitude section for 2018 of anomalous $850-\mathrm{hPa}$ zonal wind $\left(\mathrm{m} \mathrm{s}^{-1}\right)$ averaged for $10^{\circ} \mathrm{N}-10^{\circ} \mathrm{S}$ from CFSR (Saha et al. 2010). Contours identify anomalies filtered for the MJO (black), atmospheric Kelvin waves (red), and equatorial Rossby waves (blue), each contoured at $\pm 2 \mathrm{~m} \mathrm{~s}^{-1}$ with negative anomalies dashed. Significant westerly wind bursts and trade wind surges (TWS) that occurred over the equatorial Pacific and resulted in notable downwelling and upwelling oceanic Kelvin waves are labeled. (b) Time-longitude section of the anomalous equatorial Pacific Ocean heat content for 2018, calculated as the mean temperature anomaly at 0-300 m depth. Yellow/red (blue) shading indicates above- (below-) average heat content. The relative warming (dashed lines) and cooling (dotted lines) due to downwelling and upwelling equatorial oceanic Kelvin waves are indicated. The data are derived from an analysis system that assimilates oceanic observations into an oceanic general circulation model (Behringer et al. 1998). Anomalies are departures from 198I-2010 base period pentad means.

during August was associated with a WWB event caused by an equatorial atmospheric Rossby wave (blue contour, Fig. 4.9a).

MJO \#2 occurred during late September-December. Its periodicity was about 30 days during October-November, and increased to about 45 days by December. The RMM index showed the most canonical counterclockwise propagation during the October-December period (Fig. 4.8d), with an amplitude that generally increased with time. MJO \#2 was associated with two WWB events over the western and central Pacific-the first in late September and the second in late December. The associated downwelling oceanic Kelvin wave produced substantial warming of the upper ocean and was part of the gradual evolution toward weak El Niño conditions. This MJO event may also have played an important role in the extratropical circulation over the North Pacific and North America during late autumn and early winter 2018/19, supporting the relatively cold pattern over the contiguous United States east of the
Rockies during late November and early December. After the enhanced MJO phase propagated across the Indian Ocean, the pattern flipped to one favoring milder-than-normal conditions during mid-to-late December over much of North America.

\section{d. Intertropical convergence zones}

I) PACIFIC-A. B. Mullan

Tropical Pacific rainfall patterns are dominated by two convergence zones: the Intertropical Convergence Zone (ITCZ, Schneider et al. 2014) north of the equator, and the South Pacific Convergence Zone (SPCZ, Vincent 1994). Figure 4.10 summarizes the convergence zone behavior for 2018 using rainfall patterns estimated from CMORPH, a data product that uses a combination of satellite microwave and infrared data (Joyce et al. 2004). Rainfall transects from $20^{\circ} \mathrm{N}$ to $30^{\circ} \mathrm{S}$ are presented for each quarter of the year, averaged across successive $30^{\circ}$ longitude bands, starting in the western Pacific at $150^{\circ}-180^{\circ} \mathrm{E}$, comparing 2018 seasonal values against the longer-term 1998-2017 climatology.

The year began with a relatively short-lived, weak La Niña present in the Pacific. Nonetheless, the northward displacement of the ITCZ was noticeable (Fig. 4.10a). The Marshall Islands and Micronesia, on the northern boundary of the ITCZ, experienced generally wetter conditions than normal through January-March, a pattern that continued into April-June. For example, Kwajalein $\left(9^{\circ} \mathrm{N}, 168^{\circ} \mathrm{E}\right)$ in the Marshall Islands received over three times its normal rainfall in January and March, setting new records in the region (see Section $7 \mathrm{~h} 2$ and Table 7.3 for details).

The SPCZ extends diagonally from around the Solomon Islands $\left(10^{\circ} \mathrm{S}, 160^{\circ} \mathrm{E}\right)$ to near $30^{\circ} \mathrm{S}, 140^{\circ} \mathrm{W}$, and is typically most active from November to April. In early 2018, the SPCZ was especially vigorous in February, spawning the only Category 5 TC of 


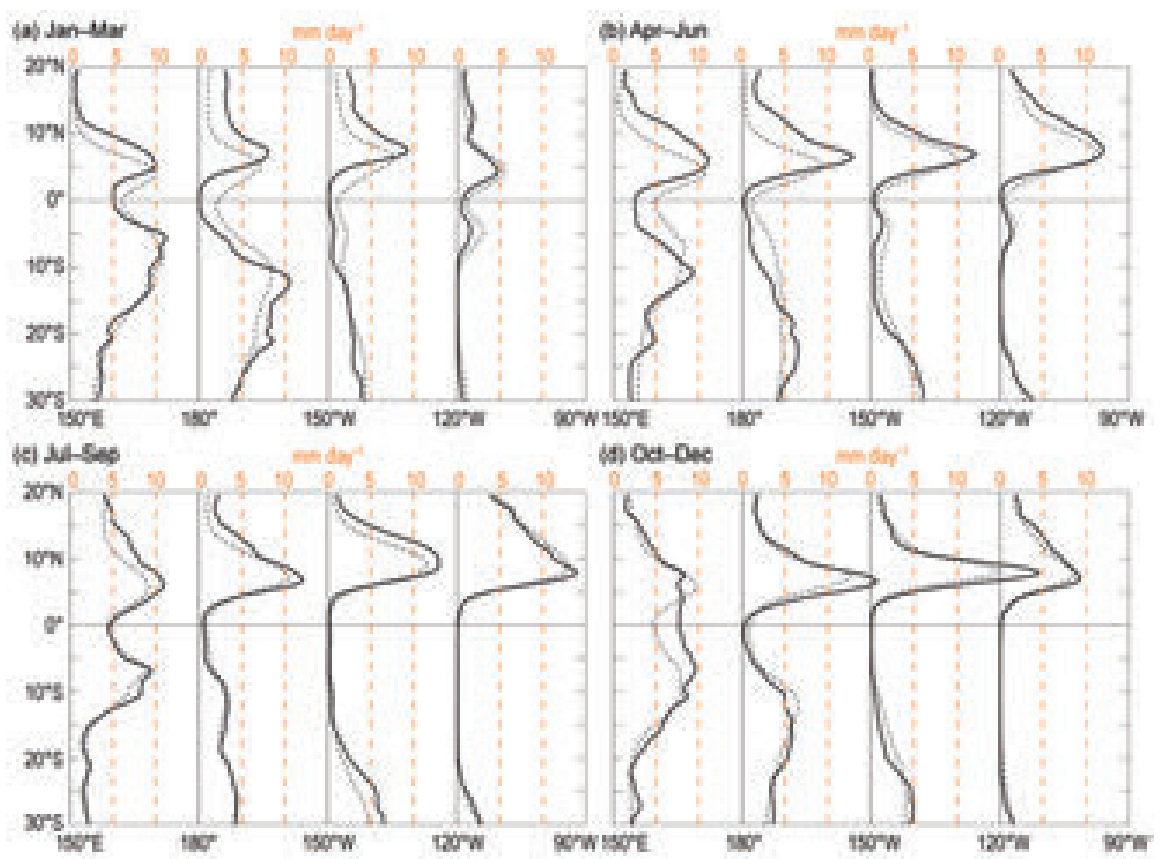

FIG. 4.I0. Rainfall rate ( $\mathrm{mm}$ day $\left.^{-1}\right)$ from CMORPH analysis for (a) Jan-Mar, (b) Apr-Jun, (c) Jul-Sep, and (d) Oct-Dec. The separate panels for 3-month period show the 2018 rainfall cross section between $20^{\circ} \mathrm{N}$ and $30^{\circ} \mathrm{S}$ (solid line) and the 1998-2017 climatology (dotted line), separately for four $30^{\circ}$ sectors from $150^{\circ} \mathrm{E}-180^{\circ}$ to $120^{\circ}-90^{\circ} \mathrm{W}$.

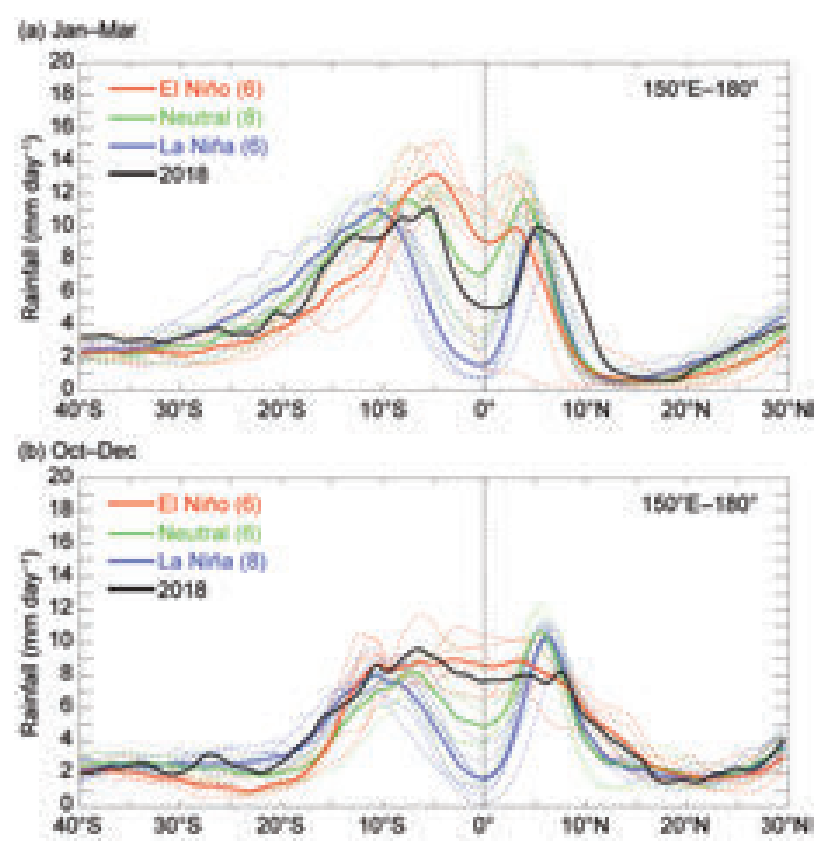

FIG. 4.II. CMORPH rainfall rate $\left(\mathrm{mm} \mathrm{day}^{-1}\right)$ for (a) Jan-Mar and (b) Oct-Dec, for each year from 1998 to 2018 , averaged over the longitude sector $150^{\circ} \mathrm{W}$ $180 \mathrm{~W}^{\circ}$. The cross sections are color-coded according to NOAA's Oceanic Niño Index, except for 2018, shown in black. Dotted lines are individual years; solid lines are the average over all years in each ENSO phase. The inset legend indicates how many years went into each composite. the year (Cyclone Gita) in the southwest Pacific. Pago Pago (American Samoa, near $\left.14^{\circ} \mathrm{S}, 170^{\circ} \mathrm{W}\right)$ experienced heavy flooding in the two days prior to Cyclone Gita's passage on 9 February, contributing to February 2018 being the second wettest of any month on record in American Samoa.

Figure 4.11a shows a more detailed comparison of the western Pacific CMORPH rainfall transect in 2018 relative to all other years in the satellite dataset. In the North Pacific $150^{\circ} \mathrm{E}-180^{\circ}$ sector, the ITCZ aligns closely with the average position of past La Niña events since 1998. However, within a few degrees of the equator, the 2018 rainfall was much higher, and the SPCZ was likewise much closer to the equator than usually found during La Niña periods.

The tropical Pacific returned to ENSO-neutral conditions during April (Section 4b). However, some La Niña characteristics persisted. A double ITCZ was present in March and April, with the southern branch between $150^{\circ} \mathrm{W}$ and $90^{\circ} \mathrm{W}$ particularly prominent in April. This is evident in Figs. 4.10a,b in the $120^{\circ}-90^{\circ} \mathrm{W}$ sector. The SH branch of a double ITCZ is typically seen only in La Niña years (Masunaga and L'Ecuyer 2010). Figure 4.10b shows other significant rainfall anomalies persisted to the west of the date line. The ITCZ was displaced north of its usual position, and the western North Pacific remained convectively active during April-June 2018.

Conversely, rainfall was below normal around $5^{\circ} \mathrm{N}-15^{\circ} \mathrm{S}$ during April-June. The SPCZ was weak and a number of island groups in the southwest Pacific experienced well-below-normal rainfall including $\mathrm{New}$ Caledonia, Nauru, Tuvalu, Tokelau, northern Cook Islands, Marquesas, and Tuamotu Archipelago (see Section $7 \mathrm{~h} 3$ ).

Figure $4.11 \mathrm{~b}$ compares the western Pacific rainfall transect of 2018 with all previous years in the CMORPH archive for October-December 2018 for the $150^{\circ}-180^{\circ} \mathrm{E}$ sector. The 2018 transect lies close to the average position of past El Niño events since 1998, even though El Niño conditions had not yet fully developed. 
In particular, rainfall was much higher on the equator than is typically found in ENSO-neutral seasons.

\section{2) Atlantic-A. B. Pezza and C. A. S. Coelho}

The Atlantic ITCZ is a well-organized convective band that oscillates approximately between $5^{\circ}-12^{\circ} \mathrm{N}$ during July-November and $5^{\circ} \mathrm{N}-5^{\circ} \mathrm{S}$ during JanuaryMay (Waliser and Gautier 1993; Nobre and Shukla 1996). Equatorial atmospheric Kelvin waves can modulate ITCZ intraseasonal variability (Guo et al. 2014). ENSO and the southern annular mode (SAM) can also influence the ITCZ on interannual time scales (Münnich and Neelin 2005). The SAM is typically positive

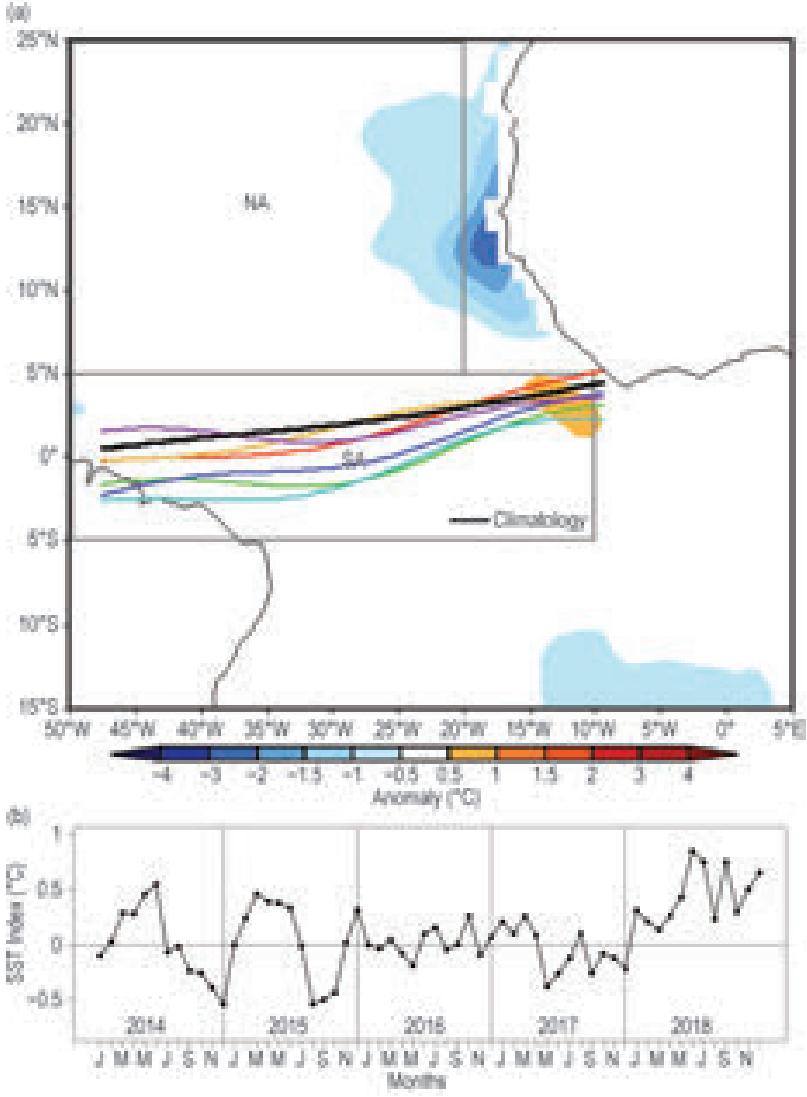

FIG. 4.I2. (a) Atlantic ITCZ position inferred from OLR (Liebmann and Smith 1996) during Feb 2018. Colored thin lines indicate approximate positions for the six pentads of the month. Black thick line indicates Atlantic ITCZ climatological position for Feb. SST anomalies $\left({ }^{\circ} \mathrm{C}\right)$ for Feb 2018 based on the 1982-2017 climatology are shaded. The two boxes indicate the areas used for the calculation of the Atlantic index in (b), which shows monthly OISST (Smith et al. 2008) anomaly time series averaged over the South Atlantic sector (SA region, $5^{\circ} \mathrm{N}-5^{\circ} \mathrm{S}, 10^{\circ}-50^{\circ} \mathrm{W}$ ) minus the SST anomaly time series averaged over the North Atlantic sector (NA region, $5^{\circ}-25^{\circ} \mathrm{N}, 20^{\circ}-50^{\circ} \mathrm{W}$ ) for $2014-18$, forming the Atlantic index. Positive phase of the index indicates favorable conditions for enhanced Atlantic ITCZ activity. during La Niña events, and it was generally so from April 2017 to February 2018 when the equatorial Pacific briefly achieved a weak La Niña state. This condition facilitated occasional bursts of the Atlantic ITCZ to the south of its climatological position such as occurred in February (Fig. 4.12a). Positive rainfall anomalies occurred in northeastern Brazil and in the South Atlantic during February, November (predominantly near the equator line and migrating south), and December 2018 (Figs. 4.13a,b) - in sharp contrast to negative anomalies observed in January 2018.
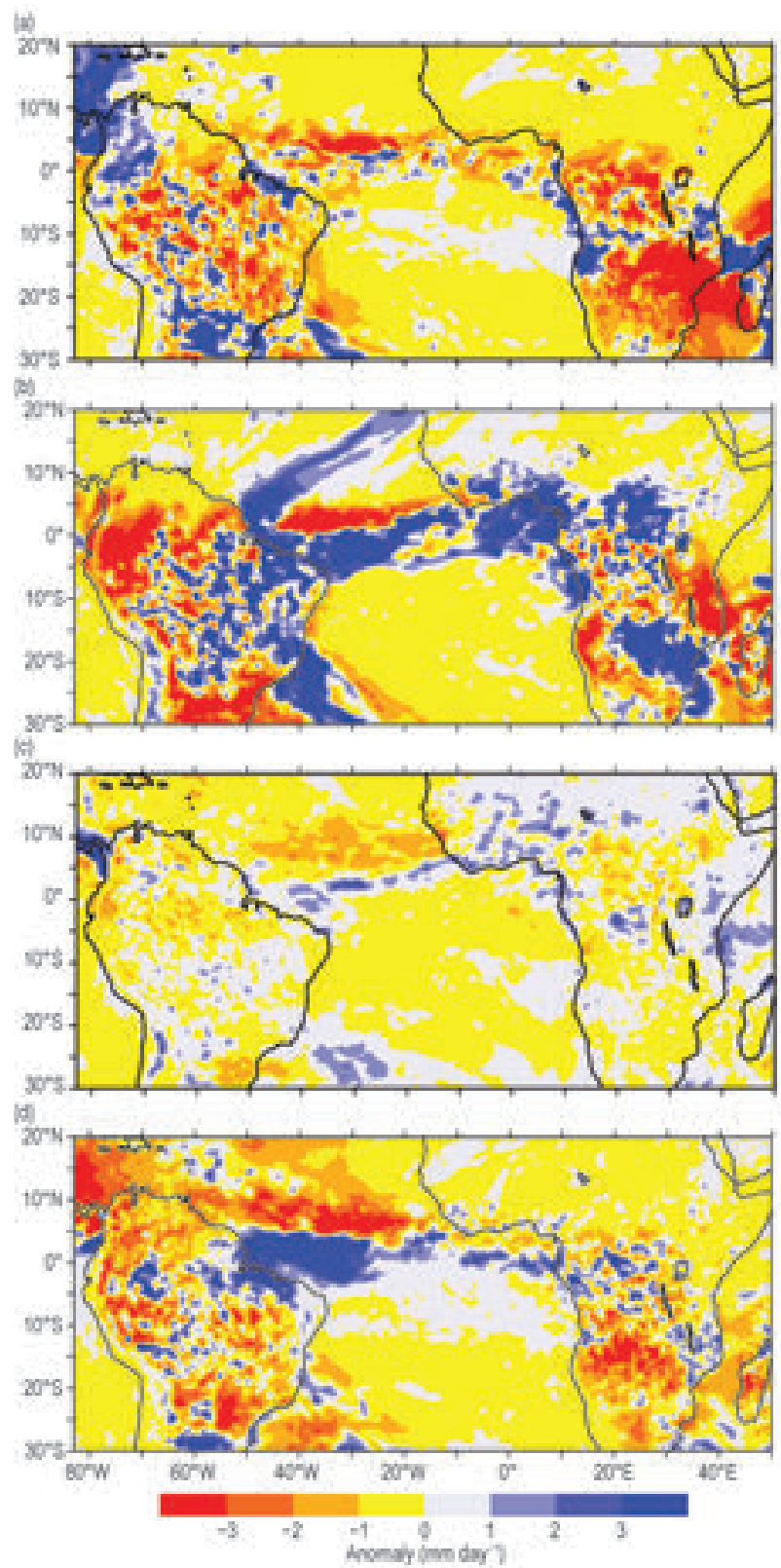

FIG. 4.I3. Observed 2018 precipitation anomaly $\left(\mathrm{mm} \mathrm{day}^{-1}\right)$ for tropical and subtropical South America during (a) Jan, (b) Feb, (c) Mar-Oct, and (d) NovDec. Anomalies calculated based on the 1998-2017 climatology derived from CMORPH (Joyce et al. 2004). 
The Atlantic Index (Pezza and Coelho 2018), as defined in Fig. 4.12, is given by the SST south of the equator minus the SST north of the equator over key areas of influence for the ITCZ. The ITCZ tends to shift toward the warmer side of this gradient. For most of 2018, a weaker subtropical South Atlantic anticyclone and a cooling of the Atlantic north of the equator compared with previous years facilitated an anomalous northerly flow. This setup contributed to higher (more positive) values of the Atlantic Index than those observed over the last five years (Fig. $4.12 \mathrm{~b}$ ), highlighting a more favorable (but not sufficient) condition for the establishment of convection south of the equator. Due to this dynamical forcing measured by the north-south SST gradient, most of the southern winter season, when the ITCZ normally migrates north, also had slightly enhanced convection south of the equator (Fig. 4.13c).

\section{e. Global monsoon summary-B. Wang and Q. He}

The global monsoon is the dominant mode of annual tropical-subtropical precipitation and circulation variability and thus a critical part of Earth's climate system (Wang and Ding 2008). Figure 4.14 shows global precipitation anomalies, focusing on monsoon rainfall anomalies, for the monsoon seasons in the (a) SH (November 2017-April 2018) and (b) NH (May-October 2018), which constitute the global monsoon year of 2017/18. Figure 4.15 shows the time series of monsoon precipitation and lowlevel circulation indices (Yim et al. 2014) for each of eight regional monsoons. Note that the precipitation indices represent the total amount of precipitation over both land and ocean areas. The definitions of the circulation indices for each monsoon region are provided in Table 4.1. In most regions, the precipitation and circulation indices are highly correlated, with correlation coefficients ranging from $0.71-0.86$, except for the South American monsoon. The precipitation and circulation indices together provide consistent measurements of the strength of each regional monsoon system.

Global land monsoon precipitation is strongly influenced by tropical SST anomalies, especially ENSO (Wang et al. 2012). As shown in Fig. 4.14a, during the $\mathrm{SH}$ monsoon season, global precipitation exhibited a La Niña-like pattern with suppressed precipitation over the Pacific ITCZ and the southern Indian Ocean convergence zone. However, the precipitation over the Maritime Continent-Australian monsoon region was below normal, which was unusual for La Niña (Fig. 4.14a). The Australian summer monsoon region received significantly less precipitation than normal, but the strength of the corresponding circulation was above normal (Fig. 4.15h). The southern African summer monsoon precipitation was above normal, but the circulation intensity was normal (Fig. 4.15f). Meanwhile, the South American monsoon showed slightly-above-normal precipitation but normal circulation intensity (Fig. 4.15g). Overall, the SH summer monsoon showed some inconsistency between the regional precipitation and circulation indices, particularly in the Australian monsoon region. This was likely due to the impacts of the warm North Pacific SST anomalies (Fig. 4.2) that coupled with anomalously low pressure in the subtropical North Pacific (Vimont et al. 2001; Wang et al. 2013). The latter shifted the positive rainfall anomaly northward from the Maritime Continent and generated deficient Indonesian-Australian summer monsoon rainfall.

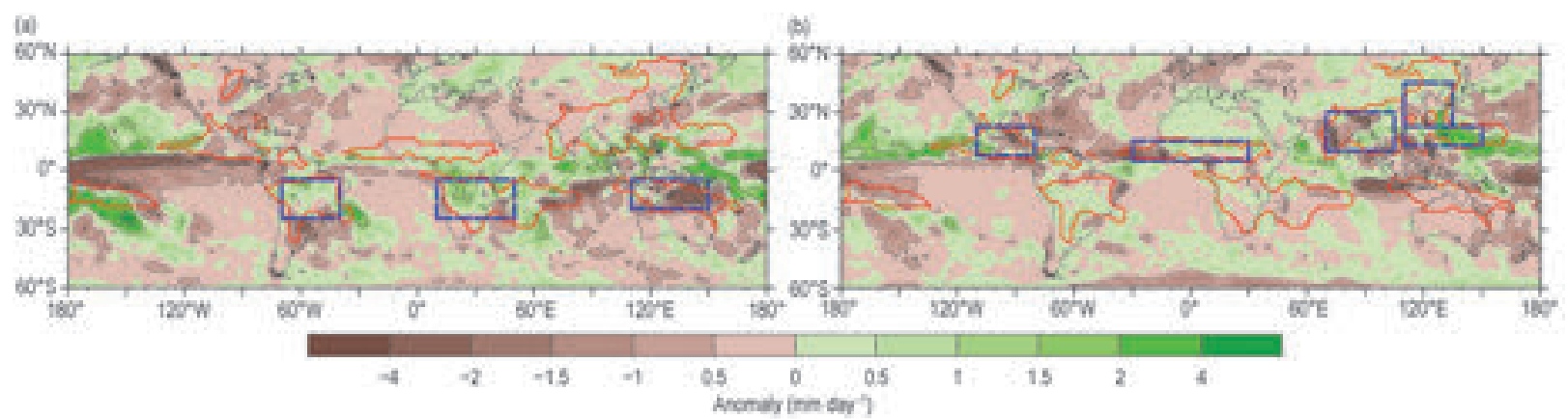

Fig. 4.14. Precipitation anomalies $\left(\mathrm{mm} \mathrm{day}^{-1}\right)$ averaged for (a) the SH monsoon season: Nov 2017-Apr 2018 and (b) the NH monsoon season: May-Oct 2018. Red lines outline the global monsoon precipitation domain defined by (a) the annual range (local monsoon season minus cool season) where precipitation exceeds 300 $\mathrm{mm}$ and (b) the monsoon season mean precipitation $>55 \%$ of the total annual precipitation amount (Wang and Ding 2008). Precipitation indices for each regional monsoon are defined by the areal mean precipitation in the corresponding rectangular regions (dashed blue), which are highly correlated with the precipitation averaged over the corresponding real regional monsoon domains (Table I in Yim et al. 2014). Rainfall data were taken from the Global Precipitation Climatology Project (GPCP; Huffman et al. 2009). 


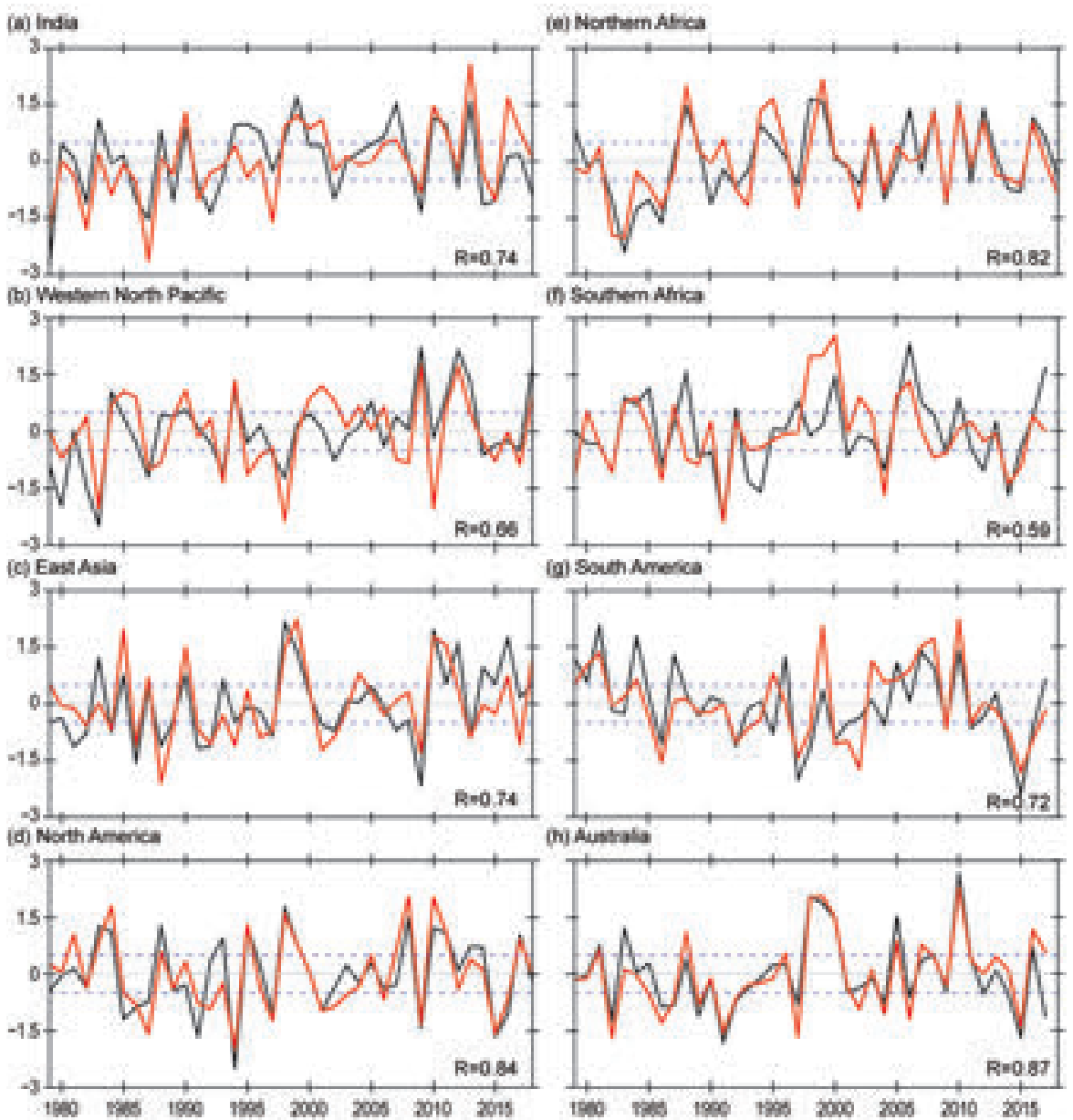

FIG. 4.I5. Normalized summer mean precipitation (black) and circulation (red) indices for each of eight regional monsoons (Table I in Yim et al. 2014). Indices are normalized by their corresponding std. dev. Numbers shown in the corner of each panel denote the correlation coefficient between the seasonal mean precipitation and circulation indices. Dashed lines indicate std. dev. of \pm 0.5 . The monsoon seasons are May-Oct for the NH and Nov-Apr for the SH. (Source: GPCP for precipitation; the normalization method is discussed in Yim et al. 2014.) f. Tropical cyclones

I) OVerview-H. J. Diamond and C. J. Schreck

The IBTrACS dataset comprises historical TC best-track data from numerous sources around the globe, including all of the WMO Regional Specialized Meteorological Centers (RSMCs; Knapp et al. 2010), and represents the most complete compilation of global TC data. From these data, Schreck et al. (2014) compiled climatological values of TC activity for each basin for 1981-2010 using data from both the WMO RSMCs and the Joint Typhoon Warning Center (JTWC). These values are referenced in each subsection.

The tallying of the global TC numbers is challenging and involves more than simply adding up basin totals, because some storms cross TC basin boundaries, some TC basins overlap, and multiple agencies are involved in tracking and categorizing TCs.
During the NH monsoon season, ENSO-neutral conditions were present (Section $4 \mathrm{~b}$ ). Tropical Pacific precipitation was dominated by a $\mathrm{NH}$-wet and a SH-dry pattern. Increased precipitation was seen across the Pacific ITCZ (Fig. 4.14b), corresponding to the anomalously low pressure in the subtropical North Pacific. On regional scales, the summer precipitation over India and the Maritime Continent was significantly below normal. The North African and North American summer monsoon rainfall was near-normal while rainfall over the western North Pacific and the East Asian monsoon was above normal (Fig. 4.15).
Compiling the activity using preliminary IBTrACS data over all seven TC basins from the National Hurricane Center and the JTWC (Fig. 4.16), the 2018 season (2017/18 in the SH) had 95 named storms (wind speeds $\geq 34 \mathrm{kt}$ or $17 \mathrm{~m} \mathrm{~s}^{-1}$ ), which is 10 more than last season (Diamond and Schreck 2018) and above the 1981-2010 average of 82 (Schreck et al. 2014). The 2018 season also featured 54 hurricanes/typhoons/cyclones (HTC; wind speeds $\geq 64 \mathrm{kt}$ or $33 \mathrm{~m} \mathrm{~s}^{-1}$ ), which is above the 1981-2010 average of 46 (Schreck et al. 2014). During the 2018 season, 27 storms reached major HTC status (wind speeds $\geq 96 \mathrm{kt}$ or $49 \mathrm{~m} \mathrm{~s}^{-1}$ ), which is also above the long-term average of 21 and seven more than the 2017 season (Diamond and Schreck 2018). All of these metrics were in the top quartile relative to 1981-2010 (Table 4.2). 
TABLE 4.I. (Modified from Yim et al. 2014). Definition of the regional summer monsoon circulation indices and their correlation coefficients (CCs) with the corresponding regional summer monsoon precipitation indices for the period 1979-2017. All circulation indices are defined by the meridional shear of the zonal wind at $850 \mathrm{hPa}$, which measures the intensity (relative vorticity) of the monsoon troughs at $850 \mathrm{~h} \mathrm{~Pa}$ except for northern African (NAF) and East Asia (EA). The NAF monsoon circulation index is defined by the westerly monsoon strength: $U 850\left(0^{\circ}-15^{\circ} \mathrm{N}, 60^{\circ}-10^{\circ} \mathrm{W}\right)$ and the EASM circulation index is defined by the meridional wind strength: $\mathrm{V} 850\left(20^{\circ}-40^{\circ} \mathrm{N}, 120^{\circ}-140^{\circ} \mathrm{E}\right)$, which reflects the east-west thermal contrast between the Asian continent and the western North Pacific. The precipitation indices are defined by the areal mean precipitation over the blue box regions shown in Fig. 4.26. The correlation coefficients were computed using monthly time series (I56 summer months) [Jun-Sep (JJAS) in NH (1979-2017) and Dec-Mar (DJFM) in SH (1979/80-2017/18)]. Bolded numbers represent significance at the $99 \%$ confidence level.

\begin{tabular}{|c|c|c|}
\hline Region & Circulation Index Definition & CC \\
\hline Indian (ISM) & $\begin{array}{l}\text { U850 }\left(5^{\circ}-15^{\circ} \mathrm{N}, 40^{\circ}-80^{\circ} \mathrm{E}\right) \text { minus } \\
\text { U850 }\left(25^{\circ}-35^{\circ} \mathrm{N}, 70^{\circ}-90^{\circ} \mathrm{E}\right)\end{array}$ & 0.71 \\
\hline Western North Pacific (WNPSM) & $\begin{array}{l}\text { U850 }\left(5^{\circ}-15^{\circ} \mathrm{N}, 100^{\circ}-130^{\circ} \mathrm{E}\right) \text { minus } \\
\text { U850 }\left(20^{\circ}-35^{\circ} \mathrm{N}, 110^{\circ}-140^{\circ} \mathrm{E}\right)\end{array}$ & 0.78 \\
\hline East Asian (EASM) & $\operatorname{V850}\left(20^{\circ}-40^{\circ} \mathrm{N}, 120^{\circ}-140^{\circ} \mathrm{E}\right)$ & 0.73 \\
\hline North American (NASM) & $\begin{array}{l}\text { U850 }\left(5^{\circ}-15^{\circ} \mathrm{N}, 130^{\circ}-100^{\circ} \mathrm{W}\right) \text { minus } \\
\text { U850 }\left(20^{\circ}-30^{\circ} \mathrm{N}, 110^{\circ}-80^{\circ} \mathrm{W}\right)\end{array}$ & 0.84 \\
\hline Northern African (NAFSM) & U850 $\left(0-15^{\circ} \mathrm{N}, 60^{\circ}-10^{\circ} \mathrm{W}\right)$ & 0.72 \\
\hline South American (SASM) & $\begin{array}{l}\text { U850 }\left(5^{\circ}-20^{\circ} \mathrm{S}, 70^{\circ}-40^{\circ} \mathrm{W}\right) \text { minus } \\
\text { U850 }\left(20^{\circ}-35^{\circ} \mathrm{S}, 70^{\circ}-40^{\circ} \mathrm{W}\right)\end{array}$ & 0.81 \\
\hline Southern African (SAFSM) & $\begin{array}{l}\text { U850 }\left(0^{\circ}-15^{\circ} \mathrm{S}, 10^{\circ}-40^{\circ} \mathrm{E}\right) \text { minus } \\
\text { U850 }\left(10^{\circ}-25^{\circ} \mathrm{S}, 40^{\circ}-70^{\circ} \mathrm{E}\right)\end{array}$ & 0.53 \\
\hline Australian (AUSSM) & $\begin{array}{l}\text { U850 }\left(0^{\circ}-15^{\circ} \mathrm{S}, 90^{\circ}-130^{\circ} \mathrm{E}\right) \text { minus } \\
\text { U850 }\left(20^{\circ}-30^{\circ} \mathrm{S}, 100^{\circ}-140^{\circ} \mathrm{E}\right)\end{array}$ & 0.86 \\
\hline
\end{tabular}

In Sections $4 \mathrm{f} 2-4 \mathrm{f} 8,2018$ seasonal TC activity is described and compared to the historical record for each of the seven WMO-defined hurricane basins. For simplicity, all counts are broken down by the U.S. Saffir-Simpson scale. The overall picture of global
TCs during 2018 is shown in Fig. 4.16; actual counts by category are documented in Table 4.2 .

Globally, 11 storms during the year reached Saffir-Simpson Category 5 strength (wind speeds $\geq 137$ kt or $70.5 \mathrm{~m} \mathrm{~s}^{-1}$ ), eight more than in 2017 and seven

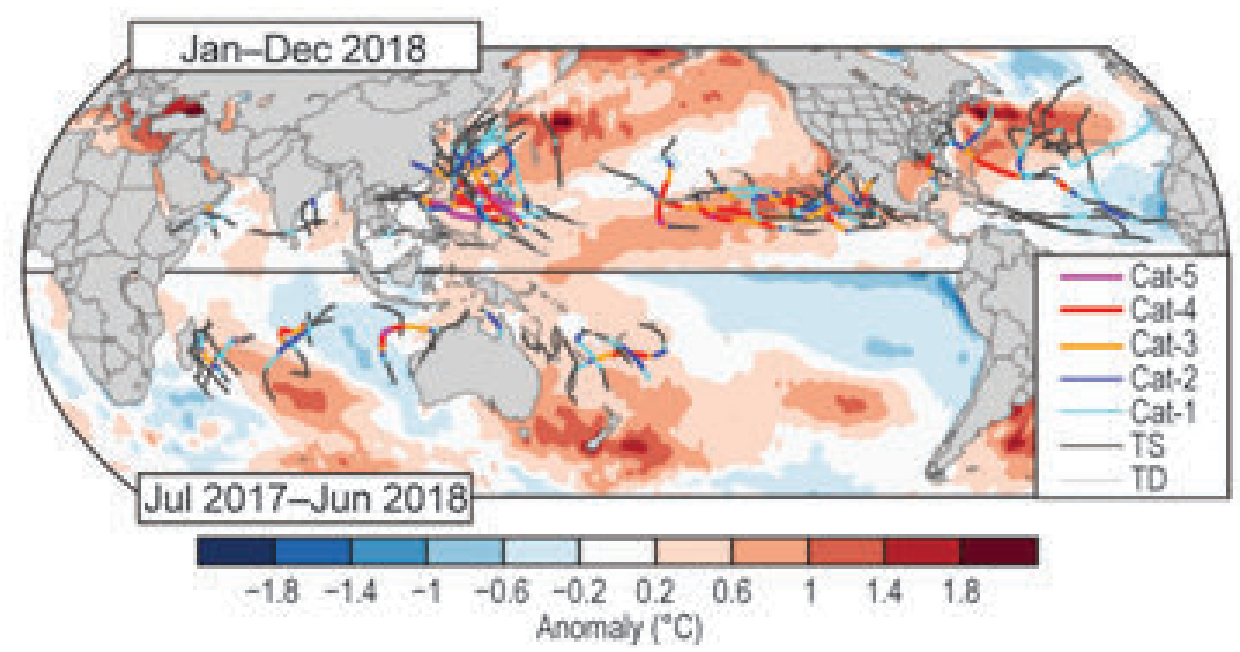

FIG. 4.16. Global summary of TC tracks overlaid on the associated OISST anomalies ( ${ }^{\circ} \mathrm{C}$; Reynolds et al. 2002) for the 2018 season relative to $1982-2010$. 


\begin{tabular}{|c|c|c|c|c|c|}
\hline Basin & TCs & HTCs & $\begin{array}{l}\text { Major } \\
\text { HTCs }\end{array}$ & SS Cat 5 & $\begin{array}{c}\text { ACE } \\
\left(\times 10^{4} \mathrm{kt}^{2}\right)\end{array}$ \\
\hline North Atlantic & 15 & 8 & 2 & I & 133 \\
\hline Eastern North Pacific & 23 & 13 & 10 & 3 & 316 \\
\hline Western North Pacific & 28 & 16 & 9 & 6 & 341 \\
\hline North Indian & 8 & 4 & I & 0 & 31 \\
\hline South Indian & 6 & 7 & 3 & 0 & 85 \\
\hline Australian & 10 & 3 & 1 & I & 46 \\
\hline Southwest Pacific & 5 & 3 & 1 & 0 & 50 \\
\hline Totals & 95 & 54 & 27 & II & 1002 \\
\hline
\end{tabular}

more than in 2016 (Diamond and Schreck 2017, 2018), and second only to 1997 when there were 12 . The 11 Category 5 storms were: (a) Super Typhoons Yutu, Mangkhut, Maria, Trami, Jebi, and Kong-Rey in the western North Pacific; (b) Hurricanes Lane, Walaka, and Willa in the eastern North Pacific; (c) Severe TC Marcus in the Australian basin; and (d) Hurricane Michael in the North Atlantic.

Sidebars 4.1 and 4.2 detail the record-setting and devastating local impacts of Hurricane Michael, a rare landfalling Category 5 storm that developed rapidly and devastated portions of the Florida Panhandle and southern Georgia.

2) Atlantic basin-G. D. Bell, E. S. Blake, C. W. Landsea, H. Wang, S. B. Goldenberg, and R. J. Pasch

(i) 2018 seasonal activity

The 2018 Atlantic hurricane season produced 15 named storms, including 8 hurricanes, 2 of which became major hurricanes (Fig. 4.17a). The HURDAT2 1981-2010 seasonal averages (included in IBTrACS) are 11.8 named storms, 6.4 hurricanes, and 2.7 major hurricanes (Landsea and Franklin 2013). The 2018 seasonal ACE value (Bell et al. 2000) was nearly $145 \%$ of the 1981-2010 median (which is $92.4 \times 10^{4} \mathrm{kt}^{2}$; Fig. $4.17 \mathrm{~b})$. This value is above NOAA's threshold for an above-normal season (120\%), and the numbers of named storms and hurricanes were also both above average. Therefore, NOAA classifies the 2018 season as above normal, making 2018 the third consecutive above-normal season, and the 16th above-normal season (of 24) since the current Atlantic high-activity

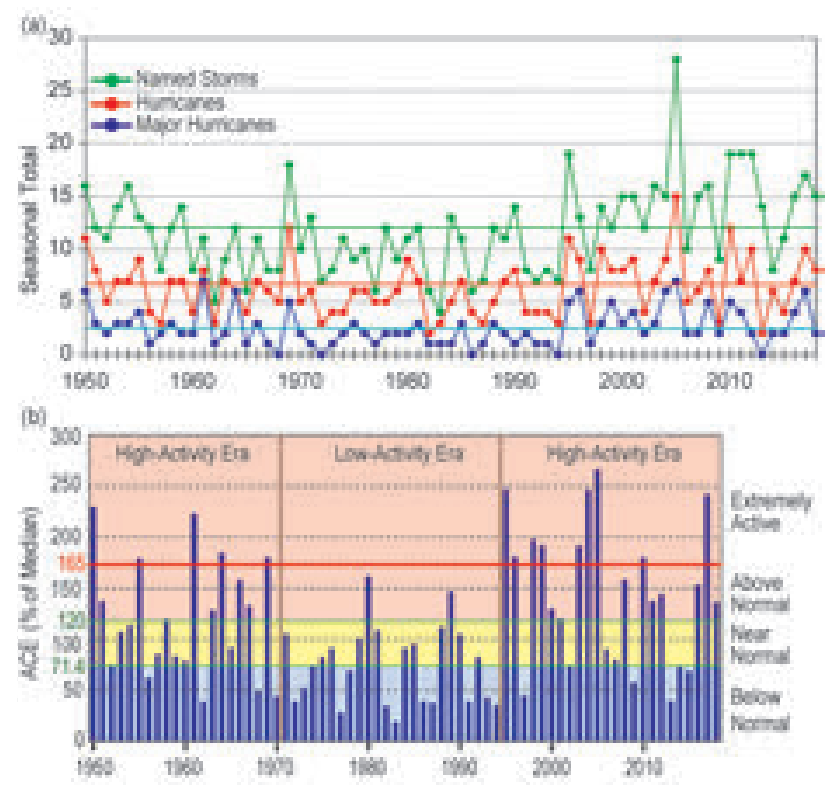

FIG. 4.17. Seasonal Atlantic hurricane activity during 1950-2018 based on HURDAT2 (Landsea and Franklin 2013). (a) Number of named storms (green), hurricanes (red), and major hurricanes (blue), with 198I-2010 seasonal means shown by solid colored lines. (b) ACE index expressed as a percent of the 198I-2010 median value. Red, yellow, and blue shadings correspond to NOAA's classifications for above-, near-, and belownormal seasons. Thick red horizontal line at $165 \%$ ACE value denotes the threshold for an extremely active season. Vertical brown lines separate high- and low-activity eras. Note: there is a low bias in activity during the 1950s to the early 1970s due to the lack of satellite imagery and the associated Dvorak technique used to interpret TC intensity for systems over the open ocean. 
era began in 1995 (Landsea et al. 1998; Goldenberg et al. 2001). The previous Atlantic high-activity era of 1950-70 also featured numerous above-normal seasons (10 of 21), while the intervening low-activity era of 1971-94 had only 2 of 24 (Bell et al. 2018). Note that reliable basin-wide records for exact season-to-season comparisons with ACE began in the mid-1970s with the advent of the geostationary satellite era (Landsea et al. 2006).

(ii) Storm formation regions, tracks, and landfalls

The vast majority of Atlantic tropical storms and hurricanes develop during the peak months of the season (August-October, ASO). During 2018, 12 of the 15 named storms formed during ASO, accounting for 6 of the 8 hurricanes, including both major hurricanes (Fig. 4.18a,b).

The activity was focused in two main regions. One was the Main Development Region (MDR), which spans the tropical Atlantic Ocean and Caribbean Sea between $9.5^{\circ} \mathrm{N}$ and $21.5^{\circ} \mathrm{N}$ (green box, Fig. 4.18a) (Goldenberg and Shapiro 1996; Goldenberg et al. 2001; Bell and Chelliah 2006). The other was located north of the MDR across the western and central subtropical North Atlantic.

Above-normal seasons typically have far more activity in the MDR compared to near-normal and below-normal seasons (Bell and Chelliah 2006; Bell et al. 2017, 2018). In 2018, eight of the 15 named storms formed in the MDR, resulting in five hurricanes, two of which were major. These eight TCs accounted for $66 \%$ of the seasonal ACE total. Six of these eight TCs, including four hurricanes and one major hurricane, formed over the eastern tropical Atlantic, while nearly the entire western half of the MDR (west of $50^{\circ} \mathrm{W}$ ) was devoid of hurricanes.

Consequently, although the 2018 MDR activity was substantial, it was fairly modest for an above-normal season. For example, the numbers of MDR-spawned named storms, hurricanes, and major hurricanes were all lower than the 1981-2010 above-normal season averages of 9.3 named storms, 6.8 hurricanes, and 4.2 major hurricanes, respectively. Also, the MDR-spawned ACE was only $95 \%$ of its median, well below the $120 \%$ threshold for an above-normal season. Historically, the MDR-spawned ACE has exceeded $120 \%$ in two-thirds (19 of 28) of above-normal seasons since 1950. Further comparison to past above-normal seasons indicates that the 2018 MDR-spawned ACE was the sixth lowest since 1950, and the third lowest (after 2012 and 2001) since the geostationary satellite era began in 1974 . The number of MDR-spawned major hurricanes was the second lowest (after 2012).
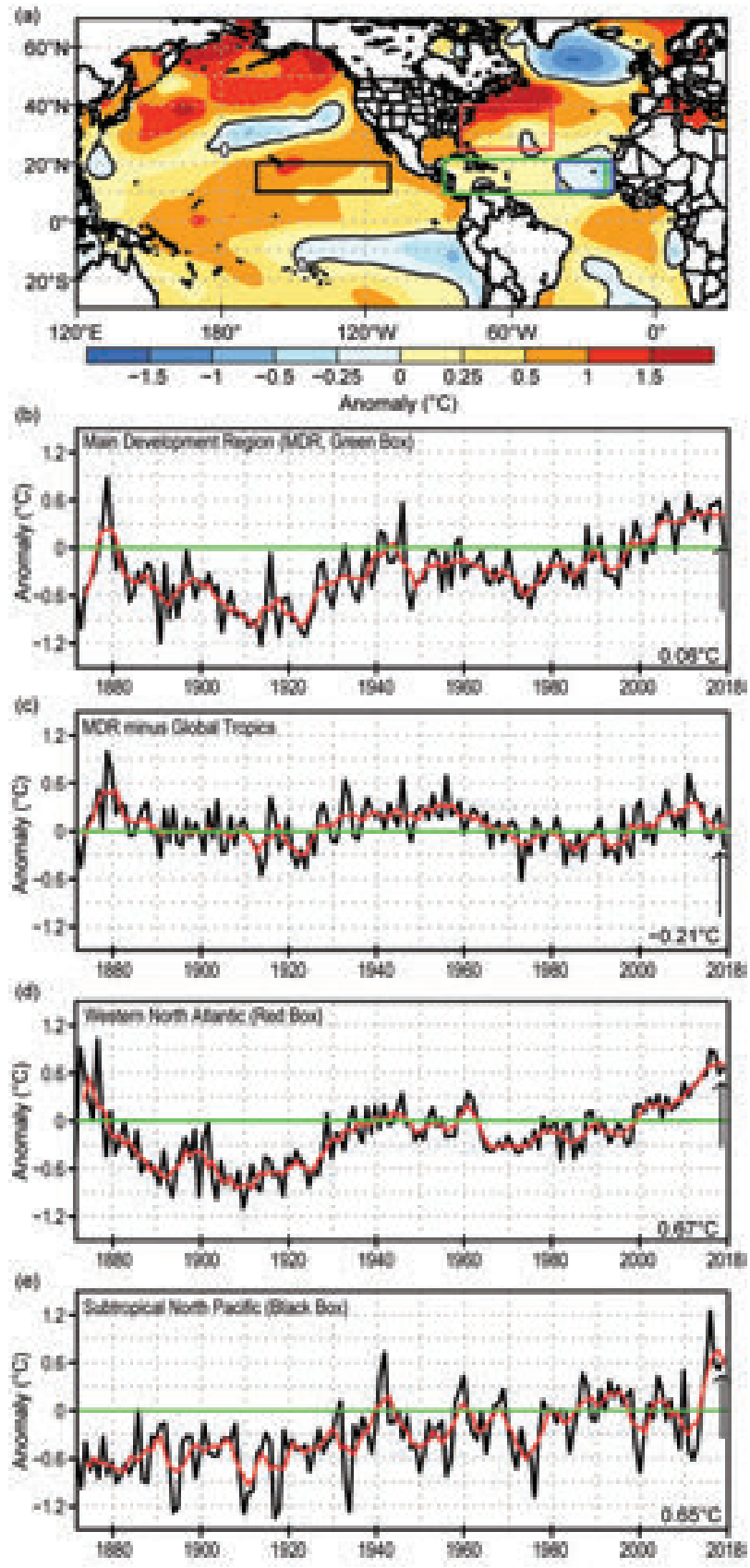

FIG. 4.18. (a) Aug-Oct 2018 SST anomalies ( $\left.{ }^{\circ} \mathrm{C}\right)$. (b)-(e) Time series of Aug-Oct area-averaged SST anomalies ( ${ }^{\circ} \mathrm{C}$, black) and 5-pt. running mean of the time series (red) in (b) the MDR [green box in (a) spanning $19.5^{\circ}-$ $21.5^{\circ} \mathrm{N}$ and $\left.20^{\circ}-87.5^{\circ} \mathrm{W}\right]$, (c) difference between the MDR and the global tropics $\left(20^{\circ} \mathrm{N}-20^{\circ} \mathrm{S}\right)$, (d) the western North Atlantic [red box in (a) spanning $25^{\circ}-40^{\circ} \mathrm{N}$ and $\left.42.5^{\circ}-80^{\circ} \mathrm{W}\right]$, and (e) the subtropical North Pacific [black box in (a) spanning $10^{\circ}-20^{\circ} \mathrm{N}$ and $165^{\circ}-110^{\circ} \mathrm{W}$ ]. The blue box in (a) denotes the eastern MDR. Data source is ERSSTv5 (Huang et al. 2017). Anomalies are departures from the 1981-2010 period means. 
In contrast, near-record TC activity was observed during 2018 across the western and central subtropical North Atlantic (north of $21.5^{\circ} \mathrm{N}$ ). This activity pushed the season into the above-normal category for the total basin. Six named storms formed in this region, with three becoming hurricanes. These six TCs accounted for $32 \%$ of the seasonal total. For above-normal seasons, this is the third highest ACE produced by TCs forming north of the MDR since 1950 (following 119\% in 2005 and 48\% in 1954). Five of these six TCs, including two hurricanes, developed initially as subtropical storms. In all, there were a record seven subtropical storms during 2018, breaking the previous record of five set in 1969.

Four TCs during 2018 made landfall in the continental United States, two as tropical storms and two as hurricanes. The first was Tropical Storm Alberto in northwestern Florida on 28 May. The second was Hurricane Florence, which made landfall in North Carolina on 14 September as a Category 1 hurricane and subsequently produced catastrophic flooding across portions of North and South Carolina. The third U.S. landfalling TC of 2018 was Tropical Storm Gordon in southwestern Alabama on 5 September. The fourth was Hurricane Michael, which developed over the northwestern Caribbean Sea on 8 October and made landfall on the Florida Panhandle in Mexico Beach, Florida, two days later. Michael had Category 5 maximum sustained winds of $140 \mathrm{kt}$ (69 $\mathrm{m} \mathrm{s}^{-1}$ ) at landfall and was the strongest TC to strike the Panhandle, and was the fourth strongest for any continental U.S. hurricane landfall on record since accurate records began in the late 1800s. For the continental United States, Michael was the strongest landfalling TC since Hurricane Andrew in 1992.

\section{(iii) Sea surface temperatures}

There were five main SST signals during ASO 2018 (Fig. 4.18). The first was near-average SSTs across the MDR (Fig. 4.18a), with most areas having departures within $\pm 0.25^{\circ} \mathrm{C}$ of average. For the MDR as a whole, the area-averaged SST anomaly was $+0.06^{\circ} \mathrm{C}$, the lowest value since 2009 (Fig. 4.18b).

The second signal was that the MDR average SST anomaly during this period was $0.21^{\circ} \mathrm{C}$ lower than the remainder of the global tropics (Fig. 4.18c). A relatively cool MDR of this magnitude has not been seen since the late 1990s and is more typical of the Atlantic low-activity eras (Vecchi and Soden 2007; Bell et al. 2018), such as 1971-94 and 1900-25.

The third SST signal focused on the eastern MDR (blue box, Fig. 4.18a), where a pronounced increase of temperature anomalies occurred during August.
As a result, the ASO area-averaged SST anomaly in this region $\left(-0.18^{\circ} \mathrm{C}\right)$ was much higher than the June-July anomaly of $-0.82^{\circ} \mathrm{C}$ (not shown). These more moderate SST anomalies made the eastern MDR increasingly hospitable to TC activity.

The fourth signal reflected near-record high SSTs during ASO in the western and central North Atlantic (red box, Fig. 4.18a), where as noted above, near-record TC activity was observed in 2018. The area-averaged SST anomaly in this region $\left(+0.67^{\circ} \mathrm{C}\right)$ was comparable to the warmest ASO period in the 1871-2018 record (Fig. 4.18d).

The fifth SST signal reflected near-record anomalous warmth (Fig. 4.18e) across the subtropical North Pacific (black box, Fig. 4.18a). Since 2015, this region has experienced exceptionally high SSTs not seen previously since the early 1940s. During 2018, this warmth was accompanied by a progressive warming of the central and east-central equatorial Pacific, with area-averaged SST anomalies reaching $+0.7^{\circ} \mathrm{C}$ during $\mathrm{SON}$ as measured by the ENSO-related ONI (see Fig. 4.1).

\section{(iv) Atmospheric conditions}

The 2018 Atlantic hurricane season was remarkable for being above normal despite strong westerly vertical wind shear (generally $12-16 \mathrm{~m} \mathrm{~s}^{-1}$ ) across the western and central MDR (blue box, Figs. 4.19a,b). The area-averaged shear in this region was $13.7 \mathrm{~m}$ $\mathrm{s}^{-1}$ during ASO (Fig. 4.19c), the strongest since the mid-1980s. This shear pattern reflected enhanced upper-level (200-hPa) westerly winds within the base of an amplified Tropical Upper Tropospheric Trough (TUTT; Fig. 4.20a). These overall conditions are typical of less active seasons (Bell and Chelliah 2006).

The enhanced upper-level westerlies and shear were related in part to an extensive pattern of anomalous upper-level divergence (Fig. 4.21a) and enhanced tropical convection (indicated by negative OLR anomalies, Fig. 4.21b) across the central and eastern subtropical North Pacific (black box, Figs. $4.21 \mathrm{a}, \mathrm{b})$. These conditions are known to increase the upper-level westerlies, and hence the vertical wind shear, in the western MDR (Klotzbach 2010). During August-September 2018, the area-averaged OLR anomaly in the subtropical North Pacific region was the third most negative in the 1979-present record (bars, Fig. $4.21 \mathrm{c}$ ), suggesting there was sufficient forcing to negatively impact the Atlantic hurricane season. These conditions were associated with a northward shift and strengthening of the Pacific ITCZ, with near-record warm SST anomalies across the region (Fig. 4.18e) and the most active eastern- 
central North Pacific hurricane season on record (as measured by ACE).

Anomalous convection across the subtropical North Pacific during August-September also has an inverse relationship with ENSO phase (i.e., the ONI) but not necessarily with the specific strength of the El Niño and La Niña episodes. Looking at SON ONI values during 1979-2018, roughly half of those years
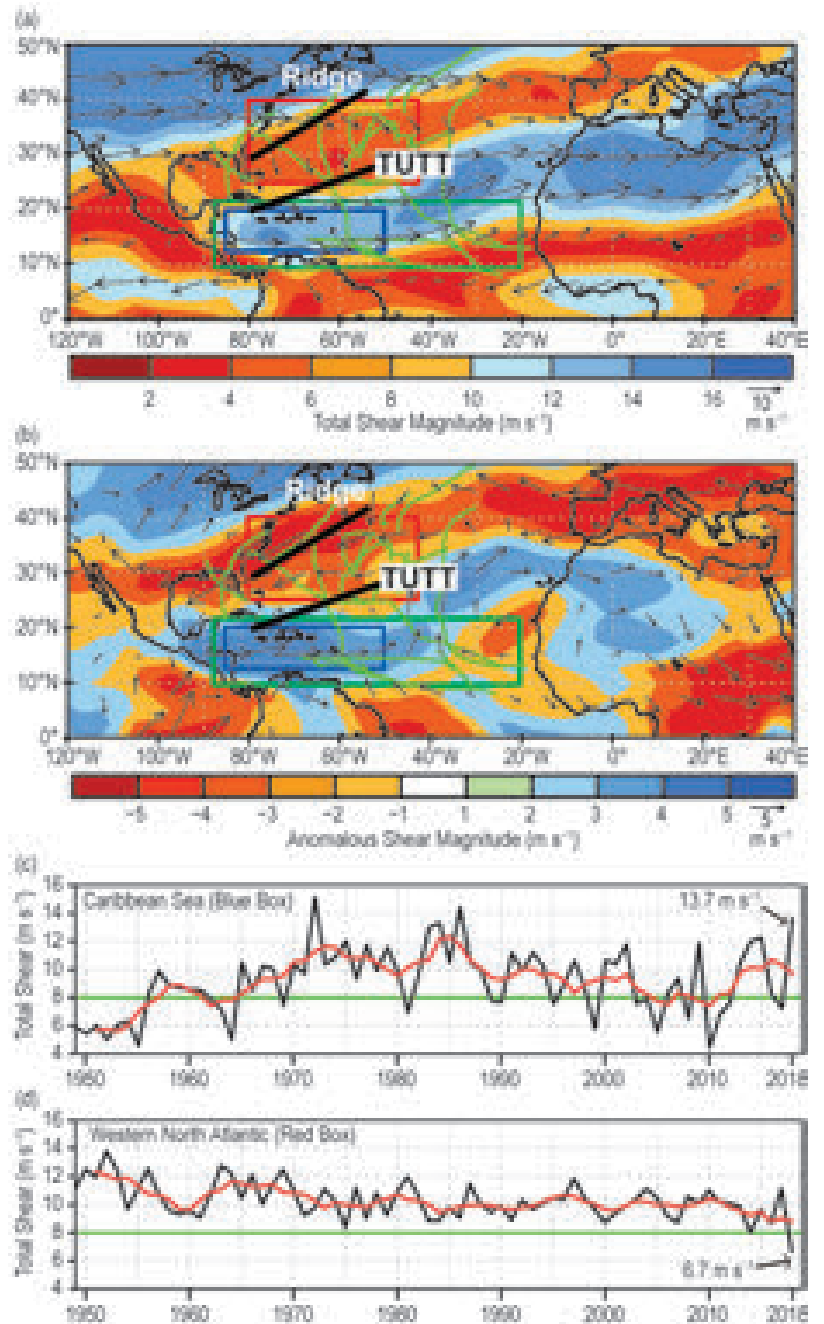

Fig. 4.19. Aug-Oct 2018, 200-850 hPa magnitude of vertical wind shear $\left(\mathrm{m} \mathrm{s}^{-1}\right)$ : (a) total magnitude (shaded, $\mathrm{m} \mathrm{s}^{-1}$ ) and (b) anomalous magnitude (shaded, $\mathrm{m} \mathrm{s}^{-1}$ ). (c),(d) Time series of ASO vertical shear magnitude (black) and 5-pt. running mean of the time series (red) averaged over (c) the western MDR [blue box in (a) spanning $12.5^{\circ}-20^{\circ} \mathrm{N}$ and $\left.85^{\circ}-50^{\circ} \mathrm{W}\right]$ and (d) the western North Atlantic [red box in (a) spanning $25^{\circ}-40^{\circ} \mathrm{N}$ ] and $80^{\circ}-42.5^{\circ} \mathrm{W}$. In (a), (b), the upper-level ridge and TUTT discussed in the text are labeled and denoted by thick black lines. The 2018 TC tracks (green lines) are shown, the vector scale $\left(\mathrm{m} \mathrm{s}^{-1}\right)$ is below right of color bar. Green box denotes the MDR. Data are from NCEP-NCAR reanalysis (Kalnay et al. 1996). Anomalies are departures from 1981-2010 means. with $\mathrm{ONI} \geq+0.5^{\circ} \mathrm{C}$ (typically El Niño) featured enhanced convection with negative OLR anomalies of more than -0.5 standard deviations across the subtropical North Pacific (Fig. 4.22a). Conversely, about two-thirds of years with an $\mathrm{ONI} \leq-0.5^{\circ} \mathrm{C}$ (typically La Niña) featured suppressed convection with positive OLR anomalies exceeding +0.5 standard deviations in that region. This inverse relationship is also seen by looking at August-September periods when
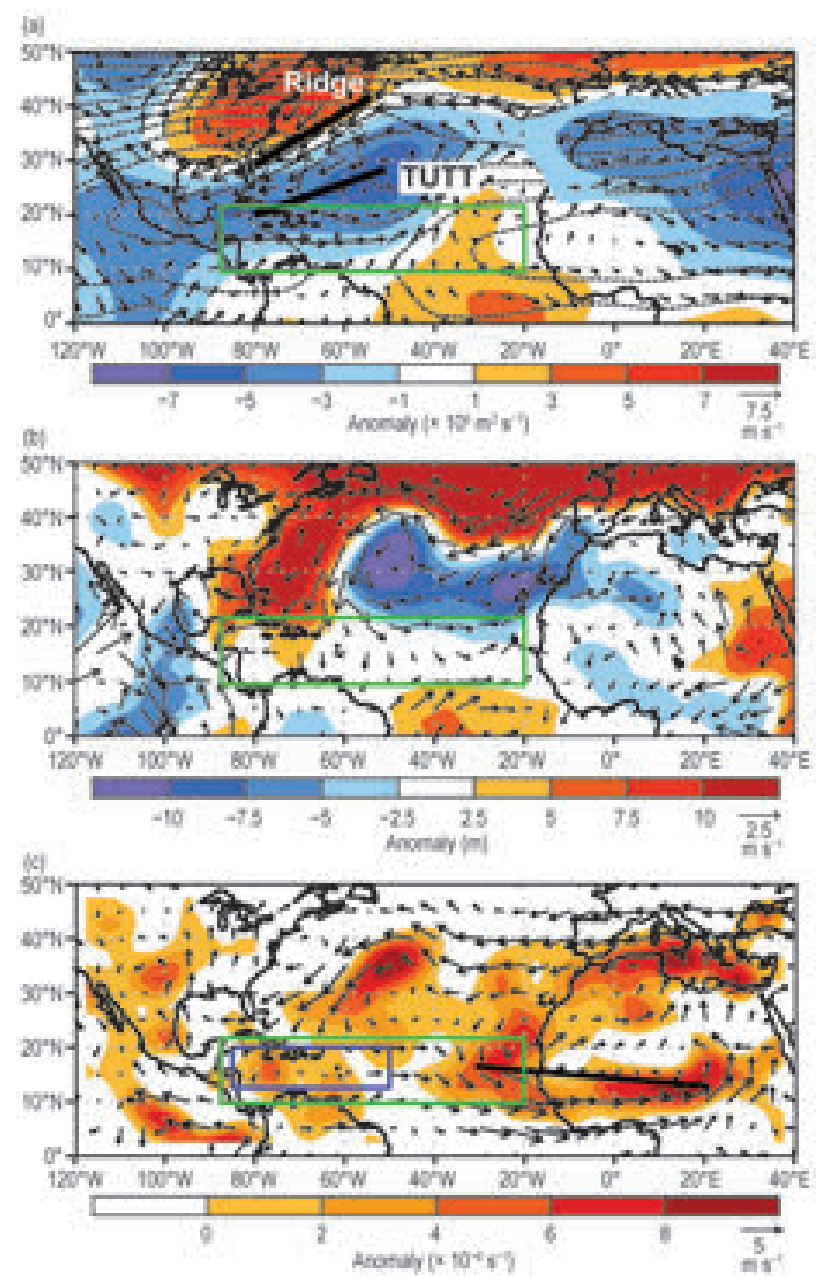

Fig. 4.20. Aug-Oct 20I8: (a) 200-hPa total streamfunction (contours, interval is $5 \times 10^{6} \mathrm{~m}^{2} \mathrm{~s}^{-1}$ ) and anomalies (shaded); (b) anomalous $1000-\mathrm{hPa}$ heights (shaded, $\mathrm{m}$ ); and (c) anomalous $700-\mathrm{hPa}$ cyclonic relative vorticity (shaded, $\times 10^{-6} \mathrm{~s}^{-1}$ ) and vector winds. The corresponding anomalous wind vectors $\left(\mathrm{m} \mathrm{s}^{-1}\right)$ are shown in each panel. In (a) the upper-level ridge and TUTT discussed in the text are labeled and denoted by thick black lines. In (c) the thick solid line indicates the axis of the mean African Easterly Jet, which was hand-drawn based on total seasonal wind speeds (not shown). Vector scales differ for each panel and are below right of color bar. Green box denotes the MDR. Anomalies are departures from 1981-2010 means. [Source: NCEP-NCAR reanalysis (Kalnay et al. 1996).] 
convection was most anomalous (OLR anomalies exceeding \pm 1 standard deviations) across the subtropical North Pacific. The SON ONI values were at least $+0.5^{\circ} \mathrm{C}$ (as in 2018) in two-thirds of years when the convection was most enhanced, and below at least $-0.5^{\circ} \mathrm{C}$ in two-thirds of years when the convection was most suppressed (Fig. 4.22b).
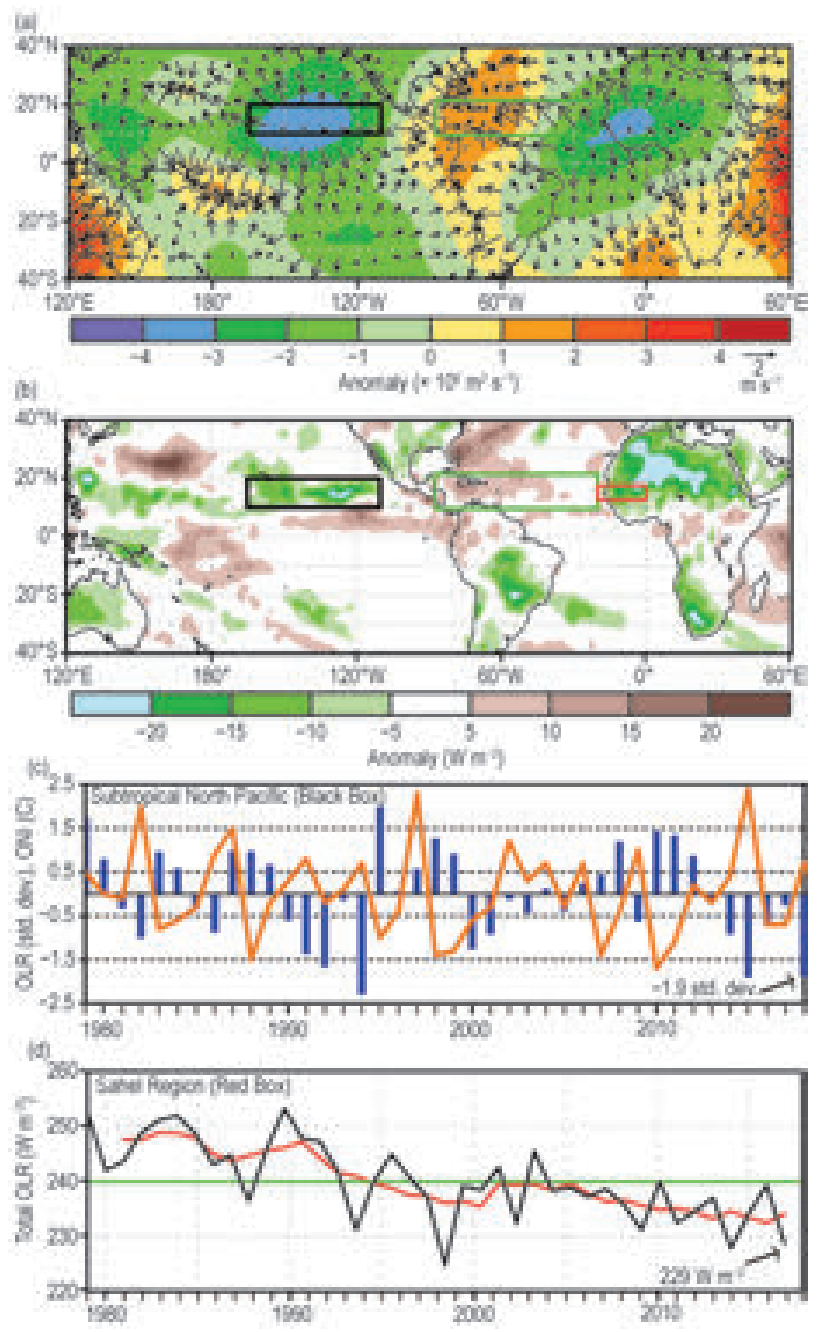

Fig. 4.2I. Aug-Sep 2018: (a) anomalous 200-hPa velocity potential $\left(\times 10^{6} \mathrm{~m}^{2} \mathrm{~s}^{-1}\right)$ and divergent wind vectors $\left(\mathrm{m} \mathrm{s}^{-1}\right)$ and $(b)$ anomalous OLR $\left(\mathrm{W} \mathrm{m}^{-2}\right)$, with negative (positive) values indicating enhanced (suppressed) convection. (c) SON ONI (red line) overlaid with time series of Aug-Sep area-averaged OLR anomaly (blue bars) over the subtropical North Pacific [black box in (a),(b) spanning $10^{\circ}-20^{\circ} \mathrm{N}$ and $\left.165^{\circ}-110^{\circ} \mathrm{W}\right]$. (d) Time series of Aug-Sep area-averaged total OLR (black) and 5-pt. running mean of the time series (red) over the African Sahel region [red box in (b) spanning $12.5^{\circ}-17.5^{\circ} \mathrm{N}$ and $20^{\circ} \mathrm{W}-0^{\circ}$ ]. Green box in (a),(b) denotes the Atlantic MDR. OLR data are based on AVHRR (Liebmann and Smith 1996). Velocity potential and wind data are from NCEP-NCAR reanalysis (Kalnay et al. 1996). Anomalies are departures from the 1981-2010 means.
Given the above conditions, the question then arises as to why the 2018 Atlantic hurricane season was above normal. One main reason was the numerous tropical storms and hurricanes (including Hurricane Florence) across the central/western subtropical North Atlantic that formed in response to exceptionally conducive wind and air pressure patterns in that region (Figs. 4.19, 4.20, 4.23). In the upper troposphere, these conditions included a ridge in the $200-\mathrm{hPa}$ streamfunction field that extended across the eastern United States and western North Atlantic, and also across the central North Atlantic mainly between $40^{\circ}-50^{\circ} \mathrm{N}$ (Fig. 4.20a). The amplified TUTT was located farther south. The corresponding height anomaly pattern extended down to the ocean surface, as seen in both the lower (1000-hPa; Fig. $4.20 \mathrm{~b}$ ) and middle (500-hPa; Fig. 4.23a) troposphere.

This overall pattern was associated with a northward shift of the jet stream and anomalously weak upper-level westerly winds (indicated by easterly and northeasterly wind anomalies; Fig. 4.20a) and exceptionally weak vertical wind shear (red box, Figs. $4.19 \mathrm{a}, \mathrm{b})$ from the eastern United States to the central
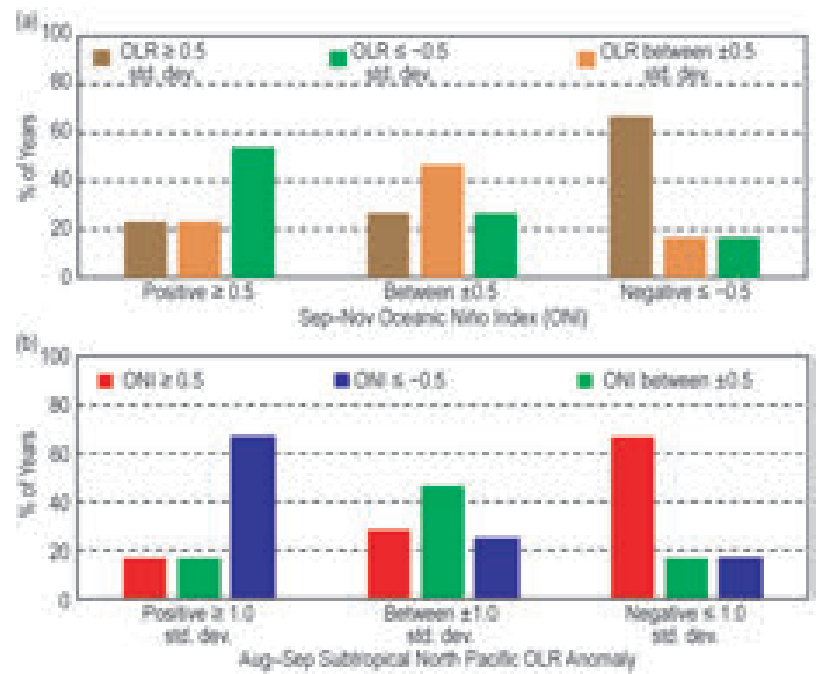

Fig. 4.22. (a) For each ENSO phase during Sep-Nov as measured by the ONI, the bars show the percent of years in which the area-averaged OLR anomaly during Aug-Sep in the subtropical North Pacific region (blue box, Figs. 4.23a,b) was positive $(\geq+0.5$ std. dev.), average (within \pm 0.5 std. dev), and negative $(\leq+0.5$ std. dev). (b) For each range of standardized OLR anomalies (Liebmann and Smith 1996) during Aug-Sep in the subtropical North Pacific region, the bars show the percent of years in which the ONI during Sep-Nov was positive $(\geq+0.5$, El Niño like), average (within \pm 0.5 , ENSO-neutral), and negative $(\leq+0.5$, La Niña-like). Negative (positive) OLR anomalies indicate enhanced (suppressed) convection, and are associated with stronger (weaker) vertical wind shear in the western MDR. 


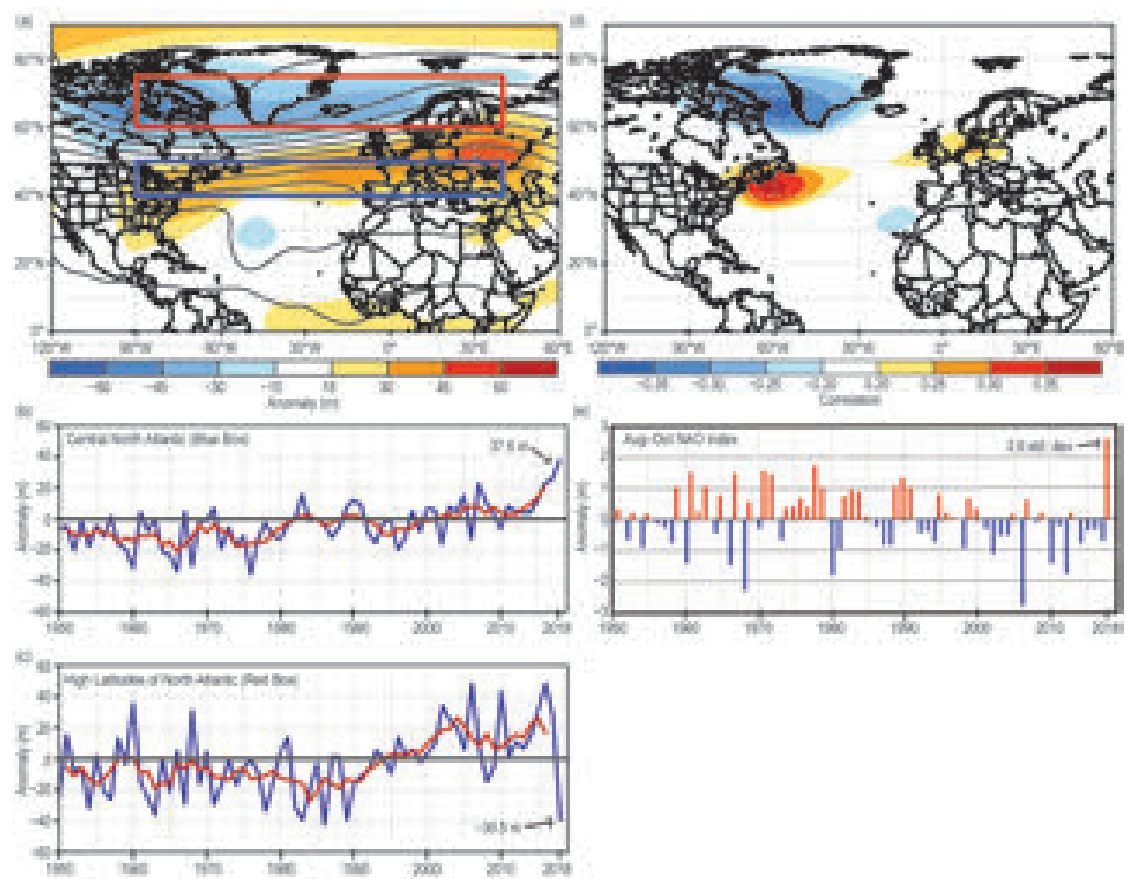

FIG. 4.23. ASO 20I8: (a) 500-hPa conditions: height ( $\mathrm{m}$, solid lines, interval is $60 \mathrm{~m}$ ) and anomalies (m, shaded). (b),(c) Time series of height anomalies ( $\mathrm{m}$, black) and 5-pt. running mean of the time series (red) averaged over (b) the central North Atlantic [blue box in (a) spanning $40^{\circ}-50^{\circ} \mathrm{N}$ and $90^{\circ} \mathrm{W}-$ $40^{\circ} \mathrm{E}$ ], and (c) the high latitudes of the North Atlantic [red box in (a) spanning $60^{\circ}-75^{\circ} \mathrm{N}$ and $90^{\circ} \mathrm{W}-40^{\circ} \mathrm{E}$. (d) $1950-2018$ correlation $(\times 100)$ loading pattern of the NAO, and (e) time series of the 500-hPa NAO index. NAO loading pattern and time series are obtained from the NOAA Climate Prediction Center (www.cpc.ncep.noaa.gov/data/teledoc/telecontents.shtml). Data are from NCEP-NCAR reanalysis (Kalnay et al. 1996). Anomalies are departures from the 1981-2010 means. in six named storms with four being hurricanes and one being a major hurricane. Atmospheric conditions in this region included weaker easterly trade winds (indicated by westerly wind anomalies) that extended upward to at least the 700-hPa level (Figs. $4.20 \mathrm{~b}, \mathrm{c})$, the approximate level of the African Easterly Jet (AEJ). This anomaly pattern had two main impacts. First, it helped to return anomalously cold SSTs during June-July in the eastern MDR toward near-average levels. Second, it contributed to a deep layer of anomalous cyclonic relative vorticity (i.e., increased cyclonic shear) along the equatorward flank of the AEJ (shading, Fig. 4.20c). These conditions are known to help maintain African easterly waves and to provide an inherent cyclonic rotation to their embedded convective cells (Bell et al. 2004, 2006, 2017, 2018).

Historically, these wind

North Atlantic. The area-averaged magnitude of the vertical wind shear in this region was $6.7 \mathrm{~m} \mathrm{~s}^{-1}$, dropping below $8 \mathrm{~m} \mathrm{~s}^{-1}$ for the first time in the ASO 1950-2018 record (Fig. 4.19d). On monthly time scales, shear values less than $8 \mathrm{~m} \mathrm{~s}^{-1}$ are considered conducive to hurricane formation (Bell et al. 2017).

Further inspection of the 500-hPa height anomaly field shows that these conducive ASO conditions were associated with a record-strength, larger-scale circulation pattern in the extratropics (Fig. 4.23). This pattern featured record positive height anomalies across the central North Atlantic, with area-averaged values nearly double the previous high (Fig. 4.23b). The pattern also featured near-record negative height anomalies across the high latitudes of the North Atlantic (Fig. 4.23c). This north-south dipole pattern reflected the strongest positive phase of the North Atlantic Oscillation (NAO, Fig. 4.23d) for the ASO season from 1950-present (Fig. 4.23e).

Another major contributing factor to the abovenormal 2018 Atlantic hurricane season was conducive conditions in the eastern MDR, which resulted patterns reflect enhanced low-level inflow into a stronger West African monsoon (Gray and Landsea 1992; Hastenrath 1990; Landsea et al. 1992; Bell and Chelliah 2006; Bell et al. 2018). The peak months of that monsoon season are July-September. At 200 $\mathrm{hPa}$, one indicator of an enhanced monsoon during August-September 2018 was an extensive area of anomalous upper-level divergence across western Africa, along with its associated core of negative velocity potential anomalies (Fig. 4.21a). Another indicator was enhanced convection (shown by negative OLR anomalies) in the African Sahel region (red box, Fig. 4.21b). The total area-averaged OLR in this region during August-September was $229 \mathrm{~W} \mathrm{~m}^{-2}$, the third lowest value in the 1979-2018 record (Fig. 4.21d). In the tropics, total OLR values below 240 $\mathrm{W} \mathrm{m}{ }^{-2}$ indicate deep convection. The conducive hurricane conditions in the eastern MDR during ASO 2018 were linked to a northward extension of deep tropical convection across much of the Sahel region, in association with a significantly enhanced West African monsoon. 
These conditions are consistent with the strong climate link that occurs on multidecadal time scales between Atlantic hurricane activity and the strength of the West African monsoon (Bell and Chelliah 2006). Specifically, the current Atlantic high-activity era (Fig. 4.17b) has featured an enhanced monsoon with total OLR values below $240 \mathrm{~W} \mathrm{~m}^{-2}$ in the Sahel region, whereas the low-activity period of the 1980s and early 1990s featured a weaker monsoon with OLR values in the Sahel region often well above $240 \mathrm{~W} \mathrm{~m}^{-2}$ (Fig. 4.21d). These multidecadal fluctuations in monsoon strength coincide with opposing phases (warm and cold, respectively) of the Atlantic Multidecadal Oscillation (AMO; Enfield and Mestas-Nuñez 1999; Bell and Chelliah 2006).

\section{SIDEBAR 4.I: HURRICANE MICHAEL: A FLORIDA PANHANDLE RECORD-BREAKING LANDFALL—P. J. KLOTZBACH}

The 2018 Atlantic hurricane season was perhaps best known for two significant hurricanes-Florence and Michaelthat brought death and destruction to the continental United States. This sidebar focuses on Michael, which was first named on 7 October and became only the fourth continental U.S. landfalling Category 5 hurricane on record just three days later (Beven et al. 2019). Michael's meteorological history is discussed, followed by a discussion of the many meteorological records the storm set in its relatively short lifetime. Historical landfall records from 1851-present are taken from the National Hurricane Center/Atlantic Oceanographic and Meteorological Laboratory archive located at: www.aoml.noaa.gov/hrd/hurdat IAll_U.S._Hurricanes.html.

Michael was first noted as a potential TC on 6 October. The tropical disturbance that spawned Michael brought heavy rainfall to Central America and resulted in 15 fatalities. Michael's initial development was hampered by strong vertical wind shear from an upper-level trough located in the Gulf of Mexico. However, despite continuing to encounter relatively strong vertical wind shear, Michael intensified into a tropical storm the following day. While statistical and dynamical model guidance called for relatively slow strengthening due to persistent westerly vertical wind shear from the upper-level trough in the central Gulf of Mexico, Michael deepened much faster than anticipated, reaching hurricane strength less than 24 hours after being named. Michael's intensification despite persistent wind shear may have been due to the trough in the central Gulf of Mexico generating upper-level difluence that somewhat counteracted the strong shear. In addition, another upper-level trough to the east of Michael likely aided its upper-level outflow (Beven et al. 2019). While Michael's peak rapid intensification rate never exceeded 40 .colostate.edu/). $\mathrm{kt}\left(2 \mathrm{I} \mathrm{m^{-1 } )} 24 \mathrm{~h}^{-1}\right.$, it intensified at a rate of $20-40 \mathrm{kt}(|0-2|$ $\left.\mathrm{m} \mathrm{s}^{-1}\right) 24 \mathrm{~h}^{-1}$ from the time that it was named until the time it made landfall near Mexico Beach, Florida.

While the dynamic environment in the western Caribbean was only marginal for Michael's development, the thermodynamic environment was much more conducive than normal. SSTs averaged $I^{\circ}-2^{\circ} \mathrm{C}$ warmer than normal, with anomalously high levels of upper ocean heat content along Michael's track (see Fig. SB4.3). Vertical wind shear impinging on Michael also weakened considerably as the storm tracked northward from the western Caribbean into the Gulf of Mexico.

As noted earlier, Michael underwent moderate-to-rapid intensification throughout its lifetime as a named storm, reaching major hurricane strength on 9 October. Unlike most recent major hurricanes making landfall along the northern Gulf Coast that weakened in the $24 \mathrm{~h}$ prior to landfall (e.g., Rita and Katrina 2005; Ivan 2004; Opal 1995), Michael continued to intensify up until its landfall in Florida (Fig. SB4.I). Michael's landfall intensity of $140 \mathrm{kt}$ was the fourth strongest for any continental U.S. hurricane landfall on record (since I85I), trailing in order from the strongest: Labor Day (1935), Camille (1969), and Andrew

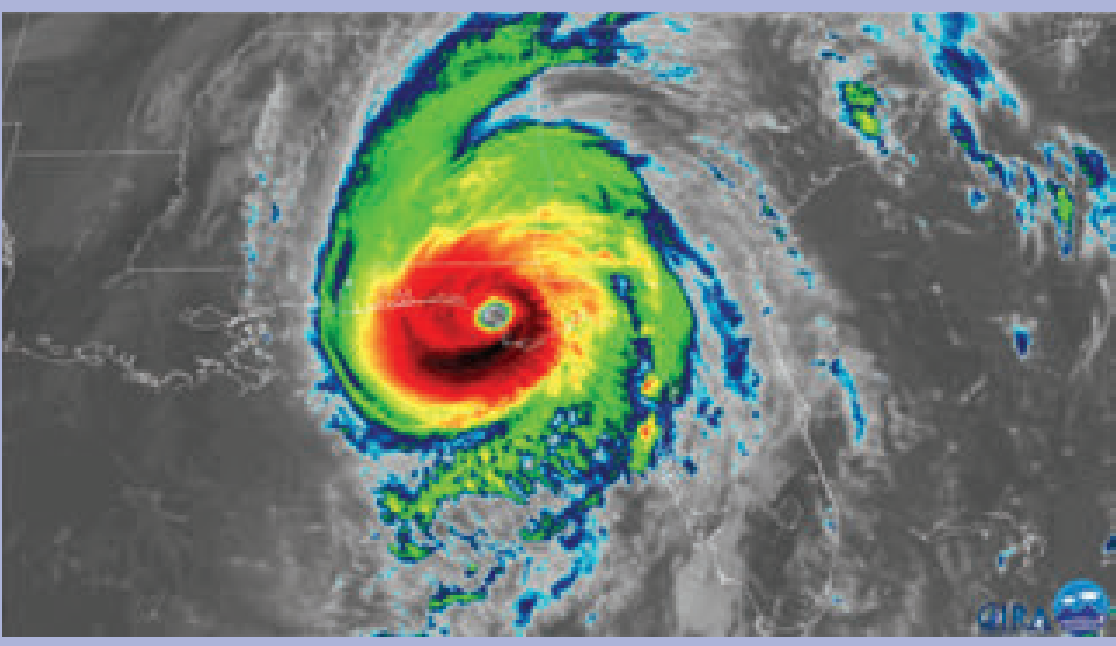

FIG. SB4.I. GOES-I6 infrared satellite image of Hurricane Michael making landfall at 1800 UTC on 10 Oct (from RAMMB CIRA; http://rammb.cira 
(1992). Michael's central pressure of $919 \mathrm{hPa}$ at landfall was the third lowest for a continental U.S. landfalling hurricane on record, trailing in order from the strongest: Labor Day (1935) and Camille (1969).

Michael also was the first storm of greater-than-Category 3 intensity on record to make landfall in the Florida Panhandle. The prior strongest Florida Panhandle landfalls were $110 \mathrm{kt}$ : Pensacola (1882) and Eloise (1975). Opal's landfall central pressure of $942 \mathrm{hPa}$ was the lowest previous central pressure for a Florida Panhandle landfall. Michael shattered both of those marks (140 kt and $919 \mathrm{hPa}$ ). It was also the first Category 5 hurricane on record to make landfall in Florida in October.

After its landfall, Michael only slowly weakened. It was still a Category 2 when it crossed the border from Florida into Georgia (Fig. SB4.2), becoming the first hurricane to bring sustained Category 2 winds to Georgia since Hurricane David in 1979. Michael continued to weaken as it tracked across the southeastern United States but began to restrengthen as it emerged off the mid-Atlantic coast. It underwent extratropical transition and became a powerful extratropical cyclone on 12 October
Given these superlatives, it is no surprise that Michael caused tremendous devastation near the point of its landfall, with exceedingly strong winds and high levels of storm surge being the primary drivers of the damage. Nearly all structures in Mexico Beach were damaged or destroyed, with significant wind damage extending through a large portion of the Florida Panhandle and into Georgia, where there was widespread timber loss and significant damage of the pecan and cotton crops.

Michael's relatively brisk forward speed prevented rainfall amounts from becoming too extreme near where it made landfall (100-150 mm), although small areas recorded over 300 $\mathrm{mm}$. Terrain interactions drove higher rainfall totals (200-300 $\mathrm{mm}$ ) over portions of the Appalachian Mountains. The highest point rainfall total from Michael in the continental United States was $330 \mathrm{~mm}$ in Black Mountain, North Carolina. Michael was responsible for 16 direct and 43 indirect fatalities in the United States, with a current damage estimate of $\$ 25$ billion (U.S. dollars; Beven et al. 2019).

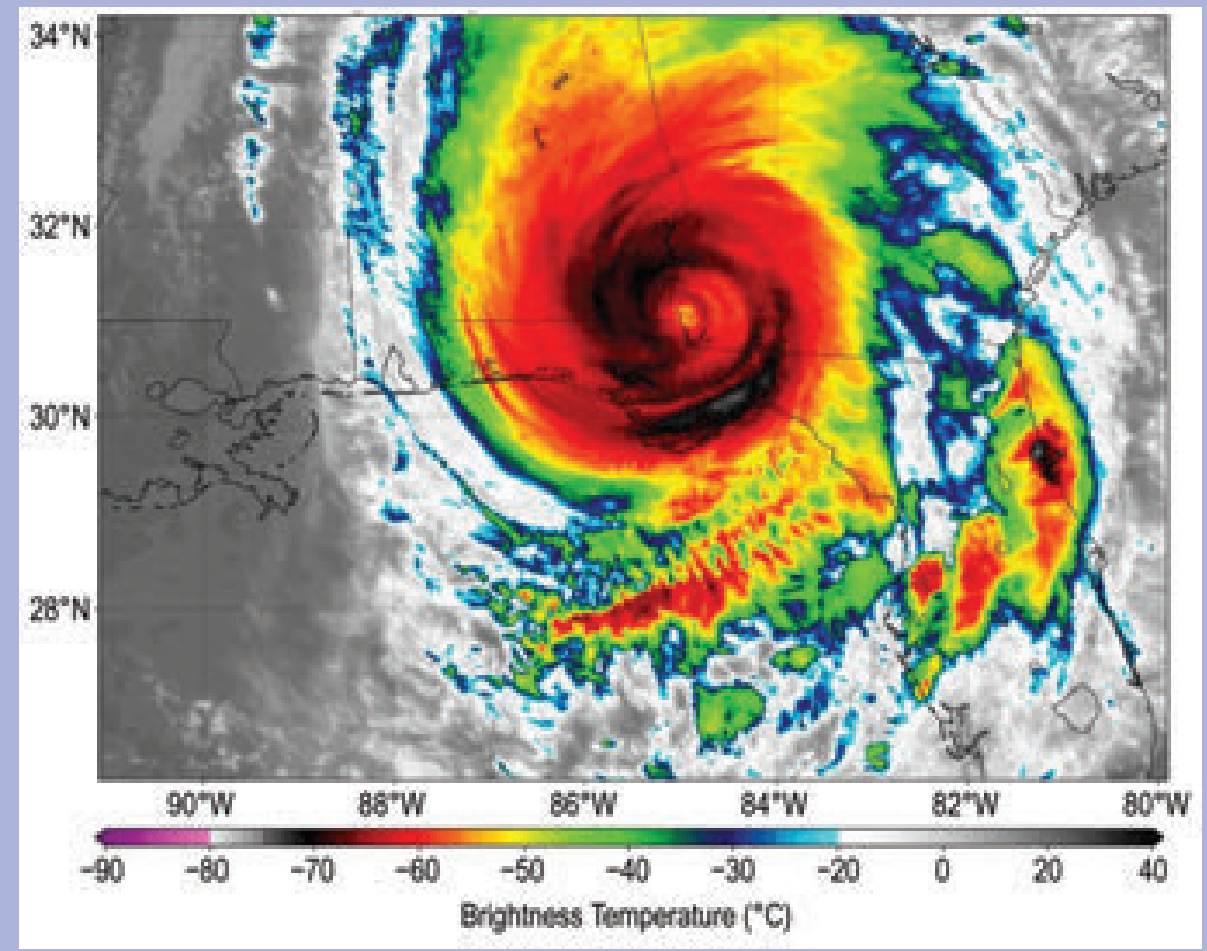

FIG. SB4.2. GOES-I6 infrared satellite image of Hurricane Michael entering southwest Georgia at 2128 UTC on 10 Oct (from Tropical Tidbits; tropicaltidbits.com). 
3) Eastern North Pacific and Central North PACIFIC BASINS-M. C. Kruk and C. J. Schreck

(i) Seasonal activity

The eastern North Pacific (ENP) basin is officially split into two separate regions for the issuance of warnings and advisories by NOAA's National Weather Service. NOAA's National Hurricane Center in Miami, Florida, is responsible for warnings in the eastern part of the basin (ENP) that extends from the Pacific Coast of North America to $140^{\circ} \mathrm{W}$, while NOAA's Central Pacific Hurricane Center in Honolulu, Hawaii, is responsible for warnings in the central North Pacific (CNP) region between $140^{\circ} \mathrm{W}$ and the date line. This section summarizes the TC activity in both warning areas using combined statistics, along with information specifically addressing the observed activity and impacts in the CNP region.

The ENP/CNP hurricane season officially spans 15 May to 30 November. Hurricane and tropical storm activity in the eastern area of the basin typically peak in September, while in the CNP, TC activity typically

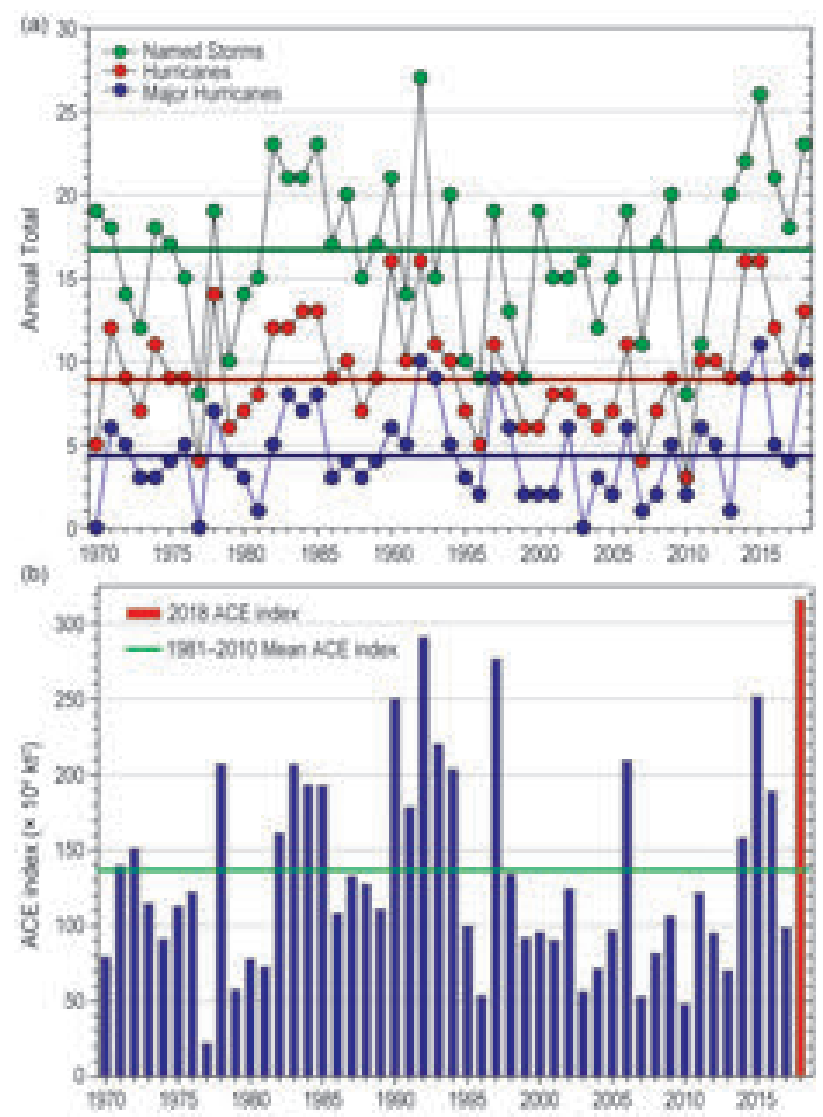

Fig. 4.24. Seasonal TC statistics for the full ENP/CNP basin over the period 1970-2018: (a) number of named storms, hurricanes, and major hurricanes and (b) the ACE index $\left(\times 10^{4} \mathrm{kt}^{2}\right)$ with the 2018 seasonal total highlighted in red. Horizontal lines denote the corresponding 1981-2010 base period means for each parameter. peaks in August (Blake et al. 2009). During the 2018 season, a total of 23 named storms formed in the combined ENP/CNP basin (Fig. 4.24a). This total includes 13 hurricanes, 10 of which were major hurricanes. The 1981-2010 IBTrACS seasonal averages for the basin are 16.5 named storms, 8.5 hurricanes, and 4.0 major hurricanes (Schreck et al. 2014).

The 2018 seasonal ACE index was $316 \times 10^{4} \mathrm{kt}^{2}$ (Fig. 4.24b), a new basin record, which is almost 2.5 times the 1981-2010 mean of $132 \times 10^{4} \mathrm{kt}^{2}$ (Bell et al. 2000; Bell and Chelliah 2006; Schreck et al. 2014). In the CNP basin, six storms formed within or moved into the basin from the east. The long-term 1981-2010 IBTrACS mean in the CNP basin is 4.7 storms, making the 2018 season slightly above average.

\section{(ii) Environmental influences on the 2018 season}

Figure 4.25 illustrates the background conditions for TC activity in the ENP and CNP during the 2018 season. Consistent with the developing El Niño, SSTs were above normal across the equatorial Pacific (Fig. 4.25a). Unique to this event, however, was that the warm anomalies were even stronger in the region inhabited by ENP TCs around $10^{\circ}-20^{\circ} \mathrm{N}$. The enhanced convection (negative OLR anomalies, Fig. 4.25b) closely aligned with those highest SST anomalies. This abundance of warm water and enhanced convection are likely two of the primary factors contributing to the record level of activity.

The dynamical environmental conditions, on the other hand, were not anomalously favorable. The $850-200 \mathrm{hPa}$ vertical wind shear anomalies were generally weak in the region where most of the storms developed (Fig. 4.25c). Nonetheless, the modest westerly shear anomalies countered the climatological easterly shear to reduce the total magnitude somewhat. More surprising were the $850-\mathrm{hPa}$ wind anomalies (Fig. 4.25d). Consistent with the developing El Niño, westerly anomalies dominated the Central Pacific. These anomalies would ordinarily favor ENP TC activity by enhancing cyclonic vorticity and strengthening the easterly waves (Maloney and Hartmann 2001; Aiyyer and Molinari 2008; Rydbeck and Maloney 2014). In this case, however, the westerly anomalies were westward of $130^{\circ} \mathrm{W}$ and thus played a minimal role. Instead, the TCs experienced enhanced southeasterlies, possibly associated with Papagayo gap winds. (The mountain gaps in the Sierra Madre Mountains help to produce regional features known as gap wind jets, and Papagayo gap winds are one of these jets that cross the Nicaraguan Lake District and blow over the Gulf of Papagayo.) 


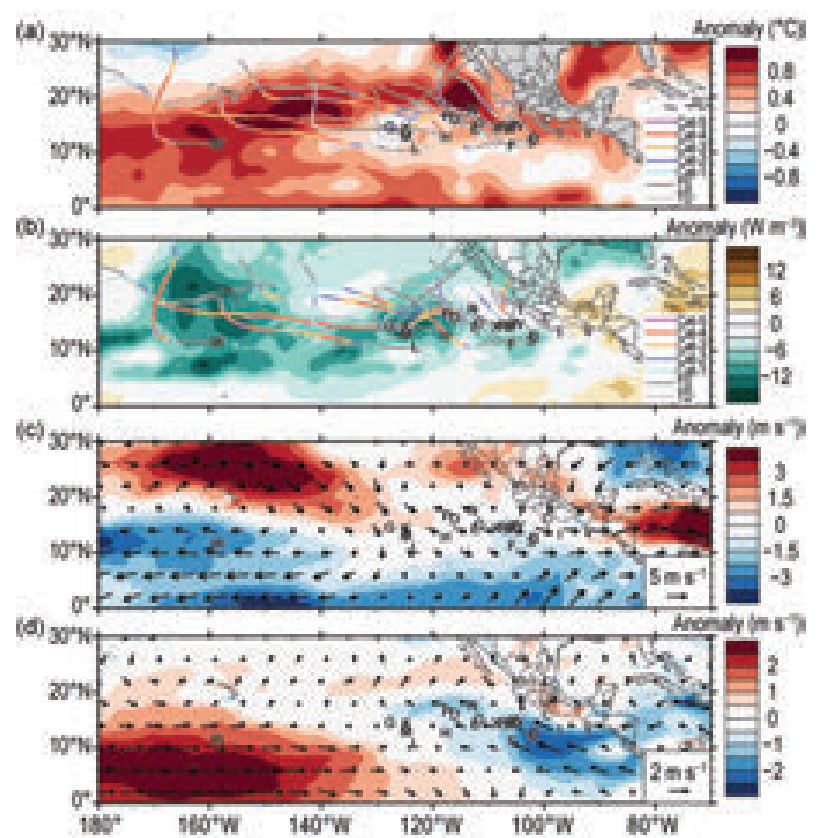

FIg. 4.25. I5 May-30 Nov 2018 anomaly maps of (a) SST ( ${ }^{\circ} \mathrm{C}$, Banzon and Reynolds 2013), (b) OLR ( $W ~ m^{-2}$, Schreck et al. 20l8), (c) 200-850-hPa vertical wind shear ( $\left.\mathrm{m} \mathrm{s}^{-1}\right)$ vector (arrows) and scalar (shading) anomalies, and (d) $850-\mathrm{hPa}$ winds ( $\mathrm{m} \mathrm{s}^{-1}$, arrows) and zonal wind (shading) anomalies. Anomalies are relative to the annual cycle from 1981-2010, except for SST, which is relative to $1982-2010$ due to data availability. Hurricane symbols with letters denote where each ENP TC attained tropical storm intensity. Wind data are obtained from CFSR (Saha et al. 20I4).

ENP TC activity is strongly influenced by the MJO (Maloney and Hartmann 2001; Aiyyer and Molinari 2008; Slade and Maloney 2013; Schenkel 2017), and recent studies have found a greater role for convectively coupled Kelvin waves in modulating tropical cyclogenesis (Schreck and Molinari 2011; Ventrice et al. 2012a,b; Schreck 2015, 2016). Figure 4.26 uses OLR to examine the evolution of convection during the 2018 ENP hurricane season. Following Kiladis et al. $(2005 ; 2009)$, the black contours identify the MJOfiltered anomalies and the blue contours identify the Kelvin waves. Easterly waves are also apparent in the unfiltered anomalies (shading) as westward-moving features, such as that leading up to Hurricane Sergio.

An MJO event helped kick off the ENP hurricane season in June, leading to three TC formations within an 8-day period (6-14 June). This MJO was punctuated by a Kelvin wave that likely played a role in Tropical Storm Carlotta's genesis. The MJO was generally inactive for the remainder of the season, but many of the tropical cyclogenesis events were promoted by a series of Kelvin waves. Cyclogenesis is typically favored 0-3 days after the passage of a Kelvin wave's

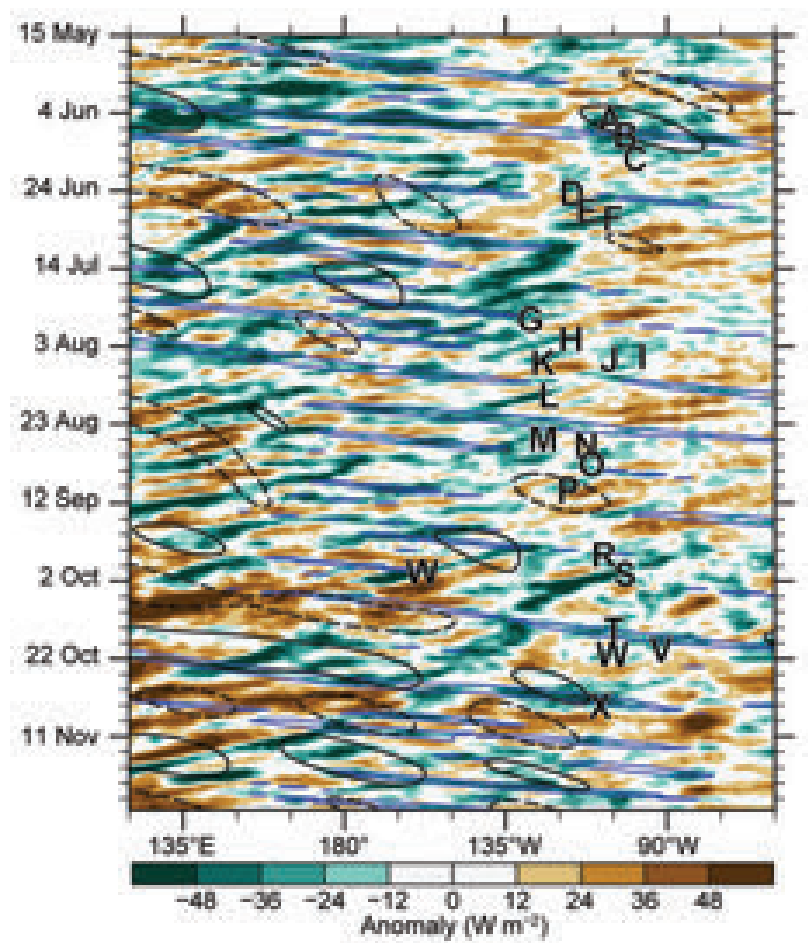

Fıg. 4.26. Longitude-time Hovmöller of OLR (W m ${ }^{-2}$, Schreck et al. 2018) averaged over $5^{\circ}-15^{\circ} \mathrm{N}$. Unfiltered anomalies from a daily climatology are shaded. Negative anomalies (green) indicate enhanced convection. Anomalies filtered for Kelvin waves are contoured in blue at $-10 \mathrm{~W} \mathrm{~m}^{-2}$ and MJO-filtered anomalies in black at $\pm 10 \mathrm{~W} \mathrm{~m}^{-2}$. Letters indicate the genesis location of ENP-CNP TCs. Note: "W" at $\left(29^{\mathrm{Sep}}, 159^{\circ} \mathrm{W}\right)$ is Walaka; "W" at $\left(20\right.$ Oct, $\left.105^{\circ} \mathrm{W}\right)$ is Willa.

peak convection, which happened for the geneses of Emilia, Fabio, Ileana, John, Kristy, Miriam, Norman, Rosa, Sergio, Vincente, Willa, and Xavier.

\section{(iii) Tropical cyclone impacts}

During the 2018 season, four named storms made landfall in Mexico, while two storms in the CNP region closely brushed or made landfall in Hawaii. The long-term annual average number of landfalling storms on the western coast of Mexico is 1.8 (Raga et al. 2013).

Hurricane Bud (9-15 June) was the first storm to make landfall along the Mexican coast, in the Baja California Sur region near Cabo San Lucas. The storm weakened to a tropical storm before landfall, when wind gusts peaked at $41 \mathrm{kt}\left(21 \mathrm{~m} \mathrm{~s}^{-1}\right)$. Notably, as it decayed, the moisture associated with Bud brought beneficial and much-needed rainfall to drought-stricken areas of New Mexico and Texas as the storm lifted northeastward.

Hurricane Lane (15-28 August), while not making direct landfall in the Hawaiian Islands, caused a number of storm-related impacts. Lane was a 
Category 5 storm with peak winds at $140 \mathrm{kt}\left(72 \mathrm{~m} \mathrm{~s}^{-1}\right)$ and a minimum central pressure of $922 \mathrm{hPa}$. It was only the second Category 5 storm on record to pass within $550 \mathrm{~km}$ of South Point, Hawaii. The hurricane moved from east to west to just south of the Big Island of Hawaii while intensifying to a Category 5 hurricane before slowing and turning north-northeast but remaining west of the Hawaiian Islands. The storm center moved within $175 \mathrm{~km}$ of Honolulu before turning west and moving away from the island chain. The strong shear that Lane experienced weakened it and changed its track due to a minimal steering flow (Velden and Leslie 1991). The storm's proximity and deep southerly and southeasterly flow resulted in tremendous rainfall across eastern and central parts of the Big Island, with total rainfall amounts in excess of $800 \mathrm{~mm}$, and some isolated areas greater than $1300 \mathrm{~mm}$. The excessive rainfall caused a number of mudslides, landslides, and school and road closures, and damaged 23 homes. Farther north on Maui, a rogue wildfire, sparked by high winds and downed power lines, threatened an evacuation center and burned nearly two dozen homes before firefighters could extinguish the blaze. The hurricane then brought torrential rainfall to the island, with many areas receiving $300-600 \mathrm{~mm}$ of rainfall, resulting in multiple landslides. Impacts to Oahu and Kauai were less than their southerly counterparts, but gusty winds, elevated seas, and above-average rainfall were observed.

Hurricane Olivia (1-13 September) initiated as a weak tropical depression just off the Mexican coastline. It steadily moved westward and intensified to a strong Category 4 storm with maximum sustained winds of $115 \mathrm{kt}\left(59 \mathrm{~m} \mathrm{~s}^{-1}\right)$ and a minimum central pressure of $951 \mathrm{hPa}$. Olivia then moved into the Central Pacific basin and weakened before making landfall on Maui as a tropical storm - the first tropical storm in recorded history to make a direct hit on the island. Olivia brought storm-force winds to the islands of Lanai, Maui, and Oahu, downing many trees and causing numerous power outages. Widespread rains of 100-300 mm were observed across these islands, causing many local flash floods, washing out roads, and forcing the overflow of a sewage pipe on Oahu that sent over 300000 gallons of raw sewage into Honolulu Harbor.

Hurricane Rosa (25 September-3 October), with maximum sustained winds of $125 \mathrm{kt}\left(64 \mathrm{~m} \mathrm{~s}^{-1}\right)$ and a minimum central pressure of $940 \mathrm{hPa}$, made landfall as a tropical storm in western Baja California. The storm fluctuated in intensity as it turned northeastward and began interacting with land late in its life cycle prior to landfall. The governor of Baja California declared a state of emergency as Rosa approached, which led to school closures. The hurricane deposited nearly $100 \mathrm{~mm}$ of rainfall across the region, resulting in multiple road closures and the flooding of many homes and businesses. The storm then rapidly decayed over land and moved northeast into the southwestern United States where additional heavy rainfall was observed. Parts of southern Arizona received 25-140 mm of rainfall, and flash flood warnings were issued for the city of Phoenix as $50 \mathrm{~mm}$ fell in 24 hours on 2 October, one of the city's wettest days on record.

Hurricane Sergio (29 September-13 October) originated several hundred miles south of the Gulf of Tehuantepec and moved west and eventually northwest before reaching its maximum intensity on 6 October. Maximum sustained winds were 120 kt $\left(62 \mathrm{~m} \mathrm{~s}^{-1}\right)$, and its minimum central pressures dropped to $943 \mathrm{hPa}$. The storm then stalled briefly before interacting with an upper-level shortwave trough that weakened the storm. Sergio then moved northeast and made landfall in Baja California on 11 October as a minimal tropical storm. Sergio's primary impacts were from gusty winds and heavy rains that closed roads, schools, and forced evacuations of 400 residents. Much like the other 2018 storms to affect Baja, Sergio also moved northeast from Baja into the desert southwest United States, bringing yet more rains to the region. The remnants of Sergio spurred the development of strong thunderstorms in southern California, causing some local power outages. Heavy rains were once again reported in Phoenix, Arizona (nearly $75 \mathrm{~mm}$ ), forcing the closure of the Arizona State Fair due to flooding. The remnant storm also resulted in the development of a few tornadoes across western Texas, including multiple twisters near I-45 in Angus, Texas.

The last storm to make landfall in the 2018 season was Hurricane Willa (20-24 October), which made landfall in Isla del Bosque, Mexico as a Category 3 hurricane with winds near $105 \mathrm{kt}\left(54 \mathrm{~m} \mathrm{~s}^{-1}\right)$. Prior to landfall, Willa was an intense Category 5 storm with maximum sustained winds of $140 \mathrm{kt}\left(72 \mathrm{~m} \mathrm{~s}^{-1}\right)$ and a minimum central pressure of $925 \mathrm{hPa}$. The storm is perhaps most well-known for its extremely rapid intensification by over $65 \mathrm{kt}\left(33 \mathrm{~m} \mathrm{~s}^{-1}\right)$ in just a 24 -h period on 21 October. The impacts from the landfall of Willa were blackouts from power outages, damages to tin roof structures, and large battering surf south of Mazatlan. Heavy rainfall of 125-250 mm was recorded along the path of the storm before it was disrupted and weakened by the high mountainous terrain of Mexico. The remnants of Willa eventually 
moved northeastward into the United States, bringing $25-50 \mathrm{~mm}$ of rain to parts of central and southern Texas before moving into the Gulf of Mexico and up the East Coast, bringing several centimeters of wet snow to northern New England.

\section{4) Western North Pacific Basin—S. J. Camargo}

(i) Introduction

The TC data used here are from the JTWC western North Pacific (WNP) best-track dataset for the 1945-2017 period and from the JTWC preliminary operational data for 2018. Climatology is defined using the period 1981-2010, with the exception of landfall statistics, where 1951-2010 was used. All statistics are based on the climatological distribution, unless specifically stated that they are based on the historical record.

The 2018 TC season in the WNP was slightly above normal by most measures of TC activity. According to the JTWC, a total of 29 TCs (median $=26$ ) reached tropical storm intensity in the WNP during 2018, including Hector, which formed in the eastern North Pacific and crossed into the WNP and is considered a TS for the WNP. From these, 16 reached typhoon intensity (median $=16)$, with 7 reaching super typhoon status ( $>130 \mathrm{kt}$; top quartile $\geq 5$ ). There were also eight tropical depressions (top quartile $\geq 5$ ), including Bolaven, which formed and peaked in December 2017, but is considered a TD for 2018, and Toraji, which was considered a tropical storm by the Japan Meteorological Agency (JMA). ${ }^{1}$ In Fig. 4.27a, the number in each category is shown

\footnotetext{
${ }^{1}$ It is well known that there are systematic differences between the JMA and the JTWC, which have been extensively documented in the literature (e.g., Wu et al. 2006; Nakazawa and Hoshino 2009; Song et al. 2010; Ying et al. 2011; Yu et al. 2012; Knapp et al. 2013; Schreck et al. 2014). Data presented here are from JTWC unless otherwise noted.
}

for the period $1945-2018$. Only 55\% of the tropical storms became typhoons (bottom quartile $\leq 57 \%$ ). In contrast, the percentage of typhoons reaching super typhoon intensity (44\%) was in the top quartile $(\geq 30 \%)$.

The JMA total for 2018 was 28 storms (median = 26). Wukong, Leepi, and Usagi were considered severe tropical storms by JMA and typhoons by JTWC. Of the 28 TCs, 10 were tropical storms (top quartile $\geq$ 7), 5 were severe tropical storms (median $=5$ ), and 13 were typhoons (bottom quartile $\leq 13$ ). Only $46 \%$ of the storms reached typhoon intensity (bottom
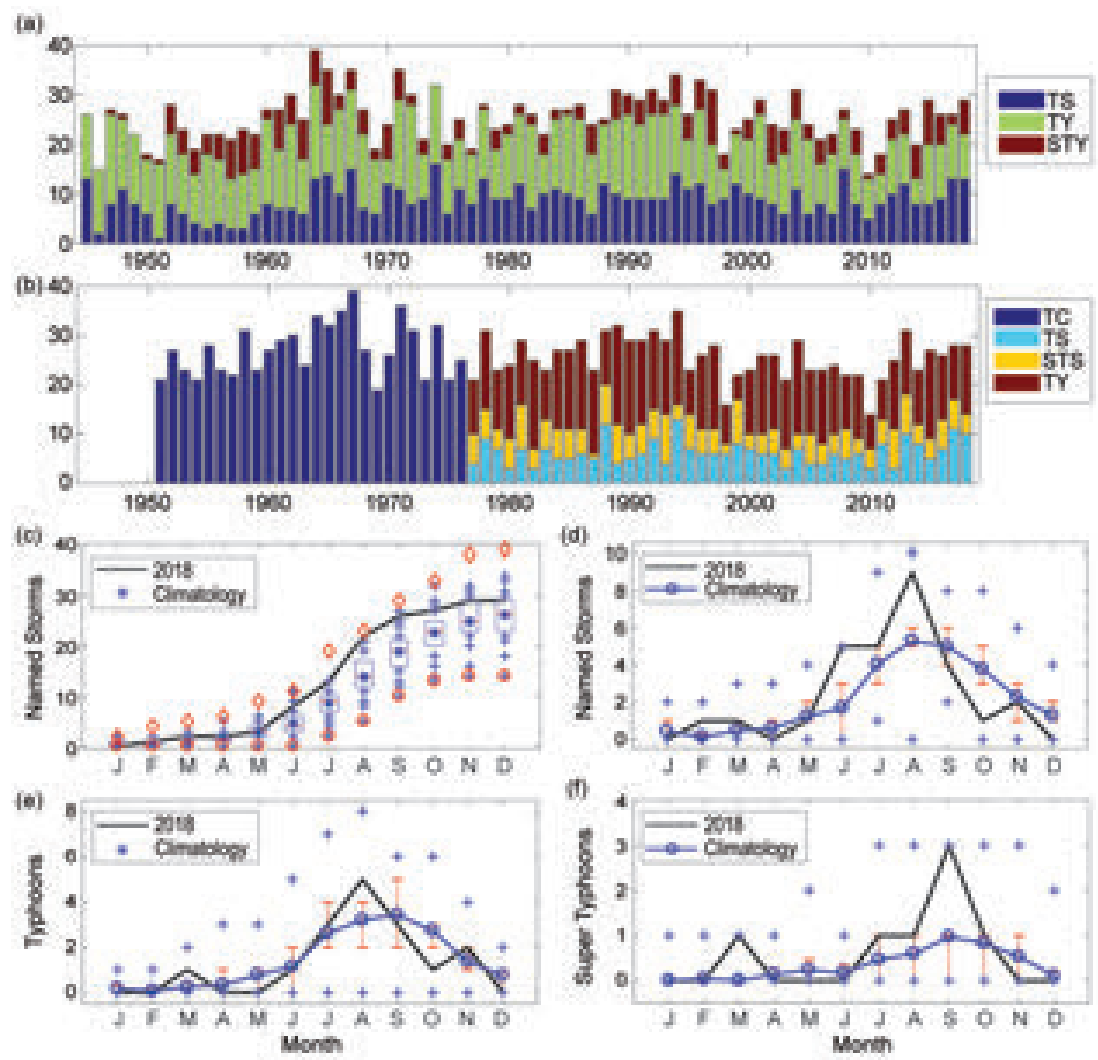

Fig. 4.27. (a) Number of tropical storms (TS), typhoons (TY), and super typhoons (STY) per year in the WNP for the period 1945-2018 based on JTWC best-track dataset. (b) Number of tropical cyclones (TC; all storms which reach TS intensity or higher) from 195I to 1976; number of TS, severe tropical storms (STS) and TY from 1977 to 2018 based on JMA best-track dataset. Panel (c) shows the cumulative number of tropical cyclones with TS intensity or higher (named storms; NS) per month in the WNP in 2018 (black line), and climatology (1981-2010) as box plots [interquartile range: box, median: red line, mean: blue asterisk, values in the top or bottom quartile: blue crosses, high (low) records in the 1945-20I7 period: red diamonds (circles)]. Panels (d), (e), and (f) show the number of NS, TY, and STY, respectively, per month in 2018 (black line) and the climatological mean (blue line); blue plus signs denote maximum and minimum monthly historical records; and the red error bars show the climatological interquartile range for each month, when they do not coincide with the median. [Sources: 1945-2017 JTWC best-track dataset, 2018 JTWC preliminary operational track data for panels (a), (c), (d), (e), and (f). I95I-20I8 RSMC-Tokyo, JMA best-track dataset for panel (b).] 
quartile $\leq 50 \%)$. The number of all TCs (1951-1976) and tropical storms, severe tropical storms, and typhoons (1977-2018) according to the JMA are shown in Fig. 4.27b. The Philippine Atmospheric, Geophysical and Astronomical Services Administration (PAGASA) named all 21 TCs that entered its area of responsibility, including Tropical Depressions Josie, Luis, and Usman, which were not named by JMA.

\section{(ii) Seasonal activity}

The first WNP storm in 2018 was Tropical Depression Bolaven, which formed in December 2017 and was active until 4 January 2018. It was followed by Tropical Storm Sanba in February and Super Typhoon Jelawat, which formed at the end of March. Only two other super typhoons have formed in March in the historical record (Typhoons Tess in 1961 and Maysak in 2015). No TCs formed in April (bottom quartile $=0$ ), and only Tropical Storm Four was active in May (median =1). In contrast, four tropical storms (Ewiniar, Maliksi, Seven, and Gaemi) and one typhoon (Prapiroon) formed in June (top quartile $\geq 3$ ). July was also an active month, with five TCs forming in the basin (top quartile $\geq 5$ ). During July, Super Typhoon Maria, Typhoons Wukong and Jongdari, Tropical Storms Son-Tinh and Ampil, and Tropical Depressions Thirteen and Sixteen developed. The active period continued in August, with the formation of eight TCs (Super Typhoon Jebi; Typhoons Shanshan, Leepi, Soulik, and Cimaron; and Tropical Storms Yagi, Bebinca, and Rumbia); and the presence of Tropical Storm Hector, which crossed from the eastern North Pacific (top quartile of all categories). In September, four TCs formed in the basin (bottom quartile $\leq 4$ ), with one tropical storm (Barijat) and three super typhoons (Mangkhut, Barijat, and Trami). The three super typhoons in September equaled the historical maximum of that month. October had a low number of storms with only one TC (bottom quartile $\leq 3$ ), named Yutu, which also reached super typhoon intensity (median $=1$ ). November had Typhoons Usagi and Man-yi (top quartile $\geq 2$ ) and Tropical Depression Toraji. The season ended with two tropical depressions in December (top quartile $\geq 2$ ): Thirty-Five and Thirty-Six. The latter formed on the last day of the year and continued into January 2019, when it reached tropical storm status and was named Babuk.

As shown in Figs. 4.27c-f, the early season (January-June) was quite active with eight TCs, including six tropical storms, two typhoons, and one super typhoon. This corresponds to top quartile values for TCs $(\geq 6)$, tropical storms $(\geq 3)$, and super typhoons $(\geq 1)$ and below the median (=3) for typhoons. The peak season (July-October) was also busy with a total of 19 TCs (median $=17$ ), including 12 typhoons (median $=12$ ) and six super typhoons (top quartile 23.5). Half of all typhoons reached super typhoon status during this period. The late season (November-December) had five TCs (top quartile), with two typhoons (median $=2$ ) and no tropical storms (bottom quartile $=1$ ). In summary, there was an active period early in the season, that is, February and March. Most of the storms occurred June-September, and there was low-to-normal activity from October to the end of the calendar year.

The total ACE in 2018 (Fig. 4.28a) was above normal, close to the top quartile. During February-March and July-October (Fig. 4.28b), ACE was above normal, with values in the top quartiles of the monthly climatologies, except for October. Most seasonal ACE occurred during the peak season (JulyOctober), with each of those months corresponding to $18 \%, 23 \%, 30 \%$, and $20 \%$ of the total ACE, respectively. Four storms in 2018 were in the top 5\% of ACE

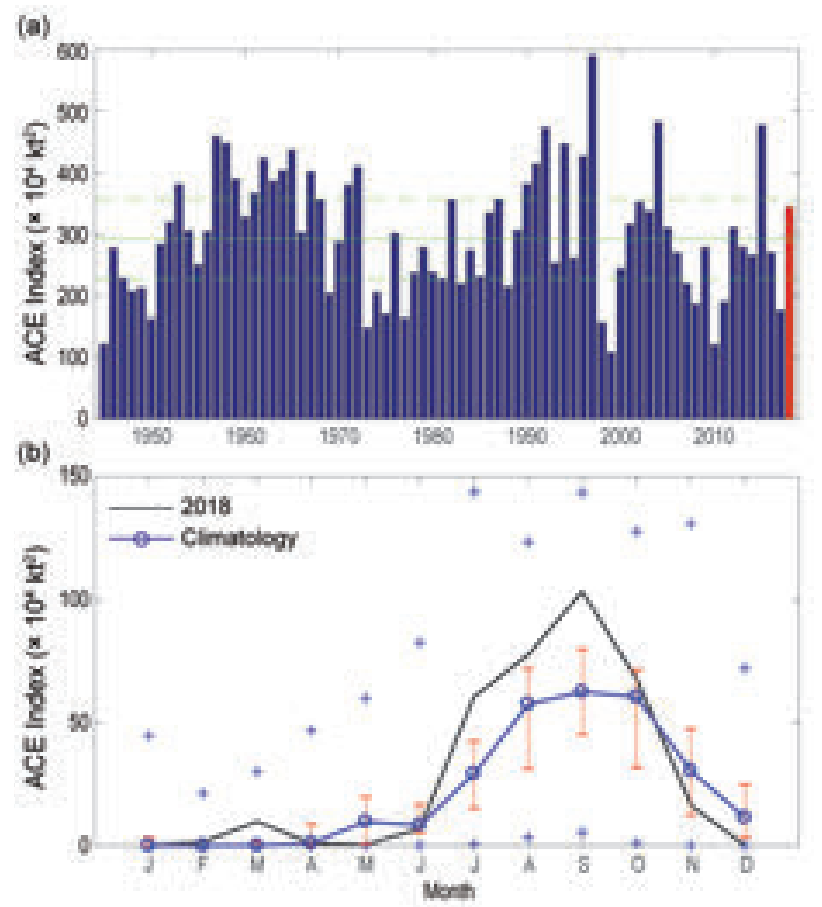

FIG. 4.28. (a) ACE index $\left(\times 10^{4} \mathrm{kt}^{2}\right)$ per year in the WNP for 1945-2018. The solid green line indicates the median for the 198I-2010 climatology; the dashed lines show the climatological 25 th and 75 th percentiles. (b) ACE index $\left(\times 10^{4} \mathrm{kt}^{2}\right)$ per month in 2018 (black line) and the median during $198 \mathrm{I}-2010$ (blue line), the red error bars indicate the 25th and 75th percentiles, when they do not coincide with the median. Blue "+" signs denote the maximum and minimum values during 1945-2017. (Source: 1945-2017 JTWC best-track dataset, 2018 JTWC preliminary operational track data.) 
per storm in the historical record: Super Typhoons Yutu, Mangkhut, Maria, and Trami, contributing respectively $14 \%, 13 \%, 11 \%$, and $10 \%$ of the seasonal ACE. Furthermore, Super Typhoons Jebi, Kong-Rey, and Typhoon Soulik were in the top quartile of the historical record. Combined, these seven storms contributed $71 \%$ of the seasonal ACE.

The mean genesis location in 2018 (excluding Tropical Storm Hector, which formed in the ENP basin) was $12.3^{\circ} \mathrm{N}, 144.7^{\circ} \mathrm{E}$, a small southeastward shift from the climatological mean of $13.2^{\circ} \mathrm{N}, 141.6^{\circ} \mathrm{E}$ (standard deviations of $1.9^{\circ}$ latitude and $5.6^{\circ}$ longitude). In contrast, the mean track position was $19.7^{\circ} \mathrm{N}, 135.0^{\circ} \mathrm{E}$, which was shifted to the northwest of the climatological mean $17.3^{\circ} \mathrm{N}, 136.6^{\circ} \mathrm{E}$ (standard deviations of $1.4^{\circ}$ latitude, $4.7^{\circ}$ longitude). There is a well-known connection between genesis and track shifts in the WNP basin and El Niño/La Niña (Chia and Ropelewski 2002; Camargo et al. 2007). However, in 2018 there was no robust shift of genesis and tracks, probably due to neutral ENSO conditions during peak typhoon season.

There were 114 days with storms reaching tropical storm intensity (median $=113$ days). From these active days, 62 had typhoons (median $=61$ ) and 29 days had intense typhoons (Saffir-Simpson categories 3-5; median $=21$ ). The percentage of days with typhoons and intense typhoons was 40\% (median = $40 \%$ ) and $19 \%$ (top quartile $\geq 17 \%$ ) respectively. The median lifetime of the 2018 season for TCs reaching tropical storm intensity and typhoon status was 7.75 $($ median $=7.6)$ and $8.75($ median $=9.1)$ days, respectively. The longest-lived storm was Hurricane Hector (15 days), but only 2.5 of those days were in the WNP (as a tropical storm). The rest of Hector's lifetime was in the ENP basin. Considering WNP-only storms, the longest lifetimes were Typhoon Jongdari (12.75 days), Super Typhoon Yutu (12 days), and Super Typhoon Trami (10.5 days) - all of which were in the top quartile ( $\geq 10.5$ days). From the 29 tropical storms and typhoons, 16 had lifetimes at or below the median (7.75 days), with 8 in the bottom quartile ( $\leq 5.25$ days). There were five TCs in the WNP basin simultaneously active on 22 July. This was a historical record for July and close to the historical record of six TCs from 14-15 August 1996. Three TCs reaching tropical storm intensity were also active simultaneously in August.

Landfall is defined when the storm track is over land, and the previous location was over the ocean. To not miss landfall over small islands, tracks were interpolated from 6-hourly to 15 -minute intervals, while using a high-resolution land mask. Including tropical depressions, 24 storms made landfall in 2018, ranking in the 95th percentile compared with the 1951-2010 climatology. Of these, five made landfall as TDs (top quartile $\geq 4$ ), and 13 as TSs (top 95th percentile $\geq 11$ ). Only 1962 had more tropical storm landfalls (14) in the historical record. Five storms (Maria, Cimaron, Jebi, Trami, and Yutu) made landfall at typhoon intensity (median $=5$ ). Super Typhoon Mangkhut made landfall as an intense typhoon (bottom quartile $\leq 1$ ). It made its first landfall in the Philippines as a Category 5 storm at $145 \mathrm{kt}\left(75 \mathrm{~m} \mathrm{~s}^{-1}\right)$, followed by a second landfall in Hong Kong as a Category 3 storm. Although Mangkhut (Ompong) was one of the strongest typhoons to make landfall in the Philippines, there were no available surface observations at the time of landfall in Baggao, Cagayan, according to PAGASA. The lowest mean sea-level pressure observed by PAGASA was $949 \mathrm{hPa}$ in Tuguegarao City, Cagayan, and the highest maximum sustained winds (10-min) were $58 \mathrm{kt}\left(30 \mathrm{~m} \mathrm{~s}^{-1}\right)$ in Aparri, Cagayan. Mangkhut's winds were the second highest in the historical record to affect Hong Kong, below only Typhoon Ellen in 1983, according to the Hong Kong Observatory. Furthermore, there were six TCs that made landfall in Japan in 2018 (top 95th percentile $\geq 6$ ). Only two years in the historical record had a larger number of landfalls: 2004 (eight) and 1993 (seven).

\section{(iii) Environmental conditions}

Figure 4.29 shows July-October (JASO) environmental conditions associated with the typhoon activity in 2018. The main feature is a borderline central Pacific El Niño SST anomaly (Fig. 4.29a) that started in the boreal summer and strengthened in October, at the end of the typhoon peak season, with belownormal SST anomalies in a horseshoe pattern around it, in particular near Asia. Despite the above-average ocean temperatures across the equatorial Pacific, the coupled ocean-atmosphere system reflected an ENSO-neutral state. This pattern is reflected in a few of the environmental fields, such as the potential intensity (Fig. 4.29b; Emanuel 1988) and the 600-hPa relative humidity (Fig. 4.29c), which have maxima in the equatorial region west of the date line. The genesis potential index (GPI; Fig. 4.29d, Emanuel and Nolan 2004; Camargo et al. 2007) had a maximum in a narrow band starting near the China coast around $25^{\circ} \mathrm{N}$ and with increasing values extending southeastward toward the central Pacific. Most TC genesis in JASO occurred close to that band. The maximum extent of the monsoon trough, as defined by the $850-\mathrm{hPa}$ zonal winds (Fig. $4.29 \mathrm{e}$ ), extended to $150^{\circ} \mathrm{E}$, influenced by the developing weak El Niño event; this is important 
(a)

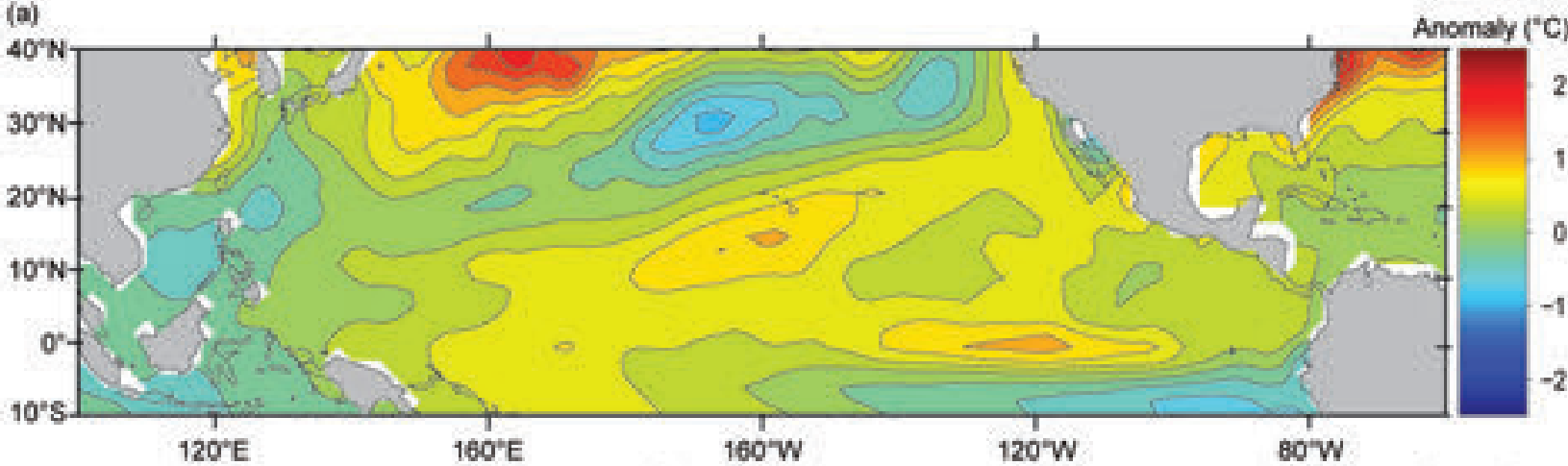

(b)

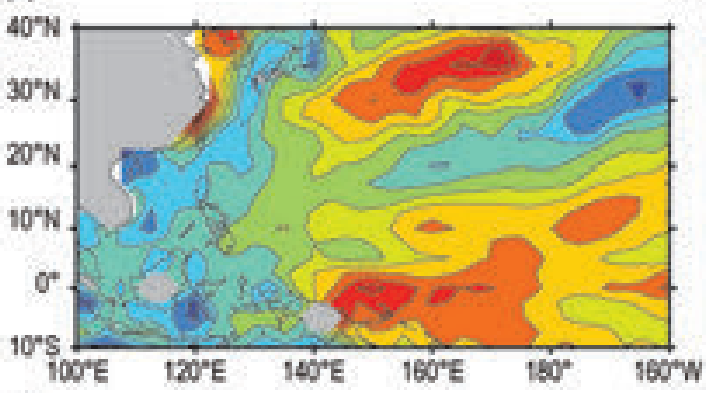

(d)
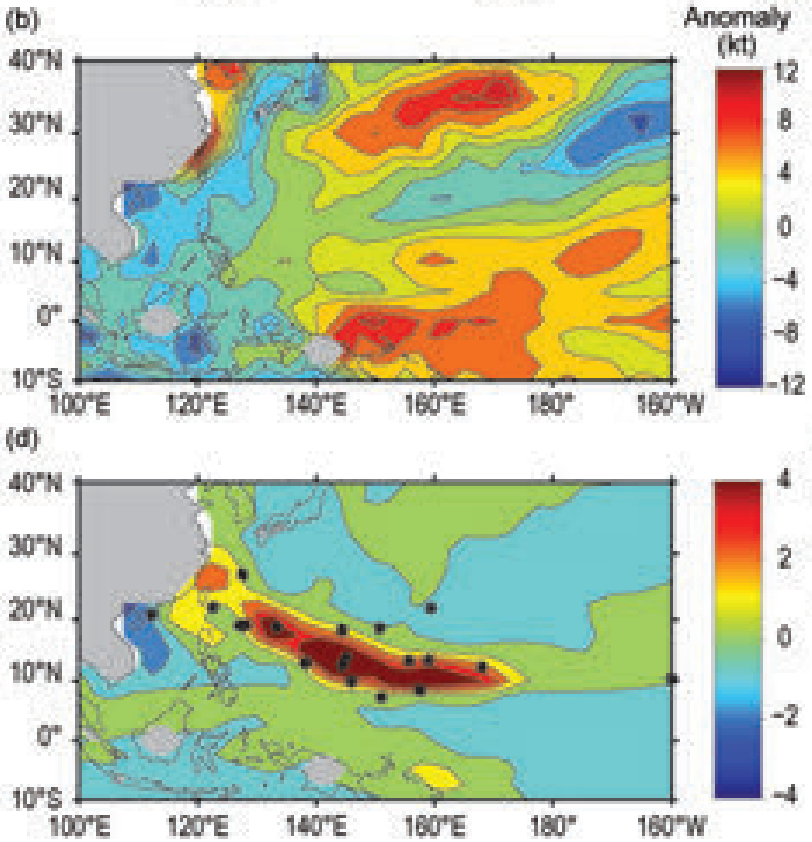

(e)

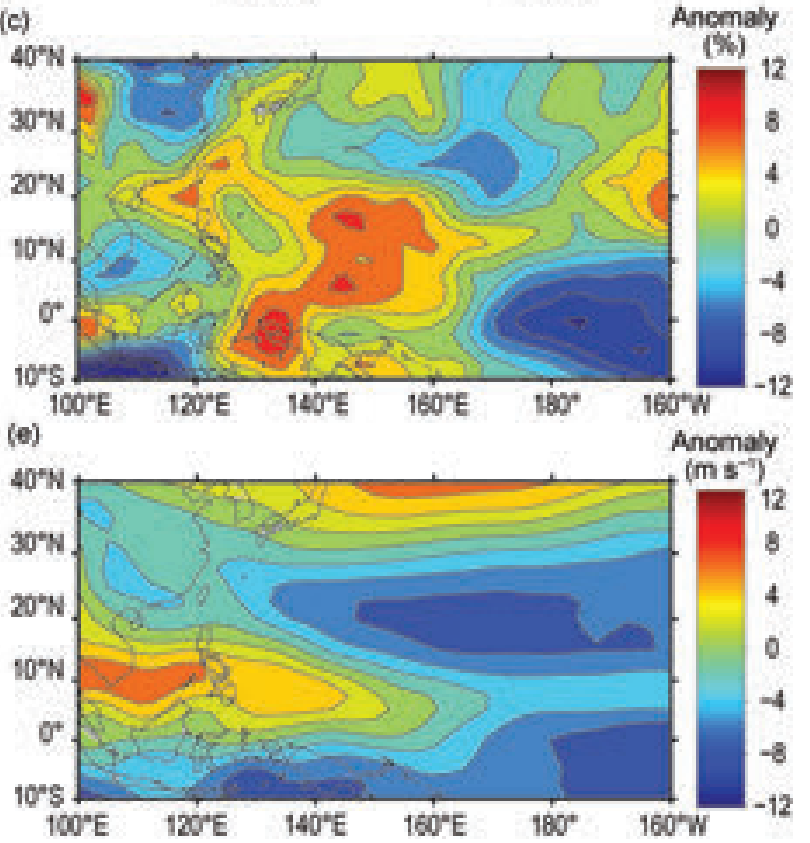

FIG. 4.29. Jul-Oct (JASO) 2018: (a) SST anomalies ( $\left.{ }^{\circ} \mathrm{C}\right)$. (b) Potential intensity anomalies (kt). (c) Relative humidity anomalies (\%) at $600 \mathrm{hPa}$. (d) Genesis potential index anomalies. First position of storms are marked with an asterisk. (e) $850 \mathrm{hPa}$ zonal winds. [Source: atmospheric variables: NCEP/NCAR Reanalysis data (Kalnay et al. 1996); SST: ERSSTv3b (Smith et al. 2008).]

to note as TC genesis in the WNP is usually associated with the location of the monsoon trough.

\section{(iv) Tropical cyclone impacts}

Many storms had a significant social and economic impact on Asia in 2018. Super Typhoon Jebi made landfall twice in Japan and severely impacted the Kansai region, including closing the Kansai International Airport for a week due to flooding. The storm was the most expensive natural disaster to affect Asia in 2018 , leading to $\$ 12$ billion (U.S. dollars) in losses in Japan, including $\$ 8$ billion (U.S. dollars) in insured losses, and 17 deaths. Super Typhoon Trami caused $\$ 4.5$ billion (U.S. dollars) in losses in Japan. Super Typhoon Mangkhut led to 160 deaths and caused $\$ 6$ billion (U.S. dollars) in economic losses across the WNP, with severe impacts in the Philippines,
Hong Kong, Macau, mainland China, Guam, and the Northern Mariana Islands. Tropical Storm Son-Tinh was responsible for the highest number of fatalities in the western North Pacific, with 170 fatalities in Vietnam and Laos due to flooding, mudslides, and the collapse of the Attapeu Dam in Laos. Son-Tinh was also responsible for $\$ 255$ million (U.S. dollars) in economic losses in China, Vietnam, and Laos.

\section{5) NORTH INDIAN OCEAN BASIN-M. C. Kruk}

The North Indian Ocean (NIO) TC season typically extends from April to December, with two peaks in activity: during May-June and again in November, when the monsoon trough is positioned over tropical waters in the basin. Tropical cyclones in the NIO basin normally develop over the Arabian Sea and the Bay of Bengal between $8^{\circ}-15^{\circ} \mathrm{N}$. These systems are usually 
short-lived, relatively weak, and often quickly move into the Indian subcontinent (Gray 1968; Schreck et al. 2014).

According to the JTWC, the 2018 TC season produced eight tropical storms, four cyclones, and one major cyclone (Fig. 4.30a). The 1981-2010 IBTrACS seasonal averages for the basin are 3.9 tropical storms, 1.4 cyclones, and 0.6 major cyclones (Schreck et al. 2014). The seasonal ACE index was $31 \times 10^{4} \mathrm{kt}^{2}$, which is almost two times the 1981-2010 mean of $16 \times 10^{4} \mathrm{kt}^{2}$ (Fig. 4.30b). Typically, there is enhanced TC activity, especially in the Bay of Bengal, during the cool phase of ENSO (Singh et al. 2000). In spite of the transition toward El Niño in 2018, the eight tropical storms recorded this year is the most since 1998 .

The first named storm of the season, Cyclone Sagar (16-19 May), was the strongest TC in recorded history to make landfall in Somalia. Sagar had maximum sustained winds of $56 \mathrm{kt}\left(29 \mathrm{~m} \mathrm{~s}^{-1}\right)$ and a minimum central pressure of $994 \mathrm{hPa}$. The storm took a rare path through the Gulf of Aden and intensified into
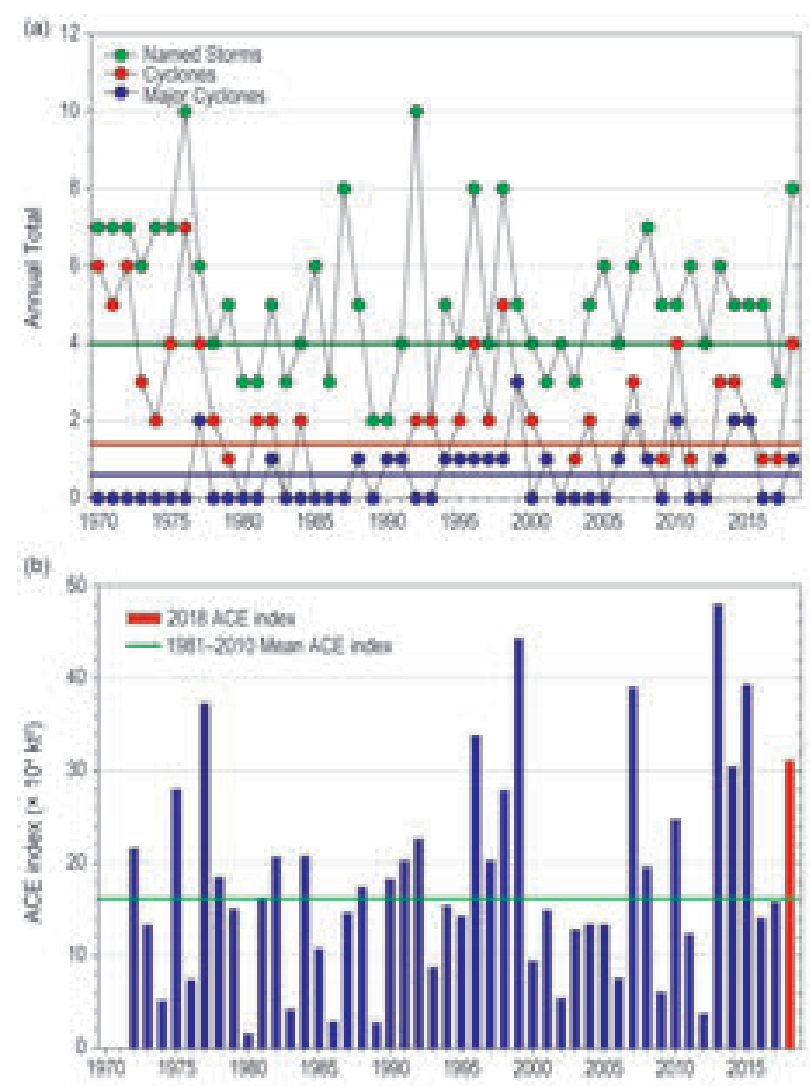

FIG. 4.30. Annual TC statistics for the NIO for 19702017: (a) number of named storms, cyclones, and major cyclones and (b) estimated annual ACE index $\left(\times 10^{4} \mathrm{kt}^{2}\right)$ for all TCs during which they were at least tropical storm strength or greater intensity (Bell et al. 2000). The 1981-2010 means (green lines) are included in both (a) and (b). a cyclonic storm (winds $34-47 \mathrm{kt}$ on the Indian Meteorological Department's scale). As the storm moved southwest, it ran parallel to the coast of Yemen, where strong winds damaged homes and heavy rainfall damaged roads and the electrical supply. The unusual event also forced the evacuation of parts of Aden, the capital of Yemen, as high winds blew through the city. In Somalia, rainfall was excessive, totaling nearly the annual average in certain parts of the country $(110 \mathrm{~mm})$ in just 24 hours. This rainfall resulted in flooding that damaged over 10000 homes and displaced over 3000 citizens. The heavy rain also killed 53 people, damaged hundreds of hectares of crop land, and killed livestock including sheep, goats, and camels.

Cyclone Mekunu (22-26 May) was the strongest TC to make landfall along the Arabian Peninsula since reliable records began in the North Indian Ocean basin in 1960. At its peak, Mekunu had maximum sustained winds of $100 \mathrm{kt}\left(51 \mathrm{~m} \mathrm{~s}^{-1}\right)$ and a minimum central pressure of $960 \mathrm{hPa}$. The storm developed in a very favorable environment, characterized by warm oceanic waters of $29^{\circ} \mathrm{C}$ and low-to-moderate wind shear. The storm moved steadily northwest and intensified into a very severe cyclonic storm (winds 64-89 kt) and then into an extremely severe cyclonic storm (90-119 kt) just a day later. Along its northwesterly track, Mekunu passed near Socotra Island, causing myriad impacts from flooding and landslides that smothered farm fields, destroyed palm trees, and washed away thousands of animals. Thereafter, Mekunu made landfall at peak intensity on southern Oman near Raysut. In Salalah, the storm brought an impressive $627 \mathrm{~mm}$ of rainfall-five times the annual average-in a 96-hour period, including $278 \mathrm{~mm}$ in just 24 hours. For the first time in nearly 20 years, the rainfall from Mekunu filled and created large lakes in the desert. These newly filled lakes were expected to benefit livestock.

During 6-14 October, Cyclone Luban formed in a similar location to that of Cyclone Sagar and moved along a northwesterly track into eastern Yemen. At peak intensity, Luban had maximum sustained winds of $75 \mathrm{kt}\left(39 \mathrm{~m} \mathrm{~s}^{-1}\right)$ and a minimum central pressure of $976 \mathrm{hPa}$. The cyclone affected nearly the same areas that were hard hit by Sagar earlier in the year. As a result, damages were very high and compounded by ongoing regional war and disease. In Al Mahrah Governorate, roughly $90 \%$ of the infrastructure was damaged or destroyed and 8000 citizens were left homeless. Thousands of livestock were lost due to flooding from over $140 \mathrm{~mm}$ of rainfall, and many dirt roads were completely lost, isolating several villages. Fourteen people were killed by the storm, and 124 more were injured. 
Cyclone Titli (8-12 October) developed in the Andaman Sea and moved into the Bay of Bengal where it intensified into a very severe cyclonic storm. Titli's maximum sustained winds were $80 \mathrm{kt}\left(41 \mathrm{~m} \mathrm{~s}^{-1}\right)$ with a minimum central pressure of $970 \mathrm{hPa}$. Unfortunately, Titli made landfall near Palasa, Andhra Pradesh, at maximum intensity. The storm was responsible for 85 fatalities, mostly from heavy rains $(90-150 \mathrm{~mm}$ in 24 hours), flooding, and landslides. The cyclone's strong winds also uprooted many trees and damaged communication lines and many homes.

Cyclone Gaja (10-20 November) was a strong lateseason storm that had a maximum intensity of $75 \mathrm{kt}$ ( 39 $\mathrm{m} \mathrm{s}^{-1}$ ) and a minimum central pressure of $983 \mathrm{hPa}$. The storm developed in the Gulf of Thailand and moved westward, gradually strengthening once it crossed into the Andaman Sea. The storm initially tracked through southern Thailand and the Malay Peninsula with only minimal impacts. Gaja then made a second landfall in Tamil Nadu and Puducherry in southern India near its peak intensity. The storm was responsible for 63 fatalities, with several individuals still missing. Affected areas also had tremendous damages, including thousands of cattle and birds killed, 18000 ha of coconut trees uprooted, and 56000 ha of other crops lost.

\section{6) South Indian Ocean basin-M. C. Kruk and} C. J. Schreck

The South Indian Ocean (SIO) basin extends south of the equator from the African coastline to $90^{\circ} \mathrm{E}$, with most cyclones developing south of $10^{\circ} \mathrm{S}$. The SIO TC season extends from July to June encompassing equal portions of two calendar years (i.e., the 2018 season includes storms from July 2017 through June 2018). Peak activity typically occurs during December-April when the ITCZ is located in the Southern Hemisphere and migrating toward the equator. Historically, most landfalling cyclones in the SIO affect Madagascar, Mozambique, and the Mascarene Islands, including Mauritius and Réunion Island. The Regional Specialized Meteorological Centre (RSMC) on La Réunion serves as the official monitoring agency for TC activity within the basin.

The 2017/18 SIO storm season was slightly above average with 10 named storms, of which seven were cyclones and three were major cyclones (Fig. 4.31a). The 1981-2010 IBTrACS seasonal median averages are eight named storms, four cyclones, and one major cyclone (Schreck et al. 2014). The 2017/18 seasonal ACE index was $124 \times 10^{4} \mathrm{kt}^{2}$, which is above the 1981-2010 average of $92 \times 10^{4} \mathrm{kt}^{2}$ (Fig. 4.31b), and nearly quadruple the value of the extremely quiet 2016/17 season.
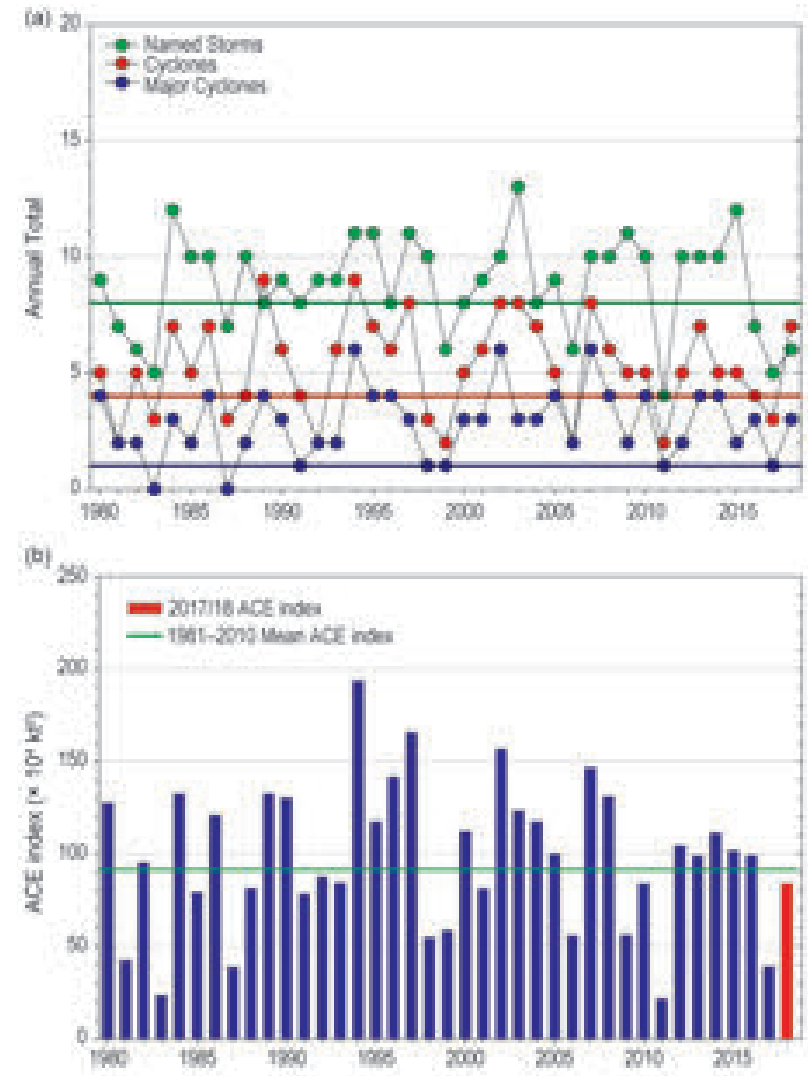

FIG. 4.3I. Annual TC statistics for the SIO for 19802018: (a) number of named storms, cyclones, and major cyclones and (b) estimated annual ACE index $\left(\times 10^{4} \mathrm{kt}^{2}\right)$ for all TCs at least tropical storm strength or greater intensity (Bell et al. 2000). The I98I-2000 means (green lines) are included in both (a) and (b).

Environmental conditions were generally near normal during the December-April peak of the season (Fig. 4.32). SSTs were below normal over the eastern portion of the basin (Fig. 4.32a). Convection was generally enhanced over the central basin where most of the TCs developed (Fig. 4.32b). Vertical wind shear was generally near normal (Fig. 4.32c). Lowlevel westerly anomalies along $10^{\circ} \mathrm{S}$ enhanced the cyclonic vorticity within which most of the storms formed.

During the 2017/18 season, the strongest storm was Cyclone Cebile (25 January-4 February), which reached Category 4 equivalent with peak sustained winds of $130 \mathrm{kt}\left(67 \mathrm{~m} \mathrm{~s}^{-1}\right)$ and an estimated minimum central pressure of $944 \mathrm{hPa}$. The storm developed over, and remained over, the open ocean throughout its lifetime. It accounted for nearly $30 \%\left(36 \times 10^{4} \mathrm{kt}^{2}\right)$ of the SIO's total ACE in 2017/18. The strength of this storm is particularly remarkable as it occurred over anomalously cool SSTs (Fig. 4.32a).

The strongest storm to make landfall in the SIO basin this season was Cyclone Ava (2-9 January), 
with maximum sustained winds of $85 \mathrm{kt}\left(44 \mathrm{~m} \mathrm{~s}^{-1}\right)$. Ava made landfall on Madagascar where it killed 51 people and displaced 17000 residents. In the eastern part of the island where Ava made landfall, flooding was extensive and the cyclone destroyed roads, communication lines, and buildings. Observed 24-hour rainfall amounts of $102 \mathrm{~mm}$ were observed at Majunga and $129 \mathrm{~mm}$ at Fianarantsoa. Area river levels peaked in excess of $8 \mathrm{~m}$, contributing to flooding and expansive crop losses.

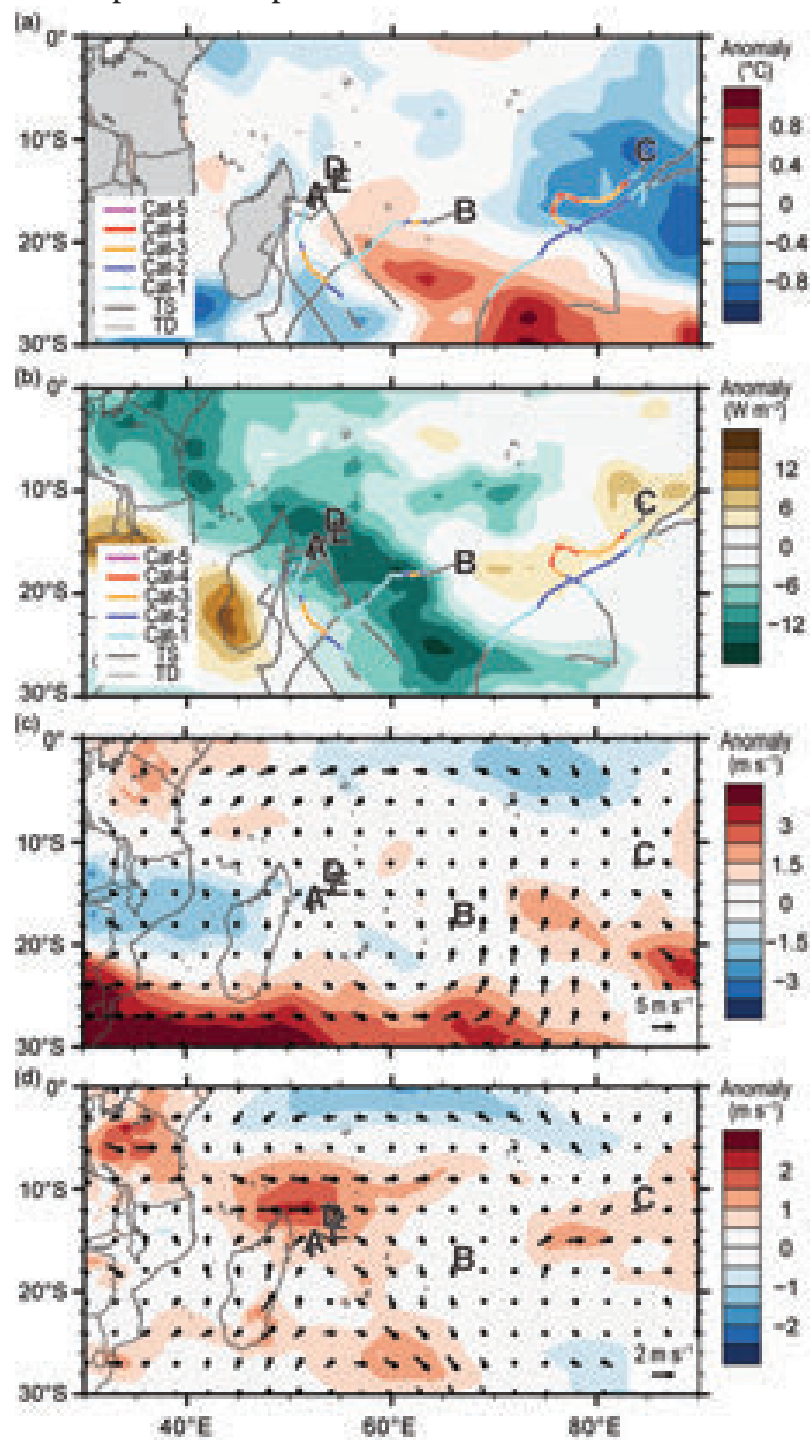

FIG. 4.32. Dec 2017-Apr 2018 anomaly maps of (a) SST ( ${ }^{\circ} \mathrm{C}$; Banzon and Reynolds 2013), (b) OLR (W m ${ }^{-2}$; Schreck et al. 2018), (c) 200-850-hPa vertical wind shear $\left(\mathrm{m} \mathrm{s}^{-1}\right)$ vector (arrows) and scalar (shading) anomalies, and (d) 850-hPa winds ( $\mathrm{m} \mathrm{s}^{-1}$ arrows) and zonal wind (shading) anomalies. Anomalies are relative to the annual cycle from 198I-2010, except for SST, which is relative to $1982-2010$ due to data availability. Letter symbols denote where each SIO TC attained its initial tropical storm intensity. Wind data are obtained from CFSR (Saha et al. 20I4).

\section{7) Australian basin-B.C. Trewin}

(i) Seasonal activity

The 2017/18 TC season was near normal in the broader Australian basin (areas south of the equator and between $90^{\circ} \mathrm{E}$ and $160^{\circ} \mathrm{E}$, which includes the Australian, Papua New Guinea, and Indonesian areas of responsibility). The season produced $11 \mathrm{TCs}$, which is near the $1983 / 84-2010 / 11$ average $^{2}$ of 10.8 and is consistent with neutral-to-cool ENSO conditions. The 1981-2010 IBTrACS seasonal averages for the basin are 9.9 named storms, 7.5 TCs, and 4.0 major TCs, which compares with the $2017 / 18$ counts of 10 , 6 , and 2, respectively. All references to TC category in this section use the Australian Bureau of Meteorology TC intensity scale. Figure 4.33 shows the standardized TC distribution for the basin (see Section 4f1).

There were eight TCs in the western sector ${ }^{3}$ of the broader Australian region during 2017/18, two in the northern sector, and three in the eastern sector, noting multiple counts for Marcus (western and northern sectors) and Nora (northern and eastern). A noteworthy feature of the 2017/18 season was that three TCs formed in the Indonesian area of responsibility (north of $10^{\circ} \mathrm{S}$ ), making it the first season where more than one TC has formed in this area since the Jakarta Tropical Cyclone Warning Centre was established in January 2008. Five systems made landfall in Australia as TCs: Nora in Queensland, Marcus in the Northern Territory (and later in Western Australia), and Hilda, Joyce, and Kelvin in Western Australia.

\section{(ii) Landfalling and other significant tropical cyclones}

Tropical cyclone intensities quoted in this section use the Australian category system (www.bom.gov .au/cyclone/about/intensity.shtml). Sustained winds are reported using 10-min means.

The strongest cyclone of the season was Marcus, which had its greatest impact in the Northern Territory, particularly over the Darwin region. Marcus formed on 16 March, north of the Coburg Peninsula and approximately $300 \mathrm{~km}$ northeast of Darwin. Having intensified to Category 2 overnight, it made landfall northeast of Darwin at about 0000 UTC on

\footnotetext{
Averages are taken from 1983/84 onward, which is the start of consistent satellite coverage of the region.

3 The western sector covers areas between $90^{\circ} \mathrm{E}$ and $125^{\circ} \mathrm{E}$. The eastern sector covers areas east of the eastern Australian coast to $160^{\circ} \mathrm{E}$, as well as the eastern half of the Gulf of Carpentaria. The northern sector covers areas from $125^{\circ} \mathrm{E}$ east to the western half of the Gulf of Carpentaria. The western sector incorporates the Indonesian area of responsibility, while the Papua New Guinea area of responsibility is incorporated in the eastern sector.
} 

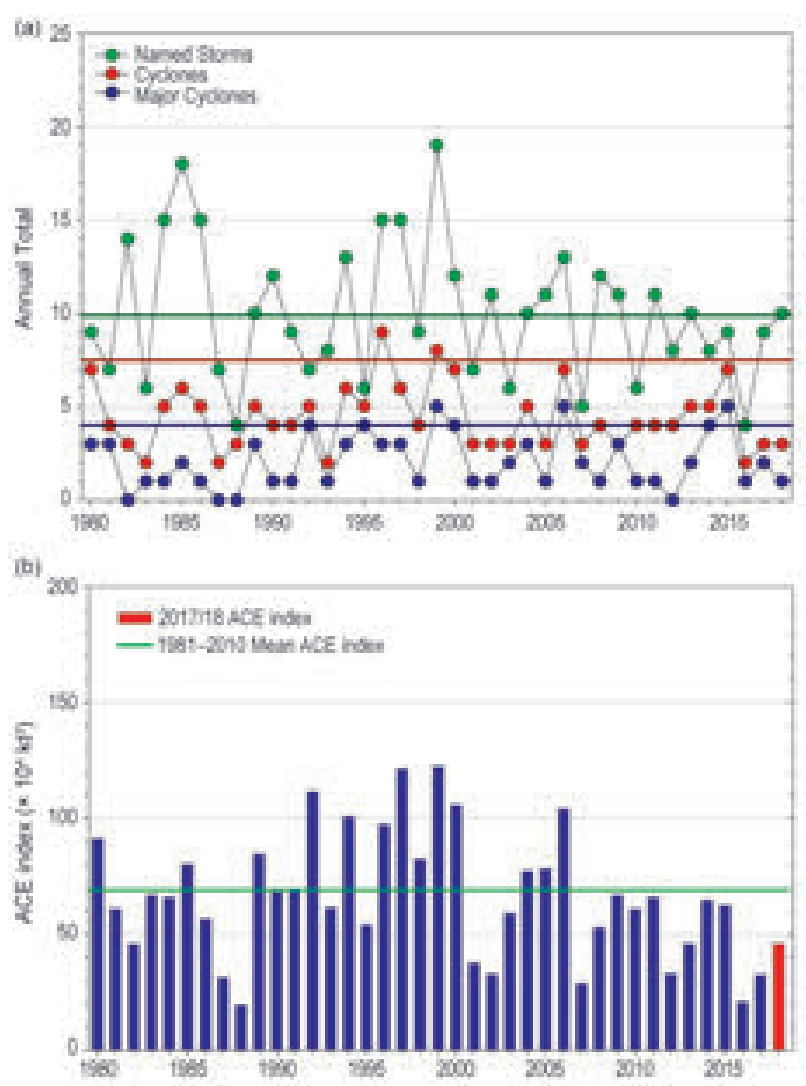

Fig. 4.33. Annual TC statistics for the Australian basin for 1980-2018: (a) number of named storms, cyclones, and major cyclones and (b) the estimated annual ACE $\left(\times 10^{4} \mathrm{kt}^{2}\right)$ for all TCs at least tropical storm strength or greater intensity (Bell et al. 2000). The I98I-2000 means (horizontal lines) are included in both (a) and (b).

17 March, then passed directly over Darwin over the next several hours, with wind gusts of $70 \mathrm{kt}\left(36 \mathrm{~m} \mathrm{~s}^{-1}\right)$ at Darwin Harbour and $68 \mathrm{kt}\left(35 \mathrm{~m} \mathrm{~s}^{-1}\right)$ at Darwin Airport. After moving out to sea over the Joseph Bonaparte Gulf, it made a second landfall east of Kalumburu, also at Category 2 strength on 18 March. It then crossed the far north of Western Australia, before continuing its westward movement into the Indian Ocean.

Once over the ocean, Marcus steadily strengthened to Category 5 intensity, reaching its peak intensity near $15^{\circ} \mathrm{S}, 110^{\circ} \mathrm{E}$ on $21 \mathrm{March}$, with peak wind gusts of $175 \mathrm{kt}\left(90 \mathrm{~m} \mathrm{~s}^{-1}\right)$, maximum sustained winds of $124 \mathrm{kt}\left(64 \mathrm{~m} \mathrm{~s}^{-1}\right)$, and a minimum central pressure of $914 \mathrm{hPa}$. These were the strongest analyzed winds for any Australian region TC since Marcia in 2006. After 22 March, Marcus weakened steadily as it turned southward, eventually weakening below TC intensity on $24 \mathrm{March}$ near $27^{\circ} \mathrm{S}, 108^{\circ} \mathrm{E}$, well off the Western Australian coast.

Marcus was the strongest TC to affect Darwin since Tracy in 1974. While no deaths or serious injuries were reported, tree damage in Darwin was extensive and there were prolonged power outages throughout much of the city. Minor damage was reported elsewhere in the Northern Territory's Top End and in the Kalumburu area of Western Australia. Rainfall totals were modest by TC standards with no 24-h totals in excess of $150 \mathrm{~mm}$ reported.

The other two cyclones in the Australian region in 2017/18 to reach severe (Category 3 or above) intensity were Kelvin and Nora. Kelvin began as a tropical low that tracked west through the Northern Territory and the far north of Western Australia for several days. It reached cyclone intensity off the coast southwest of Broome at 0000 UTC on 17 February. It then turned east and intensified rapidly to a Category 3 system, making landfall at near-peak intensity (maximum sustained winds $80 \mathrm{kt} ; 41 \mathrm{~m} \mathrm{~s}^{-1}$ ), with peak wind gusts of $111 \mathrm{kt}\left(57 \mathrm{~m} \mathrm{~s}^{-1}\right)$ at about 2300 UTC that day near Anna Plains, about $200 \mathrm{~km}$ southwest of Broome. Kelvin weakened slowly as it moved southsoutheastward over land and did not weaken below cyclone intensity until 1200 UTC on 19 February while located near Telfer. While there was some minor wind damage, Kelvin's major impact was flooding, with heavy rain falling on areas already saturated by the earlier approaches of cyclones Hilda (26-29 December) and Joyce (6-13 January), and a tropical low in late January. The two major road routes into Broome were closed for extended periods. Broome received $377 \mathrm{~mm}$ in 24 hours, West Roebuck received $370 \mathrm{~mm}$, and a number of other sites had daily totals exceeding $200 \mathrm{~mm}$ as the cyclone approached. By 19 February, Broome's total rainfall since 1 January $(1506 \mathrm{~mm})$ had already exceeded its previous record for a calendar year.

Nora was a Gulf of Carpentaria cyclone that formed in the Arafura Sea north of the Northern Territory's Top End, reaching cyclone intensity north of Cape Wessel, at 1800 UTC on 22 March. Over the succeeding days, it intensified while moving steadily southeast, reaching Category 3 on 23 March and maintaining that intensity [maximum sustained winds $86 \mathrm{kt}\left(44 \mathrm{~m} \mathrm{~s}^{-1}\right)$, peak wind gusts of $121 \mathrm{kt}$ $\left(62 \mathrm{~m} \mathrm{~s}^{-1}\right)$ ] until landfall. Nora made landfall between Cape Keerweer and Pormpuraaw, on the west coast of Cape York Peninsula, at about 1200 UTC on 24 March, and then weakened as it moved south along the coast, weakening below cyclone intensity near the Gilbert River Mouth on 25 March. Heavy rain fell in the vicinity of the decaying low, including a daily total on 26 March of $371 \mathrm{~mm}$ at Miranda Downs, northeast of Normanton. Some wind damage to trees and power lines was reported in the community of Pormpuraaw. 
Other cyclone landfalls during the season, both on the coast between Broome and Port Hedland, were Hilda (28 December) and Joyce (12 January). Neither reached severe intensity, but both contributed to flooding in the region. Moisture from the remnants of Joyce contributed to heavy rainfall on 15-16 January in southwestern Western Australia. Perth $(96 \mathrm{~mm}$ on 16 January) had its second wettest among all January days on record, and daily January records were set at many other locations in the region.

Cempaka formed south of Java in late November 2017, remaining in the Indonesian area of responsibility throughout. While it never made landfall or exceeded Category 1 intensity through its lifetime (26-29 November), rains associated with the system caused major flooding in southern Java and Bali. At least 41 deaths were attributed to the cyclone, according to Indonesian authorities.

8) Southwest Pacific basin—P. R. Pearce, A. M. Lorrey, and H. J. Diamond

(i) Seasonal activity

The 2017/18 cyclone season in the southwest Pacific officially began in November 2017, but the first named storm did not occur until late January 2018, despite numerous tropical depressions during the early part of the season. Storm track data for November 2017-April 2018 were gathered from the Fiji Meteorological Service, Australian Bureau of Meteorology, and New Zealand MetService, Ltd. The southwest Pacific basin from $135^{\circ} \mathrm{E}$ to $120^{\circ} \mathrm{W}$, as defined by Diamond et al. (2012), had eight tropical cyclones, including four severe tropical cyclones (based on the Australian cyclone intensity scale). Figure 4.34 shows the standardized cyclone distribution based on the basin spanning the area from $160^{\circ} \mathrm{E}-120^{\circ} \mathrm{W}$ to avoid overlaps with the Australian basin that could result in double counting of storms (Section 4f1). However, for reporting here, the climatological definition of the southwest Pacific basin noted earlier (Diamond et al. 2012) is used because that is how annual cyclone outlooks are produced and disseminated.

The 1981-2010 Southwest Pacific Enhanced Archive of Tropical Cyclones (SPEArTC) indicates a seasonal average of 10.4 named tropical cyclones and 4.3 major tropical cyclones. Therefore, the 2017/18 cyclone season had slightly lower-than-normal activity. The ratio of severe cyclones relative to the total number of named cyclones in 2017/18 was 50\%-the same as the previous season.
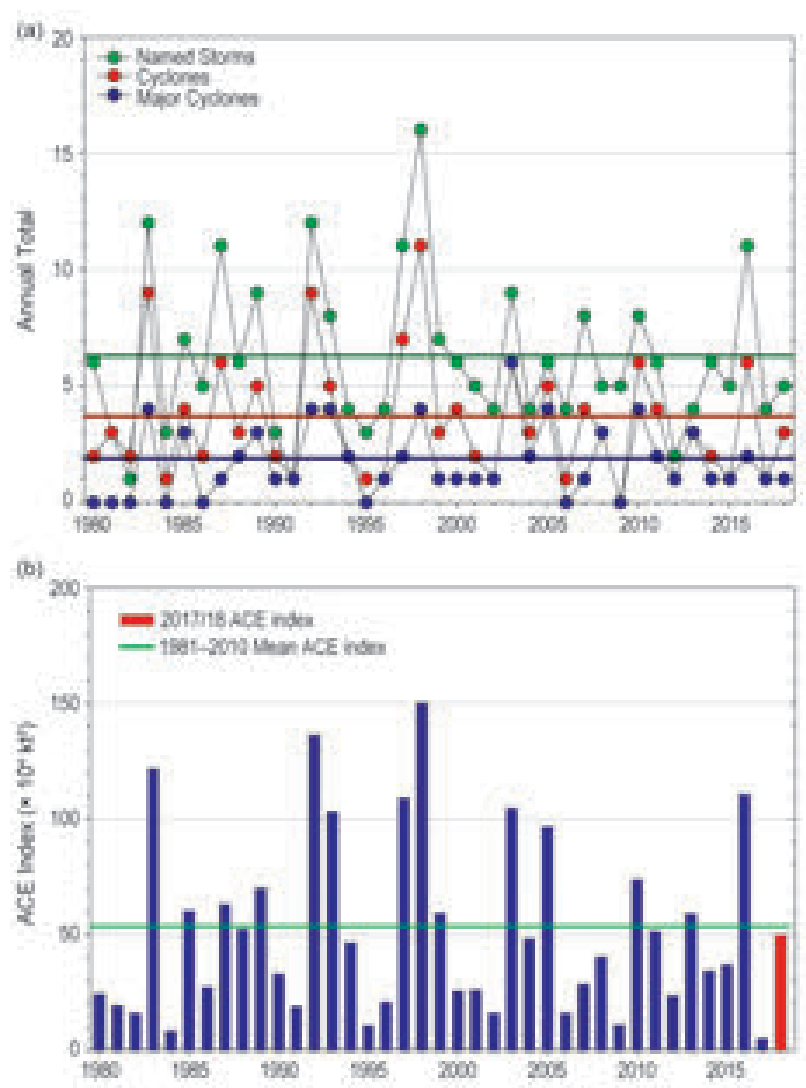

Fig. 4.34. Annual TC statistics for the southwest Pacific for 1980-2018: (a) number of named storms, cyclones, and major cyclones and (b) the estimated annual ACE index $\left(\times 10^{4} \mathrm{kt}^{2}\right)$ for all TCs at least tropical storm strength or greater intensity (Bell et al. 2000). The 1981-2000 means (horizontal lines) are included in both (a) and (b).

\section{(ii) Landfalling and other significant cyclones}

The first named cyclone of the 2017/18 season occurred in late January. Cyclone Fehi developed as a tropical low on 28 January in the northern Coral Sea. The cyclone reached Category 1 status, with peak 10 -min winds of $46 \mathrm{kt}\left(24 \mathrm{~m} \mathrm{~s}^{-1}\right)$ and a minimum central pressure of $986 \mathrm{hPa}$. Fehi caused considerable damage to the west coast of the South Island of New Zealand from strong winds and heavy rain that caused landslides, cutting off road access to multiple towns, damaging buildings, and causing coastal erosion. Insured losses were assessed at $\$ 45.9$ million $\mathrm{NZ}$ dollars (\$31.4 million U.S. dollars).

The strongest storm of the season was Cyclone Gita. Gita originated from a monsoon trough and was classified as a tropical disturbance on 3 February near Vanuatu. On 9 February it strengthened into a Category 1 cyclone near Samoa. The system rapidly intensified as it moved southward and westward and became a severe cyclone on 10 February near Niue. Gita further intensified into a Category 5 severe cy- 
clone on 11 February only $30 \mathrm{~km}$ south of Tongatapu (the main island of Tonga). Gita affected multiple island nations and territories in its path. Tonga was the hardest hit, with severe damage occurring on the islands of Tongatapu and 'Eua including two fatalities and 41 injuries, as well as thousands of damaged structures. Agriculture was devastated on the two islands. The Tongan parliament building, more than 100 years old, was flattened. Gita was the strongest storm to impact Tonga since modern records began in the 1960s. According to the Ministry of Finance and National Planning, Gita inflicted \$158 million (U.S. dollars) worth of damage, making it the costliest storm in their national history. Torrential rain and damaging wind impacted Samoa, American Samoa, and Fiji's Lau group. Wallis and Futuna, Niue, and Vanuatu were also affected. A state of emergency was declared for multiple districts on New Zealand's South Island as flooding, landslides, and high winds closed roads and damaged buildings, and \$35.6 million NZ dollars ( $\$ 24.3$ million U.S. dollars) worth of insured damage occurred. Gita's peak 10-min sustained wind speeds were $111 \mathrm{kt}\left(57 \mathrm{~m} \mathrm{~s}^{-1}\right)$; its minimum central pressure was $927 \mathrm{hPa}$.

Gita was followed by the second severe cyclone of the season, Hola, which formed as a tropical disturbance to the northeast of Fiji on 3 March. Hola was classified as a Category 1 cyclone on 6 March. One day later, Hola was classified as a Category 4 cyclone with 10 -min sustained winds of $89 \mathrm{kt}\left(46 \mathrm{~m} \mathrm{~s}^{-1}\right)$ and a minimum central pressure of $952 \mathrm{hPa}$. Hola brought severe winds to Vanuatu, destroying multiple buildings. Falling trees caused one fatality on Pentecost Island, and two children on Santo Island drowned after they were washed away by a flooded river. Hola caused minimal damage in New Caledonia and flights to be cancelled in New Zealand.

On 11 March, the Fiji Meteorological Service reported that a tropical disturbance had developed to the southwest of the Solomon Islands. As the storm moved south, it strengthened into a Category $1 \mathrm{cy}$ clone named Linda. Linda attained its peak intensity on 13 March, with 10-min sustained winds of $40 \mathrm{kt}$ $\left(21 \mathrm{~m} \mathrm{~s}^{-1}\right)$ and a minimum central pressure of $993 \mathrm{hPa}$. While Cyclone Linda was not long-lived, the deteriorating vestiges of this storm system passed near Fraser Island (Queensland, Australia) about a week later and produced large waves and swell, while the mainland near the Sunshine Coast experienced waves of up to $8 \mathrm{~m}$. Cyclone Iris formed as a tropical disturbance on 20 March over the eastern Solomon Islands. It was classified as an Australian Category 1 cyclone on 24 March. Iris' peak 10-min sustained winds (while it was in the Southwest Pacific basin) were $40 \mathrm{kt}$ $\left(21 \mathrm{~m} \mathrm{~s}^{-1}\right)$, and its minimum central pressure was $993 \mathrm{hPa}$.

On 23 March, a Category 1 tropical cyclone emerged into the Southwest Pacific basin just west of the Gulf of Carpentaria (Australia) and was named Nora by the Australian Bureau of Meteorology. Within a couple of days, Nora intensified into a Category 3 severe cyclone and tracked to the southeast before making landfall on the Cape York Peninsula at Category 3 strength. Afterward, Nora gradually weakened, degenerating into a tropical low soon afterward. On 26 March, Nora's remnant low stalled and slowly meandered counterclockwise over the Top End of the Northern Territory. On 27 March, Nora's remnant moved westward across the Gulf of Carpentaria before making landfall on the Australian coast and dissipating. Nora's peak 10-min wind speed was $84 \mathrm{kt}\left(43 \mathrm{~m} \mathrm{~s}^{-1}\right)$, and its minimum central pressure was $958 \mathrm{hPa}$.

Cyclone Josie achieved Category 1 status on 31 March. The storm passed to the south of Fiji's main islands. Despite not making landfall, the storm caused heavy rainfall and sustained gale-force winds in Viti Levu. In addition, severe flooding occurred around Nadi and $\mathrm{Ba}$, causing significant property and crop damage. At least six people were killed. More than 70 roads were closed due to flooding, mostly in the Western Division of Viti Levu. Josie's peak 10-min wind speed was $40 \mathrm{kt}\left(21 \mathrm{~m} \mathrm{~s}^{-1}\right)$, and its minimum central pressure was $993 \mathrm{hPa}$.

Severe Cyclone Keni affected Fiji about a week after Cyclone Josie had passed. It was classified as a Category 3 Severe Cyclone on 10 April and had peak 10 -min sustained wind speeds of $76 \mathrm{kt}\left(39 \mathrm{~m} \mathrm{~s}^{-1}\right)$ and a minimum central pressure of $970 \mathrm{hPa}$. Cyclone Keni caused the most damage on the island of Kadavu in the Eastern Division, with flooding and high winds destroying houses and crops. Keni was the last named cyclone of the season.

\section{g. Tropical cyclone heat potential—R. Domingues, G. J. Goni, J. A. Knaff, I.-I. Lin, and F. Bringas}

Changes in upper-ocean thermal conditions observed within the seven TC basins are described here, focusing on vertically integrated conditions observed during the 2018 TC season with respect to the long-term mean and to values observed during 2017. To accomplish this, the tropical cyclone heat potential (TCHP; e.g. Goni et al. 2017), defined as the excess heat content stored in the water column between the sea surface and the depth of the $26^{\circ} \mathrm{C}$ isotherm, is used as a key parameter in this assessment. 
The TCHP provides a metric for evaluating the heat content in upper-ocean layers, which may modulate the effective SST under a TC and affect the air-sea latent and sensible heat fluxes that can lead to storm intensification (Mainelli et al. 2008; Lin et al. 2013). For example, values of TCHP above $50 \mathrm{~kJ} \mathrm{~cm}^{-2}$ have been associated with the intensification of North Atlantic hurricanes when favorable atmospheric conditions were also present (e.g., Shay et al. 2000; Mainelli et al. 2008; Lin et al. 2014).

Year-to-year variations in TCHP during 2018 are described here based on anomalies (from the 19932018 mean values, Fig. 4.35) for the primary months of TC activity in each hemisphere: June-November 2018 in the Northern Hemisphere, and November 2017-April 2018 in the Southern Hemisphere. In addition, differences in TCHP between the 2018 and 2017 seasons are also displayed (Fig. 4.36). Generally, TCHP anomalies show large spatial and temporal variability within and among the TC basins associated mainly with oceanic mesoscale features, yearto-year variability (e.g., ENSO), or long-term decadal variability. Sustained ocean monitoring based on both satellite altimetry and in situ observations allows for a reliable assessment of ocean variability on various timescales (e.g., Lin et al. 2008; Goni et al. 2009; Goni and Knaff 2009; Pun et al. 2013).

During the 2018 season, above-normal TCHP anomalies were observed in portions of all basins. These conditions in some of the basins provided

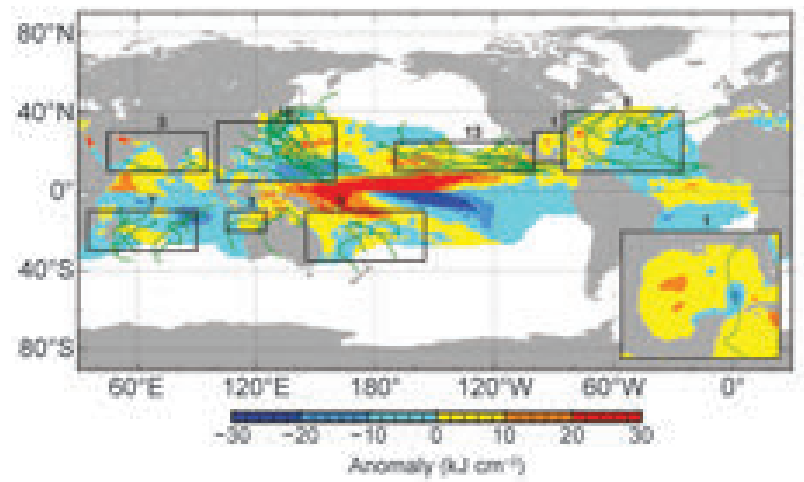

FIG. 4.35. Global anomalies of TCHP $\left(\mathrm{kJ} \mathrm{cm}^{-2}\right)$ during 2018. The boxes indicate the seven regions where TCs occur: from left to right, southwest Indian, North Indian, western North Pacific, Australian region, southwest Pacific, eastern North Pacific, and North Atlantic (shown as Gulf of Mexico and tropical Atlantic separately). Green lines indicate the trajectories of all TCs reaching at least Saffir-Simpson Category I during Nov 2017-Apr 2018 in the SH and Jun-Nov 2018 in the NH. The numbers above each box correspond to the number of Category I and above cyclones that traveled within each box. Gulf of Mexico conditions are shown in the inset in the lower right corner.

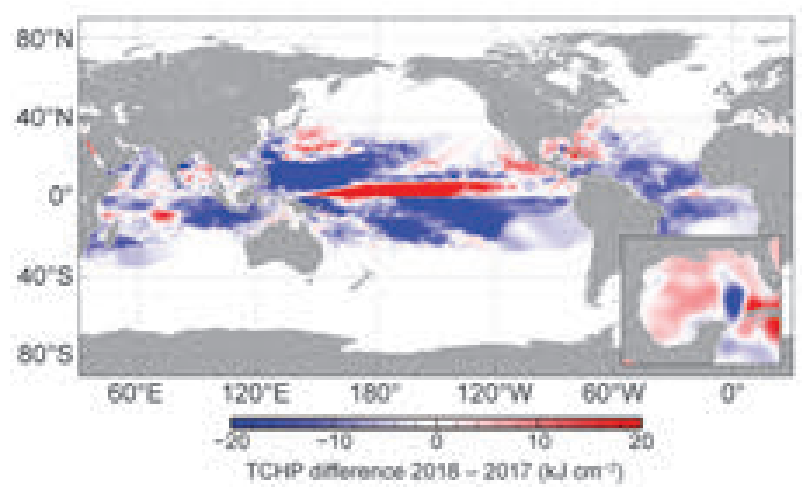

FIG. 4.36. TCHP differences $\left(\mathrm{kJ} \mathrm{cm}^{-2}\right)$ between 2018 and 2017.

favorable ocean conditions for the intensification of TCs. Negative TCHP anomalies were observed mostly in the eastern part of the North Atlantic basin, in the southern part of the western North Pacific basin, the South Indian Ocean, and the southwest Pacific basin. Differences in the TCHP values between the 2018 and 2017 seasons (Fig. 4.36) indicate that five of the seven basins exhibited a decrease in upper-ocean heat content during 2018 compared to conditions observed in 2017. The two notable exceptions were the western North Atlantic (including the Gulf of Mexico) and the eastern North Pacific basins.

In the eastern part of the North Atlantic basin, TCHP values were $10 \mathrm{~kJ} \mathrm{~cm}^{-2}(10 \%-30 \%)$ below the long-term average (Fig. 4.35). In the western part of the basin, TCHP values were $10-20 \mathrm{~kJ} \mathrm{~cm}^{-2}$ (10\%-40\%) above the long-term average (Fig. 4.35). Associated with these conditions, above-normal TC activity was observed in the North Atlantic for the third consecutive year (Section 4f2). In particular, the warmer-than-usual upper-ocean conditions in the western part of the North Atlantic basin (including the Gulf of Mexico), with TCHP values up to $40 \%$ larger than the long-term average, likely provided favorable oceanic conditions for the rapid intensification of Hurricanes Florence (31 August-17 September) and Michael (7-12 October). Oceanic conditions observed during Hurricane Michael, the strongest Atlantic hurricane in 2018, are examined in more detail in Sidebar 4.2.

In the North Pacific, upper-ocean thermal conditions were largely modulated by the transition toward weak El Niño in the third and fourth quarters of 2018 (Section 4b), with warmer waters in the eastern North Pacific (ENP) basin and slightly cooler waters in the western North Pacific (WNP) basin (Fig. 4.36). Upper-ocean thermal conditions, evaluated in terms of TCHP values, are closely modulated by ENSO variability in both the ENP and WNP basins (Lin et 
al. 2014; Zheng et al. 2015). In the ENP basin, TCHP values during 2018 were greater than those observed in 2017 (Fig. 4.36) and were $10-20 \mathrm{~kJ} \mathrm{~cm}^{-2}$ larger than the long-term average (Fig. 4.35), which represents an increase of $20 \%-40 \%$. The substantially largerthan-usual TCHP conditions in this basin provided favorable upper ocean conditions for the 2018 ENP hurricane season-especially west of $140^{\circ} \mathrm{W}$ and near the Hawaiian Islands, which was characterized by record-breaking levels of TC activity (Section 4f3).

Despite exhibiting lower-than-usual TCHP conditions during the 2018 season (Fig. 4.35), TC activity in the WNP basin was above average (section $4 \mathrm{f} 4$ ). This is because the total number of TCs in the WNP is more closely related to atmospheric dynamics (Lin and Chan 2015) than to upper-ocean thermal conditions. In addition, although lower than in 2017, TCHP values during 2018 were consistently larger than $80 \mathrm{~kJ}$ $\mathrm{cm}^{-2}$. This provided conditions that were sufficiently warm for TC intensification in most parts of the basin. Among the notable Category 5 TCs recorded, Super Typhoons Mangkhut (7-17 September) and Yutu (21 October-2 November) each reached a peak intensity of $155 \mathrm{kt}\left(80 \mathrm{~m} \mathrm{~s}^{-1}\right)$ sustained winds and were the most intense TCs globally in 2018. Both Mangkhut and Yutu reached Category 5 status while traveling over the WNP's Main Development Region, which is characterized by large TCHP values (Lin et al. 2013; 2014). In fact, Mangkhut reached peak intensity and maintained Category 5 status for 3.5 days while traveling over this area, where the TCHP had values larger than $120 \mathrm{~kJ} \mathrm{~cm}^{-2}$.

In the North Indian Ocean basin, average TCHP values observed during the 2018 cyclone season were $10 \mathrm{~kJ} \mathrm{~cm}^{-2}(\sim 10 \%)$ larger than the long-term average (Fig. 4.35), and slightly lower than 2017 conditions. In the Bay of Bengal, TCHP values were consistently larger than $70 \mathrm{~kJ} \mathrm{~cm}^{-2}$, while values above $50 \mathrm{~kJ} \mathrm{~cm}^{-2}$ were observed in most of the Arabian Sea. The warmer-than-usual conditions in this basin likely favored an above-average number (eight) of TC formations during the 2018 season, which was the most active North Indian Ocean season since 1992. In the South Indian basin, TCHP values below the longterm mean by $10-20 \mathrm{~kJ} \mathrm{~cm}^{-2}$ likely contributed to a below-average season.

In summary, 2018 was characterized by higherthan-normal values of TCHP in the western part of the North Atlantic basin, in the eastern North Pacific basin, and in the North Indian basin. Largerthan-usual ocean heat content in these basins likely contributed to both the above-normal TC activity and the intensity of TCs recorded there. Upper-ocean heat content conditions in both the ENP and WNP basins were largely modulated by the onset of weak El Niño conditions late in 2018 (see Section 4b). Overall, TCHP anomalies observed in 2018 were not as large as anomalies observed in 2017. Targeted ocean observations during 2018 indicated that upper-ocean conditions favored the intensification of several major TCs.

\section{SIDEBAR 4.2: UPPER-OCEAN CONDITIONS IN THE GULF OF MEXICO DURING HURRICANE MICHAEL-G. J. GONI AND R. DOMINGUES}

The Gulf of Mexico's upper-ocean circulation is dominated by the presence of the Loop Current, which often intrudes far into the Gulf and sheds warm, anticyclonic rings and smaller eddies. Coastal waters are heavily influenced by riverine outflow that may reach areas hundreds of kilometers away from their source. Upper-ocean conditions have been linked to the intensification of several hurricanes in the Gulf. For example, Hurricanes Opal (1995; Shay et al. 2000) and Katrina (2005; Goni et al. 2017) both intensified while traveling in the Gulf of Mexico over a warm eddy and a Loop Current ring, respectively.

Hurricane Michael, which traversed the Caribbean Sea and then the Gulf of Mexico during October 2018, was characterized by its steady intensification rate and its ex- tremely intense landfall intensity in the Florida Panhandle (Sidebar 4.I). The relevant upper-ocean conditions in the Gulf of Mexico during this period can be described in terms of the geostrophic velocity and sea surface height, SST, tropical cyclone heat potential (upper-ocean heat content), and upper-ocean salinity for pre-storm conditions at the beginning of October 2018 (Fig. SB4.3, four panels). These fields indicate that the Loop Current during early October was retracted to the south, and a warm Loop Current anticyclonic ring was centered around $88^{\circ} \mathrm{W}, 25^{\circ} \mathrm{N}$, as shown by the surface height fields and also confirmed by surface drifters (not shown). As an aside, this particular location of the Loop Current is also important for the Gulf and southeast Florida ecosystems. 
CONT. SIDEBAR 4.2: UPPER-OCEAN CONDITIONS IN THE GULF OF MEXICO DURING HURRICANE MICHAEL-G. J. GONI AND

R. DOMINGUES

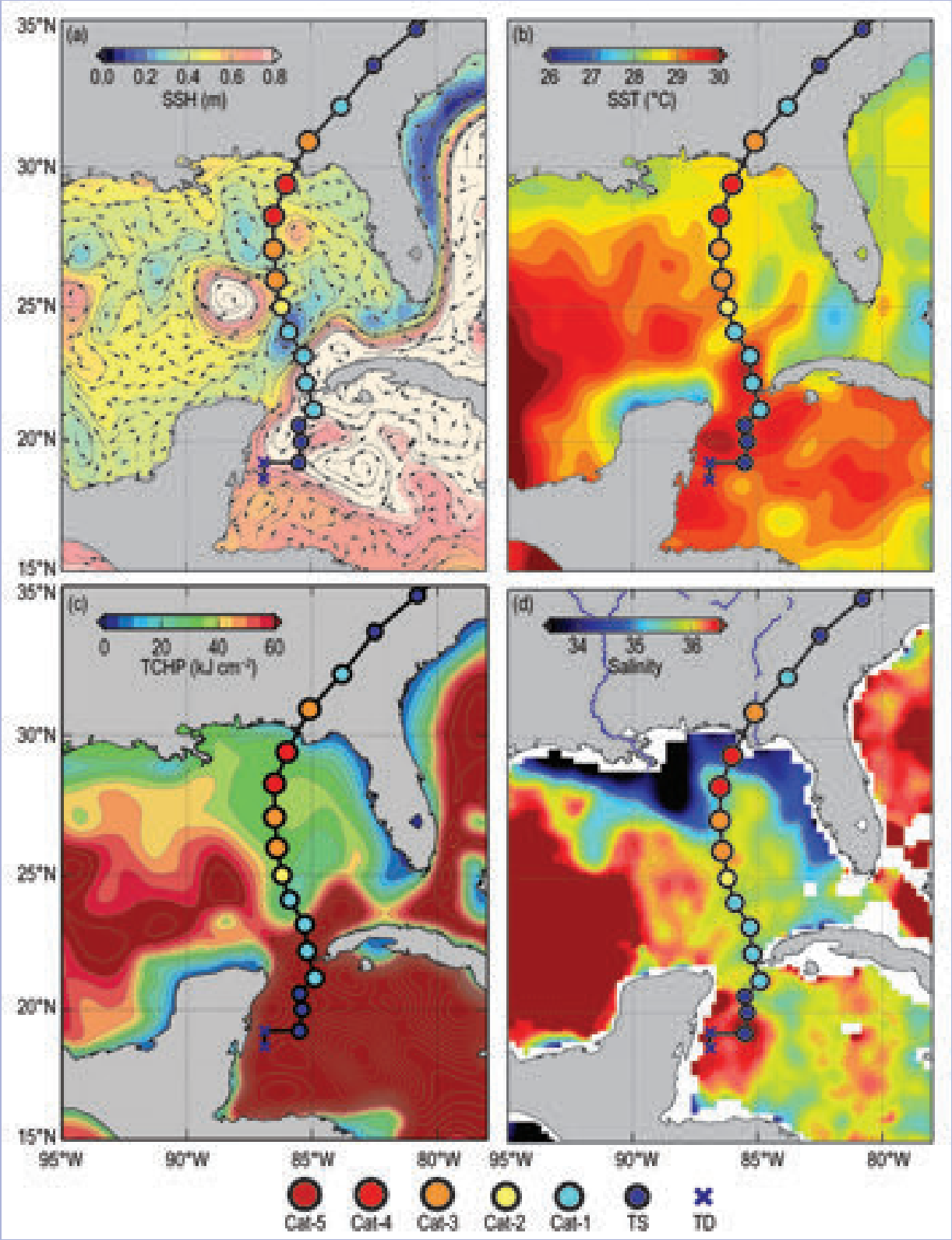

FIg. SB4.3. Trajectory of Hurricane Michael (2018). Circles are spaced every $6 \mathrm{~h}$ along its path; color indicates Michael's intensity. The background fields show the ocean conditions for 7 Oct 2018 for (a) satellite altimetry-derived sea surface height (color) with geostrophic currents during Oct (arrows); (b) SST; (c) TCHP; and (d) sea surface salinity. The altimeter products were produced and distributed by the Copernicus Marine and Environment Monitoring Service (CMEMS) (www.marine.copernicus.eu). SST data are obtained from NOAA Optimum Interpolation (OI) Sea Surface Temperature (SST), version 2 (www.esrl.noaa.gov/psd/data/gridded/data.noaa.oisst.v2.html). Fields of surface salinity are obtained from NASA's Soil Moisture Active Passive (SMAP) salinity product https://salinity.oceansciences.org Idata-smap-v3.htm. 
The southern retraction stimulates upwelling into the west Florida shelf, while also being partly responsible for flushing the waters of the west Florida shelf. It impacts local ecosystems off the southeast Florida coast with the presence of, for example, Karenia brevis, which causes red tide (see Sidebar 3.2).

On 8 October, Michael became a hurricane. This intensification continued with Michael becoming a major hurricane on 9 October as it was fueled by the eastern edge of the Loop Current ring. Hurricane Michael attained its maximum intensity on 10 October while making landfall near Mexico Beach, Florida, when it traveled over low-salinity waters found at the surface and associated with the Mississippi River plume, which was north of the ring and was also advected to the east by this ring. The low-salinity conditions near the surface associated with this plume created a barrier layer as observed by one underwater glider present in the region (not shown). Ocean barrier layers have been observed to provide favorable conditions for hurricane intensification, such as in the case of Hurricane Gonzalo (2014; Domingues et al. 2015; Dong et al. 2017). Therefore, it is highly probable that this barrier layer contributed to the intensification of Michael to Category 5 status.

The waters along the rest of the track until Hurricane Michael made landfall were $1^{\circ}-2^{\circ} \mathrm{C}$ warmer than usually observed during September (Fig. SB4.4). All of the conditions described above likely contributed to the genesis (Loop Current), intensification (warm ring and barrier layer), and peak intensity (unusually warm SSTs) of Hurricane Michael.

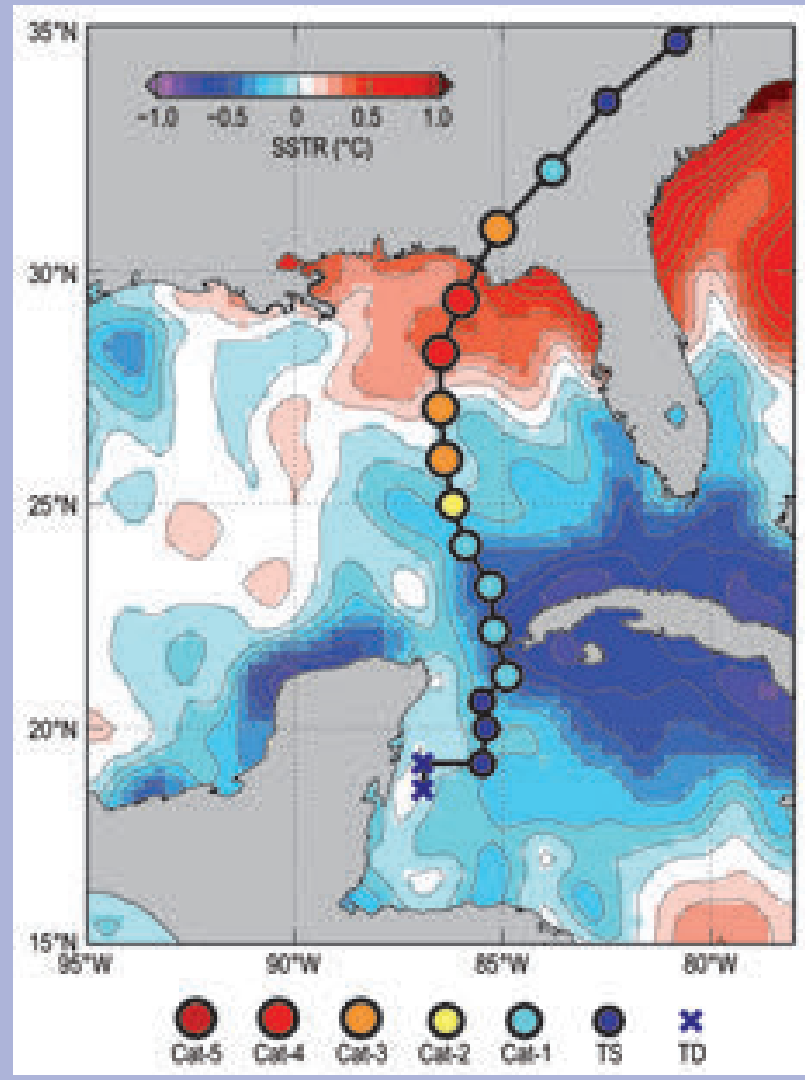

FIG. SB4.4. SST residuals (seasonal cycle removed), showing the difference between mean SSTs during Sep 2018 and the historical mean SSTs for Sep during 1985-2018. 
h. Indian Ocean dipole-L. Chen and J.-J. Luo

The Indian Ocean dipole (IOD) is the major mode of interannual climate variability in the tropical Indian Ocean (IO). It can be driven by local air-sea interactions and ENSO (Saji et al. 1999; Luo et al. 2010). The IOD generally develops in boreal summer, peaks in boreal autumn, and decays rapidly in early winter. Usually, a positive IOD (pIOD) event features below-average SST anomalies in the eastern IO and weak above-average SST anomalies in the western IO, and vice versa for a negative event (nIOD). However, the intensity of a pIOD event is generally stronger

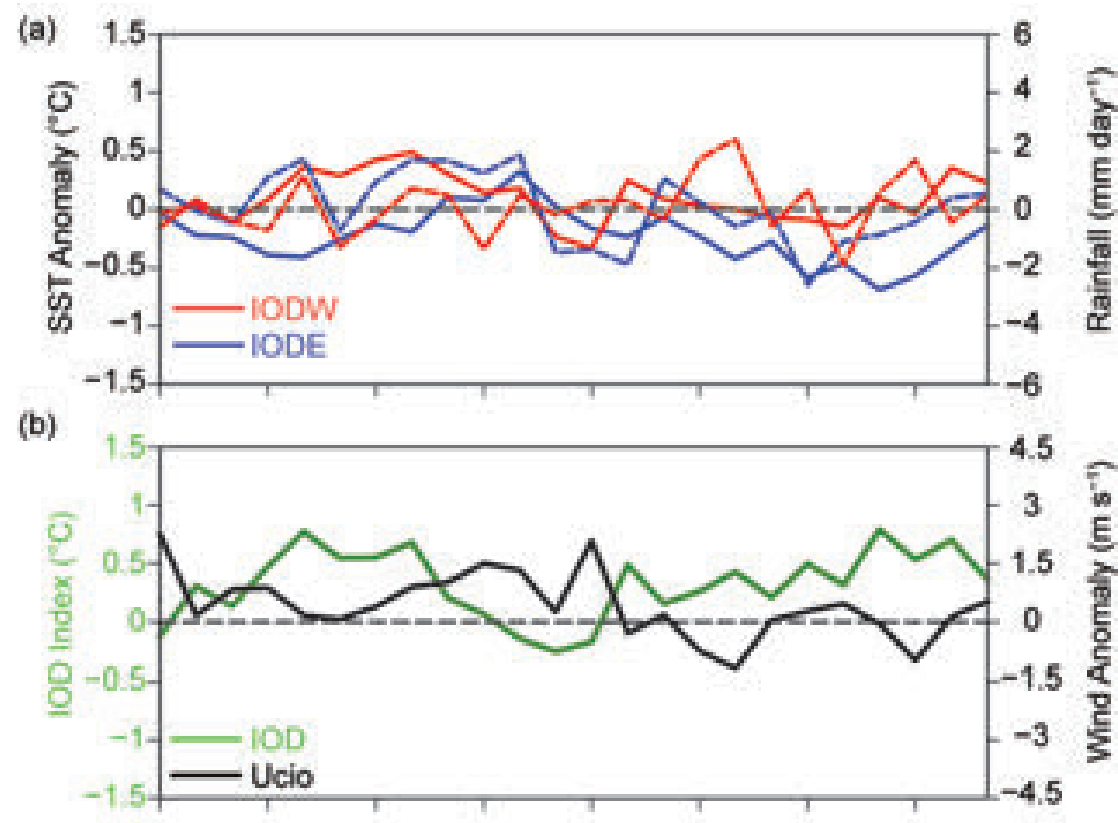

(c)

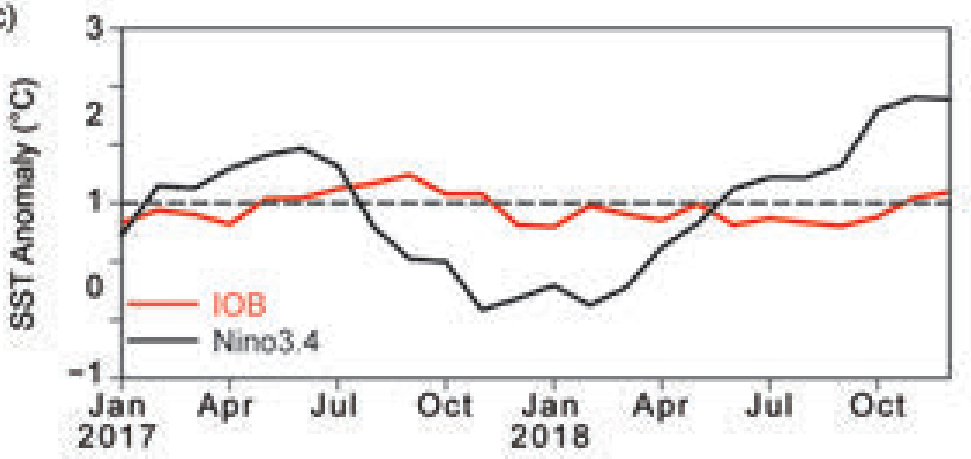

Fig. 4.37. (a) Monthly anomalies of SST ( ${ }^{\circ} \mathrm{C}$; solid lines) and precipitation ( $\mathrm{mm}$ day $^{-1}$; dashed lines) in the eastern pole (IODE; $10^{\circ} \mathrm{S}-0^{\circ}, 90^{\circ}-110^{\circ} \mathrm{E}$; blue lines) and the western pole (IODW; $10^{\circ} \mathrm{N}-10^{\circ} \mathrm{S}, 50^{\circ}-70^{\circ} \mathrm{E}$; red lines) of the IOD. (b) As in (a), but for the IOD index (measured by the SST difference between IODW and IODE, green line) and the surface zonal wind anomaly ( $m$ $\mathrm{s}^{-1}$ ) in the central equatorial IO (Ucio; $5^{\circ} \mathrm{N}-5^{\circ} \mathrm{S}, 70^{\circ}-90^{\circ} \mathrm{E}$; black line). (c) As in (a), but for SST anomalies in the Niño-3.4 region $\left(5^{\circ} \mathrm{N}-5^{\circ} \mathrm{S}, 170^{\circ}-120^{\circ} \mathrm{W}\right.$; black line) and the tropical $1 O\left(I O B ; 20^{\circ} \mathrm{N}-10^{\circ} \mathrm{S}, 40^{\circ}-120^{\circ} \mathrm{E}\right.$; red line). Anomalies are relative to the 1982-2018 base period. [Sources: NOAA OISST (Reynolds et al. 2002); monthly GPCP precipitation analysis (available at http://precip .gsfc.nasa.gov/); and JRA-55 atmospheric reanalysis (Kobayashi et al. 20I5).] than that in a nIOD, showing an asymmetry in the Hong et al. 2008).

Following weak nIOD conditions in late 2017 (Luo 2018), the negative IOD index persisted at the beginning of 2018 (Fig. 4.37b). The IOD index changed sign in February, and the positive IOD index gradually increased until November. This pIOD event was primarily due to the below-average SST anomalies in the eastern IO region, while SST anomalies in the western equatorial IO region were near zero throughout most of 2018 (Fig. 4.37a). During boreal spring to boreal summer, the below-average SST anomalies in the eastern IO gradually expanded in geographic extent, whereas the SST anomalies in the western IO were near zero. During the boreal autumn, the pIOD event peaked with anomalous SST cooling of $0.7^{\circ} \mathrm{C}$ in the eastern IO and a weak warming in the western IO. In December, the pIOD event dissipated rapidly due to its strong phase locking with monsoonal winds.

During 2018, the surface zonal wind and SST anomalies were generally coupled throughout the weak pIOD event (Fig. 4.37b). Due to the remote impact of the peak phase of the 2017/18 La Niña event, anomalous positive rainfall occurred in the Maritime Continent and the western Pacific during December-February 2017/18. This induced westerly anomalies along the central-eastern equatorial IO in early 2018; this is unfavorable for the development of cold SST anomalies in the eastern IO. It is interesting to note that the zonal wind anomalies transitioned from westerly anomalies to easterly anomalies across the central-eastern equatorial IO in the boreal spring of 2018 . 
This might have been largely driven by two strong MJO events that propagated eastward from Africa to the IO during early to mid-April and early-to-late May, respectively (Section 4c). The two MJO events induced pronounced monthly mean easterly wind anomalies in the central-eastern equatorial IO during April-May (Figs. 4.37b, 4.39b). Moreover, the two MJO events also brought anomalous positive rainfall to the western and central parts of the IO throughout
April-May (Figs. 4.37a, 4.39b), which maintained and intensified easterly wind anomalies in the central and eastern equatorial IO. The easterly anomalies induced below-average SST anomalies in the central and eastern IO during boreal spring 2018.

During boreal summer, with the enhancement of the East Asian monsoon, cross-equatorial southerly wind anomalies intensified in the eastern IO (Fig. 4.39c). Weak southeasterly anomalies initially

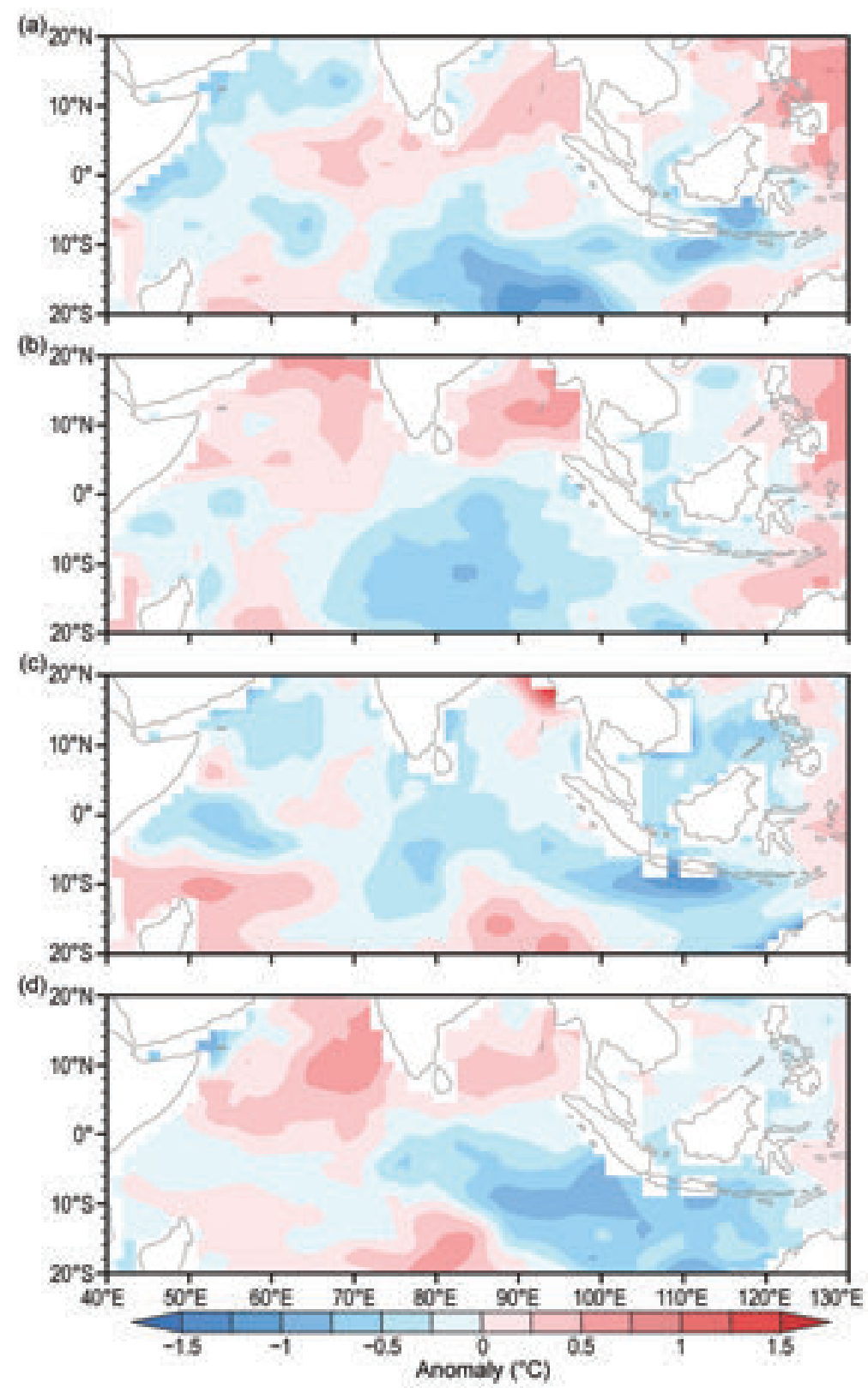

FIG. 4.38. SST anomalies ( ${ }^{\circ} \mathrm{C}$, colored scale) during (a) Dec 2017-Feb 2018, (b) Mar-May 2018, (c) Jun-Aug 2018, and (d) Sep-Nov 2018. Anomalies were calculated relative to the climatology over the period 1982-2018. [Sources: NOAA OISST (Reynolds et al. 2002) and monthly GPCP precipitation analysis (available at http://precip.gsfc .nasa.gov/); and JRA-55 atmospheric reanalysis (Kobayashi et al. 2015).] 
occurred along the west coast of Sumatra in June and then intensified sharply during July-August, in association with intensified wet conditions in the western North Pacific. The southeasterly anomalies along the west coast of Sumatra induced stronger-than-normal coastal upwelling, intensifying the below-average SST anomalies in the eastern IO (Figs. 4.37a, 4.38d). During the boreal autumn, in conjunction with the developing El Niño event (Fig. 4.37c), descending motion and dry conditions dominated the Maritime Continent. Thus, easterly wind anomalies in the central and eastern equatorial IO intensified (Figs. $4.37 \mathrm{~b}, 4.39 \mathrm{~d}$ ), and the pIOD further grew (Figs. 4.37a; $4.38 \mathrm{~d}$ ) during the season.

It appears that the 2018 pIOD event was initiated/ influenced by MJO activity, the Asian monsoon, and a developing El Niño. This pIOD case was weak, partly because of the multidecadal, basin-wide warming trend of SST in the tropical IO under global warming (Luo et al. 2012; Magee and Verdon-Kidd 2018). This trend might have partly offset the growth of cold SST anomalies associated with this pIOD event.

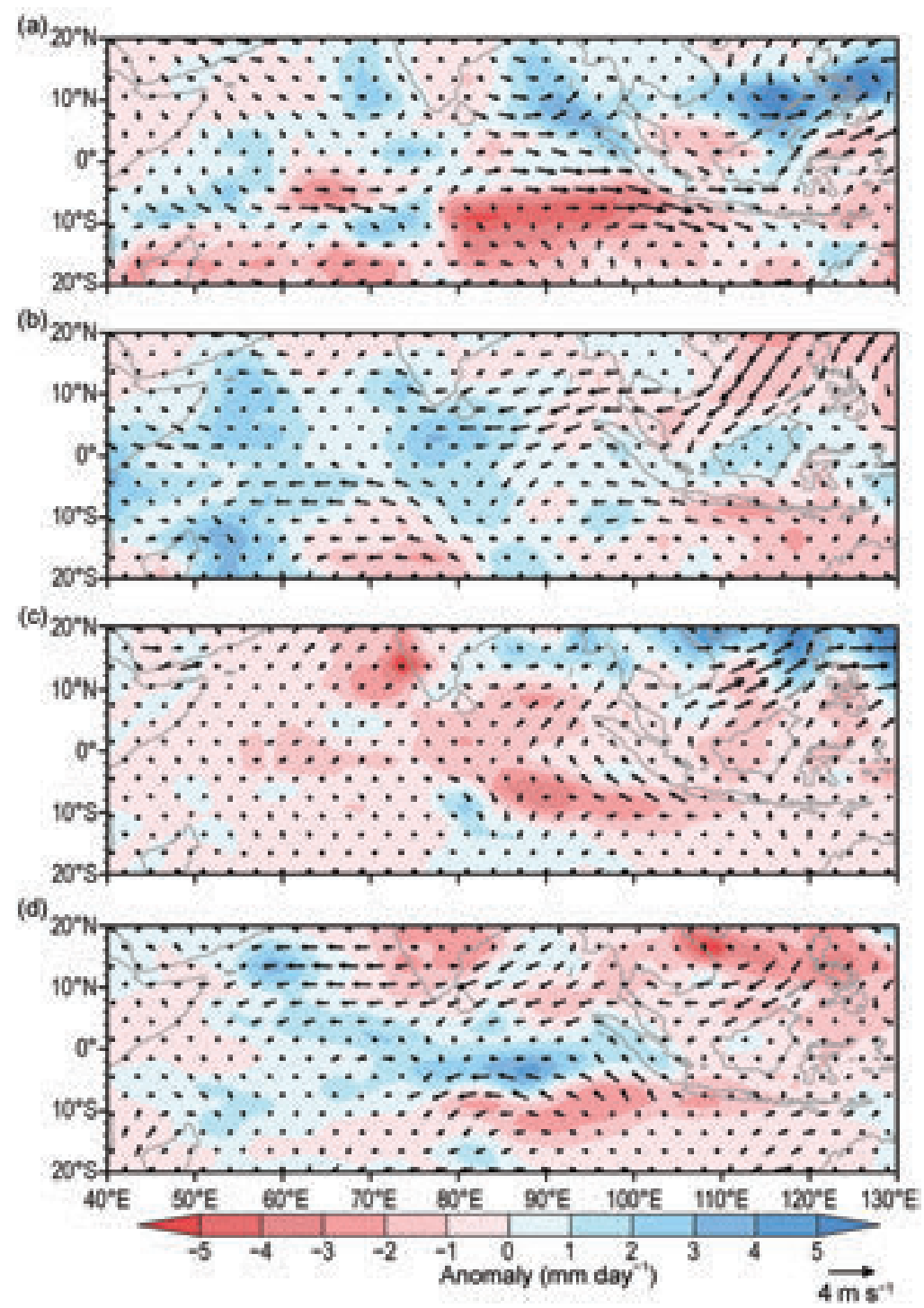

FIG. 4.39. Precipitation $\left(\mathrm{mm} \mathrm{day}^{-1}\right)$ and surface wind (vectors, $\mathrm{m} \mathrm{s}^{-1}$ ) anomalies during (a) Dec 2017-Feb 2018, (b) Mar-May 2018, (c) Jun-Aug 2018, and (d) Sep-Nov 2018. [Sources: monthly GPCP precipitation analysis (Adler et al. 2018) and JRA-55 atmospheric reanalysis (Kobayashi et al. 2015).] 
5. THE ARCTIC-Richter-Menge, E. Osborne, M. Druckenmiller, and M. 0. Jeffries, Eds.

a. Overview-J. Richter-Menge, E. Osborne, M. Druckenmiller, and M. 0. Jeffries

In 2018, annual average, near-surface Arctic air temperatures continued to increase at twice the rate of the rest of Earth. Arctic air temperatures for the past five years (2014-18) have exceeded all previous records since 1900, with 2018 being the third highest. Growing atmospheric warmth in the Arctic may contribute to a sluggish and unusually meandering jet stream that coincides with abnormal weather events in both the Arctic and midlatitude regions. Deep waves in the jet stream enable sustained southerly winds to bring warm moist air into the Arctic from the Atlantic and Pacific Oceans, resulting in spells of unusually warm weather in the Arctic region. The meandering jet stream also supports the development of strong northerly winds out of the Arctic, which contributed to severe cold winter weather events in the midlatitude regions in 2018. High above the Arctic, atmospheric ozone concentrations in winter 2017/18 were generally well above average, due to the transport of ozone-rich air from lower latitudes. UV radiation, which is controlled by atmospheric ozone concentrations and other factors such as cloud cover, varied in time and space across the Arctic.

The scale and pattern of rising surface air temperatures (SATs) are major indicators of global climate change and drivers of widespread change in the Arctic environment. Atmospheric warming continues to drive long-term trends in the ocean, such as increasing sea surface temperatures (SSTs) along with declining sea ice extent and thickness. In the terrestrial system, atmospheric warming is linked to declines in snow cover, melting of the Greenland Ice Sheet (GrIS), increasing summertime Arctic river discharge, warming and thawing permafrost, and the general expansion and greening of Arctic tundra vegetation. As a result of these changes, the Arctic is no longer characterized as the extensively and persistently frozen and largely inaccessible region of recent decades.

In 2018, Arctic sea ice remained younger, thinner, and less extensive than in the past. The wintertime maximum sea ice extent (measured in March 2018) was the second lowest in the 39-year satellite record; the previous lowest winter ice extent maximum occurred in 2017. The 12 lowest summer sea ice extents have all occurred in the last 12 years. The disappearance of older and thicker classes of sea ice are leaving an ice pack that is more vulnerable to melting in summer, and liable to move unpredictably on shorter timescales. The rate and extent of the melting of the summer sea ice cover are linked to the spatial patterns of late summer SSTs in the Arctic Ocean, along with regional air temperatures and advection of waters from the Pacific and Atlantic Oceans. August mean SSTs showed statistically significant warming trends for 1982-2018 in most regions of the Arctic Ocean that are ice-free in August. One of the more remarkable features of Arctic sea ice in 2018 was the dearth of ice in the Bering Sea, which was at a record low extent during almost the entire 2017/18 ice season. The low ice extent significantly influenced the Bering Sea ecosystem and specifically the distribution of commercially important fish stocks, including Alaska pollock. The lack of ice in the Bering Sea in 2018 also led to substantial coastal erosion and impacted coastal communities that depend on the ice as a protective barrier against winter storm surges and as a platform for hunting and travel.

Melting at the surface of the GrIS was unremarkable in extent and duration, coinciding with regional summer air temperatures that were generally below or near average. As a result, summertime area-averaged albedo for the entire GrIS was at its highest value since 2000. An annual satellite survey of 47 marineterminating glaciers, conducted since 1999 , indicates the cumulative net area change for 2017/18 stood alone as the only year with an increase in area.

Long-term terrestrial snow cover estimates (1967present) in the Arctic show overall declines in extent and SWE (snowmelt water equivalent: the amount of water stored in solid form by the snowpack). On average, Arctic snow cover extent during June was almost half of what it was 35 years ago, a loss rate close to the decline of the September sea ice extent. The Arctic Ocean makes up approximately $1 \%$ of the global ocean by volume but receives more than $10 \%$ of global riverine discharge. Observations dating back to the 1930s indicate a long-term increase in Arctic river discharge, which has been greatest for rivers of the Eurasian Arctic and provides the strongest evidence of intensification of the Arctic freshwater cycle.

Terrestrial permafrost, a critical component of the Arctic landscape that supports much of the built infrastructure in the region (e.g., buildings, highways, airstrips, pipelines), continues to experience notable change. Increasing summer air temperatures are a key climate variable driving higher permafrost temperatures and increasing active layer thickness (surface soil layer that thaws and refreezes seasonally). In 2018, increasing permafrost temperatures were reported at most observation sites, many setting new records. Increasing summer air temperatures 
over the course of the last 37 years are also a primary driver of the increase in the above-ground biomass of live vegetation in the circumpolar Arctic tundra, a process commonly referred to as "greening." Regions with the greatest increases in tundra greenness are the North Slope of Alaska, the southern subzones of the Canadian tundra, and eastern Siberia. Changes in tundra vegetation can have important effects on carbon cycling and soil-atmosphere energy exchange, with implications for active layer depth and permafrost stability, thereby impacting Arctic landscapes, infrastructure, and wildlife habitats.

Continued warming of the Arctic atmosphere and ocean are driving widespread changes in the environmental system in predictable and, also, unexpected ways. New emerging threats are taking shape and highlighting the knowledge gaps about the breadth of environmental change that is to come. To convey the scope of change in the Arctic using the most recently available observations, Arctic river discharge is featured in this year's chapter instead of glaciers and ice caps outside Greenland. Long-term observing programs are critical to understanding baseline conditions and the magnitude and frequency of the changes that are occurring in the Arctic. Such understanding is central to the livelihood of communities that call the Arctic home, as well as to the rest of Earth, which is already experiencing the changes and implications of a warming and thawing Arctic.

\section{b. Surface air temperature-J. E. Overland, E. Hanna,} I. Hanssen-Bauer, S.-J. Kim, J. E. Walsh, M. Wang, and U. S. Bhatt

The system-wide character and year-on-year persistence of rising atmospheric temperatures in the Arctic are major indicators of global climate change, which is a result of the increasing concentration of atmospheric greenhouse gases (Notz and Stroeve 2016; Overland et al. 2019). As evidenced throughout this chapter, atmospheric warming in the Arctic acts as the driver of broad Arctic change in the terrestrial and ocean systems. A linear relationship between increasing global temperature and Arctic sea ice decline suggests a direct temperature forcing (Mahlstein and Knutti 2012). Changes in Arctic tundra landscapes and glacial melt are forced by changes in atmospheric temperature (AMAP 2017).

I) Mean annual land surface air temperature

In 2018, the mean annual SAT anomaly for land stations north of $60^{\circ} \mathrm{N}$ was $+1.2^{\circ} \mathrm{C}$ relative to the 1981-2010 mean. This anomaly tied with 2007 and 2011 as the third highest on record in the Arctic (1900-present) after 2016 and 2017 (Fig. 5.1).

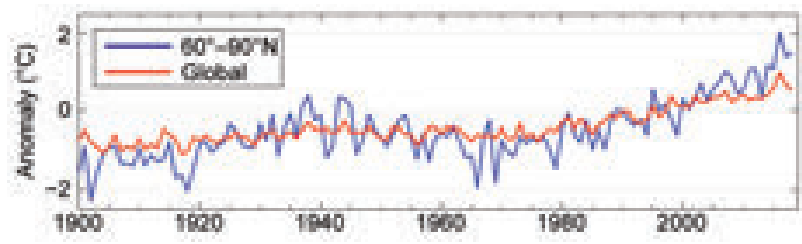

Fig. 5.I. Arctic (land stations north of $60^{\circ} \mathrm{N}$ ) and global mean annual land SAT anomalies (in ${ }^{\circ} \mathrm{C}$ ) for 1900-2018 relative to the 198I-2010 base period. Note that there were few stations in the Arctic, particularly in northern Canada, before 1940. (Source: CRUTEM4 dataset.)

The Arctic continues to warm at more than twice the rate of global mean temperatures, a phenomenon known as Arctic amplification (Fig. 5.1; see years 1980-2018). Currently there is no consensus on the exact combination of processes that are driving Arctic amplification. Proposed mechanisms include reduced summer albedo due to sea ice and snow cover loss ( $\mathrm{Pi}$ than and Mauritsen 2014; Dai et al. 2019); the increase of total water vapor content in the Arctic atmosphere (Dufour et al. 2016); changes in atmospheric transport and cloudiness (Kim et al. 2017); and changes in pollution (Acosta Navarro et al. 2016).

\section{2) Seasonal air temperature variation}

Seasonal air temperature variations are divided into winter [January-March (JFM)]; spring [AprilJune (AMJ)]; summer [July-September (JAS)]; and autumn [October-December (OND)] (Fig. 5.2). Seasonal SAT divisions are chosen to coincide with the seasonal cycles of key Arctic variables including the September summer sea ice minimum and autumnal cooling that continues through December.

Winter temperature anomalies over land were near neutral or below average while central Arctic Ocean temperatures were anomalously high (Fig. 5.2a). The northern Bering Sea and Svalbard were particularly warm, which contributed to low regional sea ice extent (Section $5 \mathrm{~d}$ ). The temperature anomaly over Svalbard in January and February exceeded $+7^{\circ} \mathrm{C}$ at most stations.

Above-average temperature anomalies persisted in spring, especially in the East Siberian Sea (Fig. 5.2b). This regional warming supported early sea ice loss in the Chukchi Sea (Section 5d). May was record warm at all regular Svalbard meteorological stations, including the composite series from Longyearbyen, which began in 1898 (Nordli et al. 2014).

Winter and spring months showed extensive above-average temperatures in the Arctic, often more than $+4^{\circ} \mathrm{C}$ above the long-term means (1981-2010). The large-scale climate mode known as the Arctic Oscillation (AO) was generally weak, which is marked 

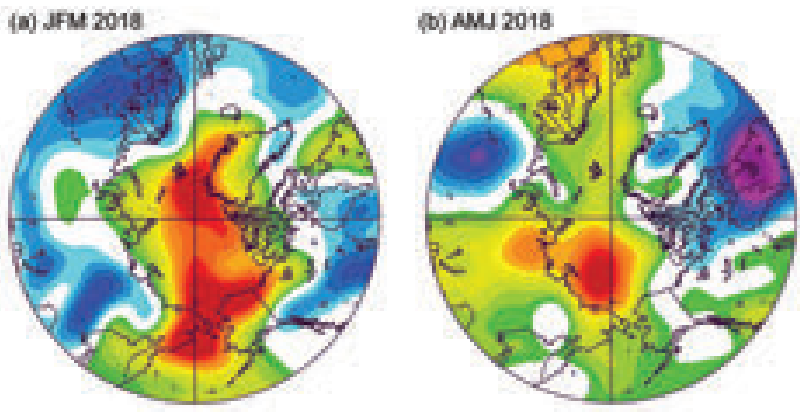

(c) IAS 2018

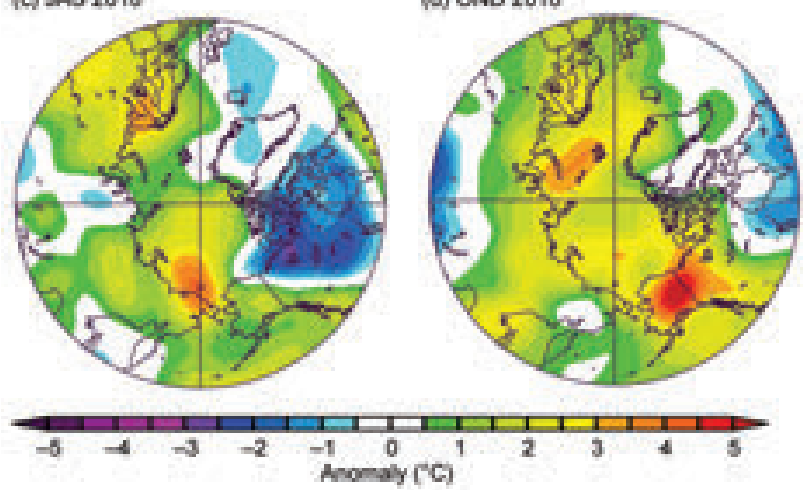

FIG. 5.2. Seasonal anomalies for near-surface air temperatures ( ${ }^{\circ} \mathrm{C}, 1981-2010$ base period) for 2018 in (a), JFM, (b), AMJ, (c), JAS, and (d) OND. Temperatures are from slightly above the surface layer $(925 \mathrm{mb})$ to emphasize large spatial patterns rather than local features. (Source: NOAA/ESRL.)

by a lack of a dominant wind pattern in the central Arctic. At the same time, climate modes occurring in the subarctic, including the North Atlantic Oscillation (NAO) and the Pacific North American (PNA) modes, characterized by deep Icelandic and Aleutian low-pressure patterns, respectively, were positive and drove considerable variability during winter and spring. As a collective result of these subarctic climate mode anomalies, large amounts of heat and moisture were transported northward into the Arctic. These weather patterns contributed to especially warm conditions between Greenland and Svalbard, the northern Barents Sea, and in the Chukchi Sea/ East Siberian Sea.

Summer 2018, similar to 2016 and 2017, had nearor slightly above-average air temperatures across the Arctic (relative to the 1981-2010 climatology) associated with low-pressure systems (Fig. 5.2c). Low central Arctic pressure also resulted in widespread cloud cover that limited the solar heating of the lower atmosphere in the central Arctic. These observations contrast with the warm conditions observed over much of the previous decade before 2016. Neutral anomalies occurring across the central Arctic in summer 2018 inhibited the continued overall rapid summer loss of sea ice (Section 5d). The July temperature anomalies for the Spitsbergen stations of Longyearbyen and $\mathrm{Ny}$-Alesund were less than $+1^{\circ} \mathrm{C}$ and precipitation was record high. Atmospheric temperatures above the East Siberian and Beaufort Seas were $3^{\circ} \mathrm{C}$ lower in July 2018 than in 2017. June and July 2018 in Greenland were not notably warm by recent standards (Section 5e). There was, however, a distinct warm feature observed in the East Siberian Sea.

During autumn, above-average temperature anomalies were especially notable in the northern Barents Sea, north of central Siberia, and Alaska (Fig. 5.2d). This warmth was due to a combination of local heating from lack of sea ice and extensive open water as well as the advection of warm air from the Pacific and Atlantic Oceans. During autumn, a split tropospheric polar vortex was present and caused highly localized air temperature anomalies.

\section{3) Geopotential heights and resulting regional} TEMPERATURE PATTERNS

In 2018, large month-to-month variability in Arctic and sub-Arctic weather patterns was associated with different amplified jet stream patterns. Anomalous atmospheric temperatures and pressures continued to provide evidence in support of Arcticmidlatitude weather connections in both directions. The jet stream can vary from a relatively circular pattern to one with large north/south waves whose winds bring heat toward the Arctic in some locations and colder temperatures southward elsewhere (Francis and Vavrus 2015; Overland and Wang 2018). The year 2018 provided several examples of a wavy jet stream pattern throughout the seasons.

Above-average Arctic temperatures during winter and spring were the result of southerly winds that advected warm moist air into the Arctic from the Atlantic and Pacific. In February, the strength of low-pressure zones (Icelandic and Aleutian Lows) increased and shifted in association with a wavy jet stream pattern (Fig. 5.3a). [Jet stream wind directions follow contours of the height of constant pressure surfaces (geopotential heights) as seen in Fig. 5.3.] Southerly winds brought warm, moist air into the Bering Sea region, contributing to the record low sea ice extent in the area (Section $5 \mathrm{~d}$ ). In contrast, the tropospheric polar vortex in March (Fig. 5.3b) shifted toward Asia and western Russia and higher geopotential heights over the northwest Atlantic and Greenland. The difference between geopotential heights in central Eurasia and Scandinavia produced strong northerly winds out of the Arctic and severe cold weather over Europe, a weather abnormality 


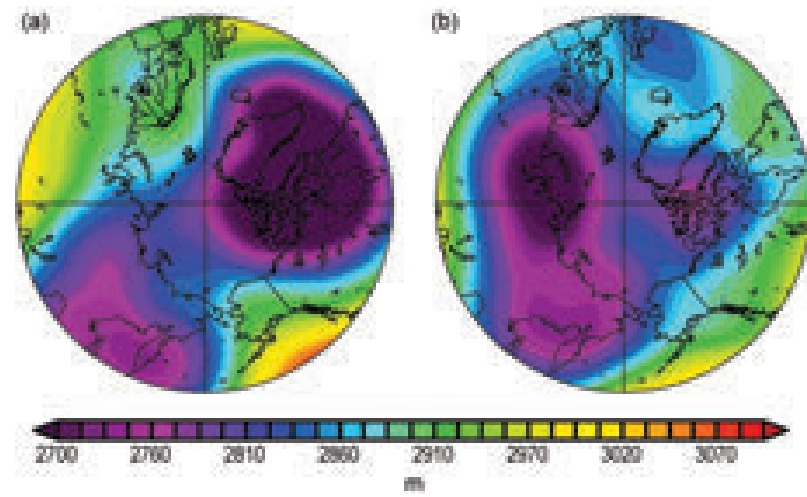

FIG. 5.3. Arctic geopotential height pattern at $700 \mathrm{hPa}$ for (a) Feb 2018 with southerly flow from the Pacific to Bering Sea, which contributes to the warm anomalies there, (b) Mar 2018 with a low geopotential height center in Europe and East Asia. (Source: NOAA/ESRL.)

called the "Beast from the East." In autumn, the large tropospheric polar vortex located on the Atlantic side of the Arctic (not shown) brought warm air into the Barents Sea and southerly winds onto the central Siberian continental shelf. The ridge/trough over western North America brought warm air into central Alaska and colder conditions downstream into eastern North America. Notable region-specific information is provided in the relevant sections of Chapter 7 .

c. Sea surface temperature-M.-L. Timmermans and C. Ladd In the Arctic Ocean, SSTs are driven mainly by the amount of incoming solar radiation absorbed by the sea surface. Solar warming of the Arctic surface ocean is influenced by the distribution of sea ice (with greater warming occurring in ice-free regions), cloud cover, ocean optical properties, and upper-ocean stratification. In the Barents and Chukchi Seas, there is an additional source of ocean heat contributed by the advection of warm water from the North Atlantic and North Pacific Oceans, respectively. Arctic SSTs are an essential indicator of the role of the ice-albedo feedback mechanism in any given melt season. As the area of sea ice cover decreases, more incoming solar radiation is absorbed by the ocean and, in turn, the warmer ocean melts more sea ice. In addition, marine ecosystems are influenced by SST, which affects timing and developmental cycles of primary and secondary production as well as available habitat for individual species.

SST data presented here are from the NOAA Optimum Interpolation (OI) SST Version 2 product (OISSTv2), which is a blend of in situ and satellite measurements for December 1981-present (Reynolds et al. 2002, 2007). Compared with purely in situ temperature measurements, the OISSTv2 product has shown average correlations of about $80 \%$, with an overall cold bias of $-0.02^{\circ} \mathrm{C}$ (Stroh et al. 2015). August SSTs provide the most appropriate representation of Arctic Ocean summer SSTs, because they are not affected by the cooling and subsequent sea ice growth that typically takes place in the latter half of September.

In August 2018, mean SSTs in ice-free regions ranged from approximately $0^{\circ} \mathrm{C}$ in some regions to as high as $11^{\circ} \mathrm{C}$ in the southern Chukchi and Barents seas (Fig. 5.4). In particular, anomalously warm SSTs of around $1^{\circ}-3^{\circ} \mathrm{C}$ higher than the $1982-2010$ August mean were observed in the Beaufort, Chukchi, Laptev, and southern Barents Seas (Fig. 5.5a). The anomalously high SSTs in the vicinity of the 2018 August mean sea-ice edge are linked to anomalously low sea ice extent, which facilitated direct solar heating of the exposed surface waters (Fig. 5.5a). Conversely, the southern boundary of the Beaufort Sea was marked by anomalously low August SSTs of around $1^{\circ}-2^{\circ} \mathrm{C}$ below the 1982-2010 mean. These low SSTs are associated with unusually cool August air temperatures along the entire southern Beaufort Sea (Section 5b) and the persistence of sea ice in the region (Section 5d; Fig. 5.8), maintained by northerly August winds in the region. Relative to August 2017, the entire Beaufort

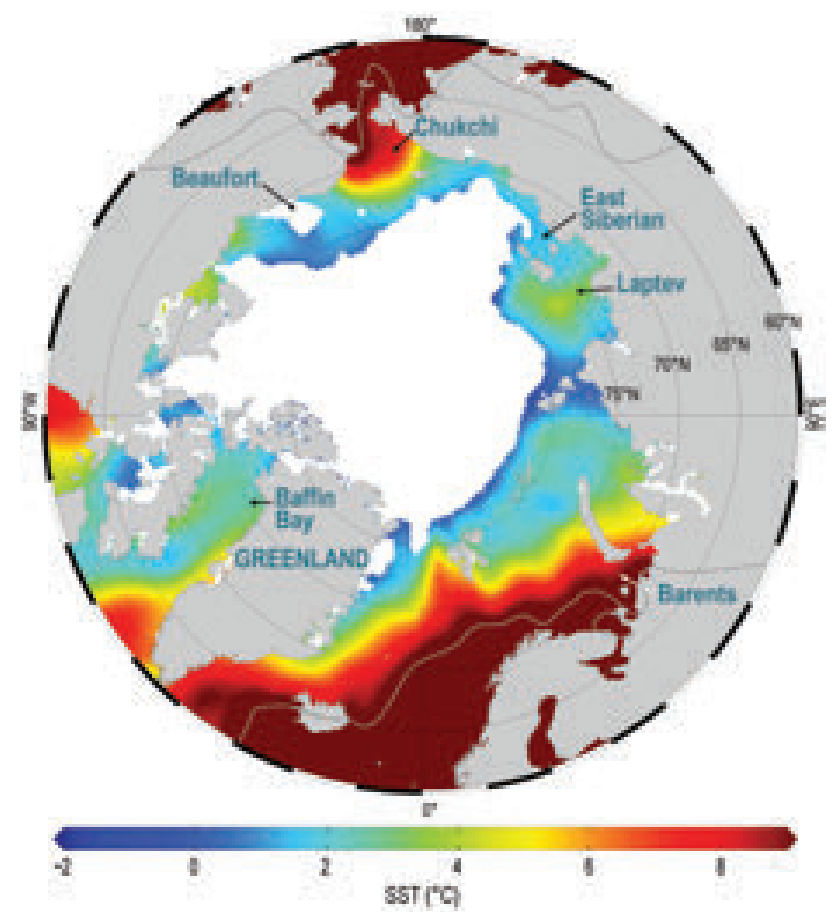

FIG. 5.4. Mean SST $\left({ }^{\circ} \mathrm{C}\right)$ in Aug 2018. White shading is the Aug 2018 mean sea ice extent, and gray contours indicate the $10^{\circ} \mathrm{C} \mathrm{SST} \mathrm{isotherm.} \mathrm{(Sources:} \mathrm{SST} \mathrm{data}$ are from the NOAA OISSTv2; sea ice extent data are from NSIDC Sea Ice Index, Version 3, Fetterer et al. 20I7.) 


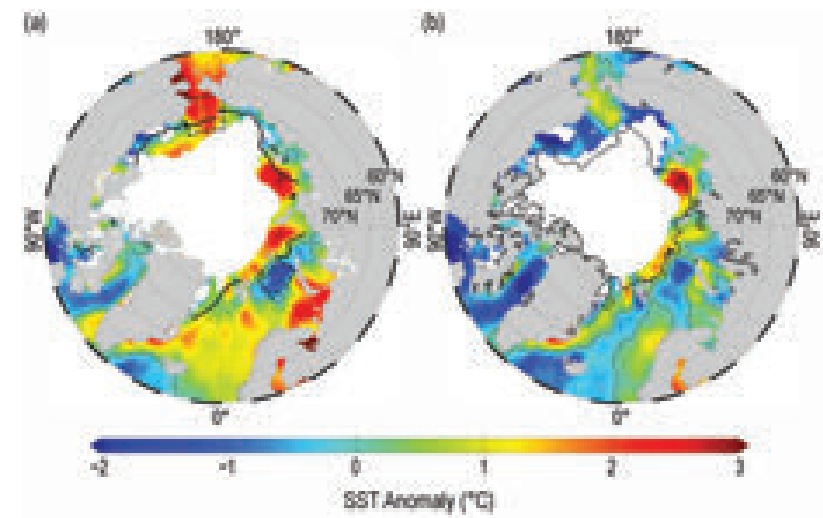

Fig. 5.5. (a) SST anomalies ( ${ }^{\circ} \mathrm{C}$ ) in Aug 2018 relative to the Aug 1982-2010 mean (dotted black contour indicates zero anomaly). Black line indicates the median ice edge for Aug 1982-2010. (b) SST anomalies ( ${ }^{\circ} \mathrm{C}$ ) in Aug 2018 relative to Aug 2017. Black line indicates the median ice edge for Aug 2017. White shading in (a) and (b) indicates the Aug 2018 mean sea ice extent. (Sources: SST data are from the NOAA OISSTr2; sea ice extent and ice-edge data are from NSIDC Sea Ice Index, Version 3, Fetterer et al. 20I7.)

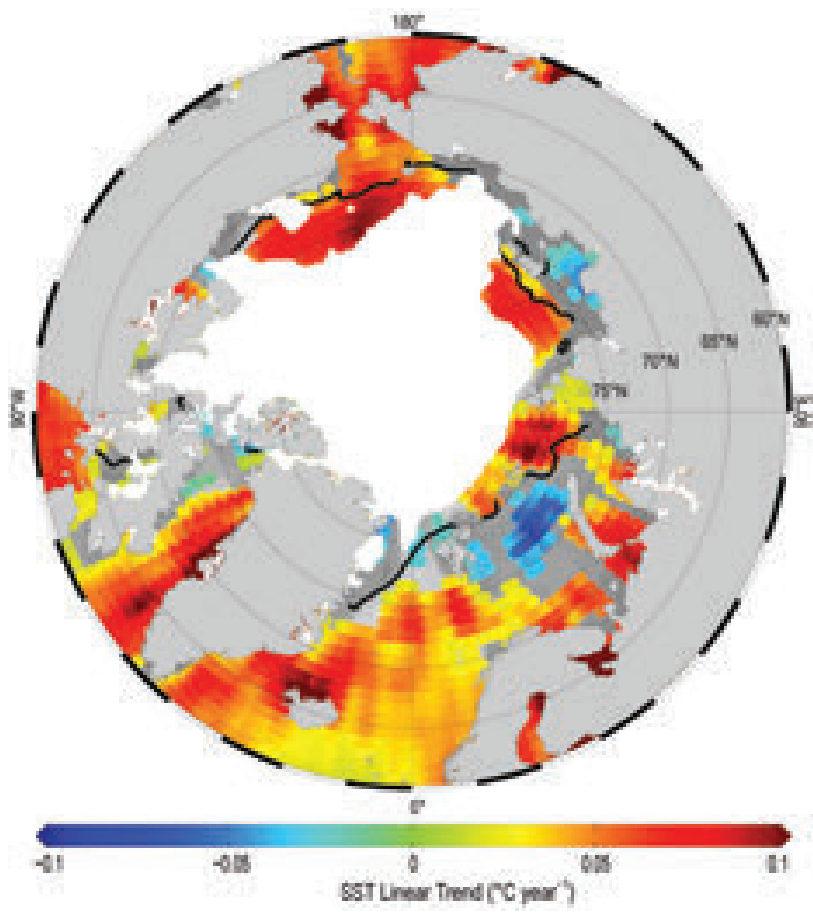

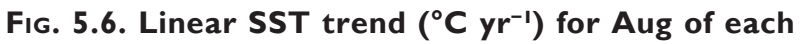
year from 1982-2018. Trend is only shown for values that are significant at the $95 \%$ confidence interval; the region is gray otherwise. Black line indicates the median ice edge for Aug 1982-2010. White shading is the Aug 2018 mean sea ice extent. (Sources: SST data are from the NOAA OISSTr2; sea ice extent and iceedge data are from NSIDC Sea Ice Index, Version 3, Fetterer et al. 20I7.)
Sea region in August 2018 exhibited up to $3.5^{\circ} \mathrm{C}$ lower SSTs (Fig. 5.5b).

Mean August SSTs for 1982-2018 show warming trends over much of the Arctic Ocean, with statistically significant (at the 95\% confidence interval) linear trends of up to $+1^{\circ} \mathrm{C}$ per decade (Figs. 5.6, 5.7). In particular, the Chukchi Sea has been anomalously warm throughout the water column during the summers of 2017 (Wood et al. 2018) and 2018, with SST exceeding the mean by approximately 2 standard deviations in August 2018. These warming trends coincide with declining trends in summer sea ice extent, including late freeze-up and early melt seasons (e.g., Parkinson 2014), increased solar absorption (e.g., Timmermans et al. 2018), and increased vertical ocean heat transport (e.g., Lind et al. 2018).

A marked exception to the prevalent August SST warming trend is the cooling trend $\left(-0.06^{\circ}\right.$ $\pm 0.03^{\circ} \mathrm{C} \mathrm{yr}^{-1}$ ) in the northern Barents Sea (Figs. 5.6, 5.7). In line with this trend, the northern Barents Sea exhibited notably low SSTs in August 2018, characterized by temperatures $1^{\circ}-2^{\circ} \mathrm{C}$ below the $1982-2010$ average (Fig. 5.5a) and around $1^{\circ} \mathrm{C}$ lower than August 2017 (Fig. 5.5b). However, a statistically significant cooling trend in the northern Barents Sea is only observed for the months of August and September, with most other months (January-June) characterized by statistically significant warming trends $\left(+0.03^{\circ}\right.$ $\pm 0.01^{\circ}{\mathrm{C} \mathrm{yr}^{-1}}^{-1}$ over the same region. The result is that annually-averaged northern Barents Sea SSTs exhibit a warming trend (e.g., Barton et al. 2018). Barton et al. (2018) attribute the Barents Sea warming trend since 2005 to changes in the inflowing Atlantic water temperature and increased ocean mixing in the Barents Sea as a result of reduced stratification. A coupled ice-ocean numerical model study reveals subtle variability in spatial and seasonal trends in the Barents

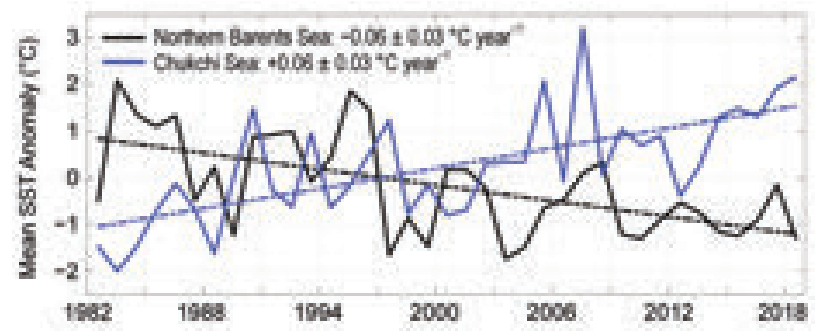

FIG. 5.7. Area-averaged SST anomalies $\left({ }^{\circ} \mathrm{C}\right)$ for Aug of each year relative to the 1982-2010 Aug mean for the Chukchi Sea region $\left(68^{\circ}-74^{\circ} \mathrm{N}, 180^{\circ}-200^{\circ} \mathrm{E}\right)$ and the northern Barents Sea region $\left(76.4^{\circ}-79.4^{\circ} \mathrm{N}, 38^{\circ}-60^{\circ} \mathrm{E}\right)$; regions are shown by black dashed lines in Fig. 5.5a. Dashed lines show linear SST anomaly trends over the period shown. Numbers in the legend correspond to

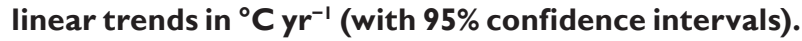


Sea region that appears to depend on the interplay between sea ice changes, local solar absorption, and lateral ocean heat transport (Long and Perrie 2017).

d. Sea ice cover-D. Perovich, W. Meier, M. Tschudi, S. Farrell, S. Hendricks, S. Gerland, C. Haas, T. Krumpen, C. Polashenski, R. Ricker, and M. Webster

I) SEA ICE EXTENT

Arctic sea ice cover varies substantially throughout the year, with end-of-winter ice extent generally twoto-three times as large as at the end of summer. An important element of the Arctic system, sea ice acts as a barrier between the underlying ocean and the atmosphere; limits the amount of absorbed solar energy during the summer due to its high albedo; provides a habitat for biological activity; provides a platform for hunting, fishing, and travel by coastal Indigenous communities; and limits human access to the Arctic Ocean. The annual cycle of sea ice extent has been monitored by passive microwave instruments on satellite platforms since 1979, providing a long-term perspective on changing coverage over the last several decades. March and September are of particular interest in sea ice time series, because they represent the typical Arctic sea ice maximum and minimum extents, respectively. Figure 5.8 shows the average ice extents during March and September in 2018.

Estimates of sea ice extent are based on products by the National Snow and Ice Data Center (NSIDC) Sea Ice Index (Fetterer et al. 2017) that are derived from NASA gridded sea ice concentration fields (Meier et al. 2012). Sea ice cover reached a winter maximum extent of 14.48 million $\mathrm{km}^{2}$ on 17 March 2018. This
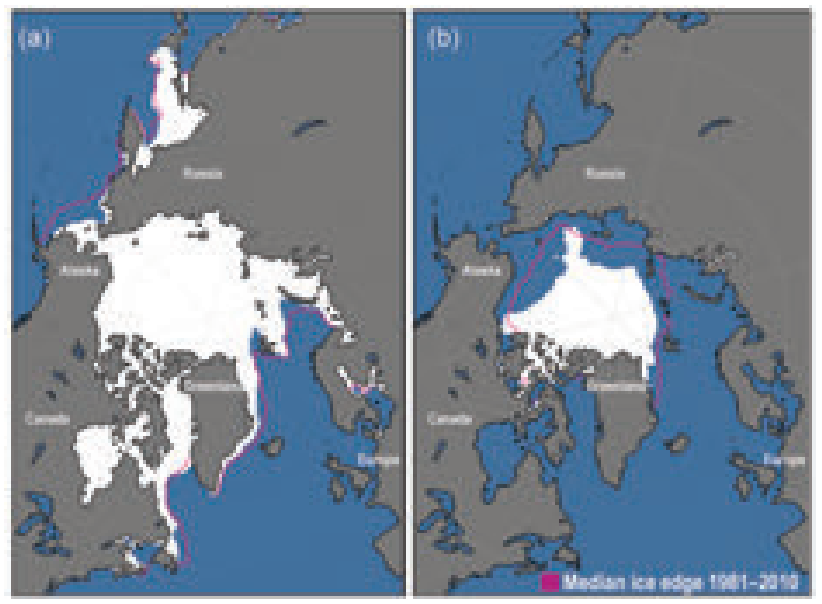

FIG. 5.8. Average monthly sea ice extent in (a) Mar (left) and (b) Sep (right) 2018 illustrate the respective winter maximum and summer minimum extents. The magenta line indicates the median ice extents in Mar and Sep, respectively, during 198I-2010. Maps are from NSIDC at http://nsidc.org/data/seaice_index. sea ice extent was $7.3 \%$ below the 1981-2010 average maximum extent and was the second lowest ever observed, above only 2017. Especially low ice coverage in the Bering Sea contributed to the low ice coverage seen across the Arctic in 2018. The past four years (2015-18) have had the four lowest maxima in the satellite record.

In 2018, the sea ice cover reached the same minimum annual extent of 4.59 million $\mathrm{km}^{2}$ on 19 September and 23 September. This extent was 1.63 million $\mathrm{km}^{2}(26 \%)$ less than the 1981-2010 average minimum ice extent and tied with 2008 and 2010 for the sixth lowest extent in the satellite record. The September ice extent has not returned to pre-2007 levels, with the 12 lowest extents in the satellite record having all occurred in the last 12 years. The 2018 minimum annual extent date of 23 September was nine days later than the long-term average (1981-2010) date of 14 September and tied with 1997 as the latest sea ice minimum date.

Meier et al. (2012), who analyzed the period 1979-2011, found that Arctic sea ice extent has shown decreasing trends in all months and virtually all regions. The September monthly average trend for the entire Arctic Ocean is now $-12.8 \%$ per decade (Fig. 5.9). Trends are smaller during March (-2.7\% per decade), but the long-term decline is statistically significant. In 2018, 9.89 million $\mathrm{km}^{2}$ of ice was lost between the March maximum and September minimum extent. This is slightly larger than the 1981-2010

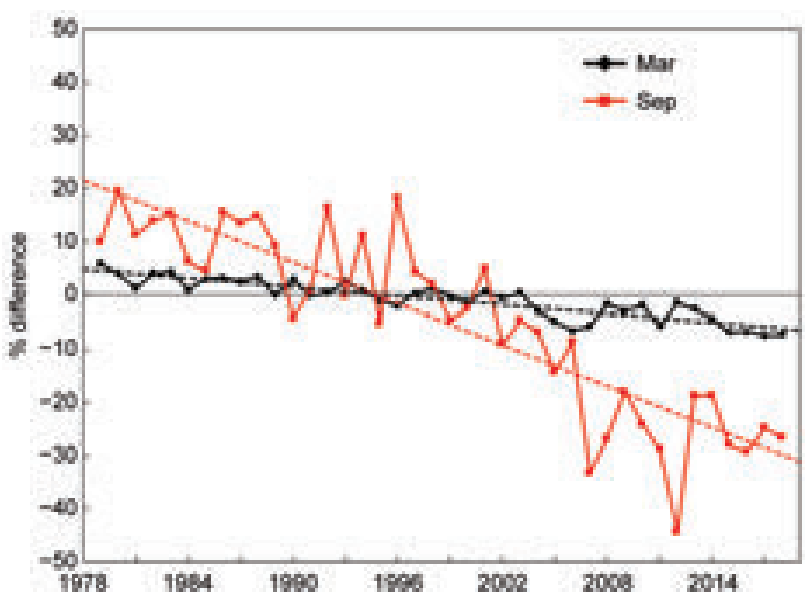

Fig. 5.9. Time series of sea ice extent anomalies in Mar (the month of maximum ice extent) and Sep (the month of minimum ice extent). Anomaly value for each year is the percent difference in ice extent relative to the 1981-2010 mean. Black and red dashed lines are least squares linear regression lines. The slopes of these lines indicate ice losses of $-2.7 \pm 0.5 \%$ and $-\mathbf{I} 2.8$ $\pm 2.3 \%$ per decade in Mar and Sep, respectively. Both trends are significant at the $99 \%$ confidence level. 
average difference between maximum and minimum extent of 9.42 million $\mathrm{km}^{2}$.

\section{2) Sea ICE AGE}

Sea ice age is an important indicator of the state of the sea ice cover; it is a proxy for physical ice properties, such as surface roughness, melt pond coverage, and thickness (Tschudi et al. 2016; Fig. 5.10). These properties are used to model both sea ice mechanical properties and ice interactions with the ocean and atmosphere, which are relevant to understanding ice movement and melt, as well as the forces exerted on structures or ships within the ice. Using a method employed since the early 1980s (Tschudi et al. 2015), sea ice age is determined using satellite observations and drifting buoy records to track the movement of ice parcels over several years (Tschudi et al. 2010; Maslanik et al. 2011).

Older ice tends to be thicker and, thus, more resilient to changes in atmospheric and oceanic heat content compared to younger, thinner ice. The oldest ice ( $>4$ years old) continues to make up only a small fraction of the Arctic ice pack in March, when the sea ice extent is at its maximum. In 1985, the oldest ice composed $16 \%$ of the ice pack (Fig. 5.10a), whereas in March 2018 old ice constituted only $0.9 \%$ of the ice pack (Fig. 5.10b). The oldest ice extent declined from 2.54 million $\mathrm{km}^{2}$ in March 1985 to 0.13 million $\mathrm{km}^{2}$ in March 2018, representing a 95\% reduction.

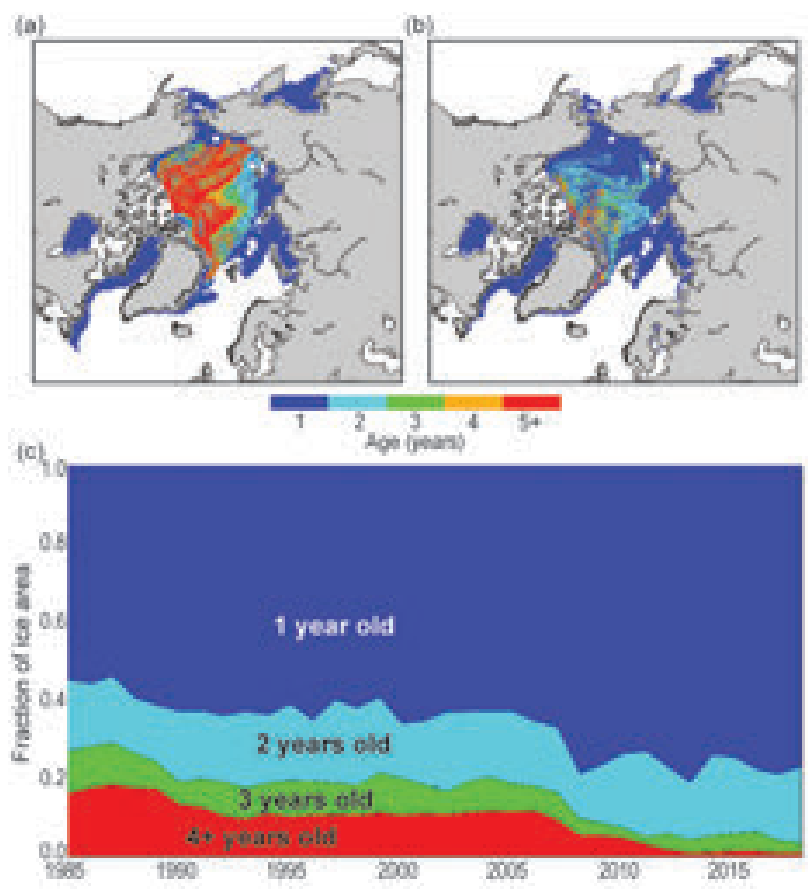

Fig. 5.10. Sea ice coverage maps for (a) Mar 1985 and (b) Mar 2018. (c) Arctic sea ice age coverage by year, expressed as the fraction of the total ice area, 1985-2018.
First-year ice now dominates the ice cover, composing $77 \%$ of the March 2018 ice pack compared to about $55 \%$ during the 1980 s. As older ice tends to be thicker, the sea ice cover has transformed from a strong, thick pack in the 1980s to a more fragile, thinner pack in recent years (Fig. 5.10c). Because thinner, younger ice is more vulnerable to melting out in summer, this shift in sea ice age has contributed to the decreasing trend in the minimum ice extent observed during September.

\section{3) Winter in the Bering Sea}

One of the more remarkable features of Arctic sea ice over the past year was the dearth of ice in the Bering Sea throughout the 2017/18 sea ice season (Sidebar 5.1). The Bering Sea supports a vibrant sea ice ecosystem with abundant seals, birds, and other pelagic species that critically depend on the timing of sea ice formation and retreat. It is also an important commercial fishing region. Ice typically begins to form in the Bering Sea around the beginning of October, expands through late March, and then melts away through late spring. By the end of June, typically most or all of the Bering Sea ice has melted (Fig. 5.11a).

For virtually the entire 2017/18 Bering Sea ice season, sea ice extent was at a record low (Fig. 5.11a). During February, typically the height of the winter season, the Bering Sea actually lost significant ice cover. From 7 to 23 February, ice extent decreased by $\sim 215000 \mathrm{~km}^{2}$, dropping from $\sim 59 \%$ to only $\sim 26 \%$ of normal (relative to the 1981-2010 median). The Bering Sea ice cover remained extremely low until midMarch, when extent increased over a couple of weeks, though it still remained at record low levels until the spring decline began. A much longer reconstructed sea ice coverage dataset (1850-present) based on a combination of historical whaling ship records, passive microwave satellite imagery, and other sources (http://seaiceatlas.snap.uaf.edu/) indicates that Bering Sea ice extent in March 2018 was by far the lowest observed since at least 1850 (Fig. 5.11b).

Anomalously high SST persisted in the Bering Sea from September 2017 through 2018 (NOAA's Optimum Interpolation Version 2 SST: www .esrl.noaa.gov/psd/map/clim/sst.shtml) and air temperatures were also well above average (NCEP/ NCAR Reanalysis: www.esrl.noaa.gov/psd/cgi-bin /data/composites/printpage.pl). A key factor in the low Bering Sea ice was persistent southerly circulation that brought warm air and surface waters from the south and pushed sea ice northward throughout winter. Moorings measuring ocean currents and heat fluxes detected very warm water in the 


\section{SIDEBAR 5.I: THE EASTERN BERING SEA: DECLINING ICE, WARMING SEAS, AND A CHANGING ECOSYSTEM-}

\section{P. J. STABENO}

The Bering Sea is located between the Pacific and Arctic Oceans and consists almost equally of a broad $(>500 \mathrm{~km})$, shallow $(<180 \mathrm{~m})$ eastern shelf, and a deep basin ( $180-4000 \mathrm{~m})$. The eastern shelf of the Bering Sea is an extremely productive ecosystem, supplying nearly half of the U.S. commercial catch of fish and shellfish. In addition, it provides subsistence resources (fish, marine mammals, and seabirds) for more than 30 Alaskan native communities, and supports large populations of seabirds and marine mammals.

The eastern Bering Sea shelf, with its extensive sea ice in winter through mid-spring, is classified as an Arctic system. Sea ice arrives on the northern Bering Sea shelf in autumn and advances southward with maximum ice extent occurring, on average, in late March; by June, the eastern shelf is usually icefree. Ice extent in the Bering Sea varies greatly among years. For instance, the greatest sea ice extent observed since 1979 occurred in 2012 (20 Mar) and the smallest maximum ice extent occurred six years later in 2018 (I7 Mar; Fig. SB5.I).

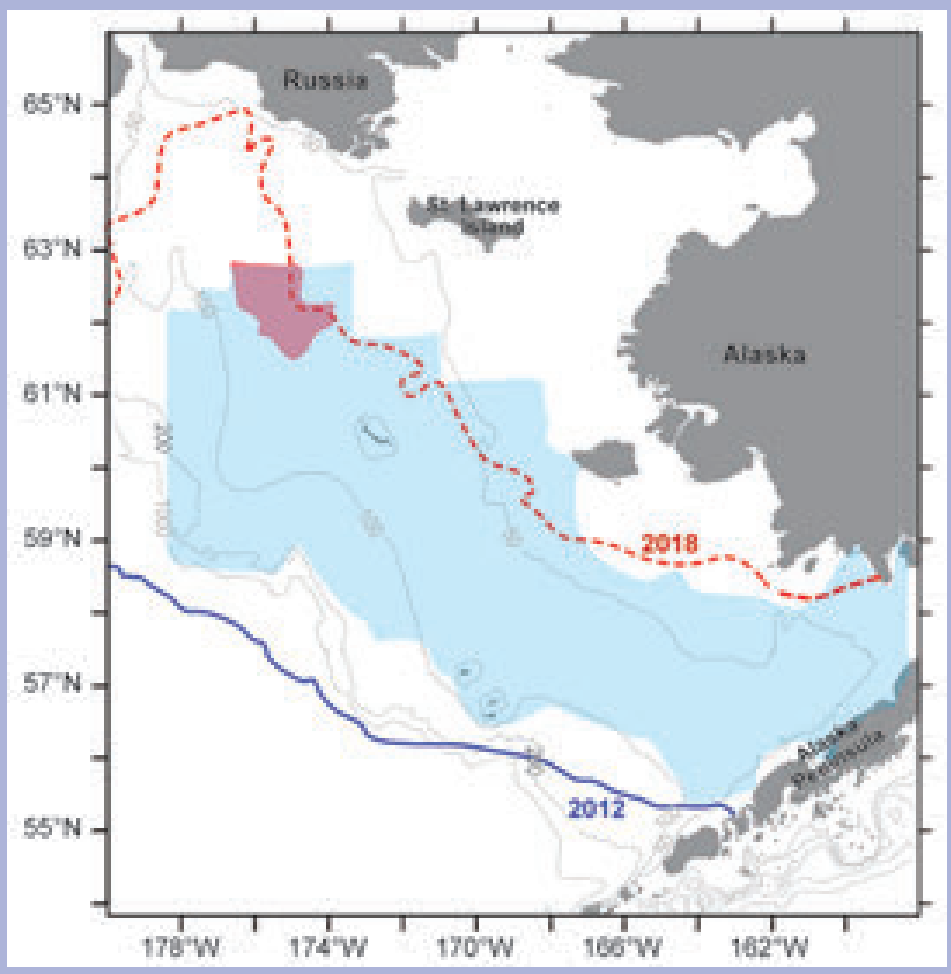

FIG. SB5.I. Range in annual maximum sea ice extent for 19792018 on the eastern Bering Sea shelf. The blue shaded area is the cold pool in summer 2012 and the red shaded area is the cold pool in 2018. Isobaths are shown in gray. Sea ice data is from NSIDC, Version 3 bootstrap prior to Dec 2017 and Version I after that date.
Sea ice is a critical system component that structures the Bering Sea ecosystem, directly determining ocean temperatures, vertical stratification, and the timing of the spring phytoplankton bloom (Stabeno et al. 2012 a,b). Specifically, sea ice extent in the Bering Sea determines the size of the "cold pool," which is that region of near-bottom shelf water that remains below $2^{\circ} \mathrm{C}$ throughout the summer. Note that over the southern shelf, the presence of ice is necessary to cool the water sufficiently to form the cold pool. This is not true on the northern shelf, where in 2018 the cold pool extended beyond maximum ice extent (Fig. SB5.I). Because adult pollock (Gadus chalcogrammus) prefer water above $2^{\circ} \mathrm{C}$, the cold pool can act as a refuge for young-of-the-year pollock, who are not as averse to cold water as their adult counterparts. In addition, the cold pool provides a corridor for arctic species to enter the southern Bering Sea.

The eastern Bering Sea shelf is divided at $\sim 60^{\circ} \mathrm{N}$ between the northern benthic-dominated ecosystem and the southern more pelagic ecosystem. Prior to 2000 , the southern Bering Sea was dominated by high year-to-year variability in annual-average temperature and sea ice coverage. Since 2000, the southeastern shelf has been dominated by alternating periods (referred to as stanzas) of limited-ice/warm conditions (200I-05 and 2014-present) and extensive-ice/ cold conditions (2007-13). It is unclear what caused this apparent change in temporal variability, nor is it known how long it will persist. On the southern Bering Sea shelf, years with extensive ice in March and April result in cold ocean temperatures throughout the following summer and an early spring bloom, likely ice algae, that occurs under the ice in March or April. In contrast, in years with little or no ice during those months, ocean temperatures are $2^{\circ}-3^{\circ} \mathrm{C}$ higher and the spring phytoplankton bloom occurs later in May or even June (Sigler et al. 2014). The northern Bering Sea experiences considerable year-to-year variability in sea ice extent but is not dominated by stanzas as is the south. Prior to 2015 , there was no trend in ice duration on the northern shelf (Stabeno et al. 2019). That appears to have changed. In three of the last four years $(2014 / 15,2016 / 17,2017 / 18)$, ice in the northern Bering Sea has arrived later and retreated earlier, which correlates with observed higher ocean temperatures (Stabeno et al. 2019). 
The lowest annual maximum sea ice extent on record occurred in the 2017/18 ice season (typically from November through May). To understand why the ice extent was so low then, it must be noted that ice forms in the northern Bering Sea and is driven southward by frigid winds out of the north and northeast. When winds are out of the south for extended periods, the ice is physically forced northward, with ice floes rafting (or piling together) to reduce the area of ice. In addition, the sustained southerly winds are often warm $\left(>0^{\circ} \mathrm{C}\right)$ and can promote early ice melt. Recent analysis has shown that the frequency of $3 \mathrm{I}$-day periods from November through March when the mean wind direction is toward the north has increased (dotted lines in Fig. SB5.2). Prior to 2016, such an event occurred, on average, once every four years, but during the last four years (2016-19) such events have occurred at least once every year. Model results suggest that winds in the Bering Sea will continue to become more southerly in the next decades, which would result in lower ice extents in the Bering Sea (Hermann et al. 2019).

The low ice extent in winter (JFM) 2018 significantly influenced the ecosystem. Ocean temperatures in the northern Bering Sea, particularly near the seafloor, were $\sim 3^{\circ} \mathrm{C}$ above average, although in the southern Bering Sea, temperatures were typical of a low ice year. Observations in 2018 indicate that the timing of the spring bloom was typical of a low ice year over the southern shelf but occurred later than usual on the northern shelf. In addition, there was poor quality (low energy content) zooplankton and a significant die-off of seabirds on the northern shelf (Duffy-Anderson et al. 2019). The cold pool, which in 2018 was the smallest on record (1979-present), influences the distribution of pollock. In years with extensive ice, adult pollock are typically concentrated in the southern Bering Sea and along the continental slope. In 2018, pollock were found in high concentrations north of St. Lawrence Island, well above the north-south ecosystem boundary at $\sim 60^{\circ} \mathrm{N}$ (A. DeRobertis, Alaska Fisheries Science Center, personal communication). This was a very unusual observation, because prior to 2018 , bottom waters on the northern shelf were consistently below $2^{\circ} \mathrm{C}$.

Sea ice in the Bering Sea also plays an important role in buffering ocean waves, even in very windy conditions, which are not uncommon in this region during winter months. In 2018 , the lack of sea ice, and hence larger ocean waves, resulted in increased coastal erosion and impacted coastal communities that were repeatedly battered by ocean waves and storms. In several cases, communities experienced damage to their coastal infrastructure. Loss of sea ice has also influenced the timing of marine mammal hunting opportunities, which are often dependent upon sea ice, for the Indigenous residents of the northern Bering Sea (Huntington et al. 2017).

The question arises of whether 2018 was an extreme year that will not be revisited in the near future. The current ice year (2018/19) began slowly with ice arriving later than average, but strong, frigid winds out of the north in December drove the ice southward to a near-average extent for that time of year. However, atmospheric conditions changed markedly in late January, and February was characterized by persistent, warm winds out of the south. Ice extent at the end of February 2019 was similar to the record-breaking low ice extent observed in February 2018. Atmospheric conditions in March will determine the extent of the cold pool in 2019.

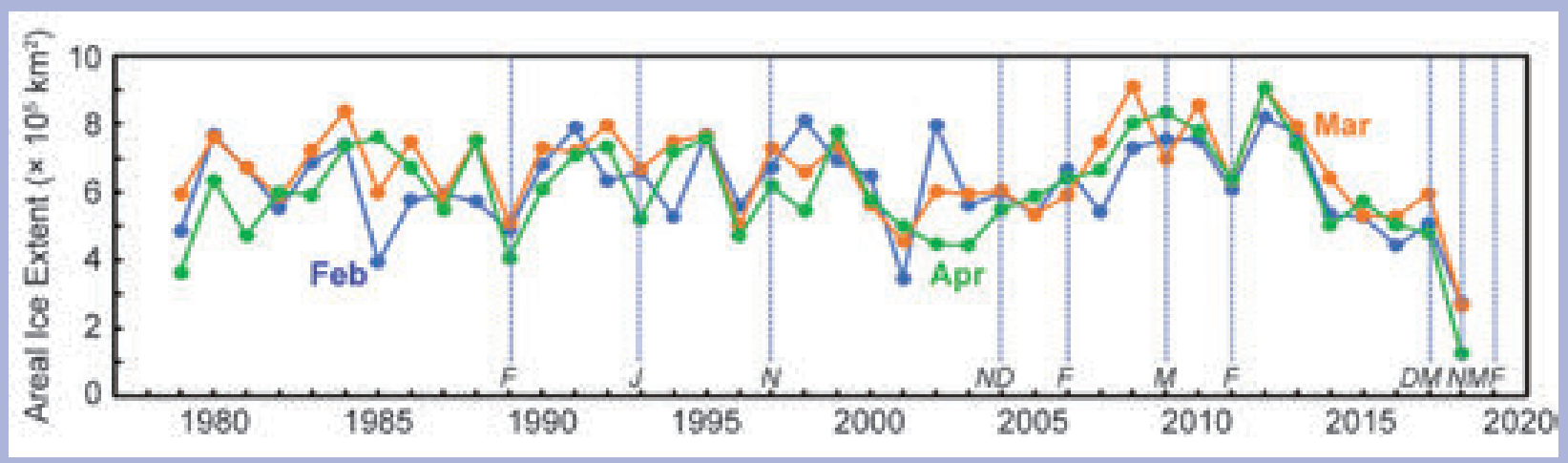

FIG. SB5.2. Time series of the monthly mean areal sea ice extent in the eastern Bering Sea in Feb (blue), Mar (orange), and Apr (green) from 1979 through spring 2018. The vertical lines indicate years in which there was at least one 31 -day period during Nov-Mar when the average winds were out of the south $\left(165^{\circ}-30^{\circ}\right.$, where $90^{\circ}$ indicates northward and $0^{\circ}$ eastward). The letters indicate the month (e.g., J is Jan, DM is Dec 20I6, and Mar 2017, etc.) in which the 3I-day period was centered. Note that conditions in Nov and Dec influence ice conditions in the following Jan-Mar. 

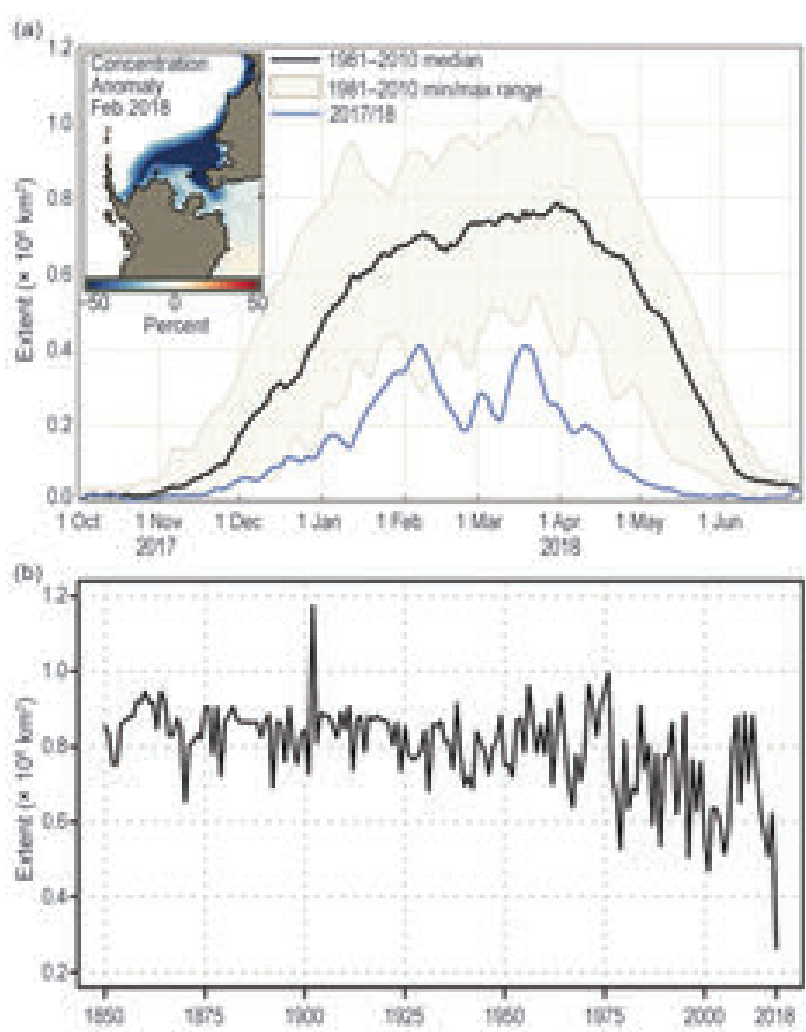

FIG. 5.II. (a) Time series of Bering Sea ice extent for the 2017/18 ice season (blue) and the 1981-2010 median (black) and minimum and maximum ranges (gray shading). The monthly sea ice concentration anomaly for Feb 2018 (based on the 198I-2010 mean) is shown in top left inset. (Source: NSIDC Sea Ice Index; https:// nsidc.org/data/seaice_index.) (b) Annual time series of Bering Sea sea ice extent for Mar for years I850-20I8. (Source: Historical Sea Ice Atlas at the University of Alaska Fairbanks; http://seaiceatlas.snap.uaf.edu.)

region in summer 2017, which likely pre-conditioned the waters for a late start to the freeze-up season. The low winter and spring ice conditions allowed for early absorption of solar insolation by the ocean and warming of surface waters. These warm ocean waters may have contributed to early summer ice melt also in the nearby Chukchi and Beaufort Seas during 2018.

e. Greenland ice sheet-M. Tedesco, J. E. Box, J. Cappelen, R. S. Fausto, X. Fettweis, J. K. Andersen, T. Mote, C. J. P. P. Smeets, D. van As, and R. S. W. van de Wal

The GrIS plays a fundamental role in the climate of our planet and in the Arctic. The relatively high albedo of the ice sheet relative to the surrounding, darker, ice-free land and ocean reduces the amount of solar energy absorbed by Earth. The GrIS also influences atmospheric circulation patterns because of its geographic location and prominent topography. On a global scale, the GrIS represents a major contribu- tor to current and projected sea level rise, through increasing rates of surface runoff and calving.

Following a persistent spring snow cover in 2018, the spatial extent of surface melt across the GrIS was unexceptional due largely to summer SATs that were generally below or near average. Consistent with these conditions, the summer albedo averaged over the whole GrIS remained relatively high in 2018. Measurements of net area change from 47 glaciers indicate that the 2017/18 season stands as the only year with an area gain since survey measurements began in 1999.

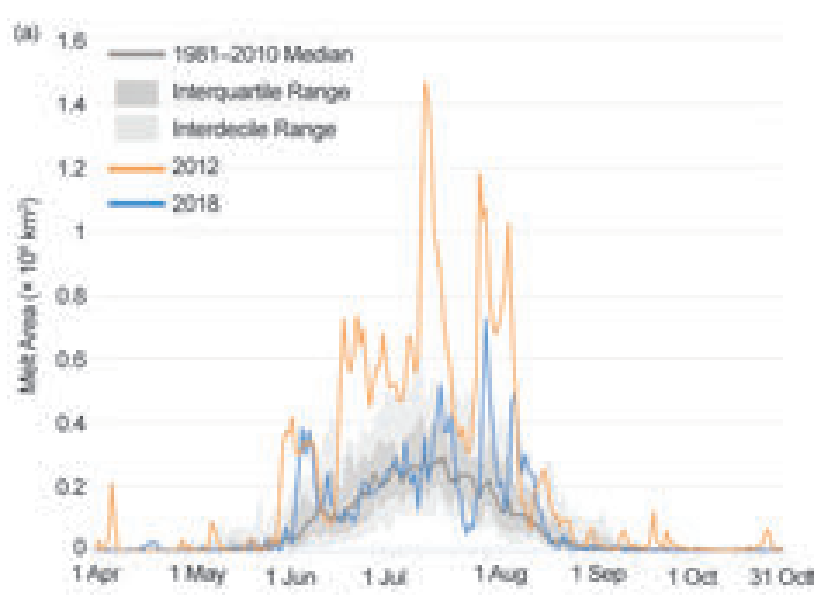

(b)

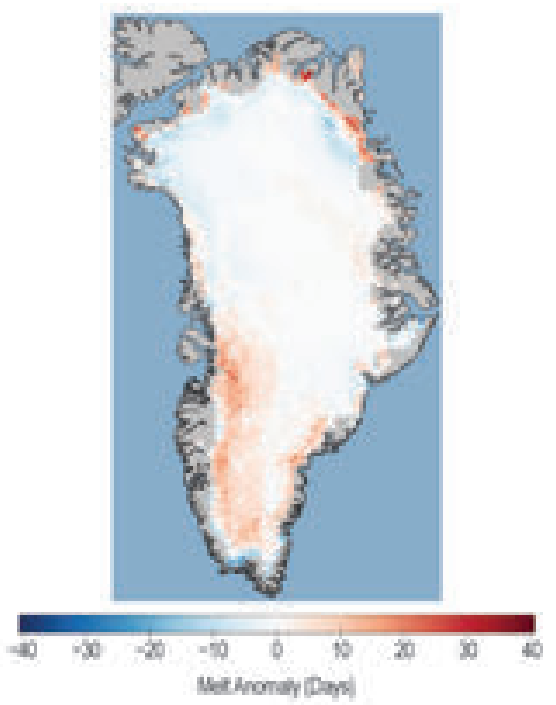

Fig. 5.12. (a) Spatial extent of surface melt, derived from the satellite product, as a percentage of total ice sheet area during 2018 (blue line), compared to 2012 (orange line), the year of record maximum surface melt extent; 198I-2010 mean (gray line); and interdecile and interquartile ranges (shaded). (b) Melt anomaly (days) with respect to $1981-2010$ mean during summer 2018 , estimated from SSMI/S spaceborne passive microwave observations. 


\section{I) SURface melt}

Estimates obtained from brightness temperatures measured by the Special Sensor Microwave Imager/ Sounder (SSMI/S) passive microwave radiometer (e.g., Mote 2007; Tedesco et al. 2013), indicate that surface melt in 2018 exceeded one standard deviation (1981-2010 base period) in early June and again briefly in late July and early August (Fig. 5.12a). Shown for contrast is the time series for 2012, when a new record high for surface melt extent was set. From mid-June to mid-July, when the melt extent typically reaches its maximum, the spatial extent of melting in 2018 remained largely within the interquartile range of the 1981-2010 mean. Surface melt reached its maximum extent at $44.4 \%$ of surface area on 31 July (Fig. 5.12a), compared to an average maximum extent of $39.8 \%$ (standard deviation of $14.9 \%$ ) over the summer (JJA). Compared to previous summers, melt duration was within \pm 5 days of the mean for most of the ice sheet (Fig. 5.12b). Notable exceptions included the southwest portion of the ice sheet and a thin margin in the northeast, where melt duration exceeded the 1981-2010 mean by more than five days.

\section{2) ICE MASS BALANCE}

The NASA GRACE provided estimates of monthly changes in the total mass of the GrIS between 2002 and 2017, when the mission ended (e.g., Tedesco et al. 2017). The GRACE Follow On (GRACE-FO, https:// gracefo.jpl.nasa.gov/) mission was launched on 22 May 2018, creating a gap from October 2017 through at least May 2018. Processing of the GRACE-FO dataset will provide estimates of total mass change anomalies for the summer of 2018 and will be calibrated to data acquired by GRACE.

Surface-based observations indicate the surface ice mass balance for the 2017/18 season was below or near the long-term mean (relative to the 1961-90 base period), consistent with average/low surface melting during summer and a snow cover that survived late into spring (Fausto and van As 2019). Ice loss in 2018 measured at 18 Program for Monitoring of the Greenland Ice Sheet (PROMICE, www.promice.dk /home.html) sites was, on average, the lowest during the 2008-18 observational period (Fig. 5.13a). Sites located in the southern and northern GrIS margin $\left(\mathrm{KPC}, 79.91^{\circ} \mathrm{N}, 24.08^{\circ} \mathrm{W}\right.$; THU, $76.39^{\circ} \mathrm{N}, 68.26^{\circ} \mathrm{W}$; and QAS, $61.03^{\circ} \mathrm{N}, 46.84^{\circ} \mathrm{W}$ ) experienced the least ablation, spanning 1.3-1.9 standard deviations below the 2008-18 mean. Anomalies at the KPC and THU sites were the most negative (least ablation) with respect to the 1961-90 climate-standard period (van As et al. 2016). Ablation at the other sites was
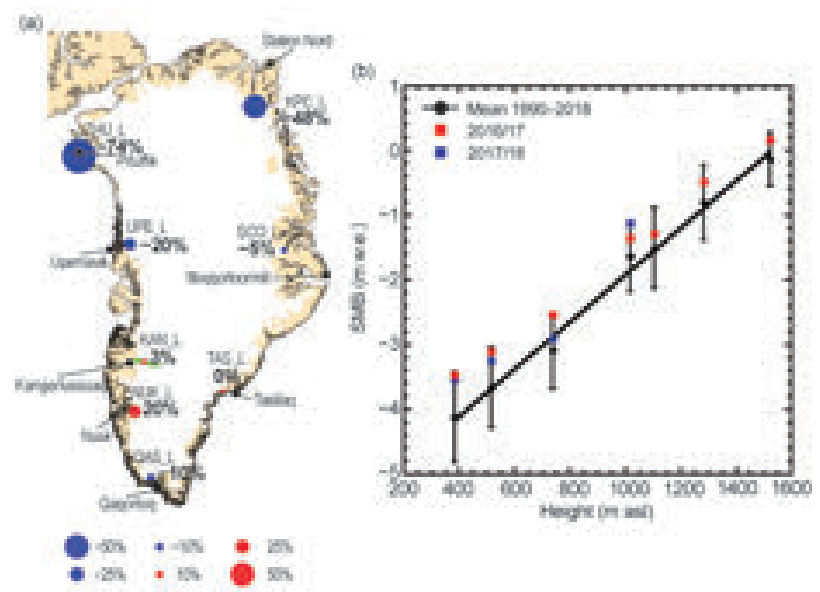

FIG. 5.13. (a) 2018 ablation anomalies (\% relative to I96I-90) at lower (“L”) PROMICE weather station sites over the GrIS ablation area following the approach by van As et al. (20l6). (b) Surface mass balance as a function of elevation ( $\mathrm{m}$ a.s.l.) along the K-transect for 2016/17 (blue), 2017/18 (red), and the 1990-2018 mean. Error bars are I std. dev. over 1990-2018.

within 1 standard deviation of the 2008-18 mean. Only two of eight sites (NUK, $64.48^{\circ} \mathrm{N}, 49.53^{\circ} \mathrm{W}$ and $\mathrm{KAN}, 67.12^{\circ} \mathrm{N}, 50.18^{\circ} \mathrm{W}$ ) experienced above-average ablation, although not beyond methodological uncertainty. Consistent with PROMICE results, the mass balance year 2017/18 along the K-transect (van de Wal et al. 2012) was characterized by moderate loss over the ablation region (i.e., where net mass loss occurs). All sites show a surface mass balance within 1 standard deviation of the 1990-2018 mean, with a tendency of ablation being below the mean (Fig. 5.13b). The average surface mass balance over the K-transect for 2017/18 was nearly identical to the average over the season 2016/17.

\section{3) Albedo}

The summer 2018 albedo averaged over the whole GrIS and estimated from MODIS (Box et al. 2017) was relatively high, at $81.7 \%$ (Fig. $5.14 \mathrm{a}$ ). This value is close to the average albedo in 2000 and represents the highest value recorded during the 19-year MODIS period of observation (2000-18). The minimum average summer albedo was recorded in 2012 (76.8\%), the year of record maximum melt extent (Fig. 5.12a). The high albedo anomalies along most of the coastline (Fig. 5.14b) are consistent with reduced melting in summer 2018 and with the late survival of snow covering the relatively darker, ice-free areas. 


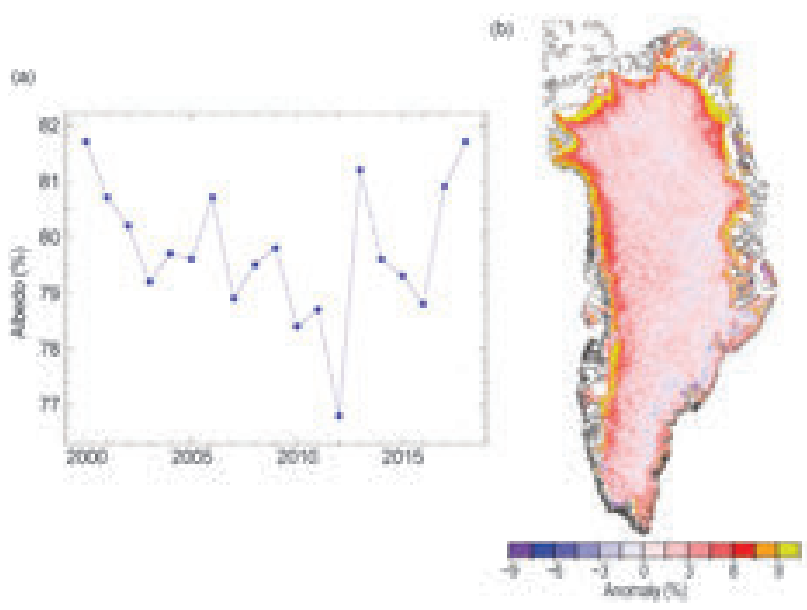

FIG. 5.I4. (a) Time series for JJA albedo (\%) averaged over the entire ice sheet. (b) Map of the summer 2018 albedo anomaly (\%) relative to the 2000-09 mean.

\section{4) Surface AIR temperature}

Measurements at 20 weather stations of the Danish Meteorological Institute (DMI, J. Cappelen 2019, personal communication) indicate widespread above- or near-average air temperatures for autumn 2017 and winter 2017/18, relative to the average for 1981-2010. Spring was generally near average except in some places along eastern Greenland, where temperatures were above normal. Summer was generally colder or near average.

Consistent with net ablation observations and DMI measurements, summer temperatures in 2018 were below the 2008-18 average at all PROMICE sites by more than 1 standard deviation along the northern, northwestern, and northeastern slopes. July 2018 was the coldest in the 2008-18 period along the northern, northwestern, and southern ice sheet ablation areas. Out of all January-December 2018 stationmonths, $47 \%$ of the recorded monthly temperatures were more than 1 standard deviation below average, and only $4 \%$ were over 1 standard deviation above average. See Section $7 \mathrm{f} 4$ for additional information.

\section{5) Marine-terminating GlaCiers}

Glacier area measurements acquired by Sentinel-2, LANDSAT, and ASTER satellite imagery since 1999 indicate that the 2017/18 cumulative net area change of 47 surveyed glaciers relative to the previous year was $+4.1 \mathrm{~km}^{2}$, standing as the only year in the survey with an area gain (Fig. 5.15). The next ranked year was $2006 / 07$, with a net loss of $-19.8 \mathrm{~km}^{2}$. Among the surveyed glaciers, 21 retreated and 12 advanced. The area changes at the remaining 14 glaciers were within $\pm 0.2 \mathrm{~km}^{2}$.
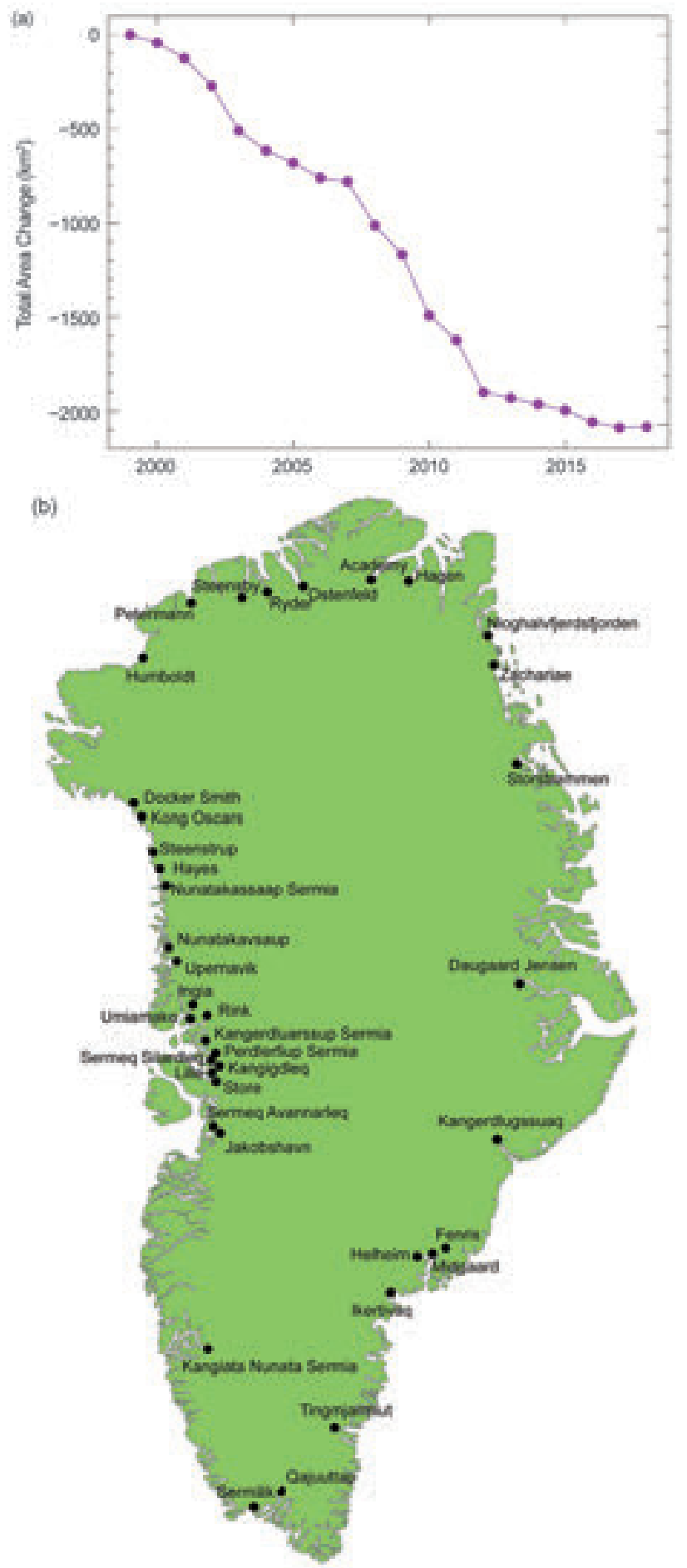

Fig. 5. I5. (a) Cumulative net glacier area change $\left(\mathrm{km}^{2}\right)$ at the $\mathbf{4 7}$ marine-terminating glaciers of the GrIS (after Box and Hansen 2015). (b) Locations of the marineterminating glaciers used in this study. 
f. Terrestrial permafrost-V. E. Romanovsky, S. L. Smith, K. Isaksen, N. I. Shiklomanov, D. A. Streletskiy, A. L. Kholodov, H. H. Christiansen, D. S. Drozdov, G. V. Malkova, and S. S. Marchenko Permafrost is an important component of the Arctic region, influencing landscapes, hydrological systems, and ecosystems, and presenting challenges for built infrastructure, e.g., buildings, roads, railways, airports, and pipelines (Sidebar 5.2). Permafrost is earth materials, such as soil, rock, and ground ice, that exist at or below $0^{\circ} \mathrm{C}$ continuously for at least two consecutive years. The active layer is the seasonally thawed layer above the permafrost. Permafrost temperature and active layer thickness (ALT) are key indicators of changes in permafrost conditions. Permafrost temperatures, at a depth where seasonal temperature variations are negligible, are powerful indicators of long-term change. On the other hand, the active layer responds to shorter term fluctuations in climate and is especially sensitive to changes in summer air temperature and precipitation.

Recent long-term changes in permafrost temperature are driven mostly by air temperature trends (Romanovsky et al. 2017). In general, the increase in permafrost temperatures observed since the 1980s is more significant in the higher latitudes and colder permafrost, where the largest increase in air temperature is observed (Fig. 5.16). Other important influences on permafrost temperatures and trends at local scales include snow depth, density, and timing; vegetation characteristics; and soil moisture. Here, changes in mean annual permafrost temperatures and ALT through 2018 are summarized for a number of sites throughout the Arctic (Fig. 5.16). Table 5.1 summarizes the rate of change for each region.

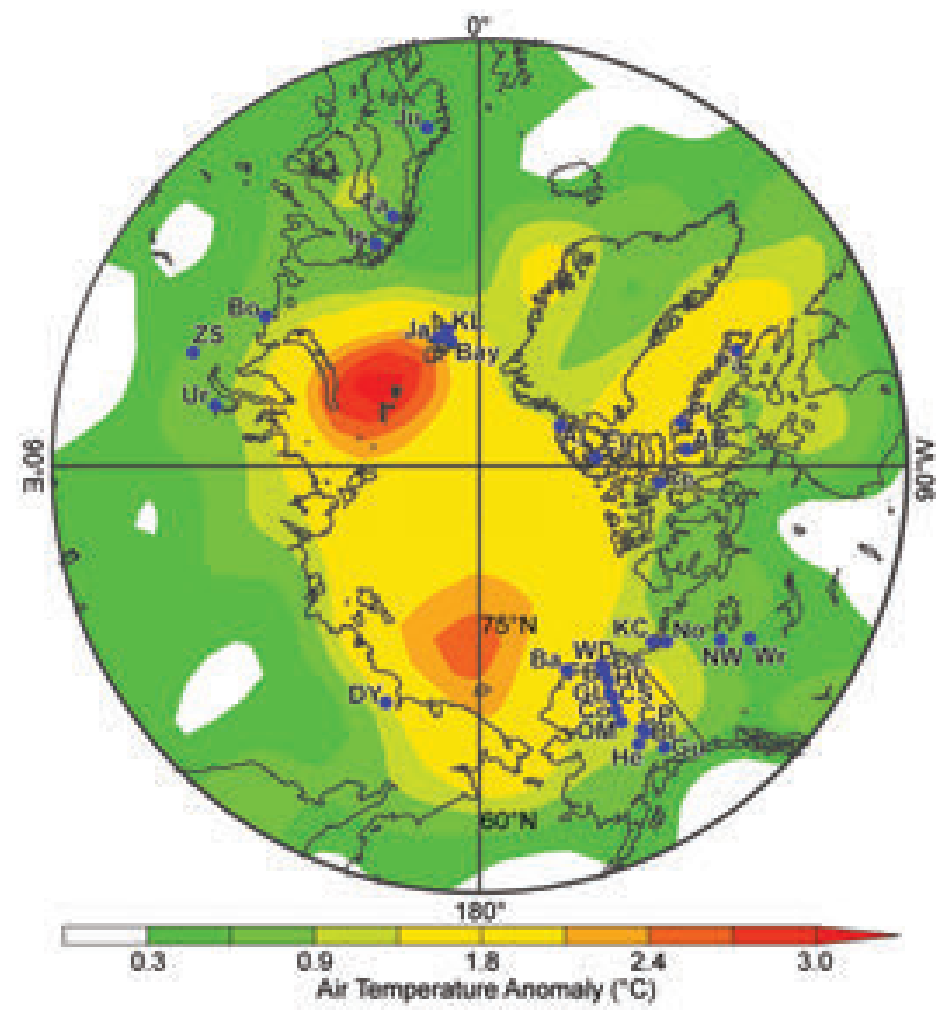

FIG. 5.16. Location of the permafrost temperature monitoring sites shown in Fig. 5.17 superimposed on average surface air temperature anomalies $\left({ }^{\circ} \mathrm{C}\right)$ during 2000-16 (with respect to the $1981-2010$ mean) from the NCEP-reanalysis (Kalnay et al. 1996). Data provided by the NOAA/ESRL Physical Sciences Division (www.esrl.noaa.gov/psd/). Sites shown in Fig. 5.I7 for (a) Barrow (Ba) (Utqiagvik), West Dock (WD), KC-07 (KC), Duvany Yar (DY), Deadhorse (De), Franklin Bluffs (FB), Galbraith Lake (GL), Happy Valley (HV), Norris Ck (No); (b) College Peat (CP), Old Man (OM), Chandalar Shelf (CS), Birch Lake (BL), Coldfoot (Co), Norman Wells (NW), Wrigley 2 (Wr), Healy (He), Gulkana (Gu), Wrigley I (Wr); (c) Eureka EUK4 (Eu), Alert BH2 (AI), Alert BH5 (AI), Resolute (Re), Alert BHI (AI), Arctic Bay (AB), Pond Inlet (PI), Pangnirtung (Pa); (d) Janssonhaugen (Ja), Bayelva (Ba), Kapp Linne I (KL), Urengoy \# I5- 10 (Ur), Juvvasshøe (Ju), Tarfalaryggen (Ta), Polar Ural (ZS), Bolvansky \#59 (Bo), Bolvansky \#65 (Bo), Urengoy \#15-06 (Ur), Bolvansky \#56 (Bo), Iskoras Is-B-2 (Is). Information about these sites is available at: http://gtnpdatabase.org/, http://permafrost.gi.alaska.edu/sites_map, https://www2.gwu .edu/ calm/data/data-links.html. 


\begin{tabular}{|c|c|c|c|}
\hline Region & Sites & Entire Record & Since 2000 \\
\hline Alaskan Arctic plain & $\begin{array}{l}\text { West Dock (WD), Deadhorse (De), } \\
\text { Franklin Bluffs (FB), Barrow } \\
\text { (Ba, Utqiagvik) }\end{array}$ & $\begin{array}{l}+0.36 \text { to }+0.82 \\
(1978-2018)\end{array}$ & $\begin{array}{l}+0.42 \text { to }+0.69 \\
(2000-2018)\end{array}$ \\
\hline $\begin{array}{l}\text { Northern foothills of the } \\
\text { Brooks Range, Alaska }\end{array}$ & Happy Valley (HV), Galbraith Lake (GL) & $\begin{array}{l}+0.31 \text { to }+0.41 \\
(1983-2018)\end{array}$ & $\begin{array}{l}+0.33 \text { to }+0.42 \\
(2000-2018)\end{array}$ \\
\hline $\begin{array}{l}\text { Southern foothills of the } \\
\text { Brooks Range, Alaska }\end{array}$ & $\begin{array}{l}\text { Coldfoot (Co), Chandalar Shelf (CS), } \\
\text { Old Man (OM) }\end{array}$ & $\begin{array}{l}+0.07 \text { to }+0.34 \\
(1983-2018)\end{array}$ & $\begin{array}{l}+0.12 \text { to }+0.29 \\
(2000-2018)\end{array}$ \\
\hline Interior Alaska & $\begin{array}{l}\text { College Peat (CP), Birch Lake (BL), } \\
\text { Gulkana (Gu), Healy }(\mathrm{He})\end{array}$ & $\begin{array}{l}+0.09 \text { to }+0.27 \\
(1983-2018)\end{array}$ & $\begin{array}{l}+0.04 \text { to }+0.21 \\
(2000-2018)\end{array}$ \\
\hline Central Mackenzie Valley & Norman Wells (NW), Wrigley (Wr) & $\begin{array}{l}\text { Up to }+0.1 \\
(1984-2017)\end{array}$ & $\begin{array}{l}<+0.1 \text { to }+0.2 \\
(2000-2017)\end{array}$ \\
\hline Northern Mackenzie Valley & Norris Ck (No), KC-07(KC) & - & $\begin{array}{l}+0.6 \text { to }+0.8 \\
(2008-2018)\end{array}$ \\
\hline Baffin Island & $\begin{array}{l}\text { Pangnirtung }(\mathrm{Pa}) \text {, Pond Inlet }(\mathrm{PI}) \text {, } \\
\text { Arctic Bay }(\mathrm{AB})\end{array}$ & - & $\begin{array}{l}+0.5 \text { to }+0.7 \\
(2009-2017)\end{array}$ \\
\hline High Canadian Arctic & Resolute (Re), Eureka (Eu) & - & $\begin{array}{l}+0.4 \text { to }+0.7 \\
(2009-2015)\end{array}$ \\
\hline High Canadian Arctic & Alert (Al) at $15 \mathrm{~m}$ at $24 \mathrm{~m}$ & $\begin{array}{c}+0.6 \\
+0.3 \text { to }+0.4 \\
(1979-2018) \\
\end{array}$ & $\begin{array}{c}+1.1 \\
+0.7 \text { to }+0.9 \\
(2000-2018) \\
\end{array}$ \\
\hline North of East Siberia & Duvany Yar (DY) & - & $\begin{array}{c}+0.3 \\
(2009-2017)\end{array}$ \\
\hline North of West Siberia & Urengoy $15-06$ and I5-10 (Ur) & $\begin{array}{l}+0.31 \text { to }+0.47 \\
(1974-2018)\end{array}$ & $\begin{array}{l}+0.1 \text { to }+0.19 \\
(2000-2018)\end{array}$ \\
\hline Russian European North & $\begin{array}{l}\text { Bolvansky 56, 59, and } 65 \text { (Bo), } \\
\text { Polar Ural (ZS-124) }\end{array}$ & $\begin{array}{l}+0.18 \text { to }+0.46 \\
(1984-2018)\end{array}$ & $\begin{array}{l}+0.1 \text { to }+0.83 \\
(2000-2018)\end{array}$ \\
\hline Svalbard & $\begin{array}{l}\text { Janssonhaugen (Ja), Bayelva (Ba), } \\
\text { Kapp Linne I (KL) }\end{array}$ & $\begin{array}{c}+0.7 \\
(1998-2017)\end{array}$ & $\begin{array}{l}+0.6 \text { to }+0.8 \\
(2000-2017)\end{array}$ \\
\hline Northern Scandinavia & Tarfalarggen (Ta), Iskoras Is-B-2 (Is) & - & $\begin{array}{l}+0.1 \text { to }+0.4 \\
(2000-2017)\end{array}$ \\
\hline Southern Norway & Juvvasshøe (Ju) & $\begin{array}{c}+0.2 \\
(1999-2017)\end{array}$ & $\begin{array}{c}+0.2 \\
(2000-2017)\end{array}$ \\
\hline
\end{tabular}

\section{I) Permafrost temperatures}

In 2018, record high temperatures at 20-m depth occurred at all permafrost observatories on the North Slope of Alaska [Utqiagvik (Barrow), West Dock, Deadhorse, Franklin Bluffs, Happy Valley, and Galbraith Lake; Fig. 5.17a]. The permafrost temperature increase $\left(+0.1^{\circ}-0.2^{\circ} \mathrm{C}\right)$ between 2017 and 2018 was substantial and comparable to the highest rate of warming observed in this region during 1995-2000 (Fig. 5.17a).

Following the slight cooling of 2007-13, permafrost temperatures increased in interior Alaska and were higher in 2018 than in 2017 nearly all sites (Old Man, College Peat, Birch Lake, Gulkana, and Healy). The exception was Coldfoot, which experienced no change. The largest changes, at Birch Lake and Old Man, were associated with new record highs in 2018 for the entire 34-year measurement period (Fig. 5.17b). As a result of long-term warming and the relatively mild and snowy winter of $2017 / 18$, the active layer did not freeze completely down to the underlying permafrost by the end of winter at many interior Alaska sites. 
In northwestern Canada, the temperature of permafrost in the central Mackenzie Valley (Norman Wells and Wrigley in Fig. 5.17b) has generally increased since the mid-1980s, with less warming observed since 2000 (Smith et al. 2018). However, temperatures in 2018 were the highest observed during the period of record (1984-2018). Since 2013, warming in the colder permafrost of the northern Mackenzie region has been greater than that in the central Mackenzie Valley (Norris Ck, KC-07 in Fig. 5.17a; Smith et al. 2018). Although the temperature at the colder site (KC-07) in 2017/18 is the highest observed during the short record, the temperatures recorded at a shallower depth at Norris Ck were slightly lower in 2017/18 compared to the previous year.

In northeastern Canada, the 2017/18 mean permafrost temperatures in the upper $25 \mathrm{~m}$ of the ground at
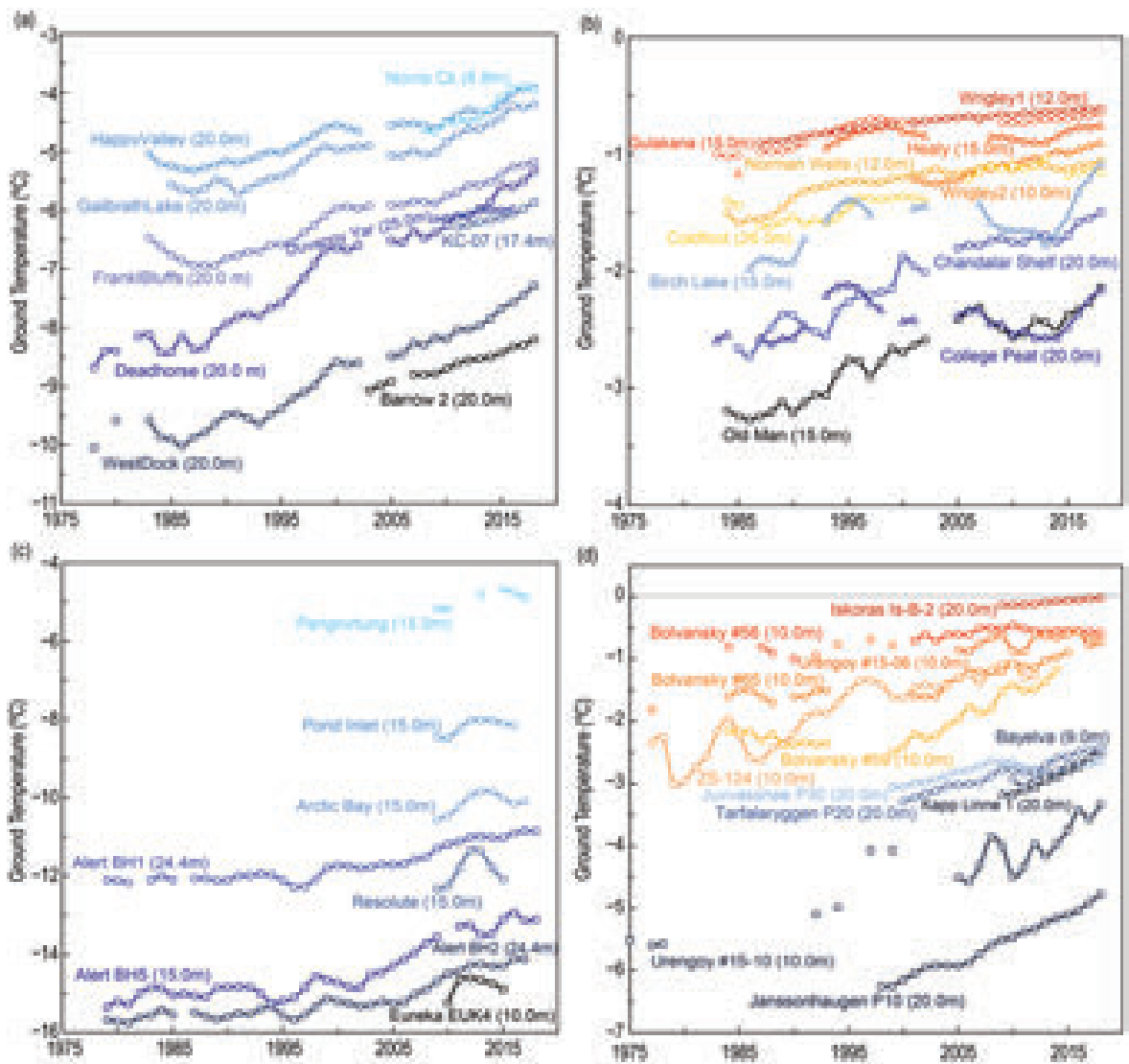

Fig. 5.17. Time series of mean annual ground temperature $\left({ }^{\circ} \mathrm{C}\right)$ at depths of 9-26 $\mathrm{m}$ below the surface at selected measurement sites: (a) cold continuous permafrost of northwestern North America and northeastern East Siberia (Beaufort-Chukchi region); (b) discontinuous permafrost in Alaska and northwestern Canada; (c) cold continuous permafrost of eastern and High Arctic Canada (Baffin Davis Strait); and (d) continuous to discontinuous permafrost in Scandinavia, Svalbard, and Russia/Siberia (Barents region). Temperatures are measured at or near the depth of zero annual amplitude where the seasonal variations of ground temperature are negligible. Data are updated from Christiansen et al. 2010; Romanovsky et al. 2017; Smith et al. 2015, 20I8; Ednie and Smith 2015; Boike et al. 2018.
Alert, northernmost Ellesmere Island in the high Arc(Fig. 5.16). Since 2010, there has been little change in permafrost temperatures at Alert (Fig. 5.17c), which is consistent with a period of lower mean annual air temperatures. However, at a depth of $15 \mathrm{~m}$, the 2017/18 temperature is higher than the previous year, reflecting recent increase in air temperature.

Increases in permafrost temperature over the last 30-35 years in northern Russia have been similar to those in northern Alaska and the Canadian high Arctic (Drozdov et al. 2015). In the Russian European North and western Siberian Arctic, temperatures rally increased since the late 1980 s at rates that are more rapid at colder permafrost sites (Fig. $5.17 \mathrm{~d}$, sites Bolvansky \#59, Urengoy \#15-5 and \#1510) compared to sites in warmer permafrost (Fig. 5.17d, sites Bolvansky \#56 and Urengoy \#15-6; Drozdov et al. 2015).

In the Nordic region, ground temperatures have increased (Fig. 5.17d) and thawing of permafrost has been observed (Isaksen et al. 2011). The response of warm permafrost at close to $0^{\circ} \mathrm{C}$ (Iskoras IsB-2, Fig. 5.17d) is slower than in permafrost with lower temperatures due to latent heat effects related to melting ground ice. On Svalbard, a significant temperature increase can be detected down to 80-m depth (not shown), reflecting a multidecadal permafrost warming, with 2018 clearly the warmest year in the observational record. In the discontinuous permafrost zone of southern Norway, permafrost warmed between 2015 and 2018, 
following a period of cooling between 2011 and 2014 (Fig. 5.17d).

\section{2) ACTIVE LAYER THICKNESS}

In 2018, standardized, mechanical probing of ALT was conducted at 88 Circumpolar Active-Layer Monitoring (CALM) program sites located in Alaska, the Nordic countries, and Russia (Fig. 5.18). Each site consists of a spatial grid varying from 1 ha to $1 \mathrm{~km}^{2}$ in size and is representative of regional landscapes (Shiklomanov et al. 2012). Additional active-layer observations are available from 25 Canadian sites located in the Mackenzie Valley, northwestern Canada, where ALT is derived from thaw tubes (Smith et al. 2018). The Canadian ALT data are complete through 2017.

The average ALT in 2018 for 24 North Slope of Alaska sites was $0.49 \mathrm{~m}$, which is above the 2003-12 mean but lower than the previous three years (2015, $2016,2017)$. Previous maxima occurred in 1998, 2013 , 2016, and 2017. There has been a pronounced ALT increase over the last 23 years in interior Alaska, where a new record of $0.80 \mathrm{~m}$ occurred in 2018 .
In the Mackenzie Valley of northwestern Canada, there has been a general increase in ALT since 2008 (Duchesne et al. 2015; Smith et al. 2018). In 2017, ALT was $0.07 \mathrm{~m}$ thicker, on average, than the 2003-12 mean, and exceeded by $0.01 \mathrm{~m}$ the previous peak value measured in 2012.

Across the Nordic countries, there has been a general ALT increase of $0.12-0.30 \mathrm{~m}$ since 1999 . The particularly warm summer of 2018 in the Scandinavian North contributed to a new maximum, while sites located in Svalbard did not reach the previous maximum recorded in 2016. A cold summer in 2018 in southern Greenland contributed to new minimum ALT in the region, where it was at least $0.2 \mathrm{~m}$ lower than the 2003-12 mean. This is a large deviation from the overall positive ALT trend for 1996-2017.

An increase in ALT from 2017 to 2018 was reported for all Russian regions. In the Russian European North, the 2018 ALT was $1.18 \mathrm{~m}$, which is above average and $0.1 \mathrm{~m}$ higher than in 2017. In West Siberia, the average 2018 ALT was close to the 2017 value of $1.25 \mathrm{~m}$. At the Eastern Siberia and Chukotka sites, 2018 ALT was $0.02-0.04 \mathrm{~m}$ higher than in 2017.
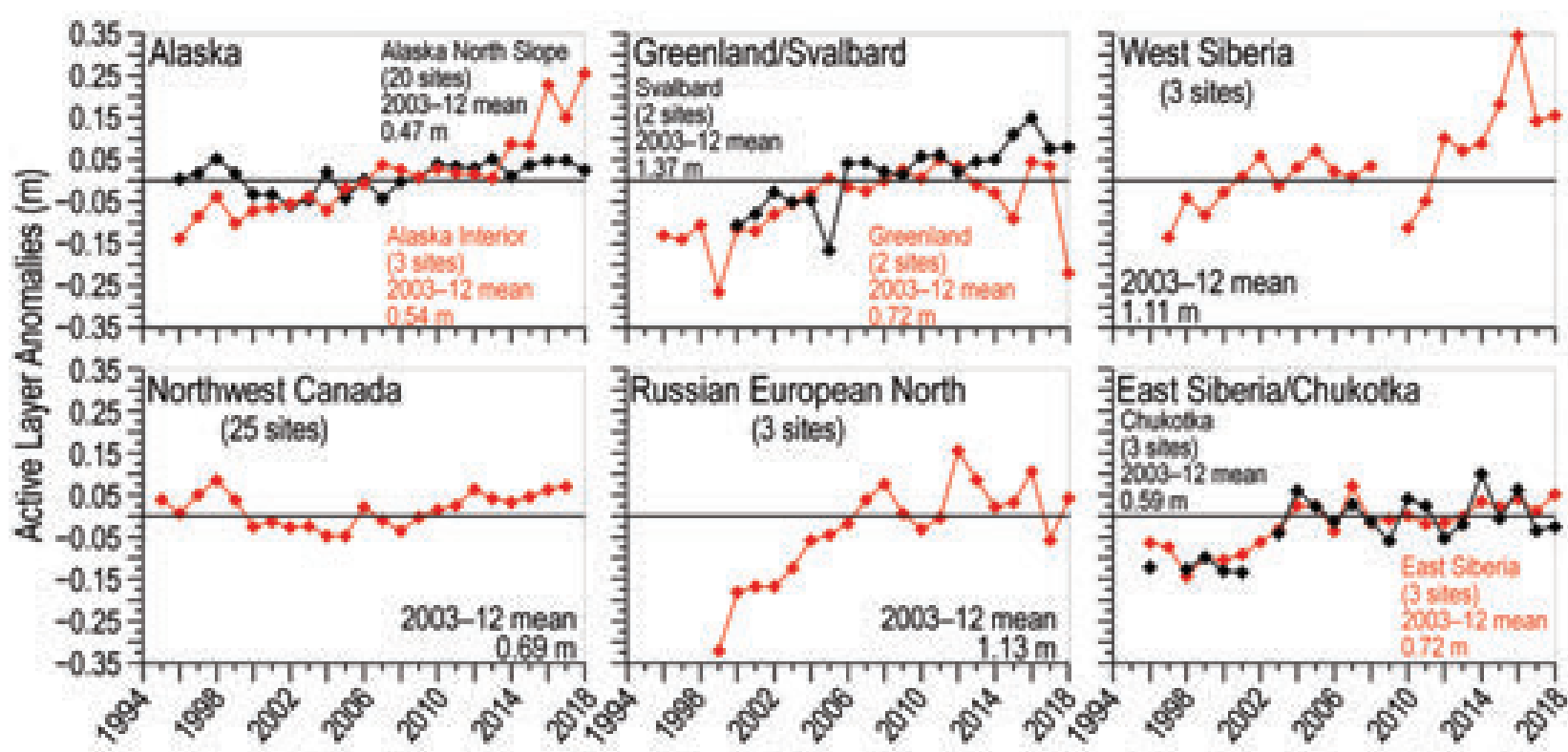

FIG. 5.18. Long-term active-layer thickness change $(\mathrm{m})$ in six different Arctic regions for 2018 as observed by the CALM program relative to the 2003-12 mean. Positive (negative) anomaly values indicate the active layer is thicker (thinner) than average. Thaw depth observations from the end of the thawing season were used. Only sites with at least 20 years of continuous thaw depth observations are shown. The number of sites used for each region varies and is shown in the figure. Site-specific data are available at www.gwu.edu/ calm. 


\section{SIDEBAR 5.2: WARMING AND THAWING PERMAFROST AND IMPACTS ON INFRASTRUCTURE-K. BJELLA}

Permafrost is defined as any earth material with a temperature at or below $0^{\circ} \mathrm{C}$ continuously for at least two consecutive years. These perennially frozen terrains consist of soil, rock, and ground ice, and provide rigid base material suitable for the foundation of Arctic infrastructure. Using unique engineering methods, permafrost has successfully supported many different types of infrastructure, both vertical (e.g., buildings, towers, fuel, and water tanks) and horizontal (e.g., roadways, runways, pipelines). However, as described in Section $5 f$, permafrost temperatures are rising throughout the Arctic, raising concerns about impacts on existing and yet-to-be-built infrastructure.

The $\leq 0^{\circ} \mathrm{C}$ temperature threshold that defines permafrost is not the primary engineering challenge per se. Rather, it is the configuration and amount of ground ice within the near-surface permafrost on which the infrastructure will be situated. Ground ice frequently occurs as massive bodies of ice, often greatly exceeding the usually modest amount of ice found in the pore spaces of the soil matrix. These massive bodies of ground ice can occur as thick layers of segregation ice, or ice lenses, and can be many centimeters in thickness and meters in lateral extent. These tabular ice formations generally lie parallel to the ground surface. Massive ice can also occur as polygonal networks of large ice wedges (Fig. SB5.3), which often are meters in width and depth and tens of meters in length. The mode of permafrost formation and the length of time since permafrost establishment, in large part, determine this ground ice character.

These icy terrains are often extremely heterogeneous in nature, often varying in ice content by an order of magnitude or more over horizontal extents of just meters. It is this heterogeneity that is the most challenging from an engineering perspective and governs the type of solution to be used when supporting infrastructure (Melvin et al. 2017). Some locations may be ice-poor or even ice-free, requiring minimal augmentation of standard design. Icerich locations, on the other hand, require a substantial expenditure in foundation and structural elements to

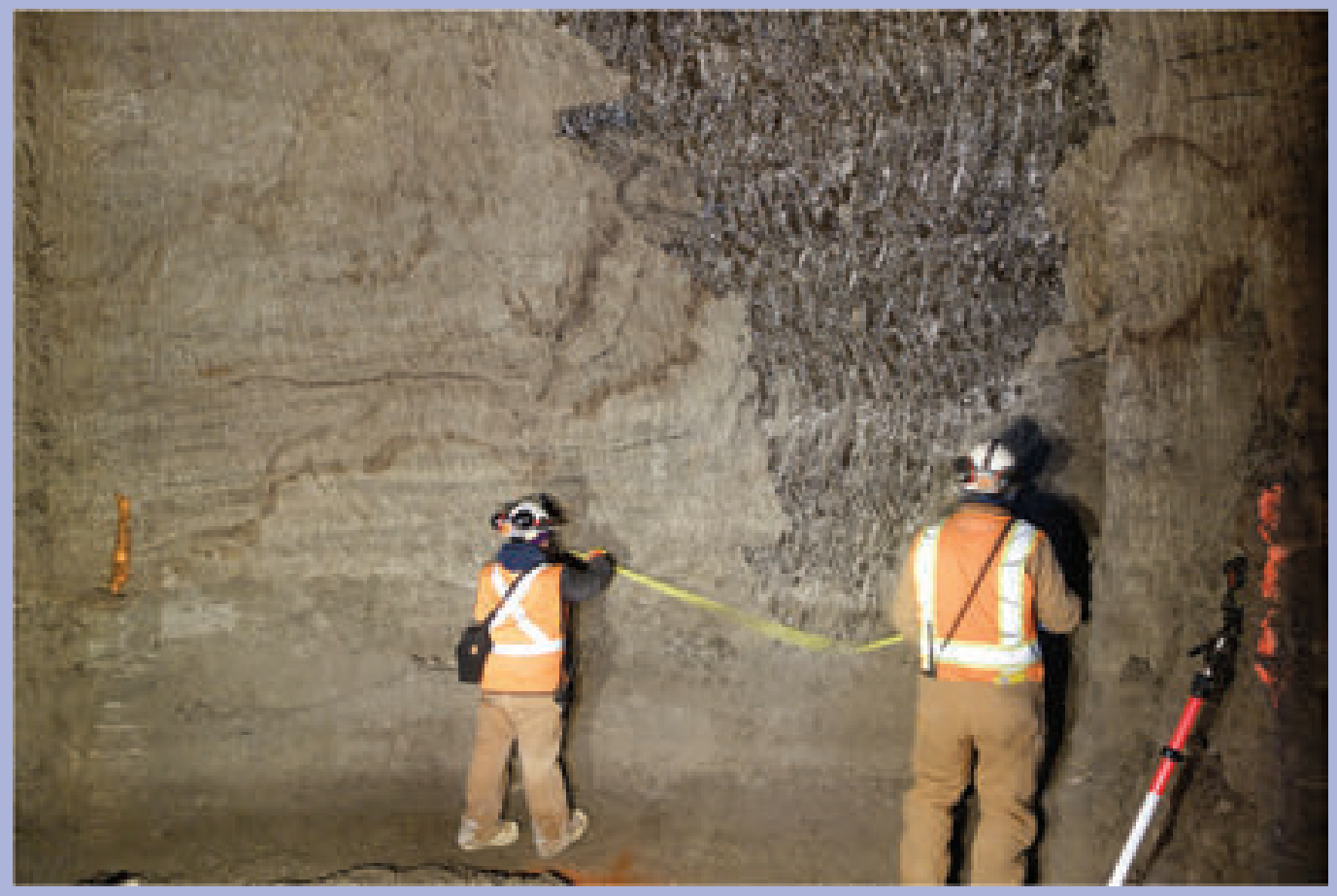

FIG. SB5.3. A large ice wedge (triangular feature in the center) exposed in the Cold Regions Research and Engineering Laboratory permafrost tunnel near Fairbanks, Alaska. The ice wedge is nearly $100 \%$ pure ice intruded into wind and slope deposited silt. Photograph by Kevin Bjella. 


\section{CONT. SIDEBAR 5.2: WARMING AND THAWING PERMAFROST AND IMPACTS ON INFRASTRUCTURE-K. BJELLA}

ensure adequate resistance against settlement and to increase the longevity. Often refrigeration is employed, either in a passive mode via ambient air ducting and structure elevation above the ground surface, or with active freezing mechanical systems, which are significantly more costly and require intensive maintenance.

Temperature is the most important factor governing the strength of permafrost. If the thermal equilibrium is upset so the temperature exceeds $0^{\circ} \mathrm{C}$, the thawing ground ice creates saturated to super-saturated conditions and soil displacement usually occurs. The once rigid base is significantly weakened, resulting in differential (i.e., unevenly distributed) thaw settlement (Fig. SB5.4), that is often sufficiently severe for any overlying infrastructure to fail. Post-construction thawing of ground ice is most often due to design deficiencies that allow detrimental introduction of heat. This can be the result of heat input via the infrastructure itself, or due to the disturbance around the infrastructure, where changes in the surface reflectivity and hydrology can significantly increase heat input.

Thawing of ground ice is not the only issue engineers must contend with when it comes to permafrost areas.

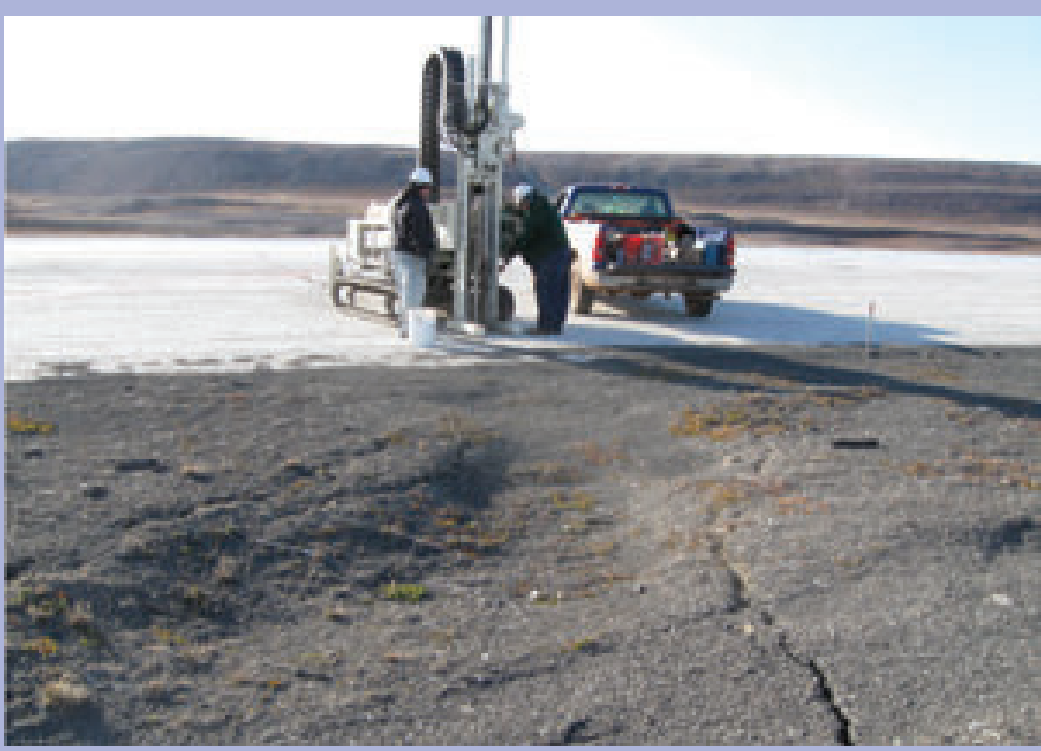

FIG. SB5.4. Thaw settlement $(\sim 0.65 \mathrm{~m})$ associated with an airfield in Greenland. Thawing of ice-rich, weathered bedrock at approximately $\mathbf{2} \mathbf{m}$ below the surface is causing severe settlement, resulting in the need for significant maintenance measures to continue operations. Photograph by Kevin Bjella.
Where infrastructure is primarily supported by ice rather than soil particles, high loadings will cause the ice to flow, or deform, also known as "creep." One significant factor that dominates the creep rate is ice temperature. As the temperature approaches the melting point, the creep rate increases significantly and the strength of the frozen materials decreases (Arenson and Springman 2005). This is of particular importance to pile-founded structures that rely on adfreeze strength for support. Adfreeze is the adhesion of a foundation pile to the surrounding frozen soil. Icerich sediments at temperatures lower than approximately $-5^{\circ} \mathrm{C}$ have significantly greater adfreeze strength than warmer soils, particularly those in the temperature range of $-2^{\circ}$ to $0^{\circ} \mathrm{C}$, which deform easily. Gradual soil warming in association with infrastructure projects might be the result of design deficiencies, as mentioned previously, but it can also be the result of rising air temperatures due to climate warming (Sections 5b,f).

Planners, policy makers, and engineers are increasingly concerned about the consequences of rising air and permafrost temperatures and how they may affect their infrastructure interests, both existing and planned.

Engineers are responding by not only designing for the current temperature condition, but also by designing with allowances for a future weakened soil state and possibly even future thawing conditions (Daanen et al. 20II). Currently, there is no strict engineering guidance on how this should be done, so those in the profession are incorporating methodologies they believe provide the least risk to the customer and to themselves. The additional allowance for rising temperatures requires more robust designs, especially for critical infrastructure and that which requires long life expectancy. Ultimately, this means more costly infrastructure to offset the risk. Although warming permafrost can have a detrimental effect 
on infrastructure not designed for that eventuality, it is some consolation that thawing permafrost due to rising air temperatures is a slow process, where permafrost degradation and thaw settling become a chronic problem rather than an overnight catastrophe.

The seemingly inevitable increase of permafrost temperature not only requires more consideration and complexity for the built infrastructure, it will also begin to reshape the frozen landscape. This is already evident along Arctic coastlines, where warming and thawing permafrost is more vulnerable to increased wave action, and accelerated coastal retreat is affecting communities and infrastructure (Larsen et al. 2008; Radosavljevic et al. 2016). Coastal and other terrains rich in ice wedge polygons can develop extensive thaw troughs where surface water often pools, or they can act as conduits for water transport (Liljedahl et al. 2016). In either case, thermal erosion of the troughs and development of gullies and surface slumping are common.

Permafrost slopes are also particularly vulnerable to changes in a warming climate (Blais-Stevens et al. 2015). Increases in moisture content and vegetation loading can lead to active-layer (Section 5f) detachment slides. In these events, the summer-thawed surface layer of organic materials and mineral soil slides on the permafrost table (the top surface of the permafrost), downhill to the toe of the slope, exposing the now uninsulated permafrost to extensive thaw deformation.

Deeper-acting slope instabilities cause large portions of hill slopes to progressively degrade in an uphill direction in what are termed retrogressive thaw slumps (Fig. SB5.5). Most often, thaw slumps are associated with either lakes or rivers undercutting the toe of the slope. Additionally, climate warming is anticipated to increase precipitation events. The associated increase in surface runoff acts in concert with the warmed and weakened bonds of the frozen soil matrix to easily disaggregate the frozen soil, resulting in thermo-erosion gullies often with significant downhill soil displacement. In contrast to the slow, chronic process of thermally degrading permafrost mentioned earlier, these rapid erosion events can occur during a single precipitation event, possibly catastrophically and without warning, and potentially affecting any infrastructure that has the misfortune to be in its path.

Anticipating that climate warming will continue, it is expected that the currently delineated permafrost zones-discontinuous and sporadic-will gradually shift poleward (Thibault and Payette 2009). Some of these zones will remain steadfastly frozen, with only minor change in overall character, for decades to come. However, some localized areas may undergo rapid changes in the near-surface character, especially in the discontinuous zone, where, by definition, permafrost temperatures already are approaching $0^{\circ} \mathrm{C}$. Changes in precipitation amount, snow cover, vegetation, and fire severity, to name a few, may cause rapid degradation of these frozen terrains. Although these changes can be envisioned, how the various aspects of warming and thawing permafrost will act in concert and affect the built and natural environments is not fully understood.

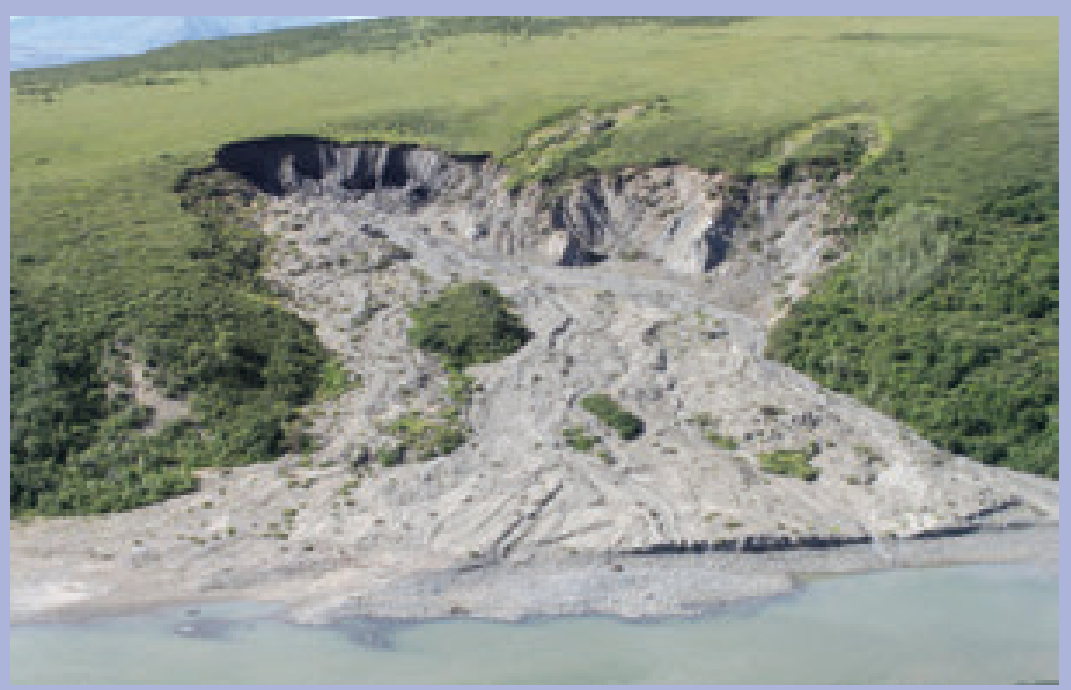

FIG. SB5.5. Retrogressive thaw slump on the Noatak River, northwestern Alaska. The U.S. National Park Service is monitoring 19 such slumps in the Noatak National Preserve and Gates of the Arctic National Park and Preserve. Photograph by Rory Nichols. 
g. Terrestrial snow cover-L. Mudryk, R. Brown, C. Derksen, K. Luojus, and B. Decharme

Snow covers the Arctic land surface for up to nine months each year. Its presence or absence affects the surface energy budget, the depth of the snowpack determines the ground thermal regime, and the total amount deposited in a given winter season is an important component of the Arctic's freshwater budget. Snow cover has consequences for ecosystems; it interacts with vegetation, affects biogeochemical activity, and influences migration and access to forage for wildlife. Over the past 15 years, snow has melted from the Arctic land surface earlier in spring (April, May, and June), with a shallower snowpack compared to past decades. However, year-to-year variability within these trends is high due to the combined influences of temperature and precipitation.

Snow cover can be characterized using three variables: how much area is covered by snow [snow cover extent (SCE)], how long snow continuously remains on the land surface [snow cover duration (SCD)], and how much water is stored in solid form by the snowpack [snow water equivalent (SWE)], which is a function of snow depth and density.

Figure 5.19 shows SCE anomalies for the Arctic in spring 2018 (relative to the 1981-2010 reference period and including land areas north of $60^{\circ} \mathrm{N}$ ). Anomalies were computed separately for the North American and Eurasian sectors of the Arctic to account for differing snow and weather conditions. Anomalies were derived from the NOAA snow chart climate data record, which extends from 1967 to present (maintained at Rutgers University; Estilow et al. 2015; Fig. 5.19). Eurasian Arctic SCE in 2018 was above average in April, only slightly above average in May, and by
June was below the historical average. Over the North American Arctic, SCE was below average for May and June but did not approach the series of recordbreaking low SCE values observed in recent years.

Snow cover depth anomalies (Figs. 5.20a,b) were calculated using the NOAA daily Interactive Multisensor Snow and Ice Mapping System (IMS) snow cover product (Helfrich et al. 2007). Snow cover onset for the 2017/18 season (Fig. 5.20a) was normal to slightly earlier than normal over most of the Arctic. Snow melted slightly later than usual over large regions of Eurasia and Alaska, but slightly earlier over the central Canadian Arctic (Fig. 5.20b).

Snow depth anomalies (Figs. 5.20c,d) were determined from the Canadian Meteorological Centre (CMC) daily gridded global snow depth product (Brasnett 1999). These data indicate that in the 2017/18 snow season, anomalously high snow depths in the Arctic and subarctic boreal zone of Eurasia were established in late autumn 2017 and persisted throughout the winter. As a result, April Eurasian Arctic snow depth anomalies averaged 60\% above normal and remained above average through June. The North American Arctic saw a mix of positive and negative snow depth anomalies in March and April, but what snow remained by May and June was generally deeper than average for that time of year.

Four products were used to generate a multidataset SWE anomaly time series (1981-2018) for April (typically the month of maximum SWE across the Arctic; Fig. 5.21): (1) modern atmospheric reanalysis (MERRA-2 ; Reichle et al. 2017b); (2) reconstructed snow accumulation driven by ERA-interim meteorology with the temperature index model described by Brown et al. (2003); (3) the physical snowpack model
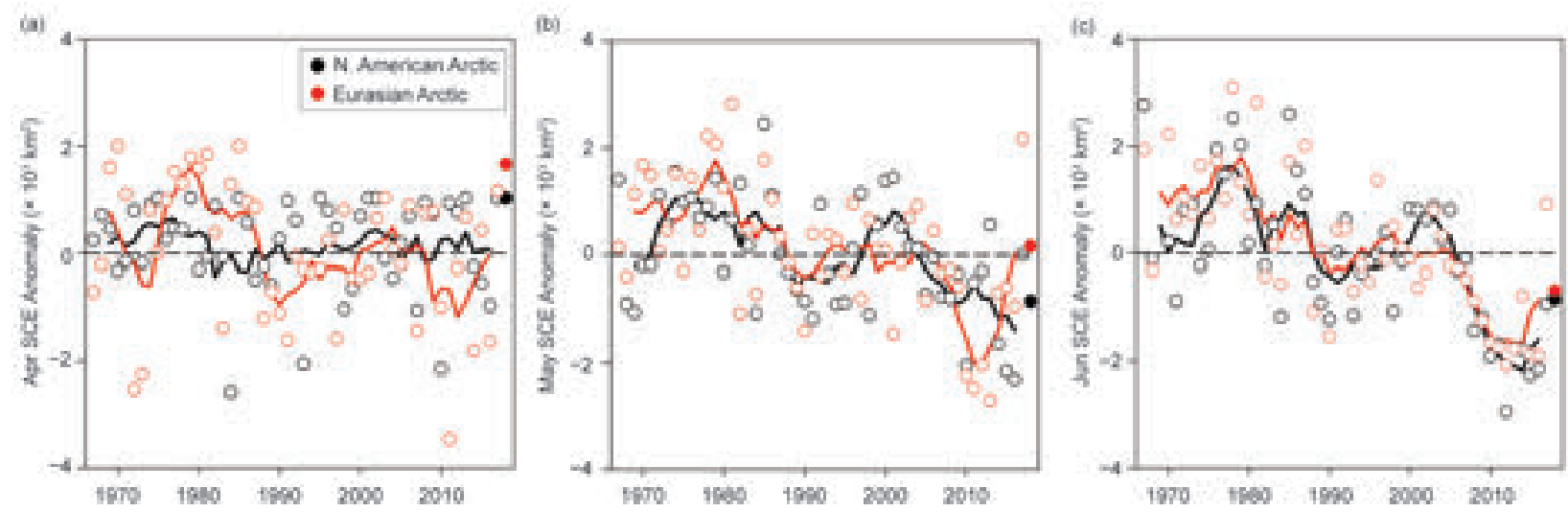

Fig. 5.19. Monthly SCE ( $\left.\times 10^{3} \mathrm{~km}^{2}\right)$ for Arctic land areas $\left(>60^{\circ} \mathrm{N}\right)$ for (a) Apr, (b) May, and (c) Jun from I967-20 I6. Anomalies are relative to the average for 198I-2010 and standardized (each observation differenced from the mean and divided by the std. dev. and thus unitless). Solid black and red lines depict 5-yr running means for North America and Eurasia, respectively. Solid circles denote anomalies for 20 I8. (Source: NOAA snow chart Climate Data Record.) 


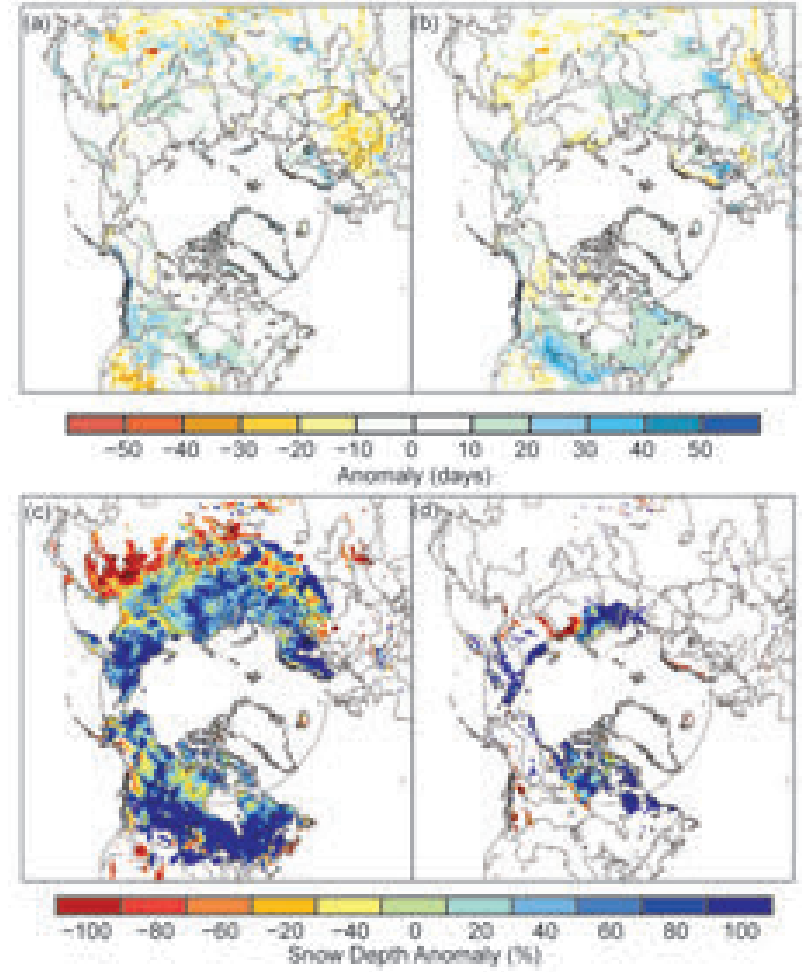

FIG. 5.20. SCD anomalies (\%) from the NOAA daily IMS cover product, relative to the 1998-2010 average, for the (a) first half of the $2017 / 18$ snow season (related to timing of snow onset) and (b) second half of the 2017/18 snow season (related to timing of snow melt). Snow depth anomaly (\% of 1999-2017 average) from the CMC snow depth analysis for (c) Apr and (d) Jun 2018. The circle in the figures denotes $60^{\circ} \mathrm{N}$.

Crocus (Brun et al. 2013); and (4) the European Space Agency GlobSnow product derived through a combination of satellite passive microwave data and climate station observations (Takala et al. 2011). SWE estimates for 2018 indicate the highest amount of SWE since 1981 over the Eurasian Arctic, consistent with the higher-than-average Arctic snow depths seen in the snow depth analysis. In contrast, North American Arctic SWE was close to average.

Despite anomalously high SCE during the 2017 melt season and anomalously high SWE at the start of the 2018 melt season (both primarily observed over the Eurasian continent), long-term trends for both SCE and SWE remain negative. On average, Arctic SCE during June is almost half of what it was 35 years ago, a loss rate that is approximately the same as September sea ice. Meanwhile total Arctic snow mass during April (near the timing of the seasonal maximum) has decreased by more than $10 \%$ since 1981. The trends in snow mass are weaker because they are less sensitive to temperature increases than

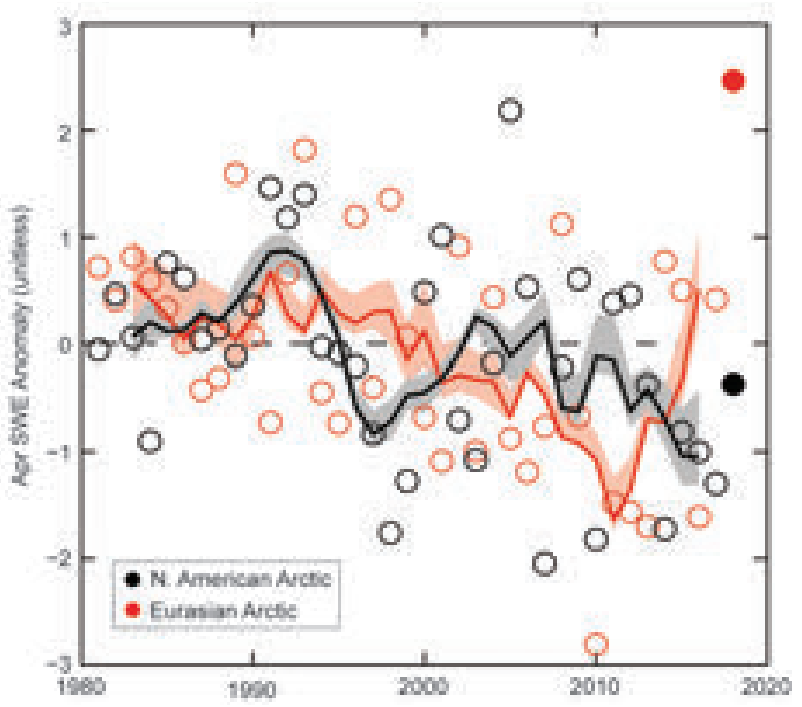

FIG. 5.2I. Mean Apr SWE anomalies for Arctic land areas calculated for North American (black) and Eurasian (red) sectors of the Arctic. Anomalies are relative to the average for 198I-2010 and standardized (each observation differenced from the mean and divided by the std. dev. and is thus unitless). Solid circles highlight 2018 anomalies; solid black and red lines depict 5 -yr running means for North America and Eurasia, respectively; shading indicates the interdataset anomaly spread ( \pm I std. dev.).

SCE and can also be influenced by precipitation variability (Sospedra-Alfonso and Merryfield 2017).

h. River discharge-R. M. Holmes, A. I. Shiklomanov, A. Suslova, M. Tretiakov, J. W. McClelland, R. G. M. Spencer, and S. E. Tank

The Arctic Ocean makes up approximately $1 \%$ of the global ocean by volume but receives more than $10 \%$ of global riverine discharge (Aagaard and Carmack 1989; McClelland et al. 2012). Consequently, terrestrial influences via river inputs are more pronounced in the Arctic Ocean than in other ocean basins. The rapid environmental change occurring in the Arctic is altering land-ocean interactions, which is also impacting coastal and ocean physics, chemistry, and biology. Because rivers naturally integrate the processes that are occurring throughout their watersheds, trends in the discharge and chemistry of large rivers can also signal widespread terrestrial change including permafrost thaw and the amount or seasonality of precipitation (Rawlins et al. 2010; Holmes et al. 2012)

A long-term increase in Arctic river discharge has been well documented by time-series data dating to the 1930s (Peterson et al. 2002; McClelland et al. 2006). While there is still some uncertainty about what is driving this trend, coincident increases in 
precipitation provide a compelling explanation (Shiklomanov and Lammers 2009; Overeem and Syvitski 2010; Rawlins et al. 2010; Déry et al. 2016; Rood et al. 2017). This long-term increase in riverine discharge has been greatest for rivers of the Eurasian Arctic and provides the strongest evidence of intensification of the Arctic freshwater cycle, which also includes increasing precipitation and evapotranspiration (Rawlins et al. 2010).

River discharge values since 2016 are presented to directly compare recent trends in the eight largest Arctic rivers. River data used in this analysis are available through the Arctic Great Rivers Observatory (arcticgreatrivers.org). Six of the rivers lie in Eurasia and two are in North America. Collectively, the

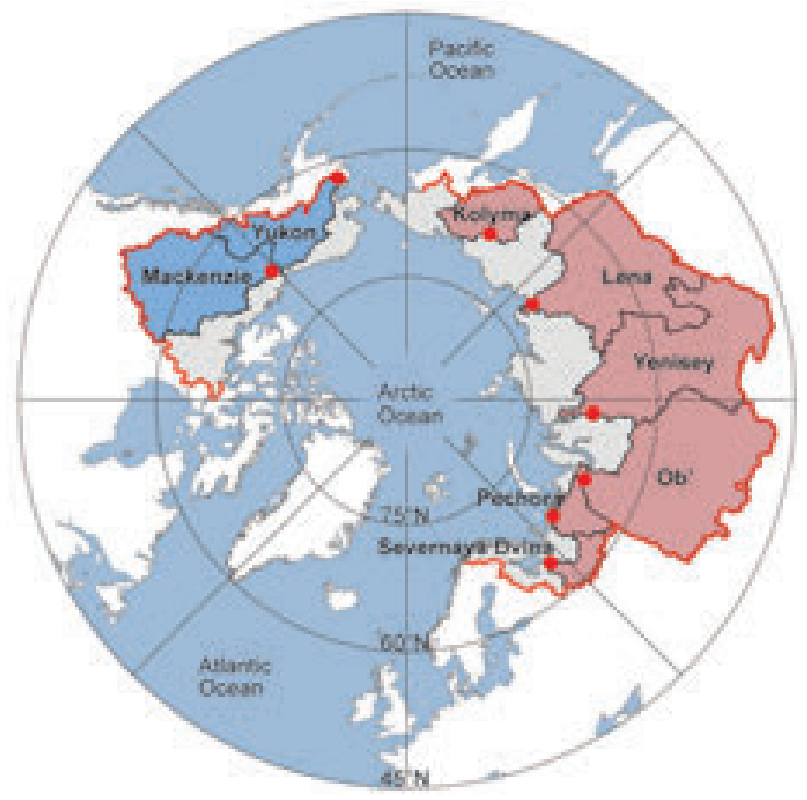

FIG. 5.22. Watersheds of the eight largest Arctic rivers featured in this analysis. Collectively, these rivers cover approximately $70 \%$ of the 16.8 million $\mathbf{k m}^{2}$ pan-Arctic watershed, as indicated by the red boundary line. Red dots show locations of the discharge monitoring stations. watersheds of these rivers cover approximately $70 \%$ of pan-Arctic drainage area and account for the majority of river water inputs to the Arctic Ocean (Fig. 5.22). Discharge measurements for the six Russian rivers began in 1936, whereas discharge measurements did not begin until 1973 for the Mackenzie River and 1976 for the Yukon River. These time-series are used to establish a reference period (1981-2010) to compare and contextualize recent observations. Years are presented as "water years," 1 October-30 September, to more closely align with the annual cycle of hydrologic processes such that precipitation and runoff occur during the same time period.

In 2018, the combined discharge of the eight largest Arctic rivers was $2508 \mathrm{~km}^{3}$, which is $6.8 \%$ greater than the 1981-2010 reference period (Table 5.2). The majority of the discharge increase was driven by the six Eurasian rivers; their combined discharge of 1990 $\mathrm{km}^{3}$ was $7.2 \%$ greater than the 1981-2010 reference period. Discharge for the two North American rivers $\left(518 \mathrm{~km}^{3}\right)$ was $5.1 \%$ greater than the reference period. In 2016 and 2017, the combined discharge of the eight largest Arctic rivers was 4.4\% and 2.2\% greater than the reference period, respectively (Table 5.2).

High Eurasian river discharge in 2018 was driven primarily by high summer discharge, presumably due to high summer precipitation. August 2018 discharge of the Eurasian rivers was $41 \%\left(80 \mathrm{~km}^{3}\right)$ greater than the August average of the reference period (Fig. 5.23). In contrast, August discharge for North American rivers in 2018 was slightly below average, although all other months exceeded the average of the reference period (Fig. 5.23).

The long time-series available for the Eurasian Arctic rivers (since 1936) demonstrates an accelerating increase in their combined discharge. The positive linear trend across this entire time series indicates that the average annual discharge of Eurasian Arctic rivers is increasing by $2.5 \mathrm{~km}^{3}$ per year. For the North American Arctic rivers, the increase over the period

TABLE 5.2. Annual discharge for the eight largest Arctic rivers for 2016, 2017, and 2018, compared to the
I98I-2010 average. Red values indicate provisional data and are subject to modification until official data
are published.
\begin{tabular}{|c|c|c|c|c|c|c|c|c|c|}
\hline Year' & Yukon & Mackenzie & Pechora & S.Dvina & Ob' & Yenisey & Lena & Kolyma & SUM \\
\hline $\mathbf{2 0 1 8}$ & 229 & 289 & 96 & 112 & 420 & 595 & 665 & 102 & 2508 \\
\hline $\mathbf{2 0 1 7}$ & 191 & 289 & 106 & 120 & 430 & 590 & 568 & 104 & 2399 \\
\hline $\mathbf{2 0 1 6}$ & 244 & 285 & 90 & 110 & 467 & 546 & 645 & 65 & 2452 \\
\hline $\begin{array}{c}1981-2010 \\
\text { average }\end{array}$ & 205 & 288 & 114 & 104 & 398 & 613 & 557 & 70 & 2349 \\
\hline
\end{tabular}

${ }^{1}$ Year refers to Water Year (1 Oct-30 Sep), with the year designated being when the Water Year ends. Thus, the Water Year 2018 began 1 Oct 2017 and ended 30 Sep 2018. 


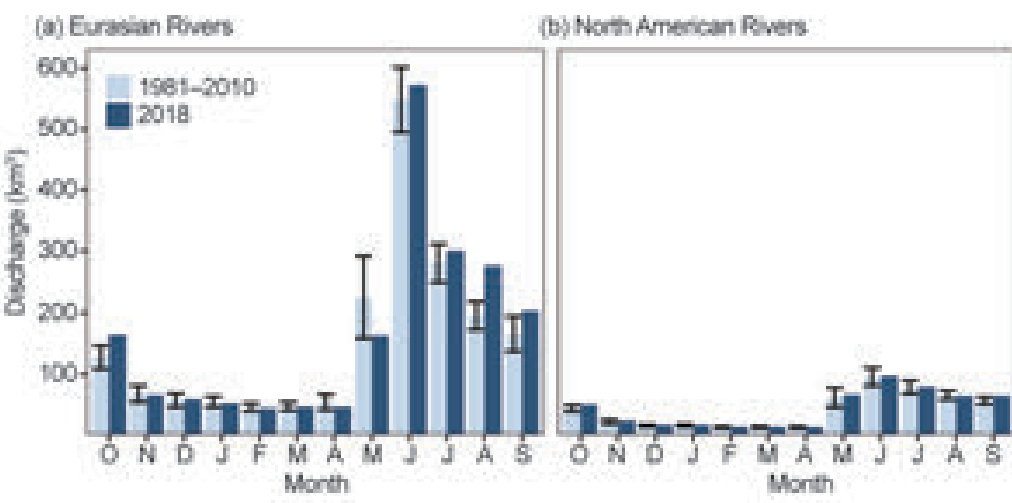

FIG. 5.23. 2018 seasonal discharge $\left(\mathrm{km}^{3}\right)$, relative to the $1981-2010$ average, for the (a) six Eurasian and (b) two North American rivers. Error bars represent \pm I std. dev.

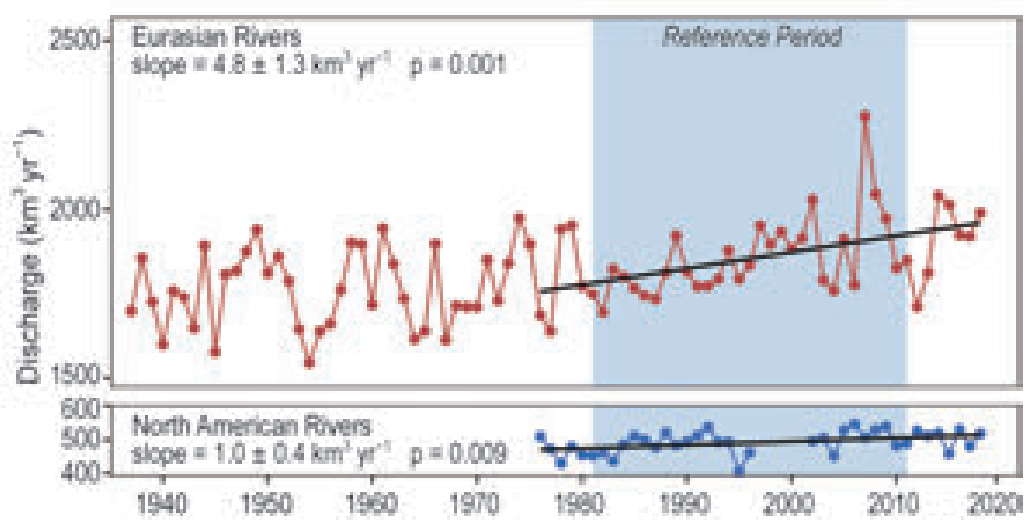

FIG. 5.24. Long-term trends in annual discharge $\left(\mathrm{km}^{3} \mathrm{yr}^{-1}\right)$ for Eurasian and North American Arctic rivers. Gaps in the North American rivers time-series span from 1996 to 2001 due to missing Yukon data from 1996 to $200 \mathrm{I}$ and missing Mackenzie measurements in 1997 and 1998. Note the different scales for the Eurasian and North American river discharge; discharge from the former is 3-4 times greater than from the latter.

of record (1976-2018) was $1.0 \mathrm{~km}^{3}$ per year. When the Eurasian data are also considered for the same period, the average annual increase in discharge was $4.8 \mathrm{~km}^{3}$ per year (Fig. 5.24). These observations indicate that Arctic river discharge continues to increase, providing powerful evidence for the intensification of the Arctic hydrologic cycle.

i. Tundra greenness-H. Epstein, U. Bhatt, M. Raynolds, D. Walker, B. Forbes, G. Phoenix, J. Bjerke, H. Tømmervik, S.-R. Karlsen, R. Myneni, T. Park, S. Goetz, and G. Jia

Arctic tundra vegetation has responded to dramatic environmental changes over the course of the last several decades by increasing the above-ground quantity of live vegetation, a process commonly referred to as greening. Vegetation changes vary spatially, in both sign and magnitude, throughout the circumpolar Arctic, and are not necessarily consistent over time (e.g., Bhatt et al. 2013; Reichle et al. 2018). This variability suggests complex interactions among the atmosphere, vegetation, soils, permafrost, and grazing animals of the Arctic system. Changes in tundra vegetation can have important effects on carbon cycling and soil-atmosphere energy exchange (e.g., Treharne et al. 2016; Frost et al. 2018; Lafleur and Humphreys 2018). The latter has implications for active layer depth and permafrost stability, thereby impacting Arctic landscapes. Changes in tundra vegetation also affect wildlife habitats. For instance, bird and terrestrial mammal species have shown favorable responses (e.g., greater range and larger populations) to Arctic greening, including shrub expansion (e.g., Wheeler et al. 2018). Continued evaluation of the current state and dynamics of circumpolar Arctic vegetation improves our understanding of these complex interactions and their influences on the Arctic system and beyond.

There is a number of controls on the inter-annual dynamics of tundra productivity. Summer air temperature is the most widely acknowledged factor responsible for increasing (greening) tundra vegetation (Ackerman et al. 2018; Keenan and Riley 2018; MyersSmith and Hik 2018; Weijers et al. 2018; Bjorkman et al. 2018). However, several reports have shown that increased temperatures can have a detrimental (browning) or no effect on tundra vegetation (Lara et al. 2018; Maliniemi et al. 2018; Opala-Owczarek et al. 2018; Xu et al. 2018). Tundra browning has also been observed in response to extreme events, such as winter snowmelt followed by frost, drought, icing during rain-on-snow episodes, and insect outbreaks (Phoenix and Bjerke 2016; Treharne et al. 2016). Precipitation and moisture availability are also important controls on tundra vegetation dynamics (Lara et al. 2018; Maliniemi et al. 2018; Opala-Owczarek et al. 2018; Wang et al. 2018; Bjorkman et al. 2018) and are linked to the effects of air temperature changes; increased temperatures may lead to reduced growing-season soil moisture and increased water stress in tundra plants (Ackerman et al. 2018; Keenan and Riley 2018; Opala-Owczarek et al. 2018). Deeper snow packs have been shown to lead to increased shrub growth, increasing vegetation net 
uptake of $\mathrm{CO}_{2}$ (Christiansen et al. 2018; Maliniemi et al. 2018; Opala-Owczarek et al. 2018; Parmentier et al. 2018; Wang et al. 2018). Changes in the land cover also affect tundra greenness; for example, reductions in cryogenic disturbances (e.g., frost circles; Becher et al. 2018) and increased lake drainage (Lara et al. 2018) can both lead to greening.

Arctic tundra vegetation has been monitored continuously since 1982 using the Normalized Difference Vegetation Index (NDVI) derived via satellites. NDVI is highly correlated with the quantity (greenness) of above-ground Arctic tundra vegetation (e.g., Raynolds et al. 2012; Karlsen et al. 2018). The data reported here are from the Global Inventory Modeling and Mapping Studies (GIMMS) 3g V1 dataset (GIMMS 2013) and are based largely on the AVHRR sensors aboard NOAA satellites (Pinzon and Tucker 2014). The GIMMS product (at $1 / 12^{\circ}$ resolution for this report) is a bi-weekly, maximum-value composite dataset of the NDVI, calculated from Earth-surface reflectances in the red and near infrared wavelengths. Two metrics based on the NDVI are used: MaxNDVI and TI-NDVI. MaxNDVI is the peak NDVI value for the year, observed during the growing season, and is related to the yearly maximum above-ground vegetation biomass. TI (time-integrated) NDVI is the sum of the bi-weekly NDVI values for the growing season and is correlated with the total above-ground vegetation productivity. Collectively, these two indices describe the abundance and activity of tundra vegetation for a given growing season.

According to the overall trend in tundra greenness for the 37-year record (1982-2018), the MaxNDVI and the TI-NDVI have increased throughout a majority of the geographic circumpolar Arctic tundra (Figs. $5.25 \mathrm{a}, \mathrm{b})$. Regions with the greatest increases in tundra greenness are the North Slope of Alaska, the southern subzones of the Canadian tundra, and eastern Siberia. Tundra greenness has declined or shown browning throughout the Yukon-Kuskokwim Delta of western Alaska, the High Arctic of the Canadian Archipelago, and the northwestern and north-coastal Siberian tundra. Specific regions of observed greening and browning tend to be consistent between MaxNDVI and TI-NDVI; however, decreases in TI-NDVI tend to be more spatially extensive than decreases in MaxNDVI, suggesting that in certain locations the length of the growing season may be decreasing, whereas the actual growth of vegetation may not be affected.

Considering variability on a year-to-year basis, NDVI declined in 2018 from the prior year for both indices over North America and slightly increased for Eurasia (Fig. 5.26). For both regions, this follows a year of decreases in NDVI from 2016 to 2017, after particularly high NDVI values were observed in 2016. In North America, TI-NDVI declined by $11.2 \%$ from 2017 to 2018 (the largest single-year decline in the record) and declined $14.7 \%$ since 2016. MaxNDVI in North America declined by 5.9\% from 2017 to 2018 (the second largest single-year decline in the record), and $9.9 \%$ since 2016. Note that the mean NDVI values for Eurasian tundra are substantially greater than those for the North American tundra, because most of the Eurasian tundra occurs at relatively lower latitudes.
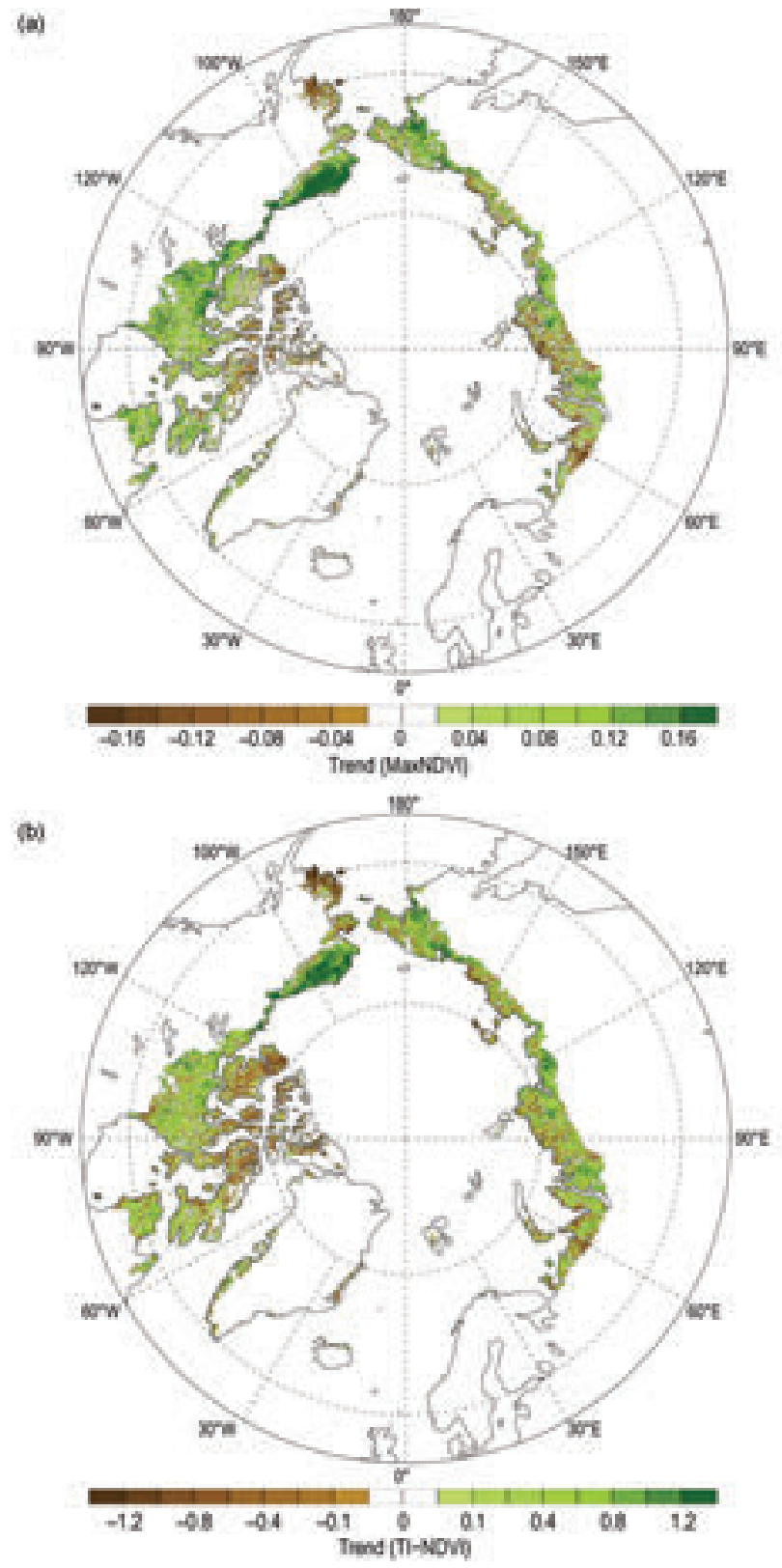

Fig. 5.25. Magnitude of the trend (calculated as the total change over a least squares, linear fit trend line) in (a) MaxNDVI and (b) TI-NDVI for 1982-20I8. 
With the 2017 to 2018 decline, the North American NDVI values dropped below the mean for the 37-year record. In 2018, MaxNDVI for North America ranked 25th and TI-NDVI ranked 36th (second lowest in the record, behind 1992). NDVI values for Eurasia remained above the mean; MaxNDVI ranked ninth and TI-NDVI ranked 11th. For the Arctic as a whole, MaxNDVI in 2018 was essentially at the mean value (ranked 19th) and TI-NDVI was less than the mean value (ranked 31st).

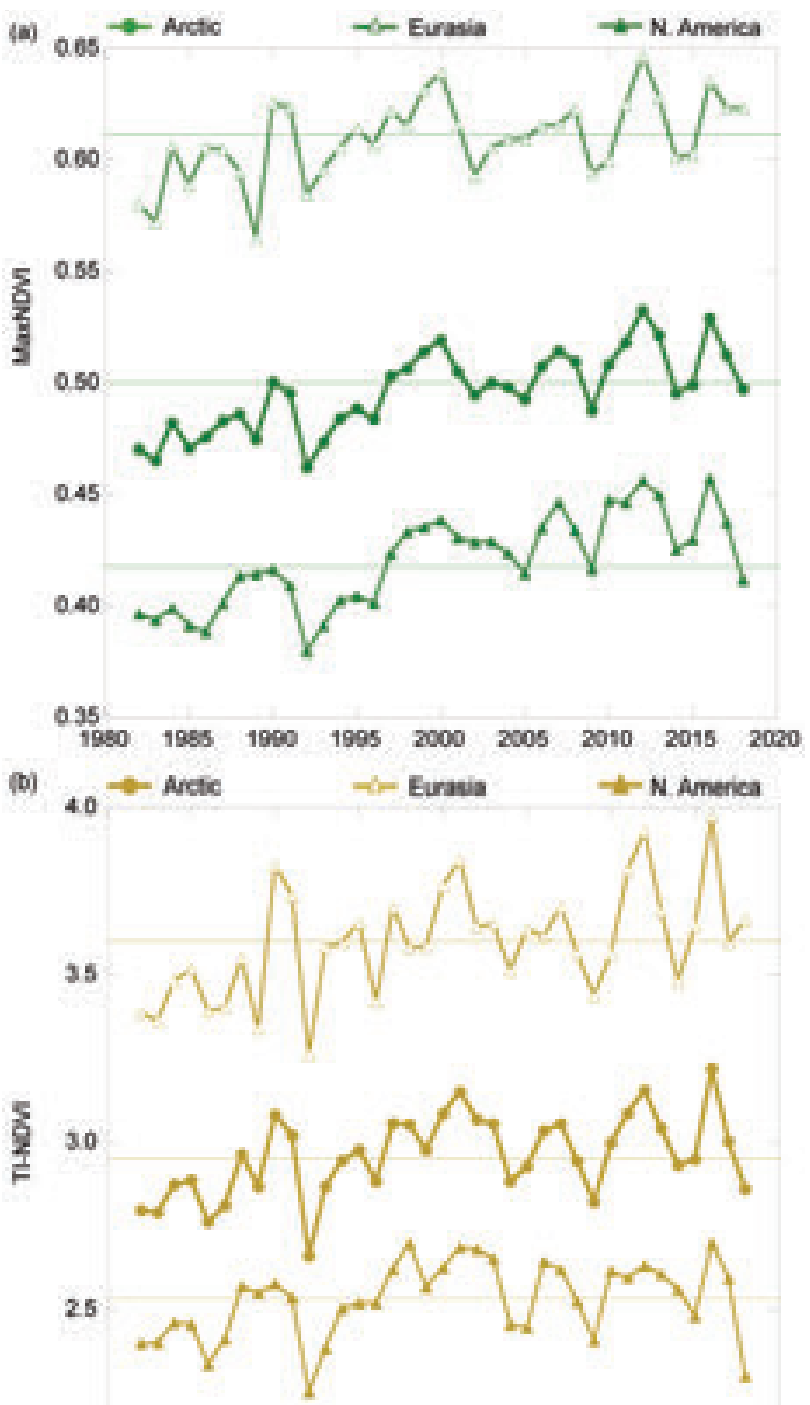

2.0

$\begin{array}{lllllllll}1980 & 1965 & 1900 & 1995 & 2000 & 2005 & 2040 & 2015 & 2020\end{array}$

FIG. 5.26. (a) MaxNDVI and (b) TI-NDVI for Eurasia (top), Arctic as a whole (middle), and North America (bottom) for 1982-2018. Horizontal lines are the means for each time series. j. Ozone and UV radiation-G. H. Bernhard, V. E. Fioletov, J.-U. Grooß, I. lalongo, B. Johnsen, K. Lakkala, G. L. Manney, and R. Müller

The release of man-made substances that deplete Earth's ozone layer, such as chlorofluorocarbons (CFCs), has reinforced the chemical destruction of ozone in the polar stratosphere. The resulting ozone loss has led to increased UV radiation with adverse effects on human health (e.g., sunburn) and Earth's environment (EEAP 2019). Chemical processes that drive ozone depletion are initiated at temperatures below about $195 \mathrm{~K}\left(-78^{\circ} \mathrm{C}\right)$ in the lower stratosphere, at an approximate altitude of $15-25 \mathrm{~km}$. These chemical processes lead to the formation of polar stratospheric clouds (PSCs), which act as a catalyst to transform inactive forms of chlorine-containing substances (e.g., $\mathrm{HCl}$ and $\mathrm{ClONO}_{2}$ ) to active, ozone-destroying chlorine species such as chlorine monoxide $(\mathrm{ClO})$. Chemically-induced loss of polar ozone occurs predominantly during winter and spring (WMO 2018a), hence November 2017-April 2018 is emphasized in this report.

Chemical destruction of ozone was unusually large over the winter/spring 2017/18. Temperatures in the lower Arctic stratosphere dropped below the threshold for PSC formation in mid-November 2017, approximately 15 days earlier than typical, and remained below the average temperature in the observational record (1979-2016) through midFebruary 2018. On 12 February, a major sudden stratospheric warming event split the polar vortex (i.e., the low-temperature cyclone in which most of the springtime chemical ozone destruction occurs), and lower stratospheric temperatures abruptly rose above the threshold temperature for PSC formation (Karpechko et al. 2018; Rao et al. 2018). The larger of the two offspring vortices remained intact, and chemical destruction of ozone continued within its boundary until late March. Despite this event, vortexaveraged ozone mixing ratios (OMRs; a measure of ozone concentrations) observed by the Microwave Limb Sounder (MLS) during February 2018 were the lowest in the MLS observational record (2004-17; Fig. 5.27). Although chlorine was not fully deactivated until late March, according to MLS measurements, OMRs within the vortex started to increase in early March, partly due to influx of ozone from higher altitudes. Vortex-averaged OMRs between March and early April 2018 were among the lowest in the MLS record, with lower values only in 2011 and 2016, the years with the largest chemical ozone loss observed to date (Fig. 5.27). 


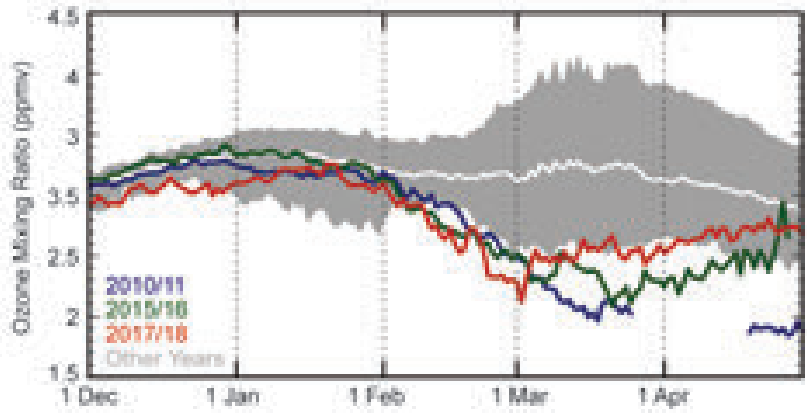

FIG. 5.27. Average ozone mixing ratios (ppmv) measured by Aura MLS at an altitude of $\sim 18 \mathrm{~km}$ for the area bounded by the polar vortex. Data from 2017/18 (red), 2015/16 (green), and 2010/II (blue) are compared with the average (solid white) and minimum/maximum range (gray shading) from 2004/05 to 2016/17, excluding $2010 / 11,2015 / 16$, and $2017 / 18$. Gaps in the record for $2010 / 11$ are due to missing data.

The evolution of the Arctic total ozone column (TOC; i.e., ozone amounts integrated from the surface to the top of the atmosphere) in March 2018 is compared to the 1979-2017 observational record in Fig. 5.28. March TOC is evaluated because chemically induced Arctic ozone loss typically has the largest variability in this month (Fig. 5.27; WMO 2018a). The minimum Arctic daily TOC measured by satellites in March 2018 was 380 Dobson units (DU), which was $1.2 \%$ (4 DU) above the average of the observational record (376 DU) and 3.7\% (14 DU) above the average when MLS data are available (2005-17).

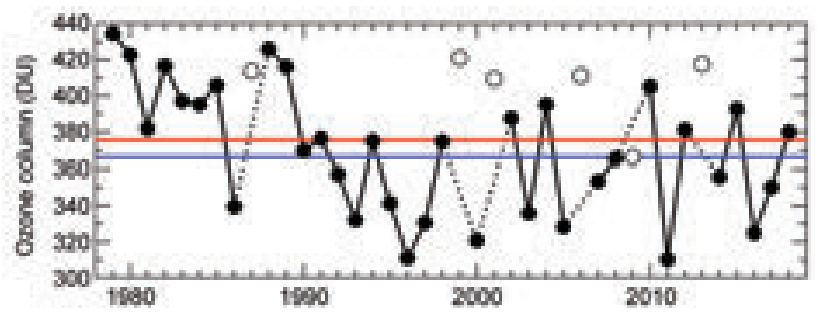

FIG. 5.28. Area-averaged monthly minimum total ozone column (DU) for Mar poleward of $63^{\circ}$ equivalent latitude (Butchart and Remsberg 1986). Open circles represent years in which the polar vortex broke up before Mar, resulting in relatively high values due to mixing with lower latitude air masses and a lack of significant chemical ozone depletion. Red and blue lines indicate the average TOC for 1979-2017 and 2005-17, respectively. Data are adapted from Müller et al. (2008) and WMO (2018), updated using ERA-Interim reanalysis data (Dee et al. 20II). Ozone data from 1979-2016 are based on the combined total column ozone database version 3.4 produced by Bodeker Scientific (www.bodekerscientific.com/data/total-column -ozone). Data for 2017/I8 are from OMI.
Spatial deviations of monthly average TOCs from historical (2005-17) averages (Figs. 5.29a,b) were estimated using ozone monitoring instrument (OMI; co-located with MLS on the Aura satellite) measurements. Despite the low ozone concentrations inside the lower stratospheric polar vortex during March (Fig. 5.27), TOCs over most regions of the Arctic were well above average (Fig. 5.29a) because Arctic TOCs are predominantly controlled by dynamical processes such as the transport of ozone-rich air from lower latitudes (Manney et al. 2011). Chemical loss in 2018 was only a secondary factor in controlling TOC within the vortex and a negligible factor outside the vortex. Average TOCs for March 2018 were about 15\% higher than the long-term mean over Scandinavia, the Norwegian Sea, Greenland, and northeastern Canada; $10 \%$ lower over north-central Siberia; and 10\% higher over northeastern Siberia (Fig. 5.29a). By July, monthly TOC anomalies showed a distinct geographical pattern that was significantly different from March (Fig 5.29b): TOCs were about 5\% below the long-term average over Scandinavia and northwest Russia and 5\% above the long-term average over Greenland, northeastern Canada, and the North Pole.

The ultraviolet index (UVI) is a measure of the ability of UV radiation to cause erythema (sunburn) in human skin (WHO 2002). In addition to its dependence on TOC, UVI depends on the sun's angle, cloud cover, and surface albedo (Weatherhead et al. 2005). In the Arctic, the UVI scale ranges from 0 to about 7 , with the smallest annual peak radiation levels (UVI values $<4$ ) observed at sites closest to the North Pole. UVI values $\leq 5$ indicate low-to-moderate risk of erythema (WHO 2002).

UVI anomalies are assessed using both satellitebased OMI and ground-based measurements, with the former providing better spatial coverage and the latter providing greater regional accuracy (Bernhard et al. 2015). Figures $5.29 \mathrm{c}$,d quantify the spatial differences in monthly average noontime UVIs from historical (2005-17) averages based on OMI measurements. Figures $5.29 \mathrm{c}$, d also indicate anomalies calculated from ground-based measurements at nine research stations located throughout the Arctic and Scandinavia.

Areas with high UVIs roughly match areas with low TOCs and vice versa, but UVI anomalies have larger spatial variability because of their added dependence on cloud cover (Fig. 5.29). In March 2018, average noontime UVIs calculated from OMI observations and ground-based measurements were $0 \%-15 \%$ below historical averages with a few exceptions, such as northwestern Siberia, where UVIs were 
(a) Mar

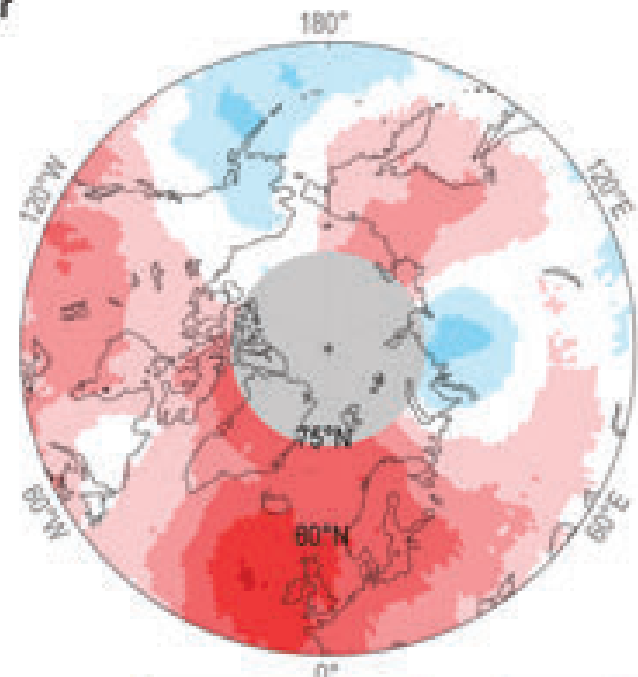

(b) Jul

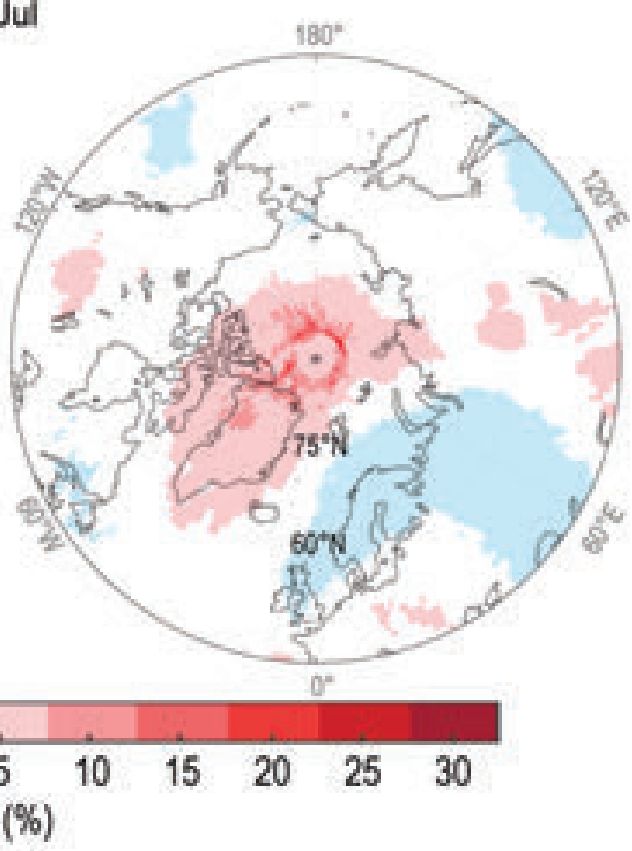

(c) Mar

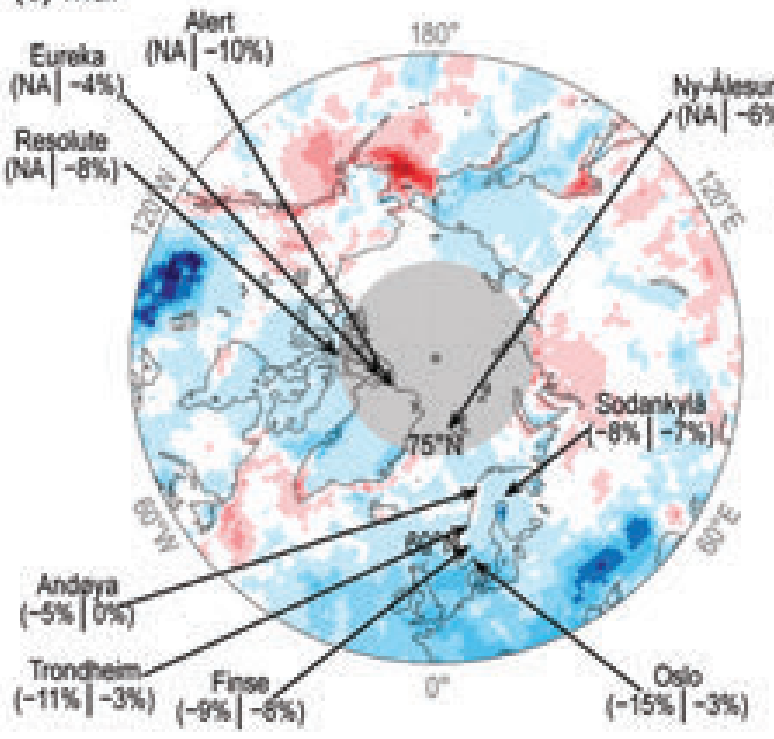

(d) Jul

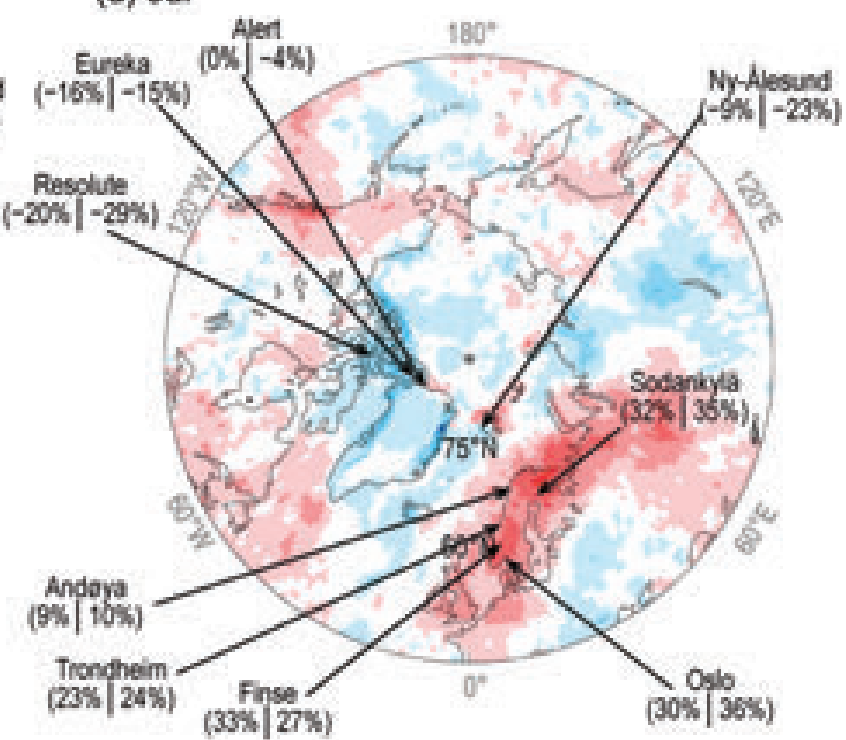

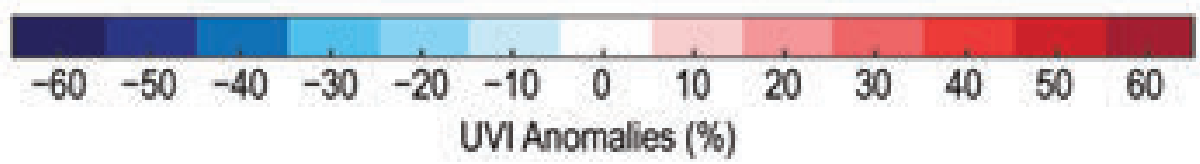

FIG. 5.29. Anomalies of TOC (\%) for (a) Mar and (b) Jul 2018. Noontime UVI (\%) for (c) Mar and (d) Jul 2018. Anomalies are relative to 2005-17 averages. Maps are based on the OMTO3 Level 3 total ozone product (Bhartia and Wellemeyer 2002). (c) and (d) also compare UVI anomalies from OMI (first value in parenthesis) with ground-based measurements at nine locations (second value presented). Gray shading indicates areas where no OMI data are available. 
actually elevated by several percent (Fig. 5.29c). Large positive UVI anomalies were observed over Scandinavia in May and July, with a $20 \%-40 \%$ range in both months (absolute anomalies of up to 1.4 UVI units). In July, areas of high UVI (Fig. 5.29d) and low ozone (Fig 5.29b) were correlated. However, these large UVI anomalies cannot be explained by low TOCs alone and were partly caused by exceptionally long periods of clear skies and record dry and warm conditions. For example, at Sodankylä, the mean temperature in July 2018 was $5.6^{\circ} \mathrm{C}$ above the 1981-2010 average and the sunshine duration in 2018 was 405 hours, exceeding the 1981-2010 average of 245 hours by $65 \%$. Anomalies at Trondheim, Oslo, and Sodankylä have exceeded historical means by $2.1,2.3$, and 2.5 standard deviations, respectively. In contrast to high UV radiation levels in Scandinavia, UV indices measured during July in northern Nunavut, Canada, were up to $29 \%$ below the long-term mean. UVI anomalies for the rest of the Arctic remained within $\pm 20 \%$ with few exceptions such as the eastern coast of Greenland (Fig. 5.29d). Generally, OMI observations are consistent with ground-based measurements (Fig. 5.29d). 


\section{ANTARCTICA AND THE SOUTHERN OCEAN-T. Scambos and S. Stammerjohn, Eds.}

a. Overview-T. Scambos and S. Stammerjohn

The year 2018 was marked by extreme seasonal and regional climate anomalies in Antarctica and across the Southern Ocean, expressed by episodes of record high temperatures on the high Antarctic Plateau and record low sea ice extents, most notably in the Weddell and Ross Seas. For the Antarctic continent as a whole, 2018 was warmer than average, particularly near the South Pole $\left(\sim 3^{\circ} \mathrm{C}\right.$ above the 1981-2010 reference period), Dronning Maud Land $\left(1^{\circ}\right.$ to $2^{\circ} \mathrm{C}$ above average), and the Ross Ice Shelf and Ross Sea (also $1^{\circ}$ to $2^{\circ} \mathrm{C}$ above average). In contrast, and despite conducive conditions for its formation, the ozone hole at its maximum extent was near the mean for 2000-18, likely due to an ongoing slow decline in stratospheric chlorine monoxide $(\mathrm{ClO})$ concentration. This section summarizes the year's progression of notable climate-related events for the southern continent and the polar ocean surrounding it. Locations discussed in this chapter are shown in Fig. 6.1.

Early in 2018 (January-February), a localized but strong low-pressure anomaly spanning the southeast Pacific to southwest Atlantic sectors produced highly contrasting regional temperature anomalies across the continent-notably, near-record low temperatures over West Antarctica and record high temperatures over the East Antarctic Plateau.

Very low summer sea ice extent in the Ross and Weddell Seas in 2018 (following on from the anomalously low spring 2017 pattern) led to the second lowest Antarctic summer minimum extent on record. This was accompanied by high SSTs in the Ross and Weddell Seas, with the latter also showing high coastal precipitation. Summer sea ice extent in the western Bellingshausen Sea and Amundsen Sea sectors was higher than typical, and was associated with low SSTs and low coastal precipitation. Cool conditions in this sector also contributed to a low ice sheet melt season overall for 2017/18. This low-melt year continues a trend, now spanning from the $1978 / 79$ to $2017 / 18$ seasons, of reduced summer melting that is statistically significant $(p<0.05)$.

From austral autumn to early winter (March-June), low-pressure anomalies continued to persist over the Antarctic Peninsula. In conjunction with negative southern annular mode (SAM) index values that contrasted with positive values both before and after this period, positive pressure anomalies emerged over the continental interior, producing widespread high temperatures across the ice sheet interior, with record highs observed at several continental stations (Relay Station AWS, Amundsen-Scott South Pole Station). Circumpolar sea ice extent remained well below average throughout the year, as has been the case since September 2016.

In spring (October), a strong but short-lived wavethree pattern developed, producing strong regional contrasts in temperature and pressure anomalies. At the same time, the stratospheric vortex intensified, but due to decreasing $\mathrm{ClO}$ in the stratosphere, the cold and intensified polar vortex resulted in only a near-average ozone hole area.

Late in the year (November-December), the atmospheric circulation was characterized by a wave-two pattern, leading to more record high temperatures on the high Antarctic Plateau (Amundsen-Scott reached $-23.3^{\circ} \mathrm{C}$; Relay Station AWS reported $-25.7^{\circ} \mathrm{C}$ in December) and daily records of low circumpolar sea ice extent, particularly in late December. The annual $P-E$ anomaly pattern was also marked by a wave-two pattern with anomalously low precipitation in coastal

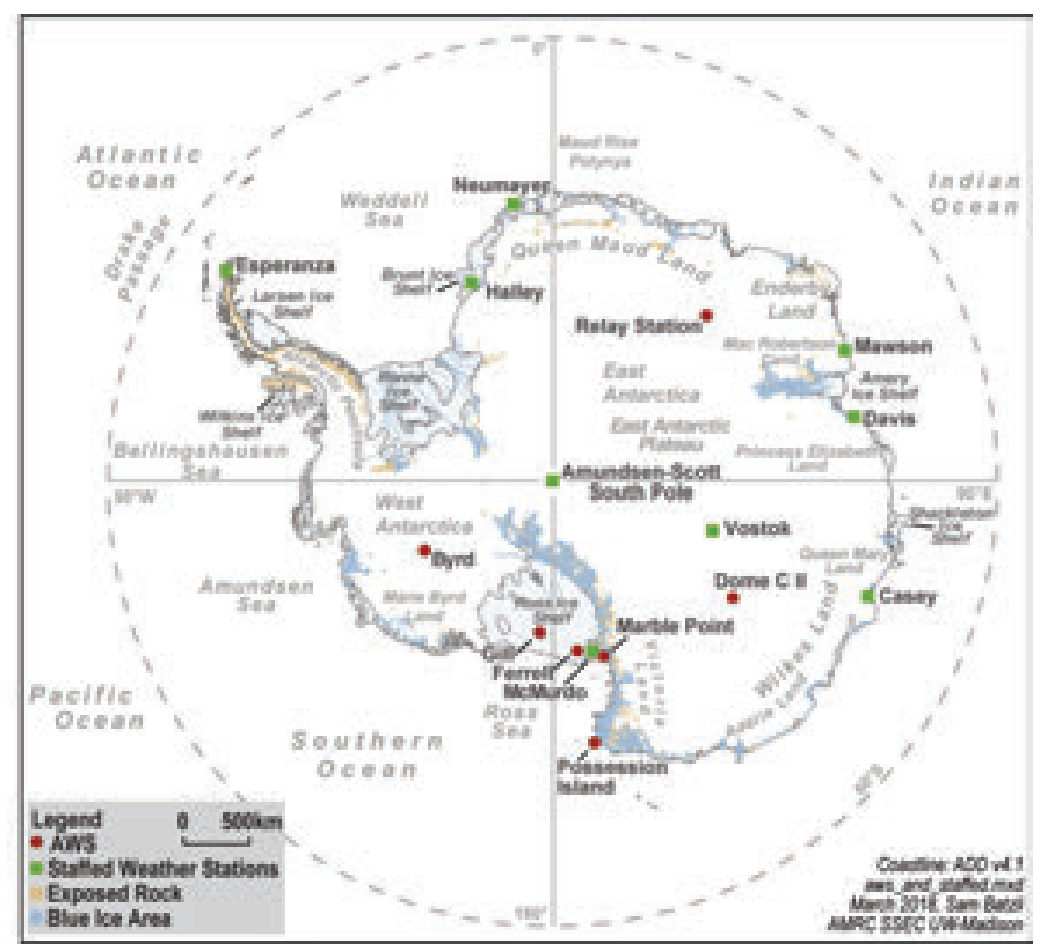

Fig. 6.I. Map of stations, locations, and other regions discussed in this chapter, and the locations of weather stations. 
West Antarctica and coastal East Antarctica $\left(\sim 170^{\circ} \mathrm{E}\right.$ to $\sim 80^{\circ} \mathrm{W}, \sim 80^{\circ} \mathrm{E}$ to $\sim 140^{\circ} \mathrm{E}$, respectively); elsewhere, precipitation was generally above average, particularly in the coastal Weddell sector.

\section{b. Atmospheric circulation and surface} observations-K. R. Clem, S. Barreira, R. L. Fogt, S. Colwell, L. M. Keller, and M. A. Lazzara.

Atmospheric circulation anomalies contributed to several record-breaking weather conditions observed in 2018. Atmospheric pressure and temperature anomalies were investigated using ERA-Interim (Dee et al. 2011), which performs with greater skill over the high southern latitudes than other modern global reanalyses (Bracegirdle and Marshall 2012), although the results shown here are consistent with the other reanalyses. Figure 6.2 shows the monthly geopotential height (Fig. 6.2a) and temperature (Fig. 6.2b) anomalies averaged over the polar cap $\left(60^{\circ}-90^{\circ} \mathrm{S}\right)$ and the monthly circumpolar zonal wind (Fig. 6.2c) anomalies averaged over $50^{\circ}-70^{\circ} \mathrm{S}$. The year was split into five periods characterized by distinctive general climate patterns: January-February, March-June, JulySeptember, October, and NovemberDecember. The normalized surface pressure and temperature anomalies for each period are shown in Fig. 6.3. Figure 6.4 shows monthly pressure and temperature anomalies for four staffed weather stations (Amundsen-Scott, Esperanza, Halley, and Mawson) and two automatic weather stations (AWS; Marble Point AWS and Relay Station AWS). The station anomalies provide an indication of the surface weather that contributed to the patterns shown in Fig. 6.3.

The year began with below-average pressure over the continent during January and February (Fig. 6.2a) and a strong low-pressure anomaly over the South Pacific and Amundsen and Bellingshausen Seas that was 2-3 standard deviations and 9-12 hPa (not shown) below the climatological average (Fig. 6.3a). Halley station tied its record lowest (a) 2018 polar-cap $\left(60^{\circ}-90^{\prime} \mathrm{S}\right)$ averaged geopotential height anomalies (m)

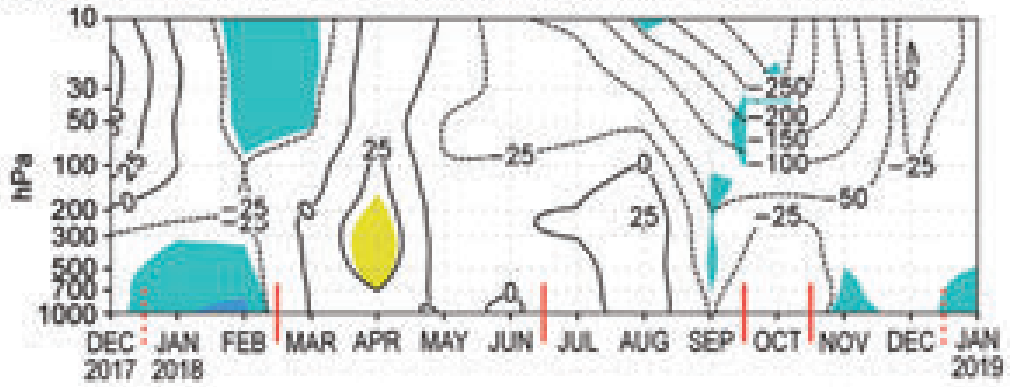

(b) 2018 polar-cap $\left(60^{*}-90^{\circ} \$\right)$ averaged temperature anomalies ("C)

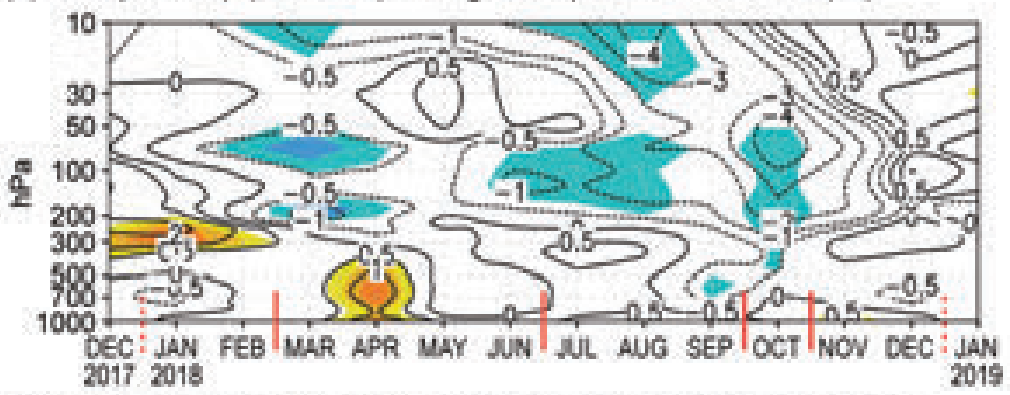

(c) 2018 circumpolar $\left(50^{\circ}-70^{\circ} \mathrm{S}\right)$ averaged zonal wind anomalies ( $\left.\mathrm{m} \mathrm{s}^{-4}\right)$

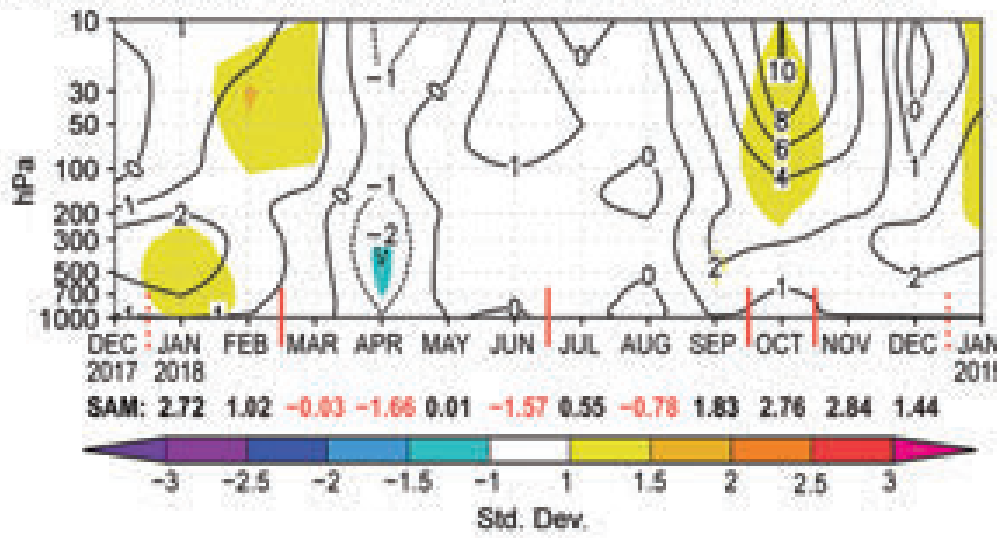

Fig. 6.2. Area-averaged (weighted by cosine of latitude) monthly anomalies over the southern polar region in 2018 relative to $198 \mathrm{I}-$ 2010: (a) polar cap $\left(60^{\circ}-90^{\circ} \mathrm{S}\right)$ averaged geopotential height anomalies (contour interval is $50 \mathrm{~m}$ with additional contour at $\pm 25 \mathrm{~m}$ ); (b) polar cap averaged temperature anomalies (contour interval is $I^{\circ} \mathrm{C}$ with additional contour at $\left.\pm 0.5^{\circ} \mathrm{C}\right)$; (c) circumpolar $\left(50^{\circ}-70^{\circ} \mathrm{S}\right)$ averaged zonal wind anomalies (contour interval is $2 \mathrm{~m} \mathrm{~s}^{-1}$ with additional contour at $\pm\left(\mathrm{m} \mathrm{s}^{-1}\right)$. Shading depicts std. dev. of monthly anomalies from the 198I-2010 climatological average as indicated by color bar at bottom. (Source: ERA-Interim reanalysis.) Red vertical bars indicate the five climate periods used for compositing in Fig. 6.3; the dashed lines near Dec 2017 and Dec 2018 indicate circulation anomalies wrapping around the calendar year. Values from the Marshall (2003) SAM index are shown below (c) in black (positive values) and red (negative values). pressure value for February, which is more than 7 hPa below its February climatological average (Fig. 6.4c). January-February surface air temperatures over central West Antarctica and the Weddell Sea were 2-3 standard deviations below normal. A localized but strong positive temperature anomaly ( 2 standard 


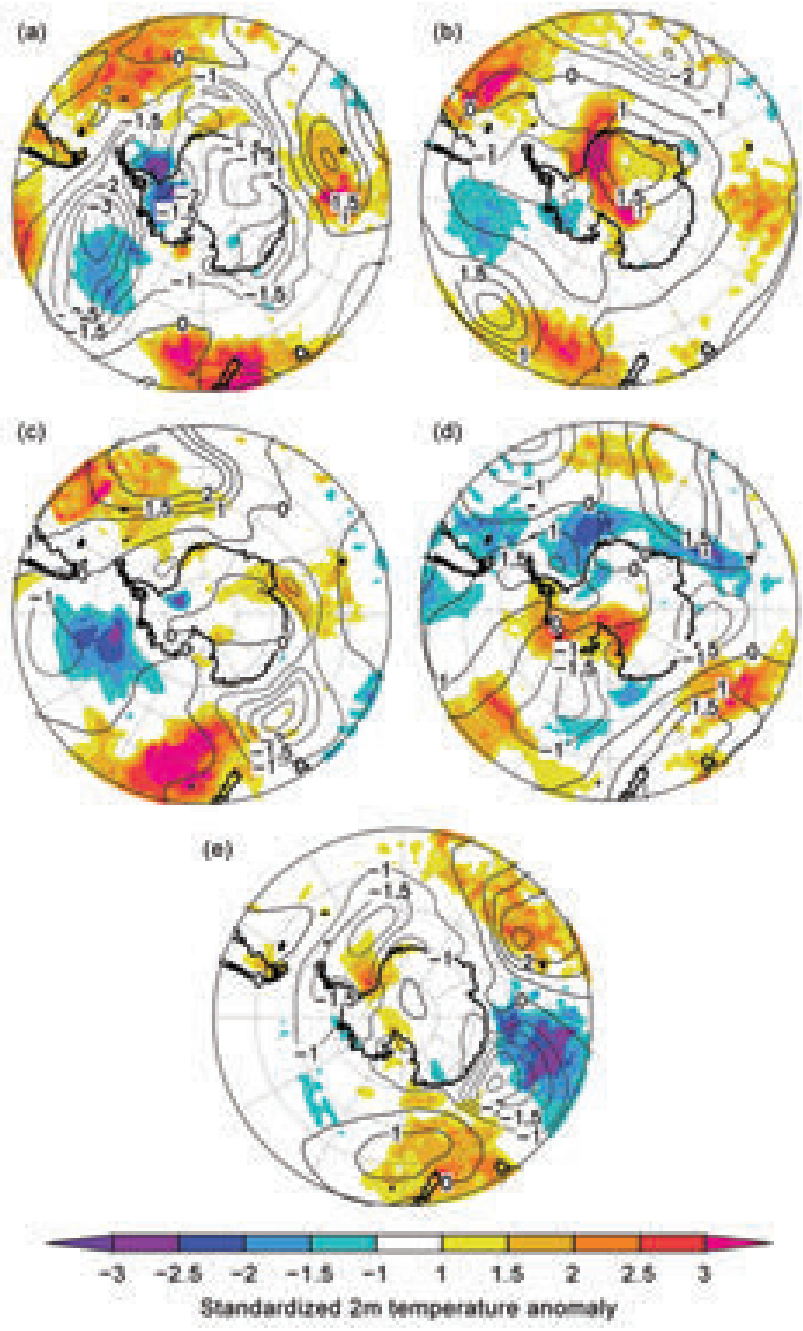

Fig. 6.3. Standardized surface pressure (contours) and 2-m temperature anomalies (shaded) relative to 198I-2010 for (a) Jan-Feb 2018; (b) Mar-Jun 2018; (c) Jul-Sep 2018; (d) Oct 2018; (e) Nov-Dec 2018. Contour interval is $0.5 \mathrm{std}$. dev. of surface pressure anomalies with the \pm 0.5 contour omitted. Shading represents std. dev. of 2-m temperature anomalies. (Source: ERAInterim reanalysis.)

deviations) was observed over the polar cap at the 200-300 hPa level during January and February (Fig. $6.2 \mathrm{~b})$. This included positive temperature anomalies observed at the highest points of the Antarctic Plateau; Relay Station AWS tied its record high monthly mean temperature for January $\left(-26.1^{\circ} \mathrm{C}\right)$ and observed a new record high monthly mean temperature of $-35.4^{\circ} \mathrm{C}$ for February (Fig. 6.4f). Elsewhere around the continent, temperatures were generally near normal for January-February. The negative pressure anomalies over the polar cap were accompanied by positive circumpolar zonal wind anomalies that were 1-2 $\mathrm{m} \mathrm{s}^{-1}$, or about 1 standard deviation, above the January climatology (Fig. 6.2c). Positive values of the southern annular mode (SAM) index were observed in both months.

With the development of a strong positive pressure anomaly ( $>1.5$ standard deviations) over the Antarctic Plateau, atmospheric circulation underwent a marked transition in March that persisted through June. Negative pressure anomalies previously present in the South Pacific region of the Southern Ocean developed over the Antarctic Peninsula (Fig. 6.3b). As a whole, the polar cap experienced the most widespread positive pressure and temperature anomalies during April (Figs. 6.2a-b), and the circumpolar westerlies were 1-2 $\mathrm{m} \mathrm{s}^{-1}$ (1 standard deviation) below normal (Fig. $6.2 \mathrm{c})$, concurrent with the year's most negative SAM index value. Through thermal advection, the positive pressure anomaly over the Plateau, combined with the negative pressure anomaly over the Peninsula, produced a narrow band of strong, positive temperature anomalies ( $>3$ standard deviations) that extended from Halley Station $\left(4^{\circ}-6^{\circ} \mathrm{C}\right.$ above climatology from March-June) to Relay Station AWS and AmundsenScott. Amundsen-Scott Station and Relay Station AWS observed temperatures more than $6^{\circ} \mathrm{C}$ above average during May and June. Relay Station AWS set a new record high temperature in May $\left(-50.1^{\circ} \mathrm{C}\right)$. Both Relay Station AWS and Amundsen-Scott Station tied their previous record high temperatures for June. On the Ross Ice Shelf, Marble Point AWS was $+4^{\circ} \mathrm{C}$ above normal for June; in the Ross Sea, Possession Island AWS observed a record high temperature $\left(-15.4^{\circ} \mathrm{C}\right)$ in June.

From July through September, temperatures and pressures over the continent were generally near average, but there were some strong month-to-month variations in temperature and pressure-particularly at Marble Point AWS and Amundsen-Scott Station. The most noteworthy and persistent feature was a strong positive pressure anomaly ( $>2$ standard deviations) over the South Atlantic and a negative pressure anomaly ( $>2$ standard deviations) south of Australia that extended westward and poleward to the Amery Ice Shelf (Fig. 6.3c). The latter, a cyclonic anomaly, produced positive temperature anomalies of $2^{\circ}-3^{\circ} \mathrm{C}$ (not shown), or 1-2 standard deviations (Fig. 6.3c), during July-September across the Amery Ice Shelf and the adjacent coast; during August, Mawson set a new record high monthly temperature of $-12.8^{\circ} \mathrm{C}$, which is $+6^{\circ} \mathrm{C}$ above its climatological average (Fig. 6.4d). Also, on the Plateau during August, Relay Station AWS observed a record high monthly mean temperature of $-50.4^{\circ} \mathrm{C}$, nearly $+8^{\circ} \mathrm{C}$ above its climatological value for that month. 
(a) Amundsen-Scott

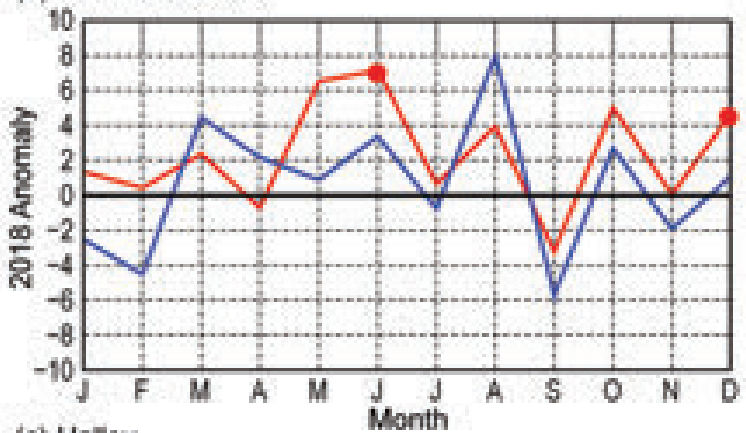

(c) Halley

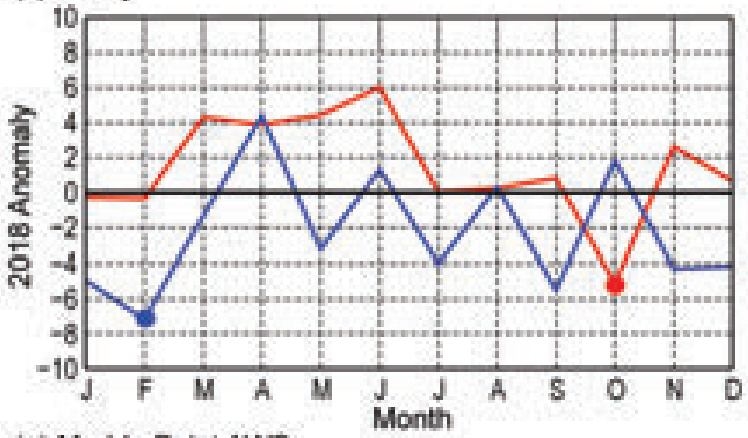

(e) Marble Point AWS

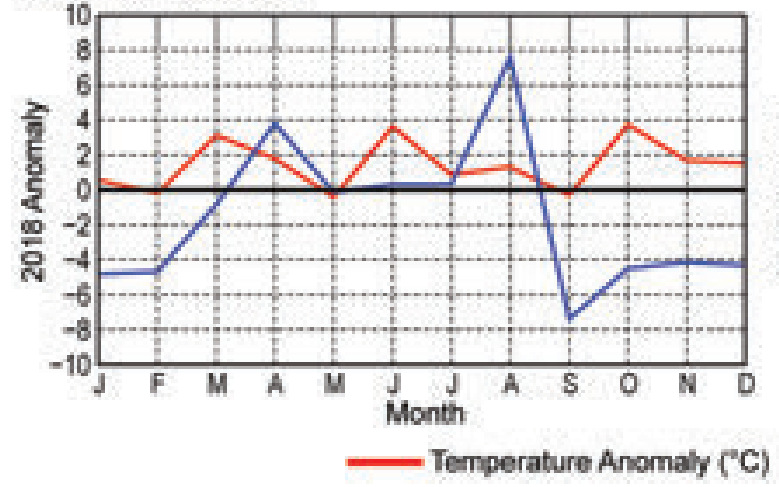

(b) Esperanza

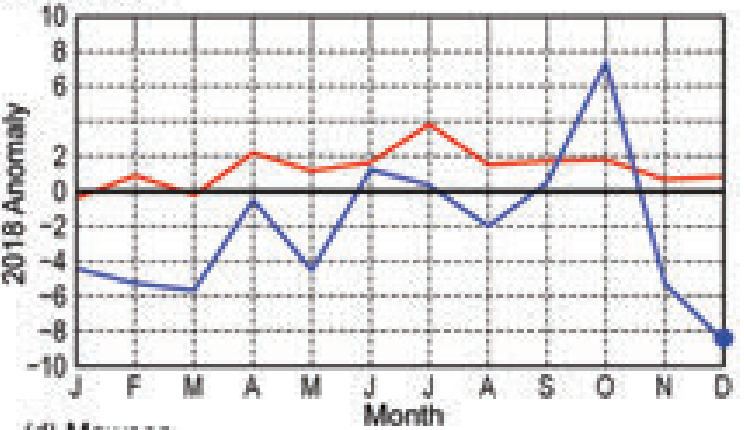

(d) Mawson

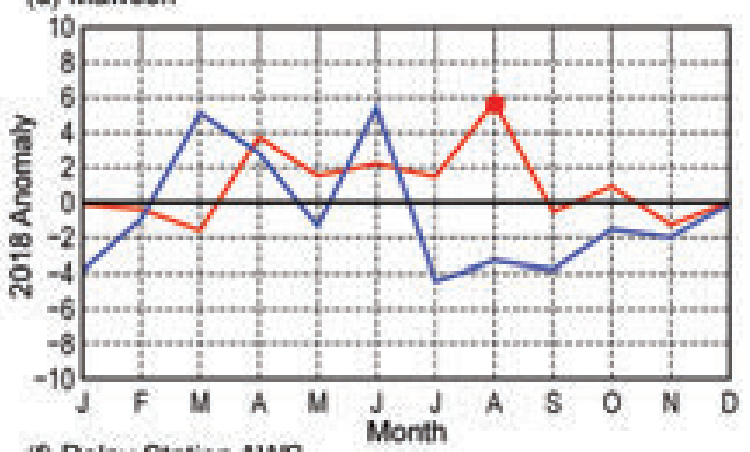

(f) Relay Station AWS

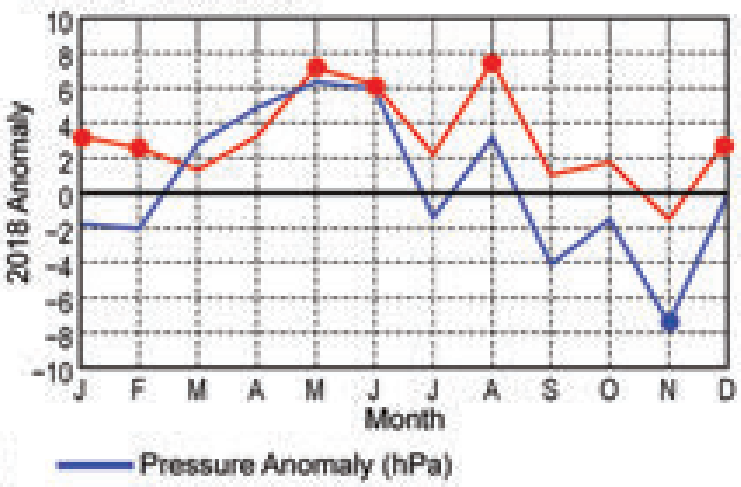

Fig. 6.4. Monthly Antarctic climate anomalies during 2018 at six representative stations [four staffed (a)-(d), and two automatic (e)-(f)]. Anomalies for temperature ( ${ }^{\circ} \mathrm{C}$ ) are shown in red and MSLP/surface pressure $(\mathrm{hPa})$ are shown in blue, with filled circles denoting record or tied record anomalies for a given month at each station in 2018. All anomalies are based on differences from the monthly 198I-2010 averages except for Relay Station, which is based on monthly 1993-2017 averages. Observational data used to calculate record values start in 1957 for Amundsen-Scott and Halley, 1945 for Esperanza, 1954 for Mawson, 1980 for Marble Point AWS, and 1995 for Relay Station AWS.

In October, a strong but short-lived wave-three pattern developed with three anomalous ridges and troughs between $40^{\circ} \mathrm{S}$ and $60^{\circ} \mathrm{S}$ (Fig. 6.3d). There was a negative pressure anomaly in the Ross Sea and a positive pressure anomaly over the Peninsula and Weddell Sea region. Esperanza Station recorded a positive monthly pressure anomaly of more than $7 \mathrm{hPa}$ (Fig. 6.4b). This regional circulation pattern produced strong warming across the western Antarctic Peninsula, Amundsen Sea, Marie Byrd Land, and the Ross Ice Shelf (Fig. 6.3d), including a $+5^{\circ} \mathrm{C}$ anomaly at Amundsen-Scott and a $+4^{\circ} \mathrm{C}$ anomaly at
Marble Point AWS (Figs. 6.4a,e). In the Weddell Sea, on the colder eastern side of the anticyclone, Halley Station set a new record low monthly temperature of $-25.1^{\circ} \mathrm{C}$ during October. The stratospheric vortex also intensified during October, as a negative pressure and temperature anomaly propagated downward to $\sim 30-100 \mathrm{hPa}$ (Figs. $6.2 \mathrm{a}$,b). Stratospheric westerlies above $100 \mathrm{hPa}$ were $4-10 \mathrm{~m} \mathrm{~s}^{-1}$ (1 standard deviation) above average during October (Fig. 6.2c).

The year closed with generally below-average pressures over the continent during November and December, possibly related to the downward propagation 
of the October stratospheric anomaly to the surface in November (Fig. 6.2a). Marked circulation anomalies included a strong negative-pressure anomaly over the Peninsula and Weddell Sea region (Relay Station AWS set a new record low monthly pressure for November and Esperanza set a new record low monthly pressure for December); a positive pressure anomaly in the Indian Ocean; and a strong negative pressure anomaly southwest of Australia (Fig. 6.3e). In December, the combination of the negative pressure anomaly over the Weddell Sea region and the positive pressure anomaly in the Indian Ocean once again produced strong warming across the Antarctic Plateau, with both Amundsen-Scott and Relay Station AWS observing new record high mean temperatures of $-23.3^{\circ} \mathrm{C}$ and $-25.7^{\circ} \mathrm{C}$, respectively (see Sidebar 6.1).

Several record monthly mean wind speeds were reported in 2018. On the Ross Ice Shelf, Ferrell AWS observed a record high mean wind speed for October of $8.2 \mathrm{~m} \mathrm{~s}^{-1}$ and Gill AWS experienced record high mean wind speeds for March $\left(5.6 \mathrm{~m} \mathrm{~s}^{-1}\right)$ and September $\left(6.4 \mathrm{~m} \mathrm{~s}^{-1}\right)$. In West Antarctica, Byrd AWS reported a record high mean wind speed for October of $11.4 \mathrm{~m} \mathrm{~s}^{-1}$. On the Antarctic Plateau, Dome C II AWS observed a record low mean wind speed for April $\left(1.9 \mathrm{~m} \mathrm{~s}^{-1}\right)$ and tied its record high mean wind speed for August $\left(4.3 \mathrm{~m} \mathrm{~s}^{-1}\right)$. Relay Station AWS reported record high mean wind speeds in August (9.7 $\mathrm{m} \mathrm{s}^{-1}$ ) and December $\left(8.4 \mathrm{~m} \mathrm{~s}^{-1}\right)$.

C. Net precipitation $(P-E)-D$. H. Bromwich and S.-H. Wang Precipitation minus evaporation/sublimation $(P-E)$ closely approximates the surface mass balance over Antarctica (e.g., Bromwich et al. 2011; Lenaerts and van den Broeke 2012), except for the near coastal areas where wind-driven transport of snow

\section{SIDEBAR 6.I: RECORD-WARM CONDITIONS AT THE SOUTH POLE AND THE UNUSUAL ATMOSPHERIC PATTERNS ASSOCIATED WITH THEM-K. R. CLEM, S. BARREIRA, R. L. FOGT, S. COLWELL, L. M. KELLER, AND M. A. LAZZARA}

The high East Antarctic Plateau is the coldest and driest region on the planet. Weather observations in this remote part of the world began in 1957 with the development of two year-round staffed scientific research stations: the United States' Amundsen-Scott Station and Russia's Vostok Station. Amundsen-Scott is located at the geographic South Pole, at an elevation of $2835 \mathrm{~m}$ a.s.l.; Vostok is located in the East Antarctic Plateau and is Antarctica's highest staffed weather station at an elevation of $3490 \mathrm{~m}$ a.s.l. (see Fig. 6.I for map). Average winter temperatures at Amundsen-Scott and Vostok range from $-60^{\circ} \mathrm{C}$ to $-68^{\circ} \mathrm{C}$; summer temperatures range from $-28^{\circ} \mathrm{C}$ to $-32^{\circ} \mathrm{C}$. Vostok Station recorded the world's lowest observed air temperature on record $\left(-89.2^{\circ} \mathrm{C}\right)$ in July 1983 (Turner et al. 2009), and neither station has ever recorded an above-freezing temperature. Additionally, satellite thermal emission temperatures of higher-elevation areas suggest that surface snow temperatures can plunge to $-98^{\circ} \mathrm{C}$ in winter, with overlying $\sim 2-\mathrm{m}$ air temperatures estimated at $-94^{\circ} \mathrm{C}$ (Scambos et al. 2018).

During 2018, there were several months of highly unusual atmospheric circulation patterns over the plateau that led to the warmest annual mean conditions on record at Amundsen-Scott and Vostok. Both stations reported an annual mean temperature anomaly of $+2.4^{\circ} \mathrm{C}$ above their respective 198I-2010 climatological means. Amundsen-Scott observed a record high annual mean temperature of $-47.1^{\circ} \mathrm{C}$, and Vostok recorded a record high annual mean temperature of $-52.9^{\circ} \mathrm{C}$.
Figure SB6.I shows the monthly mean temperature anomalies for 2018 at Amundsen-Scott and Vostok stations along with the spatial annual mean, May-June, and December surface pressure and surface air temperature anomalies. The year was characterized by a positive pressure anomaly over the plateau and a broad negative pressure anomaly stretching from the Weddell Sea across West Antarctica and into the South Pacific, with positive temperature anomalies of more than $1^{\circ}-2^{\circ} \mathrm{C}$ seen across much of the East Antarctic coast and high plateau.

Temperatures were near normal in January and February at both stations. In March, an unusual circulation pattern developed that persisted through June, and a similar pattern developed in December (Figs. SB6.Ic,d; see Fig. 6.3). During March, temperatures at both stations were $2^{\circ} \mathrm{C}$ above average and in May temperatures were $6^{\circ} \mathrm{C}$ above average. AmundsenScott recorded its largest monthly mean temperature anomaly of the year in June, at $+7.2^{\circ} \mathrm{C}$ above climatology, tying 2007 for its warmest June on record at $-51.7^{\circ} \mathrm{C}$. Figure SB6. Ic captures the anomalous circulation and temperature pattern during this period. A 6-hPa positive pressure anomaly developed over the northwest plateau in combination with a broad area of anomalous low pressure extending from the Weddell Sea, Antarctic Peninsula, and into the Bellingshausen and Amundsen Seas. This pressure pattern produced anomalous warm northerly flow that extended from the Weddell Sea (Halley Station recorded a $+6^{\circ} \mathrm{C}$ temperature anomaly in June, see Fig. 6.4c) inland across the plateau, cutting across the South Pole, 

AND THE UNUSUAL ATMOSPHERIC PATTERNS ASSOCIATED WITH THEM-K. R. CLEM, S. BARREIRA, R. L. FOGT, S. COLWELL, L. M. KELLER, AND M. A. LAZZARA

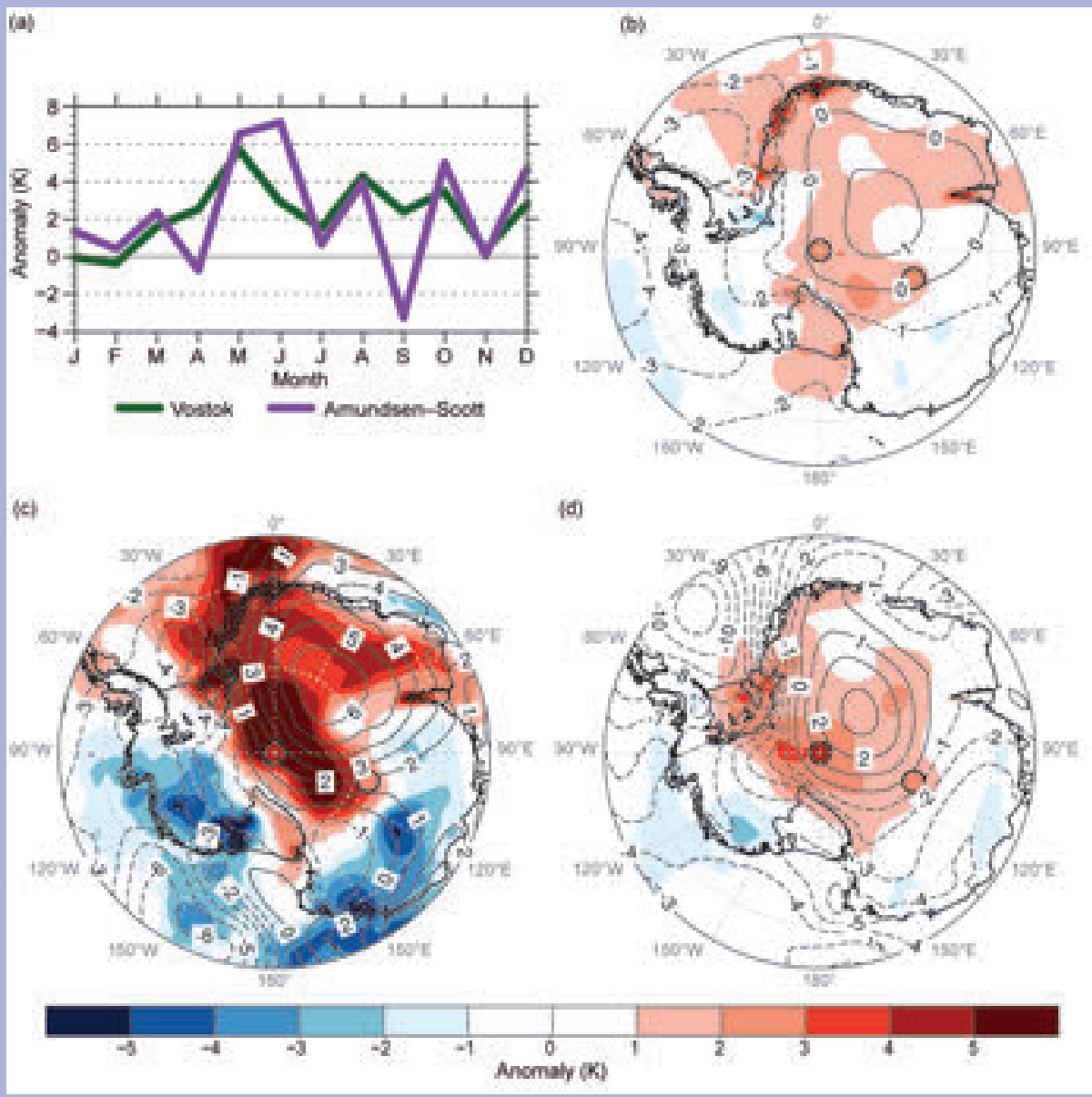

FIG. SB6.I. (a) Monthly mean temperature anomalies at Amundsen-Scott and Vostok stations in 2018 relative to 198I-2010 monthly climatology, and (b)-(d) surface pressure (contours) and $2-\mathrm{m}$ temperature (K, shaded) anomalies relative to 198I-2010 for (b) annual mean, and two periods of exceptional warming across the East Antarctic Plateau, (c) May-Jun and (d) Dec. Amundsen-Scott and Vostok stations are denoted with a circle filled with their respective temperature anomaly. (Source: ERA-Interim reanalysis.)

then descending over the Transantarctic Mountains, leading to anomalous warming on the Ross Ice Shelf. The individual pressure anomalies themselves were not highly unusual, at only $\sim$ I standard deviation from climatology, but their unique alignment and the persistence of this pattern over several months created a favorable fetch of warm flow off the South Atlantic that cut all the way across the continent.

Later in the year, Amundsen-Scott observed its warmest December on record with a monthly mean temperature of $-23.3^{\circ} \mathrm{C}$, more than $4.5^{\circ} \mathrm{C}$ above its December climatology and breaking the previous record of $-24^{\circ} \mathrm{C}$ observed in 2005 and 1974. Similar to May and June, the December circulation pattern (Fig. SB6.Id) consisted of a positive pressure anomaly over the plateau in combination with a strong cyclonic anomaly over the Weddell Sea that extended across West Antarctica and much of the South Pacific. The combined result of these two circulation anomalies was another warm, northerly flow stretching from the Weddell Sea to the South Pole and across much of the high plateau. While the circulation pattern in December was similar to that in May-June, much of the plateau experiences 24 hours of insolation in December. The anomalous subsidence commonly observed with synoptic high-pressure systems likely led to both reduced cloud cover and increased insolation, which in combination with the warm northerly flow, resulted in the warmest December on record at the South Pole. 
and meltwater runoff can become significant factors. Precipitation variability is the dominant cause of net $P-E$ changes at regional and larger scales over the Antarctic continent. Precipitation and evaporation fields from the JRA-55 reanalysis (Japanese 55-year Reanalysis; Kobayashi et al. 2015) were examined to assess Antarctic net precipitation $(P-E)$ behavior for 2018. (Antarctic $P-E$ from JRA-55 is highly ranked in relation to other global reanalyses (e.g., Liu et al., 2018). Because of the uneven distribution of $P-E$ characteristics (from Peninsula and coastal values $>1000 \mathrm{~mm} \mathrm{yr}^{-1}$ to values $<50 \mathrm{~mm} \mathrm{yr}^{-1}$ in the East Antarctic interior), annual $P-E$ anomalies relative to a 1981-2010 reference period are presented.

Figure 6.5 shows the JRA-55 2018 and 2017 annual anomalies of $P-E$ (Figs. 6.5a,b) and mean sea level pressure (MSLP; Figs. 6.5c,d). In general, annual $P-E$ anomalies over the high interior of the continent were small (within $\pm 50 \mathrm{~mm} \mathrm{yr}^{-1}$ ); much larger anomalies were observed along the coast, consistent with the low and high net accumulation in these regions. From JRA-55, both 2018 and 2017 - annual anomalies display some spatial similarity over the interior Antarctic continent. The weak 2017 anomalies located along the coast between Queen Maud Land and Mac. Robertson Land (between $5^{\circ} \mathrm{W}$ and $70^{\circ} \mathrm{E}$ ) were replaced by positive and negative anomaly centers in 2018 . The most pronounced positive center was located over Enderby Land $\left(\sim 45^{\circ} \mathrm{E}\right)$. Both Queen Mary Land and Wilkes Land (between $90^{\circ}$ and $125^{\circ} \mathrm{E}$ ) continued to have strong negative net accumulation anomalies in 2018. These are more extensive than in 2017 and have replaced a small positive anomaly for Princess Elizabeth Land $\left(\sim 80^{\circ} \mathrm{E}\right)$ observed in 2017 . The weak negative anomalies over Adélie Land and Victoria Land (between $125^{\circ}$ and $165^{\circ} \mathrm{E}$ ) became weak positive ones in 2018. The Ross Ice Shelf, which had a positive anomaly in 2017, had a weak negative anomaly in 2018. The Amundsen and Bellingshausen coastal areas, which had small negative anomalies in 2017 (between $150^{\circ}$ and $70^{\circ} \mathrm{W}$ ), had the second largest 2018 negative anomalies. The observed dipole anomaly patterns over two sides of the Antarctic Peninsula in 2017 were replaced by positive anomalies, especially on the west side. Weakly negative 2017 anomalies over the Weddell Sea coast were replaced by significantly positive values during 2018.

These annual $P-E$ anomaly features are generally consistent with the mean annual atmospheric circulation implied by the MSLP anomalies (Figs. $6.5 \mathrm{c}, \mathrm{d}$ ). In general, the 2018 annual MSLP anomalies surrounding Antarctica were more regionalized and of higher amplitude than in 2017, with strong seasonal variations during 2018 (e.g., Fig. 6.3). The observed negative anomalies over the Weddell Sea in late 2017 amplified and expanded, covering most of the Southern Ocean in early 2018 (see Fig. 6.3a). The largest negative anomaly center was in the Bellingshausen Sea (March-May), then later in the Amundsen Sea (June-August), then the Ross Sea (September-November) as the seasons progressed (Figs. 6.3b-e). A secondary negative MSLP anomaly was present along the Antarctic coast between $100^{\circ}$ and $165^{\circ} \mathrm{E}$ through 2018 (Fig. 6.5c). These seasonal variations in MSLP, when annually averaged, resulted in two large negative anomaly centers over the Bellingshausen Sea and near the coast of Adélie Land and a secondary negative anomaly center over the Weddell Sea. The annual negative anomalies produced strong onshore and offshore flows at the Antarctic coast, resulting in large $P-E$ changes in 2018 (Fig. 6.5a): positive anomalies near $150^{\circ} \mathrm{E}, 60^{\circ} \mathrm{W}$, and $15^{\circ} \mathrm{W}$, and negative anomalies near $105^{\circ} \mathrm{E}$ and $120^{\circ} \mathrm{W}$.

Earlier studies (e.g., Cullather et al. 1998; Tsukernik and Lynch 2013) show that most of the moisture transport into the interior of Antarctica occurs in the West Antarctic sector. Moisture transport shows large interannual variability associated with variations of ENSO (e.g., Bromwich et al. 2004) and SAM (e.g., Fogt et al. 2011). Figure 6.5e shows the time series (with 6-month running means) of monthly total $P-E$ over Marie Byrd Land-Ross Ice Shelf $\left(75^{\circ}-90^{\circ} \mathrm{S}\right.$, $120^{\circ} \mathrm{W}-180^{\circ}$ ) and the monthly Equatorial Southern Oscillation index (EQ-SOI) and SAM indices. The EQ-SOI is used here to represent ENSO events (negative EQ-SOI signifies El Niño events). The EQ-SOI is a standardized sea level pressure difference between the eastern Pacific $\left(5^{\circ} \mathrm{N}-5^{\circ} \mathrm{S}, 80^{\circ}-130^{\circ} \mathrm{W}\right)$ and Indonesia (the western Pacific; $5^{\circ} \mathrm{N}-5^{\circ} \mathrm{S}, 90^{\circ}-140^{\circ} \mathrm{E}$ ) and is centered on the equator.

It is clear that the climate patterns indicated by EQ-SOI and SAM were in-phase (simultaneous La Niña and positive SAM) but had opposite behavior to $P-E$ (less total precipitation) in most months from 2010 to early 2011 (Fig. 6.5e). From then until early 2017, EQ-SOI and SAM fluctuated on the time scale of a few months (weakly in-phase fluctuations except for the large out-of-phase fluctuation from late 2014 to early 2016). Thus, during mid-2011 to mid-2017, EQ-SOI and SAM were often offsetting factors modulating precipitation, resulting in little net change in total $P$ - E. In late 2017 and early 2018, the EQ-SOI and SAM indices returned to a strong in-phase pattern, and again $P-E$ showed a large decrease. 
2018

(a) $45^{\circ} \mathrm{W}$ 30\% $15^{\circ} \mathrm{W}$ O० $15^{\circ} \mathrm{W} 30^{\circ} \mathrm{E} \quad 45^{\circ} \mathrm{E}$
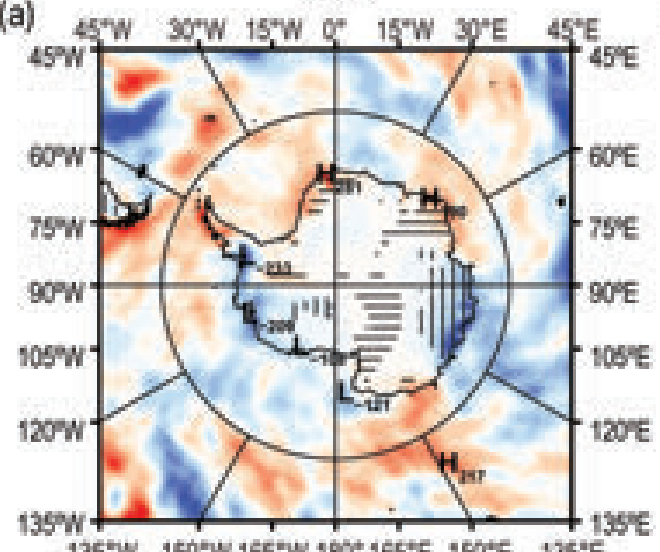

$135^{\circ} \mathrm{W} 150^{\circ} \mathrm{W} 165^{\circ} \mathrm{W} 180^{\circ} 165^{\circ} \mathrm{E}$ 150'E $135^{\circ} \mathrm{E}$

(c)

c) $45^{\circ} \mathrm{W} \quad 30^{\circ} \mathrm{W} 15^{\circ} \mathrm{W} \quad 0^{\circ} \quad 15^{\circ} \mathrm{W} \quad 30^{\circ} \mathrm{E} \quad 45^{\circ} \mathrm{E}$

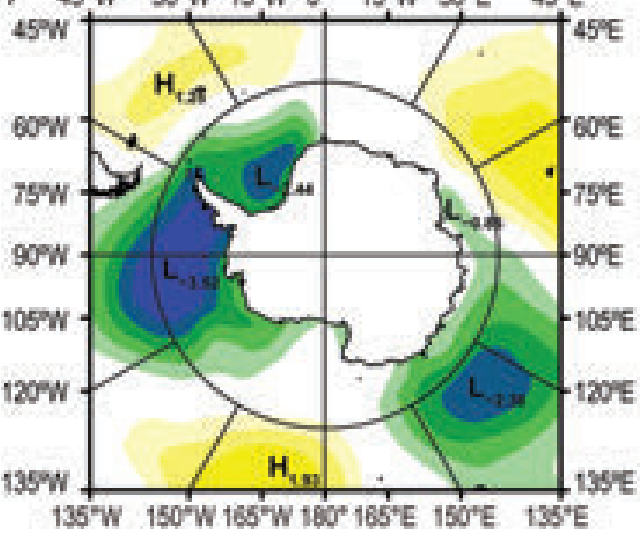

2017

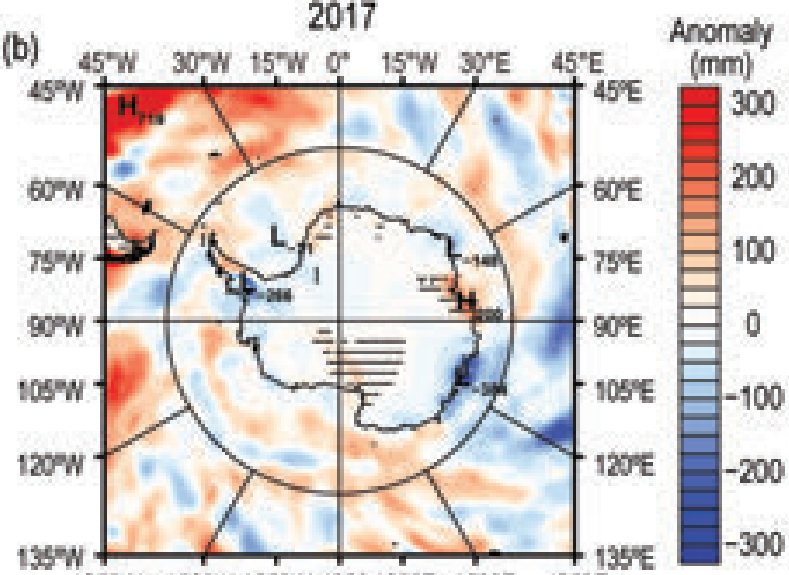

$135^{\circ} \mathrm{W} 150^{\circ} \mathrm{W} 165^{\circ} \mathrm{W} 160^{\circ} 165^{\circ} \mathrm{E}$ 150"E $135^{\circ} \mathrm{E}$

(d)

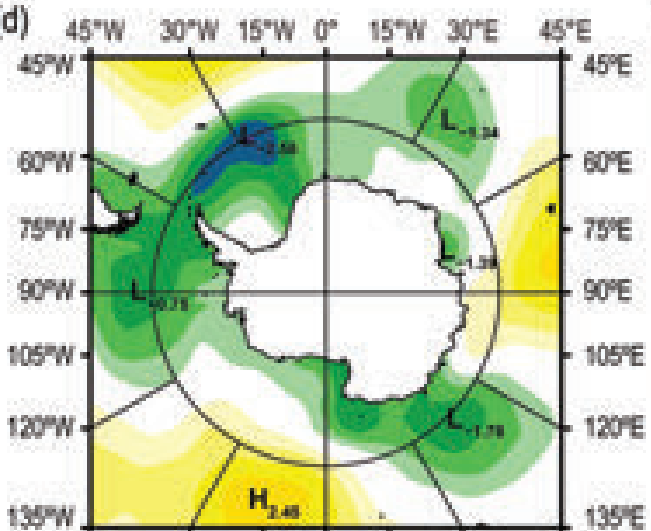

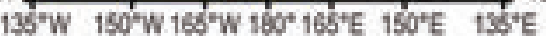

Anomaly

(hPa)

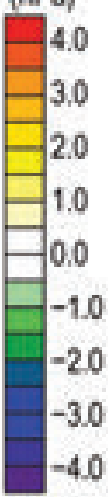

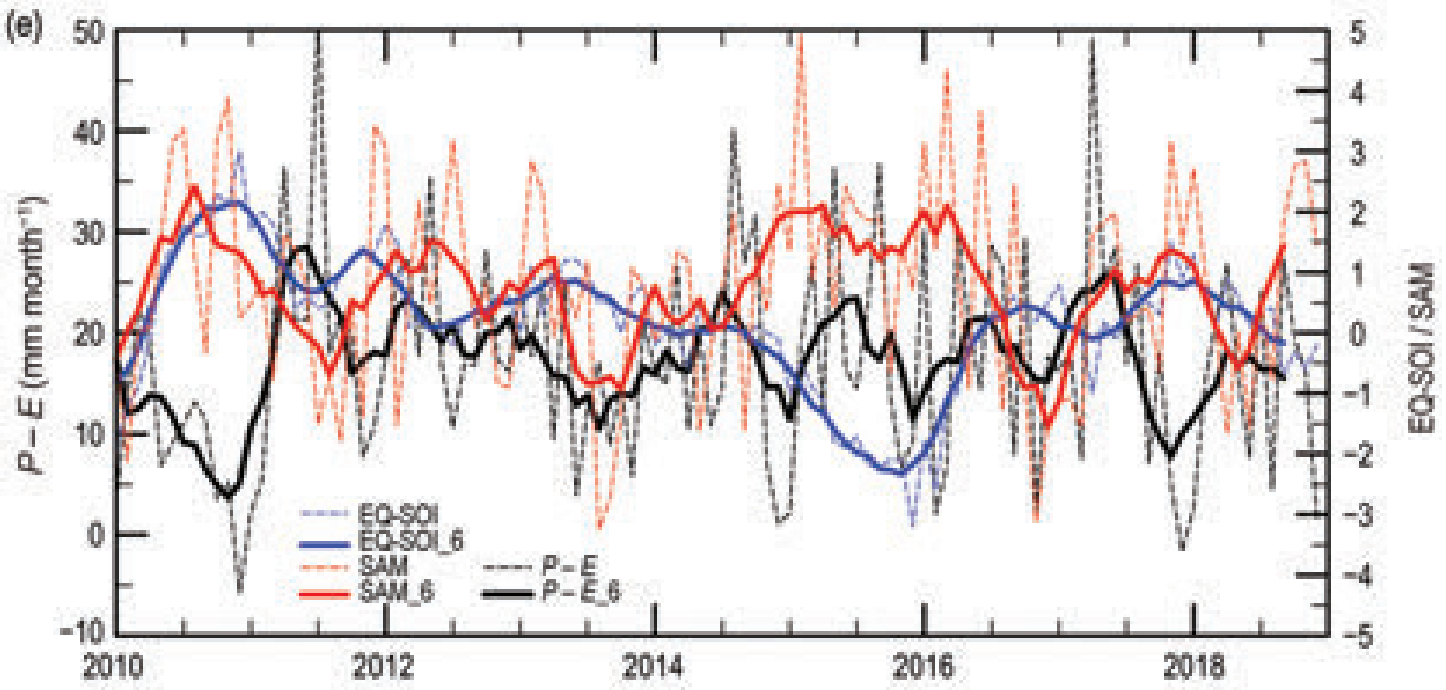

FIG. 6.5. Annual precipitation minus evaporation $(P-E)$ and MSLP anomalies: (a) $2018 P-E$ anomaly $(\mathrm{mm})$; (b) $2017 \mathrm{P}-E$ anomaly $(\mathrm{mm})$. Antarctic regions with $> \pm 30 \%$ departure from the reference mean are hatched; vertical denotes negative anomaly and horizontal is positive. (c) $2018 \mathrm{MSLP}$ anomaly (hPa); and (d) $2017 \mathrm{MSLP}$ anomaly (hPa). All anomalies are calculated with respect to 198I-2010 means. (e) Monthly total P-E (mm; dashed black) for part of West Antarctica bounded by $75^{\circ}-90^{\circ} \mathrm{S}, 120^{\circ} \mathrm{W}-180^{\circ}$, along with index trends for EQ-SOI (dashed blue, from NOAA CPC) and SAM (dashed red, from Marshall 2003). Centered 6-month running means are plotted as solid lines. 
d. Seasonal melt extent and duration-L. Wang and H. Liu

Patterns in ice sheet surface melt intensity, particularly at the continental ice margins, reflect regional and global climate change and variability. Surface melt intensity is derived from satellite passive microwave data obtained since 1978 and is associated with the number of days above melting temperature (Zwally and Fiegles 1994). Increased surface melt intensity, particularly along the coast, leads to increased percolating melt water and, in extreme cases (unusual in most of Antarctica), melt runoff (Kingslake et al. 2018). The intensity, duration, and spatial extent of surface melt can contribute to the enlargement of ice crevasses (Scambos et al. 2000), accelerated glacier ice flow (Zwally et al. 2002), and disintegration of ice tongues and ice shelves (van den Broeke 2005).

Daily passive microwave brightness temperatures for the 2017/18 austral summer melt season are from the $19 \mathrm{GHz}$ channel of the SSMIS (Special Sensor Microwave Imager Sounder) onboard the DMSP-F17 satellite (ascending passes only). The preprocessed data were obtained from NSIDC as level-3 EqualArea Scalable Earth Grid (EASE-Grid) format grids (Armstrong et al. 1994) and analyzed using a wavelet transform-based edge detection method (Liu et al.
Figure 6.6a shows that surface melt first occurred on the Antarctic Peninsula and Wilkins Ice Shelf early in the 2017/18 melt season. However, this initial melting occurred later in the season (November) than is typical for this area (mid-October is common). The continent's melt season ended earlier than in other years (Fig. 6.6b), with only the tip of the Antarctic Peninsula remaining active in March 2018 and other areas ending before February 2018. Ice shelf areas having an extended melt season ( $>45$ day duration, in orange-red) were Larsen, Wilkins, and Shackleton (Fig. 6.6c). Areas with moderate melt duration (greenyellow) included coastal Queen Maud Land and the Abbot and Amery ice shelves. Sporadic short-term melt duration $(<16$ day, blue color) occurred on the Ross Ice Shelf but with limited areal extent. Compared to 2016/17, the melt area on the Ross Ice Shelf was much smaller.

The melt anomaly map (Fig. 6.6d) shows a generally shorter melt season compared to the historical average. Therefore, austral summer 2017/18 is classified as a low melt year for Antarctica. Three regional exceptions were portions of Queen Maud Land and the northern tip and southwest sectors of the Antarctic Peninsula, which had more than eight days 2005). The first melt event observed after 1 October is the start day of the melt season (Fig. 6.6a), and the last melt event detected is the end day of the melt season (Fig. 6.6b). Melt duration is then the total number of days indicating melt between these two dates (Fig. 6.6c). The duration anomaly map (Fig. 6.6d) was created relative to the 1981-2010 mean melt duration.

Melt extent and melt index (Fig. 6.7) are useful metrics for quantifying the interannual variability in surface melt (Zwally and Fiegles 1994; Liu et al. 2006). Melt extent (in $\mathrm{km}^{2}$ ) is the total area that experienced surface melt for at least one day during the melt season. Melt index (in day. $\mathrm{km}^{2}$ ) is the sum of the daily melt extents for Antarctica for the entire season.

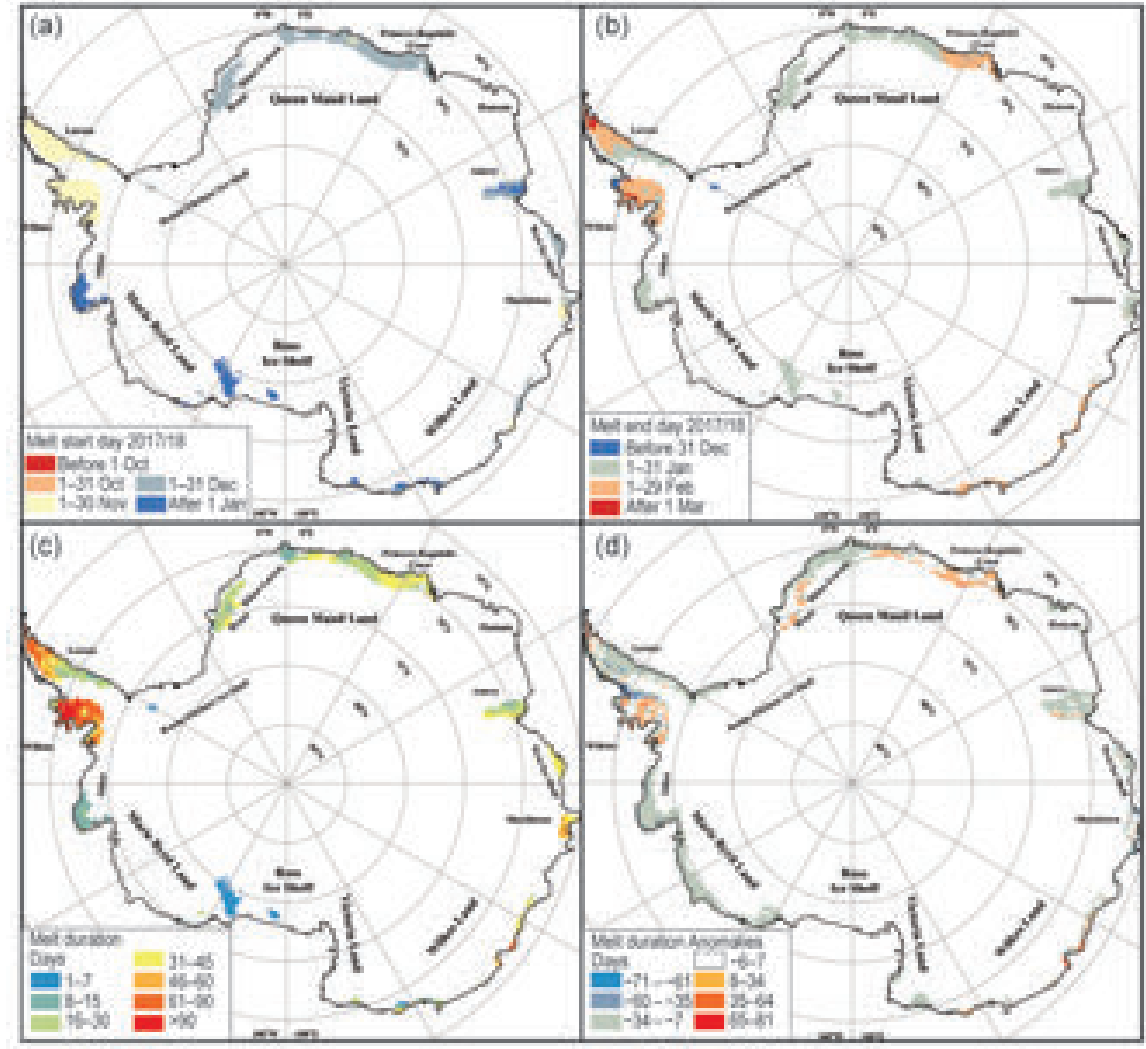

Fig. 6.6. Estimated surface melt for the 2017/18 austral summer: (a) melt start day, (b) melt end day, (c) melt duration (days), and (d) melt duration anomalies (days, 198I-2010 base period). 


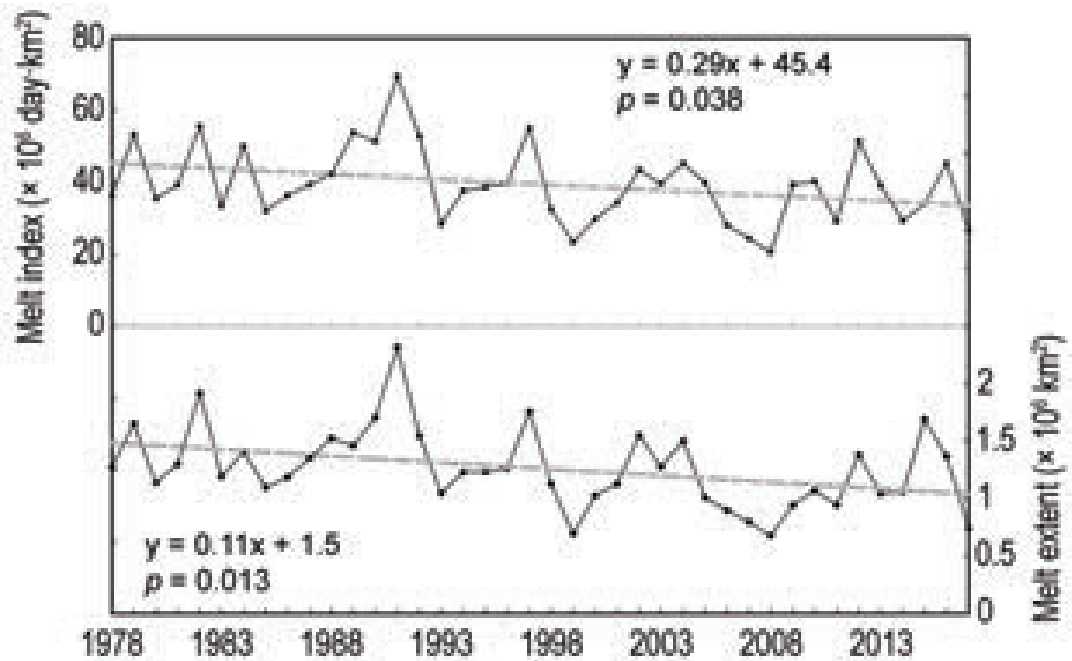

FIG. 6.7. Upper panel: Melt index for Antarctica $\left(\times 10^{6} \mathrm{day} \mathrm{km}^{2}\right)$ from

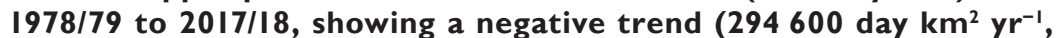
$p<0.05)$. Lower panel: Melt extent $\left(\times 10^{6} \mathrm{~km}^{2}\right)$ from $1978 / 79$ to $2017 / 18$, showing a negative trend $\left(1 / 400 \mathrm{~km}^{2} \mathrm{yr}^{-1}, p<0.05\right)$. A record low melt was observed during $\mathbf{2 0 0 8 / 0 9}$. The year marked on the $\mathbf{x}$-axis corresponds to the start of the austral summer, for example, 2008 corresponds to austral summer of $2008 / 09$.

positive anomaly, coinciding with the positive $2-\mathrm{m}$ temperature anomalies observed in this area during October-December 2017 (Fig. 6.3h in Clem et al. 2018), along with much smaller pockets elsewhere along East Antarctica.

The low melt year of 2017/18 continues a downward trend observed in both melt extent and melt intensity since 1978 , trends that are now statistically significant ( $p<0.05$; Fig. 6.7). Since 1978 melt extent has decreased on average $11400 \mathrm{~km}^{2}$ per year and the melt index by 294600 day.km ${ }^{2}$ per year. Year 2017/18 had the third smallest melt extent and fourth lowest melt intensity in the satellite record (1978-present). These observed negative trends are consistent with previous reports (Liu et al. 2006; Tedesco 2009; Tedesco et al. 2009).

e. Sea ice extent, concentration, and seasonality - P. Reid, S. Stammerjohn, R. A. Massom, S. Barreira, T. Scambos, and J. L. Lieser

Antarctic sea ice plays a pivotal role in the global climate system. Forming a highly-dynamic reflective and insulative blanket that varies seasonally from $\sim 3$ to $\sim 20 \times 10^{6} \mathrm{~km}^{2}$, sea ice and its snow cover strongly modify ocean-atmosphere fluxes and interaction processes (Bourassa et al. 2013). Moreover, brine rejection into the underlying ocean during sea ice formation leads to the generation of Antarctic Bottom Water in areas of high sea ice production that contributes to the global ocean overturning circula- tion (Johnson 2008). Antarctic sea ice also acts as a protective buffer for ice shelves against potentially destructive ocean swells (Massom et al. 2018) and modulates the interaction of warm deep waters with ice shelf basal cavities to affect melt there (Timmermann and Hellmer 2013; Stewart et al. 2019).

After record high values during 2014, Antarctic sea ice extent exhibited low annual maxima in September 2016, 2017, and 2018. Net sea ice extent has been below the 1981-2010 average since midSeptember 2016 (Fig. 6.8a). In 2018, the annual daily minimum $(2.15$ $\times 10^{6} \mathrm{~km}^{2}$ ) occurred on 18 February, and was the second lowest on record (behind 2017, using the 1979-present satellite mapping). The monthly mean sea ice area for December $\left(5.5 \times 10^{6} \mathrm{~km}^{2}\right)$ was the lowest for that month ever recorded. Spread throughout the year were 28 days of record low daily sea ice extent and in December alone, 17 days of record low daily sea ice area (Fig. 6.8a).

The persistence of well-below-average total sea ice extent from mid-September 2016 through the end of 2018 suggests that weather systems or atmospheric climate modes cannot fully explain the switch from persistent near-record high (e.g., 2012, 2013, 2014, and 2015 through May) to near-record low sea ice conditions (Fig. 6.8a). Rather, it points to changes in the upper ocean as being a significant contributing factor, particularly in the large basin regions (Section 6f; Lecomte et al. 2017; Swart et al. 2018; Meehl et al. 2019) - with underlying changes, such as warming near-surface waters, inhibiting sea ice growth and/or enhancing melt. However, and as in previous years, large-scale atmospheric patterns were the main factor in causing regional variations and anomalies in the 2018 sea ice coverage.

In terms of broad-scale sea ice behavior, 2018 can be divided into four fairly distinct periods: JanuaryApril; May; June to mid-October; and mid-October to December. In mid-summer to mid-autumn (January-April), well-below average net sea ice coverage was dominated by strong negative sea ice extent anomalies in the Ross Sea and central-western Weddell Sea, and latterly the western Amundsen Sea, with lower-magnitude negative anomalies also occurring in the western Pacific sector at $\sim 90^{\circ}-100^{\circ} \mathrm{E}$ (Fig. 6.8b). 
(a)

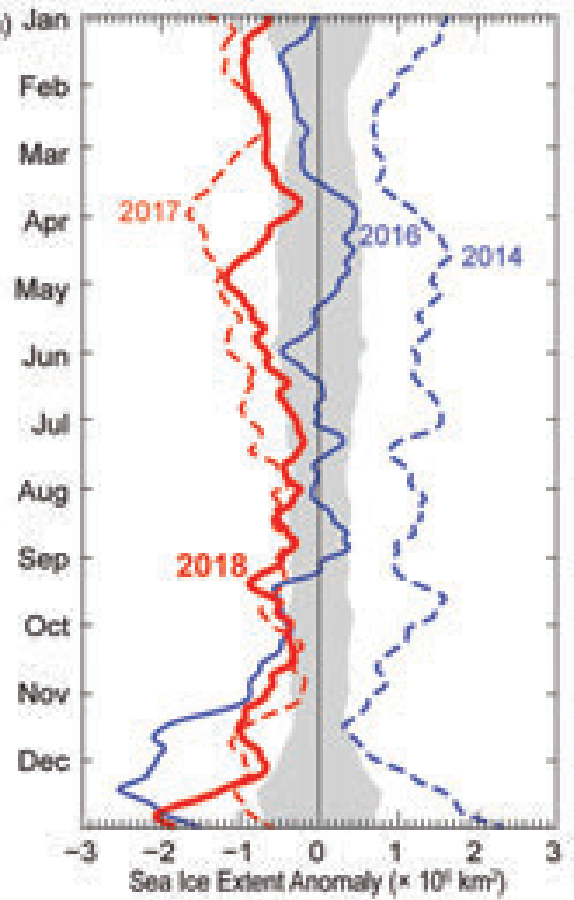

(c)

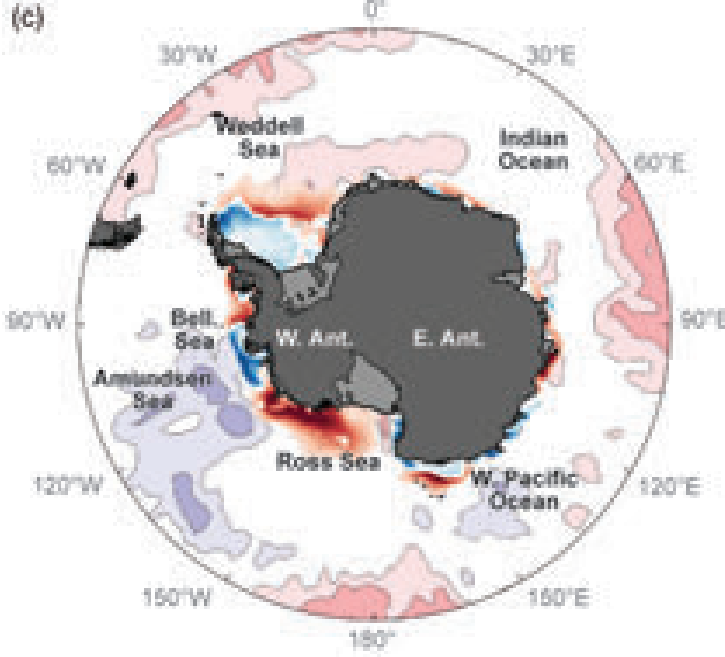

(b)

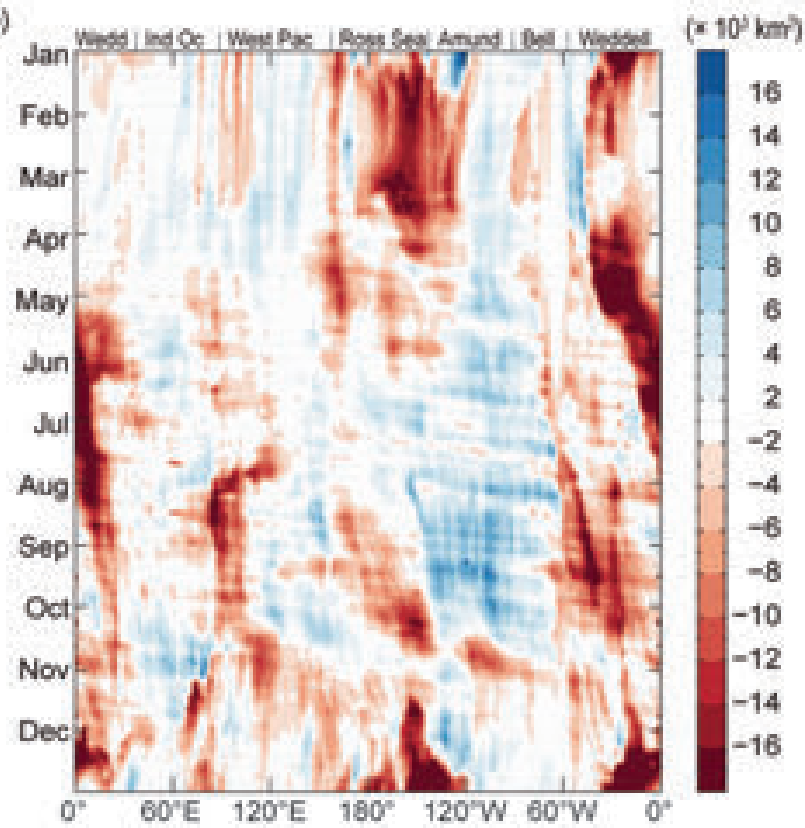

(d)

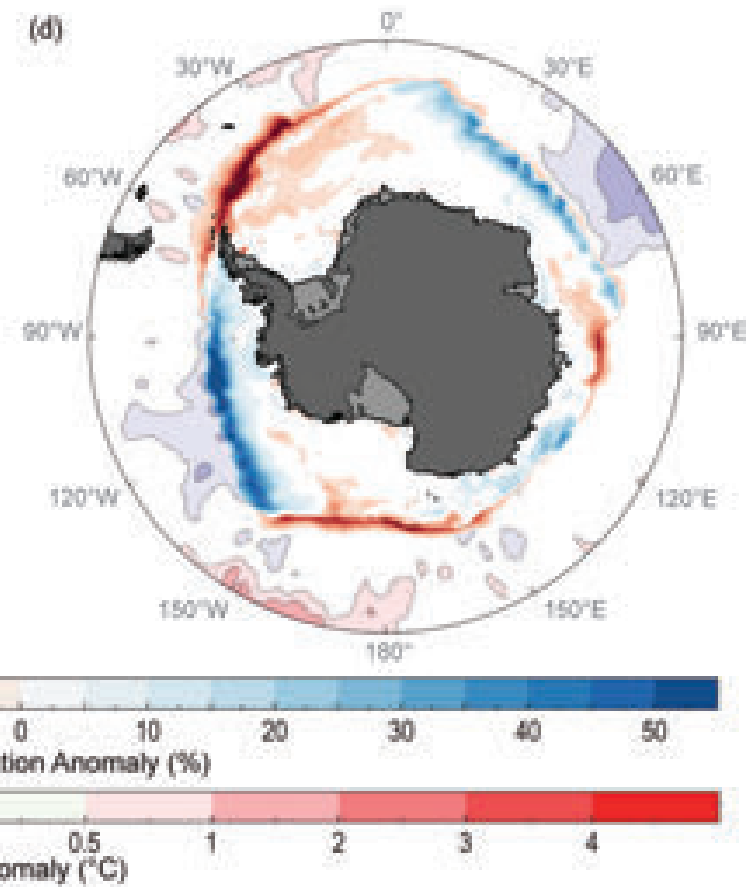

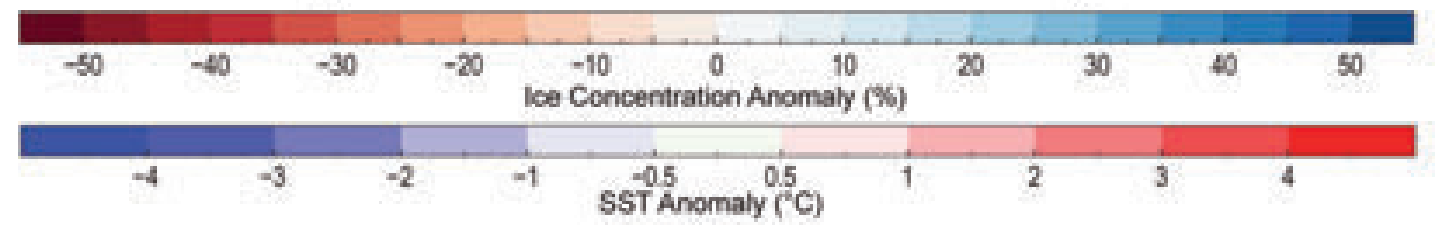

Fig. 6.8. (a) Net sea ice extent anomaly for 2014 (dashed blue line), 2016 (solid blue line), 2017 (dashed red line), and 2018 (solid red line) (from 198I-2010 climatology). The gray shading represents \pm I std. dev. of extent; (b) Hovmöller plot of sea ice extent anomalies for $2018\left(10^{3} \mathrm{~km}^{2}\right.$ per degree of longitude, from the 198I-2010 mean). Maps of sea ice concentration anomaly (\%) and SST anomaly ( ${ }^{\circ} \mathrm{C}$; Reynolds et al. 2002; Smith et al. 2008) for (c) Feb and (d) Sep 2018. "Bell." is Bellingshausen Sea. Based on satellite passive-microwave ice concentration data (Cavalieri et al. 1996, updated yearly, for climatology and Maslanik and Stroeve 1999 for the 2018 sea ice concentrations).

There was relatively extensive sea ice coverage at this time in the $\sim 100^{\circ}-140^{\circ} \mathrm{E}$ region and, notably, in the eastern Amundsen Sea and western Bellingshausen Sea. The relatively high ice concentrations in the West
Antarctic region in particular (Fig. 6.8c) imply winddriven compaction and/or enhanced freezing due to the presence of colder surface waters. Indeed, belownormal SSTs (e.g., Fig. 6.8c, Fig. 6.10b) and relatively 
fresh waters (e.g., Fig. 6.10c) were present adjacent to the ice edge in the Amundsen Sea region, with the former first appearing in September 2017 (see Fig. $6.8 \mathrm{~d}$ in Reid et al. 2018); this cold pool persisted to the end of 2018.

A change in sea ice coverage occurred during May, with the region of lower-than-normal sea ice extent transitioning from the western to the eastern Weddell Sea in response to a shift in synoptic low-pressure activity from the Amundsen Sea into the Weddell Sea region (e.g., Figs. 6.3a,b). The positive sea ice extent anomaly in the Amundsen Sea expanded into the western Bellingshausen Sea and eastern Ross Sea, while sea ice advance elsewhere was later than normal (Fig. 6.9a).

Following these events and continuing into June, sea ice expansion in the Weddell Sea was slower than average. The negative sea ice extent anomaly in the western Weddell Sea from $\sim 55^{\circ}-5^{\circ} \mathrm{W}$ displayed an eastward progression (Fig. 6.8b) that mirrors the climatological pattern of zonal sea ice transport from the western to the eastern Weddell Sea from June through November (Kimura and Wakatsuchi 2011). At the same time, there was an eastward progression of a negative sea ice extent anomaly from the eastern Bellingshausen Sea to the west-central Weddell Sea. From June through the end of the year, sea ice extent was also low across the Weddell Sea sector, from $\sim 60^{\circ} \mathrm{W}$ eastward to $\sim 30^{\circ} \mathrm{E}$ (Fig. 6.8d). The year 2018 saw no reoccurrence of the midseason Maud Polynya observed in the previous two years (Swart et al. 2018), although several late-season open-ocean polynyas developed in the central Weddell Sea pack ice from late November onward as a result of early sea ice retreat within this region (Fig. 6.9b).

The deep Amundsen Sea low-pressure system that developed in June (Section 6b) generally persisted through the end of the year. Its presence is likely responsible for the positive anomaly in mid-season ice edge advance over a broad band of the Pacific sector (from $\sim 120^{\circ} \mathrm{E}$ eastward to $75^{\circ} \mathrm{W}$; Fig. 6.8b, Fig. 6.9a). Another mid-season positive anomaly in ice edge advance was observed across a relatively narrow band in the Indian Ocean sector $\left(\sim 30^{\circ}-60^{\circ} \mathrm{E}\right)$.

Regional sea ice extent (Fig. 6.8b) and seasonal retreat (Fig. 6.9b) were subsequently affected by several variations in the large-scale atmospheric drivers (e.g., as described by Yuan et al. 2018) from mid-October onward (Section 6b; Fig. 6.3b). An atmospheric
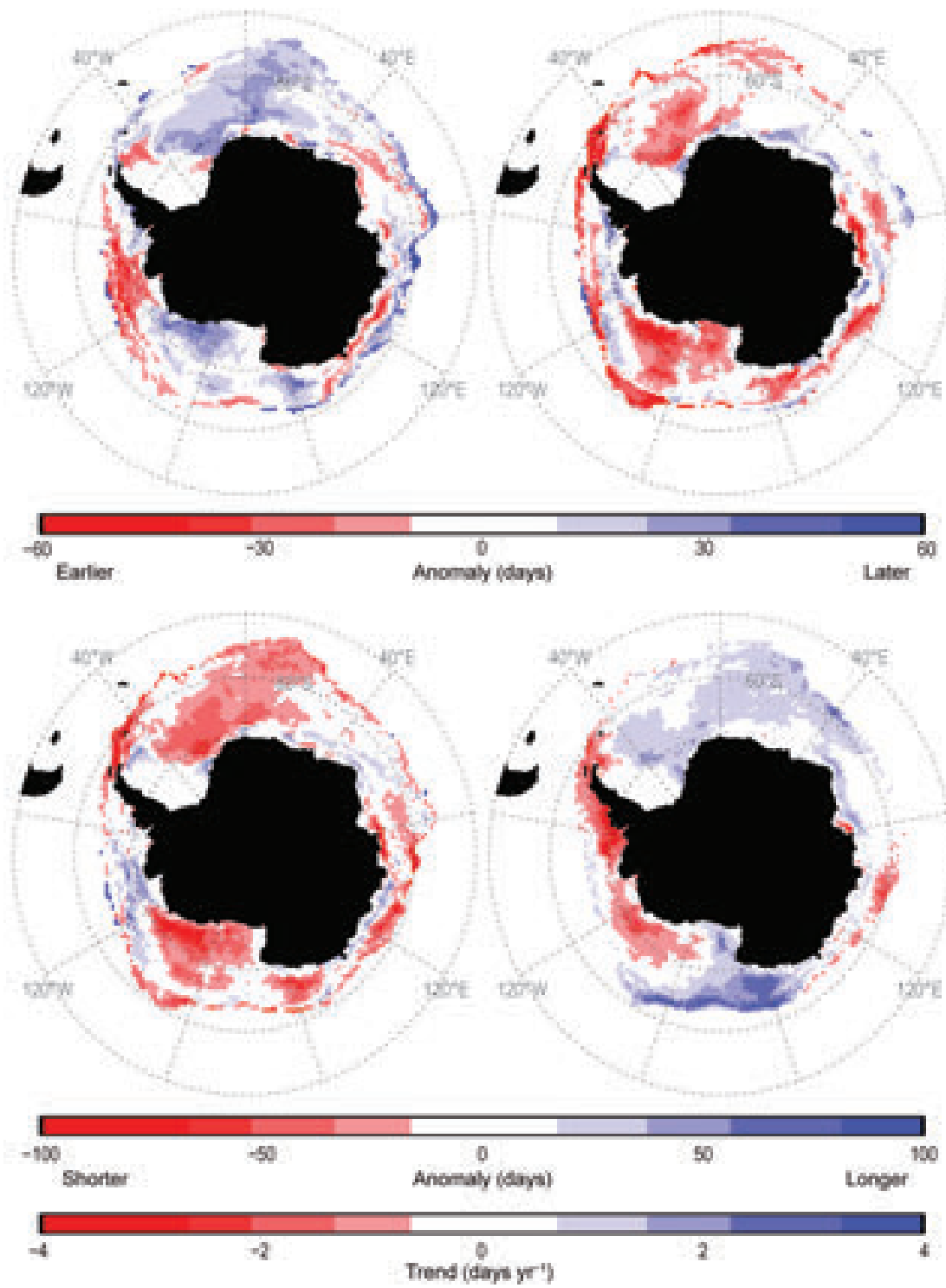

Fig. 6.9. Maps showing anomalies of days of (a) advance, (b) retreat, (c) total duration, and (d) duration trend for the 2018/19 sea ice year (Mar 2018 to Feb 2019). Both the climatology (for computing the anomaly) and trend are based on 198I/82 to 20I0/II data (Cavalieri et al. 1996, updated annualy), while the 2018/19 duration-year data are from the NASA Team NRTSI dataset (Maslanik and Stroeve 1999; Stammerjohn et al. 2008). 
wave-three pattern developed at that time, with ridges at $\sim 30^{\circ} \mathrm{E}, 160^{\circ} \mathrm{E}$, and $60^{\circ} \mathrm{W}$, which resulted in early sea ice retreat around most of the continent (Fig. 6.9b) but particularly in the Ross, Weddell, and East Amundsen Seas and the western Pacific sector (generally due to persistent warm northerly winds).

Overall, the below-average sea ice extent within the Weddell Sea and western Ross Sea in 2018 marked a strong departure from positive long-term linear trends in sea ice extent in those two regions (cf. Fig. 6.8b with Fig. 6.9c from Reid et al. 2017). A similar departure is apparent in ice season duration, with anomalously short ice seasons in 2018/19 (March 2018-February 2019) in the Weddell Sea and eastern Ross Sea (Fig. 6.9c) standing in stark contrast to the long-term positive trends observed there (Fig. 6.9d). Likewise, and along most of the western Antarctic Peninsula $\left(\sim 60^{\circ}-80^{\circ} \mathrm{W}\right)$, except the northern tip, the 2018/19 ice season was of average duration, standing in stark contrast to the long-term rapid decreases otherwise observed there. Elsewhere, the 2018/19 ice season duration anomalies (and sea ice extent anomalies from January to mid-May 2018) for (1) the western Amundsen Sea to eastern Ross Sea $\left(120^{\circ}-160^{\circ} \mathrm{W}\right)$ and (2) offshore East Antarctica between $\sim 90^{\circ}-120^{\circ} \mathrm{E}$, are consistent with the longterm trends of shorter ice season duration (Fig. 6.9d) and decreased summer-autumn sea ice extent (see Fig. 6.9c of Reid et al. 2017). However, anomalies in the eastern Amundsen Sea (spanning $\sim 80^{\circ}-150^{\circ} \mathrm{W}$ ) reflect a recovery in ice edge advance (Fig. 6.9a) and extent, with positive ice season duration and sea ice extent anomalies in 2018 contrasting with regional long-term trends there (Figs. 6.9c,d; see also Figs. 6.8a and $6.9 \mathrm{c}$ in Reid et al. 2017).

\section{f. Southern Ocean-A. Meijers, J.-B. Sallée, A. Grey, K. Johnson,} K. Arrigo, S. Swart, B. King, M. Meredith, and M. Mazloff

The Southern Ocean exerts a disproportionate influence on planetary climate due to its central role in the global overturning circulation. Here, strong upwelling, modification, and subduction of water masses result in the uptake of more than $70 \%$ and $40 \%$ of global ocean anthropogenic heat and carbon, respectively (Frölicher et al. 2015). Despite its importance, it is difficult to evaluate the state of the Southern Ocean in any given year due to the relative sparsity of ocean observations and the short historical time series against which to assess them. Satelliteborne sensors provide comprehensive measurements of the ocean surface, and autonomous instruments are beginning to address the in situ data void (e.g., Newman et al. 2015). Notable amongst the latter are state-of-the-art observations of winter $\mathrm{pH}$ that provide new insights into ocean-atmosphere carbon exchange.

\section{I) SURfaCe mixed LAyER PROPERTIES}

All available Southern Ocean hydrography data for 2018, including seal tags (MEOP April 2018), Argo floats (updated 15 December 2018), and ship-based hydrographic casts (WOA update, 15 December 2018), were combined into a coherent database comprising 38970 profiles of temperature and salinity. Anomalies in surface mixed-layer depth (MLD), temperature, and salinity, and their contributions to upper ocean

\section{SIDEBAR 6.2: RECENT DRIFT AND EVOLUTION OF LARGE ICEBERGS IN THE SOUTHERN OCEAN—A. SCARDILLI, F. CLAUS, C. A. SHUMAN, AND T. SCAMBOS}

Tabular icebergs are almost unique to the Southern Ocean because they originate from large ice shelves or ice tongues that are now nearly absent in the Northern Hemisphere. Their evolution from calving to drift to eventual disintegration illustrates many interesting aspects of both glaciology and oceanography. Several events in 2018 highlighted these iceberg processes (Figs. SB6.2a-d).

In July 2018, reports from commercial ships crossing the far southern Atlantic Ocean and Argentine Sea described several large icebergs farther north than typically encountered. Tabular icebergs generally remain south of $52^{\circ} \mathrm{S}$ (Budge and Long 2018), but reports of icebergs north of $45^{\circ} \mathrm{S}$, and, by September, as far north as $37^{\circ} \mathrm{S}$, indicated an unusual tabular iceberg drift path. In July, ice analysts at Argentina's Naval Hydrographic Service began tracking several icebergs using satellite imagery, looking back through the record for the origins of reported iceberg swarms and watching their ongoing drift, while continuing to collect ship reports. In total, approximately 25 icebergs $>1 \mathrm{~km}$ in length were identified in several regions between the Malvinas Islands (Falkland Islands), south Georgia, and Mar del Plata (Fig. SB6.2, bottom). As a result, the maximum northern limit of iceberg drift was extended by the Hydrographic Service.

The origin of the iceberg swarms is likely the breakup of several larger icebergs near the northern tip of the Antarctic Peninsula beginning in May 2018, among them icebergs B09F, B-15T, B-15Z, and A-57A. Several of these icebergs disintegrated as they reached lower latitudes (Figs. SB6.2b,d). These ruptures, or disintegration events, generated dozens of smaller icebergs that then drifted northward and northeastward. 


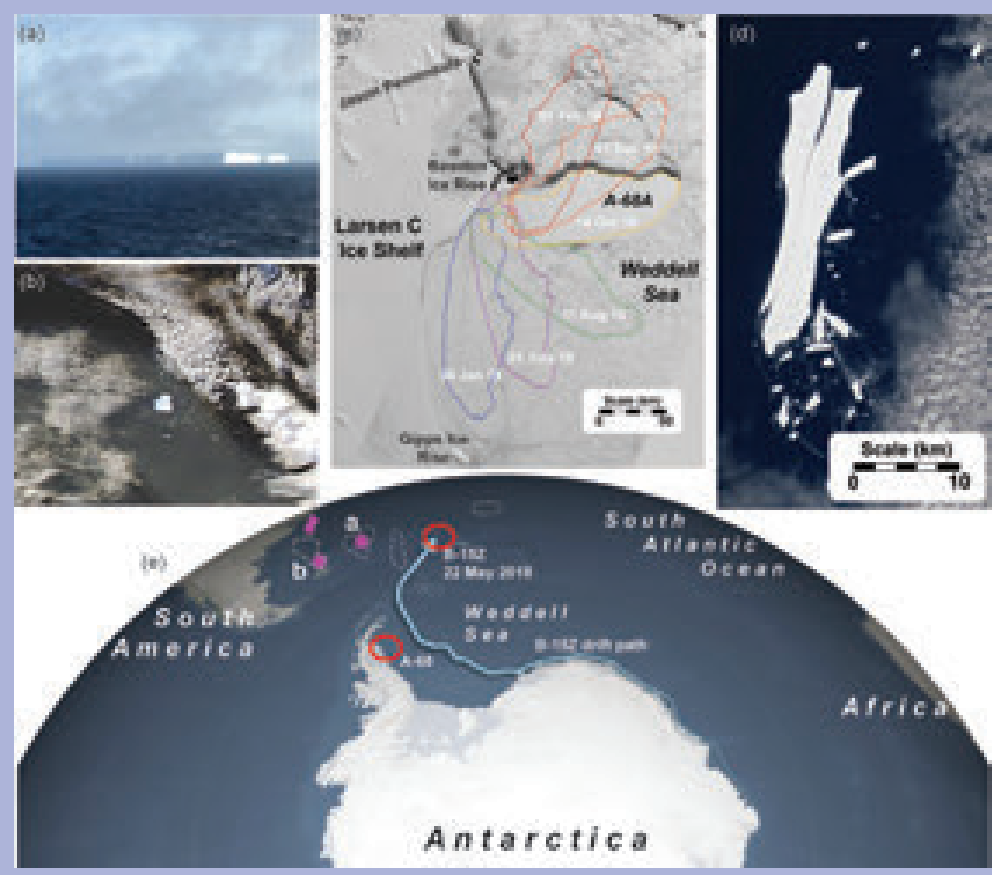

FIG. SB6.2. Bottom map: regions of the Southern Ocean and Weddell Sea with extensive iceberg activity in 2018. Dashed white areas show northernmost regions of iceberg swarms as of Sep 2018. Magenta dots indicate locations of specific icebergs in the anomalous region, with (a) and (b) locations shown in images. Red ovals indicate locations of two very large icebergs, with the recent (since 2014 ) drift path of the $\sim 18+$ year old and $\sim 170 \mathrm{~km}^{2}$ Iceberg B-I5Z (https://earthobservatory.nasa.gov/images/92238 lend-of-the-journey-for-iceberg-b-15z) shown as light blue line. (a) Photo of iceberg at $54^{\circ} \mathrm{S}$ taken from the passing bulk carrier Orient Sky; (b) MODIS Aqua image from May 2018 showing iceberg disintegration event; (c) rotation and drift of Iceberg A-68A near the Larsen C Ice Shelf front. Original position of A-68 just after calving was in the broad embayment of the Larsen $C$ just north of Gipps Ice Rise. Bawden Ice Rise (black outline) and extensive shoal area (white outline) had pinned A-68A, which rotated due to the strong northward sea ice drift and underlying current in the adjacent Weddell Sea; (d) break-up and partial disintegration of Iceberg B-I5Z captured in astronaut photo from the International Space Station (https://eol.jsc.nasa.gov/SearchPhotos/photo .pl?mission=ISS055\&roll=E\&frame=74583).

Iceberg disintegration is likely due to processes similar to ice shelf disintegration (Scambos et al. 2008; Wagner et al. 2014; Massom et al. 2018), proceeding from water-line erosion and bottom crevassing to hydrofracture-driven collapse as surface melt saturates the overlying snow and firn layers.

Using satellite image analysis, sea surface and air temperatures from both reanalysis and in situ observations, as well as surface ocean current measurements, we infer that the anomalous northward drift of the icebergs was likely a result of a combination of the following factors: the presence of large icebergs outside the sea ice field during austral winter; seasonally below-average air and ocean surface temperatures (prolonging iceberg stability); and a more rapid advection than is typical by the Malvinas Current. This unusual situation, with many large icebergs in the Argentine Sea (and, inevitably, the more numerous and thus dangerous smaller pieces) was of great concern for shipping safety, because icebergs and smaller ice blocks are rarely anticipated in this area.

At the opposite end of iceberg life cycle is the A-68 iceberg, a $5800 \mathrm{~km}^{2}$ berg that calved from the Larsen C ice shelf in July 2017. In 2018 , A-68A (the largest piece of the initial iceberg) ran aground and pivoted around a small ice rise and shoal just north of its original calving location from the Larsen C Ice Shelf. This is typical of the initial drift patterns of many large icebergs, because their draft can extend more than $250 \mathrm{~m}$ below the surface. The Bawden Ice Rise is a stabilizing pinning point for the Larsen $\mathrm{C}$ Ice Shelf (Borstad et al. 20/3). The extensive shoal to the east and north was recognized from earlier groundings of small icebergs over the past several years (Lavoie et al. 2016). Over the course of 2018 and in early 2019, northward drift of sea ice and the western boundary current of the Weddell Sea forced the massive berg to rotate by nearly $180^{\circ}$ around a shallow seabed area beneath what was its initial seaward edge (Fig. SB6.2c). The $\sim 170-\mathrm{km}$ long iceberg finally cleared the submarine obstruction by March 2019.

All information related to the position of icebergs in the Argentine Sea and adjacent areas of the Southern Ocean and sea ice field is broadcast to navigators via SafetyNet, NAVTEX, and through the website www.hidro.gob.ar.

Further information on iceberg locations worldwide is reported at the U.S. Navy/NOAA/Coast Guard National Ice Center (www.natice.noaa.gov/pub/icebergs/lceberg_Tabular .pdf) and at Brigham Young University's Antarctic Iceberg Tracking Database (www.scp.byu.edu/data/iceberg). Note, the National Ice Center also announces specific events such as such as initial calvings and subsequent breakup of icebergs (www.natice.noaa.gov). 
stability were computed relative to the climatological (2000-10) seasonal cycle (Figs. 6.10a-e). In 2018, the MLD was up to $100 \mathrm{~m}$ deeper than average in the Pacific east of $120^{\circ} \mathrm{W}$. This contrasts with the west Pacific MLD where there was a trend toward net shoaling. The split across the Pacific MLDs appears to be driven by mixed-layer temperatures that were anomalously high in the west and low in the east, with respective increases and decreases in vertical stability (Fig. 6.10d). Such a mode of variability in the South Pacific was observed by Cerovečki et al. (2019 in press), who suggest it may be wind-driven and related to the relative phases of the SAM and ENSO atmospheric modes. The 2018 Southern Ocean temperature anomaly exhibited an almost identically opposite quadrupole pattern to that observed in 2016 (Mazloff et al. 2017). In 2016, both SAM and ENSO were strongly positive, whereas SAM and ENSO were largely out of phase and weak over most of 2018 (after a period of in-phase condition early in the year; Fig. 6.5e; note that SOI and ENSO indices have opposite sign for El Niño and La Niña). Elsewhere, there was weak MLD shoaling in the Atlantic sector associated with strong mixed-layer warming of up to $2.5^{\circ} \mathrm{C}$ north of the polar front, contrasting with strong cold anomalies seen in this same sector in 2017 (Swart et al. 2018).

South of the polar front there was a consistent circumpolar deepening of the MLD in 2018, which appears to be associated with an increase in salinity. This increased salinity may be due to enhanced entrainment from below by the deeper mixed layers or reduced freshwater export by the largely reduced sea ice extent in 2018 (Section 6e, Fig. 6.9c). The increase in salinity is particularly strong in the Pacific sector and extends farther to the east than a similar positive salinity anomaly seen in 2017 , suggesting a possible advective influence. This salinification also contributed to a reduction in the stability of the upper ocean north of the sea ice edge in the Ross Sea sector, as well as farther north in the Tasman Sea and western Pacific (Fig. 6.10e). The reduced mixed-layer stability over Maud Rise $\left(\sim 66^{\circ} \mathrm{S}, 3^{\circ} \mathrm{E}\right)$ is notable given the large open-ocean polynya present there in 2016-17 (Swart et al. 2018), and suggests that it may continue to impact the region despite not appearing in 2018.

\section{2) OCEAN COLOR: PHYTOPLANKTON ABUNDANCE}

Phytoplankton abundance, as indicated by chlorophyll $a$-concentration, was slightly higher in the 2017/18 growing season (July 2017-June 2018) than the 20-year climatological mean (1998-2018), but well within the bounds of natural variation. This con- tinues a long-term trend of increasing phytoplankton abundance that has been observed since 1998 (Arrigo et al. 2008). Both the largest decreases and increases in mean surface chlorophyll- $a$ in 2017/18 (Fig. $6.10 \mathrm{~g}$ ) relative to the climatological mean (Fig. 6.10f) were observed in the Ross Sea-the decrease on the continental shelf associated with the Ross Sea polynya (where the sea ice edge retreat in 2017/18 was exceptionally early; Reid et al. 2018), and the increase in coastal waters of the eastern and western Ross Sea. This is consistent with the Ross Sea being both highly productive and highly variable. The generally productive coastal polynyas around the Antarctic continent were less productive in 2017/18 compared with the 1998-2018 climatology, likely due to an unusually early spring-summer ice edge retreat in 2017/18 (Reid et al. 2018).

\section{3) AIR-SeA CARbON DIOXIDE fLUXES}

Observation-based flux estimates for this critical region have traditionally relied on sparse and seasonally biased shipboard measurements. Autonomous biogeochemical-Argo floats, deployed by the Southern Ocean Carbon and Climate Observations and Modelling (SOCCOM) project, now provide year-round observations of $\mathrm{pH}$, oxygen, nitrate, and ocean optics in the upper $2000 \mathrm{~m}$ of the open ocean (Johnson et al. 2017), permitting new estimates of air-sea $\mathrm{CO}_{2}$ fluxes (Gray et al. 2018). Including 2018, the SOCCOM data span four full years, presenting the first opportunity to examine interannual variability in these flux estimates.

Overall, the Southern Ocean appears to have absorbed more $\mathrm{CO}_{2}$ in 2018 than the 2015-18 average, with four of five regions showing increased uptake or reduced outgassing (Fig. 6.11). The largest difference occurred in the Subantarctic Zone (SAZ), where substantially more $\mathrm{CO}_{2}$ uptake occurred in 2018. The strong wintertime outgassing revealed by the float observations in the high-latitude Antarctic Southern Zone (ASZ) during 2015-17 was reduced slightly in 2018. Given that the 2015-17 float-based carbon flux estimates are well outside the range of variability in ship-based estimates (Le Quere et al. 2018; Gray et al. 2018), these results suggest a shift toward increased carbon uptake by the Southern Ocean in 2018, notwithstanding the persistence of strong wintertime outgassing south of the polar front. However, any assessment of interannual variability at present is limited by the number of observations and their spatial and temporal coverage. 

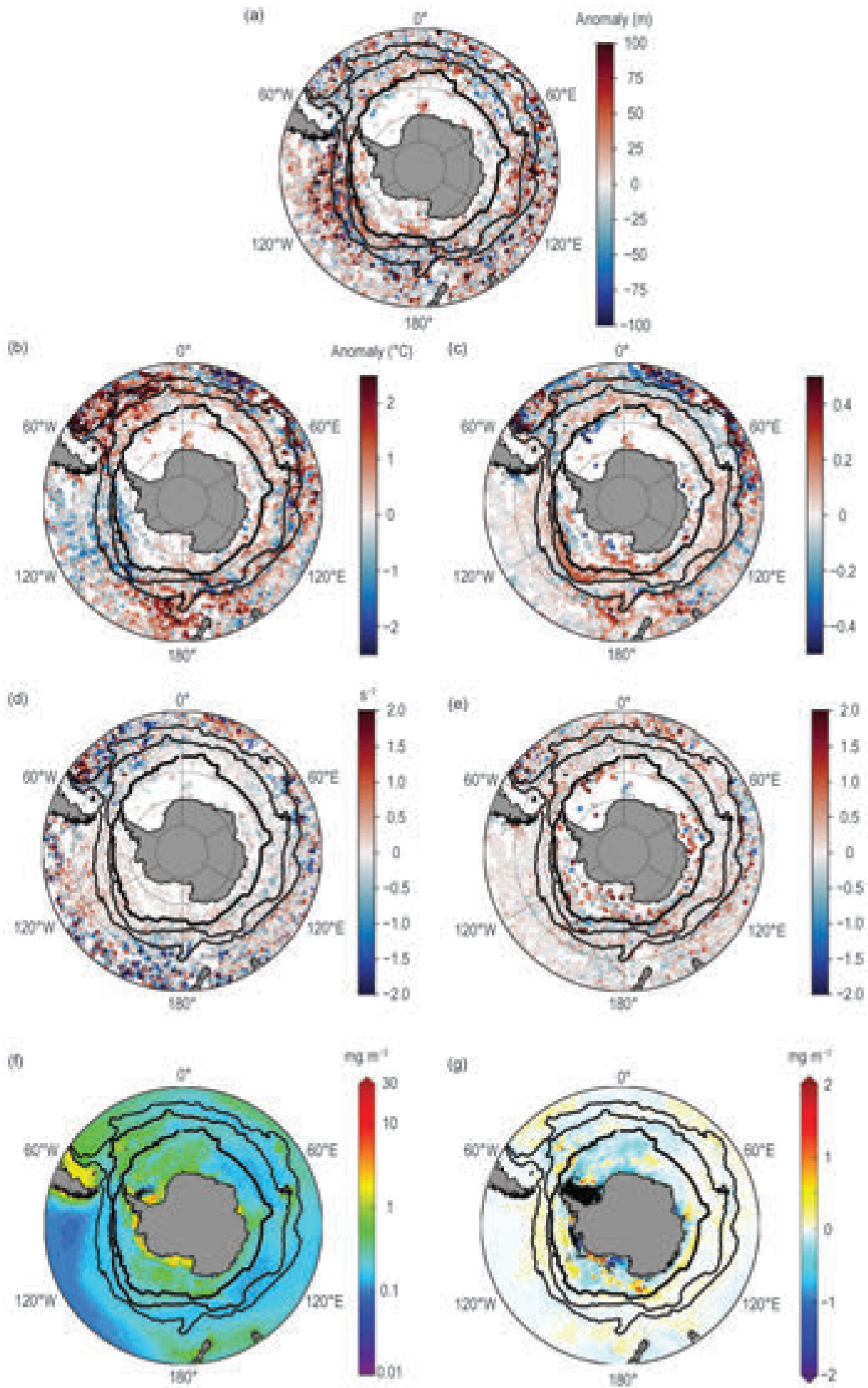

Fig. 6.10. (a) Mixed layer depth anomalies $(\mathrm{m})$ in 2018 from the 2000-10 climatological seasonal cycle. Northto-south, the black contours represent the Subantarctic Front and Polar Front (Kim and Orsi 2014) and the Sep 2018 monthly mean I5\% sea ice concentration limit from the NCEP-2 Reanalysis (Kanamitsu et al. 2002). (b) Same as (a) but for mixed layer conservative temperature $\left({ }^{\circ} \mathrm{C}\right)$. (c) Same as (a) but for mixed layer absolute salinity. (d) Same as (a) but for temperature contribution to stability $\left(\mathrm{N}^{2}\right)$ in a $15-\mathrm{m}$ layer immediately below the mixed layer $\left(\mathrm{s}^{-2}\right)$. (e) Same as for (d) but for salinity contributions. Mixed layer characteristics are computed as in Pellichero et al. (2017). (f) Climatological mean surface chlorophyll-a concentration $\left(\mathrm{mg} \mathrm{m}^{-3}\right)$ for 1998-2018, and $(\mathrm{g})$ anomaly of the austral summer bloom (2017//8) relative to the climatological mean. 

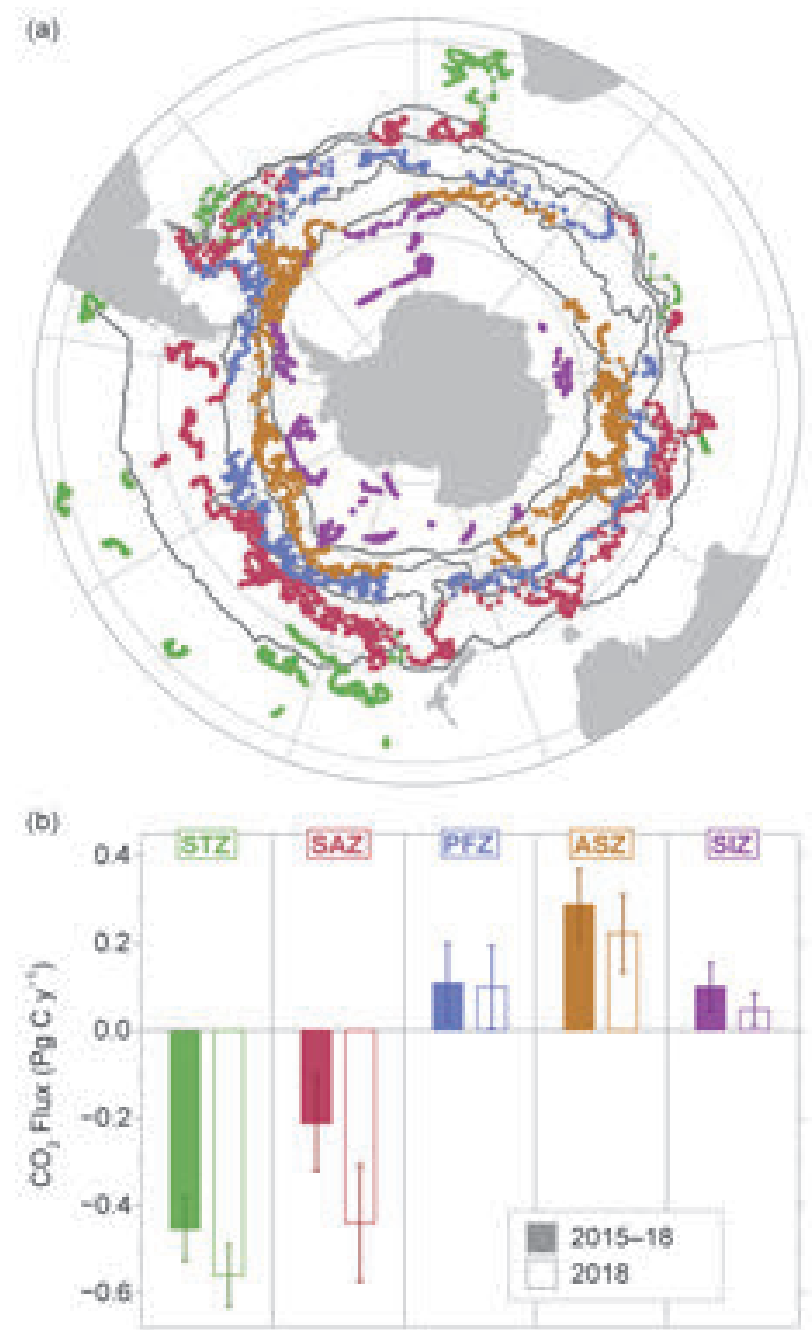

Fig. 6.II. (a) Locations of profiles from SOCCOM floats and (b) average air-sea carbon dioxide fluxes $\left(\mathrm{PgC}_{\mathrm{yr}}^{-1}\right)$ computed for five regions in the Southern Ocean (STZ = Subtropical Zone, SAZ = Subantarctic Zone, PFZ = Polar Frontal Zone, ASZ = Antarctic Southern Zone, SIZ = Sea Ice Zone). Positive values indicate flux from the ocean to the atmosphere. Carbon fluxes were estimated from float data together with ERA5 reanalysis wind speed and sea level pressure fields, Cape Grim atmospheric $\mathrm{CO}_{2}$ measurements, and NOAA CDR/ NIMBUS near-real-time sea ice estimates following Gray et al. 2018. Solid bars provide the float-based estimates averaged for I Jan 2015-3I Dec 2018; open bars correspond to I Jan 2018-3I Dec 2018.

g. 2018 Antarctic ozone hole-N. Kramarova, P. A. Newman, E. R. Nash, S. E. Strahan, C. S. Long, B. Johnson, M. Pitts, M. L. Santee, I. Petropavlovskikh, G. O. Braathen, L. Coy, and J. de Laat

The Antarctic ozone hole is a seasonal depletion of the ozone layer over Antarctica occurring every austral spring since the early 1980s. The depletion depends on the amount of ozone depleting sub- stances (ODS) and the meteorological conditions in the Antarctic lower stratosphere. The structure and evolution of the 2018 Antarctic ozone hole and its relation to previous years were studied using global reanalysis temperatures (from MERRA-2), the NOAA ozonesonde record collected at Amundsen-Scott South Pole Station, satellite observations, and insights derived from a global chemical transport model.

Figure 6.12a shows the 1980-2018 time series of the MERRA-2 reanalysis temperatures at $50 \mathrm{hPa}$ averaged over the polar cap $\left(60^{\circ}-90^{\circ} \mathrm{S}\right)$ during September. In 2018, the mean temperature of the Antarctic lower stratosphere was among the lowest $33 \%$ of September mean temperatures observed since 1980 . Low temperatures facilitate the formation of polar stratospheric clouds (PSCs), which enable heterogeneous chemical reactions that catalyze ozone loss. The stratospheric wave activity that controls vortex temperature and stability was weaker than average in August and the first half of October and near average in September, resulting in a close-to-average-sized ozone hole (for this century) that persisted until early December. We note that there is good agreement between ECMWF and MERRA-2 temperature records; a small negative bias $(\sim 1 \mathrm{~K})$ in earlier years before 1999 (not shown) does not change the conclusions reported here.

Satellite observations show that the hole's area, defined as the area where total column ozone values drop below $220 \mathrm{DU}$, averaged 22.7 million $\mathrm{km}^{2}$ $\left(\mathrm{Mkm}^{2}\right)$ in September 2018, the 15th largest out of 40 years of satellite observations (Fig. 6.12b). Effective equivalent stratospheric chlorine (EESC, an estimator of human-produced and natural ODS in the stratosphere) is shown as a green curve in Fig. $6.12 \mathrm{~b}$. The EESC level is estimated employing the method described in Newman et al. (2007), using an updated inventory of near-surface concentrations of ODS gases from ground-based observations and their respective lifetimes. Because of the Montreal Protocol and its amendments, EESC has declined about $11 \%$ since its peak in 2000. Reduced ozone depletion over Antarctica due to the EESC decline is more pronounced in September, when catalytic chemical loss is the greatest (Hassler et al. 2011; Strahan and Douglass 2018).

In September, the ozone hole is also strongly affected by meteorological conditions (Fig. 6.12a) - it is larger in colder years and smaller in warmer years. A comparison of years with similar meteorological conditions but different EESC yields a relationship between EESC and ozone hole area of about $125 \mathrm{ppt}$ EESC per $\mathrm{Mkm}^{2}$ in the five coldest years since 1984 (Strahan et al. 2014). The 2006 September mean 


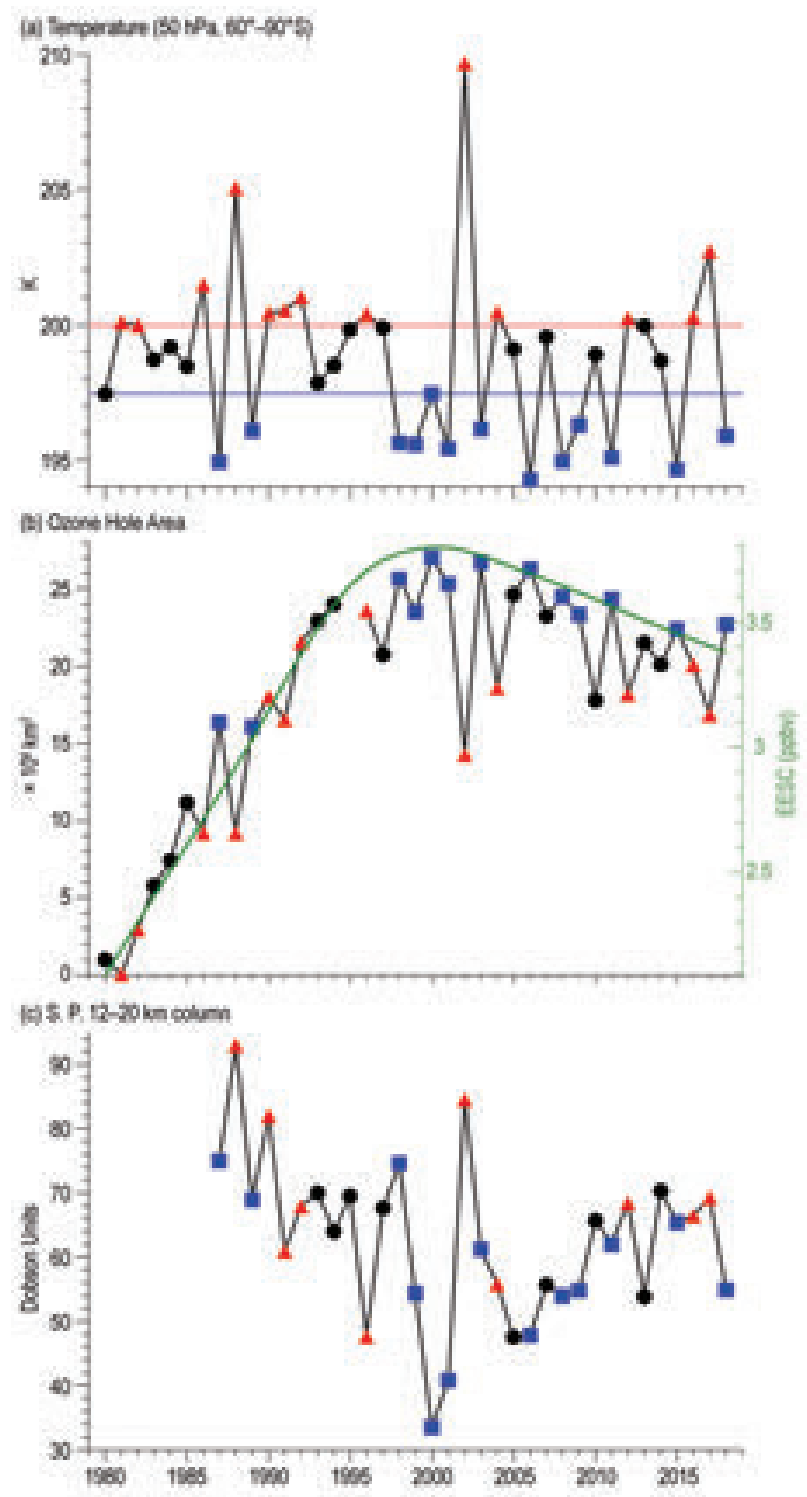

Fig. 6.I2. (a) MERRA-2 50-hPa Sep temperature averaged over $60^{\circ}-90^{\circ} \mathrm{S}$, (b) Sep average Antarctic ozone hole area, and (c) Sep average ozone column amounts measured within the primary depletion layer (12-20 km) by NOAA South Pole ozonesondes. Years with temperatures in the lowest (highest) third are shown as blue squares (red triangles). Horizontal blue and red lines indicate $33 \%$ and $66 \%$ percentiles. The green curve (and right vertical axis) in (b) shows the NASAestimated EESC level in the Antarctic lower stratosphere modeled with the assumption of a $\mathbf{5 . 2}$ mean age of air. Ozone data in (b) for 1979-92 are from TOMS Nimbus-7, 1993-94 are from TOMS Meteor-3, 1996-2004 are from EPTOMS, 2005-I5 are from Aura OMI, and 2015-18 are from SNPP OMPS. There were no satellite total ozone observations for 1995.

temperature was $\sim 1.6 \mathrm{~K}$ lower than that in 2018 and its EESC level (3.69 ppbv) was 0.31 ppbv higher than in 2018. The September 2006 mean area was 26.3
$\mathrm{Mkm}^{2}$ (third largest on record), and the September 2018 mean area was $22.7 \mathrm{Mkm}^{2}$. The loss of -0.31 ppbv over 12 years, with the sensitivity estimate and the reduction in hole size, yields a downward trend of $-0.21 \mathrm{Mkm}^{2} \mathrm{yr}^{-1}$. Analysis during the ozone recovery period (post-2000) in Fig. 6.12b indicates a downward trend of $-0.22 \pm 0.15 \mathrm{Mkm}^{2} \mathrm{yr}^{-1}$; the trend in the cold years alone is remarkably similar, -0.25 $\pm 0.05 \mathrm{Mkm}^{2} \mathrm{yr}^{-1}$.

Ozonesondes are regularly launched from South Pole station to monitor ozone vertical distributions. The largest photochemical ozone depletion associated with EESC occurs in the lower stratosphere between 12 and $20 \mathrm{~km}$ (Fig. 6.12c). Below-average temperatures in 2018 led to increased ozone depletion, reducing the minimum column ozone amount in the $12-20 \mathrm{~km}$ layer (54.9 DU, the lowest since 2013). The column ozone minimum value was $47.8 \mathrm{DU}$ in 2006, when the EESC level was close to its peak.

In 2018, satellite observations of chlorine compounds over Antarctica also showed slightly lower levels than in previous years. Figure 6.13 shows the seasonal evolution of stratospheric chlorine $(\mathrm{HCl}$ and $\mathrm{ClO}$ ), ozone, and PSC volume derived from the NASA MLS and the CALIPSO sensors. Low Antarctic temperatures during polar night lead to PSC formation (Fig. 6.13d); hydrogen chloride (HCl; Fig. 6.13a) reacts with chlorine nitrate $\left(\mathrm{ClONO}_{2}\right)$ on the PSC particle surfaces to form $\mathrm{Cl}_{2}$. This process causes $\mathrm{HCl}$ to decline during the austral winter (Fig. 6.13a). Subsequently, $\mathrm{Cl}_{2}$ is photolyzed as the sun returns in August and September, leading to an increase of ozone-reactive $\mathrm{ClO}$, whose concentration peaks in September (Fig. 6.13b). The presence of $\mathrm{ClO}$ is evidence of ongoing catalytic ozone depletion, and ozone concentration reaches its minimum in late September (Fig. 6.13c). MLS measurements show that chlorine levels (Figs. 6.13a-b) in September 2018 (red) were below the 2005-17 average and notably lower than in 2006 (blue). The vortex average ozone concentration in the lower stratosphere (Fig. 6.13c) in September 2018 (red) was close to the 2005-17 average (white) and higher than in 2006 (blue). Direct observations of PSCs from CALIPSO indicate a high volume of PSC during the 2006 (blue) and 2018 (red) winters, which is consistent with below-average temperatures observed in those years. There is a gap in CALIPSO measurements in mid-September 2018-the key month for ozone depletion-but the volume of PSC in the beginning and end of September was close to or slightly above average. These results suggest that higher September ozone abundances in 2018 compared to 2006 were due to reduced EESC levels. 


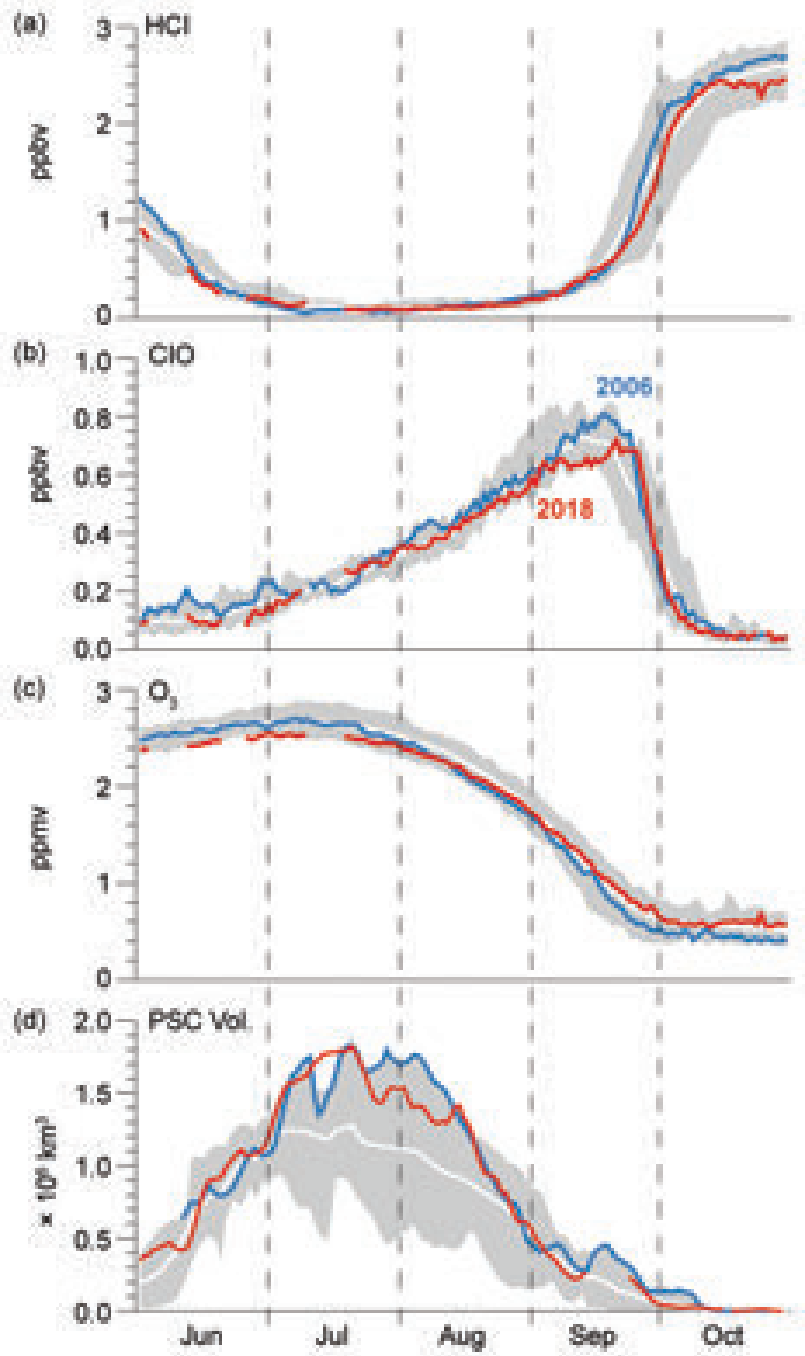

FIG. 6.13. Antarctic 2018 (red curves) and 2006 (blue curves) vortex-averaged concentrations of (a) $\mathrm{HCl}$, (b) $\mathrm{CIO}$, and (c) $\mathrm{O}_{3}$ from Aura MLS (updated from Manney et al. 20II). MLS averages are made inside the polar vortex on the 440-K potential temperature surface $(\sim 19 \mathrm{~km}$ or $60 \mathrm{hPa})$. Gray shading shows the range of daily Antarctic values for 2005-17. (d) CALIPSO PSC volume (updated from Pitts et al. 2009). Gray shading is for 2006-I7.

The NASA Global Modeling Initiative (GMI) chemistry transport model simulates stratospheric ozone and its response to changing EESC levels (Strahan et al. 2013). A model simulation with ozone-depleting source gases held constant at their maximum observed surface levels (1995) produced an ozone hole more than $4 \mathrm{Mkm}^{2}$ larger than a simulation with 2018 EESC levels (Fig. 6.14). The model simulations are driven by MERRA-2 assimilated temperatures and winds, and the simulation with realistically varying ODS levels reproduces the trend and year-to-year variations in Antarctic September ozone from the

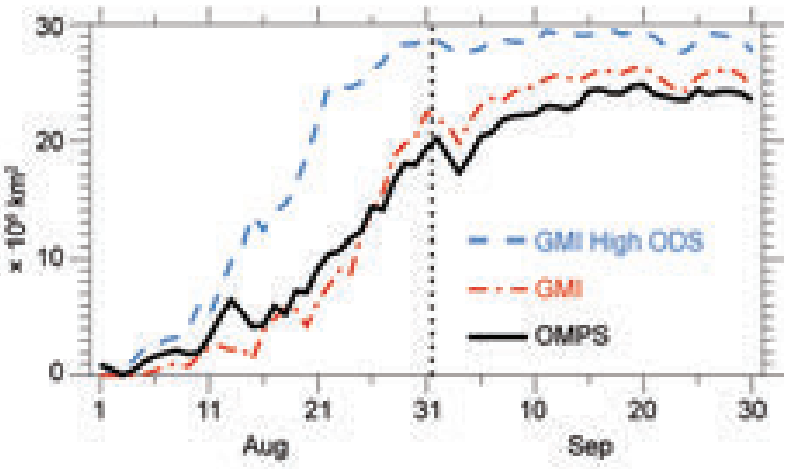

Fig. 6.14. Seasonal evolution of the area of the 2018 ozone hole from Suomi NPP OMPS observations (black). Red and blue curves show the area of the 2018 ozone hole from model simulations for two scenarios of the EESC level: with the actual EESC level (red) and with fixed high EESC (blue). The model 210 DU contours are used to account for a 10 DU low bias.

1980 s to the present. This simulation has a consistent $\sim 10$ DU low bias over the Antarctic in September, accounted for in Fig. 6.14. The $4 \mathrm{Mkm}^{2}$ difference in the September 2018 ozone hole areas in the two GMI simulations indicates a mean area change of -0.22 $\mathrm{Mkm}^{2} \mathrm{yr}^{-1}$ over the $2000-18$ period.

The 2018 Antarctic ozone hole was near average in size for this century despite below-average temperatures and a stable polar vortex. Comparisons between 2018 and 2006 observations, analysis of ozone hole area trends, and agreement among model simulations all suggest that the 2018 Antarctic ozone hole size and severity were consistent with the expected recovery due to declining EESC. 
7. REGIONAL CLIMATES —P. Bissolli, C. Ganter, T. Li, A. Mekonnen, and A. Sánchez-Lugo, Eds.

\section{a. Overview}

This chapter provides summaries of the 2018 temperature and precipitation conditions across seven broad regions: North America, Central America and the Caribbean, South America, Africa, Europe, Asia, and Oceania. In most cases, summaries of notable weather events are also included. Local scientists provided the annual summary for their respective regions and, unless otherwise noted, the source of the data used is typically the agency affiliated with the authors. The primary base period used for these analyses is 1981-2010. However, please note that on occasion different nations, even within the same section, may use unique periods to define their normals. Section introductions typically define the prevailing practices for that section, and exceptions will be noted within the text. In a similar way, many contributing authors use languages other than English as their primary professional language. To minimize additional loss of fidelity through re-interpretation after translation, editors have been conservative and careful to preserve the voice of the author. In some cases, this may result in abrupt transitions in style from section to section.

\section{b. North America-A. Sánchez-Lugo, Ed.}

This section is divided into three subsections: Canada, the United States, and Mexico. All anomalies are with respect to the 1981-2010 base period, unless otherwise noted.

The year 2018 was characterized by warmer-thanaverage conditions across much of North America, with cooler-than-average conditions across central and eastern Canada, as well as parts of the northcentral contiguous United States. Mexico was the only country that had a top 10 warm year, with 2018 ranking as its third warmest year on record. Annual precipitation for each country was near to slightly above average. Dry and warm conditions across British Columbia during late spring were associated with the most severe wildfire season in its history. Across the contiguous U.S., there were 14 weather and climate events that each caused over $\$ 1$ billion (U.S. dollars) - the fourth highest in terms of cost since records began in 1980. Twelve tropical cyclones affected Mexico, resulting in the country's most active season on record.
I) Canada-V. Y. S. Cheng, L. A. Vincent, D. Phillips, and V. Isaac

In 2018, above-average winter and spring mean temperatures prevailed across northwestern Canada, while below-average temperatures were present across most of southern Canada (south of $60^{\circ} \mathrm{N}$ ). Summer mean temperatures were higher than average in eastern Canada and the Pacific coast, while autumn brought below-average temperatures across much of the country. Precipitation measurements showed drier-than-average spring and summer conditions mainly in southern British Columbia.

\section{(i) Temperature}

The annual average temperature for Canada was $0.3^{\circ} \mathrm{C}$ below the $1981-2010$ national average (Fig. 7.1); however, 2018 ranked near the middle of the historical record as the 29th warmest year since nationwide recordkeeping began in 1948. Four of the ten warmest years have occurred during the last decade (2009-18), with 2010 record warm $\left(+2.2^{\circ} \mathrm{C}\right)$. The national annual average temperature has increased by $1.7^{\circ} \mathrm{C}$ over the past 71 years. Spatially, annual departures above $+1^{\circ} \mathrm{C}$ were recorded in the northwest, whereas annual departures below $-1^{\circ} \mathrm{C}$ were found from the interior of the Prairies to northern Quebec (Fig. 7.2a). None of the provinces/territories experienced an average annual temperature that ranked among their 10 warmest or coldest on record (since 1948).

Winter (December-February) 2017/18 was $0.2^{\circ} \mathrm{C}$ above average - the 25 th warmest winter on record. The national winter average temperature has increased by $3.4^{\circ} \mathrm{C}$ over the past 71 years. Winter anomalies above $+3^{\circ} \mathrm{C}$ were recorded in the northwestern parts of Canada, with the Northwest

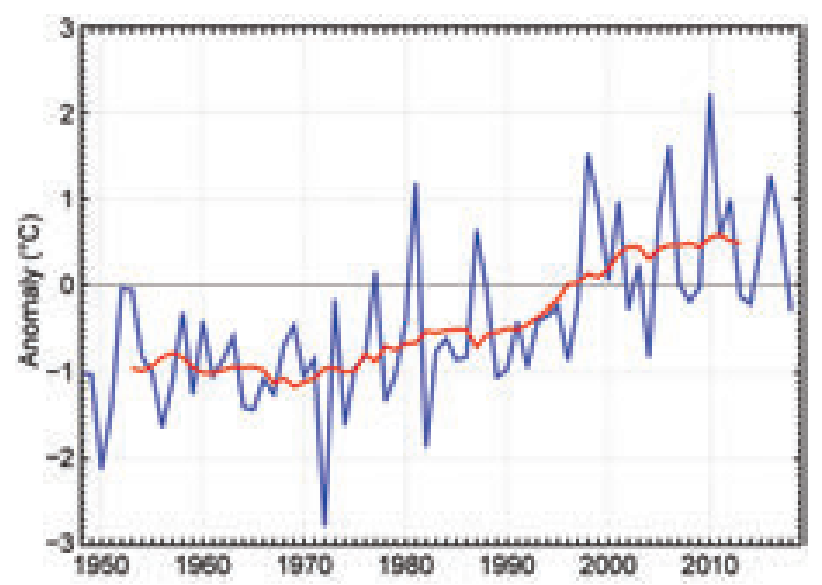

Fig. 7.I. Annual average temperature anomalies $\left({ }^{\circ} \mathrm{C}\right.$; 198I-2010 base period) in Canada for 1948-2018. Red line is the II-year running mean. (Source: Environment and Climate Change Canada.) 
(a)
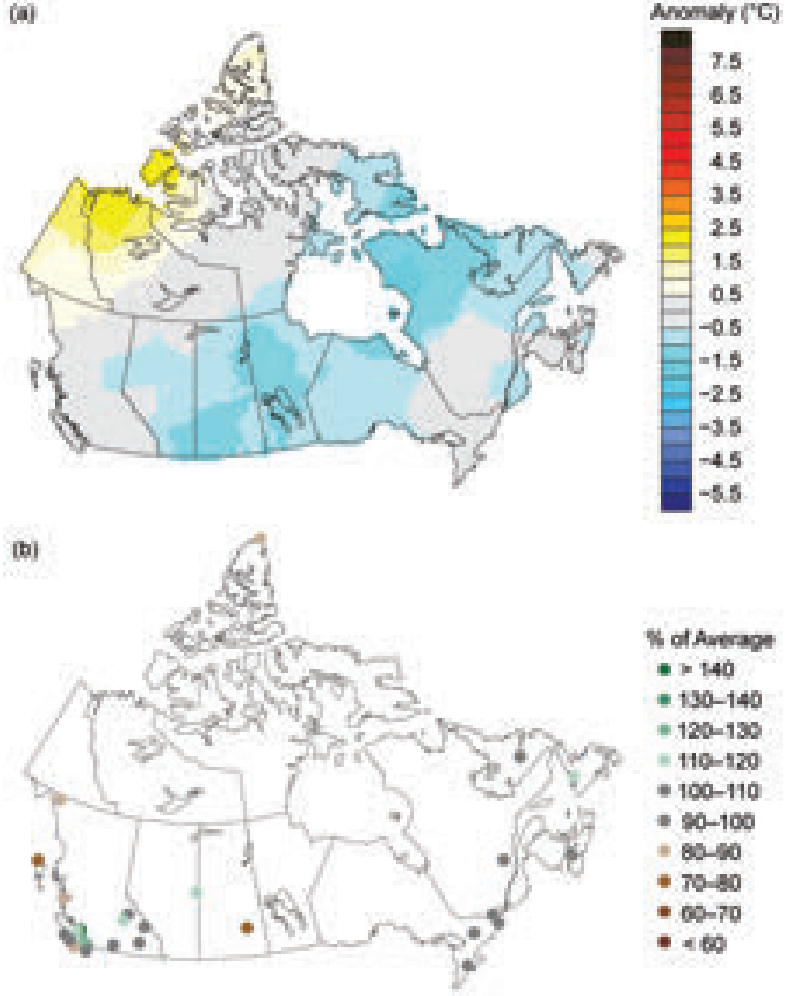

Fig. 7.2. Annual (a) average temperature anomalies $\left({ }^{\circ} \mathrm{C}\right)$ and $(\mathrm{b})$ total precipitation (\% of average) in Canada for 2018 (198I-2010 base period). (Source: Environment and Climate Change Canada.)

Territories having their third warmest winter on record. The rest of the country experienced winter anomalies below $-1^{\circ} \mathrm{C}$.

During spring (March-May), below-average temperatures were recorded from the interior of British Columbia to the Atlantic provinces, while near- or above-average conditions were observed in the northwestern parts of Canada. Spring average temperature was $0.5^{\circ} \mathrm{C}$ below average and the 31st warmest in the 71-year record. The national spring temperature has increased by $1.6^{\circ} \mathrm{C}$ over the past 71 years. None of the provinces/territories experienced an average spring temperature among their 10 warmest or coldest on record since 1948.

Summer (June-August) was $0.2^{\circ} \mathrm{C}$ above average and the 21st warmest since 1948. Most of British Columbia, Ontario, southern Quebec, and the Atlantic provinces experienced summer anomalies above $+0.5^{\circ} \mathrm{C}$. British Columbia and Ontario each had their 10th warmest summer on record. Summer temperatures were below average in northern Quebec and northern parts of the Northwest Territories. The national summer temperature has increased by $1.5^{\circ} \mathrm{C}$ over the past 71 years.
Autumn (September-November) was $1.4^{\circ} \mathrm{C}$ below average and the eighth coldest since 1948. Aboveaverage temperatures were experienced in the Yukon and northern regions of the Northwest Territories. Autumn anomalies of $-1^{\circ} \mathrm{C}$ or colder were experienced in the rest of the country, which resulted in seven provinces/territories having autumn average temperatures among their 10 coldest: Manitoba (coldest), Saskatchewan (second coldest), Newfoundland (fifth coldest), Ontario (sixth coldest), Quebec (sixth coldest), New Brunswick (ninth coldest), and Prince Edward Island (10th coldest). The national autumn temperature has increased by $1.6^{\circ} \mathrm{C}$ over the past 71 years.

\section{(ii) Precipitation}

Over the past decade, precipitation monitoring technology has evolved, and Environment and Climate Change Canada and its partners implemented a transition from manual observations to using automatic precipitation gauges. Extensive data integration is required to link the current precipitation observations to the long-term historical manual observations. While this data reconciliation due to changing monitoring technology and methods is in progress, this report presents the analysis based on 27 stations only, which have sufficient precipitation observations from similar instrumentation over the period 1981-2018. Most of these stations are located in the southern regions of the country (south of $60^{\circ} \mathrm{N}$ ).

Annual precipitation conditions were near the 1981-2010 average at many stations in western and eastern Canada (Fig. 7.2b). Seasonally, wetter-thanaverage conditions were experienced at most stations located in British Columbia during winter 2017/18; drier-than-average conditions were observed at most stations in British Columbia during the spring and summer; near-average conditions were found at most other stations in spring, summer, and autumn.

\section{(iii) Notable events and impacts}

In 2018, for the second consecutive year, British Columbia experienced its most severe wildfire season in its history in terms of the total hectares of land burned. After a long winter, May was one of the hottest and driest on record across British Columbia's interior and southern coast. A damp June temporarily eased the wildfire concern, but lightning ignited forests in the Okanagan (British Columbia) in July. By 8 August, there were 460 simultaneous wildfiresmore than any single day in 2017. A province-wide state of emergency began on 15 August and lasted through 7 September. In total, the British Columbia 
Wildfire Service reported over 2000 wildfires that destroyed more than 1.3 million ha of land, exceeding the record-breaking year of 1.2 million ha burned in 2017. More than 10 million Canadians downwind of the fire as far eastward to the shores of Lake Superior were exposed to the smoke from the August wildfires. Air quality alerts lasted for weeks across the west. Calgary recorded 478 hours of smoke and haze for the summer (the 1981-2010 average count is 12 hours) with one bout (14-20 August) lasting 141 consecutive hours. Edmonton experienced 230 hours of smoke and haze, more than double its previous smokiest summer in 2017.

Canada had a long, warm summer that started early and finished late, particularly in the east. From late June to the end of the first week of July, parts of eastern Canada endured their longest and most intense heat spell in years. Humidex (an index indicating the level of discomfort due to the combined effects of temperature and humidity) values reached recordhigh levels in Ottawa and Gatineau. Across Quebec, 93 people died from heat-related complications. July 2018 was the warmest July on record in the provinces of Prince Edward Island and New Brunswick, and the second warmest July in the provinces of Quebec and Nova Scotia since 1948, when recordkeeping began. The heat in Atlantic Canada persisted into August as the provinces of Nova Scotia and New Brunswick experienced their third warmest August, and Prince Edward Island its fourth warmest. Combined, July and August were the hottest on record in Atlantic Canada.

2) United States - K. Gleason, A. Smith, C. Fenimore, and R. R. Heim, Jr.

The annual average temperature during 2018 for the contiguous United States (CONUS) was $12.0^{\circ} \mathrm{C}$, which is $0.4^{\circ} \mathrm{C}$ above the $1981-2010$ average and was its 14th warmest year since 1895, when recordkeeping began (Fig. 7.3). The annual CONUS temperature is increasing at an average rate of $0.08^{\circ} \mathrm{C}$ decade $^{-1}$ over the 124 -year record; $0.3^{\circ} \mathrm{C}$ decade ${ }^{-1}$ since 1970 . Average precipitation totaled $880 \mathrm{~mm}$, which is $112 \%$ of the 1981-2010 average and the third largest value in the 124-year record. The annual precipitation total is increasing at an average rate of $5 \mathrm{~mm} \mathrm{decade^{-1 }}$ over the 124 -year record; $3 \mathrm{~mm}$ decade ${ }^{-1}$ since 1970 . Outside of the CONUS, Alaska had its second warmest year $\left(+2.2^{\circ} \mathrm{C}\right.$ departure; $0.8^{\circ} \mathrm{C}$ cooler than 2016$)$ since 1925, when recordkeeping began. Precipitation across Alaska ranked near the median at $103 \%$ of average.

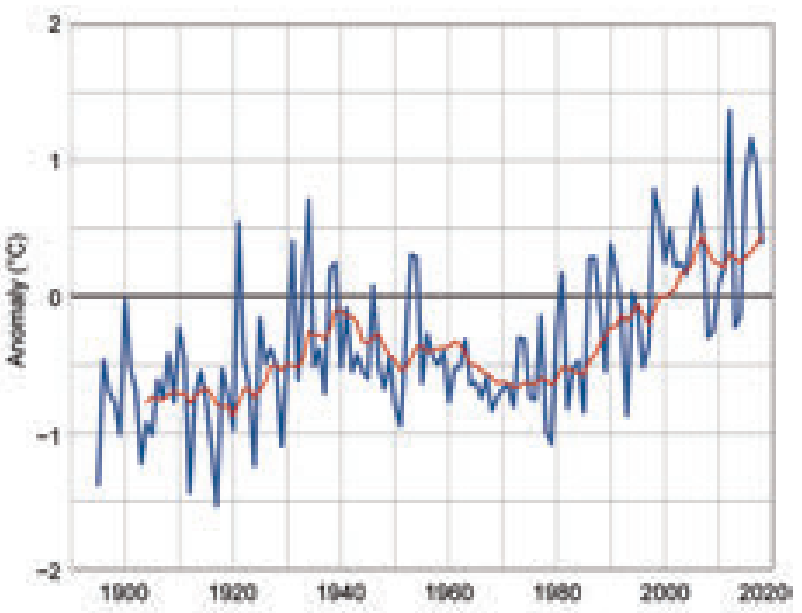

FIG. 7.3. Annual mean temperature anomalies $\left({ }^{\circ} \mathrm{C}\right.$; 198I-2010 base period) for CONUS for 1895-2018. Red line is the lagged 10 -year running mean. (Source: NOAA/NCEI.)

\section{(i) Temperature}

While much of the CONUS had near- to aboveaverage temperatures, the north-central CONUS had below-average temperatures during 2018 (Fig. 7.4a). Averaged as a whole, 2018 was the coolest year since 2014 (Fig. 7.3). For the first time since 2013, no state had record warm temperatures: Arizona had its second warmest year on record; New Mexico its third, and California its fourth. Fourteen states across the West as well as the Southeast and Mid-Atlantic states had annual temperatures among their 10 warmest on record.

Winter (December-February) 2017/18 CONUS temperature was $1.0^{\circ} \mathrm{C}$ above average, ranking in the middle third of its record. Much-above-average to record warmth was confined to portions of the Southwest and southern Florida, while average to below-average temperatures were evident from the Rockies to the Mississippi and Ohio River Valleys. The CONUS spring (March-May) temperature was $0.3^{\circ} \mathrm{C}$ above average, also ranking in the middle third of the record. Above-average temperatures were observed from the West Coast, through the Rockies, and into the Deep South. Average-to-below-average spring temperatures were present across much of the rest of the CONUS. Summer (June-August) CONUS temperatures were above average (by $0.9^{\circ} \mathrm{C}$ ), tying 2016 for sixth highest on record. Utah had its warmest summer on record with the majority of the warmth centered on the southwestern United States. Autumn (September-November) CONUS temperature was $0.1^{\circ} \mathrm{C}$ above average, ranking near the median of the record. Below- to much-below-average temperatures were present from Texas to the Canadian border. 
Much-above-average temperatures were confined to California as well as parts of the East.

\section{(ii) Precipitation}

An active storm track across the Southeast coupled with tropical precipitation contributed to aboveaverage and record precipitation during 2018 (Fig. 7.4b). Nine states had their wettest year on record: Delaware, Maryland, Massachusetts, New Jersey, North Carolina, Pennsylvania, Tennessee, Virginia, and West Virginia. Below-average precipitation was observed in parts of the West. The year began with drought in the Southwest, the Great Plains, the South, and along the East Coast. Wet conditions during late winter and spring brought drought relief to much of the East, although drought intensified in the Southwest. Following a hot, dry summer, drought developed in the Pacific Northwest and parts of New England. While a wet autumn and early winter mitigated drought across much of the CONUS, it

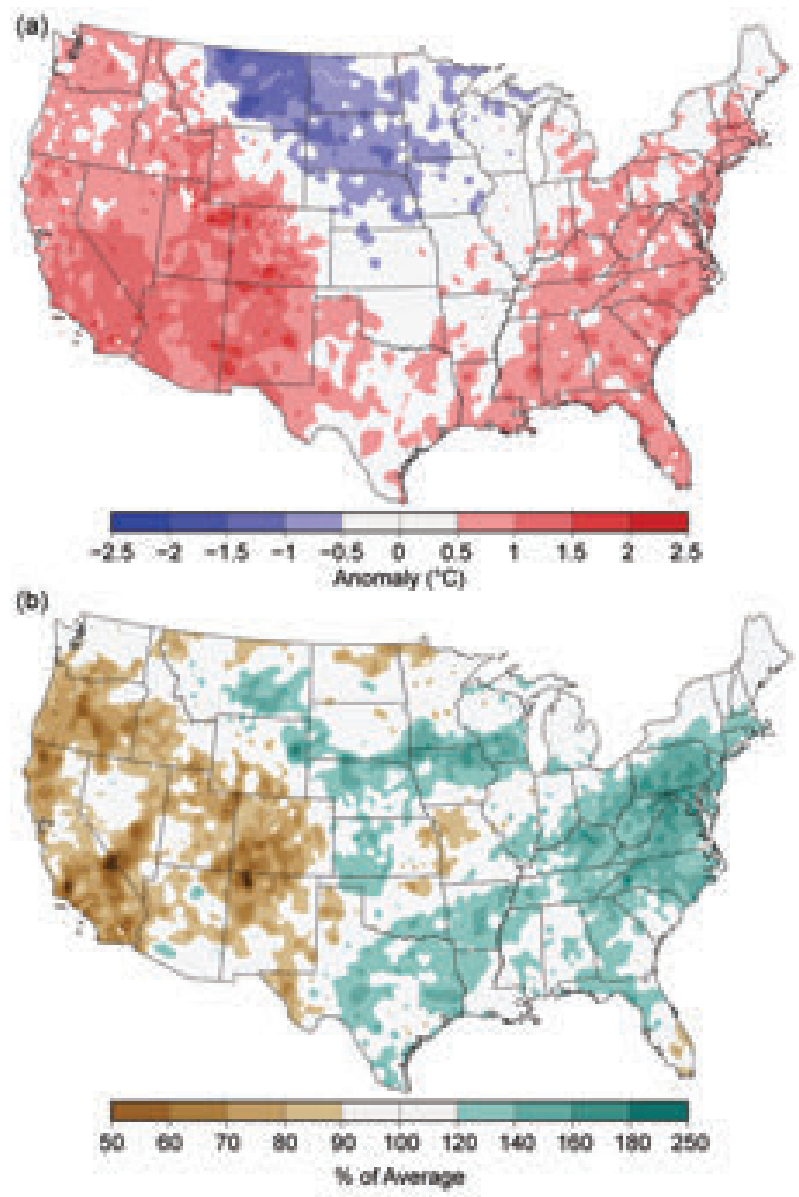

Fig. 7.4. Annual (a) average temperature anomalies $\left({ }^{\circ} \mathrm{C}\right)$ and (b) total precipitation (\% of average) in CONUS for 2018 (1981-2010 base period). (Source: NOAA/NCEI.) persisted in the West. Much of the Southwest and parts of Oregon were in drought for almost all of 2018.

Winter precipitation across the CONUS was $93 \%$ of average. Above-average precipitation occurred across much of Montana, parts of Wyoming, and from northeast Texas to New England. Below-average precipitation was confined to much of the West, northern Great Plains, and across the Southeast. Spring precipitation averaged near the long-term mean. Above-average precipitation fell across parts of the West as well as across the Southeast and into the Mid-Atlantic states. Precipitation was below average across the Southwest, Great Plains, and in parts of the northern Great Lakes. Summer precipitation was $108 \%$ of average across the CONUS with the wettest conditions occurring in the Midwest, Great Lakes, and along the East Coast. Conditions were dry from the Pacific Northwest through the central Rockies and into the Deep South. The autumn CONUS precipitation total was $141 \%$ of average and was the second wettest on record. Wet conditions occurred from Texas to Iowa and throughout many states along the East Coast. Seven states reported their wettest autumn on record.

\section{(iii) Notable events and impacts}

In 2018, there were 14 major weather and climate events across the United States, for which losses each exceeded $\$ 1$ billion (U.S. dollars): two tropical cyclones (Hurricanes Florence and Michael); one western wildfire disaster; eight instances of severe convective storms; one large drought episode; and two winter storms (Fig. 7.5). The 2018 total was the fourth highest annual number of U.S. billion-dollar disasters (adjusted for inflation) since 1980, when the record began; it was also the fourth highest with respect to total costs [\$91.0 billion (U.S. dollars)] when inflation-adjusted to January 2019 U.S. dollars. The record number of disasters is 16, which occurred in both 2011 and 2017, whereas the costliest year on record to-date occurred in 2017. Hurricanes Florence and Michael and the western wildfires were the costliest U.S. disasters of 2018 , comprising $80 \%$ of the total. Of particular note is the western wildfire disaster (Sidebar 7.1), with total costs of $\$ 24$ billion - a considerable increase over the previous U.S. annual wildfire cost record of $\$ 18$ billion set in 2017. Wildfire costs in the United States have increased exponentially over the 2017 and 2018 wildfire seasons. In 2018, wildfires burned 3.5 million ha across the United States, which is well above the 2000-10 average of 2.7 million ha.

Tornado activity for 2018 was below average and, based on preliminary data as of this writing, could be as low as it has been since 1989. For the year, there were 10 tornado fatalities, which is the fewest on record since 


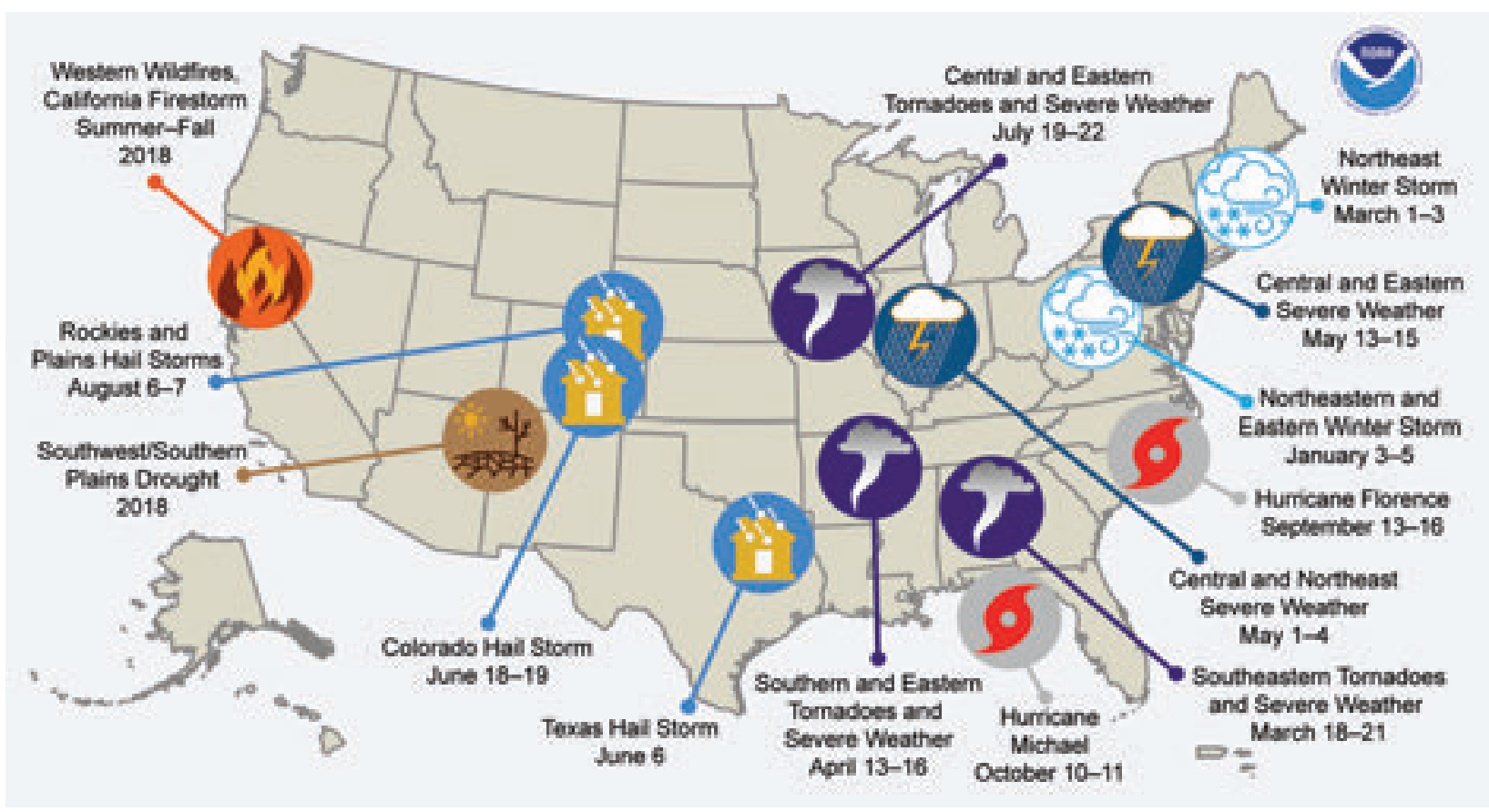

FIG. 7.5. Map depicting date, approximate location, and type of the 14 weather and climate disasters in the U.S. in 2018 with losses for each exceeding \$I billion (U.S. dollars). (Source: NOAA/NCEI www.ncdc.noaa.gov/billions.)

1950, when tornado statistics began. In addition to the low counts, there were no confirmed EF4 or EF5 tornadoes, which is the first time on record this has occurred.

\section{3) MeXico-R. Pascual Ramírez}

In 2018, Mexico's monthly national temperatures from February through October each ranked among the eight warmest for their respective months, contributing to the third warmest year in the 48year record. Precipitation varied across the nation throughout the year. Total precipitation was $103 \%$ of average, making 2018 Mexico's 29th wettest year in the 78-year precipitation record.

\section{(i) Temperature}

Mexico's mean annual temperature was $22.2^{\circ} \mathrm{C}$, which was $1.3^{\circ} \mathrm{C}$ above the $1981-2010$ average. This marks the third highest since 1971, when national temperature recordkeeping began, trailing behind 2017 and 2016 (Fig. 7.6). The year also marked the 15 th consecutive year with an above-average annual temperature. Nationally-averaged monthly temperatures were higher than average for nine consecutive months (February-October); February and May were the warmest on record for their respective months. Seasonally, the nation's summer temperature (JuneAugust) was also the second highest on record, behind 2017. January, November, and December each ranked among their 10 coldest on record.

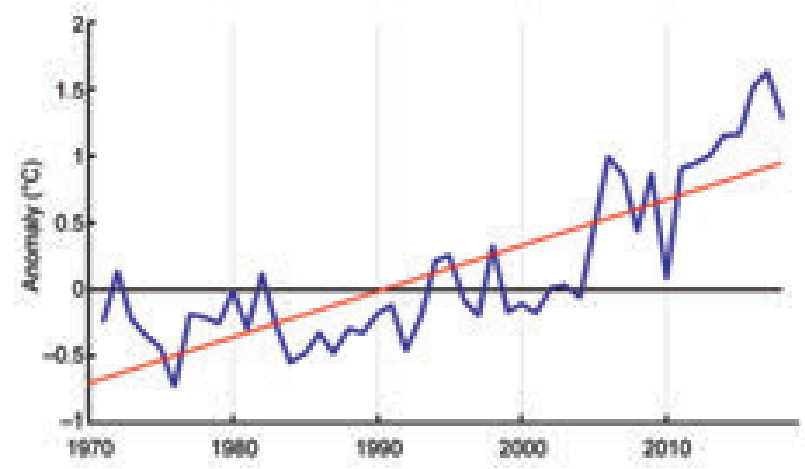

Fig. 7.6. Annual mean temperature anomalies $\left({ }^{\circ} \mathrm{C}\right.$; 198I-2010 base period) for Mexico for 197|-2018. The red line represents the linear trend over this period. (Source: Meteorological Service of México.)

Annual temperatures were above average across most of the country, with small areas in southern Mexico experiencing cooler-than-average conditions (Fig. 7.7a). Regionally, the Queretaro State in central Mexico had its warmest year on record. Colima (western Mexico on the central Pacific coast) and Durango (northwestern Mexico) each observed their second warmest year on record. No state had a top 10 cold year. 


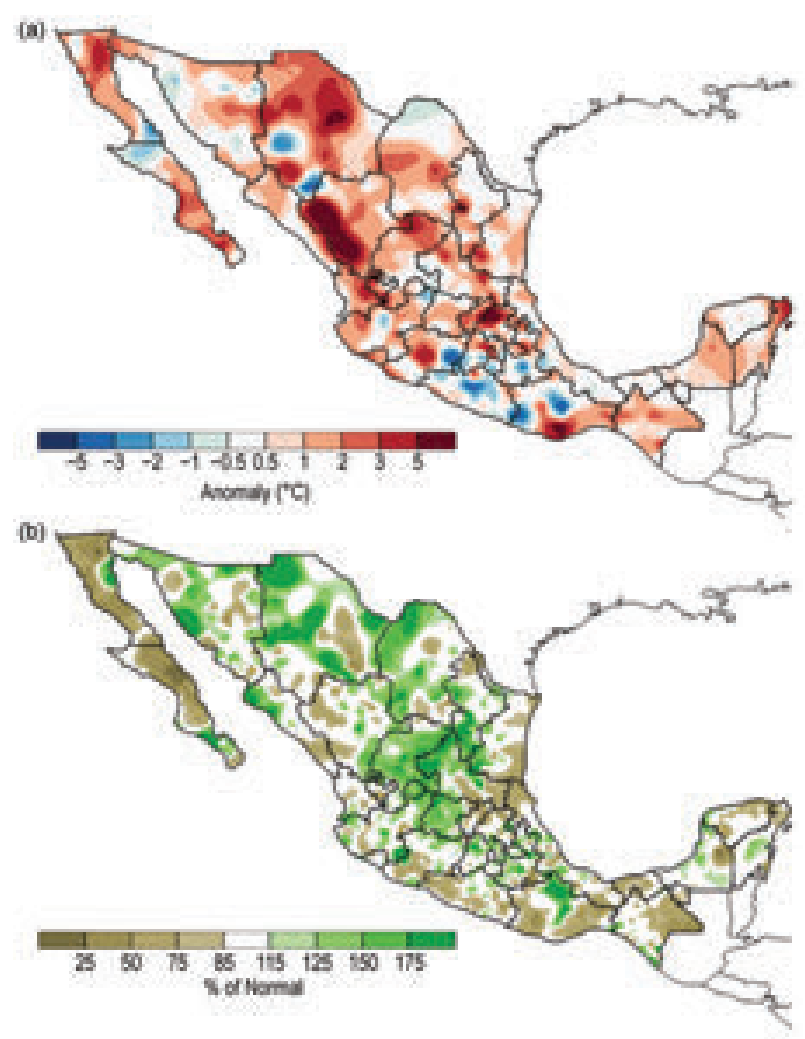

FIG. 7.7. 2018 annual (a) mean temperature anomalies ( $\left.{ }^{\circ} \mathrm{C}\right)$ over Mexico and (b) precipitation anomalies (\% of normal); (198I-2010 base period). (Source: National Meteorological Service of México.)

\section{(ii) Precipitation}

Rainfall anomalies varied greatly across Mexico, with above-average conditions across much of northern (Sonora, Chihuahua, and Coahuila) and central (Guanajuato, Aguascalientes, Zacatecas, and San Luis Potosi) Mexico. Drier-than-average conditions were present across most of the Baja California Peninsula, the northeast, the Pacific coast, the southeast, and the Yucatan Peninsula (Fig. 7.7b). Summer 2018 was the 24th driest summer in the nation's 78-year precipitation record, with the driest July on record. These dry conditions were mostly related to below-average tropical cyclone activity within $100 \mathrm{~km}$ of the country from July-September. However, wetter-than-average conditions returned across much of the nation during the peak of the tropical cyclone season (late September-October).

Climatologically, September is the most active month with respect to tropical cyclone activity and the wettest month of the year, contributing about $18.4 \%$ of the nationally-averaged annual rainfall.
September 2018 provided $20.6 \%$ of the annual rainfall; however, only one tropical depression was observed near Mexico. October 2018 was the nation's most active tropical cyclone month, with Hurricanes Rosa, Sergio, and Willa, as well as Tropical Storms Tara and Vincent, near or making landfall in Mexico. Usually, March is the driest month of the year, contributing $1.8 \%$ of the annual rainfall. This year, March contributed only $1.1 \%$ of the total rainfall.

\section{(iii) Notable events and impacts}

Generally, winds and rains from tropical cyclones begin to affect Mexico when they are within $100 \mathrm{~km}$ of the mainland. During 2018, 12 tropical cyclones affected Mexico. Ten storms in the Pacific basin were less than $100 \mathrm{~km}$ from the nation's coasts or made landfall, while two were from the Caribbean or the Gulf of Mexico. This is well above the average of five events per year, based on tropical cyclones records kept since 1950. In fact, 2018 was the most active tropical cyclone season for Mexico on record, surpassing 2010 (11). Likewise, the 10 Pacific storms by far exceeded the annual average of three and was the most active season on record, surpassing 1993 (7). Tropical Depression 19E and Hurricane Willa were the most destructive storms to affect the nation due to the heavy rain they produced. Tropical Depression $19 \mathrm{E}$ was the first cyclone on record to form in the Gulf of California and affect the coasts of southern Sonora and northern Sinaloa. During 17-20 September, rainfall from the storm totaled $382.5 \mathrm{~mm}$ in Ahome, Sinaloa, causing severe flooding. Hurricane Willa, which reached Category 5 on the Saffir-Simpson hurricane scale on 22 October, made landfall in southern Sinaloa and northern Nayarit on 24 October as a Category 3 storm, producing a maximum rainfall total of $391.0 \mathrm{~mm}$ in a single station in northern Nayarit. That total is $18.2 \%$ of the station's annual mean.

For a second consecutive year, drought conditions worsened in southern Mexico due to the absence of tropical cyclones near this region. Veracruz, Tabasco, and Chiapas, considered three of Mexico's rainiest states, each had one of their 12 driest Septembers, with Tabasco having its fourth driest September on record. Drought impacts for the region included water shortages in southern Veracruz and Tabasco, lack of pastures and water supplies, as well as reduced runoff in streams due to higher temperatures. Many farmers were forced to seek pastures in other regions at higher prices, as well as required government support. 
N. J. NAUSLAR, T. J. BROWN, D. J. MCEVOY, AND N. P. LAREAU

California experienced its deadliest and most destructive wildfire season on record in 2018 , only one year after the previous most destructive wildfire season. Two of the deadliest 2018 wildfires (Camp and Carr Fires), three of the eight most destructive wildfires (Camp, Carr, and Woolsey Fires), and three of the twenty largest wildfires (Mendocino Complex, Camp, and Carr Fires) in California's history all occurred during 2018 (CAL FIRE 2019f-h). The Camp, Woolsey, and Carr Fires were estimated to cost more than $\$ 27$ billion (U.S. dollars) in insured losses, suppression, and cleanup, with the Camp Fire being the costliest international disaster during the year (McBride 20I8; CAL FIRE 2019b-d,i; Reyes-Velarde 2019; NIFC 2019; Finch II 2019). More than 730000 ha burned across California, which is the most area burned on record in the last $30+$ years (based on reliable fire data). Most of the year's wildfire ignitions were human-related (CAL FIRE 2019a; NIFC 2019), which is not uncommon for California. The largest wildfire in California's history, the Ranch Fire, ignited on 27 July and burned 166003 ha within the Mendocino Complex (comprised of the River Fire and Ranch Fire) in northwest California (CAL FIRE 2019e-f). Following is a summary of the Camp and Carr Fires, illustrating the importance of the climate-weather nexus for wildfires.

Climate has a strong influence on vegetation availability and ignition for fire-climate enables fire while weather drives fire. The multi-year (2012-16) drought increased vegetation stress and mortality in and around California, especially with larger fuels (e.g., trees and shrubs). Because summer and early autumn in northern California is climatologically warm and dry, fine fuels (e.g., grasses) normally cure out and become available for burning. However, longer-term drought exacerbates drying of live fuel moisture in shrubs and trees. The 5-year drought abruptly ended when much-above-normal precipitation occurred in the winter-spring seasons of 2016-17, allowing for a greatly increased grass fuel load, which carried over through 2018. At the time of the Camp Fire, grass fuel loadings were $180 \%$ of normal.

The shorter climate time scales of I-6 months using the Evaporative Demand Drought Index (EDDI; Hobbins et al. 2016; www.esrl.noaa.gov/psd/eddi/) highlights the role of evaporative demand in the lead up to the Carr and Camp Fires (Fig. SB7.I). Spikes in evaporative demand (high EDDI values), driven by extended periods of high temperatures,

\section{(e) 2-month EODI 23 Jul 2018}

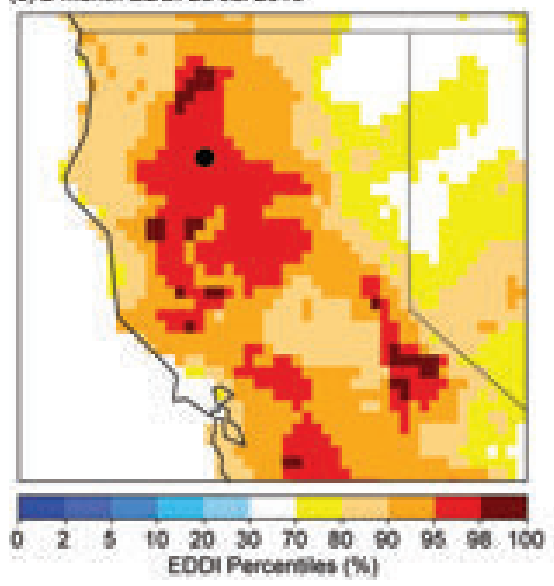

$\begin{array}{llllllllllll}0 & 2 & 5 & 10 & 20 & 30 & 70 & 00 & 05 & 90.100\end{array}$ EDOI Percensiles ( $\%$ )
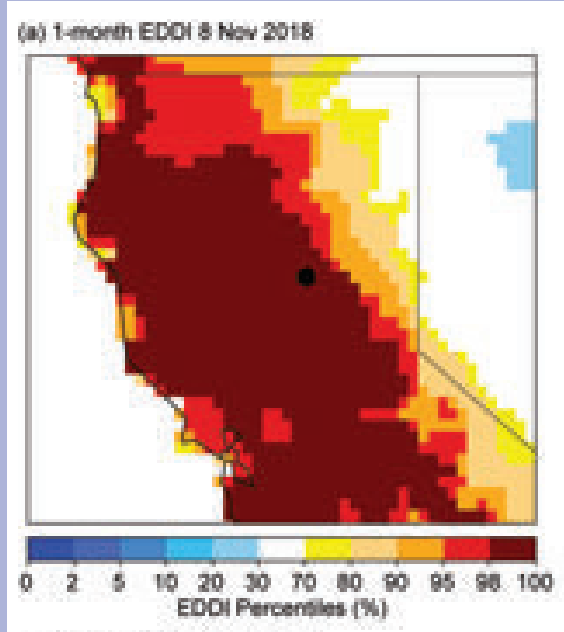

FIG. SB7.I. Evaporative Demand Drought Index (EDDI) spatial percentiles and time series during the 2018 northern California wildfires. (a) I-month EDDI percentiles ending 8 Nov 2018, (b) 6-month EDDI percentiles ending 8 Nov 2018, and (c) 2-month EDDI percentiles ending $23 \mathrm{Jul} 2018$. Black circle in (a) and (b) denotes ignition point of the Camp Fire and black circle in (c) denotes ignition point of the Carr Fire. (d) Daily time series of I-month EDDI at the grid cell nearest to the Camp Fire ignition point (orange line) and 2-month EDDI at the grid cell nearest to the Carr Fire ignition point (blue line). Vertical lines in (d) denote ignition date of the Carr Fire (23 Jul) and Camp Fire (8 Nov). 
strong winds, and low humidity, were noted prior to both fires. Peak EDDI values (above 95th percentile) coincided with fire start dates (Fig. SB7.I). The EDDI is strongly correlated to dead fuel moisture in California and was used to identify extreme fire danger leading up to the 2017 Tubbs Fire (McEvoy et al. 2019).

The Carr Fire burned nearly 93077 ha, making it the seventh largest wildfire in California's history. It caused eight deaths and destroyed more than 1600 structures (CAL FIRE 2019c,f). The Carr Fire began on 23 July northwest of Redding, California. On 26 July, driven by hot, dry, and unstable conditions, it burned downslope to the east-southeast into portions of Redding and grew more than 13354 ha, its single largest growth day (CAL FIRE 2019c). A rare tornado-strength, fire-generated vortex (FGV) formed in northwest Redding as a 12-km tall pyrocumulonimbus developed over the fire (Fig. SB7.2a; Lareau et al. 2018). A National Weather Service storm survey found EF-3 rated damage associated with this FGV, and radar data showed rotational velocity values for the FGV similar to that of EFI-2 tornadoes (Lareau et al. 2018). Anomalously wet conditions followed by low fuel moisture, record heat, and anomalously dry conditions primed this area for large, rapidly growing wildfires (Lareau et al. 2018).

In November, the Camp Fire, the deadliest and most destructive wildfire in California's history, caused 85 deaths and destroyed nearly 19000 structures as it burned 62040 ha on the western slopes and foothills of the northern Sierra Nevada (CAL FIRE 2019b, g-h). It began on 8 November near Jarbo Gap, California, fueled by strong northeast downslope winds (Fig. SB7.2b). Winds increased during the evening of 7 November and peaked early in the morning on the 8th; sustained winds exceeded $10 \mathrm{~m} \mathrm{~s}^{-1}$ with wind gusts over $20 \mathrm{~m}$ $\mathrm{s}^{-1}$ for eight consecutive hours overnight at the Jarbo Gap Remote Automated Weather Station (RAWS). Highest values of sustained wind speeds, wind gusts, and Fosberg Fire Weather In$\operatorname{dex}(F F W I)$ for the Jarbo Gap RAWS (2003-18 period of record) occurred overnight and early morning of 7-8 November. Using METDATA (Abatzoglou 2013), the National Fire Danger Rating System (NFDRS) burning index, which combines fire spread and fuel moisture, was the highest in nearly 40 years; the NFDRS energy release component and 100-hour dead fuel moisture were also the highest and lowest, respectively. The highest wind speeds and FFWI values at Jarbo Gap typically occur with a northeast wind direction during October and November, indicating the proclivity of strong downslope wind events in this area during autumn when fuels can be at their driest, similar to Diablo and Santa Ana Winds (Abatzoglou et al. 2013; Bowers 2018; Smith et al. 2018). Supported by anomalously strong downslope winds and dry fuels, the fire spread southwest across the complex terrain in the region, eventually burning through the town of Paradise, California, where many of the deaths and much of the destruction occurred (Fig. SB7.2b).

Separated by 75 miles and less than four months, the Carr and Camp Fires were fueled by climate conditions that proliferated abundant, dry fuels followed by critical fire weather conditions that drove rapid growth. Similar to the large fire events in 2017 across California (Nauslar et al. 2018), these fires occurred in a rare parameter space of weather, climate, and fuels proximate to populated areas near complex terrain. Given the expanding wildland-urban interface and wildfire-climate change relationship (Abatzoglou and Kolden 2013; Barbero et al. 2015; Abatzoglou and Williams 2016), especially in California, wildfire events like these may become more common.

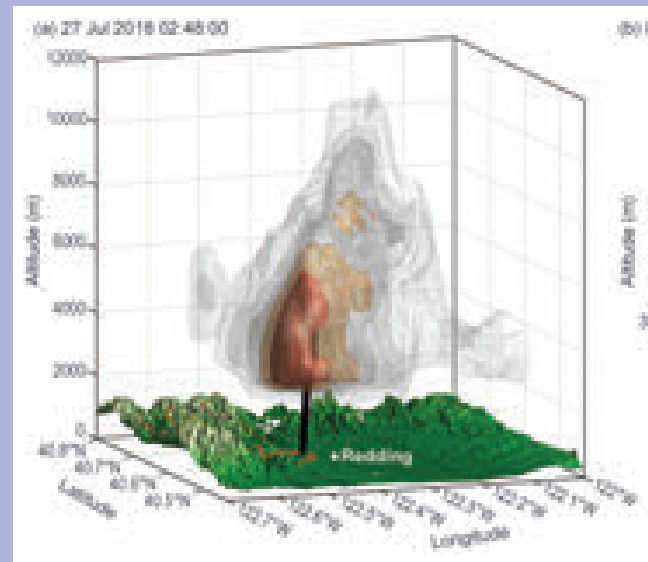

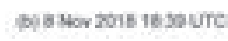

FIG. SB7.2. Radar reflectivity isosurface analyses of the (a) Carr and (b) Camp Fires. Also shown are regional topography and fire perimeters. Perimeter data for the Carr Fire is from infrared aircraft observations; Camp Fire data are from Landsat 8. Carr Fire analysis also includes a solid black line indicating the center locations of the radardetected tornado-strength, fire-generated vortex. The time of the observations are shown at the top, in UTC. 
c. Central America and the Caribbean-A. Sánchez-Lugo, Ed.

I) Central America-J. A. Amador, H. G. Hidalgo, E. J. Alfaro, B. Calderón, and N. Mora

For this region, nine stations from five countries were analyzed (Fig. 7.8). Stations on the Caribbean slope are: Philip Goldson International Airport, Belize; Puerto Barrios, Guatemala; Puerto Lempira, Honduras; and Puerto Limón, Costa Rica. Stations located on the Pacific slope are: Tocumen International Airport and David, Panamá; Liberia, Costa Rica; Choluteca, Honduras; and Puerto San José,
Guatemala. The station distribution covers the relevant regimes of precipitation (Magaña et al. 1999) and temperature (Hidalgo et al. 2019, and references within) on the Caribbean and Pacific slopes of Central America. Precipitation and temperature records for the stations analyzed were provided either by Central American National Weather Services (CA-NWS), NOAA, or University of Costa Rica. Anomalies are reported using a 1981-2010 base period and were calculated using CA-NWS data. The methodologies used for all variables can be found in Amador et al. (2011).

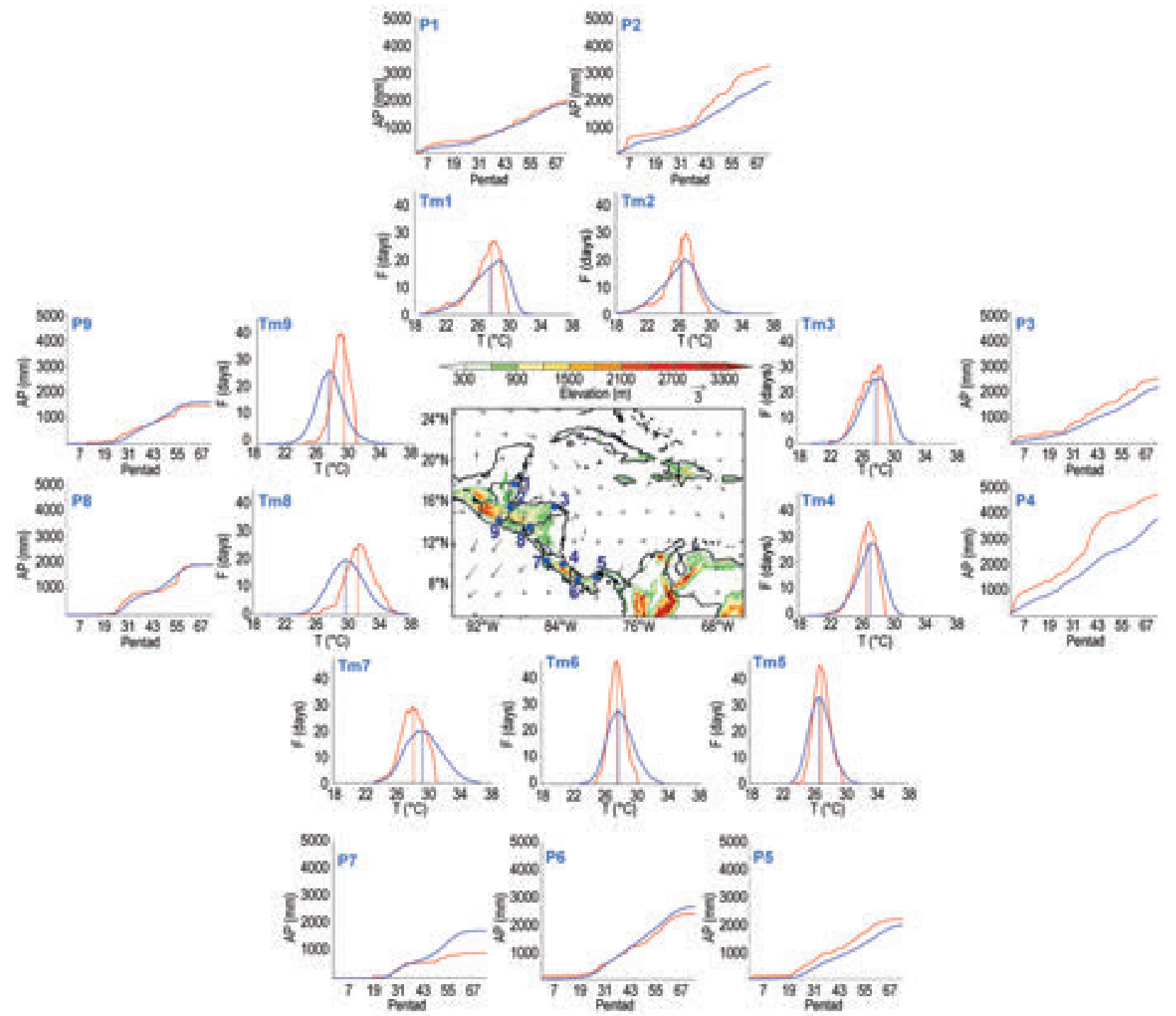

FIG. 7.8. Mean surface temperature ( $\mathrm{Tm}$; $\left.{ }^{\circ} \mathrm{C}\right)$ frequency (F; days), and accumulated pentad precipitation (P; $\mathrm{mm}$ ) time series are shown for nine stations (blue dots) in Central America: (I) Philip Goldson International Airport, Belize; (2) Puerto Barrios, Guatemala; (3) Puerto Lempira, Honduras; (4) Puerto Limón, Costa Rica; (5) Tocumen International Airport, Panamá; (6) David, Panamá; (7) Liberia, Costa Rica; (8) Choluteca, Honduras; and (9) Puerto San José, Guatemala. The blue solid line represents the $1981-2010$ average values and the red solid line shows 2018 values. Vertical dashed lines show the mean temperature for 2018 (red) and the 198I-20I0 period (blue). Vectors indicate Jul wind anomalies at $925 \mathrm{hPa}$ (198I-20I0 base period). Shading depicts regional elevation $(m)$. (Sources: NOAA/NCEI and CA-NWS.) 


\section{(i) Temperature}

The mean temperature $(\mathrm{Tm})$ frequency distribution for the climatology and for 2018 for all stations is shown in Fig. 7.8. Choluteca (Tm8) and Puerto San José (Tm9) on the Pacific slope of Central America each had a discernible shift in their statistical distributions toward warmer-than-normal conditions, whereas Puerto Lempira (Tm3) showed signs of marginal warming. Philip Goldson International Airport (Tm1), Puerto Barrios (Tm2), David (Tm5), and Tocumen International Airport (Tm6) had near-normal temperatures during 2018. Slightly cooler-thannormal conditions were observed at Puerto Limón (Tm4) and Liberia (Tm7). All stations observed less frequent maximum $\mathrm{Tm}$ values than the mean.

\section{(ii) Precipitation}

The accumulated pentad precipitation ( $\mathrm{P} ; \mathrm{mm})$ time series for the nine stations in Central America are presented in Fig. 7.8. Annual accumulations were near normal at Philip Goldson International Airport (P1), Choluteca (P8), and Puerto San José (P9). Puerto Lempira (P3) and David (P5) were slightly wetter than normal, and Puerto Barrios (P2) and Puerto Limón (P4) were significantly wetter than normal. Tocumen International Airport (P6) and Liberia (P7) reported below-normal precipitation, with Liberia having the larger precipitation deficit. Low-level circulation anomalies in the westernmost Caribbean Sea region showed slightly above-average values during July (vectors in Fig. 7.8) in the trade wind system, a condition usually associated with above- (below-) normal precipitation in the Caribbean (Pacific) slopes, especially with the mid-summer drought (Amador 1998, 2008; Hidalgo et al. 2019) as observed in 2018.

\section{(iii) Notable events and impacts}

Tropical cyclone activity during 2018 was low in the Caribbean basin and in the eastern tropical Pacific (ETP). Four systems reached tropical storm category in the Caribbean basin $\left(6^{\circ}-24^{\circ} \mathrm{N}, 60^{\circ}-92 \mathrm{~W}\right)$ : Alberto (26 May), Isaac (14-15 September), Kirk (29 September), and Michael (8 October). Michael evolved from a low-pressure system in the Caribbean that affected the region with heavy rains and accompanying human impacts in most of Central America (Online Table S7.1). In the ETP, Tropical Storm Vicente developed off Guatemala on 20 October; however, no tropical storm made landfall on the isthmus. For additional information on regional impacts from hydrometeorological events during 2018, refer to Online Table S7.1.

Several severe storms occurred across the region during April-November. During the eight-month period, a total of 28 fatalities were reported with 27 people injured by lightning strikes (Online Table S7.2).

2) Caribbean-T. S. Stephenson, M. A. Taylor, A. R. Trotman, C. J. Van Meerbeeck, J. D. Campbell, A. Brown, and J. Spence

\section{(i) Temperature}

In 2018, most of the Caribbean basin exhibited above-average annual mean surface temperatures, with the highest anomalies toward the northwest and
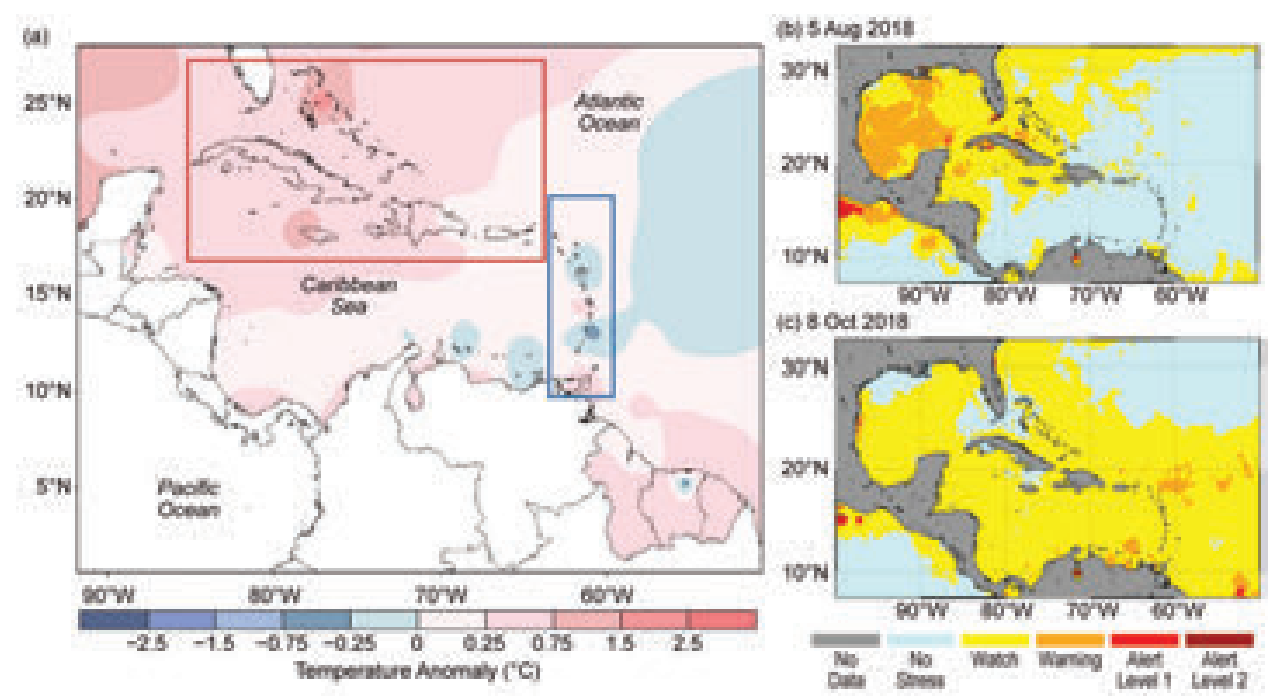

FIG. 7.9. (a) Annual mean temperature anomalies $\left({ }^{\circ} \mathrm{C}\right)$ relative to a $1981-2010$ base period. Coral reef watch maps for (b) Aug and (c) Oct 2018. The red rectangle indicates the north/west Caribbean. The blue rectangle indicates the south/east Caribbean. [Source: Caribbean Institute for Meteorology and Hydrology (CIMH).] the Guianas. Much of the northwest was at least $0.25^{\circ}-0.75^{\circ} \mathrm{C}$ warmer than normal, with Jamaica and northern Bahamas at least $0.75^{\circ}-$ $1.5^{\circ} \mathrm{C}$ warmer. In contrast, parts of the southern and eastern Caribbean experienced belowaverage annual mean temperatures (Fig. 7.9). The annual average maximum temperature$32.3^{\circ} \mathrm{C}$ observed at the Sangster International Airport 
(Jamaica) - was the highest since 1971. Lynden Pindling International Airport (Bahamas) reported its fifth highest maximum temperature since 1971$29.8^{\circ} \mathrm{C}$. Conversely, the annual average maximum temperature recorded at the Caribbean Institute for Meteorology and Hydrology (Barbados) was the third lowest since 1971 at $29.6^{\circ} \mathrm{C}$.

On 21 September, the maximum temperature of $33.3^{\circ} \mathrm{C}$ tied the record for that date set in 1993. The daily temperature of $31.7^{\circ} \mathrm{C}$ recorded at Henry E. Rohslen Airport in St. Croix on 5 December tied the record for that date set in 1972.

The Caribbean's SSTs exhibited a warm northeast and a cool southwest pattern with the highest temperature anomalies observed over the northern and western Caribbean and lowest anomalies just off the coast of South America. Normal to near-normal anomalies were observed across the rest of the region. The SST pattern persisted throughout the year with varying magnitudes and spatial extents observed in each quarter.

\section{(ii) Precipitation}

For the Caribbean as a whole, 2018 was drier than normal (Fig. 7.10), with drought conditions reported for some islands. For January-March, normal to belownormal rainfall was observed over most of the Caribbean, while the southern countries of the Lesser Antilles and parts of Puerto Rico, Hispaniola, Jamaica, and Cuba reported very wet to exceptionally wet conditions. Normal to below-normal precipitation characterized the second quarter of the year over the southern countries of the Lesser Antilles as well as the central Caribbean countries, including parts of Hispaniola and northern parishes in Jamaica. Some northern locations exhibited extremely wet conditions, including eastern Jamaica, western Cuba, and northern Bahamas.

During July-September, the eastern Caribbean observed normal to below-normal rainfall. Severely dry conditions were noted over many of the islands, suggesting an intensification of drying relative to the first half of the year. Southern Hispaniola, northwestern Jamaica, Cuba, and the northern Bahamas also experienced some level of dryness. Some relief from the dry conditions was observed over the eastern Caribbean during October-December, though amounts varied. Although dry conditions persisted over the central Caribbean, both positive and negative anomalies were evident. These mixed patterns were noted in tandem with weak El Niño conditions that developed during the last quarter of 2018. El Niño conditions typically result in below-normal rainfall over the eastern Caribbean with above-normal anomalies over the northern Caribbean during Northern Hemisphere win-

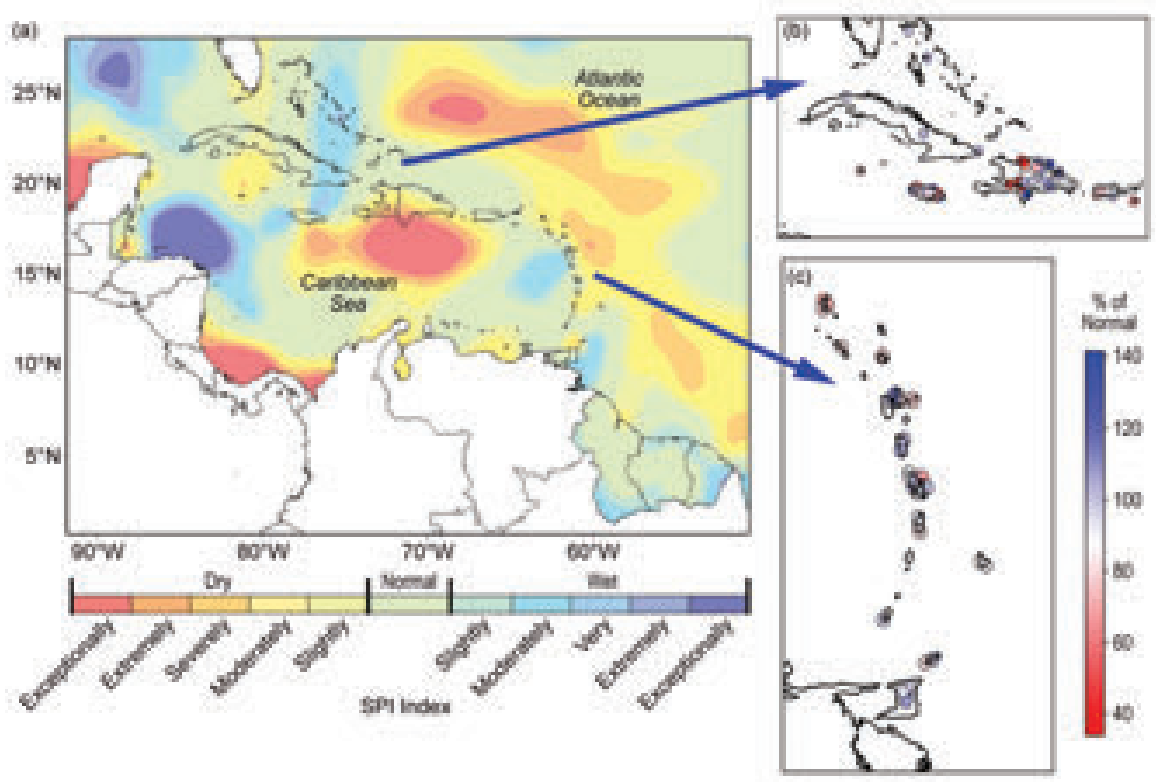

FIG. 7.10. 2018 annual rainfall pattern as characterized using the standardized precipitation index (SPI) across the Caribbean. The SPI is a representation of rainfall in units of std. dev. Positive values indicate greater-than-median rainfall; negative values indicate less-than-median rainfall [Source: Caribbean Climate Outlook Forum (CariCOF) and NCEP/NCAR Reanalysis Data. Prepared by the Caribbean Institute for Meteorology and Hydrology (CIMH).] Insets show the annual rainfall (\% of normal) using stations in different rainfall zones of the Caribbean. (Source: Climate Studies Group Mona.) ter months (Giannini et al. 2000; Spence et al. 2004; Stephenson et al. 2007). The weak 2018 El Niño conditions produced some of these features but not to the extent seen in previous events.

Record minimum annual rainfall totals were recorded at Hondo Valle and Villa Vásquez stations in the Dominican Republic, at $559.2 \mathrm{~mm}$ and $288.7 \mathrm{~mm}$, respectively. Other stations recording very high (above 90th percentile) or very low (below 10th percentile) annual rainfall totals are noted in Table 7.1. A record daily maximum rainfall total of $64.5 \mathrm{~mm}$ was observed on 8 November at Cyril E. King Airport in St. Thomas, breaking the previous record of $41.4 \mathrm{~mm}$ set in 2004 . 


\begin{tabular}{|c|c|c|c|}
\hline Country & Name of Station & $\begin{array}{c}\text { Rainfall } \\
\text { Total }(\mathrm{mm})\end{array}$ & Rank \\
\hline Anguilla & $\begin{array}{c}\text { Clayton J. Lloyd } \\
\text { International Airport }\end{array}$ & 702.7 & 2nd driest \\
\hline $\begin{array}{l}\text { Cayman } \\
\text { Islands }\end{array}$ & $\begin{array}{c}\text { Owen Roberts } \\
\text { International Airport, } \\
\text { Grand Cayman }\end{array}$ & 1108.3 & 8th driest \\
\hline $\begin{array}{c}\text { Dominican } \\
\text { Republic }\end{array}$ & Jimani & 397.3 & 5th driest \\
\hline $\begin{array}{l}\text { Dominican } \\
\text { Republic }\end{array}$ & Monte Cristo & 407.8 & 3rd driest \\
\hline $\begin{array}{l}\text { Dominican } \\
\text { Republic }\end{array}$ & Polo & 2329.0 & 5 th wettest \\
\hline $\begin{array}{c}\text { Dominican } \\
\text { Republic }\end{array}$ & Santiago Rodriguez & 913.3 & 4th driest \\
\hline Guadeloupe & La Désirade & 889.1 & 7th driest \\
\hline Haiti & Port-au-Prince & 592.0 & 2nd driest \\
\hline Martinique & Fond St-Denis & 3602.7 & 4th wettest \\
\hline Martinique & La Trinité & 1604.3 & 4th driest \\
\hline Tobago & Crown Point & 1188.6 & 6th driest \\
\hline
\end{tabular}

northern half of the island on 10 November.

\section{d. South America- A. Sánchez-Lugo, Ed. \\ Most of South America} had above-average temperatures during 2018, with the most notable high maximum temperatures across northern South America, where temperature departures were $+1.5^{\circ} \mathrm{C}$ or higher. Meanwhile, small areas across the region had minimum temperatures that were below-average. During 2018, drier-than-average conditions were present across much of the region, with the most notable dry conditions across Chile, southern Peru, southern and western parts of Argen-

(iii) Notable events and impacts

Caribbean SST anomalies were largest during July-September, triggering coral bleaching watches for the Cayman Islands, Jamaica, Puerto Rico, Virgin Islands, Trinidad and Tobago, and Panamá (Fig. 7.9). Bleaching warnings were issued in the east and northwest Cuba and alerts for southwest Cuba by mid-August. Short-term drought conditions were reported for some Caribbean islands, including the Bahamas, Cuba, Dominica, Hispaniola, St. Lucia, Tobago, and Martinique. The months of July through December were significantly drier than the historical average for a majority of the islands, adding to a longterm drought over Antigua and southern Hispaniola. The drought in Antigua impacted water availability and vegetation.

Heavy showers and thunderstorms were reported in St. Lucia, Dominica, Trinidad and Tobago, St. Vincent and the Grenadines, and Barbados on 29 September, associated with Tropical Storm Kirk. At the Grantley Adams International Airport, the passage of Kirk was accompanied by a record 24-hour rainfall total of $242.2 \mathrm{~mm}$ on 27 September. Flooding, disruption to telecommunication services, and power outages were observed.

A low-level trough produced significant rainfall across Dominica during 4-11 November, resulting in flooding, landslides, and rockfalls mainly across the tina, and across parts of eastern Brazil.

Anomalies in this section are with respect to the 1981-2010 average, unless otherwise noted.

I) Northern South America一R. Martínez, E. Díaz, D. Marín, R. Hernández, L. Cáceres, E. Zambrano, and J. Nieto

The northern South America region includes Colombia, Ecuador, French Guiana, Guyana, Suriname, and Venezuela.

\section{(i) Temperature}

In 2018, the temperature over northern South America was $+0.5^{\circ} \mathrm{C}$ above the $1981-2010$ average. Despite La Niña conditions and associated belownormal SSTs prevalent across the eastern tropical Pacific Ocean during much of the first half of 2018, air temperature was generally above normal during most of the year across the region.

Colombia, Suriname, French Guiana, Guyana, and Venezuela had annual maximum temperatures $1.5^{\circ}-2.0^{\circ} \mathrm{C}$ above normal. Some locations across eastern Venezuela and Guyana had annual maximum temperature anomalies greater than $+2.5^{\circ} \mathrm{C}$. Meanwhile, most of Ecuador observed 2018 maximum temperatures $0.5^{\circ}-1.0^{\circ} \mathrm{C}$ below average (Fig. 7.11a). Most of northern South America also experienced annual minimum temperatures $0.5^{\circ}-1.5^{\circ} \mathrm{C}$ higher than normal. Some isolated areas across southern 


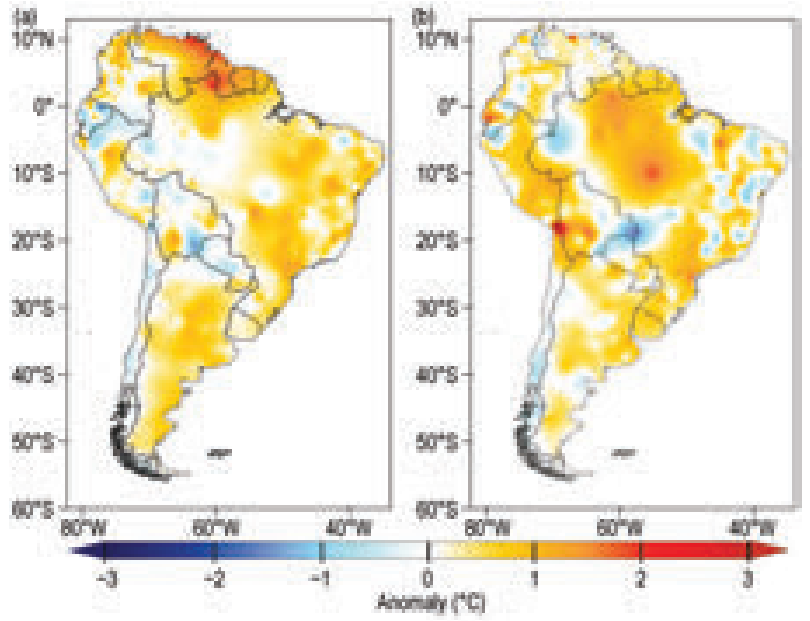

FIG. 7.II. Annual anomalies of 2018 (a) maximum and (b) minimum temperature $\left({ }^{\circ} \mathrm{C}\right.$; $1981-2010$ base period). (Source: Data from NMHSs of Argentina, Colombia, Chile, Brazil, Ecuador, Paraguay, Peru, Suriname, and Venezuela; processed by CIIFEN.)

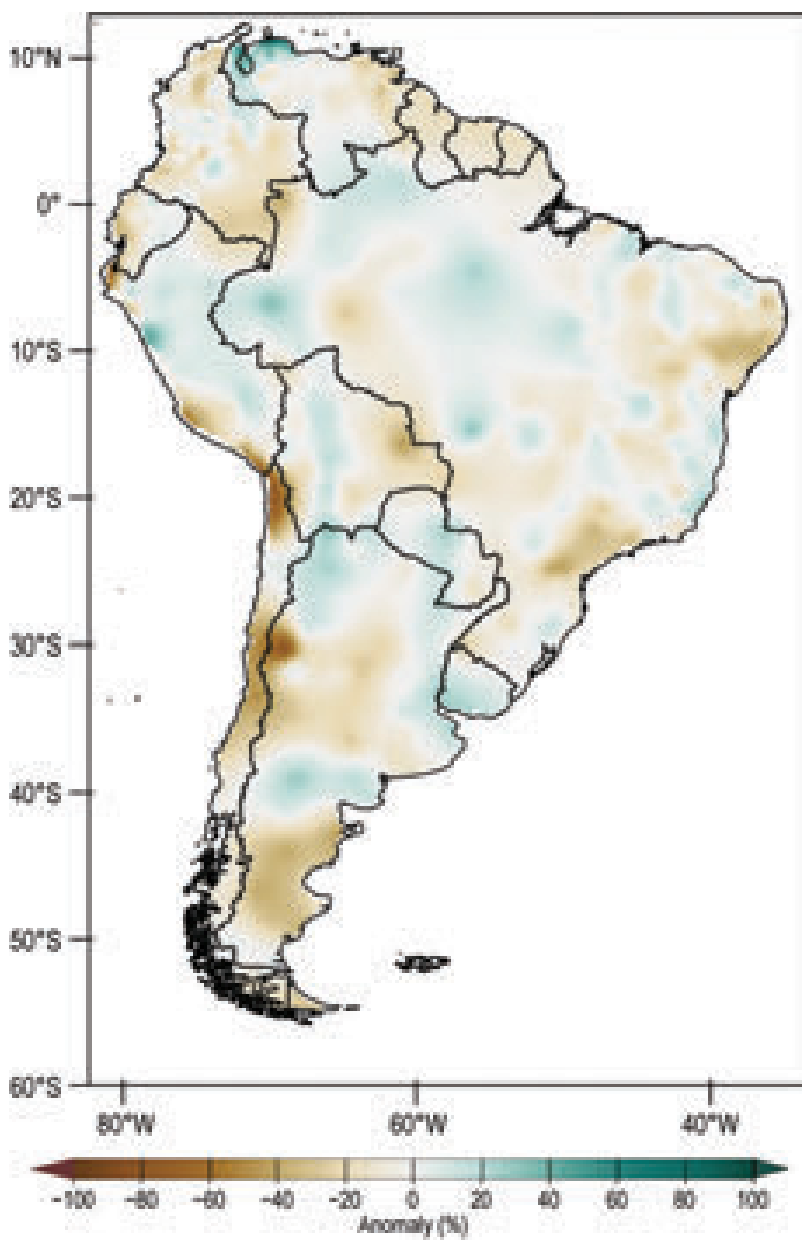

FIG. 7.12. Annual anomalies of 2018 precipitation (\%; 198 I-2010 base period). (Source: Data from NMHSs of Argentina, Colombia, Chile, Brazil, Ecuador, Paraguay, Peru, Suriname, and Venezuela; processed by CIIFEN.)
Ecuador, central Colombia, and northeastern and northwestern Venezuela had below-normal minimum temperature anomalies $\left(-0.5^{\circ} \mathrm{C}\right)$. Minimum temperature anomalies were higher than $+2.0^{\circ} \mathrm{C}$ in parts of western Ecuador, close to Guayaquil, and northern Venezuela, close to Caracas. (Fig. 7.11b).

\section{(ii) Precipitation}

Most of northern South America had belownormal precipitation during 2018. Below-normal precipitation ( $20 \%-30 \%$ below average) were observed across most of Colombia, western Ecuador, eastern Venezuela, French Guiana, and Guyana (Fig. 7.12). The most notable high precipitation anomalies $(60 \%-$ $70 \%$ above normal) during 2018 were present across the Maracaibo Lake region (northwestern Venezuela). Above-normal precipitation was particularly high during July and August in Colombia and Venezuela.

\section{(iii) Notable events and impacts}

Heavy rain fell in early April in southern Colombia. The most significant precipitation total was 58 $\mathrm{mm}$ in a 24 -h period, resulting in river floods affecting 4500 people in Nariño. In mid-April, copious rain fell in western Colombia, with $98.5 \mathrm{~mm}$ of rain recorded in a 2 -h period, causing the rapid overflow of the rivers near Cali. In Pereira (western Colombia), up to $54 \mathrm{~mm}$ rain fell in a 24 -h period, triggering a deadly landslide that killed 11 people. On 8 May, precipitation totaling $78 \mathrm{~mm}$ fell in one hour in Machala, Ecuador, causing flooding and landslides.

In August, eastern Colombia (Vichada and Guainía) and southern Venezuela (Bolivar, Apure, and Amazonas) experienced extreme rainfall events, leading to flooding and landslides. Venezuela's Orinoco River is the world's third largest river, with an average discharge of $33000 \mathrm{~m}^{3} \mathrm{~s}^{-1}$. Heavy rainfall on 24 August in Ciudad Bolivar caused a record August discharge of $50000 \mathrm{~m}^{3} \mathrm{~s}^{-1}$.

Central Venezuela experienced precipitation 60\% below average from May through July, causing 51000 cattle to die across the region. Although much needed rain fell in August, it was not enough to improve reservoir levels in southern Venezuela, which generates electricity for the main cities in the country. 
2) Central South America一J. A. Marengo, J. C. Espinoza, L. M. Alves, J. Ronchail, J. W. Lavado-Casimiro, I. Ramos, C. Dávila, A. M. Ramos, and F. A. Diniz

The central South America region includes Brazil, Peru, Paraguay, and Bolivia.

\section{(i) Temperature}

The 2018 temperature was $0.5^{\circ} \mathrm{C}$ above average across most of central South America, with $+1.0^{\circ} \mathrm{C}$ across southeastern Brazil. However, cooler-thanaverage conditions (of at least $0.5^{\circ} \mathrm{C}$ below average) was observed across the southern Andes of Peru and Bolivia.

April and May were characterized by aboveaverage temperatures across Bolivia, Paraguay, and southern Brazil $\left(+2^{\circ}\right.$ to $\left.+4^{\circ} \mathrm{C}\right)$; tropical Brazil (east of the Andes) experienced above-average temperatures between July and September. In winter (June-August), several cold episodes affected southern Brazil, into western Amazonia. In Peru, several cold episodes occurred from June through September, resulting in one of the coldest winters in recent decades in the Peruvian Andes (Sidebar 7.2). Above-average temperatures $\left(+1^{\circ}\right.$ to $\left.+2^{\circ} \mathrm{C}\right)$ were present from central
Amazonia to northeastern Brazil during JanuaryMarch and October-December.

\section{(ii) Precipitation}

Most of central South America had near-normal precipitation during 2018. The highest annual precipitation anomalies (30-50 $\mathrm{mm} \mathrm{month}^{-1}$ ) were present across central and southwestern Amazonia. Precipitation deficits of $50 \mathrm{~mm}$ month $^{-1}$ were observed over southeastern and northeastern Brazil.

The first half of 2018 was characterized by belownormal precipitation in most of central South America, from the Amazon region of Peru to northeastern Brazil (100-150 $\mathrm{mm} \mathrm{month}^{-1}$ ), and this situation continued through August. However, the Peruvian coast experienced rainfall deficits of 30\%-90\% below the annual average.

In 2018, several episodes of heavy precipitation in the region triggered landslides and floods that affected urban areas in Brazil and Paraguay to the isolated regions of the Andes of Peru and Bolivia. These incidents caused many fatalities, left thousands of people displaced, and interrupted transportation and agricultural activities (see next section).

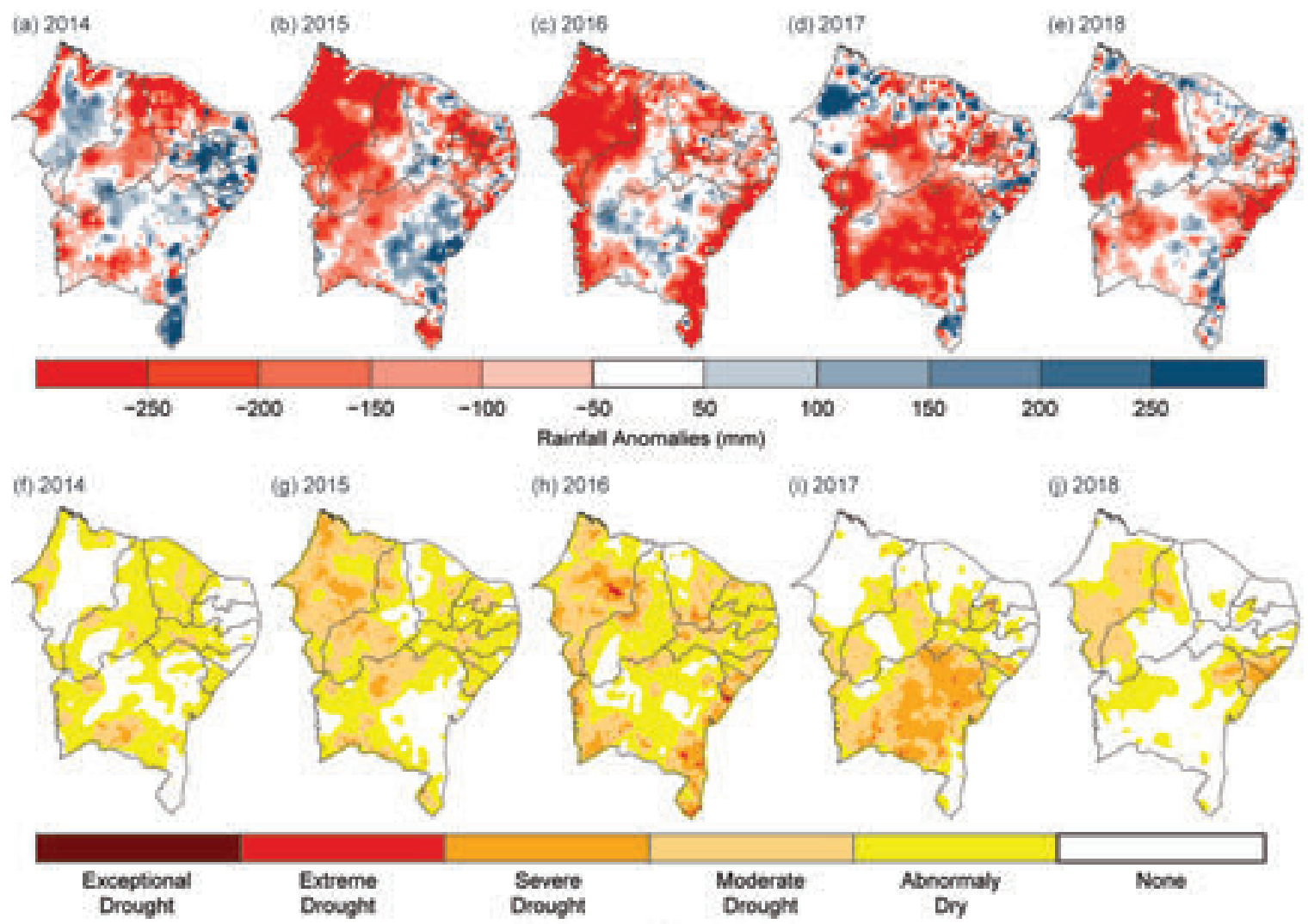

FIG. 7.I3. (a-e) Precipitation anomalies ( $\mathrm{mm}$; $198 \mathrm{I}-2010$ base period) and $(\mathrm{f}-\mathrm{j})$ integrated drought index for northeastern Brazil from 2014 to 2018. (Source: CEMADEN.) 


\section{SIDEBAR 7.2: HEAVY SNOWFALLS IN THE PERUVIAN ANDES: THE WETTEST WINTER OF THE LAST 19 YEARS- \\ I. RAMOS, V. ALIAGA-NESTARES, AND A. Y. CASTRO}

The rainy (September-April) and dry (May-August) seasons are well marked in Peru. During the rainy season, the highest precipitation totals occur in the austral summer (December-February) due to strong advection of warm, humid air from the Amazonia basin to the central Andes, a strong easterly zonal flow, and the enhancement of the Bolivian High (Garreaud 1999; Garreaud et al. 2003). Therefore, snowfalls in the Andean region of Peru are also more frequent during the austral summer.

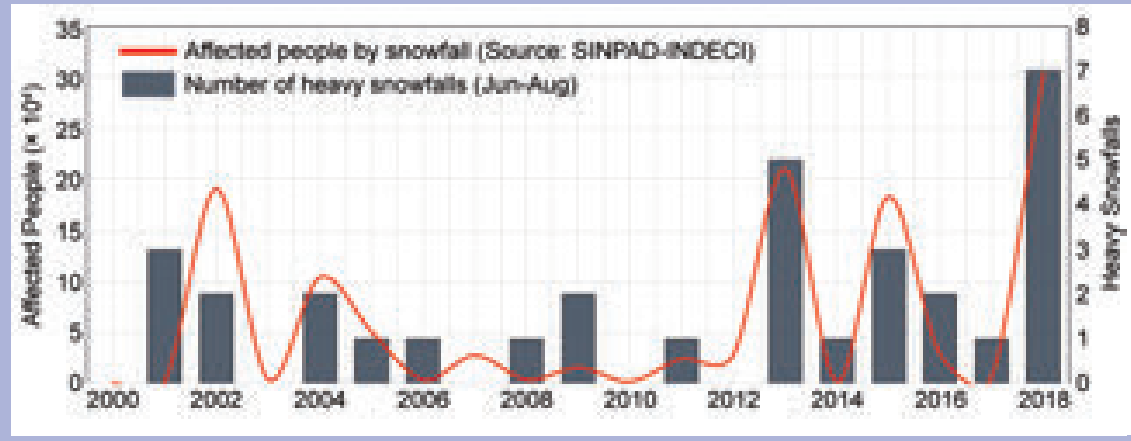

FIG. SB7.3. Number of annual heavy snowfall events (gray bars) registered for the period 2000-18 (Jun-Aug, an exception being 2005 when an event happened in Sep), and the number of people affected (red line) by snowfalls.

However, the most intense and widespread snowfalls generally occur in the austral winter (June-August) in regions above 4000 m a.s.I. (Quispe 2017; Quispe 2014). Over the last 19 years (2000-18), two to three annual snowfall events, on average, have occurred mainly in July and August (Fig. SB7.3). The years 2013 and 2018 featured the highest number of heavy snowfalls from June-August, with five and seven events, respectively.

Winter 2018 was the wettest winter in the 19-year record due to a large number of heavy snow and rainfall events, as well as a decrease in frost periods. The record seven heavy snowfalls (Fig. SB7.3) affected the southern Andean region above $3300 \mathrm{~m}$ a.s.I. (Fig. SB7.4), where normally these events occur in regions above $4000 \mathrm{~m}$ a.s.I. (Quispe 2017). Notably, June 2018 had the most snowfall episodes (three) among all months of the last 19 years; normally no snow events are detected in June.

Two of the heaviest snowfalls in 2018 occurred during 2-4 June and 19-23 July, each of which reached as much as $40 \mathrm{~cm}$ in some localities, such as Puno, located above $4000 \mathrm{~m}$ a.s.l. The July event was the most extensive in geographical coverage as compared with the other winter storms (yellow color, Fig. SB7.4). It affected the central and southern Andean regions, and the accumulated snow remained for five days. Additionally, the cloudy conditions associated with these events led to several new record low maximum temperatures: $9.7^{\circ} \mathrm{C}$ in Huancavelica (climatology of $17.7^{\circ} \mathrm{C}$ ); $11.2^{\circ} \mathrm{C}$ in Huancapi (in the Ayacucho region, climatology of $20.7^{\circ} \mathrm{C}$ ); and $9.8^{\circ} \mathrm{C}$ in Sicuani (Cusco, climatology of $19^{\circ} \mathrm{C}$ ) in June. In July, new record low temperatures include $3.8^{\circ} \mathrm{C}$, observed in Yauri (Cusco, climatology $15.8^{\circ} \mathrm{C}$ ), and $4^{\circ} \mathrm{C}$, observed in Ayaviri (Puno, climatology of $15.7^{\circ} \mathrm{C}$ ).

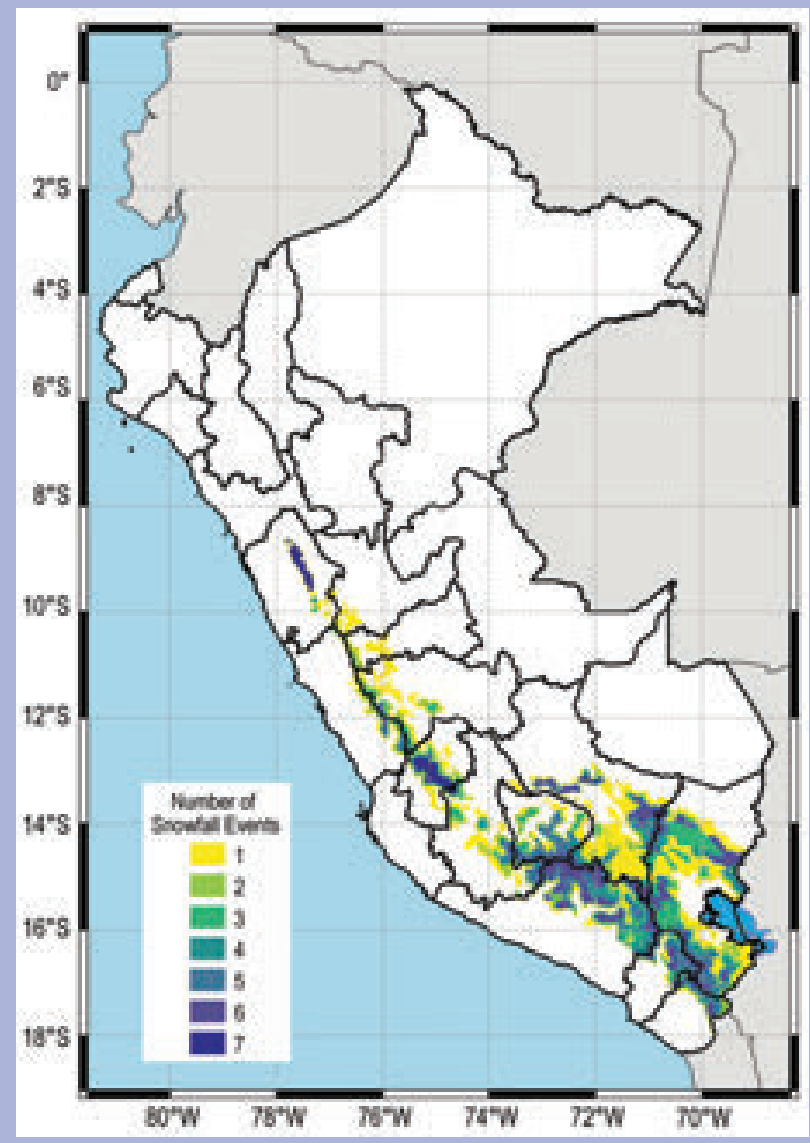

FIG. SB7.4. Spatial distribution of the seven extreme snowfall events that occurred during Jun (3 events), Jul (2 events), and Aug ( 2 events) of 2018 in the central and southern Peruvian Andes, estimated by GOES-16 and MODIS. 
Most meteorological stations in the central and southern Peruvian Andes also received heavy rainfall in June and July. On 2 June, Ananea, which is located in Puno at $4660 \mathrm{~m}$ a.s.l., recorded $32.5 \mathrm{~mm}$ (monthly climatology is $8.4 \mathrm{~mm}$ ), and Sicuani, located in Cusco at $3574 \mathrm{~m}$ a.s.l., accumulated $13 \mathrm{~mm}$ on 21 July (monthly climatology is $3.7 \mathrm{~mm}$ ).

The many precipitation events were associated with the entrance of troughs and cut-off lows from midlatitudes and by the increased moisture flux in the low and middle levels of the atmosphere (Quispe 2017; Quispe 2014; Quispe and Avalos 2006; Vuille and Ammann 1997). In the composite upper-tropospheric $(250 \mathrm{hPa})$ analysis of seven snowfall events (Fig. SB7.5), an anomalous trough over the Pacific Ocean with the divergent side of the jet stream over southern Peru and an incursion of cold air created an optimal environment for the development of convective storms in the southern Andes of Peru, all of which are most likely to occur in the afternoon and night.

Meanwhile, in the mid-troposphere, composites of daily mixing ratio analysis at the $500-\mathrm{hPa}$ level (Fig. SB7.5) during all 2018 snowfall events show anomalous moisture over the central and southern Peruvian Andes, associated with an anomalous localization of a trough over the eastern Pacific Ocean near Peru. These conditions appeared farther north than their normal position, generating advection of cold air. In most of the snowfall events, these troughs evolved into a cut-off low over the Pacific Ocean. Of the seven strong and moderate snowfall events considered here, four were associated with the development of a cut-off low over the Pacific Ocean near Peru. This was the main factor that generated snow over the Peruvian Andes in the winter. One of these cut-off low events caused hail and electric storms in the central coast of Peru on 20 July.

Overall, the snowfalls of 2018 affected over 300000 people, and roads and highways were inaccessible in several regions due to the accumulated snow. Cattle raising was affected because snow covered and damaged the pastures, causing many of the animals to starve; official numbers indicated more than 25700 sheep and 45200 camels were lost.

The dry conditions observed in northeastern Brazil since 2012 (Marengo et al. 2017; Cunha et al. 2019) persisted through 2018, but with less intensity. Drought indices (Cunha et al. 2019) depict severe-to-extreme drought for much of northeastern Brazil during 2018
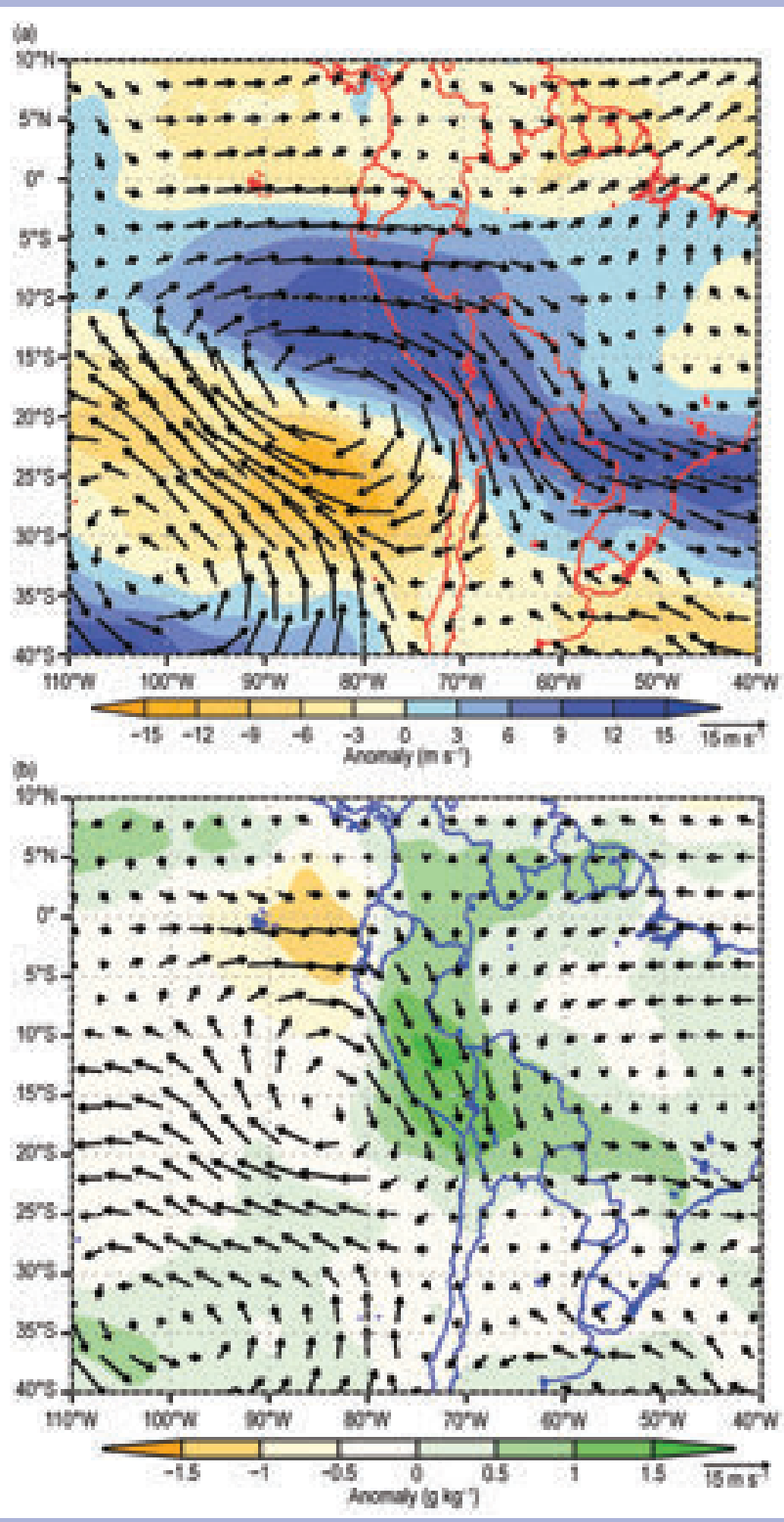

FIG. SB7.5. Composite anomaly map of (a) 250-hPa wind (vectors) and magnitude (shaded, $\mathrm{m} \mathrm{s}^{-1}$ ), and (b) 500-hPa wind (vectors) and humidity mixing ratio (shading; $\mathbf{g ~ k g}^{-1}$ ), of seven extreme snowfall events occurred Jun-Aug 2018. (Source: ERA-interim.)
(Fig. 7.13). Below-normal precipitation in the region may be attributed to an anomalously northward position of the ITCZ, which resulted from a warmer-thannormal tropical North Atlantic Ocean and reinforcing pulses of the MJO during summer and autumn 2018. 


\section{(iii) Notable events and impacts}

During the austral summer and autumn, five episodes of the South Atlantic Convergence Zone (SACZ) forming and remaining in place for several days produced heavy rainfall and, as a consequence, floods and mudslides occurred in some cities in southeastern Brazil.

Intense precipitation also affected central Amazonia during 5-12 January due to a southward displaced ITCZ. On 7 January in Eirunepé (state of Amazonas), the total daily rainfall of $106.0 \mathrm{~mm}$ was the highest January daily rainfall value observed in the city since 1961 (January climatology: $281.7 \mathrm{~mm}$ ). On 15 February, heavy rainfall in the city of Rio de Janeiro caused deadly floods and affected public transportation and the energy supply; the city received $75 \%$ of its normal February precipitation total in just nine hours. On that day, the city of Belo Horizonte and other areas of the state of Minas Gerais experienced a burst of torrential rain. In Belo Horizonte, $74.6 \mathrm{~mm}$-nearly half of February's historical average of $181.4 \mathrm{~mm}$-fell in just 20 minutes.

The metropolitan region of São Paulo experienced its driest austral summer since 2003, receiving only $572.3 \mathrm{~mm}$ of rain, which is $79 \%$ of its $1961-2017$ mean of $721.4 \mathrm{~mm}$. The extreme dry conditions contributed to the development of wildfires that affected crop fields and protected areas. According to Instituto $\mathrm{Na}-$ cional de Pesquisas Espaciais (INPE), there were 1421 fires from January to July 2018 compared to 675 fires during the same period in 2017-an increase of 111\%.

In central-southern Bolivia, intense and persistent rains and subsequent floods during January-February affected 17000 families and killed six people.

Paraguay's 2018 rainfall total was $350.8 \mathrm{~mm}$ higher than the yearly average of $883 \mathrm{~mm}$, according to the Dirección de Meteorología e Hidrología of Paraguay. In mid-January, heavy rain fell across parts of the country; some locations in the east received as much as $100 \mathrm{~mm}$ within a 48 -h period during 12-14 January (January climatology: $25 \mathrm{~mm}$ ). On 23 January, the Paraguay River level was $5.72 \mathrm{~m}$ at Asunción, well above the critical level of $5.5 \mathrm{~m}$; the flooding affected 4233 families. Meanwhile, drought conditions were present across southern Paraguay in May, forcing its government to declare a state of emergency.

On 4 June, a cold front brought cold temperatures to southern Brazil, with several locations setting new minimum temperature records. Of note, Curitiba set a new June record minimum temperature of $0.7^{\circ} \mathrm{C}$ (climatology of $8.4^{\circ} \mathrm{C}$ ). The cold front extended toward Bolivia and Peru, causing below-freezing temperatures in Peru's southern Andes by 6 June.
The below-freezing temperatures affected over 32000 people in the region. In addition, 1540 ha of crops and more than 3400 animals perished due to the extreme cold. Another cold front on 15 June affected the Bolivian and Peruvian Amazon, with several locations reporting temperatures as low as $13^{\circ} \mathrm{C}$ (climatology of $24.5^{\circ} \mathrm{C}$ ). A state of emergency was declared on 22 June for 122 districts in the southern Peruvian Andes due to the impact of frost and snowfall. During 13-23 July, several snowfall episodes occurred in the southern Peruvian Andes region; these were particularly intense over the states of Apurimac, Puno, and Tacna. Extreme cold conditions were recorded in the southern Peruvian Andes on 23 August, where minimum temperatures reached $-20^{\circ} \mathrm{C}$ in regions above 4000 $\mathrm{m}$ (climatology of $-10^{\circ} \mathrm{C}$ for August).

According to Peru's National Emergency Operations Center (COEN), heavy rain beginning 10 October in the central Andean region caused floods affecting 431 families and homes. By 8 November, 290 districts in eight departments of the mountain region were at risk of landslides and mudslides. In the Tumbes department in northwestern Peru, overflow of several gorges due to heavy rain affected 970 families and agriculture.

Heavy rains in December triggered deadly floods and landslides in the central and southern part of the Peruvian Andes. Of note, a landslide in the Department of Ancash on 19 December left residents of four districts isolated and without communication through the beginning of 2019 .

3) Southern South America一J. L. Stella, L. S. Aldeco, D. A. Campos Díaz, and N. Misevicius

This region includes Argentina, Chile, and Uruguay.

\section{(i) Temperature}

Above-normal temperatures were observed across most of southern South America (SSA) during 2018, particularly notable over Argentina and Uruguay. Conversely, central and southern Chile had normal to below-normal temperatures (Fig. 7.11). The annual mean temperature anomalies across SSA ranged between $-0.7^{\circ} \mathrm{C}$ and $+1^{\circ} \mathrm{C}$. The national mean temperature anomaly for both Argentina and Uruguay was $+0.3^{\circ} \mathrm{C}$. For Argentina, 2018 was its ninth warmest year since recordkeeping began in 1961 (Fig. 7.14).

Austral summer (December-February) 2017/18 was quite warm across most of central and southern SSA. January and February were characterized by above-average temperatures, with several heat waves 


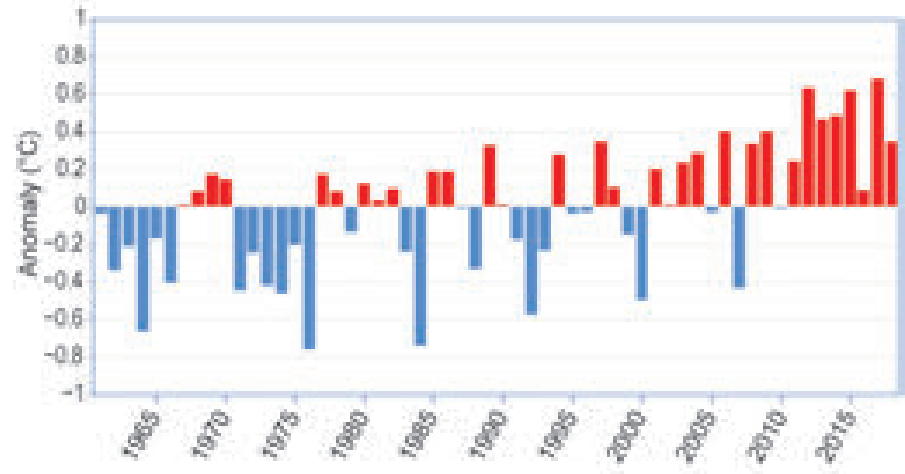

Fig. 7.14. Annual mean temperature anomalies $\left({ }^{\circ} \mathrm{C}\right.$; $1981-$ 2010 base period) for Argentina for 196I-2018. (Source: Argentina's National Meteorological Service.)

affecting Chile, Argentina, and Uruguay. The most prolonged (maximum duration of 6 days) and intense heat wave occurred in February.

Austral autumn (March-May) temperatures were $1.0^{\circ}-2.5^{\circ} \mathrm{C}$ above average. April was particularly warm with temperatures $2^{\circ}-5^{\circ} \mathrm{C}$ above average; several locations set new high-temperature records and it was the warmest April on record for Argentina and Uruguay. Mercedes, Uruguay, reached $37.2^{\circ} \mathrm{C}$ on 11 April, surpassing the previous maximum national temperature record for April (36. $6^{\circ} \mathrm{C}$ in Rivera on 2 April 2010).

Below-normal temperatures dominated most of the region during austral winter (June-August). Several eruptions of cold air affected SSA, particularly during June and July, with cold waves and intense snowfalls in the southern region of Chile and Argentina. Extreme low temperatures across Chile were observed between 1-5 June. Argentina and Uruguay each experienced their coldest winter since 2007-their seasonal mean temperature was $0.8^{\circ} \mathrm{C}$ and $1.1^{\circ} \mathrm{C}$ below normal, respectively.

Intraseasonal variability dominated austral spring (September-November) as the region experienced a record warm September $\left(+2.5^{\circ} \mathrm{C}\right.$ and $+1.9^{\circ} \mathrm{C}$ for Uruguay and Argentina, respectively), a cold October, and a near-average November. The first half of December 2018 brought cold conditions to most of central and northern Argentina and Uruguay, while the Patagonia region experienced warm conditions. Late frosts affected agriculture in the Buenos Aires province. However, the last week of December was extremely warm and wet north of $40^{\circ} \mathrm{S}$, conditions that favored the development of some heat wave events.

\section{(ii) Precipitation}

Rainfall was below average for much of central and southern SSA; central and southern Chile, central Argentina, and the Patagonia region had the most significant annual rainfall deficits. Conversely, northern and eastern SSA had above-normal rainfall.

The first months of the year were dominated by weak La Niña conditions, which, in combination with other forces, contributed to central Argentina's worst drought in at least 50 years (see Notable events and impacts for details). From April onward, coinciding with the ending of La Niña, the severe drought ended. Much of the region experi-
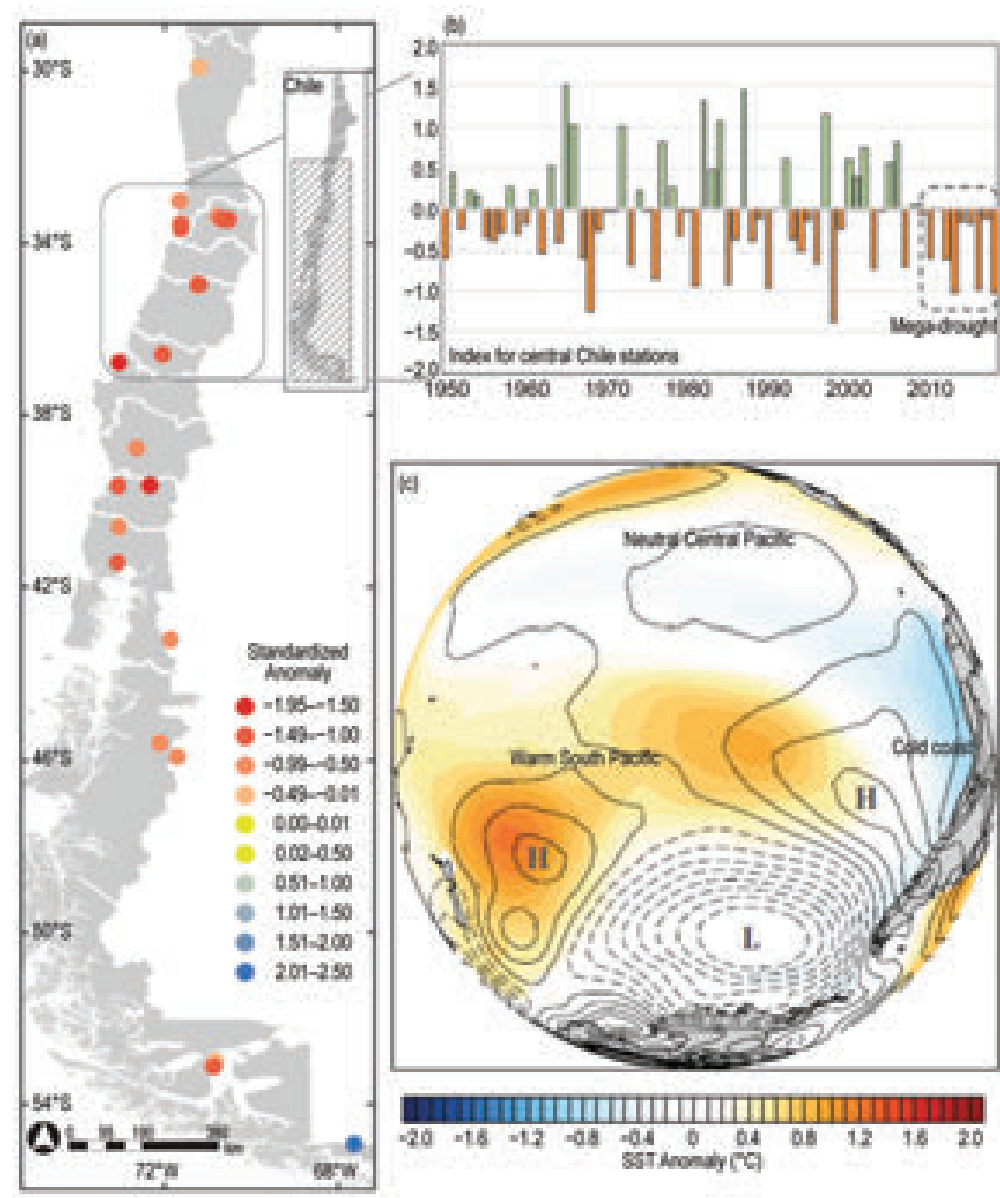

FIG. 7.I5. Standardized precipitation anomaly (a) map and (b) time series for stations in Chile for Jun-Aug 2018. (c) SST anomalies ( ${ }^{\circ} \mathrm{C}$; 1981-2010 base period) and SLP anomalies ( $\mathrm{hPa}$; dashed lines indicate negative anomalies; solid lines indicate positive anomalies) across the southern Pacific Ocean. 
enced a rainy May. Heavy rainfall affected Cordoba and the Santa Fe provinces in Argentina and across parts of Chile.

Below-normal rainfall was present across most of SSA during winter 2018. In central Chile, winter was dry. The atmospheric pattern in winter included a strong high pressure in the subtropical eastern Pacific and an anomalous low pressure over the Bellingshausen Sea (Fig. 7.15). The SST anomalies depicted near-average conditions across the central Pacific Ocean and below-average SST off the northern coast of Chile. These atmospheric and oceanic anomaly patterns are similar to those of previous years, favoring the continuation during 2018 of the prolonged drought that began in 2010. In Santiago, the 2018 annual precipitation deficit was $56 \%$ below average.

In spring, particularly during November and December, central-eastern Argentina and Uruguay experienced several daily intense rainfalls.

\section{(iii) Notable events and impacts}

The first three months of the year were extremely dry over much of central Argentina and Uruguay. Precipitation totals between January and March were $150-400 \mathrm{~mm}$ below normal, which is $50 \%-85 \%$ below normal in the areas most affected. It is important to note that these extreme dry conditions had already begun during the last quarter of 2017. Despite the weak La Niña conditions, the impacts were significant and led to the most severe drought in the last five decades with estimated losses around $\$ 6$ billion (U.S. dollars). October 2017-March 2018 was the driest period on record for a large part of central Argentina. Drought conditions deteriorated during February and March due to the combination of extreme heat and lack of precipitation.

During January and February, several heat waves affected SSA. Between 1 and 9 February, Argentina and Chile experienced prolonged heat waves, with some locations setting new February maximum temperature records: $40.6^{\circ} \mathrm{C}$ in Santa Rosa (5 February); $40.2^{\circ} \mathrm{C}$ in Comodoro Rivadavia (2 February); and $38.8^{\circ} \mathrm{C}$ in Ezeiza (8 February). Southern Chile experienced unusually high maximum and minimum temperatures, exceeding the 90th percentile in February. Of note, Chile Chico $\left(46^{\circ} \mathrm{S}\right)$ reached a maximum temperature of $30^{\circ} \mathrm{C}$, while Puerto Natales $\left(51^{\circ} \mathrm{S}\right)$ had a minimum temperature of $19^{\circ} \mathrm{C}$ during 1-6 February. A heat wave affected Uruguay during 7-12 January, resulting in a new all-time national record set in Paysandú when temperatures soared to $38.9^{\circ} \mathrm{C}$ on 11 January.
In Chile, intense precipitation with strong winds affected Juan Fernandez Island $\left(33.6^{\circ} \mathrm{S}, 78.9^{\circ} \mathrm{W}\right)$ in late May, where total precipitation of $144.7 \mathrm{~mm}$ day $^{-1}$ was recorded-the third highest daily precipitation total in the historical record. Of particular note is the intense precipitation that occurred 28 May, during 16-17 UTC, when rainfall totals reached $67.2 \mathrm{~mm}$ in a single hour. The heavy rain triggered flooding and landslides, causing roadways to be inaccessible in different parts of the island.

In December 2018, 53 daily rainfall events of more than $50 \mathrm{~mm}$ were observed across Argentina, causing severe damages in several provinces; 14 of those events happened on 13 December. On that day, a severe storm affected eastern Argentina and Uruguay, generating intense rainfall totals in short time periods, strong winds, and strong electrical activity. Some of the most affected locations were in Uruguay: Soriano (192 mm), Colonia (183 mm), Montevideo (175 mm), Canelones (170 mm), and Maldonado (170 $\mathrm{mm}$ ).

\section{e. Africa-A. Mekonnen, Ed.}

In 2018, most of North Africa, east of Morocco and north of $10^{\circ} \mathrm{N}$, as well as eastern Africa, equatorial Africa,

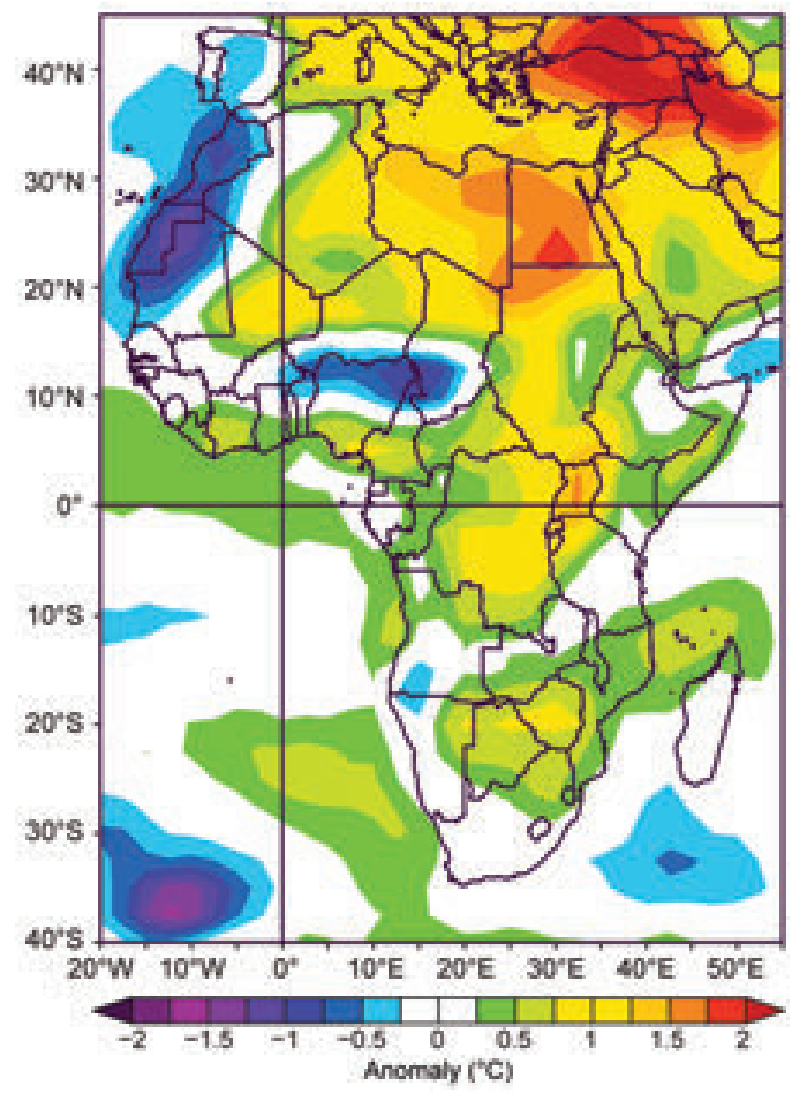

FIG. 7.16. Annual 2018 mean temperature anomalies ( ${ }^{\circ} \mathrm{C}$; 198I-2010 base period) over Africa. (Source: NOAA/NCEP.) 
and southeastern Africa, experienced above-normal temperatures, with below-normal temperatures recorded over Morocco and in pockets of West Africa (Fig. 7.16). Annual mean rainfall was near average over much of North Africa and above average over parts of Morocco and much of central and West Africa between the equator and $15^{\circ} \mathrm{N}$. Below-normal rainfall was observed across the Great East African Rift Valley extending southwestward into Namibia and Zambia (Fig. 7.17).

This report was compiled using observational records from the meteorological and hydrological services of Morocco, Algeria, Egypt, Nigeria, South Africa, and the southern Indian Ocean island countries of Madagascar, Seychelles, Mayotte (France), La Réunion (France), Mauritius, and Rodrigues (Mauritius). Also used were climate reports from the North African Regional Climate Center Network; Global Precipitation Climatology Project (GPCP) rainfall data; reanalysis data from NOAA's National Centers for Environmental Prediction/National Center for Atmospheric Research (NCEP/NCAR) and the latest fifth generation European Centre for Medium-Range Weather Forecasts (ECMWF; ERA5); and rainfall data from version 2 of the Climate Hazards Group

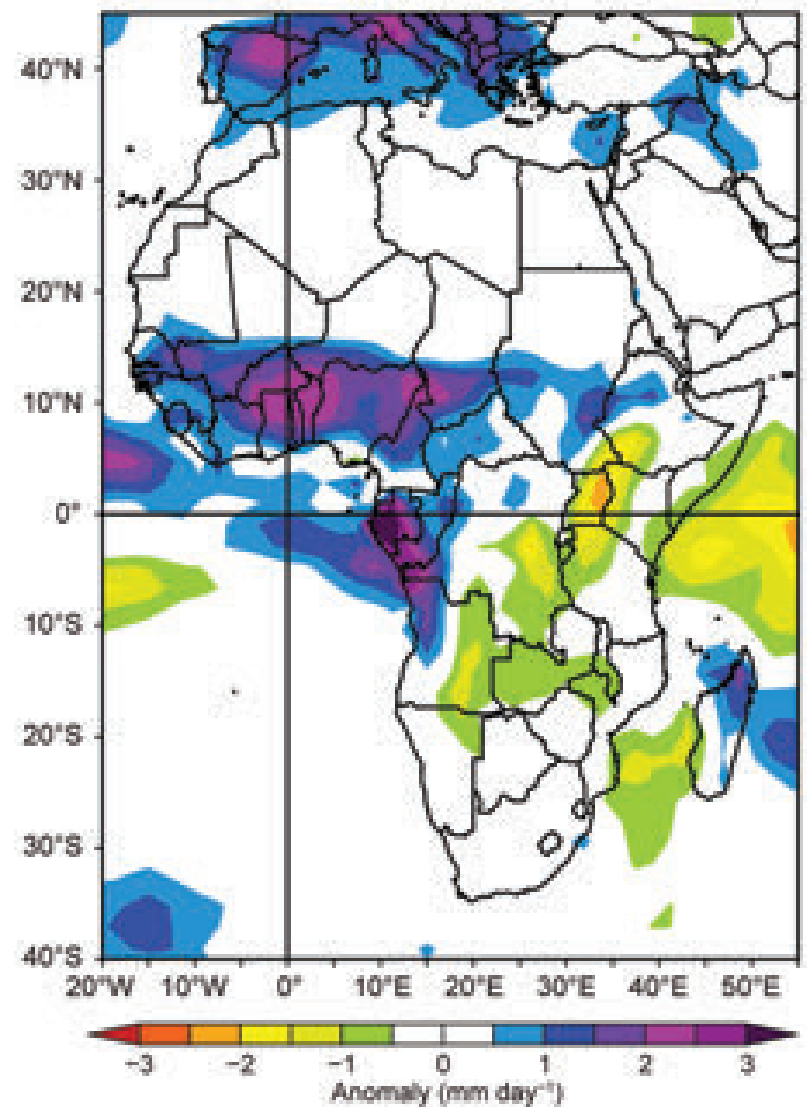

FIG. 7.17. Annual 2018 rainfall anomalies $\left(\mathrm{mm}\right.$ day $^{-1}$; 198I-2010 base period) over Africa (Source: NOAA/ NCEP.)
Infrared Precipitation with Station Data (CHIRPS). Impacts are as reported in news outlets or by official agencies. The climatological base period used is 1981-2010.

(I) North Africa—K. Kabidi, A. Sayouri, M. ElKharrim, A. E. Mostafa

Countries in this report are Morocco, Mauritania, Algeria, Tunisia, Libya, and Egypt.

\section{(i) Temperature}

Annual temperatures were below average over North Africa west of the date line, while aboveaverage temperatures were observed across the eastern parts of North Africa (Fig. 7.15). Egypt observed annual temperatures more than $1.5^{\circ} \mathrm{C}$ above normal.

During winter (December-February 2017/18), temperatures were below normal from northern Morocco southward into Mauritania (Fig. 7.18). Temperature anomalies up to $-3.5^{\circ} \mathrm{C}$ were reported over the mountains, coastal areas, and interior of Morocco. Stations in northern Algeria reported temperature anomalies of approximately $-1^{\circ} \mathrm{C}$. Near-normal temperatures were observed over most of Algeria, Tunisia, and Libya, while above-average temperatures were reported over most of Egypt.

In Tunisia and Libya, temperatures for spring were overall above normal. Summer temperatures were slightly above normal over most of North Africa (not shown); however, the mean July temperature was notably above average over most of the North African region, except for pockets in northwest Morocco. Temperature anomalies of $+4^{\circ} \mathrm{C}$ were observed over the common border between Algeria, Tunisia, and Libya in July (Fig. 7.19). Daytime temperature anomalies ranging from $+2^{\circ}$ to $+9^{\circ} \mathrm{C}$ above normal were recorded in Algeria in July.

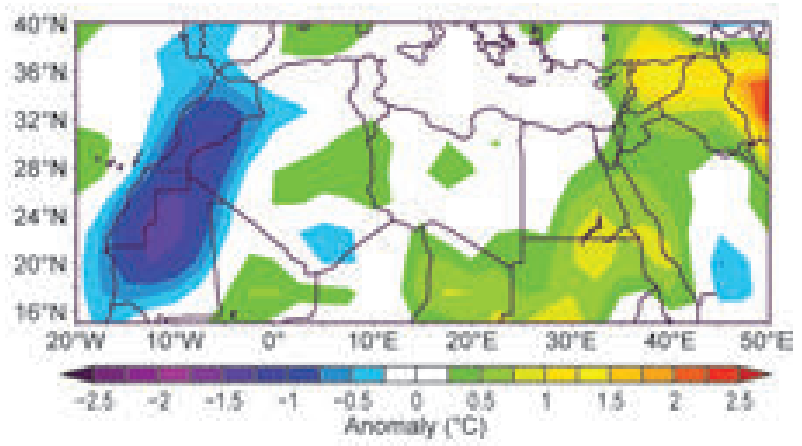

FIG. 7.18. Northern Africa temperature anomalies $\left({ }^{\circ} \mathrm{C}\right.$; 198I-20I0 base period) for Dec-Feb $2017 / 18$ (Source: NOAA/NCEP.) 


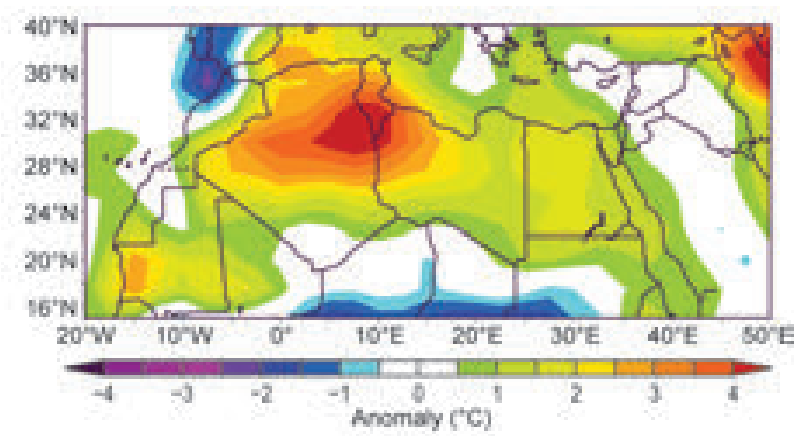

Fig. 7.19. Northern Africa temperature anomalies $\left({ }^{\circ} \mathrm{C}\right.$; 198|-2010 base period) for Jul 2018 (Source: NOAA/ NCEP.)

\section{(ii) Precipitation}

The northernmost parts of Egypt reported belowaverage precipitation in winter, while Morocco received rainfall $\geq 136 \%$ of its normal in winter and spring, which is about $40 \%$ higher than was recorded in 2017. In March and April, Morocco reported two storms with copious rainfall: $+219 \%$ and $+88 \%$, respectively (see Notable events and impacts for more detail).

Above-average precipitation was reported in northern Algeria, Tunisia, and northern Libya during the winter season 2017/18, while below-average precipitation was observed across parts of Morocco (Figs. 7.20a). During spring (March-May; Fig. 7.20b), above-normal precipitation was observed over the northern regions of Morocco, Algeria, and Tunisia, along with part of west-central Libya, and central and eastern Egypt. Departures from average were as high as $2 \mathrm{~mm}$ day $^{-1}$ over part of northwestern Morocco and a small area of northern Algeria. During autumn (September-November; Fig. 7.20c), all of Morocco and Tunisia were wetter than average, along with parts of Algeria, northern Libya, and northern Egypt. In October, Morocco recorded precipitation amounts $200 \%$ of average. No regions observed below-normal precipitation during the season. December 2018 precipitation was below average over most of Morocco, Algeria, Tunisia, and northern Libya.

For the year overall (not shown), the Saharan region of Morocco reported a significant rainfall deficit (77\% of the climatological average in Smara), while near-normal precipitation was observed in the central and northern part of the country.

\section{(iii) Notable events and impacts}

Morocco reported near-hurricane strength winds exceeding $30 \mathrm{~m} \mathrm{~s}^{-1}$ in March, April, and October, including a maximum peak of $45 \mathrm{~m} \mathrm{~s}^{-1}$ recorded on 30 April at Errachidia in the southeast of the country.

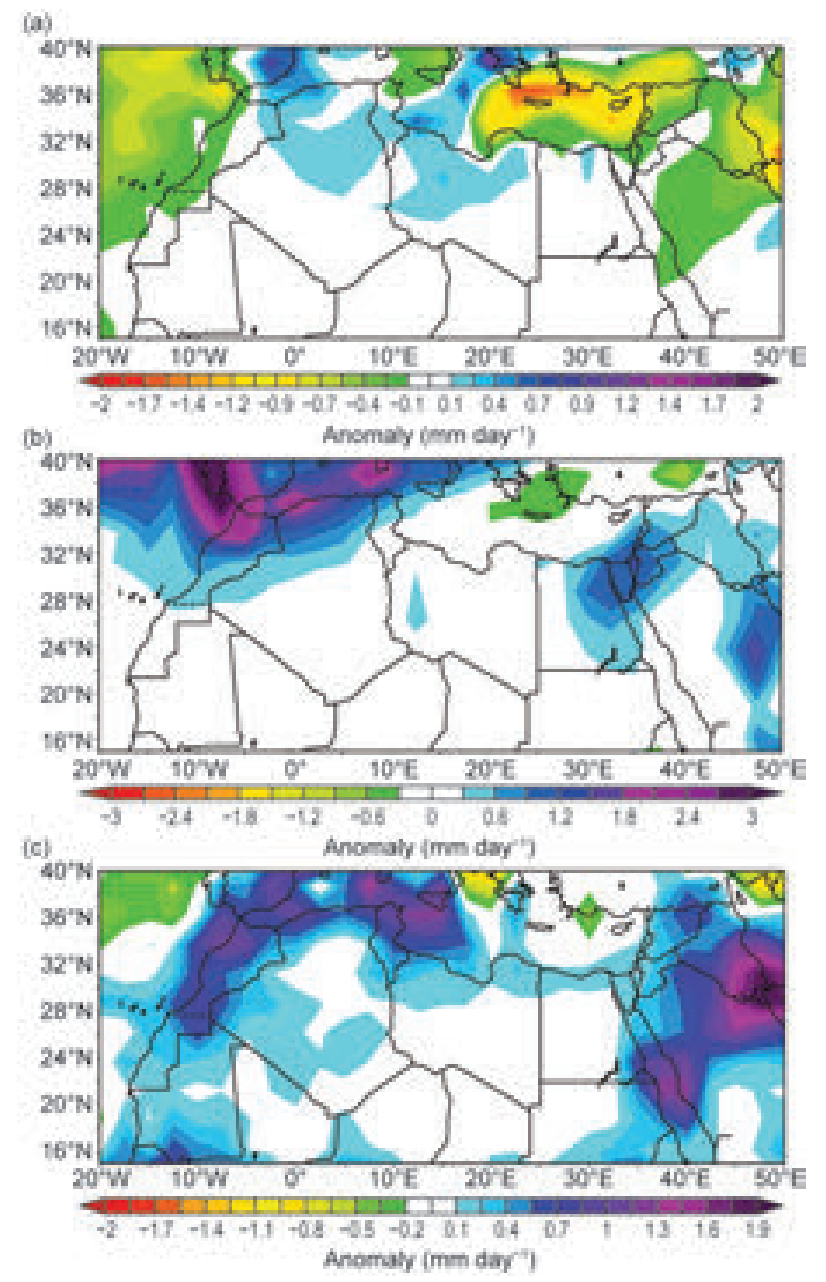

FIg. 7.20. Northern Africa precipitation anomalies (mm day ${ }^{-1}$; 198I-2010 base period) for (a) Dec-Feb 2017/18, (b) Mar-May 2018, and (c) Sep-Nov 2018. (Source: GPCP.)

Injuries and property damages were reported as a result of flooding associated with several strong storms during March and April.

During July and August, Morocco and Algeria both experienced a succession of heat waves, with temperatures exceeding $40^{\circ} \mathrm{C}$. These heat waves reached the northern region, including coastal areas. Maximum temperature records were set in south Algeria. Ouargla reached $51.3^{\circ} \mathrm{C}$ on 5 July, the highest temperature ever recorded in Algeria by reliable instruments, according to the World Meteorological Organization. Forest fires due to the heat waves were reported in northern Morocco and eastern Algeria. Nearly 230 fires in Morocco destroyed approximately 463 ha of agricultural land.

Many regions in Tunisia experienced heavy rainfall and subsequent flooding during September and October that led to at least six fatalities and property damage in the Nabeul region. 
2) West Africa一S. Hagos, Z. Feng, J. A. ljampy, F. Sima, and S. D. Francis

For this report, West Africa refers to the region between $17.5^{\circ} \mathrm{W}$ (eastern Atlantic coast) and approximately $15^{\circ} \mathrm{E}$ (along the western border of Chad) and $5^{\circ} \mathrm{N}$ north of the equator (near the Guinean coast) to $20^{\circ} \mathrm{N}$. It is typically divided into two climatically distinct sub-regions: the semi-arid Sahel region (north of about $12^{\circ} \mathrm{N}$ ) and the relatively wet coast of Guinea to the south. The rainy period over this region is associated with the latitudinal movement of the zone of convection, or the West African monsoon, and typically occurs in boreal summer (June-September). The inter-annual and decadal variabilities of this monsoon movement are controlled by the north-south SST gradient across the tropical Atlantic, ENSO, and SSTs over the Indian Ocean (Giannini et al. 2003; Hagos et al. 2008).

Summer 2018 had near-neutral ENSO conditions and, in general, the SSTs over the tropical Atlantic and Indian Oceans were close to the climatological average except for the region off the northwestern coast of Africa, which was cooler by up to $1.0^{\circ} \mathrm{C}$.

\section{(i) Temperature}

Northern Nigeria experienced some extremely high temperatures (reaching $40^{\circ} \mathrm{C}$ ), mostly from February to June (see Notable events and impacts for details). June temperatures over much of West Africa were much above average across northern Nigeria, Liberia, and Sierra Leone (Fig. 7.21).

\section{(ii) Precipitation}

For much of the Sahel region, monsoon season (June-September) precipitation was above average (Fig. 7.22), but there were some regional variations. Above-average rainfall was recorded over Burkina Faso, Nigeria, Niger, and Chad. Extended periods of dry conditions were reported over northern Senegal and southwestern Mauritania in July, likely related to the cooler SST conditions off the western coasts of these nations.

\section{(iii) Notable events and impacts}

Several extreme maximum temperatures were observed in northern Nigeria during spring 2018. The cities of Maiduguri and Sokoto recorded temperatures of $43.3^{\circ} \mathrm{C}$ and $42.8^{\circ} \mathrm{C}$, respectively, on $24 \mathrm{April}$. Dutse, Yelwa, Gusau, and Katsina also observed daily high temperatures in excess of $40^{\circ} \mathrm{C}$. In May, Nguru reported one of the highest daytime temperatures$44.0^{\circ} \mathrm{C}$ (twice, on 7 and 24 May). Nguru also had the most days (87) with daytime temperature $\geq 40^{\circ} \mathrm{C}$,

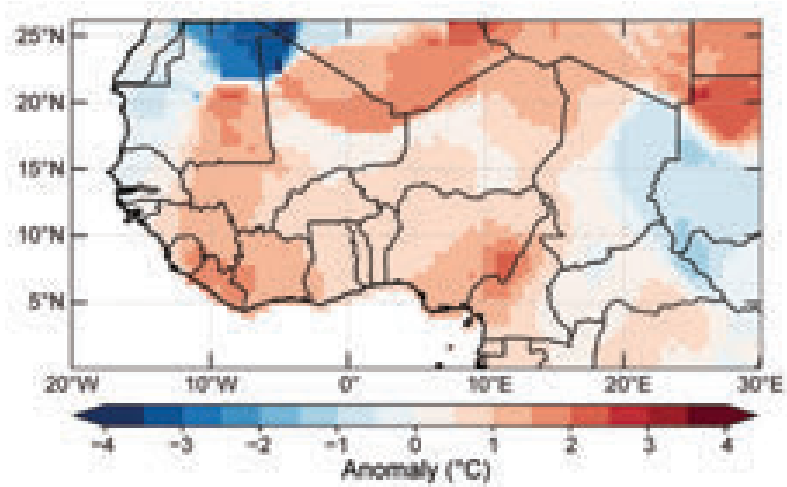

Fig. 7.2I. Jun 2018 temperature anomalies $\left({ }^{\circ} \mathrm{C}\right.$; $198 \mathrm{I}-$ 2010 base period) for West Africa. (Source: NOAA/ NCEP.)
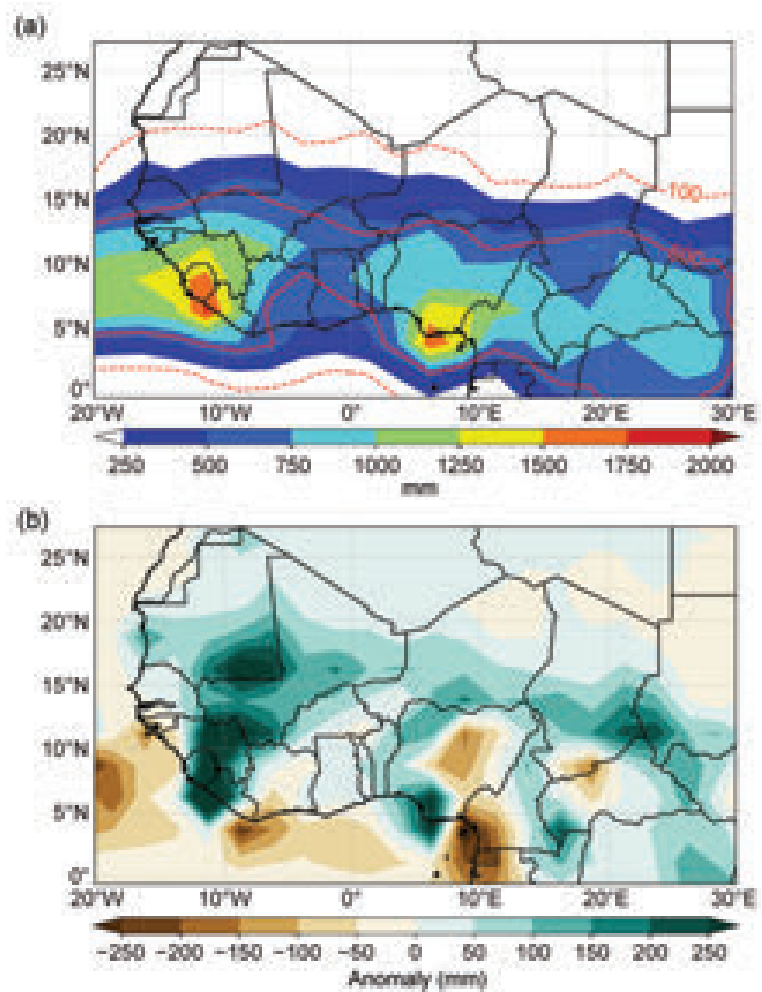

Fig. 7.22. Jun-Sep 2018 precipitation for West Africa as (a) total accumulated precipitation $(\mathrm{mm})$ and (b) anomalies (mm; base period: $198 \mathrm{I}-2010)$. The red dashed and solid lines in (a) mark $100 \mathrm{~mm}$ and $600 \mathrm{~mm}$ isohyets. (Source: NOAA/NCEP.)

followed by Maiduguri (72 days), Sokoto (66), and Yola (55).

In Nigeria, one-day rainfall values in excess of 100 $\mathrm{mm}$ were observed across the country, including the following cities: Bauchi (153.2 mm in June), Awka (182.1 $\mathrm{mm}$ in July), Jalingo (171.2 $\mathrm{mm}$ in July), and Uyo (192.2 $\mathrm{mm}$ in October). Heavy rainfall on 15 July caused the Niger and Benue Rivers to top their banks, flooding the surrounding areas including five com- 
munities in the town of Jibia. The Katsina State government confirmed that 48 people died due to the flooding.

Heavy rain that began 27 August caused flooding in the Nigerian states of Niger, Kano, and Nasarawa. Flooding also affected parts of Jigawa state in early September. According to the National Emergency Management Agency (NEMA) 2018 Flood Situation Report, 12 states were affected by floods in 2018. The agency also reported that during the rainy season, a state of National Disaster was declared in the four most-affected states: Kogi, Niger, Anambra, and Delta.

The United Nations Office for the Coordination of Humanitarian Affairs (UNOCHA) reported that in the state of Niger, Nigeria, 19 people died in flooding during the rainy season and about 65000 people were affected-thousands of homes collapsed, crops were destroyed, and many livestock perished. In Ghana, five people were confirmed dead and one missing following heavy rain on 28 June that caused flooding in some parts of Kumasi due to the overflowing White Volta River. In Abidjan, Ivory Coast, 18 people died in floods on 18 June.

\section{3) Eastern Africa—G. Mengistu Tsidu}

Eastern Africa, which spans the equator and extends between $10^{\circ} \mathrm{S}-20^{\circ} \mathrm{N}$ and $20^{\circ}-50^{\circ} \mathrm{E}$, is also called the Greater Horn of Africa (GHA). It comprises Burundi, Djibouti, Eritrea, Ethiopia, Kenya, Rwanda, Somalia, South Sudan, Sudan Republic, Tanzania, and Uganda. The region's climate is driven by a complex interaction of external forces such as the Sun, with two seasonal migrations across the equator each year, as well as local factors such as complex mountain chains and the Great Rift Valley. As a result, Eastern Africa's climate ranges from semi-arid to cool, and some parts of the region experience two separate rainy seasons.

\section{(i) Temperature}

The December-February (DJF) 2017/18 mean temperature was below average over eastern Ethiopia and most parts of Somalia. In contrast, Sudan Republic, South Sudan, western Ethiopia, Uganda, southern Kenya, northern Tanzania, Burundi, and Rwanda experienced above-average seasonal mean tem- peratures, while central and south-central Ethiopia, northern Kenya, and southern and western Tanzania reported near-average temperatures (Fig. 7.23a). Most of the GHA, north of $6^{\circ} \mathrm{N}$, was warmer than average.

During March-May (MAM), countries south of $6^{\circ} \mathrm{N}$ observed below-average temperatures (more than $-2.0^{\circ} \mathrm{C}$ anomalies in some places), with the exception of southern Tanzania, which had average to aboveaverage mean seasonal temperatures (Fig. 7.23b).

During June-August (JJA), above-average temperatures covered large parts of the GHA along the coast, northern parts of the Sudan Republic, South Sudan, and most of Uganda. However, Eritrea, northern Ethiopia, central Kenya, and northwestern Tanzania observed below-average temperatures during this period (Fig. 7.23c). By September-November (SON), above-average temperatures prevailed over nearly all of the GHA (Fig. 7.23d). 


\section{(ii) Precipitation}

During DJF 2017/18, Uganda, northern Tanzania, Kenya, and adjacent western Somalia received less than their respective normal rainfall, whereas southern Tanzania received $110 \%-130 \%$ of its average precipitation (Fig. 7.24a). During MAM, rainfall was above normal over the southern half of the GHA (Fig. 7.24b). Kenya and its neighboring border areas were exceptionally wet, receiving well over $200 \%$ of its mean rainfall.

Most of Ethiopia (except the southeastern lowlands), South Sudan, and southern Sudan Republic recorded most of their rainfall during June-September (JJAS). Normal to above-normal rainfall within the range of $110 \%-200 \%$ of the seasonal mean dominated the region, except for western Ethiopia (Fig. 7.24c).
Unseasonal rain was observed over most of Kenya and northern Tanzania.

During SON, unseasonably above-average rains were observed over Eritrea, adjoining northern Ethiopia, and Sudan Republic, with rainfall in the range of $130 \%-200 \%$ of their seasonal means (Fig. $7.24 \mathrm{~d}$ ). Most of Kenya and Tanzania also had above-average rainfall, while most of Somalia, southern Ethiopia, eastern Uganda, South Sudan, and border areas in Kenya remained dry.

\section{(iii) Notable events and impacts}

Record rainfall (150\%-200\% of average) over many parts of East Africa in March and April caused flooding in Kenya, Somalia, southern Ethiopia, and northern and central Tanzania (Fig. 7.24b). Garissa station in Kenya
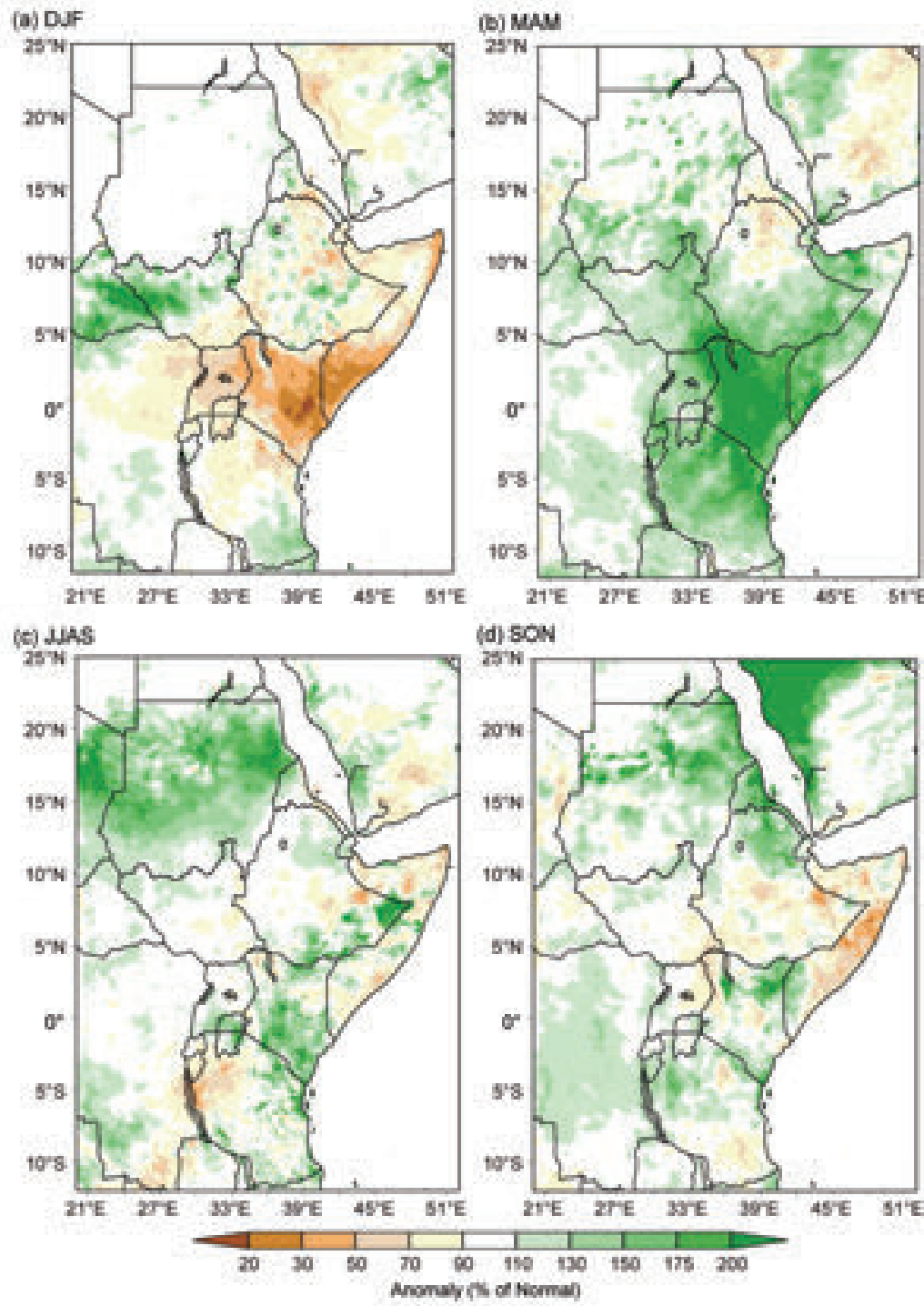

Fig. 7.24. Eastern Africa seasonal total rainfall anomalies (\% of normal; 198I-2010 base period) for (a) DJF 2017/18, (b) MAM 2018, (c) JJAS 2018, and (d) SON 2018. (Source: CHIRPS.) recorded $125 \mathrm{~mm}$ of rainfall on 17 April, much higher than its average for the entire month. Torrential rains damaged infrastructure, including railways, in Kenya, thereby limiting humanitarian access to many of the affected areas. In April, flash and river flooding affected an estimated 630000 people, with about 215000 displaced following heavy rains across Somalia, according to the UN. The two major rivers in the country, Juba and Shabelle, overflowed their banks in several locations, causing flooding.

4) Southern Africa-G. Mengistu Tsidu, A. C. Kruger, and C. McBride

Southern Africa is the region located south of $10^{\circ} \mathrm{S}$ between the Atlantic and Indian Oceans; it comprises South Africa, Angola, Botswana, Zimbabwe, Namibia, Malawi, Zambia, Lesotho, Swaziland, and Mozambique. The region has two distinct seasons-a wet season (NovemberApril) and a dry season (May-October), except for the Western Cape Province in the south-west of South Africa, which has a Mediterraneantype climate and receives most of its rainfall in the austral winter months. The east coast of Southern Africa is under the influence of the southwardflowing Mozambique current, which brings warm water from the equator and creates a humid, warm climate, 
whereas the cold Benguela current from the Atlantic Ocean on the west coast produces a drier climate.

\section{(i) Temperature}

Above-normal temperatures dominated across Angola, northeastern Zimbabwe, most parts of Namibia, Mozambique, and Malawi during DJF 2017/18. In contrast, South Africa, Botswana, southern Zimbabwe, southern Zambia, and southern Mozambique were cooler than normal except for a few isolated pockets over northeastern South Africa and western Botswana (Fig. 7.25a). Much of Mozambique, northern Zimbabwe, and Zambia reported normal mean temperatures during DJF.

During MAM, above-normal temperatures replaced the below-normal temperatures of DJF over the southern half of the region (Fig. 7.25b). By JJA, above-average warm conditions had receded from most of South Africa and southeastern Namibia (Fig. 7.25c). A cold air surge during SON impacted South Africa, Botswana, southern Zimbabwe, southern Mozambique, eastern Namibia, and southern Angola. The seasonal anomalies were more than $-2^{\circ} \mathrm{C}$ at most places across these countries. The rest of the region had moderately above-normal seasonal temperatures (Fig. 7.25d).

Overall, the annually-averaged mean temperature for South Africa, based on data from 26 climate stations, was $0.52^{\circ} \mathrm{C}$ above the $1981-2010$ average, making 2018 the fourth warmest year since recordkeeping began in 1951, with a statistically significant (at the $5 \%$ level) warming trend of $0.16^{\circ} \mathrm{C} \mathrm{decade}^{-1}$ (Fig. 7.26).

\section{(ii) Precipitation}

Rainfall exceeded $130 \%$ of normal over southeastern and northeastern South Africa, northeastern Botswana, the western half of Zimbabwe, northern Angola, and the east coast of Mozambique during DJF 2017/18. Most of Namibia, the western half of Botswana, northwestern and western South Africa, and most of Mozambique were drier than normal; Zambia had normal rainfall (Fig. 7.27a). During MAM, a significant portion of the region received above-normal rainfall-up to $200 \%$ in some places. The only dry areas were southern South Africa, southern Namibia, northeastern South

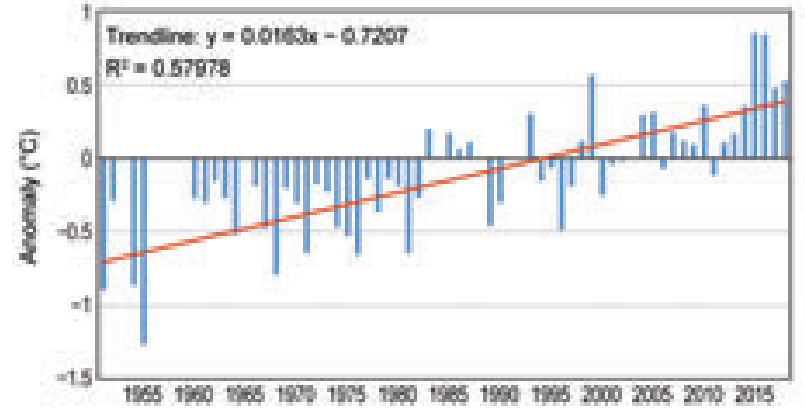

Fig. 7.26. Annual mean temperature anomalies $\left({ }^{\circ} \mathrm{C}\right.$; base period: $198 \mathrm{I}-2010)$ of 26 climate stations in South Africa, for the period 1951-2018. Red line represents the linear trend. (Source: South African Weather Service.)

Africa, southern Zimbabwe, southern Mozambique, and northern Angola (Fig. 7.27b).

During the typically dry JJA period, most of Mozambique and Malawi, isolated pockets in South Africa, Namibia, and northern Angola received above-normal rainfall (Fig. 7.27c), while the rest of the region remained normal to drier than normal. 


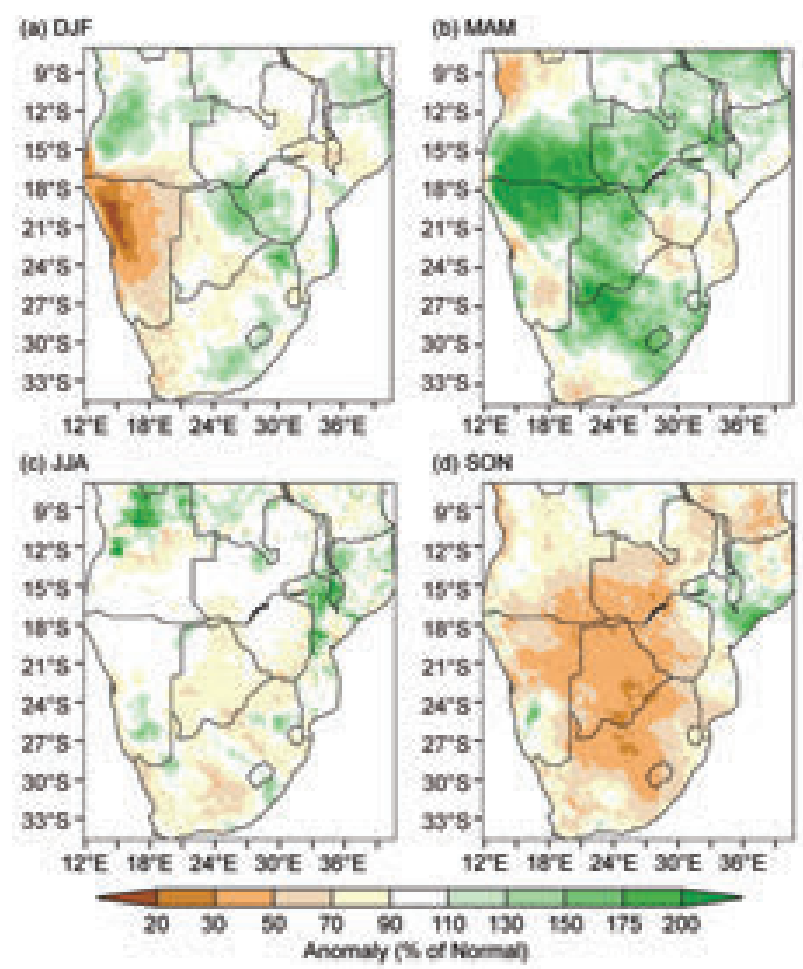

FIG. 7.27. Southern Africa seasonal total rainfall anomalies (\% of normal; 198I-2010 base period) for (a) DJF 20I7/I8, (b) MAM 20I8, (c) JJA 20I8, and (d) SON 2018. (Source: CHIRPS.)

The wet conditions in Malawi, Mozambique, and isolated pockets in Namibia persisted until the end of SON (Fig. 7.27d).

Analysis of annual total gauge rainfall over South Africa confirms that most of the country received near-normal to below-normal rainfall for the year. Notable exceptions include part of the west coast in the Western Cape and the northwestern part of KwaZulu-Natal provinces, which received more than $125 \%$ of their average annual rainfall (not shown).

\section{(iii) Notable events and impacts}

A tropical depression hit northern Nampula Province of Mozambique on 17 January. According to the Mozambique Institute for Disaster Management, 34 people died and more than 80000 people were affected by the storm. Heavy rain continued into February and March, with a record of $152 \mathrm{~mm}$ at Tete and $217 \mathrm{~mm}$ at Vilankulos airport on 27 February.

Heavy rain fell over the central province of Botswana from 23-26 February. According to the Department of Meteorology Services, 120-192 mm of rain led to dams overspilling, which caused flooding in the Tutume subdistrict. By 26 February, the villages of Gweta, Zoroga, and Tsookotshaa were entirely flooded, affecting approximately 845 households.
In South Africa, heat wave conditions affected the northern provinces during the first week of January, and unseasonably high rainfall totals were observed in the Western Cape. On 14 January, severe storms and flooding in northern KwaZulu-Natal washed away bridges, killing several people. In March, lightning killed five people and injured several others in KwaZulu-Natal. Heavy rainfall on 21 March in the province of Gauteng caused extensive damage to roads and the electrical network.

By the end of the year, South Africa was affected by drought conditions, and only limited planting could take place in the western growing areas, severely affecting crop outputs such as maize and soybeans for the foreseeable future. However, there were also several severe thunderstorms across the country during December: one caused severe hail damage to the largest hotel complex in North West Province and one produced a tornado in the Butterworth area of the Eastern Cape on 27 December, damaging a number of homes. Two deaths were also reported due to lightning associated with the storm.

5) Western Indian Ocean island countriesG. Jumaux, K. R. Dhurmea, M. Belmont, C. L. Rakotoarimalala, and L. Labbé.

This region consists of several island countries: Madagascar, Seychelles, Comoros, Mayotte (France), Réunion (France), Mauritius, and Rodrigues (Mauritius).

Overall, 2018 was characterized by above-normal mean temperatures except during the first months of the year, related to a weak La Niña event. Annual precipitation was above normal in Mascarene Islands (Réunion, Mauritius, and Rodrigues) and northern Madagascar, related to more northerly winds and fewer trade winds during the rainy season, coupled with the influence of tropical storms. Precipitation was near-to-above normal in Mayotte and below normal in Seychelles and southwestern Madagascar (Fig. 7.28).

\section{(i) Temperature}

In Mauritius, August was the warmest month and September the second warmest since recordkeeping began in 1969. Nighttime temperature anomalies were greater than those of daytime temperatures during most of the months. The mean maximum temperature anomalies at Vacoas and Plaisance, Mauritius, for August and September were $+1.71^{\circ} \mathrm{C}$ and $+0.92^{\circ} \mathrm{C}$, while the mean minimum temperature anomalies were $+1.21^{\circ} \mathrm{C}$ and $+1.76^{\circ} \mathrm{C}$, respectively. Overall for Mauritius, the annual mean maximum 


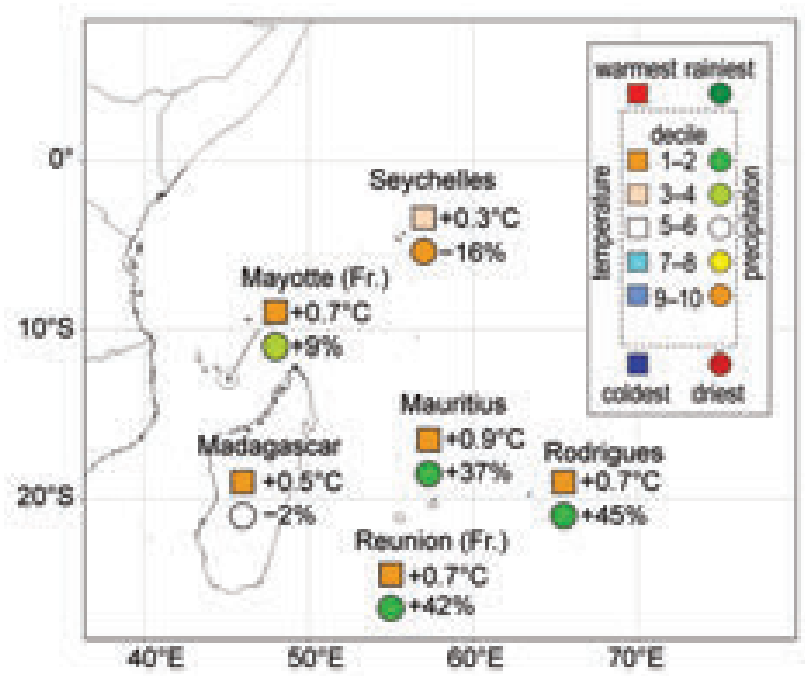

FIG. 7.28. Mean annual temperature anomalies $\left({ }^{\circ} \mathrm{C}\right.$, squares), annual rainfall anomalies (\% of average, circles), and their respective deciles for the western Indian Ocean island countries in 2018 (Sources: Météo France; and Meteorological Services of Madagascar, Seychelles, and Mauritius.)

temperature anomaly was $+0.75^{\circ} \mathrm{C}$ and mean minimum anomaly was $+1.13^{\circ} \mathrm{C}$, with a mean of $+0.94^{\circ} \mathrm{C}$, making 2018 the second warmest on record after 2017 (based on the two stations). Heat wave (temperature anomalies exceeding $2^{\circ} \mathrm{C}$ for over four days) conditions occurred over the island during 11-15 February as well as 1-3 and 11-13 April.

The annual mean temperature anomaly in Rodrigues was $+0.68^{\circ} \mathrm{C}$. Based on data from three stations, the annual mean temperature for Réunion Island was $+0.7^{\circ} \mathrm{C}$, the third highest since 1968 , when recordkeeping began and $0.2^{\circ} \mathrm{C}$ cooler than 2017 (Fig. 7.29). January-May temperatures were near-to-above average; August and September were each the warmest on record for their respective months $\left(+1.3^{\circ} \mathrm{C}\right)$.

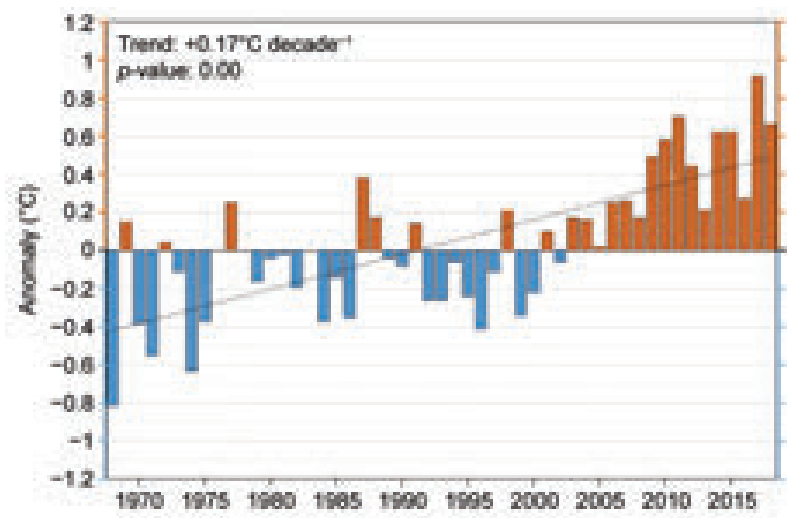

Fig. 7.29. Annual mean temperature anomalies $\left({ }^{\circ} \mathrm{C}\right.$; 1981-2010 base period) in Réunion Island, 1968-2018. (Source: Météo-France.)

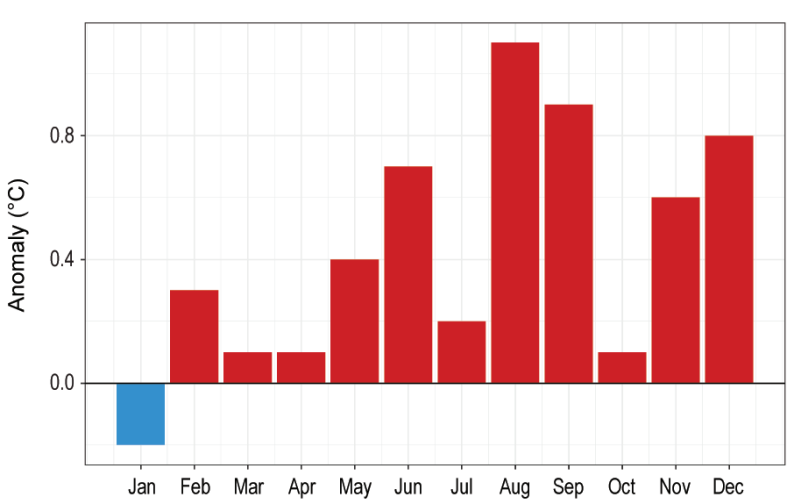

FIG. 7.30. Monthly mean temperature anomalies $\left({ }^{\circ} \mathrm{C}\right.$; 198I-2010 base period) for 2018 in Madagascar (average of 16 stations). (Source: Madagascar Meteorological Services.)

Madagascar's annual mean temperature was $24.0^{\circ} \mathrm{C}$, which is the sixth highest on record since 1961. Monthly mean temperatures were all above normal, except for January (Fig. 7.30). August had the highest anomaly among all months of 2018, about $+1.1^{\circ} \mathrm{C}$. The highest all-time maximum temperature for the country $\left(40.5^{\circ} \mathrm{C}\right)$ was recorded in Morondava on 16 March.

For Mayotte, the annual mean temperature was $0.7^{\circ} \mathrm{C}$ above normal at Pamandzi Airport, its third highest since 1961 and $0.2^{\circ} \mathrm{C}$ cooler than 2017. January-March temperatures were near average, while September and December were each warmest on record for their respective months.

At Seychelles International Airport, the annual mean temperature for 2018 was $27.4^{\circ} \mathrm{C}$, which is $0.3^{\circ} \mathrm{C}$ above the long-term mean and the 13th highest since 1972. Only April, August, and September were cooler than average.

\section{(ii) Precipitation}

In Mauritius, January 2018 was the third wettest January in its 115-year record and the wettest in the last 38 years; as some regions received as much as 1300 $\mathrm{mm}$ of precipitation (Fig.7.31). November was the second wettest in the last 45 years. Widespread flooding affected the island on several occasions. Most of the rain was associated with Tropical Cyclones Ava and Berguitta. February set a record for the most thunder days since 1971 (20 days of thunderstorms). August was the driest month of the year. The mean annual rainfall was $2736 \mathrm{~mm}$, far exceeding the long-term mean of $1999 \mathrm{~mm}$. Overall, 2018 was the ninth wettest year and the wettest in the last 30 years.

Mean annual rainfall totaled $1602 \mathrm{~mm}$ at Rodrigues (based on one station at Pointe Canon), 500 $\mathrm{mm}$ above its long-term mean. This was the third 


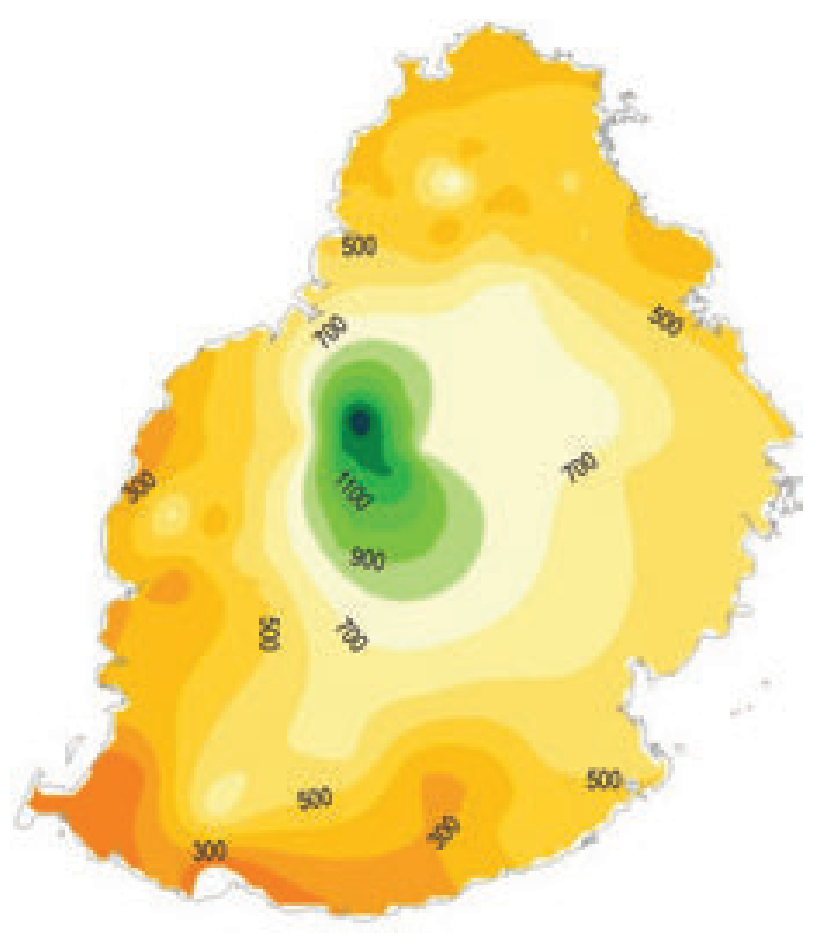

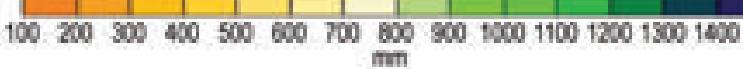

FIG. 7.31. Rainfall distribution ( $\mathrm{mm}$ ) over Mauritius in Jan 2018. (Source: Mauritius Meteorological Services.)

wettest year at Rodrigues since 1955 and the wettest in the last 30 years.

Based on data from 34 stations, the annual precipitation over Réunion Island was $142 \%$ of average, the wettest since 1987 and third wettest since 1972 . The rainy season (December-April 2017/18) was the third wettest, with five tropical storms and cyclones affecting the island. During May-November, usually the driest months of the year, rainfall was $105 \%$ of average. This period included August, which was the driest on record.

Madagascar's annual precipitation total was slightly below normal-98\% of normal (based on 22 stations). Below-normal rainfall was recorded for six months, with February the driest month at $29 \%$ below average. The highest positive annual anomaly was observed in Antsohihy (+149\%), and the lowest negative anomaly occurred in Maintirano (-74\%; Fig. 7.32).

For Mayotte, the annual rainfall amount (average of two stations) was $1612 \mathrm{~mm}$ (109\% of average). The rainy season (November-April 2017/18) was the wettest on record since 1961/62, especially in January and March. The second half of the year was drier, with monthly August-December rainfall amounts all below average.

In Seychelles, annual rainfall $(1990 \mathrm{~mm})$ was $84 \%$ of average, making 2018 its ninth driest year on record. A weak La Niña during January-March may have affected the rainfall pattern.

\section{(iii) Notable events and impacts}

During the 2017/18 cyclone season, the southwest Indian Ocean basin reported eight named low-pressure systems: Réunion was severely affected by three of them. Two of the systems contributed to heavy rainfall and flooding in Mauritius, while two others severely affected Madagascar.

During 3-8 January, outer cloud bands of Tropical Cyclone Ava provided the first significant rainfall of the year to Réunion. Ava also contributed to heavy rainfall and flooding in Mauritius (highest 24-h rainfall of $311 \mathrm{~mm}$ ). However, the most affected island was Madagascar, where the storm made landfall on 5 January near Toamasina. From 5-7 January, reported precipitation totals were: $382 \mathrm{~mm}$ (Fianarantsoa), 267 $\mathrm{mm}$ (Mahanoro), $115 \mathrm{~mm}$ (Antananarivo). The storm caused 29 deaths as well as flooding, particularly in

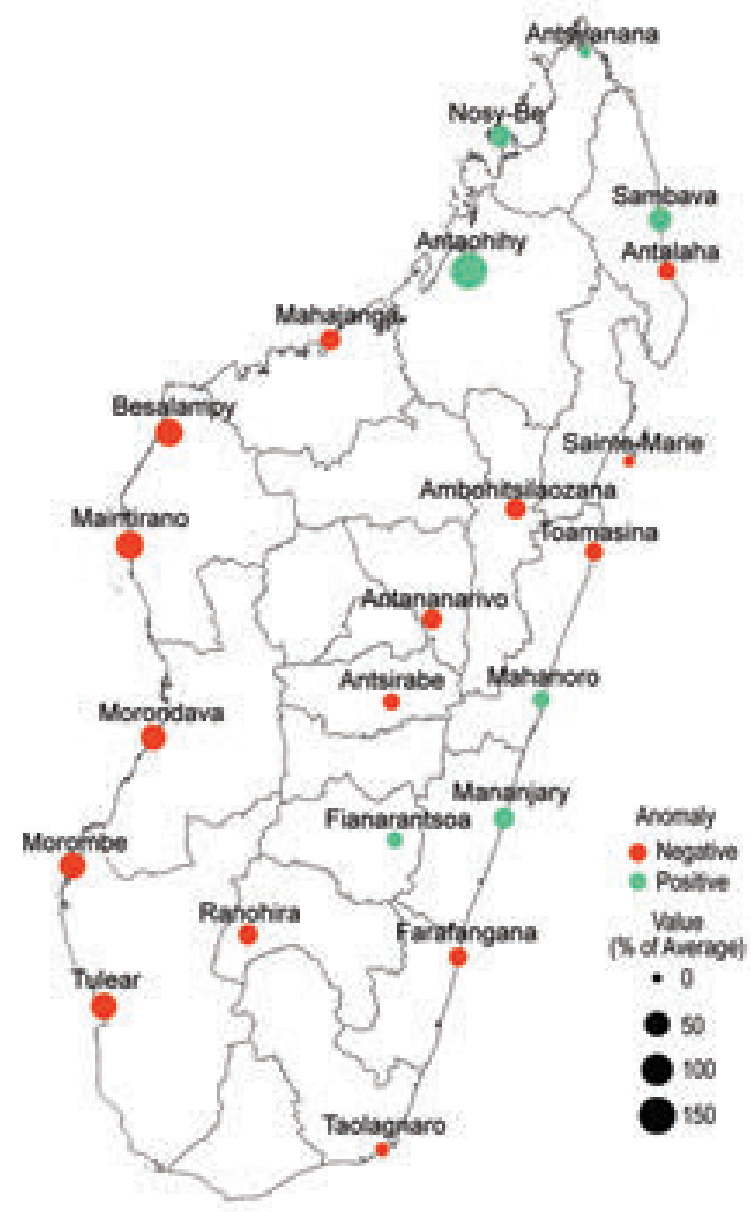

Fig. 7.32. Annual total precipitation anomalies (\% of average; 198I-2010 base period). (Source: Madagascar Meteorological Services.) 
Antsinanana, Analamanga, and Vatovavy-Fitovinany. Prior to Ava's landfall over Madagascar, on 4 January, $207 \mathrm{~mm}$ fell over Mahanoro. This was the city's fifth wettest day since 1961 and also the highest 24-h precipitation total recorded in Madagascar in 2018.

On 18 January, Tropical Cyclone Berguitta, which weakened into a severe tropical storm, caused torrential rain over the south and southwest of Réunion as it passed $80 \mathrm{~km}$ off the southern coast. Many ravines overflowed and caused landslides. Grand-Coude station recorded $848 \mathrm{~mm}$ of rain in a 24 -h period, which is the station's highest in its 38-year record. Earlier the same day, Berguitta contributed to heavy rainfall and flooding in Mauritius (highest 24-h rainfall of $305 \mathrm{~mm}$ ).

During 4-6 March, heavy rains from the outer cloud bands of Tropical Cyclone Dumazile followed one another on Réunion Island. The center of the cyclone passed about $350 \mathrm{~km}$ off the southwestern coast on 6 March, and the highest amount of precipitation received in a 24-h period for the year, $990 \mathrm{~mm}$, was recorded in the highlands at Grand-Ilet.

Tropical Storm Eliakim affected Madagascar during 15-18 March. Precipitation totals from the storm were: $388 \mathrm{~mm}$ (Sainte Marie); $356 \mathrm{~mm}$ (Nosy-Be); 319 $\mathrm{mm}$ (Mananjary); and $206 \mathrm{~mm}$ (Mahanoro). Eliakim also caused 17 fatalities and flooding.

On 24 April, the center of Tropical Cyclone Fakir passed $15 \mathrm{~km}$ off the eastern coast of Réunion, an unprecedented late date in the season. The town of Sainte-Rose experienced the eyewall. Hauts-deSainte-Rose Station recorded $176 \mathrm{~mm}$ of rain in a 1-h period, the most intense rainfall recorded on Réunion since 1990. Strong winds were also recorded: $43 \mathrm{~m} \mathrm{~s}^{-1}$ in Saint-Benoît. Fakir killed two people at Etang-Salé.

Please refer to Section $4 \mathrm{f} 6$ for more details on the South Indian Ocean basin cyclones.

\section{f. Europe and the Middle East-P. Bissolli, Ed.}

Throughout this section, 1981-2010 is the base period used for both temperature and precipitation, unless otherwise specified. European countries conform to different standards applied by their individual national weather services. All seasons mentioned in this section refer to the Northern Hemisphere (NH), with winter being DJF 2017/18. More detailed information can be found in the Monthly and Annual Bulletin on the Climate in RA VI - European and the Middle East, provided by WMO RA VI Regional Climate Centre on Climate Monitoring (RCC-CM; www.dwd.de/rcc-cm). Anomaly information has been taken from Figs. 7.34-7.37 when national reports are not available.

\section{I) Overview}

Based on the Global Historical Climate Network (GHCN) v3.3.0 dataset (Menne et al. 2012), Europe $\left(35^{\circ}-75^{\circ} \mathrm{N}, 10^{\circ} \mathrm{W}-30^{\circ} \mathrm{E}\right)$ experienced its second warmest year since at least 1950 with an anomaly of $+1.1^{\circ} \mathrm{C}$ (Fig. 7.33). Temperature anomalies varied mostly between $+1^{\circ} \mathrm{C}$ and $+2^{\circ} \mathrm{C}$, with local areas in Switzerland and Austria exceeding $+3^{\circ} \mathrm{C}$ (Fig. 7.34).

Large parts of northern and central Europe experienced a dry year with precipitation totals $60 \%-80 \%$ of normal (Fig. 7.35), and even below $40 \%$ in Latvia

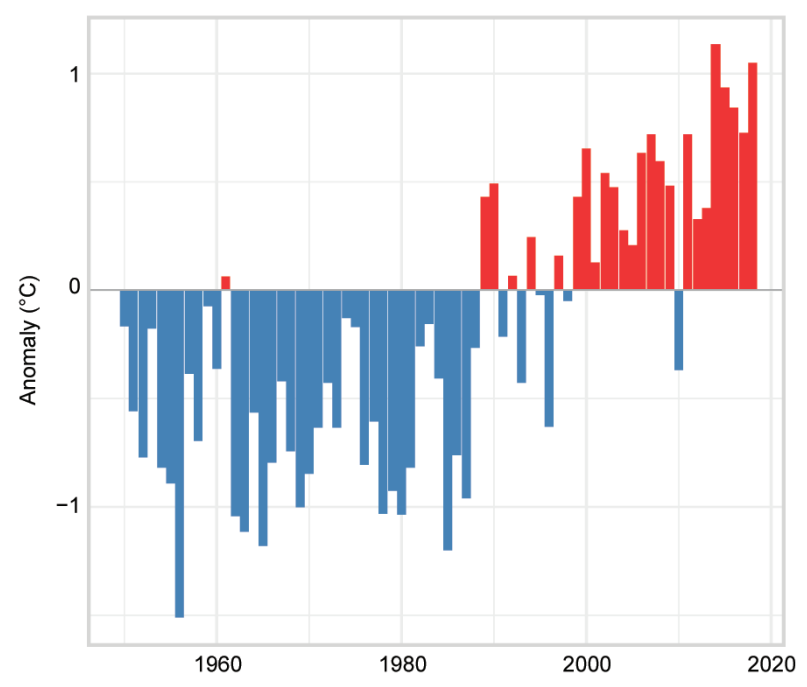

Fig. 7.33. Annual average land surface air temperature anomalies for Europe $\left(35^{\circ}-75^{\circ} \mathrm{N}, 10^{\circ} \mathrm{W}-30^{\circ} \mathrm{E}\right)$ relative to the 198I-2010 base period. [Source: GHCN version 3.3.0 dataset (Menne et al. 20 I2).]

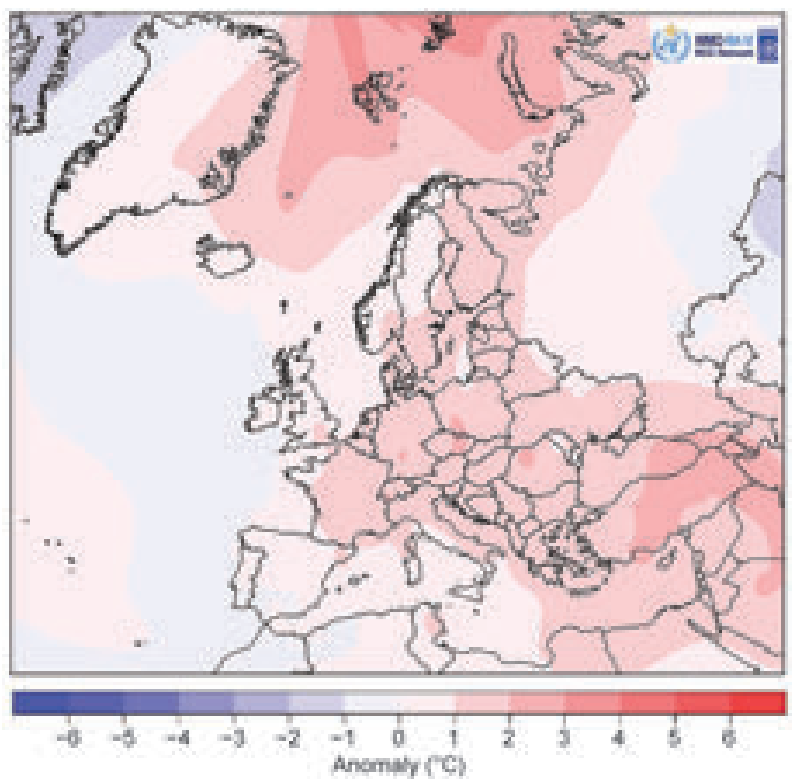

Fig. 7.34. Annual mean air temperature anomalies ( ${ }^{\circ} \mathrm{C}, 198 \mathrm{I}-2010$ base period) in 2018. [Source: CLIMAT reports, created by Deutscher Wetterdienst (DWD).] 


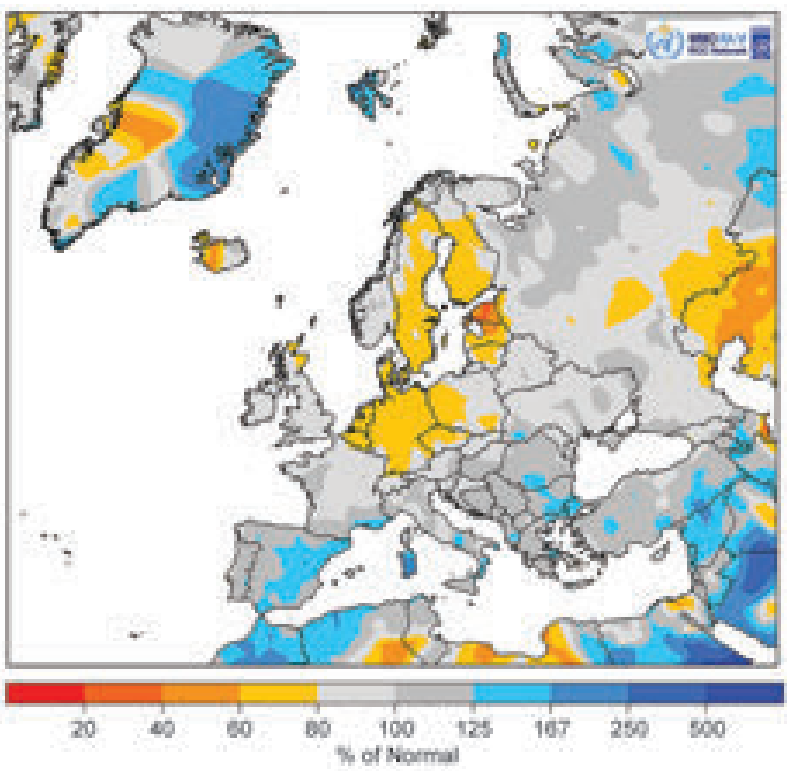

FIG. 7.35. European precipitation totals (\% of I98I-20I0 average) for 2018. (Source: GPCC, created by DWD.)

and Estonia, due to a long drought period that lasted much of the year. However, most of the Mediterranean region received above-normal precipitation (100\%-250\%), with parts of eastern Spain, Sardinia, southern Bulgaria, and Syria receiving the most.

During winter (Fig. 7.36a), Spain, southern France, the United Kingdom and Ireland, and northern Scandinavia were colder than normal; temperatures in central Europe were largely near normal. Eastern Austria, eastern Europe, and the Balkan states experienced a mild winter with temperatures ranging from $+1^{\circ} \mathrm{C}$ to $+3^{\circ} \mathrm{C}$ above normal. After a relatively mild January, a significant change took place in February, bringing several periods of cold weather to most areas. With unseasonably warm temperatures in Europe over the remainder of 2018, these cold spells made February and March the only two months with below-average temperatures. Although precipitation was scattered during winter (Fig. 7.37), many regions were near normal, with local dry spots (as low as $40 \%$ of normal) in southern Spain, eastern Germany, Poland, Estonia, and the northern west coast of Norway. Eastern Europe, the Balkan states, and many parts of France received above-normal precipitation-up to $167 \%$ of normal or more.

Spring was exceptionally mild for most of Europe, especially the central and southeastern parts (Fig. 7.36b). Temperature anomalies ranged from $+1^{\circ} \mathrm{C}$ to $+4^{\circ} \mathrm{C}$ for the Balkan states, Greece, Turkey, and the Middle East, and up to $+6^{\circ} \mathrm{C}$ in parts of Switzerland, Austria, and southern Germany. Western Europe [including the United Kingdom and Ireland, France,

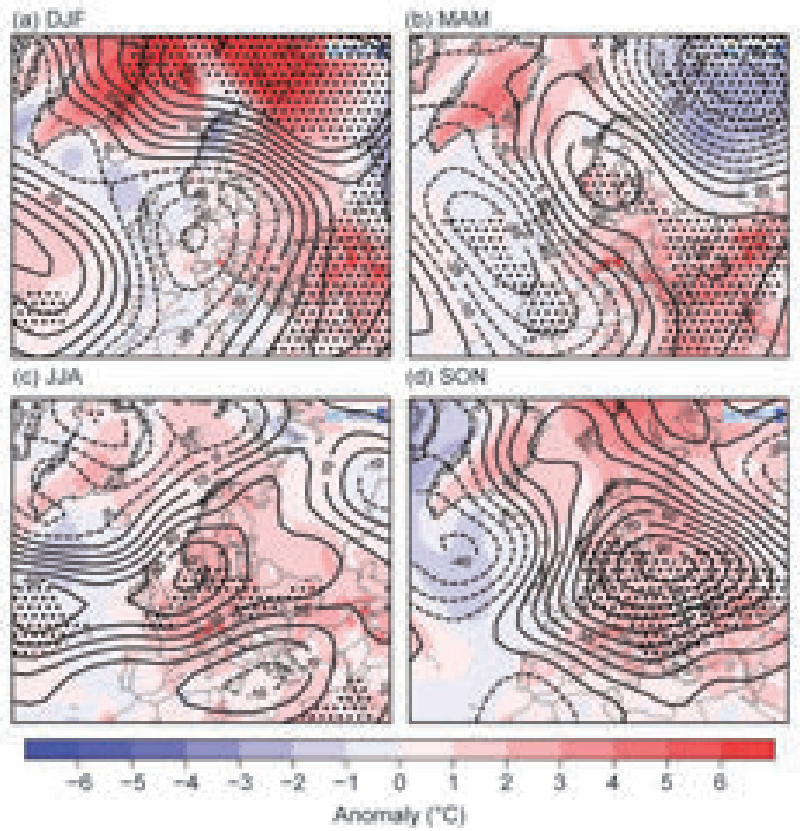

FIG. 7.36. Seasonal anomalies ( $198 \mathrm{I}-2010$ base period) of 500-hPa geopotential height (contour, gpm) and air temperature (shading, ${ }^{\circ} \mathrm{C}$ ) using data from the NCEPI NCAR reanalysis and DWD, respectively, for (a) DJF 2017/18, (b) MAM 2018, (c) JJA 2018, and (d) SON 2018. Dotted areas indicate regions where 500-hPa geopotential is higher (lower) than the 95 th percentile (5th percentile) of the 198I-2010 distribution.

Spain, Portugal, and most of the Mediterranean (except the eastern parts)] and the Balkan states had near-normal to above-normal precipitation, but central, eastern, and northern Europe was dry with widespread precipitation values around $60 \%$ of normal. This precipitation deficit grew for many countries during summer, particularly Germany and the Baltic states, with some regions observing precipitation as low as $20 \%$ of normal. The eastern Mediterranean and parts of Spain had precipitation as high as $250 \%-500 \%$ of normal.

Summer and autumn temperatures continued to be above normal, with maximum seasonal anomalies of $+2^{\circ} \mathrm{C}$ to $+3^{\circ} \mathrm{C}$ and even higher in localized areas across central Europe and the Balkan states. Except for Spain and a number of Mediterranean coasts, most of Europe reported precipitation deficits in autumn - between $20 \%-80 \%$, especially Germany, the BeNeLux countries (Belgium, the Netherlands, and Luxembourg), most parts of France, and the Balkan states. Totals less than $20 \%$ of normal were observed in northeast Germany, the Upper Rhine, and the Former Yugoslav Republic of Macedonia. 


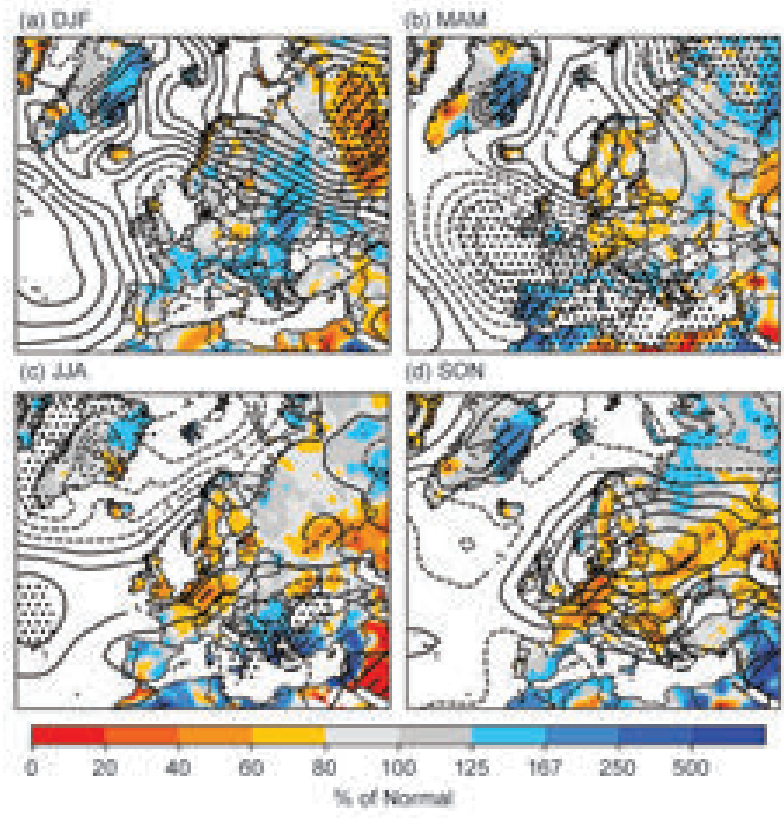

FIG. 7.37. Seasonal anomalies for 2018 (198I-2010 base period) of sea level pressure $(\mathrm{hPa})$ from NCAR/NCEP reanalysis (contours) for (a) DJF 2017/18, (b) MAM 2018, (c) JJA 2018, and (d) SON 2018. Colored shading represents the percentage of seasonal mean precipitation for 2018 compared with the 198I-2010 mean from GPCC (Schneider et al. 2018b). Dotted areas indicate regions where sea level pressure is higher (lower) than the 95th percentile (5th percentile) of the 198I-2010 distribution, while hatched areas represent the corresponding thresholds but for precipitation.

\section{2) Western Europe}

This region includes Ireland, the United Kingdom, the Netherlands, Belgium, Luxembourg, and France

\section{(i) Temperature}

Overall, most regions of western Europe were exceptionally warmer than normal, with many countries reporting 2018 as one of their five warmest years [Netherlands $+1.1^{\circ} \mathrm{C}$ anomaly (second warmest in its 300 -year record); France $+1.4^{\circ} \mathrm{C}$ (warmest since records began in the early 1900s)].

Winter temperatures were slightly below or near normal for western Europe, with January being a record warm month for some countries (France, warmest at $+3.4^{\circ} \mathrm{C}$ above normal). Conversely, February temperatures were well below normal across all of western Europe due to a high-pressure system over Scandinavia that resulted in easterly winds ushering in cold Siberian air. Many countries reported wellbelow-normal temperatures with anomalies of $-2^{\circ} \mathrm{C}$ to $-4^{\circ} \mathrm{C}$ in February.

With the Icelandic Low located close to Ireland, spring began with an unusually cold March that featured two cold waves. April and May were very warm, as much as $+4^{\circ} \mathrm{C}$ above average in eastern Netherlands, Belgium, and Luxembourg. France recorded its third warmest April since 1900. It was the warmest May in the Netherlands, and the second warmest in the United Kingdom since records began there in 1910.

Due to extended high-pressure influence, summer 2018 was one of the five warmest summers on record for a number of countries, including the Netherlands and Belgium, warmest $\left(+1.9^{\circ} \mathrm{C}\right.$ and $+2.3^{\circ} \mathrm{C}$, respectively) and France, second $\left(+2.0^{\circ} \mathrm{C}\right)$.

Autumn mainly continued to be warmer than normal with only a few cold episodes. The first autumn storms appeared at the end of September and widespread frost was reported, even in the Netherlands, which is unusual for that time of year. On 13 October, in contrast, De Bilt Station (Netherlands) reported $26.3^{\circ} \mathrm{C}-$ a temperature that high so late in the year has not been recorded in over a century. Overall, autumn 2018 was one of the warmest on record for many countries [Belgium, third $\left(+1.7^{\circ} \mathrm{C}\right)$; France, fourth $\left.\left(+1.2^{\circ} \mathrm{C}\right)\right]$.

\section{(ii) Precipitation}

In 2018, continental western Europe experienced widespread precipitation deficits $(40 \%-80 \%$ of normal). Precipitation for most of winter 2017/18 was near or slightly wetter than normal, except for the northern United Kingdom. In February, a highpressure system over Scandinavia brought cold, dry air from the east, making the month drier than normal for France, BeNeLux, and the United Kingdom. However, the winter season as a whole was wetter than normal, especially in France, with Burgundy reporting its wettest winter of the 1959-2018 record, with seasonal total anomalies $\geq 300 \mathrm{~mm}$.

During March, southern England and France received up to $170 \%$ of normal precipitation. France reported one of its wettest Marches of the 1959-2018 record, especially in Provence-Alpes-Côte d'Azur and Corsica, where it was the second wettest March following 2013. A dominant high-pressure system developed over Scandinavia in May, resulting in below-normal precipitation in Ireland, the United Kingdom, Belgium, and the Netherlands, while portions of France received above-normal precipitation, particularly in the south.

Western Europe's summer was mostly drier than normal. The Netherlands reported one of its driest summers since records began in 1906: 105-mm precipitation received compared to its normal of $225 \mathrm{~mm}$, with July the driest month observed since 
records began. Ireland reported its driest summer since 1962, with June and July each record dry (driest summer at Phoenix Park in Dublin since records began in 1850). Summer in France was wet in the south, with Cevennes in Var and South Corsica receiving up to three times their normal, while northern and northeastern France had just 30\%-60\%. Despite these summer drought conditions, there were several storms in France that brought copious rain, often 30 $\mathrm{mm}$ or more per hour, as well as frequent occurrences of hail, sometimes exceeding $5 \mathrm{~cm}$ in diameter, flooding, and landslides.

Autumn was also (on average) drier than usual. As with summer, an overall precipitation deficit was contrasted by some local records of heavy rain. In the Mediterranean region of France, several intense rainstorms in October and November resulted in precipitation totals 1.5 to 2.5 times the normal. September 2018 was France's third driest September since the start of the record in 1959, following 1977 and 1985. In the Netherlands the seasonal average was less than $50 \%$ of normal.

\section{(iii) Notable events and impacts}

During 17-20 January, wind gusts of $42 \mathrm{~m} \mathrm{~s}^{-1}$ were observed at Capel Curig (United Kingdom) on 18 January with wintry showers of rain and snow. In the Netherlands, this storm was among the 10 strongest since 1970, causing power outages, downed trees, and flight delays.

At the end of January/early February, several heavy rain events in France caused flooding due to already saturated soils. On 29 January, the Seine reached 5.85 $\mathrm{m}$ at Paris-Austerlitz Station, about $4 \mathrm{~m}$ above normal, with major up- and downstream floods.

During 28 February-1 March, the United Kingdom and Ireland experienced a spell of severe winter weather. Snow depths up to $48 \mathrm{~cm}$ were observed in the lower elevations of Ireland. Widespread road, rail, and air traffic disruptions were reported. France experienced late snowfalls with snow depths reaching 15-30 cm in Montpelier, Nîmes, and elsewhere.

During September-October, multiple storms brought strong winds and heavy rain to Ireland and the United Kingdom, leading to heavy traffic disturbances, power outages, fallen trees, and flooding. With widespread gusts as high as $40 \mathrm{~m} \mathrm{~s}^{-1}$ in western Ireland, Ali (19 September) was one of the most notable storms to occur at this time of year in recent decades. Two people were killed due to impacts from the storm. During 12-13 October, Storm Callum, with a minimum pressure of $938 \mathrm{hPa}$ (the lowest early storm season pressure for an extratropical Atlantic storm since at least 1979), brought persistent heavy rain to Ireland and the United Kingdom. In south Wales, much of Brecon Beacons National Park recorded $100-200 \mathrm{~mm}$ of rain over a 2-day period, making it the most extreme rainfall and flooding event for the last 50 years in that region.

\section{3) Central Europe}

This region includes Germany, Switzerland, Austria, Poland, Czech Republic, Slovakia, and Hungary.

\section{(i) Temperature}

Overall, the year in central Europe was exceptionally warmer than normal, with many countries reporting 2018 as one of their five warmest years on record: Switzerland, $+1.5^{\circ} \mathrm{C}$ above normal; Austria, $+1.5^{\circ} \mathrm{C}$; Poland, $+1.6^{\circ} \mathrm{C}$; Hungary, $+1.8^{\circ} \mathrm{C}$; and Czech Republic, $+2^{\circ} \mathrm{C}$. Winter $2017 / 18$ was warmer than usual, with anomalies up to $+2^{\circ} \mathrm{C}$. January was a record warm month for some countries, including Switzerland (warmest since $1858 ;+3.1^{\circ} \mathrm{C}$ ) and Austria (third; $+3.8^{\circ} \mathrm{C}$ ). On the other hand, February was colder than average across all of central Europe due to a high-pressure system over Scandinavia that resulted in easterly winds bringing in cold Siberian air. Many countries reported monthly temperature anomalies ranging between $-2^{\circ} \mathrm{C}$ to $-4^{\circ} \mathrm{C}$ (Slovakia up to $-2.4^{\circ} \mathrm{C}$, Switzerland $-3.0^{\circ} \mathrm{C}$, and Germany $-2.8^{\circ} \mathrm{C}$ ).

With the Icelandic Low located close to Ireland, spring began with an unusually cold March featuring two cold waves. Record-breaking high daily maximum temperatures were then measured in April and May. Austria reported its second warmest April since records began in 1767 , at $+4.7^{\circ} \mathrm{C}$ above normal, only cooler than that recorded in April $1800\left(+5.7^{\circ} \mathrm{C}\right.$ above normal) and an unusually high number of summer days (temperature $\geq 25^{\circ} \mathrm{C}$ ), with many regions breaking their record. Slovakia had its warmest April since records began in 1901, with temperature anomalies between $+4.5^{\circ} \mathrm{C}$ and $+6.1^{\circ} \mathrm{C}$. May was the warmest since 1858 in Austria $\left(+5.7^{\circ} \mathrm{C}\right)$ and in Germany since $1881\left(+3.0^{\circ} \mathrm{C}\right)$.

Summer was one of the five warmest on record for many countries due to extended high-pressure influence: Germany and Poland, warmest $\left(+2.3^{\circ} \mathrm{C}\right.$ and $+2.2^{\circ} \mathrm{C}$, respectively); Switzerland, third $\left(+2.0^{\circ} \mathrm{C}\right)$.

The summer season came to a close at the end of September, when the first autumn storms and widespread frost were reported. However, October was warmer than usual with anomalies between $+1.0^{\circ} \mathrm{C}$ and $+2.0^{\circ} \mathrm{C}$. A new record was set in Locarno-Monti, Switzerland, which reported a high temperature of $30.5^{\circ} \mathrm{C}$ on 24 October. Overall, autumn was one of 
the warmest on record in many countries: Hungary, second $\left(+2.1^{\circ} \mathrm{C}\right)$; Switzerland, third $\left(+1.8^{\circ} \mathrm{C}\right)$; Austria, third $\left(+1.9^{\circ} \mathrm{C}\right)$; and Poland, third $\left(+1.6^{\circ} \mathrm{C}\right)$.

\section{(ii) Precipitation}

Central Europe experienced widespread precipitation deficits in 2018 . Totals of $40 \%-80 \%$, but locally as low as $20 \%$ of normal in parts of northern Germany and its Upper Rhine Valley, resulted in drought. January was wetter than normal, with multiple storms passing over Europe; northern Germany received $125 \%$ of normal precipitation while southwestern Germany and Switzerland received up to $250 \%$. In February, a strong high centered over northern Europe brought cold, dry air from the east, which made the month exceptionally dry for Germany, Poland (totals below $20 \%$ of normal for eastern Germany and western Poland), the Czech Republic, and Switzerland. Saxony (Germany) reported its driest February since 1881, when records began.

During March, below-average precipitation continued across many parts of Germany and Poland, while Slovakia and southern Austria received up to $170 \%$ of normal precipitation. In April, southern central Europe observed below-average precipitation (20\%-60\%, locally even less) while northern central Europe was wetter than normal (locally 200\%-300\% in northern Germany). With the establishment of a dominant high-pressure system centered over Scandinavia in May, dry conditions were most outstanding in northern Germany and northwestern Poland, which received only $40 \%-60 \%$ of normal precipitation, while southern central Europe was only slightly drier than normal.

Summer in central Europe was characterized by extreme precipitation deficits, especially in Germany (most regions only $40 \%-60 \%$ of normal), but also in Switzerland, the Czech Republic, and western Poland. Monthly deficits were even higher in places, e.g., with totals of $24 \%$ of normal or below in Germany, despite multiple low-pressure systems bringing heavy convective precipitation, but only localized.

The exceptionally dry summer was followed by an also drier-than-usual autumn. Again, the overall precipitation deficit was interrupted by some heavy rain events, but with short duration or rather localized. For example, a storm brought heavy precipitation on 23 September, especially in central Germany and later in Austria; new 72-h total records were set at several stations such as Kötschach-Mauthen (441 $\mathrm{mm}$ on 27-30 October, surpassing the previous record of $373 \mathrm{~mm}$ ). The year ended with above-average precipitation in December for most of central Europe, terminating the drought of the previous two seasons in many areas.

\section{(iii) Notable events and impacts}

From 17-20 January, a storm moved over central Europe, with its cold front reaching the Alps. Maximum wind gusts reached $36 \mathrm{~m} \mathrm{~s}^{-1}$ in Leipzig, Germany, and on 18 January at the mountain station Brocken (1142 m a.s.l.), $65 \mathrm{~m} \mathrm{~s}^{-1}$ was measured. The storm caused power outages, travel disruptions due to fallen trees on the rail lines and roads, and delayed flights.

St. Michael im Lungau (Austria, $1075 \mathrm{~m}$ a.s.l.) observed $-25.2^{\circ} \mathrm{C}$ on 26 February, its lowest temperature since 1968. Similarly, Flattnitz, Austria (1400 m a.s.l.), reported $-25.4^{\circ} \mathrm{C}$, its lowest temperature since 1970 .

On 16 April at the weather station Graz-Straßgang (Austria), an unusually extreme rain event brought a daily precipitation total of $93.4 \mathrm{~mm}$, of which 78 $\mathrm{mm}$ was registered in only 3 hours. In the inner city of Graz, up to $162 \mathrm{~mm}$ of rain was measured. This amount is unusual even for a heavy summer thunderstorm and was never before seen in April.

A 10-day heat wave began 30 July in Switzerland, bringing widespread daily maximum temperatures of $30^{\circ} \mathrm{C}$ and more to places such as Basel, Zürich, and Luzern. Regionally, it was the third or fourth most intense such heat wave on record.

During June, July, and September, multiple intense rainstorms occurred in Slovakia, leading to local flooding and destroying roads and bridges. On 6 June, $54.3 \mathrm{~mm}$ of rain fell in 4 hours, just $5 \mathrm{~mm}$ short of the daily precipitation total record set in 1953. During 1-3 September, more than $100 \mathrm{~mm}$ of precipitation was reported in western Slovakia, which is twice the average monthly total in this area. 


\section{SIDEBAR 7.3: THE LONG HEAT WAVE AND DROUGHT IN EUROPE}

IN 2018 - B. RÖSNER, I. BENEDICT, C. VAN HEERWAARDEN, A. WEERTS, W. HAZELEGER, P. BISSOLLI, AND K. TRACHTE

The weather conditions of 2018 were exceptional for many countries in Europe, with record-breaking warmth and precipitation deficits. Notably, April and May were the warmest such months for many countries in central and northern Europe, with many stations reporting new record daily maximum temperatures and number of summer days (daily maximum temperatures $\geq 25^{\circ} \mathrm{C}$ ) often surpassing previous records by a wide margin. With records dating to $188 \mathrm{I}$, Germany reported 74 summer days and more than 20 heat days (daily maxima $\geq 30^{\circ} \mathrm{C}$ ) through the year, easily breaking the record of 2003. The longest regional heat wave ever recorded-from 12 July to 8 or 9 August-was reported in the south and southeast Netherlands. During 24 July-8 August, France experienced a heat wave with temperatures locally exceeding $40^{\circ} \mathrm{C}$. Notably, many high minimum temperature records were broken; for example, Perpignan: $30.3^{\circ} \mathrm{C}$ on 4 August and Lyon: $25.7^{\circ} \mathrm{C}$ on 5 August. Together, with a previous heat wave during 24-27 July, these extreme events caused about 1500 deaths, according to the French Ministry of Health.

While there were some local extreme precipitation events that brought high rainfall totals in a matter of hours, especially in western and south central Europe during the summer, the overall precipitation annual deficit was substantial and continued through the end of the year.

\section{Analysis: Blocking high-pressure system}

Beginning in April, a high-pressure blocking system continued over central and northern Europe that resulted in the breakdown or blocking of westerly flows, which lasted until September. The strong subsidence hindered cloud formation and precipitation, resulting in a long-lasting, widespread drought and record high temperatures. The causes for the long duration of this weather pattern are still under active investigation. According to recent research, slowly varying large-scale circulation patterns play a big role. High European summer temperatures are found to be associated with increases in the overall intensity of midlatitude, quasi-stationary atmospheric wave activity (Wolf et al. 2018). Some authors suggest that these types of persistent weather situations could be linked to a quasiresonant amplification of planetary waves resulting in highamplitude and stationary waves making elongated, largescale synoptic weather situations possible (Petoukhov et al.
2013; Coumou et al. 2014); however, resonance is difficult to prove from the observational record. The increasing occurrence of such conditions favorable for these types of situations, along with extreme weather in recent decades, has been suggested to be a result of amplified Arctic warming induced by climate change (Mann et al. 2017). Francis et al. (2018) found that large-scale patterns associated with Arctic warming have become more frequent, and the frequency of long-duration weather conditions, at least in the United States, has increased most for those patterns. This is, however, a topic of active investigation, and the short observational record makes it challenging to determine the significance and origin of long-term trends. Other authors have considered large-scale circulation patterns, such as the NAO and other teleconnection patterns, as possible triggering mechanisms, partly modulated by stratospheric processes, and also land-atmosphere feedbacks (as described by Richardson et al. 2019).

\section{Analysis: Moisture sources}

The persistence of high-pressure systems during summer 2018 also affected the atmospheric transport of moisture toward western Europe. Benedict (Wageningen University, Netherlands) and coworkers identified the moisture sources for western Europe during the 2018 summer drought with the use of the Eulerian offline tracking tool WAM-2layers (van der Ent et al. 2010; van der Ent 2014). This tool was run using ERA-Interim reanalysis data (Dee et al. 20Ila) for May-August, and results were compared against tracking results for the long-term (1979-2018) summer mean. Precipitation over western Europe (region indicated in Fig. SB 7.6) was tracked backward in time to determine where this water originally evaporated (i.e., the moisture sources).

The moisture sources during 2018 were determined to be much more of continental origin and less of oceanic compared to climatology. During most of the summer, a high-pressure system was located over western Europe/ southern Scandinavia (see $500-\mathrm{hPa}$ height anomalies in Fig. SB 7.6), which redirected storms that normally result in precipitation over western Europe toward the southern Alps and southeastern Europe. As a result, less moisture was transported from the Atlantic Ocean toward western Europe. Precipitation that fell over the northern Alps (within the tracking region) in 2018 was mainly recycled 
from within the basin or originated from eastern Europe following the anomalous anti-cyclonic flow. Conversely, in southern Scandinavia, where the drought was strongest, moisture recycling over land was almost half what it typically is in summer. The evaporation recycling ratio over southern Scandinavia was $6 \%$ in 2018 compared to $10 \%$ for the base period, which indicates that the drought there self-intensified due to positive soil moisture-evaporation-atmosphere feedbacks.

\section{Economic impacts}

The extreme heat and severe drought had far-reaching impacts on water supply, forests, farming, and crops. Consequently, many countries, including Sweden, Estonia, Lithuania, Latvia, Denmark, the Netherlands, Belgium, Germany, and eastern France, suffered major economic losses. Lithuania and Latvia each declared a state of emergency. The impact of the rainfall deficit was especially harmful for agriculture during April-May, which is the important shooting stage for winter grain. In combination with the above-average temperatures, the quality and quantity of the grain harvest further declined. The losses of the spring crops and grass were felt later in the year, as the losses caused animal food shortages. Overall, crop yields were greatly reduced. In Germany, the drought caused related damages of at least $€ 3$ billion (euros) [ $\$ 3.4$ billion (U.S. dollars)] as of August 2018, according to the German Federal Ministry of Food and Agriculture. Economic losses of dried out tree seedlings and the weakened resilience of older trees to pests were estimated to be as much as $€ \mathrm{I}$ billion (euros) [\$I.I billion (U.S. dollars)] by the Deutsche Forstwirtschaftsrat (German Forestry Council).
Sweden and Greece experienced large and unprecedented wildfires, especially in July. In addition to agriculture and forestry, other notable economic losses were seen. Record low water levels in many major rivers such as the Rhine and Danube hindered the transport of goods; some industrial firms and power plants, such as the nuclear power plants in Fessenheim (France), Philippsburg (Germany), and Ringhals-2 (Sweden), were forced to reduce or sometimes even temporarily shut down their production due to cooling water being too warm or unavailable. The high water temperatures also resulted in fish fatalities. There was a bright side, however. Due to the extremely high number of sunshine hours (144\% of average), new records were set during July in Germany for photovoltaic renewable energy production.

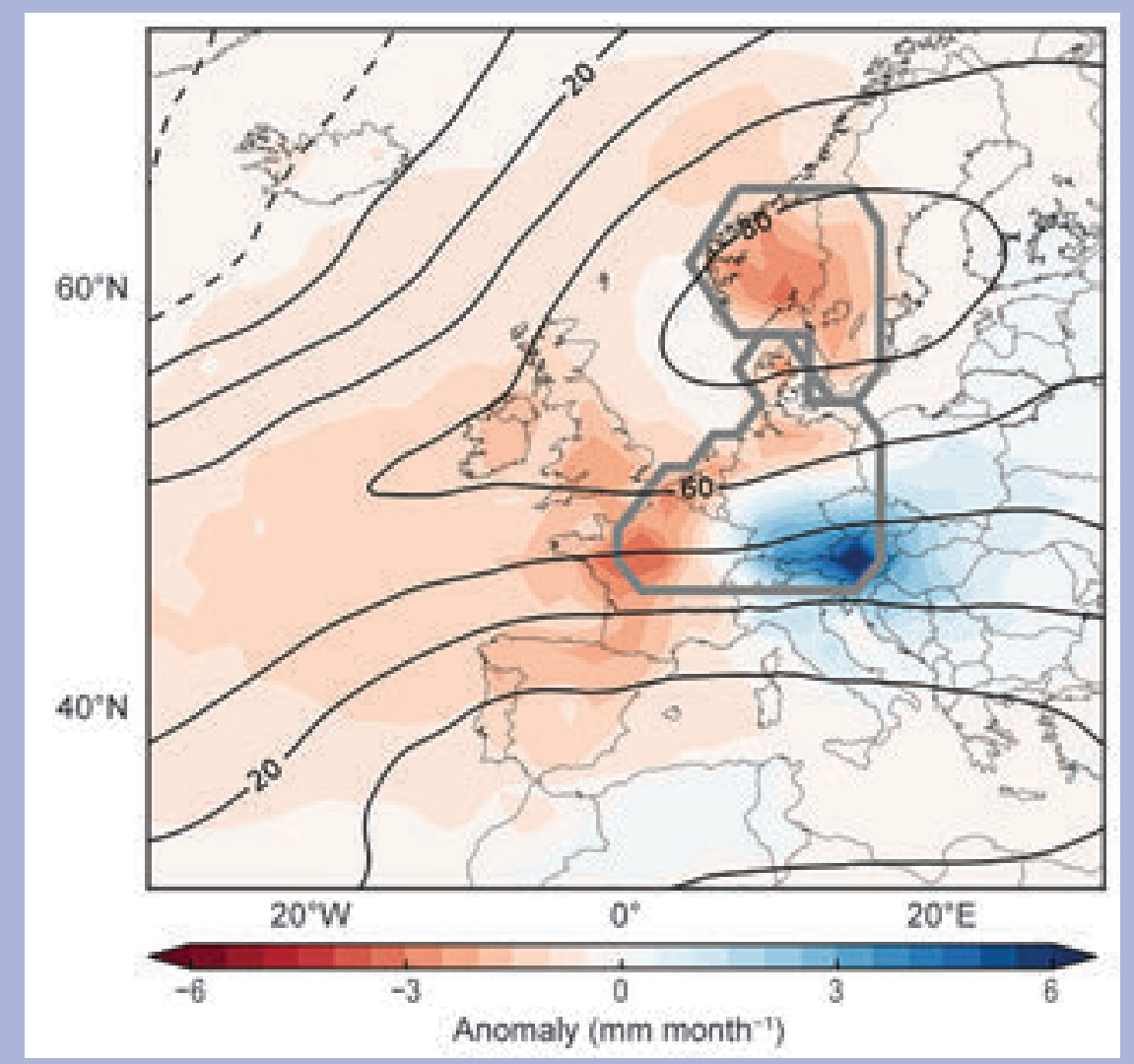

FIG. SB7.6. Absolute moisture source anomalies for western Europe region indicated with gray lines $\left(\mathrm{mm}\right.$ month $\left.^{-1}\right)$ and $500-\mathrm{hPa}$ geopotential height anomalies (m, contours: May-Aug 2018, climatology of May-Aug 1979-2018) 


\section{4) The Nordic and Baltic countries}

This section includes Iceland, Greenland, Norway, Denmark, Sweden, Finland, Estonia, Latvia, and Lithuania.

\section{(i) Temperature}

Overall, the Nordic and Baltic countries were warmer than usual in 2018 with temperature anomalies ranging between $+1^{\circ} \mathrm{C}$ and $+2^{\circ} \mathrm{C}$ in most areas. Denmark reported its second warmest year on record (after 2014) as did Lithuania (after 2015); for Latvia, 2018 was the third warmest year on record (after 2000 and 2008). Winter 2017/18 was mild in most regions except for the northern parts of Scandinavia, which were locally colder with temperatures around $-2.0^{\circ} \mathrm{C}$ below normal. February was the coldest month of the season with widespread anomalies of around $-2.0^{\circ} \mathrm{C}$, resulting in the fourth coldest February of the twentyfirst century in Latvia and Sweden, with new monthly low station records in Haparanda, Jokkmokk, Pajala, and Kiruna-Esrange, the latter of which tied with February 1984. The lowest temperature during the winter in Sweden was reported from the mountain station Gielas (577 $\mathrm{m}$ a.s.l.): $-40.4^{\circ} \mathrm{C}$ on 26 February. The lowest reading in Latvia was $-27.4^{\circ} \mathrm{C}$ on 23 February in Daugavpils.

Spring started cold but ended with record warmth in May. Denmark's average daily maximum temperature of the season was the seventh highest since 1953, and a new record for the earliest summer day since 1964 was set on 19 April. At Oskarshamn Station (Sweden), $27.2^{\circ} \mathrm{C}$ was observed on 20 April, which was never before recorded that early in the season. Under dominating high pressure, exceptionally high anomalies between $+3^{\circ} \mathrm{C}$ and $+4^{\circ} \mathrm{C}$ were observed in the northern and Baltic states in May, with some parts of Norway and Sweden even exceeding anomalies of $+5^{\circ} \mathrm{C}$. It was the warmest May on record for Latvia, Lithuania, Denmark, Estonia, Finland, Norway, and Sweden. Norway broke its previous record of 2013 by $1.7^{\circ} \mathrm{C}$. Record high temperatures were also recorded in May at all regular Svalbard meteorological stations in the Norwegian archipelago, including the composite series from Longyearbyen that began in 1898. During May, highest (warmest) minimum temperature records were broken two times at the summit on the Greenland ice cap with the final record being $-46.5^{\circ} \mathrm{C}$.

Records continued to break in summer, which was the hottest for Denmark $\left(+2.6^{\circ} \mathrm{C}\right.$ anomaly), Finland $\left(+4.0^{\circ} \mathrm{C}\right)$, and Norway $\left(+4.4^{\circ} \mathrm{C}\right)$. Latvia reported its second warmest summer since 1924, when recordkeeping began. Exceptionally high anomalies were measured in July at Gaustatoppen Station (Norway) at $+6.4^{\circ} \mathrm{C}$ (monthly mean temperature $10.6^{\circ} \mathrm{C}$ ) and in Uppsala (Sweden) with $+5.6^{\circ} \mathrm{C}$ (mean of $22.0^{\circ} \mathrm{C}$ ). Several other stations in Sweden reported new mean summer temperature records (Uppsala, Stockholm, Lund, and Gothenburg). Other notable records included: 51 summer days (maximum temperature $\geq 25^{\circ} \mathrm{C}$ ) in Lund (Sweden), the highest number since 1961 when recordkeeping began, and a monthly average temperature of $22.5^{\circ} \mathrm{C}$ in July in Stockholm, the highest monthly temperature ever recorded in Sweden.

Autumn continued in the same manner as summer. Latvia reported its second warmest September since 1934 , with a mean of $14.6^{\circ} \mathrm{C}$. For the first time, a temperature of $30^{\circ} \mathrm{C}$ was observed during the second half of the month in the country. Finland observed temperatures exceeding $20^{\circ} \mathrm{C}$ after the middle of the month. Autumn ended much warmer than normal, especially in northern Norway, Finland, and Sweden, with November anomalies of $+3^{\circ} \mathrm{C}$ to $+5^{\circ} \mathrm{C}$. At Summit Station on the Greenland ice cap, a new record high minimum temperature of $-55.4^{\circ} \mathrm{C}$ was set on 26 October, surpassing the previous record by $0.2^{\circ} \mathrm{C}$.

\section{(ii) Precipitation}

It was a dry year for all Nordic and Baltic states except along the west coast of Norway (slightly wetter than normal), Greenland, which had its third wettest year, and northern Finland, which had near-normal precipitation. In January, precipitation was distributed unequally over the Nordic and Baltic states. February precipitation totals were $<20 \%$ of normal in northern Norway and Sweden as well as in many parts of Finland. Latvia reported its third driest February in the twenty-first century. Conversely, Pituffik (Greenland) experienced a record wet winter. Most stations in Greenland reported winter as their third wettest in history.

Spring continued to be dry, and new local records were set. The station in Visby (Sweden) reported only $38 \%$ of normal precipitation for the season, with a new low monthly record for May of only $1.7 \mathrm{~mm}$ of precipitation, breaking the previous record of $2.8 \mathrm{~mm}$ set in 1866. In Latvia, all stations measured belowaverage precipitation, making it the second driest spring since the beginning of the century and 12th driest since 1924. Total precipitation was less than $60 \%$ of normal, which was similar to Estonia.

At the beginning of summer, Latvia had a severe drought. For $75 \%$ of the reporting stations, the period of 4 May-20 June was the driest since 1961. Many parts of Sweden received only $40 \%-80 \%$ of normal 
precipitation for the season. During autumn, Norway reported a surplus of precipitation while Sweden, due to lee effects, was rather dry (less than $75 \%$ of normal in most areas). September was among the wettest such months in Norway since 1900, tying with the Septembers of 1931, 1975, and 1982. Latvia, on the other hand, with only $19.2 \mathrm{~mm}$ of precipitation ( $31 \%$ of normal), observed its fourth driest November since 1924 .

\section{(iii) Notable events and impacts}

In Sweden, most of July was characterized by prolonged drought that caused severe forest fires in the central parts of the country. Estonia reported a longlasting heat wave in July/August. From 12 July to 5 August, the daily maximum temperature was at least $25^{\circ} \mathrm{C}$. In many places, the maximum temperature rose to $30^{\circ} \mathrm{C}$ or higher for two or more consecutive days. At the Lääne-Nigula Station, the maximum temperature was at least $30^{\circ} \mathrm{C}$ on eight successive days, which is extraordinarily long for Estonia. On 21 September, Latvia observed a temperature of $30^{\circ} \mathrm{C}$, the highest temperature ever recorded in the country that late in the year.

During 21-22 September, a storm passed over Sweden with mean wind speeds of $28 \mathrm{~m} \mathrm{~s}^{-1}$ and gusts of up to $33.9 \mathrm{~m} \mathrm{~s}^{-1}$. During 26-27 September, a second storm caused damage and power outages in the southern and central parts of Finland, with inland gusts of $23 \mathrm{~m} \mathrm{~s}^{-1}\left(26 \mathrm{~m} \mathrm{~s}^{-1}\right.$ in coastal areas).

\section{5) Iberian Peninsula}

This region includes Spain and Portugal.

\section{(i) Temperature}

Annual temperatures on the Iberian Peninsula were near normal overall, but generally above average in the north and east and below normal over the remainder of the Peninsula. Although January was warmer than normal for Portugal and Spain (anomalies up to $+1^{\circ} \mathrm{C}$, even $+2^{\circ} \mathrm{C}$ in some areas), winter 2017/18 was dominated by a cold February resulting in below-average temperatures for most of Spain and slightly-below-normal for Portugal. February was the third coldest since 2000 and the ninth coldest since 1931 for Portugal. Spain reported its sixth coldest February since 1965.

Except for the Mediterranean coast of Spain, spring was colder than average for the Iberian Peninsula; it was the third coldest spring for Portugal and fourth coldest for Spain since 2000. March featured widespread anomalies of around $-1.3^{\circ} \mathrm{C}$. The lowest temperatures observed in spring occurred during
15-26 March and affected the entire Iberian Peninsula and the Balearic Islands.

Summer was near normal in Spain and Portugal on average, but August was very warm, with an anomaly of $+1.7^{\circ} \mathrm{C}$ for Spain, and Portugal reporting its second warmest August in its 88-year record (after 2003). Record-breaking temperatures were observed in both Spain and Portugal, particularly during 1-7 August when new summer records of daily minimum temperature were set at eight stations in Spain, and three of the main stations of AEMET (Spanish Meteorological Service) reported record high absolute maximum temperatures. The highest value among the Spanish main stations in 2018 was $45.1^{\circ} \mathrm{C}$ in Cordoba on 4 August. In mainland Portugal, 4 August was the hottest day of the twenty-first century, with a daily maximum of $46.8^{\circ} \mathrm{C}$ in Alvega.

During early autumn, above-normal temperatures continued, resulting in the warmest September in Spain since $1965\left(+2.4^{\circ} \mathrm{C}\right.$, breaking the previous record by $0.1^{\circ} \mathrm{C}$ ) and Portugal since 1931 . Additional new records were set at Santiago de Compostela (Lavacolla) and Reus Airport on 2 and 3 September, respectively, with the highest daily minimum temperatures of autumn since records began. At Coruña Station, a new record maximum temperature of $31.9^{\circ} \mathrm{C}$ was recorded on 2 September. However, during 27-31 October, a cold spell due to the arrival of polar air masses brought unusually low temperatures for that time of the year.

\section{(ii) Precipitation}

With precipitation above $125 \%$ of normal and as much as $500 \%$ along some parts of the eastern and Mediterranean coast of Spain, 2018 was predominantly wet on the Iberian Peninsula, except for the most western part. Winter 2017/18 was dry in Portugal. February had near-normal precipitation but could not compensate for the deficit of the preceding two winter months. Thus, $84 \%$ of mainland Portugal was in severe and extreme drought by the end of February. In Spain, winter was also dry in the south (below 60\% of normal) but wet in the north (above 150\%) where exposure to low-pressure systems was greater.

Spring was very wet on the Iberian Peninsula. Under the dominant influence of low pressure reaching far to the south, four consecutive storms passed over the Peninsula. March showed widespread precipitation values ranging from $250 \%$ to well above $500 \%$ of normal. Penhas Douradas in Portugal reported a record $585 \mathrm{~mm}$ of precipitation, the most rain received since 1968 (516 mm). It was the second wettest March in Portugal, ending the previous month's drought. Most 
of Spain also received precipitation totals above 300\% of normal during spring, with many stations reporting new monthly records. Overall it was the wettest spring in Spain since 1965, when recordkeeping began.

Summer rainfall in Portugal was near normal while Spain had $122 \%$ of normal. However, the distribution of precipitation was unequal-in southwest Spain totals were less than $75 \%$ of normal and extensive areas of the Guadalquivir Basin as well as Andalusia, Ceuta, and Melilla on the Mediterranean coast received less than $25 \%$ of their normal. In the wet areas in the north, precipitation often exceeded twice the normal amount, in large part due to localized heavy rainfall from storms.

During autumn, only southern and eastern Spain reported above-normal precipitation; the rest of the Peninsula was near normal. After an extremely dry September where parts of Portugal received less than $20 \%$ of normal precipitation and many areas in northern Spain received less than $50 \%$ of normal, October was wet. Most of the precipitation fell during intense and often stormy events, for example, during 18-19 October, a 1-h total of more than $150 \mathrm{~mm}$ was registered in Vinarós (Castellón) and on 20-21 October, a 24-h total of $335 \mathrm{~mm}$ (including $118 \mathrm{~mm}$ in 1 hour) was recorded in Alpandeire (Málaga).

\section{(iii) Notable events and impacts}

Winter cold episodes were frequent in Spain, with the lowest values reported at the stations Ávila $\left(-11.4^{\circ} \mathrm{C}\right.$ on 9 January), Molina de Aragón $\left(-12.8^{\circ} \mathrm{C}\right.$ on 8 February), Teruel $\left(-11.0^{\circ} \mathrm{C}\right.$ on 8 February), and Port of Navacerrada $\left(-10.5^{\circ} \mathrm{C}\right.$ on 8 February). There was also an unusually high number of frost days in winter: at the port of Navacerrada (69), at Molina de Aragón (67), at Salamanca/airport (63).

In the first half of March, three storms contributed to precipitation totals that were twice the monthly normal value. With additional rain episodes in April and May, 11 stations in Spain set new records for spring precipitation totals.

During the first half of June, Spain experienced a cold episode with unusually low temperatures for that time of year, including: $1.8^{\circ} \mathrm{C}$ at Port of Navacerrada (5 June); $5.3^{\circ} \mathrm{C}$ at Burgos/airport (6 June); and $5.1^{\circ} \mathrm{C}$ at Molina de Aragón (14 June).

On 13-14 October, Storm Leslie (a former Atlantic tropical storm) passed mainland Portugal, causing very strong winds in Lisbon, Leiria, Coimbra, Aveiro, and Viseu. At Figueira da Foz Station, gusts reached as high as $49 \mathrm{~m} \mathrm{~s}^{-1}$.

\section{6) Mediterranean and Balkan states}

This region includes Italy, Malta, Slovenia, Croatia, Serbia, Montenegro, Bosnia and Herzegovina, Albania, North Macedonia, Greece, Bulgaria, and Turkey.

\section{(i) Temperature}

Temperatures in the Mediterranean and Balkan States were well above normal for 2018. For Italy $\left(+1.2^{\circ} \mathrm{C}\right.$ anomaly), Serbia $\left(+1.6^{\circ} \mathrm{C}\right)$, Croatia $\left(+1.4^{\circ} \mathrm{C}\right)$, Greece $\left(+1.4^{\circ} \mathrm{C}\right)$, and Bosnia and Herzegovina $\left(+1.5^{\circ} \mathrm{C}\right)$, it was the warmest year on record, while for Slovenia $\left(+1.5^{\circ} \mathrm{C}\right)$, Bulgaria $\left(+1.2^{\circ} \mathrm{C}\right)$, and Turkey $\left(+1.9^{\circ} \mathrm{C}\right), 2018$ was the second warmest year on record.

An exceptionally warm January with widespread above-normal temperatures between $+3^{\circ} \mathrm{C}$ and $+4^{\circ} \mathrm{C}$ was followed by a cold February for the northern part of the Balkan states and Italy, while above-normal temperatures continued in Albania, North Macedonia, Bulgaria, and Turkey. Winter as a whole was mostly warmer than normal, with anomalies slightly above $+1^{\circ} \mathrm{C}$, except for Italy and Malta, which were near normal.

In the north, cold weather continued into spring. In Serbia on 1 March, record low minimum temperatures were observed at seven meteorological stations. However, the whole region experienced an exceptionally warm April due to well-above-average $500-\mathrm{hPa}$ heights over the northwestern Black Sea; Turkey and Malta each reported a record warm April. On mainland Greece, monthly temperature anomalies of up to $+5^{\circ} \mathrm{C}$ and, in the northern parts, up to $+7^{\circ} \mathrm{C}$, were recorded. Spring ended with above-normal temperatures in May, resulting in one of the five warmest springs for most countries in this region, including warmest on record for Bosnia and Herzegovina, Bulgaria, Greece, Serbia, and Turkey.

Summer temperatures were between $+1^{\circ} \mathrm{C}$ and $+2^{\circ} \mathrm{C}$ above average in most of Italy, except in the south, Slovenia, and Croatia, while temperatures were mostly near normal for the rest of the region. Slovenia reported an anomaly of $+1.6^{\circ} \mathrm{C}$. During the season, extreme maximum temperature records were broken at 36 stations in Turkey.

Anomalies continued to be high in autumn with Italy reporting $+1.4^{\circ} \mathrm{C}$ and Slovenia $+2.0^{\circ} \mathrm{C}$. Serbia and Bosnia and Herzegovina each observed their warmest October on record.

\section{(ii) Precipitation}

Precipitation was spatially inhomogeneous, but overall, the region's annual average precipitation total was near normal, with higher totals locally. Winter was wet, especially in the Balkans. Serbia and 
Slovenia each reported their fourth wettest winter with precipitation $160 \%-170 \%$ of normal. Turkey's winter precipitation was mostly near normal, with some drier-than-normal areas. February was the wettest winter month in the Balkans, Italy, and Greece, while January was the driest with Italy, Greece, North Macedonia, and Bulgaria reporting precipitation totals as low as $60 \%$ of normal.

While March was wet with widespread precipitation that was $250 \%$ of normal, and locally even more, April was dry (mostly $40 \%-60 \%$ of normal, locally only $20 \%$ in some areas), and May was slightly on the wetter side again. In several countries, March was among their five wettest months on record, e.g., Bulgaria (wettest), and second wettest for Serbia and Bosnia and Herzegovina. The deficit in Greece during April was exceptional-with little to no rain reported at many stations. Nevertheless, at the end of spring, most countries, except Greece, received above normal precipitation. In central and northern Italy, precipitation ranged between $200 \%$ and $300 \%$ of normal, and in the cities of Lucca, Florence, Arezzo, and Livorno (all in Italy) seasonal totals were the highest since records began in 1955, locally exceeding $500 \mathrm{~mm}$.

At the beginning of summer, multiple cyclones crossed southern Italy and the southeastern Balkans, bringing heavy precipitation accompanied by thunderstorms and hail. These locally extreme events led to June precipitation that was $200 \%$ or more of normal and a record number of precipitation days at many stations, e.g., 27 rainy days at Sjenica Station in Serbia. In Greece, precipitation totals were exceptional, sometimes reaching multiples of the monthly normals in only a few days. For example, on 26 and 27 June, Argostoli received $83.5 \mathrm{~mm}$ of precipitation, which is 12 times its monthly normal.

The wet summer was followed by a drier-thannormal (widespread $40 \%$ to $80 \%$ of normal) autumn for most of Italy and the Balkan states. In particular, September and October were very dry in the Balkans. Ulcinj (Montenegro) and Vranje (Serbia) stations each observed a monthly precipitation total of only $1 \mathrm{~mm}$, making it the driest September on record at both stations. Serbia reported its third driest October and Bulgaria its second driest, with precipitation $<20 \%$ of normal.

\section{(iii) Notable events and impacts}

Between 26 and 28 June, intense precipitation led to landslides and destroyed roads in many areas of the Rhodope and Balkan Mountains. The districts of Smolyan, Plovdiv, Vratsa, and Haskovo in Bulgaria declared a state of emergency. The affected regions suffered from power outages and interrupted water supplies.

On 23 July, due to prevailing strong westerly gale winds, high temperatures, and dry air, wildfires broke out in the area of Gerania Mountain (west Attica, Greece) and eastern Parnitha Mountain (Greece). In the areas of Attica, Kineta, Neos Voutzas, Mati, and Kokkino Limanaki, the fire spread rapidly, destroying hundreds of houses. With official reports counting 100 deaths and 164 people injured, the fires in Neos Voutzas, Mati, and Kokkino Limanaki are considered the deadliest in the history of modern Greece.

Southeastern Bulgaria suffered local flooding after a torrential precipitation event on 1 October. In Ahtopol, a 24-h total of $134 \mathrm{~mm}$ precipitation was reported (1.5 times the monthly normal). In Burgas, a landslide destroyed a bridge linking the town with the airport.

As a consequence of intense foehn winds on 24 October, several stations in the western plain of Italy recorded new record high maximum temperatures: $31.1^{\circ} \mathrm{C}$ at Salsomaggiore, $31.0^{\circ} \mathrm{C}$ at Panocchia, $30.5^{\circ} \mathrm{C}$ at Parma, $30.0^{\circ} \mathrm{C}$ at Reggio Emilia, and $30.2^{\circ} \mathrm{C}$ at Marzaglia.

In Italy, between 27 and 30 October, extreme precipitation totals due to intense and persistent rain were observed: $340.4 \mathrm{~mm}$ at Casoni di S.Maria di Taro; $620.4 \mathrm{~mm}$ at Torriglia; and $567.4 \mathrm{~mm}$ at Cabanne. The events were accompanied by extreme wind gusts reaching up to $38.3 \mathrm{~m} \mathrm{~s}^{-1}$ at Loiano.

A new national daily maximum rainfall record of $490.8 \mathrm{~mm}$ was set in the village of Ovacik in Kemer, Antalya, Turkey, on 17 December, breaking the previous record of 466 mm set in Marmaris in 1992.

\section{7) EASTERn Europe}

This region includes the European part of Russia, Belarus, Ukraine, Moldova, Romania, and west Kazakhstan.

\section{(i) Temperature}

For eastern Europe, 2018 was warmer than usual with anomalies mostly around $+1^{\circ} \mathrm{C}$, except for west Kazakhstan, where temperatures were near normal. For many countries, it was one of their five warmest on record: Romania, third warmest $\left(+1.4^{\circ} \mathrm{C}\right.$ anomaly); Ukraine, fourth warmest $\left(+1.0^{\circ} \mathrm{C}\right)$; and Belarus, fourth warmest $\left(+1^{\circ} \mathrm{C}\right)$.

Winter was warmer than usual throughout the region. Anomalies ranged from $+1^{\circ} \mathrm{C}$ in Belarus and western parts of the Ukraine to above $+2^{\circ} \mathrm{C}$ for most of Romania, eastern Ukraine, and European Russia. For January, Romania reported widespread temperatures $+3^{\circ} \mathrm{C}$ above normal and new record high maxi- 
mum temperatures at Vărădia de Mureş, Huedin, and Săcuieni stations. Conversely, west Kazakhstan was colder than normal.

March-May temperatures were warmer than average, with the exception of west Kazakhstan and Russia, which had seasonal anomalies of $-1^{\circ} \mathrm{C}$ to $-2^{\circ} \mathrm{C}$. Romania reported its warmest April since 1900, with an anomaly of $+4.6^{\circ} \mathrm{C}$, as did the Ukraine $\left(+4.5^{\circ} \mathrm{C}\right.$ to $\left.+5.6^{\circ} \mathrm{C}\right)$ and Moldova $\left(+4^{\circ} \mathrm{C}\right.$ to $\left.+5^{\circ} \mathrm{C}\right)$.

During summer, especially August, anomalies were above $+2^{\circ} \mathrm{C}$ for most of the region. In Moldova, 15-25 days reached above $30^{\circ} \mathrm{C}$ (3-10 days normally). In Kazakhstan, July monthly mean records were set at Sam Station $\left(32.1^{\circ} \mathrm{C}\right)$ and Beyneu Station $\left(33.2^{\circ} \mathrm{C}\right)$, exceeding previous records by $+1.2^{\circ} \mathrm{C}$ and $+2.3^{\circ} \mathrm{C}$, respectively.

September and October showed widespread anomalies of $+2^{\circ} \mathrm{C}$ to $+3^{\circ} \mathrm{C}$ over large parts of the region, locally even higher. In European Russia, October was the warmest on record since 1891; in Romania 2018 tied with 1984, 2001, and 2012 as the second warmest since its record began there in 1961. For the first time in many parts of Moldova, the mean maximum air temperature reached $24^{\circ}-27^{\circ} \mathrm{C}$ in October. The season ended with a colder-than-usual November; only northern Russia and western and central Romania had above-average anomalies, with some Romanian stations reporting new records for absolute maximum temperature for November.

\section{(ii) Precipitation}

Annual precipitation was near to slightly above normal for most countries of the region except west Kazakhstan, which was drier.

With the exception of Kazakhstan, winter was wetter than normal. Most areas received precipitation totals $125 \%-167 \%$ of normal, but regionally up to $200 \%$ of normal. February was unusually wet, with Moldova observing precipitation totals up to 320\% of normal. At the Bucharest-Băneasa, BucharestAfumați, Brăila, and Stolnici stations in Romania, February precipitation records were broken, and at the station in Urziceni, Romania, a new 24 -h precipitation record was set.

Spring started wet for Romania, Moldova, Ukraine, the southern parts of European Russia, and west Kazakhstan, with March precipitation totals $170 \%$ of normal. In eastern, central, and southern Ukraine, new monthly precipitation records were set (observations starting in 1961), at $250 \%$ to $450 \%$ of normal. In Romania, six weather stations reported new monthly total precipitation records, and four stations set new records for maximum 24-h precipitation totals in March. Nevertheless, spring was overall drier than normal in many parts of the region due to very low precipitation totals in April. Moldova reported April precipitation $5 \%-15 \%$ of normal for most of its territory and May precipitation that was $20 \%-75 \%$ of normal. In Ukraine, below-normal precipitation led to drought that affected wheat crops in the south and southeast. In May, the Novy Ushtogan Station in Kazakhstan set a record for low precipitation with no measured precipitation at all.

During summer, Romania was wetter than normal, while eastern Ukraine, many parts of Russia, and west Kazakhstan were drier. Summer in Ukraine, Moldova, and Romania was characterized by several high-intensity rain events-some of which set new monthly or 24 -h precipitation total records. In July, exceptional precipitation totals were recorded at stations in the Ukraine districts of Ternopil, Chernivtsi, Ivano-Frankivsk, and Zaporizhzhya: 200\%-360\% above normal. In the districts of Zaporizhzhya and Kherson, new daily maximum rainfall records were set. Also in July, five stations in Romania exceeded previous monthly precipitation totals, and two stations set new records for 24 -h precipitation. The season ended with a drier-than-normal August, with most areas only reaching $20 \%-80 \%$ of normal and eastern Ukraine and Moldova receiving $<20 \%$ of normal.

Autumn was drier than normal $(40 \%-80 \%)$ over large parts of eastern Europe. Only some regions of Ukraine and European Russia located at the Black Sea and northern Russia received a precipitation surplus. In September, Romania reported torrential rain episodes that set new 24 -h records. Nevertheless, as a whole, September precipitation totals were deficient, with most areas not even reaching $60 \%$ of normal precipitation. October continued to be dry in Romania, eastern Ukraine, and Moldova, with the latter mostly receiving only $5 \%-30 \%$ of normal. At Fort-Shevchenko Station, it was the driest autumn since 1937. The season ended with extensive November precipitation deficits for northern Ukraine, Belarus, European Russia (except for the south), and west Kazakhstan.

\section{(iii) Notable events and impacts}

Abundant snowfall and snow storms from 17-19 January led to closed roads and power outages in 13 counties in Romania. One person died.

During 13-21 March, Moldova and Romania experienced an unprecedented extreme precipitation episode. In Romania, heavy precipitation flooded hundreds of homes and roads. Some roads were covered with sediment $40 \mathrm{~cm}$ deep. 
In June and July, Romania again experienced multiple extreme precipitation events that resulted in severe flooding leading to road closures, crop damage, and frequent power outages. After extensive rain on 2-3 July, a dam broke in the county of Covasna, flooding several villages. Belarus experienced a number of precipitation events, particularly in July; during one such event, $73 \mathrm{~mm}$ was received in 12 hours.

\section{8) Middle East}

This region includes Israel, Cyprus, Jordan, Lebanon, and Syria.

\section{(i) Temperature}

In the Middle East, annual temperatures were above normal across most of the region, with anomalies of around $+1.7^{\circ} \mathrm{C}$. For Israel, 2018 was the second warmest in the country's 68 -year record. All countries in the region experienced well-above-normal temperatures with anomalies $\geq+1.6^{\circ} \mathrm{C}$ during winter 2017/18; Jordan observed a winter temperature anomaly of $+2 \cdot 6^{\circ} \mathrm{C}$. Average temperatures were exceptionally high at many stations, with Lattakia (Syria) and Ma'an Airport (Jordan) stations reporting February as their warmest on record.

In March, above-normal 500-hPa heights continued, and anomalies of $+2.5^{\circ} \mathrm{C}$ to $+3^{\circ} \mathrm{C}$ were reported. Israel reported its warmest March on record for the central and southern parts of the country. April and May continued to be warmer than normal, making spring one of the hottest seasons $\left(\geq+2^{\circ} \mathrm{C}\right.$ of normal) for the region.

Summer temperatures were closer to normal; only Israel and southern Jordan had anomalies above $+1^{\circ} \mathrm{C}$. The year continued with a warmer-than-usual autumn and December, with anomalies ranging between $+2^{\circ} \mathrm{C}$ and $+3^{\circ} \mathrm{C}$.

\section{(ii) Precipitation}

The year was mostly wetter than normal, particularly in Lebanon, Syria, and southeastern Jordan, which received total precipitation up to $250 \%$ of normal. Winter was near normal in Israel, Lebanon, and the western parts of Jordan and Syria; Cyprus and the eastern parts of Jordan and Syria received less than $80 \%$ of their normal precipitation. Spring started with a very dry March, with either no rain or only a few millimeters across large parts of Syria, Israel, and Jordan, which is unusual for that time of year. Conversely, April and May were mostly wetter than normal; however, Cyprus and northern Syria had a spring precipitation deficit of $>10 \mathrm{~mm}$, which is a considerable amount for this arid region.
Summer is usually the dry season in this region, but some exceptional rain was observed in June, notably along the coast and in northwestern Syria. July, August, and September were dry, with precipitation totals $<10 \mathrm{~mm}$.

Despite inhomogeneously distributed precipitation during October-November, most of the Middle East had a generally normal autumn season, except in eastern Syria and Jordan, where precipitation totals were $167 \%-250 \%$ of normal. December was very wet, especially in Cyprus, along the Mediterranean coast, and northern Syria, due to frequent cyclonic activity over the eastern Mediterranean. Monthly precipitation totals were more than $200 \mathrm{~mm}$ along the coast of northern Syria, and anomalies were $+70 \mathrm{~mm}$ or more over these areas, with some localized monthly totals up to above $500 \%$ of normal.

\section{(iii) Notable events and impacts}

On 18-19 January, many parts of Israel experienced strong winds with speeds of $14-19 \mathrm{~m} \mathrm{~s}^{-1}$ and gusts of more than $25 \mathrm{~m} \mathrm{~s}^{-1}$; locally, even higher gusts (Zefat, $36 \mathrm{~m} \mathrm{~s}^{-1}$; Tel Aviv, $32 \mathrm{~m} \mathrm{~s}^{-1}$ ) injured several people, downed trees, and caused power outages.

On 25-27 April, extreme rainfall accompanied by severe hail, thunderstorms, and strong winds in Israel resulted in flash floods with casualties as well as road closures and property damage. Over large areas in the country, very intense rain-often lasting only $10-15$ minutes-resulted in precipitation totals of more than $15 \mathrm{~mm}$ at many stations. Some stations received even more, e.g., in Hafez Haim (southern Coastal Plain) and in Tel Aviv, $24 \mathrm{~mm}$ and $22 \mathrm{~mm}$ were recorded, respectively, in 10 minutes on 25 April. These rainfall intensities are considered rare to exceptional in many areas, and in a few places they were unprecedented (return periods of more than 100 years).

In mid-June, mostly from the 11th to 13th, many areas in Israel received precipitation totaling $5 \mathrm{~mm}$ to more than $60 \mathrm{~mm}$, which is unusual during the dry season. At Dorot Station (northwestern Negev), 66 $\mathrm{mm}$ was reported, breaking the previous June record of 1992 by $15 \mathrm{~mm}$.

An extreme Sharav (a southerly or southeasterly dry, sandy wind accompanied by high temperatures) on 16 June brought daily maximum temperatures of $40^{\circ} \mathrm{C}$ to most of Israel. Some stations in northern Negev reached $43^{\circ} \mathrm{C}$, in one or two cases even breaking previous records. On 25 July, another Sharav affected the coastal plains of Israel, which are usually dominated by the prevailing westerly flows from the Mediterranean Sea. Temperatures reached $42^{\circ} \mathrm{C}$, and 
relative humidity was very low $(20 \%-30 \%)$ for the area at this time of year.

In many parts of Israel, heavy rain accompanied by strong winds and hail were observed during 25-26 October. In Jordan, Syria, and Lebanon, this event caused extensive flooding. Twenty people were killed in Jordan when a bus was swept away by a flash flood.

\section{9) South Caucasus}

This region includes Armenia, Georgia, and Azerbaijan.

\section{(i) Temperature}

On average, annual temperatures in the South Caucasus were $+2^{\circ} \mathrm{C}$ to $+3^{\circ} \mathrm{C}$ above normal for 2018 . Armenia reported its second warmest year on record. Winter was warmer than normal for all countries in the region, especially February, during which Armenia observed temperature anomalies above $+4^{\circ} \mathrm{C}$.

March had above-average temperatures, with widespread anomalies of $+4^{\circ} \mathrm{C}$ to $+5^{\circ} \mathrm{C}$, even higher in Armenia. Overall, spring was warmer than usual by $3^{\circ} \mathrm{C}$ or more for most of the region. The above-normal temperatures in summer were dominated by a very hot July. In Armenia, anomalies were as high as $+4^{\circ} \mathrm{C}$, and around $+3^{\circ} \mathrm{C}$ in Georgia and Azerbaijan. At Yerevan (Armenia), a new local maximum temperature record of $43.7^{\circ} \mathrm{C}$ was set on 12 July, tying with the countrywide maximum temperature set on 31 July 2011 in Meghri. The season ended with temperatures closer to normal in August across most of Georgia and Azerbaijan; however, in Armenia, anomalies were still $+1^{\circ} \mathrm{C}$ or higher.

Autumn temperatures in the region remained above normal, with anomalies ranging between $+1^{\circ} \mathrm{C}$ and $+2^{\circ} \mathrm{C}$. Only in November were temperatures near normal in Azerbaijan, while anomalies were still above $+1^{\circ} \mathrm{C}$ in Georgia and Armenia. Across the region, December was $+1^{\circ} \mathrm{C}$ warmer than average.

\section{(ii) Precipitation}

With average precipitation totals $80 \%-100 \%$ of normal, the year was slightly dry to near normal for the South Caucasus region. Distribution of precipitation was inhomogeneous in time and space. Winter was close to normal in Georgia and western Armenia, while most of Azerbaijan received a precipitation surplus up to $250 \%$ of normal. March was wet across the region, but during April only northern Azerbaijan was wetter than normal, while dryness around the Black Sea affected the rest of the region with precipitation totals as low as $60 \%-80 \%$ of normal. Overall, spring was slightly wetter than normal for Azerbaijan and mostly near normal for Georgia and Armenia.

Eastern Azerbaijan was drier than normal during summer (precipitation totals as low as $20 \%$ of normal locally with only a few millimeters received in all summer months) in contrast with most of Georgia and Armenia, which received near-normal precipitation.

Autumn was the driest season of the year in terms of anomalies. Except for eastern Armenia, the whole region had a precipitation deficit, including only $60 \%$ to $80 \%$ of normal in northwestern Georgia and eastern Azerbaijan.

The year ended with a wet December in Armenia and Azerbaijan (125\%-250\% of normal) due to cyclonic influences from the eastern Mediterranean, whereas Georgia had near-normal precipitation.

\section{(iii) Notable events and impacts}

Armenia experienced a record drought from 21 June-24 October.

On 6 July an extreme precipitation event brought a record total of $41 \mathrm{~mm}$ in one hour at Shirak Station (Armenia).

\section{g. Asia-T. Li, Ed.}

Throughout this section the base periods used vary by region. The current standard is the 1981-2010 average for both temperature and precipitation, but earlier base periods are still in use in several countries. All seasons mentioned in this section refer to those of the Northern Hemisphere, with winter referring to December-February 2017/18, unless otherwise noted.

I) Overview - T. Li, Z. Zhu, P. Zhang, T. C. Lee, A. Ripaldi, Y. Mochizuki, Lim J.Y., L. Oyunjargal, and B. Timbal

Annual mean surface air temperatures during 2018 were above normal across most of Asia, including $+1.5^{\circ} \mathrm{C}$ in northern Siberia, but below average in much of central Asia (Fig. 7.38). Annual precipitation totals were above normal in Mongolia, northern China, Tajikstan, and regions from Myanmar to northern Laos. Total annual precipitation was below normal in the northern part of eastern Siberia, Indonesia, and regions near the Persian Gulf (Fig. 7.39).

In winter 2017/18, negative temperature anomalies were confined to the latitudinal band of $40^{\circ}-$ $60^{\circ} \mathrm{N}$ and positive anomalies appeared elsewhere (Fig. 7.40a). Negative anomalies of 500-hPa geopotential height and of 850-hPa temperature were observed over northeastern Asia (Fig. 7.41a). In spring, belowaverage temperatures were observed in western Siberia and Indochina, while above-average temperatures 


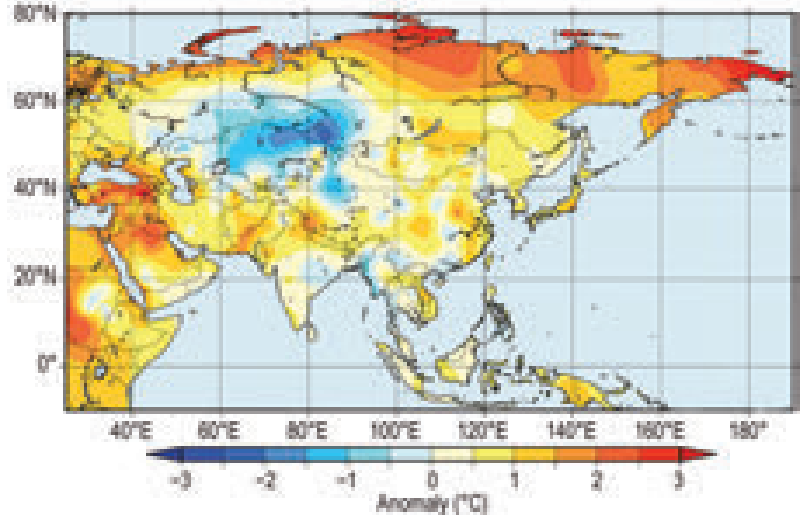

Fig. 7.38. Annual mean surface temperature anomalies ( ${ }^{\circ} \mathrm{C}$; 198I-2010 base period) over Asia in 2018. (Source: Japan Meteorological Agency.)

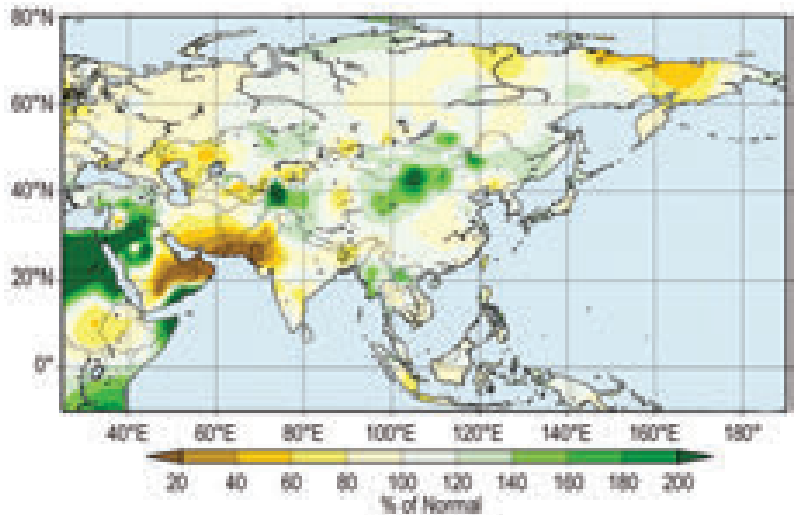

Fıg. 7.39. Annual precipitation (\% of normal; I98I-20I0 base period) over Asia in 2018. (Source: Japan Meteorological Agency.) were observed elsewhere, with maximum anomalies over southern China and Mongolia (Fig. 7.40c). The 500-hPa geopotential height and $850-\mathrm{hPa}$ temperature anomalies for spring were negative over western Siberia and positive over northeastern Asia (Fig. 7.41b). In summer, above-average temperatures occurred over central Siberia and from northern China to Korea and southern Japan (Fig. 7.40e). The western Pacific monsoon trough over Southeast Asia in the season was stronger than normal, associated with active convection around the Philippines (Fig. 7.42c). The abnormal northward shift of the western North Pacific subtropical high dominated northeastern Asia, leading to a deficient East Asian summer monsoon rainfall and a severe heat wave from north China, across the Korean Peninsula, to eastern Japan (Sidebar 7.4). In autumn, below-average temperatures dominated most parts of China and central Asia (Fig. 7.40g), corresponding well with above-average rainfall in the region (Fig. 7.40h). Anticyclonic circulation anomalies controlled the northern Indian Ocean to the South China Sea in the lower troposphere (Fig. $7.42 \mathrm{~d}$ ), and $500-\mathrm{hPa}$ geopotential height and $850-\mathrm{hPa}$
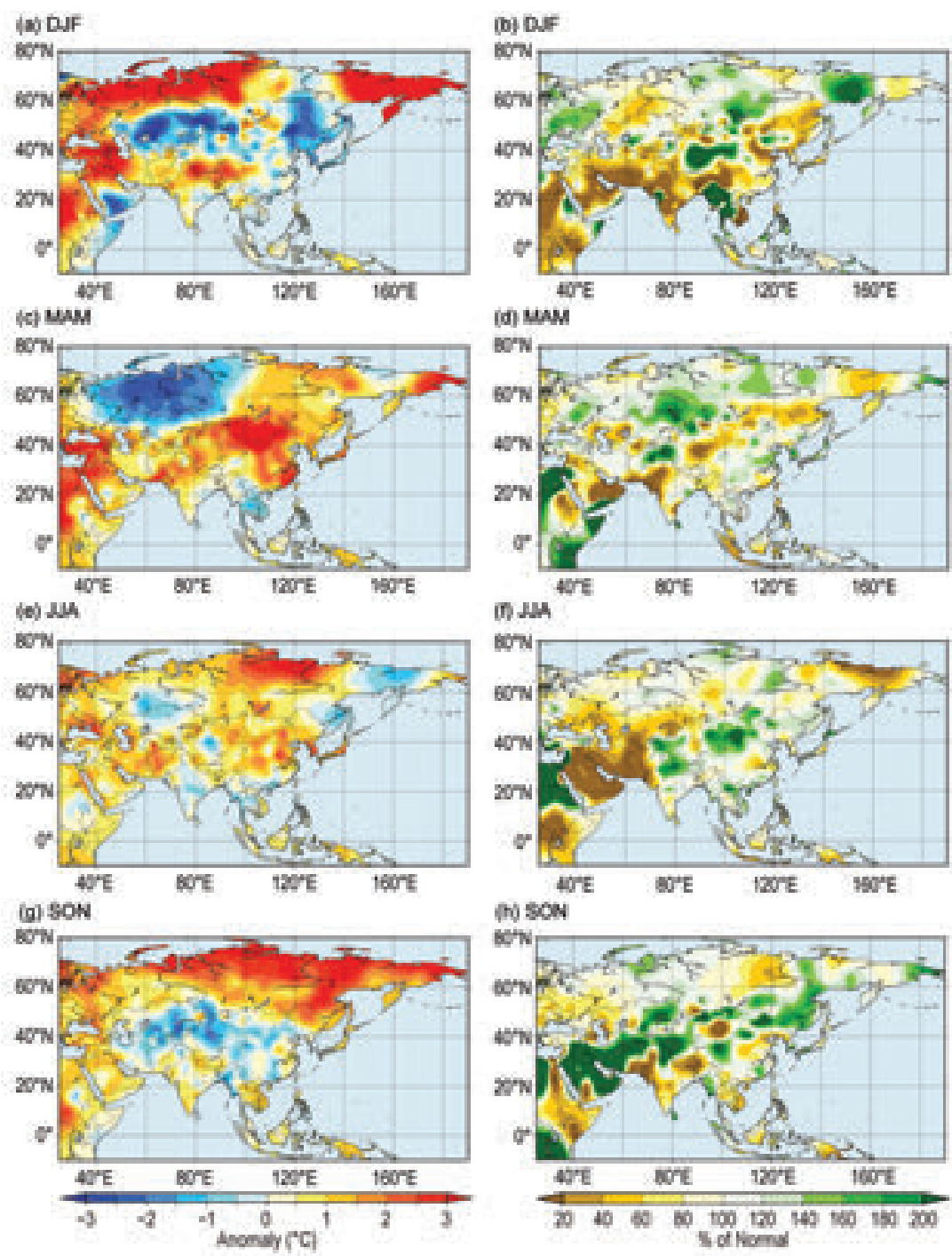

FIG. 7.40. Seasonal mean surface temperature anomalies $\left({ }^{\circ} \mathrm{C}\right.$, left column) and seasonal precipitation (\% of normal, right column) over Asia in 2018 for (a),(b) winter; (c),(d) spring; (e),(f) summer; and (g),(h) autumn. Base period: 1981-2010. (Source: Japan Meteorological Agency.) 
temperature anomalies were negative from central Asia to East Asia and positive from central Siberia to eastern Siberia (Fig. 7.41d).

\section{2) RussiA-M. Yu. Bardin and N. N. Korshunova}

Estimates of climate features for Russia are obtained from hydrometeorological observations of the Roshydromet Observation Network. Anomalies are relative to the 1961-90 base period, and national rankings and percentiles reflect the 1936-2018 period of record. The boundary between Asian Russia and European Russia is considered to be $60^{\circ} \mathrm{E}$.

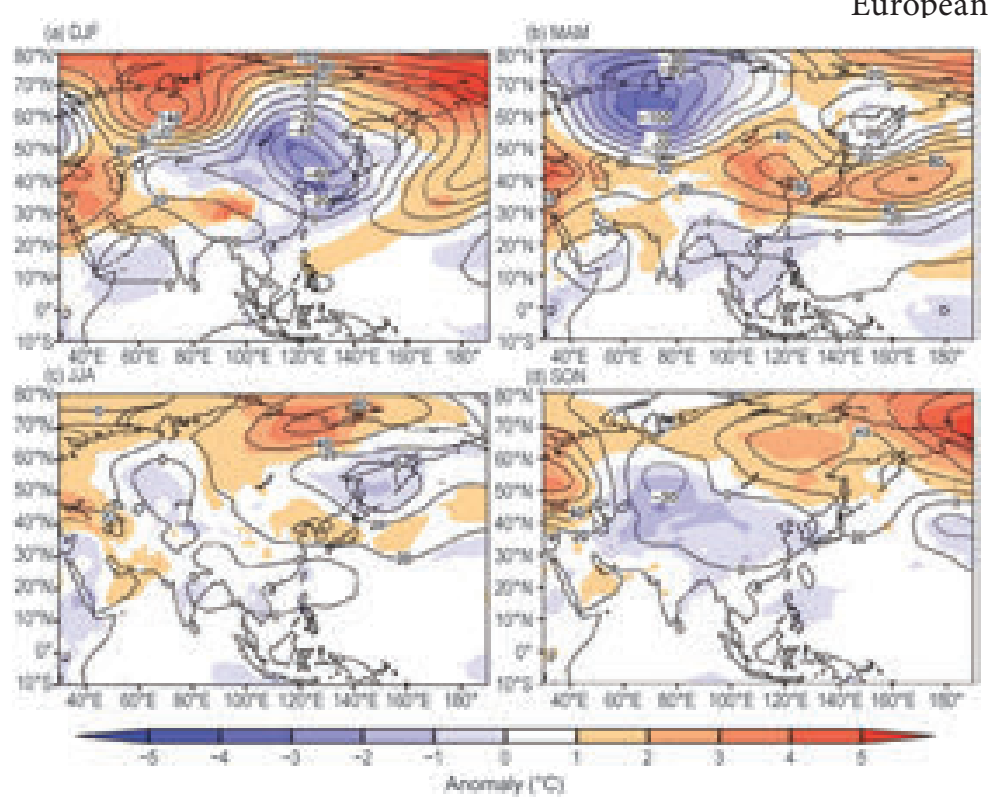

FiG. 7.4I. Seasonal mean anomalies of $500-\mathrm{hPa}$ geopotential height (contour, gpm) and 850-hPa temperature (shading, ${ }^{\circ} \mathrm{C}$ ) in 2018 for (a) winter, (b) spring, (c) summer, and (d) autumn. Base period: 198I-2010. (Source: JRA-55 reanalysis, Japan Meteorological Agency.)

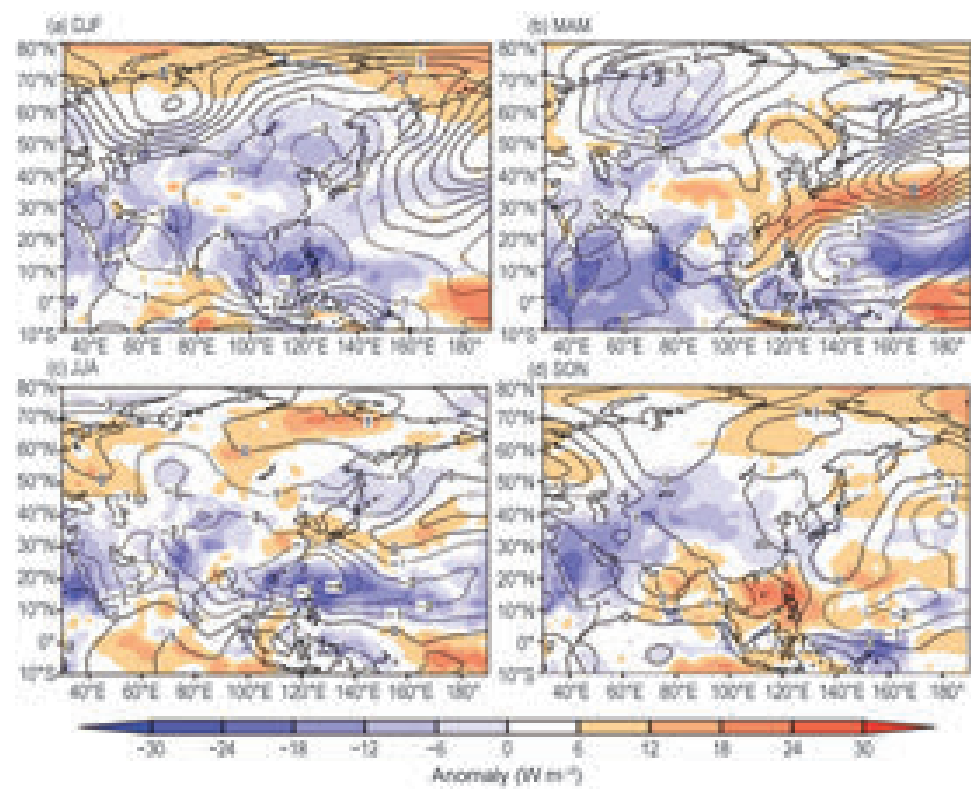

Fig. 7.42. Seasonal mean anomalies of $850-\mathrm{hPa}$ stream function (contour, $\times 10^{6} \mathrm{~m}^{2} \mathrm{~s}^{-1}$ ) using data from the JRA-55 reanalysis and OLR (shading, $\mathrm{W} \mathrm{m}^{-2}$ ) using data originally provided by NOAA in 2018 for (a) winter, (b) spring, (c) summer, and (d) autumn. Base period: 198I-2010. (Source: Japan Meteorological Agency.)

\section{(i) Temperature}

The year 2018 in Russia was quite warm - the mean annual air temperature was $1.58^{\circ} \mathrm{C}$ above normal (Fig. 7.43), the ninth highest on record. Negative annual mean air temperature anomalies were observed only in southwestern Siberia. The largest anomalies were observed in the Arctic zone of Russia north of $65.5^{\circ} \mathrm{N}$ (see Section $5 \mathrm{~b}$ for additional details). The mean annual temperature for this region was $2.72^{\circ} \mathrm{C}$ above normal, its fifth largest value since 1936 . The two highest annual temperature anomalies of $+3.51^{\circ} \mathrm{C}$ and $+3.23^{\circ} \mathrm{C}$ above normal were observed in 2016 and 2017, respectively. Temperatures exceeded the 95th percentile at many stations in the Russian Arctic, Sakha (Yakutia), the Magadan region, and the North Caucasus.

Generally, all seasons in Russia have warmed since the mid-1970s; annual and seasonal trends are statistically significant, except for winter, when the trend is accompanied by strong interdecadal variations. These variations are associated with largescale atmospheric circulation patterns, primarily the NAO and the Scandinavian mode ("Eurasia-1" pattern in Barnston and Livesey, 1987). A period of cooling from the mid-1990s ended in 2010, when the average winter temperature reached its lowest value since 1981. After this period, average winter temperatures once again began to increase.

Winter was moderately warm, with a mean temperature $2.50^{\circ} \mathrm{C}$ above normal, the 11 th highest on record for the season. Station temperatures up to $13^{\circ} \mathrm{C}$ above normal were observed in the Arctic and subarctic zones. Three intense heat waves occurred on 1-10, 12-17, and 25-31 January, in the European sector and adjacent Yamal peninsula. Daily anomalies reached $20^{\circ} \mathrm{C}$, and on some days 


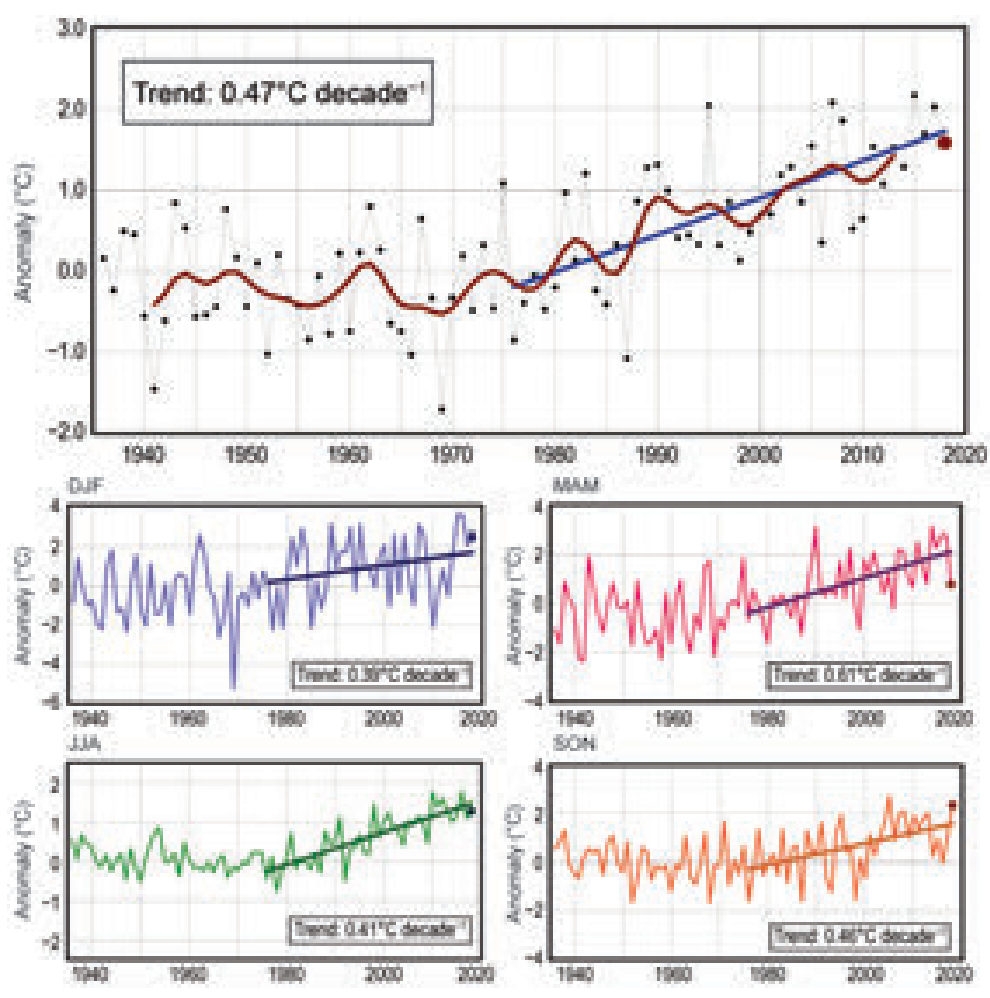

FIG. 7.43. Mean annual and seasonal temperature anomalies ( ${ }^{\circ} \mathrm{C}$; base period 196I-90) averaged over the territory of Russia: 1936-2018. The bold red line on the annual mean time series is an II-point binomial filter. Linear trend $b\left({ }^{\circ} \mathrm{C} \mathrm{decade}^{-1}\right)$ is calculated for the period 1976-2018.

daily mean temperatures reached or exceeded the absolute maxima of those days.

Spring was $0.81^{\circ} \mathrm{C}$ above normal for Russia as a whole, but $0.18^{\circ} \mathrm{C}$ below normal across its European part. March, with an anomaly of $-3.31^{\circ} \mathrm{C}$, was especially cold in European Russia.

Summer was warmer than average, with a temperature anomaly of $+1.28^{\circ} \mathrm{C}$, the sixth highest on record for the season. The warmest summer months were June in Asian Russia, at $+2.06^{\circ} \mathrm{C}$ (its fourth highest on record), and July in European Russia $\left(+2.59^{\circ} \mathrm{C}\right.$, its sixth highest). The highest anomalies were observed in the North Caucasus Federal district.

Autumn had the highest anomaly among all seasons in 2018, ranking second warmest over all of Russia and its Asian part, with area-averaged anomalies of $+2.32^{\circ} \mathrm{C}$ and $+2.48^{\circ} \mathrm{C}$, respectively. September was the second warmest on record across Russia $\left(+1.70^{\circ} \mathrm{C}\right)$, while October was the warmest on record over all of Russia $\left(+3.90^{\circ} \mathrm{C}\right)$ and its Asian part alone $\left(+4.50^{\circ} \mathrm{C}\right)$. The highest monthly anomalies in October, up to $9^{\circ}-10^{\circ} \mathrm{C}$, were observed in north central Siberia. At many stations in this region, daily, and even minimum daily, temperatures were above normal daily temperature throughout the month, and the monthly temperatures were record high (Fig. 7.44).

\section{(ii) Precipitation}

In 2018, total precipitation across Russia was slightly above average, 104\% of normal (Fig. 7.45). Asian Russia was much wetter $(107 \%$, one of its 10 wettest years on record), while its European counterpart was drier (96\%).

Winter precipitation was $112 \%$ of normal, marking the 14th and 15th wettest winter for European and Asian Russia, respectively. Excessive precipitation above $140 \%$ was notable in western European Russia, the Baikal region $\left(100^{\circ}-120^{\circ} \mathrm{E}\right)$, and the Magadan region between $140^{\circ}-160^{\circ} \mathrm{E}$ (Fig. 7.40b). Muchbelow-normal precipitation $(<60 \%)$ was observed in western Siberia between $60^{\circ}-70^{\circ} \mathrm{E}$.

Spring precipitation was $112 \%$ of normal precipitation. However, spring precipitation varied between Asia and Europe: 118\% (fifth highest) in Asian Russia, and 105\% in European Russia. It was the third wettest March in the time series with $159 \%$ of normal precipitation across Russia and the second wettest (168\%) considering its Asian part only. In April and May, the Far Eastern Federal district received $84 \%$ and $85 \%$ of its normal precipitation, respectively. Southern and North Caucasus Federal districts received less than $60 \%$ of their normal precipitation in April.

Summer was close to normal with $102 \%$ of normal precipitation. Notably, June was dry in European Russia: $78 \%$ of normal, making this one of its 10 driest years.

In autumn, Asian Russia received $115 \%$ of normal precipitation (fifth highest on record), while European Russia was dry with $95 \%$ of normal precipitation (Fig. $7.40 \mathrm{~h}$ ), including a very dry November (69\% of normal precipitation, which is among its 10 driest on record).

\section{(iii) Notable events and impacts}

During 3-5 February, extreme precipitation fell over central European Russia, especially-in the Moscow region, where snowfall persisted for those three days, paralyzing city traffic and airports. The meteorological station Moskva VDNH received $36 \mathrm{~mm}$ during that period, more than February's monthly normal. Precipitation on 3-4 February exceeded the daily records for these days. 


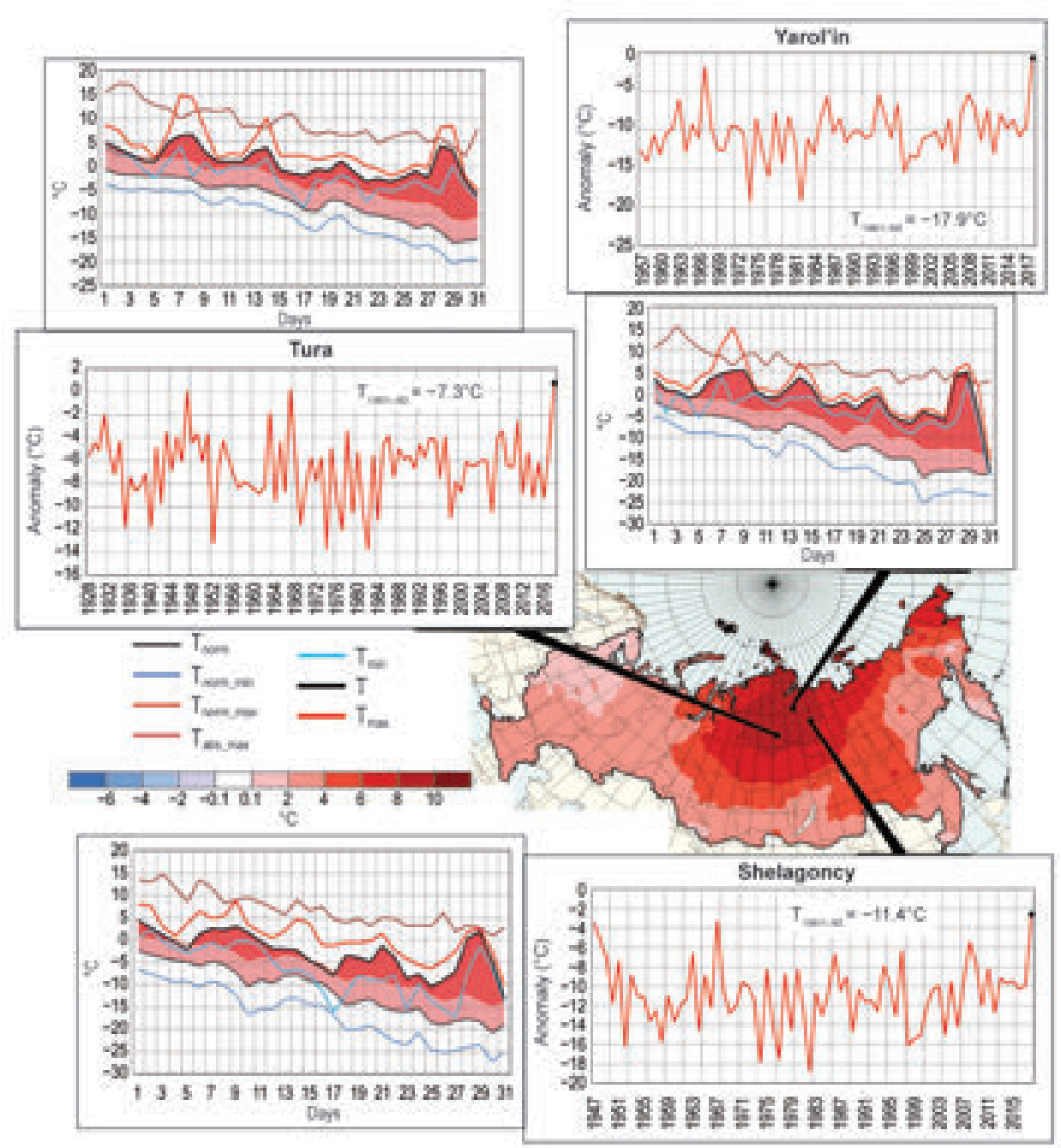

Fig. 7.44. Air temperature anomalies $\left({ }^{\circ} \mathrm{C}\right.$, shaded) in Oct 2018 . Insets: mean monthly and mean daily air temperatures $\left({ }^{\circ} \mathrm{C}\right)$ in Oct 2018 at meteorological stations Tura, Yarol'in, and Shelagoncy. Plots of daily temperature show observed daily mean (black), minimum (blue), and maximum (red) temperatures along with their climatological normals and absolute maximum temperature; the area between daily mean values above normal and the normal daily mean curve is shaded pink, and where values are above normal daily maximum, the shading is red. Periods of record vary.

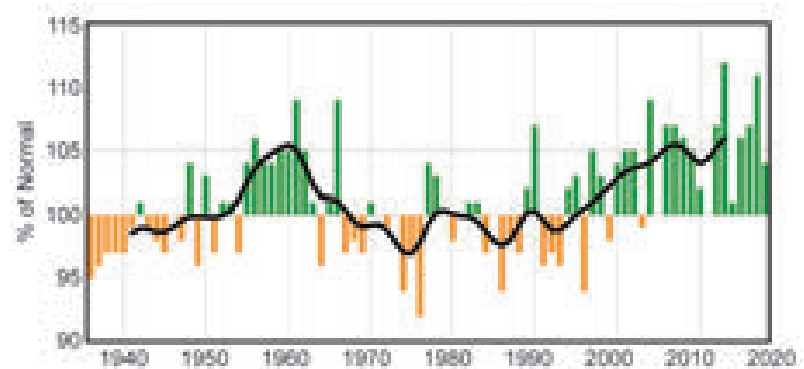

FIG. 7.45. Annual precipitation (\% of normal; 196I-90 base period) averaged over the Russian territory for 1936-2018. The smoothed time series (II-point binomial filter) is shown as a bold line.
During 1-10 July, frequent rainfall over river basins in the eastern Baikal region caused floods. Chita received $166 \mathrm{~mm}$ of precipitation over this period; its normal monthly precipitation is $90 \mathrm{~mm}$. Lower parts of the Chita city and several villages were flooded.

During 24-25 October, heavy and long-lasting rains fell along the Black Sea coast of the Krasnodar Territory, namely, Tuapse, Great Sochi, and Gornyi, which received 215,233 , and $320 \mathrm{~mm}$ of precipitation, respectively. Streets, land adjacent to buildings, and highways were flooded. Two people were killed and five were injured. These rains were associated with a strong cold front over southern European Russia, along with complex geographical features of the Sochi region, where the Caucasus Mountains approach the sea. 
During 25-27 October, the Krasnodar Territory experienced rainfall-induced floods on the rivers Pshish (levels reaching $11.5 \mathrm{~m}$; the hazardous level is $8 \mathrm{~m}$ ), Khosta, Zapadnyi Dagomys, and others. In 29 settlements in the Tuapse and Apsheron regions, as well as in Great Sochi, 2545 households and 5748 backyards were flooded; power, gas, and water supplies were interrupted; roads were washed out; and bridges were destroyed. Two railway stations were flooded. The damage to $200 \mathrm{~m}$ of railway track caused railway service to be disrupted for several days. Territories near Kudepsta and Khosta in Adler were flooded. Six people were killed.

3) East and Southeast Asia—P. Zhang, T. C. Lee, A. Ripaldi, Y. Mochizuki, Lim J.-Y., L. Oyunjargal, and B. Timbal Countries considered in this section include China, Hong Kong (China), Indonesia, Japan, Korea, Mongolia, and Singapore. Unless otherwise noted, anomalies refer to a base period of 1981-2010.

\section{(i) Temperature}

Annual mean temperatures for 2018 across East Asia are shown in Fig. 7.38. The annual mean air temperature for China was $0.54^{\circ} \mathrm{C}$ above the 1981-2010 normal, its 11th warmest year since records began in 1951. The spring and summer average temperatures were each record high, with an anomaly of $+1.6^{\circ} \mathrm{C}$ and $+1.0^{\circ} \mathrm{C}$, respectively. Hong Kong had an annual mean temperature of $23.9^{\circ} \mathrm{C}$, which is $0.6^{\circ} \mathrm{C}$ above normal and its third highest since records began in 1884 .

Annual mean temperatures were above normal across Japan, with the annual temperature for the country as a whole $1.2^{\circ} \mathrm{C}$. above the $1981-2010$ average. In particular, the summer temperature in eastern Japan was $1.7^{\circ} \mathrm{C}$ above average, the highest since records began in 1946. The annual average temperature in South Korea was $13.0^{\circ} \mathrm{C}$, which was $0.6^{\circ} \mathrm{C}$ higher than normal. The summer mean temperature in South Korea was $1.8^{\circ} \mathrm{C}$ above the normal of $23.6^{\circ} \mathrm{C}$, marking the warmest summer in its 46-year record. During this period, East Asia was strongly influenced by the western North Pacific subtropical high and the South Asian high that extended farther northwestward and eastward, respectively, compared to their normal positions (see Sidebar 7.4 for more details).

The annual mean temperature over Mongolia was $1.2^{\circ} \mathrm{C}$, which is $0.7^{\circ} \mathrm{C}$ above normal. The warmest month in 2018 was March, with an average temperature anomaly of $5.5^{\circ} \mathrm{C}$ above normal, ranging from $+0.4^{\circ} \mathrm{C}$ to $+9.0^{\circ} \mathrm{C}$ across the country. The coldest month for
2018 was December, when the mean temperature was $-20.3^{\circ} \mathrm{C}$, which is $2.6^{\circ} \mathrm{C}$ below normal.

The annual mean temperature of Indonesia was $26.7^{\circ} \mathrm{C}$, which was above normal by about $+0.5^{\circ} \mathrm{C}$ in most regions. Above-average temperatures also occurred over Singapore in 2018, with a mean annual temperature of $27.9^{\circ} \mathrm{C}$, which is $0.4^{\circ} \mathrm{C}$ higher than the 1981-2010 normal and its eighth warmest year since records began in 1929. December was the second warmest on record since 1929 , behind only December 2015. The last 10 years (2009-18) mark the warmest decadal period for Singapore, with a mean temperature of $27.89^{\circ} \mathrm{C}$, which surpasses the previous record (1997-2006) by $0.02^{\circ} \mathrm{C}$.

\section{(ii) Precipitation}

Figure 7.39 shows the 2018 annual precipitation as a percentage of normal over East Asia. The annual mean precipitation for China was $673.8 \mathrm{~mm}, 107 \%$ of normal. The annual total precipitation was above normal for the basins of the Songhua River (121\%), the Yellow River (114\%), the Huaihe River Basin (113\%), and the Yangtze River (103\%). The Haihe River and the Pearl River basins were near-normal. In 2018, the annual total rainfall in Hong Kong was 2162.9 mm, which is about $110 \%$ of normal. Mongolia's annual precipitation was $242.0 \mathrm{~mm}$, or $120.6 \%$ of normal.

In Japan, annual precipitation amounts were above normal, except on the Pacific side. Total annual precipitation in South Korea was $1386.9 \mathrm{~mm}$, which is within its normal range (1207.6-1446.0 mm). The amount of summer precipitation in $2018(585.5 \mathrm{~mm})$ was below normal. The annual rainy season-called Changma-lasted only 14-16 days, which is the second shortest Changma since 1973. In October, Typhoon Kong-rey made landfall over South Korea, contributing to a record high precipitation total of $164.2 \mathrm{~mm}$ for the month.

In Indonesia, $82 \%$ of 92 stations recorded belownormal precipitation. This was especially evident for stations in southern Sumatra, Java, Bali, Nusa Tenggara, and northern Sulawesi. The 2018 annual total rainfall at most stations across Singapore was nearaverage. The rainfall recorded at the Changi climate station, however, was $1708 \mathrm{~mm}$, about $79 \%$ of normal.

\section{(iii) Notable events and impacts}

In China, 10 typhoons made landfall during 2018 (three more than normal), causing severe damage. For the year, 83 people were reported dead or missing, and there was approximately $\$ 10$ billion (U.S. dollars) in direct economic losses. Additionally, extremely low temperatures and snow disasters oc- 
curred frequently, causing approximately $\$ 6$ billion (U.S. dollars) worth of direct economic losses, far more than China's 2010-17 average, especially for winter and early spring.

In 2018, Hong Kong experienced its hottest May on record (since 1884) with a monthly mean temperature of $28.3^{\circ} \mathrm{C}\left(2.4^{\circ} \mathrm{C}\right.$ above normal). Severe Typhoon Mangkhut struck Hong Kong on 16 September, bringing severe storm surge and heavy rain squalls that caused the most extensive damage to Hong Kong since Typhoon Ellen in 1983 (Hong Kong Observatory 2019). The record-breaking storm surge raised the water level in Hong Kong by more than $2 \mathrm{~m}$, resulting in an unusually high water level in many places and serious flooding in many coastal and low-lying areas.

Due to the strong winter monsoon, Fukui, Japan experienced a maximum snow depth of $147 \mathrm{~cm}$ on 7 February, stranding approximately 1500 vehicles. In early July, record rain fell over western Japan for several days due to an active Meiyu front (a quasipersistent, nearly stationary, east-west-oriented weak baroclinic zone in the lower troposphere), causing landslides and floods. After mid-July, hot days continued in eastern and western Japan with an all-time national record high temperature of $41.1^{\circ} \mathrm{C}$ set at Kumagaya in the Saitama prefecture. In September, Typhoons Jebi and Trami struck western Japan, causing damage from windstorms and storm surge flooding.

On 20 May, the Wajo District of South Sulawesi, Indonesia, received a record rainfall of $475 \mathrm{~mm}$ in 24 hours, which caused flash flooding in the district. Meanwhile, East Nusa Tenggara experienced its longest number of consecutive dry days (259) from March to November. Seven districts-Nagekeo, Ende, Lembata, East Sumba, Belu, Rote Ndao, and Kupang-had drought conditions that caused water scarcity and agriculture issues.

South Korea experienced a record hot summer. The nationwide average of heat wave days (daily maximum temperature $>33^{\circ} \mathrm{C}$ ) of 31.4 was the most on record (the normal is 9.8). Most notable, the maximum temperature in Seoul on 1 August was $39.6^{\circ} \mathrm{C}$, which was the city's highest value since 1907, when modern meteorological observations were introduced in Korea. The highest temperature recorded in South Korea was also broken on the same day: $41.0^{\circ} \mathrm{C}$ in Hongcheon.

In Mongolia, a total of 86 hydro-meteorological extreme events were reported, the majority of which were due to flash floods and to wind, dust, and snow storms. Together, these extreme events caused an economic loss of approximately $\$ 9.1$ million (U.S. dollars).
4) South AsıA-A. K. Srivastava, J. V. Revadekar, and M. Rajeevan

Countries in this section include: Bangladesh, India, Pakistan, and Sri Lanka. Unless otherwise noted, climate anomalies are relative to the 1981-2010 base period.

\section{(i) Temperature}

In 2018, South Asia generally witnessed significantly above-average temperatures. The annual mean surface air temperature averaged over India was $0.39^{\circ} \mathrm{C}$ above its $1981-2010$ average, making 2018 the sixth warmest year on record since nationwide records commenced in 1901 (Fig. 7.46). India's seasonal mean temperatures were above normal for all four seasons. The winter season (January-February) anomaly of $+0.59^{\circ} \mathrm{C}$ was the fifth highest on record, and the pre-monsoon season (March-May) anomaly of $+0.55^{\circ} \mathrm{C}$ was the highest. These two seasons were the main contributors to the high annual temperature. The warmest year on record is $2016\left(+0.71^{\circ} \mathrm{C}\right)$.

\section{(ii) Precipitation}

The summer monsoon season (June-September) contributes about $75 \%$ of the annual precipitation over South Asia. The 2018 summer monsoon set in over Kerala, in southern peninsular India, on 29 May. This was three days earlier than its climatological normal date. The monsoon covered the entire country on 29 June, 16 days before its normal date.

For India, the long-term average (LTA) value of the summer monsoon rainfall, calculated using all data from $1951-2000$, is $890 \mathrm{~mm}$. The standard deviation of Indian summer monsoon rainfall (ISMR) is around $10 \%$ of the LTA value. However, over smaller regions, the natural variability of the monsoon is large (standard deviation around 19\%). Therefore, an ISMR exceeding $+10 \%$ of the LTA in a year is termed excess rainfall, while an ISMR less than $-10 \%$ of the LTA in a year is termed deficient rainfall.

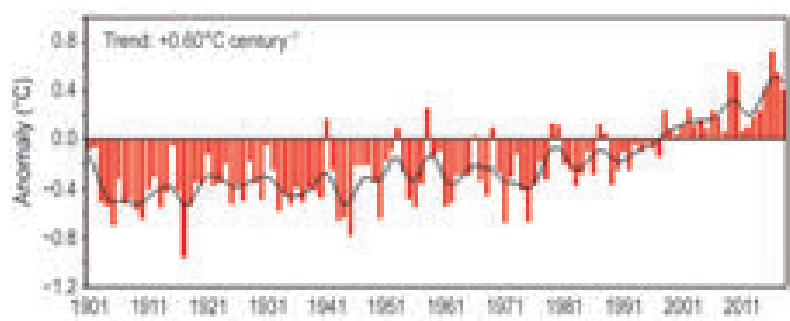

FIG. 7.46. Annual mean temperature anomalies $\left({ }^{\circ} \mathrm{C}\right.$; 1981-2010 base period) averaged over India for the period 190I-20I8. The smoothed time series (9-point binomial filter) is shown as a continuous black line. 


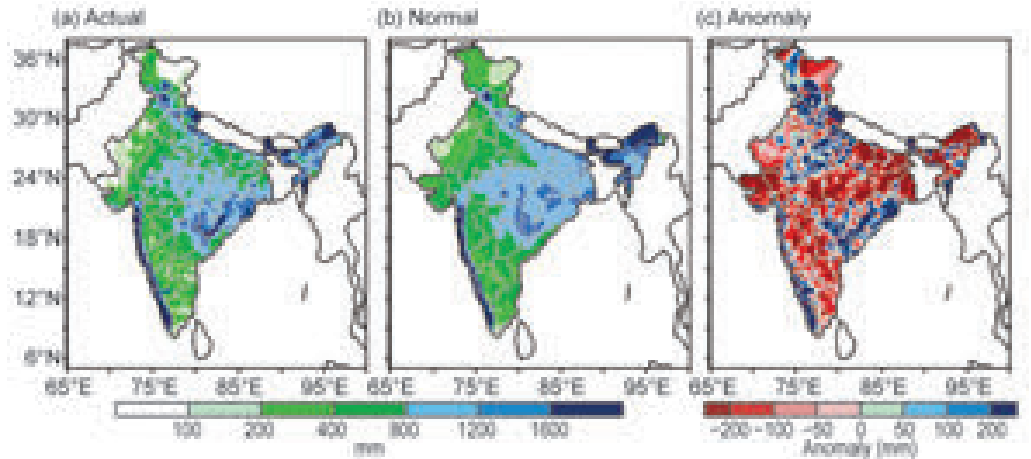

FIG. 7.47. Spatial distribution of monsoon seasonal (Jun-Sep) rainfall over India in 2018. (a) Actual, (b) normal, and (c) anomalies are in mm.

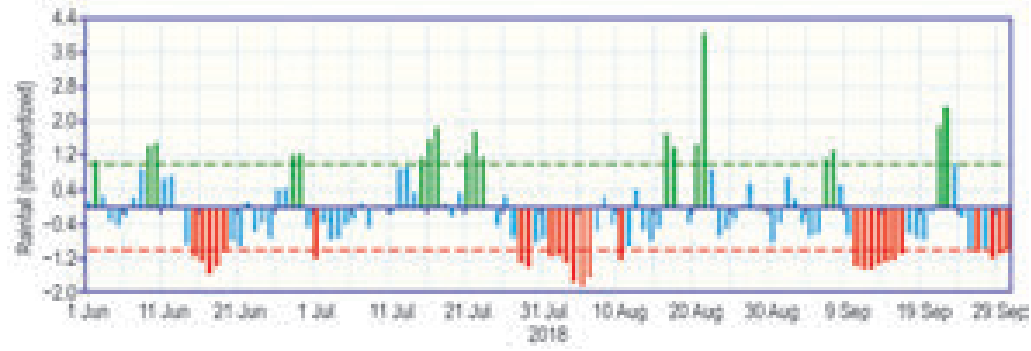

FIG. 7.48. Daily standardized rainfall time series for I Jun-30 Sep 20I8, averaged over the core monsoon zone of India.

Averaged over the country, the 2018 ISMR was $91 \%$ of its LTA value and was characterized by large spatial variability (Fig. 7.47). The homogeneous regions of northwest India, south peninsular India, and central India received $98 \%, 98 \%$, and $93 \%$, respectively, of their LTA. East and northeast India

\begin{tabular}{|c|c|c|c|c|c|}
\hline \multicolumn{2}{|c|}{ TABLE 7.2. Record 24-h rainfall during the 2018 monsoon season in India. } \\
\hline \multirow{2}{*}{ Station } & $\begin{array}{c}\text { Amount } \\
(\mathrm{mm})\end{array}$ & Date & $\begin{array}{c}\text { Amount } \\
(\mathrm{mm})\end{array}$ & Date & Year \\
\hline June & & & & & \\
\hline Karipur & 201.4 & 14 & 183.8 & 6 & 1989 \\
\hline July & & & & & \\
\hline Sambalpur & 567.0 & 22 & 401.3 & 20 & 1889 \\
\hline Salem & 133.8 & 2 & 125.5 & 12 & 1952 \\
\hline Cochi AP & 230.8 & 16 & 213.9 & 24 & 1910 \\
\hline Cial Cochi & 162.0 & 16 & 155.7 & 18 & 2009 \\
\hline August & & & & & \\
\hline Koraput & 154.4 & 15 & 143.5 & 22 & 1957 \\
\hline Puri & 394.0 & 7 & 220.3 & 6 & 2007 \\
\hline Aurangabad AP & 156.7 & 17 & 124.2 & 6 & 2006 \\
\hline Ramagundam & 264.8 & 12 & 216.3 & 5 & 2006 \\
\hline Thiruvanthapuram & 138.6 & 15 & 117.2 & 31 & 2008 \\
\hline Cial Cochi & 171.9 & 15 & 66.5 & 12 & 2008 \\
\hline Iduki & 295.0 & 16 & 223.0 & 5 & 2013 \\
\hline September & & & & & \\
\hline Anantpur & 170.6 & 17 & 167.7 & 27 & 1974 \\
\hline
\end{tabular}

received below-normal seasonal rainfall (76\% of monsoon season LTA). On a monthly scale, rainfall for the country as a whole was normal during June (95\% of its LTA value), July (94\%), and August (92\%). Rainfall was below normal during September (76\% of its LTA value). During the season, of 36 meteorological subdivisions, Kerala alone received excess rainfall, 23 received normal rainfall, and the remaining 12 subdivisions received deficient rainfall. Rainfall averaged over the core monsoon zone region was below normal during 14-25 June, 4-10 July, 27 July-7 August, and almost all of September (Fig. 7.48). Table 7.2 lists record 24-hr rainfalls during the 2018 monsoon season in India.

During the winter season (January-February), rainfall over India was significantly below normal (38\% of its LTA). Although rainfall was normal during the pre-monsoon season (March-May; 93\% of its LTA), it was below normal (56\% of its LTA) during the postmonsoon season (October-December). The northeast monsoon (NEM) normally sets in over southern peninsular India during October and over Sri Lanka in late November. The NEM contributes $30 \%-50 \%$ of the annual rainfall over southern peninsular India and Sri Lanka as a whole. The NEM set in over southern peninsular India on 1 November. The 2018 NEM seasonal rainfall over southern peninsular India was significantly below normal (66\% of LTA). During this season, the ITCZ remained mostly south of its climatological position, and weather systems moved more westward rather than northwestward, which may have contributed to deficient rainfall over southern peninsular India.

Pakistan, which is at the western edge of the pluvial region of the south Asian 
Wang et al. (2008) proposed an East Asian monsoon index that emphasized the role of Meiyu/Baiu/Changma rainfall in measuring the overall strength of the East Asian summer monsoon (EASM). According to this index, the EASM in 2018 was the weakest recorded in the past 40 years (Fig. SB7.7a). Note that this index is opposite to the traditional concept of a strong EASM, which corresponds to an abnormal northward extension of southerly but often deficient Meiyu rainfall. A weaker Meiyu/Baiu/Changma rainfall is usually accompanied by a stronger western North Pacific monsoon with enhanced convection and a deepened monsoon trough over the tropical western North Pacific.

The 2018 EASM featured a strong lower troposphere western North Pacific cyclonic (sometimes referred to as the Philippine cyclonic) anomaly (Figs. SB7.7c, SB7.8b). On the northern flank of the cyclonic anomaly, northeasterly or easterly winds appeared over the middle and lower reaches of Yangtze River basin southern Japan/ Korean Peninsula/, which led to severe precipitation deficits (second lowest since 1979) of Meiyu/Baiu/Changma rainfall in summer 2018 (Fig. SB7.7b).

The large-scale circulation associated with the predominant Philippine cyclonic anomaly and the northwardshifted western North Pacific Subtropical High (WNPSH) steered tropical cyclones toward higher latitudes. As a consequence, three destructive tropical cyclones (Ampil, Jongdari, and Rumbia) struck Shanghai City, along China's central coast, within one month, an unprecedented occurrence (Fig. SB7.7c). Note that during the previous 69 years (1949-2017), only six tropical cyclones in total made landfall in Shanghai City.

To the north of the cyclonic anomaly was a barotropic anticy- clonic anomaly (Figs. SB7.7c and SB7.7d), which corresponds to anomalous descending motion (or a positive OLR anomaly, see Fig. SB7.8c) and enhanced solar radiation. Therefore, northeast Asia experienced an extremely high summer mean temperature (Figs. SB7.7b,d). In mid-July, the northward-shifted WNPSH

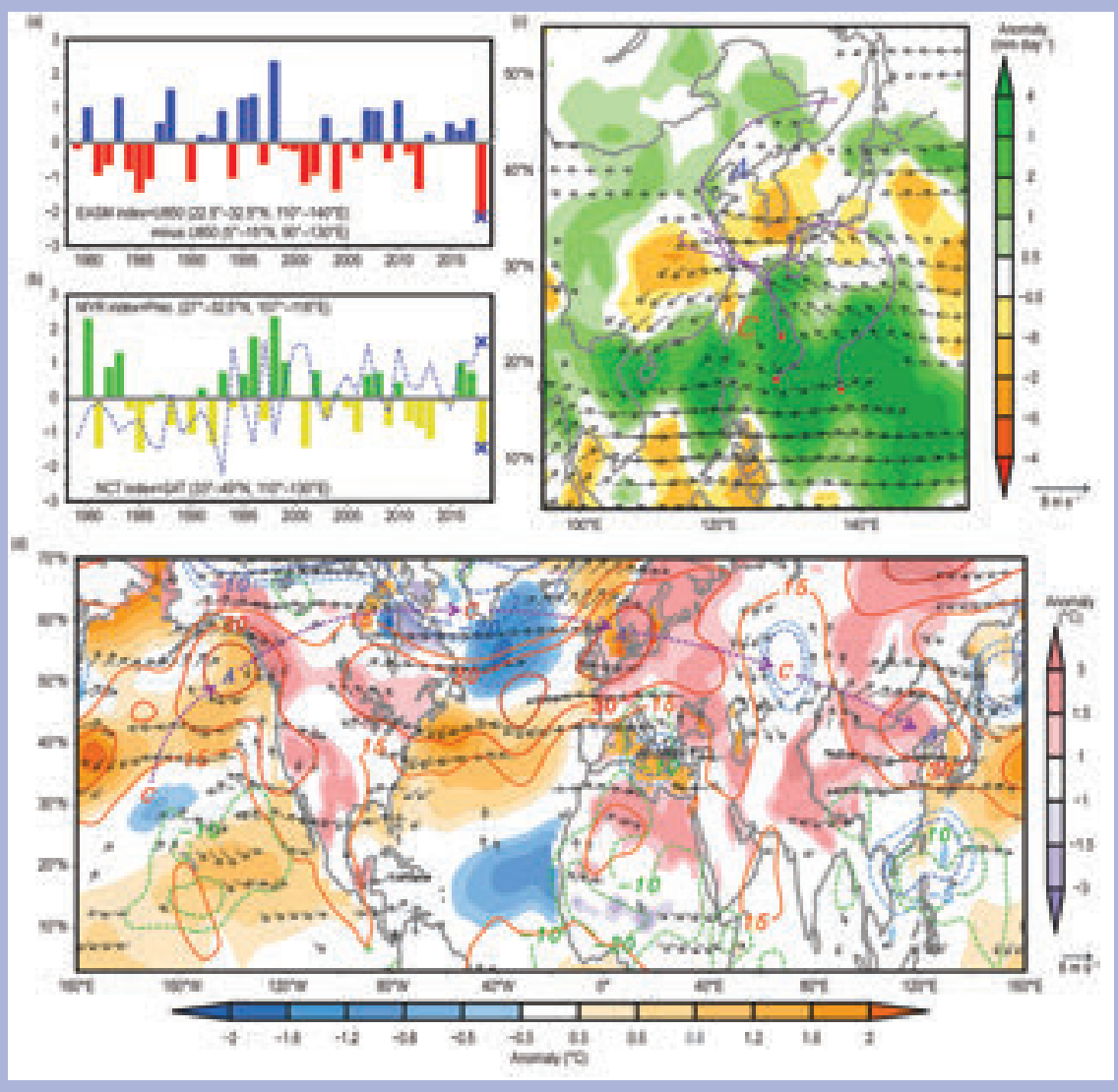

FIG. SB7.7. Time series of (a) normalized EASM index (bars, defined by JJA averaged areal-mean 850 -hPA zonal wind contrast between $22.5^{\circ}-32.5^{\circ} \mathrm{N}, 110^{\circ}-140^{\circ} \mathrm{E}$ and $5^{\circ}-15^{\circ} \mathrm{N}, 90^{\circ}-130^{\circ} \mathrm{E}$ ) and (b) normalized Meiyu rainfall (MYR) index (bars, defined by JJA areal-mean precipitation over $\left.27^{\circ}-32.5^{\circ} \mathrm{N}, 107^{\circ}-118^{\circ} \mathrm{E}\right)$ and the normalized North China surface air temperature (NCT) index [dashed line, defined by JJA areal-mean precipitation over $\left.\left(33^{\circ}-49^{\circ} \mathrm{N}, 110^{\circ}-130^{\circ} \mathrm{E}\right)\right]$. Blue cross indicates the year 2018. (c) Precipitation (shading, $\mathrm{mm}^{-1} \mathrm{day}^{-1}$ ), 850-hPa wind (vector, $\mathrm{m} \mathrm{s}^{-1}$, only winds exceeding I $\mathrm{m} \mathrm{s}^{-1}$ are shown) anomalies in JJA 2018. Red dots (purple lines) denote the genesis location (moving tracks) of the three tropical cyclones (Ampil, Jongdari, and Rumbia) that made landfall in Shanghai proper (d) SST anomalies (shading over ocean, ${ }^{\circ} \mathrm{C}$ ) and surface air temperature anomalies (shading over land, ${ }^{\circ} \mathrm{C}$ ), negative OLR anomalies (contour in green, $\mathbf{W}$ $\mathrm{m}^{-2}$ ), 200-hPa wind (vector, $\mathrm{m} \mathrm{s}^{-1}$, only winds exceeding $3 \mathrm{~m} \mathrm{~s}^{-1}$ are shown) and geopotential height anomalies (red and blue contours) in JJA 2018. The purple dashed line with arrows denotes the pathway of the mid-high latitudes Rossby wave-train. Letter A (C) denotes the center of anticyclonic (cyclonic) anomaly. Base period: $1981-2010$. 
and the northeastward-expanded South Asia high (SAH) jointly resulted in this barotropic high-pressure anomaly over northeast Asia (Figs. SB7.8a,b), leading to significant heat waves during this period. The Central Meteorological Observatory of China repeatedly announced high-temperature alerts for 33 successive days (the longest duration since 2010 when hightemperature alerts first began). Many weather stations over North China broke their historical high-temperature records.

The northward shift of WNPSH in the vicinity of the Korean Peninsula and mainland Japan was attributable to enhanced convective activity around the Philippines (Figs. SB7.7c, SB7.8c). It is well known that convective activity around the Philippines influences the extratropical circulation over East Asia in the boreal summer through a so-called Pacific-Japan teleconnection pattern (Nitta 1987; Kosaka and Nakamura 2010). While convective activity around the Philippines is enhanced, the WNPSH in the vicinity of the Korean Peninsula and mainland Japan was accordingly enhanced and expanded in association with the downward flow in the region.

Usually, the convection-induced Philippine cyclonic anomaly appears only in the lower and middle troposphere due to the Gill-type Rossby (Kelvin) wave response to anomalous atmospheric heating (cooling) over tropical western Pacific (Indian) Ocean (Li and Hsu 2017). However, a quasi-barotropic structure of the cyclonic anomaly was observed in summer 2018 (Figs. SB7.7c,d). The quasi-barotropic cyclonic anomaly coexists with the quasi-barotropic anticyclonic anomaly over northeast Asia (Figs. SB7.8a,b). From Fig. SB7.7d, it can be seen that the quasi-barotropic anticyclone is a part of a circumglobal, midto-high latitude Rossby wavetrain emanating from the central North Pacific, with three pairs of cyclonic/low pressure (anticyclonic/high pressure) anomalies centered at subtropical central Pacific (northeastern Pacific), the southern tip of Greenland (northwestern Europe), and central Asia (Northeast Asia), respectively. This large-scale mid-tohigh latitude Rossby wave-train is named the Pacific-North America-Eurasia (PNE) teleconnection (Chen et al. 2019). The PNE teleconnection was possibly caused by a pronounced atmospheric heating anomaly over the central Pacific Ocean around Hawaii, which was induced by the SST anomaly pattern that resembles the Pacific Meridional Mode (Fig. SB7.7d; Chiang and Vimont 2004). Although the North Atlantic Ocean had a significant tri-polar SST anomaly pattern, no significant rainfall anomaly was found over the region, suggesting that the North Atlantic SST anomaly was not the essential driver but a passive result of the mid-to-high latitude Rossby wave-train.

In summary, the abnormal East Asian climate in summer 2018 resulted possibly from the anomalous tropical heating over the western North Pacific (through the Pacific-Japan teleconnection) and a distinct atmospheric circumglobal Rossby wave-train (the PNE teleconnection) pattern triggered by anomalous SST over the tropical central Pacific.

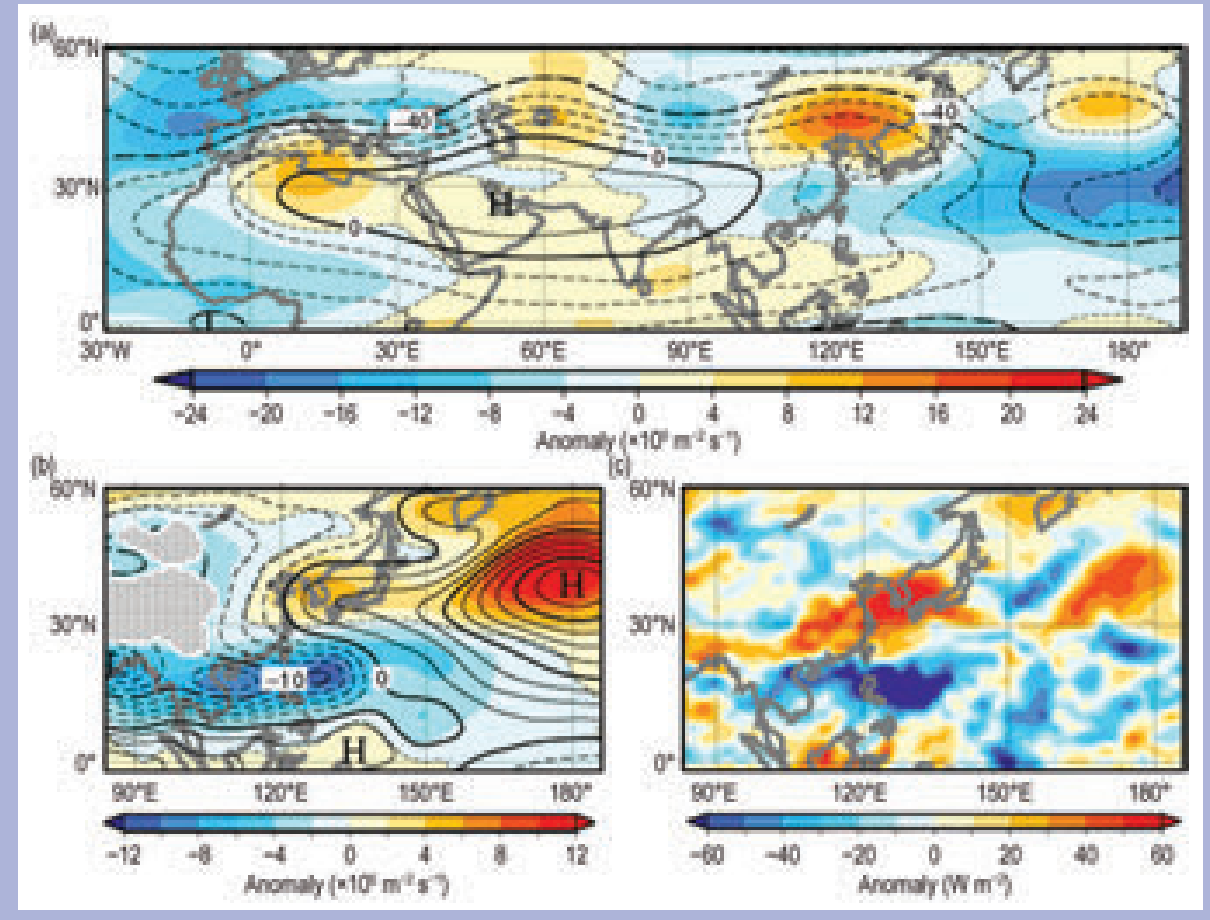

FIG. SB7.8. (a) 200-hPa stream function (contours) and anomaly (shadings) averaged over 15-19 Jul 2018. Thick and thin contours are intervals of $40 \times 10^{6}$ and $10 \times 10^{6} \mathrm{~m}^{2} \mathrm{~s}^{-1}$, respectively. (b) As in (a) but for $850-\mathrm{hPa}$ stream function. Thick and thin contours are intervals of $10 \times 10^{6}$ and $2.5 \times 10^{6} \mathrm{~m}^{2} \mathrm{~s}^{-1}$, respectively. The hatch patterns indicate areas exceeding $1600 \mathrm{~m}$ altitude. (c) OLR anomaly averaged over I5-19 Jul 2018. Base period: 198I-2010. 
monsoon, receives $60 \%-70 \%$ of its annual rainfall during the summer monsoon season (July-September). The summer monsoon typically sets in over eastern parts of Pakistan around 1 July with a standard deviation of 5 days. In 2018, onset occurred on 28 June in lower Sindh Province. Summer monsoon rainfall over Pakistan was below normal (68.0\% of LTA), with significantly below-normal rain during August and September $(46.0 \%$ and $58.2 \%$ of LTA, respectively). Rainfall was below normal in all provinces except Punjab. Southern parts (especially southwestern) of Pakistan experienced large rainfall deficits. Other areas, including central Pakistan, received normal rainfall during the monsoon season. Negative departure over the Singh province was as much as $-89.1 \%$. Bangladesh also received below normal rainfall during the 2018 summer monsoon season.

Sri Lanka received below-normal rainfall during its summer monsoon season (May-September). Northeast monsoon rainfall activity over the island nation during October-December was also below normal.

\section{(iii) Notable events and impacts}

Flood- and heavy rain-related incidents reportedly claimed over 800 lives from northern-to-northeastern, central, and peninsular parts of India during the pre-monsoon, monsoon, and post-monsoon seasons. Of these deaths, 223 were reported from the southern state of Kerala, 158 from the northern state of Uttar Pradesh, 139 from Maharashtra, and 116 from West Bengal during the monsoon season.

Kerala witnessed one of its most severe floods on record as heavy-to-extremely heavy rains lashed central and northern parts of the state during 8-23 August. The most affected district, Iduki, received an all-time record rainfall of $710.2 \mathrm{~mm}$ for a three-day period on 15-17 August. This region had already received above-normal rainfall through July.

Thunderstorm rains over northeastern India reportedly claimed 166 lives from Uttar Pradesh (April-May) and 75 from Jharkhand (June-July). Dust storms claimed over 150 lives in the northern Indian states of Uttar Pradesh (92 fatalities, 2-6 May) and Rajasthan (68 fatalities, April-May).

In March, all 34 meteorological stations across Pakistan recorded monthly temperatures well above their 1981-2010 average. Nawabshah, a city in southern Sindh province, recorded the highest temperature of $50.2^{\circ} \mathrm{C}$, which may be a new world temperature record for April (www.ffd.pmd.gov.pk/ffd_temps /temp.html). The port city Karachi experienced tem- peratures of $41^{\circ}-44^{\circ} \mathrm{C}$ for several days in the third week of May; this extreme heat claimed the lives of at least 65 people.

In Bangladesh, heavy rains during 23-25 July triggered landslides and flooding throughout the Cox's Bazar district. The station recorded $463 \mathrm{~mm}$ of rainfall in 24 hours on 25 July, the second highest recorded single-day rainfall for the district.

Northern districts of Sri Lanka were affected by severe floods during the last 10 days of December 2018. More than 11000 people were moved to evacuation centers as their homes were inundated.

\section{5) Southwest AsiA—M. Khoshkam, A. Fazl Kazemi, and S. leyaeyan}

This subsection covers only Iran. Turkey is incorporated in the Europe subsection, 7f. Climate anomalies are relative to a $1992-2017$ base period for temperature and a 1987-2017 base period for precipitation.

\section{(i) Temperature}

All seasons in 2018 were warmer than average, leading to an annual temperature anomaly of $+1.24^{\circ} \mathrm{C}$. This made 2018 the second warmest year, after 2010, in the historical record dating back to 1967. Winter $2017 / 18$ saw an anomaly of $+4^{\circ} \mathrm{C}$ (Fig. 7.49a), with the highest departures recorded in northwestern Iran. Some parts of the Lut Desert in the province of Kerman, as well as the southern provinces (such as Hormozgan, Sistan, and Baluchestan), were the warmest areas with temperatures between $20^{\circ}-25^{\circ} \mathrm{C}$. Over the Alborz and Zagros highlands, the winter temperature was in the range of $15^{\circ}-20^{\circ} \mathrm{C}$. The rest of the country had temperatures in the $10^{\circ}-15^{\circ} \mathrm{C}$ temperature range for the season.

In spring, temperatures in most areas were between $0^{\circ}$ and $20^{\circ} \mathrm{C}$. The average temperature for the country was $+0.8^{\circ} \mathrm{C}$ above average. The hottest areas were the Lut Desert, parts of Sistan and Baluchestan, and some regions of Kerman Province with average temperatures of $35^{\circ}-40^{\circ} \mathrm{C}$. The Alborz highlands, with average temperatures about $-10^{\circ} \mathrm{C}$ to $-5^{\circ} \mathrm{C}$, was the coldest area.

The summer temperature anomaly was $+1.0^{\circ} \mathrm{C}$ and spatially uniform (Fig 7.49b). In parts of the northern provinces as well as Isfahan, Khorasan Razavi, Yazd, Sistan and Baluchestan, Hormozgan, Fars, Bushehr, Khuzestan, and western Iran, the average temperature was between $30^{\circ}-40^{\circ} \mathrm{C}$. Eastern and central Iran experienced average temperatures of $25^{\circ}-30^{\circ} \mathrm{C}$.

In autumn, the average national temperature was $+0.4^{\circ} \mathrm{C}$ above average. Except for Khorasan Razavi, all provinces experienced above-average tempera- 

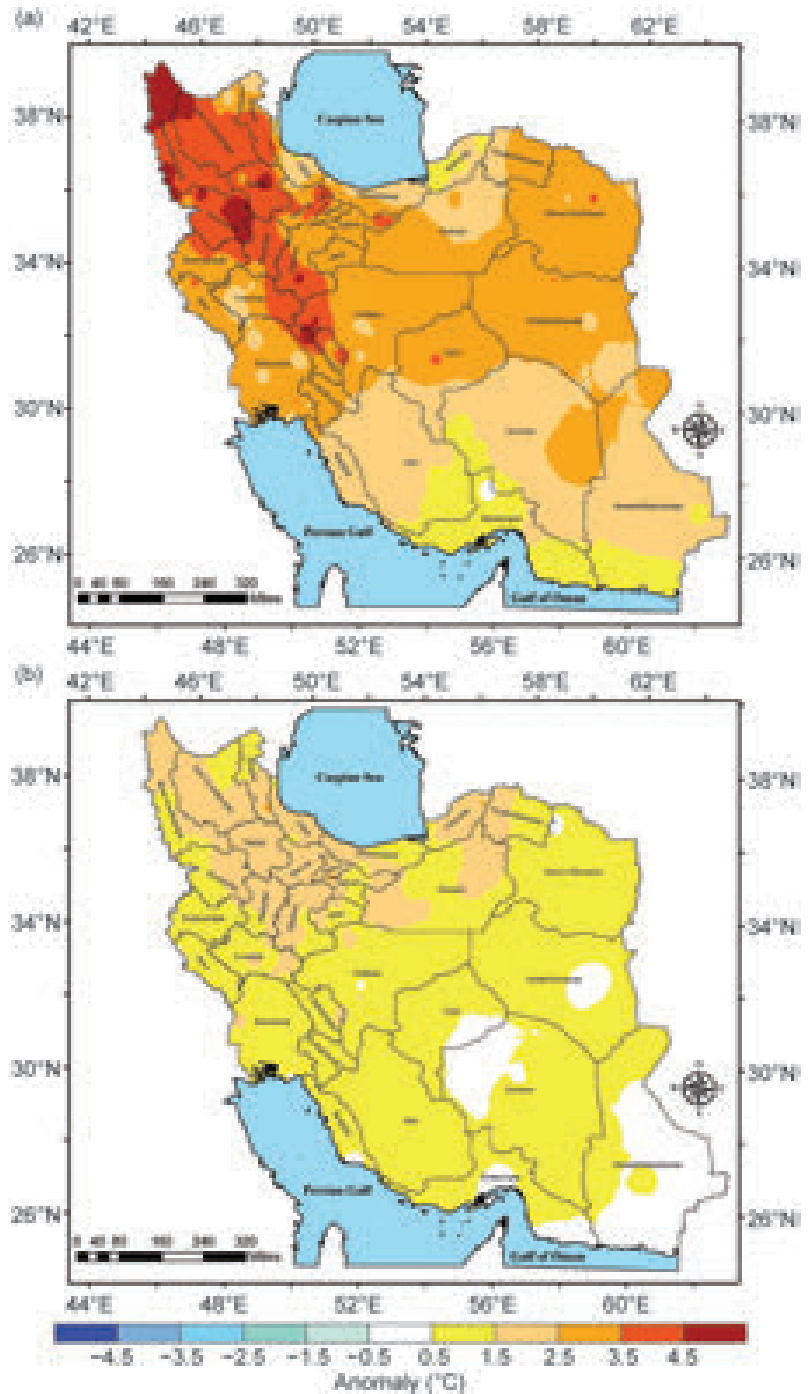

FIG. 7.49. Seasonal mean surface temperature anomalies ( ${ }^{\circ} \mathrm{C}$; 1997-2017 base period) over Iran in (a) winter 2017/18 and (b) summer 2018. (Source: I.R. of Iran Meteorological Organization.)

tures for the season, with most anomalies ranging from $+0.1^{\circ} \mathrm{C}$ to $+3.0^{\circ} \mathrm{C}$. The warmest areas were over western and southeastern Iran, Semnan and Isfahan Provinces, and a small part of northern Mazandaran, with an average temperature between $20^{\circ} \mathrm{C}$ and $30^{\circ} \mathrm{C}$.

\section{(ii) Precipitation}

In general, spring and autumn 2018 were wetter than normal, and winter and summer were drier than normal (Fig. 7.50). This led to an annual anomaly of $11.1 \mathrm{~mm}$.

During winter 2017/18, Iran received $64.7 \mathrm{~mm}$ of precipitation, which is about $67 \%$ of LTA. Winter precipitation was below average across most of the country except northwestern Iran and some small parts of northern and western Iran.
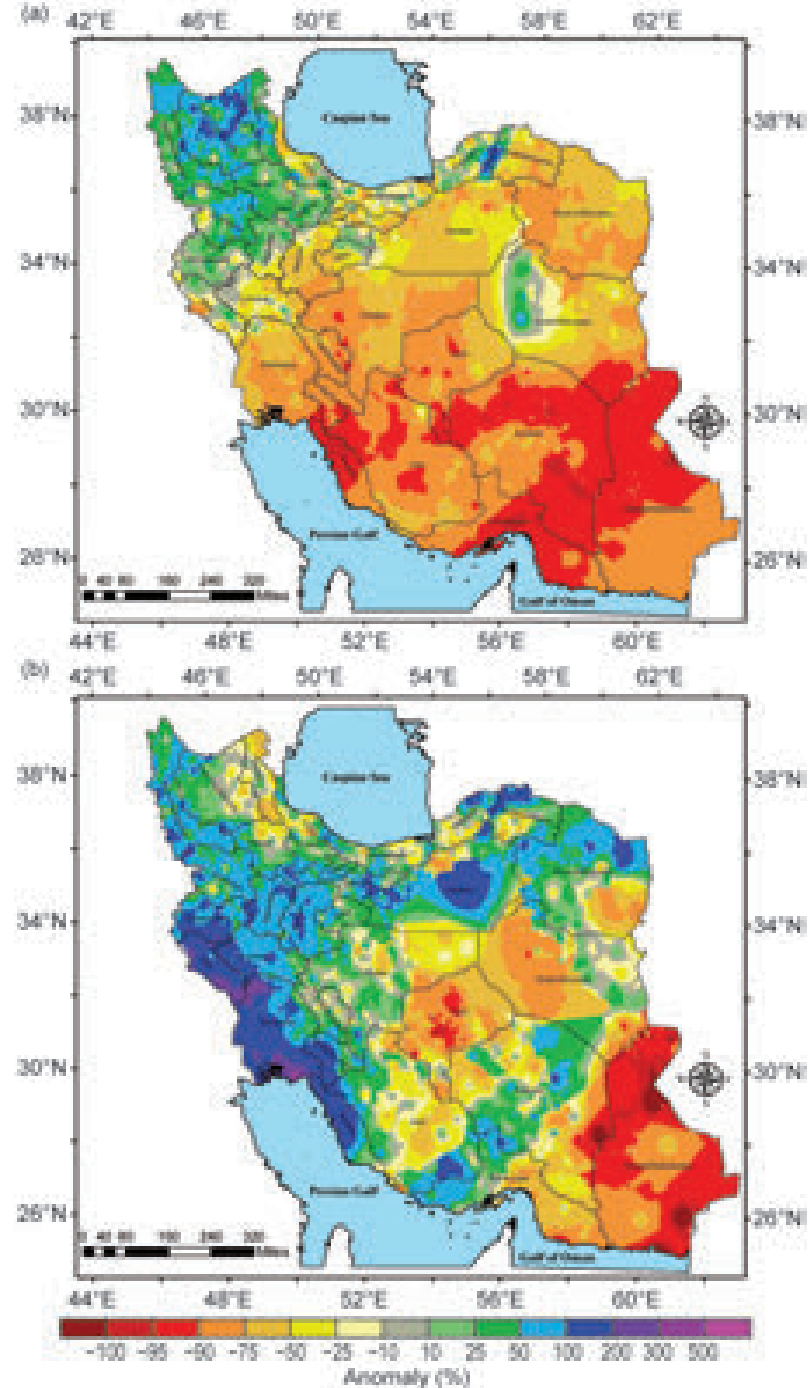

FIG. 7.50. Observed precipitation anomolies (\% relative to the 1987-2017 base period) over Iran in (a) winter and (b) autumn 2018. (Source: I.R. of Iran Meteorological Organization.)

Although average rainfall in spring was $70.8 \mathrm{~mm}$, which is $127.3 \%$ above normal for the whole country, a vast area in the southeast and a long strip from northeast to northwest, including the Caspian Sea coastal areas, experienced below-normal precipitation. Very low rainfall (about $3 \mathrm{~mm}$ ) in summer caused a significant deficit in this area (about $27 \%$ of the 1987-2017 average and 55\% of the summer 2017 total). Precipitation totals across the northeast to northwest and in the southwest ranged from $1 \mathrm{~mm}$ to $20 \mathrm{~mm}$, and it was about $25 \mathrm{~mm}$ below normal in the northern Alborz highlands of the country. In other parts of the country, rainfall was less than $1 \mathrm{~mm}$.

In autumn, total average precipitation was 91.4 $\mathrm{mm}$, which was about $150 \%$ of normal. A total of $300.6 \mathrm{~mm}$ in 24 hours was observed at Gilan Province 
in the northern part of the country. Precipitation over the southwest, west, north, northeast, and parts of Kerman and Fars Provinces was more than $150 \%$ of normal. However, areas over the southeast and the central desert were drier than normal.

\section{h. Oceania-C. Ganter, Ed.}

I) OVERVIEW-C. Ganter

Oceania was under the influence of a weak La Niña at the beginning of 2018, which gave way to a neutral ENSO state soon after. Toward the end of the year in austral spring, El Niño-like conditions began to appear. The Indian Ocean dipole (IOD) was neutral for the first part of its active period (May-November), and was in a positive phase during SeptemberNovember, with the latter likely in part contributing to drought conditions seen across Australia in 2018 (Sidebar 7.5).

A busy tropical cyclone season for the Northwest Pacific brought a number of extreme rainfall events across the region. A notable marine heatwave was in place at the start of 2018, surrounding southeast Australia and New Zealand. This ocean warmth likely contributed to warmer weather early in the year for both countries.

\section{2) Northwest Pacific and Micronesia—M. A. Lander and C. P. Guard}

This assessment covers the area from the international dateline west to $130^{\circ} \mathrm{E}$, between the equator and $20^{\circ} \mathrm{N}$. It includes the U.S.-affiliated islands of Micronesia, but excludes the western islands of Kiribati and nearby northeastern islands of Indonesia. The reference period used for this assessment is 1981-2010.

For much of Micronesia, the weather and climate of 2018 will be remembered for the widespread influence and impacts of tropical cyclones (TCs). Nearly all the islands of Micronesia experienced at least moderate impacts from various TCs, and the main islands of the Commonwealth of the Northern Mariana Islands (CNMI) experienced catastrophic damage from very intense TCs. In March, Typhoon Jelawat passed slowly through Pohnpei State, yielding over $500 \mathrm{~mm}$ of rainfall in two days on parts of Pohnpei Island. This marked the beginning of a busy typhoon season for Guam and the CNMI that would see Typhoon Mangkhut pass over Rota in the CNMI and northern Guam in September and Super Typhoon Yutu pass directly over Tinian and Saipan in the CNMI in October.

\section{(i) Temperature}

Temperatures across Micronesia through 2018 were mostly above average, but dropped slightly during the rainy season months of July through December, especially where TCs and monsoonal activity dominated. Above-average temperatures are typically experienced in the Micronesian islands when skies are clear and winds are light. Below-average temperatures occur when conditions are unusually cloudy, wet, and windy-typical conditions seen in an El Niño year. Very wet weather, especially during the first half of 2018, likely contributed to below-average maximum temperatures at Yap, Pohnpei, Kosrae, and Majuro. Average 6-month maximum and minimum temperature anomalies for select locations across Micronesia for 2018 are summarized in Table 7.3.

\section{(ii) Precipitation}

As might be expected of a year with a strong tropical cyclone influence, several extreme rainfall events occurred during 2018, with some islands seeing record high monthly and annual totals (Table 7.3). On Pohnpei Island, rains from Typhoon Jelawat along with additional high rainfall during March resulted in a record monthly high precipitation total of 1471.2 $\mathrm{mm}$. At Kwajalein and Majuro in the Republic of the Marshall Islands (RMI), rainfall totals observed in the first half of 2018 reached historical highs, and despite near-average rainfall later in the year, the annual totals at these atolls were at or near all-time high values. Pohnpei, Majuro, and Kwajalein were extremely wet from January to June and near-normal during July to December. Kapingamarangi was wet the entire year. Yap was wet over the first six months of the year, and near-normal for the last six months. Guam was near normal over January to June, and wet over July to December.

\section{(iii) Notable events and impacts}

During 2018, several of the basin's TCs tracked across the Mariana Islands: Jelewat in March; Maria in July; Cimaron and Jebi in August; Manghkut, Trami, Kong-rey in September; and Yutu in October. Super Typhoon Yutu was particularly destructive on the islands of Tinian and Saipan, with the Weather Forecast Office (WFO) Guam Yutu meteorological assessment team rating the landfall intensity at $145 \mathrm{kt}\left(75 \mathrm{~m} \mathrm{~s}^{-1}\right)$, gusting to $175 \mathrm{kt}\left(90 \mathrm{~m} \mathrm{~s}^{-1}\right)$. This placed Super Typhoon Yutu into the catastrophic Category 5 level of the Saffir-Simpson Hurricane Wind Scale.

In many ways, the 2018 weather and climate across Micronesia evolved in a way typical of El Niño, 
TABLE 7.3. Temperature $\left({ }^{\circ} \mathrm{C}\right)$ and rainfall $(\mathrm{mm})$ anomalies for select Micronesia locations during 2018 . Average (AVG) values are for the 198I-2010 base period. Latitudes and longitudes are approximate. "Kapinga" stands for Kapingamarangi Atoll in Pohnpei State, Federated States of Micronesia. Shading of the boxes indicates: light orange for above-average temperature and blue for below-average; green for above-average rainfall and yellow for below-average. Bold, numerals indicate all-time high rainfall values.

\begin{tabular}{|c|c|c|c|c|c|c|c|c|c|c|}
\hline \multirow[t]{2}{*}{ Location } & \multicolumn{2}{|c|}{$\begin{array}{l}\text { Max Temp } \\
\text { Min Temp }\end{array}$} & \multicolumn{8}{|c|}{ Rainfall (mm) } \\
\hline & Jan-Jun & Jul-Dec & Jan-Jun & Jan-Jun & Jan-Jun & Jul-Dec & Jul-Dec & Jul-Dec & Jan-Dec & Jan-Dec \\
\hline & ${ }^{\circ} \mathrm{C}$ & ${ }^{\circ} \mathrm{C}$ & AVG & 2018 & $\%$ & AVG & 2018 & $\%$ & 2018 & $\%$ \\
\hline $\begin{array}{l}\text { Saipan, } \\
15^{\circ} \mathrm{N}, 146^{\circ} \mathrm{E}\end{array}$ & $\begin{array}{l}+2.98 \\
+1.80\end{array}$ & $\begin{array}{l}+1.83 \\
+1.63\end{array}$ & 499.1 & 758.0 & 168.8 & 1322.8 & 1971.8 & 149.1 & 2729.8 & I54.I \\
\hline $\begin{array}{c}\text { Guam, } 13^{\circ} \mathrm{N}, \\
145^{\circ} \mathrm{E}\end{array}$ & $\begin{array}{l}+1.10 \\
+0.92\end{array}$ & $\begin{array}{l}+1.08 \\
+1.07\end{array}$ & 691.6 & 676.2 & 97.8 & 1788.7 & 2054.9 & 115.1 & 2731.0 & 110.3 \\
\hline \multirow{2}{*}{$\begin{array}{c}\text { Yap, } \\
9^{\circ} \mathrm{N}, 138^{\circ} \mathrm{E}\end{array}$} & -0.32 & -0.58 & \multirow{2}{*}{1169.7} & \multirow{2}{*}{1403.4} & \multirow{2}{*}{120.0} & \multirow{2}{*}{1902.0} & \multirow{2}{*}{1867.4} & \multirow{2}{*}{98.2} & \multirow{2}{*}{3270.8} & \multirow{2}{*}{106.5} \\
\hline & +0.11 & +0.67 & & & & & & & & \\
\hline $\begin{array}{c}\text { Palau, } \\
7^{\circ} \mathrm{N}, 134^{\circ} \mathrm{E}\end{array}$ & $\begin{array}{l}+1.05 \\
+0.54 \\
\end{array}$ & $\begin{array}{l}+0.52 \\
+0.10 \\
\end{array}$ & 1717.6 & 1292.4 & 75.2 & 2032.5 & 1967.8 & 96.8 & 3260.1 & 86.9 \\
\hline $\begin{array}{c}\text { Chuuk, } \\
7^{\circ} \mathrm{N}, 152^{\circ} \mathrm{E}\end{array}$ & $\begin{array}{l}+0.68 \\
+0.97\end{array}$ & $\begin{array}{l}+0.52 \\
+1.11\end{array}$ & 1584.2 & 1774.2 & 112.0 & I833.I & 1954.0 & 106.6 & 3758.4 & 110.0 \\
\hline \multirow{2}{*}{$\begin{array}{l}\text { Pohnpei, } \\
7^{\circ} \mathrm{N}, 158^{\circ} \mathrm{E}\end{array}$} & -0.46 & -0.29 & \multirow{2}{*}{2266.4} & \multirow{2}{*}{3814.6} & \multirow{2}{*}{168.3} & \multirow{2}{*}{2336.6} & \multirow{2}{*}{2484.9} & \multirow{2}{*}{106.3} & \multirow{2}{*}{6299.4} & \multirow{2}{*}{136.9} \\
\hline & +1.31 & +1.65 & & & & & & & & \\
\hline $\begin{array}{l}\text { Kapinga, } \\
I^{\circ} \mathrm{N}, 155^{\circ} \mathrm{E}\end{array}$ & - & - & 1750.8 & 2198.1 & 125.5 & 1510.5 & 2060.2 & 136.4 & 4258.3 & 130.6 \\
\hline \multirow{2}{*}{$\begin{array}{c}\text { Kosrae, } \\
5^{\circ} \mathrm{N}, 163^{\circ} \mathrm{E}\end{array}$} & -0.22 & -0.22 & \multirow{2}{*}{2567.9} & \multirow{2}{*}{2961.1} & \multirow{2}{*}{115.3} & \multirow{2}{*}{2342.5} & \multirow{2}{*}{1710.2} & \multirow{2}{*}{73.0} & \multirow{2}{*}{$467 I .3$} & \multirow{2}{*}{95.1} \\
\hline & +1.44 & +1.07 & & & & & & & & \\
\hline \multirow{2}{*}{$\begin{array}{c}\text { Majuro, } \\
7^{\circ} \mathrm{N}, 171^{\circ} \mathrm{E}\end{array}$} & +0.06 & +0.16 & \multirow{2}{*}{1368.3} & \multirow{2}{*}{2611.4} & \multirow{2}{*}{190.8} & \multirow{2}{*}{1868.2} & 17507 & $01 ?$ & 1271 & 125 \\
\hline & +0.43 & +0.97 & & & & & $1 / 59.1$ & 94.2 & $43 / 1.1$ & 133.1 \\
\hline $\begin{array}{l}\text { Kwajalein, } \\
9^{\circ} \mathrm{N}, 168^{\circ} \mathrm{E}\end{array}$ & $\begin{array}{l}+0.46 \\
+0.33\end{array}$ & $\begin{array}{l}+0.54 \\
+0.60\end{array}$ & 795.3 & 2177.8 & 273.9 & |579.| & I577.| & 99.9 & 3754.9 & I58.I \\
\hline
\end{tabular}

although NOAA's Oceanic Niño Index (ONI) did not cross the El Niño threshold until late in the year (Section $4 \mathrm{~b}$ ). Some weather features typical of actual or impending El Niño that occurred during 2018 include: a wet eastern Micronesia in the first half of the year; dryness in Palau for several months; several early season tropical disturbances in eastern Micronesia; the continual formation of typhoon precursor disturbances in central and eastern Micronesia; the seemingly endless battering of the Mariana Island chain by typhoons; some unusual westerly winds in eastern Micronesia; and a declining sea level around many islands, especially in the spring and in the final two months of the year.

In July, a strong meso-vortex with typhoon-force winds was embedded in a weak tropical storm that was passing over Guam. The event was captured on Guam's Doppler weather radar, where it was clear that the small meso-vortex was orbiting around the larger vortex circulation, appearing at first to move rapidly northward from a location southeast of
Guam. It then swung sharply to the left to pass near or over the northern most few miles of Guam, even as the parent larger vortex circulation passed near or over southern Guam. The meso-vortex passed over Andersen Air Force Base where it induced a sudden downward sharp dip of $10 \mathrm{hPa}$ in pressure and a sudden spike to a typhoon-force peak wind gust of 42.7 $\mathrm{m} \mathrm{s}^{-1}$. Severe wind damage to the jungle vegetation a few kilometers to the west of the Base near the vortex exit point suggested wind gusts of $46-51 \mathrm{~m} \mathrm{~s}^{-1}$ within the meso-vortex.

\section{3) Southwest Pacific—S. McGree}

Countries considered in this section include American Samoa, Cook Islands, Fiji, French Polynesia, Kiribati, New Caledonia, Niue, Papua New Guinea (PNG), Samoa, Solomon Islands, Tonga, Tuvalu, Vanuatu, and Wallis and Futuna (Fig. 7.51). The temperature analysis is based on Climate Anomaly Monitoring System (CAMS) Monthly Surface Air Temperature Anomalies (https://iridl.ldeo 


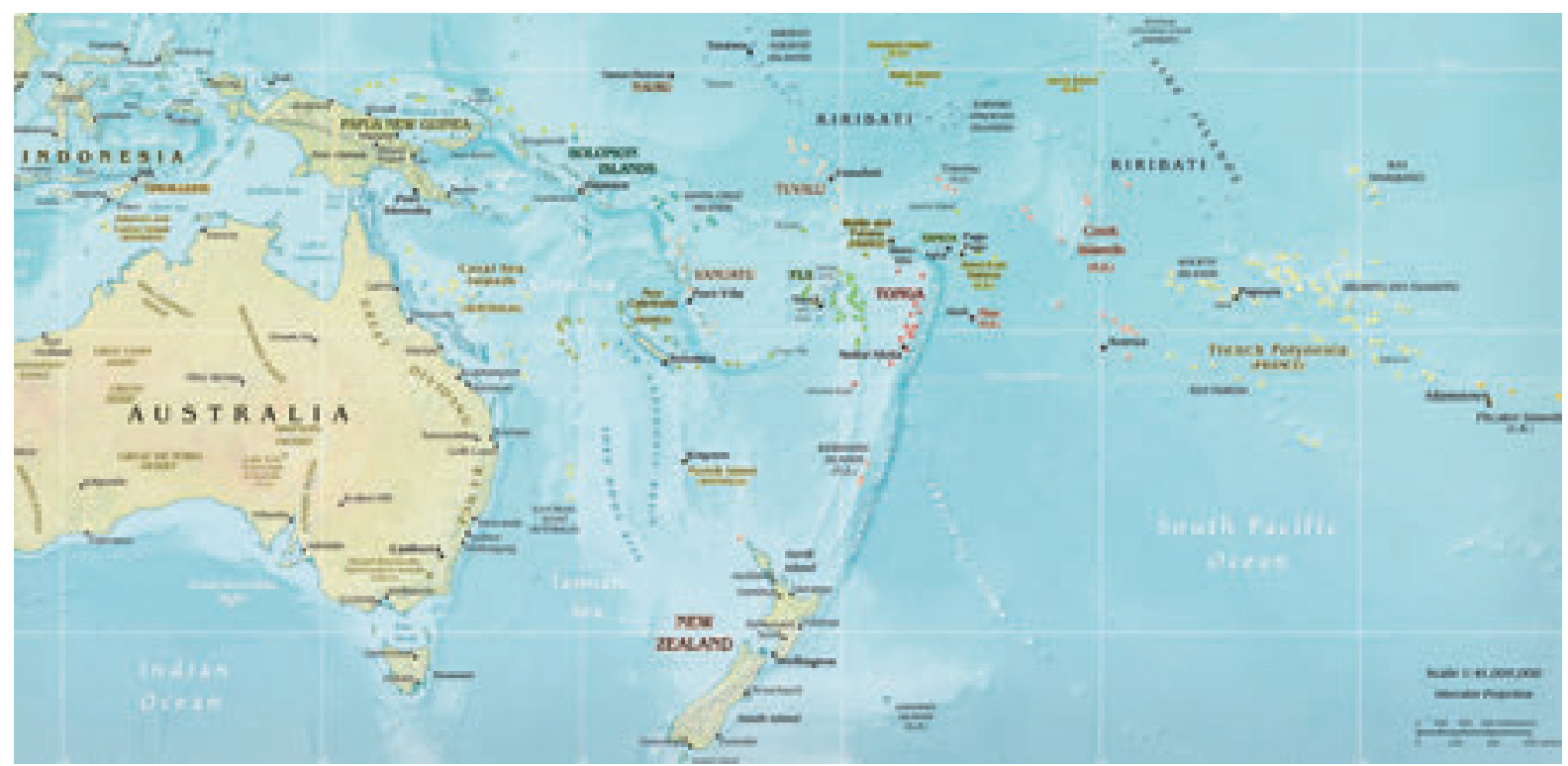

Fig. 7.5I. Map of the Southwest Pacific showing the countries considered in this section. (Source: www .geographicguide.com/oceania-map.htm.)

.columbia.edu/maproom/Global/Atm_Temp/Anomaly.html). Anomalies are with respect to the 1971-2000 base period. The precipitation analysis is based on monthly analyses presented in the COSPPac Monthly Bulletin (www.pacificmet.net/products-and-services /climate-bulletin) and COSPPac Online Climate Outlook Forum (https://www.pacificmet.net/products -and-services/online-climate-outlook-forum).

The year began with a La Niña event in place, and gave way to neutral ENSO conditions thereafter. While SSTs temperatures warmed to El Niño thresholds during the austral spring in 2018, there was little atmospheric response, meaning a proper El Niño event did not develop by year's end.

\section{(i) Temperature}

During January-March (JFM), air temperatures were near normal across most of the southwest $\mathrm{Pa}$ cific, with the exceptions of $1^{\circ}-2^{\circ} \mathrm{C}$ above normal around the central Solomon Islands in January and March and $1^{\circ}-2^{\circ} \mathrm{C}$ below normal near the central (Kiribati) Line Islands in February and March. The latter was likely associated with below-normal equatorial SSTs during the final stages of the 2017/18 La Niña event.

In June, air temperatures were $1^{\circ}-2^{\circ} \mathrm{C}$ above normal around Niue and central and southern Tonga; similar temperatures occurred around central Tonga in September. During October-December (OND), air temperatures were $1^{\circ}-2^{\circ} \mathrm{C}$ above normal across most of the equatorial Pacific. The area of warm anomalies extended southeast through the eastern Solomon Islands, northern Fiji, and northern and central Tonga in October, then through Tuvalu, Samoa, American Samoa, northern Cook Islands, and Society Islands in November. In addition to the islands along the equatorial Pacific, Tuvalu also recorded above-average temperatures in December. Warm air temperature anomalies in OND are consistent with El Niño-like conditions.

\section{(ii) Precipitation}

As would be expected during La Niña, the SPCZ, the main driver of climate variability in the southwest Pacific region, was displaced southwest of its mean position in January and March. This resulted in rainfall above the 90th percentile during JFM in eastern and southern Papua New Guinea (PNG), Guadalcanal in the Solomon Islands, Mamanuca Group in western Fiji, Tongatapu in southern Tonga, central Samoa, and Rarotonga in the southern Cook Islands. Conversely, the La Niña event was also likely responsible for rainfall totals below the 10th percentile in western and eastern Kiribati.

The SPCZ was largely suppressed in May and June. Rainfall in April-June (AMJ) was again below the 10th percentile in western and eastern Kiribati, the lowest on record $(110 \mathrm{~mm})$ at Penrhyn in the northern Cook Islands, and the second lowest on record at Nanumea (the northernmost Tuvalu island). Rotuma in northern Fiji and Pekoa in northern Vanuatu also received rainfall totals below their 10th percentile. Rainfall above the 90th percentile was recorded in western and northern Fiji, central and southern Tonga, and at central Upolu in Samoa. Lata 
in the southeastern Solomon Islands recorded its wettest AMJ in 42 years $(1860 \mathrm{~mm})$.

Rainfall activity was mixed during July-September, with no clear pattern, as is typical for the middle of the dry season in an ENSO-neutral year. Rainfall was below the 10th percentile across most of Fiji and above the 90th percentile along the northern coast, highlands, southern PNG, and parts of the central Solomon Islands. The southernmost island of Tuvalu, Niulakita, recorded its wettest July-September in 65 years $(1212 \mathrm{~mm})$.

The mixed rainfall pattern continued into the last three months of the year. There was significantly enhanced SPCZ activity near the Solomon Islands

and close to and north of Fiji and Tonga. Rainfall was above the 90th percentile in central Fiji (highest in 62 years at Nausori Airport, $1436 \mathrm{~mm}$ ) and in central Tonga (second highest in 72 years at Ha'apai).

\section{(iii) Notable events and impacts}

On 6 March, Tropical Cyclone Hola formed about $80 \mathrm{~km}$ to the east of Pentecost Island in Vanuatu. As it intensified into a Category 2 storm, Hola passed between the islands of Pentecost and Ambrym. The system subsequently passed over Malekula Island, then over the Coral Sea on 7 March. High winds associated with Hola destroyed multiple homes and a school on Ambrym. There was one fatality and two severe injuries on Pentecost caused by falling trees.

Two children were lost in the flooded Navaka River on Santo.

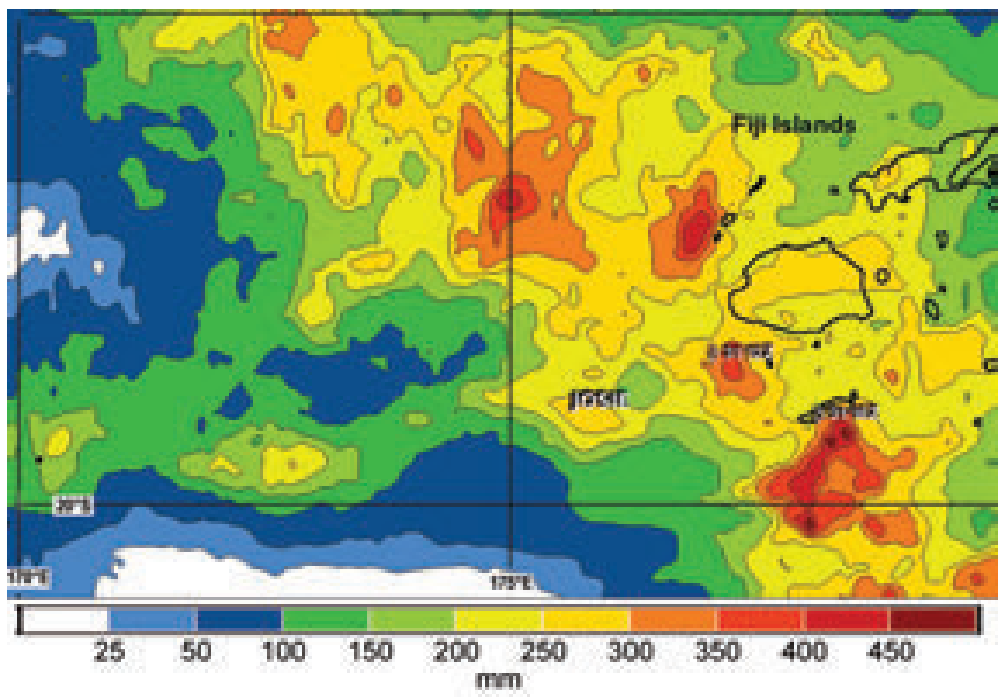

Fig.7.52. Rainfall accumulation during 26 Mar-2 Apr from IMERGbased rainfall analysis. (Source: NASA GPM.)

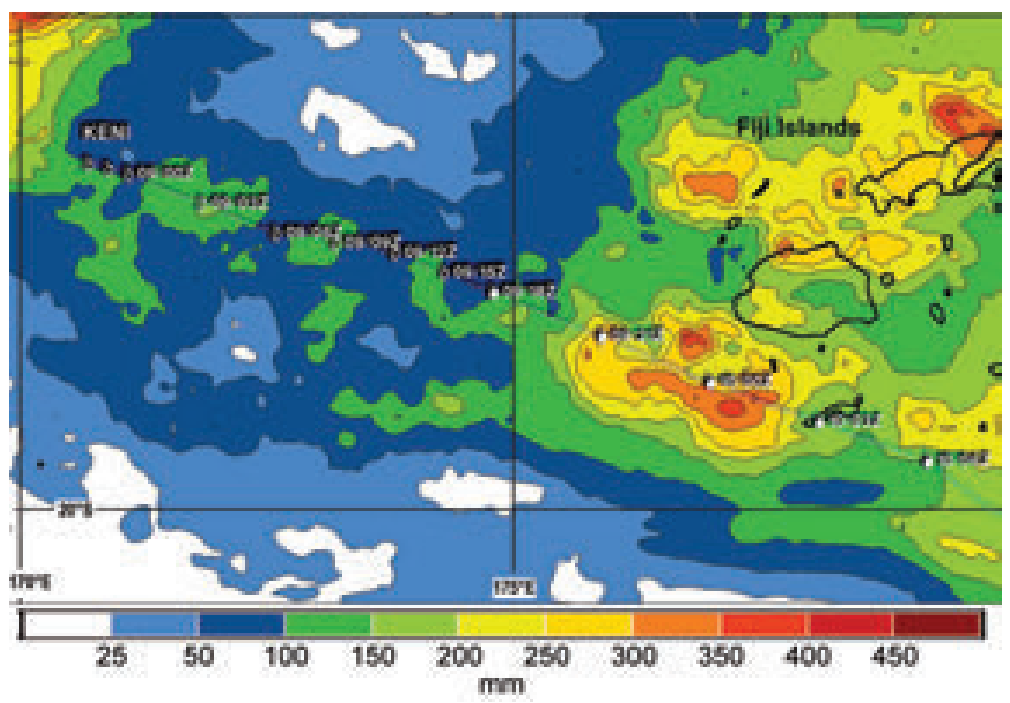

Fig. 7.53. Tropical Cyclone Keni's approximate track as shown by IMERG. The IMERG accumulated rainfall analysis shows total precipitation during 4-II April 2018. (Source: NASA GPM.)
Nine lives were lost and several thousand people were displaced in Fiji during the passage of two storms within days of each other in late March/early April. Tropical Cyclone Josie was a relatively weak Category 1 cyclone that passed to the country's southwest during 31 March-1 April. Josie was associated with heavy rainfall that caused significant flooding to the main island of Viti Levu (Fig. 7.52). Four lives were lost during this stage of the flooding. Tropical Cyclone Keni passed to the southwest of Fiji's main island, Viti Levu, as a Category 3 storm on 10 April (Fig. 7.53). Destructive winds, heavy rainfall, flash flooding, heavy swells, and storm surge devastated the islands Kadavu and Onoi-Lau. About $75 \%$ of the houses on these islands were damaged or destroyed. At Nadarivatu in the Viti Levu highlands, $1136 \mathrm{~mm}$ of rain was recorded in April, of which, $311.5 \mathrm{~mm}$ was received on 10 April alone. 


\section{4) Australia—S. Tobin and L. Bettio}

ENSO and the IOD are Australia's main natural climate drivers; however, only the IOD exerted a strong influence on Australia's climate during 2018.

For this section, monthly area-averaged temperatures are based on the ACORN-SAT dataset v2 (Trewin 2018), which begins in 1910. Rainfall and daily temperatures are based on the AWAP dataset (Jones et al. 2009), which begins in 1900 for rainfall and 1910 for temperature.

\section{(i) Temperature}

The annual mean temperatures for Australia were $0.76^{\circ} \mathrm{C}$ above the $1981-2010$ average, the third highest on record. Nine of Australia's warmest 10 years have occurred since 2005.

Australian mean maximum temperature (Fig. 7.54) was $1.17^{\circ} \mathrm{C}$ above average, the second highest on record, just $0.04^{\circ} \mathrm{C}$ below the record set in 2013 . The mean minimum temperature (Fig. 7.55 ) was $0.35^{\circ} \mathrm{C}$ above average, the 11th highest on record.

Annual mean temperature was above average across nearly all of Australia, and very much above average for most of the mainland except parts of Western Australia and parts of eastern Queensland.

Mean maximum temperatures were in the highest $10 \%$ of observations for nearly all of Australia, and above average for the remaining parts of Western

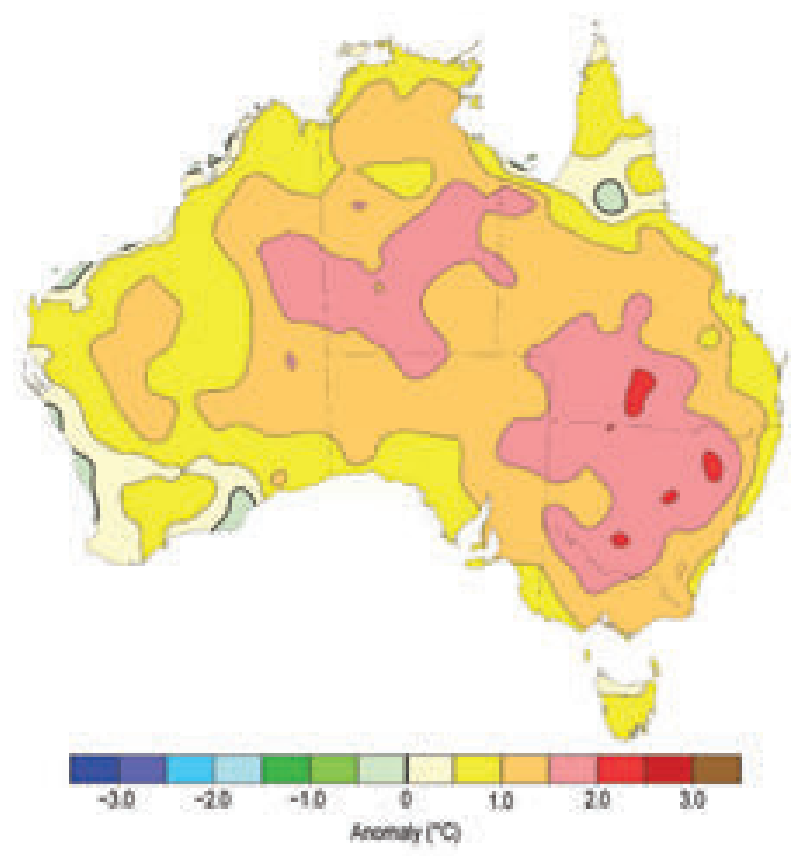

Fig. 7.54. Annual maximum temperature anomalies $\left({ }^{\circ} \mathrm{C}\right)$ in Australia for 2018, relative to a $1981-2010$ base period. (Source: Australian Bureau of Meteorology.)
Australia and an area of the southern Cape York Peninsula in Queensland.

Mean minimum temperatures were also above average for much of the country, although below average for some areas, particularly the Kimberley in Western Australia. Annual minima were in the highest $10 \%$ of historical observations for southwestern Queensland; northern, western, and coastal New South Wales; southern Victoria and Tasmania; coastal and southwestern South Australia; and southeastern Western Australia.

Warmth was widespread and persistent through the year-the national mean temperature was among the 10 highest on record for January, February, March, April, July, October, and December.

Increased diurnal temperature range and increased occurrence of frost are typical of the cool season in inland eastern Australia during drought, as in 2018, due to reduced cloud cover, low humidity, and low soil moisture. Days stayed warmer than average through the cool season, while minima were below average over large areas. September mean minimum temperature was the coolest on record from agricultural districts of South Australia to central northern Victoria.

Unusual warmth in the surrounding ocean has also been observed in recent years, including 2018. Recordhigh SSTs in the Tasman Sea in late 2017 continued into early 2018. Annual SSTs for the Australian region were the 11th highest in the 119-year record (ERSSTv5 data).

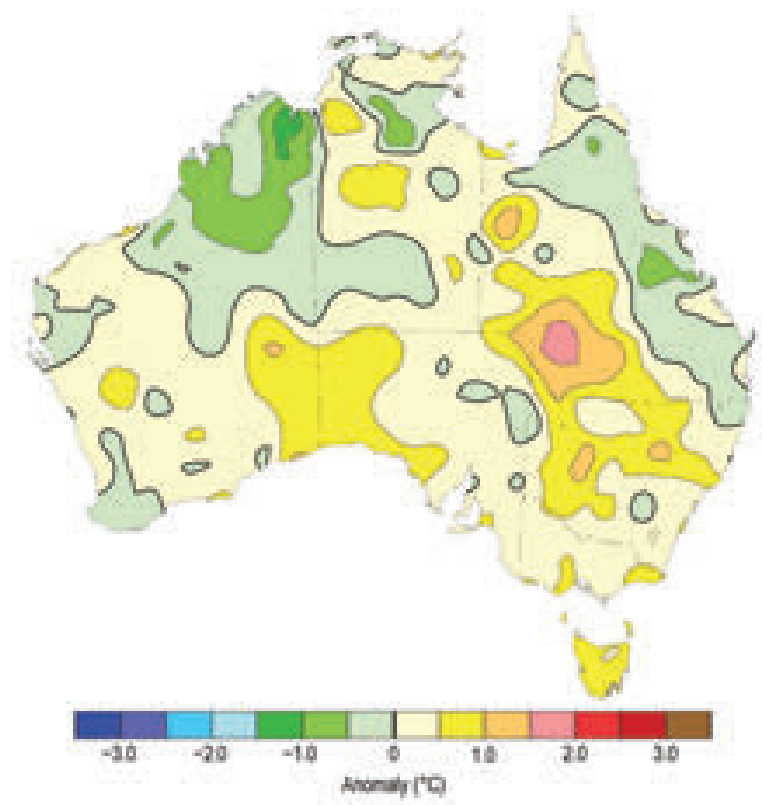

Fig. 7.55. Annual minimum temperature anomalies $\left({ }^{\circ} \mathrm{C}\right)$ in Australia for 2018 , relative to a $198 \mathrm{I}-2010$ base period. (Source: Australian Bureau of Meteorology.) 

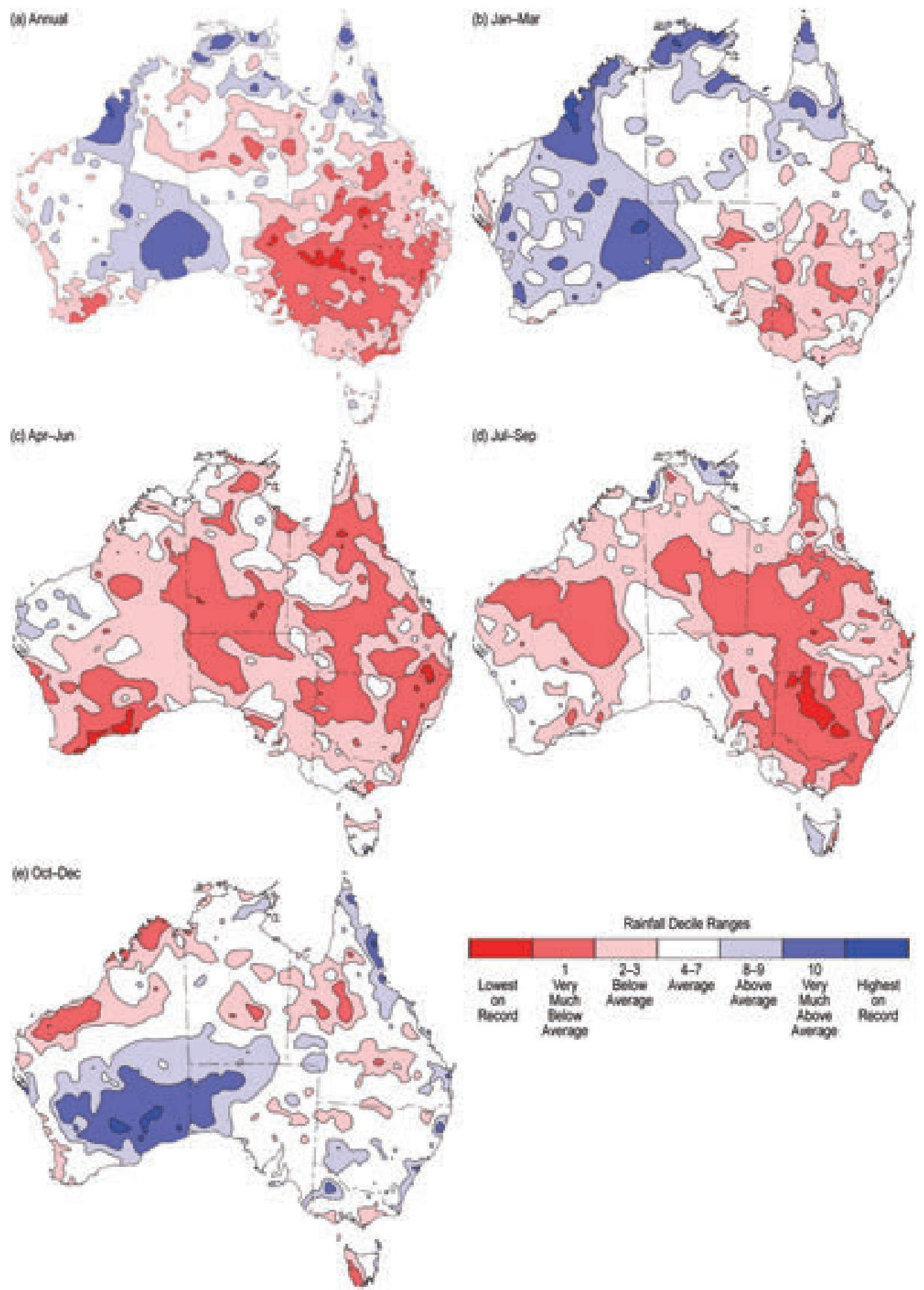

FIG. 7.56. Annual and three-month rainfall deciles for Australia for 2018, based on the 1900-2018 distribution. (Source: Australian Bureau of Meteorology.) 
SSTs were the second highest on record for the Tasman Sea region and fourth highest for the Coral Sea.

\section{(ii) Precipitation}

Averaged across Australia, rainfall for 2018 was $413.8 \mathrm{~mm}, 14 \%$ below the $1981-2010$ average. Rainfall for the year was very low over the southeastern quarter of the mainland, and in the lowest $10 \%$ of historical observations for much of the region (Fig. 7.56). Annual rainfall was above average between northwest Western Australia and the southeast of that state, and pockets scattered across northern Australia.

The west of Australia received above-average rainfall during January and February, while it was generally drier than average across the east. Southeast Queensland saw above-average rainfall in February as did the rest of the state and the southern half of the Northern Territory in March. March was drier than average across the southern mainland, and rainfall remained particularly low over most of the mainland from April through September.

The final three months of 2018 were wetter in some areas-the mainland east coast and Western Australia during October, much of the country in November, and northeastern Queensland and western to central Victoria in December.

\section{(iii) Notable events and impacts}

Following January heatwaves in southeastern Australia, summer-like warmth persisted, with heatwave conditions in the first half of April setting many records across southern Australia.

\section{SIDEBAR 7.5: EXTENDED DROUGHT IN AUSTRALIA IN 2018}

\section{S. TOBIN AND L. BETTIO}

Drought is a recurrent part of Australia's climate, with widespread impacts on the Australian community. Drought contributes to losses in livestock and agricultural production and can have far-reaching social impacts, such as economic downturn and increased incidence of mental ill-health. Recent drought conditions also contributed to a late end and an early start to the fire seasons in 2017/18 and 2018/19 (see Section 7h4 for further details).

Australia saw a rapid intensification of drought conditions during 2018, affecting large areas. These rainfall deficiencies built on dry conditions that had developed in many parts of eastern Australia from late 2016. The combination of high temperatures and low rainfall also contributed to record high rates of observed pan evaporation for winter and spring in New South Wales and Queensland, exacerbating the effects of the drought. There was little relief by the end of 2018 , despite above-average rainfall in some areas late in the year.

Much of southern Australia receives more than $60 \%$ of its annual rainfall between April and October, with this being the main period for growing many crops and recharging water resources. However, April was exceptionally warm, and was combined with below-average rainfall across large parts of the country, especially central and western New South Wales and eastern Victoria.

Rainfall for March-May was the second lowest on record, and by the second half of the year, the New South Wales government had declared $100 \%$ of the State to be in drought. Other areas of the country were also seriously affected, including southern inland Queensland, eastern South Australia, and much of eastern Victoria.
Below-average rainfall and above-average temperatures continued through winter and into September. Nationally, September was the driest on record for the month, and the second driest for any month on record behind only April 1902, which was part of the 1895-1903 Federation Drought (Foley 1957; Wright 2004). April and May were the sixth and fourth driest on record for their respective months. For the AprilSeptember period, rainfall was the third lowest on record for Australia (Fig. SB7.9).

The drought across eastern Australia was one of the most significant in the country's written history. While there have been individual years in the last century with rainfall similar to or less than that of 2018 , only twice since 1900 have dry conditions of similar intensity been sustained for a period of nearly two years across the Murray-Darling Basin: during the Federation Drought, and at the peak of the long-lived Millennium Drought, which spanned 1997 to 2009.

Drought in Australia in 2018 was strongly influenced by both natural variability and climate change. Australia's climate is largely dependent on variability in the Indian and Pacific Oceans. The IOD entered a positive phase in September. A positive IOD during (austral) spring is typically associated with reduced rainfall in central and southern Australia. From May through the end of the year, cooler-than-average waters to the northwest of Australia and more generally across parts of the eastern Indian Ocean may also have contributed to reduced rainfall over central and southeastern Australia. 
Forest Fire Danger Index levels remained elevated well into (austral) autumn, and rose again quickly over winter and spring; fire danger periods commenced two to three months earlier than usual in parts of eastern Australia. There were significant fires in March at Tathra on the south coast of New South Wales and across southwest Victoria. In August there were more than 100 fires in eastern Australia, including the longlived Bega fire on the New South Wales south coast.

Flooding affected Queensland in late February and early March in the North Tropical Coast, Gulf Country, and parts of southwest Queensland, with further flooding in the North Tropical Coast in late March.

In May, thunderstorms brought exceptionally high rainfall to southeast Tasmania, in particular Hobart and the nearby Wellington Range, with flash flooding causing extensive damage to bridges, roads, buildings, and other infrastructure.

A prolonged heatwave from late November to early December across Queensland saw some sites break temperature records by large margins. Multiple significant fires burned along Queensland's east coast, totaling over one million hectares.

During mid-December, Severe Tropical Cyclone Owen brought heavy rain across northern and east coast Queensland, resulting in localized flash flooding. Moist, unstable air from the tropics interacted with a low-pressure system over southeastern Australia, fueling thunderstorms. Flooding affected some parts of Victoria and metropolitan Sydney.

Separate storms over eastern New South Wales on 20 December produced hail larger than $5 \mathrm{~cm}$ in

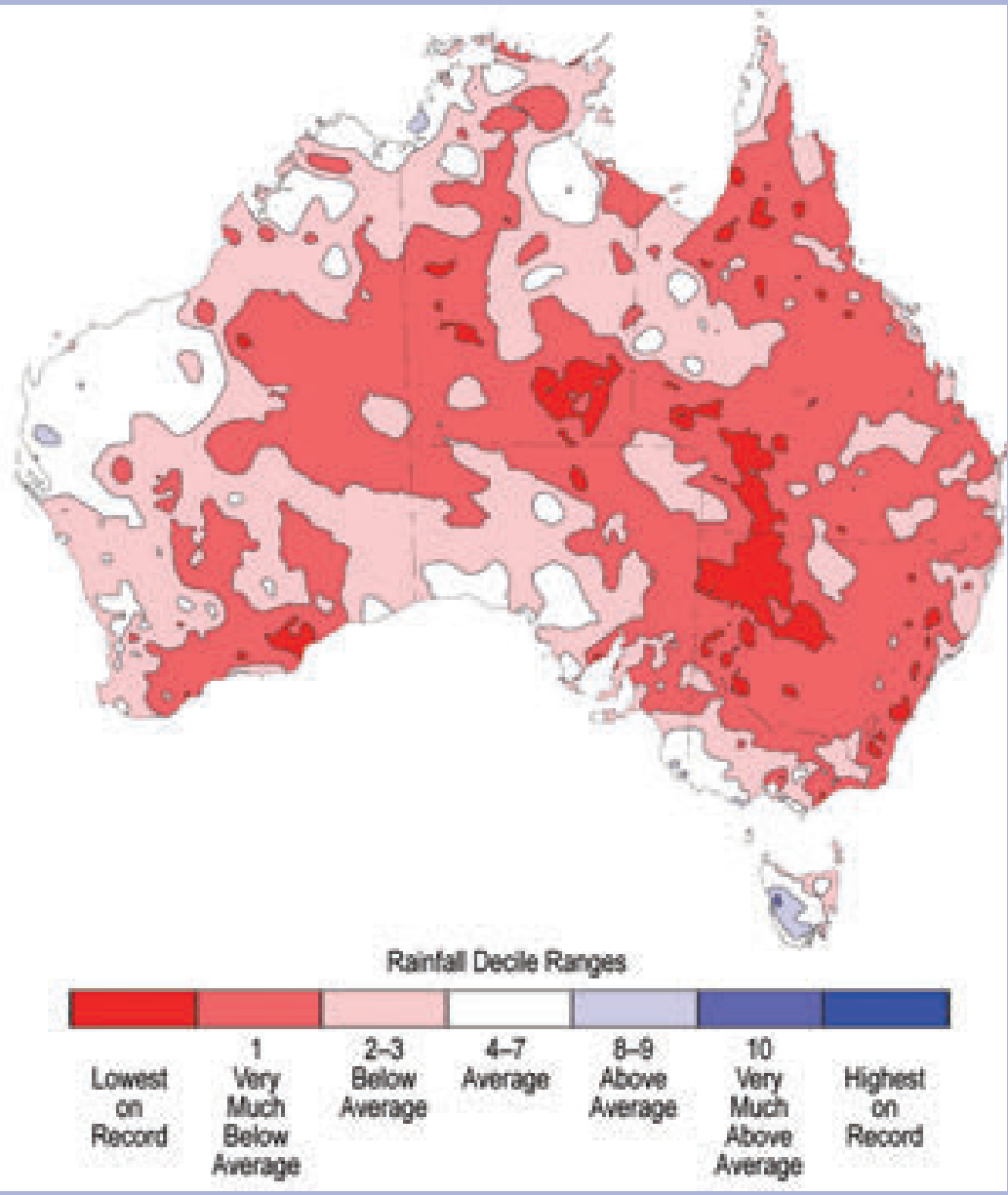

FIG. SB7.9. Rainfall deciles for Australia for Apr-Sep 2018, based on the 1900-2018 distribution. (Source: Australia Bureau of Meteorology.)
A positive phase of the southern annular mode (SAM) from late October to late December likely moderated the drying influence of the IOD in mainland eastern Australia. A positive SAM during these months is usually associated with increased onshore flow in parts of eastern Australia, increasing the likelihood of above-average rainfall. Meanwhile, after a weak La Niña decayed during February, the tropical Pacific Ocean remained ENSO-neutral for the remainder of the year despite signs of a developing El Niño emerging in October.

Sea surface temperatures in the Tasman Sea to the east of Australia were above average through 2018 , and during autumn, along with associated lower surface air pressure over eastern Australia, may have contributed to the reduced strength and more southerly position of the westerly winds and rain-bearing cold fronts across southern Australia. 


\section{SIDEBAR 7.5: EXTENDED DROUGHT IN AUSTRALIA IN 2018}

\section{S. TOBIN AND L. BETTIO}

Generally, a reduction in April-October rainfall has been observed across southern Australia in recent decades (Fig. SB7.10); this is the most sustained large-scale change in rainfall since national records began in 1900 (Bureau and CSIRO 2018). The drying trend has been particularly evident in the southwestern and southeastern corners of the country. Australia has also warmed by just over $1{ }^{\circ} \mathrm{C}$ since national records began in 1910. This has added to water stress in the landscape, with even greater reductions in streamflow observed than directly equivalent to the rainfall decline.

A major influence on the long-term drying trend over southern Australia has been the strengthening and extension of the subtropical high-pressure ridge during winter, shifting many potential rain-bearing weather systems south of the Australian continent. This southwards shift of frontal systems is an expected outcome of climate change for the region.

For further details on the 2018 drought, see Special Climate Statement 66: www.bom.gov.au/climate /current/statements/scs66.pdf.

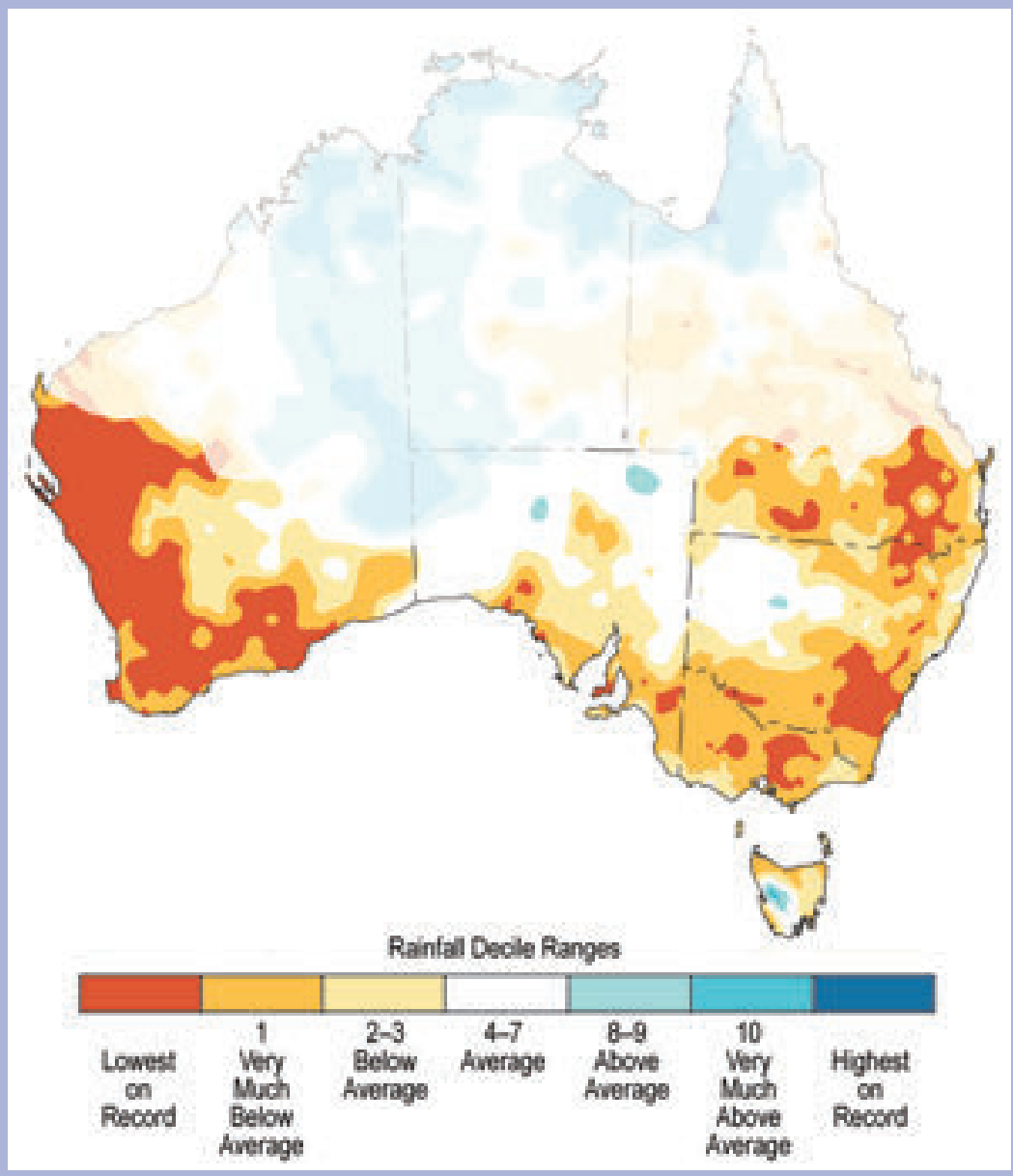

FIG. SB7.10. Rainfall deciles for Apr-Oct over the period 1999-20I8, based on the 1900-2018 distribution. (Source: Australian Bureau of Meteorology.)

diameter, damaging winds, and intense rain. Extensive property damage in and around Sydney resulted in estimated insurance claims of some $\$ 482$ million (U.S. dollars).

Extreme high temperatures during the last week of December affected large areas from the northwest of the country into the inland southeast, with records set for persistence of heat as well as for extremes.

For further details on these and other significant events, please refer to Special Climate Statements, Monthly Weather Reviews, and the Annual Climate Statement at www.bom.gov.au/climate/current/.

\section{5) New Zealand-s. B. Carrier}

In the following discussion, the base period is 1981-2010, unless otherwise noted. The nationwide average temperature is based upon the National In- stitute of Water and Atmospheric Research (NIWA)'s seven-station temperature series that began in 1909.

\section{(i) Temperature}

The 2018 annual temperature for New Zealand was $13.41^{\circ} \mathrm{C}, 0.80^{\circ} \mathrm{C}$ above average, tying with 1998 as the second highest since records began in 1909, behind only 2016. Annual mean temperatures were above average $\left(+0.51^{\circ} \mathrm{C}\right.$ to $+1.20^{\circ} \mathrm{C}$ above average) across the majority of New Zealand, but near-average temperatures (within $-0.50^{\circ} \mathrm{C}$ to $+0.50^{\circ} \mathrm{C}$ of average) occurred in parts of southern Canterbury, Otago, small parts of Auckland, and the Far North (Fig. 7.57). The three months with the largest national temperature anomalies were January $\left(+3.1^{\circ} \mathrm{C}\right)$, March $\left(+1.3^{\circ} \mathrm{C}\right)$, and December $\left(+1.3^{\circ} \mathrm{C}\right)$. These marked New Zealand's warmest January on record, sixth warmest March, 

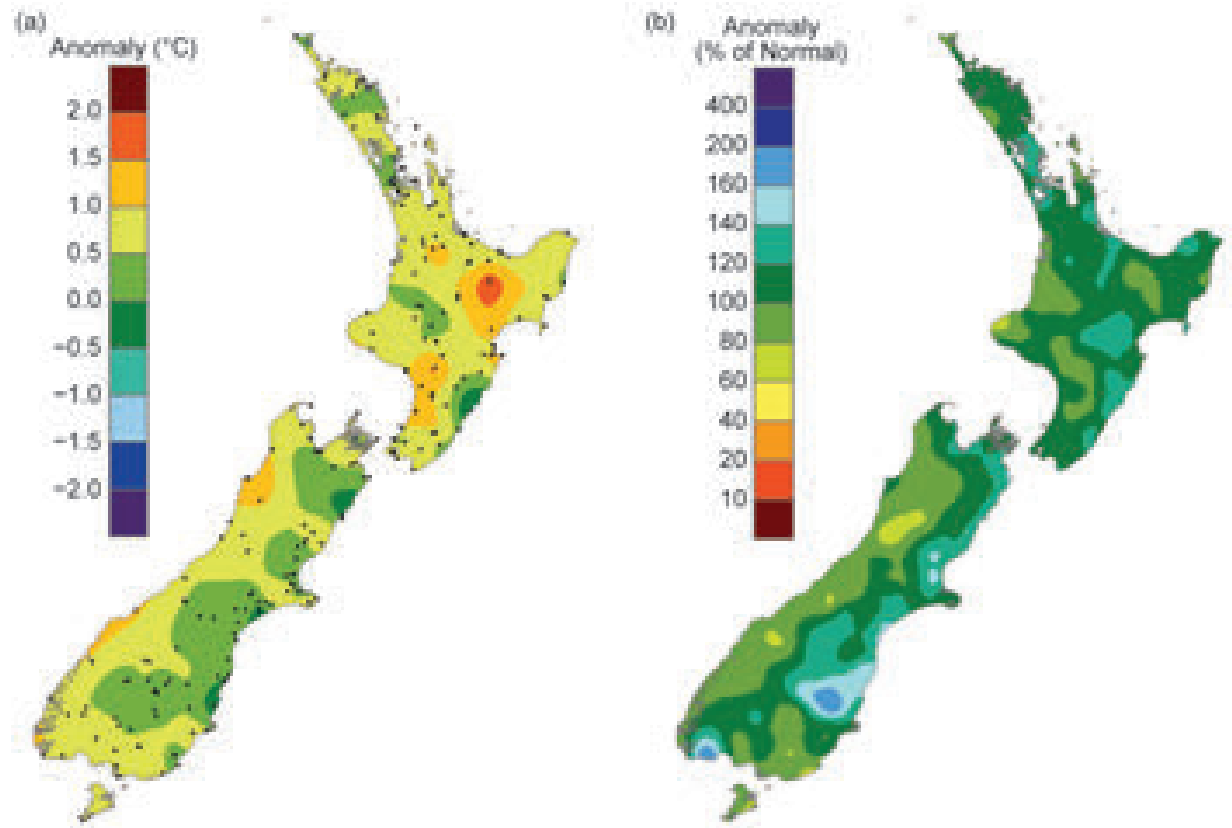

FIG. 7.57. 2018 annual (a) mean temperature anomaly $\left({ }^{\circ} \mathrm{C}\right)$ and (b) total rainfall (\% of normal), relative to I98I-20I0. (Source: NIWA.)

and ninth warmest December. In addition, January 2018 was New Zealand's warmest single month on record, with 94 locations observing their highest mean January temperatures since recordkeeping began. The January warmth was likely influenced by a "marine heatwave" in the Tasman Sea and New Zealand coastal waters, where SSTs spiked to $2^{\circ}-4^{\circ} \mathrm{C}$ above average (averages from NOAA's OISSTv2 dataset with a base period of 1971-2000) beginning in November 2017 and persisting until February 2018 (Tobin and Jacobs 2018). The highest recorded daily air temperature for 2018 was $38.7^{\circ} \mathrm{C}$, at Alexandra (Central Otago) on 30 January (see Fig. 7.58 for localities). The lowest recorded daily minimum air temperature for 2018 (excluding high-altitude alpine sites) was $-10.4^{\circ} \mathrm{C}$, observed at Mount Cook Airport (Canterbury) on 3 June.

\section{(ii) Precipitation}

Annual rainfall totals for 2018 were above normal (120\%-149\% of normal) across much of the eastern and upper South Island, as well as parts of Wellington, Wairarapa, Bay of Plenty, northern Waikato, and Auckland (Fig. 7.57). Well-above-normal rainfall (>149\%) was observed in portions of southern Canterbury. Rainfall was near-normal (80\%-119\%) for the rest of New Zealand. Four locations observed near-record (defined as a top-4 ranking since records began) high annual rainfall totals while no locations observed record or near-record low rainfall totals. Of the regularly reporting rainfall gauges, the wettest location in 2018 was Cropp River in the Hokitika River catchment (West Coast, South Island, $975 \mathrm{~m}$ a.s.l.), with an annual rainfall total of $9817 \mathrm{~mm}$. The driest of the regularly reporting rainfall sites in 2018 was Clyde (Central Otago), which recorded $526 \mathrm{~mm}$ of rainfall. Arthur's Pass (Canterbury) experienced the highest one-day rainfall total in 2018: $326 \mathrm{~mm}$ on 8 November.

\section{(iii) Notable events and impacts}

See Fig. 7.58 for a schematic of notable events. In January, the Ministry for Primary Industries classified drought as a "medium-scale adverse event" in parts of the northern West Coast as well as Otago and Southland. These drought conditions occurred following a dry end to 2017.

Two ex-tropical cyclones (Fehi and Gita) affected the country during February, leading to several oneday and monthly rainfall records in the northern and eastern South Island. Nelson recorded $234 \mathrm{~mm}$ of rain for the month, which made it the wettest February in the city's 156-year record.

A strong front moved up the country on 10-11 April. Winds speeds of more than $33 \mathrm{~m} \mathrm{~s}^{-1}$ caused heavy damage in Auckland, leaving around 120000 homes and businesses without power, some for multiple days. A wind gust of $41 \mathrm{~m} \mathrm{~s}^{-1}$ was recorded at Auckland's Sky Tower.

\footnotetext{
1 www.mpi.govt.nz/protection-and-response/responding/ adverse-events/how-we-classify-adverse-events/
} 


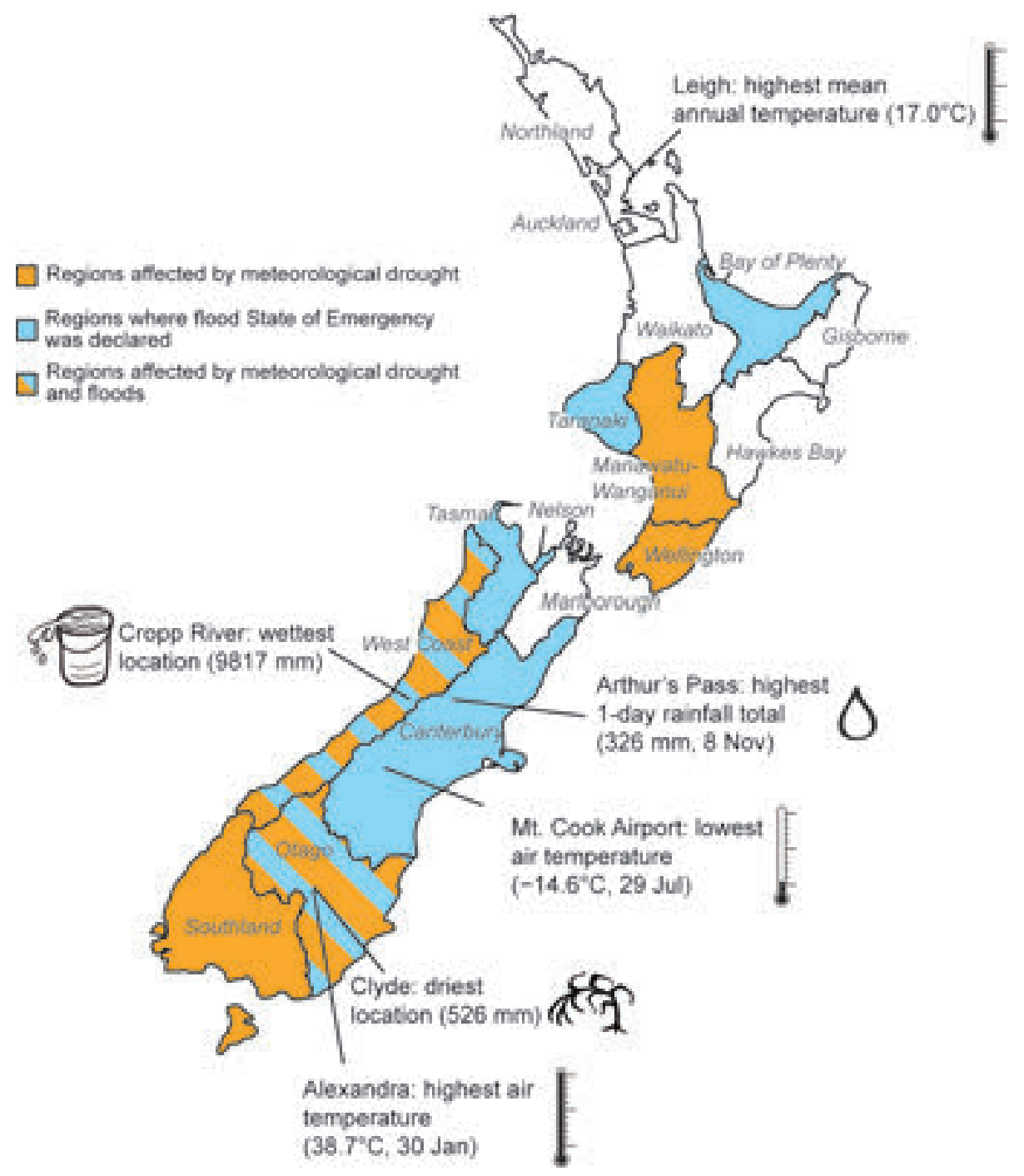

FIG. 7.58. Notable weather events and climate extremes for New Zealand in 2018. (Source: NIWA.) 
APPENDIX I: RELEVANT DATASETS AND SOURCES

\begin{tabular}{|c|c|c|c|}
\hline $\begin{array}{l}\text { General Variable } \\
\text { or Phenomenon }\end{array}$ & $\begin{array}{l}\text { Specific dataset } \\
\text { or variable }\end{array}$ & 2018 Source & $\begin{array}{l}2018 \\
\text { Section }\end{array}$ \\
\hline Aerosols & CAMS Reanalysis & https://atmosphere.copernicus.eu/ & $2 g 3$ \\
\hline \multirow{3}{*}{ Air-sea fluxes } & $\begin{array}{l}\text { CERES Energy Balanced } \\
\text { and Filled }\end{array}$ & https://ceres.larc.nasa.gov/ & $3 e l$ \\
\hline & CERES FLASHflux & $\begin{array}{l}\text { https://eosweb.larc.nasa.gov/project/ceres/ebaf } \\
\text { _surface_table }\end{array}$ & $3 e l, 3 e 4$ \\
\hline & $\begin{array}{l}\text { Woods Hole Oceanographic } \\
\text { Institute OAFlux }\end{array}$ & http://oaflux.whoi.edu & $\begin{array}{l}3 e l, 3 e 3 \\
3 e 4\end{array}$ \\
\hline Albedo & MODIS & http://ladsweb.nascom.nasa.gov & $2 \mathrm{hl}, 5 \mathrm{e} 3$ \\
\hline \multirow{3}{*}{$\begin{array}{l}\text { Biomass, Greenness } \\
\text { or Burning }\end{array}$} & GFAS & https://apps.ecmwf.int/datasets/data/cams-gfas/ & $2 \mathrm{~h} 3$ \\
\hline & GFEDv4 & $\begin{array}{l}\text { https://daac.ornl.gov/VEGETATION/guides/fire } \\
\text { _emissions_v4.html }\end{array}$ & $2 \mathrm{~h} 3$ \\
\hline & $\begin{array}{l}\text { Global Inventory Modeling } \\
\text { and Mapping Studies } \\
\text { (GIMMS) 3gvl }\end{array}$ & https://nex.nasa.gov/nex/projects//349/ & $5 i$ \\
\hline \multirow{10}{*}{ Cloud Properties } & Aqua MODIS C6 & $\begin{array}{l}\text { https://earthdata.nasa.gov/earth-observation-data/ } \\
\text { near-real-time/download-nrt-data/modis-nrt }\end{array}$ & $2 \mathrm{~d} 6$ \\
\hline & CALIPSO & $\begin{array}{l}\text { https://eosweb.larc.nasa.gov/project/calipso } \\
\text { /calipso_table }\end{array}$ & $2 \mathrm{~d} 6,6 \mathrm{~g}$ \\
\hline & CERES MODIS & $\begin{array}{l}\text { https://ceres.larc.nasa.gov/science_information } \\
\text {.php?page=ModisCloudRetr }\end{array}$ & $2 \mathrm{~d} 6$ \\
\hline & CLARA-A2 & $\begin{array}{l}\text { https://climatedataguide.ucar.edu/climate-data } \\
\text { /clara-al-cloud-properties-surface-albedo-and } \\
\text {-surface-radiation-products-based-avhrr }\end{array}$ & $2 \mathrm{~d} 6$ \\
\hline & CLOUD_CCl & www.esa-cloud-cci.org & $2 \mathrm{~d} 6$ \\
\hline & HIRS & www.ssec.wisc.edu/ donw/PAGE/CLIMATE.HTM & $2 \mathrm{~d} 6$ \\
\hline & MISR & https://I0dup05.larc.nasa.gov/L3Web/ & $2 \mathrm{~d} 6$ \\
\hline & PATMOS-x/AVHRR & $\begin{array}{l}\text { www.ncdc.noaa.gov/cdr/atmospheric/avhrr-cloud } \\
\text {-properties-patmos-x }\end{array}$ & $2 \mathrm{~d} 6$ \\
\hline & PATMOS-x/MODIS C6 & http://ladsweb.nascom.nasa.gov & $2 \mathrm{~d} 6$ \\
\hline & SatCORPS & No public archive & $2 \mathrm{~d} 6$ \\
\hline \multirow{2}{*}{ Drought } & scPSDI & https://crudata.uea.ac.uk/cru/data/drought/ & $2 \mathrm{dIO}$ \\
\hline & CRU TS 4.03 & https://crudata.uea.ac.uk/cru/data/hrg/ & $2 \mathrm{~d} I 0$ \\
\hline $\begin{array}{l}\text { Evaporation, } \\
\text { Interception, } \\
\text { Transpiration, } \\
\text { Sublimation } \\
\end{array}$ & GLEAM & www.gleam.eu/ & $2 \mathrm{dII}$ \\
\hline \multirow{3}{*}{ FAPAR } & MERIS & http://earth.esa.int/level3/meris-level3/ & $2 \mathrm{~h} 2$ \\
\hline & MODIS-TIP & http://ladsweb.nascom.nasa.gov/ & $2 \mathrm{~h} 2$ \\
\hline & SeaWiFS v 2010.0 & http://fapar.jrc.ec.europa.eu/ & $2 \mathrm{~h} 2$ \\
\hline \multirow{2}{*}{ Geopotential Height } & ERA-Interim & $\begin{array}{l}\text { www.ecmwf.int/en/research/climate-reanalysis } \\
\text { /era-interim }\end{array}$ & $6 \mathrm{~b}$ \\
\hline & $\begin{array}{l}\text { NCEP/NCAR Reanalysis } \\
\text { I: Pressure }\end{array}$ & $\begin{array}{l}\text { www.esrl.noaa.gov/psd/data/gridded/data.ncep } \\
\text {.reanalysis.pressure.html }\end{array}$ & $4 f 2,5 b 3$ \\
\hline \multirow{2}{*}{$\begin{array}{l}\text { Glacier Mass, Area or } \\
\text { Volume }\end{array}$} & $\begin{array}{l}\text { Sentinel-2, LANDSAT, } \\
\text { ASTER }\end{array}$ & & 5 e5 \\
\hline & $\begin{array}{l}\text { World Glacier Monitoring } \\
\text { Service }\end{array}$ & https://wgms.ch/latest-glacier-mass-balance-data/ & $2 \mathrm{c} 3$ \\
\hline
\end{tabular}




\begin{tabular}{|c|c|c|c|}
\hline $\begin{array}{l}\text { General Variable } \\
\text { or Phenomenon }\end{array}$ & $\begin{array}{l}\text { Specific dataset } \\
\text { or variable }\end{array}$ & 2018 Source & $\begin{array}{l}2018 \\
\text { Section }\end{array}$ \\
\hline $\begin{array}{l}\text { Groundwater and } \\
\text { terrestrial water } \\
\text { storage }\end{array}$ & GRACE & https://gracefo.jpl.nasa.gov/data/grace-data/ & $2 \mathrm{~d} 8$ \\
\hline \multirow{9}{*}{$\begin{array}{l}\text { Humidity, [Near] } \\
\text { Surface }\end{array}$} & Dai & by email to adai@ucar.edu & $2 \mathrm{dl}$ \\
\hline & ERA5 & $\begin{array}{l}\text { www.ecmwf.int/en/forecasts/datasets/reanalysis } \\
\text {-datasets/era5 }\end{array}$ & $2 d l$ \\
\hline & ERA-Interim & $\begin{array}{l}\text { www.ecmwf.int/en/forecasts/datasets } \\
\text { /archive-datasets/reanalysis-datasets/era-interim }\end{array}$ & $2 \mathrm{dl}$ \\
\hline & HadCRUH & www.metoffice.gov.uk/hadobs/hadcruh & $2 \mathrm{dl}$ \\
\hline & HadISDH & www.metoffice.gov.uk/hadobs/hadisdh & $2 \mathrm{dl}$ \\
\hline & HOAPS & $\begin{array}{l}\text { https://doi.org//0.5676/EUM_SAF_CM/HOAPS } \\
\text { /V00I }\end{array}$ & $2 d \mathrm{l}$ \\
\hline & $\begin{array}{l}\text { JRA-55 Atmospheric } \\
\text { Reanalysis }\end{array}$ & http://jra.kishou.go.jp/JRA-55/index_en.html & $2 d \mathrm{l}$ \\
\hline & MERRA-2 & https://gmao.gsfc.nasa.gov/reanalysis/MERRA-2/ & $2 \mathrm{dl}$ \\
\hline & NOCS 2.0 & http://badc.nerc.ac.uk/data/nocs_flux & $2 d \mathrm{~d}$ \\
\hline \multirow{4}{*}{$\begin{array}{l}\text { Humidity, Upper } \\
\text { Atmosphere }\end{array}$} & ERA5 & $\begin{array}{l}\text { https://www.ecmwf.int/en/forecasts/datasets } \\
\text { /reanalysis-datasets/era5 }\end{array}$ & $2 \mathrm{~d} 3$ \\
\hline & HIRS & $\begin{array}{l}\text { www.ncdc.noaa.gov/cdr/fundamental/hirs-ch } 12 \\
\text {-brightness-temperature }\end{array}$ & $2 \mathrm{~d} 3$ \\
\hline & NCEP/NCAR Reanalysis & $\begin{array}{l}\text { www.esrl.noaa.gov/psd/data/gridded/data.ncep } \\
\text {.reanalysis.html }\end{array}$ & $4 \mathrm{f} 4$ \\
\hline & UTH, Microwave & by email to Viju.John@eumetsat.int & $2 \mathrm{~d} 3$ \\
\hline \multirow{2}{*}{$\begin{array}{l}\text { Ice Sheet } \\
\text { Characteristics }\end{array}$} & DMSP-SSMIS & http://nsidc.org/data/nsidc-0032 & $5 e l, 6 d$ \\
\hline & PROMICE (Greenland) & www.promice.dk/home.html & $5 e 2$ \\
\hline \multirow{7}{*}{ Lake Temperature } & Globolakes & www.globolakes.ac.uk & $2 b 2$ \\
\hline & Lake Vättern (Sweden) & Vättern Water Protection Association & $2 \mathrm{~b} 2$ \\
\hline & Lake Zurich (Switzerland) & $\begin{array}{l}\text { City of Zurich Water Supply and Amt für Abfall, } \\
\text { Wasser, Energie und Luft of the Canton of Zurich }\end{array}$ & $2 b 2$ \\
\hline & Mondsee (Austria) & http://hydro.ooe.gv.at/\#Startseite & $2 \mathrm{~b} 2$ \\
\hline & Neusiedler See (Austria) & $\begin{array}{l}\text { http://wasser.bgld.gv.at/hydrographie/online-daten } \\
\text {.html }\end{array}$ & $2 b 2$ \\
\hline & Polish Lakes & www.imgw.pl & $2 b 2$ \\
\hline & Wörther See (Austria) & $\begin{array}{l}\text { https://info.ktn.gv.at/asp/hydro/daten/hydroportal } \\
\text { /see_wt.asp }\end{array}$ & $2 b 2$ \\
\hline \multirow{5}{*}{ Modes of Variability } & Arctic Oscillation (AO) & $\begin{array}{l}\text { www.cpc.ncep.noaa.gov/products/precip/CWlink } \\
\text { /daily_ao_index/teleconnections.shtml }\end{array}$ & $2 \mathrm{el}$ \\
\hline & $\begin{array}{l}\text { Madden-Julian Oscillation } \\
\text { (MJO) - Real-time } \\
\text { Multivariate MJO }\end{array}$ & $\begin{array}{l}\text { www.bom.gov.au/climate/mjo/graphics } \\
\text { /rmm.74toRealtime.txt }\end{array}$ & $4 c$ \\
\hline & Niño-3.4 (detrended) & $\begin{array}{l}\text { www.cpc.ncep.noaa.gov/products/analysis } \\
\text { _monitoring/ensostuff/detrend.nino34.ascii.txt }\end{array}$ & $2 \mathrm{~d} 4$ \\
\hline & $\begin{array}{l}\text { North Atlantic Oscillation } \\
\text { (NAO) }\end{array}$ & $\begin{array}{l}\text { https://climatedataguide.ucar.edu/climate-data } \\
\text { /hurrell-north-atlantic-oscillation-nao-index } \\
\text {-station-based }\end{array}$ & $2 \mathrm{el}$ \\
\hline & $\begin{array}{l}\text { North Atlantic Oscillation } \\
\text { (NAO) }\end{array}$ & www.cpc.ncep.noaa.gov/data/teledoc/nao.shtml & $4 \mathrm{f} 2$ \\
\hline
\end{tabular}




\begin{tabular}{|c|c|c|c|}
\hline $\begin{array}{l}\text { General Variable } \\
\text { or Phenomenon }\end{array}$ & $\begin{array}{l}\text { Specific dataset } \\
\text { or variable }\end{array}$ & 2018 Source & $\begin{array}{c}2018 \\
\text { Section }\end{array}$ \\
\hline \multirow{7}{*}{$\begin{array}{l}\text { cont'd Modes of } \\
\text { Variability }\end{array}$} & Oceanic Nino Index (ONI) & $\begin{array}{l}\text { www.cpc.ncep.noaa.gov/products/analysis } \\
\text { _monitoring/ensostuff/ensoyears.shtml }\end{array}$ & $\begin{array}{l}2 \mathrm{~d} 7,3 \mathrm{il}, \\
4 \mathrm{~b}, 4 \mathrm{f} 2\end{array}$ \\
\hline & $\begin{array}{l}\text { Pacific Decadal Oscillation } \\
\text { (PDO) }\end{array}$ & www.cpc.ncep.noaa.gov/products/GODAS/ & $2 \mathrm{~d} 7$ \\
\hline & $\begin{array}{l}\text { Southern Annular Mode } \\
\text { (SAM) }\end{array}$ & www.antarctica.ac.uk/met/gjma/sam.html & $6 b, 6 c$ \\
\hline & $\begin{array}{l}\text { Southern Annular Mode } \\
\text { (SAM, AAO) }\end{array}$ & $\begin{array}{l}\text { www.cpc.ncep.noaa.gov/products/precip/CWlink } \\
\text { /daily_ao_index/aao/aao.shtml }\end{array}$ & $2 \mathrm{el}$ \\
\hline & $\begin{array}{l}\text { Southern Oscillation Index } \\
\text { (SOI) }\end{array}$ & https://crudata.uea.ac.uk/cru/data/soi/ & $2 \mathrm{~d} 10$ \\
\hline & $\begin{array}{l}\text { Southern Oscillation Index } \\
\text { (SOI) }\end{array}$ & www.bom.gov.au/climate/current/soi2.shtml & $2 \mathrm{el}$ \\
\hline & $\begin{array}{l}\text { Southern Oscillation Index } \\
\text { (EQ-SOI) }\end{array}$ & www.cpc.ncep.noaa.gov/data/indices & $6 c$ \\
\hline \multirow{4}{*}{ Ocean Carbon } & $\mathrm{PCO}_{2}$ & www.socat.info & $3 \mathrm{il}$ \\
\hline & $\mathrm{PCO}_{2}$ & www.soest.hawaii.edu/whots/ & $3 \mathrm{i} 3$ \\
\hline & $\begin{array}{l}\text { Global Ocean Ship-Based } \\
\text { Hydrographic Investigations } \\
\text { Program }\end{array}$ & www.go-ship.org & $3 \mathrm{i} 4$ \\
\hline & SOCCOM & https://soccom.princeton.edu/content/float-data & $6 f 2$ \\
\hline \multirow{8}{*}{ Ocean Heat Content } & $\begin{array}{l}\text { CLIVAR and Carbon } \\
\text { Hydrographic Data Office }\end{array}$ & https://cchdo.ucsd.edu/ & $3 c$ \\
\hline & $\begin{array}{l}\text { CSIRO/ACE CRC/IMAS- } \\
\text { UTAS estimate }\end{array}$ & $\begin{array}{l}\text { www.cmar.csiro.au/sealevel/thermal_expansion_ } \\
\text { ocean_heat_timeseries.html }\end{array}$ & $3 c$ \\
\hline & IAP/CAS & $\begin{array}{l}\text { https://climatedataguide.ucar.edu/climate-data } \\
\text { locean-temperature-analysis-and-heat-content } \\
\text {-estimate-institute-atmospheric-physics }\end{array}$ & $3 c$ \\
\hline & PMEL/JPL/JIMAR & http://oceans.pmel.noaa.gov & $3 c$ \\
\hline & $\mathrm{MRI} / J M A$ & $\begin{array}{l}\text { www.data.jma.go.jp/gmd/kaiyou/english/ohc/ohc } \\
\text { _global_en.html }\end{array}$ & $3 c$ \\
\hline & NCEP Ocean Reanalysis & $\begin{array}{l}\text { http://apdrc.soest.hawaii.edu/datadoc/godas } \\
\text { _pentad.php }\end{array}$ & $4 c$ \\
\hline & NCEI & www.nodc.noaa.gov/OC5/3M_HEAT_CONTENT/ & $3 c$ \\
\hline & UK Met Office EN4.0.2 & $\begin{array}{l}\text { www.metoffice.gov.uk/hadobs/en4/download-en4 } \\
-0-2-109 . h t m l\end{array}$ & $3 c$ \\
\hline Ocean Mass & $\begin{array}{l}\text { NASA Gravity Recovery and } \\
\text { Climate Experiment }\end{array}$ & $\begin{array}{l}\text { https://grace.jpl.nasa.gov/data/get-data/monthly } \\
\text {-mass-grids-ocean/ }\end{array}$ & $3 f$ \\
\hline \multirow{5}{*}{ Ocean Salinity } & Aquarius V3.0 & http://podaac.jpl.nasa.gov/aquarius & $3 \mathrm{~d} 2$ \\
\hline & \multirow{2}{*}{ Argo } & www.argo.ucsd.edu & \multirow{2}{*}{$3 \mathrm{~d} 2,3 \mathrm{~d} 3$} \\
\hline & & http://argo.jcommops.org & \\
\hline & $\begin{array}{l}\text { Blended Analysis for } \\
\text { Surface Salinity }\end{array}$ & ftp://ftp.cpc.ncep.noaa.gov/precip/BASS & $3 \mathrm{~d} 2$ \\
\hline & World Ocean Atlas 2013 & www.nodc.noaa.gov/OC5/woal3/ & $3 \mathrm{dl}, 3 \mathrm{~d} 2$ \\
\hline
\end{tabular}




\begin{tabular}{|c|c|c|c|}
\hline $\begin{array}{l}\text { General Variable } \\
\text { or Phenomenon }\end{array}$ & $\begin{array}{l}\text { Specific dataset } \\
\text { or variable }\end{array}$ & 2018 Source & $\begin{array}{l}2018 \\
\text { Section }\end{array}$ \\
\hline \multirow{3}{*}{$\begin{array}{l}\text { Outgoing Longwave } \\
\text { Radiation }\end{array}$} & AVHRR & $\begin{array}{l}\text { www.esrl.noaa.gov/psd/data/gridded/data } \\
\text {.interp_OLR.html }\end{array}$ & $4 f 2$ \\
\hline & CERES FLASHFlux Project & http://flashflux.larc.nasa.gov & $3 e l, 3 e 4$ \\
\hline & Daily OLR & $\begin{array}{l}\text { www.ncdc.noaa.gov/cdr/atmospheric/outgoing } \\
\text {-longwave-radiation-daily }\end{array}$ & $\begin{array}{l}4 \mathrm{~b} 2,4 c \\
4 f 3,4 f 6\end{array}$ \\
\hline \multirow{16}{*}{$\begin{array}{l}\text { Ozone, Total Column } \\
\text { and Stratospheric }\end{array}$} & Bodeker Scientific & $\begin{array}{l}\text { www.bodekerscientific.com/data/total-column } \\
\text {-ozone }\end{array}$ & $5 j$ \\
\hline & $\begin{array}{l}\text { GOME/SCIAMACHYI } \\
\text { GOME2 (GSG) Merged } \\
\text { Total Ozone }\end{array}$ & www.iup.uni-bremen.de/gome/wfdoas/ & $2 \mathrm{~g} 4$ \\
\hline & $\begin{array}{l}\text { GOME/SCIAMACHYI } \\
\text { GOME2 (GTO) Merged } \\
\text { Total Ozone }\end{array}$ & www.esa-ozone-cci.org & $2 g 4$ \\
\hline & GOZCARDS ozone profiles & https://gozcards.jpl.nasa.gov/info.php & $2 g 4$ \\
\hline & \multirow{4}{*}{ Aura OMI/MLS } & $\begin{array}{l}\text { "https://disc.sci.gsfc.nasa.gov/Aura/data-holdings } \\
\text { /MLS }\end{array}$ & \multirow{4}{*}{$5 \mathrm{j}, 6 \mathrm{~g}$} \\
\hline & & ftp://toms.gsfc.nasa.gov/pub/omi/data/ozone/ & \\
\hline & & $\begin{array}{l}\text { https://disc.gsfc.nasa.gov/datasets/OMTO3d_003 } \\
\text { /summary }\end{array}$ & \\
\hline & & $\begin{array}{l}\text { https://disc.gsfc.nasa.gov/datasets/OMUVBd_003 } \\
\text { /summary" }\end{array}$ & \\
\hline & $\begin{array}{l}\text { Multi Sensor Reanalysis } \\
\text { (MSR-2) of total ozone }\end{array}$ & www.temis.nl & $2 g 4$ \\
\hline & $\begin{array}{l}\text { NASA BUV/SBUV v8.6 } \\
\text { (MOD v8.6) Merged Ozone }\end{array}$ & http://acdb-ext.gsfc.nasa.gov/Data_services/merged & $2 g 4$ \\
\hline & $\begin{array}{l}\text { NOAA BUV/SBUV v8.6 } \\
\text { (MOD v8.6) Merged Ozone }\end{array}$ & ftp://ftp.cpc.ncep.noaa.gov/SBUV_CDR & $2 g 4$ \\
\hline & $\begin{array}{l}\text { Ozone Mapping \& Profiler } \\
\text { Suite (OMPS) }\end{array}$ & https://ozoneaq.gsfc.nasa.gov/omps/ & $6 g$ \\
\hline & Ozonesonde & www.esrl.noaa.gov/gmd/dv/spo_oz & $6 g$ \\
\hline & SAGE II/OSIRIS & dataset linked to Bourassa et al. (20I4) & $2 g 4$ \\
\hline & SWOOSH & www.esrl.noaa.gov/csd/groups/csd8/swoosh/ & $2 g 4$ \\
\hline & $\begin{array}{l}\text { WOUDC Ground-based } \\
\text { Ozone }\end{array}$ & $\begin{array}{l}\text { https://woudc.org/archive/Projects-Campaigns } \\
\text { /ZonalMeans/ }\end{array}$ & $2 g 4$ \\
\hline \multirow[t]{2}{*}{ Ozone, Tropospheric } & Aura OMI/MLS & $\begin{array}{l}\text { http://acd-ext.gsfc.nasa.gov/Data_services/cloud } \\
\text { _slice/new_data.html }\end{array}$ & $2 g 6$ \\
\hline & NOAA Observatory Data & ftp://aftp.cmdl.noaa.gov/data/ozwv/SurfaceOzone/ & $2 g 6$ \\
\hline \multirow{8}{*}{ Permafrost } & Active Layer Thickness & www2.gwu.edu/ calm/ & $2 \mathrm{cl}, 5 \mathrm{~h} 2$ \\
\hline & $\begin{array}{l}\text { Global Terrestrial Network } \\
\text { for Permafrost (GTN-P) }\end{array}$ & http://gtnpdatabase.org/ & $5 \mathrm{hl}$ \\
\hline & Permafrost Temperature & http://permafrost.gi.alaska.edu/sites_map & $5 \mathrm{hl}$ \\
\hline & $\begin{array}{l}\text { Permafrost Temperature at } \\
\text { French sites }\end{array}$ & permafrance.osug.fr & $2 \mathrm{cl}$ \\
\hline & \multirow{2}{*}{$\begin{array}{l}\text { Permafrost Temperature at } \\
\text { Norwegian sites }\end{array}$} & www.tspnorway.com & \multirow{2}{*}{$2 \mathrm{cl}$} \\
\hline & & www.met.no & \\
\hline & $\begin{array}{l}\text { Permafrost Temperature at } \\
\text { Swedish sites }\end{array}$ & https://bolin.su.se/ & $5 \mathrm{hl}$ \\
\hline & $\begin{array}{l}\text { Permafrost Temperature at } \\
\text { Swiss sites }\end{array}$ & www.permos.ch & $2 \mathrm{cl}$ \\
\hline
\end{tabular}




\begin{tabular}{|c|c|c|c|}
\hline $\begin{array}{l}\text { General Variable } \\
\text { or Phenomenon }\end{array}$ & $\begin{array}{l}\text { Specific dataset } \\
\text { or variable }\end{array}$ & 2018 Source & $\begin{array}{l}2018 \\
\text { Section }\end{array}$ \\
\hline \multirow[b]{2}{*}{ Phenology } & Budburst Quercus robur & www.usanpn.org/node/2274I & $2 \mathrm{~h} 3$ \\
\hline & NDVI & $\begin{array}{l}\text { https://modis.gsfc.nasa.gov/data/dataprod/modl3 } \\
\text {.php }\end{array}$ & $2 \mathrm{~h} 3$ \\
\hline \multirow{2}{*}{$\begin{array}{l}\text { Phytoplankton, } \\
\text { Ocean Color }\end{array}$} & MODIS-Aqua R20I8.0 & https://oceancolor.gsfc.nasa.gov/data/aqua/ & 3h, SB3.I \\
\hline & SeaWiFS R2018.0 & https://oceancolor.gsfc.nasa.gov/data/seawifs/ & $3 \mathrm{~h}$ \\
\hline \multirow{9}{*}{ Precipitation } & Climate Extremes Index & www.ncdc.noaa.gov/extremes/cei/ & $2 \mathrm{~d} 5$ \\
\hline & CMORPH & $\begin{array}{l}\text { www.cpc.ncep.noaa.gov/products/janowiak } \\
\text { /cmorph_description.html }\end{array}$ & $4 \mathrm{dl}, 4 \mathrm{~d} 2$ \\
\hline & ERA5 & $\begin{array}{l}\text { www.ecmwf.int/en/forecasts/datasets } \\
\text { /reanalysis-datasets/era5 }\end{array}$ & $2 \mathrm{~d} 5, \mathrm{SB} 2 . \mathrm{I}$ \\
\hline & ERA-Interim & $\begin{array}{l}\text { www.ecmwf.int/en/research/climate-reanalysis } \\
\text { /era-interim }\end{array}$ & $2 \mathrm{~d} 4$ \\
\hline & GHCN & $\begin{array}{l}\text { www.ncdc.noaa.gov/temp-and-precip/ghen } \\
\text {-gridded-products/precipitation }\end{array}$ & $2 \mathrm{~d} 4, \mathrm{SB} 2 . \mathrm{I}$ \\
\hline & GHCNDEX & www.climdex.org/view_download.html & $2 \mathrm{~d} 5$ \\
\hline & GPCP v2.3 & http://precip.gsfc.nasa.gov & $2 \mathrm{~d} 4,4 \mathrm{e}, 4 \mathrm{~h}$ \\
\hline & GPCC & www.dwd.de/EN/ourservices/gpcc/gpcc.html & $2 \mathrm{~d} 4, \mathrm{SB} 2 . \mathrm{I}$ \\
\hline & MERRA-2 & http://gmao.gsfc.nasa.gov/reanalysis/MERRA-2/ & $2 \mathrm{~d} 4, \mathrm{SB} 2 . \mathrm{I}$ \\
\hline \multirow{3}{*}{$\begin{array}{l}\text { Precipitation (net), } \\
\text { Freshwater Flux }\end{array}$} & $\begin{array}{l}\text { JRA-55 Atmospheric } \\
\text { Reanalysis }\end{array}$ & http://jra.kishou.go.jp/JRA-55/index_en.html & $6 c$ \\
\hline & \multirow{2}{*}{ GPCPv23, OAFlux } & http://precip.gsfc.nasa.gov & \multirow{2}{*}{$3 e 2,3 e 4$} \\
\hline & & http://oaflux.whoi.edu & \\
\hline \multirow{5}{*}{$\begin{array}{l}\text { Pressure, Sea Level } \\
\text { or Near-Surface }\end{array}$} & $\begin{array}{l}\text { Antarctic Meteorological } \\
\text { Research Center (AMRC) } \\
\text { AWS }\end{array}$ & http://amrc.ssec.wisc.edu/data & 6b, SB6.I \\
\hline & ERA-Interim & $\begin{array}{l}\text { www.ecmwf.int/en/research/climate-reanalysis } \\
\text { lera-interim }\end{array}$ & $6 b$ \\
\hline & HadSLP2r & www.metoffice.gov.uk/hadobs/hadslp2/ & $2 \mathrm{el}$ \\
\hline & $\begin{array}{l}\text { JRA-55 Atmospheric } \\
\text { Reanalysis }\end{array}$ & http://jra.kishou.go.jp/JRA-55/index_en.html & $6 c$ \\
\hline & NCEP/NCAR Reanalysis & $\begin{array}{l}\text { www.esrl.noaa.gov/psd/data/gridded/data.ncep } \\
\text {.reanalysis.html }\end{array}$ & $4 f 2$ \\
\hline \multirow[t]{2}{*}{ River Discharge } & $\begin{array}{l}\text { Arctic Great Rivers } \\
\text { Observatory }\end{array}$ & arcticgreatrivers.org & $5 \mathrm{~h}$ \\
\hline & ELSE & No public archive & $2 d 7$ \\
\hline Sea Ice Age & EASE-Grid v3 & http://nsidc.org/data/nsidc-06II/ & $5 \mathrm{~d} 2$ \\
\hline \multirow[t]{2}{*}{ Sea Ice Duration } & $\begin{array}{l}\text { Near-Real-Time DMSP } \\
\text { SSM/I-SSMIS Daily Polar } \\
\text { Gridded }\end{array}$ & http://nsidc.org/data/nsidc-008I.html & $6 e$ \\
\hline & $\begin{array}{l}\text { Nimbus-7 SMMR and DMSP } \\
\text { SSM/I (Bootstrap) }\end{array}$ & http://nsidc.org/data/nsidc-0079.html & $6 e$ \\
\hline Sea Ice Extent & $\begin{array}{l}\text { Nimbus-7 SMMR and DMSP } \\
\text { SSM/I (Bootstrap) }\end{array}$ & http://nsidc.org/data/seaice_index/ & $\begin{array}{l}5 c, 5 \mathrm{dl} \\
5 \mathrm{~d} 3, \text { SB5.I }\end{array}$ \\
\hline
\end{tabular}




\begin{tabular}{|c|c|c|c|}
\hline $\begin{array}{l}\text { General Variable } \\
\text { or Phenomenon }\end{array}$ & $\begin{array}{l}\text { Specific dataset } \\
\text { or variable }\end{array}$ & 2018 Source & $\begin{array}{l}2018 \\
\text { Section }\end{array}$ \\
\hline \multirow{3}{*}{$\begin{array}{l}\text { Sea Level / } \\
\text { Sea Surface Height }\end{array}$} & NOAA/NESDIS/STAR & $\begin{array}{l}\text { www.star.nesdis.noaa.gov/sod/lsa/SeaLevelRise } \\
\text { /LSA_SLR_timeseries.php }\end{array}$ & $3 f$ \\
\hline & $\begin{array}{l}\text { Ssalto/Duacs Multimission } \\
\text { Altimeter Products }\end{array}$ & $\begin{array}{l}\text { http://marine.copernicus.eu/services } \\
\text {-portfolio/access-to-products/?option=com } \\
\text { _csw\&view=details\&product_id=SEALEVEL } \\
\text { _GLO_PHY_L4_NRT_OBSERVATIONS_008_046 }\end{array}$ & $3 f$ \\
\hline & Tide Gauge & http://uhslc.soest.hawaii.edu/ & $3 f$ \\
\hline \multirow{5}{*}{ Sea Surface Current } & $\begin{array}{l}\text { Brazil-Malvina Region } \\
\text { Confluence Region }\end{array}$ & $\begin{array}{l}\text { www.aoml.noaa.gov/phod/altimetry/cvar/mal } \\
\text { /BM_anm.php }\end{array}$ & $3 g$ \\
\hline & $\begin{array}{l}\text { Long Term Time Series of } \\
\text { Surface Currents: Agulhas } \\
\text { Current }\end{array}$ & www.aoml.noaa.gov/phod/altimetry/cvar/agu/ & $3 g$ \\
\hline & $\begin{array}{l}\text { Long Term Time Series of } \\
\text { Surface Currents: North } \\
\text { Brazil Current }\end{array}$ & www.aoml.noaa.gov/phod/altimetry/cvar/nbc & $3 g$ \\
\hline & $\begin{array}{l}\text { Ocean Surface Current } \\
\text { Analysis - Real time } \\
\text { (OSCAR) }\end{array}$ & www.esr.org/research/oscar/data-access/ & $3 g$ \\
\hline & Yucatan Current & $\begin{array}{l}\text { www.aoml.noaa.gov/phod/altimetry/cvar/yuc } \\
\text { /transport.php }\end{array}$ & $3 g$ \\
\hline \multirow{6}{*}{$\begin{array}{l}\text { Sea Surface } \\
\text { Temperature }\end{array}$} & ERSSTV3b & $\begin{array}{l}\text { www.ncdc.noaa.gov/data-access/marineocean-data } \\
\text { lextended-reconstructed-sea-surface } \\
\text {-temperature-ersst-v4 }\end{array}$ & $4 f 4$ \\
\hline & ERSSTv5 & https://doi.org//0.7289/V5T72FNM & $3 b, 4 f 2$ \\
\hline & HadSST3 & www.metoffice.gov.uk/hadobs/hadsst3 & $2 \mathrm{bl}, 3 \mathrm{~b}$ \\
\hline & $\begin{array}{l}\text { NOAA Optimum } \\
\text { Interpolation SST (OISST) } \\
\text { v2 }\end{array}$ & $\begin{array}{l}\text { http://apdrc.soest.hawaii.edu/dods/public_data } \\
\text { /NOAA_SST/OISST/monthly }\end{array}$ & $4 d 2,4 f$ \\
\hline & $\begin{array}{l}\text { NOAA Optimum } \\
\text { Interpolation SST (OISST) } \\
\text { v2 }\end{array}$ & $\begin{array}{l}\text { www.ncei.noaa.gov/data/sea-surface-temperature } \\
\text {-optimum-interpolation/access/ }\end{array}$ & $\begin{array}{l}3 b, 4 b l \\
4 f 3,4 f 6, \\
4 h, 5 c, 6 e\end{array}$ \\
\hline & NCEP Ocean Reanalysis & www.cpc.ncep.noaa.gov/products/GODAS/ & $4 \mathrm{bl}$ \\
\hline \multirow[t]{2}{*}{ Snow Properties } & $\begin{array}{l}\text { NOAA Interactive Multi- } \\
\text { sensor Snow and Ice } \\
\text { Mapping System (Snow } \\
\text { Cover Duration) }\end{array}$ & www.natice.noaa.gov/ims/index.html & $5 g$ \\
\hline & $\begin{array}{l}\text { NOAA Snow Chart Data } \\
\text { Record (Snow Cover Extent) }\end{array}$ & www.snowcover.org & $2 c 2,5 g$ \\
\hline Soil Moisture & ESA CCI SM & www.esa-soilmoisture-cci.org/index.php & $2 d 9$ \\
\hline
\end{tabular}




\begin{tabular}{|c|c|c|c|}
\hline $\begin{array}{l}\text { General Variable } \\
\text { or Phenomenon }\end{array}$ & $\begin{array}{l}\text { Specific dataset } \\
\text { or variable }\end{array}$ & 2018 Source & $\begin{array}{l}2018 \\
\text { Section }\end{array}$ \\
\hline \multirow{14}{*}{$\begin{array}{l}\text { Temperature, [Near] } \\
\text { Surface }\end{array}$} & $\begin{array}{l}\text { Antarctic Meteorological } \\
\text { Research Center (AMRC) } \\
\text { AWS }\end{array}$ & http://amrc.ssec.wisc.edu/data & 6b, SB6.I \\
\hline & \multirow{2}{*}{ CRUTEM4 } & www.metoffice.gov.uk/hadobs/crutem4 & \multirow{2}{*}{$5 \mathrm{bl}$} \\
\hline & & https://crudata.uea.ac.uk/cru/data/temperature/ & \\
\hline & ERA5 & $\begin{array}{l}\text { www.ecmwf.int/en/forecasts/datasets } \\
\text { /reanalysis-datasets/era5 }\end{array}$ & $2 \mathrm{bl}$ \\
\hline & ERA-Interim & $\begin{array}{l}\text { www.ecmwf.int/en/forecasts/datasets } \\
\text { /archive-datasets/reanalysis-datasets/era-interim }\end{array}$ & $\begin{array}{l}2 b l, 6 b \\
\text { SB6.l }\end{array}$ \\
\hline & GHCNDEX & www.climdex.org/view_download.html & $2 b 3$ \\
\hline & GHCN v3 & $\begin{array}{l}\text { www.ncdc.noaa.gov/data-access/land-based } \\
\text {-station-data/land-based-datasets/global-historical } \\
\text {-climatology-network-monthly-version-3 }\end{array}$ & $2 b 2$ \\
\hline & $\begin{array}{l}\text { HadCRUT4 Global } \\
\text { Temperature }\end{array}$ & www.metoffice.gov.uk/hadobs/hadcrut4/ & $2 b l$ \\
\hline & JMA Global Temperature & $\begin{array}{l}\text { https://ds.data.jma.go.jp/tcc/tcc/products/gwp } \\
\text { /temp/map/download.html }\end{array}$ & $2 \mathrm{bl}$ \\
\hline & $\begin{array}{l}\text { JRA-55 Atmospheric } \\
\text { Reanalysis }\end{array}$ & http://jra.kishou.go.jp/JRA-55/index_en.html & $2 \mathrm{bl}$ \\
\hline & MERRA-2 & http://gmao.gsfc.nasa.gov/reanalysis/MERRA-2/ & $2 \mathrm{bl}$ \\
\hline & $\begin{array}{l}\text { NASA/GISS Global } \\
\text { Temperature }\end{array}$ & https://data.giss.nasa.gov/gistemp/ & $2 \mathrm{bl}$ \\
\hline & NCEP/NCAR Reanalysis & $\begin{array}{l}\text { www.esrl.noaa.gov/psd/data/gridded/data.ncep } \\
\text {.reanalysis.html }\end{array}$ & $5 b 2,5 f$ \\
\hline & $\begin{array}{l}\text { NOAA/NCEI } \\
\text { NOAAGlobalTemp }\end{array}$ & $\begin{array}{l}\text { www.ncdc.noaa.gov/data-access/marineocean-data } \\
\text { /noaa-global-surface-temperature-noaaglobaltemp }\end{array}$ & $2 \mathrm{bl}$ \\
\hline \multirow{9}{*}{$\begin{array}{l}\text { Temperature } \\
\text { Upper Atmosphere }\end{array}$} & ERA5 & $\begin{array}{l}\text { www.ecmwf.int/en/forecasts/datasets/reanalysis } \\
\text {-datasets/era5 }\end{array}$ & $2 b 4,2 b 5$ \\
\hline & ERA-Interim & $\begin{array}{l}\text { www.ecmwf.int/en/research/climate-reanalysis } \\
\text { lera-interim }\end{array}$ & $2 \mathrm{~b} 4,2 \mathrm{~b} 5$ \\
\hline & $\begin{array}{l}\text { JRA-55 Atmospheric } \\
\text { Reanalysis }\end{array}$ & http://jra.kishou.go.jp/JRA-55/index_en.html & $2 \mathrm{~b} 4,2 \mathrm{~b} 5$ \\
\hline & MERRA-2 & http://gmao.gsfc.nasa.gov/reanalysis/MERRA-2/ & $\begin{array}{l}2 b 4,2 b 5 \\
6 g\end{array}$ \\
\hline & RAOBCORE, RICH & www.univie.ac.at/theoret-met/research/raobcore & $2 \mathrm{~b} 4,2 \mathrm{~b} 5$ \\
\hline & RATPAC A2 & $\begin{array}{l}\text { www.ncdc.noaa.gov/data-access/weather-balloon } \\
\text { /radiosonde-atmospheric-temperature-products } \\
\text {-accessing-climate/ratpac-a }\end{array}$ & $2 \mathrm{~b} 4,2 \mathrm{~b} 5$ \\
\hline & RSS v4.0 & www.remss.com & $2 b 4,2 b 5$ \\
\hline & NOAA/NESDIS/STAR & www.star.nesdis.noaa.gov/smcd/emb/mscat/ & $2 b 5$ \\
\hline & UAH MSU v6.0 & http://vortex.nsstc.uah.edu/public/msu & $2 b 4,2 b 5$ \\
\hline \multirow{2}{*}{$\begin{array}{l}\text { TOA Earth } \\
\text { Radiation Budget }\end{array}$} & CERES EBAF Ed4.0 & $\begin{array}{l}\text { https://ceres-tool.larc.nasa.gov/ord-tool/jsp } \\
\text { /EBAF4Selection.jsp }\end{array}$ & $2 \mathrm{fl}$ \\
\hline & CERES FLASHFlux & $\begin{array}{l}\text { https://ceres-tool.larc.nasa.gov/ord-tool/jsp } \\
\text { /FLASH_TISASelection.jsp }\end{array}$ & $2 \mathrm{fl}$ \\
\hline
\end{tabular}




\begin{tabular}{|c|c|c|c|}
\hline $\begin{array}{l}\text { General Variable } \\
\text { or Phenomenon }\end{array}$ & $\begin{array}{c}\text { Specific dataset } \\
\text { or variable }\end{array}$ & 2018 Source & $\begin{array}{c}2018 \\
\text { Section } \\
\end{array}$ \\
\hline Total Solar Irradiance & SORCE/TIM & http://science.nasa.gov/missions/sorce/ & $2 \mathrm{fl}$ \\
\hline \multirow{12}{*}{ Trace Gases } & $\begin{array}{l}\text { Atmospheric Greenhouse } \\
\text { Gas Index (AGGI) }\end{array}$ & www.esrl.noaa.gov/gmd/aggi & $2 \mathrm{gl}$ \\
\hline & Carbon Dioxide $\left(\mathrm{CO}_{2}\right)$ & www.esrl.noaa.gov/gmd/dv/iadv & $2 g I$ \\
\hline & Carbon Dioxide $\left(\mathrm{CO}_{2}\right)$ & www.esrl.noaa.gov/gmd/ccgg/trends/data.html & $3 \mathrm{i} 4$ \\
\hline & Carbon Monoxide (CO) & https://atmosphere.copernicus.eu/ & $2 g 7$ \\
\hline & $\begin{array}{l}\text { Chlorine Monoxide }(\mathrm{ClO}) \text { - } \\
\text { Aura MLS }\end{array}$ & http://mls.jpl.nasa.gov/products/clo_product.php & $6 g$ \\
\hline & $\begin{array}{l}\text { Halocarbons (CFCs, HFCs, } \\
\text { HCFCs) }\end{array}$ & www.esrl.noaa.gov/gmd/hats/data.html & $2 g l, 2 g 2$ \\
\hline & $\begin{array}{l}\text { Hydrogen Chloride }(\mathrm{HCl}) \text { - } \\
\text { Aura MLS }\end{array}$ & $\begin{array}{l}\text { http://disc.sci.gsfc.nasa.gov/datacollection } \\
\text { /ML2HCL_V004.html }\end{array}$ & $2 g l, 6 g$ \\
\hline & Methane & www.esrl.noaa.gov/gmd/dv/iadv & $2 g I$ \\
\hline & Nitrous Oxide & www.esrl.noaa.gov/gmd/hats/combined/N2O.html & $2 g l$ \\
\hline & $\begin{array}{l}\text { Ozone-Depleting Gas Index } \\
\text { (ODGI) }\end{array}$ & www.esrl.noaa.gov/gmd/odgi & $2 g 2$ \\
\hline & Perfluorocarbons & http://agage.eas.gatech.edu & $2 \mathrm{gl}$ \\
\hline & Sulfur Hexafluoride & www.esrl.noaa.gov/gmd/hats/combined/SF6.html & $2 g l$ \\
\hline \multirow{5}{*}{$\begin{array}{l}\text { Tropical Cyclone } \\
\text { Data }\end{array}$} & HURDAT2 & www.aoml.noaa.gov/hrd/hurdat/Data_Storm.html & $4 \mathrm{f} 2$ \\
\hline & $\begin{array}{l}\text { International Best Track } \\
\text { Archive for Climate } \\
\text { Stewardship (IBTrACS) } \\
\end{array}$ & www.ncdc.noaa.gov/ibtracs/ & $\begin{array}{l}4 f, 4 f 3 \\
4 f 6,4 f 7\end{array}$ \\
\hline & $\begin{array}{l}\text { JTWC Best-track Dataset } \\
\text { (2011 preliminary) }\end{array}$ & $\begin{array}{l}\text { www.usno.navy.mil/NOOC/nmfc-ph/RSS/jtwc } \\
\text { /best_tracks }\end{array}$ & $4 \mathrm{f} 4,4 \mathrm{f5}$ \\
\hline & $\begin{array}{l}\text { RSMC-Tokyo, JMA best- } \\
\text { track data }\end{array}$ & $\begin{array}{l}\text { www.jma.go.jp/jma/jma-eng/jma-center/rsmc-hp } \\
\text {-pub-eg/besttrack.html }\end{array}$ & $4 \mathrm{ff}$ \\
\hline & $\begin{array}{l}\text { Southwest Pacific Enhanced } \\
\text { Archive of Tropical Cyclones } \\
\text { (SPEArTC) }\end{array}$ & http://apdrc.soest.hawaii.edu/projects/speartc & $4 f 8$ \\
\hline \multirow{5}{*}{ UV Radation Data } & Canadian sites & $\begin{array}{l}\text { ftp://exp-studies.tor.ec.gc.ca/pub/uvdata } \\
\text { /Preliminary/MSC }\end{array}$ & $5 j$ \\
\hline & Greenland site & http://uv.biospherical.com/Version2/data.asp & $5 j$ \\
\hline & \multirow{2}{*}{ Finnish sites } & http://litdb.fmi.fi/soundingst_uvradiation.php & \multirow{2}{*}{$5 j$} \\
\hline & & http://uv.fmi.fi/uvdb/ & \\
\hline & Norwegian sites & https://github.com/uvnrpa/Minute_Data & $5 j$ \\
\hline \multirow{3}{*}{$\begin{array}{l}\text { Water Vapor, } \\
\text { Stratosphere }\end{array}$} & $\begin{array}{l}\text { Frost Point Hygrometer } \\
\text { Data (Boulder, Hilo, Lauder) }\end{array}$ & www.esrl.noaa.gov/gmd/ozwv/wvap/index.html & $2 g 5$ \\
\hline & $\begin{array}{l}\text { Frost Point Hygrometer } \\
\text { Data (San Jose) }\end{array}$ & http://physics.valpo.edu/ozone/ticosonde.html & $2 g 5$ \\
\hline & $\begin{array}{l}\text { NASA Aura Microwave Limb } \\
\text { Sounder }\end{array}$ & https://mls.jpl.nasa.gov/products/h2o_product.php & $2 g 5$ \\
\hline
\end{tabular}




\begin{tabular}{|c|c|c|c|}
\hline $\begin{array}{l}\text { General Variable } \\
\text { or Phenomenon }\end{array}$ & $\begin{array}{l}\text { Specific dataset } \\
\text { or variable }\end{array}$ & 2018 Source & $\begin{array}{l}2018 \\
\text { Section }\end{array}$ \\
\hline \multirow{7}{*}{$\begin{array}{l}\text { Water Vapor, Total } \\
\text { Column }\end{array}$} & COSMIC GPS-RO & $\begin{array}{l}\text { http://cdaac-www.cosmic.ucar.edu/cdaac/products } \\
\text {.html }\end{array}$ & $2 \mathrm{~d} 2$ \\
\hline & ERA5 & $\begin{array}{l}\text { www.ecmwf.int/en/forecasts/datasets } \\
\text { /reanalysis-datasets/era5 }\end{array}$ & $2 \mathrm{~d} 2$ \\
\hline & ERA-Interim & $\begin{array}{l}\text { www.ecmwf.int/en/research/climate-reanalysis } \\
\text { lera-interim }\end{array}$ & $2 \mathrm{~d} 2$ \\
\hline & $\begin{array}{l}\text { GNSS Ground-Based Total } \\
\text { Column Water Vapor }\end{array}$ & https://rda.ucar.edu/datasets/ds72I.I/ & $2 \mathrm{~d} 2$ \\
\hline & $\begin{array}{l}\text { JRA-55 Atmospheric } \\
\text { Reanalysis }\end{array}$ & http://jra.kishou.go.jp/JRA-55/index_en.html & $2 \mathrm{~d} 2$ \\
\hline & MERRA-2 & http://gmao.gsfc.nasa.gov/reanalysis/MERRA-2/ & $2 \mathrm{~d} 2$ \\
\hline & $\begin{array}{l}\text { RSS SSM/I -AMSR-E Ocean } \\
\text { Total Column Water Vapor }\end{array}$ & www.remss.com & $2 \mathrm{~d} 2$ \\
\hline \multirow{7}{*}{ Wind, [Near] Surface } & Australian (McVicar) & http://doi.org//0.4225/08/56A8549IDDED2 & $2 \mathrm{e} 2$ \\
\hline & ERA5 & $\begin{array}{l}\text { www.ecmwf.int/en/forecasts/datasets } \\
\text { /reanalysis-datasets/era5 }\end{array}$ & $2 e 2$ \\
\hline & ERA-Interim & $\begin{array}{l}\text { www.ecmwf.int/en/research/climate-reanalysis } \\
\text { lera-interim }\end{array}$ & $2 e 2,6 b$ \\
\hline & HadISD3 & www.metoffice.gov.uk/hadobs/hadisd/ & $2 e 2$ \\
\hline & $\begin{array}{l}\text { JRA-55 Atmospheric } \\
\text { Reanalysis }\end{array}$ & http://jra.kishou.go.jp/JRA-55/index_en.html & $2 \mathrm{e} 2,4 \mathrm{~h}$ \\
\hline & MERRA-2 & http://gmao.gsfc.nasa.gov/reanalysis/MERRA-2/ & $2 \mathrm{e} 2$ \\
\hline & RSS SSM/I Ocean Winds & www.remss.com/measurements/wind & $2 \mathrm{e} 2$ \\
\hline \multirow{7}{*}{$\begin{array}{l}\text { Wind, Upper } \\
\text { Atmosphere }\end{array}$} & CERA-20C & $\begin{array}{l}\text { www.ecmwf.int/en/forecasts/datasets } \\
\text { /archive-datasets/reanalysis-datasets/cera-20c }\end{array}$ & $2 \mathrm{e} 3$ \\
\hline & $\begin{array}{l}\text { Climate Forecast System } \\
\text { Reanalysis }\end{array}$ & $\begin{array}{l}\text { www.ncdc.noaa.gov/data-access/model-data } \\
\text { /model-datasets/climate-forecast-system-version2 } \\
\text {-cfsv2 }\end{array}$ & $4 c, 4 f 3,4 f 6$ \\
\hline & ERA5 & $\begin{array}{l}\text { https://www.ecmwf.int/en/forecasts/datasets } \\
\text { /reanalysis-datasets/era5 }\end{array}$ & $2 \mathrm{e} 3$ \\
\hline & ERA-Interim & $\begin{array}{l}\text { www.ecmwf.int/en/research/climate-reanalysis } \\
\text { /era-interim }\end{array}$ & $2 \mathrm{e} 3$ \\
\hline & $\begin{array}{l}\text { JRA-55 Atmospheric } \\
\text { Reanalysis }\end{array}$ & http://jra.kishou.go.jp/JRA-55/index_en.html & $2 \mathrm{e} 3$ \\
\hline & MERRA-2 & http://gmao.gsfc.nasa.gov/reanalysis/MERRA-2/ & $2 \mathrm{e} 3$ \\
\hline & NCEP/NCAR Reanalysis & $\begin{array}{l}\text { www.esrl.noaa.gov/psd/data/gridded/data.ncep } \\
\text {.reanalysis.html }\end{array}$ & $4 \mathrm{~b} 2,4 \mathrm{f} 2$ \\
\hline
\end{tabular}


S262 | BAMF SEPTEMBER 2019 
In addition to the specific acknowledgments below readers are directed to Appendix 1: Relevant Datasets and Sources for information on specific data and products availability and relevant climate variables or phenomena.

The editors thank the AMS Journals editorial staff, in particular, Andrea Herbst, Gwendolyn Whittaker, and Erin Gumble, and the NCEI Graphics team for facilitating the construction of the report, and executing the countless number of technical edits needed. We welcome and thank our new technical editor, Andrea Andersen, who stepped into this challenging role with surprising ease and an eagle eye. We also express our gratitude to Dr. Rick Rosen, who again served as the AMS special editor for this report. Finally, we thank all of the authors and chapter editors who provide these valuable contributions each year, always with an aim to improve and expand their analyses for the readers.

\section{Chapter 2}

- The chapter editors thank Paul Berrisford and Julien Nicholas (ECMWF), Mike Bosilovich (NASA), and Shinya Kobayashi (JMA) for timely provision of reanalysis data used herein. We thank Philip Brohan, Mark McCarthy, David Parker, Roger Saunders, and Christoforos Tsamalis for their reviews and thoughts on this chapter.

- Robert Dunn, Colin Morice, and Kate Willett were supported by the Joint UK BEIS/Defra Met Office Hadley Centre Climate Programme (GA01101).

\section{2.b.2 (Lake Surface Temperatures):}

- The lake surface water temperatures used for this contribution have been derived within the Copernicus Climate Change Service (C3S) - Hydrology Programme using the algorithm developed within the UK Natural Environment Research Council (NERC) GloboLakes project.

\section{2.b.3 (Land Surface Temperature Extremes):}

- Robert Dunn was supported by the Met Office Hadley Centre Climate Programme funded by BEIS and Defra.

\section{2.b.4 (Temperature of the Troposphere):}

- Work performed by Stephen Po-Chedley at LLNL was performed under the auspices of the U.S. Department of Energy under Contract DE-AC5207NA27344 and LDRD 18-ERD-054.

\section{2.c.1 (Permafrost Thermal State):}

- The Swiss Network PERMOS is financially supported by MeteoSwiss in the framework of GCOS Switzerland, the Federal Office for the Environment, and the Swiss Academy of Sciences and acknowledges the important contribution of the partner institutions and principal investigators. The French Network PermaFRANCE is financially supported by OSUG (Observatoire des Sciences de l'Univers Grenoble) and the French Research Infrastructure OZCAR.

\section{2.c.2 (Northern Hemisphere Continental Snow Cover} Extent):

- This work is funded in part by NOAA's Climate Data Record (CDR) Program located in Asheville, $\mathrm{NC}$ at the National Centers for Environmental Information.

\section{2.d.1 (Surface Humidity):}

- Kate Willett was supported by the Met Office Hadley Centre Climate Programme funded by BEIS and Defra.

\section{2.d.7 (River Discharge and Runoff):}

- Hyungjun Kim was supported by the Japan Society for the Promotion of Science KAKENHI (16H06291 and 18KK0117) for this contribution.

\section{2.d.8 (Groundwater and Terrestrial Water Storage):}

- This research was supported by NASA's Terrestrial Hydrology Program and GRACE and GRACE Follow-On Science Team.

\section{2.d.9 (Soil Moisture):}

- The ESA CCI SM datasets and the authors were supported by ESA's Climate Change Initiative for Soil Moisture (Contract No. 4000104814/11/I-NB and 4000112226/14/I-NB). We would also like to thank support from the Copernicus Climate Change Service implemented by ECMWF.

2.d.10 (Monitoring Global Drought Using the SelfCalibrating Palmer Drought Severity Index):

- Jonathan Barichivich received funding from Chile FONDECYT grant No. 1181956. Tim Osborn received funding from UK NERC (NE/P006809/1). Ian Harris received funding from UK National Centre for Atmospheric Science (NCAS). 


\section{2.d.11 (Land Evaporation):}

- D.G.M. acknowledges support from the European Research Council (ERC) under grant agreement 715254 (DRY-2-DRY).

2.f.1 (Earth Radiation Budget at Top-of-Atmosphere):

- This research has been supported by the NASA CERES project. The NASA Langley Atmospheric Sciences Data Center processed the instantaneous Single Scanner Footprint (SSF) data used as input to EBAF Ed4.0 and processes the FLASHFlux TISA v3C.

2.g (Long-lived Greenhouse Gases):

- The CAMS reanalysis has been produced by the Copernicus Atmosphere Monitoring Services (CAMS), which is a program funded by the European Union. The European Centre for MediumRange Weather Forecast (ECMWF) operates CAMS on behalf of the European Commission. Melanie Ades, Olivier Boucher, Zak Kipling, and Samuel Rémy are funded by CAMS.

- Melanie Coldewey-Egbers, Daan Hubert, Diego Loyola, Victoria Sofieva, and Mark Weber are grateful to ESA's Climate Change Initiative Ozone project and to the EU Copernicus Climate Change Service 312a Lot4 Ozone project for supporting the generation and extension of the GTO-ECV total ozone and SAGE-CCI-OMPS data records. Stacey M. Frith is supported by the NASA LongTerm Measurement of Ozone program WBS 479717. Lucien Froidevaux's contribution, with the assistance of Ryan Fuller, was performed at the Jet Propulsion Laboratory, California Institute of Technology, under contract with NASA. Daan Hubert acknowledges the partial support by the EU/ERC Horizon 2020 project GAIA-CLIM.

- Dale Hurst would like to thank NASA's Upper Atmosphere Composition Observations program and NOAA's Climate Program Office for funding that helps sustain the frost point hygrometer soundings at Boulder, Lauder, and Hilo.

- We are grateful to Emillio Cuevas (AEMET) for providing monthly mean flask observations from Izana station for 2018.

\section{2.h.1 (Land Surface Albedo Dynamics):}

- The authors thank Monica Robustelli for her technical support.

\section{2.h.2 (Terrestrial Vegetation Dynamics):}

- The author thanks Monica Robustelli for her technical support.

\section{2.h.3 (Biomass Burning):}

- The GFASv1.4 dataset was provided the by GFASCLIM project, funded by the German Bundesministerium für Wirtschaft und Energie (BMWi/DLR FKZ 50EE1543), and the Copernicus Atmosphere Monitoring Service (CAMS_44).

2.h.4 (Phenology of Primary Producers):

- Debbie Hemming was supported by the Met Office Hadley Centre Climate Programme funded by BEIS and Defra, and thanks all co-authors for their interesting and helpful contributions, and Robert Dunn for his expertise finalizing the figures for this section. The work for MODIS land surface phenology was funded by NASA Earth Science Directorate (grants NNX16AO34H, NNX14AP80A, and NNX14AI71G). Support for the development and maintenance of PhenoCam network infrastructure has come from the National Science Foundation, through the Macrosystems Biology program, awards EF-1065029 and EF-1702697. Nature's Calendar thanks all of its volunteer recorders without whom it could not function. Stephen Thackeray thanks Heidrun Feuchtmayr for managing the Windermere database, and Mitzi De Ville, Ben James, Ellie Mackay, Mike Clarke, and Bev Dodd for collecting the data (current field team).

\section{Chapter 3}

- The editor thanks Greg Johnson for experience and advice, sidebar editor Gustavo Goni for identifying lead authors, and the report editors for their constructive comments and suggestions. All authors worked diligently to write their sections in the face of the 22 December 2018-25 January 2019 U.S. government shutdown that caused a monthlong furlough of many authors and an inability to access complete 2018 government-compiled datasets until well into 2019.

\section{Chapter 4}

- The editors would like to extend their thanks and appreciation to Andrew Magee from the University of Newcastle; Newcastle, NSW, Australia for his inputs. Carl Schreck was supported by NOAA through the Cooperative Institute for Climate and Satellites - North Carolina under Cooperative Agreement NA14NES432003. 


\section{Chapter 5}

- Matthew Druckenmuller was supported by the Study of Environmental Arctic Change (SEARCH, NSF grant PLR-1331100).

\section{f. (Terrestrial Permafrost)}

- Vladimir Romanovsky and co-authors of the Permafrost essay acknowledge the support of the State of Alaska, the National Science Foundation (grants PLR-0856864 and PLR-1304271 to the University of Alaska Fairbanks; PLR-1002119 and PLR-1304555 to the George Washington University), and by Natural Resources Canada. Support was also provided by the Russian Science Foundation (project RNF 16-17-00102) and by the government of the Russian Federation.

h. (River Discharge):

- Arctic Great Rivers Observatory (NSF 1602615).

- Russian Fund for Basic Research (18-05-60240 and 18-05-60192).

\section{j. (Ozone and UV Radiation):}

- G. Bernhard and coauthors acknowledge the support of Biospherical Instruments, San Diego; the Research Council of Norway through its Centers of Excellence funding scheme, project number 223268/F50; and the Academy of Finland for supporting UV measurements through the FARPOCC, SAARA, and DACES projects. We also thank the Microwave Limb Sounder team at NASA's Jet Propulsion Laboratory for data processing and analysis support; Tove Svendby from the Norwegian Institute for Air Research and Arne Dahlback from the University of Oslo for overseeing UV measurements at Oslo, Andøya, and Ny-Ålesund; and Juha M. Karhu, Tomi Karppinen, and Markku Ahponen from the Finnish Meteorological Institute for operating the Brewer UV spectroradiometer at Sodankylä.

\section{Chapter 6}

- The editors wish to acknowledge and thank the authors for their timely contributions, with additional special thanks to the internal and external reviewers and document editors for their thoughtful and constructive comments. The editors also wish to thank Dr. Sam Batzli of the Space Science and Engineering Center at the University of Wisconsin-Madison for his generation of the map in Figure 6.1.
- Ted Scambos was supported under NASA grant NNX16AN60G and NSF PLR 1565576, and thanks the National Snow and Ice Data Center. Sharon Stammerjohn was supported under NSF PLR 1440435; she also thanks the Institute of Arctic and Alpine Research and the National Snow and Ice Data Center, both at the University of Colorado Boulder, for institutional and data support.

- Kyle Clem would like to thank the Rutgers Institute of Earth, Ocean, and Atmospheric Sciences for postdoctoral support. Linda Keller and Matthew's contribution is based upon work supported by the National Science Foundation under Grant No. 1543305.

- David Bromwich and Sheng-Hung Wang were supported by NSF grant PLR 1823135.

- The work of Rob Massom, Phil Reid, Jan Lieser, and Steve Rintoul was supported by the Australian Government's Cooperative Research Centre program through the Antarctic Climate \& Ecosystems CRC, and contributes to AAS Project 4116. PR was also supported through the Bureau of Meteorology. JLL was supported under Australian Research Council's Special Research Initiative for Antarctic Gateway Partnership (Project ID SR140300001).

- Andrew Meijers was supported by the Natural Environment Research Council via award NE/ J008494/1. Jean-Baptiste Sallée was supported by the European Research Council (ERC) under the European Union's Horizon 2020 research and innovation program (Grant Agreement no 637770). Sebastiaan Swart was supported by a Wallenberg Academy Fellowship, (WAF 2015.0186). Mike Meredith received funding from the Natural Environment Research Council via award NE/N018095/1. SOCCOM is supported by the National Science Foundation under NSF Award PLR-1425989. ORCHESTRA is funded by the Natural Environment Research Council, and is a joint program of the British Antarctic Survey, National Oceanography Centre, Plymouth Marine Laboratory, British Geological Survey, Sea Mammal Research Unit, Centre for Polar Observation and Modelling, and the UK Met Office. The authors thank the teams of scientists from these centres that are contributing to the programs. 
- Irina Petropavlovskikh and Bryan Johnson would like to thank NOAA/ESRL Global monitoring division and the Cooperative Institute for Research in Environmental Sciences at the University of Colorado Boulder for institutional and data support. Work at the Jet Propulsion Laboratory, California Institute of Technology, was done under contract with the National Aeronautics and Space Administration (NASA).

- Christopher Shuman was supported by NASA's Cryospheric Sciences Program and thanks the University of Maryland, Baltimore County's Joint Center for Earth System Technology and the Cryospheric Sciences Laboratory at NASA Goddard Space Flight Center.

\section{Chapter 7}

- The editors wish to thank the numerous National Meteorological and Hydrological Services for collecting and providing data for this report. Special thanks to all the authors in this section for their timely contributions, and the thoughtful and constructive comments from internal and external reviewers, and the document editors. Data centers such as NCEP/NCAR, ECMWF-ERA, GPCC and CHIRPS are also acknowledged for making their data freely available. Specific grants and programs are acknowledged as follows:

- The authors I. Benedict, C. van Heerwaarden, A. Weerts, and W. Hazeleger have kindly sent a summary of their recent research as a contribution to Sidebar 7.3.
Africa

- S. Hagos is supported by NOAA's Oceanic and Atmospheric Research, Climate Program Office, under NOAA Grant No. NA17OAR4310263 and Z. Feng is supported by U.S. Department of Energy Office of Science Biological and Environmental Research as part of the Atmospheric Systems Research Program. Pacific Northwest National Laboratory is operated by Battelle for the U.S. Department of Energy under Contract DE-AC0576RLO1830.

- We acknowledge the meteorological and hydrological services of: Morocco, Algeria, Nigeria, The Gambia, South Africa and the southern Indian Ocean Island countries of Madagascar, Seychelles, Mayotte (France), La Réunion (France), Mauritius, and Rodrigues (Mauritius).

Europe

- Valuable climate information was provided by National Meteorological and Hydrological Service (NMHCs) of the WMO RA V1 Region.

Asia

- The following grants (China National Key R\&D Program 2017YFA0603802 and 2015CB453201, NSFC grant 41630423, NSF grant AGS-1643297 and NOAA grant NA18OAR4310298) are acknowledged. 


\section{ACRONYMS AND ABBREVIATIONS}

BASS:

BOM:

CCI:

CDAS: Centro Nacional de Monitoramento e

Alerta de Desastres Naturais (Brazil)

CERES:

CFSR:

CIIFEN:

CLIVAR:

CMAP:

CMEMS:

$\begin{array}{ll} & \text { Environment Monitoring Service } \\ \text { CPC: } & \text { Climate Prediction Center (NOAA) } \\ \text { CSIRO/ACE CRC/IMAS-UTAS: }\end{array}$

(Australia) Commonwealth

Scientific and Industrial Research

Organisation

Antarctic Climate \& Ecosystems

Cooperative Research Centre

Institute for Marine and Antarctic

Studies - University of Tasmania

DWD:

ECV:

ESA:

ESRL:

FLASHFlux:

GUIB:

GO-SHIP:

GODAS:

GPCP:

GRACE:

INMET:
Deutscher Wetterdienst

Essential Climate Variable

European Space Agency

Earth System Research Laboratory

(NOAA)

Fast Longwave And Shortwave

Radiative Fluxes

Geographisches Institut der

Universität Bern (Switzerland)

Global Ocean Ship-based

Hydrographic Investigations

Program

Global Ocean Data Assimilation

System

Global Precipitation Climatology

Project

Gravity Recovery and Climate

Experiment

Instituto Nacional de Meteorologia

(Brazil)
KNMI:

Royal Netherlands Meteorological Institute

MLO:

Mauna Loa Observatory (Hawaii,

US)

MRI/JMA: $\quad$ Meteorological Research Institute/ Japan Meteorological Agency

NASA:

National Aeronautics and Space

Administration (US)

NCAR: $\quad$ National Center for Atmospheric

Research (US)

NCEI: National Centers for Environmental Information (NOAA)

NCEP: $\quad$ National Centers for Environmental Prediction (NOAA)

NOAA: National Oceanic and Atmospheric Administration (US)

NSIDC: $\quad$ National Snow and Ice Data Center (US)

OLR: $\quad$ outgoing longwave radiation

PMEL/JPL/JIMAR: (US)

Pacific Marine Environmental

Laboratory/Jet Propulsion

Laboratory/

Joint Institute for Marine and

Atmospheric Research

RAPID-MOC/MOCHA/WBTS: (International,

UK-led)

RAPID Climate Change ProgrammeMeridional Overturning Circulation Meridional Overturning Circulation and Heatflux Array Western Boundary Time Series

RSW: $\quad$ reflected shortwave

SENAMHI-Bolivia:

Servicio Nacional de Meteorologia e

Hidrologia (La Paz)

SENAMHI-Peru: Servicio Nacional de Meteorologia e Hidrologia (Lima)

TOA: $\quad$ top of atmosphere

TRMM: $\quad$ Tropical Rainfall Measuring Mission TSI: $\quad$ total solar irradiance

WOA: World Ocean Atlas

WOCE: World Ocean Circulation

Experiment

Additional acronyms and abbreviations can be found at this AMS website: https://www.ametsoc.org/ams/index.cfm/publications/authors/journal-and-bams-authors/authorresources/list-of-acronyms-and-abbreviations/ 


\section{REFERENCES}

Aagaard, K., and E. C. Carmack, 1989: The role of sea ice and other fresh water in the Arctic circulation. J. Geophys. Res., 94, 14485-14498, https://doi.org/10.1029/ JC094iC10p14485.

Abatzoglou, J. T., 2013: Development of gridded surface meteorological data for ecological applications and modelling. Int. J Climatol., 33, 121-131, https://doi .org/10.1002/joc.3413.

— , and C. A. Kolden, 2013: Relationships between climate and macroscale area burned in the western United States. Int. J. Wildland Fire, 22, 1003-1020, https://doi.org/10.1071/WF13019.

— , and A. P. Williams, 2016: Impact of anthropogenic climate change on wildfire across western US forests. Proc. Natl. Acad. Sci. USA, 113,11770-11775, https://doi.org/10.1073 /pnas.1607171113.

—, R. Barbero, and N. J. Nauslar, 2013: Diagnosing Santa Ana winds in Southern California with synoptic-scale analysis. Wea. Forecasting, 28, 704-710, https://doi.org/10.1175/waf-d-13-00002.1.

Abraham, J. P., and Coauthors, 2013: A review of global ocean temperature observations: Implications for ocean heat content estimates and climate change. Rev. Geophys., 51, 450-483, https://doi.org/10.1002 /rog.20022.

Ackerman, D. E., D. Griffin, S. E. Hobbie, K. Popham, E. Jones, and J. C. Finlay, 2018: Uniform shrub growth response to June temperature across the North Slope of Alaska. Environ. Res. Lett., 13, 044013 , https://doi.org/10.1088/1748-9326/aab326.

Ackerman, S. A., R. E. Holz, R. Frey, E. W. Eloranta, B. C. Maddux, and M. McGill, 2008: Cloud detection with MODIS. Part II: Validation. J. Atmos. Oceanic Technol., 25, 1073-1086, https:/doi .org/10.1175/2007jtecha1053.1.

Adler, R. F., and Coauthors, 2003: The version-2 Global Precipitation Climatology Project (GPCP) monthly precipitation analysis (1979-present). J. Hydrometeor., 4, 1147-1167, https://doi.org/10.1175/1525-7541 (2003)004<1147:tvgpcp $>2.0$. co;2.

_ , and Coauthors, 2018: The Global Precipitation Climatology Project (GPCP) Monthly Analysis (New Version 2.3) and a Review of 2017 Global Precipitation. Atmosphere, 9, 138, https://doi.org/10.3390/ atmos9040138.

Aiyyer, A., and J. Molinari, 2008: MJO and tropical cyclogenesis in the Gulf of Mexico and eastern Pacific: Case study and idealized numerical modeling. J. Atmos. Sci., 65, 2691-2704, https://doi .org/10.1175/2007jas2348.1.
Allan, R., and C. K. Folland, 2017: Atmospheric circulation: 1. Mean sea level pressure and related modes of variability [in "State of the Climate in 2016"]. Bull. Amer. Meteor. Soc., 98, S35-S37, https://doi.org /10.1175/2017BAMSStateoftheClimate.1.

Allan, R. J., and R. D. D’Arrigo, 1999: 'Persistent' ENSO sequences: How unusual was the 19901995 El Niño? Holocene, 9, 101-118, https://doi .org/10.1191/095968399669125102.

— monthly historical gridded mean sea level pressure dataset (HadSLP2): 1850-2004. J. Climate, 19, 5816-5842, https://doi.org/10.1175/jcli3937.1.

—, J. A. Lindesay, and D. E. Parker, 1996: El Niño Southern Oscillation and Climatic Variability. CSIRO Publications, 405 pp.

Amador, J. A., 1998: A climatic feature of the tropical Americas: The trade wind easterly jet. Top. Meteor. Oceanogr., 5, 91-102, https://doi.org/10.1196/annals .1446 .012 .

- 2008: The intra-Americas sea low-level jet. Ann. NY Acad. Sci., 1146, 153-188, https://doi.org/10.1196 /annals.1446.012.

— E. E. Alfaro, H. G. Hidalgo, and B. Calderón, 2011: Central America [in "State of the Climate in 2010"]. Bull. Amer. Meteor. Soc., 92, S182-S183, https://doi .org/10.1175/1520-0477-92.6.s1.

AMAP, 2017: Snow, Water, Ice and Permafrost in the Arctic (SWIPA) 2017. Arctic Monitoring and Assessment Programme, 269 pp., https://www.amap .no/documents/doc/snow-water-ice-and-permafrostin-the-arctic-swipa-2017/1610.

Andela, N., and Coauthors, 2017: A human-driven decline in global burned area. Science, 356, 1356-1362, https://doi.org/10.1126/science.aal4108.

Anderson, M. C., and Coauthors, 2011: Mapping daily evapotranspiration at field to continental scales using geostationary and polar orbiting satellite imagery. Hydrol. Earth Syst. Sci., 15, 223-239, https://doi .org/10.5194/hess-15-223-2011.

Anderson, R. G., M. H. Lo, S. Swenson, J. S. Famiglietti, Q. Tang, T. H. Skaggs, Y. H. Lin, and R. J. Wu, 2015: Using satellite-based estimates of evapotranspiration and groundwater changes to determine anthropogenic water fluxes in land surface models. Geosci. Model Dev., 8, 3021-3031, https://doi.org/10.5194 /gmd-8-3021-2015.

Aragão, L. E. O. C., and Coauthors, 2018: 21st Century drought-related fires counteract the decline of Amazon deforestation carbon emissions. Nature Comm., 9, 536, https://doi.org/10.1038/s41467-017-02771-y. 
Arenson, L. U., and S. M. Springman, 2005: Mathematical descriptions for the behaviour of ice-rich frozen soils at temperatures close to $0{ }^{\circ} \mathrm{C}$. Can. Geotech. J., 42, 431-442, https://doi.org/10.1139/t04-109.

Armstrong, R., K. Knowles, M. J. Brodzik, and M. A. Hardman, 1994, updated 2016: DMSP SSM/I-SSMIS Pathfinder Daily EASE-Grid Brightness Temperatures. National Snow and Ice Data Center, https:// doi.org/10.5067/3EX2U1DV3434.

Arndt, D. S., J. L. Zdrojewski, and P-S. Chu, 2018: National Record 24-Hour Precipitation at Waipā Garden, Hawai'i. National Climate Extremes Committee Memo., 16 pp., https://www.ncdc.noaa.gov /monitoring-content/extremes/ncec/precip-24hr -kauai-2018.pdf.

Arosio, C., A. Rozanov, E. Malinina, M. Weber, and J. P. Burrows, 2018: Merging of ozone profiles from SCIAMACHY, OMPS and SAGE II observations to study stratospheric ozone changes. Atmos. Meas. Tech. Discuss., 2018, 1-24, https://doi.org/10.5194/ amt-2018-275.

Arrigo, K. R., G. L. van Dijken, and S. Bushinsky, 2008: Primary production in the Southern Ocean, 1997-2006. J. Geophys. Res., 113, C08004, https:// doi.org/10.1029/2007JC004551.

Azorin-Molina, C., R. J. H. Dunn, C. A. Mears, P. Berrisford, and T. R. McVicar, 2017: Surface winds [in "State of the Climate in 2016"]. Bull. Amer. Meteor. Soc., 98, S37-S39, https://doi.org/10.1175 /2017BAMSStateoftheClimate.1.

$-, \ldots, \ldots, \ldots$, and,$- 2018 \mathrm{a}$ : Surface winds [in "State of the Climate in 2017"]. Bull. Amer. Meteor. Soc., 99, S41-S43, https://doi.org/10.1175 /2018BAMSStateoftheClimate.1.

—, S. Rehman, J. A. Guijarro, T. R. McVicar, L. Minola, D. Chen, and S. M. Vicente-Serrano, 2018b: Recent trends in wind speed across Saudi Arabia, 1978-2013: A break in the stilling. Int. J. Climatol., 38, e966-e984, https://doi.org/10.1002/joc.5423.

—, J. Asin, T. R. McVicar, L. Minola, J. I. LopezMoreno, S. M. Vicente-Serrano, and D. Chen, 2018c: Evaluating anemometer drift: A statistical approach to correct biases in wind speed measurement. Atmos. Res., 203, 175-188, https://doi.org/10.1016 /j.atmosres.2017.12.010.

Bakker, D. C. E., and Coauthors, 2016: A multi-decade record of high-quality $f \mathrm{CO}_{2}$ data in version 3 of the Surface Ocean $\mathrm{CO}_{2}$ Atlas (SOCAT). Earth Syst. Sci. Data, 8, 383-413, https://doi.org/10.5194/essd-8383-2016.
Ball, W. T., and Coauthors, 2018: Evidence for a continuous decline in lower stratospheric ozone offsetting ozone layer recovery. Atmos. Chem. Phys., 18, 1379-1394, https://doi.org/10.5194/acp-18-1379-2018.

Bândă, N., M. Krol, M. van Weele, T. van Noije, and T. Röckmann, 2013: Analysis of global methane changes after the 1991 Pinatubo volcanic eruption. Atmos. Chem. Phys., 13 (4), 2267-2281, doi:10.5194 /acp-13-2267-2013.

Banzon, V. F., and R. W. Reynolds, 2013: Use of WindSat to extend a microwave-based daily optimum interpolation sea surface temperature time series. J. Climate, 26, 2557-2562, https://doi.org/10.1175/ jcli-d-12-00628.1.

Barbero, R., J. T. Abatzoglou, N. K. Larkin, C. A. Kolden, and B. Stocks, 2015: Climate change presents increased potential for very large fires in the contiguous United States. Int. J. Wildland Fire, 24, 892-899, https://doi.org/10.1071/WF15083.

Barnston, A.G. and R.E. Livezey, 1987: Classification, Seasonality and Persistence of Low-Frequency Atmospheric Circulation Patterns. Mon. Wea. Rev., 115, 1083-1126, https://doi.org/10.1175/15200493(1987)115<1083:CSAPOL >2.0.CO;2

Barton, B. I., Y.-D. Lenn, and C. Lique, 2018: Observed Atlantification of the Barents Sea Causes the Polar Front to Limit the Expansion of Winter Sea Ice. J. Phys. Oceanogr., 48, 1849-1866, https://doi. org/10.1175/jpo-d-18-0003.1.

Bauer-Marschallinger, B., W. A. Dorigo, W. Wagner, and A. I. J. M. van Dijk, 2013: How oceanic oscillation drives soil moisture variations over mainland Australia: An analysis of 32 years of satellite observations. J. Climate, 26, 10,159-110,173, https://doi. org/10.1175/jcli-d-13-00149.1.

Baxter, S., S. Weaver, J. Gottschalck, and Y. Xue, 2014: Pentad evolution of wintertime impacts of the Madden-Julian oscillation over the contiguous United States. J. Climate, 27, 7356-7367, https://doi .org/10.1175/jcli-d-14-00105.1.

—, C. J. Schreck, and G. D. Bell, 2017: Tropical intraseasonal activity [in "State of the Climate in 2016"]. Bull. Amer. Meteor. Soc., 98, S98-S101, https://doi.or g/10.1175/2017BAMSStateoftheClimate.1.

— - _ and —-, 2018: Tropical intraseasonal activity [in "State of the Climate in 2017"]. Bull. Amer. Meteor. Soc., 99, S104-S107, https://doi.org/10.1175 /2018BAMSStateoftheClimate.1.

Becher, M., J. Olofsson, L. Berglund, and J. Klaminder, 2018: Decreased cryogenic disturbance: one of the mechanisms behind the vegetation change in the Arctic. Polar Biol., 41, 101-110, https://doi .org/10.1007/s00300-017-2173-5. 
Becker, A., P. Finger, A. Meyer-Christoffer, B. Rudolf, K. Schamm, U. Schneider, and M. Ziese, 2013: A description of the global land-surface precipitation data products of the Global Precipitation Climatology Centre with sample applications including centennial (trend) analysis from 1901-present. Earth Syst. Sci. Data, 5, 71-99, https://doi.org/10.5194/ essd-5-71-2013.

Behrenfeld, M. J., and Coauthors, 2006: Climate-driven trends in contemporary ocean productivity. Nature, 444, 752-755, https://doi.org/10.1038/nature05317.

— , K. H. Halsey, and A. J. Milligan, 2008: Evolved physiological responses of phytoplankton to their integrated growth environment. Philos. Trans. Roy. Soc. London, B363, 2687-2703, https://doi.org /doi:10.1098/rstb.2008.0019.

— , and Coauthors, 2016: Revaluating ocean warming impacts on global phytoplankton. Nat. Climate Change, 6, 323-330, https://doi.org/10.1038 /nclimate2838.

Behringer, D. W., M. Ji, and A. Leetmaa, 1998: An improved coupled model for ENSO prediction and implications for ocean initialization. Part I: The ocean data assimilation system. Mon. Wea. Rev., 126, 1013-1021, https://doi.org/10.1175/15200493(1998)126<1013:aicmfe>2.0.co;2.

Bell, G. D., and M. Chelliah, 2006: Leading tropical modes associated with interannual and multidecadal fluctuations in North Atlantic hurricane activity. J. Climate, 19, 590-612, https://doi.org/10.1175/ jcli3659.1.

_- and Coauthors, 2000: The 1999 North Atlantic and eastern North Pacific hurricane season [in "Climate Assessment for 1999"]. Bull. Amer. Meteor. Soc., 81, S19-S22, https://doi.org/10.1175 /1520-0477(2000)081<1328:caf>2.3.co;2.

—, S. Goldenberg, C. Landsea, E. Blake, R. Pasch, M. Chelliah, and K. Mo, 2004: Tropical storms: Atlantic hurricane season [in "State of the Climate in 2003”]. Bull. Amer. Meteor. Soc., 85, S20-S24.

_ , E. Blake, K. C. Mo, C. W. Landsea, R. Pasch, M. Chelliah, and S. B. Goldenberg, 2006: Tropical cyclones: Atlantic basin [in "State of the Climate in 2005”]. Bull. Amer. Meteor. Soc., 87, S33-S37.

— - — C. W. Landsea, C. Wang, J. Schemm, T. B. Kimberlain, R. J. Pasch, and S. B. Goldenberg, 2017: Tropical cyclones: Atlantic basin [in "State of the Climate in 2016"]. Bull. Amer. Meteor. Soc., 98, S108-S112, https://doi.org/10.1175 /2017BAMSStateoftheClimate.1.
,,,--- S. B. Goldenberg, and R. J. Pasch, 2018: Tropical cyclones: Atlantic Basin [in "State of the Climate in 2017"]. Bull. Amer. Meteor. Soc., 99, S114-S118, https://doi.org/10.1175 /2018BAMSStateoftheClimate.1.

Bellouin, N., J. Quaas, J. J. Morcrette, and O. Boucher, 2013: Estimates of aerosol radiative forcing from the MACC re-analysis. Atmos. Chem. Phys., 13, 20452062, https://doi.org/10.5194/acp-13-2045-2013.

Bernhard, G., and Coauthors, 2015: Comparison of OMI UV observations with ground-based measurements at high northern latitudes. Atmos. Chem. Phys., 15, 7391-7412, https://doi.org/10.5194/acp-15-7391-2015.

Berry, D. I., and E. C. Kent, 2009: A new air-sea interaction gridded dataset from ICOADS with uncertainty estimates. Bull. Amer. Meteor. Soc., 90, 645-656, https://doi.org/10.1175/2008bams2639.1.

—, and —, 2011: Air-sea fluxes from ICOADS: The construction of a new gridded dataset with uncertainty estimates. Int. J. Climatol., 31, 987-1001, https://doi.org/10.1002/joc.2059.

Bhartia, P. K., and C. W. Wellemeyer, 2002: TOMS-V8 total $\mathrm{O}_{3}$ algorithm. OMI Algorithm Theoretical Basis Document Vol II, 15-31 pp.

Bhatt, U., and Coauthors, 2013: Recent declines in warming and vegetation greening trends over panArctic tundra. Remote Sens., 5, 4229, https:/doi. org/10.3390/rs5094229.

Bichet, A., M. Wild, D. Folini, and C. Schär, 2012: Causes for decadal variations of wind speed over land: Sensitivity studies with a global climate model. Geophys. Res. Lett., 39, L11701, https://doi. org/10.1029/2012GL051685.

Biskaborn, B. K., and Coauthors, 2019: Permafrost is warming at a global scale. Nat. Comm., 10, 264, https://doi.org/10.1038/s41467-018-08240-4.

Bjerknes, J., 1969: Atmospheric teleconnections from the equatorial Pacific. Mon. Wea. Rev., 97, 163-172, https://doi.org/10.1175/1520-0493(1969)097<0163:at ftep $>2.3 . c 0 ; 2$.

Bjorkman, A. D., and Coauthors, 2018: Plant functional trait change across a warming tundra biome. Nature, 562, 57-62, https://doi.org/10.1038/s41586-0180563-7.

Blais-Stevens, A., M. Kremer, P. P. Bonnaventure, S. L. Smith, P. Lipovsky, and A. G. Lewkowicz, 2015: Active layer detachment slides and retrogressive thaw slumps susceptibility mapping for current and future permafrost distribution, Yukon Alaska Highway corridor. Engineering Geology for Society and Territory - Volume 1, Springer, 449-453. 
Blake, E., E. J. Gibney, D. P. Brown, M. Mainelli, J. L. Franklin, and T. B. Kimberlain, 2009: Tropical cyclones of the eastern North Pacific basin, 1949-2006. Historical Climatology Series 6-5, 162 pp.

Bock, O., and A. C. Parracho, 2019: Consistency and representativeness of integrated water vapour from ground-based GPS observations and ERA-Interim reanalysis. Atmos. Chem. Phys. Discuss., 2019, 1-26, https://doi.org/10.5194/acp-2019-28.

Boden, T. A., R. J. Andres, and G. Marland, 2017: Global, Regional, and National Fossil-Fuel $\mathrm{CO}_{2}$ Emissions. Carbon Dioxide Information Analysis Center, Oak Ridge National Laboratory, https://doi.org/10.3334/ CDIAC/00001_V2017.

Boening, C., J. K. Willis, F. W. Landerer, R. S. Nerem, and J. Fasullo, 2012: The 2011 La Niña: So strong, the oceans fell. Geophys. Res. Lett., 39, L19602, https:// doi.org/10.1029/2012GL053055.

Boike, J., and Coauthors, 2018: A 20-year record (19982017) of permafrost, active layer and meteorological conditions at a high Arctic permafrost research site (Bayelva, Spitsbergen). Earth Syst. Sci. Data, 10, 355-390, https://doi.org/10.5194/essd-10-355-2018.

Bomshoms, M., N. Quispe, and K. Quispe, 2018: Estudio de la frecuencia de nevadas en Perú (in Spanish). SENA-46, 54 pp., https://www.senamhi.gob.pe/load/ file/01401SENA-46.pdf.

Bond, N. A., M. F. Cronin, H. Freeland, and N. Mantua, 2015: Causes and impacts of the 2014 warm anomaly in the NE Pacific. Geophys. Res. Lett., 42, 3414-3420, https://doi.org/10.1002/2015GL063306.

Bonjean, F., and G. S. E. Lagerloef, 2002: Diagnostic model and analysis of the surface currents in the tropical Pacific Ocean. J. Phys. Oceanogr., 32, 2938-2954, https://doi.org/10.1175/15200485(2002)032<2938:dmaaot>2.0.co;2.

Bony, S., and J.-L. Dufresne, 2005: Marine boundary layer clouds at the heart of tropical cloud feedback uncertainties in climate models. Geophys. Res. Lett., 32, L20806, https://doi.org/10.1029/2005GL023851.

Borstad, C. P., E. Rignot, J. Mouginot, and M. P. Schodlok, 2013: Creep deformation and buttressing capacity of damaged ice shelves: theory and application to Larsen C ice shelf. Cryosphere, 7, 1931-1947, https:// doi.org/10.5194/tc-7-1931-2013.

Bosilovich, M. G., and Coauthors, 2015: MERRA-2: Initial evaluation of the climate. NASA/TM-2015104606, Vol. 43, 136 pp., https:/gmao.gsfc.nasa.gov/ reanalysis/MERRA-2/docs/.

Boucher, O., and Coauthors, 2013: Clouds and aerosols. Climate Change 2013: The Physical Science Basis, T. F. Stocker et al., Eds., Cambridge University Press, 571-658.
Bourassa, M. A., and Coauthors, 2013: High-latitude ocean and sea ice surface fluxes: Challenges for climate research. Bull. Amer. Meteor. Soc., 94, 403-423, https://doi.org/10.1175/bams-d-11-00244.1.

Bowers, C. L., 2018: The Diablo Winds of northern California: Climatology and numerical simulations. M.S. thesis, Dept. of Meteorology and Climate Science, San Jose State University, 55 pp., https://scholarworks.sjsu.edu/etd_theses/4962.

Bowman, D. M. J. S., and Coauthors, 2009: Fire in the Earth system. Science, 324, 481-484, https://doi.org /10.1126/science.1163886.

Box, J. E., and K. Hansen, 2015: Survey of Greenland glacier area changes. PROMICE Newsletter, 8, 1-2.

_ D. van As, K. Steffen, and The PROMICE Project Team, 2017: Greenland, Canadian and Icelandic land-ice albedo grids (2000-2016). Geol. Surv. Den. Greenl. Bull., 38, 53-56.

Boyer, T., and Coauthors, 2013: World Ocean Database 2013. NOAA Atlas NESDIS 72, 209 pp., https://www. nodc.noaa.gov/OC5/WOD13/.

Bracegirdle, T. J., and G. J. Marshall, 2012: The reliability of Antarctic tropospheric pressure and temperature in the latest global reanalyses. J. Climate, 25, 7138-7146, https://doi.org/10.1175/jcli-d-11-00685.1.

Brasnett, B., 1999: A global analysis of snow depth for numerical weather prediction. J. Appl. Meteor., 38, 726-740, https://doi.org/10.1175/15200450(1999)038<0726:agaosd >2.0.co;2.

Broeker, W. S., 1991: The great ocean conveyor. Oceanography, 4, 79-89, https://doi.org/10.5670/ oceanog.1991.07.

Bromwich, D. H., A. J. Monaghan, and Z. Guo, 2004: Modeling the ENSO modulation of Antarctic climate in the late 1990s with the polar MM5. J. Climate, 17, 109-132, https://doi.org/10.1175 /1520-0442(2004)017<0109:mtemoa>2.0.co;2.

— , J. P. Nicolas, and A. J. Monaghan, 2011: An assessment of precipitation changes over Antarctica and the Southern Ocean since 1989 in contemporary global reanalyses. J. Climate, 24, 4189-4209, https:// doi.org/10.1175/2011jcli4074.1.

Brown, R. D., B. Brasnett, and D. Robinson, 2003: Gridded North American monthly snow depth and snow water equivalent for GCM evaluation. Atmos.-Ocean, 41, 1-14, https://doi.org/10.3137/ao.410101.

Brun, E., V. Vionnet, A. Boone, B. Decharme, Y. Peings, R. Valette, F. Karbou, and S. Morin, 2013: Simulation of Northern Eurasian local snow depth, mass, and density using a detailed snowpack model and meteorological reanalyses. J. Hydrometeor., 14, 203-219, https://doi.org/10.1175/jhm-d-12-012.1. 
Brutsaert, W., 2017: Global land surface evaporation trend during the past half century: Corroboration by Clausius-Clapeyron scaling. Adv. Water Res., 106, 3-5, https://doi.org/10.1016/j.advwatres.2016.08.014.

Budge, J. S., and D. G. Long, 2018: A Comprehensive Database for Antarctic Iceberg Tracking Using Scatterometer Data. IEEE Journal of Selected Topics in Applied Earth Observations and Remote Sensing, 11, 434-442, https://doi.org/10.1109/ JSTARS.2017.2784186.

Bureau of Meteorology and CSIRO, 2018: State of the Climate 2018. 23 pp., http://www.bom.gov.au/stateof-the-climate/State-of-the-Climate-2018.pdf

Butchart, N., and E. E. Remsberg, 1986: The area of the stratospheric polar vortex as a diagnostic for tracer transport on an isentropic surface. J. Atmos. Sci., 43, 1319-1339, https://doi.org/10.1175/15200469(1986)043<1319:taotsp>2.0.co;2.

C3S (Copernicus Climate Change Service), 2017: ERA5: Fifth generation of ECMWF atmospheric reanalyses of the global climate. Copernicus Climate Change Service Climate Data Store (CDS), https://www. ecmwf.int/en/forecasts/datasets/reanalysis-datasets/ era5.

Caesar, L., S. Rahmstorf, A. Robinson, G. Feulner, and V. Saba, 2018: Observed fingerprint of a weakening Atlantic Ocean overturning circulation. Nature, 556, 191-196, https://doi.org/10.1038/s41586-018-0006-5.

CAL FIRE, 2019a: California wildfires and acres for all jurisdictions. California Department of Forestry and Fire Protection, accessed 3 March 2019, http:// cdfdata.fire.ca.gov/incidents/incidents_statsevents.

_ 2019b: Camp Fire incident information. California Department of Forestry and Fire Protection, accessed 3 March 2019, http://cdfdata.fire.ca.gov/incidents/ incidents_details_info?incident_id=2277.

_ 2019c: Carr Fire incident information. California Department of Forestry and Fire Protection, accesed 3 March 2019, http://cdfdata.fire.ca.gov/incidents/ incidents_details_info?incident_id=2277.

_ _ 2019d: Emergency fund and fire suppression expenditures. California Department of Forestry and Fire Protection, accessed 3 March 2019, http:// cdfdata.fire.ca.gov/incidents/incidents_details_ info?incident_id=2277.

— $2019 \mathrm{e}$ : Mendocino Complex fire incident information. California Department of Forestry and Fire Protection, accessed 4 March 209, http://cdfdata.fire. ca.gov/incidents/incidents_details_info?incident_ $\mathrm{id}=2175$.
— , 2019f: Top 20 largest California wildfires. California Department of Forestry and Fire Protection, accessed 3 March 2019, http://www.fire.ca.gov/communications/downloads/fact_sheets/Top20_Acres.pdf. _ 2019g: Top 20 deadliest California wildfires. California Department of Forestry and Fire Protection, accessed 3 March 2019, http://calfire.ca.gov/communications/downloads/fact_sheets/Top20_Deadliest. pdf.

— , 2019h: Top 20 most destructive California wildfires. California Department of Forestry and Fire Protection, accessed 3 March 2019, http://www.fire. ca.gov/communications/downloads/fact_sheets/ Top20_Destruction.pdf.

—, 2019i: Woolsey Fire incident information. California Department of Forestry and Fire Protection, accessed 3 March 2019, http://cdfdata.fire.ca.gov/ incidents/incidents_details_info?incident_id=2282.

Calafat, F. M., T. Wahl, F. Lindsten, J. Williams, and E. Frajka-Williams, 2018: Coherent modulation of the sea-level annual cycle in the United States by Atlantic Rossby waves. Nat. Commun., 9, 2571, https://doi. org/10.1038/s41467-018-04898-y.

Camargo, S. J., K. A. Emanuel, and A. H. Sobel, 2007: Use of a genesis potential index to diagnose ENSO effects on tropical cyclone genesis. J. Climate, 20, 4819-4834, https://doi.org/10.1175/jcli4282.1.

—, M. C. Wheeler, and A. H. Sobel, 2009: Diagnosis of the MJO modulation of tropical cyclogenesis using an empirical index. J. Atmos. Sci., 66, 3061-3074, https://doi.org/10.1175/2009jas3101.1.

Capotondi, A., and Coauthors, 2015: Understanding ENSO diversity. Bull. Amer. Meteor. Soc., 96, 921-938, https://doi.org/10.1175/bams-d-13-00117.1. Carpenter, E. J., and J. L. Cox, 1974: Production of pelagic Sargassum and a blue-green epiphyte in the western Sargasso Sea. Limnol. Oceanogr., 19, 429-436, https://doi.org/10.4319/lo.1974.19.3.0429.

Carpenter, L. J., and Coauthors, 2019: Scenarios and information for policy makers. Scientific Assessment of Ozone Depletion: 2018, World Meteorological Organization, 6.1-6.69.

Carrea, L., O. Embury, and C. J. Merchant, 2015: Datasets related to in-land water for limnology and remote sensing applications: Distance-to-land, distanceto-water, water-body identifier and lake-centre co-ordinates. Geosci. Data J., 2, 83-97, https://doi. org/10.1002/gdj3.32. 
Carrington, D., and S. Marsh, 2018: Deaths rose 650 above average during UK heatwave - with older people most at risk. The Guardian, https://www .theguardian.com/society/2018/aug/03/deaths -rose-650-above-average-during-uk-heatwave-with -older-people-most-at-risk.

Carter, B. R., and Coauthors, 2017: Two decades of Pacific anthropogenic carbon storage and ocean acidification along Global Ocean Ship-based Hydrographic Investigations Program sections P16 and P02. Global Biogeochem. Cycles, 31, 306-327, https:// doi.org/10.1002/2016GB005485.

Cassou, C., 2008: Intraseasonal interaction between the Madden-Julian oscillation and the North Atlantic oscillation. Nature, 455, 523-527, https://doi. org/10.1038/nature07286.

Castro de la Guardia, L., X. Hu, and P. G. Myers, 2015: Potential positive feedback between Greenland Ice Sheet melt and Baffin Bay heat content on the West Greenland Shelf. Geophys. Res. Lett., 42, 4922-4930, https://doi.org/10.1002/2015GL064626.

Cavalieri, D. J., C. L. Parkinson, P. Gloersen, and H. Zwally, 1996, updated yearly: Sea Ice Concentrations from Nimbus-7 SMMR and DMSP SSM/I-SSMIS Passive Microwave Data (1981-2011). National Snow and Ice Data Center, https://doi. org/10.5067/8GQ8LZQVL0VL.

Cerovečki, I., A. J. S. Meijers, M. R. Mazloff, S. T. Gille, V. M. Tamsitt, and P. R. Holland, 2019: The effects of enhanced sea ice export from the Ross Sea on recent cooling and freshening of the Southeast Pacific. J. Climate, 32, 2013-2035, https://doi.org/10.1175/ JCLI-D-18-0205.1.

Chen, M., and P. Xie, 2008: CPC unified gauge-based analysis of global daily precipitation. Western $\mathrm{Pa}$ cific Geophysics Meeting, Cairns, Australia, Amer. Geophys. Union, Abstract A24A-05, ftp://ftp.cpc .ncep.noaa.gov/precip/CPC_UNI_PRCP/GAUGE _CONUS/DOCU/Chen_et_al_2008_Daily_Gauge _Anal.pdf.

Cheng, L., and L. Zhu, 2018: 2017 was the warmest year on record for the global ocean. Adv. Atmos. Sci., 35, 261-263, https://doi.org/10.1007/s00376-018-8011-z.

Cheng, L., and Coauthors, 2017: Recent increases in terrestrial carbon uptake at little cost to the water cycle. Nat. Comm., 8, 110, https://doi.org/10.1038/ s41467-017-00114-5.

Chia, H. H., and C. F. Ropelewski, 2002: The interannual variability in the genesis location of tropical cyclones in the northwest Pacific. J. Climate, 15, 2934-2944, https://doi.org/10.1175/1520-0442(2002)015<2934:ti vitg $>2.0 . c 0 ; 2$.
Chiang, J. C. H., and D. J. Vimont, 2004: Analogous Pacific and Atlantic meridional modes of tropical atmosphere-ocean variability. J. Climate, 17, 4143-4158, https://doi.org/10.1175/jcli4953.1.

Chipperfield, M. P., and Coauthors, 2018: On the cause of recent variations in lower stratospheric ozone. Geophys. Res. Lett., 45, 5718-5726, https://doi. org/10.1029/2018GL078071.

Christiansen, C. T., M. J. Lafreniére, G. H. R. Henry, and P. Grogan, 2018: Long-term deepened snow promotes tundra evergreen shrub growth and summertime ecosystem net $\mathrm{CO}_{2}$ gain but reduces soil carbon and nutrient pools. Global Change Biol., 24, 3508-3525, https://doi.org/10.1111/gcb.14084.

Christiansen, H. H., and Coauthors, 2010: The thermal state of permafrost in the nordic area during the international polar year 2007-2009. Permafr. Periglac. Process., 21, 156-181, https://doi.org/10.1002/ppp.687.

Christy, J. R., and C. Covey, 2018: Lower stratosphere temperature [in "State of the Climate in 2017"]. Bull. Amer. Meteor. Soc., 99 (8), S18-S20, https://doi.org /10.1175/2018BAMSStateoftheClimate.1.

—, S. Po-Chedley, and C. Mears, 2018: Lower tropospheric temperature [in "State of the Climate in 2017"]. Bull. Amer. Meteor. Soc., 99 (8), S16-S18, https://doi .org/10.1175/2018BAMSStateoftheClimate.1

Chung, E., B. Soden, and V. O. John, 2013: Intercalibrating microwave satellite observations for monitoring long-term variations in upper- and midtropospheric water vapor. J. Atmos. Oceanic Technol., 30, $2303-$ 2319, https:/doi.org/10.1175/JTECH-D-13-00001.1

_- _ _ X. Huang, L. Shi, and V. O. John, 2016: An assessment of the consistency between satellite measurements of upper tropospheric water vapor. J. Geophys. Res. Atmos., 121, https://doi .org/10.1002/2015JD024496.

Ciais, P., and Coauthors, 2013: Carbon and other biogeochemical cycles. Climate Change 2013: The Physical Science Basis, T. F. Stocker et al., Eds., Cambridge University Press, 465-570.

Clem, K. R., S. Barreira, R. L. Fogt, S. Colwell, C. Costanza, L. M. Keller, and M. A. Lazzara, 2018: Atmospheric circulation and surface observations [in "State of the Climate in 2017"]. Bull. Amer. Meteor. Soc., 99, S176-S179, https://doi.org/10.1175/2018BA MSStateoftheClimate.1.

Clement, D., and N. Gruber, 2018: The eMLR(C*) Method to Determine Decadal Changes in the Global Ocean Storage of Anthropogenic CO2. Global Biogeochem. Cycles, 32, 654-679, https://doi. org/10.1002/2017gb005819. 
Coburn, J. J., 2019: Assessing Wind Data from Reanalyses for the Upper Midwest. J. Appl. Meteor. Climatol., 58, 429-446, https://doi.org/10.1175/ JAMC-D-18-0164.1

Cohen, Y., and Coauthors, 2018: Climatology and longterm evolution of ozone and carbon monoxide in the upper troposphere-lower stratosphere (UTLS) at northern midlatitudes, as seen by IAGOS from 1995 to 2013. Atmos. Chem. Phys., 18, 5415-5453, https:// doi.org/10.5194/acp-18-5415-2018.

Coldewey-Egbers, M., and Coauthors, 2015: The GOME-type total ozone essential climate variable (GTO-ECV) data record from the ESA Climate Change Initiative. Atmos. Meas. Tech., 8, 3923-3940, https://doi.org/10.5194/amt-8-3923-2015.

Cooper, O. R., and J. R. Ziemke, 2013: Tropospheric ozone [in "State of the Climate in 2012"]. Bull. Amer. Meteor. Soc., 94, S38-S39, https://doi.org/10.1175/20 13BAMSStateoftheClimate.1.

Coumou, D., V. Petoukhov, S. Rahmstorf, S. Petri, and H. J. Schellnhuber, 2014: Quasi-resonant circulation regimes and hemispheric synchronization of extreme weather in boreal summer. Proc. Natl. Acad. Sci. USA, 111, 12331-12336, https://doi.org/10.1073/ pnas.1412797111.

Coy, L., P. A. Newman, S. Pawson and L. R. Lait, 2017: Dynamics of the disrupted 2015/16 quasi-biennial oscillation. J. Climate, 30, 5661-5674, https://doi .org/10.1175/jcli-d-16-0663.1.

Cullather, R. I., D. H. Bromwich, and M. L. V. Woert, 1998: Spatial and temporal variability of Antarctic precipitation from atmospheric methods. J. Climate, 11, 334-367, https://doi.org/10.1175/1520 0442(1998)011<0334:Satvoa>2.0.CO;2.

Culliney, J. L., 1970: Measurements of reactive phosphorus associated with pelagic Sargassum in the northwest Sargasso Sea. Limnol. Oceanogr., 15, 304-305, https://doi.org/10.4319/lo.1970.15.2.0304.

Cunha, A. P. M. A., J. A. Marengo, L. A. Cuartas, J. Tomasella, M. Zeri, R. C. S. Alvalá, K. R. DeusdaráLeal, and O. L. L. Moraes, 2019: Drought monitoring and impacts assessment in Brazil: The CEMADEN experience. ICHARM Newsletter, 13, 10-11.

Daanen, R. P., T. Ingeman-Nielsen, S. S. Marchenko, V. E. Romanovsky, N. Foged, M. Stendel, J. H. Christensen, and K. H. Svendsen, 2011: Permafrost degradation risk zone assessment using simulation models. Cryosphere, 5, 1043-1056, https://doi.org/10.5194/ tc-5-1043-2011.

Dai, A., 2006: Recent climatology, variability, and trends in global surface humidity. J. Climate, 19, 3589-3606, https://doi.org/10.1175/jcli3816.1.
Dee, D. P., and Coauthors, 2011: The ERA-Interim reanalysis: Configuration and performance of the data assimilation system. Quart. J. Roy. Meteor. Soc., 137, 553-597, https://doi.org/10.1002/qj.828.

Deeter, M. N., and Coauthors, 2013: Validation of MOPITT Version 5 thermal-infrared, near-infrared, and multispectral carbon monoxide profile retrievals for 2000-2011. J. Geophys. Res. Atmos, 118, 6710-6725, https://doi.org/10.1002/jgrd.50272.

Deeter, M. N., and Coauthors, 2014: The MOPITT Version 6 product: Algorithm enhancements and validation. Atmos. Meas. Tech., 7, 3623-3632, https:// doi.org/10.5194/amt-7-3623-2014.

Dehecq, A., and Coauthors, 2019: Twenty-first century glacier slowdown driven by mass loss in High Mountain Asia. Nat. Geosci., 12, 22-27, https:/doi. org/10.1038/s41561-018-0271-9.

Demarée, G. R., and T. Rutishauser, 2011: From "Periodical Observations" to "Anthochronology" and "Phenology" - the scientific debate between Adolphe Quetelet and Charles Morren on the origin of the word "Phenology". Int. J. Biometeor., 55, 753-761, https://doi.org/10.1007/s00484-011-0442-5.

Déry, S. J., T. A. Stadnyk, M. K. MacDonald, and B. Gauli-Sharma, 2016: Recent trends and variability in river discharge across northern Canada. Hydrol. Earth Syst. Sci., 20, 4801-4818, https://doi. org/10.5194/hess-20-4801-2016.

Dessler, A. E., M. R. Schoeberl, T. Wang, S. M. Davis, K. H. Rosenlof, and J. P. Vernier, 2014: Variations of stratospheric water vapor over the past three decades. J. Geophys. Res. Atmos., 119, 12,588-512,598, https:// doi.org/10.1002/2014JD021712.

DeVries, T., M. Holzer, and F. Primeau, 2017: Recent increase in oceanic carbon uptake driven by weaker upper-ocean overturning. Nature, 542, 215-218, https://doi.org/10.1038/nature21068.

Dewitte, S., D. Crommelynck, and A. Joukoff, 2004: Total solar irradiance observations from DIARAD/ VIRGO. J. Geophys. Res., 109, A02102, https://doi. org/10.1029/2002JA009694.

Dhomse, S. S., and Coauthors, 2018: Estimates of ozone return dates from Chemistry-Climate Model Initiative simulations. Atmos. Chem. Phys., 18, 8409-8438, https://doi.org/10.5194/acp-18-8409-2018.

Di Girolamo, L., A. Menzies, G. Zhao, K. Mueller, C. Moroney, and D. J. Diner, 2010: Multi-angle imaging spectroradiometer level 3 cloud fraction by altitude algorithm theoretical basis document. JPL Publ. D-62358, 23 pp. 
Diallo, M., and Coauthors, 2018: Response of stratospheric water vapor and ozone to the unusual timing of El Niño and the QBO disruption in 2015-2016. Atmos. Chem. Phys., 18, 13055-13073, https://doi. org/10.5194/acp-18-13055-2018.

Diamond, H. J., A. M. Lorrey, K. R. Knapp, and D. H. Levinson, 2012: Development of an enhanced tropical cyclone tracks database for the southwest Pacific from 1840 to 2010. Int. J. Climatol., 32, 2240-2250, https://doi.org/10.1002/joc.2412.

—, C. J. Schreck, and Eds., 2017: The tropics [in "State of the Climate in 2016"]. Bull. Amer. Meteor. Soc., 98, S93-S128, https://doi.org/10.1175 /2017BAMSStateoftheClimate.1.

_ _ _ _ and Eds., 2018: The tropics [in "State of the Climate in 2017"]. Bull. Amer. Meteor. Soc., 99, S101S141, https://doi.org/10.1175/2018BAMSStateofthe Climate.1.

Dierssen, H. M., 2010: Perspectives on empirical approaches for ocean color remote sensing of chlorophyll in a changing climate. Proc. Natl. Acad. Sci. USA, 107, 17073-17078, https://doi.org/10.1073/ pnas.0913800107.

Djakouré, S., M. Araujo, A. Hounsou-Gbo, C. Noriega, and B. Bourlès, 2017: On the potential causes of the recent Pelagic Sargassum blooms events in the tropical North Atlantic Ocean. Biogeosci. Discuss., https:// doi.org/10.5194/bg-2017-346.

Dlugokencky, E., 2018: Trends in atmopsheric methane. NOAA Earth System Research Laboratory, https:// www.esrl.noaa.gov/gmd/ccgg/trends_ch4/.

_, K. A. Masaire, P. M. Lang, P. P. Tans, L. P. Steele, and E. G. Nisbet, 1994a: A dramatic decrease in the growth rate of atmospheric methane in the northern hemisphere during 1992. Geophys. Res. Lett, 21, 45-48, https://doi.org/10.1029/93GL03070.

— L. L. Steele, P. M. Lang, and K. A. Masarie, 1994b: The growth rate and distribution of atmospheric methane, J. Geophys. Res., 99 (D8), 17,021-17,043, https://doi.org/10.1029/94JD01245.

_-, E. G. Nisbet, R. Fisher, and D. Lowry, 2011: Global atmospheric methane: Budget, changes and dangers. Philos. Trans. Roy. Soc., A369, 2058-2072, https://doi. org/10.1098/rsta.2010.0341.

Dolman, A. J., D. G. Miralles, and R. A. M. de Jeu, 2014: Fifty years since Monteith's 1965 seminal paper: The emergence of global ecohydrology. Ecohydrology, 7, 897-902, https://doi.org/10.1002/eco.1505.

Domingues, C. M., J. A. Church, N. J. White, P. J. Gleckler, S. E. Wijffels, P. M. Barker, and J. R. Dunn, 2008: Improved estimates of upper-ocean warming and multi-decadal sea-level rise. Nature, 453, 1090-1093, https://doi.org/10.1038/nature07080.
Domingues, R., and Coauthors, 2015: Upper ocean response to Hurricane Gonzalo (2014): Salinity effects revealed by targeted and sustained underwater glider observations. Geophys. Res. Lett., 42, 7131-7138, https://doi.org/10.1002/2015GL065378.

Donat, M. G., and Coauthors, 2013a: Updated analyses of temperature and precipitation extreme indices since the beginning of the twentieth century: The HadEX2 dataset. J. Geophys. Res. Atmos., 118, 2098-2118, https://doi.org/10.1002/jgrd.50150.

—, L. V. Alexander, H. Yang, I. Durre, R. Vose, and J. Caesar, 2013b: Global land-based datasets for monitoring climatic extremes. Bull. Amer. Meteor. Soc., 94, 997-1006, https://doi.org/10.1175 /bams-d-12-00109.1.

Dong, J., and Coauthors, 2017: Impact of assimilating underwater glider data on Hurricane Gonzalo (2014) forecasts. Wea. Forecasting, 32, 1143-1159, https:// doi.org/10.1175/waf-d-16-0182.1.

Dorigo, W. A., and Coauthors, 2017a: Soil moisture [in "State of the Climate in 2016"]. Bull. Amer. Meteor. Soc., 98, S30-S32, https://doi.org/10.1175 /2017BAMSStateoftheClimate.1.

_ - and Coauthors, 2017b: ESA CCI soil moisture for improved Earth system understanding: State-of-the art and future directions. Remote Sens. Environ., 203, 185-215, https://doi.org/10.1016/j.rse.2017.07.001.

_ - and Coauthors, 2018: Soil moisture [in "State of the Climate in 2017"]. Bull. Amer. Meteor. Soc., 99, S35-S36, https://doi.org/10.1175 /2018BAMSStateoftheClimate.1.

Doyle, E., and J. Franks, 2015: Sargassum fact sheet. Gulf and Caribbean Fisheries Institute, 4 pp.

Drozdov, D., and Coauthors, 2015: Monitoring of permafrost in Russia and the international GTN-P project. Proc. 68th Canadian Geotechnical Conf. and Seventh Canadian Conf. on Permafrost (GEOQuébec 2015), GEOQuébec 2015, Paper 617.

Duchesne, C., S. L. Smith, M. Ednie, and P. P. Bonnaventure, 2015: Active layer variability and change in the Mackenzie Valley, Northwest Territories. Proc. 68th Canadian Geotechnical Conf. and Seventh Canadian Conf. on Permafrost (GEOQuébec 2015), GEOQuébec 2015, Paper 117.

Duffy-Anderson, J. T., and Coauthors, 2019: Responses of the Northern Bering Sea and Southeastern Bering Sea ecosystems following record-breaking low winter sea ice. Geophys. Res. Lett., in press.

Dufour, A., O. Zolina, and S. K. Gulev, 2016: Atmospheric moisture transport to the Arctic: Assessment of reanalyses and analysis of transport components. J. Climate, 29, 5061-5081, https://doi.org/10.1175/ jcli-d-15-0559.1. 
Duncan, B. N., J. A. Logan, I. Bey, I. A. Megretskaia, R. M. Yantosca, P. C. Novelli, N. B. Jones, and C. P. Rinsland, 2007: Global budget of CO, 1988-1997: Source estimates and validation with a global model. J. Geophys. Res., 112, D22301, https://doi. org/10.1029/2007JD008459.

Dunn, R. J. H., K. M. Willett, P. W. Thorne, E. V. Woolley, I. Durre, A. Dai, D. E. Parker, and R. S. Vose, 2012: HadISD: A quality-controlled global synoptic report database for selected variables at long-term stations from 1973-2011. Climate Past, 8, 1649-1679, https://doi.org/10.5194/cp-8-1649-2012.

— , C. Azorin-Molina, C. A. Mears, P. Berrisford, and T. R. McVicar, 2016a: Surface winds [in "State of the Climate in 2015"]. Bull. Amer. Meteor. Soc., 97, S38-S40, https://doi.org/10.1175 /2016BAMSStateoftheClimate.1.

— , K. M. Willett, D. E. Parker, and L. Mitchell, 2016b: Expanding HadISD: Quality-controlled, sub-daily station data from 1931. Geosci. Instrum. Method. Data Syst., 5, 473-491, https://doi.org/10.5194 /gi-5-473-2016.

Durack, P. J., 2015: Ocean salinity and the global water cycle. Oceanography, 28, 20-31, https://doi. org/10.5670/oceanog.2015.03.

—, S. E. Wijffels, and R. J. Matear, 2012: Ocean salinities reveal strong global water cycle intensification during 1950 to 2000. Science, 336, 455-458, https:// doi.org/10.1126/science.1212222.

$\longrightarrow$ - — , and P. J. Gleckler, 2014: Long-term sea-level change revisited: The role of salinity. Environ. Res. Lett., 9, 114017, https://doi.org/10.1088/1748-9326 /9/11/114017.

Ebita, A., and Coauthors, 2011: The Japanese 55-year reanalysis "JRA-55": An interim report. SOLA, 7, 149-152, https://doi.org/10.2151/sola.2011-038.

Ednie, M., and S. L. Smith, 2015: Permafrost temperature data 2008-2014 from community based monitoring sites in Nunavut. Geological Survey of Canada, Open File 7784, 18 pp., https://doi.org/10.4095/296705.

Edson, J. B., and Coauthors, 2013: On the exchange of momentum over the open ocean. J. Phys. Oceanogr., 43, 1589-1610, https://doi.org/10.1175/jpod-12-0173.1.

EEAP, 2019: Environmental effects and interactions of stratospheric ozone depletion, UV radiation, and climate change: 2018 Assessment Report. UNEP Environmental Effects Assessment Panel, 390 pp., https://ozone.unep.org/sites/default/files/Assessment_Panel/EEAP_assessment-report-2018.pdf.
Emanuel, K. A., 1988: The maximum intensity of hurricanes. J. Atmos. Sci., 45, 1143-1155, https://doi. org/10.1175/1520-0469(1988)045<1143:tmioh $>2.0$ .co;2.

- , and D. S. Nolan, 2004: Tropical cyclone activity and the global climate system. Proc. 26th Conf. on Hurricanes and Tropical Meteor., Amer. Meteor. Soc., 10A.12.

Enfield, D. B., and A. M. Mestas-Nuñez, 1999: Multiscale variabilities in global sea surface temperatures and their relationships with tropospheric climate patterns. J. Climate, 12, 2719-2733, https://doi. org/10.1175/1520-0442(1999)012<2719:mvigss $>2.0$ .co;2.

Engel, A., and Coauthors, 2019: Update on ozonedepleting substances (ODSs) and other gases of interest to the Montreal Protocol. Scientific Assessment of Ozone Depletion: 2018, World Meteorological Organization, 1.1-1.87.

Esaias, W. E., and Coauthors, 1998: An overview of MODIS capabilities for ocean science observations. IEEE Trans. Geosci. Remote Sens., 36, 1250-1265, https://doi.org/10.1109/36.701076.

Estilow, T. W., A. H. Young, and D. A. Robinson, 2015: A long-term Northern Hemisphere snow cover extent data record for climate studies and monitoring. Earth Syst. Sci. Data, 7, 137-142, https://doi.org/10.5194 lessd-7-137-2015.

Etheridge, D. M., L. P. Steele, R. L. Langenfelds, R. J. Francey, J. M. Barnola, and V. I. Morgan, 1996: Natural and anthropogenic changes in atmospheric $\mathrm{CO}_{2}$ over the last 1000 years from air in Antarctic ice and firn. J. Geophys. Res., 101, 4115-4128, https://doi. org/10.1029/95JD03410.

Falkowski, P. G., R. T. Barber, and V. Smetacek, 1998: Biogeochemical controls and feedbacks on ocean primary production. Science, 281, 200-206, https:// doi.org/10.1126/science.281.5374.200.

Fausto, R. S., and D. van As, 2019: Programme for monitoring of the Greenland ice sheet (PROMICE): Automatic weather station data, v03. Geological Survey of Denmark and Greenland, https://doi.org/10.22008/ promice/data/aws.

Feely, R. A., R. Wanninkhof, T. Takahashi, and P. Tans, 1999: Influence of El Niño on the equatorial Pacific contribution to atmospheric $\mathrm{CO} 2$ accumulation. Nature, 398, 597-601, https://doi.org/10.1038/19273. — , and Coauthors, 2002: Seasonal and interannual variability of $\mathrm{CO}_{2}$ in the equatorial Pacific. DeepSea Res. II, 49, 2443-2469, https://doi.org/10.1016 /S0967-0645(02)00044-9. 
, T. Takahashi, R. Wanninkhof, M. J. McPhaden, C. E. Cosca, S. C. Sutherland, and M.-E. Carr, 2006: Decadal variability of the air-sea $\mathrm{CO}_{2}$ fluxes in the equatorial Pacific Ocean. J. Geophys. Res., 111, C08S90, https://doi.org/10.1029/2005jc003129.

Feng, Z., L. R. Leung, R. A. Houze Jr., S. Hagos, J. Hardin, Q. Yang, B. Han, and J. Fan, 2018: Structure and evolution of mesoscale convective systems: Sensitivity to cloud microphysics in convectionpermitting simulations over the United States. J. Adv. Mod. Earth Syst., 10, 1470-1494, https://doi. org/10.1029/2018MS001305.

Fennig, K., A. Andersson, S. Bakan, C.-P. Klepp, and M. Schröder, 2012: Hamburg Ocean Atmosphere Parameters and Fluxes from Satellite Data - HOAPS 3.2 - Monthly Means / 6-Hourly Composites. Satellite Application Facility on Climate Monitoring (CM SAF), https://doi.org/10.5676/EUM_SAF_CM /HOAPS/V001.

Fetterer, F., K. Knowles, W. Meier, M. Savoie, and A. K. Windnagel, 2017, updated daily: Sea Ice Index. National Snow and Ice Data Center, https://doi .org/10.7265/N5K072F8.

Field, C. B., M. J. Behrenfeld, J. T. Randerson, and P. Falkowski, 1998: Primary production of the biosphere: Integrating terrestrial and oceanic components. Science, 281, 237-240, https://doi.org/10.1126 /science.281.5374.237.

Finch II, M., 2019: Camp Fire tops 2018 list of costliest disasters in the world. Sacramento Bee, 10 January, https://www.sacbee.com/news/state/california/fires /article224185765.html.

Fioletov, V. E., G. E. Bodeker, A. J. Miller, R. D. McPeters, and R. Stolarski, 2002: Global and zonal total ozone variations estimated from ground-based and satellite measurements: 1964-2000. J. Geophys. Res., 107, 4647, https://doi.org/10.1029/2001JD001350.

— based total ozone network assessed using satellite data. J. Geophys. Res., 113, D14313, https://doi .org/10.1029/2008JD009809.

Fischer, E. M., U. Beyerle, and R. Knutti, 2013: Robust spatially aggregated projections of climate extremes. Nat. Climate Change, 3, 1033-1038, https://doi. org/10.1038/nclimate2051.

Fisher, J. B., and Coauthors, 2017: The future of evapotranspiration: Global requirements for ecosystem functioning, carbon and climate feedbacks, agricultural management, and water resources. Water Resour. Res., 53, 2618-2626, https://doi. org/10.1002/2016WR020175.
Flemming, J., and A. Inness, 2016: Carbon monoxide [in "State of the Climate in 2015"]. Bull. Amer. Meteor. Soc., 97, S55, S58, https://doi.org/10.1175/2016BAM SStateoftheClimate.1.

— , and —_, 2018: Carbon monoxide [in "State of the Climate in 2017”]. Bull. Amer. Meteor. Soc., 99, S59-S61, https://doi.org/10.1175/2018BAMSStateoftheClimate.1.

— , and Coauthors, 2017: The CAMS interim reanalysis of carbon monoxide, ozone and aerosol for 2003-2015. Atmos. Chem. Phys., 17, 1945-1983, https://doi.org/10.5194/acp-17-1945-2017.

Floodlist, 2019: Floodlist. Accessed 27 March 2019. http://floodlist.com/.

Fofonoff, N. P., and E. L. Lewis, 1979: A practical salinity scale. J. Oceanogr. Soc. Japan, 35, 63-64, https://doi .org/10.1007/bf02108283.

Fogt, R. L., D. H. Bromwich, and K. M. Hines, 2011: Understanding the SAM influence on the South Pacific ENSO teleconnection. Climate Dyn., 36, 1555-1576, https://doi.org/10.1007/s00382-010-0905-0.

Foley, J. C., 1957: Droughts in Australia: Review of records from earliest years of settlement to 1955. BoM Bull. 43, Australian Bureau of Meteorology, 281 pp.

Font, J., and Coauthors, 2013: SMOS first data analysis for sea surface salinity determination. Int. J. Remote Sens., 34, 3654-3670, https://doi.org/10.1080/014311 61.2012.716541.

Fore, A. G., S. H. Yueh, W. Tang, B. W. Stiles, and A. K. Hayashi, 2016: Combined active/passive retrievals of ocean vector wind and sea surface salinity with SMAP. IEEE Trans. Geosci. Remote Sens., 54, 73967404, https://doi.org/10.1109/TGRS.2016.2601486.

Frajka-Williams, E., and Coauthors, 2019: Atlantic Meridional Overturning Circulation: Observed transports and variability. Front. Mar. Sci., https:// doi.org/10.3389/fmars.2019.00260, in press.

Francis, J. A., and S. J. Vavrus, 2015: Evidence for a wavier jet stream in response to rapid Arctic warming. Environ. Res. Lett., 10, 014005, https://doi. org/10.1088/1748-9326/10/1/014005.

—, N. Skific, and S. J. Vavrus, 2018: North American weather regimes are becoming more persistent: Is Arctic amplification a factor? Geophys. Res. Lett., 45, 11414-11422, https://doi.org/10.1029/2018gl080252.

Frank, W. M., and P. E. Roundy, 2006: The role of tropical waves in tropical cyclogenesis. Mon. Wea. Rev., 134, 2397-2417, https://doi.org/10.1175/mwr3204.1.

Franks, J., D. R. Johnson, and D. S. Ko, 2014: Retention and growth of pelagic Sargassum in the North Equatorial Recirculation Region (NERR) of the Atlantic Ocean. Proc. Annu. Gulf Caribb. Fish. Inst., 67. 
$\ldots$, — and 2016: Pelagic Sargassum in the Tropical North Atlantic. Gulf Caribb. Res., 27, SC6SC11, https://doi.org/10.18785/gcr.2701.08.

Franz, B. A., E. M. Karaköylü, D. A. Siegel, and T. K. Westberry, 2018: Global ocean phytoplankton [in "State of the Climate in 2017"]. Bull. Amer. Meteor. Soc., 99, S94-S96, https://doi.org/10.1175 /2018BAMSStateoftheClimate.1.

Frith, S. M., N. A. Kramarova, R. S. Stolarski, R. D. McPeters, P. K. Bhartia, and G. J. Labow, 2014: Recent changes in total column ozone based on the SBUV version 8.6 merged ozone data set. J. Geophys. Res. Atmos., 119, 9735-9751, https://doi .org/10.1002/2014JD021889.

_ R. S. Stolarski, N. A. Kramarova, and R. D. McPeters, 2017: Estimating uncertainties in the SBUV Version 8.6 merged profile ozone data set. Atmos. Chem. Phys., 17, 14,695-14,707, https://doi.org/10.5194 /acp-17-14695-2017.

Frölicher, T. L., J. L. Sarmiento, D. J. Paynter, J. P. Dunne, J. P. Krasting, and M. Winton, 2015: Dominance of the Southern Ocean in Anthropogenic Carbon and Heat Uptake in CMIP5 Models. J. Climate, 28, 862-886, https://doi.org/10.1175/jcli-d-14-00117.1.

Frost, G. V., H. E. Epstein, D. A. Walker, G. Matyshak, and K. Ermokhina, 2018: Seasonal and long-term changes to active-layer temperatures after tall shrubland expansion and succession in Arctic tundra. Ecosystems, 21, 507-520, https://doi.org/10.1007 /s10021-017-0165-5.

Fung, I., J. John, J. Lerner, E. Matthews, M. Prather, L. P. Steele, and P. J. Fraser, 1991: Three-dimensional model synthesis of the global methane cycle. J. Geophys. Res., 96, 13,033-13,065, https://doi. org/10.1029/91JD01247.

Garane, K., and Coauthors, 2018: Quality assessment of the Ozone_cci Climate Research Data Package (release 2017): 1. Ground-based validation of total ozone column data products. Atmos. Meas. Tech., 11, 1385-1402, https://doi.org/10.5194/amt-11-1385 -2018 .

Garreaud, R. D., and Coauthors, 2017: The 2010-2015 megadrought in central Chile: Impacts on regional hydroclimate and vegetation. Hydrol. Earth Syst. Sci., 21, 6307-6327, https://doi.org/10.5194/hess-21 $-6307-2017$.

Gaubert, B., and Coauthors, 2017: Chemical feedback from decreasing carbon monoxide emissions. Geophys. Res. Lett., 44, 9985-9995, https://doi .org/10.1002/2017GL074987.
Gaudel, A., and Coauthors, 2018: Tropospheric Ozone Assessment Report: Present-day ozone distribution and trends relevant to climate and global model evaluation. Elementa, 6, 39, https://doi.org/10.1525 /elementa.291.

GCOS, 2016: The global observing system for climate: Implementation needs. GCOS-200 (GOOS-214), WMO, 315 pp., https://unfccc.int/files/science/ workstreams/systematic_observation/application/ pdf/gcos_ip_10oct2016.pdf.

Geider, R. J., H. L. MacIntyre, and T. M. Kana, 1997: Dynamic model of phytoplankton growth and acclimation:responses of the balanced growth rate and the chlorophyll a:carbon ratio to light, nutrientlimitation and temperature. Mar. Ecol. Prog. Ser., 148, 187-200.

Gelaro, R., and Coauthors, 2017: The Modern-Era Retrospective Analysis for Research and Applications, version 2 (MERRA-2). J. Climate, 30, 5419-5454, https://doi.org/10.1175/JCLI-D-16-0758.1.

Ghilain, N., A. Arboleda, and F. Gellens-Meulenberghs, 2011: Evapotranspiration modelling at large scale using near-real time MSG SEVIRI derived data. Hydrol. Earth Syst. Sci., 15, 771-786, https://doi.org/10.5194/ hess-15-771-2011.

Giannini, A., Y. Kushnir, and M. A. Cane, 2000. Interannual variability of Caribbean rainfall, ENSO and the Atlantic Ocean. J. Climate, 13, 297-311, https:// doi.org/10.1175/1520-0442(2000)013<0297:IVOCR $\mathrm{E}>2.0 . \mathrm{CO} ; 2$.

-, R. Saravanan, and P. Chang, 2003: Oceanic forcing of Sahel rainfall on interannual to interdecadal time scales. Science, 302, 1027-1030, https://doi. org/10.1126/science.1089357.

GIMMS, 2013: Global Inventory Modeling and Mapping Studies, https://ecocast.arc.nasa.gov/data/pub/ gimms/3g.v1/.

GISTEMP Team, 2016: 2016 GISS Surface Temperature Analysis (GISTEMP). NASA Goddard Institute for Space Studies, 9 February 2018 https://data.giss.nasa. gov/gistemp/.

Gleason, K. L., J. H. Lawrimore, D. H. Levinson, T. R. Karl, and D. J. Karoly, 2008: A Revised U.S. Climate Extremes Index. J. Climate, 21, 2124-2137, https:// doi.org/10.1175/2007jcli1883.1.

GMAO (Global Modeling and Assimilation Office), 2015a: MERRA-2 tavg1_2d_slv_Nx: 2d,1-Hourly,TimeAveraged,Single-Level,Assimilation,Single-Level Diagnostics V5.12.4. Goddard Earth Sciences Data and Information Services Center (GES DISC), https:// doi.org/10.5067/VJAFPLI1CSIV. 
- 2015b: MERRA-2 tavg1_2d_int_Nx: 2d,1Hourly,Time-Averaged,Single-Level, Assimilation, Vertically Integrated Diagnostics V5.12.4. Goddard Earth Sciences Data and Information Services Center (GES DISC), https://doi.org/10.5067/Q5GVUVUIVGO7.

Gobron, N., 2018: Terrestrial vegetation activity [in "State of the Climate in 2017"]. Bull. Amer. Meteor. Soc., 99, S62-S63, https://doi.org/10.1175 /2018BAMSStateoftheClimate.1.

— the global terrestrial surfaces. Proc. 2013 ESA Living Planet Symp., European Space Agency.

—, A. Belward, B. Pinty, and W. Knorr, 2010: Monitoring biosphere vegetation 1998-2009. Geophys. Res. Lett., 37, L15402, https://doi .org/10.1029/2010GL043870.

Goldenberg, S. B., and L. J. Shapiro, 1996: Physical mechanisms for the association of El Niño and West African rainfall with Atlantic major hurricane activity. J. Climate, 9, 1169-1187, https://doi.org/10.1175/1520 -0442(1996)009<1169:pmftao>2.0.co;2.

_ C. C. W. Landsea, A. M. Mestas-Nuñez, and W. M. Gray, 2001: The recent increase in Atlantic hurricane activity: Causes and implications. Science, 293, 474-479, https://doi.org/10.1126/science.1060040.

Goni, G. J., and J. A. Knaff, 2009: Tropical cyclone heat potential [in "State of the Climate in 2008"]. Bull. Amer. Meteor. Soc., 90, S54-S56, https://doi. org/10.1175/BAMS-90-8-StateoftheClimate.

_ derived ocean measurements to tropical cyclone intensity forecasting. Oceanography, 22, 190-197, https://doi.org/10.5670/oceanog.2009.78.

— , F. Bringas, and P. N. DiNezio, 2011: Observed low frequency variability of the Brazil Current front. J. Geophys. Res., 116, C10037, https://doi .org/10.1029/2011JC007198.

— ian ocean observations for Atlantic tropical cyclone studies and forecasts. Oceanography, 30, 92-103, https://doi.org/10.5670/oceanog.2017.227.

Gordon, A. L., 1986: Interocean exchange of thermocline water. Journal of Geophysical Research: Oceans, 91, 5037-5046, https://doi.org/10.1029/ JC091iC04p05037.

Gower, J., E. Young, and S. King, 2013: Satellite images suggest a new Sargassum source region in 2011. Remote Sens. Lett., 4, 764-773, https://doi.org/10.1080 /2150704X.2013.796433.
Graff, J. R., T. K. Westberry, A. J. Milligan, M. B. Brown, G. Dall'Olmo, V. v. Dongen-Vogels, K. M. Reifel, and M. J. Behrenfeld, 2015: Analytical phytoplankton carbon measurements spanning diverse ecosystems. Deep-Sea Res. I, 102, 16-25, https://doi.org/10.1016 /j.dsr.2015.04.006.

Granier, C., and Coauthors, 2011: Evolution of anthropogenic and biomass burning emissions of air pollutants at global and regional scales during the 1980-2010 period. Climatic Change, 109, 163, https:// doi.org/10.1007/s10584-011-0154-1.

Gray, A. R., and Coauthors, 2018: Autonomous biogeochemical floats detect significant carbon dioxide outgassing in the high-latitude Southern Ocean. Geophys. Res. Lett., 45, 9049-9057, https://doi. org/10.1029/2018GL078013.

Gray, W. M., 1968: Global view of the origin of tropical disturbances and storms. Mon. Wea. Rev., 96, 669-700, https://doi.org/10.1175/1520 -0493(1968)096<0669: gvotoo>2.0.co;2.

— , and C. W. Landsea, 1992: African rainfall as a precursor of hurricane-related destruction on the U.S. East Coast. Bull. Amer. Meteor. Soc., 73, 1352-1364, https://doi.org/10.1175/1520-0477(1992)073<1352 :Araapo $>2.0 . \mathrm{Co} ; 2$.

Gray DiLeone, A. M., and C. H. Ainsworth, 2019: Effects of Karenia brevis harmful algal blooms on fish community structure on the West Florida Shelf. Ecol. Modell., 392, 250-267, https://doi.org/10.1016 /j.ecolmodel.2018.11.022.

Gruber, A., W. A. Dorigo, W. Crow, and W. Wagner, 2017: Triple collocation-based merging of satellite soil moisture retrievals. IEEE Trans. Geosci. Remote Sens., 55, 6780-6792, https://doi.org/10.1109/ TGRS.2017.2734070.

Gruber, N., and Coauthors, 2019: The oceanic sink for anthropogenic $\mathrm{CO}<\mathrm{sub}>2</$ sub $>$ from 1994 to 2007. Science, 363, 1193-1199, https://doi.org/10.1126/science.aau5153.

Guo, Y., X. Jiang, and D. E. Waliser, 2014: Modulation of the convectively coupled Kelvin waves over South America and the tropical Atlantic Ocean in association with the Madden-Julian oscillation. J. Atmos. Sci., 71, 1371-1388, https://doi.org/10.1175/ jas-d-13-0215.1.

Hagos, S. M., and K. H. Cook, 2008: Ocean warming and late-twentieth-century Sahel drought and recovery. J. Climate, 21, 3797-3814, https://doi .org/10.1175/2008jcli2055.1. 
Haimberger, L., C. Tavolato, and S. Sperka, 2012: Homogenization of the global radiosonde temperature dataset through combined comparison with reanalysis background series and neighboring stations. J. Climate, 25, 8108-8131, https://doi.org/10.1175 /JCLI-D-11-00668.1.

— - and M. Mayer, 2016: Upper Air winds [in "State of the Climate in 2015"]. Bull. Amer. Meteor. Soc., 97 (8), S40-S41, https://doi.org/10.1175 /2016BAMSStateoftheClimate.1.

Halpert, M. S., and C. F. Ropelewski, 1992: Surface temperature patterns associated with the southern oscillation. J. Climate, 5, 577-593, https://doi. org/10.1175/1520-0442(1992)005<0577:stpawt $>2.0$ .co;2.

Hansen, J., R. Ruedy, M. Sato, and K. Lo, 2010: Global surface temperature change. Rev. Geophys., 48, RG4004, https://doi.org/10.1029/2010RG000345.

— Requirement of negative $\mathrm{CO}_{2}$ emissions. Earth Syst. Dyn., 8, 577-616, https://doi.org/10.5194/esd-8-577 $-2017$.

Harris, I., P. D. Jones, T. J. Osborn, and D. H. Lister, 2014: Updated high-resolution grids of monthly climatic observations - the CRU TS3.10 Dataset. Int. J. Climatol., 34, 623-642, https://doi.org/10.1002/joc.3711.

Harris, J. M., and J. D. Kahl, 1990: A descriptive atmospheric transport climatology for the Mauna Loa Observatory, using clustered trajectories. J. Geophys. Res., 95, 13,651-613,667, https://doi.org/10.1029/ JD095iD09p13651.

Harris, N. R. P., D. J. Wuebbles, J. S. Daniel, J. Hu, L. J. M. Kuijpers, K. S. Law, M. J. Prather, and R. Schofield, 2014: Scenarios and information for policymakers. Scientific Assessment of Ozone Depletion: 2014, World Meteorological Organization, 5.1-5.58.

Hartmann, D. L., and Coauthors, 2013: Observations: Atmosphere and surface. Climate Change 2013: The Physical Science Basis, T. F. Stocker et al, Eds., Cambridge University Press, 159-254.

Hassler, B., J. S. Daniel, B. J. Johnson, S. Solomon, and S. J. Oltmans, 2011: An assessment of changing ozone loss rates at South Pole: Twenty-five years of ozonesonde measurements. J. Geophys. Res., 116, D22301, https://doi.org/10.1029/2011JD016353.

Hastenrath, S., 1990: Decadal-scale changes of the circulation in the tropical atlantic sector associated with Sahel drought. Int. J Climatol., 10, 459-472, https:// doi.org/10.1002/joc.3370100504.

Heidinger, A. K., M. J. Foster, A. Walther, and X. Zhao, 2014: The Pathfinder atmospheres-extended AVHRR climate dataset. Bull. Amer. Meteor. Soc., 95, 909-922, https://doi.org/10.1175/bams-d-12-00246.1.
Held, I. M., and Soden, B. J., 2000: Water vapor feedback and global warming. Annu. Rev. Energy Environ., 25, 441-475, https://doi.org/10.1146/annurev .energy.25.1.441.

Helfrich, S. R., D. McNamara, B. H. Ramsay, T. Baldwin, and T. Kasheta, 2007: Enhancements to, and forthcoming developments in the Interactive Multisensor Snow and Ice Mapping System (IMS). Hydrol. Proc., 21, 1576-1586, https://doi.org/10.1002/hyp.6720.

Hemming, D. L., and Coauthors, 2018: Phenology of terrestrial and freshwater primary producers [in "State of the Climate in 2017"]. Bull. Amer. Meteor. Soc., 99 (8), S150-S152, doi:10.1175/2018BAMSState oftheClimate.1.

Hendon, H. H., C. Zhang, and J. D. Glick, 1999: Interannual variation of the Madden-Julian oscillation during austral summer. J. Climate, 12, 2538-2550, https://doi.org/10.1175/1520-0442(1999)012<2538:iv otmj>2.0.co;2.

Hermann, A. J., G. A. Gibson, W. Cheng, I. Ortiz, K. Aydin, M. Wang, A. B. Hollowed, and K. K. Holsman, 2019: Projected biophysical conditions of the Bering Sea to 2100 under multiple emission scenarios, ICES J. Mar. Sci., fsz043, https://doi .org/10.1093/icesjms/fsz043

Hersbach, H., and Coauthors, 2019: Global reanalysis: Goodbye ERA-Interim, hello ERA5. ECMWF Newsletter, No. 159, ECMWF, Reading, United Kingdom, 17-24, https://www.ecmwf.int/sites/default/files /elibrary/2019/19001-newsletter-no-159-spring-2019 .pdf.

Hidalgo, H. G., E. J. Alfaro, J. A. Amador, and Á. Bastidas, 2019: Precursors of quasi-decadal dry-spells in the Central America Dry Corridor. Climate Dyn., https://doi.org/10.1007/s00382-019-04638-y, in press.

Higgins, M., 2011: Where's the beach? Under the seaweed. New York Times, 11 October, TR4.

Ho, S.-P., Y.-H. Kuo, W. Schreiner, and X. Zhou, 2010a: Using SI-traceable global positioning system radio occultation measurements for climate monitoring [in "State of the Climate in 2009"]. Bull. Amer. Meteor. Soc., 91, S36-S37, https://doi.org/10.1175/BAMS91-7-StateoftheClimate.

— , X. Zhou, Y.-H. Kuo, D. Hunt, and J.-H. Wang, 2010b: Global evaluation of radiosonde water vapor systematic biases using GPS radio cccultation from COSMIC and ECMWF analysis. Remote Sens. Environ., 2, 1320-1330, https://doi.org/10.3390/rs2051320. 
Hobbins, M. T., A. Wood, D. J. McEvoy, J. L. Huntington, C. Morton, M. Anderson, and C. Hain, 2016: The Evaporative Demand Drought Index. Part I: Linking drought evolution to variations in evaporative demand. J. Hydrometeor., 17, 1745-1761, https://doi. org/10.1175/jhm-d-15-0121.1.

Hofmann, D. J., J. H. Butler, E. J. Dlugokencky, J. W. Elkins, K. Masarie, S. A. Montzka, and P. Tans, 2006: The role of carbon dioxide in climate forcing from 1979 to 2004: Introduction of the annual greenhouse gas index. Tellus, 58B, 614-619, https:// doi.org/10.1111/j.1600-0889.2006.00201.x.

Holland, P., 2010: Warm bath for an ice sheet. Nat. Geosci., 3, 147-148, https://doi.org/10.1038/ngeo801.

Holmes, R. M., and Coauthors, 2012: Climate change impacts on the hydrology and biogeochemistry of Arctic rivers. Climatic Change and Global Warming of Inland Waters, C. R. Goldman, M. Kumagai, and R. D. Robarts, Eds., Wiley, 3-26.

Hong, C.-C., T. Li, LinHo, and J.-S. Kug, 2008: Asymmetry of the Indian Ocean dipole. Part I: Observational analysis. J. Climate, 21, 4834-4848, https://doi. org/10.1175/2008jcli2222.1.

Hong Kong Observatory, 2019: Report on Super Typhoon Mangkhut (1822): 7 to 17 September 2018. https://www.weather.gov.hk/informtc/mangkhut18 /mangkhut.htm

Hrbáček, F., and Coauthors, 2018: Active layer monitoring in Antarctica: An overview of results from 2006 to 2015. Polar Geogr., 1-16, https://doi.org/10.1080 /1088937X.2017.1420105.

Hu, C., Z. Lee, and B. Franz, 2012: Chlorophyll $a$ algorithms for oligotrophic oceans: A novel approach based on three-band reflectance difference. J. Geophys. Res., 117, C01011, https://doi .org/10.1029/2011jc007395.

—_, and Coauthors, 2016: Sargassum watch warns of incoming seaweed. Eos, Trans. Amer. Geophys. Union, 97, https://doi.org/10.1029/2016EO058355.

Huang, B., and Coauthors, 2016: Further exploring and quantifying uncertainties for extended reconstructed sea surface temperature (ERSST) version 4 (v4). J. Climate, 29, 3119-3142, https://doi.org/10.1175 /jcli-d-15-0430.1.

— , and Coauthors, 2015: Extended reconstructed sea surface temperature version 4 (ERSST.v4). Part I: Upgrades and intercomparisons. J. Climate, 28, 911-930, https://doi.org/10.1175/jcli-d-14-00006.1.

— , and Coauthors, 2017: Extended Reconstructed Sea Surface Temperature, Version 5 (ERSSTv5): Upgrades, validations, and intercomparisons. J. Climate, 30, 8179-8205, https://doi.org/10.1175 /jcli-d-16-0836.1.
Huang, C.-Y., W.-H. Teng, S.-P. Ho, and Y.-H. Kuo, 2013: Global variation of COSMIC precipitable water over land: Comparisons with ground-based GPS measurements and NCEP reanalyses. Geophys. Res. Lett., 40, 5327-5331, https://doi.org/10.1002/grl.50885.

Huffman, G., 2015: GPM IMERG Late Precipitation L3 Half Hourly 0.1 degree x 0.1 degree V05. Goddard Earth Sciences Data and Information Services Center (GES DISC), https://doi.org/10.5067/GPM/ IMERG/3B-HH-L/05.

—, R. F. Adler, D. T. Bolvin, and G. Gu, 2009: Improving the global precipitation record: GPCP Version 2.1. Geophys. Res. Lett., 36, L17808, https://doi .org/10.1029/2009GL040000.

Hummels, R., P. Brandt, M. Dengler, J. Fischer, M. Araujo, D. Veleda, and J. V. Durgadoo, 2015: Interannual to decadal changes in the western boundary circulation in the Atlantic at $11^{\circ} \mathrm{S}$. Geophys. Res. Lett., 42, 7615-7622, https://doi.org/10.1002/2015gl065254.

Huntington, H., L. Quakenbush, and M. Nielson, 2017: Evaluating the effects of climate change on Indigienous marine mammal hunting in northern and western Alaska using traditional knowledge. Front. Mar. Sci., 4, 40, https://doi.org/10.3389/ fmars.2017.00319.

Hurst, D. F., and Coauthors, 2016: Recent divergences in stratospheric water vapor measurements by frost point hygrometers and the Aura Microwave Limb Sounder. Atmos. Meas. Tech., 9, 4447-4457, https:// doi.org/10.5194/amt-9-4447-2016.

Huss, M., and Coauthors, 2017: Toward mountains without permanent snow and ice. Earth's Future, 5, 418-435, https://doi.org/10.1002/2016EF000514.

— A. Bauder, C. Marty, and J. Nötzli, 2018: Schnee, Gletscher und Permafrost 2016/17. Alpen, 40-45.

IEA, 2018: Global energy \& $\mathrm{CO}_{2}$ status report: The latest trends in energy and emissions in 2018. International Energy Agency, https://www.iea.org/geco /emissions.

Inness, A., and Coauthors, 2013: The MACC reanalysis: An 8 yr data set of atmospheric composition. Atmos. Chem. Phys., 13, 4073-4109, https://doi.org/10.5194/ acp-13-4073-2013.

— atmospheric composition. Atmos. Chem. Phys., 19, 3515-3556, https://doi.org/10.5194/acp-19-3515-2019. IPCC, 2013: Climate Change 2013: The Physical Science Basis. Cambridge University Press, 1535 pp.

_ 2018: Summary for Policymakers. Global Warming of $1.5^{\circ} \mathrm{C}$. An IPCC Special Report, V. Masson-Delmotte et al., Eds., World Meteorological Organization, 32 pp. 
Isaksen, K., J. L. Sollid, P. Holmlund, and C. Harris, 2007: Recent warming of mountain permafrost in Svalbard and Scandinavia. J. Geophys. Res., 112, F02S04, https://doi.org/10.1029/2006JF000522.

_ - and Coauthors, 2011: Degrading mountain permafrost in southern Norway: Spatial and temporal variability of mean ground temperatures, 1999-2009. Permafr. Periglac. Process., 22, 361-377, https://doi. org/10.1002/ppp.728.

Ishihara, K., 2006: Calculation of global surface temperature anomalies with COBE-SST (in Japanese). Sokko-jiho [Weather Service Bull.], 73, S19-S25.

Ishii, M., and Coauthors, 2009: Spatial variability and decadal trend of the oceanic $\mathrm{CO}_{2}$ in the western equatorial Pacific warm/fresh water. Deep-Sea Res. II, 56, 591-606, https://doi.org/10.1016/j.dsr2.2009.01.002. — , and Coauthors, 2014: Air-sea $\mathrm{CO}_{2}$ flux in the Pacific Ocean for the period 1990-2009. Biogeosciences, 11, 709-734, https://doi.org/10.5194/bg-11-709-2014.

- , Y. Fukuda, S. Hirahara, S. Yasui, T. Suzuki, and K. Sato, 2017: Accuracy of global upper ocean heat content estimation expected from present observational data sets. SOLA, 13, 163-167, https://doi .org/10.2151/sola.2017-030.

Jansen, D., B. Kulessa, P. R. Sammonds, A. Luckman, E. C. King, and N. F. Glasser, 2010: Present stability of the Larsen $C$ ice shelf, Antarctic Peninsula. J. Glaciol., 56, 593-600, https://doi.org /10.3189/002214310793146223.

Jiménez-Muñoz, J. C., C. Mattar, J. Barichivich, A. Santamaría-Artigas, K. Takahashi, Y. Malhi, J. A. Sobrino, and G. v. d. Schrier, 2016: Record-breaking warming and extreme drought in the Amazon rainforest during the course of El Niño 2015-2016. Sci. Rep., 6, 33130, https://doi.org/10.1038/srep33130.

John, V. O., and B. J. Soden, 2007: Temperature and humidity biases in global climate models and their impact on climate feedbacks. Geophys. Res. Lett., 34, L18704, https://doi.org/10.1029/2007GL030429.

—, G. Holl, R. P. Allan, S. A. Buehler, D. E. Parker, and B. J. Soden, 2011: Clear-sky biases in satellite infra-red estimates of upper tropospheric humidity and its trends. J. Geophys. Res., 116, D14108, https:// doi.org/10.1029/2010JD015355.

Johnson, D., D. Ko, J. Franks, P. Moreno, and G. Sanchez-Rubio, 2013: The Sargassum invasion of the eastern Caribbean and dynamics of the equatorial North Atlantic. Proc. Annu. Gulf Caribb. Fish. Inst., 65, 102-103.

Johnson, G. C., 2008: Quantifying Antarctic bottom water and North Atlantic Deep Water volumes. J. Geophys. Res., 113, C05027, https://doi. org/10.1029/2007JC004477.
—, and J. M. Lyman, 2012: Sea surface salinity [in "State of the Climate in 2011"]. Bull. Amer. Meteor. Soc., 93, S68-S69, S72, https://doi.org/10.1175 /2012BAMSStateoftheClimate.1.

— Pacific warm pool expands, ocean gains more heat. Geophys. Res. Lett., 44, 438-445, https://doi. org/10.1002/2016GL071767.

—, and J. M. Lyman, 2018: Sea surface salinity [in "State of the Climate in 2017"]. Bull. Amer. Meteor. Soc., 99, S78-S79, https://doi.org/10.1175 /2018BAMSStateoftheClimate.1.

$\longrightarrow,-$ J. K. Willis, T. Boyer, J. Antonov, S. A. Good, C. M. Domingues, and N. Bindoff, 2014: Ocean heat content [in "State of the Climate in 2013"]. Bull. Amer. Meteor. Soc., 95, S54-S57, https://doi.org/10. 1175/2014BAMSStateoftheClimate.1.

— of the Climate in 2014"]. Bull. Amer. Meteor. Soc., 96, S64-S66, S68, https://doi.org/10.1175/2015BAMSSta teoftheClimate.1.

_- J. M. Lyman, and N. G. Loeb, 2016: Improving estimates of Earth's energy imbalance. Nat. Climate Change, 6, 639, https://doi.org/10.1038/nclimate3043. — , and Coauthors, 2018: Ocean heat content. [in "State of the Climate in 2017"]. Bull. Amer. Meteor. Soc., 99, S72-S77, https://doi.org/10.1175 /2018BAMSStateoftheClimate.1.

Johnson, K. S., and Coauthors, 2017: Biogeochemical sensor performance in the SOCCOM profiling float array. J. Geophys. Res. Oceans, 122, 6416-6436, https://doi.org/10.1002/2017JC012838.

Jones, D. A., W. Wang, and R. Fawcett, 2009: Highquality spatial climate data-sets for Australia. Aust. Meteor. Oceanogr. J., 58, 233-248, https://doi.org/ https://doi.org/10.22499/2.5804.003.

Jones, P. D., D. H. Lister, T. J. Osborn, C. Harpham, M. Salmon, and C. P. Morice, 2012: Hemispheric and large-scale land-surface air temperature variations: An extensive revision and an update to 2010. J. Geophys. Res., 117, D05127, https://doi. org/10.1029/2011JD017139.

Joyce, R. J., J. E. Janowiak, P. A. Arkin, and P. Xie, 2004: CMORPH: A method that produces global precipitation estimates from passive microwave and infrared data at high spatial and temporal resolution. J. Hydrometeor., 5, 487-503, https://doi.org/10.1175/15257541(2004)005<0487:camtpg>2.0.co;2.

Jung, M., and Coauthors, 2010: Recent decline in the global land evapotranspiration trend due to limited moisture supply. Nature, 467, 951-954, https://doi. org/10.1038/nature09396. 
Kaiser, J. W., and Coauthors, 2012: Biomass burning emissions estimated with a global fire assimilation system based on observed fire radiative power. Biogeosciences, 9, 527-554, https://doi.org/10.5194/ bg-9-527-2012.

— W. Xu, A. Heil, T. Nikonovas, I. Hüser, and M. J. Wooster, 2017: How to use SEVIRI fire radiative power in the Copernicus Atmosphere Monitoring Service. Proc. 2017 EUMETSAT Meteorological Satellite Conf., EUMETSAT.

Kalnay, E., and Coauthors, 1996: The NCEP/NCAR 40-year reanalysis project. Bull. Amer. Meteor. Soc., 77, 437-471, https://doi.org/10.1175/15200477(1996)077<0437:tnyrp >2.0.co;2.

Kanamitsu, M., W. Ebisuzaki, J. Woollen, S.-K. Yang, J. J. Hnilo, M. Fiorino, and G. L. Potter, 2002: NCEP-DOE AMIP-II Reanalysis (R-2). Bull. Amer. Meteor. Soc., 83, 1631-1644, https://doi.org/10.1175/ bams-83-11-1631.

Kaplan, A., 2011: Patterns and indices of climate variability [in"State of the Climate in 2010"]. Bull. Amer. Meteor. Soc., 92, S20-S25, https://doi. org/10.1175/1520-0477-92.6.s1.

Karlsen, S. R., H. B. Anderson, R. v. d. Wal, and B. B. Hansen, 2018: A new NDVI measure that overcomes data sparsity in cloud-covered regions predicts annual variation in ground-based estimates of high arctic plant productivity. Environ. Res. Lett., 13, 025011, https://doi.org/10.1088/1748-9326/aa9f75.

Karlsson, K. G., and Coauthors, 2017: CLARA-A2: The second edition of the CM SAF cloud and radiation data record from 34 years of global AVHRR data. Atmos. Chem. Phys., 17, 5809-5828, https://doi. org/10.5194/acp-17-5809-2017.

Karpechko, A. Y., A. Charlton-Perez, M. Balmaseda, N. Tyrrell, and F. Vitart, 2018: Predicting sudden stratospheric warming 2018 and its climate impacts with a multimodel ensemble. Geophys. Res. Lett., 45, 13,538-13,546, https://doi.org/10.1029/2018gl081091.

— - and Coauthors, 2019: Stratospheric ozone changes and climate. Scientific Assessment of Ozone Depletion: 2018, World Meteorological Organization, 5.1-5.61.

Karplus, V. J., S. Zhang, and D. Almond, 2018: Quantifying coal power plant responses to tighter $\mathrm{SO}_{2}$ emissions standards in China. Proc. Natl. Acad. Sci. USA, 115, 7004-7009, https://doi.org/10.1073/ pnas. 1800605115.

Kato, S., and Coauthors, 2018: Surface Irradiances of Edition 4.0 Clouds and the Earth's Radiant Energy System (CERES) Energy Balanced and Filled (EBAF) Data Product. J. Climate, 31, 4501-4527, https://doi. org/10.1175/jcli-d-17-0523.1.
Kayano, M. T., and V. E. Kousky, 1999: Intraseasonal (30-60 day) variability in the global tropics: Principal modes and their evolution. Tellus, 51 A, 373-386, https://doi.org/10.3402/tellusa.v51i3.13459.

Keenan, T. F., and W. J. Riley, 2018: Greening of the land surface in the world's cold regions consistent with recent warming. Nat. Climate Change, 8, 825-828, https://doi.org/10.1038/s41558-018-0258-y.

Kennedy, J. J., and Coauthors, 2010: How do we know the world has warmed? [in "State of the Climate in 2009”]. Bull. Amer. Meteor. Soc., 91, S26-S27, https:// doi.org/10.1175/BAMS-91-7-StateoftheClimate.

- , N. A. Rayner, R. O. Smith, D. E. Parker, and M. Saunby, 2011a: Reassessing biases and other uncertainties in sea surface temperature observations measured in situ since 1850: 1. Measurement and sampling uncertainties. J. Geophys. Res., 116, D14103, https://doi.org/10.1029/2010JD015218.

$-, \ldots,-, \ldots$, and — 2011b: Reassessing biases and other uncertainties in sea surface temperature observations measured in situ since 1850: 2. Biases and homogenization. J. Geophys. Res., 116, D14104, https://doi.org/10.1029/2010JD015220.

Kent, E. C., and Coauthors, 2017: A call for new approaches to quantifying biases in observations of sea surface temperature. Bull. Amer. Meteor. Soc., 98, 1601-1616, https://doi.org/10.1175/bams -D-15-00251.1.

Khatiwala, S., and Coauthors, 2013: Global ocean storage of anthropogenic carbon. Biogeosciences, 10 , 2169-2191, https://doi.org/10.5194/bg-10-2169-2013.

Kiladis, G. N., and K. M. Weickmann, 1992: Circulation anomalies associated with tropical convection during northern winter. Mon. Wea. Rev., 120, 1900-1923, https://doi.org/10.1175/1520-0493(1992)120<1900:ca awtc $>2.0 . c 0 ; 2$.

—, K. H. Straub, and P. T. Haertel, 2005: Zonal and vertical structure of the Madden-Julian oscillation. J. Atmos. Sci., 62, 2790-2809, https://doi.org/10.1175/ jas3520.1.

—, M. C. Wheeler, P. T. Haertel, K. H. Straub, and P. E. Roundy, 2009: Convectively coupled equatorial waves. Rev. Geophys., 47, RG2003, https://doi .org/10.1029/2008RG000266.

Kim, B.-M., and Coauthors, 2017: Major cause of unprecedented Arctic warming in January 2016: Critical role of an Atlantic windstorm. Sci. Rep., 7, 40051, https://doi.org/10.1038/srep40051.

Kim, H., 2017: River discharge [in "State of the Climate in 2016"]. Bull. Amer. Meteor. Soc., 98 (8), S28-S30, https://doi.org/10.1175/2017BAMSStateoftheClimate.1. 
_ 2018: River discharge and runoff [in "State of the Climate in 2017”]. Bull. Amer. Meteor. Soc., 99 (8), S33-S34, https://doi.org/10.1175/2018BAMSStateof theClimate.1.

— , P. J.-F. Yeh, T. Oki, and S. Kanae, 2009: Role of rivers in the seasonal variations of terrestrial water storage over global basins. Geophys. Res. Lett., 36, L17402, https://doi.org/10.1029/2009GL039006.

Kim, J., and K. Paik, 2015: Recent recovery of surface wind speed after decadal decrease: A focus on South Korea. Climate Dyn., 45, 1699-1712, https://doi. org/10.1007/s00382-015-2546-9.

Kim, Y. S., and A. H. Orsi, 2014: On the variability of Antarctic circumpolar current fronts inferred from 1992-2011 altimetry. J. Phys. Oceanogr., 44, 3054-3071, https://doi.org/10.1175/jpo-d-13-0217.1.

Kimura, N., and M. Wakatsuchi, 2011: Large-scale processes governing the seasonal variability of the Antarctic sea ice. Tellus, 63A, 828-840, https://doi. org/10.1111/j.1600-0870.2011.00526.x.

Kingslake, J., J. C. Ely, I. Das, and R. E. Bell, 2017: Widespread movement of meltwater onto and across Antarctic ice shelves. Nature, 544, 349, https://doi. org/10.1038/nature22049.

Kirkpatrick, N., 2015: Beautiful Caribbean beaches now a smelly mess after massive seaweed invasion. Washington Post, 14 August, https://www.washingtonpost. com/news/morning-mix/wp/2015/08/14/paradiselost-caribbean-beaches-face-a-massive-seaweedinvasion-ahead-of-winter-tourism-season/?utm_ term=.80da6ale81aa.

Kjøllmoen, B., L. M. Andreassen, H. Elvehøy, and M. Jackson, 2018: Glaciological investigations in Norway 2017. NVE Rep. 82-2018, Norwegian Water Resources and Energy Directorate (NVE), 84+ pp., http://publikasjoner.nve.no/rapport/2018/rapport2018_82.pdf.

Klein, S. A., A. Hall, J. R. Norris, and R. Pincus, 2017: Low-cloud feedbacks from cloud-controlling factors: A review. Surv. Geophys., 38, 1307-1329, https://doi. org/10.1007/s10712-017-9433-3.

Klotzbach, P. J., 2010: On the Madden-Julian Oscillation-Atlantic Hurricane Relationship. J. Climate, 23, 282-293, https://doi.org/10.1175/2009jcli2978.1.

Knapp, K. R., M. C. Kruk, D. H. Levinson, H. J. Diamond, and C. J. Neumann, 2010: The international best track archive for climate stewardship (IBTrACS). Bull. Amer. Meteor. Soc., 91, 363-376, https://doi.org/10.1175/2009bams2755.1.

_, J. A. Knaff, C. R. Sampson, G. M. Riggio, and A. D. Schnapp, 2013: A pressure-based analysis of the historical western North Pacific tropical cyclone intensity record. Mon. Wea. Rev., 141, 2611-2631, https://doi.org/10.1175/mwr-d-12-00323.1.
Knutson, T. R., and K. M. Weickmann, 1987: 30-60 Day atmospheric oscillations: Composite life cycles of convection and circulation anomalies. Mon. Wea. Rev., 115, 1407-1436, https://doi.org/10.1175/15200493(1987)115<1407:daoclc>2.0.co;2.

Kobayashi, S., and Coauthors, 2015: The JRA-55 reanalysis: General specifications and basic characteristics. J. Meteor. Soc. Japan, 93, 5-48, https://doi.org/10.2151/ jmsj.2015-001.

Kopp, G., and J. L. Lean, 2011: A new, lower value of total solar irradiance: Evidence and climate significance. Geophys. Res. Lett., 38, L01706, https:// doi.org/10.1029/2010GL045777.

Kosaka, Y., and H. Nakamura, 2010: Mechanisms of meridional teleconnection observed between a summer monsoon system and a subtropical anticyclone. Part I: The Pacific-Japan pattern. J. Climate, 23, 5085-5108, https://doi.org/10.1175/2010jcli3413.1.

Kousky, V. E., and M. T. Kayano, 1994: Principal modes of outgoing longwave radiation and 250mb circulation for the South American sector. $J$. Climate, 7, 1131-1143, https:/doi.org/10.1175/15200442(1994)007<1131:pmoolr>2.0.co;2.

Kratz, D. P., P. W. Stackhouse Jr., S. K. Gupta, A. C. Wilber, P. Sawaengphokhai, and G. R. McGarragh, 2014: The fast longwave and shortwave flux (FLASHFlux) data product: Single-scanner footprint fluxes. J. Appl. Meteor. Climatol., 53, 1059-1079, https://doi. org/10.1175/jamc-d-13-061.1.

Krishnamurti, T. N., and D. Subrahmanyam, 1982: The 30-50 day mode at $850 \mathrm{mb}$ during MONEX. J. Atmos. Sci., 39, 2088-2095, https://doi.org/10.1175/15200469(1982)039<2088:TDMAMD>2.0.CO;2.

Kuttippurath, J., and P. J. Nair, 2017: The signs of Antarctic ozone hole recovery. Sci. Rep., 7, 585, https:// doi.org/10.1038/s41598-017-00722-7.

L'Heureux, M. L., and Coauthors, 2017: Observing and predicting the 2015/16 El Niño. Bull. Amer. Meteor. Soc., 98, 1363-1382, https://doi.org/10.1175/bams -d-16-0009.1.

—, G. D. Bell, and M. S. Halpert, 2018: ENSO and the tropical Pacific [in "State of the Climate in 2017”]. Bull. Amer. Meteor. Soc., 99, S102-S104, https://doi .org/10.1175/2018BAMSStateoftheClimate.1.

Lafleur, P. M., and E. R. Humphreys, 2018: Tundra shrub effects on growing season energy and carbon dioxide exchange. Environ. Res. Lett., 13, 055001, https://doi .org/10.1088/1748-9326/aab863.

Lander, M. A., and C. P. Guard, 2018: Northwest Pacific and Micronesia [in "State of the Climate in 2017"]. Bull. Amer. Meteor. Soc., 99, S221-S222, https://doi .org/10.1175/2018BAMSStateoftheClimate.1. 
Landschützer, P., N. Gruber, D. C. E. Bakker, U. Schuster, S. Nakaoka, M. R. Payne, T. P. Sasse, and J. Zeng, 2013: A neural network-based estimate of the seasonal to inter-annual variability of the Atlantic Ocean carbon sink. Biogeosciences, 10, 7793-7815, https://doi.org/10.5194/bg-10-7793-2013.

$-, \ldots, \ldots$, and U. Schuster, 2014: Recent variability of the global ocean carbon sink. Global Biogeochem. Cycles, 28, 927-949, https://doi .org/10.1002/2014GB004853.

$\longrightarrow, \ldots$, and ——, 2016: Decadal variations and trends of the global ocean carbon sink. Global Biogeochem. Cycles, 30, 1396-1417, https://doi .org/10.1002/2015gb005359.

Landsea, C. W., and J. L. Franklin, 2013: Atlantic hurricane database uncertainty and presentation of a new database format. Mon. Wea. Rev., 141, 3576-3592, https://doi.org/10.1175/mwr-d-12-00254.1.

—, W. M. Gray, P. W. M. Jr., and K. J. Berry, 1992: Long-term variations of western Sahelian monsoon rainfall and intense U.S. landfalling hurricanes. J. Climate, 5, 1528-1534, https://doi.org/10.1175/1520 -0442(1992)005<1528:Ltvows>2.0.Co;2.

—, G. D. Bell, W. M. Gray, and S. B. Goldenberg, 1998: The extremely active 1995 Atlantic hurricane season: Environmental conditions and verification of seasonal forecasts. Mon. Wea. Rev., 126, 1174-1193, https://doi.org/10.1175/1520-0493(1998)126<1174: Teaahs $>2.0 . \mathrm{CO} ; 2$.

—, B. A. Harper, K. Hoarau, and J. A. Knaff, 2006: Can we detect trends in extreme tropical cyclones? Science, 313, 452-454, https://doi.org/10.1126 /science.1128448.

Langin, K., 2018: Mysterious masses of seaweed assault Caribbean islands. Science, https://doi.org/10.1126/ science.aau4441.

Lapointe, B. E., 1995: A comparison of nutrient-limited productivity in Sargassum natans from neritic vs. oceanic waters of the western North Atlantic Ocean. Limnol. Oceanogr., 40, 625-633, https://doi .org/10.4319/lo.1995.40.3.0625.

—, L. E. West, T. T. Sutton, and C. Hu, 2014: Ryther revisited: nutrient excretions by fishes enhance productivity of pelagic Sargassum in the western North Atlantic Ocean. J. Exp. Mar. Biol. Ecol., 458, 46-56, https://doi.org/10.1016/j.jembe.2014.05.002.

Lara, M. J., I. Nitze, G. Grosse, P. Martin, and A. D. McGuire, 2018: Reduced arctic tundra productivity linked with landform and climate change interactions. Sci. Rep., 8, 2345, https://doi.org/10.1038 /s41598-018-20692-8.
Lareau, N. P., N. J. Nauslar, and J. T. Abatzoglou, 2018: The Carr fire vortex: A case of pyrotornadogenesis? Geophys. Res. Lett., 45, 13,107-113,115, https:/doi. org/10.1029/2018gl080667.

Larsen, P. H., S. Goldsmith, O. Smith, M. L. Wilson, K. Strzepek, P. Chinowsky, and B. Saylor, 2008: Estimating future costs for Alaska public infrastructure at risk from climate change. Global Enviorn. Change, 18, 442-457, https://doi.org/10.1016/j.gloenvcha.2008.03.005.

Lau, W. K.-M., and D. E. Waliser, 2012: Intraseasonal Variability in the Atmosphere-Ocean Climate System. Springer, $642 \mathrm{pp}$.

Lavoie, C., and Coauthors, 2015: Configuration of the Northern Antarctic Peninsula Ice Sheet at LGM based on a new synthesis of seabed imagery. Cryosphere, 9, 613-629, https://doi.org/10.5194/tc -9-613-2015.

Le Quéré, C., and Coauthors, 2018: Global Carbon Budget 2018. Earth Syst. Sci. Data, 10, 2141-2194, https:// doi.org/10.5194/essd-10-2141-2018.

Lecomte, O., H. Goosse, T. Fichefet, C. de Lavergne, A. Barthélemy, and V. Zunz, 2017: Vertical ocean heat redistribution sustaining sea-ice concentration trends in the Ross Sea. Nat. Comm., 8, 258, https:// doi.org/10.1038/s41467-017-00347-4.

Lenaerts, J. T. M., and M. R. van den Broeke, 2012: Modeling drifting snow in Antarctica with a regional climate model: 2. Results. J. Geophys. Res., 117, D05109, https://doi.org/10.1029/2010JD015419.

Leuliette, E. W., and J. K. Willis, 2011: Balancing the sea level budget. Oceanography, 24, 122-129, https:/doi .org/10.5670/oceanog.2011.32.

Levitus, S., and Coauthors, 2012: World ocean heat content and thermosteric sea level change (0-2000 m), 1955-2010. Geophys. Res. Lett., 39, L10603, https:// doi.org/10.1029/2012GL051106.

Levy, R. C., S. Mattoo, L. A. Munchak, L. A. Remer, A. M. Sayer, F. Patadia, and N. C. Hsu, 2013: The Collection 6 MODIS aerosol products over land and ocean. Atmos. Meas. Tech., 6, 2989-3034, https://doi. org/10.5194/amt-6-2989-2013.

Li, B., M. Rodell, and J. S. Famiglietti, 2015: Groundwater variability across temporal and spatial scales in the central and northeastern U.S. J. Hydrol., 525, 769780, https://doi.org/10.1016/j.jhydrol.2015.04.033.

Li, T., and P.-C. Hsu, 2017: Fundamentals of Tropical Climate Dynamics. Springer, 229 pp.

Lieb, G., and A. Kellerer-Pirklbauer, 2018: Gletscherbericht 2016/2017: Sammelbericht über die Gletschermessungen des Österreichischen Alpenvereins im Jahre 2017. Bergauf, 02/2018, 20-29. 
Liebmann, B., and C. A. Smith, 1996: Description of a complete (interpolated) outgoing longwave radiation dataset. Bull. Amer. Meteor. Soc., 77, 1275-1277.

Liljedahl, A. K., and Coauthors, 2016: Pan-Arctic icewedge degradation in warming permafrost and its influence on tundra hydrology. Nat. Geosci., 9, 312, https://doi.org/10.1038/ngeo2674.

Lin, H., G. Brunet, and J. Derome, 2009: An observed connection between the North Atlantic oscillation and the Madden-Julian oscillation. J. Climate, 22, 364-380, https://doi.org/10.1175/2008jcli2515.1.

Lin, I.-I., and J. C. L. Chan, 2015: Recent decrease in typhoon destructive potential and global warming implications. Nat. Comm., 6, 7182, https://doi. org/10.1038/ncomms8182.

— C.-C. Wu, I.-F. Pun, and D.-S. Ko, 2008: Upperocean thermal structure and the western North Pacific category 5 Typhoons. Part I: Ocean features and the category 5 typhoons' intensification. Mon. Wea. Rev., 136, 3288-3306, https://doi .org/10.1175/2008mwr2277.1.

— tial intensity index for tropical cyclones. Geophys. Res. Lett., 40, 1878-1882, https://doi.org/10.1002 /grl.50091.

— , I.-F. Pun, and C.-C. Lien, 2014: "Category-6" Supertyphoon Haiyan in global warming hiatus: Contribution from subsurface ocean warming. Geophys. Res. Lett., 41, 8547-8553, https://doi .org/10.1002/2014GL061281.

Lin, M., L. W. Horowitz, R. Payton, A. M. Fiore, and G. Tonnesen, 2017: US surface ozone trends and extremes from 1980 to 2014: Quantifying the roles of rising Asian emissions, domestic controls, wildfires, and climate. Atmos. Chem. Phys., 17, 2943-2970, https://doi.org/10.5194/acp-17-2943-2017.

Lind, S., R. B. Ingvaldsen, and T. Furevik, 2018: Arctic warming hotspot in the northern Barents Sea linked to declining sea-ice import. Nat. Climate Change, $\mathbf{8}$, 634-639, https://doi.org/10.1038/s41558-018-0205-y.

Liu, H., 2006: Spatiotemporal variations of snowmelt in Antarctica derived from satellite scanning multichannel microwave radiometer and special sensor microwave imager data (1978-2004). J. Geophys. Res., 111, F01003, https://doi.org/10.1029/2005JF000318.

—_, L. Wang, and K. C. Jezek, 2005: Wavelettransform based edge detection approach to derivation of snowmelt onset, end and duration from satellite passive microwave measurements. Int. J. Remote Sens., 26, 4639-4660, https://doi .org/10.1080/01431160500213342.
Liu, W., S.-P. Xie, Z. Liu, and J. Zhu, 2017: Overlooked possibility of a collapsed Atlantic meridional overturning circulation in warming climate. Sci. Adv., 3, e1601666, https://doi.org/10.1126/sciadv.1601666.

Liu, Y., F. Li, and W. Hao, 2018: Evaluation of seasonal and synoptic changes in snow accumulation in Antarctica between five reanalyses products and in situ observations. Atmosphere, 9, 473, https://doi. org/10.3390/atmos9120473.

Liu, Y. Y., W. A. Dorigo, R. M. Parinussa, R. A. M. de Jeu, W. Wagner, M. F. McCabe, J. P. Evans, and A. I. J. M. van Dijk, 2012: Trend-preserving blending of passive and active microwave soil moisture retrievals. Remote Sens. Environ., 123, 280-297, https://doi. org/10.1016/j.rse.2012.03.014.

Loeb, N. G., B. A. Wielicki, D. R. Doelling, G. L. Smith, D. F. Keyes, S. Kato, N. Manalo-Smith, and T. Wong, 2009: Toward optimal closure of the Earth's top-ofatmosphere radiation budget. J. Climate, 22, 748-766, https://doi.org/10.1175/2008jcli2637.1.

—, S. Kato, W. Su, T. Wong, F. G. Rose, D. R. Doelling, J. R. Norris, and X. Huang, 2012: Advances in understanding top-of-atmosphere radiation variability from satellite observations. Surv. Geophys., 33, 359-385, https://doi.org/10.1007/s10712-012-9175-1.

— diant Energy System (CERES) Energy Balanced and Filled (EBAF) Top-of-Atmosphere (TOA) Edition-4.0 Data Product. J. Climate, 31, 895-918, https://doi .org/10.1175/jcli-d-17-0208.1.

Long, Z., and W. Perrie, 2017: Changes in ocean temperature in the Barents Sea in the twenty-first century. J. Climate, 30, 5901-5921, https://doi.org/10.1175 /jcli-d-16-0415.1.

Lozier, M. S., and Coauthors, 2019: A sea change in our view of overturning in the subpolar North Atlantic. Science, 363, 516-521, https://doi.org/10.1126/science.aau6592.

Lu, X., and Coauthors, 2018a: Severe Surface Ozone Pollution in China: A Global Perspective. Environ. Sci. Technol. Lett., 5, 487-494, https://doi.org/10.1021 /acs.estlett.8b00366.

— ozone trends in the Southern Hemisphere since 1990: Possible linkages to poleward expansion of the Hadley circulation. Sci. Bull., https://doi.org/10.1016 /j.scib.2018.12.021.

Lumpkin, R., and S. Garzoli, 2011: Interannual to decadal changes in the western South Atlantic's surface circulation. J. Geophys. Res., 116, C01014, https://doi.org/10.1029/2010JC006285. 
Lund, J., J. Medellin-Azuara, J. Durand, and K. Stone, 2018: Lessons from California's 2012-2016 Drought. J. Water Resour. Plann. Manage., 144, 04018067, https:// doi.org/10.1061/(ASCE)WR.1943-5452.0000984.

Luo, J.-J., 2018: Indian Ocean dipole [in "State of the Climate in 2017"]. Bull. Amer. Meteor. Soc., 99, S133-S135, https:/doi.org/10.1175/2018BAMSState oftheClimate.1.

— , S. Masson, S. Behera, and T. Yamagata, 2007: Experimental forecasts of the Indian Ocean dipole using a coupled OAGCM. J. Climate, 20, 2178-2190, https://doi.org/10.1175/jcli4132.1.

_-, R. Zhang, S. K. Behera, Y. Masumoto, F.-F. Jin, R. Lukas, and T. Yamagata, 2010: Interaction between El Niño and extreme Indian Ocean dipole. J. Climate, 23, 726-742, https://doi.org/10.1175/2009jcli3104.1.

_- W. Sasaki, and Y. Masumoto, 2012: Indian Ocean warming modulates Pacific climate change. Proc. Natl. Acad. Sci. USA, 109, 18701-718706, https://doi .org/10.1073/pnas.1210239109.

Lyman, J. M., and G. C. Johnson, 2014: Estimating global ocean heat content changes in the upper $1800 \mathrm{~m}$ since 1950 and the influence of climatology choice. J. Climate, 27, 1945-1957, https://doi.org/10.1175 /jcli-d-12-00752.1.

MacCallum, S. N., and C. J. Merchant, 2012: Surface water temperature observations of large lakes by optimal estimation. Can. J. Remote Sens., 38, 25-45, https://doi.org/10.5589/m12-010.

MacFarling Meure, C., D. Etheridge, C. Trudinger, P. Steele, R. Langenfelds, T. van Ommen, A. Smith, and J. Elkins, 2006: Law Dome $\mathrm{CO}_{2}, \mathrm{CH}_{4}$ and $\mathrm{N}_{2} \mathrm{O}$ ice core records extended to 2000 years BP. Geophys. Res. Lett, 33, L14810, https://doi .org/10.1029/2006GL026152.

Madden, R. A., and P. R. Julian, 1971: Detection of a 40-50 day oscillation in the zonal wind in the tropical Pacific. J. Atmos. Sci., 28, 702-708, https://doi. org/10.1175/1520-0469(1971)028<0702:doadoi $>2.0$ .co;2.

$\longrightarrow$, and - 1972: Description of global-scale circulation cells in the tropics with a $40-50$ day period. J. Atmos. Sci., 29, 1109-1123, https://doi.org/10.1175/1520 -0469(1972)029<1109:dogscc >2.0.co;2.

$\longrightarrow$, and — 1994: Observations of the 40-50day tropical oscillation-A review. Mon. Wea. Rev., 122, 814-837, https://doi.org/10.1175/1520 -0493(1994)122<0814:ootdto>2.0.co;2.

Magaña, V., J. A. Amador, and S. Medina, 1999: The midsummer drought over Mexico and Central America. J. Climate, 12, 1577-1588, https://doi. org/10.1175/1520-0442(1999)012<1577:Tmdoma $>2$ $.0 . \mathrm{CO} ; 2$.
Magaña, H. A., C. Contreras, and T. A. Villareal, 2003: A historical assessment of Karenia brevis in the western Gulf of Mexico. Harmful Algae, 2, 163-171, https:// doi.org/10.1016/S1568-9883(03)00026-X.

Magee, A. D., and D. C. Verdon-Kidd, 2018: On the relationship between Indian Ocean sea surface temperature variability and tropical cyclogenesis in the southwest Pacific. Int. J Climatol., 38, e774-e795, https://doi.org/10.1002/joc.5406.

Magnin, F., P. Deline, L. Ravanel, J. Noetzli, and P. Pogliotti, 2015: Thermal characteristics of permafrost in the steep alpine rock walls of the Aiguille du Midi (Mont Blanc Massif, $3842 \mathrm{~m}$ a.s.1). Cryosphere, 9, 109-121, https://doi.org/10.5194/tc-9-109-2015.

Mahlstein, I., and R. Knutti, 2012: September Arctic sea ice predicted to disappear near $2^{\circ} \mathrm{C}$ global warming above present. J. Geophys. Res., 117, D06104, https:// doi.org/10.1029/2011jd016709.

Mainelli, M., M. DeMaria, L. K. Shay, and G. Goni, 2008: Application of oceanic heat content estimation to operational forecasting of recent Atlantic category 5 hurricanes. Wea. Forecasting, 23, 3-16, https://doi. org/10.1175/2007waf2006111.1.

Maliniemi, T., J. Kapfer, P. Saccone, A. Skog, and R. Virtanen, 2018: Long-term vegetation changes of treeless heath communities in northern Fennoscandia: Links to climate change trends and reindeer grazing. J. Veg. Sci., 29, 469-479, https://doi. org/10.1111/jvs.12630.

Maloney, E. D., and D. L. Hartmann, 2001: The Madden-Julian oscillation, barotropic dynamics, and North Pacific tropical cyclone formation. Part I: Observations. J. Atmos. Sci., 58, 2545-2558, https:// doi.org/10.1175/1520-0469(2001)058<2545:tmjobd $>2.0 . \operatorname{co} ; 2$.

Manabe, S., and R. T. Wetherald, 1967: Thermal equilibrium of the atmosphere with a given distribution of relative humidity. J. Atmos. Sci., 24, 241-259, https:// doi.org/10.1175/1520-0469(1967)024<0241:Teotaw $>2.0 . \mathrm{Co} ; 2$.

Mann, M. E., S. Rahmstorf, K. Kornhuber, B. A. Steinman, S. K. Miller, and D. Coumou, 2017: Influence of anthropogenic climate change on planetary wave resonance and extreme weather events. Sci. Rep., 7, 45242, https://doi.org/10.1038/srep45242.

Manney, G. L., and Coauthors, 2011: Unprecedented Arctic ozone loss in 2011. Nature, 478, 469-475, https://doi.org/10.1038/nature10556.

Mantua, N. J., and S. R. Hare, 2002: The Pacific Decadal Oscillation. J. Oceanogr., 58, 35-44, https://doi. org/10.1023/a:1015820616384. 
Marengo, J. A., L. M. Alves, R. C. S. Alvala, A. P. Cunha, S. Brito, and O. L. L. Moraes, 2017: Climatic characteristics of the 2010-2016 drought in the semiarid Northeast Brazil región. Ann. Brazilian Acad. Sci., 80, 1973-1985, https://doi.org/10.1590/00013765201720170206.

Marshall, G. J., 2003: Trends in the southern annular mode from observations and reanalyses. J. Climate, 16, 4134-4143, https://doi.org/10.1175/15200442(2003)016<4134:titsam>2.0.co;2.

Martens, B., W. Waegeman, W. A. Dorigo, N. E. C. Verhoest, and D. G. Miralles, 2018: Terrestrial evaporation response to modes of climate variability. $n p j$ Climate Atmos. Sci., 1, 43, https://doi.org/10.1038/ s41612-018-0053-5.

Martens, B., and Coauthors, 2017: GLEAM v3: Satellitebased land evaporation and root-zone soil moisture. Geosci. Model Dev., 10, 1903-1925, https://doi .org/10.5194/gmd-10-1903-2017.

Marzeion, B., J. G. Cogley, K. Richter, and D. Parkes, 2014: Attribution of global glacier mass loss to anthropogenic and natural causes. Science, 345, 919-921, https://doi.org/10.1126/science.1254702.

Marzeion, B., N. Champollion, W. Haeberli, K. Langley, P. Leclercq, and F. Paul, 2017: Observation-based estimates of global glacier mass change and its contribution to sea-level change. Surv. Geophys., 38, 105-130, https://doi.org/10.1007/s10712-016-9394-y.

Maslanik, J., and J. Stroeve, 1999, updated daily: Nearreal-time DMSP SSM/I-SSMIS Daily Polar Gridded Sea Ice Concentrations. National Snow and Ice Data Center, http://nsidc.org/data/docs/daac/nsidc0081_ ssmi_nrt_seaice.gd.html.

,-- , C. Fowler, and W. Emery, 2011: Distribution and trends in Arctic sea ice age through spring 2011. Geophys. Res. Lett., 38, L13502, https://doi .org/10.1029/2011GL047735.

Massom, R. A., T. A. Scambos, L. G. Bennetts, P. Reid, V. A. Squire, and S. E. Stammerjohn, 2018: Antarctic ice shelf disintegration triggered by sea ice loss and ocean swell. Nature, 558, 383-389, https://doi. org/10.1038/s41586-018-0212-1.

Masunaga, H., and T. S. L'Ecuyer, 2010: The southeast Pacific warm band and double ITCZ. J. Climate, 23, 1189-1208, https://doi.org/10.1175/2009jcli3124.1.

Maycock, A. C., and Coauthors, 2018: Revisiting the mystery of recent stratospheric temperature trends. Geophys. Res. Lett., 45, 9919-9933, https://doi. org/10.1029/2018GL078035.

Mazloff, M. R., and Coauthors, 2017: Southern Ocean [in "State of the Climate in 2016"]. Bull. Amer. Meteor. Soc., 97, S166-S167, https://doi.org/10.1175/2017BA MSStateoftheClimate.1.
McBride, A., 2018: Debris cleanup for November wildfires will cost California $\$ 3$ billion. San Francisco Chronicle, 11 December, https://www.sfchronicle. com/california-wildfires/article/Debris-cleanup-forNovember-wildfires-will-cost-13458802.php.

McCabe, M. F., A. Ershadi, C. Jimenez, D. G. Miralles, D. Michel, and E. F. Wood, 2016: The GEWEX LandFlux project: Evaluation of model evaporation using tower-based and globally gridded forcing data. Geosci. Model Dev., 9, 283-305, https://doi. org/10.5194/gmd-9-283-2016.

— , and Coauthors, 2017: The future of Earth observation in hydrology. Hydrol. Earth Syst. Sci., 21, 38793914, https://doi.org/10.5194/hess-21-3879-2017.

_ D. G. Miralles, T. R. H. Holmes, and J. B. Fisher, 2019: Advances in the remote sensing of terrestrial evaporation. Remote Sens., 11(9), 1138, https://doi .org/10.3390/rs11091138.

McClain, C. R., 2009: A decade of satellite ocean color observations. Annu. Rev. Marine Sci., 1, 19-42, https:// doi.org/10.1146/annurev.marine.010908.163650.

McClelland, J. W., S. J. Déry, B. J. Peterson, R. M. Holmes, and E. F. Wood, 2006: A pan-arctic evaluation of changes in river discharge during the latter half of the 20th century. Geophys. Res. Lett., 33, L06715, https://doi.org/10.1029/2006gl025753.

— , R. M. Holmes, K. H. Dunton, and R. Macdonald, 2012: The Arctic Ocean estuary. Estuaries Coasts, 35, 353-368, https://doi.org/10.1007/s12237-010-9357-3.

McEvoy, D. J., M. Hobbins, T. J. Brown, K. VanderMolen, T. Wall, J. L. Huntington, and M. Svoboda, 2019: Establishing relationships between drought indices and wildfire danger outputs: A test case for the California-Nevada Drought Early Warning System. Climate, 7, 52, https://doi.org/10.3390/cli7040052.

McLeod, J. T., 2016: Linking interannual variability in extreme Greenland blocking episodes to the recent increase in summer melting across the Greenland ice sheet. Int. J. Climatology, 36, 1484-1499, https:/doi. org/10.1002/joc.4440.

McVicar, T. R., T. G. Van Niel, L. T. Li, M. L. Roderick, D. P. Rayner, L. Ricciardulli, and R. J. Donohue, 2008: Wind speed climatology and trends for Australia, 1975-2006: Capturing the stilling phenomenon and comparison with near-surface reanalysis output. Geophys. Res. Lett., 35, L20403, https:/doi. org/10.1029/2008GL035627.

— , and Coauthors, 2012: Global review and synthesis of trends in observed terrestrial near-surface wind speeds: Implications for evaporation. J. Hydrol., 416-417, 182-205, https://doi.org/10.1016 /j.jhydrol.2011.10.024. 
Mears, C. A., D. K. Smith, L. Ricciardulli, J. Wang, H. Huelsing, and F. J. Wentz, 2018: Construction and uncertainty estimation of a satellite-derived total precipitable water data record over the world's oceans. Earth Space Sci., 5, 197-210, https://doi .org/10.1002/2018EA000363.

Meehl, G. A., J. M. Arblaster, C. T. Y. Chung, M. M. Holland, A. DuVivier, L. Thompson, D. Yang, and C. M. Bitz, 2019: Sustained ocean changes contributed to sudden Antarctic sea ice retreat in late 2016. Nat. Comm., 10, 14, https://doi.org/10.1038/s41467 -018-07865-9.

Meier, W. N., J. Stroeve, A. Barrett, and F. Fetterer, 2012: A simple approach to providing a more consistent Arctic sea ice extent time series from the $1950 \mathrm{~s}$ to present. Cryosphere, 6, 1359-1368, https://doi. org/10.5194/tc-6-1359-2012.

Meinen, C. S., and M. J. McPhaden, 2000: Observations of Warm Water Volume Changes in the Equatorial Pacific and Their Relationship to El Niño and La Niña. J. Climate, 13, 3551-3559, https://doi. org/10.1175/1520-0442(2000)013<3551:Oowwvc $>2$ $.0 . \mathrm{Co} ; 2$.

— culation transport variability at $34.5^{\circ} \mathrm{S}$ during 2009 2017: Baroclinic and barotropic flows and the dueling influence of the boundaries. Geophys. Res. Lett., 45, 4180-4188, https://doi.org/10.1029/2018gl077408.

Melvin, A. M., and Coauthors, 2017: Climate change damages to Alaska public infrastructure and the economics of proactive adaptation. Proc. Natl. Acad. Sci. USA, 114, E122-E131, https://doi.org/10.1073/ pnas.1611056113.

Menne, M. J., I. Durre, R. S. Vose, B. E. Gleason, and T. G. Houston, 2012: An overview of the Global Historical Climatology Network-Daily database. J. Atmos. Oceanic Technol., 29, 897-910, https://doi .org/10.1175/jtech-d-11-00103.1.

Menzel, W. P., R. A. Frey, E. E. Borbas, B. A. Baum, G. Cureton, and N. Bearson, 2016: Reprocessing of HIRS satellite measurements from 1980 to 2015: Development toward a consistent decadal cloud record. J. Appl. Meteor. Climatol., 55, 2397-2410, https://doi. org/10.1175/jamc-d-16-0129.1.

Merrifield, M. A., 2011: A shift in western tropical Pacific sea level trends during the 1990s. J. Climate, 24, 4126-4138, https://doi.org/10.1175/2011jcli3932.1.

Milillo, P., E. Rignot, P. Rizzoli, B. Scheuchl, J. Mouginot, J. Bueso-Bello, and P. Prats-Iraola, 2019: Heterogeneous retreat and ice melt of Thwaites Glacier, West Antarctica. Sci. Bull., 5, eaau3433, https://doi. org/10.1126/sciadv.aau3433.
Miller, B. R., and Coauthors, 2010: HFC-23 ( $\left.\mathrm{CHF}_{3}\right)$ emission trend response to $\mathrm{HCFC}-22\left(\mathrm{CHClF}_{2}\right)$ production and recent $\mathrm{HFC}-23$ emission abatement measures. Atmos. Chem. Phys., 10, 7875-7890, https://doi.org/10.5194/acp-10-7875-2010.

Minnis, P., K. Bedka, Q. Trepte, C. R. Yost, S. T. Bedka, B. Scarino, K. Khlopenkov, and M. M. Khaiyer, 2016: A consistent long-term cloud and clear-sky radiation property dataset from the Advanced Very High Resolution Radiometer (AVHRR). CDRP-ATBD-0826 Rev 1, 159 pp., https://doi.org/https://doi.org/10.789/ V5HT2M8T.

Minnis, P., and Coauthors, 2008: Cloud detection in nonpolar regions for CERES using TRMM VIRS and Terra and Aqua MODIS data. IEEE Trans. Geosci. Remote Sens., 46, 3857-3884, https://doi.org/10.1109/ TGRS.2008.2001351.

Miralles, D. G., T. R. H. Holmes, R. A. M. De Jeu, J. H. Gash, A. G. C. A. Meesters, and A. J. Dolman, 2011: Global land-surface evaporation estimated from satellite-based observations. Hydrol. Earth Syst. Sci., 15, 453-469, https://doi.org/10.5194/hess-15-453-2011.

_, A. J. Teuling, C. C. van Heerwaarden, and J. Vila-Guerau de Arellano, 2014a: Mega-heatwave temperatures due to combined soil desiccation and atmospheric heat accumulation. Nat. Geosci., 7, 345-349, https://doi.org/10.1038/ngeo2141.

—_, and Coauthors, 2014b: El Niño-La Niña cycle and recent trends in continental evaporation. Nat. Climate Change, 4, 122-126, https://doi.org/10.1038/ nclimate2068.

— - Part 2: Evaluation of global terrestrial evaporation data sets. Hydrol. Earth Syst. Sci., 20, 823-842, https://doi.org/10.5194/hess-20-823-2016.

Miyazaki, K., H. J. Eskes, and K. Sudo, 2015: A tropospheric chemistry reanalysis for the years 2005-2012 based on an assimilation of OMI, MLS, TES, and MOPITT satellite data. Atmos. Chem. Phys., 15, 8315-8348, https://doi.org/10.5194/acp-15-83152015.

Monks, P. S., and Coauthors, 2015: Tropospheric ozone and its precursors from the urban to the global scale from air quality to short-lived climate forcer. Atmos. Chem. Phys., 15, 8889-8973, https://doi.org/10.5194 /acp-15-8889-2015.

Montzka, S. A., J. H. Butler, R. C. Myers, T. M. Thompson, T. H. Swanson, A. D. Clarke, L. T. Lock, and J. W. Elkins, 1996: Decline in the tropospheric abundance of halogen from halocarbons: Implications for stratospheric ozone depletion. Science, 272, 1318-1322, https://doi.org/10.1126/science.272.5266.1318. 
, E. J. Dlugokencky, and J. H. Butler, 2011: Non- $\mathrm{CO}_{2}$ greenhouse gases and climate change. Nature, 476, 43-50, https://doi.org/10.1038/nature10322.

— , and Coauthors, 2018: An unexpected and persistent increase in global emissions of ozonedepleting CFC-11. Nature, 557, 413-417, https://doi .org/10.1038/s41586-018-0106-2.

Moon, T. A., and Coauthors, 2019: The expanding footprint of rapid Arctic change. Earth's Future, 7, 212-218, https://doi.org/10.1029/2018ef001088.

Morice, C. P., J. J. Kennedy, N. A. Rayner, and P. D. Jones, 2012: Quantifying uncertainties in global and regional temperature change using an ensemble of observational estimates: The HadCRUT4 data set. J. Geophys. Res., 117, D08101, https://doi. org/10.1029/2011JD017187.

Mote, T. L., 2007: Greenland surface melt trends 1973-2007: Evidence of a large increase in 2007. Geophys. Res. Lett., 34, L22507, https://doi. org/10.1029/2007GL031976.

Mu, Q., M. Zhao, J. S. Kimball, N. G. McDowell, and S. W. Running, 2013: A remotely sensed global terrestrial drought severity index. Bull. Amer. Meteor. Soc., 94, 83-98, https://doi.org/10.1175/bamsd-11-00213.1.

Mühle, J., and Coauthors, 2010: Perfluorocarbons in the global atmosphere: Tetrafluoromethane, hexafluoroethane, and octafluoropropane. Atmos. Chem. Phys., 10, 5145-5164, https://doi.org/10.5194/ acp-10-5145-2010.

Müller, R., J. U. Grooß, C. Lemmen, D. Heinze, M. Dameris, and G. Bodeker, 2008: Simple measures of ozone depletion in the polar stratosphere. Atmos. Chem. Phys., 8, 251-264, https://doi.org/10.5194 /acp-8-251-2008.

Munich RE, 2019: Extreme storms, wildfires and droughts cause heavy nat cat losses in 2018.

Münnich, M., and J. D. Neelin, 2005: Seasonal influence of ENSO on the Atlantic ITCZ and equatorial South America. Geophys. Res. Lett., 32, L21709, https://doi. org/10.1029/2005GL023900.

Myers-Smith, I. H., D. S. Hik, and R. Aerts, 2018: Climate warming as a driver of tundra shrubline advance. $J$. Ecol., 106, 547-560, https://doi.org/10.1111/13652745.12817.

Myhre, G., and Coauthors, 2013: Anthropogenic and natural radiative forcing. Climate Change 2013: The Physical Science Basis, T. F. Stocker et al., Eds., Cambridge University Press, 659-740.

Nakazawa, T., and S. Hoshino, 2009: Intercomparison of Dvorak parameters in the tropical cyclone datasets over the western North Pacific. SOLA, 5, 33-36, https://doi.org/10.2151/sola.2009-009.
NASA, 2018: The EOFs of the 1980-present QBO from the Singapore sonde monthly mean winds. The Stratospheric Quasi-biennial Oscillation (QBO), Goddard Space Flight Center.

Naus, S., S. A. Montzka, S. Pandey, S. Basu, E. J. Dlugokencky, and M. Krol, 2019: Constraints and biases in a tropospheric two-box model of $\mathrm{OH}$. Atmos. Chem. Phys., 19, 407-424, https://doi.org/10.5194 lacp-19-407-2019.

Nauslar, N. J., J. T. Abatzoglou, and P. T. Marsh, 2018: The 2017 North Bay and Southern California fires: A case study. Fire, 1, 18, https://doi.org/10.3390/ fire1010018.

Nerem, R. S., B. D. Beckley, J. T. Fasullo, B. D. Hamlington, D. Masters, and G. T. Mitchum, 2018: Climatechange-driven accelerated sea-level rise detected in the altimeter era. Proc. Natl. Acad. Sci. USA, 115, 2022-2025, https://doi.org/10.1073/pnas.1717312115.

Newchurch, M. J., E.-S. Yang, D. M. Cunnold, G. C. Reinsel, J. M. Zawodny, and J. M. Russell, 2003: Evidence for slowdown in stratospheric ozone loss: First stage of ozone recovery. J. Geophys. Res., 108, 4507, https://doi.org/10.1029/2003JD003471.

Newman, L., and Coauthors, 2016: Understanding the Southern Ocean through sustained observations. Bull. Aust. Meteor. Oceanogr. Soc., 28, 170-174.

Newman, P. A., J. S. Daniel, D. W. Waugh, and E. R. Nash, 2007: A new formulation of equivalent effective stratospheric chlorine (EESC). Atmos. Chem. Phys., 7, 4537-4552, https://doi.org/10.5194/acp-7-4537-2007.

NIFC, 2019: National report of wildland fires and acres burned by state. National Interagency Fire Center, accessed 3 March 2019, https://www.predictiveservices. nifc.gov/intelligence/2018_statssumm/fires_acres18. pdf.

Nitta, T., 1987: Convective activities in the tropical western Pacific and their impact on the Northern Hemisphere summer circulation. J. Meteor. Soc. Japan, 65, 373-390, https://doi.org/10.2151/jmsj1965.65.3_373.

NOAA ESRL Global Monitoring Division, 2017: Atmospheric Carbon Dioxide Dry Air Mole Fractions from quasi-continuous measurements at Mauna Loa, Hawaii (updated annually). NOAA ESRL, https://doi. org/http://dx.doi.org/10.7289/V54X55RG.

NOAA NCEI, 2018: State of the Climate: Global Climate Report for Annual 2017. National Centers for Environmental Information (NCEI), 22 February 2018, https://www.ncdc.noaa.gov/sotc/global/201713.

Nobre, P., and J. Shukla, 1996: Variations of sea surface temperature, wind stress, and rainfall over the tropical Atlantic and South America. J. Climate, 9, 2464-2479, https://doi.org/10.1175/15200442(1996)009<2464:vosstw>2.0.co;2. 
Noetzli, J., and Coauthors, 2018: Permafrost thermal state [in "State of the Climate in 2017"]. Bull. Amer. Meteor. Soc., 99, S20-S22, https://doi.org/10.1175/20 18BAMSStateoftheClimate.1.

Nordli, Ø., R. Przybylak, A. E. J. Ogilvie, and K. Isaksen, 2014: Long-term temperature trends and variability on Spitsbergen: The extended Svalbard Airport temperature series, 1898-2012. Polar Res., 33, https:/doi. org/10.3402/polar.v33.21349.

Notz, D., and J. Stroeve, 2016: Observed Arctic sea-ice loss directly follows anthropogenic $\mathrm{CO}_{2}$ emission. Science, 354, 747-750, https://doi.org/10.1126/science .aag2345.

Olsen, A., and Coauthors, 2016: The Global Ocean Data Analysis Project version 2 (GLODAPv2) - An internally consistent data product for the world ocean. Earth Syst. Sci. Data, 8, 297-323, https://doi. org/10.5194/essd-8-297-2016.

Oltmans, S. J., and W. D. Komhyr, 1976: Surface ozone in Antarctica. J. Geophys. Res., 81, 5359-5364, https:// doi.org/10.1029/JC081i030p05359.

— and Coauthors, 2006: Long-term changes in tropospheric ozone. Atmos. Environ., 40, 3156-3173, https://doi.org/10.1016/j.atmosenv.2006.01.029.

Opała-Owczarek, M., and Coauthors, 2018: The influence of abiotic factors on the growth of two vascular plant species (Saxifraga oppositifolia and Salix polaris) in the High Arctic. CATENA, 163, 219-232, https://doi.org/10.1016/j.catena.2017.12.018.

O'Reilly, C. M., and Coauthors, 2015: Rapid and highly variable warming of lake surface waters around the globe. Geophys. Res. Lett., 42, 10,773-10,781, https:// doi.org/10.1002/2015GL066235.

Osborn, T. J., J. Barichivich, I. Harris, G. van der Schrier, and P. D. Jones, 2017: Monitoring global drought using the self-calibrating Palmer drought severity index [in "State of the Climate in 2016"]. Bull. Amer. Meteor. Soc., 98, S32-S33, https://doi.org/10.1175/20 16BAMSStateoftheClimate.1.

Osprey, S. M., N. Butchart, J. R. Knight, A. A. Scaife, K. Hamilton, J. A. Anstey, V. Schenzinger, and C. Zhang, 2016: An unexpected disruption of the atmospheric quasi-biennial oscillation. Science, 353, 1424-1427, https://doi.org/10.1126/science.aah4156.

Otto, F. E. L., and Coauthors, 2018: Anthropogenic influence on the drivers of the Western Cape drought 2015-2017. Environ. Res. Lett., 13, 124010, https://doi .org/10.1088/1748-9326/aae9f9.

Overeem, I., and J. P. M. Syvitski, 2010: Shifting discharge peaks in arctic rivers, 1977-2007. Geogr. Ann., 92A, 285-296, https://doi.org/10.1111/j.14680459.2010.00395.x.
Overland, J. E., and M. Wang, 2018: Resolving future arctic/midlatitude weather connections. Earth's Future, 6, 1146-1152, https://doi.org/10.1029/2018ef000901. - and Coauthors, 2019: The urgency of Arctic change. Polar Sci., in press, https://doi.org/10.1016 /j.polar.2018.11.008.

Palmer, M. D., K. Haines, S. F. B. Tett, and T. J. Ansell, 2007: Isolating the signal of ocean global warming. Geophys. Res. Lett., 34, L23610, https://doi. org/10.1029/2007GL031712.

Park, T., and Coauthors, 2016: Changes in growing season duration and productivity of northern vegetation inferred from long-term remote sensing data. Environ. Res. Lett., 11, 084001, https://doi. org/10.1088/1748-9326/11/8/084001.

Parkinson, C. L., 2014: Spatially mapped reductions in the length of the Arctic sea ice season. Geophys. Res. Lett., 41, 4316-4322, https://doi. org/10.1002/2014GL060434.

Parmentier, F.-J., D. Rasse, M. Lund, J. W. Bjerke, B. G. Drake, S. Weldon, H. Tømmervik, and G. H. Hansen, 2018: Vulnerability and resilience of the carbon exchange of a subarctic peatland to an extreme winter event. Environ. Res. Lett., 13, 065009, https://doi. org/10.1088/1748-9326/aabff3.

Parr, A., 1939: Quantitative observations on pelagic Sargassum vegetation of the western North Atlantic. Bull. Bingham Oceanogr. Collect., 6, 1-94.

Partlow, J., and G. Martinez, 2015: Mexico deploys its navy to face its latest threat: Monster seaweed. Washington Post, 28 October, https://www. washingtonpost.com/world/the_americas/mexico-deploys-its-navy-to-face-its-latest-threatmonster-seaweed/2015/10/28/cea 8 ac28-710b11e5-ba14-318f8e87a2fc_story.html?utm_term $=$. f11ae98918b5.

Pellichero, V., J.-B. Sallée, S. Schmidtko, F. Roquet, and J.-B. Charrassin, 2017: The ocean mixed layer under Southern Ocean sea-ice: Seasonal cycle and forcing. J. Geophys. Res. Oceans, 122, 1608-1633, https://doi. org/10.1002/2016JC011970.

Pelto, M. S., 2018: How unusual was 2015 in the 19842015 period of the North Cascade glacier annual mass balance? Water, 10, 543, https://doi.org/10.3390/ w10050543.

PERMOS, 2016: Permafrost in Switzerland 2010/2011 to 2013/2014. Glaciological Report (Permafrost) No. 12-15 of the Cryospheric Commission of the Swiss Academy of Sciences, 85 pp., https://www.permos. ch/downloads/permos10-14.pdf. 
Peterson, B. J., R. M. Holmes, J. W. McClelland, C. J. Vörösmarty, R. B. Lammers, A. I. Shiklomanov, I. A. Shiklomanov, and S. Rahmstorf, 2002: Increasing river discharge to the Arctic Ocean. Science, 298, 2171-2173, https://doi.org/10.1126/science.1077445.

Peterson, T. C., and R. S. Vose, 1997: An overview of the global historical climatology network temperature database. Bull. Amer. Meteor. Soc., 78, 2837-2849, https://doi.org/10.1175/1520-0477(1997)078<2837:ao otgh>2.0.co;2.

Petoukhov, V., S. Rahmstorf, S. Petri, and H. J. Schellnhuber, 2013: Quasiresonant amplification of planetary waves and recent Northern Hemisphere weather extremes. Proc. Natl. Acad. Sci. USA, 110, 5336-5341, https://doi.org/10.1073/pnas.1222000110.

Phlips, E., and C. Zeman, 1990: Photosynthesis, growth and nitrogen fixation by epiphytic forms of filamentous cyanobacteria from pelagic Sargassum. Bull. Mar. Sci., 47, 613-621.

Phoenix, G. K., and J. W. Bjerke, 2016: Arctic browning: Extreme events and trends reversing Arctic greening. Global Change Biol., 22, 2960-2962, https://doi .org/10.1111/gcb.13261.

Pinty, B., 2012: Land surface albedo [in"State of the Climate in 2011"]. Bull. Amer. Meteor. Soc., 93, S52-S53, https://doi.org/10.1175/2012BAMSStateof theClimate.1.

Pinty, B., and N. Gobron, 2018: Land surface albedo dynamics [in "State of the Climate in 2017"]. Bull. Amer. Meteor. Soc., 99, S61-S62, https://doi.org/10.1175 /2018BAMSStateoftheClimate.1.

Pinty, B., and Coauthors, 2011: Exploiting the MODIS albedos with the Two-stream Inversion Package (JRC-TIP): 2. Fractions of transmitted and absorbed fluxes in the vegetation and soil layers. J. Geophys. Res., 116, D09106, https://doi.org/10.1029/2010JD015373.

Pinzon, J., and C. Tucker, 2014: A non-stationary 19812012 AVHRR NDVI3g time series. Remote Sens., 6, 6929, https://doi.org/10.3390/rs6086929.

Pithan, F., and T. Mauritsen, 2014: Arctic amplification dominated by temperature feedbacks in contemporary climate models. Nat. Geosci., 7, 181-184, https:// doi.org/10.1038/ngeo2071.

Pitts, M. C., L. R. Poole, and L. W. Thomason, 2009: CALIPSO polar stratospheric cloud observations: Second-generation detection algorithm and composition discrimination. Atmos. Chem. Phys., 9, 7577-7589, https://doi.org/10.5194/acp-9-7577-2009.

Pogliotti, P., M. Guglielmin, E. Cremonese, U. Morra di Cella, G. Filippa, C. Pellet, and C. Hauck, 2015: Warming permafrost and active layer variability at Cime Bianche, Western European Alps. Cryosphere, 9, 647-661, https://doi.org/10.5194/tc-9-647-2015.
Popp, T., and Coauthors, 2016: Development, production and evaluation of aerosol climate data records from European satellite observations (Aerosol_ cci). Remote Sens., 8, 421, https://doi.org/10.3390 /rs8050421.

Prein, A. F., C. Liu, K. Ikeda, S. B. Trier, R. M. Rasmussen, G. J. Holland, and M. P. Clark, 2017: Increased rainfall volume from future convective storms in the US. Nat. Climate Change, 7, 880-884, https://doi .org/10.1038/s41558-017-0007-7.

Price, S., and J. C. Pales, 1963: Mauna Loa observatory: The first five years. Mon. Wea. Rev., 91, 665-680, https://doi.org/10.1175/1520-0493(1963)091<0665:Ml otff $>2.3 . \mathrm{CO} ; 2$.

Pun, I.-F., I. I. Lin, and M.-H. Lo, 2013: Recent increase in high tropical cyclone heat potential area in the western North Pacific Ocean. Geophys. Res. Lett., 40, 4680-4684, https://doi.org/10.1002/grl.50548.

Purkey, S. G., and G. C. Johnson, 2010: Warming of global abyssal and deep Southern Ocean waters between the 1990s and 2000s: Contributions to global heat and sea level rise budgets. J. Climate, 23, 6336-6351, https://doi.org/10.1175/2010jcli3682.1.

Qi, L., C. Hu, M. Wang, S. Shang, and C. Wilson, 2017: Floating algae blooms in the East China Sea. Geophys. Res. Lett., 44, 11,501-511,509, https:/doi. org/10.1002/2017gl075525.

Qiu, B., and S. Chen, 2005: Variability of the Kuroshio Extension jet, recirculation gyre, and mesoscale eddies on decadal time scales. J. Phys. Oceanogr., 35, 2090-2103, https://doi.org/10.1175/jpo2807.1.

,$- \ldots$, L. Wu, and S. Kida, 2015: Wind- versus eddy-forced regional sea level trends and variability in the North Pacific Ocean. J. Climate, 28, 1561-1577, https://doi.org/10.1175/JCLI-D-14-00479.1.

Quispe, K., 2017: Patrones sinópticos de una Dana asociados a la ocurrencia de nevadas en la Sierra Central y Sur del Perú (in Spanish). Ingeniero Meteorólogo, Facultad de Ciencias, Universidad Nacional Agraria La Molina, 82+ pp., http://repositorio.lamolina.edu. pe/handle/UNALM/3632.

Quispe, N., 2014: Evaluación climática de la depresión aislada en niveles altos (DANA) sobre Sudamérica y océanos adyacentes y estudio de un caso en el Pacifico Oriental. M.S. thesis, Universidad Nacional Agraria La Molina, 151 pp.

- , and G. Avalos, 2006: Intense snowstorm in the southern mountains of Peru associated to the incursion of cut-off low-pressure systems at upper level. Proc. 8th Int. Conf. on Southern Hemisphere Meteorology and Oceanography (ICSHMO), INPE, 1945-1948. 
Radosavljevic, B., H. Lantuit, W. Pollard, P. Overduin, N. Couture, T. Sachs, V. Helm, and M. Fritz, 2016: Erosion and flooding-Threats to coastal infrastructure in the Arctic: A case study from Herschel Island, Yukon Territory, Canada. Estuaries Coasts, 39, 900-915, https://doi.org/10.1007/s12237-015-0046-0.

Raga, G. B., B. Bracamontes-Cevallos, L. M. Farfán, and R. Romero-Centeno, 2013: Landfalling tropical cyclones on the Pacific coast of Mexico: 1850-2010. Atmosfera, 26, 209-220, https://doi.org/10.1016/ S0187-6236(13)71072-5.

Ramos, M., G. Vieira, M. A. de Pablo, A. Molina, A. Abramov, and G. Goyanes, 2017: Recent shallowing of the thaw depth at Crater Lake, Deception Island, Antarctica (2006-2014). CATENA, 149, Part 2, 519-528, https://doi.org/10.1016/j.catena.2016.07.019.

Randel, W. J., and F. Wu, 1996: Isolation of the ozone QBO in SAGE II data by singular-value decomposition. J. Atmos. Sci., 53, 2546-2559, https://doi. org/10.1175/1520-0469(1996)053<2546:Iotoqi $>2.0$ .CO;2.

Rao, J., R. Ren, H. Chen, Y. Yu, and Y. Zhou, 2018: The stratospheric sudden warming event in February 2018 and its prediction by a climate system model. J. Geophys. Res. Atmos., 123, 13,332-13,345, https:// doi.org/10.1029/2018jd028908.

Ravishankara, A. R., S. Solomon, A. A. Turnipseed, and R. F. Warren, 1993: Atmospheric lifetimes of longlived halogenated species. Science, 259, 194-199, https://doi.org/10.1126/science.259.5092.194.

Rawlins, M. A., and Coauthors, 2010: Analysis of the Arctic system for freshwater cycle intensification: Observations and expectations. J. Climate, 23, 5715-5737, https://doi.org/10.1175/2010jcli3421.1.

Rawlins-Bentham, J., 2018: Sargassum: A national emergency and energy source. Barbados Government Information Service, https:/gisbarbados.gov.bb/blog/ sargassum-a-national-emergency-energy-source/.

Ray, E. A., F. L. Moore, J. W. Elkins, K. H. Rosenlof, J. C. Laube, T. Röckmann, D. R. Marsh, and A. E. Andrews, 2017: Quantification of the $\mathrm{SF}_{6}$ lifetime based on mesospheric loss measured in the stratospheric polar vortex. J. Geophys. Res. Atmos., 122, 4626-4638, https://doi.org/10.1002/2016JD026198.

Raynolds, M. K., D. A. Walker, H. E. Epstein, J. E. Pinzon, and C. J. Tucker, 2012: A new estimate of tundra-biome phytomass from trans-Arctic field data and AVHRR NDVI. Remote Sens. Lett., 3, 403411, https://doi.org/10.1080/01431161.2011.609188.

Reagan, J., T. Boyer, C. Schmid, and R. Locarnini, 2018: Subsurface salinity [in "State of the Climate in 2017"]. Bull. Amer. Meteor. Soc., 99, S79-S81, https://doi.org /10.1175/2018BAMSStateoftheClimate.1.
Reager, J. T., A. S. Gardner, J. S. Famiglietti, D. N. Wiese, A. Eicker, and M.-H. Lo, 2016: A decade of sea level rise slowed by climate-driven hydrology. Science, 351, 699-703, https://doi.org/10.1126/science.aad8386.

Reichle, L. M., H. E. Epstein, U. S. Bhatt, M. K. Raynolds, and D. A. Walker, 2018: Spatial heterogeneity of the temporal dynamics of Arctic tundra vegetation. Geophys. Res. Lett., 45, 9206-9215, https:/doi. org/10.1029/2018gl078820.

Reichle, R. H., Q. Liu, R. D. Koster, C. S. Draper, S. P. P. Mahanama, and G. S. Partyka, 2017a: Land surface precipitation in MERRA-2. J. Climate, 30, 1643-1664, https://doi.org/10.1175/jcli-d-16-0570.1.

— C. S. Draper, Q. Liu, M. Girotto, S. P. P. Mahanama, R. D. Koster, and G. J. M. D. Lannoy, 2017b: Assessment of MERRA-2 land surface hydrology estimates. J. Climate, 30, 2937-2960, https://doi.org/10.1175/ jcli-d-16-0720.1.

Reid, P. A., S. Stammerjohn, R. A. Massom, J. L. Lieser, S. Barreira, and T. Scambos, 2017: Sea ice extent, concentration and seasonality [in "State of the Climate in 2016"]. Bull. Amer. Meteor. Soc., 97, S163-S166, https://doi.org/10.1175/2017BAMSState oftheClimate.1.

,,,,----- , and,- 2018 : Sea ice extent, concentration and seasonality [in "State of the Climate in 2017”]. Bull. Amer. Meteor. Soc., 98, S183-S185, https://doi.org/10.1175/2018BAMSState oftheClimate.1.

Ren, L., K. Speer, and E. P. Chassignet, 2011: The mixed layer salinity budget and sea ice in the Southern Ocean. J. Geophys. Res., 116, C08031, https://doi .org/10.1029/2010jc006634.

Resplandy, L., and Coauthors, 2018: Revision of global carbon fluxes based on a reassessment of oceanic and riverine carbon transport. Nat. Geosci., 11, 504-509, https://doi.org/10.1038/s41561-018-0151-3.

Reyes-Velarde, A., 2019: California's Camp Fire was the costliest global disaster last year, insurance report shows. Los Angeles Times, 11 January, https:// www.latimes.com/local/lanow/la-me-ln-camp-fireinsured-losses-20190111-story.html.

Reynolds, R. W., N. A. Rayner, T. M. Smith, D. C. Stokes, and W. Wang, 2002: An improved in situ and satellite SST analysis for climate. J. Climate, 15, 16091625, https://doi.org/10.1175/1520-0442(2002)015 $<1609$ :aiisas $>2.0$. co;2.

— , T. M. Smith, C. Liu, D. B. Chelton, K. S. Casey, and M. G. Schlax, 2007: Daily high-resolution-blended analyses for sea surface temperature. J. Climate, 20, 5473-5496, https://doi.org/10.1175/2007jcli1824.1. 
Rhein, M., and Coauthors, 2013: Observations: Ocean. Climate Change 2013: The Physical Science Basis, T. F. Stocker et al., Eds., Cambridge University Press, 255-316.

Richardson, A. D., 2019: Tracking seasonal rhythms of plants in diverse ecosystems with digital camera imagery. New Phytol., 222, 1742-1750, https://doi .org/10.1111/nph.15591.

— , K. Hufkens, T. Milliman, and S. Frolking, 2018: Intercomparison of phenological transition dates derived from the PhenoCam Dataset V1.0 and MODIS satellite remote sensing. Sci. Rep., 8, 5679, https://doi .org/10.1038/s41598-018-23804-6.

Richardson, D., C. G. Kilsby, H. J. Fowler, and A. Bárdossy, 2019: Weekly to multi-month persistence in sets of daily weather patterns over Europe and the North Atlantic Ocean. Int. J Climatol., 39, 2041-2056, https://doi.org/10.1002/joc.5932.

Riddle, E. E., M. B. Stoner, N. C. Johnson, M. L. L'Heureux, D. C. Collins, and S. B. Feldstein, 2013: The impact of the MJO on clusters of wintertime circulation anomalies over the North American region. Climate Dyn., 40, 1749-1766, https://doi.org/10.1007 /s00382-012-1493-y.

Rintoul, S. R., M. P. Meredith, O. Schofield, and L. Newman, 2012: The Southern Ocean Observing System. Oceanography, 25, 68-69, https://doi.org/10.5670 /oceanog.2012.76.

Rödenbeck, C., and Coauthors, 2015: Data-based estimates of the ocean carbon sink variability - first results of the Surface Ocean $p \mathrm{CO}_{2}$ Mapping intercomparison (SOCOM). Biogeosciences, 12, 7251-7278, https://doi.org/10.5194/bg-12-7251-2015.

Roderick, M. L., L. D. Rotstayn, G. D. Farquhar, and M. T. Hobbins, 2007: On the attribution of changing pan evaporation. Geophys. Res. Lett., 34, L17403, https://doi.org/10.1029/2007GL031166.

Roemmich, D., and J. Gilson, 2009: The 2004-2008 mean and annual cycle of temperature, salinity, and steric height in the global ocean from the Argo Program. Prog. Oceanogr., 82, 81-100, https://doi .org/10.1016/j.pocean.2009.03.004.

- , and - 2011: The global ocean imprint of ENSO. Geophys. Res. Lett., 38, L13606, https://doi .org/10.1029/2011GL047992.

Roessler, A., M. Rhein, D. Kieke, and C. Mertens, 2015: Long-term observations of North Atlantic Current transport at the gateway between western and eastern Atlantic. J. Geophys. Res. Oceans, 120, 4003-4027, https://doi.org/10.1002/2014jc010662.
Romanovsky, V., and Coauthors, 2017: Changing permafrost and its impacts. Snow, Water, Ice and Permafrost in the Arctic (SWIPA) 2017, Arctic Monitoring and Assessment Programme (AMAP), 65-102.

Rood, S. B., S. Kaluthota, L. J. Philipsen, N. J. Rood, and K. P. Zanewich, 2017: Increasing discharge from the Mackenzie River system to the Arctic Ocean. Hydrol. Processes, 31, 150-160, https://doi.org/10.1002 /hyp.10986.

Rooker, J. R., J. P. Turner, and S. A. Holt, 2006: Trophic ecology of Sargassum-associated fishes in the Gulf of Mexico determined from stable isotopes and fatty acids. Mar. Ecol. Prog. Ser., 313, 249-259, https://doi .org/10.3354/meps313249.

Ropelewski, C. F., and M. S. Halpert, 1989: Precipitation patterns associated with the high index phase of the southern oscillation. J. Climate, 2, 268-284, https:// doi.org/10.1175/1520-0442(1989)002<0268:ppawth $>2.0 . \mathrm{co} ; 2$.

Rydbeck, A. V., and E. D. Maloney, 2014: Energetics of East Pacific easterly waves during intraseasonal events. J. Climate, 27, 7603-7621, https://doi .org/10.1175/jcli-d-14-00211.1.

Saha, S., and Coauthors, 2014: The NCEP climate forecast system version 2. J. Climate, 27, 2185-2208, https://doi.org/10.1175/jcli-d-12-00823.1.

Saji, N. H., B. N. Goswami, P. N. Vinayachandran, and T. Yamagata, 1999: A dipole mode in the tropical Indian Ocean. Nature, 401, 360-363, https:/doi. org/10.1038/43854.

Sánchez-Lugo, A., C. P. Morice, P. Berrisford, and A. Argüez, 2017: Global surface temperatures [in "State of the Climate in 2016"]. Bull. Amer. Meteor. Soc., 98, S11-S13, https://doi.org/10.1175/2017BAMS StateoftheClimate.1.

Santoso, A., and Coauthors, 2019: Dynamics and predictability of the El Niño-Southern Oscillation: An Australian perspective on progress and challenges. Bull. Amer. Meteor. Soc., 100, 403-420, https://doi .org/10.1175/BAMS-D-18-0057.1.

Satheesh, S. K., S. Suresh Babu, B. Padmakumari, G. Pandithurai, and V. K. Soni, 2017: Variability of Atmospheric Aerosols Over India. Observed Climate Variability and Change over the Indian Region, M. N. Rajeevan, and S. Nayak, Eds., Springer Singapore, 221-248.

Scambos, T. A., C. Hulbe, M. Fahnestock, and J. Bohlander, 2000: The link between climate warming and break-up of ice shelves in the Antarctic Peninsula. J. Glaciol., 46, 516-530, https://doi. org/10.3189/172756500781833043. 
- - O. Sergienko, A. Sargent, D. MacAyeal, and J. Fastook, 2005: ICESat profiles of tabular iceberg margins and iceberg breakup at low latitudes. Geophys. Res. Lett., 32, L23S09, https:/doi. org/10.1029/2005GL023802.

—, R. Ross, R. Bauer, Y. Yermolin, P. Skvarca, D. Long, J. Bohlander, and T. Haran, 2008: Calving and ice-shelf break-up processes investigated by proxy: Antarctic tabular iceberg evolution during northward drift. J. Glaciol., 54, 579-591, https://doi .org/10.3189/002214308786570836.

—, G. G. Campbell, A. Pope, T. Haran, A. Muto, M. Lazzara, C. H. Reijmer, and M. R. van den Broeke, 2018: Ultralow Surface Temperatures in East Antarctica From Satellite Thermal Infrared Mapping: The Coldest Places on Earth. Geophys. Res. Lett., 45, 6124-6133, https://doi.org/10.1029/2018GL078133.

Schaaf, C., and Z. Wang, 2015: MCD43C3 MODIS/Terra+Aqua BRDF/Albedo Albedo Daily L3 Global 0.05Deg CMG. NASA EOSDIS Land Processes DAAC, https://doi.org/10.5067/MODIS /MCD43C3.006.

— , and Coauthors, 2002: First operational BRDF, albedo nadir reflectance products from MODIS. Remote Sens. Environ., 83, 135-148, https://doi .org/10.1016/S0034-4257(02)00091-3.

Schaefer, H., and Coauthors, 2016: A 21st-century shift from fossil-fuel to biogenic methane emissions indicated by ${ }^{13} \mathrm{CH}_{4}$. Science, 352, 80-84, https://doi .org/10.1126/science.aad2705.

Schamm, K., M. Ziese, A. Becker, P. Finger, A. MeyerChristoffer, B. Rudolf, and U. Schneider, 2013: GPCC First Guess Daily Product at $1.0^{\circ}$ : Near Real-Time First Guess Daily Land-Surface Precipitation from Rain-Gauges based on SYNOP Data. Deutscher Wetterdienst, https://doi.org/10.5676/DWD_GPCC /FG_D_100.

Schell, J. M., D. S. Goodwin, and A. N. S. Siuda, 2015: Recent Sargassum inundation events in the Caribbean: Shipboard observations reveal dominance of a previously rare form. Oceanography, 28, 8-10, https:// doi.org/10.5670/oceanog.2015.70.

Schenzinger, V., S. Osprey, L. Gray, and N. Butchart, 2017: Defining metrics of the Quasi-Biennial Oscillation in global climate models. Geosci. Model Dev., 10, 2157-2168, https://doi.org/10.5194/gmd-10-21572017.

Schmidtko, S., K. J. Heywood, A. F. Thompson, and S. Aoki, 2014: Multidecadal warming of Antarctic waters. Science, 346, 1227-1231, https://doi .org/10.1126/science.1256117.
Schneider, P., and S. J. Hook, 2010: Space observations of inland water bodies show rapid surface warming since 1985. Geophys. Res. Lett., 37, L22405, https:// doi.org/10.1029/2010GL045059.

Schneider, T., T. Bischoff, and G. H. Haug, 2014: Migrations and dynamics of the intertropical convergence zone. Nature, 513, 45-53, https://doi.org/10.1038 /nature13636.

Schneider, U., P. Finger, A. Meyer-Christoffer, M. Ziese, A. Becker, 2018: Global Precipitation Analysis Products of the GPCC. Deutscher Wetterdienst, Offenbach a. M., Germany, https://opendata.dwd. de/climate_environment/GPCC/PDF/GPCC_intro_ products_v2018.pdf

Schreck, C. J., 2015: Kelvin waves and tropical cyclogenesis: A global survey. Mon. Wea. Rev., 143, 3996-4011, https://doi.org/10.1175/mwr-d-15-0111.1. — , 2016: Convectively coupled Kelvin waves and tropical cyclogenesis in a semi-Lagrangian framework. Mon. Wea. Rev., 144, 4131-4139, https://doi. org/10.1175/mwr-d-16-0237.1.

— sociated with Kelvin waves and the Madden-Julian oscillation. Mon. Wea. Rev., 139, 2723-2734, https:// doi.org/10.1175/mwr-d-10-05060.1.

,-- , and A. Aiyyer, 2012: A global view of equatorial waves and tropical cyclogenesis. Mon. Wea. Rev., 140, 774-788, https://doi.org/10.1175/mwr -d-11-00110.1.

_ J. J. M. Cordeira, and D. Margolin, 2013: Which MJO events affect North American temperatures? Mon. Wea. Rev., 141, 3840-3850, https://doi.org/10.1175 /mwr-d-13-00118.1.

— , K. R. Knapp, and J. P. Kossin, 2014: The impact of best track discrepancies on global tropical cyclone climatologies using IBTrACS. Mon. Wea. Rev., 142, 3881-3899, https://doi.org/10.1175/mwr -d-14-00021.1.

— , H.-T. Lee, and K. R. Knapp, 2018: HIRS outgoing longwave radiation-daily climate data record: Application toward identifying tropical subseasonal variability. Remote Sens., 10, 1325, https://doi .org/10.3390/rs10091325.

Schwietzke, S., and Coauthors, 2016: Upward revision of global fossil fuel methane emissions based on isotope database. Nature, 538, 88-91, https://doi.org/10.1038 /nature19797.

Sévellec, F., A. V. Fedorov, and W. Liu, 2017: Arctic sea-ice decline weakens the Atlantic Meridional Overturning Circulation. Nat. Climate Change, 7, 604-610, https://doi.org/10.1038/nclimate3353. 
Shay, L. K., G. J. Goni, and P. G. Black, 2000: Effects of a warm oceanic feature on Hurricane Opal. Mon. Wea. Rev., 128, 1366-1383, https://doi.org/10.1175/1520 -0493(2000)128<1366:eoawof>2.0.co;2.

Shiklomanov, A. I., and R. B. Lammers, 2009: Record Russian river discharge in 2007 and the limits of analysis. Environ. Res. Lett., 4, 045015, https://doi .org/10.1088/1748-9326/4/4/045015.

Shiklomanov, N. I., D. A. Streletskiy, and F. E. Nelson, 2012: Northern Hemisphere component of the global Circumpolar Active Layer Monitoring (CALM) program. Proc. 10th Int. Conf. on Permafrost, 377-382.

Siegel, D. A., S. Maritorena, N. B. Nelson, M. J. Behrenfeld, and C. R. McClain, 2005: Colored dissolved organic matter and its influence on the satellite-based characterization of the ocean biosphere. Geophys. Res. Lett., 32, L20605, https://doi. org/10.1029/2005GL024310.

—_, and Coauthors, 2013: Regional to global assessments of phytoplankton dynamics from the SeaWiFS mission. Remote Sens. Environ., 135, 77-91, https:// doi.org/10.1016/j.rse.2013.03.025.

Sigler, M. F., P. J. Stabeno, L. B. Eisner, J. M. Napp, and F. J. Mueter, 2014: Spring and fall phytoplankton blooms in a productive subarctic ecosystem, the eastern Bering Sea, during 1995-2011. Deep-Sea Res. II, 109, 71-83, https://doi.org/10.1016/j.dsr2.2013.12.007.

Simmons, A. J., and P. Poli, 2015: Arctic warming in ERA-Interim and other analyses. Quart. J. Roy. Meteor. Soc., 141, 1147-1162, https://doi.org/10.1002 /qj.2422.

—, K. M. Willett, P. D. Jones, P. W. Thorne, and D. P. Dee, 2010: Low-frequency variations in surface atmospheric humidity, temperature, and precipitation: Inferences from reanalyses and monthly gridded observational data sets. J. Geophys. Res., 115, D01110, https://doi.org/10.1029/2009JD012442.

— , P. Berrisford, D. P. Dee, H. Hersbach, S. Hirahara, and J. N. Thépaut, 2017: A reassessment of temperature variations and trends from global reanalyses and monthly surface climatological datasets. Quart. J. Roy. Meteor. Soc., 143, 101-119, https://doi .org/10.1002/qj.2949.

Singh, O. P., T. M. Ali Khan, and M. S. Rahman, 2000: Changes in the frequency of tropical cyclones over the north Indian Ocean. Meteor. Atmos. Phys., 75, 11-20, https://doi.org/10.1007/s007030070011.

Skliris, N., R. Marsh, S. A. Josey, S. A. Good, C. Liu, and R. P. Allan, 2014: Salinity changes in the World Ocean since 1950 in relation to changing surface freshwater fluxes. Climate Dyn., 43, 709-736, https:// doi.org/10.1007/s00382-014-2131-7.
Slade, S. A., and E. D. Maloney, 2013: An intraseasonal prediction model of Atlantic and east Pacific tropical cyclone genesis. Mon. Wea. Rev., 141, 1925-1942, https://doi.org/10.1175/mwr-d-12-00268.1.

Smeed, D. A., and Coauthors, 2018: The North Atlantic Ocean is in a state of reduced overturning. Geophys. Res. Lett., 45, 1527-1533, https://doi .org/10.1002/2017GL076350.

Smetacek, V., and A. Zingone, 2013: Green and golden seaweed tides on the rise. Nature, 504, 84-88, https:// doi.org/10.1038/nature12860.

Smith, C., B. J. Hatchett, and M. Kaplan, 2018: A surface observation based climatology of Diablo-like winds in California's wine country and western Sierra Nevada. Fire, 1, 25, https://doi.org/10.3390/fire1020025.

Smith, S. L., A. G. Lewkowicz, C. Duchesne, and M. Ednie, 2015: Variability and change in permafrost thermal state in northern Canada. Proc. 68th Canadian Geotechnical Conf. and Seventh Canadian Conf. on Permafrost (GEOQuébec 2015), GEOQuébec 2015, Paper 237.

- J. Chartrand, and C. Duchesne, 2018: Report on 2017 field activities and collection of groundthermal and active-layer data in the Mackenzie corridor, Northwest Territories. Geological Survey of Canada Open File Rep. 8492, 109 pp., https://doi. org/10.4095/313036.

Smith, T. M., R. W. Reynolds, T. C. Peterson, and J. Lawrimore, 2008: Improvements to NOAA's historical merged land-ocean surface temperature analysis (1880-2006). J. Climate, 21, 2283-2296, https://doi.org/10.1175/2007jcli2100.1.

Song, J.-J., Y. Wang, and L. Wu, 2010: Trend discrepancies among three best track data sets of western North Pacific tropical cyclones. J. Geophys. Res., 115, D12128, https://doi.org/10.1029/2009JD013058. Sonnentag, O., and Coauthors, 2012: Digital repeat photography for phenological research in forest ecosystems. Agri. For. Meteor., 152, 159-177, https:// doi.org/10.1016/j.agrformet.2011.09.009.

Sospedra-Alfonso, R., and W. J. Merryfield, 2017: Influences of temperature and precipitation on historical and future snowpack variability over the Northern Hemisphere in the Second Generation Canadian Earth System Model. J. Climate, 30, 4633-4656, https://doi.org/10.1175/jcli-d-16-0612.1.

Sousa, P. M., R. C. Blamey, C. J. C. Reason, A. M. Ramos, and R. M. Trigo, 2018: The 'Day Zero' Cape Town drought and the poleward migration of moisture corridors. Environ. Res. Lett., 13, 124025, https://doi. org/10.1088/1748-9326/aaebc7. 
SPARC LOTUS Activity, 2019: SPARC/IO3C/GAW Report on long-term ozone trends and uncertainties in the stratosphere. SPARC Report 9; GAW Report 241; WCRP report 17/2018, 78 pp., https:// doi.org/10.17874/f899e57a20b.

Spence, J., M. A. Taylor, and A. A. Chen, 2004: The effect of concurrent sea surface temperature anomalies in the tropical Pacific and Atlantic on Caribbean rainfall. Int. J. Climatol., 24, 1531-1541, https://doi. org/10.1002/joc. 1068 .

Stabeno, P. J., and Coauthors, 2012a: A comparison of the physics of the northern and southern shelves of the eastern Bering Sea and some implications for the ecosystem. Deep-Sea Res. II, 65-70, 14-30, https:// doi.org/10.1016/j.dsr2.2012.02.019.

—, N. B. Kachel, S. E. Moore, J. M. Napp, M. Sigler, A. Yamaguchi, and A. N. Zerbini, 2012b: Comparison of warm and cold years on the southeastern Bering Sea shelf and some implications for the ecosystem. Deep-Sea Res. II, 65-70, 31-45, https://doi .org/10.1016/j.dsr2.2012.02.020.

—, S. W. Bell, N. A. Bond, D. G. Kimmel, C. W. Mordy, and M. E. Sullivan, 2019: Distributed Biological Observatory Region 1: Physics, chemistry and plankton in the northern Bering Sea. Deep-Sea Res. II, 62, 8-21, https://doi.org/10.1016/j.dsr2.2018.11.006.

Stackhouse, P. W., D. P. Kratz, G. R. McGarragh, S. K. Gupta, and E. B. Geier, 2006: Fast longwave and shortwave radiative flux (FLASHFlux) products from CERES and MODIS measurements. Proc. 12th Conf. Atmospheric Radiation, Madison, WI, Amer. Meteor. Soc., P1.10, https://ams.confex.com/ams /Madison2006/techprogram/paper_113479.htm.

—, T. Wong, D. P. Kratz, P. Sawaengphokhai, A. C. Wiber, S. K. Gupta, and N. G. Loeb, 2016: Earth radiation budget at top-of-atmosphere [in "State of the Climate in 2015”]. Bull. Amer. Meteor. Soc., 97, S41-S43, https://doi.org/10.1175/2016BAMSStateof theClimate.1.

Stammerjohn, S. E., D. G. Martinson, R. C. Smith, X. Yuan, and D. Rind, 2008: Trends in Antarctic annual sea ice retreat and advance and their relation to El Niño-Southern Oscillation and southern annular mode variability. J. Geophys. Res., 113, C03S90, https://doi.org/10.1029/2007JC004269.

Stasi, L., 2015: Tourism officials can't hide the threat of Sargassum seaweed as it's taking over beaches from Florida to Texas and damaging the environment. New York Daily News, 17 October, https://www. nydailynews.com/news/world/sargassum-seaweedbeaches-article-1.2401435.
Steidinger, K. A., 2009: Historical perspective on Karenia brevis red tide research in the Gulf of Mexico. Harmful Algae, 8, 549-561, https://doi.org/10.1016/j. hal.2008.11.009.

Steinbrecht, W., and Coauthors, 2017: An update on ozone profile trends for the period 2000 to 2016. Atmos. Chem. Phys., 17, 10,675-610,690, https://doi. org/10.5194/acp-17-10675-2017.

Stengel, M., and Coauthors, 2017: Cloud property datasets retrieved from AVHRR, MODIS, AATSR and MERIS in the framework of the Cloud_cci project. Earth Syst. Sci. Data, 9, 881-904, https://doi. org/10.5194/essd-9-881-2017.

Stephenson, T. S., A. A Chen, and M. A. Taylor, 2007: Toward the development of prediction models for the primary Caribbean dry season. Theor. Appl. Climatol., 92, 87-101, https://doi.org/10.1007/s00704007-0308-2.

Stewart, C. L., P. Christoffersen, K. W. Nicholls, M. J. M. Williams, J. A. Dowdswell, 2019: Warm Antarctic surface waters drives rapid melting of Ross Ice Shelf. Nat. Geosci., 12, 435-440, https://doi.org/10.1038/ s41561-019-0356-0

Strahan, S. E., and A. R. Douglass, 2018: Decline in Antarctic ozone depletion and lower stratospheric chlorine determined from Aura microwave limb sounder observations. Geophys. Res. Lett., 45, 382390, https://doi.org/10.1002/2017GL074830.

_ , A. R. Douglass, and P. A. Newman, 2013: The contributions of chemistry and transport to low arctic ozone in March 2011 derived from Aura MLS observations. J. Geophys. Res. Atmos., 118, 1563-1576, https://doi.org/10.1002/jgrd.50181.

$-, \ldots, \ldots$, and S. D. Steenrod, 2014: Inorganic chlorine variability in the Antarctic vortex and implications for ozone recovery. J. Geophys. Res. Atmos., 119, 14,098-14,109, https://doi .org/10.1002/2014JD022295.

Stroh, J. N., G. Panteleev, S. Kirillov, M. Makhotin, and N. Shakhova, 2015: Sea-surface temperature and salinity product comparison against external in situ data in the Arctic Ocean. J. Geophys. Res. Oceans, 120, 7223-7236, https://doi.org/10.1002/2015JC011005.

Sutton, A. J., and Coauthors, 2014: A high-frequency atmospheric and seawater $p \mathrm{CO}_{2}$ data set from 14 open ocean sites using a moored autonomous system. Earth Syst. Sci. Data, 6, 353-366, https://doi .org/10.5194/essd-6-353-2014.

_, R. Wanninkhof, C. L. Sabine, R. A. Feely, M. F. Cronin, and R. A. Weller, 2017: Variability and trends in surface seawater $p \mathrm{CO}_{2}$ and $\mathrm{CO}_{2}$ flux in the Pacific Ocean. Geophys. Res. Lett, 44, 5627-5636, https://doi. org/10.1002/2017GL073814. 
- and Coauthors, 2019: Autonomous seawater $p \mathrm{CO}_{2}$ and $\mathrm{pH}$ time series from 40 surface buoys and the emergence of anthropogenic trends. Earth Syst. Sci. Data, 11, 421-439, https://doi.org/10.5194/essd-11 $-421-2019$

Swain, D. L., B. Langenbrunner, J. D. Neelin, and A. Hall, 2018: Increasing precipitation volatility in twentyfirst-century California. Nat. Climate Change, 8 , 427-433, https://doi.org/10.1038/s41558-018-0140-y.

Swart, S., and Coauthors, 2018: Return of the Maud Rise Polynya: Climate litmus or sea ice anomaly [in "State of the Climate in 2017"]. Bull. Amer. Meteor. Soc., 99, S188-S189, https://doi.org/10.1175/2018BA MSStateoftheClimate.1.

Sweet, W. V., J. Park, J. J. Marra, C. Zervas, and S. Gill, 2014: Sea level rise and nuisance flood frequency changes around the United States. NOAA Tech. Rep. NOS CO-OPS 73, 58 pp., https://tidesandcurrents. noaa.gov/publications/NOAA_Technical_Report_ NOS_COOPS_073.pdf.

Takahashi, T., and Coauthors, 2009: Climatological mean and decadal change in surface ocean pCO2, and net sea-air $\mathrm{CO} 2$ flux over the global oceans. Deep-Sea Res. II, 56, 554-577, https://doi. org/10.1016/j.dsr2.2008.12.009.

— S. C. Sutherland, and A. Kozyr, 2017: Global Ocean Surface Water Partial Pressure of $\mathrm{CO}_{2}$ Database: Measurements Performed During 1957-2017 (LDEO Database Version 2017) (NCEI Accession 0160492). NOAA National Centers for Environmental Information, https://doi.org/10.3334/CDIAC/OTG .NDP088(V2015).

Takala, M., K. Luojus, J. Pulliainen, C. Derksen, J. Lemmetyinen, J.-P. Kärnä, J. Koskinen, and B. Bojkov, 2011: Estimating Northern Hemisphere snow water equivalent for climate research through assimilation of space-borne radiometer data and ground-based measurements. Remote Sens. Environ., 115, 3517-3529, https://doi.org/10.1016 /j.rse.2011.08.014.

Talley, L. D., 2003: Shallow, intermediate, and deep overturning components of the global heat budget. J. Phys. Oceanogr., 33, 530-560, https://doi. org/10.1175/1520-0485(2003)033<0530:Siadoc $>2.0$ .Co;2.

Tans, P., 2009: An accounting of the observed increase in oceanic and atmospheric $\mathrm{CO}_{2}$ and an outlook for the future. Oceanography, 22, 26-35, https://doi. org/10.5670/oceanog.2009.94.

Tapley, B. D., S. Bettadpur, J. C. Ries, P. F. Thompson, and M. M. Watkins, 2004: GRACE measurements of mass variability in the Earth system. Science, 305, 503-505, https://doi.org/10.1126/science.1099192.
Tedesco, M., 2009: Assessment and development of snowmelt retrieval algorithms over Antarctica from K-band spaceborne brightness temperature (1979-2008). Remote Sens. Environ., 113, 979-997, https://doi.org/10.1016/j.rse.2009.01.009.

- , and A. J. Monaghan, 2009: An updated Antarctic melt record through 2009 and its linkages to high-latitude and tropical climate variability. Geophys. Res. Lett., 36, L18502, https://doi .org/10.1029/2009GL039186.

_ - X. Fettweis, T. Mote, J. Wahr, P. Alexander, J. E. Box, and B. Wouters, 2013: Evidence and analysis of 2012 Greenland records from spaceborne observations, a regional climate model and reanalysis data. The Cryosphere, 7, 615-630, https://doi.org/10.5194 /tc-7-615-2013.

—-, and Coauthors, 2017: Greenland ice sheet. Arctic Report Card 2017, NOAA's Arctic Program, https://www.arctic.noaa.gov/Report-Card/Report -Card-2017/ArtMID/7798/ArticleID/697/Greenland -Ice-Sheet.

Teng, W.-H., C.-Y. Huang, S.-P. Ho, Y.-H. Kuo, and X.-J. Zhou, 2013: Characteristics of global precipitable water in ENSO events revealed by COSMIC measurements. J. Geophys. Res. Atmos., 118, 8411-8425, https://doi.org/10.1002/jgrd.50371.

Terray, L., L. Corre, S. Cravatte, T. Delcroix, G. Reverdin, and A. Ribes, 2012: Near-surface salinity as nature's rain gauge to detect human influence on the tropical water cycle. J. Climate, 25, 958-977, https://doi. org/10.1175/jcli-d-10-05025.1.

Thibault, S., and S. Payette, 2009: Recent permafrost degradation in bogs of the James Bay area, northern Quebec, Canada. Permafrost Periglacial Processes, 20, 383-389, https://doi.org/10.1002/ppp.660.

Timmermann, A., and Coauthors, 2018: El Niño-Southern Oscillation complexity. Nature, 559, 535-545, https://doi.org/10.1038/s41586-018-0252-6.

Timmermann, R., and H. H. Hellmer, 2013: Southern Ocean warming and increased ice shelf basal melting in the twenty-first and twenty-second centuries based on coupled ice-ocean finite-element modelling. Ocean Dyn., 63, 1011-1026, https://doi .org/10.1007/s10236-013-0642-0.

Timmermans, M.-L., J. Toole, and R. Krishfield, 2018: Warming of the interior Arctic Ocean linked to sea ice losses at the basin margins. Sci. Adv., 4, eaat6773, https://doi.org/10.1126/sciadv.aat6773.

Tobin, I., P. Berrisford, R. J. H. Dunn, R. Vautard, and T. R. McVicar, 2014: Land surface wind speed [in "State of the Climate in 2013"]. Bull. Amer. Meteor. Soc., 95, S28-S29, https://doi.org/10.1175/2014BAM SStateoftheClimate.1. 
Tobin, S., and S. J. Jacobs, 2018: Summer arrives early in Australia as the austral spring breaks records [in 'State of the Climate in 2017"]. Bull. Amer. Meteor. Soc., 99 (8), S253-S254, doi: 10.1175/2018BAMSStateofthe Climate.1.

Torralba, V., J. D.-R. Francisco, and G.-R. Nube, 2017: Uncertainty in recent near-surface wind speed trends: A global reanalysis intercomparison. Environ. Res. Lett., 12, 114019, https://doi.org/10.1088/1748 -9326/aa8a58.

Treharne, R., J. W. Bjerke, L. D. Emberson, H. Tømmervik, and G. K. Phoenix, 2016: Arctic browning: vegetation damage and implications for carbon balance, Geophysical Research Abstracts, Vol. 18, Abstract EGU2016-8838, http://meetingorganizer.copernicus. org/EGU2016/EGU2016-8838.pdf.

Trenberth, K. E., 1998: Atmospheric moisture residence times and cycling: Implications for rainfall rates and climate change. Climatic Change, 39, 667-694, https://doi.org/10.1023/A:1005319109110.

Trepte, Q. Z., P. Minnis, C. R. Trepte, S. Sun-Mack, and R. Brown, 2010: Improved cloud detection in CERES edition 3 algorithm and comparison with the CALIPSO vertical feature mask. Proc. 13th Conf. Atmospheric Radiation and Cloud Physics, Portland, OR, Amer. Meteor. Soc., JP1.32, https://ams. confex.com/ams/13CldPhy13AtRad/webprogram /Paper171785.html.

Trewin, B., 2018: The Australian Climate Observations Reference Network-Surface Air Temperature (ACORN-SAT) version 2 Bureau Research Report - 032, 57 pp.

Tschudi, M., C. Fowler, J. Maslanik, and J. Stroeve, 2010: Tracking the movement and changing surface characteristics of Arctic sea ice. IEEE J. Sel. Topics Appl. Earth Obs. Remote Sens., 3, 536-540, https:// doi.org/10.1109/JSTARS.2010.2048305.

_ $\_$, and J. Maslanik, 2015: EASE-Grid Sea Ice Age, Version 2. National Snow and Ice Data Center, https://doi.org/10.5067/1UQJWCYPVX61.

- J. Stroeve, and J. Stewart, 2016: Relating the age of Arctic sea ice to its thickness, as measured during NASA's ICESat and IceBridge campaigns. Remote Sens., 8, 457, https://doi.org/10.3390/rs8060457.

Tsukernik, M., and A. H. Lynch, 2013: Atmospheric meridional moisture flux over the Southern Ocean: A story of the Amundsen Sea. J. Climate, 26, 80558064, https://doi.org/10.1175/jcli-d-12-00381.1.

Turner, J., and J. Rooker, 2006: Fatty acid composition of flora and fauna associated with Sargassum mats in the Gulf of Mexico. Mar. Biol., 149, 1025-1036, https://doi.org/10.1007/s00227-006-0269-5.
Tye, M. R., S. Blenkinsop, M. G. Donat, I. Durre, and M. Ziese, 2018: Lake surface precipitation extremes [in "State of the Climate in 2017"]. Bull. Amer. Meteor. Soc., 99, S29-S31, https://doi.org/10.1175 /2018BAMSStateoftheClimate.1.

van As, D., R. S. Fausto, J. Cappelen, R. S. W. Van de Wal, R. J. Braithwaite, H. Machguth, and PROMICE project team, 2016: Placing Greenland ice sheet ablation measurements in a multi-decadal context. Geol. Surv. Denmark Greenland Bull. 35, 71-74 pp., https:// www.geus.dk/DK/publications/geol-survey-dk-glbull/35/Documents/nr35_p71-74.pdf.

van de Wal, R. S. W., W. Boot, C. J. P. P. Smeets, H. Snellen, M. R. van den Broeke, and J. Oerlemans, 2012: Twenty-one years of mass balance observations along the K-transect, West Greenland. Earth Syst. Sci. Data, 4, 31-35, https://doi.org/10.5194 lessd-4-31-2012.

van den Broeke, M., 2005: Strong surface melting preceded collapse of Antarctic Peninsula ice shelf. Geophys. Res. Lett., 32, L12815, https://doi .org/10.1029/2005GL023247.

van der A, R. J., M. A. F. Allaart, and H. J. Eskes, 2015: Extended and refined multi sensor reanalysis of total ozone for the period 1970-2012. Atmos. Meas. Tech., 8, 3021-3035, https://doi.org/10.5194/amt-8 $-3021-2015$.

van der Ent, R. J., 2014: A new view on the hydrological cycle over continents. Ph.D thesis, Delft University of Technology, 96 pp., https://doi.org/10.4233 /uuid:0ab824ee-6956-4cc3-b530-3245ab4f32be.

- , H. H. G. Savenije, B. Schaefli, and S. C. SteeleDunne, 2010: Origin and fate of atmospheric moisture over continents. Water Resour. Res., 46, W09525, https://doi.org/10.1029/2010wr009127.

van der Schrier, G., J. Barichivich, K. R. Briffa, and P. D. Jones, 2013: A scPDSI-based global data set of dry and wet spells for 1901-2009. J. Geophys. Res. Atmos., 118, 4025-4048, https://doi.org/10.1002/jgrd.50355. van der Werf, G. R., and Coauthors, 2017: Global fire emissions estimates during 1997-2016. Earth Syst. Sci. Data, 9, 697-720, https://doi.org/10.5194/essd -9-697-2017.

Vautard, R., J. Cattiaux, P. Yiou, J.-N. Thepaut, and P. Ciais, 2010: Northern Hemisphere atmospheric stilling partly attributed to an increase in surface roughness. Nat. Geosci., 3, 756-761, https://doi. org/10.1038/ngeo979.

Vecchi, G. A., and B. J. Soden, 2007: Effect of remote sea surface temperature change on tropical cyclone potential intensity. Nature, 450, 1066-1070, https:// doi.org/10.1038/nature06423. 
Ventrice, M. J., C. D. Thorncroft, and M. A. Janiga, 2012a: Atlantic tropical cyclogenesis: A three-way interaction between an African easterly wave, diurnally varying convection, and a convectively coupled atmospheric Kelvin wave. Mon. Wea. Rev., 140, 11081124, https://doi.org/10.1175/mwr-d-11-00122.1.

Ventrice, M. J., C. D. Thorncroft, and C. J. Schreck, 2012b: Impacts of convectively coupled Kelvin waves on environmental conditions for Atlantic tropical cyclogenesis. Mon. Wea. Rev., 140, 2198-2214, https:// doi.org/10.1175/mwr-d-11-00305.1.

Vincent, D. G., 1994: The South Pacific convergence zone (SPCZ): A review. Mon. Wea. Rev., 122, 1949-1970, https://doi.org/10.1175/1520 -0493(1994)122<1949:tspcza>2.0.co;2.

Volkov, D. L., S.-K. Lee, F. W. Landerer, and R. Lumpkin, 2017: Decade-long deep-ocean warming detected in the subtropical South Pacific. Geophys. Res. Lett., 44, 927-936, https://doi.org/10.1002/2016gl071661.

Von Storch, H., and F. W. Zwiers, 1999: Statistical Analysis in Climate Research. Cambridge University Press, 484 pp.

Vuille, M., and C. Ammann, 1997: Regional snowfall patterns in the high, arid Andes. Climatic Change, 36, 413-423, https://doi.org/10.1023/a:1005330802974.

Wagner, T. J. W., and Coauthors, 2014: The "footloose" mechanism: Iceberg decay from hydrostatic stresses. Geophys. Res. Lett., 41, 5522-5529, https://doi .org/10.1002/2014GL060832.

Waliser, D. E., and C. Gautier, 1993: A satellite-derived climatology of the ITCZ. J. Climate, 6, 2162 2174, https://doi.org/10.1175/1520-0442(1993)006 $<2162$ :asdcot $>2.0 . \operatorname{co} ; 2$.

Wallace, J. M., R. L. Panetta, and J. Estberg, 1993: Representation of the equatorial stratospheric quasibiennial oscillation in EOF phase space. J. Atmos. Sci., 50, 1751-1762, https://doi.org/10.1175/1520 -0469(1993)050<1751:Rotesq >2.0.Co;2.

Wan, W., and Coauthors, 2017: A comprehensive data set of lake surface water temperature over the Tibetan Plateau derived from MODIS LST products 20012015. Sci. Data, 4, 170095, https://doi.org/10.1038 /sdata.2017.95.

Wang, B., and Q. Ding, 2008: Global monsoon: Dominant mode of annual variation in the tropics. Dyn. Atmos. Oceans, 44, 165-183, https://doi.org/10.1016 /j.dynatmoce.2007.05.002.

— Z Z. Wu, J. Li, J. Liu, C.-P. Chang, Y. Ding, and G. Wu, 2008: How to measure the strength of the East Asian Summer Monsoon. J. Climate, 21, 4449-4463, https://doi.org/10.1175/2008jcli2183.1.
— - J. Liu, H.-J. Kim, P. J. Webster, and S.-Y. Yim, 2012: Recent change of the global monsoon precipitation (1979-2008). Climate Dyn., 39, 1123-1135, https:// doi.org/10.1007/s00382-011-1266-z.

Wang, C., C. Deser, J.-Y. Yu, P. DiNezio, and A. Clement, 2017: El Niño and Southern Oscillation (ENSO): A review. Coral Reefs of the Eastern Tropical Pacific: Persistence and Loss in a Dynamic Environment, P. W. Glynn, D. P. Manzello, and I. C. Enochs, Eds., Springer Netherlands, 85-106.

Wang, M., 2017: Predicting Sargassum blooms in the Caribbean Sea from MODIS observations. Geophys. Res. Lett., 44, 3265-3273, https://doi .org/10.1002/2017gl072932.

_- 2018: Spatial and temporal distributions of pelagic Sargassum in the Intra-Americas Sea and Atlantic Ocean. Ph.D. dissertation, University of South Florida.

- , and C. Hu, 2016: Mapping and quantifying Sargassum distribution and coverage in the Central West Atlantic using MODIS observations. Remote Sens. Environ., 183, 350-367, https://doi.org/10.1016/j. rse.2016.04.019.

— gassum biomass, nutrients, and pigments. Geophys. Res. Lett., 45, 12,359-12,367, https://doi .org/10.1029/2018gl078858.

Wang, X., T. Wang, H. Guo, D. Liu, Y. Zhao, T. Zhang, Q. Liu, and S. Piao, 2018: Disentangling the mechanisms behind winter snow impact on vegetation activity in northern ecosystems. Global Change Biol., 24, 1651-1662, https://doi.org/10.1111/gcb.13930.

Wang, Z., C. B. Schaaf, Q. Sun, Y. Shuai, and M. O. Román, 2018: Capturing rapid land surface dynamics with Collection V006 MODIS BRDF/NBAR/ Albedo (MCD43) products. Remote Sens. Environ., 207, 50-64, https://doi.org/10.1016/j.rse.2018.02.001.

Wanner, H., S. Brönnimann, C. Casty, D. Gyalistras, J. Luterbacher, C. Schmutz, D. B. Stephenson, and E. Xoplaki, 2001: North Atlantic Oscillation - Concepts and studies. Surv. Geophys., 22, 321-381, https://doi. org/10.1023/a:1014217317898.

Wanninkhof, R., 2014: Relationship between wind speed and gas exchange over the ocean revisited. Limnol. Oceanogr.: Methods, 12, 351-362, https://doi. org/10.4319/lom.2014.12.351.

— , and J. Triñanes, 2017: The impact of changing wind speeds on gas transfer and its effect on global air-sea $\mathrm{CO}_{2}$ fluxes. Global Biogeochem. Cycles, 31, 961-974, https://doi.org/10.1002/2016GB005592.

_- and Coauthors, 2013: Global ocean carbon uptake: Magnitude, variability and trends. Biogeosciences, 10, 1983-2000, https://doi.org/10.5194/bg-10-1983-2013. 
Watanabe, S., K. Hamilton, S. Osprey, Y. Kawatani, and E. Nishimoto, 2018: First successful hindcasts of the 2016 disruption of the stratospheric Quasi-biennial Oscillation. Geophys. Res. Lett., 45, 1602-1610, https://doi.org/10.1002/2017GL076406.

WCRP Global Sea Level Budget Group, 2018: Global sea-level budget 1993-present. Earth Syst. Sci. Data, 10, 1551-1590, https://doi.org/10.5194/essd-10-15512018.

Weatherhead, B., A. Tanskanen, and A. Stevermer, 2005: Ozone and ultraviolet radiation. Arctic Climate Impact Assessment, Cambridge University Press, 151-182.

Weatherhead, E. C., and Coauthors, 1998: Factors affecting the detection of trends: Statistical considerations and applications to environmental data. J. Geophys. Res., 103, 17,149-17,161, https://doi. org/10.1029/98JD00995.

Weber, M., M. Coldewey-Egbers, V. E. Fioletov, S. M. Frith, J. D. Wild, J. P. Burrows, C. S. Long, and D. Loyola, 2018: Total ozone trends from 1979 to 2016 derived from five merged observational datasets - the emergence into ozone recovery. Atmos. Chem. Phys., 18, 2097-2117, https://doi.org/10.5194 /acp-18-2097-2018.

Weijers, S., I. H. Myers-Smith, and J. Loeffler, 2018: A warmer and greener cold world: summer warming increases shrub growth in the alpine and high arctic tundra. Erdkunde, 72, 63-85, https://doi.org/10.3112/ erdkunde.2018.01.04.

Weisberg, R. H., A. Barth, A. Alvera-Azcárate, and L. Zheng, 2009: A coordinated coastal ocean observing and modeling system for the West Florida Continental Shelf. Harmful Algae, 8, 585-597, https:// doi.org/10.1016/j.hal.2008.11.003.

Wells, N., S. Goddard, and M. J. Hayes, 2004: A self-calibrating Palmer drought severity index. J. Climate, 17, 2335-2351, https://doi.org/10.1175/15200442(2004)017<2335:aspdsi>2.0.co;2.

Wentz, F. J., 1997: A well-calibrated ocean algorithm for special sensor microwave / imager. J. Geophys. Res., 102, 8703-8718, https://doi.org/10.1029/96JC01751.

— 2015 : A 17-yr climate record of environmental parameters derived from the Tropical Rainfall Measuring Mission (TRMM) microwave imager. J. Climate, 28, 6882-6902, https://doi.org/10.1175 /jcli-d-15-0155.1.

—, L. Ricciardulli, K. Hilburn, and C. Mears, 2007: How much more rain will global warming bring? Science, 317, 233-235, https://doi.org/10.1126 /science.1140746.
Werdell, P. J., and Coauthors, 2013: Generalized ocean color inversion model for retrieving marine inherent optical properties. Appl. Opt., 52, 2019-2037, https:// doi.org/10.1364/AO.52.002019.

— , and Coauthors, 2019: The Plankton, Aerosol, Cloud, Ocean Ecosystem (PACE) mission: Status, science, advances. Bull. Amer. Meteor. Soc., in press, https://doi.org/10.1175/BAMS-D-18-0056.1

Westberry, T. K., P. Schultz, M. J. Behrenfeld, J. P. Dunne, M. R. Hiscock, S. Maritorena, J. L. Sarmiento, and D. A. Siegel, 2016: Annual cycles of phytoplankton biomass in the subarctic Atlantic and Pacific Ocean. Global Biogeochem. Cycles, 30, 175-190, https://doi .org/10.1002/2015gb005276.

Wever, N., 2012: Quantifying trends in surface roughness and the effect on surface wind speed observations. J. Geophys. Res., 117, D11104, https://doi .org/10.1029/2011JD017118.

WGMS, 2017: Global Glacier Change Bulletin No. 2 (2014-2015), M. Zemp, S. U. Nussbaumer, I. GärtnerRoer, J. Huber, H. Machguth, F. Paul, and M. Hoelzle, Eds., World Glacier Monitoring Service, 244.

Wheeler, H. C., T. T. Høye, and J.-C. Svenning, 2018: Wildlife species benefitting from a greener Arctic are most sensitive to shrub cover at leading range edges. Global Change Biol., 24, 212-223, https://doi. org/10.1111/gcb.13837.

Wheeler, M. C., and G. N. Kiladis, 1999: Convectively coupled equatorial waves: Analysis of clouds and temperature in the wavenumber-frequency domain. J. Atmos. Sci., 56, 374-399, https://doi .org/10.1175/1520-0469(1999)056<0374:ccewao> 2.0.co;2.

— , and H. H. Hendon, 2004: An all-season realtime multivariate MJO index: Development of an index for monitoring and prediction. Mon. Wea. Rev., 132, 1917-1932, https://doi.org/10.1175/1520 -0493(2004)132<1917:aarmmi>2.0.co;2.

WHO, 2002: Global solar UV index: A practical guide. WHO/SDE/OEH/02.2, 28 pp., https:/www.who.int /uv/publications/en/GlobalUVI.pdf.

Wielicki, B. A., B. R. Barkstrom, E. F. Harrison, R. B. Lee III, G. L. Smith, and J. E. Cooper, 1996: Clouds and the Earth's radiant energy system (CERES): An Earth observing system experiment. Bull. Amer. Meteor. Soc., 77, 853-868, https://doi.org/10.1175/1520 -0477(1996)077<0853:catere $>2.0 . c 0 ; 2$.

— diant energy system (CERES): Algorithm overview. IEEE Trans. Geosci. Remote Sens., 36, 1127-1141, https://doi.org/10.1109/36.701020. 
Willett, K. M., P. D. Jones, N. P. Gillett, and P. W. Thorne, 2008: Recent changes in surface humidity: Development of the HadCRUH dataset. J. Climate, 21, 5364-5383, https://doi.org/10.1175/2008jcli2274.1.

—, C. N. Williams Jr., R. J. H. Dunn, P. W. Thorne, S. Bell, M. de Podesta, P. D. Jones, and D. E. Parker, 2013: HadISDH: An updateable land surface specific humidity product for climate monitoring. Climate Past, 9, 657-677, https://doi.org/10.5194/cp-9-6572013.

— , R. J. H. Dunn, P. W. Thorne, S. Bell, M. de Podesta, D. E. Parker, P. D. Jones, and C. N. Williams Jr, 2014: HadISDH land surface multi-variable humidity and temperature record for climate monitoring. Climate Past, 10, 1983-2006, https://doi.org/10.5194/cp-101983-2014.

Willis, J. K., D. Roemmich, and B. Cornuelle, 2004: Interannual variability in upper ocean heat content, temperature, and thermosteric expansion on global scales. J. Geophys. Res., 109, C12036, https://doi .org/10.1029/2003JC002260.

Winker, D. M., W. H. Hunt, and M. J. McGill, 2007: Initial performance assessment of CALIOP. Geophys. Res. Lett., 34, L19803, https://doi. org/10.1029/2007GL030135.

Witherington, B., H. Shigetomo, and R. Hardy, 2012: Young sea turtles of the pelagic Sargassum-dominated drift community: Habitat use, population density, and threats. Mar. Ecol. Prog. Ser., 463, 1-22, https:// doi.org/10.3354/meps09970.

WMO, 2018a: Scientific assessment of ozone depletion: 2018. Global Ozone Research and Monitoring Project Rep. 58, World Meteorological Organization, 588 pp., https://esrl.noaa.gov/csd/transfer/shared/ozoneassessment2018report.

— , 2018b: WMO Provisional Statement on the State of the Global Climate 2018. World Meteorological Organization, http://ane4bf-datap1.s3-eu-west-1. amazonaws.com/wmocms/s3fs-public/ckeditor/ files/Draft_Statement_26_11_2018_v12_approved_ jk.pdf?NKxFEzQf_oC80ccPsdsMDUIFw5EdKJDl.

Wohland, J., N.-E. Omrani, D. Witthaut, and N. S. Keenlyside, 2019: Inconsistent wind speed trends in current twentieth century reanalyses. J. Geophys. Res. Atmos., 124, 1931-1940, https://doi. org/10.1029/2018JD030083.

Wolf, G., D. J. Brayshaw, N. P. Klingaman, and A. Czaja, 2018: Quasi-stationary waves and their impact on European weather and extreme events. Quart. J. Roy. Meteor. Soc., 144, 2431-2448, https://doi.org/10.1002/ qj.3310.
Wolter, K., and M. S. Timlin, 1998: Measuring the strength of ENSO events: How does 1997/98 rank? Weather, 53, 315-324, https://doi. org/10.1002/j.1477-8696.1998.tb06408.x.

Wood, K. R., and Coauthors, 2018: Results of the First Arctic Heat Open Science Experiment. Bull. Amer. Meteor. Soc., 99, 513-520, https://doi.org/10.1175/ bams-d-16-0323.1.

Woolway, R. I., and C. J. Merchant, 2017: Amplified surface temperature response of cold, deep lakes to inter-annual air temperature variability. Sci. Rep., 7, 4130, https://doi.org/10.1038/s41598-017-04058-0.

— , and _ 2018: Intralake heterogeneity of thermal responses to climate change: A study of large Northern Hemisphere lakes. J. Geophys. Res. Atmos., 123, 3087-3098, https://doi.org/10.1002/2017JD027661.

— , and Coauthors, 2017: Lake surface temperature [in "State of the Climate in 2015"]. Bull. Amer. Meteor. Soc., 98, S13-S14, https://doi.org /10.1175/2017BAMSStateoftheClimate.1.

— "State of the Climate in 2017"]. Bull. Amer. Meteor. Soc., 99, S13-S15, https://doi.org/10.1175/2018BAM SStateoftheClimate.1.

Wright, W. J., Ed., 2004: Drought, Dust and Deluge: A Century of Climate Extremes in Australia. Australian Government, Bureau of Meteorology, 78 pp.

Wu, J., J. Zha, and D. Zhao, 2016: Estimating the impact of the changes in land use and cover on the surface wind speed over the East China Plain during the period 1980-2011. Climate Dyn., 46, 847-863, https:// doi.org/10.1007/s00382-015-2616-z.

Wu, M.-C., K.-H. Yeung, and W.-L. Chang, 2006: Trends in western North Pacific tropical cyclone intensity. Eos, Trans. Amer. Geophys. Union, 87, 537-538, https://doi.org/10.1029/2006EO480001.

Wylie, D., D. L. Jackson, W. P. Menzel, and J. J. Bates, 2005: Trends in global cloud cover in two decades of HIRS observations. J. Climate, 18, 3021-3031, https:// doi.org/10.1175/jcli3461.1.

Xie, P., and Coauthors, 2014: An in situ-satellite blended analysis of global sea surface salinity. $J$. Geophys. Res. Oceans, 119, 6140-6160, https://doi .org/10.1002/2014JC010046.

Xu, X., W. J. Riley, C. D. Koven, and G. Jia, 2018: Observed and simulated sensitivities of spring greenup to preseason climate in northern temperate and boreal regions. J. Geophys. Res. Biogeosci., 123, 60-78, https://doi.org/10.1002/2017jg004117.

Yim, S.-Y., B. Wang, J. Liu, and Z. Wu, 2014: A comparison of regional monsoon variability using monsoon indices. Climate Dyn., 43, 1423-1437, https://doi. org/10.1007/s00382-013-1956-9. 
Ying, M., E.-J. Cha, and H. J. Kwon, 2011: Comparison of three western North Pacific tropical cyclone best track datasets in a seasonal context. J. Meteor. Soc. Japan, 89, 211-224, https://doi.org/10.2151/jmsj.2011 $-303$.

Yoon, H., M. J. Widlansky, and P. R. Thompson, 2018: Nu'a Kai: Flooding in Hawaii caused by a "stack" of oceanographic processes [in "State of the Climate in 2017”]. Bull. Amer. Meteor. Soc., 99, S88-S89, https:// doi.org/10.1175/2018BAMSStateoftheClimate.1.

Yu, H., Y. Lu, P.-Y. Chen, and W.-C. Zhou, 2012: Intensity change characteristics of tropical cyclones in the western North Pacific as revealed by three different datasets. J. Trop. Meteor., 18, 119-126, https://doi. org/10.3969/j.issn.1006-8775.2012.02.002.

Yu, L., 2019: Global air-sea fluxes of heat, fresh water, and momentum: Energy budget closure and unanswered questions. Annu. Rev. Mar. Sci., 11, 227-248, https:// doi.org/10.1146/annurev-marine-010816-060704.

— , and X. Jin, 2014: Insights on the OAFlux ocean surface vector wind analysis merged from scatterometers and passive microwave radiometers (1987 onward). J. Geophys. Res. Oceans, 119, 5244-5269, https://doi.org/10.1002/2013JC009648.

Yuan, X., M. R. Kaplan, and M. A. Cane, 2018: The interconnected global climate system-A review of tropical-polar teleconnections. J. Climate, 31, 5765-5792, https://doi.org/10.1175/jcli-d-16-0637.1.

Zelinka, M. D., C. Zhou, and S. A. Klein, 2016: Insights from a refined decomposition of cloud feedbacks. Geophys. Res. Lett., 43, 9259-9269, https://doi .org/10.1002/2016GL069917.

Zemp, M., and Coauthors, 2015: Historically unprecedented global glacier decline in the early 21st century. J. Glaciol., 61, 745-762, https://doi. org/10.3189/2015JoG15J017.

Zeng, Z., and Coauthors, 2018: Global terrestrial stilling: Does Earth's greening play a role? Environ. Res. Lett., 13, 124013, https://doi.org/10.1088/1748-9326/ aaea84.

Zepp, R. G., G. C. Shank, A. Vähätalo, E. Bartels, and R. P. Jones, 2008: Photobiogeochemistry of Sargassum: A potentially important source of chromophoric dissolved organic matter in the upper ocean. 2008 Ocean Sciences Meeting, Orlando, FL, American Society of Limnology and Oceanography, 460.

Zhang, C., 2005: Madden-Julian oscillation. Rev. Geophys., 43, RG2003, https://doi.org/10.1029 /2004RG000158.

_-, 2013: Madden-Julian oscillation: Bridging weather and climate. Bull. Amer. Meteor. Soc., 94, 1849-1870, https://doi.org/10.1175/bams-d-12-00026.1.
- - and J. Gottschalck, 2002: SST anomalies of ENSO and the Madden-Julian oscillation in the equatorial Pacific. J. Climate, 15, 2429-2445, https://doi .org/10.1175/1520-0442(2002)015<2429:saoeat> 2.0.co;2.

Zhang, R., S. Zhang, J. Luo, Y. Han, and J. Zhang, 2019: Analysis of near-surface wind speed change in China during 1958-2015. Theor. Appl. Climatol., https://doi. org/10.1007/s00704-019-02769-0, in press.

Zhang, X., L. Alexander, G. C. Hegerl, P. Jones, A. K. Tank, T. C. Peterson, B. Trewin, and F. W. Zwiers, 2011: Indices for monitoring changes in extremes based on daily temperature and precipitation data. Wiley Interdiscip. Rev.: Climate Change, 2, 851-870, https://doi.org/10.1002/wcc.147.

Zhang, X., and Coauthors, 2018: Evaluation of land surface phenology from VIIRS data using time series of PhenoCam imagery. Agri. For. Meteor., 256-257, $137-$ 149, https://doi.org/10.1016/j.agrformet.2018.03.003.

Zhang, Yo., and Coauthors, 2016: Multi-decadal trends in global terrestrial evapotranspiration and its components. Sci. Rep., 6, 19124, https://doi.org/10.1038/ srep19124.

—, D. Kong, R. Gan, F. H. S. Chiew, T. R. McVicar, Q. Zhang, and Y. Yang, 2019: Coupled estimation of $500 \mathrm{~m}$ and 8-day resolution global evapotranspiration and gross primary production in 2002-2017. Remote Sens. Environ., 222, 165-182, https://doi .org/10.1016/j.rse.2018.12.031.

Zhang, Yu., O. R. Cooper, A. Gaudel, A. M. Thompson, P. Nedelec, S.-Y. Ogino, and J. J. West, 2016: Tropospheric ozone change from 1980 to 2010 dominated by equatorward redistribution of emissions. Nat. Geosci., 9, 875-879, https://doi.org/10.1038/ngeo2827.

Zheng, Z.-W., I. I. Lin, B. Wang, H.-C. Huang, and C.-H. Chen, 2015: A long neglected damper in the El Niño-typhoon relationship: A 'Gaia-like' process. Sci. Rep., 5, 11103, https://doi.org/10.1038/srep11103.

Ziemke, J. R., and O. R. Cooper, 2018: Tropospheric ozone [in "State of the Climate in 2017"]. Bull. Amer. Meteor. Soc., 99, S56-S59, https://doi.org/10.1175/20 18BAMSStateoftheClimate.1.

— S. Chandra, R. D. McPeters, and P. A. Newman, 1997: Dynamical proxies of column ozone with applications to global trend models. J. Geophys. Res., 102, 6117-6129, https://doi.org/10.1029/96JD03783.

— spheric ozone inferred from a composite record of TOMS/OMI/MLS/OMPS satellite measurements and the MERRA-2 GMI simulation. Atmos. Chem. Phys. Discuss., 2018, 1-29, https://doi.org/10.5194 /acp-2018-716. 
Zwally, H. J., and S. Fiegles, 1994: Extent and duration of Antarctic surface melting. J. Glaciol., 40, 463-475, https://doi.org/10.3198/1994JoG40-136-463-375.

, W. Abdalati, T. Herring, K. Larson, J. Saba, and K. Steffen, 2002: Surface melt-induced acceleration of Greenland ice-sheet flow. Science, 297, 218-222, https://doi.org/10.1126/science.1072708.
Zweng, M. M., and Coauthors, 2013: Salinity. Vol. 2, World Ocean Atlas 2013, NOAA Atlas NESDIS 74, 40 pp., https://www.nodc.noaa.gov/OC5/woa13/. 


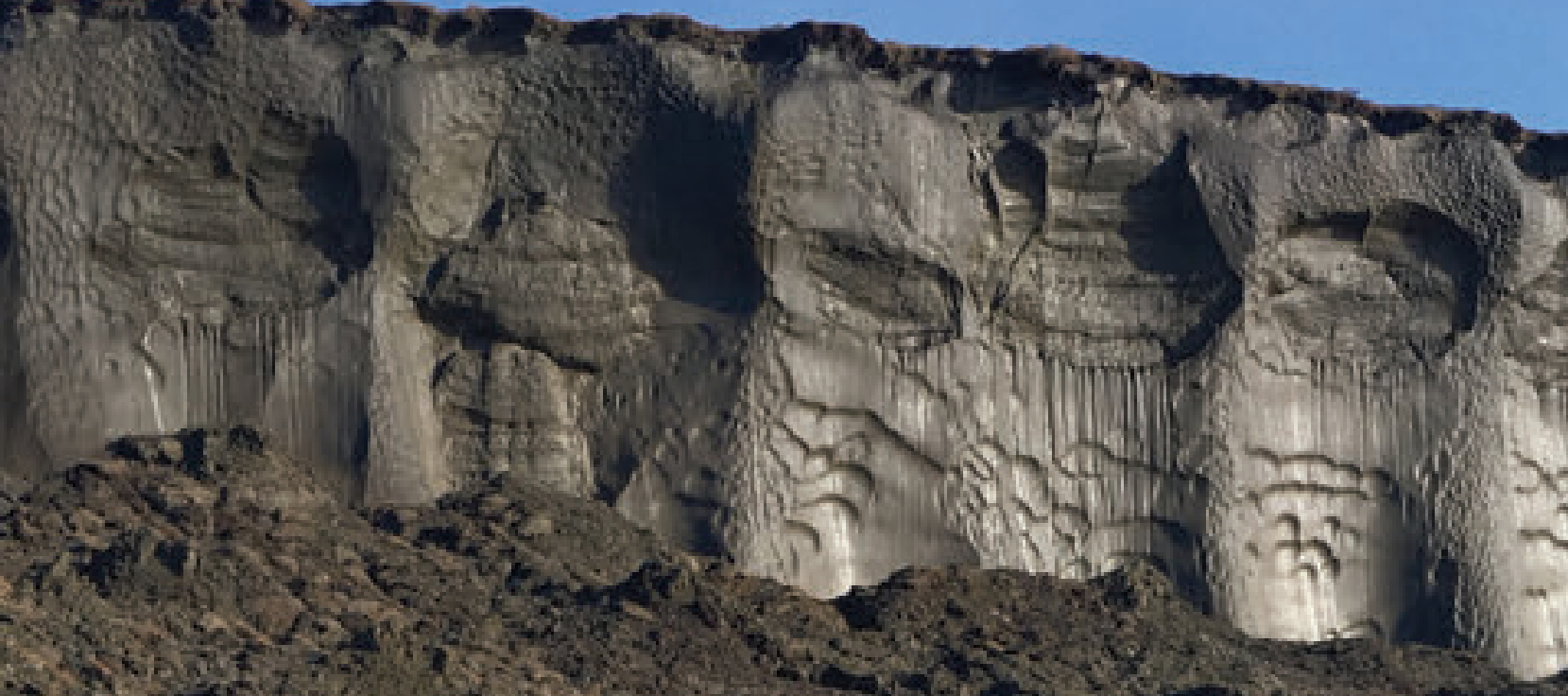

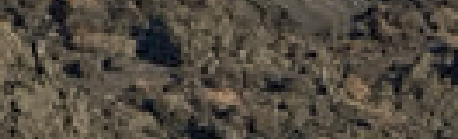

nes

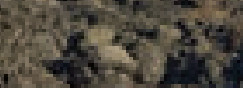

3.

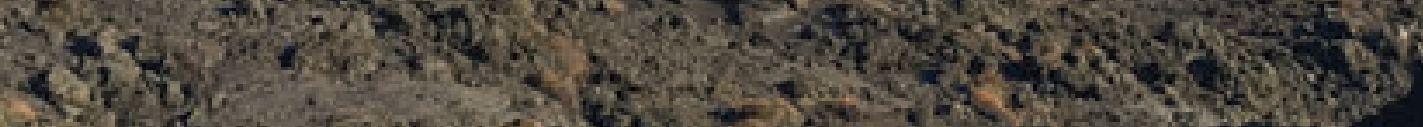

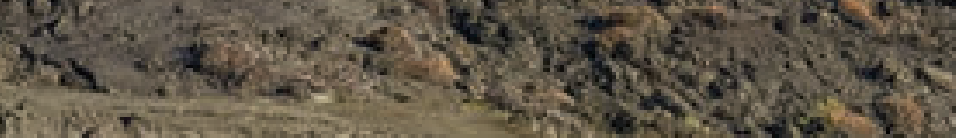

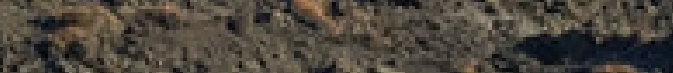

S.

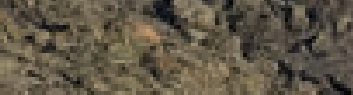

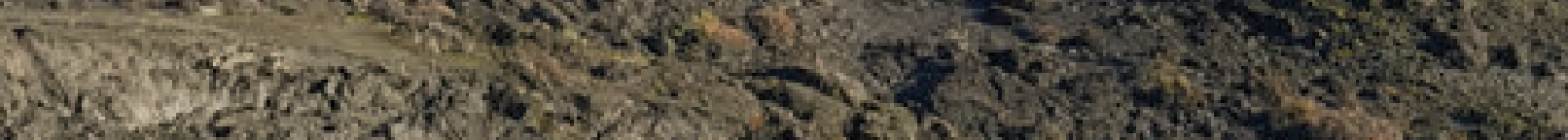

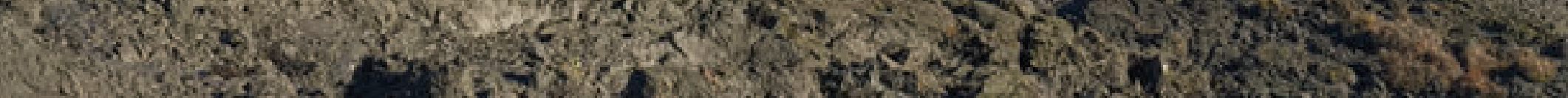

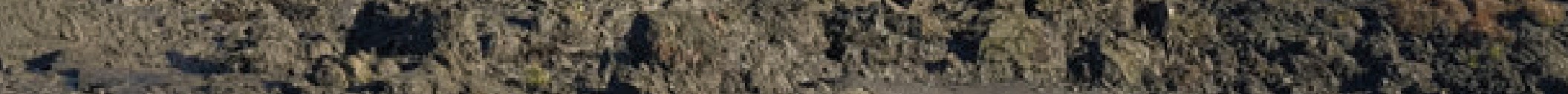
- 30 .

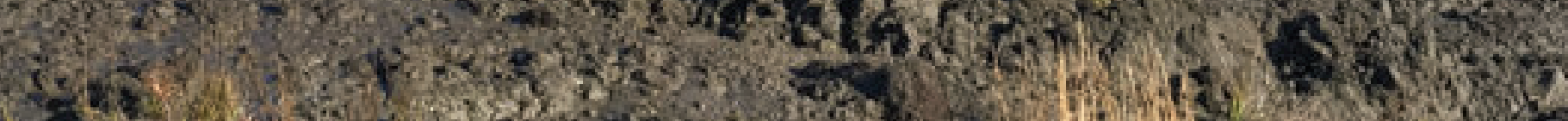

W.

$\cos$

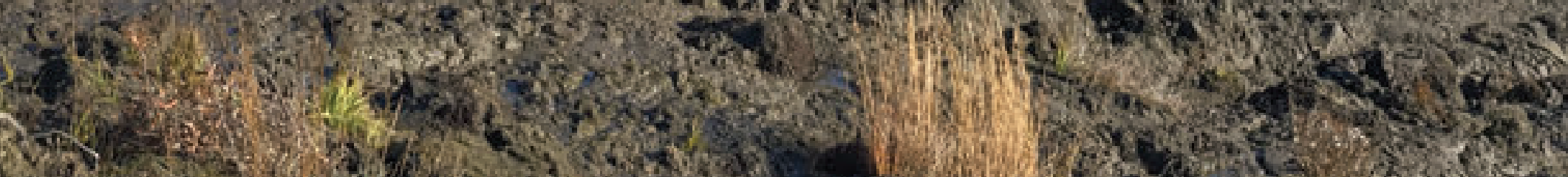

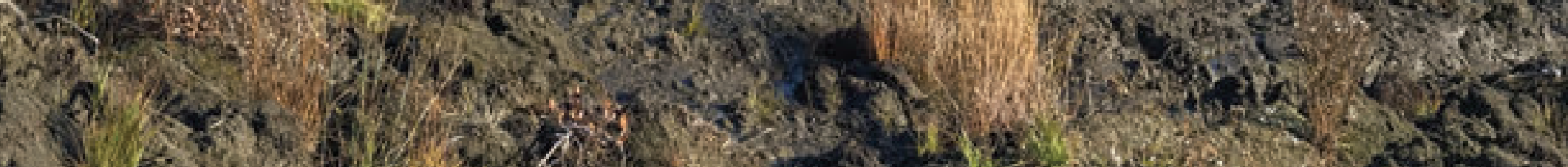

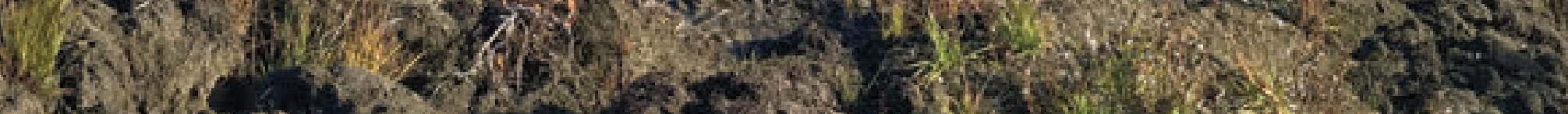
V.

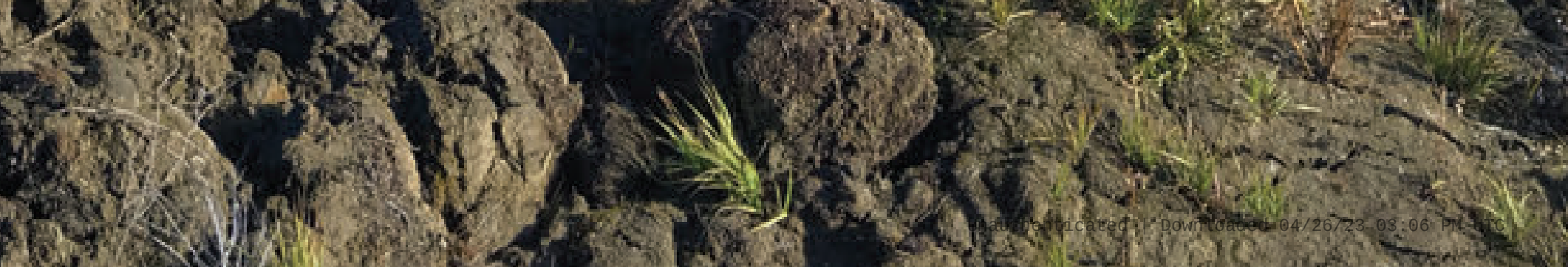

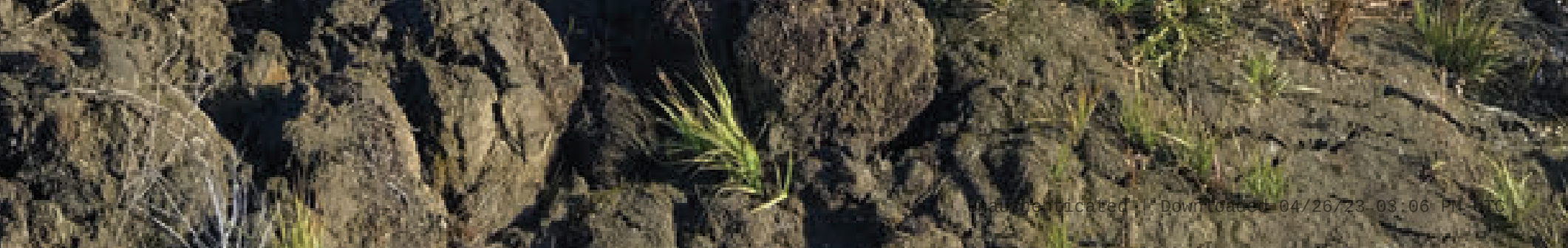

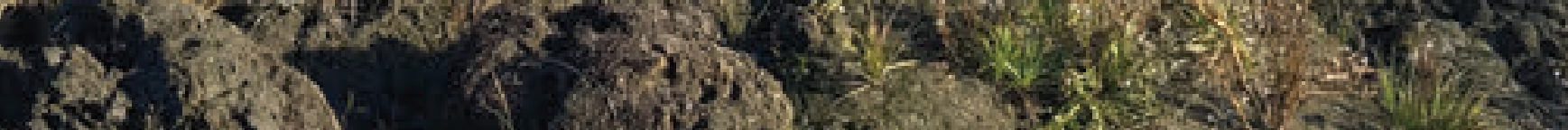

